

$$
\text { - }
$$




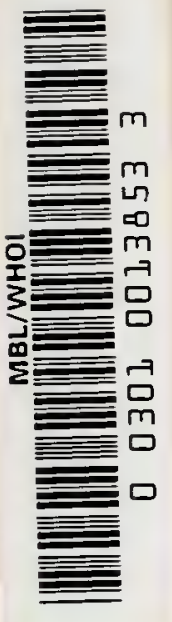





\title{
INDEX DESMIDIACEARUM
}

CIIATIONIBUS LOCUPLETISSIMUS

ATQUE

\section{B I B L IO G R A PH I A}

AUCTORE

\author{
C. F. O. NOR D S T E D T
}

OPUS SUBSIDIS ET EX AERARIO REGNI SUECANI ET EX PECUNLA REGLE SOCIETATIS SCIENT. HOLMIENS. COLLATIS EDITUII

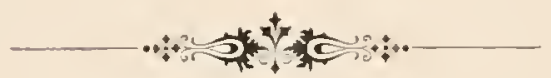

L U X D E

TYYIS BERLINGISIS

$18^{11}, 194$

BEROLINI

FRATRES BORNTR ÆGER

VIA DIC'TA GCHOENEBERG $1 \bar{i}$ a 
5881

ज? 9 
$U_{t}$

plantar quadam ad systema redigantur et ratione tractentur, primum necesse est cognitum habere que ab alis de ea re seripta sint. (tuamobrem quo magis Desmidiaceis cognoscenlis operam dabam, en magis intellexi ad in opus essu descriptionum ac figurarum locos liabere "x libris plenins vitatos: ea enim re arbitrabar posse monographiam pleniorem compensari, prasertim cum numerus librorum qui de hac re seriberentur his trmporibus multum anctus esset. Matne igitur adnotata congessi omnium qua ar bibliographiam Dosmidiacearum pertinebant et locos sumptos ex libris retustioribus in indicem refrre institui. Cum antem Sylloge Algarum anctore J. B. De-Toni anno 1889 erlita esset, opms tali ratione perfectum, si non illo ipso tempore tantum, at alifuantum requirebatur. Perseveravi igitur in eo quod snsceperam elaborare, fund nune in publicum edo, ut $\mathrm{H}^{\circ}$ vilili parte illi desiderio satisfacian.

Nimirum bibliographia plena fieri non potuit. Spero tamen non multos libros, qui quidem magni sint momenti, in hoc libro deesse. (Hoc loco magnas gratias ago omnibus, quicunque ex is libris yui mihi prasto non fuerme, confecerunt excerpta).

Illos autem libros qui ad institutionem juventutis atque vulgi accommodati eraut omisi prater pancos, nisi ea continerent quibus nove planta describerentur.

Illos autem libros qui ad geographiam tantummodo spectabant neque quidquam habebant quo magis comoseeretur quem locum in systemate aliqua planta obtineret ant quo modo nominareretu in Bibliographiam recepi sed omisi in Indice. Nee vero censuras in Ephemeridibus nec translationes commemoravi, nisi in quibus quid novi invenerim.

Ordo locorum citatorum etsi potuit csse alius, tamen hunc ad tempora digestum secutus sum ordinem, qui ad id quor hoc indice spectabam, videbatur esse aptissimus. Et quamquam joinum in animo hahneram magis ostendere quo loco qureque planta cuins mentio facta esset, in systemate collocanrla esse videretur, tamen cum tot nove species rarietatesque, quas inspicicndi mihi nulla data esset copia, his proximis temporibus descriptre essent, eo consilio destiti. Nee duhium est quin futurum sit ut posthac et aliquot varietates inveniantur esse verce species et rursum multæ quæ nuc species essc videantur, nihil aliud reperiantur esse nisi status quidam evolutionis ex specie quadam profecte vel varietates. Si quie antem sunt hac re dubix, res ar liquidum perduei tum reniqne poterit, cum quxque illarum plantarum penitus arit cognita. Certe nimis multa quasi nove species et varietates ex pancioribus inspectis exemplis descriptre sunt. cum quie esset cuipue speciei vis variandi non satis esset examinata. Illud sane difficile est dictu, sententia eorum qui discrimina generum pounnt potissimum in characteribus hine ductis utrum comprobari possit, necue, si studio longiore magis cognitum erit, ea quie continentur cellulis quali sint structura.

Olim cognitis pancis Desmidiaceis, descriptiones specierum (pariter ac generum) scilicet fiebant tam caraces, ut singula multas harm que nunc sunt specierum possent complecti. Quod ideireo moneo, quia sepe supersedi unoquoque loco ostendere esse symonyma antiquiora. At recentiorum synonymormm mentionem frequrnter feci.

Ut loci citati satis intelligantur, annus unicuique loco prepositus animadvertendus est, quia is amms in ipso loco citando non iteratur. Hoc vero maxime iis qui aliquos locos citatos sumere volent ex hoc Indice, observandum est.

Primum locum nore speciei sine descriptione commemorans hoc solum spectari ut hune defectum demoustrarem. 


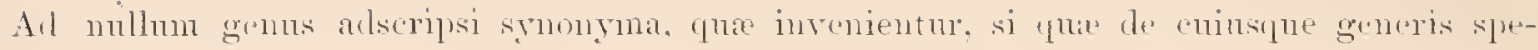
(iveluts scripita sint, cognoveris.

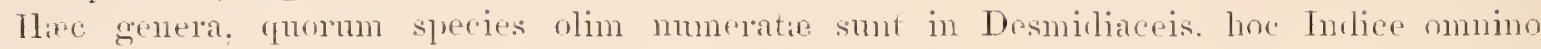
omittuntule:

Amphitritions Ehrb. Anliastiondesmms Corda. Anmere Elirb.

Arthrotomar Corda. Astricimm Colrda. Bidelelphin Gray. Comelustrum Nag. Comigrmin Morren. Crencigminllu Gaill. Eremosphteren De Bary. Eucrmmpir Elırb.. Kü̈z. Gemimelle. T'ure.

Cilocrmemen Elinb.

Coloimmemur Kütz.

Gomplusshlmerin Kï̈z.

Gomidimm Ehlob.

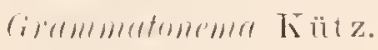

rivenmmomema Ag.

Helineliss Kïtz.

Lithorlesminm Elirb.

Losmentr Trev.

Detosivel Ag.

forralinum Nieg.
Prdiustram Mryen.

Plomerorerse Menegh.

linghillillll Küitz.

seleneel Nitszel.

smorestrumll Kïtz.

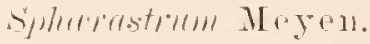

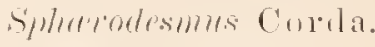

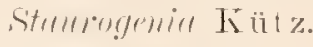

Trerrïløul Kïtz.

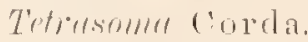

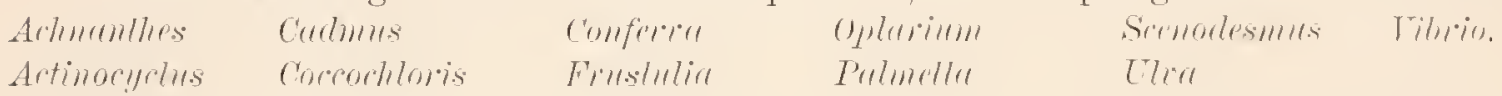

lllas antem species recepi omnes. que etsi non sunt in Desmieliaceis numerandit. tamm

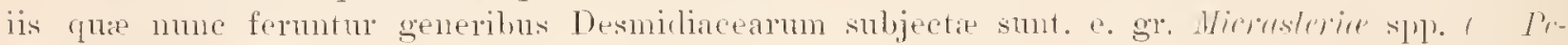

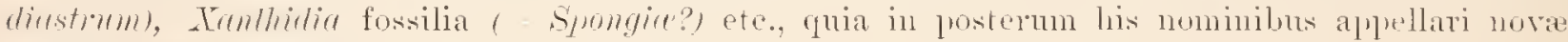
sleecies debent nullix.

Signa et abbreviationes sipins allibiti:

$\mathrm{d}=$ diagnosis 1 . descriptio.

o observatio l. nota brevior (non tantum de distributione geographica).

$m$ = mensura tantum. $\quad n=n o m e n$ tantum.

$z$ - zygospora descripta.

zf zygospora figurata.

ph observatio tantum pliysinlogica l. de contentu cellularum.

t. -.. tabula.

f. ante auctorem forma.

f. post anctorem figma.

[n. v.] - opus a me nom risum. Cetera opera ant ipse inspexi am al, anicis milii excerpta legi.

$[\mathrm{g}]=$ opus tantum olservationes Desmidiacearum geographicas continens.

( ) synonyma et anmotationes aucturis citati.

[ ] synonyma ah aliis l. hir a me commemorata: - - 1. anctor non citatus) a quo figura citata me juclice sumptit est.

\begin{tabular}{|c|c|c|}
\hline 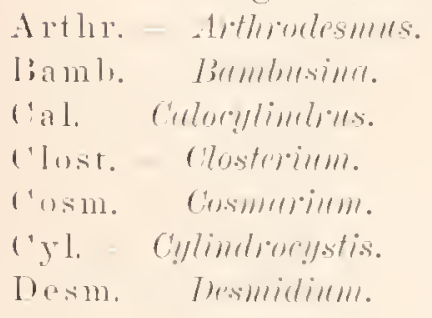 & 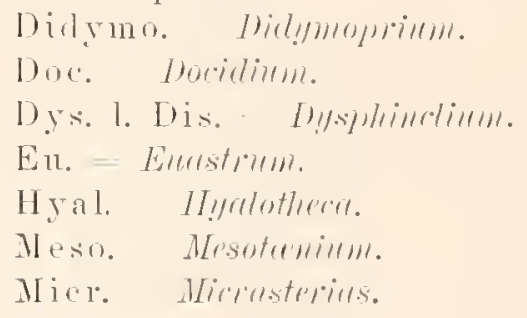 & 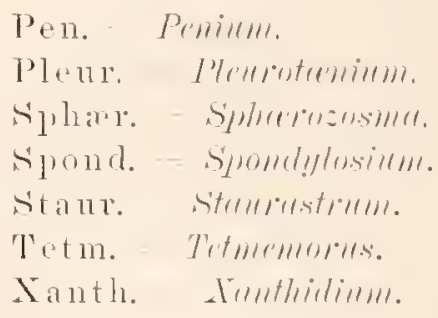 \\
\hline
\end{tabular}

l)il. Didlymillimm.

Daban Lundie d. ! Sept. 1S!\%. 


\title{
1. Bibliographia Desmidiacearum.
}

\author{
A. Libri. \\ pui tituli per compondium seripti his signis ( ) inclusi sunt, $\ddot{u}$ in sectione 2 afferentur.
}

Abeleven, T. H. A. J. Eine teekening eener Alge [Mierasterias denticulata Bröh.. Ralfs] (In: Verslag der Tijfite Alugencene Íijeenliomst der Leden van de Vereeniging voor de Tederlandsche Flora, gehoulen te Deventer den 30 en 31 Aug. 1950. 1'. 125-182: - Federl. kituidk. Areh. Vol. 3. prt. 1, Leyden 1851, 1. 177.

- lijilrage tot Ie Flora ran Nijmegen (in: Terslar van de zeste algemeene Bijeenkonst der Leden van de Vereeni-

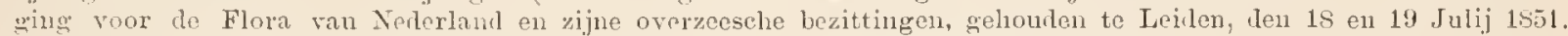
I'. 137 226) - [g] - Veulerl. kruilk. Areh. Vol. 3, prt. 2. Leilen 1552, 1) $215-226$.

Acharius, E. Echinella, Tovun Mgan Genns. - Woher F. et Molı MI. D. H. Beiträge zur Naturkunde. Tol. 2 1810 1.: $: 310-342+$ t. 4 part. infer.

Acheson, Geo, Biological stuly of the tap-water in the school of practical seience, Toronto. - Proceed. Canadian Tustit.. 11. \&. 1 1. $413-426$. Toronto 18s4. [Nulla tabula figurarum publicata!]

(1y. Disl. Alg. sues. Agardh, Carl Adolph. Dispositio Algarm Suecias, quam publico examini subjiciunt C. A. Ag. - et Fiar Magnus Fries. Die - - - Aprilis MDCCCXII. P. III, p. 207-42. Lumle 1812.

1y. Algar. Dec.) - Algarum Ireeas prima. 'fuam publico Examini subjiciunt - - et Petrus Abralıam Asping, Seanus. Die XIX Decemb. A. MDCCCXII. Lunde 1812. 15 pl.

(1g. in Sv, But.) - in: Srensk Botanik utgifven af G. J. Billberg, merl text författad af O. Swartz. Sjunde Bandet. 1:0 2.2. Stockholm 1815.

(.Iy. Syt, Alg. Seaml.) - Syuopsis algarum scandinavix, aljecta dispositione universali Algarum, Lunde 1817. XI $+135 \mathrm{pl}$.

(.1y. Syst. Aly.) - systema Algarum. Luudrs 1824, $38+312$ pl.

(A\% in Flura 182厅: - Aufzählung einiger in den östreichischen Ländern gefundenen newen Gattungen und Arteu von Algen. nebst iluer. Diagnostili und beigefïgten Bemerkungen. 22, 1p. - Flora oder Botanische Zeitumg n:o to 41. Regenslure 1827. 1. 625-611, 612-616.

1\%. S1\% Al - - species Algarum rite cognitum cum synonymis, differentiis specificis. et descriptionibus succinctis. Fol. 2 sect. 1. Gryphie 1\$28, TAXVI et 159 pl.

(Ay. Consp. Tint.) - Conspectus critieus diatomacearum, quem Venia Ampl. Ord. Plil. Iundensis praside Carolo All. 1. pro exereitio publice defendet C. P. Liljeborg, scanus. In Lyeeo Car. Die IV Dec. MDCCCXXX. P. 1. Lunuze

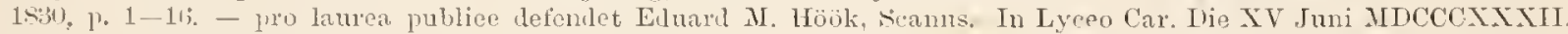
P. IV. Lundiat 18:32, p. 45-63.

Ahromke (hlorosp. Kihark.) Alexenko, M. A. Précis des algues Chloroporées des envirous de Kharkov. [Charkow, 1897 sec. Bot. Jahresber.] - Travaux d. 1. soc. d. naturalistes it l'Univers. i. de Kharkow. Vol. 21. 18s7. Kharkow

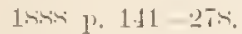

Hemnlio Alg. I'oltava) - Matériaux pour servir i la flore les algues lin gouvernement de Poltava. I. -- 'Travaux

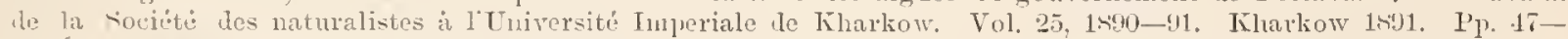
sit + t. 3. [Fere plane rossiee. diagnos. latin.].

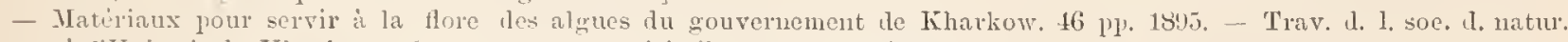
a. l'Lniv, i. de Kiliakow. [n, v. - opus verisinile quoque de Desm.].

(Aulers. sverig. Clhlor.) Andersson, 0. Fr. Bidrag till liänedomen on Sveriges Chlorophyllophyecer. I Chloro-

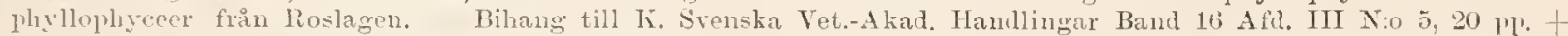
1 t. Stocklrolin 1:90. [Andersson = Borge $]$.

(Aele. (intalog) Archer. W. List of Desmiliaces found in the neighbourhood of Dublin. - Nat. Hist, Rev. (I'roc.)

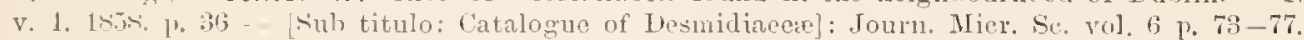

(. Hch. Supl. Cat.) Supplementary Catalogue of Desmidiacew found in the neighbourhool of Dublin, with Deseription and ligures of a proposed New Genus, and of Four New species. - Nat. Hist. Rev. (Proc.) v. 5 1.5.s p. $23.1-263$ t.

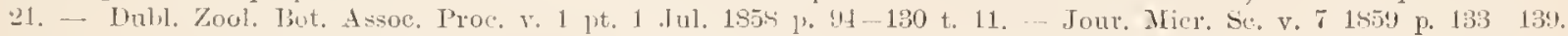

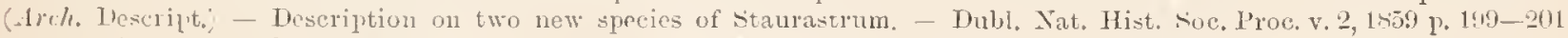
t. 1 f. 1-1. - Yat. Hist. Review v. 6 (Proc.) oct. 1959 p. I61- 463 t. 33\%. - Jour. Micr. Ac. v. 8, 1860 p. $75-79$ t. 
7 ex p. - Sieparatim cum: Dixen, R. V. On a new Genus aud speeies in the Desmidiacere, et: W. Archer: Notice of some cases of abnormal growtl in the Desmidiacece. 17 ple +1 tab.)

(Arch. Abnorm. Desm.) - Totiee of some cases of abnormal growth in the Desmidiaceæ; et: Futher notes on abnormal growth in the Desmidiacer. - Dublin Nat. Hist. Soc. P'oc. v. 2 p 201 - 213, v. 3 p 37 - 35 t. 1 ex p. Nat. Hist. Review Proe. v. 6 oet. 1859, p. $469-47$ t t. $33^{*}$ ex 1); vol. 7 p. $391-392$ t. 13 f. 6-7. - Journ. Mier. Se. v. 81860 p. $85-93$ t. 7 ex p.

(Arch. Zoospor. in Desm.) - On the ()ecurrenee of Zoospores in the Family Desmidiaceit. - Nat. IIst. Rev. v. 7 July 1810 p. 375-391 t. 13 ex p. - Journ. Mier. Sc. v. 8, 1860 p. $215-235$ t. 11 ex p.

(Arch. Deseript. New Species) - Deseription of a New Species of Cosmarium, and of a New Species of Xanthidiun. Dubl. Nat. Hist. Soc. Proc. v. 3 p. $49-52$ t. 1 ex. p. - Nat. Hist. Rev. v. 7 (Proc.) p. $403-106$. t. 13 ex n. - R. Jour. Mier. Sc. v. 81860 p. $235-239$ t. 11 ex p.

(Arch. in Pritch. Inf.) - Sub-group Desmidiese or Desmidiacere. - Tritehard. A. A History of Infusoria including the Desmidiacere and Diatomacere british and foreign. Fourth Ed. 1861. p. 715-751 + tab.

(1 1 reh. Clost. acic.) - On Closteriun aeiculare. - Micr, Śc. Journ. n. s. v. 2 (1862) 1. 31-35.

(Areh. New Micrast.) - Deseription of a new Species of Micrasterias (Ag. et aliorum, non Ehr.), with Remarks on the Distinction between Mierasterias rotata (Ralfs) and M. denticulata (Bréb.). - Dubl. Nat. Hist. Soc. Proc, v. 3 pt. 2, 1863 , p. 61 - is t. 2 ex p. - Jour. Mier. Soc. n. s. vol. 2 (oet. 1862) p. 236-247, t. 12 ex p.

(Aich. New Cosm. ete.) - Deseription of a new Species of Cosmarium (Corda), of Staurastrum (Meyen). of two new Species of Closterinm (Nitzsch), and of Spirotitnia (Bréb.). (Sep. 1\% 10-16.) - Dubl. Nat. Hist. Soc, Proe. v. 3 pt. 2, 1S63, p. $78-85$ t. 2 ex. 1. - Journ. Mier. Se. u. s. v. 2 (oct. 1862) 1. 247-254 t. 12 ex l.

(Arch. On Ankistrod.) - On a new (?) speeies of Ankistrodesmus ('orda), with Remarks in comexion therewith as regarls Closterium Griffithii (Berk), and C. subtile (Bréb.). - Dubl. Nat. Hist, Soe. Pr. v. 3 p. 85 -.90 t. 2 ex p. Jour. Micr. sce. 11. s. v. 2 (1862) p. 255261 t. 12 ex p.

(Arch. Deseript (1861).) - An endeavour to identify Palmogloea maeroeocea (Kítz.) with deseription of the plant he. lieved to be meant. and of a new species, both, however, referrible rather to the genus Mesotieninm (Xäg.); - Description of a new species of Cosmarium (Corda). and of Penium (Brob); - Deseription of a new species of Cosmarium (Corla), and of Arthrodesmus (Ehr.) 31 pl +1 tab. - Dubl. Nat. Hist. Soc. Iroc. v. 4 pt. 1, 1861, p. 12-33; 49-5i3; 66-69, t. 1. - Qual. Jour. Mier. Sce. n. s. v. 1 (1861) 1. $109-132 ; 174-182$, t. 6.

(Alch. Olss. on Mier. Mahal.) - Observations on Mierasterias Mahabuleshwarensis (Iobson), and Docidium Pristidie (Hobson). - Dubl. Nat. Hist. Soe. Pr. v, 4 pt. 2, 1865 , p. 78 -81 t. 2 ex p. - Q. Jour. Mier. Sc. 11, s. v. 5, 18ti5, p. $255-262, \mathrm{t}, 7 \mathrm{ex} \mathrm{p}$.

(Arel. New Docid.) - Deseript. of a new species of Docidium Brib.) from IIong-Kong. - Inbl. Nat. Hist. Soc. Pr. v. 4 pt. 2 p. $81-85$ t. 2 ex p. - Q. Journ. Mier. Se. 11. s. v. 5, 186.', p. $290-297$ t. 7 ex p.

(Arch. Obs. on Cylindr.) - Observations on the genera Cylindrocystis (Meneghini), Mesotrenium (Niag.), and Spirotienia (Bréb.) (= Palmogloea, Kïtz. pro maxima parte). mainly induced by a paper by dr J. Braxton Hicks, F. R S., F. L. S., on the lower forms of algie); 19 pp. - Q. Journ. Hier. Se v. 6, 18tif. p. 203-22.

(Arch. On Asteridia) - Note on "Asterilia" oceuring in Penium digitus (Brib.). 4 lp. - Q. Jour. Micr. Se. n. s. vol. 7 July 1 siti p. $193-186$ t. 8 ex p.

(1reh. Conjug. Spiroten.) - On the Conjugation of Spirotrenia condensata (Bréb.) and of Spirotienia truncata (Arch.) 8 1]. - Q. J. Mier. Se. 11. A. v. T. July 1867. p. $186-193$ t. 8 ex p.

(Areh. On Chlanydomyxa labyr.) - On Chlamylomyxa labyrinthuloides, nov. gen. et sp. A New Freshwater Sareodie Organism. - Proced. of the R. Irish Acar. ser. "2 v. 2 science 1. 110-159. t. 11, 15. 1875. - Q. Jour. Micr. Sc. v. 15,1575, p. $107-130$ t. 6 et 7 .

(Arch. in Linn. Tourn.) - Notes on some Collections made from Furnas Lake, Azores, eontaining Algit and a few other Organisms. - Jomn Linm. Soc. Botan. v. 14, 12. 77 oct. 1974 p. 328 -340.

(Arch. Alg. Kerguel.) - Note on tlie Freshwater Algit collected by II. N. Moseley, M. A., in Kerguelen's Land. Journ. Limn. Soc. Bot. V. 15 p. 455-6, 1877.

(Arch. in Grevillea) - New Zealand Desmidiece, [W. M. Maslell, Contrib. New Zeal. Desm.] - Grevillea vol. 10 11:0 53,1881, p. 28-31.

(Arch. in Q. J. M. S) - Archer, W. in proeeenings of the Dublin Microneopical Club. - in 'quarterly Journal of Microscopical Science n. s.

- 1865 v. 5: A slide of Desmidiacer, oltained from Mr Leipuer: of Bristol. eollected near Dresden. p. 169-170 - [g]. A paper lately published by $\mathrm{I}^{\prime}$. 'T. ('leve, 1) 170.

- 1866 v. 6: A number of globular, donsily spined bodies [the asteridia of Penium] exhibited. P. 58-60. - [ph]. A Cylindrocystis (Menegl.) as yet undescribed (exhibited) 1) 60.

- Specimens of Leptoeystimema Kinahani (ejus) showed p.63. - [g].

- A number of very rare Desmidiacen. 1) 66-67.

Specimens of a Desmilian. Which, as far as he was aware, had not been found in Ireland - Cosmarium curtum (Ralfs) = Penium curtum (Brib.), exhibited p. 70-71.

- - Sperimens of ('losterim linea (Perty) presented p. 71-72.

- Specimens of the zyoospore of Enastrum elegans and of Staurastrum orbieulare, exhibited p. 73 - [ 8 ].

- Specimens of Spondylosium pulchellum (ejus) showed. p. 120.

- The, with us, rare Cosmarium moniliforme p. 121.

- A minute alga which formed a new speeies of the genus Dictyosphierium, Näg. [D. constrictum = Cosmocladium con.] p. $127-128$.

- Specinens, obtained from Yorkshire, of Closterium acieulare West-Gronatozygon Ralfsii De Bary (= Docidium asperum Ralfs) - Cosmarium quadratum showed, p. $181-182$.

- Staurastrum oligaeantlum (Breb, in litt.) and Staurastrum eristatum exlibited, p. 189. 
Specimens of Spirotenia parvula. p. 1!1.

- Cosmariun curtum (Ralfs) showed. p. 192-3.

- - A number of fresh examples of the zygospores of some Desmidiaced, which, so far as he was aware, had not yet been met with. 1. 273-7t.

- A very puzzling little form (Cosmarium tuberculatum). p. 27o.

- IS67 v. 7: Mierasterias Thomasiana, exlibited. P. 8s - [gr].

- A rery minute new species of Cosmarium with its zygospore, gathered at kilhridr, near lilessington, eounty of Wicklow. (rosmarium lobatospormm) p. 170-2.

- Exhibited fine specimens of the various stages of conjugation in c'losterium lineatum, showing its lemarkable louble zygosiores p. 173.

Showed specinens and drawings of the various stages of the development and of the perfect zygospore of sirotetnia condensata Bréb.) especially interesting as being the first... . 1. 233.

- Slowed in the sano gathering eonjugated examples of Penium closterioites I. 231.

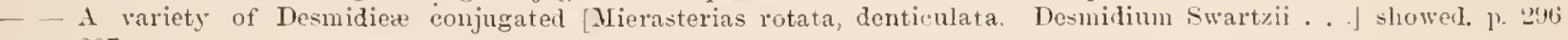
-297 .

- - T'wo forms not hitherto met with in Ireland. (Docidium baculum (Bréb.) and Euastrum circulare var. $\beta$, Ralis 1. $297-8$.

- A minute alga new to Broitain. Cosmocladium Saxonicum, de Bary p. 248 -9.

- LiS r. s: Irish specimens of Euastrum didelta, conjugated p. 66.

_- Showed specimens of a staurastrum whieh he considered identical witl sitaurastrum apiculatum (Bréb.) p, lit - 8. showed. new to Ireland. Sirirotiania minuta Thuret p. 65. -. [g].

- Exhibited good reent specimens of the two little algie lately recordci by him from Wales - Dictyospherim renifolme and Cosmocladiun saxonicum p. 6S. - [g].

- - Slowed conjugated specimens. with the zygospores, of Peniun (Ehr.) Bréb. p. 6S.

- Desired to recoril anl to exhibit some examples of the zygosprore of Closterinu costatum (urdic for the first time scen conjugated. p. 118.

- Likewise showed a Closterium new to this eomntry. Closterimm eynthia De Notaris p. 118.

- Cosmocladium saxonicum from callery bog p. 120 - $[\mathrm{g}]$.

- Specimens of Micrasterias Hermanniaua (Reinseh) p. 190.

- Micrasterias fimbriata. Ralfs. p. $246-7$.

- A curions case of malformation in Closterimm striolatum p. 2.4.

- - Presented numerous examples of a very singular-looking encysted state, so to eall it. of staurastrum cuspidatum Bréb. 259 - 291.

- Malformation seen in Desmidiere p. 291-2.

- - A number of Desmitliew showing their zygospores. p. 292-4.

Staurastrum Arachue in Irelank, p. $29 \%$. - [n].

- Recorded the occurence of Micrasterias fimbriata (Ralfs) from Callery, 1. 2!li.

- 1869 v. 9: A few new or rare forms of Desmidiece, chiefly staurastra, taken un an excursion to County Galway, p. (17-s. $-[g]$.

The three rery interesting forms shown by Dr. Barker. 1. 191-196.

- A fine new staurastrun from Connemara (fitaurastrum verticillatum), p. 196.

- - The ceeurence of Micrasterias crux melitensis (Elur.) Ralfs in ('onnemara, 1\%. 196. - [g].

- - specimens taken in Co. Tipperary of ipherozosma filiforme (Ehr.) Auct.; - a form of Gonatozygon Ralfsii (de Bary). p. 1!'s.

- A new stamastrum from Galway (Ntaurastrum maamense), p. 200.

- Bronght forwarl a number of Desmilica, taken at rilengariff. p. 122-t.

- Zygospore of a Cosmarium, confounded with Cosmarium margaritifelum, p. 125.

- 1870 v. 10: A singular and interesting form of Staturastrum gracile: p. $86-\bar{i}$. A ninute little itaurastrum most resembled sitaurastrum lave). 1). 89.

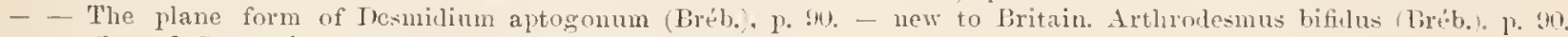

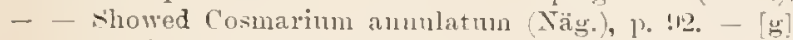

- - An interesting conclition of a minute scytonematous plant [Palmogloca micrococea (Küitz).], 1. 202-3.

- A new and very minute form of spinotinia. (s. tenerrima). p. 203. A very pretty. seemingly new. Cosmarium, which most approached $\mathrm{C}$. cristatum [ = Cosmarium qualrifarium Lutud. ?]. p. 205.

- A new Cosmarim - nearest C. eommissurale p. 308.

- 15i1. v. 11: Exhibited several Desmidies, Fphrozosma secedens le Bary - itauastrum læve. var. Clevei Wittr.

- Staurastrum clongatum. showed. - A new species of Euastrum. p.92-3.

- - showed examples of staurastrum mamense, and of Mierasterias fimbriata. 1. 95. [g].

- The zygospores of staurastrum fureigerum, 11.95.

- Bronght for exhibition two new species of Staurastium, one of Cosmarium, 1) 100-1. - [g].

- Examples of the desmid Pleuroteninm cosurarioides, p. 211-2.

1872 v. 12: Conjugated examples of Surotenin truncuta F. s5 \& 50.

- Farer Desmidieas p. 8j - $[\underline{g}]$.

- Staurastrum oxyacanthum [compressel form] $\mathrm{p}$. 8?.

- A plane or compressed variety of staurastrum vestitum p. 94.

- One or two sketches of new Iresmidian species [Docidium nodosum] p. 193-194.

- A rare little Alga [Cosmocladium saxonienm] p. 195. 
- Some additional Desmirlien. a fow of them new, from the late Galway gatlıerings l3. 19y-202.

- - Three very "elosely allicd" and mnch resembling mimts forms of Cosmarim 1. 421.

- Dietyospherinm constrictum 1. 122.

- - The Cylindroeystis detected some years ago. 11. 422.

1873 v. 13: A gathering male near "Toole s Rocks" containing various Conjugate. includingDesmilieu, renarkable for the great number of listinet speeies simnltaneonsly presenting themselves therein in eonjugated state p. 90 - 100 .

- A very minute form of Euastrum [Euastrum clegans $\beta$ angustatum Wittr.] 1. 101 \& $102-103$.

- A very pretty Cosmarim [Cosmarium speriosm Lund.] p. 101.

- A sketeh of a remarkahle zygospore, liandly to de donbted to be lesmidian l. 103.

- The Freshwater Algr of Fotlanl anl Öand. by Dr. W. B. Wittrock. Translated in abstract with notes p.

$117-13$ ?

- Several rave Desmiliese - taken in Westmoreland and North Wales p. 212-213.

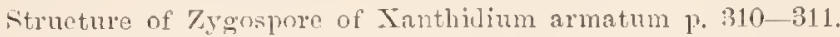

Sitaurnstrum Ophiura, Lundell. new to England. p. 311.

Enastrum binale, var, angnstatm Tritt, anl E. binale var. insulare, Wittr., their ocenenee in Ireland. l) 315. Cosmarium tetrahonlrimm. I und, new to England 1). 315. -- [g].

New localities for Closterinm Areherianmm ('leve) and ('l. Cynthia de Notaris p. 319. - [q].

Enastrum binale var, insularn Wittrock p. 431.

Zygospore of Staurastrum Frehissonii. p. 135. - [g].

187t v. 14: Algar and Rhizopoda from Hot springs of Azores p. 107.

- Cosmocladium saxonicum. The Bary exhibited. p. 212.

- Zygospore of Mierastelias jajillifora, for the first time fonml in Irelanel 1. 213.

Micrasterias furcata. found for the first time in Irelanl, exhibited alons with M. radiusa p. 213.

Docidium enronatum Ehrh, exlibitesl 1\% 211. - [g].

- A new species of sitaumstrum cxlibited p. 192. - - [g].

- Donblesporen or 'Three-spored form of Cylinlrocystis Frebissonii p. 12:3.

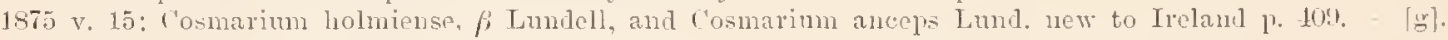
Cosmarium cyclienm Lunilell new to Ireland p. 112.

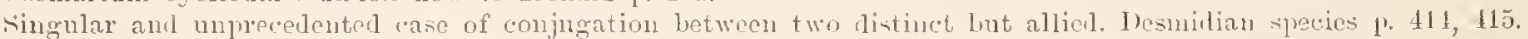

Irietyospherium constrictum Areher, olim foumd enujugated and a true, though aherraut, Desmitiau. p. 115.

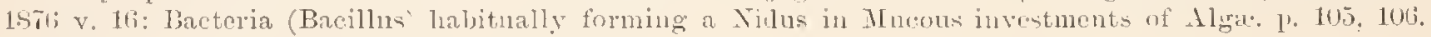

- Micraterias angulosa, Hantsch exhibited for the first time in Irelani 1. 10\%. - [g].

Cosmarium Reinschii. n. s, exlititel 1) 109.

Penim enrtum Brib. exlihiterl. p. 235. - [g].

A Psento-Cosmarim - in other rords, a Cosmarium-like exeptional state of an Artliodesuus-incus form

exhilited. 1. 236, 237.

Totice of some Desmidian forma allied to Closteritum obtusum Brób. p. 23s.

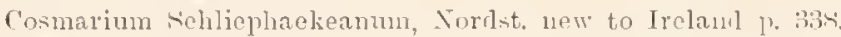

- C'losterim obtusum. Bréb., new to Ireland. exhibited p. 33s.

- A very small form of Cosmarim Holniense. Inundell exhibitel. 1) 331.

Now species of closterium, cxlihited ['l. monotinium] p. 415.

New rosmarium sp. exhibited $\%$. 116.

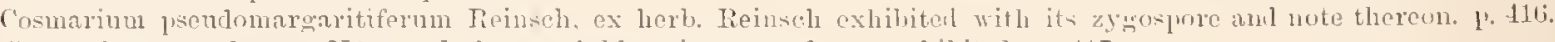
('osmarim ammlatum, Xäg. and three neighbouring new forms cxhibiterl. p. 117.

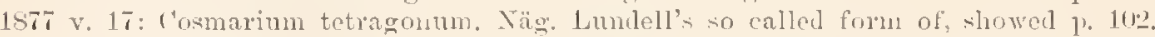

New species of staurastrum, exhihited [s. Royanum] ]). 11:3.

The unlike 7xyospores of two minute smooth closely lesembling Cosmaria, exhibited, proving their slecifie li-

stinctuesis, the puzzling resemblance of the forms themselves nothwithstamling. 1\%. 105.

A purzling Desmidian form p. 106

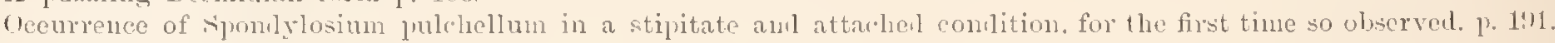
Exhihition of rare (some rery striking Desmilian species p. 192.

Extremely uninte Cosmarium form with zygospore. held to be a new species.exhilited. [C. ninutissinuml p. 19l. On a minute speries of "osmarinm with smooth lark brom rygospores p. :301.

(1) a cosmarium form seeningly the sane as Jacolwen's so called rar. of Cosm. Brebissonii p. 305-30ti.

A new species of statuastrum shown 1 . 16.1.

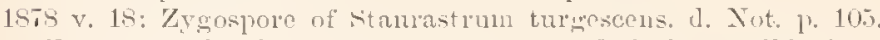

Enastrum divaricatum, Lundell, new to Britain, exhibited 1\% 10s. - [g].

New species of Closterium [mediolive], shown p. 214.

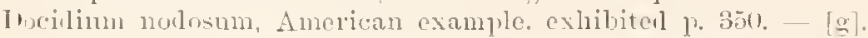

- 187! v. 19: New ('losterium from New Jersey [erassistriatum p. 1:0.

- Elongated unicellular alea, allied to the so called rlosterinu olbtuxum 1. 121.

Cosmarium 11. sp. very minute, with finely spinous Zygospore, exhilited. [lasiosporum] p. [23.

Cosmarium fontigenum, Tordst. 1. 121.

Pocilium Livsutum, Iniley; ocruling in sicotland. exhibited. p. 138.

A pobably new Cosmarim shown p. 411

Santhilium acanthophorun Noristedt, exlibited. 1' 11.

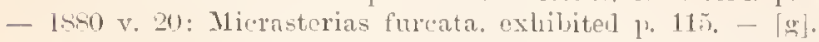

Cosmarium istmuehondrum, Nordst. new to Ireland, exhibitell p, 380. 


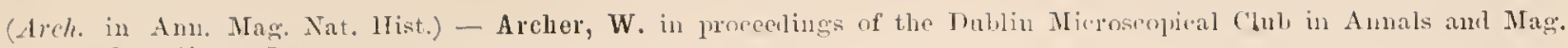
ot Nat. llistor. 5 ser.

- IS8L ช. Т: Cosmalium isthmochoudrum, Nurlst, new to Ireland. p. 335.

_. Stamrastrum lorasiliense, Lumbll, new to Trelaul. p. 340.

- The "puneta" distributed orer the smooth eell-walls of Desmidiete me really pits or depressions, not thiekenings 01. peints diflepent in tint from the rest uf the menbrauc p. $311-342$.

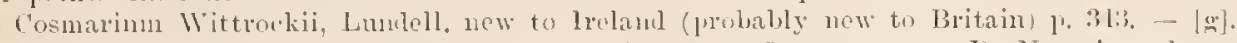

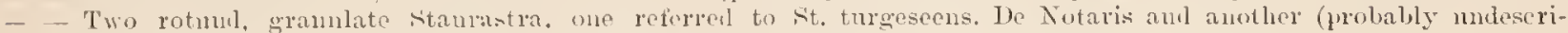
hell superficially resemluling hur. esscutially distinct, and with distinct zygospores 1 . 417.

- - Problematic c'losterinm-like "Semicell", its Nature, or its Plaee in Nature, muleciled, 1. 121.

- 1kir1 v. s: itaurastrum 11, s]. [it. colmutum] 1. 2:3:2.

Conjugated state of a compressed or twoungled form of citamastrum pterosporm, Lumlell p. 233 - 23.1.

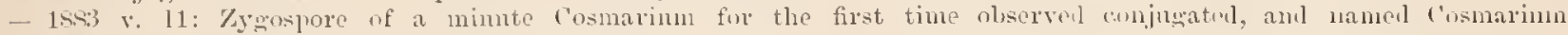
Wrightianum l. 20.s.

- Euastrum Almstrongiaunm, Arch, a very rase Form. exhibited p. 213-214.

Cosmarium platyisthmmn, n. s. p. 215-216.

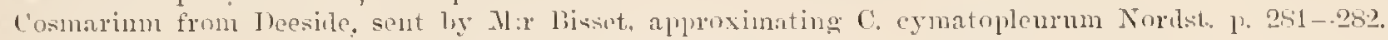

Cosmarim eymatopientum. Fordst., and hisottish and Irish Form p. 285.

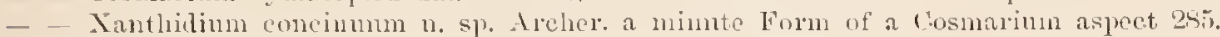

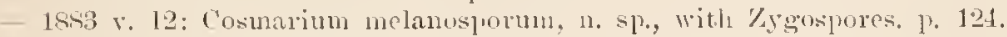

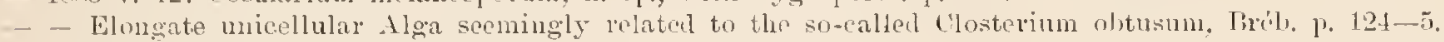

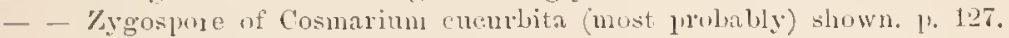

- 1.s.t v. 13: Ponim rufopellitm. Roy, from Comemara. exhibited, to show the exfoliation of the external relilish cortical Coating p. 140.

- Cosmarium arauthophorum. Nortst, exhibitel tu show that the form appartains ratler to Xantlialium. p. 142.

- - Spirotienia acuta. Irilse, not strictly appartaining to the geuns though of singular liabit. p. 111.

- - Staurastrum mesoleim n. s. exhibited p. 14.

- 1854 r. 14: Cosmariun striolatum, Nïg. ex horl, Reinsch, but seemingly a distinct speries therefrom p. 208.

- Micrasterias brachyptera, Lumdell. collectel in Westmoreland by Mir Biset aud uew to Great-Fritain, exhibited pag. 210.

- 1585 v. 16: Zygospore of Cosmarimu cucurbita l'. 145-146.

- Cauadian species of Cosmarium notabile, Bréb. 1. 147.

Ardissone, Fransesco. Enumerazione delle Alghe della Harea di Aneona. 32 plp. Fano 186io. - [g].

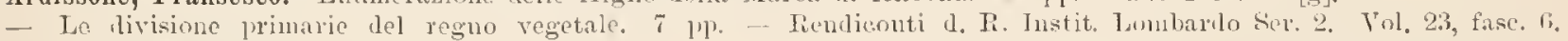
$18901 \% .281-285$.

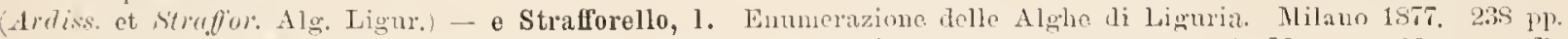

(Avtari Liste alg. Moscon.) Artari A. Liste les algues nloserves dans le gonvernement de Moseon. 2:3 pp. - Bull. de la Soc, des nat, de Moseon. 1851. 11 3. Tol. 5!, pt. 2. Mosron 1881. p. 121-11.1.

(Avtri Mater. alg. Moscon)- Materianx pour servir a lietude dos Algues de Mosent. Moscon $18 s$, 22 pp. - Bull. de la soe. i, les nat. de Moseon 1896 n:1) 3 l. 1tĩ - 184.

Askenasy, F. und Förster, F. Beiträge zur balischen Algenflora. - Mitteil. d. Badiscls. Botan. Tereins, 1s!r. X:o 101 1. $1-1 ;,-[\mathrm{s}]$.

Aspegren, G. Casten. Fïrsök till en Blekingok Flork. Carlslirona 1823. NTI + 107 l'll.

(Iiritey Contr. (queensl. Fl.) Bailey, F. M. Contributions to the Queenslands Flora. - Department of Agrieult, Bris-

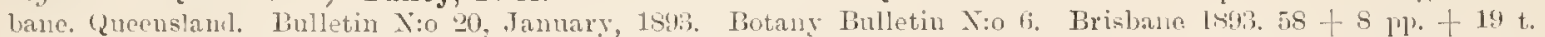

(Priley Amer. Bacill.) Bailey, J. W. Americau Bacillarin. Part I Desmidiacere. 1 + 21 p. - American Jouru. of

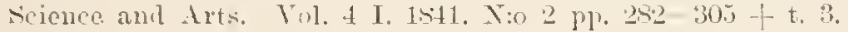

(Iniley Catsk. Desm.) On some new species of american Desmiliem from the Catskill Momntains. -- 「Ameriean Geo-

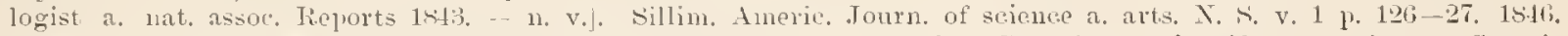

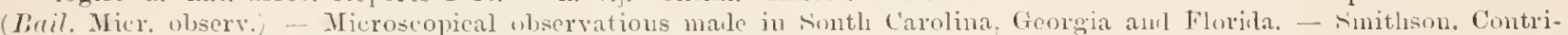
but. to knowlelge 1500 . Fol. 2. $4811 \%+3$ t. 1551.

- Totes on new species and localities of mieroseopieal organisms. Washington 1851. - [r]. Tmithson. Contrib. to knowletge Tol. T. (165.) 14 ple + 1 t.

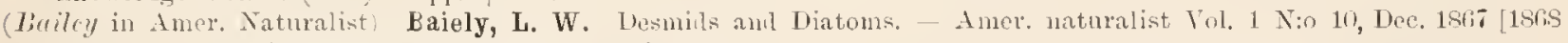

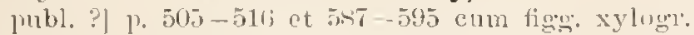

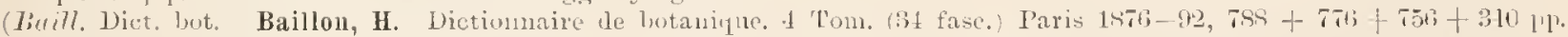

Balsamo, F. Kelipuic Cesatiane Crittogame del K. Orto lutanico racenlte lal. Prof. Barone V. Cesati. Alghe.

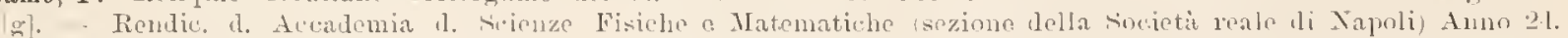

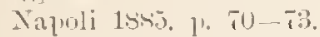

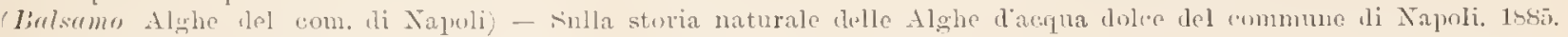

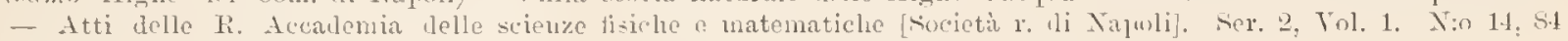
pl +2 tal. Napoli 1888.

Hnmonymia Algarum in plantis auimalilnsune tentamen. Neapoli 1888 . 25, p.

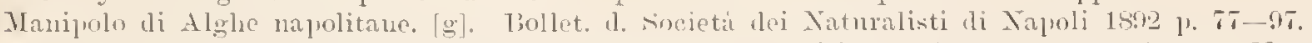

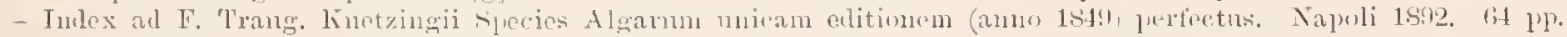

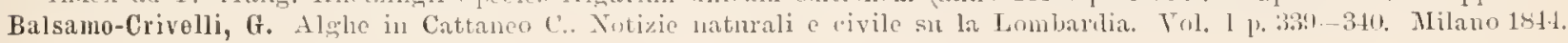

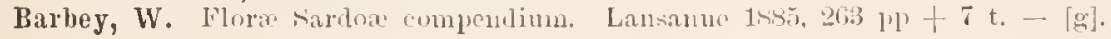


(Burker in Q. J. M. S.) Barker, J. in Proceeslings of the Dublin Microscopical Club. - Qnaterly Journal of Microscopical rieience $n$. $\mathrm{s}$.

- $1.9,6 \%$ v. 6: A minute Cosmariun ["C. quadratum or a small variety of that species"] 1) 118.

- Staurastrum seabrum new to Treland; also ... Griffithianum, slowed p. 184. - [g].

- Micrasterias Americana showed. ]. 275. - [g].

- 1868 v. 8: Showed specimens of Micrasterias fimbriata Ralfs. p. 286.

- - Showed examples of the conjugated state of Closteriun Lumula, for the first time seen in Ireland. 1. 294.

- 1809 v. 9: A new and remarkable species of Penim [P. spirostriolatum Park.] P. 194.

- - Shower Desmilium aptogonum new to Jreland p. 198 - 199. - [g].

- On a supposed new Staurastrum [St. clongatum Bark] p. 424.

- 1870 v. 10: Ftaurastrum gracile - haring but two arins. p. 86.

- 1873 v. 13: Zygospore of Arthrodesmus convergens exlibited p. $100-101 .-$ [g].

- Closterium rostratum conjugater, also occulence of Cosmarium plicatum Feinseh. p. 435. - [g].

(Ie Jury in Bot. Zeit.) Bary, A. de, Ïber die Copulation der Desmidiaceen, Zyguemaceen und Pilze (Syozygites). ïber die Feimung der Copulationsprodukte und die Ansichten über die Bedentumg der Copmlation. (Vortrag - - in Bericht über die Verlandlungen der botanischen iektion den 33 . Versanmlumg deutseluer Naturforselier und Ärzte, gehalten in Bom rom 18 bis 24 reptember 1857 von Dr Rob. Caspary). -. Botan. Zeitung 185̃. 1'. $765-7$.

(de Bury in Bot. Zeit. 185s, - Bericht uber die Fortichritte der Algenkunde in den Jahren 1855.1856 und $185 \overline{.}$ - Beilage 2. Botan. Zeitung 1859 p. $55-100$.

(Bary in Hedwig.) - Zn Gonatozygon monotenium. Hedwigia 1 n.o 16 is 185 p. 105-6.

(de Mary Copnlationsproc. im Pflanz.) - Ueber die Copulations-processe im PHanzenreich. - Berichte d. Natnof. Ges. 2u Freiburg. i. B. Heft. 3, N:0 20, A pril 1857. 21. 325-314.

(de Driy Conjugat.) - Untersuchungen äber dic Familie der Conjugaten (Zygnemeen und Desmidieen) 91 p. 8 tab. Leiprig $185 \mathrm{~s}$.

(re Tiary in Flora 1805) - Ueber Cosmocladium. - Flora 1,65 n:o 21 p. 321-830, tab. IV. ex p.

Beck, G. Flora von Hernstein in Niederösterreich nnd der weiteren Umgebung. Wien 1854.464 p. + 11 tab. apud: Becker. M. A., Hernstein in Niederösterreich (1. 179-612 + 11 tab.). [g].

- Flora von siudbosnien und der angrenzenden Herzegowina. I Theil. 55 pp. [g].; IV Theil 34 pl. (Algae. "Bearbeitet von kiegfried titockmayer p. T-10,-Annal. d. k. k. Naturhistor. IIofmuseums Vol. 1 n:0 4 p. 271 - 325 (Wien 1886). Vol. 4 n:o 4 p. 338-372 (Algie p. 345-34s) Wien 1890.

(Becli in Verh. d. Zool. bot. Ges. Wicn) - Uebersicht der bisher bekannten Kryptogamen Nieder-Österreichs. - Verlıandl. der k. k. zool. bot. Gesellsch. in Wien. Bd. 37. 1887. 1. 253-380. - - [g].

Belloc, $\mathrm{E}$ Aperçu général de la végétation lacustre dans les Pyrénécs. Paris 18:18. 21 pl. - Association Frą̣aise p. l'avancement des sciences. $189 \%$. $-[\mathrm{g}]$.

(Bem. Fr.w. Alg. Engl. Lake Distr.) Bennett, A. W. Fresh-water Alge (ineluding Chlorophyllaceous Protophyta) of the English Lake District; with descriptions of twelve new species. (I.) - Tourn. Roy. Microseop. Soc. Ser. 2 Vol. 6 Febr. 1856, p. $1-10$ + t. 1-2. - II. Witl description of a new genus and five new slecies. Ibid. vol, 8, 1888 P. $1-6+$ t. 1 .

(Dem. Fr.-w. Alg. Nortl Cornw.) - Fresh-water Alga (including Clilorophyllacens I'rotophyta) of North Cornwall; with deseriptions of six new species. 12 plo. t. 3 et 4. - Journ. Roy. Microseop. Soc. Febr. 18 i p. 8 - $19+$ t. 3 et 4.

(Brm. in J. Lin. Soc.) - On the affinities and ctassification of Algat. - Journ. Timn. Soe. Bot. 1887 v. 24 X:o 158, 30 Jun. p. $49-61$.

(Temn. Hybr. Desm.) - A hybrid Desmid. - Anu. of Botany Tol. 4 N:o 13 Nov. 18s9, p. 171-2. TVith TVoodent 4. [.Jan. 1890!]

(Benn. Fr. Alg. Irampsh.) - Freshwater Alge and Sichizophycere of Hampshire and Devonslipe. 10 pag. $t 1$ t. Jomn. R. Nicr. Soc. 1890 p. $1-10$ t. 1.

(Bem. Reprodr. Lower forms) - Reproduction among lower forms of regetable life. - Transact. Biol. Soc. Liverpool. Vol. 4, 1890. p. $97-114$ t. 2 et 3.

(Bem. Fr. Alg. SW. Surey) - Freshwater Alga and sihizophycere of south-west. Surey. 9 pp. +1 tab. - Jonrn. R. Microse. Soc. 1832 (Febr.) p. $4-12+$ t. 2.

- Non-sexual Formation of spores in the Desmirliacers. - Report of the 61 meeting of the British Association for the advancement of Science held at Cardifi in Angust 1891, p. 678 London 1892.

- Algological Notes. N:o 3. Spere-like borlies in Closteriun. - Ann. of Botany V. A N:o 21 Apr. 1892 p. 150 -152 c. fig. xyl.

and Murray, G. A reformed rystem of Terminology of the reproductive Organs of the Cryptogamia. - Q. Jonrn. Mier. Aic. v. 20, 1850, p. 413-120.

(Tergyr. in Ofvers. Vet. Aliad. Förhandl.) Berggren, S. Alger frin Grönlands inlantsis. - Öfvers. af k. Tetensk. Alial. Förhandl. Stockholm, 28:de irg., 1871 p. $293-6$, t. 5.

(Jerggr. in Ofvers. Vet. Akau. Förhandl.) - Bidrag till kännedom on Fanerogamfloran vid Diskobugten och Auleitsi-

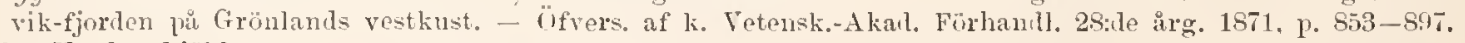

- Cfr Nordenskiöld.

Jerkel. Tntrod. ('rypt. Bot.) Berkeley, M. J. Introduction to Cryptogamic Botany. Isondon 1857 , 601 pp.

(Jerkel. in Anu, a. Mag.) - Description of a new species of ("losterium Cl. Griffithii). - Annals and Magaz. of Nat. Hist. ser. 2 vol. 13, 1854, 1\% 256 t. 14. f. 2.

Cfr J. E. Smith. English Botany.

Berthold, A. A. Lehrbuch der Zoningie, Guttingen 1St. 


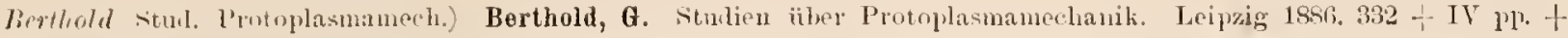
7 "ant.

Bessey, Ch. E. List of (ryptogams) - linlletin of Jowa Agriculinmal College, issuel by the Departempnt of liotany, Nor. I sst, part. 2 p. $1: 33-171 .[\mathrm{m}]$.

Botanical work in Minnesota. - Amer. Nat. v. 22 13. $66-67.18 .88$.

A supplementary List of recently reportel specins. - Recond Eilit. of Webber's List p. 45-5i3 ('fr Webler), - [g]. Cout. Tout. Dept. Unir. Nelraska. 11. s. 3, 1892.

(Bisset Desm. Windermere) Bisset, J. P. List of Desmidien fomm in gatherings male in the neighbourhood of Lake

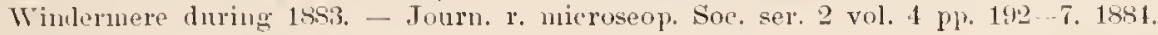

- (i) $R(1) y$.

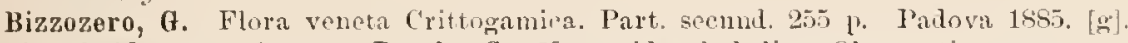

Boecli Naturv. (bserv.) Boeck, C. Naturvidenskabelige Olservationer m. n1. - Magazin for Naturvidenskaberne, Aare. 1826. 1 Hatie. Tigivet af et Samfind af Videnskahslykere. Christiania 1826 p. $16-t i 5+1$ tah.

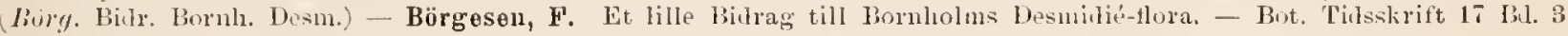
1.. P. $111-152$, t. (i, 18s?)

limg. Desm. Brasil.) - Particula 34. Desmilieie in: E. Warming, "Nymbolit ad Floram Brasilice centralis engnoseen-

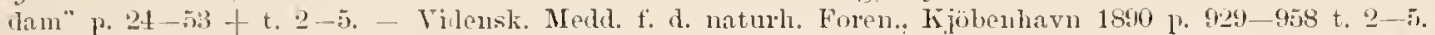

(Biiry. F. alg. (̈stgrönl.) - Ferskvandsalger fra Östgrönland. 11 p’. 72 t. Kjubenhavn 18n1. - Medilelelser om itrönland. 18.

(Bollin Snöalg̨ Pit. Lappm.) Bohliu, Knut. Snöalger fro̊ı Pite Lappmark. - Bntan. Notiser 1893 p. 12-46.

Bokorny, Th. Ueber die Thetheiligung chlorophyllführender PAanzen an der Selbstreinigung der Flüsse. - [g] - Areliv f. Hrgiene, 1s91, p. $181-196$.

(Buldt Sibir. Chloroph.) Boldt, Robert. Bidrag till kännedomen om sibiriens ChloroplyyHophyceer. - Ötvers. af K. Vet. Akad. forhandl. 1885, n:o 2 1. $91-128+$ t. $5-6$.

- En tapetartad algvegetation frin ett af vattenledningens filtra vid fianuelstaden. [Ref. in Soc. p. Faun. et flor. feun. 8 oct. 1SSi]. [g]. - Lotaniska Notiser 1857 p. 273; - et: Meddelanden af Sorietas pro fauna et Hora fenuica. Pars 15 l11. 215-216; - et "Ueber eine Algenvegetation aus dem Filtriraplarate der stältisehen Wasserleitung bei Helsingfors") in Fotan. Centralblatt vol. 36 (15ss) p. $156-7$.

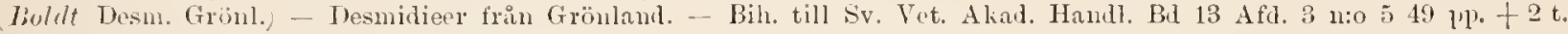
18st. Cir ejus "stulier ö. sütvattensalger ...")

(Boldt Desin. utbred. Nord.) - Grumdragen af Desmidieernas utbredning i Norden Bib. K. S'v. Yet, Akad. Hand. Bd 13 Aft. 3 11:0 6 [184i] 110 p. (Cfr ejus "Stulier öfver sötvattensalger ...")

- Studier örver sötvattensalger och deras utbredning:

I. Bidrag till kännedomen om sibiriens Chlorophyllophyceer (In: Öfvers. I. Yet. Akad. förh. 1885 N:o 2.) [Pars I non separatim publicata est].

II-IH. Akalemisk aflandhing . . . 31 Maj 188s. IIelsingfors 4 pp. + Stoekholm 154 pl. + 2 Tab. [Separ. ex: K. Sr. Vet. Ak. Bih. Bd 13. Afd. III n:o 5 et $6.18 x+$, t prefatio. II Desmidieen frăn Grönland. III. GrumlUragen af Desinitieernas ntbredning i Norden.

Bolton, Thom. Mieronganisms in a swampy ditch in Sutton park. - Midland Naturahist July 1s86. [n. v.]

(Tionliom. Totes) Bonhomme, J. Notes sur quelines algues d'eau donee. 1:er fragment. 8 pl. +2 pl. Rodez Juin 1sä́.

Biorge Bidr. Sibir. (Chloropl.,) Borge, 0. Ett litet bidrag till Sibiriens Chlorophyllophyeé-flora. - Bils. t. Sv. Tet. Akad. Handl. Bu. 17 Atd. 3 N:o 2 (1s91) $16 \mathrm{ll}+1 \mathrm{t}$.

(Borge subfoss. sötv. alg. Gotl.) - Subfossila sötvattensalger frin Gotiand. - Botaniska Notiser 1892 p. $55-58$ t. 1 f. $1-10$.

(Borge Alg. notis.) - Algologiska notiser 1-2. 1 Chlorophylloplyceer frin Japan. 2 Chlorophyllophyceer från inpetsbergen. - Botall. Notiser 1892 p. $58-60$ t. 1 f. 11 et 12.

(Borge Chloroph. Norsk. Finmark.) - Chlorophyllophyeer från Norska Finnmarken. - Bih. k. Śv. Vet. Akad. Iand.

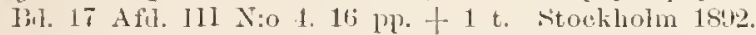

(Borge in Nuov. Totar.) - Uebersicht der neu erseheinenden Desmidiacen-Litteratur. I-IV. - Nuova Notarisia sur. 4 (1513) 1. 349-395; ser. 5 (1594) p. 490-519; ser. 6 (1595) 1. 15-29. p. $111-137$.

(Borge Sïssw. Chlor. Arehang.) - Süsswasser-Chlorophyeeen gesammelt von Dr. A. Osw. Kihlman in nördliehsten Russhad. Gouvernuent Arehangel. - Bih. k. Sv. Vet. Akad. Handl. Ibd. 19. Afil. IIL N:o 5.11 p. +3 t. Stockholm 1 s.'!l.

- Cir Sernander.

Bornet, E. Algues du département de la Haute Vienne eontenues dans l'herbier d'Édonard de la Chapelle. - [g]. - Bull. 1. 1. sne. bot. 1. Franee t. 39. 1si11. p. 24i-2\%.

Les Algues de P.-K.-A. Selınusboe récoltés au Maroe et dans la Mediterrarte de 1815 i 1839. Paris 18.r. 216 pl †

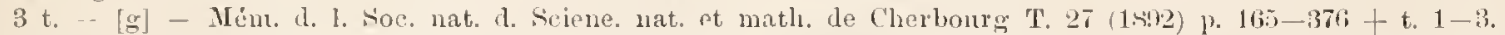

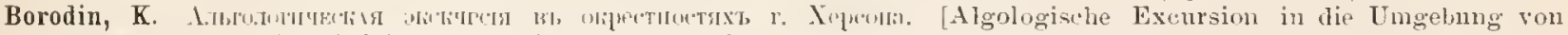

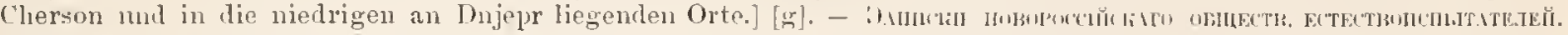
[Sehriften d. neurussisch. Gesellsch. d. Naturforseher. Tom. IV. 2. Odessa 1sit. ") yp.

Borščw, J. G. Materialien zur Flor der Algen des Tsehernigow'schen Guvernement) - Nehrift. d. Kiewsehen Naturforseliergesellsehaft. Bd. 1. 1570. Heft. 1. [Desmidiea 1) 52.1

- (Finige nene einzellige Algen aus der Umgebung vou Kiew). - Schriften der Kiewschen Naturforschergesellsehaft Bd. 1 1.70 Heft. 1. [Stanr. p. 148 t. i; f. 2. - Ninorein partem operis, nullam tabulam vidi].

(Bory in Encych. net. Planch. Vers.) Bory de St. Vincent. - in: Encychpedie métonlique XLVI:e Livraison. Planches.

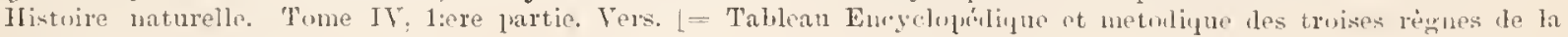
Simistedt, Index lesmil. 
nature contenant l'Helmintologie, ou les Vers infusoires, les Vers intestines. les Ters nollusques (etc). Par M. Bruguière-Septième livraison. Paris 17 it.

(Bory in Dict. class. hist. nat.) - in: Dietionnare claswiqne d'Histoire naturelle. Vol. 1 - 1522, $2-1822.3-1823$. 4 - 1525 (Nept.). $9-1520,17$ (Atlas) - 1.431.

(Bory in Eneyelop. mitl. Hist. Nat. d. Zoophyt.) -- Eneyel. méthod. Hist. nat. d. Zoophyt. on animanx rayonné. '1'ome 2. II part. 1'?21 [1-26? ]

(Dory Essa classif, anin. mier.) - Essai d"une classification des animanx mieroseopiques. Extrait du tome II (Zooplytes). llistoire Naturelle, de l’Eneyclopetie méthodirue. Paris 1isis. 101 pp.

Bosch, R. B. vau den. Enmeratio Plantarun Zeelandice Belgice indigenarum quarta. - [g']. - Nederlandselı kinidk. Areh. Vol. 1. 1848, 1).84-115.

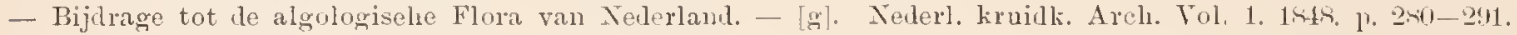

Brady, S. Desmidiex on the Northumberland moors. - Transact. of Tymeside Field Club. Vol. fi. part. 1 p. 90 1sias [n. v.].

(Brmun Pexjung.) Braun, A. Betrachtungen ïber die Erseheinung der Verjüngung in der Natur. XVI + 363 pp +

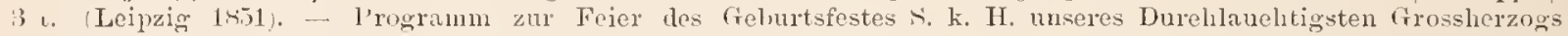
Leopold den 2!I Angust 1si!!. Im Name der Albert-Ludwigs-[riversität der dernalige Prorector. - [Npaitere Beigabe:] pp. V-XVI + $13(3 ;+3$ t. Freiburg in Bresgan 184?-50. [1850].

(Braun Alg. unicelJ.) - Algarum unicellulariun genera nova rel minus cognita, lumissis observationilus de algis nuicellularibus in genere. Lipsia 1 s.5. $111 \mathrm{pp}+\mathrm{t}$ t.

Bran in Bot. Zeit.) - Beobachtungen des Dr Itzigsoln in Nen-I ham iber verschierlene mikroskopisehe Algen (Tortrag in der Versammlung der Gesellsehaft taturforschender Freunde zu Berlin am 18 Deeember 1sĩsa). - Botanische Zeitung. Den 1is Januas 1sisti p $46-47$.

(Brum Teber Chytrid.) - Ïber Chytridium, eine Gattung einzelliger Schmarotzergewächse auf Algen und Infusorien.

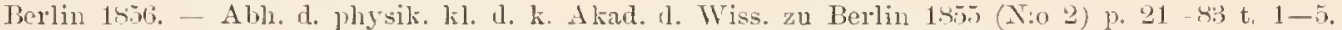

(Brmu in vitz. Bex. naturf. Frennd. 1s67.) - Zeichnungen von Herrn Dr. Ilerm. Itzigsohn in Quartsehen, betreffend Entwicklungsvorgänge von Zooglvea, Oscillaria. Synedra. Staurastrum. Spirotania und Chroolepus. - NitzungsBericht d. Ges. naturf. Freunde zu Jerlin 1sir p. 30-31.

Vorlüufige Mittheilungen über die Algenflora der Gewäehshänser des botaniselıen Gartens. -. [rr?. - Sitzungsberiehte der naturforschenden Freunde. 20 Juli Berliu 1kits. p. 9y-100.

(Brib. Alg. Falaise) Brébisson, Alph. de et Godet P. Algues des environs de Falaise deserites et dessinées ... . Falaise 183i. liti py $+\boldsymbol{T}$ t. - Mem. le la Soc. aeal. d. sc. arts et bell. lettr. de Falaise. 1835. Falaise 1.5315. 1pl.

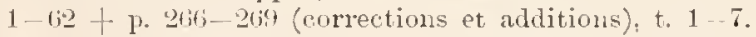

(Bréb. in Chev. mier.) - Sur les preparations néeessaires a l'étude des Algues inferieures. ¿ Catalogue des Especes connues des Desmidiées: et des Diatomées ou Baeilarices. - In: Chevalier Des microseopes et de leur usage Paris 1839. [Desmidiés ]. $271-3$.

(Brélb. List.) - Liste des Desmidiées, observées en Basse-Normandie. - Additions ì la liste . . . et Expliıations des

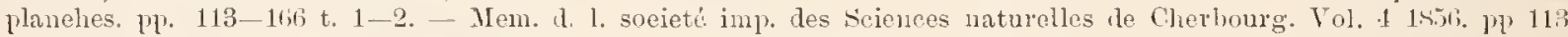
- 10i2, 301-4 t. 1-2. - [Cir Itzigsolu $]$.

(Bréb. in Diet. univ. hist, nat.) - in: Dictiounaire universelle d'histoire naturelle . . dirigè par Mr. Charles d'Or-

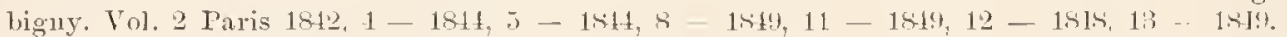

Britton, N. C. A Priliminary Catalogne of the Flora of New Jersey. Compiled for the geologital Snrvey. New Bramswick $1841233 \mu$ (Cfr Hulle).

Catalogue of plants found in New Jerser. (Desmidiea by F. Wolle p.413-130). 'l'renton 1sit!. - [g]. Final Report of the State Geologist II. 1). 25- (i;2. Issued Mai 1

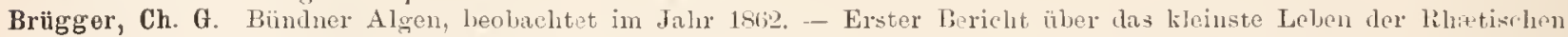

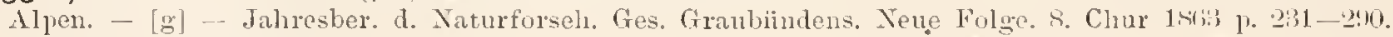

Brun, L. Su les Diatomées des Alpes et ilu Jura. -- [ph.] - Ann. d. l. Soeiété Belge de Nlicrosiop. t. 4. Bullet. p. CL - CLII. Biturelles 1sis.

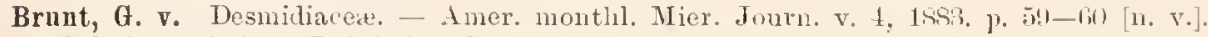

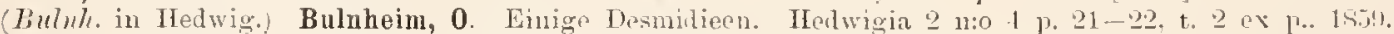

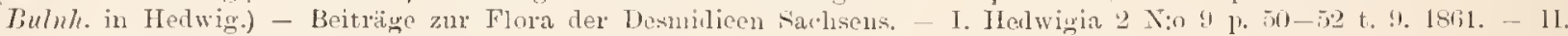

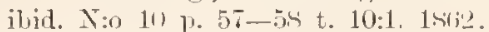

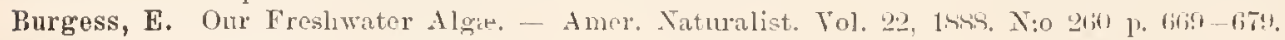

(Bumett Ontlin. Algol.) Burnett, G. 'T. Outlines of Potiny; being a practical guile to the stuly of plants. Nos. II III. Outlines of Algologia. London. April 1833. $161 \mathrm{lpp}$.

(Buller in Amer. Naturalist) Butler, E. An activ besmill. - [pls]. - Americ. Naturalist v. 16. July 1se? p. Isl.

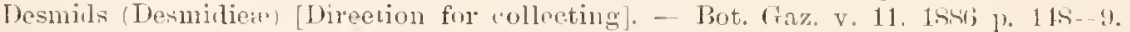

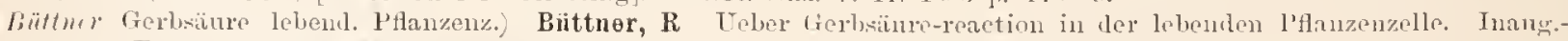
Diss. Erlangen den 4 Mär\% lsin!. til p].... [1].].

Buxton, R. A Botanical Guide to the flowering plants. ferns. mosses and alge, found indigenous within eighteen mi-

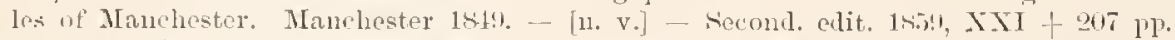

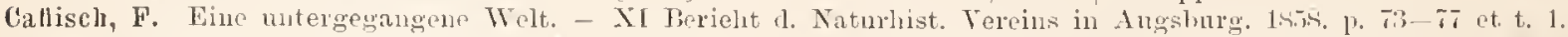

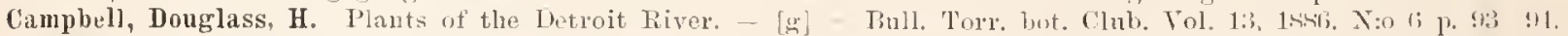

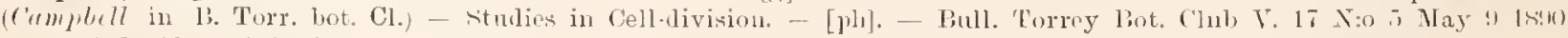
1. $113-121$ t. $1112-3$.

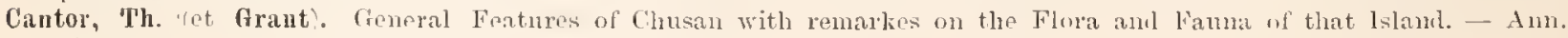

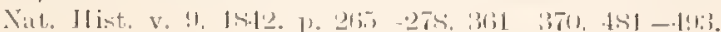




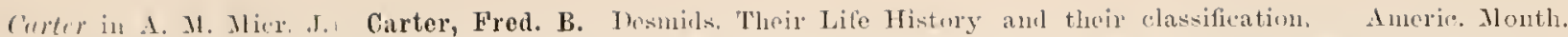

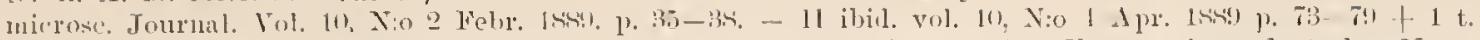

Caspary, R. Bericht über die Verlandlungen lor botaniwchen Sektion der 33. Fersamnlumg dentscher Naturforscher mul derzte, gehalten in Ponn vom 1S. bis 21 september 14.7. (Cfr A. de Bary \& Focke). - Botauiselı Zeitung

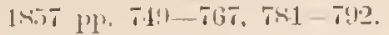

Cattaneo, Achille. Eleneo delle alghe della provineia di Pavia. - [g]. R. lnstit. Lombarlo di Sei. e Lett. Ser. 22 v. 1:3 p. 19.5-2011. Milano 18 sion.

Cosati, V. v. lie Pflüenwelt in Gehiete zwisehen dem Tessin. dem Po, der Sesia und den Alpen. - [g]. Linnza v.

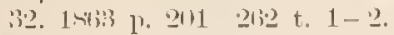

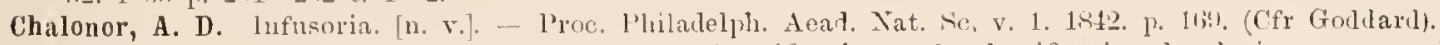

Chauvin, J. F. Recherelues sur lorganisation. la fruetification et la classification le phusieurs genres d'algues avee la Irscription de quelques espiees inédites ou peu connues. Cä̈11 1.212. 1322 1p.

Chmielewski, W. Materialien zur Algenflora des Gouvernements Besarabien. [ڤ̈]. - Memoiren d. Neurussiselien Na-

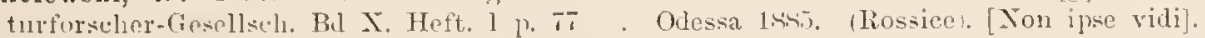

(hmicle. in Fr. Sue, nit. Khark.) - Jateriaux pour servir it la morpholngie et physiologie des procés sexuels cluez

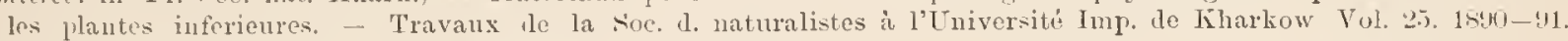

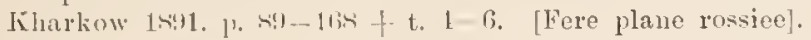

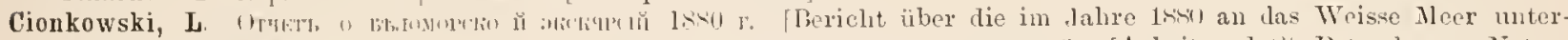

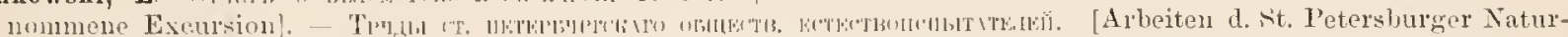
forseher-Gesellschaft.) Tom. XII. s. 130 -171 + 3 t. St. Petershurg 1 sisi.

Clerbois, P. et A. Mansion. I'remière liste d'Alones Clilorophycées et P'hycochromaces ubserves anx environs de Ifuy. [er]. Bull. de cerele des Taturalistes Ifutois. Bull. Y:o 1. 1.\$13. p. 35.

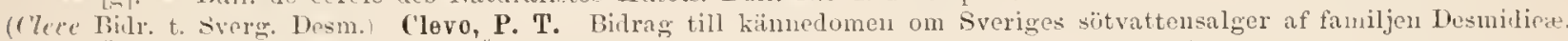

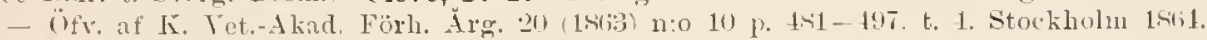

Close, M. H. Stauratrum pileolatum Brél.) at Leenane. Dubl. mieroscop. Chub. 1s July 1sis -- [g]. - Quart. Journ. nicr. Soc. 11 s. vol. 12, 1463 p. 1411.

(cohn Mikr. Alg. u. Pilz.) Cohn, F. Untersuchungen über die Entwickehugsgerchichte der mikroscopisehen Algen

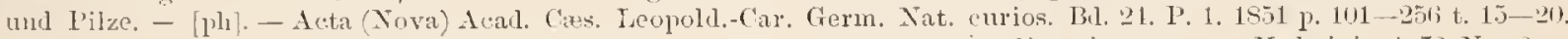

- Conspectus familiarun cryptogamarum secundum methodum naturalein dispositarum. Hedwigia 1sie Xio 2 P. 17. 211 .

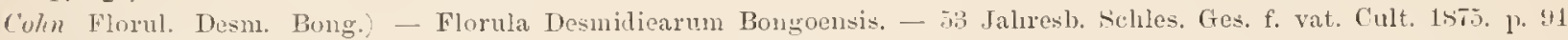
: Mi. Breslau 1:iti;

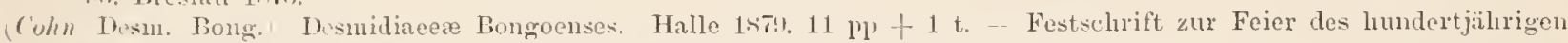
Besteliens der Taturf. Ges. in Halle a S. p. 2-59-27.2 t. X゙T.

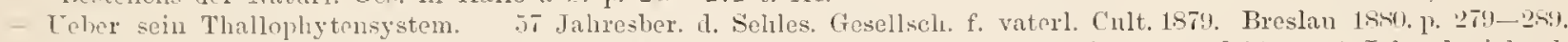

- Coher ein merkwiiliges Torkommen von Algen in den Breslanex Wasserteichen. - [1, - 61 Jahresberieht d. Schles. Gesell. f. vaterl. Cult. $(1-6 \times 3)$. Breslau 1881 p. 1:m.

Collins, F. S. Alga of Midlesex County. Malden. 1ss', 11; pl. - [g] - Dame, L. L. and Collins F. S. Flora of Midlesex County, Vassachusett.

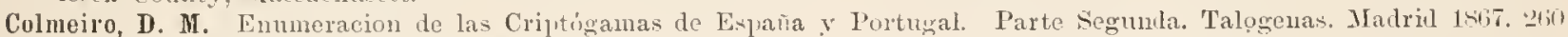

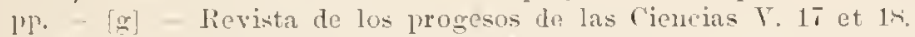

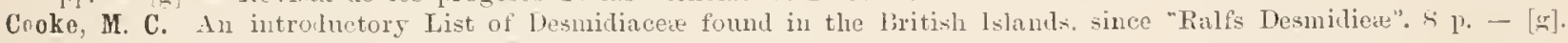

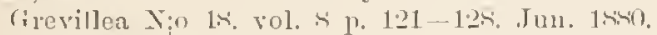

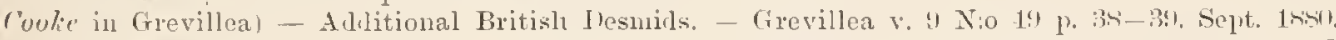
Cooke. M. (') New Cosmarium in Trafalgar Square. (Cosmarium trafalgariem Wittr.). - Grevillea v. 9 X:o 1!! P. 11i. Sept. 1siri.

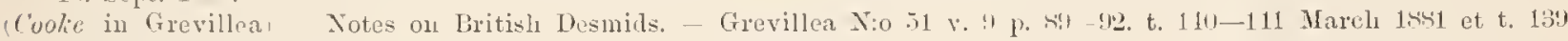
in N:0 5il Dee. 1sisi).

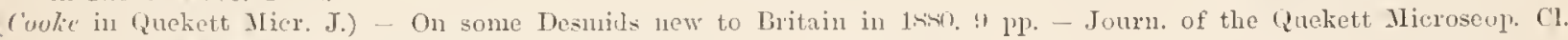
vol. it X:o 1ti llarele 1 sist p. 2013-211 t. 13--16.

(coolic Brit. Fr. Wat. Alg.) - British Fresh-water Algie. Exclusive of Desmilliea and Diatomaces. Vol. 1 Xo "2. Lnidon 1isto?.

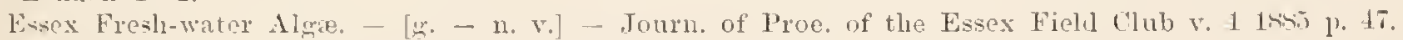

(roule Brit. Desul.) - British Desmils. A supplement to British Freshwater Algev. N:o 1-1; 1. 1-ik. t. 1-48. Londou

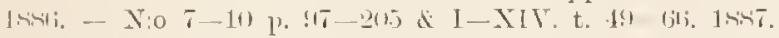

(orlu in Alm. de (arlst). 1835.) Corda, A. J. C. Observations sur les aninaleules microseopinues, 'pu'ou trouve aupres les caux thermales de Carlsbal. - Almanach de Carlsbal par le chevalier Jean de Carro. ise Annce. Prague

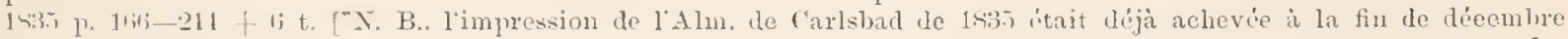

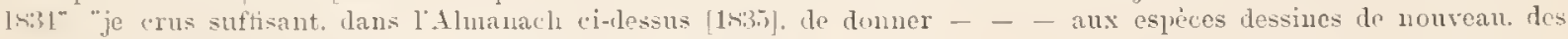

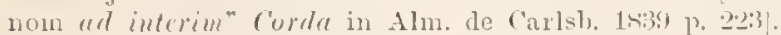

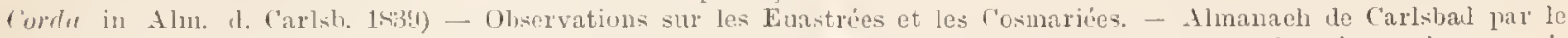
chevalier J. de Carro bie Amée Prague 1sis! p. 213-211 + li t. [Tag. "216: "C"est par la méme raison que jo niabstins de fixer dans les animalcules dessinés les caractères distinctifs des genres et des esprees. nue eontenant de nominations provisoires". - - - J.

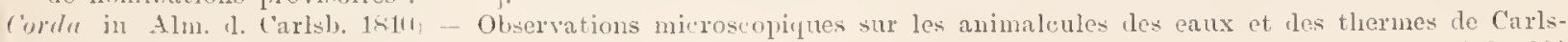

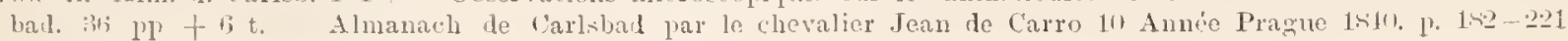
$+i \mathrm{t}$.

- Cir. Sturm. 


\section{CORTI}

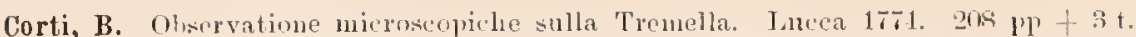

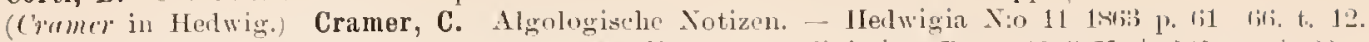

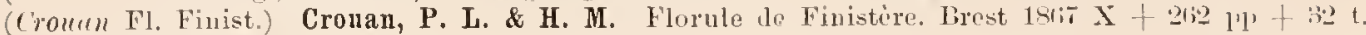

(reve in Q. J. M. S.). (rowe in proceedings of the Dublin Microseopical C'lub. - Quaterly Journal of Microsecpical Science. 11. s.:

- 1Sirif v. li: Cosmarium curtum slowed. p. 192. [g].

Cosurarinm tubereulatum. 1). 2-5.

- 1sis v. S: Exhibited Welsh sperinens of Enastrum didelta conjugaterl. showing the zygospore finlly formet. p. litj.

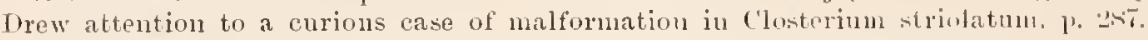

Recorter Micrasterias fimbriata from the late gathering. male on the occasion of the Club excursion to Timehely. p. 2:11. $[\mathrm{g}]$.

- Slowed examples of the zygospore of Mierasterias denticulata. 1. 294. [i.].

- 186 . v. 9: Closterinm linea Perty, conjugated. 1. 12.5.

Ix/1 v. 11: A Cosmarimm from near Multifarman. p. !

- 1472 Y. 12: A cmious. as it were, arrested state of conjugative process in Stanrastrum cunpidatum. p. it.

Stanrastrom sexeostatum. p. 311, [o $]$.

1si: v. 1:3: Tetrachastrum mneronatum (Dixon) = Micrasterias ucitans (Ralfs) in part. p. 21:.

Habitat of Cosmarium curtum. p. 311). [g].

- Mesotreninm violascens (De Bary), p. 31!. $[\mathrm{g}]$.

- Exhibited Staurastrum Meriani Reinsch. 1\%. 137.

1.7. v. 1.1: Conjugated state of Desmidinn Swartzii. 11. 1115.

Exhibited Cosmarinu Holmicuse $\beta$ Lundell. 1. 21:3. [g].

Exlibited ('losterinm linea Perty, p. 211. [g].

- 1иті v. 16: Several species of Micrasterias. p. 105. [g].

- Exhibited new Cosularinu sp.. 1). 411 .

Conjugated state of undeseribed Cosmarium slown at preceding meeting of the Club. 1\%. 117.

- Liti v. 7: Exlibited cosmarinm cyclieum Lnnd, p. 112: [o].

- Exhibited Cosmarium form coming elose to Cosm. Hanmeri Feinsch and homalodermum, Nordstelt; its identification as yet in abeyance. 1. 301.

1880 v. 20: Santhidiun Robinsonianum Arel... shown from a new uidland irish locatity. 1\% 111.

$Z_{y}$ yospore of Xanthidium Robinsonianum exhibited. p. 115.

- Kyogospres of Xunthidinm Robinsonianm. Areher. exhibited for the secoud season ([n proceed. Muhl. Micr. Club.). - Alin. a. Magaz. Nat. Hist. i ser. vol. 7. 18sis. p. 3 t3.

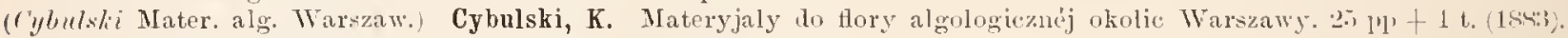
- Pamietnik Fizyjografiezny v. 3, 1483. p. 24. -273 + t. 1i-11).

(I)alrymple in Ann. Tat. Ifist.) Dalrymplo. C'losterium, a detail of its appearance and general structure. [in l'rocee-

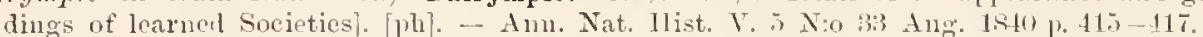

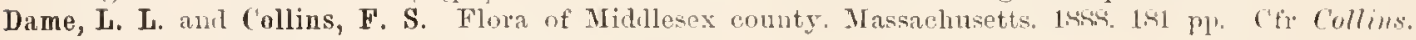

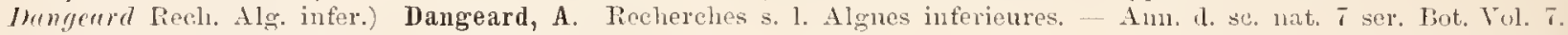

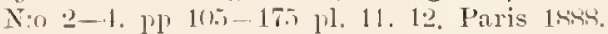

(Dongeard in L.e Botaniste) - Reclerehes histologiclue sur les Champignons. - Le Botaniste 22 ser. 22 fase. (10) aout

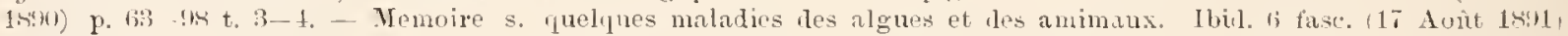
1. $231-20$ is + t. $16-1 !$.

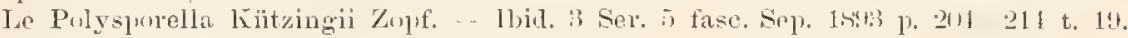

Deane, H. On the Ocenrence of Fossil Xanthilia and Polythalania in C'haleh. - Trans. Micr. Soc. of London vol.

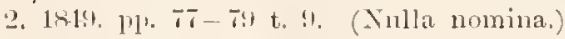

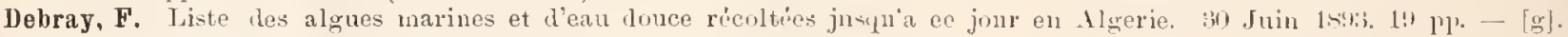
Bull. scientifique d. 1. France et d. 1. Belgique tom. 25. 15!3:.

Decaisne, E. in: Dictionnaire univers. d'histoil natur. Vol, 1;. 1sis.

Decaisne, J. Essais sur une classifieatinn des Algnes et des Polypiers calcifires de Lamouronx. - An. d. scienc. nat.

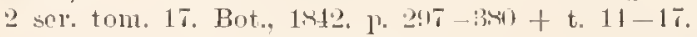

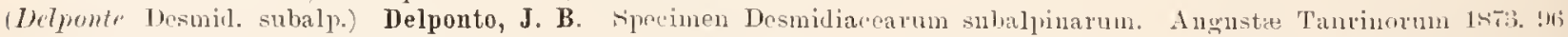

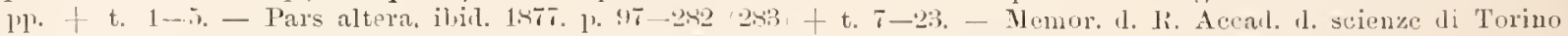

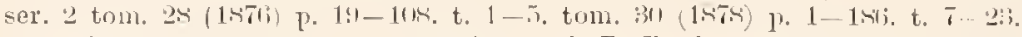

(Desmrä, Descr. esp. nouv.) Desmazieres, J. B. H. J. Deseription de plusienus espioses nouvelles, et remariues sur queliues antres qui seront publićes, on nature. dans le fuscicule XVIl des plantes cryptoganes de France. et lans

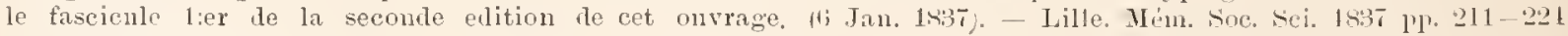
tiab.

Dickie, A. Fotanist's Guide to the counties of Aberdeen and Banff and Fincarline. 1sfo. (1)ist of Desmids p. 2un$3(n i) .-[\mathrm{g}]$.

"Freshwater" Algw" in Rolort Brown. Florula Discoana. - [g]. - Transact. Jot. Soc. Edinburg rol. !1. 1sik, p. $11 ; 2-41 i 1$

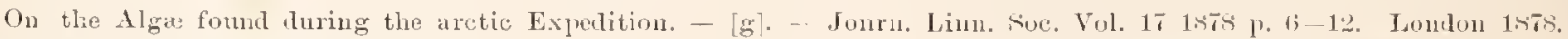

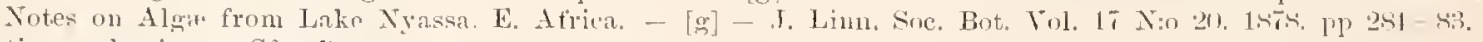

Dictionn. clasinue. Cfr. Bory.

Dictionmaire des ticienees Natmelles. Dr. Mlaimille, Leman.

Dictionn. miv, d'histoire natur. Cfr Bribisson, F. Decuisne et Wontayne. 
Dillwyn, W. Britisle Conforvit or Colored Figures and Peseriptions of the Fritisli plants referred ly Botanists to the

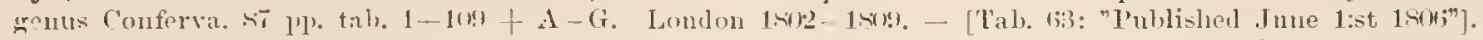

Jixon On a new Genus) Dixon, R. V. On a new Genus anl species in the Desmidinece; witl some remarks on the arrangement of the renera and species of Micrasterias and Euastrum. - Dubl. Nat. Hist. Soc. Pr. v. 2 145!' 1.202

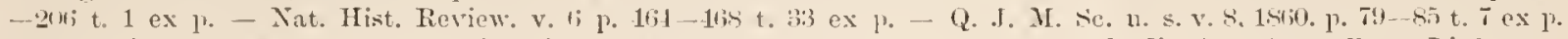

Dodel-Port, A. \& C. Anatomisch-plysiologiseher Atlas der Botanik für Hoeh und Mittelschuleu. Erste Liefertung. lisilingen a. N. 1ヘז́s.

Dorofejow, N. Materialien zur Algrntlora der. Unuegend von Kischinew und theilweise des kischinewer lineises). -

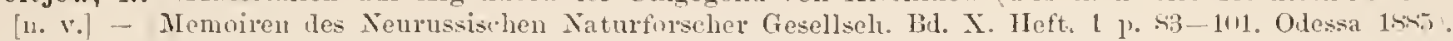

Duby, J. E. Aug. Prrami de Candolle Botanicon Gallicum ses rynopsis plantarum in Flora Gallica descriptarum. Elitio secunda. Pars seeunda. Paris $1 \% 30$ p. $545-1068$.

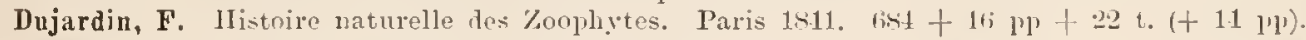

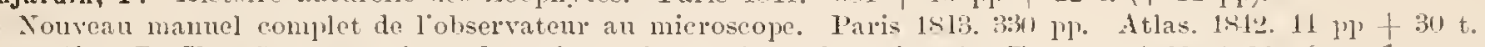

Dumortier, B. Ch. Connentationes botaniea Observationes botaniques'. Tournay 1422 1142:3 . [11. v.].

Edwards, Arthur Mead. Tote on a point in the liabits of the Diatomacee and Desmilliacere. Proc. ut the Buston

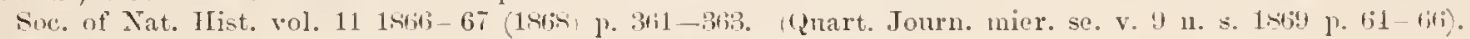

What is a Desmid.? - Amer. Nat. v. 3 1. $: 313-323$ + t. 5. 1864.

On "Species" in the Desmidieit. [n. 1.]. - Amer. Monthl. Micr. Jo11. v. 15. 1891. 1. 2!n-300.

khronl. Symb. Plyss.) Ehrenberg C. G. Symbola Physicie seu Icones et descriptiones animalium evertelinatorum. sepoxitis insectis ftu ex itinere pre Afrieam borealen et Asiam occidentalem Frederici Guielui IIemprich pt Christiani G. Ehrenber medicine et chirurgie doetorum studio novie aut illustratie redierunt. l'ercensuit et regis jussu et impensis edidit... Deeas prima, Berolini 1 128 [1828-1832].

(Khenl. Beitr. z. Kenut d. Infus.) - Beiträge zur Kenntniss der Organisation der Infusorien un! ilurer geographiselıen Verbreitung besonders in sibirien. Gedruekt am 13 Aug. 1830. - I'hys. Abhandl. d. K. Akar. d. Wissenschaft. zu Berlin 1:30. p. 1-4.4, t. 1-8. Berlin 1832.

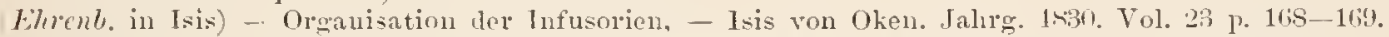

(F) Wenb. in All. 1. Berl. Akad. 18-9.) - Die Geographische Verbreitung dor Infusiousthierehen in Norl-Africa und West-Asien. beobachtet aut Hemprich und Ehrenbergs Reisen, mitgetheilt von Ehrenberg. - Abh. d. li. Acad. d.

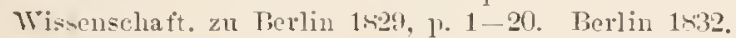

(Khrub. Entw. d. Infus.) - Ueber die Entwiekelung und Lebensdauer der Infusionsthiere nebst fernere Beiträge zur einer Fergleiehung ihter organischen Systeme. Gedruckt im Jantar 1832. - Phys. Abl. d. k. Akad. d. Wissensch. zu Perlin 18:31, $15 \mathrm{l} \mathrm{pl}$. $+4 \mathrm{t}$. Berlin 1-33.

rymonyme \%u Müllers und Ehrenbergs Infusorien. - Isis, von Oken. 1s33 col. 211 -255. Symonyme zu Bory do St. Vincent's Infusorien. - Isis, vou Oken, 1831 eol. 1191-1219.

(Ehrenb. Organ. kl. Raum.) - Dritter Beitrag zur Erkenntniss grosser Oroanisation in der Richtung des lileisten Raumes, - Physikal. Ahh. d. k. Aead. d. Wiss. zu Berlin 1.93 1\% 145-33i + t. 1-6. Berlin 1535. - Separatim: Orcranisation in der Richtung des kleinsten Raunes. Dritter Beitrag 192 p. Berlin 1831.)

Ehronb. in Abh. d. Berl. Ak. 1s35, - Zusätze zur Erkenntuiss grosser organiseher Aushildung in den kleinsteu thierischen Organismen. Berlin 1836. - Phys. Abhandl. d. k. Nhar. d. Wissensch. z. Borlin. Aus dem Jahre 1s35, 1. $1.01-1,90$, t. 1. Berlin 18:37.

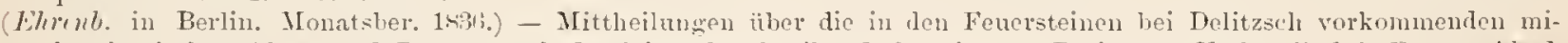
krosnopisehen Alwen und Bryozoen als Begleiter der fossilen lnfusorien. - Bericht ï. Verhamll. d. k. Preuss. Aliad. d. Wiss. z. Berlin. I. 18:36 1) 114-115.

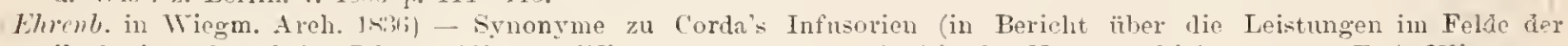

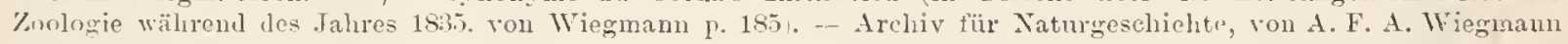
2 Jalirg. 2 Bd. 1 (si3t).

Ehronl. in Fres deutsch. Naturf.) - Die nenesten Fortschritten in der Erkenntniss der Infusorien als Felsunasen.

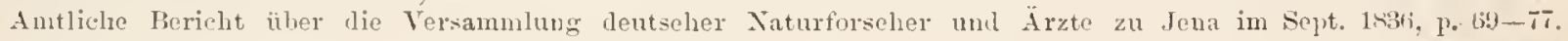
Neintar 18,37 .

¿̈ber die fossilen Infusorien-Gattungen Xanthidium und Peridinium. - Wriegmanus Areh. f. Naturg. III, 1, 1sş 1). $273-5$.

(Flumb: Entileck.) - Ehrenberg's nenere Entdeckungan ïler die Baeillarien (von Wiegman?). - Arehiv f. Naturge-

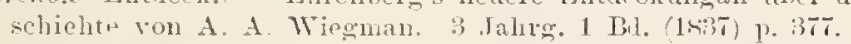

Teber das Massenverhältniss ler jetzt lebenden Fiescl-Infusorien und über ein neues Infusorien-Conglomerat als Polirsehiefer von dastraba in Ungarn. [g]. - Beri'ht. d. Terh. Preuss. Akad d. Wiss. zu Berlin II. 1837. P. 10j-10T. Loher die Knospemparung oder Toppelknospenbildung, Zygosis s. Conjugatio gemmarun. als hesondere, bisher wenimer beobachtete Fort, itanzungsweise bei lflanzen unt Thieren. [g]. Berieht. d. Verh. Preuss. Akad. Wiss. z. Berlin I1, 1483 1. 153-1.ivi.

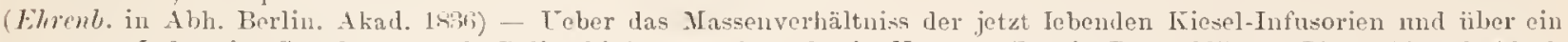
nenes Infuserien-fonglnmerat als Polirsehiefer von fastraba in Ungarn. (Berlin Dec. 1837). -- Phys. Ablı. d. Akaul. 1. Wiss. qu Berlin. 1s:3t. 1) 10s 1:3i + 2 t. - Q Quorue separatim in fol.: Die fossilen Infusorien und dite lebendige

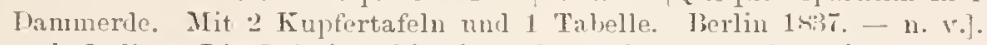

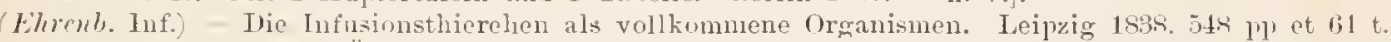

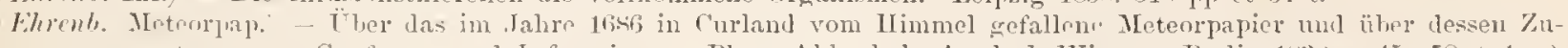

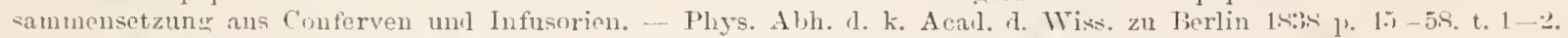
Torlin 1.3\%) 1:0 Repratiu: Mikrosknpische Analyse des eurländischen Meteorlapiers und Erläuterung desselben als ein Irodukt jetzt lelender Conferven und Infusorien. 11 pl. Berliu 1534. Fol.?

- Beobachtungen iiber neue Lager fossiler Tufusorien und das Vorkommen von Fichten-Blüthenstaub neben deutlichem 


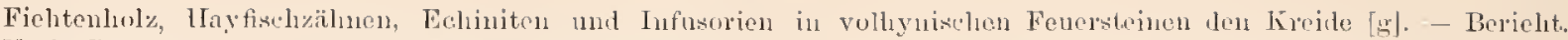

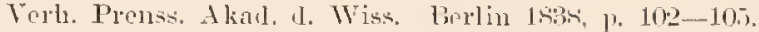

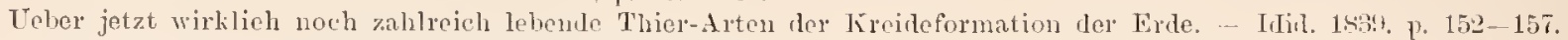

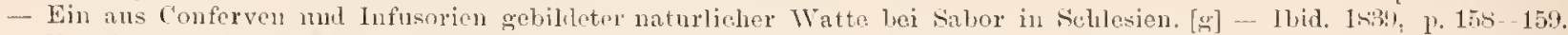

- Erweiterung seinel Mitheilung iiber jetztlebende Organismen der Kreile. [g] - Ibid. 1839, p. 17.5-17!.

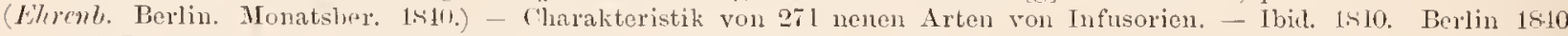
1. $1 \leqslant 17-219$.

(Fhenb. in Berieht. d. Berl. Ak. 1st1.) - Über Verbreitnng und Einfuss des miliroscopisehen Lebens in Süd- nud

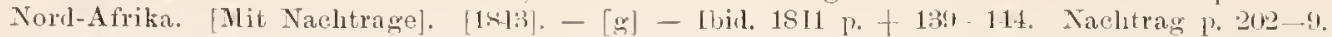

Ehrenb. Mikr. Leb. Süd. 11. X. Amer: - Verbreitung nud Eimfnss des nikroskopiscehen Lebens in fïu- und Nortamerika. 155 p., 4 t. Berlin 1.43. - Thysik. Abh. Prenss. Ak. d. Wiss. zn Berlin 1st1, 13. 201 - 115 + 1 t. Berlin 1.413.

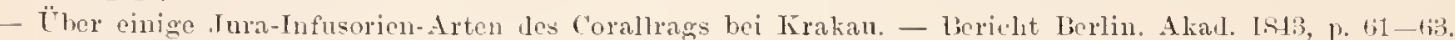

- Reiche boimisehung von mikroskopischen Organisnen in chinesisch. Blumen-Culturerde und Ver\%eichniss von 12t Arten chines. kleinster Lehensformen. - Ibid. 1.447, p. titi-1:4.

Untersuelnng des mit dem rothen sichnee in Pnster-Thale vorgekommenen rothen Staubregens. [g] -- Ihid. 1sis, 1. 43-139.

Ueber das nuikroskopiachen Lehen in 'Texas [y]. - Ibid, 1919, p. 4t- \$1.

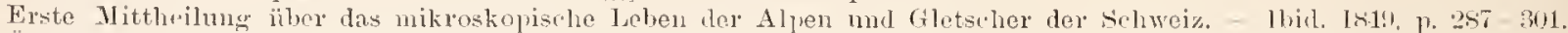
Über die nuesten die Formbestäntigkeit und den Entwicklungskreis der Formen letreffenden Bewegnngen in den organischen Xatmuissenschaften. [ph.] - Ilir. 1sit, p. 7i1- 7!5.

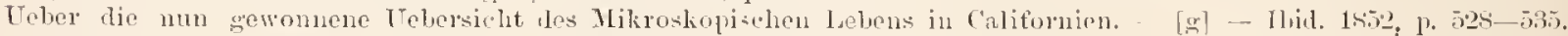

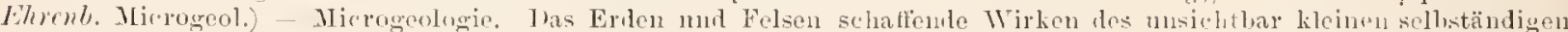

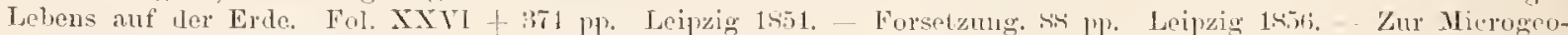
logie. Einundvierzig 'lafeln mit iilue viertawent grossentheils coloriten Figuren gezeichnet von Verfasser. Leipzig 1sis: $: 31 \mathrm{pp}$. $+41 \mathrm{Tab}$.

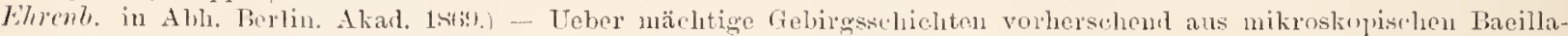

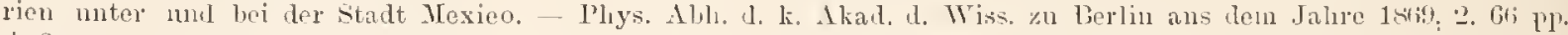
+ $3 \mathrm{t}$.

Eichhorn, J. C. Beyträge zur Naturgeschichte der kleinsten Wasserthiere die mit blossem Ange nicht können geselien werten nul lie sich in den Gewässcru in und um Danzig befinden. Danzig al pu + s tab. (Berlin und stettin in Commission bei Nirolats. 1Tí1)

(Eichler syllab. d. Vorlesung.: - Eichler, A. W. Syllabus der Vorlesungen ïber specielle und medicinisch-plariuacoutische Botanik als zweite vermelnte und umgeabeitete Anllage des "syllabus der Vorlesungen über I'hanero-

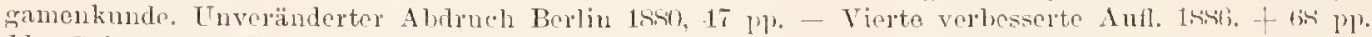

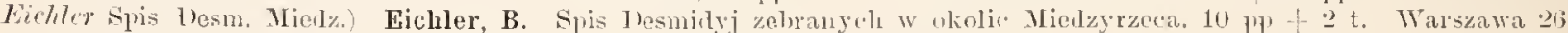

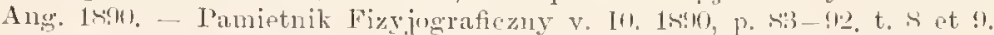

Eichler Mat. flor. Miedz.) - Materyaly do flory wolorostow ololic Miedzyrzeca. 19 p1 + 2 t. Warszana sept. 1s'l3.

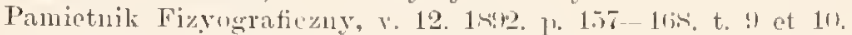

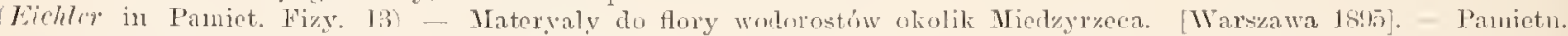
Fizyograf. Tons. 13. Drial 111, 1, i:3- $(i 3$, t. 1

(Wichl. et Ciutu. in Frakan Anzoig.) - Eichler, B. ct Gutwinski, R. De nomnllis spreichus algarum novarun. Arzeiger d. Akat. A. Wistenseluat. in Krakan. Juli 1 sol 1. 237-211.

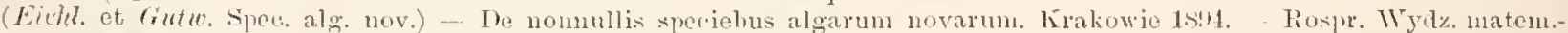

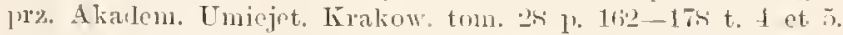

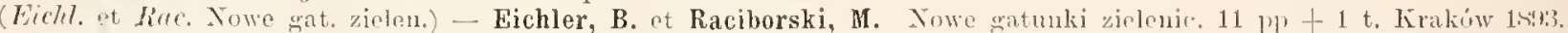

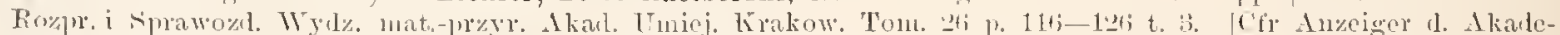

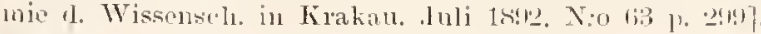

Fichwald, v. Beitrag zur Infusorienkunde Rnsslanis. Mit Natlitr. 1-3. [n. v.] - Bull. Soc. Nat. Moscou v. 17. 20, 21. ‥5).

Fiff. Finsk. Desm.) Elfving, Fred. Anteckiningar on Finka Desnilieer. - Arta Soe. pro fauna et Hora fenuica v.

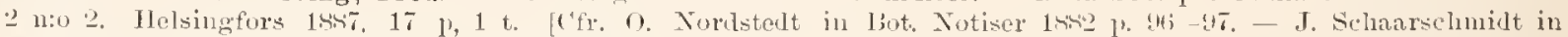

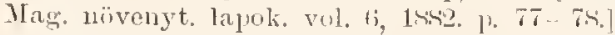

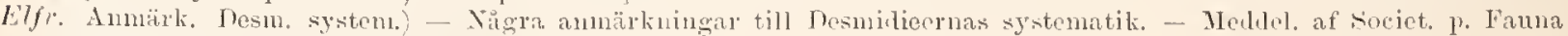

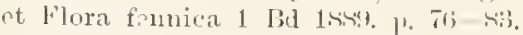

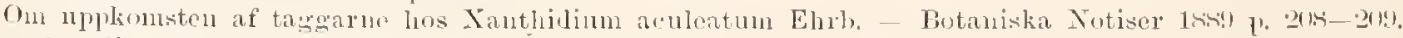

Eneyclopedio methodinue. riti bion?.

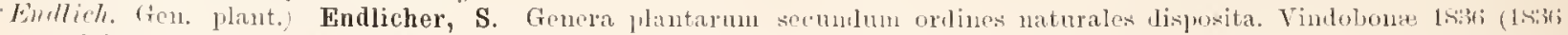

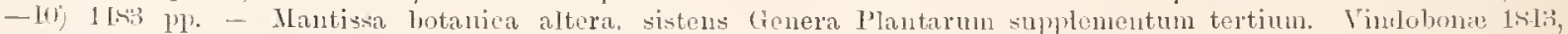
111 lp.

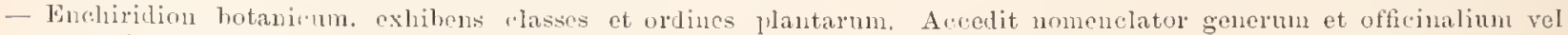
nsualium inlicatio. Wien 1. 111 . This ll.

Ersch, J. S. und Grnber, J. G. Allgemeine Eneycopedie mler Wissenschaften und Lünste in Alplabetiselier Folge.

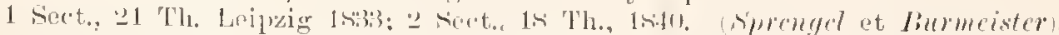

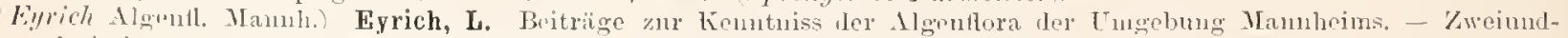

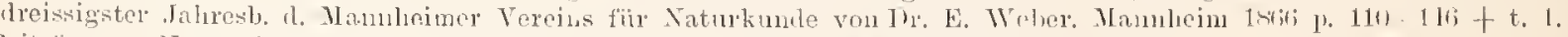

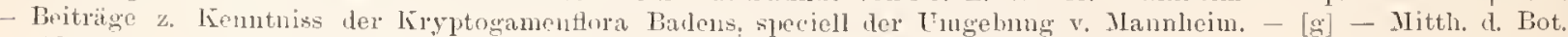

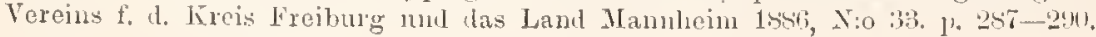


(Fulkend, in Shenk IIandb. d. Bot.) Falkenberg, P. Die Algen im weitesten Sinne. Furyelopiulie der Naturwis-

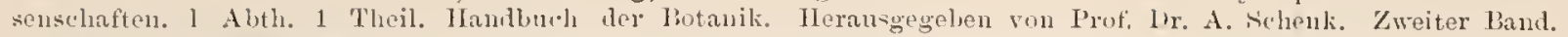

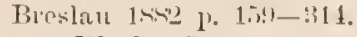

Farlow, W. G. Remarlis on some Algie found in the water supplies of the city of lBoston. [1'l.] - Bull. Bussey [n-

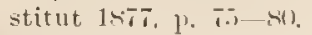

(Furlou Impurit. of llink, wat.) - On some impurities of lrinking-water eaused by vegetalule growtls. - [pls.] - Suppl.

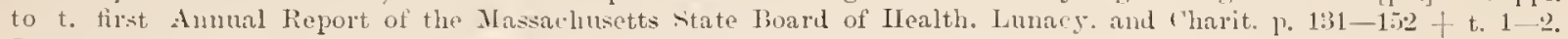
Ibostun 1hat).

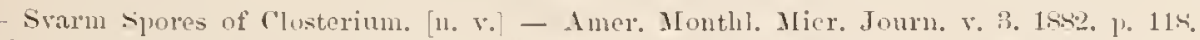

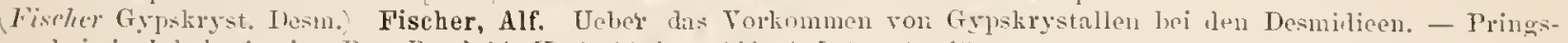

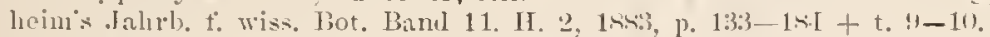

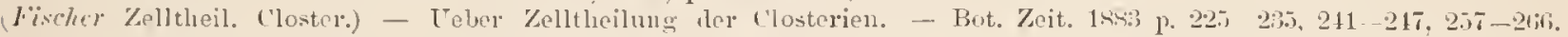
$273-271 ;$ t. 33.

Flotow, J. v. Teber Hematococcus pluvialis. - X゙. A. Acal. Caes. Leop.-Carol. Nat. cur. Vol. 20 pars poster. p.

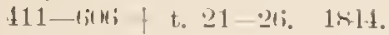

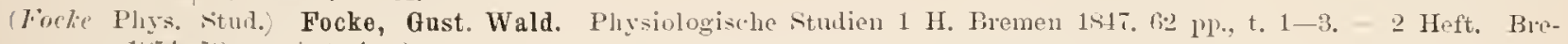

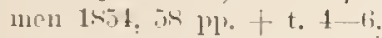

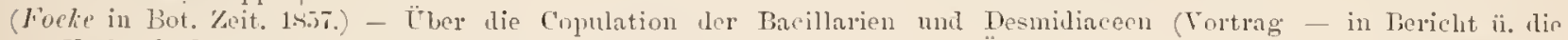

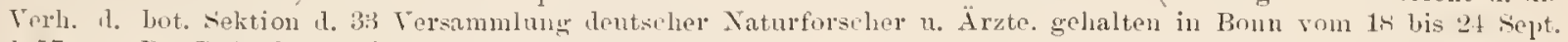

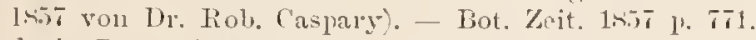

(Focke in Bot. Zeit.) - Ueber Copulationen (in Forhandl. d. Seet. f. Botanik und Pflanzenphysiol, u. 43 Versammlung deutsch. Naturforscher u, Aerzte zu Innsbruk). - Botanische Zeitung 1869 p. T50-1.

Forel, F. A. Les micro-organismes pélagicues des laces de la région subalpine. 6 p. 18st. - [g]. - Bull. Soc. Vanul. sc. nat v. 23 11:0 97

(Fronli in Leunis Syops.) Frank, A. B. in: Synopsis der drei Natureiche. II. Botanik [rynopsis der Pflanzenkunde]. 2 Aut. - bezighlich der Frsptogamen neu bearbeitet vou Tr. A. B. Frank. 3 Abtl. Kiylogamen. 18í. 8 IP. + P.

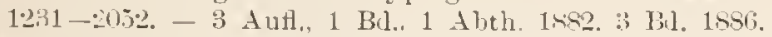

Franzé, R. Adatok a Scenedesinus morphologiíjához. - Beiträge zur Morphologie des Sicenedesmus. - Természetrajzi Füsetek kialja a Magyar nemz. múzenm. 15 kötet. 3 fïzet, p. 65-83, (ed. germ. p. 141-165) + t. 3. Budapest. I’ubl. 1. 31. $189 ?$.

Jranze in Österr. Lot. Zeit.) - Ueber einge nielere Algenformen, - Öterr. botan. Zeitschr. 43 Jahrg. 1893, P. 20m205. 217-252, 282-286, $346-350,381-38 t i+t .13$.

(Fesen. in Act. Senekenb.) Fresenins, G. Beiträge zur Kenntniss mikroskopischer Organismen. 1858,34 pp + 3 t. Abh. d. Senckenb. naturf. Ges. v. 2 18ă; 58 1. $211-242$ + t. $10-12$.

Fries Plant. Homonen.) Fries, E. Systema orbis Vegetabilis. Primas lineas noya constructionis periclitetur - - Pars. I. Plante Ilomonemere. Lunder 1925 VIII + 366 pp. ( lis: Plantie homonemeie. Revisit et disposuit - . - -)

(Fics Flor. San.) - In Fucacearum faniliam observationes contiultate, aljectis ulvaceis seania. ynas - - - pripside Elia Fries p. p. Laur. Mag. Altin - d. XXTIH. Maji 1830. Topographin stirpium seanensium. (pt. XXI). Upalia 1. 315-331). (Quoque sub titulo: Corpus Florarum provincialium Suceit. I. Floram suceiam scripsit -

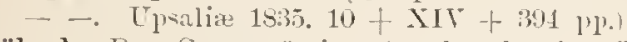

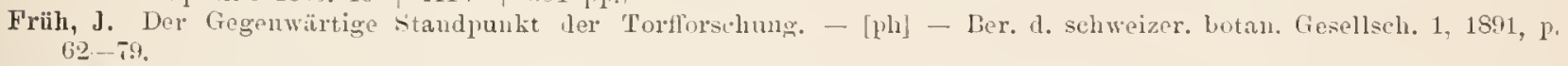

Garcke, A. Flora von Halle. 2 Th. Kryptogamen TII + $27 i$ pl]. Berlin 1S5̆ - [g].

Gruy Monogr. loc. Conjug.) Gay, F. Essai d'une monographie locale cles Conjugés (Thi-se presentée et snutenue pu. bliquement it I'Eeole superieure de Pharmacie le Montpellier, le Fébrier 1 Sst pour obtenir le diplome de pharma. cien superieur. [X:o 3]. 112 pp. +4 t. Montpellier 1SSt. - [Quotue in: Revue 1. seiene. nat. 3 ser.. t. 3 X:o 1 p. $187-2.25,255-335:$ t. $Y-V I$ a.]

Gay Xote Conj. 1. m. France.) - Note sur les Conjuguées du mili de la France. - Bulletin d. 1. Soc. botanique de France Yol, :31. 1851 p. 331-342.

- Chlorosporées: in Flahault "Liste des algues recolties anx environs de Milau peulant. la session de 1ssti". - [g]. - Bull. sine. Bot. Fr. Vol, 33, 1ssn 1. CXX CXIX- ('XXI).

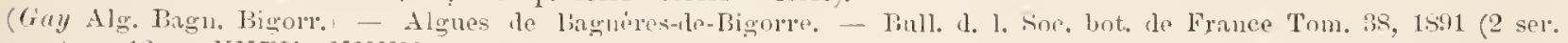

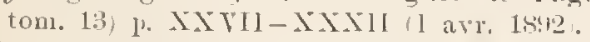

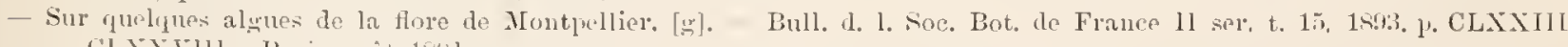

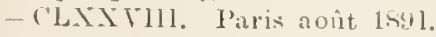

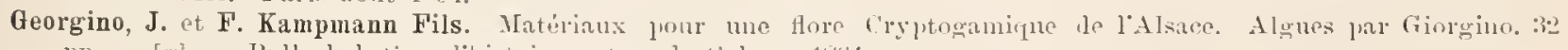

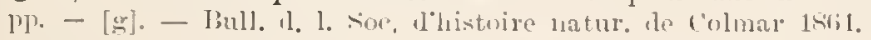

Gibbons, S. Air and Water poisulug in Melboume - Transact. R. Soc. of Victoria. Vol. 10, Melbourne 1sat. p. 1sil 2012 c. 5 tig. plootogr.

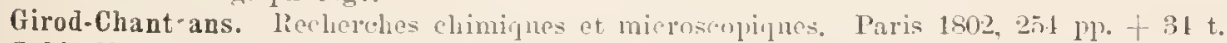

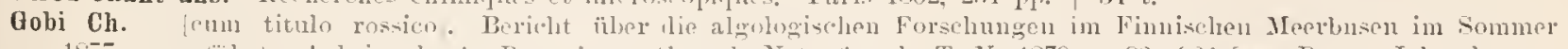

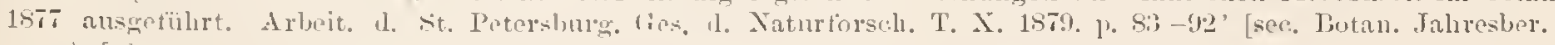
1.. $v.] \cdot[\underline{m}]$.

- [eum titulo rossion] "Kurzer Bericht ïlor die in simmer 1sis ansgefülırten algologischen Exeursion. Arbeit. 1. St.

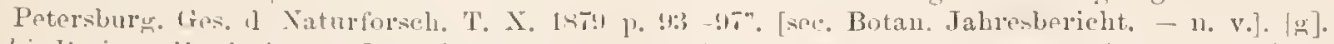

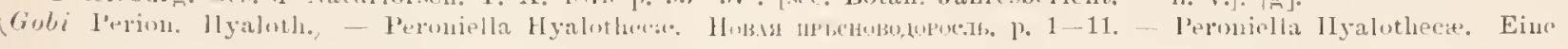


nene Süssvasseralge. P. 12 18, t. 1. - Seripta botanica Horti Tuiversitatis imp. Petrojolit. v. 1, pt. 1I, 188f-8T, p. $233-255$.

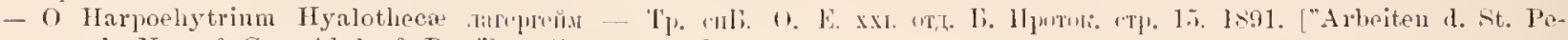
tersb. Naturf. Ges. Abth. f. Bot."] p. $15-16 .[\mathrm{g}]$. [n. v.].

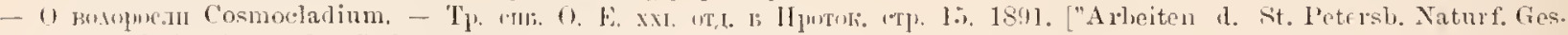
Alith, f. Bot."] 7. 16--17. [R. - 11. v.]

Goddard, P. B. Infusoria. - [n. v.] - Proceel. Philad. Acal. Nat. Sie. v. 1. 1812, 1. 172.

Goebel, K. Ptanzenbiologische trehildermugen. IT. 1. Marburg 18s1, 16il pp. +16 t.

Goeppert. Teber einige jünst beobachtete algenartige Einschlisse uml Dentriten in Diamanten. 45 Jalıresber. a. sehles. Ges. v. vaterl. Cult. v. Jalu ls67 p. 34. 11. Breslau 1868.

- Ueler algenartige Einschïsse in Diamanten nul über Bilınng derselben. 7 p. + 1 t. - Abh. f. Naturw. n. Medic.

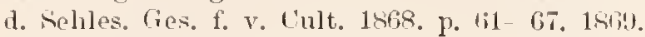

Goeppert und F. Cohn. Teber die Algen Sehlesiens. - Jahresb. d. Schlesisch. Gesellsch. fovaterl. Cultur vom Jahre 1.4!, Y. 9:-4. Breslau 1850.

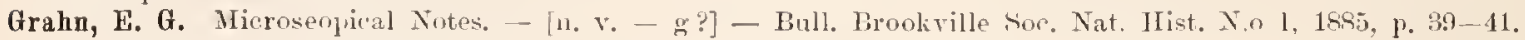

Gratacap, L. P. and Woodward, A. The Fresh-Water Flora and Fauna of Contral Park. I'reliminary paper. - [m]. - Scientifie Amerionn. Snpplement, Nin 4li!. 27 Dee. 1881 p. 7.181)-81.

(Grm, J. L. Arrang. Fan. \& Gen.) Gray, J. E., On the Arrangenent of the Families and Genera of Chlorospermons Algap. - Ann. \& Mlar. Nat. Hist. 3 ser. vol. 8, 1861, p. 10.1-120.

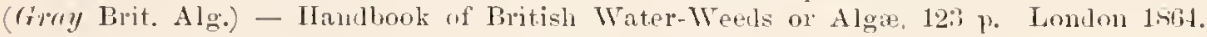

(rimy Nat. arrang. Blit. plants) Gray, S. F. A natural arangenent of British Plants. Vol. 1. I 821 pp. +21 tab.

Greville, R. K. Flora Edinensis. Edinburgh 1824.

(frer. Sicot. eryjt. Fil.) Sicottish eryptogamie Flora. Vol. V, Edinburgh 1827, Vol. VI, 1828.

(free, in Hook. Br. Fl.) -- Div. IV Diatomacese, in: Dr Hooker"s lsritisli Flora. Vol. II. 1) 40I-415. Lonton 1833. [Cfr. Smith, J. H:.].

- Crir. Lindley, 1836.

(frogn. Plant. Crypt.) Grognot (Aine). Plantes cryptogames-celhulaires du departrment de Saone-et-Loire avee des Tablean synoptiques pour les ordres, les Fanilles, les tribus et les genres, et la leseription sucemete de plusienrs

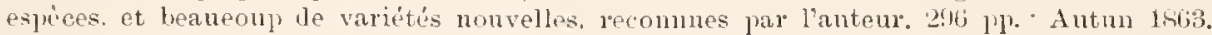

Gruithuisen, F. v. P. Beitrïge zur Physiognonie und Eautognosie für Fremde der Naturforschung aus den Erfalıungen von den Jahren 180?. 1810 mil 1st1. Niunchen 1812.

(Gruthwis. in Niv. act. eur.) - Die Branchiensehneeke und eine aus ihren Ïberresten hervorwaehsenke lehendig-gebaerende Conferve. - Nova acta Natur. ('ur. Vol. 10 , t, 21821 p. 437-452, t. 34.

(Grun. Desmid.) Grunow, A. Die Desmidiaceen und Pediastreen einiger osterreichischen Moore. - Verlı. d. zool. bot. Ges. in Wien 1558. 1. 45! -502.

(Grm. lus. Bank.) - Ueber die von Herrn Gerstenherger in Ralrenlorst's Deeaden ausgegebenen siisswasser-Diatonaceen und Desmidiateen von fer Insel Banka, nebst Untersuchungen über die Gattungen Ceratoneis und Frustulia. -- Beiträge zur nüheren Renntniss und Verbneitung der Algen. Heransgegeben von L. Rabenlorst. Heft. 2, 16 pp. + 2 t. Leiprig $13 \% 5$.

- Algen. 101 pp. + 11 tah. Wien 1867. - [a] - Reise seiner Majestït Fregatte Novara um lie Erde. Botanischer Theil, 1 Band.

(Cutwimsli Fl. wodor. Galic.) Gutwinski, R. Materyjaly do Flory wodorostów Galicyi. - F prawozd. Komisyi fizyjograficznej Alial. miniej. v. t. 18 p. 127-188. Kraliowie 18s1. 12 lp.

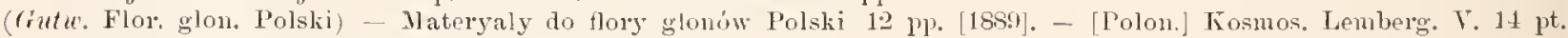
(1). $2012-302$.

O glonarh slodkuworluych w ogúle, a w szczegónosei o glonach okolie Lwow. 12 pp. [g]. -. (Poh.) Kosmos, v. 1-1 188 ! pt. $10-12$, p. $332-343$.

(Gute. Fl. glon. Galie. 2) - Materyjaly to Flory glouów Galicyi. Cresc II 43 jp. + 1 t. Krakúw 18 sto. - Sprawozd. Komisyi fizyjografiezuej Alkalemii Tmiejetuosei, v. 25 p. $1-43+$ t. 1 .

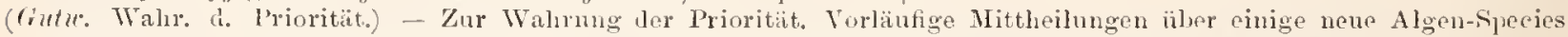

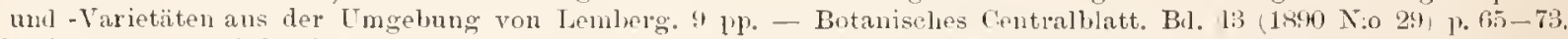

- O pionowem rozsedleniu glonow jeziora Bajkalskiegn. (Ueber die senkrechte Verbreitung d. Algen in der Tiefe les

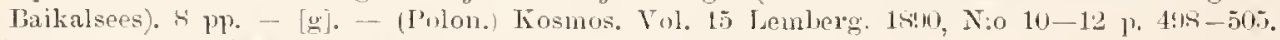

- Algarme e laun Baykal et e peninsula Ramtsehatka a clariss, pof. Dr. B. Hybowski anno 187 reportatarum enumeratio et diatomacearm lacus Baykal cum iislem tatrieormm. italiorum atule franeo-gallieormo lacum comparatio, 27 p. Padova 1891. - [e] - - La nuova Notarisia ser. 2, 1891. p. $3010-305.357$ - 34t. 407-417.

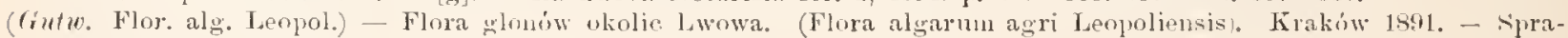
wozd. kom. fizyjogr. Akalem. Uniejet. tom. 27. Materyal. do fizyogr. krakow. Czese 11. Pag. [1]-[124] + t. 1-3. Krakiow 1892.

(rufw. in Noov. Notar.) - salvaule prioritatis causa. Diagnoses nonmularum algarum novarum in Galicia orientali amno 18 !n colleetarum. - La Nuova Nutarisia ser. 3, fase. 2. 5 A pr. 1492. p. 17 - 22.

— Staw 'Tarnopolski. 15 l’]. Tarnopol. 1492. [g] - 1. Pocznik kílka nankowego tarnapolskiego p. Bfi-7R.

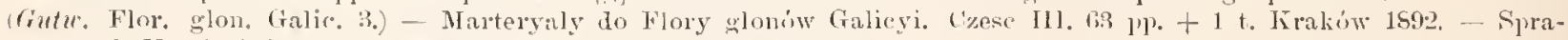
wozd. Lomisyi fayografie. Alial. Trmiej. W Kiakowie. 'lum. 2S.

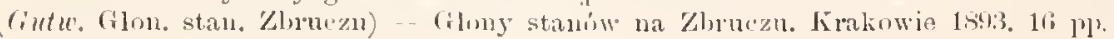

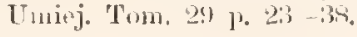




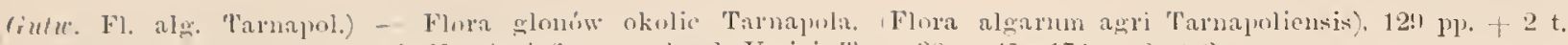

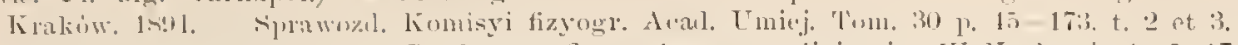

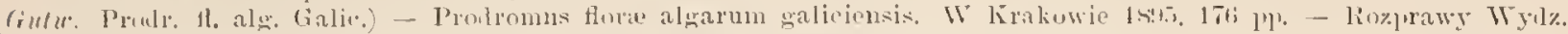

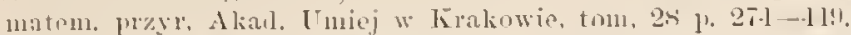

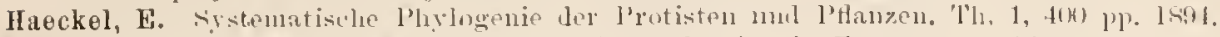

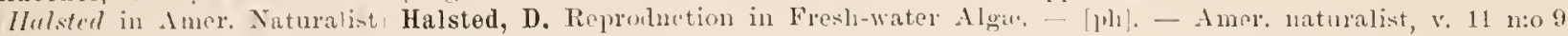

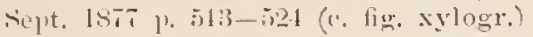

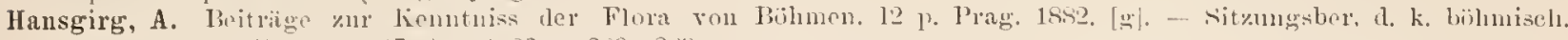

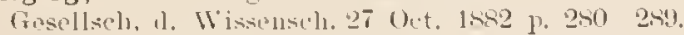

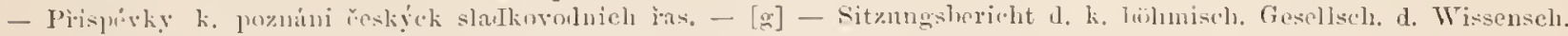

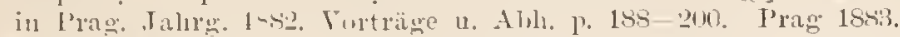

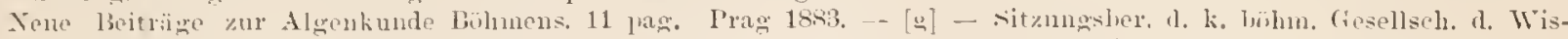

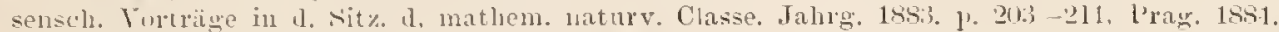

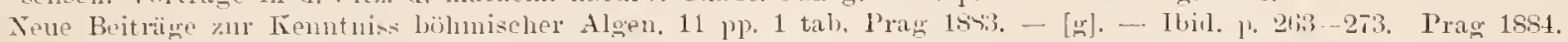

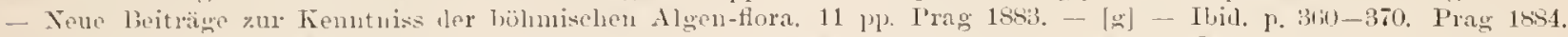

(Monsy. Einzell. Bilu. Musrort.' - Ein Beitrag zur Kenutniss pingelliger Bildungen dor Moosvorkeime, nebst einigen Bemerkmugn \%ur śstematik der Algen. 13 l'p. - Flora 1siti p. $291-303$.

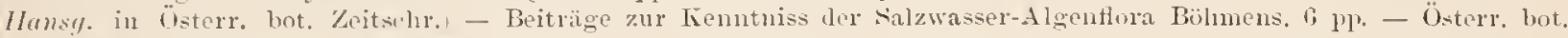

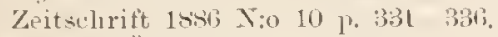

Munsy. in (̈sterr. Bot. Keitschr.) - Beiträge zur Kenntniss ler Bergalgenflora Bülnmens. - Üsterreich. Bot. Zeituehr.

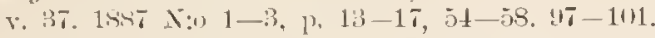

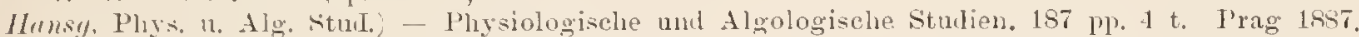

- Nene Boiträre zm kenntuiss der halophilen der thermophilen und der Berg-digenflora. sowie der thermophilen

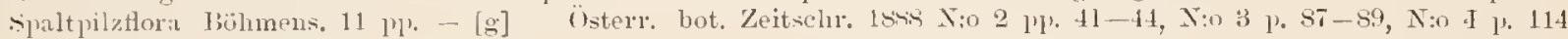
-117. N:0 5 p. $14 ! 1-151$.

(IImsy. Prorlr. Algenfl. Bülm.) - Prollonus der Algenfora ron Böhmen. Erster Theil 2 Heft. Prag 1s8s. Zweiter

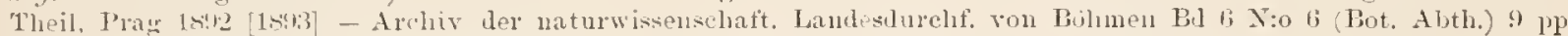

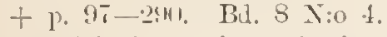

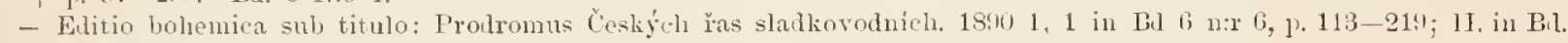
is. $4.1892 \mathrm{XI}+152 \mathrm{pp}$.

- Resultate der rom Verfasser im .T. 1858 nusgeführten Durchforschung der Niisswasseralgen und ler saprophytischen Baterien bülmmens. - [s] - sitzungsber. d. k. bühnisch. Gesellsch. d. Wissenschaften. Math. 11atmw. Cl. 1s89 p. $121-161$.

Ilunsy. Tene tiins- u. Meeres-Alg.) - Teber nene Siisswasser- nul Meeres-Algen und Bacterien mit Bemerkungen zur Systematik dieser Plyycophyten und iber den Einfuss des Tichtes ant die Ortsbewegungen des Bacillus Pfefferi nob. - vitzungsher. d. böhm. Gesellsch. I. Wissensch. Matl., naturw. Cl. 18.10, 1 Bd. p. 3-34 t. 1 et 2.

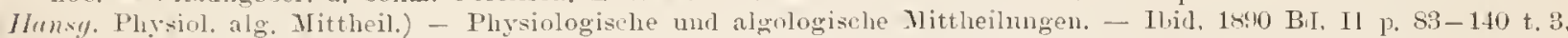

(Ihusy. Alg. u. bacter. Mittheil.) - Algologische und bacteriolugiselıe Nittheilnugen. I-III. (IlI. IBeiträge zur Kenntniss der Süswasser-Algen und Bacterien-Flora Böhnens. Steiermarks, der österneichisch-1ugarischen Küistenländer und Bosniens. - sitzungsher. d. k. böhm. Gesellsch. d. Wissensch. math. naturw. Cl. 1891 p. 2!r-365.

(Munsy. Beitr. Alg, But. 'Trol u. Bïlm.) - Beiträge zur Fenntuiss der süsswasser-Algen und Bacterien-Flora von

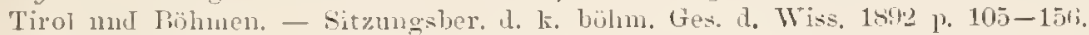

Hariot, P. Contribution it l'étule des algues deau douce t'Tslante. [g] - Journ. de Botaniı. T:e ann., 1893, Xi:o 17 et 18 p. $313-31$.

Homop Desm. 'Tasman.) Harrop, E, D. Olservations on Desmiliaceie, with a list of species, found in Tasmania, Tasmania R. - i. Monthly Not. 1568. p. 1!1-23.

Hartog, M. M. Decided mucleus found in Closterinm aggregatum.) [ph]. - Proe, of the literary and philosoph. Soe. of

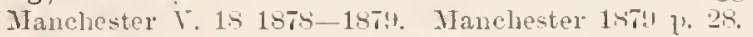

(Harl. in Hook. Br. Fl.). Harvey, W. H. "Confervoidea" et "Gloiocladea" in Hooker British Flora II p. 32.2401, $1-33$,

(Hare, Man. Br. Alg.) - A manual of the British Alga. 22 pp. London 184 .

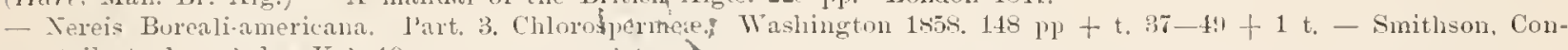
trib. to knowledge Vol. 10.

Hurey Index gen. alg.) - lndex generum alyam : or a Fystematic Catalogue of the genera of Alga. marine and freswater: with an alphaberical liey to all nanes and synonyms. London 18ilu. $22+8$ pl.

Hri\%. Fr. Alg. Maine) Harvey. F. L. The Fresh-water Algit of Maine I. - Bull, of t. 'l'orrey bot. Club, v. 15 X:o 6. Juni 1 sss p. 15is-161

- - II - ibill. ห. 16 X:o T, Juli 1889, p. 181-148,

- IlI - ibid. v. 19 N:0 I, A pril 1\$:12 l\% $118-125$ t. 126.

Ilrss. Brit. Alg.) Hassall, A. H, A History of the British Freshwater Alge Vol. 1. 462 + 8 pp. Vol. II. 21 pp. 103

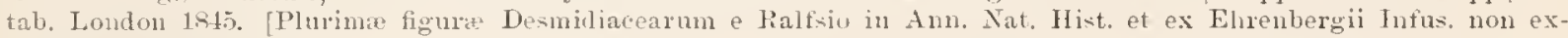
arte delineatio sunt.|

(Hrist. in Am. month. micr. Jour.) Hastings, Wm. N. A proposel New Desmid. - Americ. monthly Microscop. Journ. v. 13 र:0 2. Febr. 1s(1) $\mathrm{N}: 0$ 146) p. 29 c. fig.

Hust. in Amer, monthl. Nicr. J.) - New Desmids From New Hampshire. I. -. Amer. monthl. Mier. Journ. V. 133 Xio T July 1sy2 p. 153-15is + 1 t. [Amplificatio fignarum 1. 15520 o major dicta est quam revero, sec. auct, in litt.]

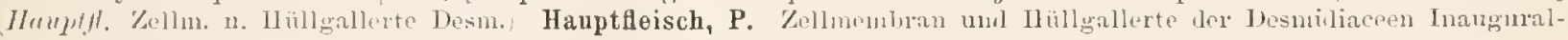
Sortletest, Indix Lesmid. 


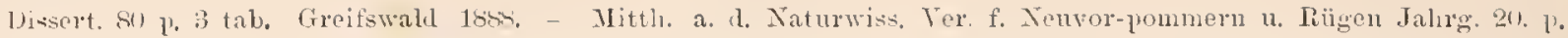
$5: 1-136+$ t. $1-3$.

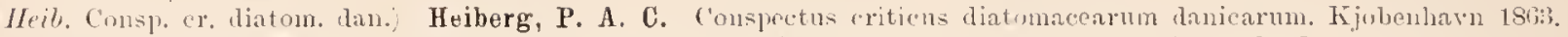

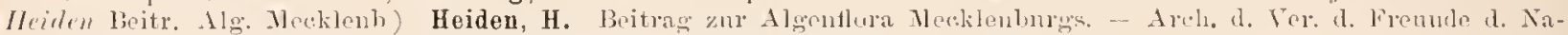

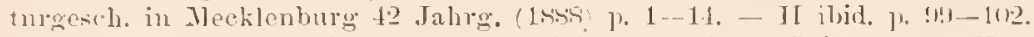

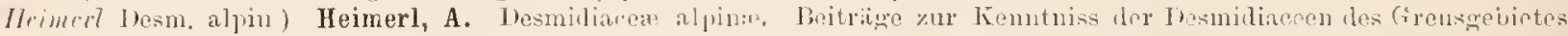

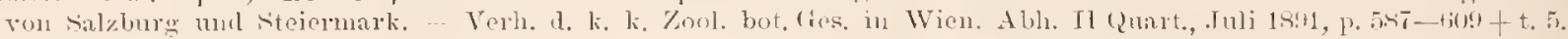

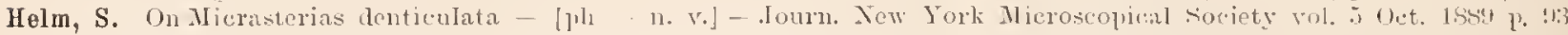
- 14. t. 20 .

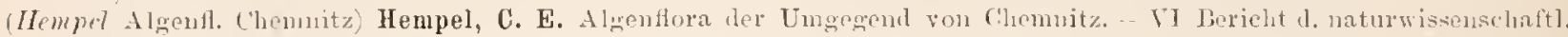

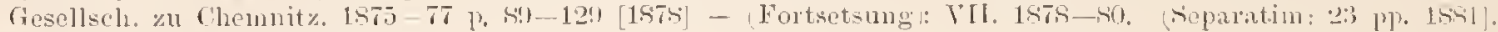

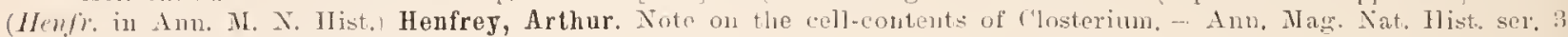
vol. $1,1.559$ T. $419-423 .[1]$. 1.

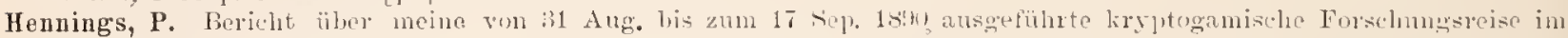

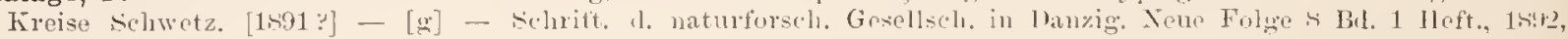
1).

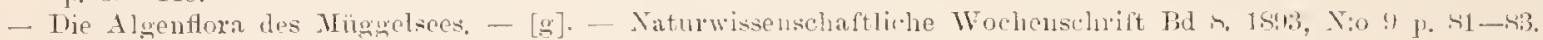

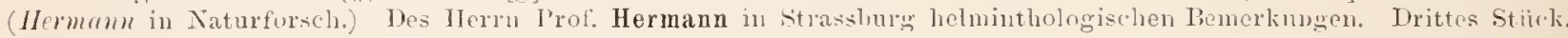

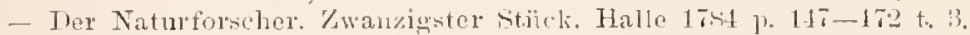

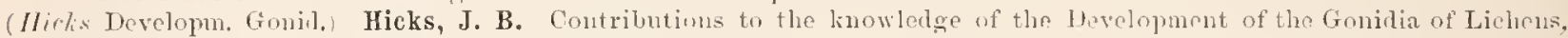
in relation to the Unicellular Alga. Fascienlus H. Cladonia. Fasciculus III. Collema nud Nostor, ete. ete. - (2.

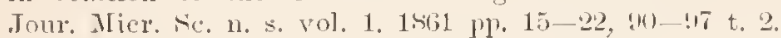

(Micks in Trans. Linn. Soc.) - Mn the Gondia \& coufervoid filaments of Mosses and on relation of their Gonidia to

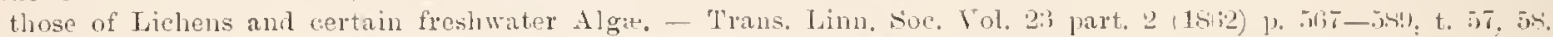

(Hicks in Q. J. M. S. - Jiemarlis on Mr. Archer's Japer on Algu. - Quart. Journ. Mier. Se. n. S. v. I. 1Fiil p. $2,3-258$.

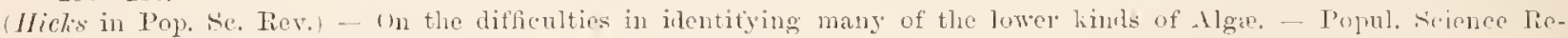
view IV 1865 P. 3335 312, t. 14.

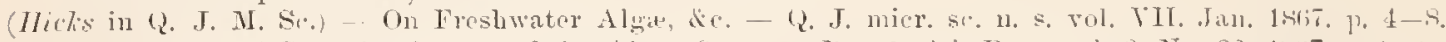

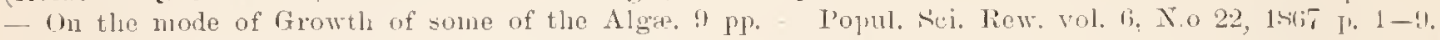

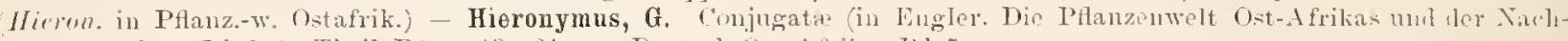
barkebiete. Lief. 1 (Theil B, 1) 19-21). - Deutsel-Ost-Afrika. 13 5.

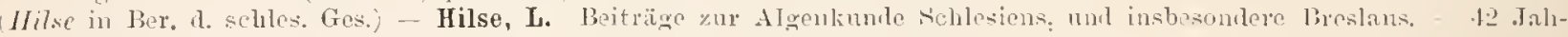

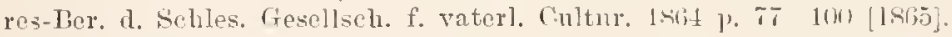

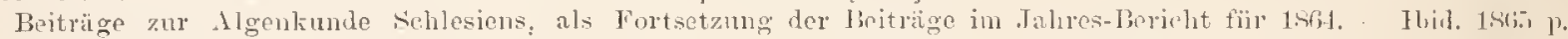
[119-129. [1,660].

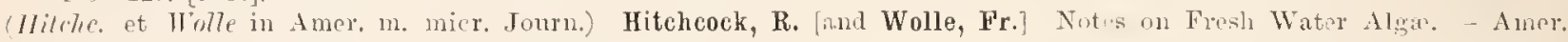
monthly mier. J. Yol. I n:0 1 Jan. Istill p. 6-is:

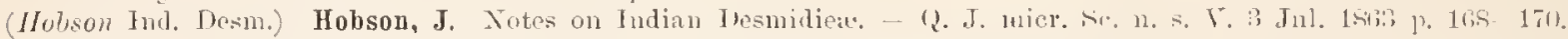

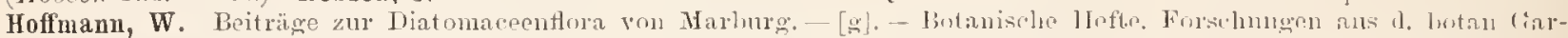

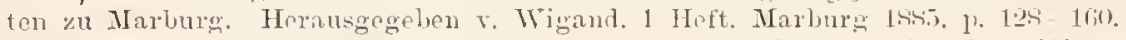

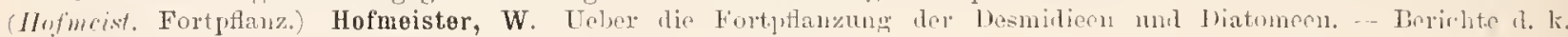

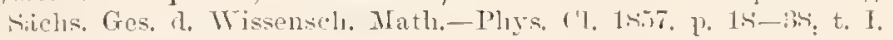

Hogg, Jabez. Cfr. S. C. Osluorne.

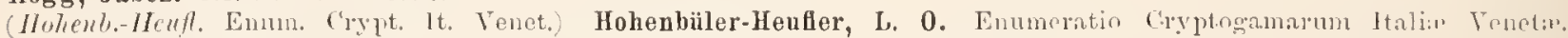

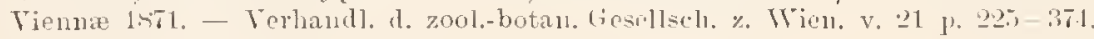

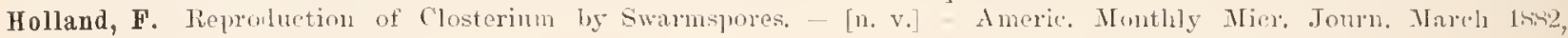
1) $41-42$.

Hooker, W. J. British Flora - ('fr J. E. Smith

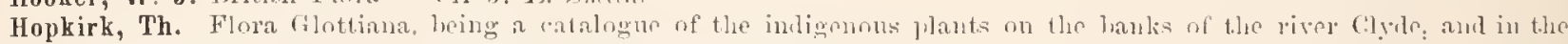

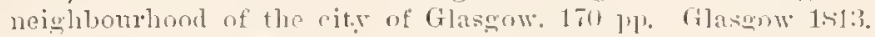

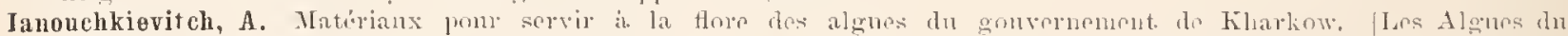

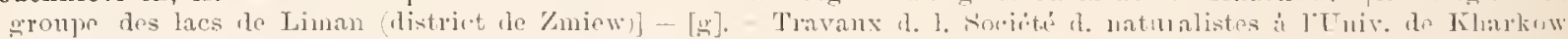

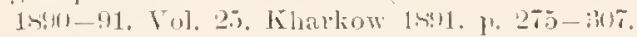

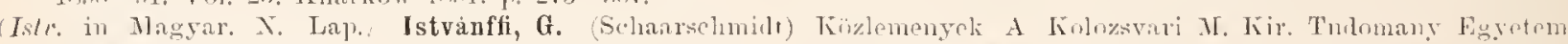

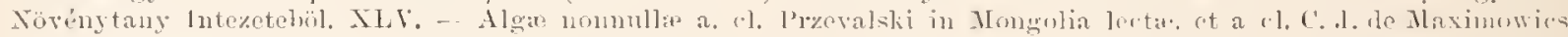

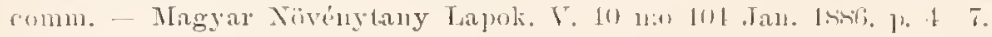

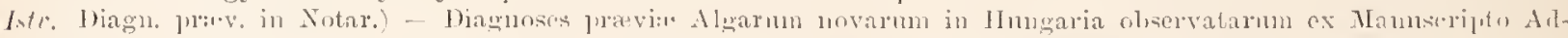

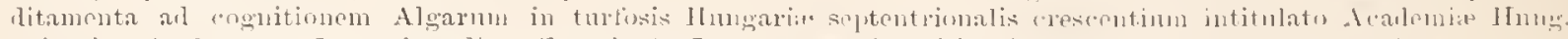

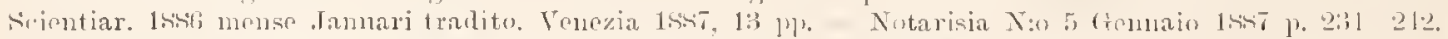

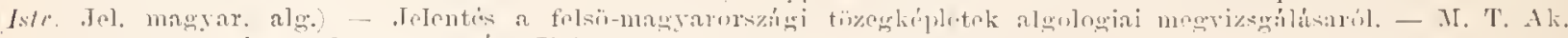

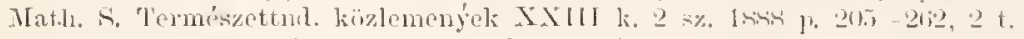

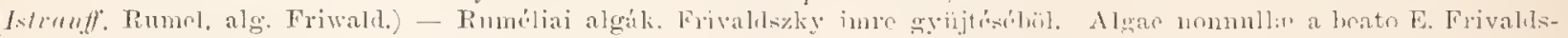

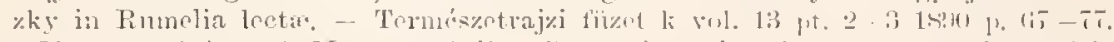

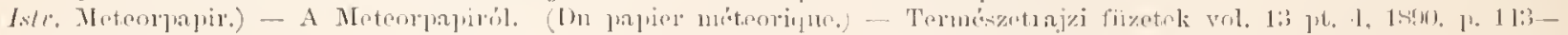
$151(1: 1-1,82) \cdot 1,591$.

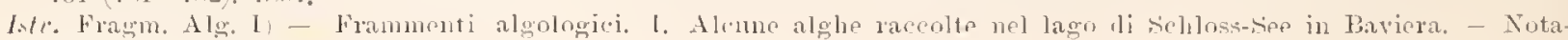
risia $1.6,15 \$ 1,1), 116 f-9$. 


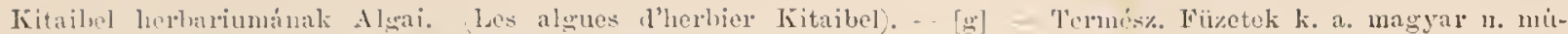

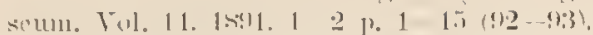

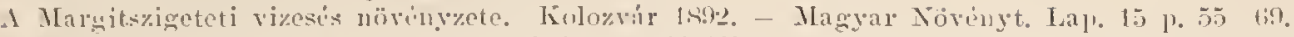

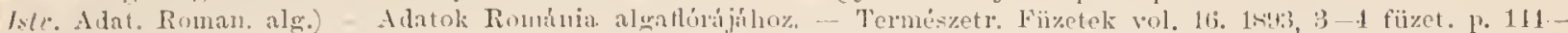

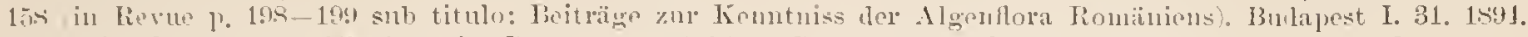

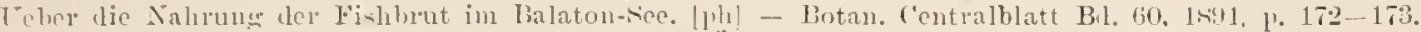

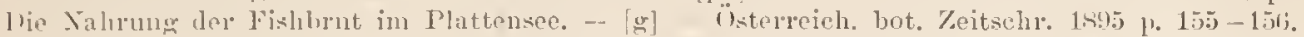

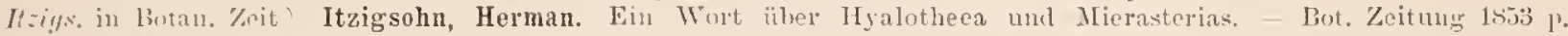
$14,-1,4$ :

(Il:igs: in Bot. \%oit.)

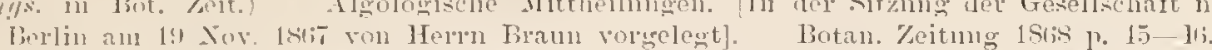

Jackson, E. E. Letter on Monnting Desmid.. [1. v.] - The Micinscope v. -1. 18it, p. 117.

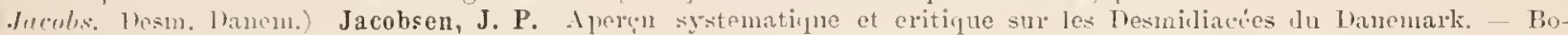

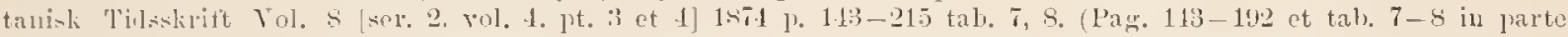

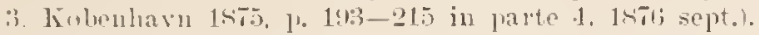

Jelliffe, S. E. A l'peliminary List of the Plants found in the Ridgewool Water Sinply of the City of Brooklyn,

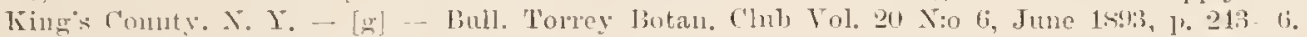

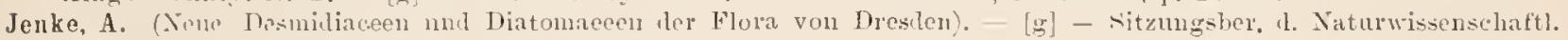

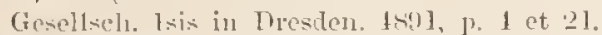

Jennor, E. A lilura of 'Tunhrise Wels heing a list of inligenous plants within a rarlius uf fifteen miles around that

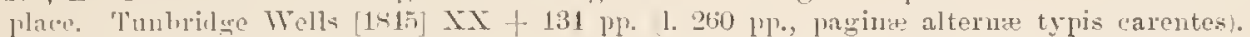

Jessen, C'tr. Mirgli.

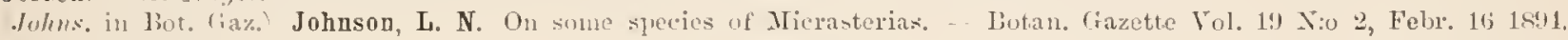
1. int (30), t. 13 .

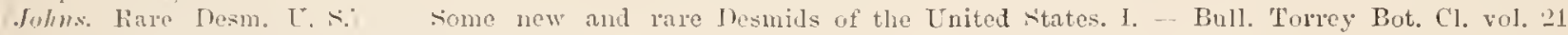

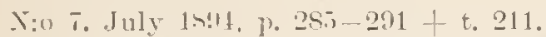

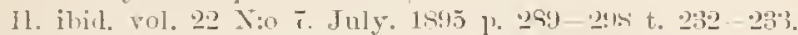

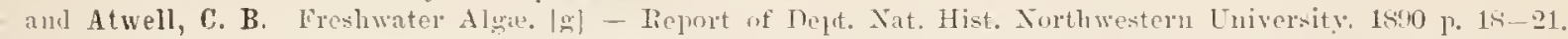

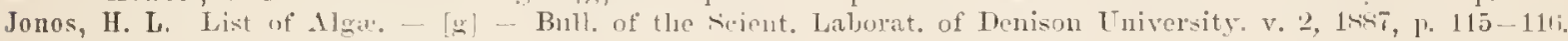

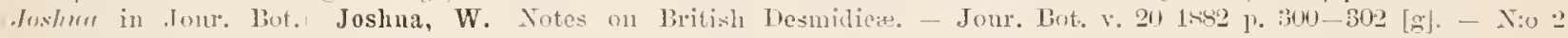

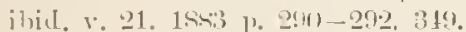

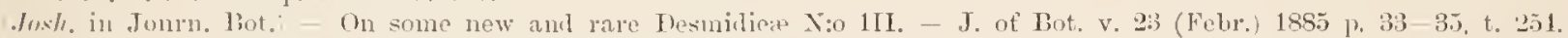

Fush. Bum. Desm.) Burnese Desmidien. with teseriptions of new species oecurring in the neighbourloou of Ran-

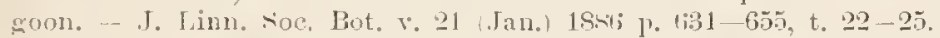

Journal Qnecket Microsepical C'lub [Emmerationes multe sub varis titulis: "Objects found on tlse Exeursion to

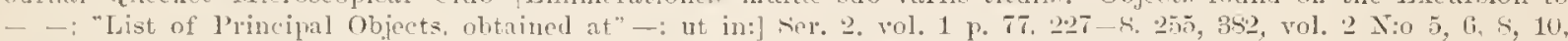

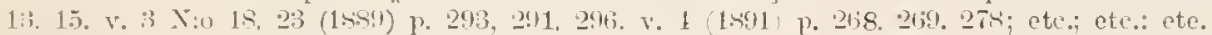

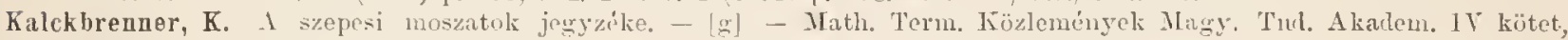

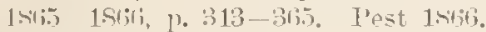

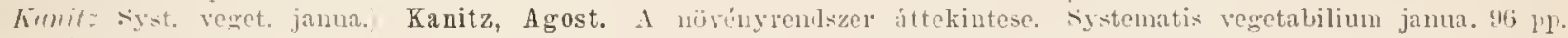
Finlowirart 1sit

Kellerman, W. A. and Werner, W. Catalogne of (1hio l'lants. - [g] - Geology of (H)io, v. 7. part. 2, 1895. p. 56- 106.

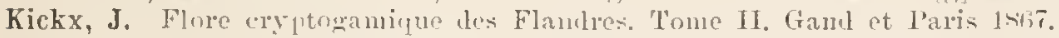

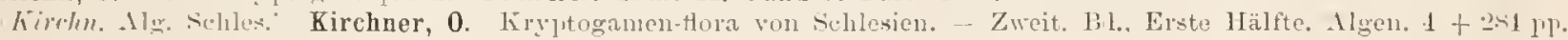
Bresian 1sit.

Kirchn. Puitr. Algenfl. Wïrteub.) - Beiträge zur Alyeshlora von Württemberg. - Jahreshefte d. Vereins f. vaterl.

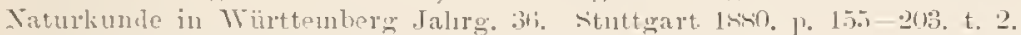

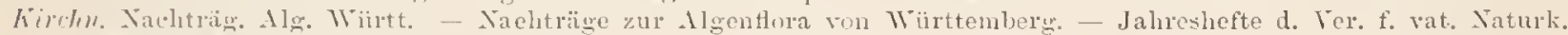

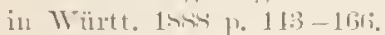

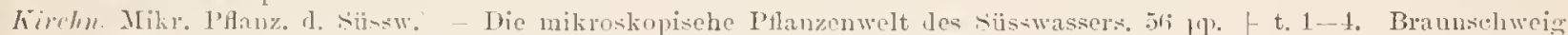

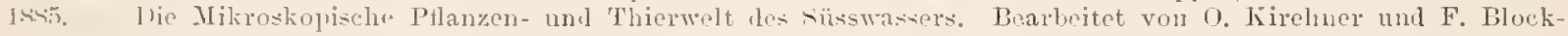

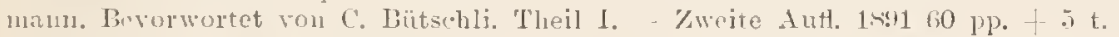

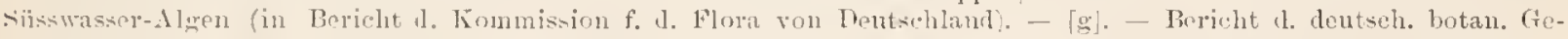

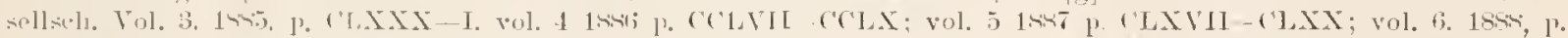

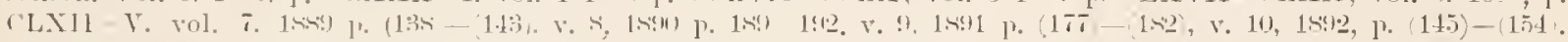

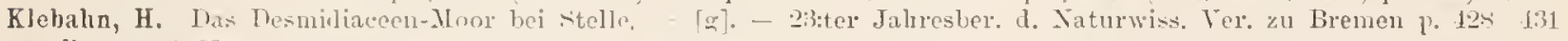

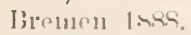

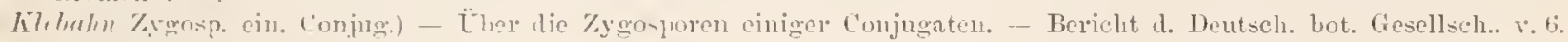

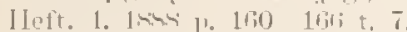

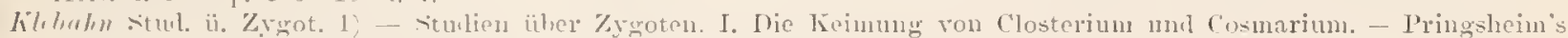

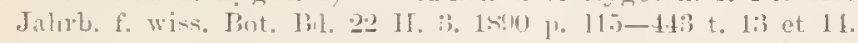

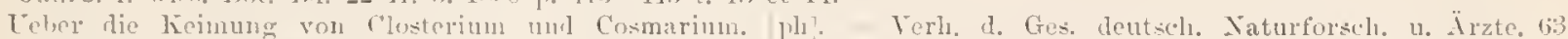

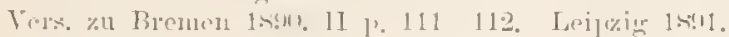

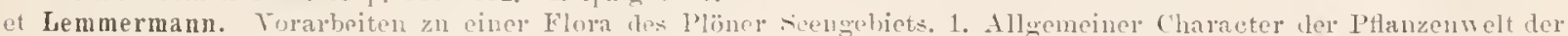

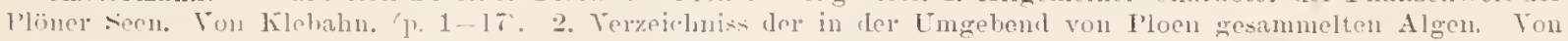

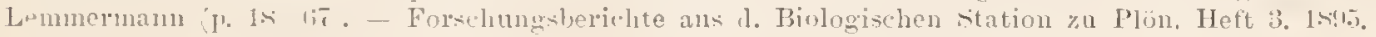


Klebs Desm. Ostpreuss.) Klebs, G. Ueber die Fumen einiger Gattungen der Desmidiaceen Ostpreussens, 42 plo, 3 t,

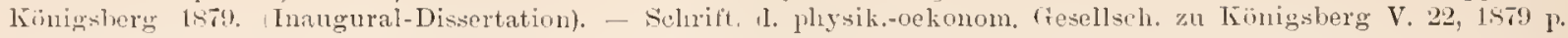
$1-12$. t. $1-3$.

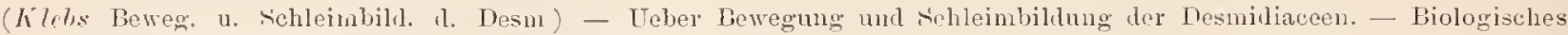
Centralblatt Bd V n:o 12 1587. p. $353-367$.

(Flels Organisat. Gallerte b. Algen) - Uber die organisation der Gallerte lei einigen Algen um Flagellaten. - Untersuchungen a, d. bot, Instit. z. 'Tübingen. Vol, 21646 p. $3333-118$ t. $3-4$.

(Klels in Ber. deutsch. bot. Gesell,) - Beiträge zur Plyysiologie der Pflanzcnzchle. Berichte d. deutsch, botan. Gesellsch. Bd. 5, 1sisi, p. 181-18s.

(Kllus Beitr. Physiol. d. Pflanzenz.) -- Beiträge zur P'lysiologi der Pfluzenzelle. - Wutersurlı, aus d. botan. Instit. zu Tühingen Bd 2. II. 3. 1s.9. p. 189-51t'. t. 5-6.

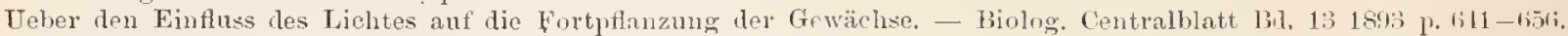

Klein, L. Ein par Kunstgriffe beim Sammeln von Süsswasscraluen. - [1. v.]. - Mittheilung. 1]. lad. botan. Vereins 1.45\% 1. 2!) - 30 .

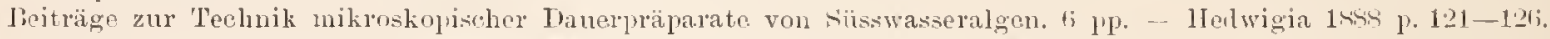

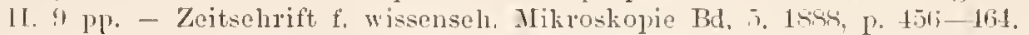

Koenig, Fr. [Teber ehlorophyllhaltige sïsswasser-Algen. - [pli] - 32 und 33 Rericht des Vereines für Naturlunde zu

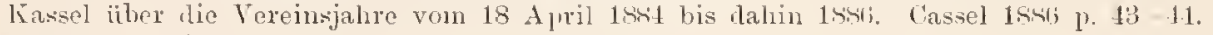

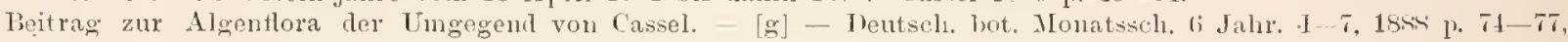
.

Kozlowski, W. Materiaux pour servir à l'étude de la flore algologinue l'eau duuce de la sibríle. 10 pl' +1 t. [ge]. -

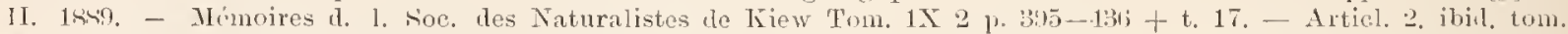
Xl Livraison 1, 1sise p. 1-31i t t. 1 .

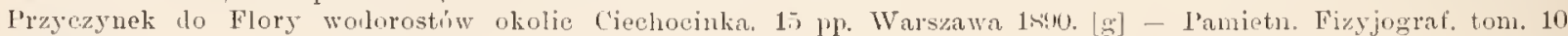
1810 .

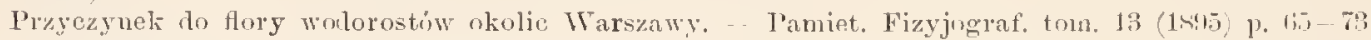

Kravogl, Hermann. Zur Kryptoganenflora von siultirol. - [g]. - Progran d. k, k. Staats-frymnasiums in Bozen, Bozen $18 \% 7$ 1.:3-21,

Kür. Syı. Diat.) Kützing, F, T. Synopsis Diatomacearum oder Versu.h einer systematiselen Zusanmenstellung der

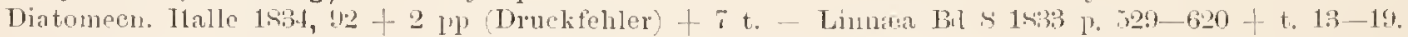

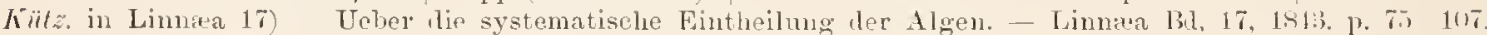

Kütz. Phyc, gener.) - Plycologia generalis oder Anatonie, Plysiologie und systenkunde der Tange. Leipzig. 1sl:3, IXXII + 458 p., 10 t.

(Kïtz Thycol. gem.) - Phyrologia germanica, d, i. Deutschlands Algen in bïnligen Beschreibungen. Northansen $1815 . x+310 \mathrm{pP}$.

(Kinti, in Botan. Zeit. 1s17.) - Diagnosen unl Bemerkmgen zu nenen orler kritischen Algen. - Butanische Zeitung $15: 7$ N:o 13 P. 22: 1 .

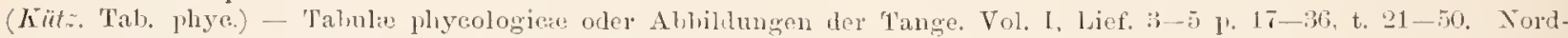
hausen 1.47 .

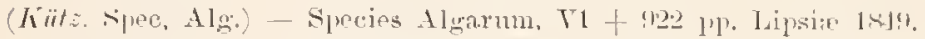

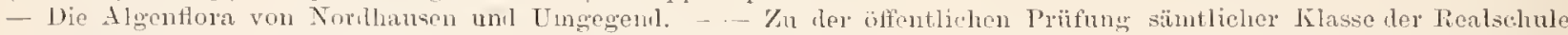

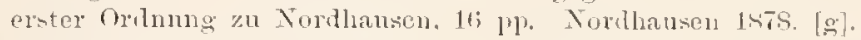

(Kunter liev, gen. pl.) Kuntze, 0. Revisio generun plantarum vasenlarium nmuium atque eellulariun uultaruu secumlun leges nomenclaturit internationales enu pnumeratione plantarum exoticarum in itinere unndi collectartum,

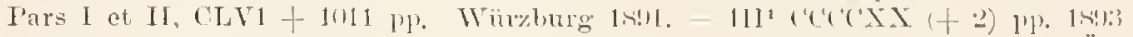

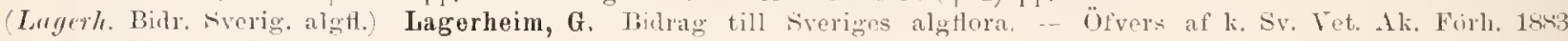
Tors N:0 2 T, 37-7S, t. 1.

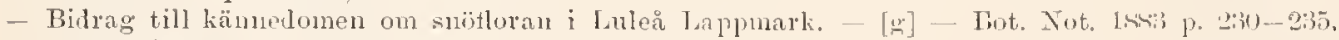

- Algologiska och myliologislia anteckningar froin cu botanisli resa i Lulci Lappmark. - [g]- Ofv. k. Vet. Akal, Forh. 1881 र:o 1 p. !1-121)

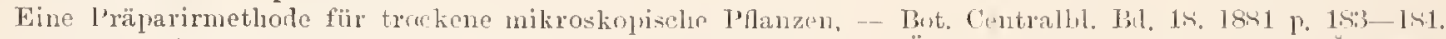

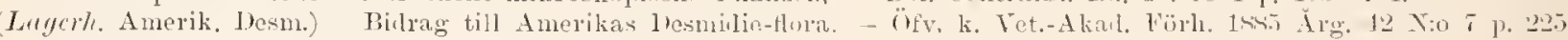
2.55 t. 27. [Febr. 1shit].

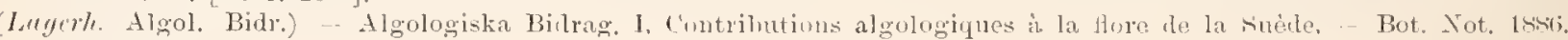
1) $41-51$.

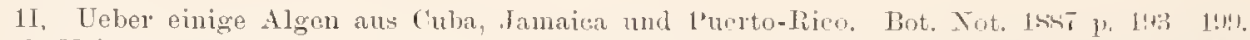

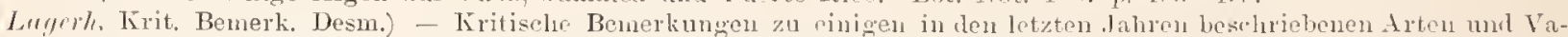

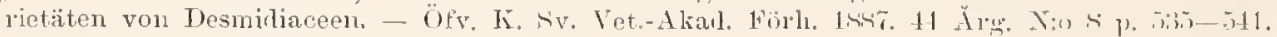

(Lryrk. Anwend, v. Milehsäure) - Ueber die Anwemimg von Milchsäure bei der. Untersuchung von trockenen Al. gen. 2 1'1. - Hedwigia $185 s$ 1\%. is - in.

Lugchl. Bengal besm.) - Über Desmidiaepen aus Bengnlen nebst. Benerkungen ïber die geographische Verbreiturg

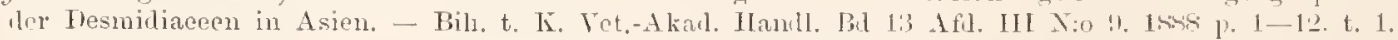

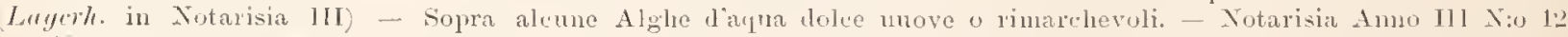
(1)et. $1 \operatorname{sis}$ r. 5 .

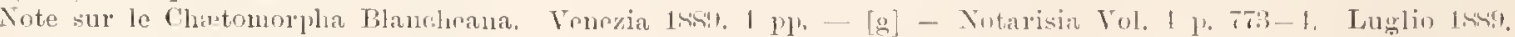

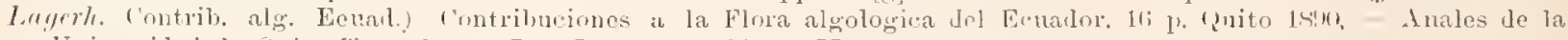

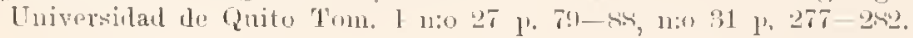




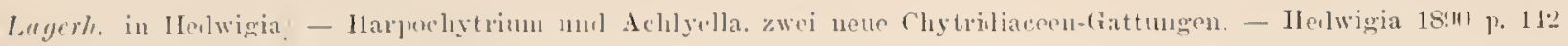
-1.15 t. 2.

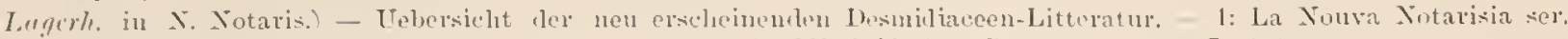

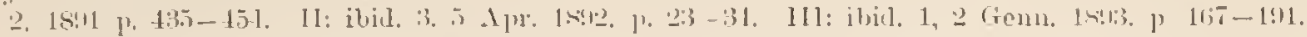

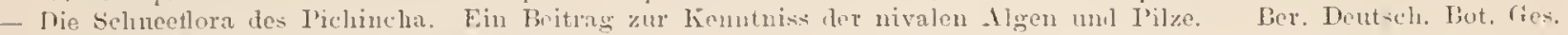

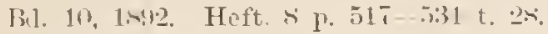

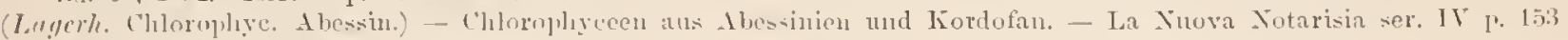

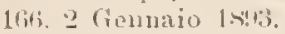

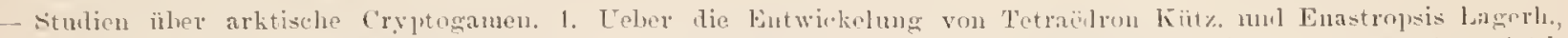

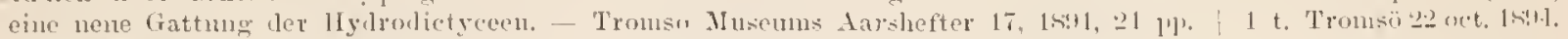

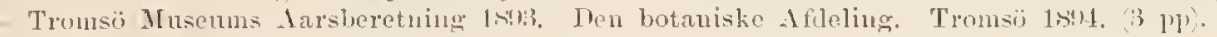

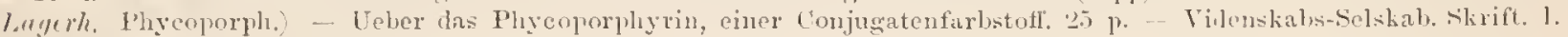
Matlı, -uat. Kl, 1.:45 X:0 is.

Lendsher. IBrit. Sen-Weeds) Irandsborough, D. A Popular Ilistory of British Sen-Woeds, coupprising their structure, fructication. specific charactes. arrangement. ant general distribution, with notices of some of the Fresh. Water Algie. $\mathrm{XI}+368 \mathrm{pp}$. + 2) t. London 1.4!!

Lannesan de in Dict, botan. Cfr. licillom.

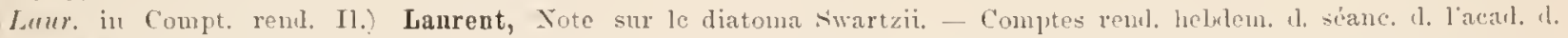
sciences t. 2 p. 167. 1836 .

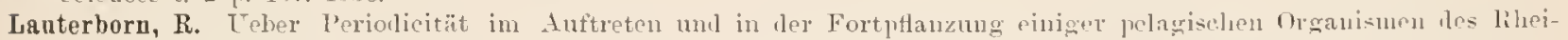

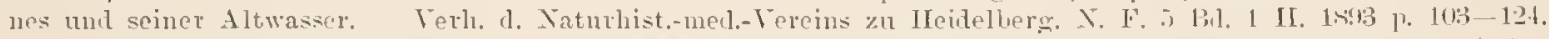

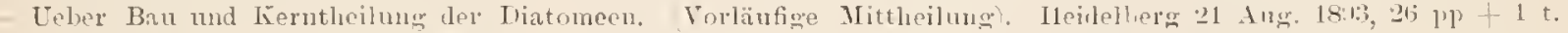

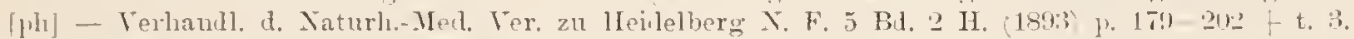

Lawson, George. Report on the Musci and Hesmilies, collerted, during a trip to West Lonond Hill. Fife, :He . Tume

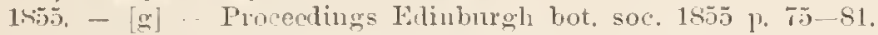

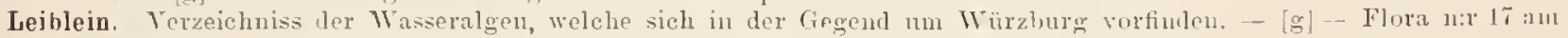
17 Maj 1827. Regeushurg 1627 p. 259-260. 273-281.

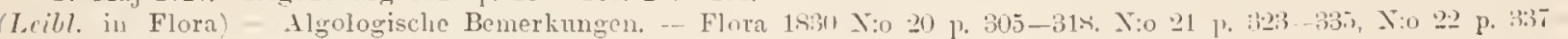
3.1 t. 1.

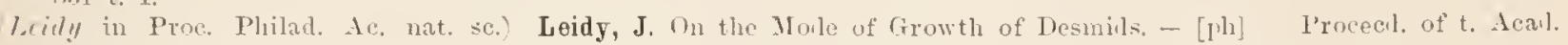
nat. sc. Plijadelplia 18it. I. p. 15. Philirlelphia $18 \pi 1$.

Leithe, F. Beiträge zur Kenutniss der Kryptogamentlora von Tirol, - [q] - Gesterr. bot. Zeitschr. 30̄ Jalurg.. Jan. 1.85.i p. S-12.

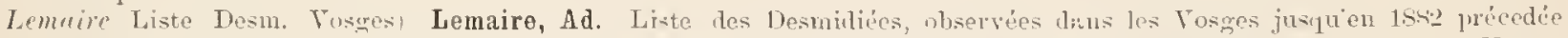
l'une introduction contenant des iulications sur la róoltc et la prépration de ces Algues. 29 plot 1 t. Yancy

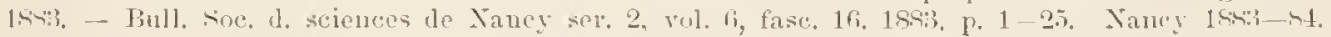

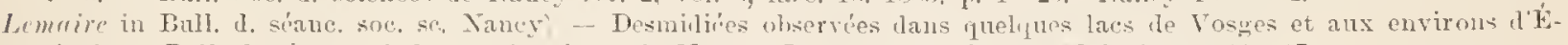

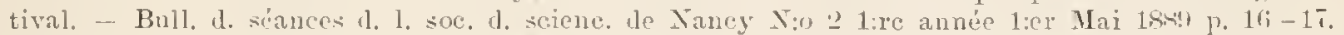

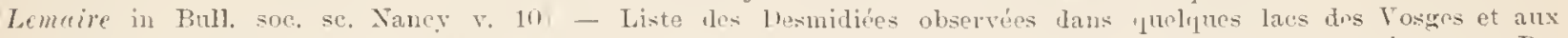

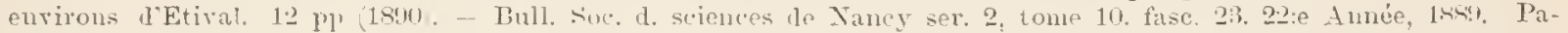
ris $18(k)$

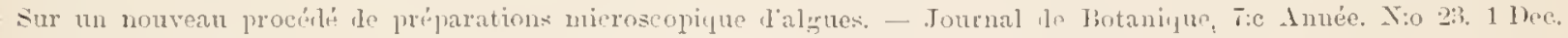
1.:? 1. 131-4111.

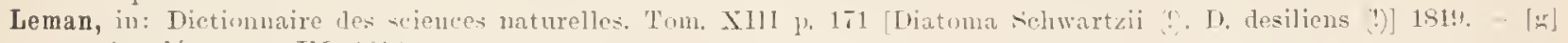
implím. tont. IlI. 1sit.

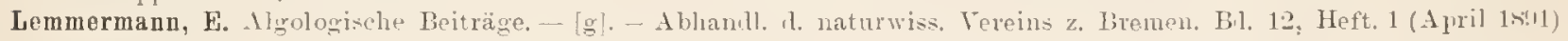
1. $115-151$.

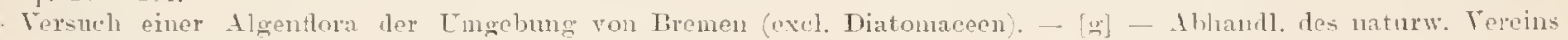

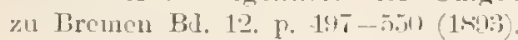

Die Algenflora iler Filter des bremischen Wassmerkes. - [g] - Abh. d, natuw. Ver. z. Bremen, Bd. 13, Febr.

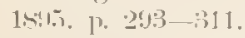

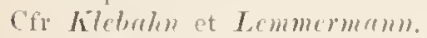

Leni in Merkienb. Arrhiv) Lenz, H. Beitrag zni Tienutniss der Desmidicen Mechlenburgs. Aruhiv res Tereins

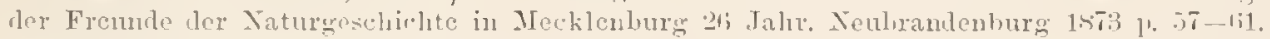

Leunis ceft. Front:

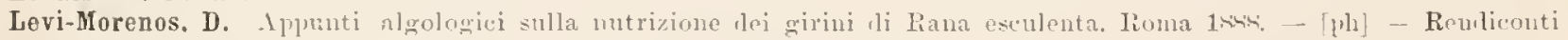
1. R. Accall. dei Lincei, vol, 4. fase.

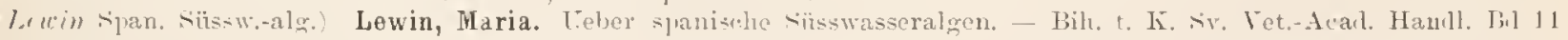

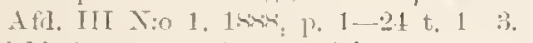

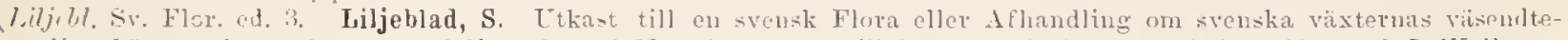

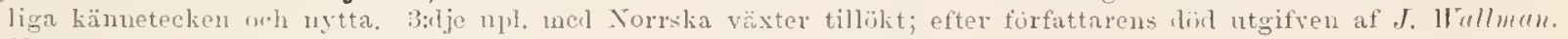

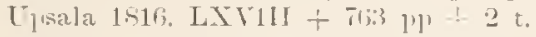

Lindley, J. A natural syotem of lintauy. Second al. Loncton $15: 36,526 \mathrm{~m}$.

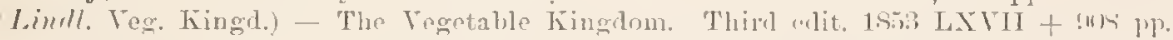

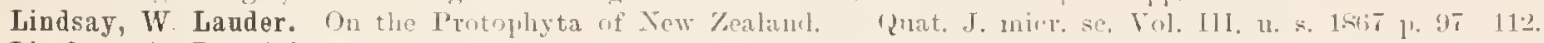

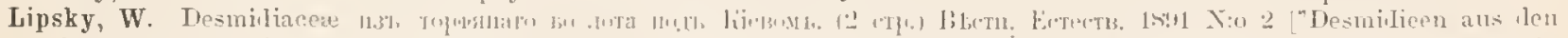

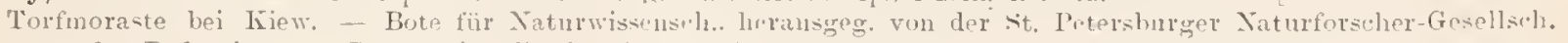

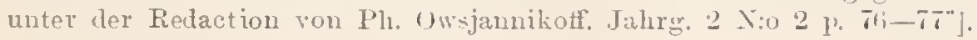




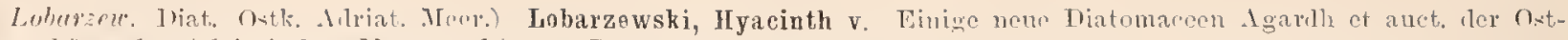

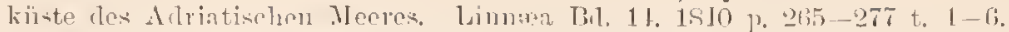

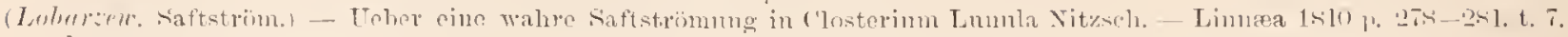

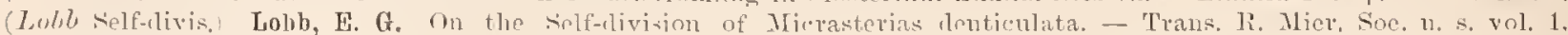
1 sil , r. 1 2. . . 1.

(L.obl in (2. Journ. Micr. su.) - On aceount of a varation visit to Oakshntt. near Teatherlearl. in Surmey, anul to Kic-

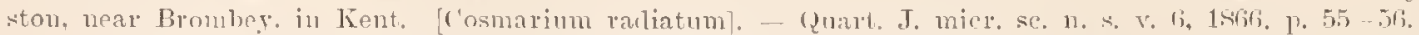

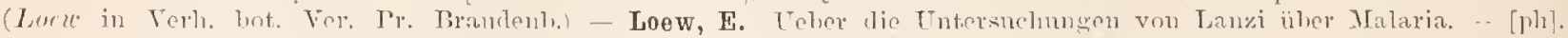

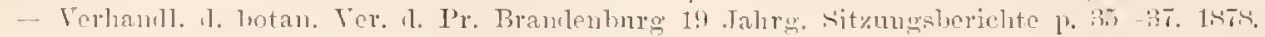

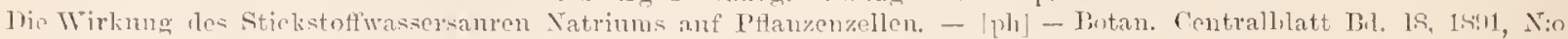
9 l. $250-251$ (sml,: Sitzungsb. 1. bot. Yer. in Mïnchen).

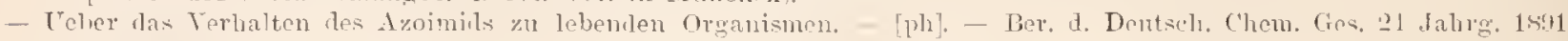
1). $2917-2.153$.

Telon die physiolngisclen Fanetionen der Caleinm- mul Magnesinmsalze in Pfanzenorganismen. - [pll]. - Flora

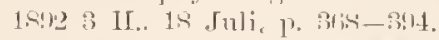

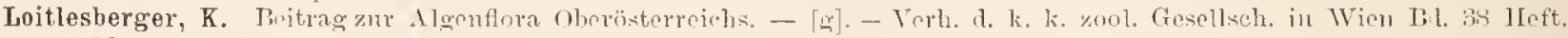
1, März 18ss Abh. 1. 22:2 220\%.

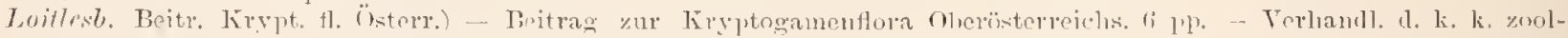

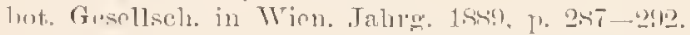

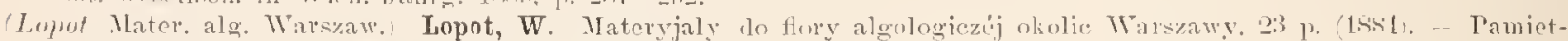

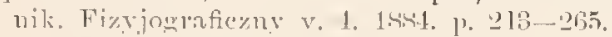

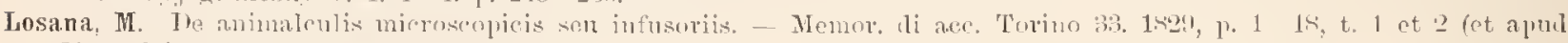

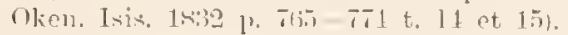

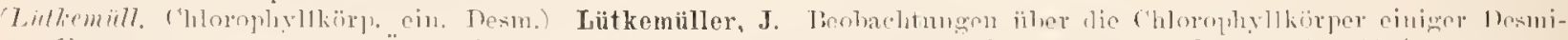

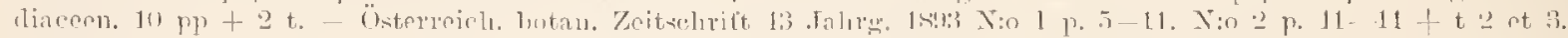

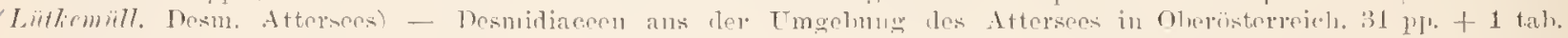

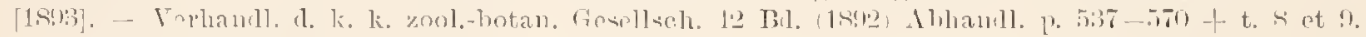

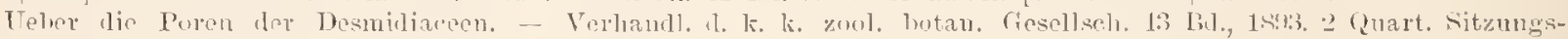
$\ln r$. p. BS.

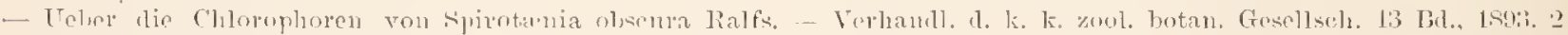

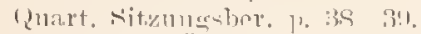

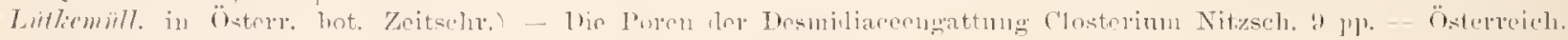

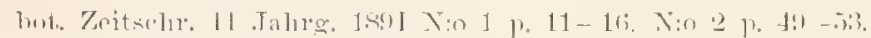

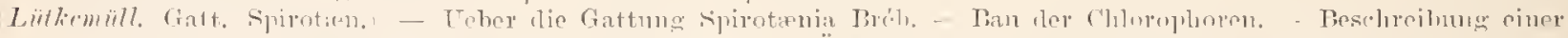

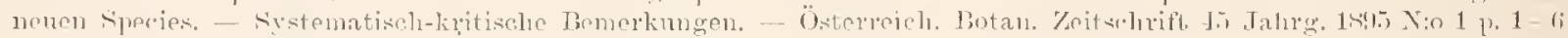
+ t. 1. $\mathrm{N}: 02$ 1, 51-ij t t. 2.

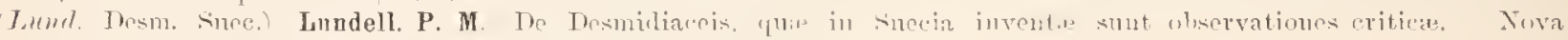

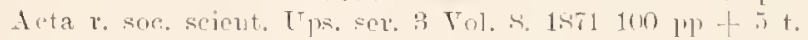

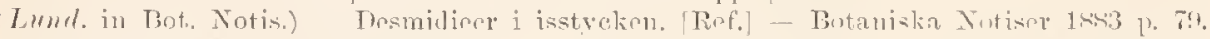

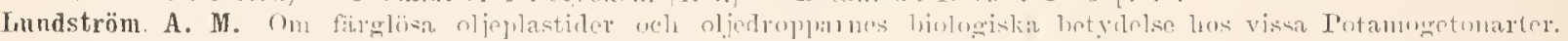

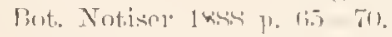

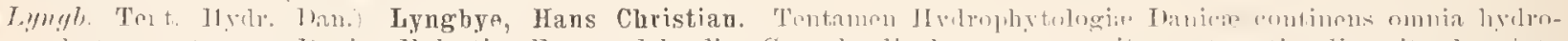

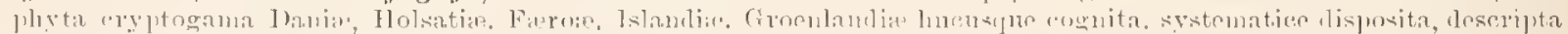

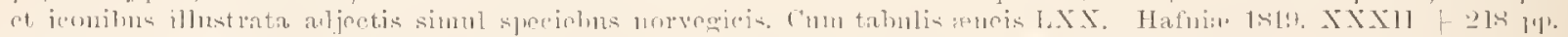

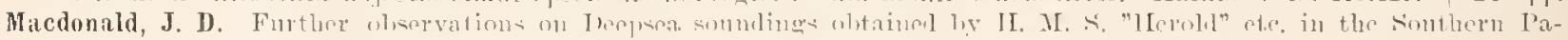

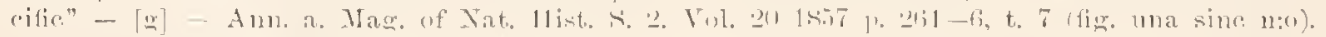

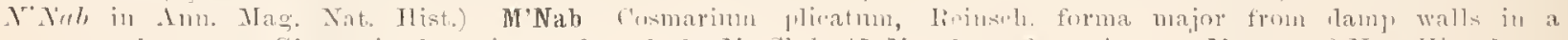

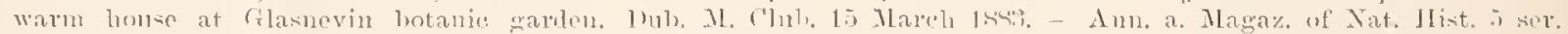

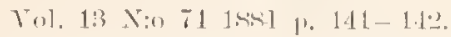

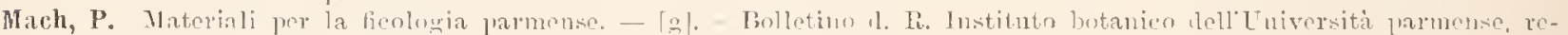

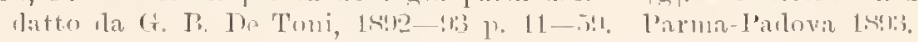

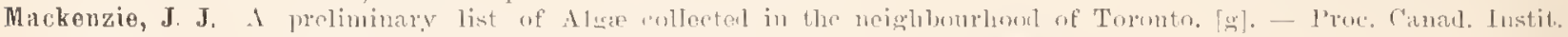

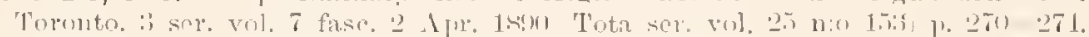

Manoury. (fir Billon in liet. Bot.

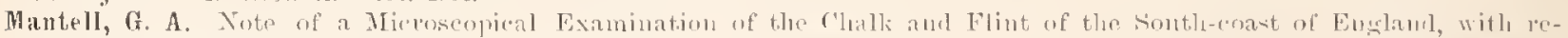

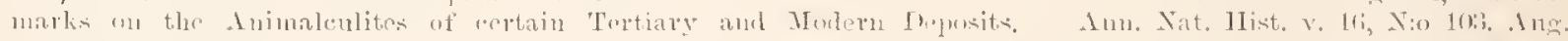

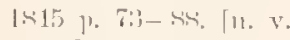

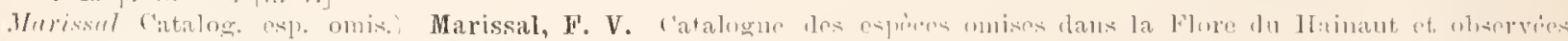

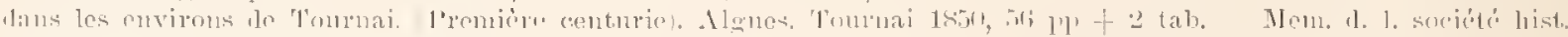
1. litieraire te Turruai. vol. 1. 18il.

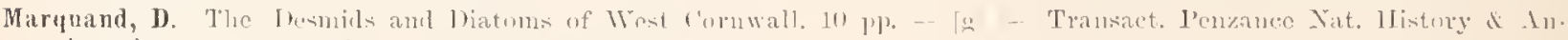

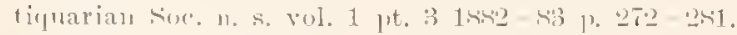

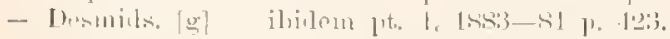

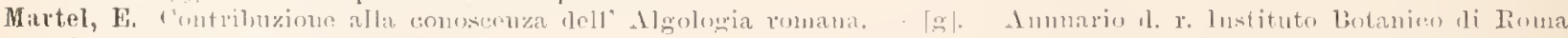

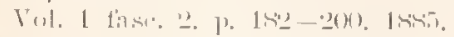

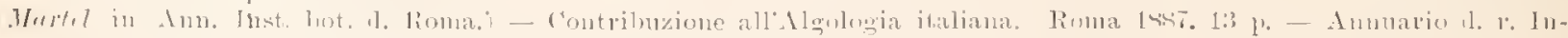

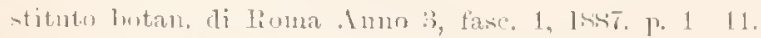

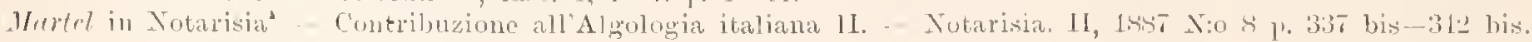




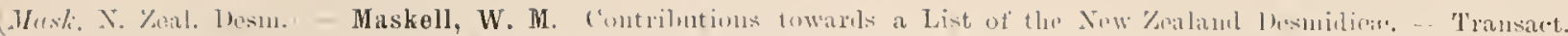

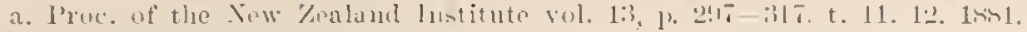

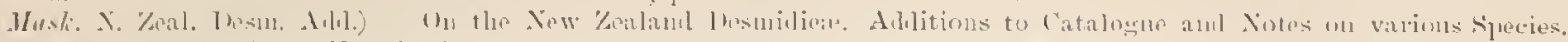

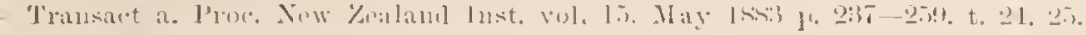

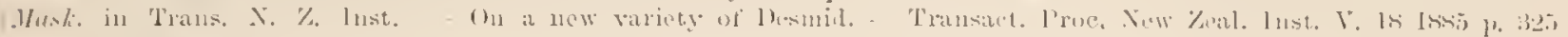
maj. Lisili)

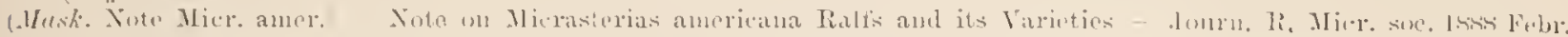
1. 7 - 111, t. 2 .

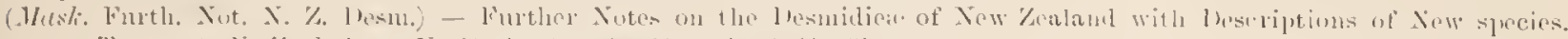

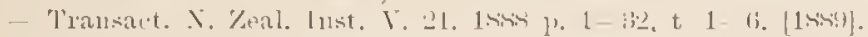

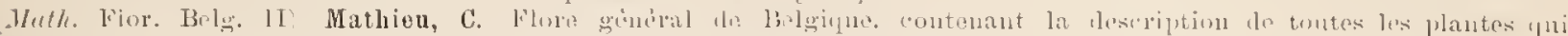

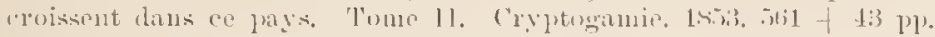

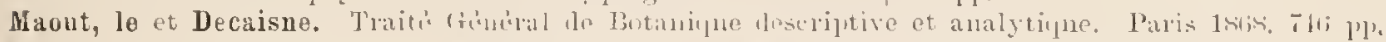

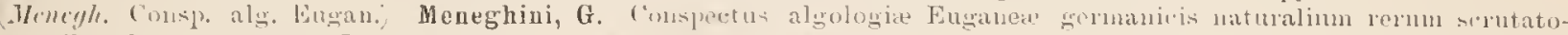

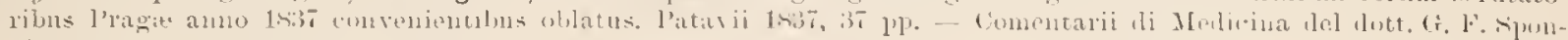

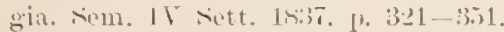

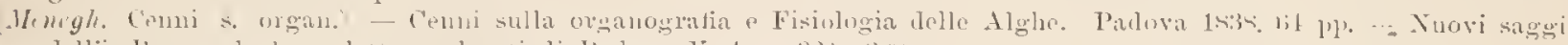

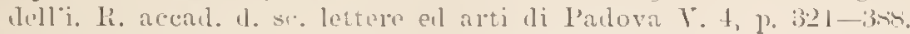

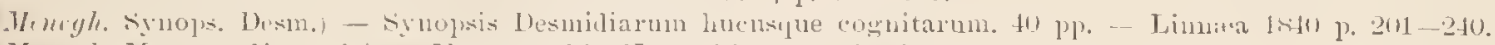

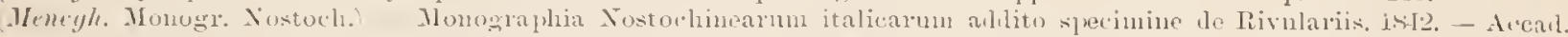

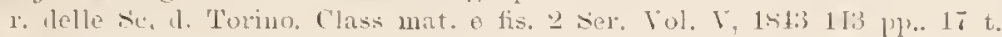

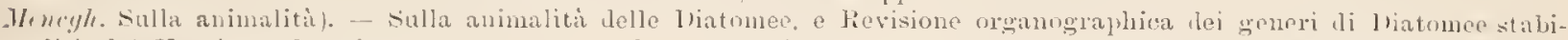

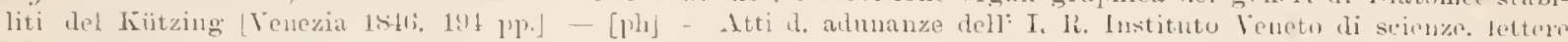
al Alti. Jol, is 1sito. 1, $4: 3-23 !$.

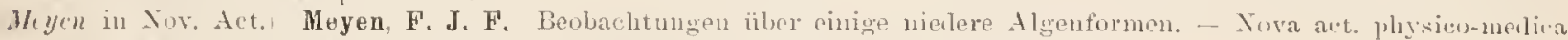

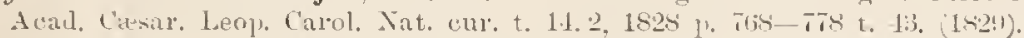

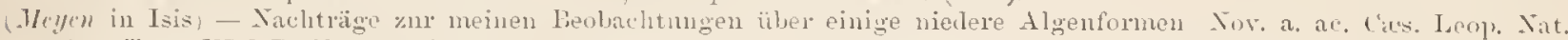

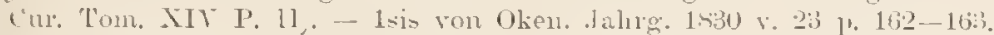

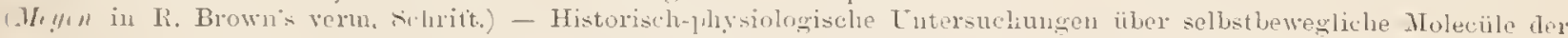
Materie. - Rubert brow's vernischte lotanische folniften. - - - iberstzt und mit Aumerimgen versehen

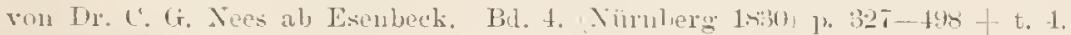

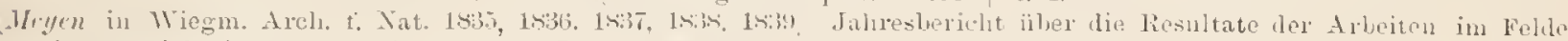

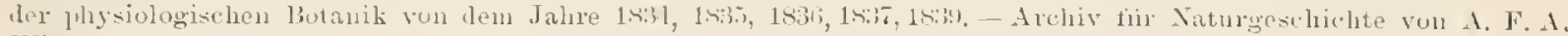

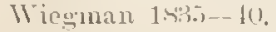

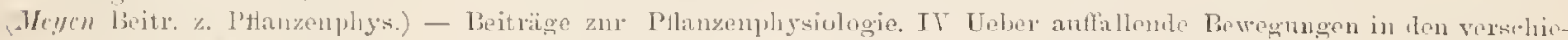

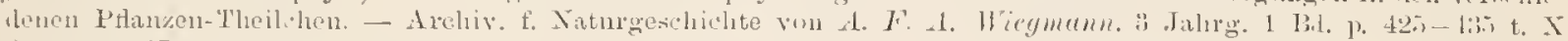
t. $2 .-1335$.

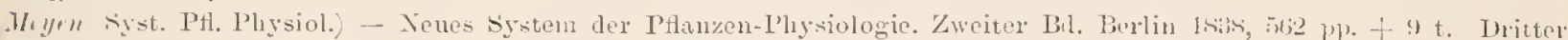

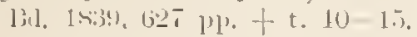

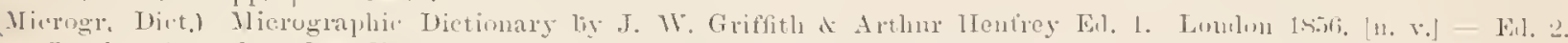

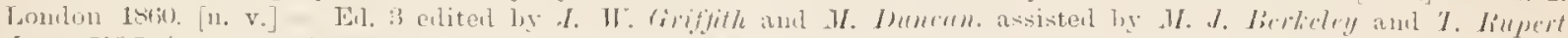

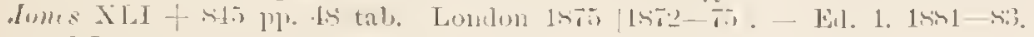

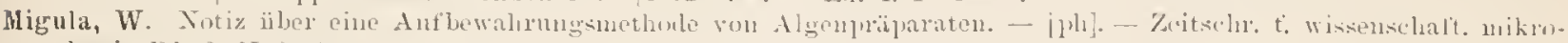

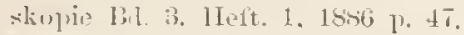

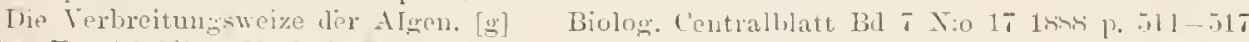

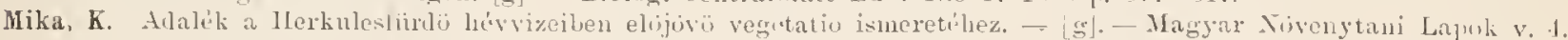

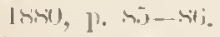

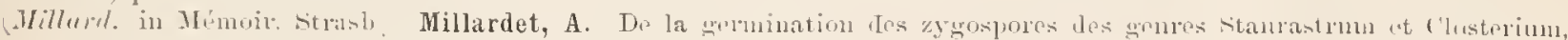

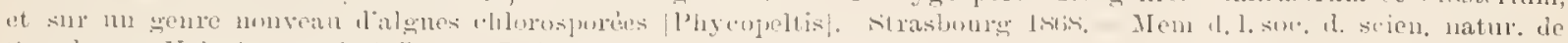

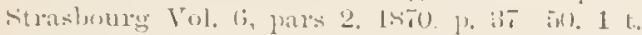

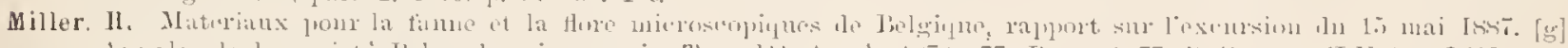

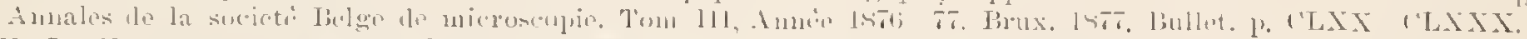

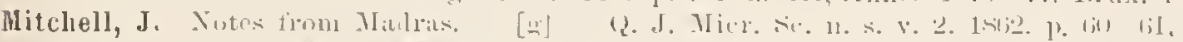

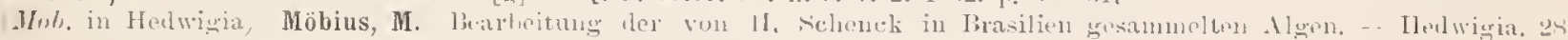

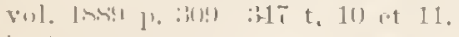

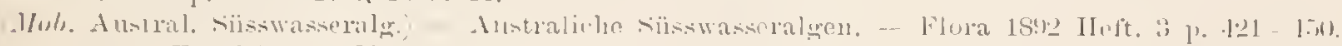

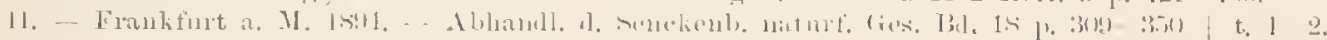

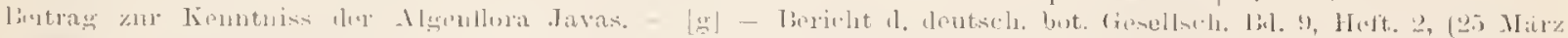

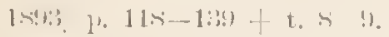

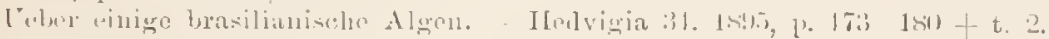

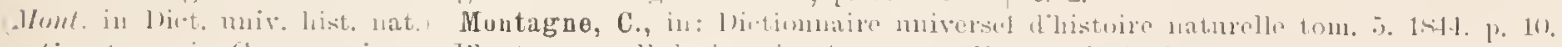

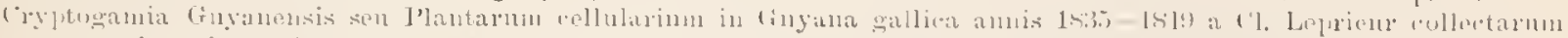

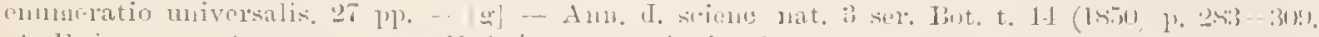

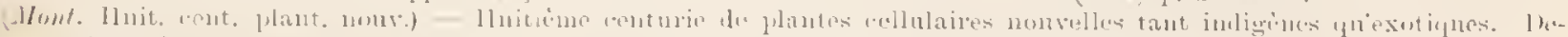

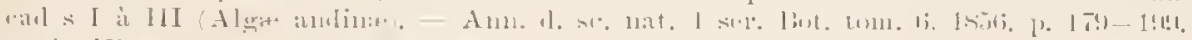

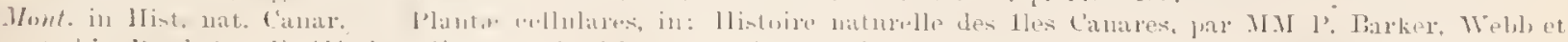

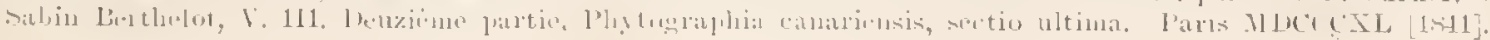


Montemartini, L. Contributo alla ficologia insubriea. 18 pl. Paria 1491. - [o]. - Atti d. r. Instituto bot. ll. Unir. al. Paria Anmo 1.8:1.

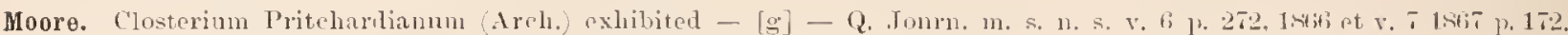

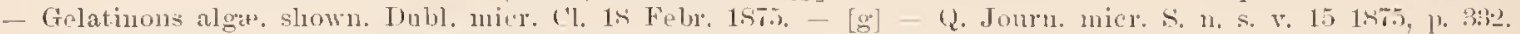

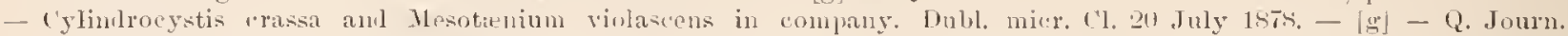
micr. S. 11. S. v. 1!, 1sis, 1'. 12?.

(Homen Recherch. Hhysiol.) Morren, Auguste et Charles. Rerherrhes sur la rulufaction les eaux rt leur oxygénation par les animaleules et. les algnes. Ouvrage orné ile rinit planches coluriées pt publiés sous les auspices de

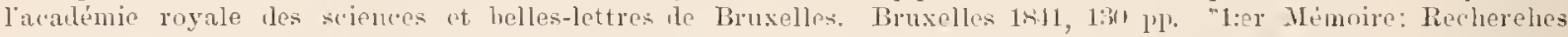

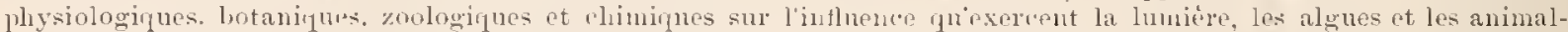
cules de coulenr verte ou rouge. contenus dans les eaux stannantes et rourantes. et sur quantité et la qualité des gaz que celles-ci peuvent coutenir" "quoque sub titulo: Recherehes plyssiologiques sur les Hrdroplytes te Belgiture

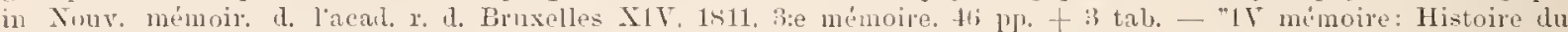

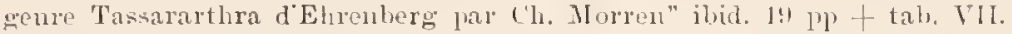

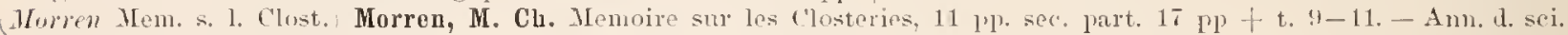

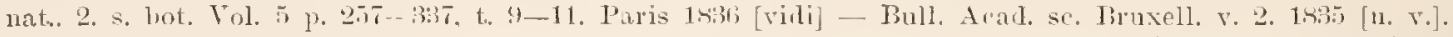

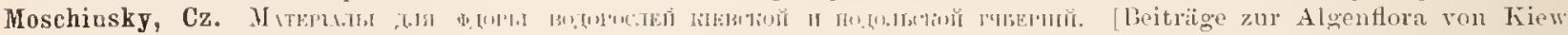

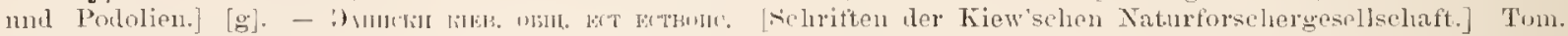

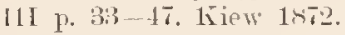

Moseley, H. N. Notes on Fresh-water Alga obtainel at the Boiling sirings at Furnas. St. Nir.hael's, Azores, and

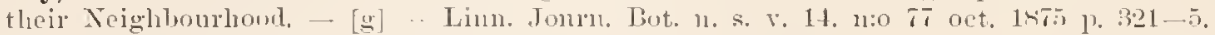

Mougeot, A. Algues (in: La Hore les Vinges). Epinal 1siz. [g. - 11. v.]. - Le Département des Vosges: Description. Ifistoire, statistique; mblic par Léon Louis. 'Tom. 2. 65.1 l'p.

(Niiller in Naturforsch.) Müller, 0. F. Fortsetzung der Anmerkungen beym Durcllesen einiger Anfsitze in den zelien

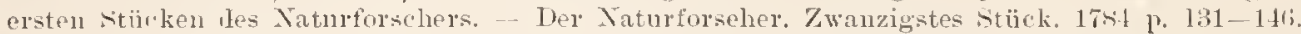

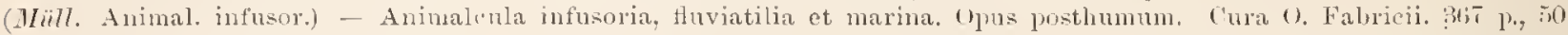
tab. Hamile 17sti.

(Nr\%. Nen. Algensyst.) Nägeli, C. Die nenen Algensysteme und Versu»lı zur Begründung eines eigenen Systems der

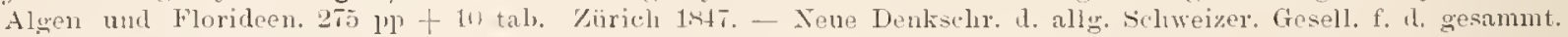
Naturwissenschaft. v. !).

(Nrg. einz. Alg. - Gattungen einzelliger Algen plysiologisuh mu systematisch bearbeitet. VII + 13! lu. + 8 t.

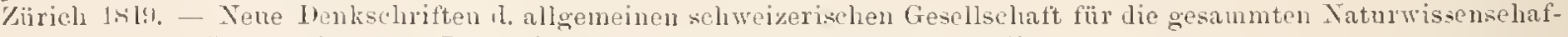

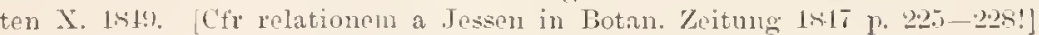

- Die Glitsehbewegung cine besondere Art fer ptriofischen Bewegung des Inhaltes in Pflanzenzellen. - [plı.] - Nä̈geli nmi Cramer. 1'Hanzenphysiologisehe Untersuehungen. 1 Heft. von C. Nügeli. p. 19-53. Zürich 1559.

Bejträge zu wissensehaftliche Botanik. Bd. 2. Leipzig 1silo.

Nardo, G. D. Considerazioni generali snlle alghe. Venezia $1635,47 \mathrm{pp}$.

Nave, J. Anleitnng \%um Einsanmeln, Präpariren und Untersuchen der Ptlanzen mit besonderer Rücksielıt auf die Kryp-

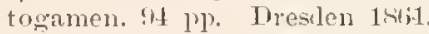

I. Algen. in: Vorarbeiten zu einer Kryptogamenflora ron Mähren mul Oesterr. Schlesien rou T. Kalmus. J. Nave d G. v. Niessl. - [g] - Verh. 1. Naturf. Vereins in Brïnn 186it. p. $1 \bar{t}$ - is.

Neos C. G. von Esenbeck. Die Algen des sissen Wassers. Bamberg. 1s14. 1: pp.

(Nit..sch Beitr. \%. Infus.) Nitzsch, Christian Ludwig. Beitrag zur Infusorienliunte oder Naturbeselueibung der Zerlarien und Bazillarien. - Neue Sehriften der natmforschenden Geselhshaft zu Halle. Dritter Bant. Ifeft. 1. Halle

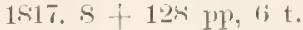

(Aordenskinll in ïvers. Vet. Akat. Fürl.) Nordenskiöld, A. E. Redogïrelse för en experlition till Grönlanul. [Pag.

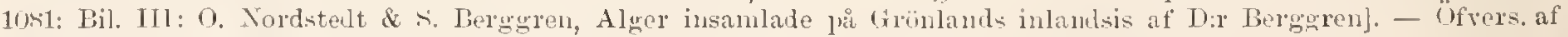

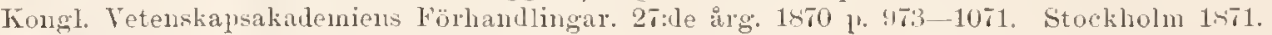

- Cfi. Wittrock.

(Nordst. Bidr. Sverig. Desm. Nordstedt, C. F. 0. Bidrag till kïmectomen rm Steriges Desmidiexe.-- Bot. Notiser 1stin p. Bh- 13 .

(Nordst. Desm. Brasil.) - Part. is. Lis Fam. Desmidiacest, in: E. Warming symbolat ad Floram Brasibie centralis cog-

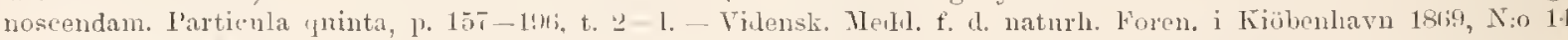

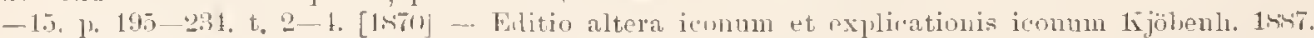

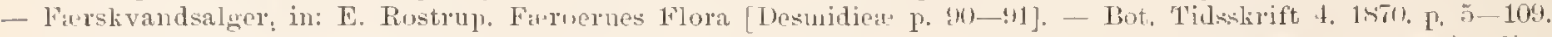

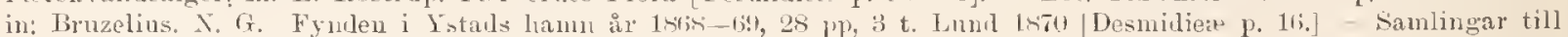
Sikunes historia, lornliunskap och Beskifining. 1,71.

Tre amerikanska arter funua i Nverge. - [g] - Botaniska Xotiser 1sĭt p. Llit,

"Desmiliacen", in: Exkursion till Kongens Murler. in: Den botaniske Forenings virlisonliet fra Jan. 1sín till Maj

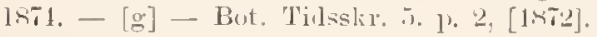

(Nordst. Desm. spetsb.) - Dosmidica ex insulis Spetslergensilus et Becren Eiland in expeditionibus annorum 1s6r et

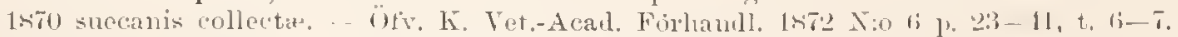

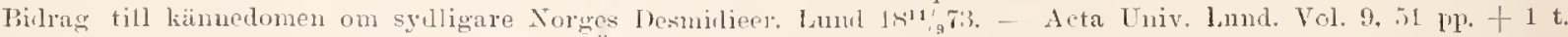

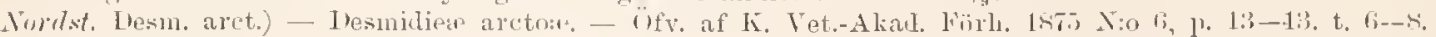

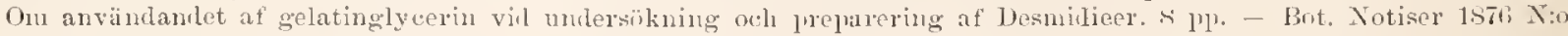
$2 \mathrm{p}, 3 \overline{-}-\mathrm{H}$.

(Nordst. in Hedwigia) - Einge Benerlingen iiber the Desmilieen in "Contribntiones ad Algologiam et Fungologiam,

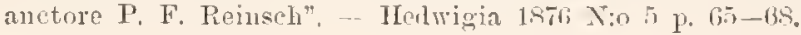




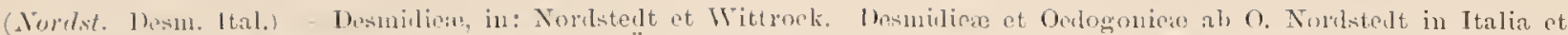

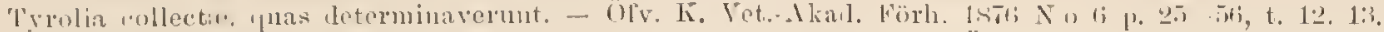

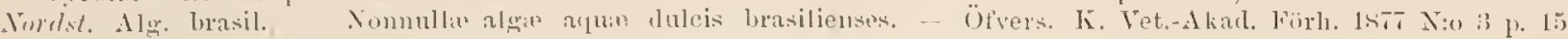
- ․․, t. 2.

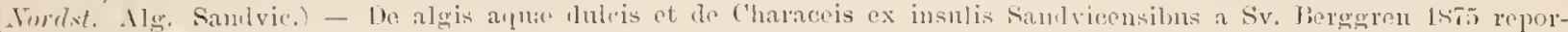

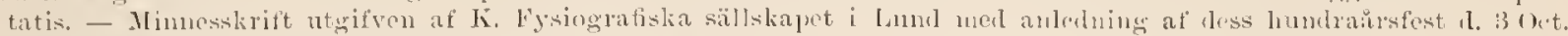

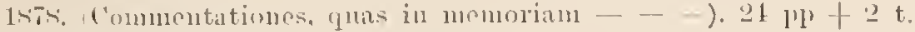

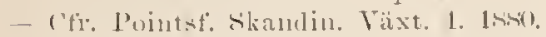

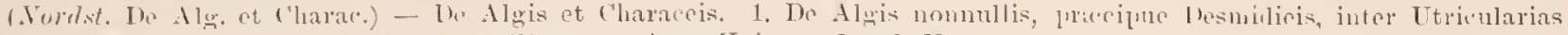

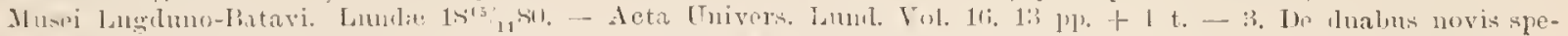

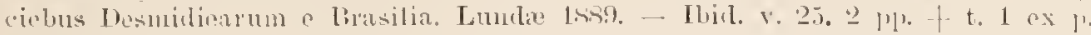

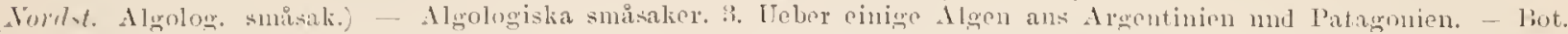

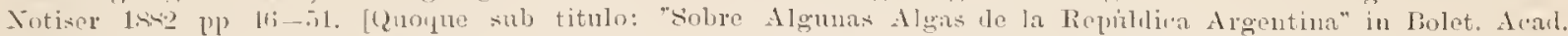

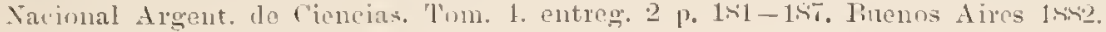

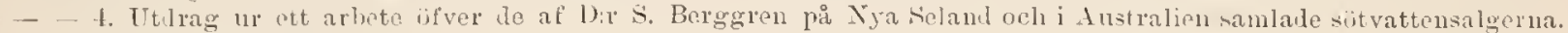
- lbiil. 1.4isi p. 15i3-1til.

Wordst. in Bot. Not. 1Kre - Anmülan af: Fr. Elfvings "Anteckningar om Finskin Desmidiacécr". - Botaniska Notiser 1 1

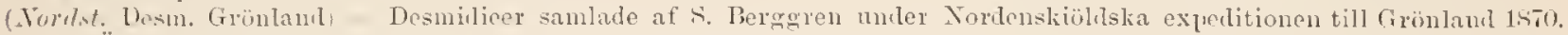

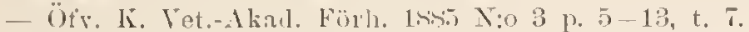

- Teber dio ron I'rof". S. Brogren auf Nen-Seeland gesammelten Nïsswasseralgen. Tn: Botanischer Verein in Land

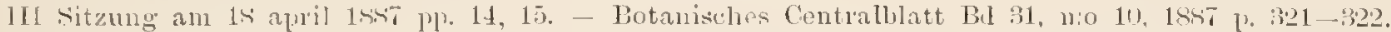

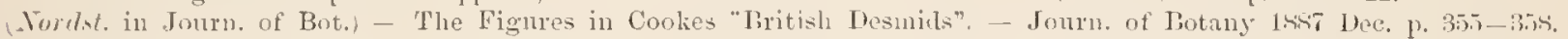

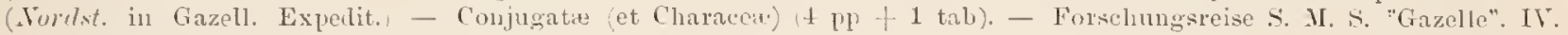
'l'heil: liotanik. Alyen von E. Askenasy. Berlin 14s. p. 3-4, t. 1 ex p.

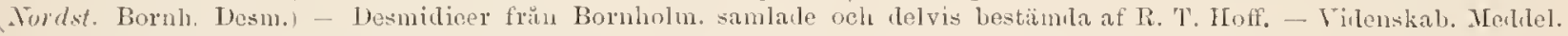

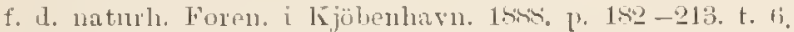

(Furlst. Fr.wat. alg. X. Zeal., - Fresh-water Algre collected by D:1. S. Berogren in New Zealand and Australia. -

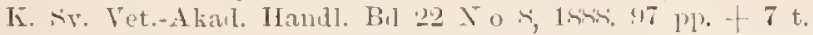

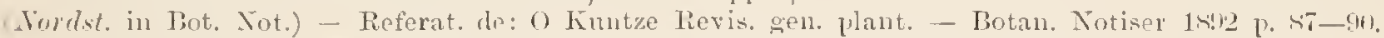

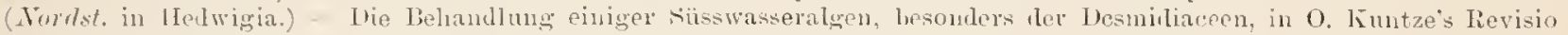

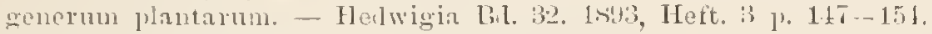

Nordstedt, 0. d Berggren, S. ('fr. Tordenslicild.

Nut. Desm. Ital.) Notaris, G. de Elementi per lo studio delle Desmidiacen Italidhe. (Desmiliaeee lella Val Tutrasea) sit plo.. it.

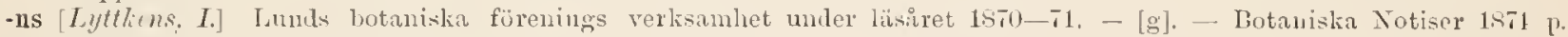
16i1-1ili.

Orbigny, de - Cfr Mrebissun, L. Decrisne et Muntayne.

(Misted Luvsporpl.) Oersted, A. S. Lorsporplanterne. En morploologisk og systematisk Udsigt over denne Plante-

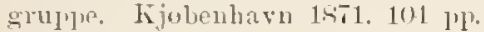

Osbume in (2. J. M. Nic. v. 2.) Osborne, Sydney G. On Closterim Lumula. Communirated by Jahez Hogg, Esণ. Q. Journ. mices. se, v. 22 1sist. p. 231-211.

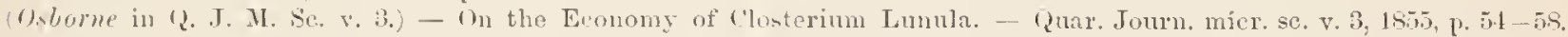

Oudemans, C. A. J. A. Bijdrage tot de Fłlora Algologiea valı Nelerlanıl. - [g] - Nederl. Kruidk. Arehief. Tweede

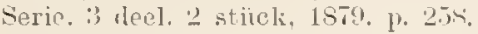

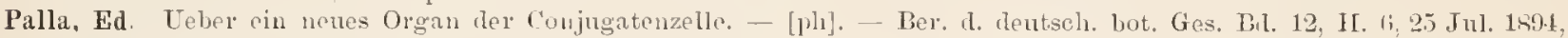
[. $153-162+$ t. $\mathrm{s}$.

- Ueher sine nene. pyrenoillose Art un] rattung ider Conjugaten. - [pli] - Berieht il. dentsels. bot. Ges. Bu. 12.

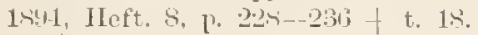

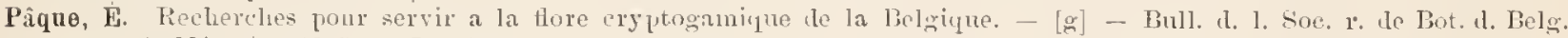

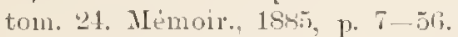

Payne, C. L. List of Algu from Granvile, Olio. - [n] - Bull. Seint. Labor. Denison Univ.. v. 1. 18ss. p. 132.

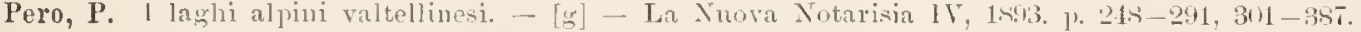
- Parte secomlo. - [ $[\mathrm{c}]$ - L La Notarisia 1893-45.

(Perty iu Bern. Mitth.) Perty, M. Über verticale Verbreitung mikroskopischer Lebensformen. - Mittheil. 凡. naturforsch. Gesellsch, in Bern 184! p. 17-15. Heru 1819.

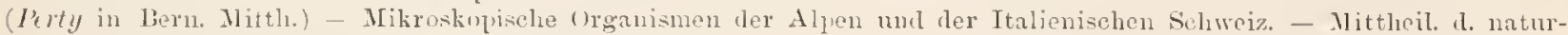

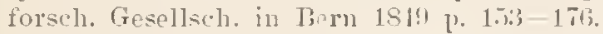

(Pevty kleinst. Lebensf., - Zur Kenntuiss kleinster Lebensformen nach Ban. Funktimen, Systematik. mit Specialver-

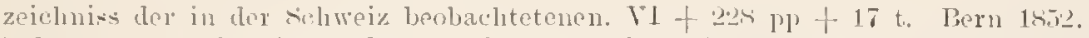

(l'etit Desm. de Paris) Petit, Paul. Liste des Diatomies et des Desmidies, ohserves daus les environs de Paris. pre-

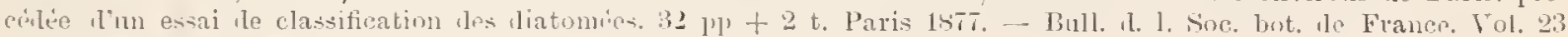
p?. 37.2 3\$3. vol. 24 p. 3-s et [1. 31-31j+t. 1. [Liste les Desmidièes observies dans les environs le Paris I. $e$. p. $3-8$.

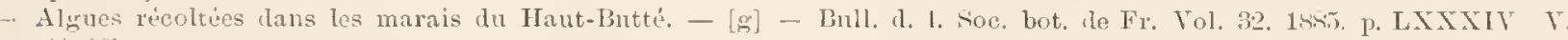
[1:inii).

Pfoiffer, L. Synongmia botanica locupletissima Generum, Sectiouum vel Subgenerum art finem anni 1 s5s promulga-

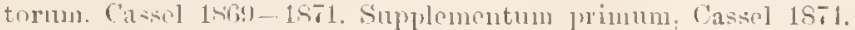
Himtsielt, Iuiles I'sumit. 
I'feiff'r Nomenel, bot.) - Nomenclator botanicus. Nominum ad finem anni 1850 publici juris factorum, classes, ordines. tribus. familias, divisiones, genera. subgen'ra vel sectiones lesignantimu enmmeratio alphabetica. Adjectis Anetoribus. Temporibus, Lncis systematicis apul Varios, Notis literaris atque etymologicis et Synonymis. Vol. 1 et 2. Cassellis $1873-74.1876+1698 \mathrm{p}$.

Pfitzer, E. Ancylistes Closterii, ein neuer Algen-Parasit aus der Ordnung der Phyconyceten. - Monatsb. d. Berl. Akad. 1872. p. 379-39s et 1 t.

Piccone, A. Florula algologica della Sardegna. - [g]. - Nover. Giom. bot. Ital. Tol. 10. N:o 3 18rs p. 289--367.

Pitra, A. Mitheilung'en über eine ausserordentliche Anlünfung der Ga]]ert-Algen. ‥ [g] - Bot, Zeitung 1863 p. 79 - -2.

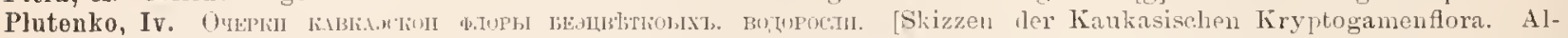

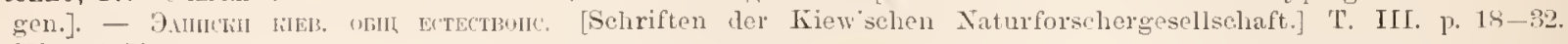
Kiew 1872 .

Pootsch, J. S. und Schiedermyr, K. B. Systematische Aufzälnlung der in Erzlierzogtlume (isterreich ob der Enus bisher beobachteten samenlosen Pflanzen Kryptogamen). Heransgegeben von der k. k. zoologiseh-botanischen Gesollschaft in Wien. Wien 1872. XLVIII + 384 lp. - Nachträge - - - Unter Mitwirkung der Herren Moriz Heey nnd Dr. Siegfried Stochmuger bearbeitet ron Dr. C. B. Sichiedermayr. Wien 1s!1. 216 pp. [g].

Pokorny, A. Vorarbeiten zur Kryptogamenflora von Unter-Österreich. - [g] - Verh. d. zool. bot. Tereins in Wien. B]. 4. 1854. p. 35-168.

(Pointsf. Skandin. Växt. 4) Points-förteckning öfver Skandinaviens växter. (Enumerantur plantæ Scandinavie) Ł. Characeel. Alger och lafvar. Lund 1880, $116 \mathrm{pl}$. Cfr. Nordstedt (Desmidieæ), Jithvek.

Poteat, W. L. Nortlı Carolina Desmids. A Preliminary List. - 4 pl. - [g] - Journ. Elisha Mitchell seientific. Soc. Vol. 5. part. 1. 18s:s. p. 14.

(lritch. Inf.) Pritchard, A. A History of infusorial Aninalcnles, living and fossil: Ed. 1 1s3t [n. v.] - Ed. II 1811 [n. v.] - Ed. III London 1852. $701 \mathrm{pl}$. $+24 \mathrm{t}$.

- A History of Infusoria, including the Desmiliacese and Diatomacee. Britislı and foreign. Ed. IV. London 1861. [Cifr. Archer].

Prodromus Florie Batava. In sociorum inprimis usum edendum curavit societas promovenło Flor:e Batava studio. Vol. 2. 1,t. 2, 301 l 1). $1553-[\mathrm{g}]$.

(hal. Deut. Krypt. Fl.) Rabenhorst, L. Dentsehlands Iirytogamenflora oder Handbuel zur Bestimmung der kryptocramischen Gewächse Deutschlands, der Schweiz, des Lombardisch-Venetianischen Königreichs und Istriens, 2 Bd. 2 Abth. Algen. Leipzig 1847.

(Rabenh. in Flora 1550) - Systematische Uebersicht der auf meiner italienischen Reise beobachteten Kryptogamen. Cl. I Alg:e. - Flora Vol. 33. N:o $33-34$ p. $513-525,1850$.

- Mikroskopische Analyse der Moorbäder zu Bad Elster in säehsischen Voigtlande. - Allgemeine dentselıe naturh. Zeitung. Im Auftrage der Gesells. Isis in Dresden - herausgegeben von D. A. Dreschler. Neue Folge. 1 Bd. 3 Heft. 18:5. $[\mathrm{g}]$.

(Tubenle. Beitr. Irypt. Süd-Afr.) - Beitrag zur Kryptogamenflora Siid-Afrikas, Pilze n. Algen. - Ibid. 1855. 7 Heft.

(Rab. Frypt. Fl. Sachs.) - Kryptogamenflora von Sachsen, der Ober-Lansitz, Thüringen und Nordböhmen, mit Berüchsichtigung der benachbarten Ländel. 1:ste Abth. Algen im Weitesten Sinne, Leber- mul Lanbmonse. Leipzig 1863. $\mathrm{XX}+(953 \mathrm{pl}$.

(Rab. Fl. Eur. Alg. 3) - Flora Europea Algarum. arue duleis et submarinx. Sect. 3, XX + 461 lp. Lipsie 1 Stis.

- Cri Alg. Sachsen's (sub I B., Collect. exsiceat.

(Rreib. Desm. oknl. Krakowa) Raciborski, M. Desmidyje okolic Krakowa. 24 p, 1 t. Krakowie $189 t$ - Sprawozh. liom. fizyjogr. Akad. Um. w Kirakowie Tom. 19. p. - - t. 1.

(Rucit. Nonn. Desm. Polon.) - De nommllis Desmiliaceis novis pel minus cognitis, qua in l'olonia invente sunt. lt

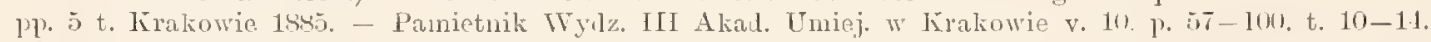

(Rucil. Mat. flor. glon. Polst, - Materyjaly do fory glonow Polski. Kraliow 1sss. 13. pp. - sprawozdan. Kinmisyi fizyjogr. Akadem. Uniej. w Krakowie. 'Tom, 22 Cs. II. p. S0-122.

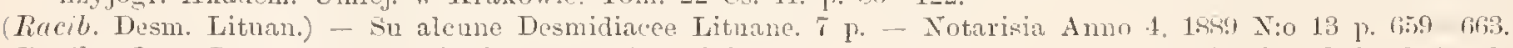

(Rucit. Now. Desm.) - Desmidyje nowe. (Uesmidliacere nove.) 41 pp. 3 t. - Pamietnik Wydz. 3 Akrl. Umiej. w

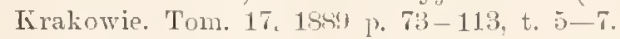

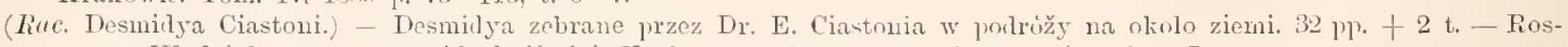
prawy Wydzial. mat. przyr. Aliad. Umiej. Kiraknw. t. 22 (1892) p. $361-3 ! 2+$ + t. 0 , t 7 .

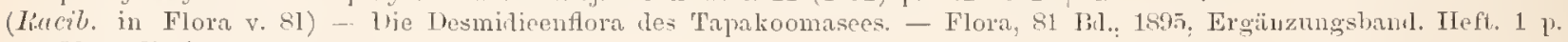
$30-35+$ t. $3-4$.

- Cfr Eicher et Rociborshi.

Rafinesq. in Journ. bot. applie.) Rafinesch, (Schmaltz). Description de ruelques Végetanx de sicile et des Etats-

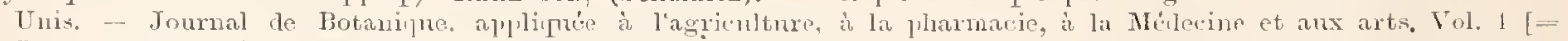
Jonrn. de Bot. Sécond Amée. Tome :3:e] p. 235 - 7. I’aris 1s13.

(Kulfs in Amn. Nat. Ilist. v. 9). Ralfs, John. On new species nf Desmidium. - Ann. Mag. Nat. IIat. Vol. 9. 1812 p, 1:i. [In Proced. of Bot. Soc. Ellinb.]

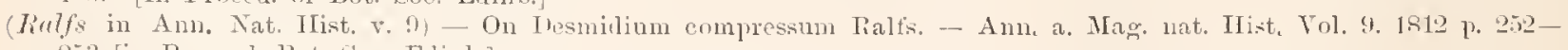
2.33 [iı Proceerl. Bot. Sor. Erliub.].

(Rolfs. Ann. Nat. Hist, v. 11) - 'l'rans. Bot. Soc, Ellinh, v, 2) - Remarks on the species of Desmidium, - Ann. Mag.

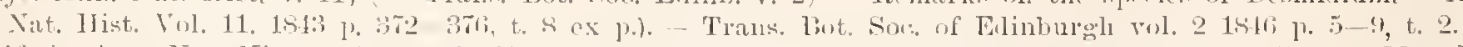

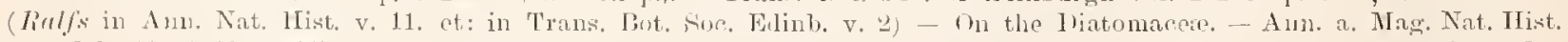

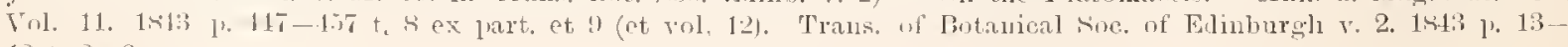
12 t. $2-6$. 
(hulfs in Anll. Nit. Ilist. v. 13-16; et: in Trans, Bot. Soc. Edinb. v. 2). - On tle British Desmidiexe. - Ann. Mag.

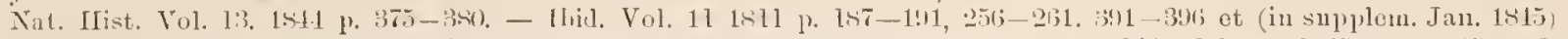

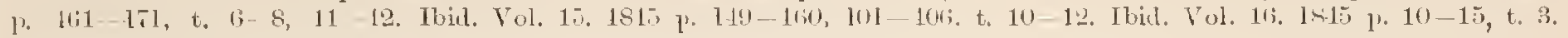
Trans, Bot. Soc. Eilinb. Yol. 2. 1s16 \%. 119-169 t. 10-18.

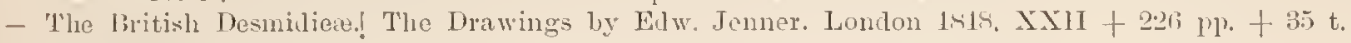

- Cfr. Jenner.

Reichenbach, H. Th. L. Conspectns Regni Vegetabilis per gradus naturales evoluti. Pars prima. Lipsias 1828 , IlV $+2 \mathrm{pl}$.

(licichenb. Nomenel. gen. pl.) - Repertorium herbarii sive nomenclator generum plantarum systematieus, synonymicus et alphaticus. - Der deutsehe Botaniker. - Erster Band. Das IIerbarienbuch. 1 et $2 \mathrm{Abth.} \mathrm{X}+211+\mathrm{XCV}+$

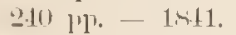

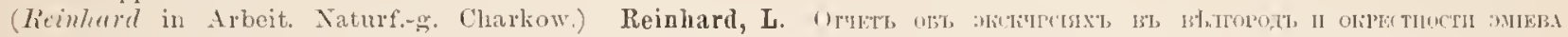

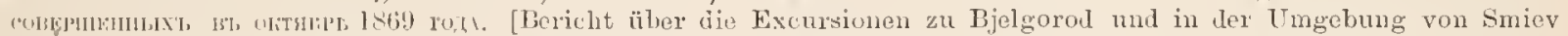

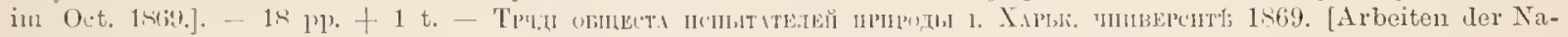
turforschergesellschaft hei der kais. Universität in Charkow.] Ton. 1, Charkow 1nio.

(lieinsch Morplol. Fragn.) Reinseh, P. Morphologische, Anatomische und Physiologisehe Fragmente. 4. Ueber die I'rotoplasnabewrgung in tem ('losterium Limula, p. 17-21. 7. Ueber durch abuormen Vorgang der '1heilung lier-

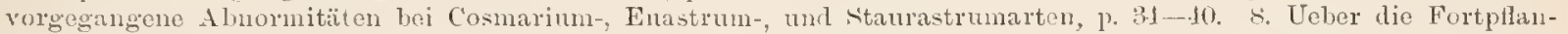
zung der Eunstren und Phyeastren dureh den Vorgang der Zelltheilung, sowie Peobachtung der analogen Fortpflan-

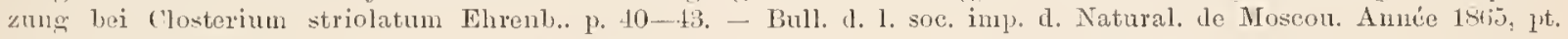
2. 1. 1 - 5 \%. t. 1 2.

(Reinsch Algenf. Frank.) - Die Algenflor les mittleren Theiles von Franken. enthaltend die von Autor bis jetzt in dicsem Gebieten beolacliteten Sïsswasserilgeu. $8+238$ pl.. 13 t. Nüruberg 1.66. - Ablankl. d. Naturhistor. Ge.

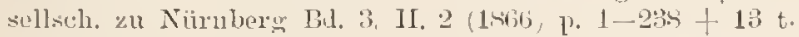

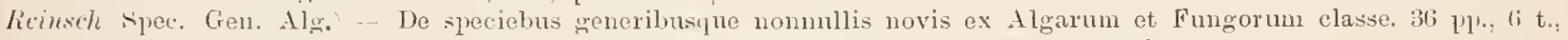

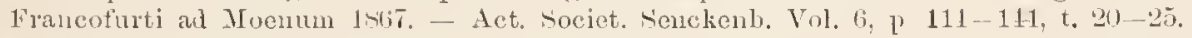

(Reinsch Contrib.) - Contributiones ad Algologiam et Fungologian. Vol. 1. Lipsie 1875, XII + 103 pp., $41+18$ [Chlorophrllophyceie] + a t.

(leinsch in Journ. Linn. Soc.) - Speeies ac Genera nova Algarun arue dulcis, que smut inventa in specininibus in

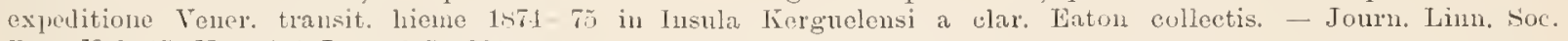
But., Tol. 15. N:o sil 14iti; P. 2015-221.

(leinsch in Pringsh. Jahrb. v. 11.) - Jeobachtungen über einige nene Saprolegniea, über die Parasiten in Desmilienzellen und aber die Stachelkugeh in Achlyaschläuchen. 29 pro, 1 t. - Pringsleims Jahrl. f. wissenseh. Bot. Bul.

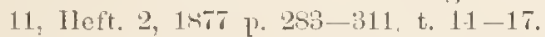

(leinsch Alg. Prom. Bon. Spei) - Contributiones ad floram Algarum aque dulcis Promontorii Bona Spei. - Journ.

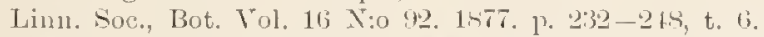

- Botanische Notizen ans Nordamerika. - [g] - Botan. Zeitung 1878 p. $359-3155$.

(lecinsch Freshw. Alg. Kerguel.) - Freshwater Algre of Tierguelen colleeted by the Rev. A. E. Eaton. - Algre aqua dulcis insnlw Kerguelensis (Cum notulis de distributione geographica a G. Dickie adjectis). 20. pp. [187s]. - Pliil. Trans.

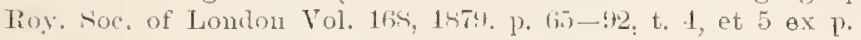

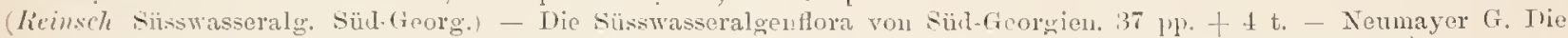
internationale Polarforselung 1.4\% - 1ks:3. Die Deutschen Expeditionen und ihe Ergebnisse. Allg. Theil, Bd. 2, Xio

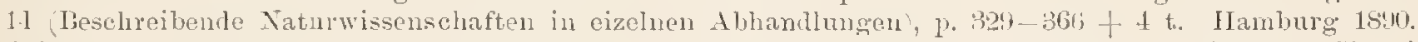

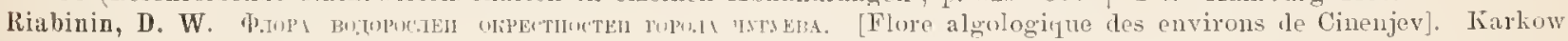
1sse, IV + th pp. - [g]. - Travanx d. I. Soc. 1. Naturalistes a l'univ. 1. de Kliarkow. 'Tom. 22.

likebin Chloroph. envir. Kharkow) - Les chlorophycées des environs de Kharkow. 60 pl. t t. 8. - Bull. d. 1. boc. inp. d. Natural. de Moscon, amée 1ssts. $11: 02$ p. $24 !-31$, t. s.

Richter, A. Über tie Anpassung der Süsswasseralgen an Kóohsalzlösungen. Tnanpural-Dissertation ... zu Erhàgen.

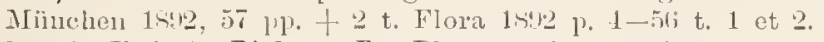

(lichter in Hedw.) Richter, P. Pleurotienium nohile nov, sp. - Hedwigia X:o \& 1805 p. $129-130$.

Nene Algen ler Phycothece universalis. Fasc. NIll. - Helwigia Bd. 34. 1495, 1. 22 -26 e. fig. xylogr.

Riess, Felix. Beiträge zur Fauna der Infusorien, mit dem beigefügteu Elrenberg'sehen Systeme. Inanguraltissertation. Wien 1:10. 10 Pp.

(limemer Alg. St. Pülten) Rimmer, F. Algen. Bacillarien wnd Pilze ans ler Ungebung von St. Pölten. I. Mitthei-

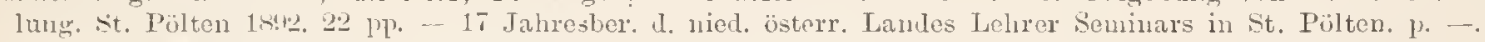

Rischawi, A. (Materialien zur Algentlora des Fiew'schen (rouvernement.) - Schrift. d. Iiew'schen Naturforscherge-

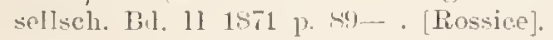

Rodriguez ig Femenias Juan J. Algas de las Baleares. (Continuación). - [g]. - Annal. d. 1. Soeicu. Española de Hist. Nat, tom. 14, 1 s. $1.199-274$.

(livem. Alg. Deutsehl, Roemer, F. A. Die Algen Dentschland's. Hannover 1815, 72 pl. t 11 t.

(hossm. Nachtr. Wetter. Alg.) Rossmann, J. Einige Taehträge zu dem Verzeichniss der Wetterauer Algen von f.

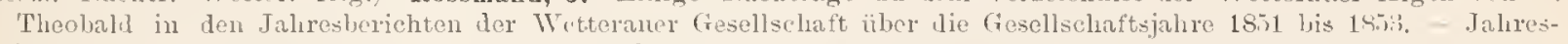

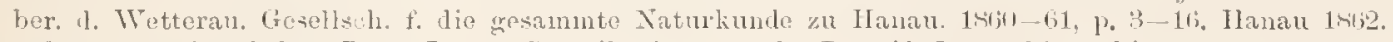

(lioy Desm. of Perthsh.) Roy, John. Contributions to the Desuid Hora of Pertshire. T Il). - The Scot. Naturalist.

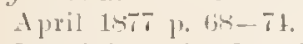

"Inesmidie:" in G. Dickie, Totes of Alge from the Amazonas anl its Tributaries, - [n] - Tourn. Limn. Soc, Bot.

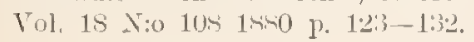


Desmiliace in: Dickie G. Notes on Algar from the Jimalayas.

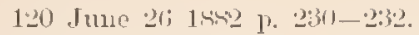

(lion in Scott. Natural.) - List of the Desmids hitherto fouud in Mull. - Scottish Naturalist. 11. s. Vol, 1 No:o 1 July $184: 31,37-.1 \%$.

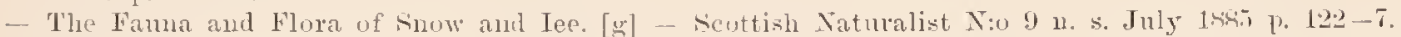

(Roy in Flora of Leicestrisll.) - The lesiniliea of the County of Leicester [in: F. Thates "Catalogue of the Algae of

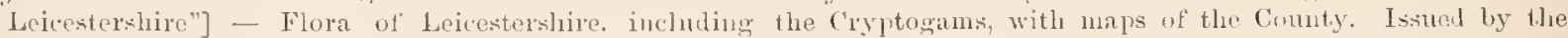

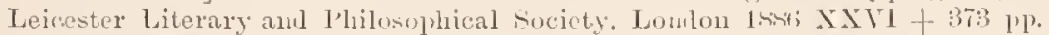

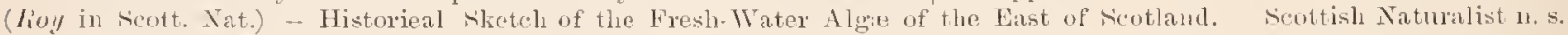

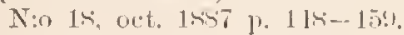

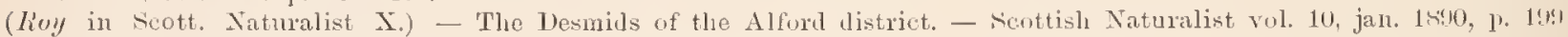
$-210$.

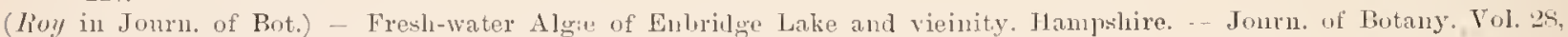

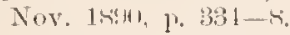

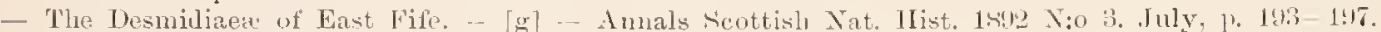

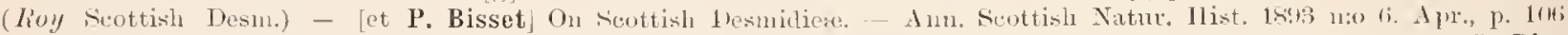

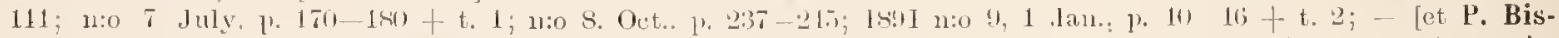

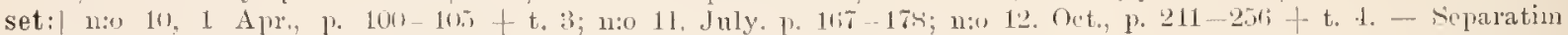
"By" the late John Roy, LL. D.. and J. P. Bisset" $(2+)$ lil Pl. + I t.

(lioy et Piss, dap. Hesm.) - et Bisset, J. P. Notes on Japanese Desnids. In 1'. t. 268. - Joum. of Bot. July \& Aug.

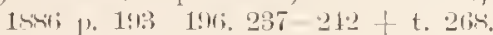

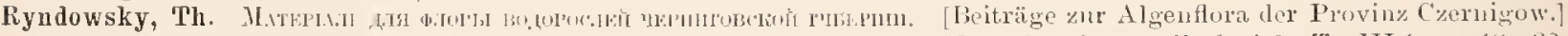

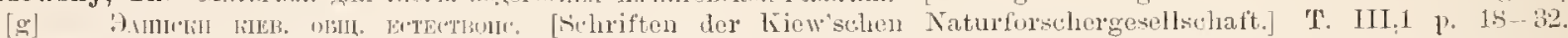
Kiew $187 \cdot 2$.

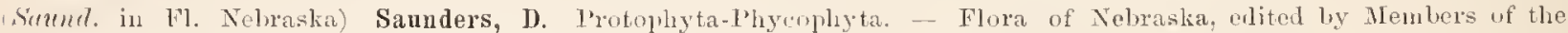

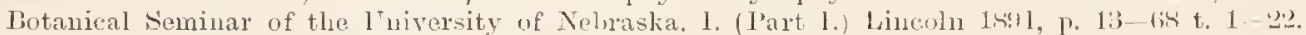

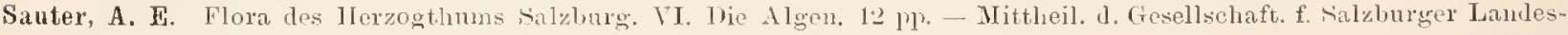
kunde. Bd. $131873 \% 17-24$.

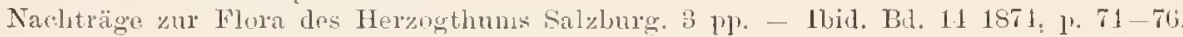

Sauvagean, C. Sn les algues dean donee réeoltíes en Algúric pendant la session de la socićté botani 1 ne en listr. I'aris (16)3). - [

Schaarschmidt, J. (et Tamás. A.) Additamenta at Algoiogian dacieam. I. Enumeratio Alyarmu nomnnllularum in co. mitatibus Jíolos. Torda-Alanyos, Udvarhely et Hunyad lectarum. - [g] - Magyar Növénitani Lapoli v. 1, 1ksu, N:o $13-11$ 1. 17 10.

Adlitamenta ad Algologian dacicam. II. Enumeratio Algarum nonullarum in comitatibus Nassinl-Beszterce, Do-

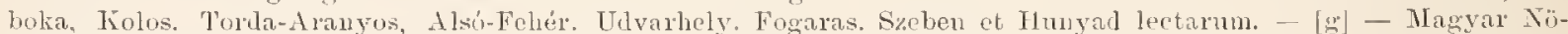
vénytani Lapok v. 1. 1.4\% . N:0 46. p. 129-137. -- (111. ibid. v. 6, 1582. 11. 37-17).

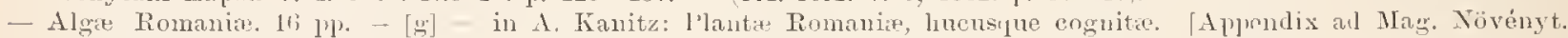

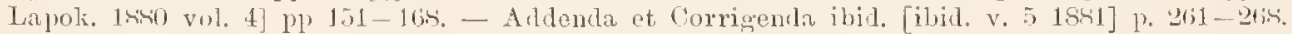

(Scherurschm. in Mngry. Nïv. Lap.) - A C'losterinm intermedimn Ralfs. oszlasa, - Magyar Növinytani Lajwk. Vol. 5.

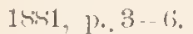

specimen phycologiz Aequatoriensis. Clautiopoli 14si, 16 pp. - [g] - Magyar Növénytani Lapok. Vol, 5. 1S91. 1. $17-21$.

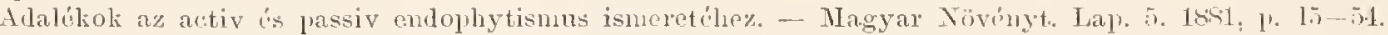

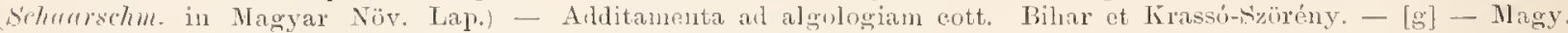

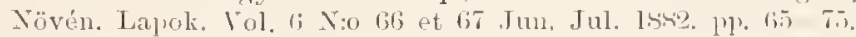

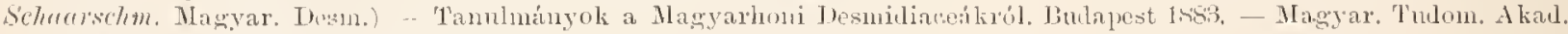

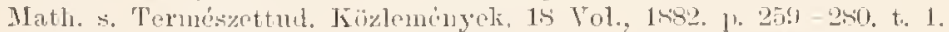

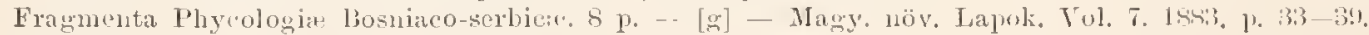

(Sehaurschm. Alghan. Alg.) - Notes on Afghanistan Alga, - lour. Limn. Sor., Bot. Tol. 21: N:o 13! 1481, 1. 211$2.31+t .5$.

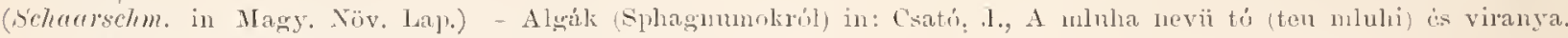

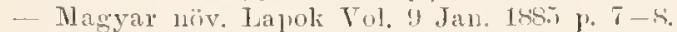

(Schuarschm. in Bull. 'Torr. 13ut. Club.) - Tliree Desinils new to the United States, - [Bul]. Torr. Bot. Chub. Vol. 12. Ni:o 5 , May 1 kisio, 1, 51.

Schiedermayr, C. Das Wasser der Lomau hej Linz, - [g] - 1 T Jahesbericht d. Vereins für Naturkunde zu Lin\%. 1 SST p. $\mathrm{i}-13$.

Schiedermayr, K. B. Cfr l'oetsert.

(Schmill, Teue ein\%. Alu.) Schmidle, W. Ueber einige neur und selten beobnchtete Formen ein\%elliger Algen. -

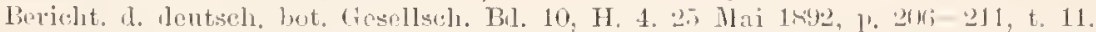

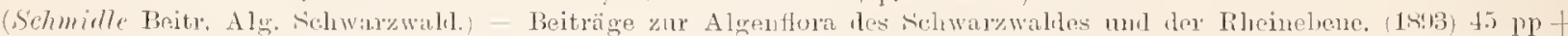

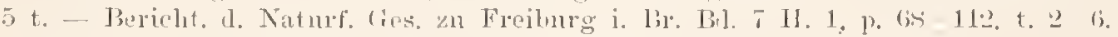

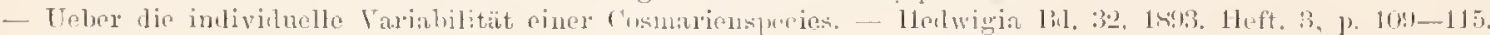

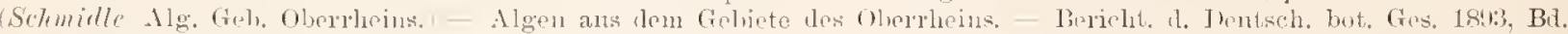

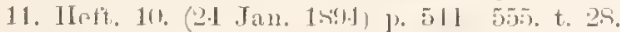

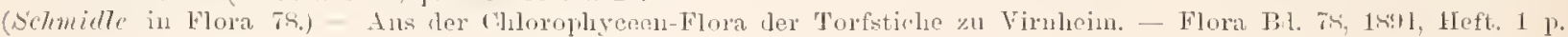
1.2 liti, t. 7 . 


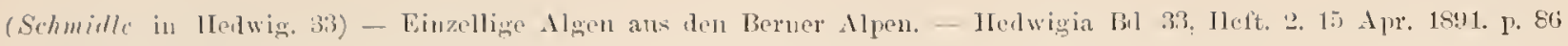
-?11;. t. li.

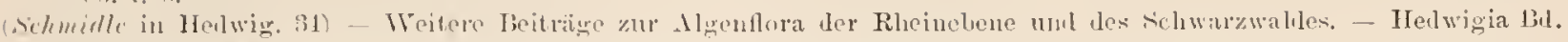

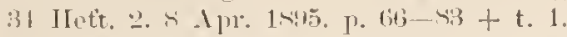

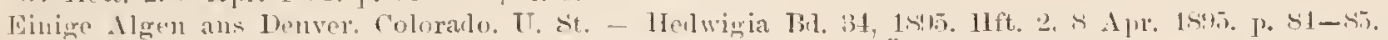

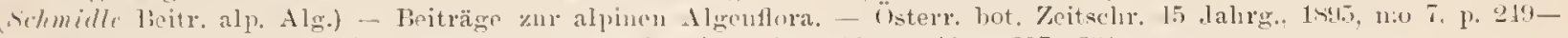

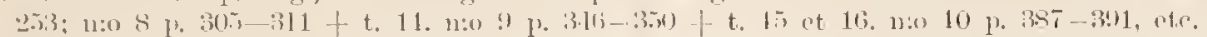

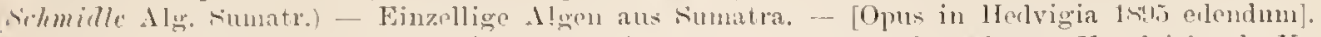

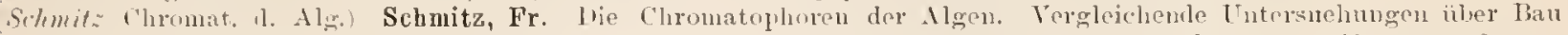

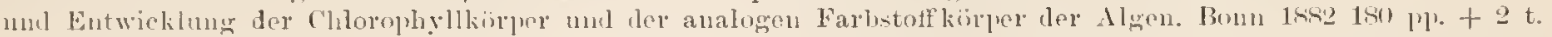

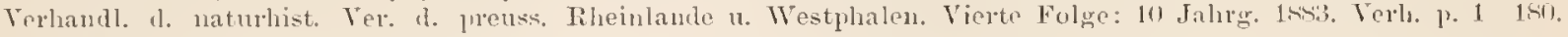
'l'at. $1-2$.

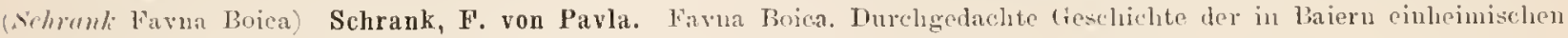

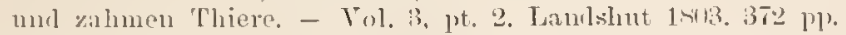

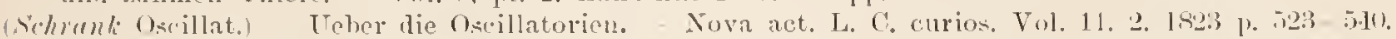

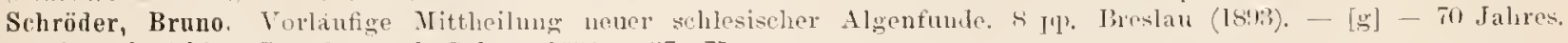

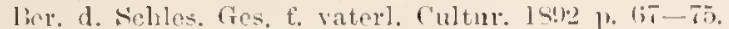

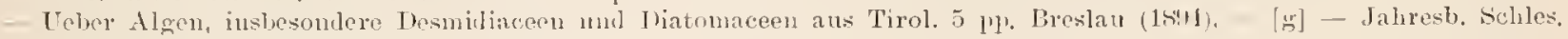
(ies, f. vaterl. Cultur. Sitz. znol, bot. Sect. 1 is Mär\% 1 s!)1.

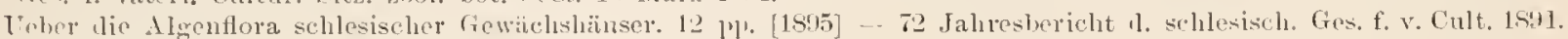
Il Abth. Naturw. Sect. f. Obst- u. Gartenb. p 24--3T.

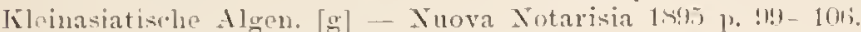

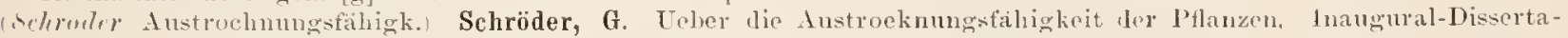

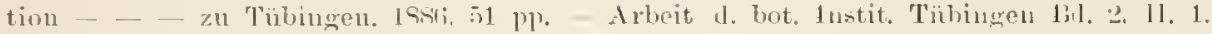

Shrötr X. Beitr. Alg. Selıles.) Schrötor. Nene Beiträge zur Algenlumule Sehlesiens. G1 Jahres-Bericht d. Schles.

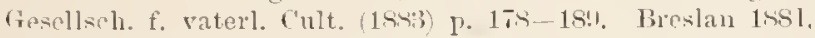

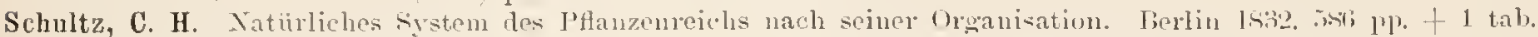

Shmmem in Flora) Schumann, Carl. Keber die Bewegungen in her Zelle ron Closterium Lunula. 12 1p. + t. 2.

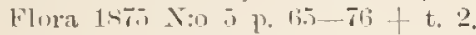

Sernander, R. studier ofver den gotlïmlsa vegetationeus ntvecklingshistoria. Aliademisk afluandliug . . Upsala d.

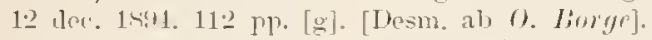

Shuttleworth, R. J. Touvelle observations sur ba matiere eolorate de la neige ronge, - Bibliotlienue universelle de

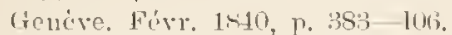

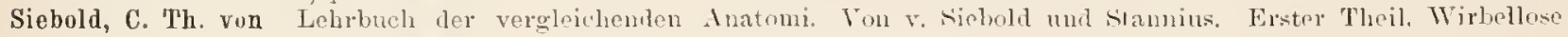
'Thiere tron ... S. Heft. 1. 1ists.

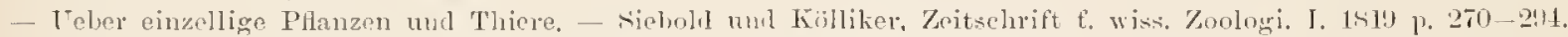

Smith, H. I. Diatomacere v. Desmiliacee. - [1. v.] - Michel's Sicience v. 1. 1S80). I. 7.

Smith, J E. English botany or eoloured figures of British I'lants. 'thle figures hy J. Sowerly. Vol, 35. London 1813. Vol. :36, Lonlon 181. Supplement. rol t. The descriptions by W. Burrer. Ch. Babington. M. J. Berkeley. W. Wilson. 'The figures by J. de Carle sowerby anl J. W. Salter) Loulon 1st!s.

- The English Flora, Class XXIV. Cryptogania by W. J. Hooker. Tol. I or Tul. II of It:r Hooliers British Flora)

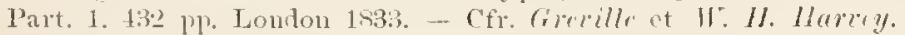

(Simith Conjug. of Clost.) Smith, W. Olsservations on the coujugation of Closterium Elurenbergii. - Anu. a. Mag. of

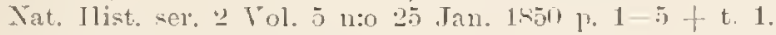

- On the stellate hodies oecuring in the cells of Frenliwater Alece. - Transact. Mieroce. Aoc. 1. 1453. p. 69-72. l'liytologrist. I. 4. 15is. [1. v.]

Sorokin. N. Aprẹ systématique des Chytriliacés récoltées en Russie et dans lisie centrale. 11 pp. Lille 1893. Archives botaniepues la Ford de la France r. 2; 1sitis, 1. 1-12.

Soubeiran, E. Essai sur la matiere organise des sourees sulfureuses des Pyruies - Jouru. de 1'harmacie v, 33. 18is,

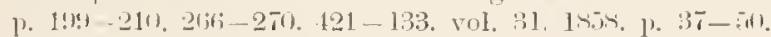

Sowerby. Cfr. Smith, . F.

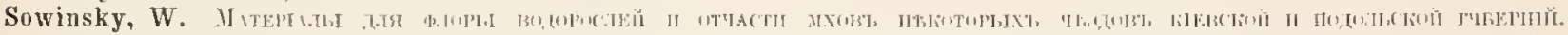

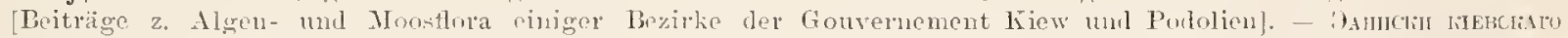

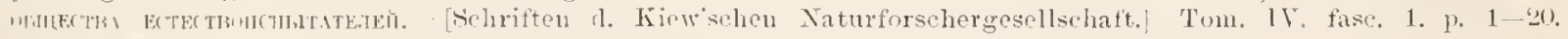
liew lisi.

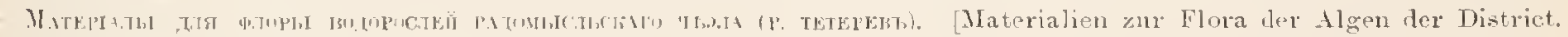

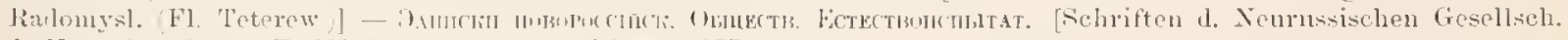

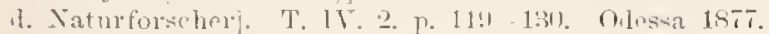

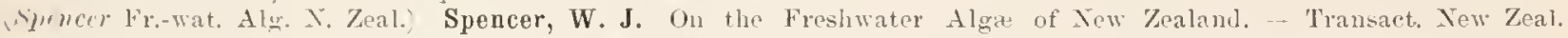

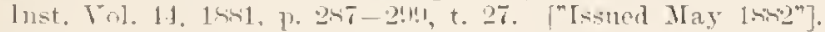

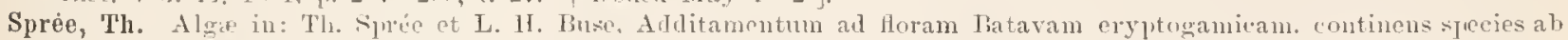
ipsis collectas imdigenas noxas aut rariores (Als hijlageu tot: Verslag van de Zeventiende Jaarlijlische Vergadering

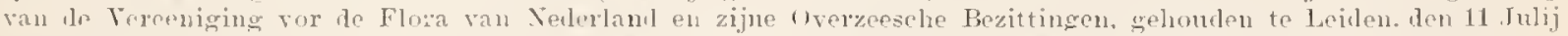

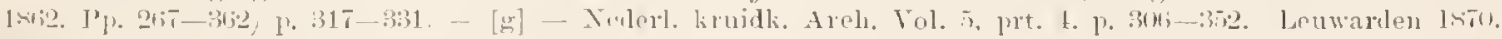

sum. Syrst, veget.) Sprengel, C. Caroli limmi systema vegetabilimm. Ellitio decina sexta curante C. S. rol, 2.

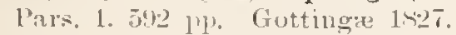

- Cir brich und craber. 
(Siquinab. Catal. Desm. Genov.] Squinabol, S. Primo eontrihuto ad un eatalogo delle Desmiliexe dei dintorni di Ge11ova. 1: Pp. Genova 188\%, - Lav. fat. n. lahorator. di Zool. ed Anatomia comp. d. R. Universitít di Genova. 1 isi-1-8i;,

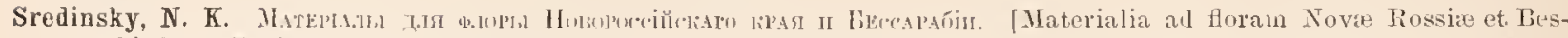
sarabiat. - Kapisky Noworossiaskago Obsczestwa Estestwoispitatelei. (Memoir. d. 1. Soc. d. 12aturalist. d. l. Nouv. Russie.) Tom. 2, 1 15i3, 1\% 17-131.

(Stuhl Eintl. Licht. Beweg. d. Desm.) Stahl, E. Ueber den Einfluss des Lichts auf die Bewegungen der Desmidicen nelost einigen Benerliungen ïber den richtenden Einfluss des Lielites auf schwärmsporen. 11 p). - [pll] - Verh.

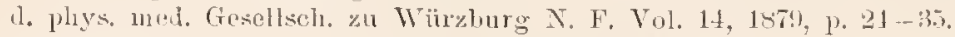

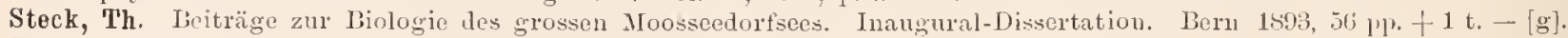

Steward, Hngh G. .... collecterl on the Ireadalbane Mountains in Perthslire. - [g] - Proc. Bot. Soe. Edinb. $1850 \mathrm{p} .1 \%$

(Stizcub. Index Rab. Als.) Stizenbergor, Ernst. Dr Ludwig Rahenlor'st's Algen Sachsens resp. Mitteleuropa's. Deeade I C. Systematiseh georinet (mit Zugrumlelegung eines neuen systens). Dresden 1860.11 11).

(Stuckmayer in Sitzungsber. d. zool.-bot. Ges.) Stockmayer, S. Ueber eine neue Vesmidinceengattung. - Verl. đl. ls. k. zoolig.-bot. Gesell. in Wien. 13ss. Sitzungsher. p. \&ō.

(Stockmayer Algeng. Gloeotan.) - Die Algengattung Gloeotienium. Wien (15y1) 6 p. - Sitzungslyerichte d. k. k. zoolog.bot. Gesellsel. in Wien. Bu. 11,1891 j. $21-26$.

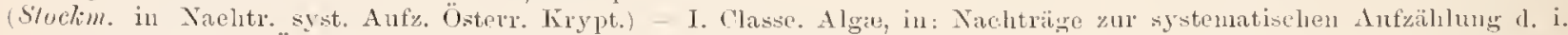
Erzherzogthum Österreich ob dor Enns bisher beobaehteten samenlosen PHanzen (Kryptoganen) - von Sichiedermayr; 1. 23-5!. Wien 15!1. Cfr l'uetsch et Schiedermayr.

- Cfr G. Bitck.

Stokes, A. C. Splogumu, Desmids, Rhizopols and Eels. -... [g] — The Americ. Monthly Microsc. Journ. Vol. 3 n:o is A 119.1582 15. 153.

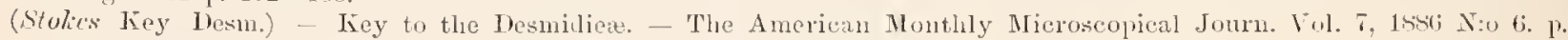

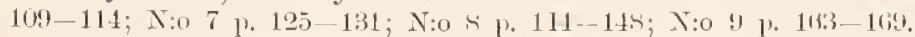

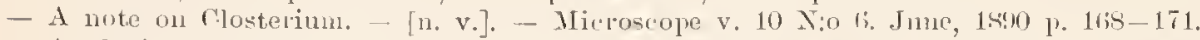

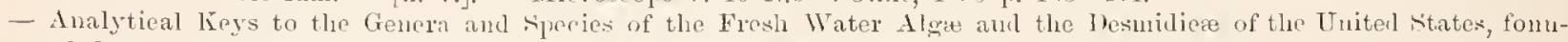

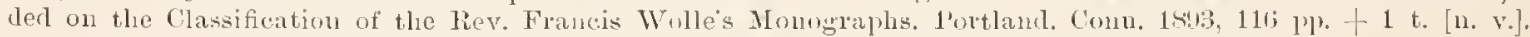

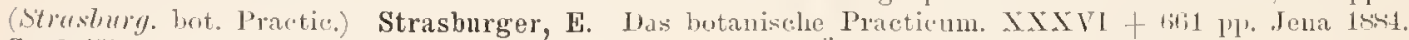

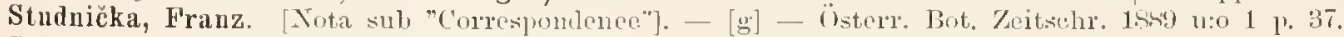

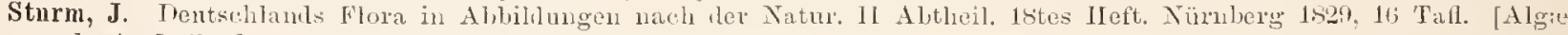
al) 1. I. Cordu. Ctr Jitteraturbericlite z. Linnata 1532 p. 10ril.

Suringar, F. W. R. Eene bijlrage over pene verzineling nienwe inlandsche algen, p. 6.5 - 72 in: Versohlag vau de tiende jaarlijksche vergadering der Vereeniging voor de Flora van Nederland en rijne overzeesche bezittingen, ure-

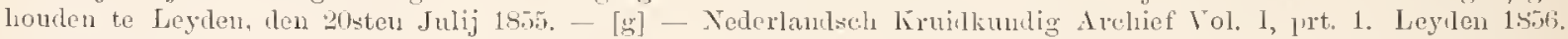
1). $15-81$.

Suring. (Ols. Phye.) - Observationes phycologica in foram Batavam. $11+75$ pl + I t. Leovardia 185̄.

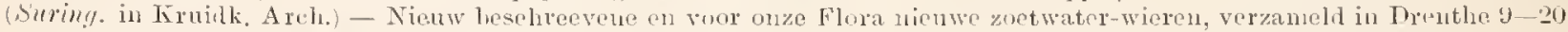

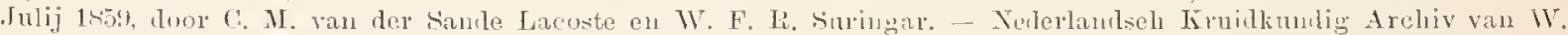

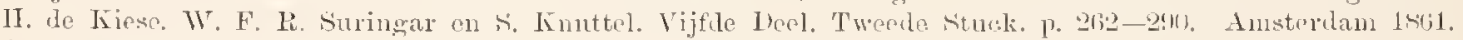

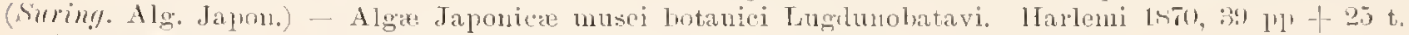
Alme (Wieren). - [g] - Algemeene Statistiek van Nelerland (uitgegeven door le Verceniging vour Statistiek in

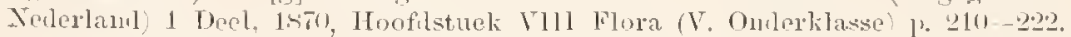

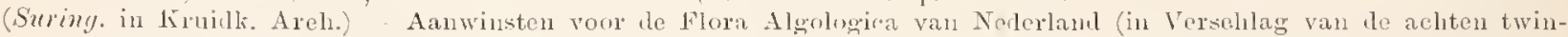
tigste janrvergalering der Teuterlandsche Butaniscle Vereeniging, gelunden te Leiden, den 17:den , Iuli 1Sr5:

[g] - Nelerlandseh Kruidkundig Archi f. Versthlagen en Medeleelingen der Nederlandsche Botanische Vereening 2.e Ser.. 2:e Ueel. 1:0 st. 1\$75.

Sivensli Botanik. Cfr. C. A. Agrrah.

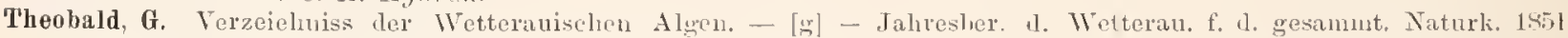
53 1. $111-163$. IIanau 185\%.

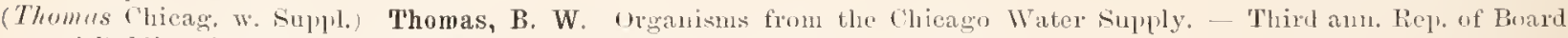

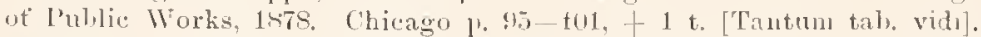

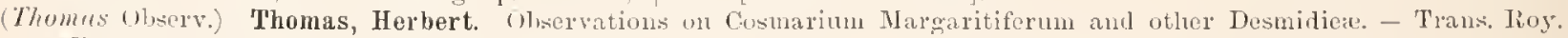

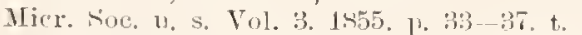

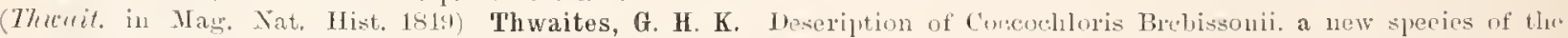

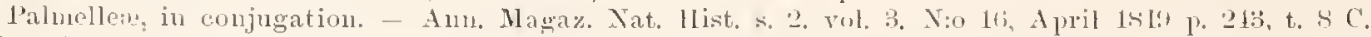

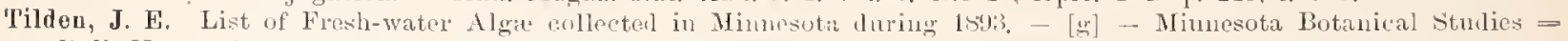

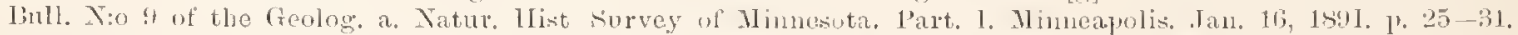

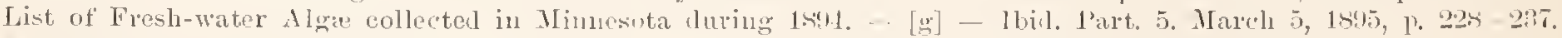

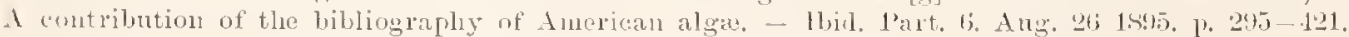

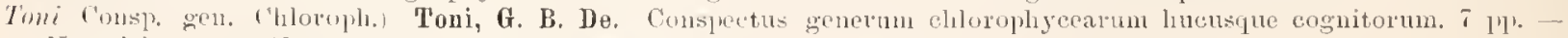

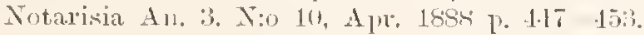

Note snlla flora del Bellunese. - [g] - N. Giorn, butan, ital. vol. 21, Ja11. 1889 p. 55 - 10.

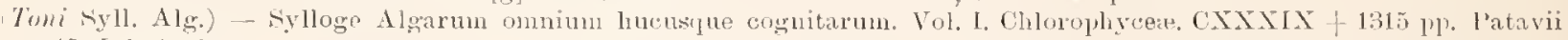
15 . Ful. 1 s.s.

(Toni Alg:e abyssin., in Malpigh.) - Algre abyssiuie a cl, Prof. Penzig unleetre. - Malpighia. Anu. 5. fasc, 6, 1str. 1. $261-273$. 
(Tuni \& Lewi in Notarisia) Toni, G. B. Do \& Lewi, David. Eumneratio Conjugatarum in ltalia lumeusine eognitarum. Notarisia An110 1. 1S86 N:02 1). $110-115$.

- Spigolalure per la ficologia Teneta. - $[g]$ - Niov. Giorn. Bot. 1tal. x. 19 11:0 2. 1887, p. 101;-110.

- Lialgarium Zanardini. 141 pl. Vene\% 1ssa.

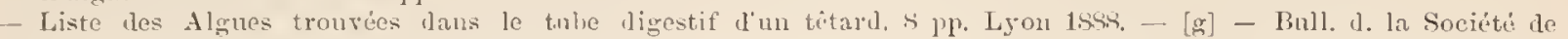

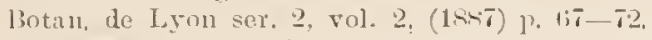

Tomi if La wi Fl. Alg. Venez.) - Flora algolorica della Venezia. Parte terza. Lo Cloroficee. Venezia 1sss.

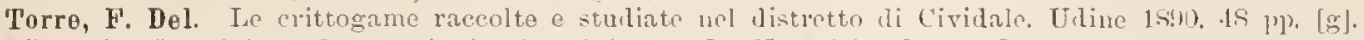

Turre in Notaris.) - Osservazioni sulle algle. - La Notarisia Vol. T N:o 42 Aug. 1892. p. 1470-1176,

(Tretis. Itt. IV Riun. Ital.) Trevisan, V. B. A. Sopra una nuova elassificatione delle Alege; memoria letta alla Sezione di botanica e fisiologia vegetale della IV Rinuione degli Scienziati italiani in Patova nella adunanza de 28

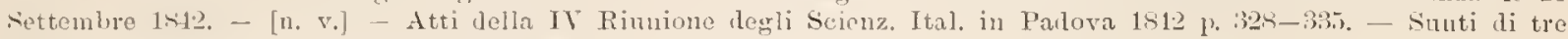
Memorie Algologiche. Padova 14.2. p. !-.

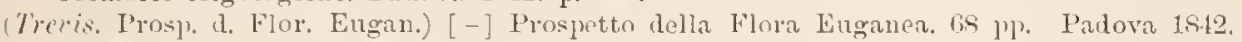

(Treris. Nomencl, alg.) -- Nomenclator Algarum ou Collection des Noms imposis aux plantes do la famille des algues. Fol. I. 1. $1-\$ 0$. Padove 1845 .

(Treris. Alghe coceot.) -- Saggio di nna monografia delle Alghe coceotalle. 112 pl. Palova 1sh. - Atti Congr. Sc. ltal, in Venezia 181T.

Trybom, F. Ringsjön i Malmöhus län, dess natnförluillanłen oeh fiske. Stocklolm 1s93, 18 pp. + 1 chart. - [g] Meddelande frĭu Ki. Landtbruksstyrelsen. N:r 1 år 1893 (N:o 13 !

Turner, W. Barwell The Freshwater Algie of the Leeds district. 5 pl. - [g] - The Naturalist Oct. 1879 pl. 38 40. Leeds.

(Turner Alge Strensall.) - The Alge of strensall common. 5 plo, 1 tab. - The Naturalist Dec 18s3. pp.? + 1 tab.

- Mounting and staining Desmids. - [ph] - Jomm. R. Mier. Foc. ser. 2 vol. 5, 1.54... 13. 7t2.

(7ume. New rare Desm.) - On some new and rare Desmids. 8 pp. + 2 t. - Journ. R. Micr. Soc. ser. 2. vol. 5, part. 6 (Dec.) 1sis. 1)?. 1933-940. t. 15-16.

(Tumer Not. Freshw. Alg.) - Notes on Freslumer Algin with descriptions of new species. - The Naturalist Febr. 1846. Pl]. $33-35$ tab. I.

(Turner Not. alg. Gormire) - Notes on Algie eollected at Gormire and Thirklebs, with description of a new form. The Naturalist sept. \& oct. 18st. pp. $2 \pi-2 \pi$ - 29 a 290

(1urner Alg. Ind. orient.) - Alge aque duleis lndie orientalis. The Freshwater Algre (prineipally Desmidiea) of East India. - K. Srenska Vet. Akad. Hand]. Fu. 25 N:0 5. Stockholm 1892 [1.893!] 18T pp. + 2:3 t. [Commennrat. ab 0. Nordstedt in Beilnefte 2. Bot. Centralbl. 1s:14, Bil. 4. Heft. 1 p. 1-s; Cfr. Wildeman].

(Tumev Desm. Notes.) - Desmid Yotes. - Naturalist, Leers, Xov. 1893 p. 343-317 r. figg. p. 311).

(Turner in Leeds nat, club transact.) (-) et: J. Abbot, F. Ernsley, Th. Hick, J. Stubbins d W. West. Algre (exelusive of Diatomacese). Aren West Torkinire. 10 pl. +1 tab. [im Contrib. to a Fauna et Flora of West Yorkshire] - Trans. Leeds nat. Club. Yol. I [1ss6] p. 6i. - is et t. 1.

Turp. in Dict. sc. nat.) Turpin, P. J. F.: in Dictionnaire des sciences naturelles - — par Plusienrs Professaurs dn Jarilin du Foi. et des principales Écoles de Paris. Tom. 13. Paris 1519. 53 et 5f et as (182. $)$. 61 (1815). - Planches botaniques. V'égetaux aeotyledons. l'aris 1s1;-2!!.

(Turp. Apery. organ.) - Aperęu organographique sur le nombre deux - Mémoires du Muséum d’histoire naturelle par les professenrs de cet établissement. Tom. 16. pag. 2yi-311 + Pl 13. 4:o. Paris 182.4.

Varley. On openings in the lorica of Desmillice. - [n. v.] — [Ubi ?].

Vorce, C. M. Microscopic Forms observed in the water of Lake Erie. - [11. v.] - Proc. Am. Sor. Mic. 18s1 p. 51

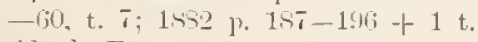

(Wahlub. Fl. snec.) Wahlenberg, Georgius. Flora siveciea enumerans Plantas sveciæe indigenas cum synopi elassimm orlinumque, claracteribus generum. diftrentis specierum, synonymis eitationibustue selectis, locis regionibusine natalibus, descriptionibus labitualibus usuina incolarum et qualitates plantarum illustrantibus post Linnwum edita Pars posterior pp. 42!-1117 + I-LXXXYlI Upsaliæ 1s26. - El. Il, 453 pp. Upsali. 1 s33.

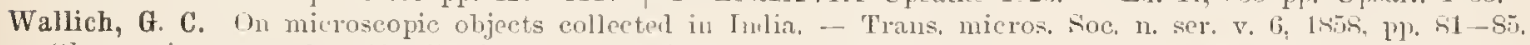
Olservations on the Tistribution and llabits of the I'elagic aud Fresluwater Free-floating Diatomacese. Ann. Mag. nat. Ilist. ser. 3 rol. 51 1.660 p. 1-20.

(Hallich 1hesm. Low. Bangal) - Desmidiacear of lower Bengal. - Amn. Mag. Nat. Ilist. ser. III Vol. 5 1860. p. 181. $197,273-2+7$, t. $8.13,14$

Desmidie of Greenland. - Journ. R. Micr. Soc. Vol. 1 186! p. 130.

(Wullich in Pop, Re. Ror.) - Are the Destnils and Diatoms simple cells? - Pop. Sci. Rov. 18it p. 130 - 112.

Wallman, J. (fir Liljeblud.

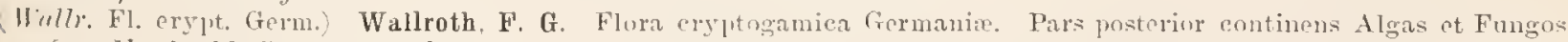

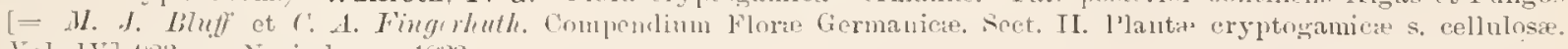
YoL. [V] :23 p. Norimberga 1S:3:3.

Walmsley, W. H. The Preparation of Dosmils. - [n. r.] - (Joum. Mic. Nat. Sei.: Jour. Post. Mic. Soe. and Wesley

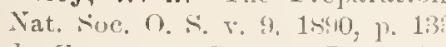

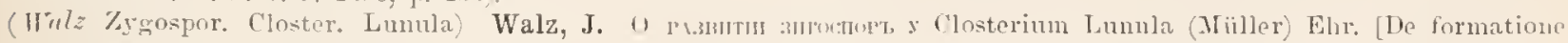

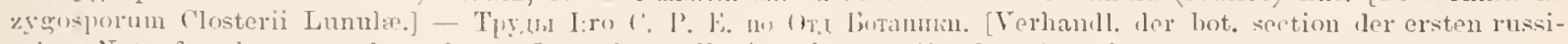

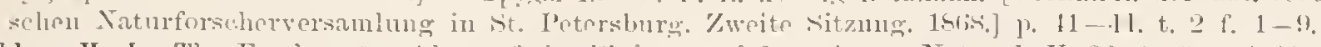

Wobber, H. J. The Fresli-water Algie of the l'laiss. - [g] - Amer. Natmral. V. 2:3. 1s-4!. p 1011-1013.

- Catalogue of the Flora of Nebraska. - [g] - Report of the Nebraska state Board of Agrieulture for $18 \mathrm{sg}$ p. 35 - 162. Lincoln 15:10. 
- Appendix to the Catalogue of the Flora of Yebraska. - [g] - Transact. of the Acad. of Sci. of R. Lonis Tol. 6; T:o 1. $4 \bar{i}$ pr. 1 sin

- A seconl edition of Webbers Apendix - - With a supplementary Jist of Recently Reponted species, by

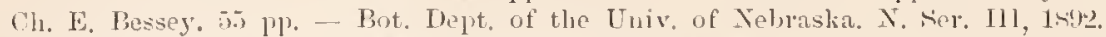

(Weist in Der. liayer. bot. Ges.) Weiss, J. E. Resultate der bisherimen Eufursehung der Algenfora Bayerns, -

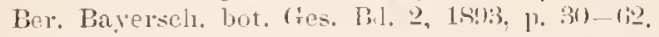

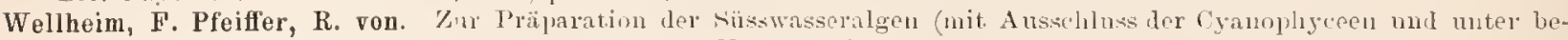

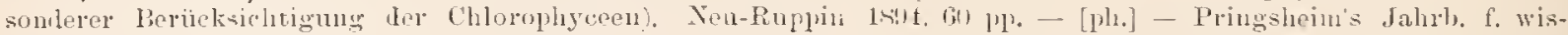
sensch. Bot. 13. 26. IIeft. 1. 1. 1;7t-7:32.

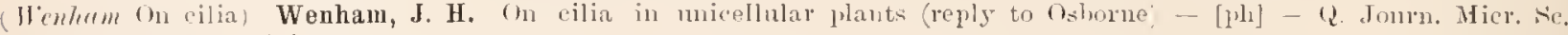
Fol. 5, $15 i t$, p. $157-t i ; 0$.

(ITest Yew Desm.) West, T. Remulis on some Diatmacea new or inperfectly deseribed and a new Tesmil. -

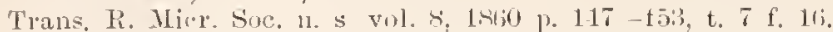

West, William. Fresli-water Algar. - in: F. A. Lees, The Flora of West Yorkshe p. 7t5-77t. Tondon 1stit. - [g] - Trans of the lorkshire Naturalist Union, Botanical Nix. rol. 2.

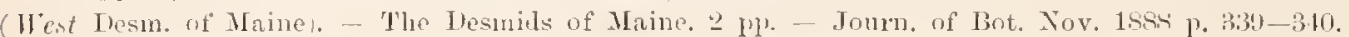

(ITest Massachus. Desm.) - List of Thesuids from Massachusetts. U. S. A. fi Mp., t. 2-3. - Jouru. R. Mier. Soc, 1.si!! p. $14 i-21.1$. $2-3$.

(West Addit. West Yorksh.) - Adlitions to the Alge of West Yorkshire. - The Naturalist Marel \& $\mathbb{1}$ pril 1 ss?. p. s.-110.

(I'st Fresluw.alg. Maine) - The Freshwater Alga of Maine. 3 pp. - Journ. of Bot. Yol. 27. July 18si. 1. 205-2ut et t. $291 \mathrm{ex} \mathrm{p.} \mathrm{(octob.)}$

(I'est Freshw. alg. Maine II) - The Freshwater Alga of Maine. 5 pp. + 1 t. - Journ. of Botany. Vul. 29 Dec. 18u1 p. $853-7$, t. 315 .

- Alga at Birkiale 'Taru. - [g] - Naturalist. Leeds, Aug. $1 \mathrm{ksg}$ [n. v.].

(West Fr. Alg. North Yorksli) - The 1'reshwater Alge of North Yorkshire, 10 pp. + 1 t. - Journ. of Bot. Tol. 27,

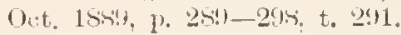

Hest Fr. w. Alg Yortl Wales) - Contribution to the Freshwater Algre of North Wales. - Journ. R. Minroseop.

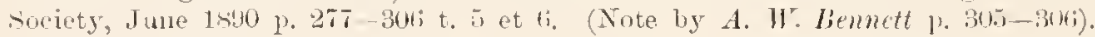

(Wrst Adu. Freshw. Alg. W. Yorksh.) -- Addition to the Freshwater Algae of West Forkshire. - The Naturalist, Aug. $14: 11$ 1. $213 \quad 252$.

(West Dinish Alga? - Notes on Danish Alge. \& pl. - La Nuova Notaris ser. 22, 1.991. 1. 118-425.

(Wret Fr. W. Alg. W. lrel.) - A Contribution to the Fresluater Algat of West Lreland. - Jonz.n. Linn. Sou, Bot. vol.

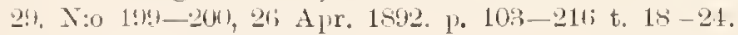

West Alg. Engl. Take Distr.j - Algit of the English Take District. 34 pl 12 t. - Tutrn. R. Microse. Roc. 18rt2 p. $713-748+t$. 1 et 10 .

(West in Notaris.) - Nonnulle algie aque duleis Lusitanice. - La Notarisia Vol. 7 Nio 33-3I, Oet.-Dec. 1s92. H. $145 \overline{1}-1 \mathrm{num}$

(1) Nent Drit. Alg.) - West, W. et West, G. S. New British Freshwater Alga. - Jomm. R. Microse. Soe. 1sit p. $1-7+\mathrm{t} .1$ et 2 .

(West F1. Alg. West Ind.) - On some Freshwater Algit from the West Iudies. - Journ. Linn. Soc. Bot. v. 3u, 1s!l, p. $264-2,50+$ t. $13-16$.

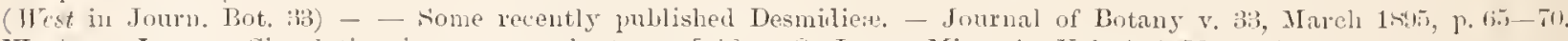

Western, James. Circulation in aqueons plants. - [ph] - Q. Joum. Micr. Á. Vol, 4, 1-inh p. si.

Wettstein, R. v. Beitrag zur Flora des Grientes. Bearbeitung des von Dr. A. Heider im Jalne this in l’isidien nul

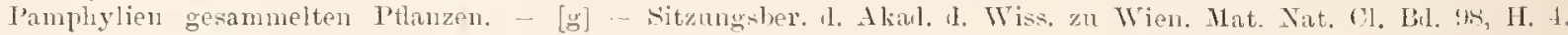
Alstl. 1 (158:3) p. $345-3.99$, t. $1-3$.

White, H. H. On fussil Xanthilia. - Micr. Journ. v. 2, 1812 1. 3\%-4n, t. 4 [11. v.] - Mier. soe, transact. v. 1, 1stt p. $77-89$ t. 8 . [vili].

- On a New species of Fossil Xantlinlia. -- Ibiul. p. 8 t. 20 f. 1.

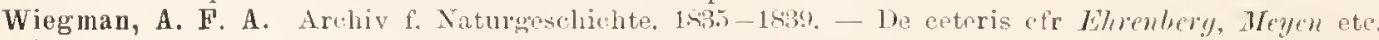

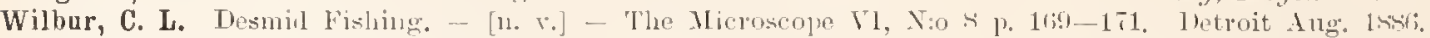

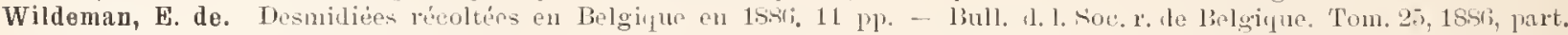
2 Gonpte-rendn p. $153-1133 \mid 18 \mathrm{sis} !$.

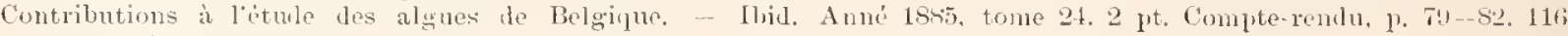
$-127 .-[\underline{g}]$.

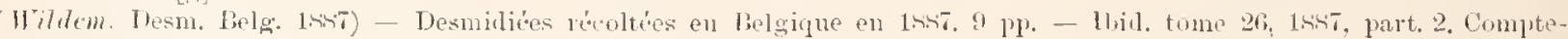

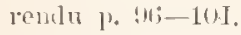

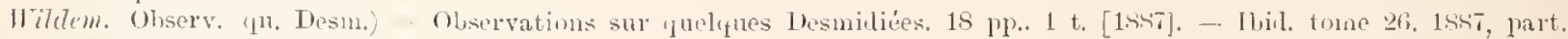
1. Memoires p. 271 - 24. 1 [1-ithis].

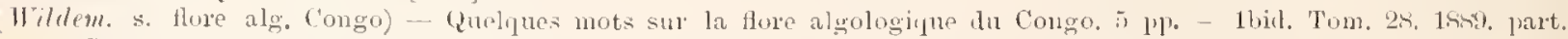
2. Compt.-rend. p. (i-11\%.

Sote sur queliues Saprolegnibes parasites clos algnes. - [g] - Bull. d. 1. Sociéte belge le Microscopie Ton. 16.

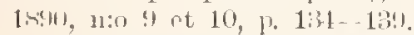

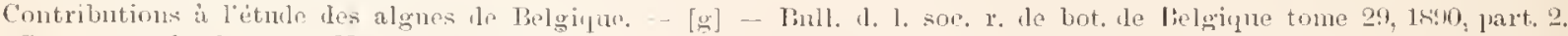
Compte-romlu al. se. 11 Now. 1. 1:3 - 13!).

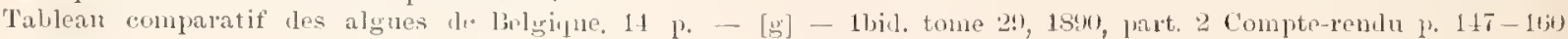
$[15: 1]$. 
(Wildem. Rech. temperatur. caryocin.) - Recherches an sujet de l'influenco de la température sur la marche, la dnrée ot la frégnence de la caryocinèse dans le règne végétal. - Ann. d. 1. soc. Belge de Mieroscop. tom. 15 Memoir. p. $3-28$, t. 1-2. 1890.

(IIildem. Observ. alg. 1891.) - Observations algologiques, 39 pp. + 2 t. -- Bull. d. 1. Soc. r. d. botan. d. Belg. t. 29 Momoir. 1 part. p. $93-131+$ t. $1-2$.

- Contribution a l'étude des algues de Belgique. - Ibil. tome 32, 1893, part. 2, Compt. rend. d. sc. 11 oct. p. $88-101$.

(Wildeman Yot. mycolog.) - Notes mycologiques, 2:e faseicule. (IV-VII) - Anual. Societ. belge de microscop. Tom. 17, 189:, Mémoir. p. 33-63 t. 4-7. - 4:0 fasc. (XII-XIV): ibid. tom. 19, 1895, p. 57 - 92 t. 2. - 5:e fasc. (XV): ibid. p. $83-117$ t. $3-4$.

(Wildem. in Notarisia) - Quelques réflexions sur les espèces dn grompe des Desmidiées à propos des "Fresli-water Alga of East-India" de M. IT. B. 'T"urner. - La Notarisia, 1893, N:o 6, p. 162-172.

(Irildem. Obs, crit. Desm.) - Observations critiques sur quelques espéces de la famille des Desmidiées. - Ann. d. I. soc. belge de mieroscopie. Mémoir. tom. 1s, 1894, p. $55-132$.

(Wildem. Note algolog. I.) - Note algologique. I. Sur les variations morphologique de quelques Desmidiées. - La Notarisia vol. 10, 1895,1 , $3-11$, t. 1.

- Tableau comparatif des algues de Belgirue, - Bull. Soc. r. de Bot. de Belgique. 34 tom.. 1 fase., 1895, p. 22 - 50.

(Wille Ferskv.-alg. Nov. Semlj.) Wille, N. Ferskwandsalger fra Novaja Semlja samlede af Dr. F. Kijellman paa Nordenskiolds Expedition 1s75. - Öfvers. Ki. Vet. Ak. Förh. 1879 N:0 5 p. 13-7t, t. $12-14$.

(Wille Norg. Ferskv. alg. I.) - Bidrag til Kundskaben om Norges Forskvandsalger. I. Smaalenenes Chlorophyllophyceer. - Clnoistiania Fid.-Selsk. Forhandl. 1880 N:o 11 p. 1-72, t. 1-2.

(Wille Sydamerik. Algf.) - Bidrag till Sydamerikas Algflora. I-III. - Bihang t. K. Sv. Vet.-Akad. Handl. Bd. 8 N:o is p. $1-6 . t$, t. $1-3$. Stockholm 1884 .

(Wille Entwick. d. Pollenk.) - Ueber die Entwickelungsgeschichte der Pollenkörnex der Angiospermen und das Wachsthum der Membranen durch Intussusception. - [pll] - Christiania Videnskabs-Selsk. Forh. 1886, N:o 5 p. 1-i1, t. $1-3$.

(Wille in Naturl. Pflanzenfam.) - Desmidiacew. - Engler, A. et Prantl Die naturlichen Pflanzenfamilien. I. 2 (40 Lief). p. 1-16. Leipzig 1590 (im März).

- Cfr Trybum.

(Wille in Dijmphn. togt. Udb.) - Wille, N. og Rosenvinge, L. Kolderup. Alger fra Novaija-Zemlia og Kara-Havet, samlede paa Dijmphna-Expeditionen 1852-83 af Th. Holm, 18 1]. + t. 13-14. Kjöbenhavn 1885. [1886 pmblic.]. Wille: A. 1. 3-12. - Dijmphna-Togtets zoologisk-botaniske Udbytte, p. 81-96, t. $13-14$.

Wills, A. W. Confervoid Algie of the Birmingham district. - [g] - Transact. Birmingham Nat. Hist. \& Microsc. Soc. [1872?].

(Wills in Midland Naturalist) - Note on the movement of the cell-contents of Closterium Lunula. - Midland Naturalist. vol. 31880 p. $15 i-8$.

- List of Desmidiece found in sutton Park. Warwichshire. - [g] - The Midland Natnralist. Vol. 3 1880 p. $265-266$.

(Wins in Midland Naturalist) - On the Desmidieie of North Wales. - The Midland Naturalist. Vol. 4 1881. No 38. Febr. 13. 40-43, N:o 40, A]ril, 1. $73-75+$ t. 5 .

Wilkinson, S. J. Observations on Xanthidium, both Fossil and Recent. - 'Transact. Micr. Soc. vol. 2, London 1846, p. $59-92+$ t. 13 .

(Wittr. Skandin. Desm.) Wittrock, V. B. Anteckningar om Skandinaviens Desmidiaceer. Upsala 1869, 28 pl\%. +1 t. - Nova Acta Societ. Upsal. Sier. 3. Vol. 7.

(Wïtr. Gotl. Öl. sötv. Alg.) - Om Gotlands och Ölands sötvattensalger. - Bih. t. K. Vet.-Akad. Handl. Bd. I N:o 1, 1872 p. $1-72$, t. $1-4$.

(Wittr. in Bot. Notis.) - Nigra meddelanden om snöns och isens flora, särskildt i de arktiska trakterna. - Botaniska Notiser 1883 n:o $2\left(18^{2}, 83\right)$ p. $76-79$

(Wittr. Snöns o. isens f.) - Om snöns och isens flora, särskildt i de arktiska trakterna. Stockholm 1883 . - A. E. Nordenskiöld, Studier och forskningar föranledda af mina resor i höga norden. H. 2, 3, 1883. p. 65一-124, t. 3-7.

- Cfr. Pointfört. Skand. Växt. 4, 1880.

(Wolle in Bull. Torr. bot. Club) Wolle, Fr. Freshwater Algre:

\begin{tabular}{|c|c|c|c|c|c|c|c|c|c|c|}
\hline II & $"$ & $"$ & $"$ & $"$ & $"$ & " & - & $"$ & $27,187 \pi$ & $" 13 \bar{\imath}-141$. \\
\hline III & " & " & $"$ & $"$ & " & ;) & E & $"$ & $35.187 \%$ & $.181-185$. \\
\hline IV & $"$ & $"$ & $"$ & " & $"$ & $"$ & 7 & • & 4,1880 & $" \quad 43-48$ (et p. 41. t. 5). \\
\hline V & $"$ & " & $"$ & $"$ & $"$ & $"$ & 8 & $"$ & 4. 1851 . & $" \quad 37-40[\mathrm{~g}]$. \\
\hline Tit & " & $"$ & $"$ & $"$ & $"$ & $"$ & 9 & ") & 3,1882 & $n \quad 25-30$, t. 13. \\
\hline $\begin{array}{l}\text { VII } \\
\text { VII }\end{array}$ & $"$ & $"$ & 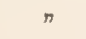 & $"$ & $"$ & " & 10 & $"$ & 2,1883 & $13-21$, t. 27. \\
\hline IX & "y & " & $"$ & $\eta$ & 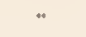 & $\Rightarrow$ & 11 & y & $2,188$. & $13-17$, t. 44 \\
\hline$\frac{1}{\mathrm{I}}$ & $n$ & " & $"$ & $"$ & " & $"$ & 12 & $"$ & 1,1885 & $1-6$, t. 47. \\
\hline & & $"$ & $"$ & $"$ & "̈. & $"$ & 12. & 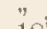 & 53 & $125-129$, t. 51. \\
\hline
\end{tabular}

- Synopsis of Discoveries and Resear"hes in 1878. - [g] - Bnll. Torr. bot. Clnb Tol. TY N:0 49, 1879. p. $281-288$.

(Wolle in Bull. Torr. bot. Club) - New American Desmids. - Bull. Torr. Bot. Club. Vol. 7 11:1 8, 1s80, p. 91, t. 5.

- American Freshwater Algre. Species and Varieties of Desmids new to science. - Bull. Torr. Bot. Club. Vol. S N:o 1881 p. $1-4$, t. 6 .

- Freshwater Alga. - Britton, A preliminary Cat. of the Flora of New Jersey p. 210-223. (Cfr. Britton).

(Wolle Desm. U. S.) - Desmids of the United States and list of American Pediastrums with eleven lundred illustrations on fifty-three colored plates. Bethlehem, Pa. 1884, XIT + $169 \mathrm{pp} .+53 \mathrm{t}$.

Bortstedt, Index Desmid. 
(- ed. II.) - - New and enlarged edition. - - - with nearly fourteen hundren illustrations on sixty four colored plates. Bethlehem. Ya. 1802. XIV + $1821 \mathrm{p} .+13 t$ t.

(Wolle in Bull. Torr. Bot. Club, - New Desmids of the United States. - Bull. Torr. bot. Club Tol. 13, 11:0 4 1886 p. 5 ri- 60 .

(IVolle Desm. Pacif. Const) - Desmids of the Pacific Coast. - Bull. Califolı. Acarl. Sci. Vol. 2 N:o 7, 1887, p. 432437: - (Proceed.) Vol. I. 1 1859 p. 79-80.

(Wulle Fr. Alg. U. A. A.) - Fresluwater Alge of the United States (exclusive of the Diatomacere); complemental to Desmids of the United ritates. 2 Yol. 365 pp. + t. 54-210. Bethlehem. Pa, 18s7.

(Woll, Desm. Minnesnta) -- Desmidiex in: I'lants collested between Lake superior and the international Boundary. July 1856. By J. C. Arthur, L. H. Bailey. J. and E. W. D. Holway. Report on Botanical work in Minnesota for the year 1886 by J. C. Arthur), - Geolog. and Natural IListory survey of Mimuesota. Bull. N:o 3, p. 36-3!. st. Panl 1 inst.

- Cfr N. R. Britton.

- Cfr Hitch. et IIolle.

(Hood in Proe. Philad. Ac. X. S. 1869) Wood, H. C. Colored drawings and mounted slides of a variety of desmid, and - remarlis. - Biological and Microscopical department of the Academy of Natural Sciences p. 15-19 (in Proceedings of the Academy of Natural sciences of Pliladelphia 1809. Philadelphia 1869). [18ro].

(Wood Prodr. Alg. Amer.) - Prodromus of a Study of the Freshwater Alga of Eastern North America - Proc. Americ. Philosoph. Soc. Tol. 11 (Meeting 1s Jine 1869) pp. 119-145. 1871.

(Woud Fr. Alg.) - A Contribution to the History of the Fresh-water Algre of North America. Jan. 1s73. - Smithson. Contrib. to Knowl. 11:0 241 Vol. 19.187t. IX + 262 pp. + 21 t.

Woods, A. F. Note on the Canon Flora of Sioux county, with List of Plants Collected in July and Augnst, 1892. [11. v. - g?] - Botan. Surv. Nebrask. v. 2, 18!13, p. 31-46.

(Wright in Q. T. M. Se.) Wright, F. G. Structure of Closterium. - Q. Tourn. Micr. Sc. Vol. 3, 1855. p. 171-2.

Zacharias, 0. Ueber die Verwendung von Eisensalzen zur Sichtbarmachung feinster Zellstrukturen. - [ph] - Verlı. d. Ges. deutsch. Naturf. u. Ae. z. Bremen 1890 II p. 121-122. Leipzig 1891.

- Beobachtungen am Plankton des Grossen Plöner Sees. - $[\mathrm{g}]$ - Forschungsbericht. ans d. Biologisch. Station zu Plón. Th. 2. p. $11-137$. Berlin 1894.

Zanardini, G. Catalogo delle piante Crittogame racolte finora nelle Provincie Venete. - [g] - Atti dell' J. R. Instituto Veneto. Ner. 3. v. 3 p. $245-272$. Venezia 185i-5s.

Zeller, G. Alga collected by m:r S. Kurz in Arracan and British Burma. - [g] - Journ. Asiatic Soc. of Bengal. Tol. 42 p. 2, 1873. P. 175-193.

Zopf, W. Zur Kenntniss der Infections-Krankheiten niederer Thiere mud Pflanzen. ijt l'l t 7 t. - Nova act. Acad. Ces. Leop.Carol. Nat. cni. Tom. 52. 1858, p. 313-376 + t. 17-23.

- Untersuchungen über Parasiten aus der Gruppe der Monadinen. Halle 1856. 39 pl) + 3 t. - Festschrift zu Kützings So:sten Geburtstag'e.

(Zukal in Österr. Bot. Zeitschr.) Zukal, Hugo. Phycologische Notizen. 2. Ueber Closteriun moniliferum. - Österreich. Bot. Zeitschrift. Jahro. 13, N:o 5, 1863. p. 252-255.

(Zukal in Österr. bot. Zeitschr.) - Epigloea bactrospora. (Eine neue Gallertfechte mit chlorophyllhaltigen Gonidien). - Österr. botan. Zeitschrift. 1890 N:o 9 p. $323-328$ et t. 3. 


\section{B. Collectiones exsiccatæ editæ.}

Åkerman, S. Typsamling af Skandinariens Alger innelı̊llande 100 arter. Götheborg 1ito. [g].

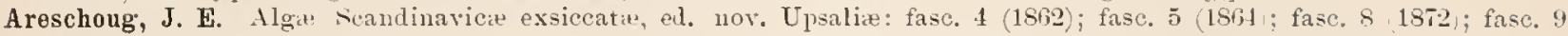
$1579 .[\mathrm{g}]$.

(Chuur. Alg. Normand.) Chauvin, Ch. Algues de la Normandie. recueillies et publiés. la partie des Articulées par 11. Koberge, et la parti des inarticulées par M. C'lauein. Caen. Fase. 6. 1s36; fase. T. 1837.

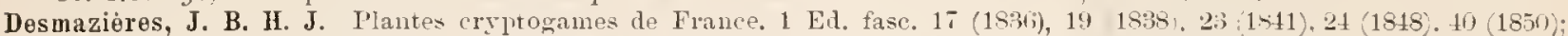

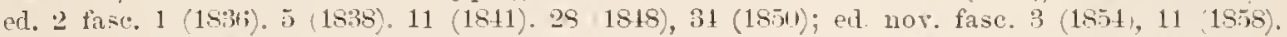

(Erb. critt. It.) Erbario crittogamico italiano publicato dai Signori M. Anzi. F. Arlissone etc. Genova. Fasc. XXI-

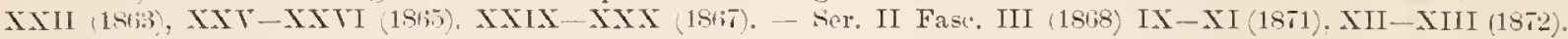
[Iragnoses et observationes partim in Hedwigia reddita sunt].

(Phykotheka univ.) Hauck, F. et Richter, P. Phykotheka universalis. Sammlung getrockneter Algen såmmtlicher Ordnungen und aller Gebiete. - Fasc. 1 n:o 1-jo. Leipzig 1885), II et III (1885). IV-V (1888). VI-VII (1889), VIII IX (1891), X-XI (1893). XII-XIII 1895). [Diagnoses quoque in Hedwigia].

Hennings, P. Plyykotheca Marchica. Sammlung getrochneter Algen aus der Mark Brandenburg. Fasc. 1. X:o 1-50. Berlin 1893. $[\mathrm{g}]$.

Jack, J. B., Leiner, L. et Stizenberger, E. Kryptogamen Badens. Fasc. 1(-10). [bau, W. Alphabetisches Te1. zeichniss nebst Standortsangaben der von - - - herausgegebenen 10 Centurien Kryptoganen Badens. Mittheil. Bad. Bot. Ver. N:o 87-8.1. 18s1, p. 301-305].

Kerner, A. Schedit ad floram exsiccatan austrohungaricam. Opus cura musei botanici universitatis vindobonensis conlitun. I. Tündobone 18s1. V, 158T. TI 18:13. -- [g].

- Flora exsiccata Austro-Hungarica e nuseo botanico Tniversitatis Tindobonensis edita. Cent. 3-4. Tindob. (1852). cent. (2) (1S48). $24(1893)$. [gig].

(Küt. Alg. an. Aule. Dec.) Kützing, F. T. Algarum arlude dulcis germanicarum. Halis Saxorum. Decas 3 1533. 8 1533). $11(1<: 31)$.

Marcuoci. Un, itin. Crypt. 186ri. fase. 3 [g. - n. r..

Mougeot, J. B., C. Nestler et W. P. Schimper. Stiryes Cryptogame Vogeso-rhenand, quas in Rheni superioris inferiorisque, nec non Togesorum prefecturis - - Bruyerii (Fasc. I-XV. 1810-61). Fase. XI1I. 1850; XIV, 185t: XV, 186i). $[\mathrm{g}]$.

(Rab. Bacill. Rabenhorst, L. Die Bacillaren sachsens resp. Deutschlands. Ein Beitrag zur Fauma von Sachsen. Gesammelt und heranggegebenen von. Inr L. Rabenlorst. Dresden. Fase. 1-2. 1845; $3+$ t. 1, 1850; $4+$ t. $2: 5+$ t. 3. $18 ., 1 ; 6+$ t. $4,7+t .5,15 i 2$.

(Rab. Alg.) - Die Algen Sachsens. Dresden. Desunidiacere in Dec.: 1 (1851); f et T 1850); [sub titulo: "Die Algen

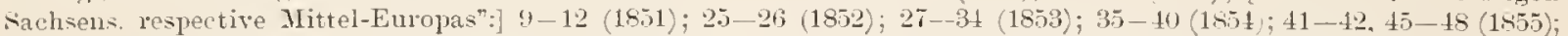

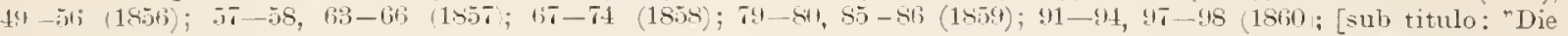
Algen Europa:":] 101-102, 165-114. 121-124 (1861); 129-142 (1852); 143-152. 155-160) (1883); 164-167. 170-

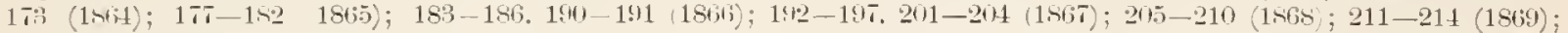

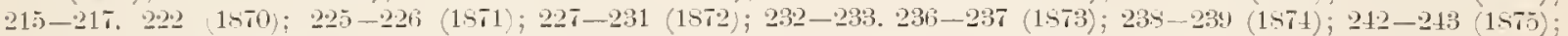

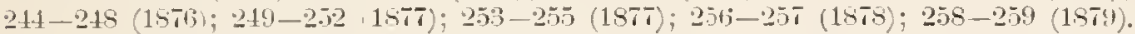

Alphabetisches Terzeichniss der Gattungen und Arten welche bis jetzt in Rabenhorst's Algen und Bacillarien sachsens resp. Hitteleuropas ansgegeben sind. Dresden 155ti. $17 \mathrm{pp}$.

- Alphabetisches Verzeichniss der Gattungen und Arten. Welche in Rabeuhorst's Algen und Bacillarien Sachseus resp. Mitteleuropa's Decade 1 bis 100 und Decade I. bis VII. der Bacillarien ansgegeben sind. Dresien 1860. 16 lp.

Ralfs, J. British Algae. Dried specimens of marine and fresh-water alga. incluring the Desmidiex and Diatomacex. Vol. I n:o 1-41\%. Pinzance. [Alia vol. non ridi].

Toni, G. B. de et Levi. D. Phycotheca italica. Collezione di alghe italiane essiccate. Fase. 2 (1886), 3 (18ss).

Wartmann et Schenk. Schweizerische Kryptogamen. St. Gallen. Fase. 1 et 3 (1862). 7 (1863). 9 (1)61.

(Wittr. et Norlst. Alg. exs.) Wittrock, V. et Nordstedt, 0. Algæ aque dulcis exsiccace preciqua scandinavice, quas adjectis algis marinis chlorophyllaceis et phycochromaceis. Upsalie. Lunde et Stockholmix 187\%. - Fasc. 2 $18^{20}{ }_{1} 7,4-18^{29}, 75,5-18^{11}, 796-18^{11}, 79.8-18^{10} / 80.10-18^{10}{ }_{2} 42.11-18^{23}, 53.12-18^{25}, 83.13-$

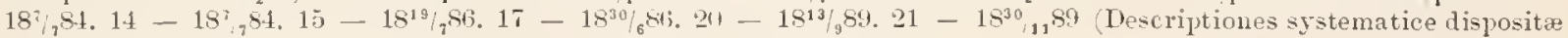
et Index generalis fasciculorum $1-24 \%, 23-18^{5} / 993.24-18^{12} / 3^{9} 13$. 


\section{Index Desmidiacearum.}

I. Nominum familiam, tribus, divisiones, genera, subgenera vel sectiones, species (cum subspeciebus, varietatibus ac formis) designantium enumeratio alphabetica cum citationibus suo loco chronologice ordinatis.

In annis positis antc locos citatos omittuntur duo primi mumeri (18).

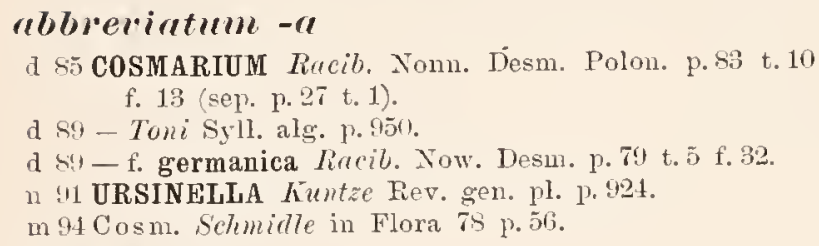

d 85 COSMARIUM Racib. Nonn. Desm. Polon. p. 83 t. 10 f. 13 (sep. p. 27 t. 1).

d 89 - Toni Syll. alg. p.950.

d si-f. germanica Racib. Now. Desm. p. 79 t. 5 f. 32.

n 11 URSINELLA Kuntze Rev. gen. pl. p. 924.

m 94 Cosn. Selmidle in Flora 78 p. 56.

\section{abbreviatum}

d 93 TRIPLOCERAS (Bacteridium) Tumer Alg. Ind. orient. p. 27 t. \& f. 17.

o A DOCIDIUM Eudoeidium) Witdcm. Obs, erit, Desm. p. 69 et 71 .

\section{abuorme}

d 72 COSMARIUM $\beta$ triquetrum Norlst. Desm. Spetsb. p. 32 t. 6 f. 15 [non vere deseriptum nee depietum; est C. costatum $\beta$ Nordst. 1875].

o 75 - Reinsch Algr. Prom. Bon. Spei 1. 241 t. 6 f. $5-6$.

\section{aboense - is}

d 81 EUASTRUM Elfo. Finsk. Desm. 1. 7 t. 1 t. 2. [Cfr. Nordst. in Botan. Notis. 1882 p. 96. - Eu. inerme aboense Rucil. 1885].

d s9-Toni syll. alg. p. 1103.

1191 HeLIERELLA huntze Rev. gen. pl. p. 89 .

\section{abruptum}

a 12 CLOSTERIUM West Alg. Engl. Lake Distr. p. i19 t. 9 f. 1.

- - f. punctata ibicl.

o :3 - v. cambricum Turncr Desm. Notes p. 346.

o :14 - f. brevior West New Brit, Desm. p. 3 t. 1 f. 1.

m 95 - Johns. Rare Desm. U. S. Il p. 291 t. 239 f. 5.

\section{(1) 11$)$ twm $-r$}

d 91 Cosmakidm Lund. Desm. snee. p. 43 t. 2 f. 22.

m sis - $\mathrm{f}$. minor W'ille Nore. Felskv. alg. I p. 30.

d sit - f. simplex schurischm. Afghan. Alg. p. 247 t. 5 f. 24.

o 85 - n. suecinm Racil. Tonn. Desm. Polon. p. So (sep.p. 21).

d -. b. gostynieuse ibid., t. 11 (sep. 2) f. 13. [Nova spee?]. m S8 - v, gostyniense Riabin. Chloroph. env. Kharkow p. 320 t. 8 f. 7 .

mss - f. minor Nordst. Bornh. Desm. p. 198.

d 89 - Tomi Syll. alg. p.917.

d - f. simplex ibid.

d - f. gostyniense ibirl.

n 91 URSINELLA Kuntzc Rev, gen. pl. p. 894.

d 91 Cosm. f. Gutw. Flor. alg. Leopol. p. 57 t. 2 f. 18.

- $93-\beta$ Gostyniense Tumer Alg. Ind. orient. $\mathrm{p} .71 \mathrm{t}$. 11 f. S.

\section{abrulutum,}

a 93 DOCIDIUM Turner Alg. Ind. orient. p. 32 t. 4 f. 11.

\section{abruptum $-a$}

d 70 EUASTRUM Nordst. Desm. Brasil. p.217 (sep.p. 179 t. 2 f. 3.

o 77 - Nordst. Alg. brasil. p. 21.

d $-\beta$ evolutum ibid. p. 21 t. 2 f. 7. [Propria spee?].

m $80-\beta$ evolutum Nordst. De Alg. et Charae. 1 p. 10.

d st-Wolle Desm. U. s. p. 107 t. 52 f. $21-22$ (forma).

o sti - Stokes Key Desm. p. 145.

d 80 - Tomi syll. alg. p. 1095.

$\mathrm{m}$ - v. evolutim ibid.

11 11 HELIERELLA Iruntze Rev. gen. pl. p. 998 .

m 91 Eu. v. evolutum Hest Freshw. alg. Maine If p. 35 f

d 32 - Wolle Desm. U. S. ed. II p. 120 t. 63 f. 21 et 22 .

m 94 - Borge süssw, Chlor. Archang. p. 21.

\section{ACINTHASTIRUM}

o 93 Tamer Alg. Ind. orient. 13. 133. Subgen. Staurastri.

\section{reanthoirles}

d 7 STAURASTRUM Delponte Desmid. Snbalp. 1. 11 (sep.p. 13i) t. 11 f. $5-6$.

a si-Tomi syll. alg. p. 1161.

\section{acallthophor"llu}

a :18 EUASTRUM Turner Alg. Ind. orient. p. 82 t. 10 f. $5 \%$. 


\section{recunthophorum - -}

1 so XANTHIDIUM Norlst. De Alg. et Charac. 1 p. 11 t. 1 f. 20 . (Form. javanica et suecica p. 12).

a 81 - Arch. in Ann. Mag. Yat. Hist. s. 5 11:0 it p. 142.

- s8-(Centrenterium) Boldt Desm. Grönl. ]. 31.

o ss - $\beta$ bengalicum Lregerh. Bengal. Desm. 1.9 t. 1 f. 7.

d 89 - Holacanthium) Toni syll. alg. p. (125).

o - v. benmalicum ibid. p. 926 .

d sa ARTHRODESMUS f. Racib. Now. Desm. p. 97 t. $f$ f. 18. m 90 - Eichler spis Desm. Miedz. p. $\$ 8$.

\section{ucumthopleur'um}

d 93 EUASTRUM Tumer Algæ Ind. orient. p. 52 t. 11 f. 4 t.

\section{(1e(t)(thos) $)(1,1 \mathrm{~m}$}

dzf $\$ 3$ PENIUM Lagerh. Bidr. Sverig. algfi, p.51 t. 1 f. $15-17$.

lz 89 - Toni syll. Alg. p. 863.

\section{urarides}

d 72 STAURASTRUM Norlst. Desm. Spetsb. p. 40 t. 7 f. 26. in 83 - Joshua in fourn. Bot. v. 21 p. 292.

d si-Cooke Brit. Desm. p. 153 t. 60 f. 5.

d 89 - Toni Syll. alg. p. 1169.

o 89 - v. eboracense Test Fr. Alg. North Yorksh. p. 293 t. $291 \mathrm{f}$. $\mathrm{s}$ et $\mathrm{T}$ (hexagonum).

\section{(lecrosum) - $11-11 \mathrm{~s}$}

d 03 VIBRI0 Schrank Favna boica v. 3 pt. 2 p. 47 11:0 2848 . ph 23 BACILLARIA Sehrenk Oscillat. p. 533 .

2s CLOSTERIUM Ehrent. Symb. Phys. Plytozon t. II Sinaitica f. 9.

ph 30 - Ehrenb. in Isis 1. 168.

d] 30,:31) - Ehrenb. symb. Plys. Evertebrata [Context.] Polygastica Fol. b. a. 2.

d 32 - Entw. d. Inf. p. is (incl. Lnnul. monilifera Bory). ph 37-Ehrenb:s Entdeck. (in Wiegm. Arch. 1837) p. 377. ph 37 - Ehrent. in Abl. d. Berlin. Akad. 1836 p. 129.

d 38 - Ehrenb. Inf. p. 93 t. 2 f. XT, t. 6 f.I et t. 22 f. V. $3 ;$ p. 242. (Corpicetti a baccello, Curti? Osservaz. micr. s. Trem. 1774 , p. 111 t. 2 f. 17 i, g; r, s. Bacillaria multistriata $E h r b$.)

d 4i) - Menegh. Synops. Desm. p. 233 (sep.p. 33) (inclus. Cl. didymotocum Corda ete).

d 41 - Pritch. Inf. f. 63, 64, 65 [ex Ehrent. Inf.].

d 45 - Hriss. Brit. Alg. p. $37 t$ t. 57 f. 5 [ex Ehrend. Inf.].

d $45-$ Kü̈t. Phỹe. germ. p. 131.

d 17 - Focke Phys. Stud. p. 5 s t. 3 f. $2 s$.

dzf 4 S - Ralfs Brit. Desm. p. 164 t. 27 f. 2.

d $49-$ Kütz. Spee. Alg. p. 164.

1 52 - Mritch. Inf. 1. 280 t. 1 f. 63, 64, 65 [ex Ehrenb. Inf. diminuatæ]

A 53 - Math. Fl. Belg. II p. 525.

d $56-$ v. elongatum Breb. List. p. 152.

ph 56 - Wenham On cilia p. 158.

om $5 \overline{6}$ - suring. Obs. Phyc. p. 61.

ph $5 S-$ De Bary Conjug. p. 51 .

n $61-\beta$ minor Hantzsele in Rab. Alg. Eur. n:o 1047 [Cl. angustum Hantzsch].

d 61 - Arch. in Pritcl. Inf, p. 747.

m 62-Wartmann et Schenk: Schweizer. Krypt. sub n:o 131.

d 63 - Rab. Frrpt. Fl. Sachs. p. 170.

fit-Crouan Fl. Finist. t. 4 f. 32.

d 6. - f. membrana striata et spiraliter plicata $R a b . \mathrm{Alg}$. Eur. 11:0 195\%.

m 15 - A. majos Reinsch Algenfl. Frank. p. 1S6. Schronk).

m - B. medinm ibid. $\beta$ minus Hantzsch 1S61).

o - C. ambigaum ibid. 1.1\%i Cl. a mbigu um Ilentzsch m - D.? lanceolatum ibid. (Cl. In nceol. K.')

$\mathrm{m}$ - E. angustum ibid. (Cl. angustum Hantisch).

d $67-K i c k z$ Flora erypt. Flandr. II p. 415.

67 - Not. Desm. Ital. t. 7 f. (i5.

o 68-Richt. in Rab. Alg. Eur. n:0 2051.

d th - Kab. Flor. Eur. Alg. 1. 128; form. a.

- f. b. ibid. (v. clongatum Breb. .

- f. c. ibid. [ $[$ inl. 1 1 $66 \mathrm{~d}]$.

- f. d. ibid. (Clost. a mbiguum Huntz?)

- var. $\beta$ minus (Hantzsch 1861) ibid.

m 70 - Reinhard in Arbeit. d. Saturf.-g. Charkow I. p. 15.

d $72-v$. I'fitzer in Monatsb. Berl. Akad. 1'381 etc. t. 1 f. $1.8-12$ et 1 it.

dzf $73-v$ maximum Wood Fr. Alg. p. 111 t. 11 f. 5 [Propria sit species].

m 75 - Sowinsliy in Lapiski Kiew. IV. 1 p. 14.

dz 75 - Microgr. Dict. p. $17 ;$ t. 10 f. 41 et 42 [e Ralfs Br. Desm., non bona].

d 77 -Delponte Desmid. subalp. p. 97 (sep.p. 193) t. 16 f. 4-13.

d TS-Kirchn. Alg. Sichles. 1.138.

m $7 s$ - Hempel Algenfl. Cliemnitz p. 111.

o 79 - Wille Fersliv. alg. Nov. Semlj. p.61.

d 79 - a typicam Klels Desm. Ostpreuss. p. 7 t. 1 f. 6.

d - b. laveeolatnon ibil.

o c subangustum ibid., t. 1 f. 9 b et c.

o 81 - Mrrst. Y. Zenl. Dcsin. p. 312 t. 12 f. 33.

m 82 - Nordst. Algolog. smasak. 3 p. 18.

ozf 83 - Mash. N. Zeal. Desm. Add. p. 256 t. 25 f. 18.

m 84 - Lnpot Mater. alg Warszaw. 1.252.

dzf 81 - Wolle Desm. U. s. p. 11 t. 6 f. 7 et 11, t. 8 f. 17 .

d S5̆-Kirclen. Milit. I'flanz, d. Süssw. 1). 21 t. 2 f. 62.

ph 85 - Kleles Beweg. u. Śchleimbild. d. Desur. p. 354 etc.

d. S5-Brelsamo Alghe del com. di Napoli p.3t.

d 86 - Frank in Leunis Synops. 3 p. 19.8.

o 86 - Stulies Ficy Dcsm. p. 112.

m S6-Artari Mater. alg. Moscou p. 170 (sep.p. 8).

dzf 86 -- Cooke Brit. Desm. p. 20 t. 9 f. 1.

ozf 87 - f. striolatum Wolle Fr. Alg. U. S. A. p. 24 et $t$. (i) f. 1-2.

d 87 -Alexentio Chlorosp. Kliarts. p. 223.

d 88 - Ilansg. Prodr. Algenfl. Bihm. p. 179.

- $\quad-\beta$ minus ibid.

d 85 - Toni et Leri Fl. Alg. Venez. p. 32.

m 88 - Riabin. Chloroph. env. Kluarkow p. 316 (sep.p. 2s).

m S8 - Ist $v$. Jel. magyar. alg. p. 238.

o 89 - Nordst. Fr. wat. alg. X. Zeal. p. 68 et 78.

m 88 - Lewin span. süssw.-alg. p. 10.

o 89 - v. elongatum West Massachus. Desm. p. 17 [non Bréb. 1856).

m $89-$ Harv. Fr. Alg. Naine II p. 185.

d $89-$ Tomi Sy-11. Alg. p.824.

d $-\mathrm{r}$. minus ibil. p. 825.

o 90 - c. truncatum Gutw. Walır. d. Priorität p. 66.

m 10 - Eichler Spis Desm. Miedz. p. 85.

phs 1 - Wildem. Recherch. temperat. caryoc. p. 51 t. 2 f. 32.

d $91-K i$ chn. Mikr. Pfanz. d. Siissw. ed. 2 p. 22 t. 3 f. 71 et t. 5 f. $16 i 3$ (e Pfitzer).

m 91 - Borge Bidr. Sibir. Chloroph. p. 13.

1191 - ARTHRODIA Kuntze Rev. gen. plant. p. 893.

m 91 Clost. b. sub angustum Gutue. Flor. alg. Leopold p. 33.

d - c. truncatum ibid. et t. 1 f. 7 .

o $92-M \omega \ell$. Austral. Siisswasscralg. p. $¥ \pm 0$.

daf: - Wolle Desm. U. A. en. II p. 42 t. 7 f. 7 et 11. t. 10 f. 1 et 2 [\%], t. $y$ f 17 .

m 92 - v. subangustum Gutw. Flor. Glon Galic. 3 p. 121.

d $92-B$ wiley Contr. Quecnsl. Fl. p. 40.

mat - West in Notaris. T p. 11:48. 
o - f. ibil

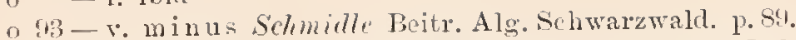

d 93 - (Campyloceras) f. attenuata Tunce $\mathrm{Alg}$. Ind. orient, p. 1s t. \& f. 15.

ph 94 - Jathemïll. in Österr. bot. Zeitschr. 14 p. 14.

o $y 1$ - $\beta$ subangustum Rorge Sissw. Chlor. A rehang. P. 14 t. 1 f. 7 .

- 94 - Simuml. in Fl. Nobraska p.38 t. 5 f. 1.

in 41 - Alorenle Mater. Alg. lihark. p, 21.

Cfr. Clost. Lnnula, Cl. attenuatum Borge 1894, Polysolenia Closterium.

\section{Achrerii}

d 24 ECHINELLA Ay. Nist. Alg. 1. 15 (Ech. radiosa Achar. 14111. non Lyngl. 181!).

1 $31-$ hütz. Syu. Diat. p.611 (sep.r. S3) t. 19 f. 101 [Ovula animal, sec. Ehrmh. Inf. 1, 220].

\section{ariculare -is}

a 60 CLOSTERIUM West New Desm. p. 153 t. 7 f. 16.

o $62-$ - Arch. Clost. acic. 1.31

o 66 - Arel. in Q. T. Ml. S. v. 6 p. 181 .

d s6-Cooke Brit. Desm. p. ali t. 15 f. 1.

d 89-Tomi virll. Alg. 1. 8:3.

n 91-ARTHRODIA Kunt:" Rev. gen. plant. p. 883.

\section{reieuliferum}

a 0 STAURASTRUM Auders. Sverig. Chlor. 1 p.11 t.1 f. 4 (S. Avicula v. acirul. West 1889).

\section{ACTINASTRUM}

d 93 Twmer Alg. Int. orient. 1.49. Nubgen. Euastri.

\section{ACTINOCISTIS}

a 93 Turner Alg. Ind. orient. p. IS. Snbgen. Micraster.

\section{ACTINOTANIUN}

d 49 Nag. einz. Alg. p. 10!. subgen. Dysphinctii.

73 Pfeiffer Nomencl. bot. I P. 46.

d so IIursg. I'rodr. Algenfl. Böhm. p. 184 (inelus. Dysphinct. sers. strict.). Sect. Dysphinctii.

d 89 Tomi syll. Alg. p. S7. Idem.

\section{arilerita}

d lif MICRASTERIAS Rostock in liab. Alg. 11:n 1556 (Mr. fimbriata var. ornata.

\section{aculeritime -r}

d 83 COSMARIUM Wro7le in Bull. Torr. bot. Club $x^{10} \mathrm{p}$. 17 t. 27 f. 12. [Non Corda].

d 84 - Tolle Tesm. U. S. p. 66 t. $10 \mathrm{f}$. 15

o sti-stokes Key Desm. p. 120i.

d 89 - Tomi srll. alg. p. 1082.

11 URSINELLA hintze Rev. gen, pl, p.9.4.

d 92 Cosm. Wolle Desm. U. S. ed. 11 p. 71 t. 19 f. 15. Cfr. Cosm. rostratum Tumer 1855.

\section{"remleritum}

EUASTRUM Ehrent. Inf. t. 12 f.II. Nomen al, auctore ipso in "Infus," (1.:38) 1. 161 in Euastrum apiculatun transmutatum.

11 3) COSMARIUM Corde in Alm. d. Carlsb. 1834 p. 243.

\section{"ruleatum}

d GONOTOZYGON Hast. in Am. montl. micr. Jomrn. $1: 3$ l. 291 e. fig.

11 (h) .lolins. Rare Desm. IT. S. II 1, 291 t. 23,4 f. 6.

\section{(1r) uleritum) -r}

d 3s DESMIDIUM Elrent. Infus. p. 142 t.10. f. XiI [a

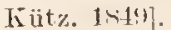

d 40) STAURASTRUM Hemegh. Synops. Desm. p. 22f (sep.1. $2(i)$.

d 41 - Elroub. in Berlin Monatsber. 1810 p.217 [Pliycastrum acul. or Kätz. sp. Alg.; st. acul. c. Elıren-

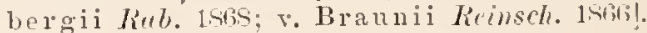

d $\$ 1$ Desm. Iritch. luf. p. 14t.

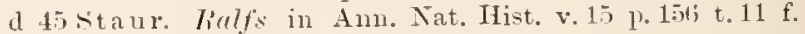
4 (et 1,it; in 'Trans. Bot. Soc. Edin. T. 2 p. 142 t. 14) [St. controversum Birb.].

d 45 GONIOCYSTIS Trignnocystis?) Huss. Brit. Alg. p. 85:3 t. S4 f. 12 [e Rualfs 1. c. depicta].

d 45 PHYCASTRUM K̈̈̈z. Phycol. grem. p.13\%.

d 18 staur. Iiulfs Brit. Desm. p. 142 t. 23 f.2.

d 4! l'lycastruin hö̈tz. Spec. Alg. 1) 182; a (Threnb. 1,38 ).

o - $\beta$ ibid. p. 1.43 (Bail. 1s+1 t. 3 f. 6 ).

o - $\quad$ ibir. (Ithenb. 1841 ).

- $)$ ibid. (Nt. controversum

n 19 -- Stenactinium Nirg. einz. Alg. 1. 128.

d 52staur. IJitch. Inf. p. 267.

56 - P proboscideum Rrib. List. 1\% 13s. [Nomen tantum?]

d b1-Arch. in Priteh, Inf. p. T42.

d 63 - hab. Frypt. Fl. Saclss. p. 1:14.

d $36-\uparrow$. Braunii Rrinsch. in Rab. Alg. Eur. n:o $16 n 0$ [st. acul. o. Ehrenbergi Rab.]

d $67-$ - - Lieinsch spec. Gen. Alg. p.12t t. 5 f. D. II 1.

a 67 DIDYMIDIUM staur., Feinseh Algenfl. Frank, p. 176 Forme I A trigonum $\alpha, \beta ; \mathrm{B}$ tetragonum (1.17T), C pentagonum, II St. controversum), III Brauni i t. 1:2 t.2.

d Gestaur. Liub. Flor. Eur. Alg. 3 p. $21 \%$.

d b. controversum ibid. (st. coutroversum .

o c. Ehrenbergii (St. a cul. Ehrenb. 1kt1.) ibid p. 218.

z 71 - Lund. Desm. Suec. p.68.

d 72 - p ornatum Nordst. Desm. Spetsb. p. 40 t. 7 f. 27.

d 77 -Delponte Desmid. subalp. p. 63 sep.p. 154 t. 13 f. $3-5$.

dz 7 - Kirchn. Aly. Sohles. p. 160.

d - r. controrersum ibid.

d 7g-fi ornatum fo spinosissima Winle Ferskr. alg. Nor. Semlj. p. 54 t. 13 f. 6 ir - 65 .

d -2 depauperatum ibid. 1.55 t. 13 f. 69 .

d so- $\beta$ intermedium Witle Norg. Ferskr. alg. I 1, 44 t. t.. 24

83 - Tumer Algie Strensall f.9

d $84-$ Iloht Desin. U. S. p. 140 t. 45 f. $1-8$.

d 85 - Kirchn. Mikr. IPlanz. A. Sirssw. P. 23

d 86 - Framk in Lemis synops. 3 1. 197.

o sti-Nolukes liey Desm. p. 167.

dz 87 - Cooke Brit. Desm, p. $17 \pm$ t. 60 f. 2.

dz 8s - Ilansy. Prodr. Algenfi. Böhm. p.215.

dz 85 - Toni et Levi Fl. Alg. Venez. 13.41i.

o s8 - $\beta$, ornatum f. simplex Bolilt Desm. Grönl. 1. 35 (sep.p. 3ii) t. 2 f. 4 !

sy - *osmospiuosum Birg. Bidr. Bornh. Desin. 1'117 et 151 t. 6 f. $\leftrightarrow$.

dz S9 - Tomi syll. alg. p. 1216.

d - v. intermedium ibid. p.1217.

d - v. depauperatum ibid.

d - r. ornatum ibid.

d - f. fpinosissimum ihid.

d - - f. simples ihid.

- subsp. cosmospinosum ibid. l, 121k.

m 10 - Jichler spis Desm. Hiedz. p. 90 . 


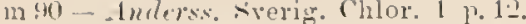

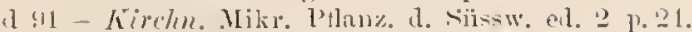

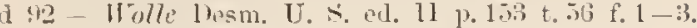

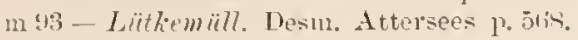

m-v. orintum ibil.

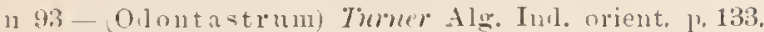

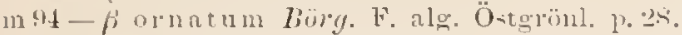

11 - $t$. spinosissima ibil.

m - - t. simulex ibil.

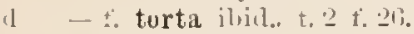

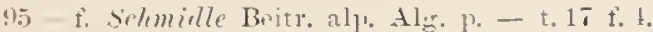

\section{"r:"leatuml- -}

(1) 34 XANTHIDIUM kihronb. Organ. kl, Raum. p. 31s sep.p. 17t. X. aculeatum et X. fasciculatum Ekrenb. in Infusionstlt. 1, 1.17].

(1) 35 BINATELLA Prib. Alg. Fal. p. 5⿺ t. 5 [X. Brebissonii sec. Iiulfs?.

37 Xanth. Ehrenb. in Ablandl. Berlin Arad, 1833 t. 1 f. $11[=1.6 .1834]$

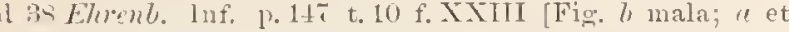
c fortasse alia species].

n 39 HeTEROCARPELLA Prib. in Cher. Nier. 1.2T2.

1) $39 \mathrm{X}$ anth. Hhrenb. Weteorp. p. it sep.p. 1.2 t. 1 f. 22

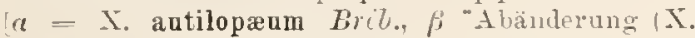
quadricorue " $=\mathrm{X}$. octocurne

a to CoSMARIUM Prell. in Menegh. rymops. llesm. p. 2ls sep.p. 1s. [Xantl. fasciculatumet Bre bisson i?].

1 to Xantl. Mem yh. Symops. Desm. 1. 224 sep.r. 2t)

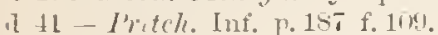

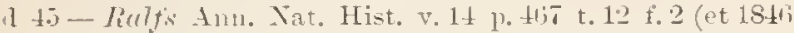
in Trans. Bot. Soc. Elin. v. 2 p. $15 j$ t. 17).

14i-Hass. Brit. Alg. p. Bugl t. S!l f. B [Figg. e Ralfs 1. c.. nt mihi viletur. delineatis. sed non exacte].

d $\pm \overline{7}-$ Rab. Deut. Kirypt. Fl. p.5.5.

14 - Rulfs Brit. Desm. p. 113 t. 19 f. 1.

d 4! ZYGOXANTHIUM Kïz. spec. Alg. p.17s.

d 5.2 Xantl. Pritch. Inf. p. 25i.

it Ehrenl. Microgenl. t. 3.1 XII B f. 2 [e Weteor W. 183! delineata].

1 61 -- Arr/l, in Priteh. Inf. p. T31?.

a 63 - Kalb. kivpt. Fl. Sachs. p. 195, fig. xyl. a et b p. 150) L Rililfs.

1 - $\beta$ brevispina Rub. ibid. p. 195.

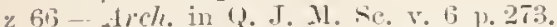

o if DIDYMIDIUM (Xanthidium) Reinsch Algenf. Frank, 1). 120.

It tix Xanth. Rub. Flor. Eur. Alg. 3 p.222; Fig. xyl. p. 111) [ut supra 1si,is]

o - $f$, brevisuina ibid. p, 2023.

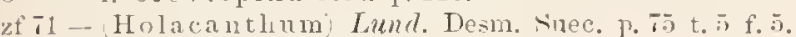

d Ti- Wood Fr. Alm. 1. 150.

dz To-kirchn. Ale. Schles. p. 15.

m is - b. brevispina Hempel Algenfl. Chemnitz p. 11.t.

n1 - 1rtari Liste alg. Inseou p. 142.

a 84 - Wolle Lesm. U. \&. p. 4. t. 23 f. 14-12.

1 45 . - Kirchn. Mik1. PHa.1z. d. Süssw. p. 25 t. 3 f. 75.

o $\$ 13$ - stakes Fier Desm. p. 130.

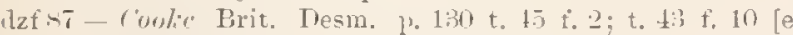
Lund. 1-iil].

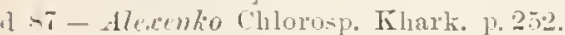

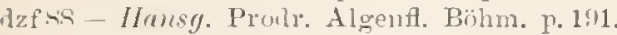

d - provevisuinum ibir. 11. 142.

1z 49 - Tuni syll. alg. p.918.

d - - v. locrispinum iljid.

0 sy-Elfi. in Botan. Jotis. 1889 1. 208.

n 90 HOLACANTHUM Tille Tatiarl. Pflanzenfam. p. 11.

m. $90 \mathrm{Xanth}$. II est Fr. W. Alg. Forth Wales p.2!1. o-f. ibid.. t.6 t.3!l IX. Brebissonii?).

1) 91 - Kirchn. Mikr. PHan\%. d. Siissw. ed. 2 p. 246j t. 3 f. 85.

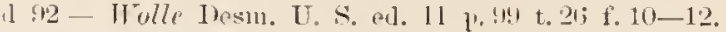

\section{remminatum}

o m 34 CLOSTERIUM cord" in .thn, de cartsb. 1s35 p.

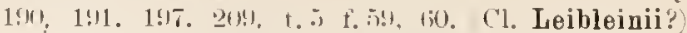
[Cl. Lunula sec. Meneyh. Sin. Desm. p. 2:31. sed sal. ten fig. 60 alia spec. est].

uruminretum-r

d t5 CLOSTERIUM Kütz. l'hyc. germ. p. 130. (Cl. Acus Ky. Tree. VIII. M(1). [Cl. Dianæ sec. Jacubs. 157is et Richt. in Phykntheen miv. 12:0 tiB:3].

1 4! - Kütz, spec. Alo. 1.161 (Cl. arcuatum Lirèb. 1848).

d tis-Rub. Flor. Enr. Alg. 3 \%. 1333.

o T.2 - Irittr. Gotl. Ol. sitv, Ale. p. fit t. 4 f. 18 .

d $78-$ Kirchn. Alg. Sehles. p. 113.

dzf 84 - Wulle Thin. U. S. p. 44 t. 7 f. 18-19[?].

o 8 si-Stukes Key Desm. p. 11:3.

d S. - Mansy. Prodr. Algenfl. Bühn. 1. 182.

d s9 - Toni syll. Alg. p. S40.

m 90 - Eichler spis Desm. Miedz. 1'. 8.5.

n !1 ARTHR0DIA Kuntir Rev, gen. plant. p. 863.

in 91 Clost. Gutx. Flor. alg. Leopold. p. 35.

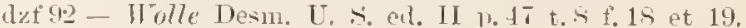

d 91 - Smmeters in Fl. Nebraska p.3s t. 4 f. 21.

\section{Acus}

ph 17 CLOSTERIUM Nitzsch Entw. d. Inf. p. ii [Englena Acns Mitl.) Ehr. sec. Ehrl. Inf. 1. !S, non Closterium]

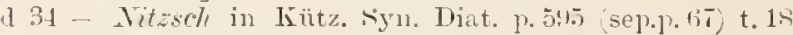
f, 81 Cl. rostratum Ehrl. Inf.].

d 33 - Kütz. Alg. aq. dulc. Dec, 11:0 80 [Cl. acuminatum Kïitz.. see. Kritz.].

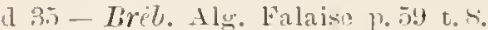

d 1.5 STAUROCERAS Kütz. Phycol. germ. 11. 133.

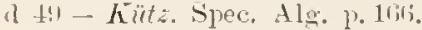

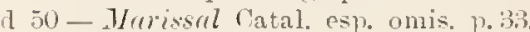

d 53 - Muth. Fl. Belg. II p. 5291.

un 57 - suring. Obs. Hlyye. p. 61 .

\section{erelle}

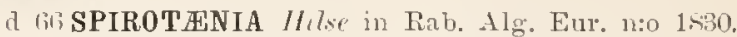

1 bis-Milse in Ber. 1. schles. Ges. 186- p. 121.

a th- Rul. Flor. Eur, Aler. 3 p. 14 s.

d To-Kirch. Schles. Alg. 1. 137.

o $84-$ Penium? Arch. in Am. Mag. Nat. Hist. J ser. 11:0 $7 t \mathrm{p} .14 t$.

d 8 i - Cooke Brit. Desin. p. 16i, t. $16 \%$ f. 5 .

matis-Iste. Jel. nagrar. alg. 13.243.

d sor Toni Syll. Aly. p. sit).

o 95 - (Polytruia Lütkemïll. Gatt. Ajpotren. p. of et 93. m 45 - Eichler in Paniet. Fizy. 13 1) 5 r.

\section{arotilobum}

d "1 EUASTRUM liorge silissw. Chlor. Arehang. p. 33 t. :) f. 3 i.

\section{(Ir) $11 \| m-r$}

(1) 1! ECHINELLA Lymgl. Hydr. Dan. p. 20!n t. 1 1 !) G. Spongilla lacustris et Synedra fascicularis sec. Heib. Cons]. crit. diat. dan. 11. 14. Cymbella acuta Aly. Frustulia a cuta ilg.. Kütz. Brèl, ete.

(1 29) - Corda in stum Deutachl. Flor. II 18 n'ro 15 . $A$ et $B$.

dzf ts Clo-terium lifulfs Brit. Desm. M. 17i. 
- $a$ iljill.; t. 30 f. 5 a et b, $d-f(?) ;$ t. 34 f. 5. (Cl. acut um Preb. in litt.). [t. 31 f. 5 est Cl. Linea Perty sec. Roy 1894].

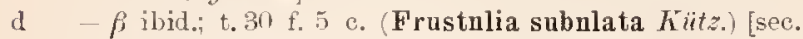
Bréb. List. Desm. nulla fignra Rolfsii ad Cl. subulatum pertinet].

zf 48 - Brèl. in Desmaz. Pl. crypt. d. France fase. 34 n:o 1653 , ed. 2, fasc. 2 n n:o 1353 c. icon.

d 44 - Brit. apud Kütz. spec. Alg. p. 164.

o 52 - Perty Kleinst. Lebensf. p. 214 t. 16 f. 2.2.

d 52 - Pritch. Inf. 17.283.

ph 57 - Hofmeist. Fortpflanz. p. 35 t. 1 f. 10.

zf 57 - Bertiel. Introd. Crypt. Bot. p. 121 f. 32 (e Ralfs).

ph 58 - De Bury Conjug. p. 11, 12, 50. t. 5 f. 13.

n 58 Stauroceras Grun. Desm. p. 497.

d 61 Clost. Areler in P'ritch. Inf. p. 750, $\alpha$ et $\beta$.

o 62 - Arch. On Ankistrodesmus (sep.p. 21). in Dubl. Nat, Hist. Soc. Pr. p. 59 t. 2 f. $5 \mathrm{~s}-60$; in Q. J. Micr. Sc. p. 260 t. 12.

d $63-R a b$. Krypt. Fl. Sachs. p. 175.

d $6 f_{-}$- Eyrich Algenfl. Mamnl.p 138.

d 67 - Reinsch Algenf. Frank. p. 189. Forme: A. Cornu Cl. Cornu).

d - B. Lyugbyannm ibil. Lymgb, 1S19, Ralfs $\beta$.

d $68-$ Rob. Flor. Eur. Alg. 3 p. 137 .

b. F. elongata ibil. 1). 13- (Clost. subula tum Bréb. von hütz.)

d 75 - Microgr. Dict. p. 176.

in 75 - Novdst. Desm, aret. p. 15.

- 55 -Jacols. Desm. Danen. 1. 173 (inelus. Cl. Cornuj.

dz $78-$ Kirchn. Alg. sichles. p. 140.

m 78 - Hempel Algenf. Chemnitz p. 112.

m79- Withe Ferskv. alg. Nor. Semlj. p.61 t. 14 f. 86 (f. major et minor).

dzf 80 - f. Wille Norg. Ferskv. alug. 1 p. 57 t. 2 f. 39.

n $83-\beta$ tenerrima scharaschm. Nagyar. Desm. p. 2т6 (1.1. tenerr. Kititz. 1tis).

o st-Gry Mon. loc. Conj. p. 76; $\beta$ Ralfs.

dzf 81 - Wolle Desm. U. S. p. 41 t. 7 f. 11-12.

o s6-Stolies Key Desm. p. 112.

dzf 86 - Coolit Brit. Desm. p. 35 t. 14 f.5 [e lialfs].

d $8 \mathrm{\tau}-\mathrm{Alexenko}$ Chlorosp. Filiark. p. 227.

m 8s-Riabin. Chloroph. env. Kharkom p. 317 (sep.p. 2y).

m s8-? Norrlst. Fr. wat. alg. N. Zeal. p. 70.

dzf - f. tenuior ibid. t. $;$ f. $2 \overline{-}$.

dz 89 - Tomi syll. Alg. p. $\$ 336$.

dz $\quad$ f. tenuius ibil. p. 837.

oz 90 - Reinsch Sïsswasseralg. Süu-Geor.g. p. 353 t. 2 f. 12

m90-Anders. Sverig. Chlor. 1 p. 1 \%.

m 90 - Fichter sipis Desm. Miedz. p. sõ.

m 91 - Heimer Desm, alpin. 1) 593.

n 91 ATHRODIA Kmutze Rev. gen. plant. p. 883.

m 91 Clost. Gutu. Flor. alg. Leopold. p. 34.

m 12 - Jiorge Chloroph. Torsk. Fimmark. p. 11.

m 12 - Rimmer Alg. Nt. Puiten I. 1.t.

in $-\beta$ elongatum ibid. $p .5$

m $: 2$ - Mül. Arstral. Nüsswasseralg. 1\%. 440.

daf 92 - Wollc Desin. U. .. ed. II p. 43 t.s f. 11-12.

def 12 - Bulley Contrib. Queensl. Fl. p. 41 t. 13 f. 32 (e Berliel. 1857 ).

ozf 93 - f. tenuior Tumer Alg. Ind. orient. p. 22 t. 1 f. 14. m 91 - Büryes. F. alg. Cistgrönt. p. 10.

m. 4 - Gutw. Fl. alg, Tarnapol. p.so.

Cfr. Clost. candatnm, tenerrimum, tenne, et pronum b. Kleles $187 !$.

\section{(lc.utum}

d 56 STAURASTRUM $B w$. Liste l'. 143 t. 1 f. 26 . [An
St. granulosnm? st. cristatnm f. Reiuschii Istv. 18s8; non recte?].

d 68 - Fab. Flor. Eur. Alg. 3 p. 202.

d - b. læve (St. erlangense Rinsch.) ibid. p. 203.

d $7 \mathrm{~s}-$ Kirchn. Alg. Schles. p. 168.

m 90 - Eichler Spis Desm. Miedz. 1. 94.

\section{acutus}

n 36 ARTHRODESMUS ( $\beta$ obtusior) Ehrenb, in Wiegm. Arch. 1833 p. 185 (Scenedesmas Pyras Corr..).

d 38 - Ehrend. Inf. P. 151 (Scenedesmus sp. anct.).

\section{adrmantimus}

d 69 PALMOGLOEITES Göppert Algenart. Einschl. in Diamanten in Abh. Schles. Ges. vat. Cultur 1864 p.6.1 t. 1 f. 7 [Certe nulla Desnid.. Cfr Göppert in Jahr. Schl, G. v. C. $186 i$ P. 39].

d sif-Frank in Leunis Symops. 3. p. 199.

\section{adelochondrum}

d 81 PENIUM Elft. Finsk. Desm. 1. 17 t. 1 f. 13.

d 89 - Tomi Syll. Alg. p. 857 .

m.12 - West Fr. W. Alg. W. Irel. p. 12 s t. 19 f. 19.

d 94 -- v. pnuctata Schmidle Alg. Geb. Oberrheins p. 547 t. 25 f. 2 [fig. falsa see. auct. in litt.].

\section{red.srendens}

a $7 S$ MICRASTERIAS Nordst. alg. Sandvic. p. 15 t. 1 f. 14. d s9-Toni Syll. alg: p. 111 .

n :11 HELIERELLA Tintze Rev. gen. pl. p. s:8.

\section{requale}

d 113 COSMARIUM Turuer Alg. Int. orient. p. 61 t. 9 f. 31.

\section{requale}

d :13 DOCIDIUM Turner Alg. Ind. orient. p. 28 t. 3 f. 11 , t. 2 f. 10 (monstr.).

\section{armullu}

d !3 STAURASTRUM Twner Alo. Ind. orient. p. 115 t. 13 f. $26^{\frac{4}{7}}$.

\section{reffine}

d !' CLOSTERIUM Gay Alg. Bagn. Bigorr. p. XXXI e. fig.

\section{reffine}

d 9.2 Cosmarium Piac. Desinitya Ciastoni p. 363 t. 6 f. 25.

\section{rffine -is}

d 4 EUASTRUM Relfs. Aun. Nat. IIist. v. 14 p. 191 t. 7 f. 3 ; et $(1816)$ Trans. Bot. Soc. Edin. v. 2 p. 128 t. 11.

d 45 - Ilass. Brit. Alg. p. 382 t. 90 f.9 [e Ralfs 1. c. delineatum].

d 18 - Rulfs Brit. Desm. 1. 82 t. 13 f. 3.

d 19 - huitz. spec. Alg. p. 172.

d 52 - Mritch. Inf. p. 249.

d 61 - Arch. in Pritch. Inf. p. T24\%

d 63 - hirb. Firypt. Fl. Sachs. p. 185.

d 68 - Siab. Flor. Eur. Alg. 3 p. 182.

d 73 - f. scrobicnlata Nordst. Norg. Desm. p.s.

d 73 - Wood Fr. Alg. p. 13.

d 81 - Wolle Desm. U. S. p. 100 t. 25 f. 11-12 [Cfr Wildem. Not. 1895 .

o 86 - Stokes Kiey Desm. P. 145 .

d si - Cooke Brit. Desm. 1.67 t. 33 f. 2 [ex. p. saltem e lialfs].

noss-7ste. Jel. magyar alg. p. 221.

d sst-Tom syll. nlg. p. 1091. 
m $9(0)$ - Anders. suerig. Chlor. 1 p. 11!.

11 91 HELIERELLA Kunter liev, gen. pl. p. StR.

1] 13 En. IFulle Desm. U. $\therefore$ e ell II P. 110 t. 2 s. f. 11-12.

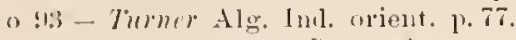

m! - liorge Süssw. Clilon. Archang. p. 32.

('ir Idelyulitum va rians, En. humerosum var.

\section{affine}

1 I9 PENIUM (Doeidium) Kïtz. Spec, Alg. p.16f.

\section{Ay!jegrate?}

o $7: 3 / 3,7$. Desm. subalp. 35 et 54 (sep.p. 23 et 17 ). Sect. (1. (ohors) Desmidiacear. Gen.: Hy̆alotl., Mixotenium, Dinlymoprium. Bambus.. Desm., Aptog., Spheroz., Nanthidiastrum.

\section{reg! $)$ regutum}

1] 7!) CLOSTERIUM Hartoy in Proced. Manehest. Liter. a. philos. Soc. v. 18 p. 25 [?; lapsu ealini l. errore typograpluieo $1^{n+0}$ Clost. attenuato l. angustato 1. gregario?]

\section{Aitchisomii}

a st COSMARIUM Schatakm. Afglan. Alg. 1). 246 t. 5 f. 2 (1).

d . 8! - Toni syll. alg. 1, \$35.

11 !1 URSINELLA Kuntae Rev. gen. pl. p. @2.

o !13 Cosm. Tumer Alg. Ind, orient. p. 55 t. 8 f. 51 (Enastrum monodentatum nov. spee.? sec, auct. ipse).

o - v. punctatnm ibiel.; t. 9 f. 18.

\section{relretre}

d 60 MICRASTERIAS Wullich Desm. Low. Bengal p. 279 t. 13 f. 11 .

ozfsi-Lagerle. Amorik. Desm. 1'. 231 t. 27 f. 5.

si - Wulle Fr. Alg. U. s. A. p. 411 t. 62 f. 1.

d $89-7$ mi syll. alg. 1. 1136.

n "1 HELIERELLA hunta Rev. gen. pl. p. s9.

d 2 lf ier. Wolle Desm. U. S. ed. II p. 125 t. $41 \%$ f. 1.

ozf 93 - f. typica Twnev Alg. Iul, orient. p.93 t.6 f. 3 et 5 , (fig. 4 zygospor.).

o - f. depressa iloid.; t. if f. 2.

\section{relatum}

d 39 COSMARIUM Cordu in Alm. d. Carlsb. 1839 p. 243 t. 6 f. 31 [Enastrum verrucosum $\beta$ alatum Wolle (forma)].

\section{alritum - a}

d Ts COSMARIUM Kirehn. Alg. Schles. p. 153 [nom (ordu].

n 85 - a. silesiacum lácib. Nonn. Desm. Polon, 1. T3 (sep.p. 17) (Кirehn. 1878).

d -- bo gostyniense ibit., t. 11 (sep. 2) f. 17.

d $89-$ Tomi sirll. alg. p. 1021 .

d - v. gostyniense ilid. 11. 1022.

n 91 URSINELLA Funtze Rev. gen. pl. p. 121.

d $93 \mathrm{Cosm}$. v. Indicnm Turner Alg. Ind. orient. p. 57 t. \& $\mathrm{f} .36$ et 57

d $93-\beta$ irquatoriense Nordst. in Wittr. ot Nordst. Alg. exs. 11:0 1116.

\section{alpestre}

d y4 COSMARIUM Roy et Iiss, in Roy Seottish Desm. p. 11 (sep.p. 20) t. 1 f. 6 .

\section{alpina}

d 55 SPIR0T ENIA Sclemille Beitr. alp. Alg. p. 308 t. 14 f. $11-13$.

Sordstelt, Iudex Inesmid.
(1)

a sil COSMARIUM 7omi syll. alg. p. 9.4 (C. cronatum e a lpinum Jiarit. 1885).

11 91 URSINELLA Kuntze liev. gen. pl. p. 92.

1) 91 Cosm. $\checkmark$. helveticum schmille in Iledwig. 33 p. 89 t. 1) f. 11 (15) Apr. 1S!M). [Cosm. Garrolense fion et Jiss. 15!l]

" - $\mathrm{v}$. monspeliense ibid. $\mathrm{p} .90$ (C. undulatum $\mathrm{v}$. mons $\mathrm{p}$. Groly 1ssi).

\section{al)iumm}

d SS STAURASTRUM liucil. Mat, flor, glon. Polsk. p. $10 \mathrm{~s}$ (sep.p. 2!)!

1) 85 - $\beta$ tropicum Lagk $\%$. in Notarisia III $\mathrm{p}$. 593.

d s!! - Joni Syll. alg. 13. 1195.

d - v. tropicum ibil. [S. tropienm Lagerh. 1891].

o 8.4 - Rucib. Now. Desm. p. 9.9 (sep.p. 27) t. 7 f.6.

\section{al)imum}

(1) 15 XANTHIDIUM Schmidle Beitr. alp. Alg. 1. 350 t. 15 f. 9

\section{alteruans}

f 70D0CIDIUM Norlst. Desm. Frasil. p. 205 (sep. 167), t. 3, f. $3 i$.

m 80 PLEUR0T ÆNIUM Nordst. De Alg. et Charae. 1 p. 2. d s.l Doe. Toni Syll. Alg. p. 875.

d :18-f. minor Turner Alg. Ind. orient. p. 29.

\section{relteruans}

dzf 7 PHYMATODOCIS Nordst. Alg. brasil. p. $19 \mathrm{f}$. xylogr. 1. t. 2 f. 4.

da $89-7$ - 7oni syll. Alg. p. 800.

n :10 - Wille in Natiill. Ptlanzenfam. p.15 f.9 G. (e Nor(lst.). o 50 - Börg. Desm. Brasil. p. 26.

\section{ritermans}

d 4 STAURASTRUM Bréb. in Ralfs Brit. Desm. p.132 t. 21 f. 7. (Staur. tricorne Ralfs 18t5, non Mencyh., Gonioc. hexaceros Ilass.).

d 52 - Pritch. Inf. p. 205 t. 13 f. $16-17$ [e Ralfs delin.].

d lil-Arch. in I'ritch. Inf. p. $7: 11$ t. 2 f. 16-17 [e Jillfs]. - 72 - Wittr. Gotl. Öl. sütv. Alg. 1.52.

daf 77 -Delponte Desmid. subalp. p. 47 (sep.p. 143) t. $11 \mathrm{f}$. $39-47$.

o 79 - Wi7le Ferskv. alg. Nov. Semlj. 1, 53.

d $-\beta$ pulchrum ibid.. t. 13 f. 66.

d 8.1 - Wolle Desm. U. S. p. 128 t. 41 f. 26 - 28.

m 85 - $\beta$ pulchrum Boldt Sibir. Chloroph. p. 115.

0 S6-Stolies Key Desm. p. 167.

dzf 87 - Cooke Brit. Desm. p. 162 t. 51 f. 7 [e Ralfs et Delp.].

d 89 - Mansg. Proulr. Algenf. Bühm. p. 25.5.

o 88 - Boldt lyesm. Grönl. p. 37.

ni - $\beta$ pulelum ibid.

a 89 - v. subalternans Mask: Furth. Not. N. Z. Desm. P. 22 t. +4 f. 35

d $89-T o m i$ sjll. alg. p. 1193.

d - v, pulehrum ibid.

m 90 - Anderss. Sverig. Chlor. 1 p. 11.

m t - Surge Chloroph. Norsk. Finmark. 1. 7.

m 12 - Hest Fr. w. Alg. W. Irel, p. 180.

d 12 - Wolle Desm. U. s. ed. II p. 142 t. 52 f. $26-28$

m 13 - Lütliemüll. Desm. Attersees 1. 56i.

m 93 - Turner Alg. Ind. orient. p. 105 t. 16 f. 6 .

d $95-\mathrm{v}$. coronatum Schmidle in Hedwig. $3+$ p. 82 t. 1 f. 21 Cfr. Didymirium punctulatnm A. ' Reinsel: Pliycastrum trilobatum; Staur. dispar, dilatatum b. Jíul. 


\section{rembigumm}

d tiz CLOSTERIUM IJantasch in Rab. Alg. n:o 1337 [Cl. acerosum C. ambig. Reinseh 1sfit].

\section{("mbigllum -r"}

d 73 EUASTRUM? Delponte Desmid. snbalp. p. 13 (scp.]). (i1) t. 6 f. 1.

d s: - ? Toni Syll, alg. 1\% 1106 .

n !1 HELIERELLA huntze Rev. gen. p]. p. s!s.

\section{ambigllum}

d Is STAURASTRUM Tumer Alg. Ind. orient. p. $128 \mathrm{t}$. 16 f. 18.

\section{AM BII Y ACTINIC H}

d 49 Nrog. einz. Alg. p. 125. Subgen. Phycastri.

63 (romet in Rab. Alg. Eur. 11:0 1445 cum specie A. hirsuti Ehrbg. [Genus?]

d SS Ilansy. Prodr. Algenft. Böhnn. p. 251. Sect. Staurastri.

\section{AMBLTASTRUM}

d 43 Twrner Alg. Ind. orient. p. 88. Subgen. Euastri.

\section{amblyorlon}

52 DESMIDIUM Itzigs, in Rab. Bacill. Sachs, fasc. 7 n:o 65 t. V f. 65 [Desm. Swartzii b. amblyodon $R a$. 186:3].

\section{amblyonema}

d 43 CLOSTERIUM Ehrent. Mikr. Leb. Süd. u. N. Amer. (335. 369 et) 411 (sep.p. 12:3) (lineatum Bail. 1841).

d 4 - Rulfs Brit. Desm. 13.230. "Amblyonema".

d 49 - Kitz. spec. Alg. p. 164.

d 52 - Pritch. Inf. p. 281.

d 61 - Areh. in Pritch. Inf. p. Tt7.

d $68-R a b$. Flor. Eur. Alg. 3 p. 138.

d 73 - Wood Fr. Alg. p. 116.

d 89 - Toni Syll. Alg. p. 835 .

n 1 ARTHR0DIA Kuntze Rev. gen. plant. p. 883.

\section{Americance.}

d 8.5 GENICULARIA Tumer New rare Desm. p. 933 (sep.]?. 1) t. 1ti f. 1 a, b, c. [Oedogonium sp., ut mihi videtur].

o 86 - Stukis Key Desm. p. 110.

d 89 - Toni syll. Alg. p. 803.

\section{rmerirama-ım}

d 43 EUASTRUM Ehrnb. Mikr. Leb. Sint. 11. N. Amer. p. (334, 337, 334. 372 et.) 413 (sep.p. 125) t. IV f. I. 15 (Eu. no 4 builey Amer. Bacill. p. 245 (sep.p. 1.t) t. $3 \mathrm{f} .25$ ).

d 48 MrCRASTERIAS Rulfs Brit. Desm. p. IIX et it t. 10) f. 1 a-c.

o - $P$ ibid.; t. 10 f. 1 d et e.

d 49 - Kiutz. Spec. Alg. p. 171.

d 52 - Iritch. Inf. p. 215 t. 13 f. 11 [ex Ellend. 1. e.].

d $61-A r c h$. in Pritch. Inf. p. 726 t. 2 f. 41 [ex Lhrenberg. "bad" Archt.

o 65 - Arch. Obs. on Micr. Malıab. in Dubl. N. II. S. I'r. ]. 79 , in Q. J. M. S. 13. 250 etc

d 68 - Tiab. Flor. Eur. Alg. 3 p. 1 se; form. b. p. 190.

d 73 - Wood Fr. Alg. p. 113 t. 12 f. 17.

o 76 - v. recta Wolle in Bull. 'Torr. Lot. Club 6 1. 122.

d $78-$ Kiredin. Alg. Sehles. p. 11 il.

81 - v. recta $\|^{\prime}$ olle in Bull. Torr. loot. Cluh. 8 t $6 \mathrm{f} .2$

81 - f. Wills in Midland Natural. 4 t.5 f. 4.

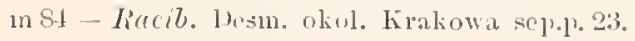

d 81 - Wolle Desm. U. S. p. 112 t. 32 f. 2.

o - v. recta ibicl.. f. 3.

o- - v. Hermanniana ibid., f. 5 [M. Malıabuleshwalensis B compacta, americana Nordst. 1888 ex p.; II. amer. f. incisa Then. 1s:33].

a 8 i - v. spinosa Turn. New rare Desm. p.936 t. 16 f. 13. o 86 - Stokes licy Desm. p. 146.

o - v. spinosa ibid.

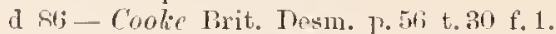

d 87 - v. spinosa Holle Fr. Alg. U. S. A. P. 39 t. 60 f. 30 [e Twner 18500].

d $87-\mathrm{v}$. orbicularis Iste. Diagn. prav. in Notar. p. 235 (sep.p. 6) Cfo Istv. 18s8.

o 88 - Mask. Not. Micr. amer. p. $9(T-10)$.

- f. genuina ibill. t. 1 f. 1.

- f. integra "Twn." (forma b. Rab.) f. 2 ilbil.

- f. recta ibid., f. 3 .

-f. spinosa ibil., f. 4 .

-f. Ralfsii " Turner" ibid., f. 5 (forma b. Rulfs).

- f. major "Wills" ibid., f. 6.

- f. excelsior "Wallich (Tumer MS.)" ibid., f. 7 [M. Ma li a b.?.].

- - f. Mahabuleshwarensis ibil., f. 8 (Mier. Mal. Mobson 1863).

— f. Wallichii ibid., f. 9. (M. Wallichii (rmen.).

f. Wallichii f. suecica "(Turner Ms)" ibid. f. 10.

- f. Hermanniana ibid., f. 11 (Micr. Herm.).

- f.? fijiensis "Nacdonald "ibid., f. 12 [M. Wallichii f. Tum. 18937

- f. ampollacea ibid., f. 13 [M. a m pull.].

o - f. ampullacea $\beta$ Spencer ibid., f. 14.

o ss - Boldt Desm. Grönl. p. 5 (sej.j). 2) t. 1 f. 1 (f. monstr.) [b. Boldtii Gulw. 18:0; sec. Lagerh. in N. Notaris. 1893 p. $18+$ non ita].

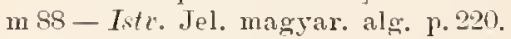

- v. orbicularis ibid. p. 221 et t. 1 f. 3 [fortasse monstros. MI. denticalatae],

m S8 - Racib. Mat. flor. glon. I'olsk. p. 110 (sep.1. 31).

d 89 - Toni Syll. alg. p. 1131.

d - v. recta ibid.

d - v. spinosa ibid. p. 1135.

d - v. orbicularis ibid.

o 89 -v. typica Racib. Now. Desm. p. 106 (Ralfs 1818 fig. 1 c.).

d - v. Wollei ibid. t. 7 f. 3 (an Ralfs 1 cits fig. 1 d?).

89-v. recta West Fr. Alg. North Yorksh. t. 291 f. 13.

d $(10-v$. Lewisiana West Fr. w. Alg. North Wales p. 286 t. 5 f. 13 .

m 90-Euchler Spis Desm. Miedz. p.89.

n $10-$ h. Boldtii Gutw. Wahr. d. Prioritat p. 73 (Boldt 1888 .

n 91 HELIERELLA Tuntze Rev. gen, pl. p. 89.

m 91 Micr. a. typica Gutw. Flor. alg. Leopol. p. 74 t. 3 f. 2 i

$m$ - b. Boldtii ibil., t. 3 f. 27 [Cfr Lager\%. in N. Notaris. $1893 \%$ 181].

d 92 - Wolle Desm. U. S ed. II p. 121 t. 36 f. 2.

- v. recta ibid, f. 3 .

o - v. IIermanniana ibid. f. 万̃.

o $93-\mathrm{f}$. incisa Turner Alg. Ind. orient. p. 96 (v. Hermanniana Wolle 185t, non M. Herm. lieinsch). - a (typica) iluicl. p.97.

d 9-1 - Sumd. in Fl. Nebraska 13.43 t.6 f. 1 [ex Wulle]. m 55 - v. orbicularis Eichler in Pamiet. Fizy. 13 p. 61.

55 - f. Sclmidle Beitr. alp. Alg. p. - t. 14 f.s.

\section{Amerianum - a}

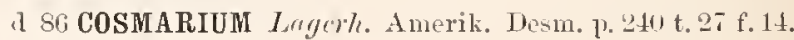


d si - Wolle Fr. Alg. U. S. A. p. 24 t. 60 f. 1516 [male e langerh.].

(1) 8. - Tomi s.tlo alg. p. 950.

n !l URSINELLA huntze Rev. gen. pl. p.!24.

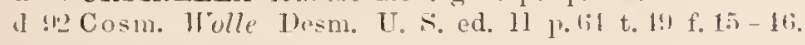

\section{ameriramum}

d 61 TETRACHASTRUM Areh. in Pritch. lıf. 1) T:2li Mier. incisa Brailey, non Kït:-) [Micr. Iaticeps $\beta$ f. minor Sordst.; M. disputata $1 H^{\circ}$ ood.].

\section{"monenum-"}

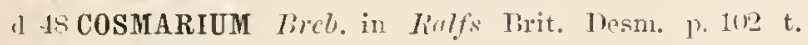
17 f. 3 .

41 522-I'ritch. Inf. 1. 254.

d 61 - . reh. in Pritch. Inf. p. 733.

1 $6: 3$ - Rals. Firypt. Fl. Sachs. p. 201.

o $6 \bar{t}$ - Tot. Mesm. Ital. p. 44 t. 4 f. 30.

d (sin-liub. Flor. Eur. Alg. 3 p. 15 !

n 70 -f. crassior Nevdst. Desm. Brasil. p. 20?.

o $71-$ Lmml. Desin. Suec. p. 16.

1) - f. ibid. [ $\beta$ Lindellii Roy 1s:!t].

d 73 - Ifoorl Fr. Alg. 1) 13!).

o ti-Jacols. Desm. Dinem. p. 19u.

d $78-$ Kirch. Alg. Schles. p. 152.

o $8.3-v$. tumidam Wohe in Bull. Torr. lot. ('luls v. 10 p. 17 t. 27 f. 16 .

8.3 Turuer Algae Strensall f 18.

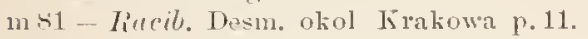

I $\$ 1$ - 11 ulle Desm. U. S. P. Ts t. 11 f.j-4).

1) - v. tumidum ibid., f. т.

o sij- Stolies Key Desm. p. 12?.

1) 97 - Cuolic Brit. Desm. p. 111 t. 40 f. 2 [e Riflfs].

m 87 - Murtel in Amn. Inst. bot. di Roma v. 3, I p.6.

d sis-Alerento Chlorosp. Kuhark. p. 2liti.

o 87 - $\beta$ mediolave Nordst. Algolog. sminals. 4 p. 160.

- $\quad$ " intumescens ibid.

m si-Kinbin. Chloropl. env. Kharkow p. 323.

In $x$ - Poldt Desm. Grönl. p. 29.

d so- $\beta$, mediolave Nordst. Fr. wat. alg. N. Zeal. 1, 50 t. 5 f. 12 . et p. 79 .

(l) - $y$ intumescens ibid. et t. 5 f. 13.

d s?-Toni Syll. alg. p. Mss.

d - r. mediolitve ibid. p.989.

d - r. intumescens ibid.

o - v. tumidum ibid.

m 10 - Jörg. Desm. Brasil. p. 3T.

m! - Anderss. Siverig. Chlor. 1 p. 14.

$\mathrm{m} ! 1$ - $B$ int umescens Heimerl. Desm. alp. 1?.5\%\%.

n 91 URSINELLA Kumtze Rer. gen. pl. p. !2.1.

$m$ gr Cosm. We.t Fr. w. Alg. W. Irel. p. 156.

m - v. mediolære ibid.

d 92 - Wulle Desm. U. S. ed. II p.85 t. 17 f. 5-6.

d - v. tumidum ibid. p. $86 ;$ f. 7.

in 93 -- Lüthemiäl. Desm. Attersees p.55s.

n !1 - $\beta$ Lundellii Fioy Seottislı Desm. 1. 42 if. major Luml. 1s:1).

m! 14 - Iste. Alat. Roman. alg. p. 155.

- 94 - v. annulatum Eichl. et Gutw. in Iirakal Anzeig. p. 2:3:.

d 9t-r. annulatum Eichl. et Gutu. in sipec, alis. nov. p. 163 t. 1 f. 5 .

In 1 - Alexevko Mater. alg. Kilark. p. 21.

\section{amormum}

d St EUASTRUM Gay Mon. loc. Conj. p. 53 t. 1 f. 7 ( lere E. binale $\beta$ Tialfs Br. Desm.) [E. denticulatum Gay Not.]. m 89 - Iiecib. Jat. flor. glon. Yolsk. p.113 (sep.p. 34).

\section{rmoenum}

1) fit; STAURASTRUM Wilse in 13er. d. schles. Ges. 1stin 1) 123. [Nt. Capitulum b. amoenam Ifab. 1sik].

II is - f. spetsbergensis Vordst. Desm. aret. p.3t st. Capitulum b. amoenum fo spetsbergensis Nordst. 1si:e).

1) 76 - $\beta$ italicum Nordst. Desn. Ital. p. 13 t. 13 f. 18.

1) - * acanthophormm ilid. 11. 13 t. 13 f. 1:.

1) $t 8-$ Kirchu. Alg. schles. 16. 165 .

o 7 - Winle Ferskv. alg. Nor. Nemlj. 1.54.

d Ris-f. Iircil. Yonn. Ilesm. Polon. p. St t. 1:2 f. 2 (sep-p. 31 t. 3).

a ș - $\beta$ tmmidiusculum Nordst. Algolog. smaisal. 1 p. 158. m 89 - f. spetsbergensis lioldt Desur. Ciroul. 13.3!.

d 88 - $\beta$ tumidiuseulun Nordst. Fr. wat. alg. N. Zal. l. 38 t. 1 f. 13.

d 84 - Tomi Syll. alg. p. 1161.

d - v. italicum ilid. p. 11:42.

d - subsp. acanthophorum ibid.

d - v. tumidiuseulum ibid.

d - f. spetsbergense ibid.

1 $20-\beta$ Brasiliense Bory. Desm. brasil. 1. 4.5 t. 1 f. 11 [St. pileolatum r. sec. Lütlitmilll. 1593].

m!10-Fichler spis Desm. Miedz. p.8\%.

o 91 - Heimerl Desm. alpin. p. tirki.

o 42 - v. brasiliense West Fr. w. W. Trel. p. 17 t. 23 f.9 [St. pileolatum sec. Lïthemïll. 1s!13].

m 93-subsp. acant lo ophorum Littiemill. Desn. Attersees p. 566 .

n $93-$ - (Cylindriastrum) Turner Alg. Ind. orient. 1. 133.

m at - f. spetsbergens is Borge Sitssw. Chlor. Arehang. I. $3 \bar{\gamma}$.

\section{amphidoxom.}

a 94 STAURASTRUM West New Brit. Alg. p. 10 t. 1 f. 17. 95 - v. alpinum Schmille Beitr. alp.alg. p. t. 16 f. 17.

\section{(a)mplum $-a$}

d si COSMARIUM Nordst. Algol. småsak. 1 p. 163.

d s9-Nordst. Fr. wat. alg. N. Zeal. 1. 133 t. 6 f. 20 ? C. margaritiferum Mask. $15 s 1$ f. 28 .

d - f. trigona ibid., t. 6 f. 21.

o 89 - Mask. Furth. Tote N. Z. Desm. p. 19 t. 3 f. 31 (forma).

d se PLEUROT无NIOPSIS (Cosmarilinm)? Toni Syll. alg. 1.912.

d - f. trigona ibid. p. !13.

\section{ampullaced}

d S1 MiCRASTERIAS Mask. N. Z. Desm. p. $30 t$ t. $11 \mathrm{f}$. (i-S Cfr. Arch. in Grevillea 10, 18\&1, p. 29. Micr. Mahabnleshwarensis $\beta(1 \mathrm{~m})$. Norkst. 1.8S8].

o $83-$ v. $\beta$ Spencer Fr. wat. Alg. N. Zeal. p. 296 t. 27 f. 6. [I. Wallichii f. Speneerii Tumer 1.4!3].

d. s. $\beta$ bengalica Lagerh. Bengal. Desm. p.5 t.1 f. 2.

\section{rmmitlacea}

d 11 TESSARARTHRA Morren Recherel, physiol. p.121 t. $7 \mathrm{~B}=$ I'lantula germinales 0edogonii? sec. A. Iirawn.

\section{(1) M) lluceum-a}

d 18 EUASTRUM Ralfs Brit. Desm. 1..83 t. 13 f. 1. (Eu. sine nomine II ass. Brit. Alg. 1815, t.90 f. 11)

d 52-Iritch. Inf. p. 219 .

d 61 - Areh. Pritch. Inf. p. $72 \%$.

d 63 - liab. Kirypt. Fl. Sachs. p. 185. 
1 68 - Rab. Flor, Eux, Alg. 3 p. 1 . 33.

d 73 - Delponte Desm. subalp. p. 104 (sep.p. 92) t. 6 f. 3 -.t.

d 73 - f. scrobiculata Nordst. Norg. Desm. p.8.

d 73 - Hood Fr. Alg. p. 138.

d 78 - Kirchm. Alg. Schles. p. 1is.

m 81 - Gray Monog. loc. Conjug. p. 5 f.

d 81 - Wolle lesm. U. S. p. $1(n)$ t. 28 f. $8-11$ (3 forma).

o s6-Stokes Key Desn. 1. 115.

d si-Cooke Brit. Desm. p. 68 t. 33 f. 3 [ex p. e Ralfs].

d si - Mtusg. Prodr. Algenfl. Bühm. 1. 205.

d 89-Toni Syll. alg. p. 1091.

a -f. scrobieulatum ibid. p. 109?.

n !1 HFLIERELLA Kuntze Rev, gen. pl. p.8\%.

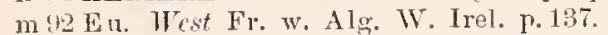

d 92 - Wulle Desm. U. S. ed. II p. 110 t. 32 f. $8-11$.

d $93-v$. incavatnm Tumer Alg. Ind. orient. p. 78 t. 10 f. 59.

z 93 - Roy Scottish Desm. p.175.

m94-Alexenko Mater. alg. Kihark. 1. 23. Cfr. Didym. varians.

\section{(1) intinum}

d S1 STAURASTRUM Cooke \& Wills in rooke in Grevillea 9 p. 92 et (1\&80) t. 139 f. 6 .

81 - Cooke in Quekett Mier. J. 0 t. 15 f. 12 et 13.

d 81 - Wills in Midland Tatural. 1 p. 74 t. 5 f. 3.

8:3 - ? Turne: Algre Strensall, f. 4.

84 - Wolle in Bull. Torr. bot. Club. t. 14 f. $1-2$.

d 81 - Wolle Desm. U. S. p. 139 t. 51 f. $1-2$.

o 86 - Stokes liey Desm. p. 164 .

d 87 - Cooke Brit. Desm. p. 170 t. 61 f. 2.

d 89 - Toni Syll. alg. p. 1221.

o 90 - West Fr. w. Alg. North Wales p. 280 t. 5 f. 12.

m 92 - West Fr. w. Alg. W. Irel. p. 185.

d - v. truncatum ibicl. t. 24 f. 2 .

d - v. biradiatum ibid, t. 24 f. 3.

d 92 - Wolle Desin. U. S. ed. II p. 152 t. 62 f. 1 -2.

\section{aneeps}

d 77 COSMARIUM Delponte Desmid. subalp. p. 82 (sep.p. 128) t. 9 f. $26-29$.

\section{anceps}

d 71 COSMaRIUM Lund. Desm. Suee. p. 45 t. 3 f. 1.

o 72 - Nordst. Desm. Spetsb. 1. 3i.

o 73-Nurdst. Norg. Desm. 1. 21; forma.

(12) $75-\mathrm{f}$. crispnla Nordst. Desm. aret. 1. 38 f. Nordst. 1873).

in 79 - Wille Ferskv. alg. Nov. Semlj. p. 39.

d 81 - Wolle Desin. U. S. p. 59 t. 18 f. 11.

m 85 - Doldt Sibir. Chloroph. p. 100.

o 813 - f. Richter in Wittr. et Nordst. Alg. exs. N:o 830; et in fase. 21 (1889) p. 43.

o 86 - Stokes Key Desm. 1. 126.

1 sili-Conke Brit. Desm. P. 82 t. 33 f. 5 [e Lundell].

d 88 Dysphinctium (Tetmemoridium) IIansg. I'rodr. Algenfl. Böhm. p. 187 et 278 .

1 $-\beta$ pnsillum ibid. (T. pusillum ibid. p. 1si f. 109). un 8f Cosm. Boldt Desm. Grönl. p. 12.

d 89 Dis. Toni syll. alg. p. 893.

d - v. pusillum ibid. 1. Sig4.

d $90 \mathrm{Cosm}$. v. minimnm Gutw. Fl, glon. Galic. p.9 t. 1 f.?. d 52 - Wolle Desm. U. S. ed. II p.63 t. 21 f. 11 .

m 93 - Liuthemüller Desm. Attersees p. 519.

m 9. Börg. F. alg. Ötgroonl. p. 18.

m 95- $\beta$ pusillum Eichler in Pamiet. Fizy. 13 p. 50?. Cfr Iysp. parvulum v, undulatum.

\section{INCYLONEMLA}

[d 71 "Alg froำ Grönlands inlandsis "Berggr. in Öfvers. Vet. Aliad. Fiorliandl. 18 it p. 293].

n 71 Pergyren apud Nordenstivild in Öfvers. Vet. Akad. Fürh. 1870 p. 1081 (et !y!?).

(1 S!) Toni syll. Alg. p. 817.

11 (4) Wille in Natiorl. Ptlanzenfam. 1.8.

ph 55 Lagerh. Plyecoporph. p. 4 etc.

\section{anglicanum}

o 93 EUASTRUM Tumer Desm. Notes p. 343, et f. 6 p. 34.

\section{"ungulare}

(1) COSMARIUM Johns. Rare Desm. U. S. p. $2: 10$ t. 211 f. 14 .

\section{"uylure}

1) 13 STARASTRUM Tumer Alg. Int. orient. p. 130 t. $1 \pm$ f. 17 .

\section{angulatum}

nzf 61 CLOSTERIUM IIantzsch in Rab. Al. Eur. n:o 1112 e. fig. a-d (sine deseriptione). [Cl. monilifernm B angulatum Reinsch 1867j.

\section{angulatum -a}

d 52 EUASTRUM Jerty kleinst. Lebensf. p. 2119 t. 16 f. 11. 5 fi-f. major Grun. Ins. Bank. p. 15 t. 2 f. 21.

a 68 COSMARIUM Rab. Flor. Em. Alg. 3 p. 167 .

d s.9 - Toni syll. alg. p. 1017.

n 11 URSINELIA Kumtze Rov. gen. pl. p.924.

o 93 Cosm. f. major Tumer Alg. Ind. orient. p. 56 t. 8 f. 35, t. 9 f. 25.

Cfr Cosm. Meneghinii Tordst. 1873.

\section{cugrulatum,}

d s9 STAURASTRUM Tiest Massachus. Desm. 1.20 (sep.p. 5) t. 3 f. 20 .

d 89 - v, subangulatum IVest Freskw.-alg. Maine p. 206 t. 291 (in Journ. Bot.) f. 16.

d 92 - Wolle Desm. U. S. ed. 2 p. 132 t. 43 f. 5 et 6 [ex WVest].

Cfr Stanr. granulatum v. Reinschii Ist:

\section{(ln!)ulosa-um}

d 34 MICRASTERIAS Ehrent. Organ. kil. Raun. p. 301 (sep.]. 157) = Pediastrum ang.

n 39 EUASTRUM cordu in Aln. d. Carlsb, 1829 p. $238=$ Pediastrum ang.

\section{angulosu- $2 u m$}

d 62 MICRASTERIAS Mrontzseh in Rab. Alg. n:0 1407, [non Elevenb.].

d rit- lieinsch in Rab. Alg. Eur. n:0 16.4.

d 67 -Reinseh Spee. Gen. A'lg. p. 121 t. 21 D f. 1 -1 (sep.p. 13 t. 2). Forma $A$ et $B$.

d 67 DIDYMIDIUM (Micrasterias) Ricinseh Algenfl. Frank. p. 147 t. 8 f. 2 , form. a et $b$.

o 71 II ic 1. Land. Desm. Suee. p. 11.

m 81 - Raeib. Desm. okol. Lraliowa 1) sep.p. 22.2.

m 85 - Norlst. Desm. Grönl. p. 10.

d si3-Cooke Brit. Dessn. p. $\left(i^{\circ 2}\right.$ t. 2!)

in 58 - Torelst. Fr. wat. alg. N. Zeal. p. 2y et 78.

1 8 - Tomi Syll. alg. p. 1133 .

11 91 HELIERELIA Kuntze Rev. gen. 11. p. 89.

ozf 93 II ier. Roy seottish Desm. p. 172 t. 1 18!1) f. 2 (sep.p. 11). 
('fi. Micr, derticulata Hood, Jenneri Rah, Lent. radiosa v. West $18 \mathrm{~s}$ ), rotata.

\section{"11!)}

a st COSMARIUM lircb. Liste p. 127 t. 1 f. 17 [Cosi. Meneghinii c. liab. Intisi.

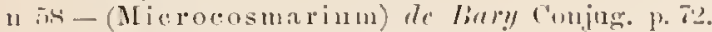

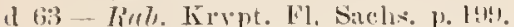

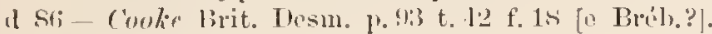

z.1 - Roy Seottish Desm. p.12.

\section{angmlosim!}

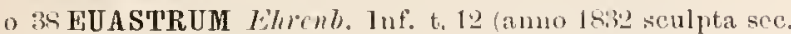
auct.) f. VIlt; p. 1 tis in Eu. Botrytiden transnutatum.

\section{nl1!mlosus:}

d ta PITHISCUS Krätz. P'hycol. germ. P. 129) [Cosuarium Cucumis sec. liatf: 14.4, an pyramidatum?].

d 49 -Kiitz, spee. Alg. 1). 162. Itlem.

\section{allgustatiml - a}

d 45 CLOSTERIUM kïtz. Phyeol. germ. p. 132 .

d 48 - Rulfs Brit. Desm, p. 172 t. 29 f. 1.

d $49-k$ - hïtz. spec. Alg. p. $14 k$ i.

d 52 - T'ritch. Inf. p. 282 .

d fil-Arch. in Pritch. Inf. p. 719.

d 63 - Lab. Krypt. Fl. Sachs. p. 173.

o 63 - Cramer in Rab. Alg. Eur. n:0 14.5.

d 67 - lieinsch Algenfl. Frauk. p. 195, Form. A et Li p. 196.

o $(\mathrm{i}$ - Vot. Desm. Ital. p. $66 \mathrm{t}$ t. 8 f. 72.

d 68 - Rub. Flor. Eur. Alg. 3 p. 126.

d 73 - Wood Fr. Alg. p. 110.

d $75-$ Microgr. Dict. p. 176 .

mis-Hempel Algenfl, Chemnitz. p. 112.

o 53 - v. reticulatum Wolle in Bull. Torr. bot. Club. v. $10 \mathrm{pr} .15$.

d 81 - Wolle Desm. U. S. p. 4t) t. 6 f. 21.

- - v. decussatum ibid. in nota tab: VI (cfr p. 40), t. 6 f. 22 et 23 [v. reticulatum supra].

ph 85 - Kilebs Bewegung n. Scheimbild. d. Desm. p. 365.

m 86-Lagerh. Amerik. Desm. p. 254.

o 8i-Stules Kiey Desm. 1. 112.

d 86 - Cooke Brit. Desm. 1. 30 t. 11 f. 3.

d 88 - Ilansq. Prodr. Algenfl. Böhm. p. 178

m S8 - Istr. Jel. magyar. alg. p. 238.

o $8: 1$ - Mörg. Bidr. Bornh. Desm. p. 142 t. 6 f. 1.

d 89 -Toni syll. alg. p. 821 .

d - v. reticulatum ibid.

m 90 - Fichler Spis Desm. Miedz. p. 85 t. 8 f. 10.

o 91 - Heimerl Desm. alpin. p. 592.

m 91 - Gutw. Flor. alg. Leopold. p. 32.

n 91 ARTHR0DIA Kuntze Rev. gen. plant. 1.8.93.

nu 9 Clost. Wrest Fr. W. Alg. W. Irel. p. 121

d 92 - v. clavatum Ilast. in Amer. montlıl. micr. J. $13 \mathrm{p}$. 1ว.) $\mathrm{t}, 1$ f. $\mathrm{T}$.

f 1 . - Wolle Desm. U. S. ed. I1 p. 11 t. 7 f. 21 - 23.

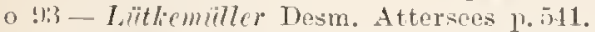

13 - sehmidle Beitr. Alg. Schwarzwald. p. s! t. 3 f. 1:.

o - v. subrecta ibil.: t. 3 f. 13 (Cfr 11 oll 1881 t. 5 f. 21) $[\mathrm{Cfr}$ Cl. speciosum Twmer].

o $! 3$ - 7urner Alg. Ind. orient. p. 20.

m 13 - v. clavatum Johns. Rare Desm. U. S. I1 p. 291 t. 23: f. 6

m $95-v$ - subrectum Lichler in Paniet. 1izy. 13 p. 58.

\section{allgustatumlil -re}

n Tis COSMARIUM Nordst. Desm. aret. p. 20 (Fu, binale $\beta$ ang. Wittr. 1872; Eu. polare Nordst. 1s72)

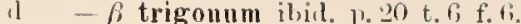

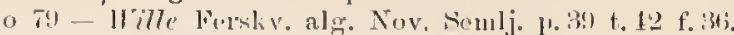
o sl - Gay Mon. loe. Conj. p. 5.

III st - Wrille syliumerik, Algft. p. 14.

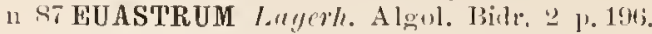

m sis cosin. Dotelt posm. Grönl. 1'. 12.

in f. ibil.. t. 1 f. 1 !s.

I s! Tomi syll. alg. T. 1011.

d - v. trimonum ibisl.

(1) 8! - Tincib. Now. Jesm. p. 85.

m!1 - Heimerl Desm, alpin, 1) 5!!?.

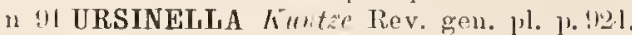

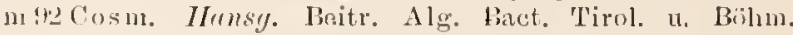
p. 133.

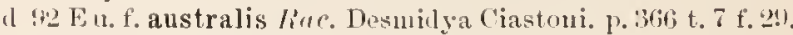
11193(:osm. Lithemiall. Desm. Attersees posin.

n 9.t - Borge Niissw. Clılor. A reliang. p.31.

o 91 - Stockm. Nachtr. syst. Aufz. Öter. Krypt. 1.12.

m 6.5 Eu. Fichler in l'aniet. Fizy. 13 p.til. Cfr Cosm. Meneghini, Eu. Pokornyanum.

\section{"llgustum -n}

dzf ti1 CLOSTERIUM Thutzseh in Rab. Alw. n:o 1:206 fig. a-d. [Clost. acerosum c. lieinsch 1stiz].

d\% 68 - Rab. Flor. Enr. Alg. 3 p. 132

d 70-Torscow in Selurift. Kiew. Naturf. Ges, 1, 1 p. 52. dz 89-Toni Syll. Alg. p.819.

m in - F rutw. Fl. glon. Galic. 2 p. 8.

n 11 ARTHRODIA huntze Rev. gen. plant. p. 883.

\section{misorhomallmm -}

d 7 COSMARIUM Nordst. Alg. Sandvic. p, 12 t. 2 f. 7 .

m 80 - Hitle Norg. Ferskv. alg. p.27.

d 81 - Wolle Desm. U. S. p. 72 t. 16 f. $43--45$.

o 86 - Stokes liey Desm. p. 128.

d 8i - Toni ryll. alg. p. 102?.

11 Q1 URSINELLA Kuntae Rev. gen. pl, p.y24.

4 92 Cosm. Wolle Desm. U. S. ed. II p. 78 t. 19 f. $43-4$.

\section{amlinmoides}

d 81 STAURASTRUM Wolle in Bull. Torr. bot. Club. 1881. p. 14 t. 41 f. 1; v, hex rcerum f. 3 .

d si ... Wolle Desin. U. S. p. 137 t. 51 f. $t$; r. hexacerum f. 3

o sf - Stokes Key Desm. 1) 16.)- 6.

(1) 89-Toni Syll. alg. p. 1226. ("ancyroides").

d 5 - Wolle Desm. U. s. ed. I1 p.150 t.62 f. 3 et 1.

\section{"1Imulnre}

(1) 11 PENIUM West Freshw. alg. Maine I1 p. 35.1 t. $315 \mathrm{f}$. $5-6$.

v. obesum ilvid., f. 7 .

o 15 - Johms. Rare Desm. U. S. II p. 290 t. 239 f. 1.

\section{allmmlatum- -11.8}

d 1! DYSPHINCTIUM (Calocylindrus) Nag. ein\%. Alg. p. 110 t. $6 . \mathrm{F}$.

n 58? COSMARIUM De liary Conjug. p. 46. 72.

d (i) PENIUM Areh, in Pritch. Inf, ]). 51

m 67 Dis. Teimeh. Algenfl. Frank. p. 181.

d lis L'en. kiub. F'. Eur. Alg. 3 p. 122.

แแ 70 - Nordst. Desm. Brasil. p. 2 (r).

o Tl Cosm. Lund. Desm. Snec. p. Hi.

(f $73-\beta$ elegans Nordst. Norg. Desm. p 23.

(15-(Pleurotinniopsis?) Nordst. Desm. aret. p.30.

m 7i-(Pleurotaniopsis) $\beta$ elegans Nordst. Desm. Ital. p. 42.

o is- Nordst. Alg. sandv. p. 11.

d 78 CALOCYLINDRUS Firch. Alg. Scliles. p. 143 
m Ti) Cosm. Wille Fersliv. als. Nov. Semlj. p. 19.

d - $\beta$ bicrenulatum ibiu., t, 13 f. 11.

ns sit CaI. Rucib. okol. Lirakowa p. 5.

m 85 Cosm. Liuld sihir. C'hloroph. p. 10R.

in 8is Cal. Arteri Matar. Alg. Moscou p. 170 (sep.p.si.

d 87 -Couke Brit. Desm. p. 122 t 43 f. 15 [e Nag.].

11188 - Ist\%. Jel. magyar. alg. 1. 2329.

d ss D frsp. Jlarsg. Prodr. Algentl. Böhm. p. 1s6,

m sh Cosm. Doldt Desun. Gröul, p. 29.

d $88-\beta$ elegaus f, Nordst. Fr. wat. ald. N. Zeal. 1. 52 t. 5 f. 19 .

d 81 Disp. Tomi syll. alg. p. SA.

d-v. eIogans ibid. p. kss.

d - v, I)icrenuIatum ibis.

m no Cosm. Lïrg. Desm. Brasil. p. 12.

m 40 - Eichler spis Derm. Miedz. p. 86.

m! Dysp. Hrim. Desm. alp. P. Iit.

m ? $\mathrm{Cosm}$. West $\mathrm{Fr}^{\circ}$ w. Alg. W. lrel. p. 157.

m S - v. elegaus West Alg. EngI. Lake listr. p. Ter.

n! Pen. Lintliemin̈. Dosm. Attersees p.511.

m 91 Cosm. II st New Brit. Alg. 1) 7 t. 2 f. 1.2.

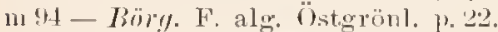

m $94 \mathrm{Cal}$. llexenlio Mat. Alg. Kilıark. p. 27.

Cf

\section{(1). 11$)$ tritum) -}

daf 77 COSMARIUM Jolpomte Domill. subal p. p. 18 (sep.l. 114) t. 8 f. $1.1-19$, non alior.

a s:1-Tumi rivll. alo. p. 1016.

1) "1 URSINELLA himtze Rev, gen, pl. 1?!21.

\section{reimulatum}

d sf D0CIDIUM Jush. Burm. Desin. p. 65i t. 2.5 f. 13.

d s9-Toni syll. Alg. 13.875.

\section{(l)mulatiur}

d 93EUASTRUM Twmer Alg. Ind. orient. p. 80 t. 10 f. 39 . 52. [Eu. elegans $v$. monodentatum f. anuulatum Hillilem. 1894].

\section{(1)оmaln}

d 93 MICRASTERIAS Schizoeystis Tumr Ald. Ind. orient p. 96 t. 22 f. 1 a ot $l$ ? M. apiculata f. Joshus Tomi et Le? 18kii).

o - v. irregularis ibid.; f. 1 e.

\section{rllomralum.}

d. 7 cosMARIUM Whomte Desm, subalp. p. 29! (sep.p. 12i) t. f. 10 1.. (C. biretum Breb., C. conspersum Rirlfs et latum Liréb.).

m. 48 - Lenein Span. Sïss.-wass. Alg. p. 8.

\section{(1)0M(1)lu) -}

d 8.1 EUASTRUM Culy Mon. loc. Conj. 1, 55 t. 1 f. 10 ; et Note Conj. 1. un. France p.335.

d $89-$ ? Tomi syll. alg. 1). $117 \pi$.

1191 HELIERELLA Kumťe Rev. gen, pl. 1) sos.

\section{(1).}

d GS COSMARIUM Rub. Flor. Eur, Alg. 3 p. $17 t$ (Euastrum ansatum Ehrent. et Killz.. 1101 lirlfs sec. anct. ipsum; Cosm. lagenarium) [Cfr Eu, ausatum infra! species milui dubial.

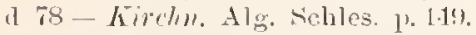

a 81 - Walle Desm. U. S. p. 64 t. 16 f. 22 (non bona)

o si- Stokes Key Desm. 1) 127.

n 87 CALOCYLINDRUS bect; in Verh. zool, bot. Ges. Wien 1. 278. d ss Cosm. Ilumsty. Prodr. Algenfl. Böhm. p. 197.

o si - ? Tomi et Leri Fl. AIg. Venez. p. 51.

o.98 - Isto. Jel. manyar. alg. p. 205.

d s.t-Tumi Syll. aIg. 1.918.

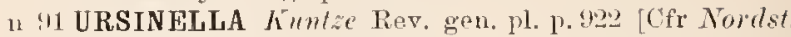
in Hedwigia 18113 p. 1501 .

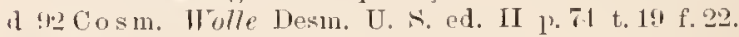

\section{(11).s(1) 111$)-\| 1$}

d 32 EUASTRUM Elmmb. Eutw. d. Inf. p. 82. [Descriptio nimis brevis].

a 38 - Ehrenb. Inf. 1. 162 t. 12 f. VI $1-1$ sinclus. Heterocarp. didelta TwP.?, H, polymorpha Kïtz. ex P., Cosm. lagenarium (orlo). [Mixtum compositum. Fin. 3 est Cosm. psendopyramidatum fo majol, nt mili videtur, f. 1 Cosm. trilobulatum ?? vel spec.? - Si cellula non recte delineate, sod revera apiee incise sunt, fortasse figg. 1 et : Eu. ansatum sensu Fuchei, Rulfsii et ancet. recent. representant; si non ita. Cosmarinm, nt Rabenhorst. putat.].

m 39 - Ehrenb. Meteorp. p. 56 t. 1 f. 17 [Cosm.?].

11 3i) COSMARIUM Corla in Alm. d. Carlsb. 1839 p. 2.13 (Ehronl. 1. c. fig. 1, 2, I non 3).

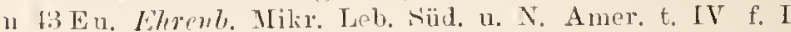
is [Cosm. pisendopyranidatum. - Cosm. integerrimum $h \ddot{i} t z$.].

1 17 - Rub. Dent. Krypt. F1. P, 5.t.

(1) $4 \pi$ - Focle Phys. Sturt. I p. 43 et 6il t. 1 f. 8. [Eu. Ralfsii]. 1) 18 - Rulf. Brit. Desm. p. 85 t. 11 f. 2. [Eu. Ra Ifsi i Rul.].

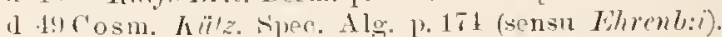

(1 4! Eu. Neg. einz. Alg. p. 122 t. 7 1) f. 3.

1 folcosm. Mrriss. Catalog. esl. omis. p. 31 t. 1 f. 8 [e Кй̈z. Syn. diat.].

1 $52 \mathrm{Eu}$. Priteh. Inf. p. 250.

in 52 - I'rty Kleinst, Lehensf. p. 208 (sensu Likrenb.).

d 53 - Math. Fl. Belg. II p. 527.

51 - Ehremb. Nierogeol. t. 31 f. XII B (e Neteorpap.).

d 131 - Arch, in Pritch. Inf. 1. 723!.

1 1 i3 Iint. Firypt. Nit. Saehs, 1. 186.

o 137 - Wut Jesm. Ital. 1. 85 t. 3 f. 11.

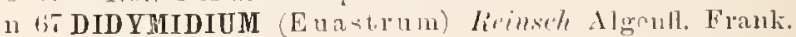
P. 130 .

- - f. A ibid.

f. $B$ ibid.

o 71 Eu. Tuml. Desm. Suec. 1. 20); forma [Eu. circulare Huss.).

a 78 - Jelponte Desm. subalp. p. 101 (sep.p. 89) t.6 f. 31.

d - a sublobatum ibic. p. $10: 3$ t. 6 f. $35-36$.

l $-\beta$ pyxidatum ibicl. p. $10: 5$ t. 6 f. $32-3-t$.

o 73 - Norlst. Norg. Desm. p. ?.

lz $-\mathrm{f}$. scrobicnlata ibid.

m 78 - Nordst. Alg. sandvic. p. 14.

d $88-$ Kirchm. Alg. sichles. p. 158.

d 83 - r. valleculatum Schantschm. Magyar. Desnı. 1. 263 t. 1 f. 1.

m 81 - Artari Liste al Moscou p. 1t2.

d 3 Eu. Wolle Desm. U. S. p, 99 t. 25 f. $8-10$ t. 24 f. $11-12$.

d 85 - Kivhln. Mikr. l'flanz. A. Süssw. 1'2-1.

u Sti-f. Lagerh. Desm. Amerik, p. 283.

- Stulices Kiey Desin. p. 115.

d sij-Coolie Brit. Dosm. 1). 70 t. 33 f. 5 [partime Rulfsistis].

o 87 - $\beta$ suprapositum Vordst. Algolog. Hurisak. 1 1. 156.

d $s \bar{t}$ - Alexemko Chlorosp. Kìlıark. P. 213 .

d 88 - IItms/. Prodl. Algenf. Bühn, p. 24k\%

o 88 - Nordist. Bornlı. Desm. 1.191.

m.88 - Iste. JeI. nagyar, alg 1.222.

m s - Norlst. Fr, wat, alg. N. Zeal. 1. 33. 
d -f.supraposita ibid. t. 3 f. 1.

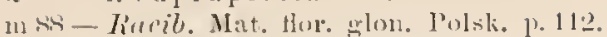

1 s:i - Toni siyll. alg. 1. 10!11.

d-v. suprapositum ibil. p. lls:t.

1) - v. sublobatum ibil.

d - - veriegatum ibil.

d - re ralleculatum ibid.

m !n - Gutu. l'l. glon. Galic, 2 p. th.

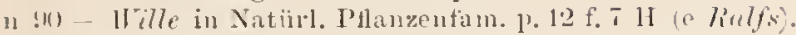

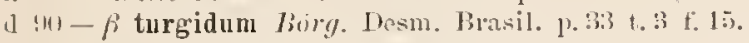

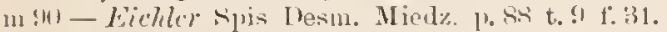

m (3) - Auterse. Sverig Clilor. 1 p. 10.

1 !1 - Kirch. Mikr. Mtlanz. I. Niissw. ed. 2 p. 225.

m!1 - Heimcr Desum. nlpin. p.1001.

n !) HELIERELLA huntze Rev. gren. 11. p. sos.

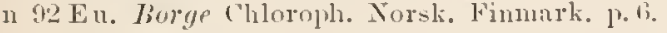

I $92-\beta$ omarginatum $/ / \mathrm{rusg}$. Beitr. Alg. Bact. Tirol u.

Bühn. 1) 131. [Cfr lsorge in Nuor. Notar. 1s!: 1. 3311$]$.

d $92-\beta$ enarginatum IIonsg. Prodr. Algrenfl. Böhm. el. bohen. II P. 175 ; ed. ererm. II 1.25i:

m 92 - West $\mathrm{Fr}_{1}$. w. Alg. W. Irel. p. 138 .

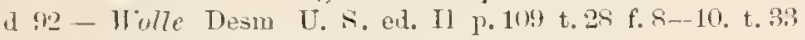
f. $11-12$.

m $12-G u t w$. Flor. glon. Galic. 3 p. 133.

o $4: 3$ - Tiuthemiill. Desm. Attersees p. 5rit).

o - v. sublobatum ibid.

d (z) 93 - (Colpodastrum) y supposita Turner Alg. Ind. orient. p. 7 .

z $9: 3$ - Jioy Scottish Desm. p.175 (sep.p. 14).

m! - Iste. Adat. Roman. Alg. p. 151.

d ! - f. Pory. F. alg. Üstgrönl. p. 30) t. 2 f. 32.

1 94 -v. triocellatam Eichl. et Gutw. Spec. alg. not. p. 172 t. 5 f. 313 .

d 95 - f. intermodia Sclmille in Hedwig. 34 p. 80 t. 1 f. 1 s.

m5 - v. pyxidatum Eichler in Pamiet. Fizy. 13 p.61.

(15)-f. Schmidle Beitr. alp. Alg. p. t. 27 f. 10 ,

- f. scrobieulata ibid. f. 11.

Cfr. Cosm. ansatum Rab., fenestratum; Eu. binale Kït $z$, cuneatum $\beta$ subansatum, Didelta $\beta$ 1sio; Ilass. Brit. Alg. t.90 f.6? (sine nomine).

\section{antroptirem}

n 5.t CLOSTERIUM Ehenb. Mierogeol, p. 260 et 262 [et sub nomine $\mathrm{Cl}$. austıalis t. 35 A f. II. 4 ?].

\section{artareticum}

n 5.l EUASTRUA Ehrenb. Mierngeol. p. 260 et 262 t. 35 A. II f. S.

\section{antiacerosum}

d 6 T CLOSTERIUM Not. Desin. Ttal. p. 61 t. 6 f. 63. [Cl. Baillyanum sec. Nortst. Bornll. Desm. 1. 1saj.

m 73 - Norrlst. Norw. Desm. p. 41. Cf ${ }^{\circ}$ Clost. Libellula et didymotocum

\section{(lntiloperum -}

n 3:) HETEROCARPELLA liréb. in Chev. Mier. p. 272.

d 41) COSMARIUM Jirib. aput Ueneyl. Sym. Desm, p. 218 (se 1.$]$. 18) [X. cristatum $f ;$ uncinatum].

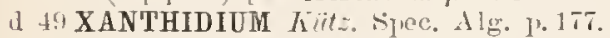

o 5 fi-liril I List. p. 131.

(1) $1 ; 3$ - liab. Krypt. F1. Sachs. p. 1!n;.

mz 71 - (110lacanthum) Lund. Desm. Suec. p. 75.

d $-\beta$ triquetrum ibid. 1 . 7 to t. 5 f. 6. [r. fasciculuides t. Leithem. 15:13!.
11 73 - y dimazum Norrlst. Norg. Desm. p. 38 t. 1 f. 19.

d of polymazum ilsil. 1. Bs f. 20 .

d 7 - $p$ triquetrum f' brasiliensis Nordst. Algr. brasil. 1.2. $25,1.26$ fig. xylogr. 4.

1 - f. ibill. 1.20 fig. xyl. 5.

(l - f. ilid. 1). 27 f. $x y$ l. (i.

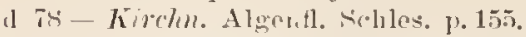

(1 st) - f. javanica Nordst. De Alg. et Charac. 1 1. 12 t. 1 t'. 21 [X. hastiferum Turu. 1shos].

S1-C'oolie in Qnelett Micr. .J. 6 t. 13 f. B.

d s.t -.. Minneapoliense Wolle' in Bull. 'T'or'r. Bot Club. 1). If.

d $84-\beta$ hirsutmm Guy Mon. loc. Conj. P. TT; et Note ('onj. 4. m. France p. 310.

d S.1 - Wolle Desm U. ... p. 94 t. 23 f. 1-2.

l - v. polymazum iliul. f. $3-1$.

d\%f - v. triquetı.11m ibid., t. 22 f. $1-3$.

d $-r$. Minneapoliense ibiu. t. 52 f. 16.

o Sij-r. candeuse Josh. in Journ. Bot. v. 23 p. 34 t. 254 f. $\therefore$.

11 85 - Boldt Nibir. Chloroph. p. 110 t. 5 f. 18. [r. fascicu loides Lith icm. 18:13].

d $S 6$ - f. angulatum Josh. Burm. Desm. 13.613 t. 24 f. 16 [X. losstiferum Tum. 18xio].

m 86 - f. javanica Lagerh. Amerik. Desm. p. 246.

o si-Stulies key Desm. r.130.

o - v. polymazum ibid.

o - v. Itinneapnliense ibia.

I 87 -Cooke Brit. Desm. 1) 132 t. 46 f. 2 [a. e Rinlfs; 2 b = r. fasciculoides Lï̈liem. 1893].

d $8 \bar{\tau}$ - $\beta$ tropicum Lagert. Algal. Bidr. "2 p. 198, cum icone.

dzse - Hunsy. Prodr. Algenfl. Bühm. p. 192.

o sil - d polymazum Tivrg. Bidr. Boruh. Desm. 1) 149.

dz 89 - Toni syll. alg. p.920.

d - v.tropicum ibid.

d $-v$ canadense ibid.

- v. hirsutum ibid.

- f. javanieum ibid.

- v. triquetrum ibid. p. !ri. f. brasiliense ibid.

- v. dimazum ibid.

- v. polymazum ibid.

- v. minneapoliense ibid.

m 89 - $\beta$ triquetrum f. minor Racil. Now. Desm. p. 107. m 90 - West Fr.w. Alg. North Wales p. 291.

in $90-$ Lichler Spis Desm. Miedz. p. 88.

m sio - Anderss. Sverig. Chlor. 1. p. 13.

- v. ornatum ibid. et t. 1 f. 6.

n! !1 - Heimerl Desm. alp. 1. $5 ! 5$.

n p.s.

d (12-f. Wrest Fr. w. Alg. W. Irel. p. 165 t. 22 f. 2.

d 92 - Wolle Desm. U. S. ed. II p. 101 t. 26 f. 1 et 2.

- volymazum ibil., f. $3-4$.

dzf - v. triquetrum ilid, t. 25 f. $1-3$.

d - $r$. Minneapoliense ibil., t. $43 \mathrm{f} .16$.

d - v. truncatum ibid. t. 12 f. 3 - 5 [ex Westii x. Tyloriano] [X. truncat num Mlest. 1stiz)].

1) - v. Canadense ibid. p. 102 t. 43 f. $2-3$ [e Josh. $1855]$.

o (1:3)- Züthemüll. Desin. Attersees p. itt.

d v. fasciculoides ibid. (X. fasciculatum 1848 t. 8 f. 1 b., etc)

d - - f. triquetrum ibid. (Lumal. 187i).

I $\quad$ - $-\mathrm{f}$. inevolutum ibia. 13.518.

d 93 - v. basiornata Eichl. et Fifrc. Nowe gat. zielen I\% 125 t. 3 f. 31. 
4) 98 - v. læve ["leve"] Sehmidle Beitr. Alg. Schwarzwald. p. 94 t. 4 f. 7 .

o $93-v$ p polyıazun f. major Thrner Alg. Ind, orient. p. 100 t. 13 f. 1.

1] - f. depressa ibid., t, 12 f. 24 .

m 93 - $\beta$ trijuetrum Eichler Mat. flor. Miedz. p. 1tit t. 10 f. 3.5.

oz 93 - Roy Seottish Desm. 1.24! (et 1,it4, (sep.]. 26) t. 3 f. 13; formie.

d a.t voligacauthum Schmille in Flora 78 p. 5o t. 7 f. 10. d] $44-\mathrm{v}$ l we f. irregularis II est New Brit. Alg. p. 8 t. 2 f. 4.4 .

1 9.1 - v. Minueapoliense f. Johns. Rare Iesun. TT. S. p. $2 \rightarrow$ t. 211 t: 1 .

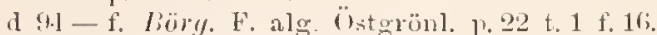

d - f, ilid., t. 1 f. 17.

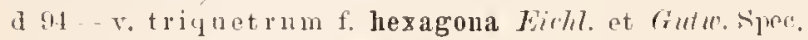
alg. nov. p. $18: 3$ t. 4 f. 4.

095- v. Sclmmidlei Borge in Nunv. Notar. 4 ]. 25 (I fasciculatum $v$, ornatum simille 1s(3).

o 9.5 f. favanieum .lolins. Rare Desin. U. S. II l, 995 t. 239 f. 10 .

0.95-- Schmidle Beitr. alp. Alg. p. 349.

Gir. Xintl, acnleatum, fasciculatum, spinulosum; Xanth. Thomas Climago wat. Suppl. fo 26;

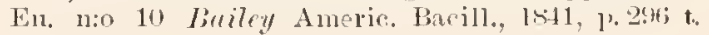
$3+10$

\section{apertum}

d 93 COSMARIUM Turner Alg. Ind, orient. p. 54 †. 8 f. 11.

\section{aphanichoud.rum - -}

d if COSMARIUM Nordst. Desm. Ita]. 1. 36 t. 12 f. 12.

d 89-Tomi syll. alg. p.967.

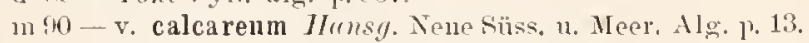
n !1 URSINELLA huntze Rev. gen, pl. p. Met.

m!l Cosm. Gute. Flor, alg. Lenpol, p.

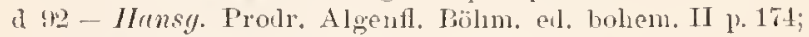
ed. germ. 1. 25t.

d - - c calcareum ibid. p. 175 ; ibid. p. 25.

m 82 - Gutw. Flor. glon. Galie. 3 p. 127.

m (4. Gutev. Fl. alg. Tamajol. 1), š.

\section{(l) irmlata- - 1 m}

d 31 EUASTRUM Ehrenb. Organ. kl. Raum p. 245 (sep.p. 101).

d 38 - Nhrenb. Infus, p. 161 t. 12 f. II

d to MICRASTERIAS Menegh. synops. Desm. p. 216 isep.p. 16) [M. fimbr. v. apiculata Tiolle 1,81].

41 - Desmaz. Pl. cryptog. France fasce, 23 11:0 1100 e. icone, ed. 2 fasc. 11 11:0 50.

d 45 Eu. Kïtz. Pliyeol. germ. p. 131.

d 47 - Rub. Deut. Krypt. Fl. p. 53.

o 47 - Foelie Phys. Stur]. 1 p. 50 et. 6.1 t. 1 f. 16 [M. fimbriata].

d 45 Micr. Ralfs Trit. Desm. p. 209

d $49-K$ - kitz. Spee. Alg. p. $17 \%$.

n 49 En. (Micrasterias) Nug. einz. Alg. 1. 123.

d $50 \mathrm{Micr}$. Murissul Catal. esp. onnis. 13.333.

d $52 \mathrm{Micr}$. Jritch. Inf, p.24t.

d 5:3-Muth. Fl. Delg. II p,506.

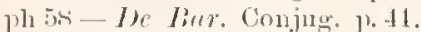

d 61 - Arch. in Pritch, Inf. p. 727.

d 63 - Rub. Iírypt. Flor. Sachs, p 620 .

o 6.1 - reere Bidr. t. Siverg. Desm. 1) 14is (ircl. MI. fimbriata r. oriata).

67 DIDYMIDIUM (M i crasterias) Reinseh Algent. Frank. ]. 145 . d 6.s Micr. Rulb. FInr. Fur. Alg. 3 p. 193.

daf 73 - Delponte Desm. subalp. p, so (sep.p. 76) t. 5 f. 1-5 [f. $1,3,4-\beta$ II alis (liue.) Nordst. 1siss].

o 6 - Juculs. Desm. Danem. p. 1 s's.

1] To-Kirchn. Alg. Ficlles, p 163.

mst-liucil. Desin. oliol. Krakowa p. sep.p. 22.

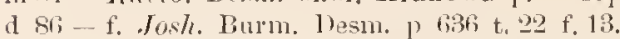

1) si - f. Joshna Toni et Leri in Notarisia p.91 (f. Josh. 18s6) [M. anomala Thm. 1898?].

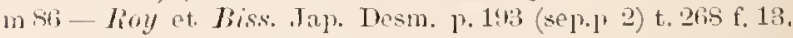

o sfi - Stokrs liey Desm, 1. 147.

d 57 - $\|$ ofl, Fr. Alg. U. S. A. 1. 39 t. 56 f. 3.

1] 87 - Coolir Brit. Desm, ]. 1 sif t. 48 f. 1 a. $b$ (Twm. del.); r: [e lmo. 1, s.83].

o 88 - Norilst. Bornl. Desm. p. 18 .

- $\beta$ Halis ibid. p. 1Rs et 190 (M. IIalis liae. 1845 et M. apicul, Delp. 1883 ex p.).

- fimbriata ibiul., t.6 f. 1 et 2. [inclus. f. nuda, elephanta,? simplex et apiculata 1 olle

- Pornata Nordst ibid. 1. 189 et 150 (M. fimlir. $\beta$ ortiata Buluh. 1859?

- - y brachyptera Norlst. ibid. (M. br. Lumul. 1s71). f. glabriuscula ibid, T. $189-190$ t. is f. 3 .

d s.) - Tom, sill. alg. 1. 113\%.

- f. Jush uar ibirl.

m!n-Eichler Spis Desm. Miedz. ]. 8n.

m 91 - Heimerl Desm, alpin. 1. 602.

1) "1 HELIERELLA Tuntze Rev, gen, pl, p sax.

d (r) Micr. Wulle Desm. U. s. ed. II p. 124 t. 45 f. 3.

d $4:$ - r. lacerata Turner Alg. Ind, orient. p. 44 t. 22 f. 3.

\section{"lpirulatum.}

dz ig STAURASTRUM Breb. Liste p. 1.12 t. 1 f. 23 . [st. do. jectum $\beta$ apieulatum Junel. 1S71].

d bi -..Areh. in Pritch. Inf. p. 783.

o 6 S - Arch. in Q. T. M. Sic. 8 p. 67 .

dzsi-Cooke Brit. Desm. p. 139 t. Lit f. 2.

m it.1-Horye süissw. Chlor. A lohang. p, 37.

\section{apirulatum}

n ist XANTHIDIUM Ehrenb. Microgeol. p. 321.

\section{apirulatus}

d sf ARTHRODESMUS Josh. Burm. Desm. p. f. 11 t. 24 f. 15. d 89 - Toni syll. alg. p. 1060.

\section{apiruliferum,}

d : 13 STAURASTRUM Turner Alg. [nd. orient. p. 127 to $16 \mathrm{ft} .7$.

m - f. minor ibid.

\section{alienlifermm}

d 92 XANTHIDIUM West Fr. w. Alg. W. lrel. p. $167 \mathrm{t}$. $24 \mathrm{t} .17$.

\section{(ep)irulosum,}

d as DESMIDIUM Ehrenb. Tuf. p. 142. [St. muricatum sce. Monegh. et Rulfs].

11 - Iritch. Inf. p. 14s [sec. Ralfs].

n 1:3-Ehenl. Mikr. Leb. Sïd. 1. $N$. Amer. t. IV I f. 20 [Pliycastrum hispidum sec. Külz.].

d t5 PHYCASTRUM Kütz̃. I'hyeol. germ. ]) 1:37 [Plycast. hispidnu see. Kütz.].

d tiDesm Relb. Deut. Kiryt. Fl. 1, 5i.

A 4:9 Plycastrum Küzz. Spec, Alg. p. 182 [Staur. hirsutinm]

11 49-(Ambly actinium) Nóry. einz, Alg. p. 125. 


\section{APIOHESHLS}

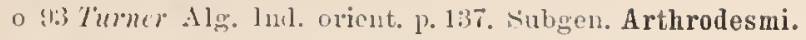

\section{Ajtogom $111 \%$}

n 38 E7renl. Infus. p. 381 et 342 (Desm. Aptogonum. Novum Genus?).

d Is lialfis Brit. Desm. 1)63.

(I : 2 I'ritch. Int. p. 21 '?

o is ("A ptogonium") Grun. Desm. p. 194.

d ho Wullich Desm. Lnw. Bengal p. 1.40 et 191.

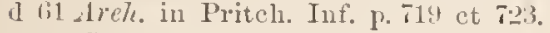

d (i.1 Gruy I3rit. Alg. p. Tt.

d lis liab. Flor. Eur. Alg. 3 p. 15i. ["A ptogonin un w. 106?.

d 73 Irood Fr, Alg. 1. 1:6.

(1) Tis Delponte Desm. subalp. p. 36 et 73 (sep.p. 21 et (il).

n 73 Nordst. Norg. Desm. p. 50. Subgen. Desinidii.

d 75 Microgr. Dict. 62 et 231 .

d Ti Lumesarm in Baill. Dict. bot. 1 fasc. p. 212.

d si Ilansy. P'rodr. Algenfl. Bölım. p. 171. Seet. Desm.

d Sy Toni Syll. Alg. p. Tol. Subgen. Desmilii.

\section{(1)togonum}

d 35 DESMIDIUM Bril. Alg. Falaise p. 268 (sep.p. 65) t.2 Aptogonum Desmidium nor. sen.? sec. Hzucul. Int. 1435 p. 381].

d 40 - . Ienegh. Synops. Desm. p. 203 (sep.p. 3).

d $45-$ hütz. Phycol. germ. p. 141.

d $1 \bar{T}$ - limb. Ieut. Firypt. Fl. p. 57 .

d $t 9$ - kïtz. vipec. Alg. 13. 150.

d - $\beta$ Ehrenbergii ibid. (Odontella Desmidinm Elerenb.) [A ptogronum Diagonnm Delp.].

o 5s- he liar. Conjug. 1. 76 t. 6 f.

d 61 - Arch. in Pritch. Inf. p. 723 t. 3 t. 7 - 8 [e livelfs].

d 63 - liab. Krypt. Fl. Sachs. p. 181.

d 66 - Eymich Algenfl. Mannh. p. 11!.

o tiт-Linsch Algent, Frank. p. 20i.

d 6r-líl. Flor. Eur. Alg. 3 p. 154 ("a ptogonium").

d - $\beta$ Elnrenberoii ibid.

z 70 - Tordst. Desm. Brasil. p. 206.

d 73 - Irood Fr. Alg. p. 124.

n $73-($ A ptogonum) Nordst. Norg. Desm. p. 50.

d $75-\beta$ acutius Norelst. Alg. sandric. p. 11 t. 1 f. 21 et 22 .

d TS- Kirchn. Alg. Folles. 1. 1:32.

m SO - P acutius Norrlst. De Alg. et Charac. 1 p. 3 (f. 3- et 4-gona)

d 84 - Tolle Desn. U. S. p. 27 t. 2 f. 6 - 7, t. 49 f. 7.

m $86^{3}$ - Lagert. Amerik. Desm. p. 227.

m $\quad-\beta$ acutius ibid.

o sfi-stolies liey Dosm, p. 110.

d sti-Cootie Brit. Desin. p. 11 t. 5 f. 1 a-c.

d - v. $\beta$ ibid. $\mathrm{p} .12$ t. 5 f $1 \mathrm{~d}-\mathrm{f}$.

d Ss-Hemsg. Prodr. Alı̈. Böhm. p. 172.

a $\quad-\beta$ Elırenber $\alpha$ ii ibil.

d ss-Huw, Kellm. u. Hiillgallerte Desm. 1. is ct 109 (sep.p. 20 et 51 t. 2 f. 6, 10-15.

zm so - Nordst. in Gazell. Expadit. 1. 3.

m St - Iste. Jel. magyar. aler. p. 245.

d Sy - Toni srll. alg. p. 781 .

d - v. Flirenbergit ibid.

d - v. acutius ibid. p. 78 .

แโด-- $\beta$ Elurenbergii Eichler Spis Desm. Mielz. p. \&1 t. 8 f. 3 .

d 91 - Kirelen. PHanz. d. Süssw. ed. 2 p. 22.

d 92 - Irulle Desm. U. S. cd. II p. 27 t. 2 f. $6-7$ t. 130 f. 7.

my? - v. acutius Gutu. Flor. Glon. Galie, 3 p. 119 (sep. 1. 1.1).

dordstede, Iudex Ilesuid. o 93 - Tumer Alg. Int. orient. p. 117.

d !H-Sumbl. in Fl. Nobraska p, :36; t. 6 f.6 [ex Wolle; "7" errore typographico].

Cfr. Desm. Swartzii 1s60.

\section{Arachue}

(1) 45TAURASTRUM lialfis Anm. Nat. Hist. v. $15 \mathrm{p} .15 \pi$ t. 11 f. 6 (ct $1 s \|$ Trans, Tot, Soc. Edin. v. 2 p. 1.13 t. 14 ).

d t5 GONIOCYSTIS Pentasterias Ilass. Brit. Alg: p. 355 t. $\$ 5$ f.s [e Rulfs l. c. depicta]. "Ârachnis".

d. Is Staur. Rulf's Brit. Desm. 1). 130 t. 23 f.6.

d 49 PHYCASTRUM Kïtz. Spee. Alg. p. 181.

n 19 - Stenactinium) Noy. cinz. Alg. p. 125.

d 52 staur. 1'ritch. Inf. p. 26ti.

d bi-Arch. in Priteh. Inf. p. TH.

d 43 - Kab. Krypt. Fl. Sachs. p. 191, f. 2 p. 1 is [ex Massall].

d 68 - Kab. Flor. Eur. Alg. 3 p. 210, fig. xyl. p. 109 [ut supra 1862 ?.

d 73 - Wood Fr. Alg. p. 152 t. 21 f. 21 [?].

1176 - v. tetracera Jaculs. Desm. Danem. P. 205 (Micr. tetrac. Kitis...

d $7 s$ - Kirchn. Alg. Schles. p. 168.

S3 - Tume Algæ Streusall f. 20.

d 84 - Wolle Desm. U. S. p. 129) t. 42 f. $38-42$.

m 85 - Boldt sibir. Chloroph. p. 118.

m 86-Lregerh. Amerik. Desm. 1) 219.

o 86 - Stolies Krey Desm. p. 166.

d $5 i$ - Cooke Brit. Desm. p. $1 \% 2$ t. 63 f. 1 [saltem partim c lialfs].

us 88 - f. minor Boldt Desm. Grönl. p. 39.

o 88 - Norelst. Bornh. Desm. 13. 206.

d s9-Toni syll. alc. p. 1329.

1n $90-$ Eichler Spis Desm. Miedz. p. 90.

n 90 - Anderss. Sverig. Chlor. 1 p. 12.

m 12 - West Fr. w. Alg. W. Irel. 1. 187.

m 92 - Rac. Desmidya Ciastoni. p. 350 .

d 4 r - Tolle Desm. U. A. ed. II p. 113 t. 53 f. $39-12$.

n $13-($ Cyptastrum) Turner Alg. Ind. orient: p. 132.

\section{arachmoides}

l 12 STAURASTRUM West Fr.w. Alg. W. Irel. p. 186 t. 24 f. 4.

\section{Archeri}

d 4 COSMARIUM Roy et Riss. in Roy Scottisn Desm. p. 42 (sep.p. 30 , t. 1 f. 5.

\section{Arherii}

a 7 T PLEUROTENIUM Delponte Desmid. subalp. p.12S (sep.p. 224) t. 19 f. 12-11\%.

1 83 - v. triannnlatum Schaurschm. Magyar. Desm. p. 278 t. 1 f. 23.

m 84 - Wille sydannerit. Algfl. p. 23.

11 85 DoCIDIUM ITulle in Bull. Tor. Bot. Club. 12 p. 2.

d si-TTolle Fr. Alg. U. S. A. p. 25 t. jt f. 2.

d s9 Pleur. Toni syll. alg. p.902.

d - v. triannulatun ibid. p. 903 ["trimacnlatum" errore typographico].

m!1 - Gutw. Flor. alg. Lcopol. p. 3\%.

4 92 Doc. Wrolle Desm. U. S. ed. II p. 51 t. 12 f. 2.

o 93 Plenr. Lïtlimäll. Desm. Attersees 1) 5iti.

m! - Gutw. Fl. alg. 'Tarnapol, p. 83 t. 3 f. 1.1.

o 91 - Stockm. Nachtr. syst. Antz. Osterr. Kiryt. p. 12.

\section{Arrheri}

dz90 SPHAR ÁZOSMA Cime. Waln. d. Prioritit 1.66 
(Nill. vertebratnm f. Novdst. 188:). [Sph. filiforme sec. Tw'n. 1893].

dzf 91-Gintw. Flor. Alg. Leopol. p. 29 t. 1 f. 4.

mo2 - Gulu. Flor. glon. Galic. 3 p. 119.

oz 93 - Roy Scottish Desm. p. 171 (sep.p. 10).

o 94 - Schmillc Alg. Geb. Oberrlseins p. 546.

o 94-Gute. F1. alg. Tarnapol. p. 7 -

\section{Archerii}

d y2 STAURASTRUM W'est Fr. w. Alg. W. Irel. p. 183 t. 23 f. 15.

\section{Archerirmum - a}

d 71 CLOSTERIUM Cleve in Lund. Desm. Suec. p. if t. 5 f. 13.

m 73 - Nortst. Norg. Desm. p. 10.

75-Jacols. Desm. Danem. p. 175 t. 7 f. 4 .

d $79-a$ typicum Klebs Desm. Ostprenss. p. 13 t. 1 f. 13 h, t. 2 f. 1.

d - b compressum ibid. p. 13 t. 1 f. 11 a et b.

d - c Cynthia ibid. p. 13 t. 1 f. 12 a et c. (Cl. Cynthia l) Not. 1867).

d 85 - Kirchn. Mikr. Pflanz. d. Sïssw. p. 21.

d 80 - Coolie Brit. Desm. 1. 27 t. 13 f. 5.

d 89 - Toni Syll. Alg. p. 842.

m 90 - H'est F1: w. Alg. North Wales p. 295.

d 91 - Kirchn. Mikr. Pflanz. d. Süssw. ed. 2 p. 23.

n 91 ARTHRODIA Kuntze Rev. gen. plant. p. 883.

m 92 clost. West Fr. w. Alg. W. 1rel. p. 123.

o s? - linc. Desmidya Ciastoni 1) 370.

m93-b. compressum Schmidle Beitr. Alg. Schwarzwald. p. 10.

- 93 - Turner Alg. Ind. orient. p. 19.

my4-Borge Sïssw. Chlor. Archang. p. 16.

\section{Arrtiscon}

d 13 XANTHIDIUM Elrenb. Mikr. Leb. Sïd. u. N. Amer. p. (331, 339, 390 et) $426^{\circ}$ (sep.p. 138). [Deseriptio mala]. (Xanth. n:o 2 Builey Amer. Baeill. 1841 p. 291 (sep.p. 10) t. 3 f. 15 ).

d 15-Iinlfs Brit. Desm. 13. 212.

d 4.) ASTER0XANTHIUM Kït s. spee. Alg. p. $18 t$.

d 52 Xinth, Protel. Inf. p. $25 \%$

d 61 -? Arch, in Pritch. Inf. 1. 736.

d 68 - Rab. Flor. Eur. Alg. 3 1. 224.

d 7 STAURASTRUM Lum. Desm. Suee. p. 60 t. 4 f. 8.

d $73 \mathrm{Xanth}$. Wood Fr. Alg. p. 156.

d 78 - Kirchn. Alg. Schles. p. 155.

sostaul. Cooke in Quekett Mier. J. 6 t. 14 f. 6 et 7.

81 - Wills in Midland Naturalist 4 t. 5 f. 9 .

a 81 - Wrolle Desm. U. S. 1'. 118 t. 17 f. $9-10$.

o 8f - stolies liey Desm. 1\%. Uit.

o 87 - Trolle Fr. Alg. U. S. A. p. 1, t. f.2 f. 4.

d 87 -Cooke Brit. Desm. 1. 179 t. 198 t' 1 [ex p. e Laml. $18.1]$.

n S! - ('arter in A. M. Mier. J. 10 f. 19 (ex Trolle).

d 8.7 - Toni Syll. Aler. p. 1226 .

d $99-v$. crenulatum Ilure. Fr. Alg. Maine III p. 123 t. 120 f. 18 [Quid.? (ff Wrst in Jomrn. Bot. $18 \%$ l\% 71). - An Stanr. Wolleannm?.

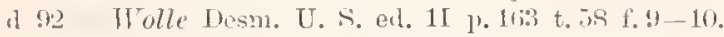

11 : 13 - Hoplastrum) Twher Alg. Ind. mient. p. 1:32. Cfr. Staur. munitum Tlooel.

\section{(er.tout) $-r$}

d 75 COSMARIUM Norlst. Desm. aret. p. 28 t. 7 f. 22 (et f. 23 forma).

d - $\beta$ trigonum ilid ; f. mixta ibil. f. 21. o 85 - Nordst. Desm. Grönl. p. 9.

n 55 - a. typicnm Rac. Nomn. Desm. Polon. p. 78 (sep.p. 22).

d - b. tatricum ibil., t. 11 (sep. 2 ) f.fo.

m 88 - $\beta$ trigonn m lioldt Desm. Grönl. p. 17.

m 8s-Nordst. 1r. wat, alg. N. Zeal. p. 61 t. 7 f. 29 .

d 89 - Toni syll. alg. p.94.

d - v.trigonum ibid.

d - v.tatricum ibid.

m 90 - Eichler sopis Desm. Niedz. p.ss.

1) 91 URSINELLA humbe Rev. gen. pl. p. 124.

m $92 \operatorname{Cosm}$. f. minor West Frow. Alg. W. Trel, p. 102 t. 21 f. 24.

m 94-Börg. F. alg. Östgrönl. p. 20.

\section{arematre}

1139 HeterocarpelLA Treb. in Chev. Nier. 1. 272 [Nomen tantum!].

\section{(1) eurceta}

d 51 MICRASTERIAS Mril. Micr. observ. p. 35 t. 1 f. 6 [II. expansa $\beta$ areuata $\Pi^{r}$ all 1860].

d 52 - Pritch. 1nf. p. 247.

a 61 - Arch. in Pritch. Inf. p. 725.

a $68-R a b$. Flor. Eur. Alg. 3 p. 1 ss.

a 73 - Wood Fr. Alg. p. 141.

o $7 \tau$ - Nordst. Alg. brasil. p. 22, p. 23 fig. xylogr. II 1 , 2 et $c$.

$m-\beta$ expansa ibid. p. 23 fig. xyl. II 5 , 6 et $b$. (M. expansa Bail.)

o - f. intermedia ibid. f. xyl. II $3-4$.

d 84 - Wolle Desm. U. S. p. 117 t. 38 f. 5.

m $86-\beta$ expansa Lagerh. Amerik. Desm. 1. 232.

o s6-Stolies Key Desm. 1) 147.

d 89 -- Toni Syll. alg. p. 1121.

13 91 HeLIERELLA Kimtze Rev. gen. pl. p. 898.

a 92 Micr. Holle Desin. U. A. ed. II p. 129 t. 11 f. 5.

m $95-$ Möbius in Iledwigia 34 p. 178.

\section{aremetum}

d dricLOSTERIUM Brét. in Ralfs Brit. Desm. p. 21:. ("Cl. acuminatum see. Kätz. in litt."). [Cfr. Cl. Diana $\theta$ ).

a $52-$ Irilch. Inf. P. 281 .

o 50 - Bréb. List. 1\%. 14! t. 2 f. 38.

1n 71 -- Lund. Desm. Snee. p. 80.

1] 77 - Delponte Desinid. subalp. p.106 (sep.p. 20?) t. $17 \mathrm{f}$. $54-59$.

o 193 - Twner Alg. Ind. orient. 1. 19 t. 1 f. 17.

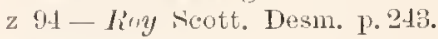

\section{(l).*utum}

11 Tis STAURASTRUM Norlst. Norg. Desm. p.30 t. 1 f. 19. a 4 - - v. Wolle Desm. IT. S. p. 189 t. 19 f. 13-1.t. [Quid?]. in 8. - Boldt sibir. (liloroph. 1. 120).

o sti - Stolies Key Hesn. p. 16it.

d 87 - Coolie Brit. Desm. p. 169 t. 51 f. ?.

in SS - Joldt Desm. Grönl. 1. 10.

1) 89 - Toni syll, alg. p. 1207.

$\$ 1$ - West Freshw. alw. Maine II t.31\% f. 1:3.

d (19-v. guitanonso II est Fr. w. Alg. W. Irel. p. 181 t. $2: 3$ f. 111.

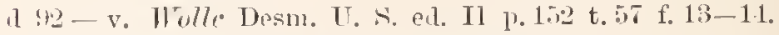

d 12 - v. subavicula II est Alg. Engl. Lake Distr. p. 632 t. \& f. 25. [Nit. subavicula 11 est 1s:1].

m98-Tumer Alg. 1nd. mient. p. 120 t. 1 t f. 20 .

o $\$ 1$ - v. vasta [!] Schmille in Hedwig. 33 p. 94 t. 6 f. 7. [Quil??.

n 95 - v. pseudopisciforme West in Jomm. Bot. 33 p. 69 (Staur. pseudop, Gichl. et Gulw.). 


\section{"roverus}

d si ARTHRODESMUS Josh. Burm. Desm. p. ill t. 24 f. 11. d so-Toni syll. alg. p. 16 - Tol.

o $12-R u c$. Desmidya Ciastoni. p. 377 t. 7 f. 24.

\section{areolutum -}

a 73 CLOSTERIUA Wool Fr. Alg. p.111 t.11 f. (;

d 81 - Wulle Desm. T. S. p. 13 t. 7 f.3-1. [E.x Wood non exacte].

o .96 - Stukes Key Desm. p. 112.

d 89 - Toni syll. Alg. 1.812.

n!1 ATHRODIA Kuntze Rev. gen. plant. p. 883.

d 92 Clost. Wulle Desm. U. S. ed. II P. 44 t. 8 f. B-t.

d 91 - f. simplicior Gutu. Fl. alg. Taruapol. 17. 80 t. 2 f. 10.

d - f. glabra ibid. 1). 81 t. 2 f. 11. [Quid? Cl. acerosum f.?].

Cfr. Clost, Braunii.

\section{aristiferum}

d Is STAURASTRUM Rulf: Brit. Desm. p. $12: 3$ t. 21 f. 2.

(1) 5 - I'ritch. Inf. 1.262.

d iil - Wreth. in Priteh. Inf. p. Tas.

d lis-liab. Flor. Eur. $1 \mathrm{l}$ @. 4 p. 201.

$m 70$ - Nortst. Desm. Brasil. p. 2026?.

a 73 - Iood Fr. Als. 1) $11 ! 1$.

d $75-v$. Rimseh Contribut. p. 90 t. 9 f. 2.

d $7 s-$ Kirchu. Alo. Sichles. p. 169.

8t-Coulic in Quekett Micr. J. 6 t. 16 f. 32 et 33.

s:i-Turner Algre Strensall f. 6 .

1) 44 - Wulle Desm. U. S. p. 122 t. 40 f. 15-1t.

d $\mathrm{si}$ - Lagerh. Amerik. Desm. 1.247 t. 27 f. 25.

o Sli-stulies Key Desm. p. 265.

o 86-Cuotic Brit. Desm. p. 141 t. 19 f.ti.

d 89 - Toni syll. alg. p. 1141.

o 91 - ? Heimerl Desm. alpin. p.60t t. 5 f. 20 .

d ge- Wolle Desm. U. S. ed. II p. 135 t. 51 f. $15-16$.

d !3-(Acanthastrum) r.? planum Tumer Alg. Ind. orient. I. 106 t. 16 f. 3 ?

d 94 - Sumel. in Fl. Nebraska p. 43 t. 7 f. 21 [ex WT/7e].

\section{(1)"ulte}

d so GYMNOzYGA (Ho plozyga) Nordst. De Alg. et Claarac. 3 p. 1 t. 1 f. 1 -3.

o 95 - lincib. in Flora r. 81 p. 32 t. $3-1$ f.6.

\section{"rimerum -r}

(1) R6 Cosmarium Josk. Burm. Desm. p. 1316 t. 21 f. $21-25 ;$ [uee Inet).].

4 8.7 - Tomi ryyll. alg. p. 1(13:3

n 91 URSINELLA himize Rev. gen. pl. p.921.

\section{(1)"urtum}

d 93 PENIUM Fich. et lirls. Nowe gat. zielen. p. 117 t. 3 f. 2. Cfr. Anzeig. Ak. W. Krakau Juli 14:12 1. 2u!1).

\section{(1) $)\|t u\|)$}

d 10 COSMARIUM Bréb. in Menegh. Synops. Desm. p. 21\%.

d 1.5 EUASTRUM Kïtz. I'lye. germ. 17. $13 \%$.

d 17 XANTHIDIUH hiub, Deut, Krypt, Fl, p. 5\%,

dzf 4 S - Ralfs Brit. Desm. 1. 112 t. 18. 1X. furcatnu Ralfs 1815 .

d $522-$ Iritch. Inf. p. 257.

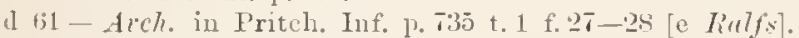
'Zygoxanthium Echinas)

d 133 - Rub. Kiylt. Fl. Sachs. p. 19.7. f. xyl. p. $15 \%$.

m 6б DIDYMIDIUM (Xant li idium) Reinsch ilgent. Flank, I. $12 !$.

67 Xantl. Not. Desm. Ital. t. 1 f. 35 . o 68 - Areh, in Q. J. 11. Sc. 5 p. 291.

d tis-liab. Flor. Fur. Alg. 3 p. 222; fig. xyl. p. 110 [ut supra 18ti3].

oะ 71 - (Schizacauthum) Lund. Desm. Suec. p. T5 t. 5 f.1.

\% 73 - Areh, in Q. J. M. S. v. 13 p. 310.

z 73 - Nordst. Norg. Desm, p. 37 .

d 73 - 11 ood Fr. Alg. p. 150 t. 13 f. 17.

d 55 - Microgr. Diet. p. 839 t. 10 f. 23 et $2 . t$ [e Ralfs.

d 78 - $\beta$ fissum Nordst. Alo. Sandvic. p. 17 t. 2 t. 6 .

dz 7 - Kirchn. Alg. Selıles. p. $15 t$.

d 81 - Wolle Dosm. U. S. p. 12 t. 21 f. $1-4$.

d $85-$ Kirchm. Mikr. Pflanz. d. Süssw. p. 25.

o 85 - v. Wolleanum Timer New rare Desm. p. 638 t. 15 f. 18. [ = " sec. Irildem. Obs. cr. $18 \% 4$ p. 11T].

o - v. Americanum ibid., f. 19. [forma tantum?. sec. Wildem. 1sit].

m S6 - Lagerh. Amerik. Desm. p. 215.

o 81 - Stokes Fiey Desm. p. 130.

dzf 87 - Coulie Brit. Desm. p. 129 t. 45 f. 1. [e Rulfs 1818, saltem p. max. p.].

o 87 - $\beta$ basidentatum Nordst. Algolog. småsak. 1 p. 158.

d 87 - Alexentio Chlorosp. Khark. p. 252.

1\% S8 - Hunsg. Prodr. Algenfl. Bühm. p. 191 f. 114 [e Lund].

dz SS - Tomi et Levi Fl. Alg. Venez. p. 52.

m 88 - Riquin. Chloroph. env. Tharkow p. 332.

m 88 - Iste. Jel. magyar. alo. p. 236.

d $88-\beta$ basidentatum Nordst. Fr. Wat. alg. X. Zeal. P. 12 t. \pm f. 21 .

dz 89 - Toni syll. alg. 1.916.

o - v. americanum ibid. p. 917.

o - v. Wolleanmm ibid.

d - v. basidentatum ibid.

d - v, fissum ibid.

n 90 SCHIZACANTHUM Wille Natürl. Pfanzenfam. p. 11 et 12 f. $7 \mathrm{E}$ (c Lishd.).

un Io Xanth. Auderss. sverig. Chlor. 1 p. 13.

11190 - Eichler Spis Desm. Miedz. p. 88.

d !1-Kirchn. Mikı. PHanz. d. Süssw. cd. 2 p. 26.

m 91 - Heimerl Desm. alpin. p. $5 \%$.

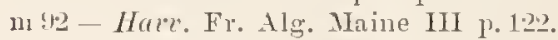

d $0-v$. irregularins Wrest Fr, w. Alg. W. Irel. p. 16:1 t. 22 f. 1.

d ! 12 - Wolle Desm. U. S. ed. II p. 99 t. 2.1 f. $1-4$.

d : $: 3$ - v. incongrumm Turnes Alg. Int. orient. P. 102 t. 13 f. $t$.

pla 93šchizacanthum Franzé in Österr. bot. Zeitsclur. p. 384

ph93 Xauth. Lïlliemüll. in Verh. zool. bot. Ges, 18913 Sitzb. p. 38.

d 95 - - supernumerarium Schmidle Beitr. alp. Alg. p. 315 t. $15 \mathrm{f} .8$. Cfr, Xantl, Bigorrianum.

\section{armillare}

(1 73 MIX0T'ENIUM Delponte Desmid. subalp. p.62 (sep.p. 50) t. 1 f. $13-19$. (Hyalotheca mucosa).

\section{crmillatum}

(1 93 COSMARIUM Tumer Alg. Ind. wrient. p. 55 t. 8 f. 22.

\section{almillatum}

o : SPONDYLOSIUM Tuner Desm. Notes p.346. et f. 20 1. 311.

\section{Armstrongiemme}

n $\$ 3$ EUASTRUM Areh, in Ann. Mag. Nat. Hist. 5 ser. 11:0 193 p. 213. [Eu, sp. Arch. in Q. J. II. Sc. 1871 p. 19 
(En. piuque Elfe. 1R81) see. Roy Scottish Desm.; 1St3, p. 176 .

\section{Arnellii.}

d s5 COSMARIUM Boldt Sibir. Cliloroph. p. 107 t. 5 f. 15. d s?-Tomi syll. alg. p. 994.

n 11 URSINELLA fiuntzo Rev. gen. pi. p. 121.

d 92 Cosm. f. compressa West Fr. w. Alg. W. Irel. p. 151 t. 21 f. 10 .

m 93 - f. Tumer Alg. Ind. orient. 1. 60 t. 8 f. 60.

d. 94 - v. rotundatum Gutw. Fl. alg. Tarnapol. p. 94 t. 3 f. 26. [Quid?].

d $94-\mathrm{v}$. irregulare Eichl. et Gutw. Spee. alg. nov. p. 166 t. 4 f. 11. [?].

\section{Aluellii}

d 85 STAURASTRUM Boldt Sibir. Chloroph. p. 112 t.5 f. 21.

d 89 - Toni syll. alir. p. 1170.

o $90-\beta$ inornatnm lioy in seott. Naturalist. x. p. 208 .

o 93 - $\beta$ inornatum lioy Scottish Desm. 1. 178.

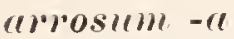

d 6 COSMARIUM Nordst. Desm. arct. p. 20 t. 6 f. 7.

In 88 - Boldt Desm. Grönl. 1. 1T.

d 8 - Toni Syll. alg. p. $1(131$.

1191 URSINELLA Kuntze Rev. gen. p1. p.921.

\section{ARTHRODESHUS}

n 36 Ehrenl. in Wiegm. Arell. f. Nat. 1836 p. 185 [Nomen tantim].

d 38 Ehrenl. Inf. p. 149. [A rthr. Rrilfs et Scenedesmus].

d 10 Eurmeister in Erseh 12. Grub. Allg. Eneyklop. d. W. II, 1 is p. 205 .

o 45 Tialfs Amn. Nat. IIist. v. 15 p.150 (et 1846 Trans. Bot. Soe. Elinl, v. 2 p. 136).

d 45 Hass. Brit. $1 \lg$. 1. 3 õ .

d 17 Rab. Dent. Krrpt. Fl. Y' VIII et 55. [Seenedesmus].

d 18 Ralfs Brit. Desm. 1. 11\%.

d til Kïtz. Spec. Alg. p.17\%.

d 5.2 Pritch. Inf. 1.25.

o 59 Grum. Desm. p. 193.

d 55 Dc Bary Conj. 1. 72 Subseet. Microcosmarii).

d li1 Arch. in Pritch. Inf. p. T21 et 736.

d 63 Fial. Frypt. Fl. Sachs. p. 19t5.

d bit Gray Brit. Alg. 1. 6!).

d 68 lial. Flor. Eur. Alg. 3 1.2.5.

0 T0 Arch. in Q. J. M. S. v. $10 \mathrm{p} .8 \mathrm{~T}$.

o 72 Arch. in Q. J. Mi $(r$. Se. v. $12 \mathrm{p}$. Si).

d 72 Alicrogr. Diet. ed. 3 p. 73.

d 73 Hood Fr. Alg. 1. 157.

d 75 Microgr. Diet. 13.73 et 231.

d 7 T Frank in Lemis Synops. P. 1633.

d TT Lancssan in Baill. Diet. hot. I p.2TI.

d Ts Kirchn. Alg. Schles. 1. 15t;.

o 81 Arch. in Ann. Mag. Nat. Hist. 5 ser. v. 5 p. 233.

d stray Ionogr. loc. Conjug. p. 36. Sect. Euastri.

d 81 Tolle Desm. T. A. p. 45.

d 85 Kirchn. Mikr. Pflanz. d. Siissw. 1.20.

o sio Stokes Key Desm. p. 109.

d St Fromli in Lelunis synops. 3 1. 196\%.

d si Cuole Brit. Desm. 1. 1:31.

d 87 Alexentio Clilorosp. Kuliark. 11. 25T.

d 58 Hansg. Prodr. Algenfl. Bülnu. 1,202 sect. 1 Tetracanthium Nipg.).2. Octaeanthinu p.203.

d 88 Toni et Levi Fl. Alg. Tene\%. 1\% it.

o Ss Ilauptfl. Zellm. u. II ililgallelte 1. Sy (sep.p. 31). d so Tomi Syll. alg. p.1056. (Seet. I. Tetraeanthinm p. 10.5. II. Oetaeantlium p. 1063\%

o 89 Racil. Now. Desm. p.

d - 1. Enarthrodesmus. 2. Centrenterium ibid. (Subg. Xanthidii Boldt 1858).

d 90 Wille in Natïrl. Pflanzenf. p. 11.

d st Kirchr. Mikr. Pflanz, 凡. Siissw. ed. 2 p. 21.

d 12 Wrolle Desm. L'. s. ed. II p. 103.

o !3 Turner Alg. Ind. orient. 1.137. Subspee: Aplodesmus et fichizorlesmus.

- 91 Hildem. Obs. crit. Desm. p.95-101. Sect. Tetraeanth i um.

d 94 Sanmd. in Fl. Nebraska p. 12.

ph 94 Wellheim in Pringsh. Jahrb. 26 p. 730 (sep.1. 50).

\section{ARTHRODIA}

d 13 Rafinesq in Joum. bot. appliq. 1 p. 235. [Closterium see. Trevis. Nomenclat. Alg. et O. Kuntac Rev. Gener. plant. 2 p. 882 ; cfr Nordst. 1893].

d 16 Leman in Die.t. Seiene. natur. Supplenn. tom. I1I p. 32 et 159 [Bacillaria].

o 22 Sec. Tory in Diet. elass. hist. nat. 1 p. 59l verisimiliter $=$ Palmella rupestris Lyngb,; ibil. 1825, v. 8 p. $180=$ Heterocarpella geminata.

d 12 Bréb. in Dict. univ. hist. nat. v. 2 p.17.t.

- 91 humze Rev. gen. plant. 2 p. S8.

- 93 Nordst. in Hedwigia 32 p. 14t.

o 93 Kuntze Rev, gen, plant, III' p. CCCXLIV.

\section{(Arthrodiées)}

d 22 Bory in Dict. elass, hist. nat. I 1\% õ . Regumm inter animalia et plantas.

\section{ARTHRORHABDIUM}

o $6 !$ Eluenb. in Abh. Berlin. Aliad. 1869. II 13.13.

o 87 Lagerh. Krit. Bemert. Desm. p. 511 (1'leurotienium??

\section{avtivulatu}

d 31 MICRASTFRIAS Küt. Sym. Diat. p. bith; (sc1'p. TS) [Rivularia?].

\section{almigerum}

a jo STAURASTRUM Try. Liste 7.136 [Staur: furcigerum Jacubs: 1856. - v. armig. Nordst. 1-sise].

d 61 - 1 reh. in IPritch. Inf. p. T3S (St. spinosum Ralfs].

1 1n 85 - Ruldt sibir. Cliloroph. p. 119.

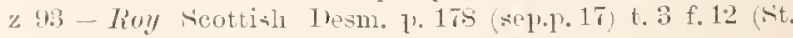
pseudofurcigerum tieinsch $186 \%$ ).

\section{artirulatum}

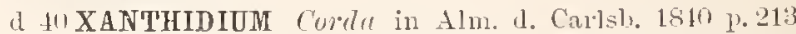
(sel.1).2s) t. 5 f. 35 [Figura mala. Stamrastrum furcigerum liréb. verisiniliter].

11 10 STAURASTRUM Rilfs Erit. Desin. p. 216.

d 52 - Iritch. Inf. 1.26\%.

d $61-1 \cdot 6 h$. in Pritels. Inf. p. T13.

d lis-liab. Flor. Eur. Alg. 3 p. 221.

\section{Aslienrisyi}

(1) COSMARIUM selmidle $\mathrm{Alg}$. Sumatr. 1).301 t. 1 f. 7.

\section{(1.5)er}

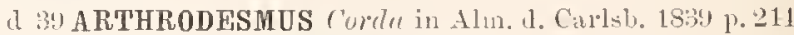
t. 6 f. 31 [A. couvergens 1. ? ]

\section{(c.s)ersum}

d 43 DYSPIINCTIUM Turner $1 \lg$. Ind. orient. 1.11 t. 7 f. 16. 


\section{"s.spevilum}

d it COSMARIUM Reinseh Contribut. Alw. Promont, B. Sp. p. 242 t. 6 f.9. Cfr. Eu. Satkii Gutw.

\section{(1) sper"ll)}

(1) 1 Cosmanium West New Brit. Alg. p. 8 t. 1 f. 21.

\section{- $(\mathbf{s}) e r \| m$}

d 48 DocIDIUM ? [Bréb. in] Ralfs Brit. Desm. p.1is t. 21 f. ${ }^{\prime}\left[a\right.$ et $b$, spec. anglic. $=C_{\text {t. }}$ monotaenium $D_{e}$ Bary 18:6, e. spce. gallic, Brebissonii $=$ Gon. asperum Bréb. 1856].

d i2 - ? Jritch. Int. p. $27 t$.

o 56 - Brit). List. p. 14 t t. 1 f. 33 [Gonatoz. Brobissonii de lia). 18581 .

- $58-$ Aich. Catalog. p. 76.

d 5 L LPPOCYSTINEMA Arch. Suppl. Cat. in Nat, llist. Rev. v. 5 p. 251 t. 21 f. 5 (in Pr. Dubl. Zool. Bot. Assoc. I p. 115 t. 11; in Transact Micr. Sc. 7 p. 131) [G. monotien.].

dz 63 GONAT0ZYGON líb. Krypt. Fl. Sachs. \%. 181 (G. monotreniun De $B(a) y)$

1161 - Clece Bilr. t. Srerig. Desm. p. 496 (G. Brebisson i The bromy 185s?

o 67 - licinseh Algen1. Frank. p. 209.

d b8-Rub. Flor. Eur. Alg. 3 p. 15 [G. monot.].

dzfst - Wolle Desm. U S. 1. 2.2 t. 1 f.'1. [G. monot.].

d 8j-Kirche. Mikr. Pflanz. d. Sulssw. 1. 20 t. 2 f. 57 (e T) Bary Conjug. f. 23 .

o s6-Stokes Kicy Desm. p.110,

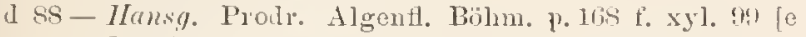
Le liary f. $2[i-27]$.

z st-rarter in A. M. Mier. J. X. f. 1 (e Wolle)

d 89 -Toni Syll. Alg. p. 801.

n 90 - EVichler Spis Desm. Miedz. p. 84.

d $91-$ Kirchu. Mikr. Pflanz. d. Süissw. ed. 2 p. 22 t. 3 f. 65 (e be $\mathrm{Ba}(1 \mathrm{r})$ ).

m 91 - Borge Bidr. Mibir. Chloroph. p. 1.1.

d 22 - Wolle Desm. U. s. ed. II p. 22 t. 1 f. 1.

m12 - Gutu. Flor. glon. Galic. 3 \%. 120.

o 93 - Liltlicmäll. Desm. Attersees 1.539 (inel. G. minn. tum $W^{\prime}(s t)$

1395 - Juhns. Rare Desn. U. S. II p. 291 t. 239 f.s.

\section{"s)er"ll}

d t!) PHYCASTRUM (Stenactidinm) I'rty in Bern. Mitl. $181 ! 1$ P. 171.

d $52-\operatorname{lirly}$ klcinst. Lebensf. P. 210 t. 16 f. 31 [Nitau. Pertyi? Toni \& Levi 18s6; st. ornatum v. asp. Srhmidl?.

"d gs STAURASTRUM liub. Flor, Eur. Alug. 3 p. 221 [non Iirib.].

\section{(1.5) $110 \pi m$}

dzt LS STAURASTRUM liveb. apul linlfs Brit, Desm. 1. 133) t. 22 t'. 6 . t. 23 f. 1.2 $a$.

d $-\beta$ proboscidenm ibid.; t. 23 f. $12 b$ et c. [Nt. proboscideum].

de 52 - Tritch. Inf. p. 267 .

d\%ti1-Arch. in I'riteh. Inf. p. 710.

d (;) DIDYMIDIUM (Sitaur.) A. minus licissele Algentl, l'rank. 1. $1100 ; a$ et $\beta$

d - T. majus iluil.

d lisitaur. Mab. Flor. Eur. Alg. 3 p. 20!.

d b. silesiacum (St. silesiac $1 \mathrm{~m}$ Hits.) ibid.

o 81 - Wolle Desm. U. S. p. 127 t. 42 f. т-8. [ $\beta$ Wollea п им Tm\%. 18:13]. d 86 - Stolies Rioy Desm. p. 16 t.

daf 87 - Coole Drit. Dosm. p. 151 t. 53 f. $4[d$ et $\ell=0$ linlfs].

dz s9-Toni syll, alg. 13. 117.5.

d 22 - Wolle Desm. U. s. ed. II p. 1.10 t. 53 f. 7 et 8.

$1193-\beta$ Wolleanum Twmor Alg. Ind. orient. p.116 (Tolle 185.1).

m 91 - West New Brit. Alg. p. 11 t. 2 f. 18.

\section{(1.s)}

n To COSMARIUM Nordst. in Wittr. et Nordst. alg. exs. n:o 268 et 1859 in fase. 21 1.49 (C. Schliephacheanum Grun. (f. spetsbergensis) Nordst. Desm. aret. p. 24, 1575, non Grum.).

dz 87 - $\beta$ productum Norlst. Algolog. småsak. 4 p. 162. dzfsi - - Norlst. Ir. wat. alg. N. Zeal. p. 61 t. 6 f. 18. dz S - - Tomi Nyll. alg. p.911.

dz $-a$ ibid. 17.913.

n 91 URSINELLA huntze licv. gen. pl, p. 924.

\section{"s)i川Osum}

d $8 \pm$ STAURASTRUM Wolle in Bull. 'Torr. Bot. Club. 155.1 1). 14 t. 41 f. 22 - 23.

d st.- Wolle Desm. U. \&. p. 143 t. 51 f. 22 \& 23.

o s6-Stoles Kiny Desm. p. 165.

d 89 - Toni syll. alg. p. 1.231.

d 92 - Wolle Desm. C. S. ell. Il p. $15 \%$ t. 02 f. $22-23$. Cfr. Stanr. platycernm.

\section{"s.suryens}

d st STAURASTRUM Nordst. Alwolog. småsak. \pm p. 157. I 8.5 - Nwrlst. Fr. wat, alg. N. Zeal. p. 37 t. 4 f.s.

d 89 -Toni syll. alg. p. 1234.

\section{asteptum}

d 81 XANTHIDIUM Nordst. in Wolle Desm. U. S. p. 93 t. $21 \mathrm{f} .9-21$

o si - Sifoles Key Desm. p. 130.

d. S: - (Tolacantlium) Toni syll. alg. p. 929.

d 12 - Wolle Desm. U. S. 1.1100 t. 21 f. 9-11.

\section{ASTEROSEIENE}

d fis Wittr. Skand. Desm. P. 2. subgen. Closterii. d :10 Tritle in Natürl. I'llanzenfan. p. o. Sect. Clost.

\section{ASTERONANTIIIUN}

d 15 Kït\%. Spee. Alg. p. 18\%. = Staurastrum ex p. et Xanthidium ex $\mathrm{p}$.

d 75 Lanessan in Baill. Dirot. Lot. p. 302 .

\section{ASTEIOCOSMIUM}

o SS Stockmayer in sitzungsher. 1. zool.-bot. Gos. $15 S 9$ 1. S5.

\section{"tlumtoirleum -}

d 7 C COSMARIUM Jorponte Desmid. subaly p. p.5 (scp.p. 101) t. 7 f. $22-21$.

o in 85 - Bolelt Sibir. Chloroph. p. 10ir.

d S:I - Tomi syll. alg. p. $100 \mathrm{~s}$.

o 91 - f. rectiuscula Ilcimcrl Desm. alpin. p. 597 t. 5 f. 9 [C. Bicardia|.

n :" URSINELLA Kunlac Rev. gen. pl. p.121. na 31 Cosm. Wrest Freshw. alg. Maine II p. 355.

\section{ATOHOCISTIS}

d 93 Turner Alg. Ind. orient. 1.98. Subgen. Micrasteriao. 


\section{attenuatum - r}

d 38 CLOSTERIUM Ekronb. Inf. 1) 1.4 t. 6 f. IV [nom sensu auct. reennt.].

d $10-\pi$ - Icgh. Syrops. Desm. p. 233 (sep.1.33).

d 15 - Kiitz. Pliye. germ. 13.131.

d 48 - Malf's Brit. Desin. 1. 169 t. 2! f. 5े [Alia spee. ruam Ehrenbergii sec. Jacols. 1875. Cl. candianum Delp. 1 siti].

d $19-K \ddot{1} t z$. Spee. Alg. 1. 16t.

o 51 - Rrub. Bacill. Saehs. fase. 5 t. 3 f. 43 . Quid? Cl. rustratnm?].

d 52 -Iritch. Inf. p. 2as1.

d til - Arch. in Pritch. Inf. p. 719 t. :3 f. Is [e Ralfs].

o 61 - Rub. Alg. Enr. 11:0 1230.

d 63 - Iiab. Krypt. Fl. Sacls. 1. 172.

d ts - hul. Flor. Enr. Alg. 3 p. 130.

d 75 - Mierog. Dict. p. 170.

o 75 - Jucols. Desm. Danem. p. 174.

d $78-K i v c h n$. Alg. Sehles. p. 138.

d 80 - " sculptum Nortst. in Wittr. et Nordst. alg. exs. 1n:o 382; et in fase. 21 (1859) p. 41 .

m 81 - Tiucib. Thesm. okol. Krakowa 1. 7 .

d. 84 - Wulle Dosm. U. S. p.41 t.s f. i.

o $86^{2}$ - Stokes Key Desm. 1. 112.

o 86 - Coolic Brit. Desm. p. 32 t. 14 f. 1 [e liulfs ?].

d 89 - Tomi siyll. Als. p. 829.

d - v. seulptun ibiel

m!n-Eichler Sipis Desm. Miedz. p. 85.

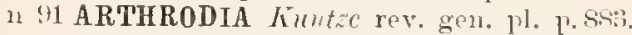

d (12Clost. Wolle Desm. U. S. el. II p.11 t.9) f.5.

o 93 - Lütlémill. Desm. Attersees 1.512.

94 - Tlithem. Not. myeolog. t. if f. 7-11). [s alia sper.]. m 14 - f. Borge Silssw. Chlor. Arehang. 1. 11 t. 1 f. 6 [Cl. acerosum ?].

\section{attemation $-r$}

d s1 EUASTRUM $W$ olle in Bull. Torr. inot. Club $18 s 1 \mathrm{p}$. 3 t. 6 f. 2 ).

d 84- Hulle Desm. U. S. p. 10:3 t. 26 f. 17 .

o 86 - Stolics Fiey Desm. 1. 115.

d 89 - Tomi syoll. alg. p. 1078.

n! 11 HELIERELLA Kuntze Rev. gen. pl. p. sus

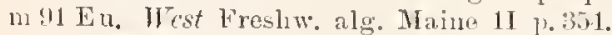

a 12 - Wolle Pesm. U. s. ed. Il p.113 t. 30 t. 17 .

\section{attenu(utum- $-11 \mathrm{~s}$}

d 18 COSMARIUM Jined in lidfs Brit. Desm. p. $110 \mathrm{t}$ 17 f. 9 .

d $52-I$ - Initch. Inf. p. $25 \%$.

d 61 - Arch. in Pritel. Inf. p. 735.

o 69 - IIttr. Skandiu. Desm, 1.15.

m 75 - f. latior Jondst. Desm. atet. 1, ㄴ.

11. CALOCYLINDRUS Rucib. Desm. okol. Krakuwa p.!. [tosmarium (Pleuroteniopsis) elongatum Rie. $1885]$.

d 87 - coolie Brit. Desm. 1) 12 t. 13 f. 12 [e lialfs].

u 93 DYSPHINCTIUM (Cyindroplinetinu) Tuner Alg. furl. orient. 1\%. H.

Cfr. Calooylindrus 1. Cosmariun cartum var., Cosm. Thwaitesii rar.

\section{Anbertirmume}

d S. SPH 291 (in Jouru. Bot.) f. 17.

m 92 - West Fr. w. Alg. W. Irel. p. 115 t. 19 f. 1.

\section{Auersurnlatii}

d 55 CLOSTERIUM Raし. in Rab. Alg. n:o 411.

d 6 - Liab. Krypt. Fl. Sachs. p. 171, f. 2 a-d p. 152.

d 65 - Tab. Flor. Eur. Alg. 3 p. 133, f. a-d p. 103 (ut supra).

d 89 - Tomi Syll. Alg. p. 819 .

n I1 ARTHRODIA Kuntze Rev. gen. pi. p. 883.

alviculatum -re

d 75 COSMARIUM Reinsch Contribut. p. 83 t. 14 f. 5 .

d 89 - Toni Syll. alg. p. 1040.

n 11 URSINELLA Kuntzc Rev. gen. 1) p. 921.

o 93 -Cosm. Tumer Alg. Ind. orient. p. 50 t. 7 f. 35.

d - $\beta$ verrucosum ibid.; t. 9 f. 8 .

\section{rustrale -is}

n 54 CLOSTERIUM Ehrenb. Microgeol. 35 A f. II 4. [Cl. antarcticam ibid, p. 260 et 262 ?].

d 68 - I a ab. Flor. Eur. Alg. 3 p. 138.

d 89 - Toni riyll. Alg. 1). 819

1291 ARTHRODIA Kuntze Rev. gen. pl. p. 853.

\section{allsturale}

$115 \pm$ EUASTRUM Ehrent. Mierogeol. 1) 7 .

\section{ritstrale}

d 92 PENIUM Ruc. Desmidya Ciastoni. p.367 t.f. f. 11.

\section{A UTISUASTREII}

d 81 Gay Monogr. loc. Conjug. p. 35. Seet. Euastri.

\section{"cersum)}

d 7 STAURASTRUM L.m l. Desm. Suee. p. 59 t. 3 f. 27.

81 -. Cooke in Greville : $\mathrm{t} .110 \mathrm{f} . \mathrm{i}-\mathrm{k}$.

o 81 - Cooke in Quckett Micr. J. 6 p. 206 (sep.p. 4) t. 16 f. 36 .

1. 87 - Cooke Brit. Desm. 1. 166 t. 55 f. 6.

d sit-Tomi syll. alg. 1) 120 .

\section{Avicula}

a 1S STAURASTRUM Trib. in linlfs lirit. Desm. p. 140 f. 23 f. 11

a $5 \mathrm{z}-$ Iritch. Inf. p. 267 .

d fil - Arch. in Pritch. Inf. 1. 739 t. 3 f. 1S-19 [e Iinlfs].

d lis - Liab. Flor. Eur. Alg. 3 1) 204

uи Tu-Nortst. Desm. Brasil. p. 22ㅡㄴ

o $71-$ I und. Hesur. Snee. 1.61.

o $7 \tau$ - Inelponte Desmil. subalp. p. 69 (sep.p. 165) t. 12 f. $23-2-29$

o 81-? Musti. N. Zeal. Desm. 1.316 t.12 t.31-32. [St. subdenticulatum Nordst. 18ss. - Cfr. 1reh. in Grevillea Tol. 10, 1881. 10.29].

o 83 - Tmmer Alg. Strensall sep. 1.5 t. f. 1.

d 84 - Wrolle Desm. U. S. p. 128 t. 10 f. 30 - 32.

o $\$ 30$ - Stolics Fey Desm. p. 167 .

d 87 - Coolie Brit. Desur. p. 1.15 t. 50 f. 6.

$11 \mathrm{~s}$ - f. Tioldt Desm. Gronl. p. 37 (St. denticulatum f. Elf $f$. 1 isini).

d s9-Toni Syll. alg. p. 1153

d s. - v. acicnlifernm If est Fr. Als. North Yorksh. P. 293 t. 291 f. 12 [Ntaur. aciculif. Inderss. 18941].

A $92-\mathrm{v}$. brevispinum Hare. Fr. Alg. Maine $1 \mathrm{Il}$ \%. L2. t. 12if. 13 [fig. mala; efr Irest in .Ton"m. Thot. 1845 p. Tu].

un 192 - Diorge Chloroph. Norsk, Finmark. p. 7 .

d 92-Hansg. I'rohtr. Algenfl. Böhm. ed. bohen. II p.176; ed. gevm. Il p. 25.

d. 23 f. 2 inelus.? St. subarcuatuon Holle 1581) [= ?. subcruciatum see. Schmille 1s9.1; St. Avicula v. subarcuatum West 1891]. 
d. 22 - Wolle Desm. U. S. or. II p. 136 t.51 t. 30-32.

(2?) 193 - Roy sicottish Desm. p. 16s (et 1s:9 I) t. 3 f. 11 .

o 94 - v. subarcautum II st New bit. Alg. 1) 10) (v. vorrucosum II'est 18(1)2; Nit. subarouatum Wolle 180()$;$ st. denticulatum litfe. 18si).

\section{bareifermm}

a 93 COSMARIUM Turner Alg. Inul, orient. p. fo t. 10 f. 8

\section{bacillure -is}

„3: BIN A TELLA Brib. Alg. Fal. 1, 269 (sep.p. 66 .

d 10 STAURASTRUM Ireb. in Menegh. Symops. Desm. 1) -2.2s (sep.p. 2s).

I) 19 - Rulfs Brit. Desm. 1.214 t. 35 f. 11. [a Brebissoni i Lag. 1892].

d 4! PHYCASTRUM Külz, spec. .lg. p. $18 \mathrm{I}$.

d 52 staur. Iritch. Int. p. 268.

o $5 h$ - Lrèt. List. p. 145.

d 61 - Arch. in Pritch. Inf. P. $7+1$.

d 67DIDYMIDIUM (Staurastrum) f. A. glabrum Reinsch Algenfl. Frank p. 153 .

d - f. B. granulatum ibid. (Nt. globulatum Rrib.)

d Rs Staur. Rub. Flor. Eur. Alg. 3 p. 201.

d $71-\beta$ obesum Land. Desm. Suee. p. 57 t. 3 f. 24.

o 85 - Wolle Bull. 'Torr. Bot. Club. 12 p. 5 t. 47 f. 5[y Wollei Lag.].

m 85 - $\beta$ o besum Boldt sibir. Clyoroph. p. 115.

d st- Wolle Fr. Alg. U. S. A. p. 11 t. 56 f. 5 - is [cx Wolle 1885 ].

d 59 - Toni Syrll. alg. p. 1156.

d - v. obesum ibid. p.11si.

in $59-\beta$ obesum llest Fr. w. Alg. North Wales p. 292 t. 5 f. 1. [S Westii Lag.].

m $90-\beta$ obesum Eichler Spis Desm. Miedz. p. 89 t.9 f. \pm 1 .

- 22-a Brebissonii Lagerh, in N. Notaris. II p. 29 (Tulfs 1818.

- $\quad$ - Pobesum ibid.

o - $\quad$ Wollei ibid. (Wolle 1585).

- $\quad-\delta$ Westii ibid. ( $\beta$ Mrest 1999).

m 82 - West Fr. w. Alg. W. Ircl. p. 173.

d 62 - Wolle Desm. U. S. cd. 2 p. 132 t. 4.9 f. 5 6.

n 93 - (Ceplualastrum) Turner Alg. Ind. orient. p. 132.

\section{BACILLARIA}

(17ss fimel. in Linn. Syst. nat. ed. 13 Tom. 1 P. 6 p. 3903). d 17 Nitzsch Beitr. z. Infus. p. 55.

d 23 Schronk Oseillat. p. 533. Species dure ad Closterinm pertinent.

d 38 Fhrenb. Infus. p. 136, Familia Polygastricarum, Sect: 1. Desuridiaca. 2. Navieulacea. 3. Eclinellea. 1. Lnecrata.

d 10 Riess Beitr. z. Faun. d. Infus, p.6 (sensu Ehr:i).

o 45 Siebold Vergleich. Anatonn. 1. wirbenl. Thiere p. 7 (Plante unicellulares) [Ctr. Eltrull, in licrlin. Bericht 1851 1). 7\%ㄹ. ].

Cfi. Arthrodia Lem. 1sib.

\section{Burillum}

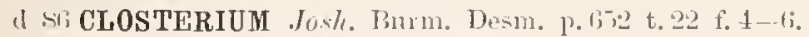
d 89 - Toni siyll. Alg. p. s.3.

n 1 ARTHR0DIA liuntize hev. gen. pl. p. s4:\%

\section{BACTERIDIUM}

d 93 Turner Alg. Ind, orient. p. 27. Subgen. Triplocerat.

\section{buruliferum}

d 53 STAURASTUM Turner Aler. 1nd. orient. p. 105 t. 1.1 f. 25.

\section{baruliforme}

d 93 D0CIDIUM Twmer Alg. Ind, orient. p. 33 t. 1 f. 15. $\mathrm{n}$ ! ti PLEUROTANIUM Hist Alg. Madag. p.16.

\section{brentoirles}

d S6Docididm koy \& Tiss. Japan. Desm. p. 211 (sep.p. (1) t. 20 . f. 18 .

d 89 - Toni syll. Alg. p.872.

\section{Baculum}

1 35 CLOSTERIUM Brib. Alg. Fal. p. 59 t. \& [Doc. Trabecula sec. Jacubs, 1sis].

11 DOCIDIUM Breh. in Diet. univ, hist. nat. tom. 5 p. !2 Clost, trabecula Ehrend. Inf., cx p.).

d 18-Tréb. in Iialfs Brit. Desm. 1.15s t. 33 f. 5 . (Clost. traheculoides Corda; Cl. Sceptrum Kütz. .

d ts PENIUM Docidium) Kütr. S̈pec. Alg. p. Ifis.

d 522 Doc. Pritch. Inf. p.274.

o $5 \mathrm{SCl}$ ost. Soubeiran in Journ. d. Pharmae. v. 33 p. 121 t. 1 f.5 [mala].

1 5S PLEUROT ÆENIUM De Iiar. Conjug. p. 75.

d 61 Doc. Arch. in Pritch. Inf. p. 745 t. 3 f. 35 [e lialfs].

d 63 Pleur. Rab. Frypt. Fl. Sachs. p. 176, fig. xyl. p. 153.

6. Doc. Crouan Fl. Finist. t. 4 t. 34 [fig. mala].

l 69 Plcur. Liab. Flor. Eur. Alg. 3 p. 111, f. xyl. p. 101.

n 70 Doc. Nurdst. Desm. Biasil. p. 204.

o 71 - Lund. Desm. Snec. p. 88.

d 73 Plenr. Hood Fr. Alg. 1. 119.

d 75 Doc. Nicrogr. Dict. p. 257 t. 10 f. 39 [e Ralfs].

o 75 -Jacols. Desm. Danem. p. 179.

d To Pleur. Delponte Desm. subalp. 1. 130 (sep.p. 226) t. 20 f. $12-16$.

m 7 Doc. Nordst. Alg. brasil. p. 17.

-d Ts-Kirchu. Alg. Sichles. p. 14.

m $78-H e m p e l$ Algenf. Chemmitz p. 112.

d 84 - Wolle Desm. U. S. p. 49 t. 11 f. $3-4$.

d 85 - Kirchn. Mikr. Ptlanz. d. Süssw. p. 22 t. 3 f. 68 (c Ralfs).

d $S_{5}$ - Frank in Lempis riynops. 3 p. 195.

m 86 - Lagerh. Amerik. Desm. p. 252.

o s6 -- stokes Kicy Desm. p.113.

d sf - C'oule Brit. Desm. p. 16 t. 7 f. 1 [e Ralfs?].

o 87 - v. Floridense Wolle Fr. Alg. U. S. A. p. 26 t. 51 f.

d 87 - Herentio Chlorosp. Ǩ́liark. p. 237.

d ss'-Hansy. Prodr. Algenfl. Bölın. p. 185.

d 8 - Toni et Levi Fl. Alg. Venez. p. 35 .

m 88 Pleur. Riabin. Chloropli. env. Kinarkow p.31s.

plı 88 - Hauptfl. Zellm. u. IIiillgallertc Desm. p. 83 (scp.p. 25) t. 2 f. $40-11$.

d 89 Doc. Tuni Syll. Alg. 1..472.

1) - v. florilense ibil.

50 - Wille Natürl. Pflanenfan. p.10) f. f) Ha (c Deljomt.).

m 90 - Birg. Desm. Trasil. p. 28 (scp.p. 93:3).

(l $-\beta$ hexagonum ibil. et t. 2 f. 2.

m (ii) - Hichle" spis Desm. Miedz. 11. sti.

m!1 P'leur. Iste. Fragm. Alg. 1 p. 116 .

1) 31 Doc. Kirchr. Mikir. IPlanz. 1. Sirssw. ed, 2 1. 21 t. 3 f. T. (e liulfs:

m 91 - Heimerl Desin. alp. 1.504.

o (12) Har. Fe Alg. Maine III p. 122.

m 5 - West Fr. w. Alg. W. Mel. p. 117.

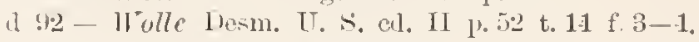

d - v. Floridense ibid. t. 12 f. 5.

ph 9.3 - Lïtkemiall. Chlorophy:llküp. ein. Desm. p. 10 t. 2 1: 9-15 [Lenium minutum sec. Wist 1895].

1n 903 Liatkemill. Desm. Attersees 1) 346 . 


\section{BAHUSIENSIS}

n 93 - Tumer Alg. Ind. orient. p. 39.

ma1-Liorge Siissw. Chlor. Archang. 1. 18.

d 9.1-Sumul. in Fl. Nebraska p. 39 t. 5 f. 1 (e Coolec) ["baculina" errore typographico pro "baculum"].

in 95 - Racib. in Flora v. 81 1. 32.

Non omnes auctores hane speciem sensu Lundellii tenent.

\section{IBahusiensis}

d 95SPIR0T屌IA Nordst. et Lülk. in Lïllemüll. Gatt. spiroten. p. is t. 2 f. 1-13. (Subuen. Polytænie).

\section{Brileyi}

a 84 Cosmarium Wolle Desm. U. S. p. $1 i 1$ t. 16 f. 17 - $1 \mathrm{~s}$ (Cosm. depressum Bait.. non Eu. depr. Nay.).

o 86 - Stoles Key Desm. 1. 127.

d s9-Toni syll, alg. p. 1030.

o 91 - H.imerl Desm. alpin. p. $59 \%$.

n :1 URSINELLA Funtze Rev. gen, 11. p.

d 92 Cosm. ITulle Desm. U. S. ed II p. 69 t. 19 f. 17 et 18 .

\section{IBuileyi}

dzf 18 APTOGONUM Tulf: Brit. Desm. p. 2os t. 35 f. 1.

d 52 -I'ritch. Inf. P. 243.

laf 60 - Wallich Desm. Low. Bengal, p. 191 t. 7 f. 5 -9 et var. quadrangulatum p. 192 et fof $[\beta$ bengalense Nordst. 1885 (tantum quod f. 7 (et s?) Tum. 1si3); f. 5. 6 et $8=5$ Wallichii Turner 1.993].

1 $61-A r c h$, in Pritch. Inf. p. 723 t. 3 f. $5-1$ i [e Rivlfs].

zf $6 \mathrm{~s}$ - liab. Flur. Eur. Alg. 3 p. 106 fig. 62 b. a. b, c. [e Iialfs].

d 73 - Delponte Desm. subalp. p. 7 (sep.p. 62) t. 3 f. 16 19 Apt. calatum v. trigonum f. italica liae. 1855].

(1) 78 - Wood Fr. Alg. P. 127.

a 75 - Mierogr. Dict. P. 63 .

ozf 80 - Hitele et Wolle in Amer. m. Mier. Journ. v. 1 D. 7 f. 6 .

n So DESMIDIUM (Norlst. in) Pointsf. Skanlin. Växt. 4 p. 24.

z so - Nordst. De Alg, et Charac. I p.1.

daf 81 - Irolle Desm. U. S. 1. 27 t. 2 f.s-12 [f. \&, !, 12? $=a \mathrm{f}$. minor, 10-11 f. major Turner 1s!13].

o s6-Stolies Iiey Desm. p. 110.

dzse-Nordst. Fr. wat. alg. N. Zeal. p. 2\%

$\circ \quad-a$ ibict. p. 27 t. 2 f. $4-5$.

$\mathrm{dz}-\beta$ bengalense ibid. (Wall. 15tit); D. tetragonum $\beta$ excavatum scherr. 18s4).

d - $\rho$ caelatum ibid. t. 2 f.b-7 (1). caelatum Kirchn. $1878)$.

o - - t. italica ibicl. (Apt. caelat. T. v. trigonnm f. italica liac. 1-sis).

o - - f. polonica ibil. (- - f. polonica liue. 1 risi).

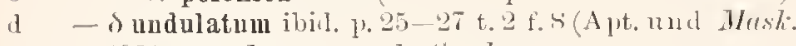
1881, non lesm. und. (orta).

a $84-70 m i$ syll. Alg. 11. Tั2.

d - - v. bengalense ibid.

il - v. crelatum ibirl.

1) - f. italieum ilis.

d - f. polonicum ibir.

1 - v. undulatun ibid. 13. 783.

n $90 \mathrm{~A} \mathrm{ptogonum} \mathrm{Wille} \mathrm{in} \mathrm{Naturl.} \mathrm{PHanzenf.} \mathrm{p.} \mathrm{15} \mathrm{f.:} \mathrm{ti}$ (e I lelp.).

o ! Desm. f. genuina Börg. Desm. Brasil. p. 25.

o S2-Harv. Fr. Alg. Maine III p. 121.

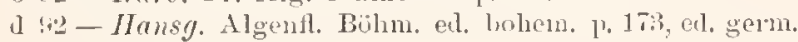
$21 \%$. dzf 92 - Wolle Desm. U. S. er. II p. 27 t. 2 f. 8 - 12.

o 43 - $r$ gennina Tumer Alg. Ind. orient. p. 14. F. minor.

zf - - - f. major ibid., t. 19 f. 11.

dzf - $\beta$ Bengalense ibid. Wu/l. 1860 quoad f. Tet 9?), t. 19 f. 10 (et 11 v. exeavatum Scharrsehm.?).

d - $\gamma$ coelatum ibid.

d - - f. Italica ibid.

d - f. Polonica ibid.

d $-i$ und ulatum ibid.

d $\quad-z$ Indicum ilid. p. 149 t. 19 f. 5.

d - 5 Wallichii ibid.; t. 19 f. 4 ( Hall. 1560 quonl f. 5 , (i) et 8 ).

m94- M/ob. Austral. Sisswasseralg. 11 p. 337.

o $(5)$ - schmille Alg. Sumatr. p. 248 t. 1 f. 15.

\section{Buileyi}

d 1 MICRASTERIAS Ralfs Brit. Desm. p. 211 t. 35 f. 4. (XI. morsa $\beta$ Wrillich 1860 .

d 5 - Iritch. Inf. p. 247 .

d $1 ; 1-$ drch. in Pritch. Inf. p. T:26.

o 65-Rul. Flor. Eur. Alg. 3 p. 195.

d 73 - Wood Fr. Alg. p. 143.

d sit - Irolle Iesm. U. S. p. 118 t. 37 f.6.

o si - Stohes Kiey Desin. p. 147.

d 89 - Toni sirll. ale. p. 1122.

n 91 HELIERELLA kintze Rev, gूen. pl, p. 8! 19.

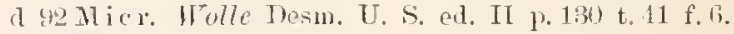

\section{Breillynere}

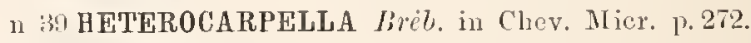

\section{Brillyrumm}

n 45 CLOSTERIUM Trét. in Jemn. Fl, Tunbr. Wells p. XIX. [d is - Tiulfs Brit. Desm. p. 164 ut synonym. (Cl. didymotocum $\beta j$.].

d

o ss-Nordst. Bornh. Desm. p. Lšo (Cl. didyınot. Ralfs at et $\beta ;$ Cl. antiace rosum).

a 93 - ["Baileyanum"] v. annulatum Eichl, et Iiac. Nowe gat. zielen. p. 118 t. 3 f. 11 [Cfr. Anz. d. Ak. d. W. Frakan Juli 1s!t? p.19!)].

\section{Iinlmarerenense}

(1) (1) CLOSTERIUM Turner Desm. Notes p.31\%.

m - $\beta$ minor ihicl.

d (14-lioy Scott. Desin. p. 243 (sep.p. 51) t. 1 f. 6.

o- $\beta$ minor ibid. p. 24 t. 4 f. 7.

\section{IBAMIBUSINA}

d 1.5 Kit: Plycol, germ. P. 1.10.

d 17 firl. Dent. Firypt. Fl. p. V1ll et sis.

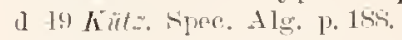

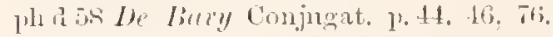

d $(: 3$ likh. Kirypt. Fl. Sachs. p. $17 \%$.

d (s) Limb. Flor. Eur. Alg. 3 p. 105 et 152.

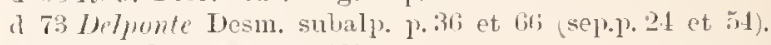

d is Hoorl Fr, $A 1 \mathrm{~g}$. P. 125.

d 7 Fronk in Lemuis Symols. p. 1 fis3.

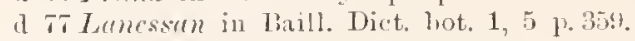

il to Kiretm. Silloles. Alg. 1) 132.

n St Grey Honogr. loc. Conj. p. 43. Sectio Hyalothacae.

il sil llolle Desm. U. S. p. 21.

(1) 85 Kïrch. Nikr. Pflauz. 1. Sü̈sw. 1) 20.

o Sti s\%okes liey Desm. P. 109.

a Sti fromk in Lemis synops. 3 p. 1:1.

d sof fooke Brit. Desm. p.s.

d. 4 II Holle Desm, U. S. ed. II 1, 21. 


\section{brembusimoirles}

d 6!SPHÆR0Z0SMA Witt. Skandin. Desm. 1, 25 t. $1 \mathrm{f}$. 12. Spondylosium pulchellum $\beta$ bambusinoides

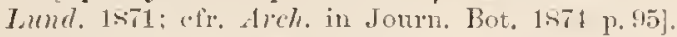

ms!1-Rucib. Hesm. Lithuan. protio.

mso- Fichler sipis Desm. Miedz. p, sil t.8 to.

o !1 - ? Ilcimerl Desin. alpin. 1. 5sil t. 5 f. 1. Hyalotheca nndulata see. Borye in Nuov. Notar. 1593 p.3\%5. - Spondylosium tetragonum f. sec. West in Journ. Bot. 18.95 p. 6.5]

bambusinum-us-a

n 3!! DESMIDIUM Rrél, in (\%er. micr. p. $2 \bar{i} 1$ absque deseriptione [Bambusina Brebissonii hütr. sec. Brél. Desm. Vorm. 1, 11!!].

n ti GYMNODESMUS Tice is. Highe Coceot. p. wh.

n Ti GMMNOZYGA Jaculs. Desm. Danem. p. 213.

n 81 HYAL0THECA (sect. Bambusina) Gruy Mon. Ioc. Conj. p. .00 .

d sitG gmozyga Ilaksy. Prodr. Algenfl. Bohm p. 169 f. xyl. 101 [e Je liny Conj.].

m - $\beta$ gracilescens ibid.

1091 - Heimerl Desm. alpin. p. 545.

$m-\beta$ gracilescens ibid.

\section{Baronii}

d 95 COSMARIUM West Alg. Madag. p.61 t.7 f. 30 .

\section{Iirromii}

d :5 STAURASTRUM l] ost Alg. Madag. p. 76 t. 8 f. 36.

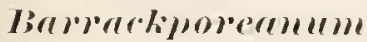

d 93 COSMARIUM Tumer Alg. Ind. orient. p. 68 t. 10 t. 4.

\section{basideromm}

d !3 DYSPHINCTIUM Tumer AIg. Ind. orient. p. 12 t. si f. t?.

\section{basidentrutume}

d re STAURASTRUM Rorge Chloroph. Norsk. Finmark. p. 8 t. 1 t. 5

$1-\beta$ simplex ibir., f. $f$.

d 15 - $\gamma$ basigranulatum Schmille Alg. Sumatr. p. $30 \%$ t. 4 f. 17 .

m.5 -. v. simplex Hest Alg. Madag. p. 60 t. 8 f. 15.

\section{bresiumerlatum}

d 95 PLEUR0T ÆNIUM West Alg. Madag. p. 45 t. 5 f. 35

\section{bertilu}

d 95 COSMARIUM West Alg. Madag. p. 60 t. 7 f. 8.

\section{bellum}

d 5 COSMARIUM West Alg. Madag. p. 60 t. 7 f. 5

\section{bellmm-r}

d ToEUASTRUM Tordst. Desm. Brasil. p. 21 (s (sep.p. 1SO) t. $2 \mathrm{f} . \mathrm{if}$.

o s. - Wildem. s. flore alg. Congo p.8.

d S9-Toni srll. alg. p. 1ris3.

d 89 - v. italicum Jiacib. Now. Desm. p. 105 (sep.p. 33) t. (f f. 3. [E. platycerum? sec. Tum. 1893]

n !1 HELIERELLA fiuntz̈e Rev, gen. pl. p. 898 .

d $95 \mathrm{E}$ u. ז. Madagascariense W"est $\mathrm{Alg}$. Madag. p. 49 t. 6 f. 7 . Cfr. Eu. breviceps.

\section{bellum}

d 93 STAURASTRUM Tumer Alg. Ind, orient. p.12s t. $11 ; \mathrm{f} .9 \%$

lordstedt. Iudex Itesmid.

\section{bengulense}

d !:3 COSMARIUM Tumer Alg. Ind. orient. p. 5i; t. \& f. 33 , t. ? f. $33: 3$.

\section{Bengralense}

d 13 DoCIDIUM Thm. Alw. Ind, orient. p. 30 t. 3 f. 4 ,

\section{Beuguleuse}

d !3 SPH两ROZOSMA Tumer Alg. Ind. orient. p. 141 t. 18 f. 5 .

\section{Brugaleuse}

d 13 STAURASTRUM Tumer Alg. Ind. orient. p. 121.

m f. minor ibid.. t. 14 f. 13.

\section{Bengralirelme}

d 43 DESMIDIUM Tumer Alg. Ind, orient. p. 147 t. $19 \mathrm{f}$. $1-3$ (D. Swartzii var. $\beta$ Irall. 1860).

\section{Bengalicum}

d 93 XANTHIDIUM Thmer Alg. Ind, orient. p. 160 t. $12 \mathrm{f}$. $32\left[A_{\Perp} \mathrm{X}\right.$. hastiferum?].

\section{Benlioei}

d s sTAURASTRUM Schuersectm. Magyar. Desm. p. 271 t. 1 f. 15

d 89 - Tomi Syll. alg. p. 1185.

\section{Benllettii}

1191 HeLIERELLA hentze Rev. gen. pl. p. 898 Micr. cornuta Benn. 18s's, non Eu. cornutum hütz. 1845).

\section{Berginii}

d as PENIUM Arch. Suppl. Cat. in Dub. Univ. Zool. Bot. Ass. Pr. I p. 121 t. 11 f. $11-15$ (in Nat. Hist. Rev. 5 p. 256 t. 21 f. 11-15. in J. Micr. Sc. 5 p. 138). [P. Navicula see. Areh, 1\$61].

\section{Berggrenii}

m 92 MESOT AENIUM Lagerh. in Ber. Deut. Bot. Ges. X 1. $52-\bar{\tau}$ t. $2 \mathrm{~S}$ f. 22 (Ancylonema Nordenskioeldii fi Berggrenii Wittr. et Nes. obscurum.

\section{Berlini}

d sisUASTRUM Boldt Desm. Grönl. p. 10 (sep.p. 8) t. 1 f. 12.

d 89 - 7omi syll. alg. p. 1073.

11 HELIERELLA Kuntze Rev. gen. pl. p. 895.

\section{birenritum -re}

d 70 COSMARIUM Nordst. Desm. Brasil. p. 212 (sep.p. 174) t. 3 f. 30

d $8: 1-$ Toni syll. alg. p. $103 \overline{\text {. }}$

o 10 - Burg. Desm. Brasil. p. 3s.

n !1 URSINELLA Kuntze Rev, gen. pl. p.924.

\section{bibrerhiatum}

d 75 STAURASTRUM Reinsch Contrib. p. 85 t.16 f. 2.

d Sy - Toni syll, alg. 1) 1203.

d 95 - v, cymatium West Alg. Madag. p. 44 t. 8 f. 28.

o - - f. brevior ibic. p. 75 t. \& f. 29.

\section{bibrerleivetum}

d 76 STAURASTRUM Tolle in Bull. Torr. bot. Club $6 \mathrm{p}$. 123 [non Reinsch]. [A Toni Srll. alg. 1889, p. 1203 in st. snbbibrachiatum transmutatum. - Quid?]. 


\section{Birenerlin}

(1) ij COSMARIUM Reinsch Contribut. 1).83 t. 16 f. 15 [f. 1 i) a non exacte e fronte].

o 88 - Nowdst. Bornh. Desm. p. 201.

d su - Tomi Syll. alg. p. 1007.

d $90-\beta$ latins Gutw. Wahr. 1. Prioritit p. 39.

a 91 - - Gutw. Flor. alg. Leopol. 1. 54 t. 2 f. 11.

n URSINELLA huntze Rov. gen. pl. p. 24.

m 91 Cosm. Rorge Sussw. Clilox. Archang. 13.31 t. 3 f. 33.

(1) 94 - v. trapezicnm Eichl. et Gutw. in Krakan Anzeig. p. 239. et Spee. alg. nov. 1. 169 t. 4 f. 21 .

m 95 - Eichler in Pamiet. Fizy. p. 60.

Ctr. Cosm. atlantoidenm f. Heim. 1891; Clepsydra Lund. Jac.; tithophornm f. 1894.

\section{birletvatum}

d 90 CLOSTERIUM Birg. Desm. Brasil. p. 30 t. 2 f. 9.

\section{birorne}

d Ss STAURASTRUM IIauptf. Zellm. u. Hiilgallerte p. 95 (sep.p. 37) t. 3 f. $21,24.27,30$ - 33 ("nov. spec.(?)").

d $8: 1$ - Borg. Bidr. Bornh. Desm. p.118 et 151 t. 6 f. 9.

d 89 - Toni ryll. alg. 1. 1210.

d - v. danicum iljid. (Börg. supra).

d $92-\mathrm{v}$. australis Ruc. Desmidya Ciastoni. p. 332 t. 7 f. 8 . m $4 . \mathrm{v}$. danicum schmidle in Flora 78 p.60.

\section{birormutum}

d 30 EUASTRUM Börg. Desm. Brasil. p. 31 t. 4 f. 26.

\section{birornllum - 11.}

d 67 XANTHIDIUM Reinsch Spec. Gen. Alg. p.119 t. 20 A III f. 1-6 (sep.p. 11 t. 1).

d 67 DIDYMIDIUM (Xanthidinm) Reinsch Algenfl. Frank. 1. $12 S$ t. 9 f. 7 . ( $\mathrm{X}$, octocorne $\beta$ major Ralfs).

d Si ARTHRODESMUS? (Octacanthium) Toni Syll. alg. 1. $106 \pm$

\section{biroromatum}

d 1 STAURASTRUM Johns. Rarc Desm, U. S. p.290 t. 211 f. !.

\section{bievenutum}

n Si3 COSMARIUM Joshua in Journ. Bot. v. 21 p. 201 [Terisimile "crenatum $\beta$ " omissum est! - Cfr C. crenatum $\beta$ bicrenatum Nordst. 18r2]

d sij-C'ooke Brit. Desm. p. 96 t. 42 f. 13 [e Nordst.?].

\section{birerenateme}

d 93 COSMARIUM Twner Alg. Ind. orient. p. 54 t. 8 f. 13 [non Josh. 1483, sec, Cooke 1886].

\section{bicumertum -"l}

d st eUASTRUM (Cosmarium) G(ay Mon. loc. Conj. p. 57 t. 1 t. 13; et Note Conj. A. m. France p. 333 .

a sil COSMARIUM Norlst. in Toni Syll. alg. p. 435.

n :1 URSINELLA Kimte Rev. gen. pl. p. 921.

\section{birervatum -"}

d 77 CLOSTERIUM Delponte Desmid. subalp. p. 112 (sep.p. 204 t. 15 f. 37 - 39. [Cl. gracile Ifeim. 1891].

d 89 - Hansg. Prodl. Algenfl. Bihhm. p. 178.

a 89 - Tomi śyll. Alg. 1.819.

m : $(0$ - Eichler Spis Desm. Miedz. p. sis.

n :1 ARTHRODIA humtie Rev. gen. pl. p. x83.

\section{birenspictutum}

n 3!) COSMARIUM Corlu in Alm. d. Carlsb. 19439 p. 243 t. .2. f. 2 [ Enastrum elegans f.].

\section{birlentutum}

d 43 COSMARIUM Tume Alg. Ind. orient. p. 55 t. 8 f. 24 [C. bigemma Ruc. v. Turnerianum Gutw. 1894].

\section{bidentrutum!}

d 49 EUASTRUM $\$ a \%$ einz. Alg. p. 122 t. 7 D f. 1 a-f. [Eu. elegans v. bidentata Jacols. 1875. See. Wil$1 \mathrm{~cm}$. 1s.4: $b$ et $c=$ Eur. elegans, $a$ et $f$. $=$ idem $v$. medianum f. punctatum?

d 90 - f. Brasiliensis Kor\%. Desm. Brasil. p, 35 t. 3 f. 21.

\section{bideutrutum}

d 7 PLEUROTANIUM (Triploceras) Norlst. Alg. brasil. p. 1 ts t. 2 f.3. [Triplocer, gracile subspec. Nordst. 1548.

\section{birlentatume}

d GSTAURASTRUM Hittr. Skand. Desm. p. 16 t. 1 f. 7. [St longispinnm Lumlell Desm. Suec. p. 73, et Cookc, non Brit.) Areh.?

o 72 -Arch. in (2. J. M. Sc. v. 12 p. 201

n 93 - Schizastrum) Turner Alg. Ind. orient. p. 132.

\section{bidentulutulu -n}

n 89 COSMARIUM Bold Desm. utbredn. Nord. p. 21 (sep.p. 6ii) (C. pnnctulatnm $\beta$ bidentulatnm Wille 1579 .

d 89 -Toni syll. alg. p. 1050.

n 91 URSINELLA funtzc Rev, gen, pl. p. 124.

\section{Birneammm}

d 62 STAURASTRUM Rab. Alg. n:o 1410. [St. muticnm f. Bien. Reinsch 1867 ; St. orbicnlare b. Bien. Rab. 1 s6s; St. muticum I'erty??).

d 75 - f. spetsbergensis Nordst. Desm. aret. p. 32 t. 8 f. 35. [St. Clepsydra Nordst. 1872, non 1870].

z 77-Nordst. in Wittr. et Nordst. Alg. exs. n:o 73; et (18s9) in fasc. 21) p. 36.

A $79-\beta$ ellipticnm Wille Ferskv. alg, Nov. Semlj. p.50 t. 13 f. 49

d 4 -v. ellipticum Holle Desm. U. S. p. 124 t. 42 f. $1-2$.

o 85 - f. spetsbcrgensis Boldt Sibir. Chloroph. p. 110.

m - $\beta$ ellipticum ibid. p.111.

d $-y$ connectens inid. p.111 t. 5 f. 19

o 86 - Stokes Key Desm. p.164.

mis-Iste. Jel. magyar. alg, p. 231.

- f. convexa ibil.

d 59 - f. minor Mask. Furth. Not. X. Z. Desm. p. 22 t. 4 f. 36 (fig. sec, anct. in litt, non accurate sculpta).

d s.4 - Toni Syll. alg. p.11:1.

d - v. ellipticum ibid.

d - f. spetsbergense ibid.

d - v. connectens ibid.

d 12 - v. ellipticum Wolle Desm. U. s. ed. II p. 137 t. 53 f. $1-2$.

m93 -- v. ellipticum Schminle Beitr. Alg. Schwarzwald. p. 104 t. 5 f. 29 .

m 91 - f. spetsbergensis Bürg. F. alg. Grönland. p. 25. m 45 - West Alg. Marlag. 1. it.

\section{bienense -is}

d 199 CLOSTERIUM Not. Desm. 1tal. p. 65 t. 7 f. 70.

d 89 - Toni syll. Alg. p. 821.

n !1 ARTHR0DIA huntze Rev. gen. pl, 1'893.

\section{bifurimm}

d si COSMARIUM $J_{0 .} h$, Burm. Desm. p. 649 t. 25 f. 5 \& d s! DISPHINCTIUM ? Tomi syll. alg. p. 856. 


\section{bificlull}

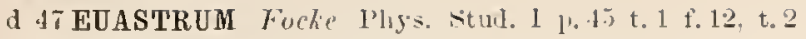
f. 22.2. [Micer. pinnatifida?.

\section{bifillm-r}

d 31? DESMIDIUM E7renz, Organ. kl. Raum. p. 293 (sep.p. 144).

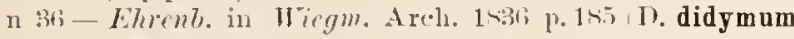
corder.

d 3 is- Elmenl. Inf. 1. 141 t. 10 f. Xl.

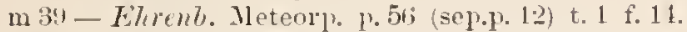

o 10 - Curde in Alm. d. Carlsb. 1.411 1. 203.

d 10 -Menegh. Synops. Desm. p. 203 (sep.p.3).

d 45staurastrum Ralfs Ann. Nat. Hist. v. 15 p.151 t. 10 f. 3 (et 1riffi in Trans. Bot. Soc. Edin. v. 2 p. 138 t. 13. [ it. brachiatum?

a to GONIOCYSTIS (Staurastum?) H/rss. Brit. Alg. p. $35 \overline{5}$ t. $\$ 5$ f. 2 [e Ralf: l. c․ delineata].

d to PHYCASTRUM Kitiz. Phrcol, germ, p. 138.

d 4 Desu. Rib. Deut. Kiylt. Fl. p. 57 (inclus. D. eustephan.?).

d 4S STAURASTRUM 7ive in Ialfs Brit. Desm. p.215.

d 4t) Phreastruin hütz. spec. Alg. P. 1sil.

y 19 - (stenactinium) Vreg. einz. Alg. p.12s.

d 52staur. Iritch. Inf. p. 264.

54 Desm. Ehrenb. Mierogeol. t. 34 XII B. f. 13 ie Mleteorpap. delineata].

d filstanr. Arch. in I'ritch. Inf. p. Tit.

d $63-$ Rab. Krspt. Fl. Sinchs. p. 192.

d Gin - Rab. Flor. Eur. Alg. 3 p. 20 .

d $71-$ L.und. Desm. Suec. p. 62 t. 4 f. 2.

d Ts-Kirchn. Alg. Scliles. p. 169.

m su - Nordst. De Alg. et Charac. 1 p. 10.

o 53 - r. hexagonum Scharischm. Magyar. Desm. p. 273 t. 1 f. $1: 1$

m s5 - Boldt sibir. Chloroph. p. 114.

n si-Josh. Burm. Desm. 1. 1,10 t. 24 f. s-4! rat.

d si-Cuoke Brit. Desm. 1. 163 t. 5 - f. 3 [e Lumd. 1s61].

d ș-Hunsy. Prodr. Algenf. Böhm. p. ㄴ1ㄹ.

d s.y - Toni Syll. al]. 1. 1198.

d - v. hexagonum ibid. p. 1199.

m 90 - Eirhler spis Desn. Miedz. p. 10 t.9 f. 43.

m $! 1$ - Ileimert Desin. alpin. p. 604.

d 93 - (richizastrum) v. tortum Tumer Alg. Ind. orient. p. 10 s t. 15 f. S, t. 14 ; f. 37 .

- f. unciuata ibid.

- v. diptilum ibid. (St. diptilu in Nordst. 1s70).

\section{bifidus:}

d 5 f ARTHRODESMUS Brib. List. p. 135 t. 1 f. 19.

d 61 - Arch. in Pritch. Inf. p. 736.

d 6 s - Lab. Flor. Eur. Alg. 3 p. 229.

o 70 - Arch. in Q. J. M. ice. 5.10 p. 10 .

m 71 - Lumel. Desm. Snee. 1].55.

m. หร - Boldt sibir. Chloroph. p. 109.

d si-Cooke Brit. Desm. p. 1:37 t. 4 - f. 2.

d ss-f. Boldt Desm, Grönl. p. 30 t. 2 f. 34.

d 89 - Octacantlium) Toni Nyll. alg. p.1064.

o 89 - Lucib. Now. Desin. 1. $\$$.

o- f. ibid. p. 97 t. 6 f. 11.

d 8. - r. truncatus West Fr. Alg. North Yorksh. p. 293 t. 291 f. 4 .

m (1) - Eichler Spis Desm. Miedz. p.Ss.

m 31 - Gutw. Flor, alo. Lropol. p. 61 t. 3 f. . .

d 92 - ₹. latidivergens West Fr. W. Alg. W. Irel. p. 169 t. $22 \mathrm{f} \mathrm{s}$

(13 - Sichmidle Beitr. Alg. Schwarzwald. t.5 f. 25. [?].
11413 - Rehizodesmus) Tumer Alg. Ind. orient. p. 137.

d ! $1-v-$. trulucatus f. succisa West New Brit. Alg. p. t. 2 f. 52 .

\section{bifurellu}

d St STAURASTRUM Josh. Burm. Desm. p. 1it2 t. $2: 3$ f. 25 -2s. $[\mathrm{F} .27=$ st. Burmense Tumer 1S:3].

d sa - Tomi syll. alg. p. 1231.

o 93 - Tumcr Alg. Ind. orient. p. 128.

\section{BIGASTRIDIUM}

d s9 Racib. Now. Desm. p. 7.. Sect. Cosmarii. Subsect.: Microbigastridium et Enbigastridium.

\section{bigemma}

d si cosmaridm lincib. Now. Desm. 1. 4is sep.]. 13) t. 5 f. 10.

11 ).- ve genuinum Gutu. Fl. alg. 'Tamapol. p. 99 (Rac. $185 \%$.

d - v. podolicum ibid.. t. 3 f. 3 .

o - v. Turnerianum ibid. p. 10n) (C. bidentatum Turn. 159:3).

\section{bigorremse}

d 92 COSMARIUM Gay Alg. Bagn. Bigorr. p. XXXI c. fig. xyl. [An C. tetragoni forma?]

\section{Bigorrianum}

d 49 EUASTRUM Perty in Bern. Mitth. p.174.

d 5o ZYGOXANTHIUM I'erty kleinst. Lebensf. p. 209 t. 16: f. 23. [Xastlicl. armatum f.]

(1) tis XANTHIDIOM Rab. Flor. Fur. Alg. 3 p. 222.

d 89 - (Schizacantlium) Toni s.sll. alg. p.91s.

\section{bigrenulatum!}

d so COSMARIUM Anderss. Srerig. Chlor. 1 p. 16 t. 1 f. 11. d 93 - v. polonica Eichl. et Rac. Nowe gat. zielen. p.11 t.3 f. 5. [Quid?].

m94-Borge Süssw, Chlor. Archang. p.31.

\section{bilobum}

d 93 EUASTRUM Lütlemüll. Desm. Attersees p. 561 t. 9 f. 13 (Eu. elegans v. inerme Not.. Eu. inerme v. cracoviense liac.).

\section{binaruleatum}

d in STAURASTRUM Wolle in Bull. Torr. bot. Club r. 6 p. 123. [An St. Avicula Tolle 18st??]

d $84-T o n i$ śyll. alg. p. 1210.

\section{bincle -is}

1120 HETEROCARPELLA Turp. in Diet. sc. nat. Planch. bot. Vésic. f. 14 [fig. mala sine descriptione].

d $25-T u p$. aperec. organ. p. 315 t. 13 f. 17 [e Turpinii fig. 1 - 20 male depicta?.

d 34 - hütz. Syn. Diat. p 598 (sep.p.

d. $35-$ Breb. Alg. Falais. p. 56 t. $i$ [fig. sinistra e Turp.? dextra?.

o 40 COSMARIUM Menegh. Synops. Desm. p. 221 (sep.p. 21). d 41 EUASTRUM Ehrenb. Berlin. Monatsber. 1810 p. 208. d 44 -- a Ralfs Ann. Nat. Hist. v. 14 p. 193 t. 7 f. 7 a (et 1 inf Trans. Bot. Soc. Edint. r. 2 p. 130 t. 11) [Fig. 1. sinistra $=$ Eu. Ralfsii $a$ inflatum $K u t z .1849$. a. dextra $=\beta$ emarginatum ibid].

d $-\beta$ truncatum ibid.: f. 7 lo

o 45 Heterocarpella Turp. Dict. d. se. nat, tom, 61 p. 26. d $45 \mathrm{Eu}$. Hass. Brit. Alg. p. 384 t. 11 f. 4-5 [e Talfs 1. c.]. d 45 - Kuitz. Phycol. germ. p. 135 [Eu. Didelta]. 
dzfts - Rulfs Brit. Desm. p. (n) t. 14 f.s a-e, g. h $[b .=$ En. Ralfsii $t$ inflatum Kütz. 14t! $b$. = f. ventricosa Turn. 1893; c. = f. secta Turn.; e =f. minuta Tum.].

d - $\beta$ ibid.. f.s f. [En. denticnlatum (Kirclu.) Gray]. (rec. descriptionem $\beta$ truncatum Ralfs 1 stt cum hac varietate identicum esse videtur. sed figuro T b. b) malie sunt. et descriptio non satis verbosa.].

d 4!)-K̈̈̈tz. spec. Alg. p. 172.

d 52 - Pritch. Inf. p. 2.0) isensu Rulfsii) et p. 251 (sensu Ehronb:i).

d $61-A r c h$. in Pritch. Inf. p. 730; et $\beta$ t. 3 f. 13 [e Ralfs].

d $93-R a b$. Krypt. Fl. Sachs. p.1s7.

d 67 DIDYMIDIUM (Eu.) A. corniculatum Reinsch Al. genf. Frank. 1. 139, $\alpha$.

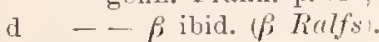

d - - $\gamma$ ibicl. (Eu. spinosum Focke quoad f. 16. Eur. dubium Neq. incl.).

d - B. tetralobulum ibid.; $a$ et $\beta$.

1) - C. integrum ibid.

o $67 \mathrm{Eu}$. Not. Desm. Ital. p. 3 t t. 3 f. 18.

d 68 - hirl. Flor. Eur. Alg. 3 p. 186.

m 70 - Nordst. Desin. Brasil. 1.218; r. et $b$.

d c. forma maxima, ibjd.

d d. forma Lagoensis, ibid. p. 218 t. 2 f. $t$.

o 71 - Lumd. Desm. Suec. p. 22-23: forme a. b. c.

d -y elobatum ibid. p. 23 t. 2 f. 7. [E. Lundelli Benn. 1856 , see. Bem.. sed ut viletur non ita?

o 72 - Wittr. Gotl. Öl. sütv. Alg. p. 49 .

d - $\beta$ insulare ibid., t. 4 f. T. [E. insulare Roy 18S3].

d $-\gamma$ angustatum ibid. $\rho^{\circ} 50$ t. 4 f. 8 [C. angust. Noredst. 1575].

m 72 - Nordst. Desm. Spetsb. p. 37.

o 73 -v. angustatum Arch. in Q. T. М. s. v. 13 p. 315 (et 101).

o 73 - v. insulare Arch. in (2. J. M. S. v. 13 p. 434.

d 73 - Delponte Desm. subalp. p. 107 (sep.p. (15) t. 6 f. $9-10$.

d 73 - Hood Fr. Alg. p. 140 t. 13 f. 3.

zf 75 -- Re'mseh Contribut. p. 92 t. $16 \mathrm{f} .7$.

a 75 - dissimile Tordst. Desm. aret. p. 31 t. 8 f. 31 .

m 7 s - Nordst. Alg. Sandvic. p. 15.

a 78 - a. typicum Kirchn. Alg. Schles. p. 15s.

d - b. denticulatum Kirchn. ibid. (var. $\beta$ Rulfs 18ts) [E. denticulatum Gray 1884].

d $78--\therefore$ gibbosum lieinsch Freshw. Alg. Fierguel. p. 83 (sep.p. 19 ).

$79-$ v.? Cohn Desm. Bong. t. 11 f. 10.

m 79 - Wille Ferskv. alg. Nov. Semlj. p.32.

m 79 - f. Wittr. in Wittr. \& Yordst. Alg. exs. 11:0 252.

m so - Wille Norg. Ferskv, alg. I p. 23; var. $\beta$ Fialfs.

o s1 - ? Mask. X. Zeal. Desm. p.306 t. 12 f. 26 (non bona sec. Mask. 18s3 et 18s:) Eu. denticulatum Mask. 18s9) [Cf. Areh. in Grevillea 1881 1.29. Eu. Turneri West 1592].

m $8: 3$ - v. majns Wolle in Bull. Torr. bot. Club. v. 10 1. 18.

d $8: 3$ - v. obtusiusculum Schaarschm. Magyar. Desm. 1) 243 t. 1 f. 3.

83 - Turne Algce Strensall f. 5.

m 81 - Artari Liste alg. Muscon p. 142.

mst - Gay Mon. loc. Conj. p. $5 t$.

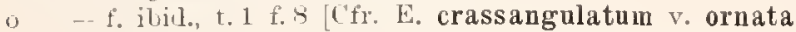
West].

d 4 - Wolle Desu. U. S. P. 107 t. 27 f. $23-21$.

(1 bi -- Kirchn. Mikr. PHanz, d. Kiissw, p. 24.

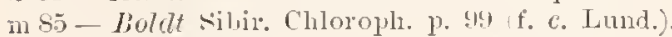

n $s 6$ - f. crassum Jowh. Bumu. Desin. p.1387 t. 23 f. $11-13$ [Alia spee?]. d sf-Fronk in Leunis sinops. 3 p. 19k;

o S6-Stolies Kiey Dean. p. 145.

d 86-Contie Brit. Desm. p. Tis t. 3.5 f. (5 [e Ralfs partim?].

d -v. $\beta$ denticulatum ibid.; t. Bas f. $T$ [fortasse e Tirifs].

d - v. angustatum ibid., f. 9 .

d - v. insulare ibid., f. 10.

4 - v. elobatum ibid., f. 8 [e Lumd. 1si1].

d $s \overline{-}-\mathrm{v}$. rotundata 1ste. Diagn. prev. in Notar. p. 236 (sep.p. 7) ("Brib. sub. E. lobulat. 18.36")

d 87 - v.? Martell in Ant. Inst. bot. di Roma v. 3 p. 8 fig. xyl. t.

d 8 - Alexenlio Clrlorosp. Kihark, p. 241 .

d 88 - Ilansg. Prodr. Algenf. Böhm. p. 207 et 25ㄹ.

d - Pdentieulatum ibid.

d $-y$ granulatum ibid. 1.253.

1 - $-\delta$ simplex ibid. p. 253 (E. simplex Wolle).

m 88 - Boldt Desm. Gröıl. 1.8 (formæ Rulfs).

m ss - Iste. Jel. magyar, alg. j. 2220.2.

o - v. rotundata ibid p. 20.3 t. 1 f. 7.

un Ss - f. minor West Desmo of Maine p. 340 .

m sì-Racil. Mat. flor. glon. Polsk. p. 113.

m 89 - f. minor TVest Massach. Desm. p. 19 t. 3 f. 24.

ozst-v. elolatum Whest Freshw. alg. Maine p. 20r3,

d 89 - Toni syll. alg. p. 1084.

d - v. granulatum ibid.

d - v. insulare ibil. p. 10s.

d - v. dissimile ibid.

d - v. obtusiusculum ibid.

d - v. crassum ibid.

o-v. lotumatum ibid.

m - v. majus ibil.

d - v. simplex ibid.

m 9 - a. typicum Gutw. Fl. glon. Galic. 2 p. 16.

m 4 - f. minor Thest Fr. W. Alg. North Wales p. 295.

o 9 -f. Gutw. Wahr. d. Priorität p. T2.

m

m 90 - Anderss. Sverig. Chlor. 1 p. 10. (form. c. Lund.).

m!11-Kirchn. Mikr. I'flanz. d. Siissw. ed. 2 p. 25.

m 91 - Heimcrl Desm. alpin. p. 60?.

m 91 - Borge Bidr. Sibir. Chloroph. p.!.

n 91 HELIERELLA Kuntze Rev. gen. pl. p. s98.

d $91 \mathrm{Eu}$. f. Gutw. Flor, alg. Teop. p. 73 t. 3 f. 25 [f. Gutwinskii sichmille 18?4.

my2-p insulare Borge subfoss. sütv. alg. Gotl. p. 50 et 58 .

d $92-f$. hians Hest Fr. W. Alg. W. Irel. p. 140 t. 20 f. 1 .

1 - - subelobatum ibid, et t. 20 f. 15.

o !2 - Mob. Anstral. Sirsswasseralg. 1. 145 [E. denticulat $n \mathrm{~m}$ ].

m 92 - Rac. Desmidya Ciastoni, p. 379.

d 92 - Wolle Desm. U. S. ed. II p.117 t. 31 f. 23 et 24 .

d $92-v$. retusum WTest Alg. Engl. Lake Distr. p. T23 t. 9 f. 6.

d !13-Builey Contrib. Anstral. Sisswasseralg. p. t9 t. 1ij f. 4 if.

m 43 - Liitliemïll. Desm. Attersees p. 55!).

on - f. ibid. (Gay 1sist).

$m$ - r. elobatum ibid.

nu - v. obtusiuseulum ibid.

d - v. elongatum ibid.; t. 8 f. 11.

u: 13 - v. colniculatum Weiss in Bayer. bot. Ges.p.48. n - v. tetralobum ibid.

m $9: 3$ - f. minuta Twmer Alg. Ind. orient. p.81 t. 10 f. 50 (lialfs 1sitis fig. $8 \mathrm{e}$ ).

$m$ - f. ventricosa ibil. Ralfs l, e. 8 b; forma b. Lumd. 18.11

d - f. subsecta ilid.; t. 10 f. 30 .

d -f. secta ibid.; t. 10 f. 35, 39. 47.t. 11 f. 5 (Lund.1871 
forma c. liulfs \& e; rerisimile E. elewans r. danica Jucubse 1sion.

(l - v, uuicorne ibid.; t. 1n f. is.

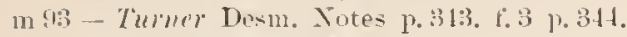

o : $1-f$. Gutwioskii schmiale Alg. Geb. Oberrleins 1 . 52 f: Litw. 1sil).

m 94 - Iste. Adat. Roman. alg. p. 1it.

d 9.1 - f. Dorge silissw. Chlor. Areluang. 1) 333 .

y. - v. insulare Juhns. Rare Desm. T. S. p. 2uij t. $211 \mathrm{ft}, \mathrm{s}$.

m 94-Alerentio Mater. alg. Klınk. l. 23.

m94-* dissimile liorg. F. alg. Östgrünl. p. 32.

o - f. ibid.. t. 2 f. 34 .

dz:4a - f. schmidle in Hedrig. 31 p. is t. 1 f. $1: 3$ et 14.

m 95- - elobatum Eichler in Paniet. Fiz. 13 p. 61.

o 9 - v. granulatum t. ? Schmille Beitr. alp. Alg. p. 21 et $(18.5)$ t. $16 \mathrm{f} .7$.

1295 - West Mlg. Madas. p. 53 .

Cfr. Eu. Diodon, formosum, lobulatum, polare, spinosum.

\section{IBINATELLA}

d 35 Rreb. Alg. Falaise 10.56 et 269.

d 39 Breb. in Chev. Mic1. 10.272.

d 42 Bréb. in Diet. univ. hist. nat. p. 57\%. Sec. auct. ipse hoe genus delendum est, pro max. parte cum Staurastro. et p. min. parte cum Cosmario identicum.

\section{binere}

a 1 COSMARIUM Lund. Desm, Suec. p. 49 t. 3 f. 15 ? C. quadratum Hess. 1845 quoad f. 12 [Relfs 1811 f. "dextraj.

d s! DISPHINCTIUM Toni syll, alg. p. $88 \%$.

\section{binodulum -re}

d $\overline{7}$ COSMARIUM Reinscle Contribut. p. $8: 3$ t. 15 f. 5 [C. isthmochoudrum Nordst. $18 \mathrm{i} 3$ sec. Nordst. in Hedwigia 18t; p. fio].

o sy-Tomi syll. alg. p. $103 t$.

n 11 URSINELLA Kuntse Rev. gen. pl. p. 42 .

\section{binum -re}

d $\rightarrow$ COSMARIUM Nordst. in Wittr. \& Norlst. Alg. exs. n:o 3s:3; et (1S69) in fase. 21 p.33.

4) 89 - Toni syll. alg. p. 993 .

a sy-v. Racib. Now. Desm. p. 93 t.5 f. 25.

d s1 URSINELLA huntze Rev. gen. [1]. p. that.

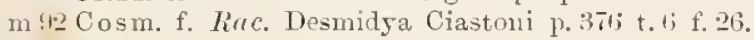

m93 - - Lïtlemiill. Desm. Attersecs 13.5\%9.

\section{bioculatume -a}

1 35 HETER0CARPELLA Brél. Alg. Fal. p. 56 t. 7 [Ex p.

$=$ C. Phaseolus sec. Nordst. Bornh. Desm. 1. 201 t. if f. $12-14$ ).

n 3 - CosmaRIUM Menegh. Consp. alg. Engan. p. 18 (sep.) [C. Meneghinii Rret. sec. Rrilfs Brit. Desm.].

d to-Menegh. Sinnops. Desm. 1.220) (sep.p.20). = idem.

d ti EUASTRUM Kütz. Plycol, germ. 1.136. = idem.

d $4 \bar{\gamma}-$ Rab. Dent. Irspt. Fl. p.51. - idem.

dzf 48 COSMARIUM Jirit. apud Rulfs Brit. Desm. p. 95 t. 15 for [Non una species sec. Nordst. in Bornh. Desm. 1. 201].

d 4 - Kütz. Spec. Alg. 1'. 16j sensu Menegh.

d $-\beta$ punctatum ibid.

dz $52-$ Pritch. Inf. p. 2052.

lzfil--1reh. in Pritel. Inf. p. 731. o bi DIDYMIDIDM, cosma ium Re inseh Algenfl. Frank. 1'. 10 T [inclus. C. tiuctum].

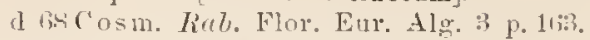

1) - b. crennlatum ibil. Eus. erenulatum Tay. 1St! t. $T$ f. 1 I $\mathrm{e}$.

ก 72 - f. Noidst. Desm. Nipetsh. p. 29r [C. pseudoprotuberans]. $\mathrm{d}(\%)$ T3-Wworl Fr. Alg. P. 131.

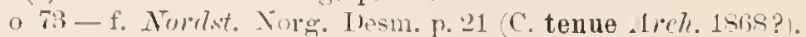

d\% 75 - Microgr. Irict. p. 202.

7.) - Ticinsch Contribut. t. 12 f. A. [Quid?].

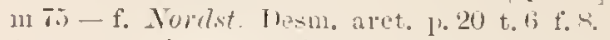

1) - $\beta$ triquetrum ibial. p. 20 t. 6 f. 3.

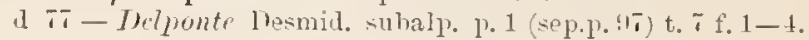

d\% $\mathrm{ti}-$ Kirchn. Alg. Fihles. p. 14\%.

o 7 - t. iutermedia Winle Ferskv. alg. Nov. Semlj. p. 11 t. 13 f. 39 !.

1 $\$(0)-\beta$ parcum lWhe Norg. Fersk. alg. I p. 35 t. 1 f. 21.

d 83 - v. omphalnm Schureschm. Magyar. Tresm. p. 270 t.

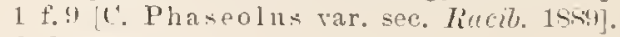

(1) - f. depressum ibid: f. 10.

m st - b. evenulatum Lopot Mat. alg. Warszaw. 17. 252. mint Eu. Cosmarium) Gay Mouogr. loe. Conj. p. j7.

dzf $31 \mathrm{Cosm}$. Wolle Ihesm. U. S. p. 160 t. 15 f. $21-22$ [C. teune Arch. sec. Johns 1s94. sed verisimile nou ita].

d s.̃ - Kirehn. Milir. Pflanz. d. Siissw. p. 24.

m. Sis - Boldt Sibir. Chloroph. p. 103.

m $\quad-\beta$ pareum ibid.

matj - $\beta$ pareum Lagerh. Americ. Desm. p. 241 .

o st-stokes liey Desm. P. 127.

lzf 86 - Cooke Brit. Desm. p. 89 t. 37 f. 6 [partim e Rulfs].

d 8 - Alexemko Chlorosp. Khark. P. 260.

dzss-Hrensy. Proll. Alueuf. Böhm p. 193.

d $-\beta$ parcum ibirl. p. 2in.

m s8 - Rivbin. Chloroph. env. Kharkow p.325.

ms - Boldt Desm. Grönt. p. 16.

in - f. ibid. (f. Nordst. 1855).

m - $\beta$ pareum ibil.

ms - Iste. Jel. nagyar. alg. p. 227.

o ss - $p$ omphalum Norlst. Fr. wat. alg. X. Zeal. p.54.

$n-y$ depressum ibirl. p. Gu.

dz 89 - Toni Syll. alg p.933.

d - v. parcum ibid. p.934.

d - v. crenulatum ibil.

d - v. omphaImm ibid.

d - f. depressum ilir.

d - v. triquetrum ibid.

d $10-c$ - excavatum Gutw. Walne. 1. Prioritat. 1)67.

d 91 - Kirehn. Mikir. Pflanz. d. Sï̌sw, et. 2 p. 24.

m 91 - Heimer? Desm. alpin. p. 59 .

m s1 - Borge Bith. Sibir. Chloroph. p. 1…

1. "1 URSINELLA huntze Rev. gen. pl. p. pl.

o 91 Cosm. v. omphalum f. subquadrata W'e.t Fresliw. alg. Naine 11 3. 35.5 t. 315 f.?.

m 91 -. f. Gutw. Flor. alg. Leopol. p. 46 t. 1 t.25.

1 - r.excavatum ibil. et t. 1 f. 21;

m 12 - Burge Chlolopli. Torsk. Finmalk. 1. 12.

dzf 92 - Wolle Desm. U. ז. ed. II p. if t. 19 f. 21-22.

m 13 - Lïthemiull. Desm. Attersees p. $54: 4$.

m - v. pareum ibid.

met - f. Selumidle in Flora is p.51 (Gutw. 1w91).

$\mathrm{m}$ - v. depressum ibid.

m (3) - Alecenko Mater. ale. Thinark. p. 2 t.

mitH-Ibirg. F. alg. Ötgrönl. p. 1s.

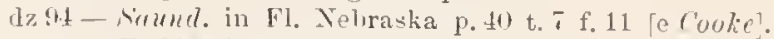

mas- Eirhler in P'aniet. Fizy. p.54.

Cir. Colpopelta deplanata, Cosm. Meneghinii ff.. Phaseolus f.. undulatum 


\section{biprepillatum}

n. 4 CosmarIUM West New Brit. Alg. p. T (C. Boeckii $\because$ bipapillatum West 1s, 2 ).

\section{biprestitus}

24 GYGES Lhromb. Symb. phys. Erertebr. Zool. Phytoz. t. 2 f. 114.

d 31 - ibirl. "Text" Polygastrica fol. d. a " "Var." = Gy" ges Grannlnm sect, anct. in Infus, p. 52).

d 32-Ehroub. Entw. d. Infus. in Abh. d. Berl. Ak. 1831 p. (i1.

d 3r-Ehremb. Infus, p. 52 t.2 f. 20.

o $4 \bar{\imath}$ - Focke Plys. Studien I p. 29) (Xanthidinm (sensu latiss.) s s.. 1 .

o 91 - Kuntze Rer. gen. plant. II p. 896 (Cylindrocystis Brebissonii Menegh. 183๖).

o 13 - Nordnt. in Hedwigia 1893 p. 148 [Hec sprecies El. renb:i nulla planta desmidieacea est].

\section{bipes}

pli 31 COSMARIUM Cordr in Alm. d. Carlsb. 1835 p. 178 157 t. 2 f. 21 . Enastr. margaritaceum sec. Ehrenb. in Wiegm. Areh. 1836 p. 1s5, Cosm. Botrytis see. lintfs].

o 39 STREPHOCYSTIS Corda in Alm. d. Carlsbad 1839 p. 242.

\section{bipuesetetum}

a !) COSMARIUM Bü\%. Desm. Brasil. p. to to 4 f. 33 .

\section{bireme -is}

d 70 COSMARIUM Nordst. Desm. Brasil. p. 212 (sep.p. 174) t. $: 3 \pm 3.3$

o $71-$ f. Lund. Desm. šnec. p. 38.

o 73 - Nordst. Norg. Desm. p. 18.

d 84 - Wolle Desm. U. \&. p. A2 t. 19 f. 23-21.

m 84 - Wille Sydamerik. Algft. p. 1i;.

o sh-stokes key Desin. p. 12!.

o se-f. Fordst. Fr. wat. alg. N. Zeal. p. ril.

d sit - Toni syll. alg. p.1083.

d $10-\beta$ Galicionse Gute. Wahr. d. Priorität p.fog.

n 91 URSINELLA hiuntze hev. gen. pl. p. 9.24.

m 91 Cosm. frutu. Flor. alg. Leopol. p. 5 \%

d - p galiciense ibil.. t.: f. 15.

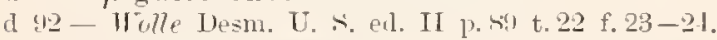

m 13 - f'. major ("Lmd.") Schmidl" Beitr. Alg. Schwarzwalit. p. 103 t. 6 f. 1 .

m 44 - lioy Scottish Desm. p. 43.

d 55 - r. rotundatum West Alg. Madag. p. 56 t. 6 f. 37 .

a - r. crassum ibid.; t. 6 f. 36.

\section{bivetull - "l}

d th COSMARIUM linlfs Brit. Desm. 1) 10.2 t. 16 f. 5 .

d 50 - Pritch. luf. 1. 254 .

a $5 f-\beta$ triquetrom Bréb. List. p. 130 t. 1 f. 9.

o li1-Huntzsh in Rab. Alg. Eur. Hby $b$ (in Dec. 121 $-12 \%$

d fil-Arch. in Friteh. Inf. p. $733(+\beta)$.

d 63 - Lab. Krypt. Fl. Sachs. p. 201 (et $\beta$ )

d 68 - Iíl. Flor. Eur. Alg. 3 p. 171.

d - b. triquetrum ibid.

o 71 - Lumel. Desm. Śnee. 1. \$30; forma.

o 72 - Wittr. Gotl. Ol. sötr. Alg. 1. 55; forma.

m 75 - Nordst. Desm. aret. 1'. 26.

d - f. snpernumeraria ibit. p. 29 t. 7 f. 18.

d — trigibberum ibid. 1. 26 t. 7 f. 19.

m i6-Nordst. Desm. Ital. 12.40. d 78 - Kivchn. Alg. Sclrles. p. 1it.

d $7-\beta$ intermedium Wille Ferskv, alg. Nov. Semlj. p. 3 i t. 12 f. 15.

o 83 - v. trigibberum Joshuu in Journ. Bot, v. 21 p. 291.

$\mathrm{mS4}$ - Artari Liste alg. Moscou p. 141.

d 84 - Wulle Desm. U. S. p. Sti t. 17 f. 1-2.

o sti-Stokes Key Desm. p. 129.

d st-Cooke Brit. Desm. p. 10.8 t.34 f.5.

d - votriquetrum ibid. p. 109.

o 57 - r. Floridense Wolle Fr. Alg. U.S. A. p. 34 t. fi2 f. 6.

d 87 - Alexenlo Chlorosp. Filıak. p. 269.

d 88 - Hansg. Prodr. AJgeufl. Böhm. p. 2922 et 251 .

d $-\beta$ minus ibid. p. 2.1.

d sa - f. groenlandica Boldt Desm. Grönl. 1. 25 t. 2 f. 26.

d $-\mathrm{f}$. subconspersa ibid.

mss-Hoff. in Nordst. Bornh. Desm. p. 195.

m 89 - Ist $\ell$. Jel. magyar. alg. p. 224.

in Sr-Nordst. Fr. wat. alg. N. Zeal, p. 78.

m sil-Hare. Fr. Alg. Maine II p. 186.

d. 8 - Toni syll. alg. p. 1015.

o - v. triquetrum ibid.

d - subsp. trigibberum ibid.

d - r. intermedium ibid.

d - f. groenlandieum ibid.

d - f. subconspersum ibid p. 1019.

- - r. floridense ibid.

oz 89-liacib. Now. Desm. p. 92.

$m$ m- West Fr. w. Alg. North Wales p. 2s\%.

non-Anderss. Sverig. Chlor. 1 p. 17.

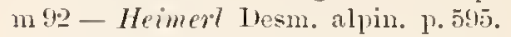

n "1 URSINELLA Kuntze Rev. gen. pl. 1, !21.

m 91 Cosm. Gutu. Flor. alg. Leopol. p. 60.

m 92 - limmer Alg. Nt. Pölten I p. 4.

d 42 - Wolle Desm. U. S. ed. II p. 93 t. 20 f. 1 -2.

o - -v. Floridense ibid.. t. 46 f. 6.

m:13-Gutw. Glon. staw. Zhruczu p. 29. Cfr. Cosm. anomalum et quadrangulatum.

\section{bisenarium}

d 43 XANTHIDIUM Elreul. Mikr. Leb. Süd. u. N. Amer. p. 334. 339. 3914) et 126 (sep.p. 13S). (Euastrum N:o 11 Bailley Amer. Bacill. 1841 p. 296 (sep.p. 15) t. 3 f. 13). [X. cristatum $\beta$ nncinatum lirib. 1848. sec. Tum. 1sib, X. Brebissonii see. Rulfsj.

d 1 i ASTEROXANTHIUM Kïtz. spee. Alg. p. 183. [St. furcatum lirib.].

17 67 DIDYMIDIUM ( $\mathrm{X}$ a $\mathrm{n}$ t h i d in m) leinsch Algenfl. Frank. p. 125 ; a. minns. b. majus.

d $68 \mathrm{Xanth}$. Kab. Flor. Eur. Alg. 3 1) 224.

d 73 - Woud Fr. Alg. p. 156.

d 81 - Wolle Desm. U. S. p.93 t. 23 f. 7-9. [X. Brebissonii.

o 86 - Ntolics Kiey Desm. p. 130.

d 89 - Molacanthium) Toni syll. alg. p. \$26.

d 42 - Wolle Desm. U. S. ed. II p. 1001 t. 26 f. T-9.

○ 93 - f. t.jpica Turner Alg. Ind. orient. p. 99 t. 12 f. 30.

d $-v$. rotundatum ibid.; f. 28 . [X. cristatum $\mathrm{v}$, rot. Wild. 18:4].

d - - ornatum ibil.; t. 13 f.2 [X. crist. v. orn. Wild. 18.47 .

\section{bispinostm}

d 4() DESMIDIUM Corele in Alm. d. Carlsb. 1810 p. 204 t. 4 t. 28 (U):i Swartzii var, verisimiliter sec. II ansg.: 184s. Prodr. Alg. Böhm. 1. 172].

\section{bispiralis}

d W SPIR0TANIA West Fr. w. Alg. W. Irel, p. 133 t. 20 
f.s [^]. obscura f. verisimiliter sec. Lüthiemiall. Gatt. Sipirot:11, 1..3i].

\section{bispormll!}

dzf (13 PENIUM Tumer Alg. | hul. orient. 1) 17 t. 1 f. 10.

\section{Bissettii}

d 13 COSMARIUM Timer Alg. Int. orient. p. 50 t. 7 f. :30.

\section{Bissettii}

d :3 STAURASTRUM Tumer Alg. Ind, orient. p.121 t. 16 f: $21 \%$

\section{bisuldertum}

d "s STAURASTRUM Tumer Alg. Ind. orient. p.111 t. $16 \mathrm{f}, 41$.

\section{bivertrex}

d s. CosmariUm Racib. Now. Desm. p. 95 sem.p. 23) t. 5 f. 20 .

\section{blandlum}

dz 85 PENIUM Rucib. Nonn. Desm. Polon. p. 60 (sep.p. 1). P. Brebissonii? Iacit. Desm, okol. Krakow. 1581). $\mathrm{dz} 86-$ Toni Syll. Alg. p. 864 .

\section{blarlelum}

d stSTAURASTRUM Ricil. Desm. okol. Krakowa p. (sep.]. 11i) t. 1 f. $\%$

d s5-Tiacid. Nomn. Desm. Polon. p. 8 (sep.1. 31).

d 89 -- Toni syll, alg. p. 1235.

\section{Blonsliti}

d 92 COSMaRIUM huc. Desmidya Ciastoni. p. 395 t. $6 \mathrm{f}$. 10 [C. Portianom $\beta$ brasiliense frille 1Sst. sec. auct., sed non ita sec. Borge in Nuov. Notar. 5 1. 19:1].

\section{Iilyttii}

d 81 COSMARIUM Wille Norg. Ferskv. alg. 1 p. 25 t. 1 f. d st - Wolle Desm. U. S. p. 8 t. 19 f. 31 - 33.

m 85 - Boldt Sibir. Chloroph. p. 106.

o 85 - f. Nordst. Desm. Grönl. p.8 t. 7 f. 4.

- 86-Stokes Key Desm. p. 129.

d 8 - f. Norelst. Fr. Wat. alg. X. Zeal. p. 49.

d 89 - Hoffii Eüry. Bidr. Bornh. Desm. p. 14 t. 6 f.

d S9-Toni Syll. alg. p.1013.

d $89-f$. A. (berolinensis Racit. Now. Desm. p. 81 (sep.p. (1) t. 5 f. 33 [C. substriatum v. beroliensis Lager. 1891; C. homile r. sec. Schmidle?.

d -f. B. lithuanica ibid. f. 31 [C. loumile vo sec Schmidle].

m91-Eichler Spis Desm. Miedz. p.8\%.

n !1 URSINELLA Kuntze Rev, gen. pl. 1. 124.

n :11 Cosm. West Freshw. alg. Maine II p, 35..

d 92 - Holle Desm. U. S. el. II p. 4.5 t. 22 f.31-33.

m 92 - West Alg. Engl. Lake Distr. p. 727

d 93 - f. tristriatum Lïtkemiall. Desm. Attersees p. 5.53 t. 8 f. 5 .

d - subsp. II offii f. qnadrinotatnm ibid.; t. 8 f. $f$.

m 94 - Börg. F. alğ. Ostgrönl. p. 15.

m!5- West Alg. Madag. p. 11.

\section{Boerliii}

d sul Cosmarium lialle Xorg. Ferskv. alg. I p. $2 \mathrm{~S}$ t. 1 f. 10. m 85 - Boldt Sibir. Chloroph. p. 1005.

d si-Coole Brit. Desm. p. 111 t. 42 f. 4 [ex frille male!] o si-Pstaurochondrum Lagerle. Firit. Bemerk. Desm. p.

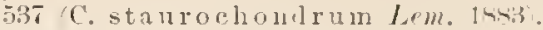

n ss - Vordst. Bornh. Desin. p. 1!n.

d $8.9-$ Joni s.yll. aler. p. 102 t.

d 90 - $\beta$ papillatum Gutu. Waln. d. Pringitit $p .69$.

d 91 - - Gutu. Flor. alg. I.eopol. p. 5 t. 2 f. 17.

m:1 - Hcimerl Desin. alyin. p. $59 \%$.

n.11 URSINELLA huntze Rev. gen. 1]. 1).424.

miz Cosm, Harr. Fr. Alg. Mlaine III 1. 122.

d. 920 - bipapillatum West Fr. W. Alg. W. Irel. p. 157 t. 21 f. 14 [C. bipalillatum West 1s:44].

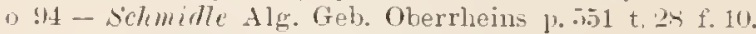

o 54 - Sehmidle in Flora Ti p.5?. C"ir. Cosm. staurochondrum.

\section{boengessmii}

n (2) STAURASTRUM Riac. Desmidya Ciastoni. p. 384 st.

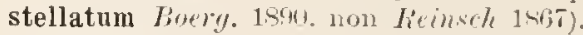

d $-\beta$ simplicior ilid . t. 7 f. $\bar{\tau}$.

\section{Boergesenii}

d 93STAURASTRUM Twmer Alg. Ind. orient. p.110 t.13 f. 23. [Staur. Turneri West 1;:15].

\section{Boldtianum}

d. 94 COSMARIUM Gutw. Fl. alg. Tarnapol. p. 100 t. 3 f. 36 (C. crenatum f. tricrenata livoldt 1sh5 [?]; C. costatom f. Gutu. 1892; C. tricrenatum Gutw. 189.5.

- 95 - Schmidle Alg. Sumatr. p.301.

\section{Bolatii}

d 93 COSMARIUM Turner Alg. Ind. orient. p. 49 t. 7 f. 24.

\section{Bolltii}

d \% EUASTRUM schmirlle Beitr. alp. Alg.t. 16 f.j (Eu. denticulatom f. Roldt 1859). et (18:16) p. 21

\section{Boldtii}

d s. STAURASTRUM Tomi syll.alg.p.1160) (St. e luea tum Boldt 1585. non lfulle 1siti

\section{Borgei}

d 95 EUASTRUM Schmidle in Hedwig. 34 p. 7.1 t. 1 f. 11.

\section{Borreri}

d 43 DESMIDIUM Rulfs Anu. Nat. Hist. v. 11 p.375 t.s f. 4 (et 18th Trans. Bot. Soc. Ellinb. v. 2 p. 8 t. $2 \mathrm{f} .4$

n 15 DIDYM0PRIUM Ralfs in Tenu. Fl. Tunbs. Wells $\mathrm{r}$. 192 (sep.p. 616 ).

d 45 Didymoprinu Relfs Ann. Nat. Hist. $\mathrm{r}$. $16 \mathrm{p}$. 10 t. 3 f. 5 et 1.216 in Trans. Bot. Soc. Edinh. v. 2 p. 164 t. 18 .

d t5 Desin. Hass. Brit. Alg. p. 343 t. $\$ 3$ t.. \&, 10.

dzf 4 Sidrmoprium Fulfs Brit. Desm. 1).5s t. 3.

dz 52-I'riteh. Inf. p. 240 t. 13 f. $38-34$ [fig. $b$ et h Kalfsii repetitie?

dzb1 - Arch. in Pritcl. Inf. p. 723 t. 2 f., 3s-39 [e Ralfs].

1] 64 BAMBUSINA clece Bidr, vierg. Desm. p. 4 ! 1 .

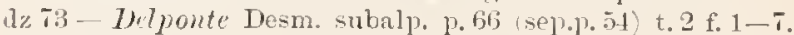

d 六 Didymoprium Mierogr. Dict. p. 251 t. 1 f. 11 Ralfs].

d s0 Bambusina $\beta$ gracilescens Nordst. in Wittr. et Cordst. alg. exs. n:0 367 , et 185.4 in fase. $21 \mathrm{p} .31$. m so- Nordst. De Alg. et Charac. 1 p. 3.

z 83 - $\beta$ gracilescens Nordst. in Wittr. et Norlst. Alo. exs. 1n:0 504, et (14.5y, in fase. 21 p. 34. 
Cfr. Banbusina Brebissonii, Gymnozyga moniliformis

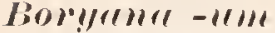

a 2 HELIERELLA T'mp. Aperc. organ. 1).31s t. 13 f. 22 [Pediastrum Bor.]

d 3.4 MICRASTERIAS Ehrul. Org. kl. Raum. p.son (sep. 1. $176 \%$.

39 EUASTRUM Corda Alm. de Carlsb. 1839 p. 238.

\section{Boryii}

(1) 34 MICRASTERIAS Kütz. Sin. Diat. p. 003 (sep.p. 25) = Helierella Boryana Turp.

\section{botrophilum}

d 81 STAURASTRUM Trolle in Bull. Torr. bot. Club 1881 1. 2 t. 1 f. 13.

d 54 - Wulle Desm. IT. S. 1. 131 t. 42 f. 11-13.

o 86 - Stokes Key Brit. Desm. p. 167.

d 8 s - Toni syll, alg. p. 1170.

d !12-Wolle Desm. T. A. ed. It p. 145 t. 53 f. 11-13.

\section{B otrutis}

d 25 HETEROCARPELLA Bory in Tiot. class, hist. nat. v. \& p. Lisi [descriptio mala! Quicl est?]

n $3 \pm$ EUASTRUM Ehrent. in Isis $183 \mathrm{f}$ eol. 1193-1 (Echinella radiosa $L y n g l$.).

d st-- Ehrenb. Inf, p. 163. Echinella ricciaeformis Ag. ex 1.; Mier, r'adiosa Ay. ex $1 . ;$ Cosm. deltoides et bipes Cordu; Eunst, angulosum Ehrb. I. c. t. 12 f. VIII.

d to COSMARIUM Menerh. Synops. Desm. p. 220 (sep.p. 20).

d 14 - Ralfs Amm. Nat. Hist. v. 14 p. 399 f. 11 f. 5 (et 1846 in '1'ans. bot. Foe. Edin. p. 149 t. 16).

d 45 - Hross. Brit. Alg. 1. 363 t. $\$ 4$ f. 2 [e Tiralfs 1. c. delinenta, ut mili videtur].

d 45 - hütz. Phrcol. germ, p. 130.

d $\pm \mathbf{7}-$ Rab. Dent. Frypt. Fl. T.5.t.

o 47 Eu. Fucke Phys. Ntud. I p. $4:$ [Cosm. Turpinii].

dzf 18 Cosm. Rulfs Brit. Desm. 1. 49 t. $16 \mathrm{f} .1$ Eu, interstitiale inclus.)

d 19 - Kiit:.. spec. Alg. 13. 175.

d - $p$ interstitiale ibid. (E. interstitiale olim).

o 19 - Rab. Bacill. Sachs. fasc. 2 n:0 17.

d 19 Eu. (Cosmarium) Nog. einz. Alg. p. 11 t t. 7 A. f. 3. dz 52 Cosm. Pritch. Inf. p. $25 \%$.

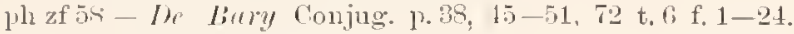
d $58-\mathrm{v}$.? Arch. Catal. 1. 75.

dzffil-Aroh. in Pritch. Inf. p. 793 t. 3 f. $45-54$ [e De Bary 1,55s].

d 63 - Rab. Krypt. Fl. Sachs. 13. 200.

d b. Brebissonii ibid. C. Brebiss. Menegl.o)

ph 63 - C'ome' in Hedwig. p. 64 t. 10 f. 6 .

o 1is-Bieb. in Rab. Alg. Eur, 11:0 154s.

n1 i-1 - Warm. et Schenli schweizer. Kryptog. f. y n:o 437.

65 - f. parva Crum. Ins. Bank. 1. 15 t. 2 f., 26.

67 - Cronum lil. Finist. t. 4 f. 37 [mala].

o vit DIDYMIDIUM (Cosmarium) f. A. minns Feinseh Algentl. Frank. p. 119 (C. Corbula Iiveb.].

n - f. B. medium ibid.

- $a$ ibill.

- - pibid. (C. Broomei lialfs).

d - f. C. majus $a$ ibid.; $\beta$ ibid. 1 r. 120 ( $\alpha$ et $\beta$ Cosm. Botrytis Rulfs, $\beta$ cuogue Cosm. Ungeriannm Nirg.

$6 \tau$ Cosm. Not. Desm. Ital. t. 4 f. 2 S.

d 35 - Tab. Flor. Eur. Alg. 3 p. 158. m 70 - Reinhard in Arbeiten Naturf. g. Charkow I p. 15. m 70 - Torrlst. Desm. Brasil. p. 207.

ph 71 - (hist. Lessporpl. p. 5 f. 5 i [ex p. e I)e Bumy]

d $72-\beta$ subtnmidum Wittr. Cotl. Ol. sütr. Alg. p. 5 t. 4 f. 12 .

o 72 - Norelst. Desm. Spetsh. 1.27; forma.

d 73 -- 1 Tood Fr. Aly. 1.12s t. 12 f. 14, t. 21 f. 5 .

o 76 -Jaculs. Desm. Danem. p. 193 (incl. C. tetrophthalmum et protractum!

d $76-\beta$ mesoleinm Tordst. Desm. Ital. n. 27 t. 12 f. 2 .

plit 7 - Framl: in Leunis Synops. p. $135 \mathrm{f} \mathrm{fig.} 1031$ [e De Dary Conjug.].

d 77 - Delponte Desmid. subalp. 1.22 (sep.p. 118) t. 8 f. $81-8 \%$.

77 - Reinsch in Pringslı. Jahrb. v. 11 t. 17 f. 11.

d is-Dodel-1'ort Anat.phys. Atl. d. Bot. t. 8 f. $1-4$ [e De Rary Comjug.??.

dz $78-K i m c h$. Alg. Sichles. p. 151.

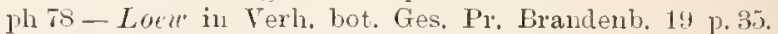

m 78 - Itempel Algenfl. Chemnitz p. 114.

$m-b$. Brebissonii ibid.

m 79 - Wille Ferskv, alg. Nov, Semlj. p. 31.

d - f. obliqua ibil. p. 3.5 t. 12 f. $1 \mathrm{f}$.

o $74-K 7$ t $\mathrm{s}$ Desm. Ostpreuss. p. 35 t. 3 f. 60 - 7 .

A. a. verruculosum t, 3 f. $63,64,68$, t. 4 f. 1.

b. tuberculatum t. 3 f. $62,05,67,70-75$.

c. t. 3 f. $76-7 \%$

d. ochthodes ibill. p. 39 ( $($ o ochthodes Nordst.). e. subovale ibid. p. 3\%.

B. ibid. p. 10. a. t. 3 f. 81.82 . - b. t. 3 f. 80 .

zf $80-$ Farlow Impurit. of drink. wat. t. 1 f. 6 a-d [e Ralis Brit. Desm.].

m 80 - Kivchn. Beitr. Algenf. Würtemb. p. 17 .

ph 82 - Falleend. in Schenk. Handb. d. Bot. 1.293 f. 23 IVI lex be Bury Conjug.].

phs 52 - Butler in Amer. Naturalist 16 p. 581.

ph 83 - Fischer Gyplirystall. Desm. 1. 155 t. 9 f. 17-20.

ph $\$ 3$ - Mrask. N. ZenL. Desm. Ad\}. 1. 251.

o 83 - v. glabrum Sidenursehm. Magyar. Desm. p. 263,

o 83 - - granulatum ibid.

d - - squamulosum ibid. t. 1 f. 13.

m81-Artari Liste alg. Moscou l', 111.

d. S4 Eu. Gosmarium: ff. Gay Monogr. loc. Conj. p. 63. dzfst Cosm. Walle Hesm. U. S. 17. 74 t. 13 f. $5-7$ (3 forma); t. 24 f. $27-3.3$.

dzf - v. tumidnm Wolle ibid. ]. 5 t. 17 f. $3-5$. [C. subbotrytis Schmille 1.991].

ms - Lopot Water, alo. Marszaw. n. 253.

d 84 - v. afghanicum Schaursehm. Afghan. Alg. 1. 245 t. 5 f. 1 !.

in 8.1 - Wille sirlamerik. Alogt. p. 14.

phsi - Strusburg. bot. Practic. p. 33S.

d s5-Kirclu. Mikr. Pflanz. d. Suissw. p. 24 t. 3 f. 73.

o 85-v. mesoleium Racib. Nonn. Desm. Polon. p. i2 (sep.]. 16)

d 85 - Balsumo Alg. del. con. di Napoli p. 35.

d 86 - r. regularis Iste, in Magyar. X. Laj. v. 10 p. 6.

d sib-v. indicum Josh. Burm. Desm. p. 645 t. 24 f, 19 [C. Josluae Tum. 18937.

zph St - Isethold Stud. Protoplasmamecl. p. 317 ete.

d 86 - Fonti in Leun. Synopsis p. 196 f. 15 xylogr. [e Le Dirry 1850].

o s6-f. Nords\% in Wittr. et Nordst. Alg. exs. n:o 826, a et b; et in fase. 21 (18s9) p. 11 (incl. Cosm. gem miferum).

- f. ibid. $820 \mathrm{c}$.

o s6- Dtolif's Kiey Desm. 1.128. 


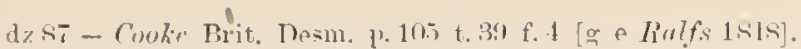

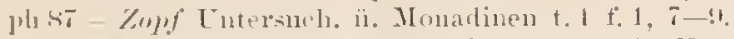

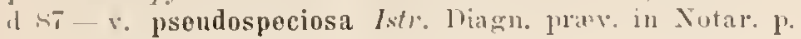

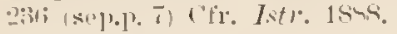

d - s. pulchra iljid.

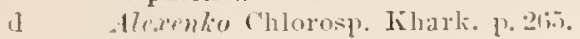

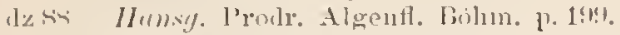

(l) fiomarginatum ibil.. f. 116\%

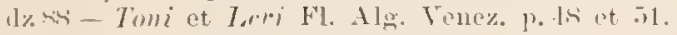

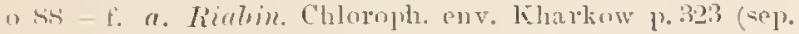
1.. 35 ).

a - lo ibill.

1) - e. ilid.

(1) - ilinil.

in \&4 Doldt Dosin. Gribul. p. 24.

m.subtumida ibil.

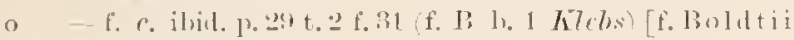
(iutw. [Sit)

n f. $/$. ilill.

d se-Mumitl. Zellm, n. Hiillgallerte Desm. 1. Sij ot 111

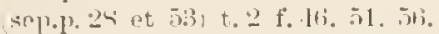

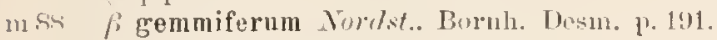

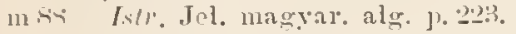

m. $\quad \therefore$ a follonicnm ibicl.

1 r. pisendospeciosum ibil. et t. 1 f.s.

v. pulchrum ibis. et t. 1 f.! r. gemmifermm Whit.??.

I sin - f. Nordst. Fr. wat, alg. X゙. Zeal. p. 17.

$0 \quad-$ f. ibil.. t.j f. T (C. Sportella var.?.

(1\% S!) - Toni syll. alg. 10.17\%.

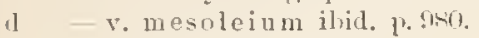

(] - v. afghanicum ibid.

d $-v$, iudieum ibia.

d - r regulare ibid. p. asi.

o - v. olabrum ibid.

- v. ura $u$ ulatum ibid.

- v. sinamosum ibid.

- v. pseind ospeciosum ibid.

- v. pulchrum ibid.

- v. emar $1^{*}$ inatum ibid.

- r. subtimidum ihid.

m 9n - b. tubercnlatum Giutw. Fl. glon. Galic. 2 p. 13. m-c. subovale ibid.

n m - d. f. Boldtii ibid. (Boldt 1858 forma $c_{0}$ ).

n! (k) - Istranff. Rumel. alg. Frivald. 1). 6.

phef:M - Wille in Natirl. Pflanzenfam. p. 3 f. 2. p. 1 f. 1 , p. $5 \mathrm{f} .5$ (e l)e linry)

m !n) - Fichle spis Desm. Miedz. I. st.

d (n) - h. Janoviense Gufw. Wahr. d. Priorität p. 6!\%

(] (n) - r. crenulata Reinsch Siisswasseralg. Siitl-Georg. p. 347 t. 2 f. 39

m!10-Iiviry. Desm. Brasil. p. 37.

ozf $30-$ K [Nia species sec. Lagerh. in X. Xutar. 1891 p.115].

m 10 -... Inderss. Siverig. Chlor. 1 p. 11.

u. - $\beta$ subtumidum ibid.

11191 - Istr. Fragm. Alg. 1 p. $110 \%$.

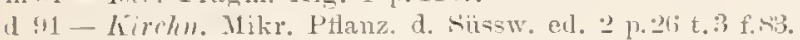
ph!1 - Wildem. Observ. alg. (1s!1) p. 1:0.

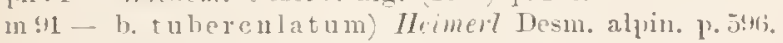

m - f. pemarginata ibid.

11 it - Ifist Witnish Algre p. 120 .

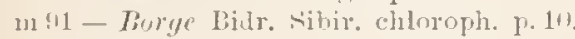

m - $\beta$ silbtumidum ibid. p.il.

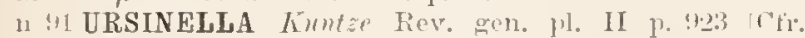
Sorl.t. in Hedwigia 18:3 j, 152].

m st Corm. c. subovale Gutic. Flor. alg. Lcopol. 1. 52.

in- - e. gemmiferum ihid.

dordatede, Index l'esuid. n- - g. squamosnm ilid.

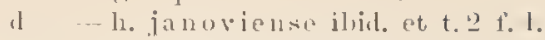

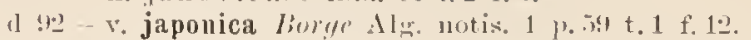

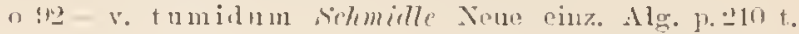
11 f. $13-11$.

m r. - r. emarginatum Hunsy. Beitr. Aler. Bact. Tirol. u. Böhm. p. 1:3:3.

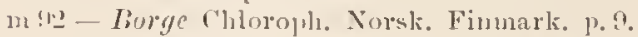

d $12-\mathrm{r}$. mediolaevo W'st Wr. w. Alg. W. Irel. p. 15is t. 21 f. 12.

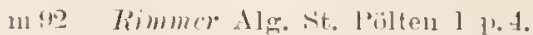

m 52 - Riac. Desmilya Cinstoni. p. 393!.

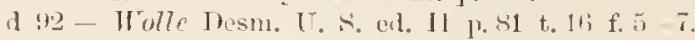

def - v. tumidum i\}id. p. 8.2 t. 20 f. $3-\bar{i}$.

11193 - Lïtlemilll. Inesm. Atterseos $1 \%$ s.st.

13 - v. tnmisum selminle Pritr. Alg. Seluwarzwald,

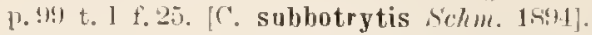

93. Ficrstenberger in Plypkotheca univ. $\mathrm{I}$ 11:0 lis a (transitus ad Cosm. tetraophthalmnm).

$1193-$ - Pringidium) Turner Alg. Ind. orient. p. 73.

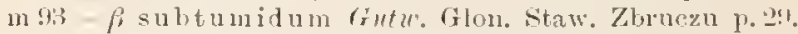

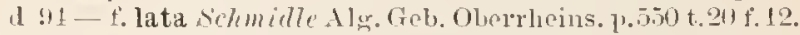
o $94-v$ subt.umidum Siehmidle in Nlora 78 p. 5 s.

n! !H - Iste. Adat. Roman. alg. p. 15 ì.

ple 94 - I'tlle in Ber. dentseh. bot. Ges. 12 p. 15 ? t. 9 f.9. (1) - borg. F. alg. Cistgriull. 13. 13.

o 41 - Stockm. in Nachtr. syst. Anfz. Osterr. Kirypt. p.4fi.

d $45-v$. emarginato-constrictum Lemmermomn in Forschungsb. hiol. Station. I'lön. 3 p.57 c. icone [An Cosm. Lidanum, an Turpinii?].

o:45 - f. Sehmidle Beitr. al]. Alg. 1..391 t. 16 f. 3.

m 95 - c) sn hovale Fichle in Pamiet. Fizy. 13 p. 59. C'ri. Strephoc. didymella, Cosm. margaritiferom, tetrophthalmum, undulatum v. obtusum Schmidle 1s.45. Cosm. Thomas Chicago IV. Suppl. t. 17?

\section{BRACIIASTRLII}

n 93 Turner Alg. Ind. orient. p. 133. subgen. Staurastri.

\section{brorhiortume}

Izf tS STAURASTRUM Tielfs Brit. Derm. ap. 131 t. 2.3 f.! [staur. bifidum lielfs 1s.5̄; Phycastrum Ralfsii Kiilz.?

dz $32-$ Iritch. Inf. p. $26 \pm$.

o 5.2 PHYCASTRUM T'erty lileinst. Lehensf. t. 11; f. 33.

d til staur. Areh. in I'ritch. Inf. 1'. 71.

d (i3-Rab. Krypt. Fl. Sachs. p. 19) c. icone [ex Hassall].

o 1.7 - Not. Desm. Ital. p. 51 t. 5 f. .0 .

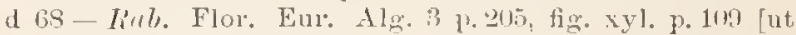
supra 1:50:3].

d - Notarisii ibill. (St. bracl. Not. 1. c.).

1) 81 - Wolle Desm. T. S. p. 12.1 t. 40 f. 37-39.

$n-$ v. Notarisii ibid. t. 52 f. 2931.

o \$67 - Stokes Kev Ilesm. p. 115.

daf sit-f'oolie Brit. Desn. p. 16; t. 58 f. 1 [c e Ralfs in Ann. d Mag. 18ti, cetera figg. e liulfs 184.9].

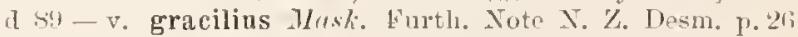
t. $5 \mathrm{f} .4 \mathrm{~s}$.

d sil -- Tomi sinll. alg. p. 1202.

m 91 - Fichler sipis Desn. Miedz. 1).90.

111 !n-Anderss. Sverig. Chlor. 1 p. 11.

in!r - Heimerl Desm. alpils. p. 40 it.

d 12 - Wolle Desm. U. S. ed. H p. 131 t. 51 f.37-39.

$11-$ r. Xotarisi ibid. p. 137 t. 633 t..

o 13 - lichter I'hykothee. miv. X n:0 415.

maf:33-Eichlo Mat. flor. Niellz. p. $11 ; 1$ t. 10 f. 37.

d 4. - v. longipedum Lincib. in Flora v. 41 p. 34 t. 4 f. 20. Crr. Stanr. Pertyi. 


\section{brerthiolmomilurus}

a mSTAURASTRUM Büry. Iosin. brasil. 1. 17 t. 5 f. 52. o ?ly-linc. Desmidya Ciastoni. p. 3S1.

\section{brerelegrecentheme}

1) $\$ 3$ STAURASTRUM Nordst. in Wiut. A Fordst. Alg. exs. 554; et $(1889)$ in fasc, 21 1.37.

d s9-Toni syll. alg. p. 1196 .

\section{brarhycerum}

d JisTAURASRTUM Irib. Liste 1) 139 t. 1 f. 2t. [St. polymorpham $b$. Rub. 1sijos.

a 61 - Hech. in Priteh. Inf. 1) T12.

o lis - Tordst. Binl. Sverig. lesm. 7.40.

\section{brarleyptera}

d Tl MICRASTERIAS Lmol. Desm. Sirec. 1. 12 t. 1 f.t. [Micr. apiculata $\div$ fimbriata v. Nordst. 1584].

o sil - f. Wille Norg. Ferskv. alg. I p. 20 t. 1 f. 2.

a 833 - v. americana Wolle in Bull. 'torr. bot. Club, vol. 10 1. 18 t. 27 f. $1 \%$

d 84 - Wolle Desm. U. \&. p. 110 t. 32 f. $\{$ - . 7.

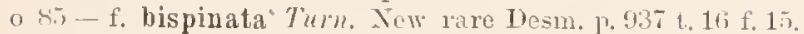

u si- Stokics liey 1lesin. 11. 117.

o - $\quad$ f.) bispinata ibil.

d sto-Coolic Brit. Desm. 1. 63 t. 30 f. 2. [f. 2 c et de Lunel].

1) 87 -Alcechlo ('hlorosp. Kliark. 1.249.

d so-Tomi Syll. alg. 1.1120.

d - v. amerieana ibil.

d - v. bispillata ibid.

m! 19 - Fichler Spis Desm. Miedz. 10.84.

11 91 HELIERELIA Kuntio Rev. ga11, 11. p. s.9s,

$192 \mathrm{Nicr}$. Wolle Desm. U. S. el. 11 p. 121 t. 33 f.6-7.

d 93 - f. dispersa Eich. et Ruc. Nowe gat. zielen. p. 123 t. 3 f. 8 .

1195 - Eichler in Pamiet. Fizy. 13 pr.1il.

\section{brosiliense - is}

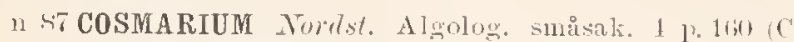
sphalerostichum Novelst. $\beta$ brasilicuse Wi7l. 1sbt). dz - $\beta$ taphrosporum ibil.

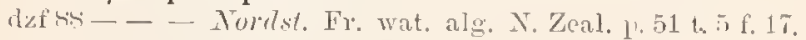

d sil Toni íyll. alg. 1. 10:89.

dz - v. taphrosporum ibirl.

d 50 -. Fordinatum Bör\%. Hesm, Hrasil. p. 40 t. 4 f. 32

119 URSINELLA Kuntio Rev. gen. pl. 1\% ¿21.

\section{Bresiliense}

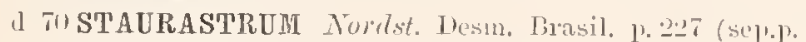
$18(1) t, \pm f, i y$

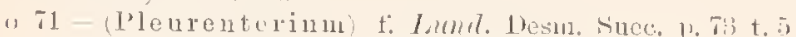
f. $2[=$ nov. spee, sece, dirle, 1881].

is .. C'outir in Grevillea !) t. 140 f. d-c.

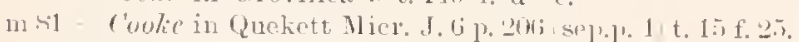

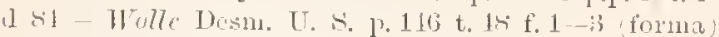

n1 si - L Lafert. Amerik. Desin. 1) 2-19.

o Si-Stolies liey 1)esm. 1. 168.

o 87 - Wolle Fr. Alg. U. S. A. 1. 16 t. 60 f. 39 - 40.

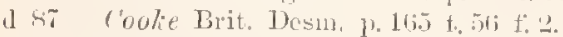

d 89 - Tmi syll, alg. 1. 1:2k!

a 5.2 - Whlle Desm. U. S. ed. II p. 16 in t. 59 f. 1 - B. 1. 19 f. $39-10$.

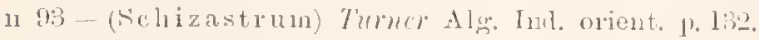

\section{Brellutii}

d 67 CLOSTERIUM licinth spec, Gen, Alg. p. IBs t. 20 ('I f. 15 isep.]. (3) t. 1). d 67-["Buanianum"] Reinsch Algent. Frauk. p. 1!ni t. 12 f. is.

85 - Jish. in .Jonrn. 13ot, v. 23 t. 254 f.?

d 89 - ? Toni íyll. Alig. p. 854 .

n 91 ARTHRODIA Kuntze hev. gen. pl. p. S6s?.

d 92 CIost. Hulle Desm. U. s. ed. II p. 15 t. 13 f. 19.

in 95 - Fichler in Pamiet. Fizy. 13 p. 5 s.

\section{Biolumi}

d 67DIDYMIDIUM (Cosmarium) Leinseh Irrypt. Fl. Frank. p. 114 t. 10 f. 3 a $-\mathrm{g}$.

d . f. A. ibil. p. 115 Cosm. Meneglinite Bunuii IIInsy. 1S85].

m - $a$. majus ibid, f. a.

a - $p$ intermedium ibil.. f. $c$ et $f$.

- y Meneghinil ibin.; f. $l$. (Cosm. Meneglinii Bréb.) Eu. venustum f. (Spondylosium ?) Lmel. $1: T 1]$.

- f. B. ibil.

- $\delta$ minimum il,id.; f. $g$.

- a majus ibid.; f. $b$.

- $\beta$ minus ilid.: f. $c$.

"s SosmariUM f. major Wolle Bull. Torr. bot. Club. 12 p. 3 t. 47 f. $28-29$. "Braunii".

187 - f. major Wolle Fr, Aler. U. S. 1. 1, 29 t. 57 f. 28 -29 [ex trolle 18s0].

21185 - Riabiu. Chloropli. env. Flarkow p. 325.

n - pintermediun ibid.

n. - b) minimum ibit.

d st-f. major Wolle Desm. U. S. ed. 11 1. T2 A t. $18 \mathrm{f}$. $28-29$.

d 13 - v. lobulatum Schmille Beitr. Al s. Schwartwald. $\mathrm{p}$. (H; t. 1 f. $11-11$.

- f deformata ibil. p. 95 t. 4 f. 15.

1194 - Schmille Alg. Geb. Oberheins p.519.

\section{Brentui}

dz 5 S MESOT ENIUM de liary Conjng. p. 71 t. 7 . 1 f. 1 \&. (Palnogloca macrococea A. Br. 1hor).

11 - minus ibid. t. 7 A f. $9-11$ [Mesot, micrococcum Firchl. suce. Stoctimnyr Nachtr. syst. Aufeähl. P. 10].

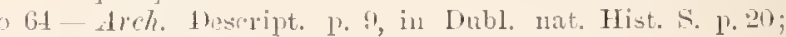
in Q. J. M. Ace. 1, 117 .

d is Kirelun. Alg. Reliles. 13. 1:H.

dzf 81 . Woll. Desm. U. S. p.31 t. 3 f. is -

a si-stulice liey Desill. 1. 111.

A sit Alerentio Chlorosp. Klark. p. 2021

dztas - l'almogloca) Hansog. 1'roild. Algentl. Bohm. P, 173 f. 111$]$ [e the Intry].

m - P minus ibid.

dzss Toni et Levi r"l. Alg. Venez. 1) 10.

m ss - Ist $v$. Jel. magyar. alg. p. 210 .

dzs! Toni s.rll. Alg. 1.811.

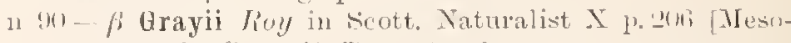

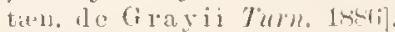

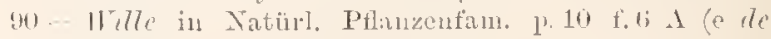
li(1)!y).

o (30). Zulial in Osterr. bot. Zeitselrr. v. $10 \mathrm{p}, 32.1 \mathrm{t} .3 \mathrm{f}$. 2:3 (Palmella botryoides? sec. auct.).

in 91 Tste. Meteorpapir $\% 119$.

dzf tre - Wolle Ilesm, IT. S. ed. II 1. 32 t. 3 t:5-9.

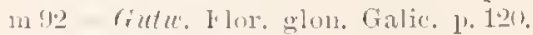

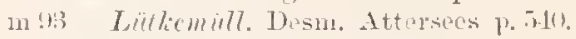

m 93-Turue Alm. Ind. oriest. p. 15.

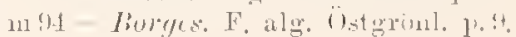




\section{Iirebissemii}

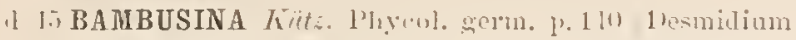
bambusinum Irril., Gymnozyga moniliformis Ellionb.).

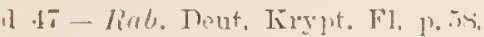

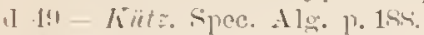

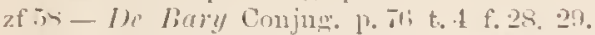

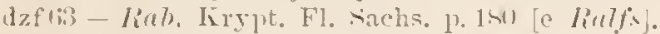

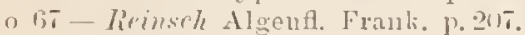

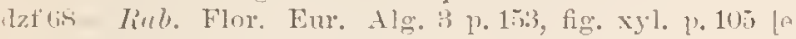
lialfs]. (Desm. Borrori)

II 73 - Wond Fr. Alg. P. 125.

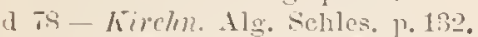

lafs s.t - Wulle Desm. U. \&. p. 21 t. 1 f. 1.j-21.

o - r.gracilescens ibil. p.25 Bamb. Borrerif; Numkt. $1 \mathrm{si}(0)$.

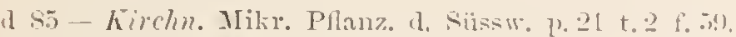

m Si - Lagerh. Amerik. Desm. 13.22!!

$m \quad-\beta$ graeilesechs ibill.

o st Stolies Kiey Dasm. 11.110.

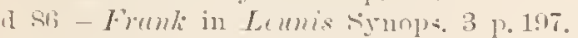

dxfsti-roolie Brit. Desm. p.! t. 1 fol ex parte e Ihe limry, [et e livelfs].

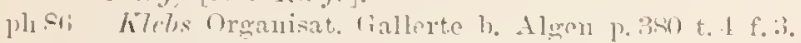

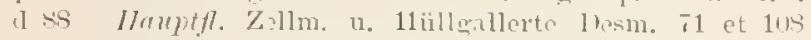

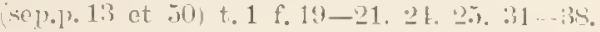

mas - Istr. Tel, magrar. alg. 11.214.

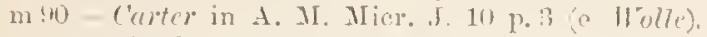

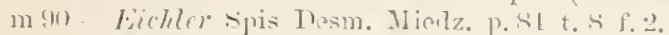

o sh GYMN0ZYGA Withe in Natürl. Ptanzenfim. 1). 2. f. 1,

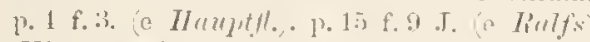

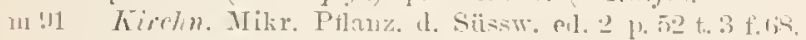

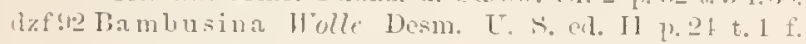
$15-21$.

o- - renarilescens ibil.

\section{Birelissomii}

d T- CLOSTERIUH Delponte Desnicl. subalp. p.111

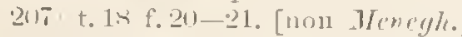

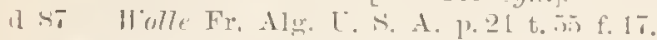

a s., Tomi sivll, alg. p. 1.

n 9l ARTHRODIA humtze Rev. gen. pl. posł3.

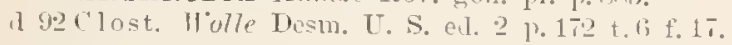

\section{Brebissomii}

(2 1:) COCCOCHLOR IS Thurewt. in Mag. Nit. 1[ist. ]. 243 t. \& C. [Palmogloen macrococea sec. A. Lremon. ext verisimile = Cylindrocsatis crassa lic bur. sec.

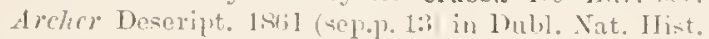
Soc, Pr. p. 21].

\section{lirebissonii}

n 3. COSMARIUM "Menegh." in Desmaz. l'l. cropt. France

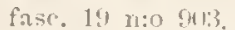

1] In-Menegh. Synops. Nesul, p. 21s 'sepep. 1s. [Her

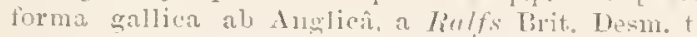
If f.:3 delineata. albloret, nt vilfetur].

d th - Iialfs Erit. Desm. p. 100 t. 1 fi fo: fi horrilla Ju cols. 1.5.

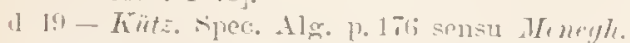

(1) 52 - Trotrk. Inf. p, 20;3.

(1) (i1-Areh, in Fritch. Inf. p, 73,2.

o liт DIDYMIDIUM( ก. 1.2.3.

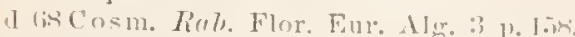

1) 11 Laturl. Desm. sines. 1.20 fli. .

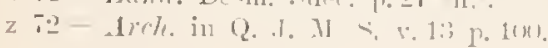

1) $7: 3$ - 11 wod Fr. .1lg. p. 128 t. 21 f.ri.

o 7.3 - f. subtumida Vordst. For. Dism, f. 1.2.

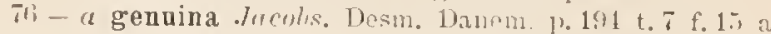
(form. latior) et $b$ (f. angustior) [C'. confusmm Coolie 185T].

- Phorrida ibil. p. 1!1 C. Brebiss. linlfs Ro. Dosin.).

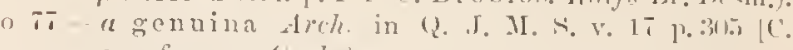
confusum r wolit!

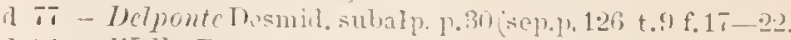

1. $\mathrm{SI}$ - Holle Desm. U. S. 1. T.s t. 1:3 f. 111-11.

o sit - stolifs liny Desm. p. 126.

A si-roolic Brit. Desm, p. 100 t. Bus f. 2.

d si-llansy. Prolr. Algenfl. Bühm p.20u.

(1) s!l - fisubtumila Birry. Bill. Dorn. Desm. p.111.

(1) T!) Toni s.yll. alg. 1. (19,3.

m (n) - Eichter suis Desm. Midz. p.si.

11 91 URSINELLA huntze Rev. gen. pl. p. 1?t.

a to Cosm. f. erosa West $F_{1}$. w. Alg. W. Irel. p. 1.te t, 21 f. 1\%.

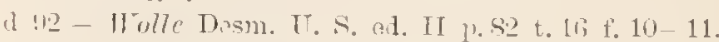

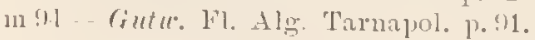

Cir. Thomas Clicago w. Suppl. f. 1.i.

\section{Inrebissonii}

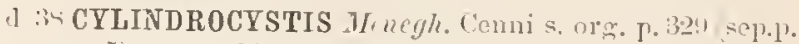
5) et P. BH (sep.p. 2fi) ("Palmella cylindrospora Brib. inedit.").

1) 12. - Benegh. Monogr. Nostoch. 1. A. t.12 f. 3 (Palmella cylindrospora Bret). Aler. Falnis. 143ij).

4 1.5 - IIass. Brit Hg. 1.361 t.92 f. 17 a Menegh. 1. с. furtasse inlineata.

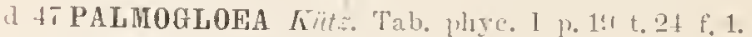

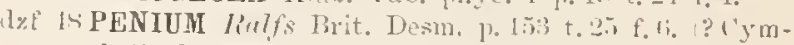
bella laetovirens, Clost. Cylindrocrstis Kïtz.).

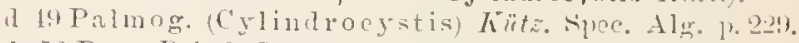
1) it2 Pen. Mritch. Inf. p. 27.

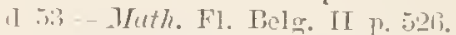

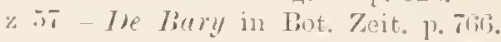

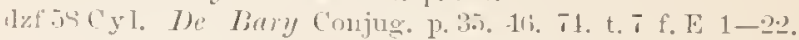
o Dalmogloia frme Desmid. 1. 1!12.

(il Palmogloca Hicks Derelopm. Gonil. 1. 17 t.2 f. 11 -12 Mesntiplninm sp.? see. Arch.].

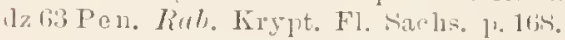

o (i) I'almogloea Areh, Doseript. (sep.p. fi et 11) in Ibul. Nat. Hist. Soce p.17. 22; in Q. I. N. \&. 1. 113. 1201. opllitit-Hicks in U. I. M. Se. p. $\tau$.

1it romun lit. linist. t. is f. $\mathrm{s}$ a et b.

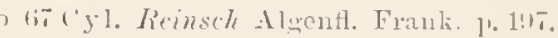

af 1 it - llicks in Fopul. se. Rew. 6 p. T t. 1 t. 12.

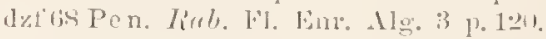

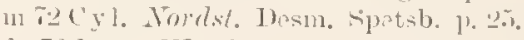

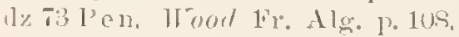

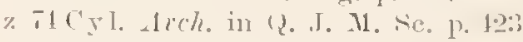

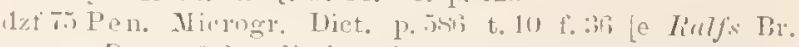
Desm. f.: a liminuta].

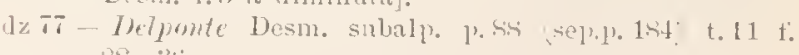
$28-31 ;$.

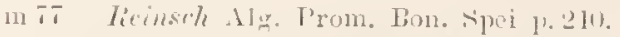

le Ts- Kirchn. Jler. helles. p. 1:313; a trenuinum.

dz - be Jenneri ibil. P. Jenucri Rnlfs.

(1) T!) ('yl, f. Murdat. in Wittr. et Nurlst. alg. exs, 1):0 $21 ;$; et in fase. 21 (18-4) ], $1 ! !$. 1. ibill. n:0 206:9,

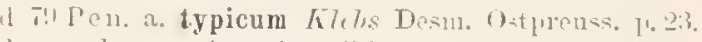

1 - T. crassiusculum ibid., t. 3 ti. 1 a ot b. P'en. rinssiuseulum $[$ in Bury

ozf st -? liacil. 1)osm. nkol. Krakowa p. i t. 1 f. 1 (P. blandum liacit. 1sisi. 
dzf R.t ‥ Ifolle Dosm. L. S. P. 36; t.5 f. T-8.

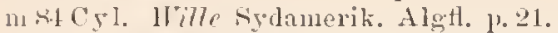

d sō Pen. Kirchn. Mikr. Pllanz. 1. Sï̈ssw. p.22.

111 h̆̈ - Secharrschm. in Magy. Növ, Lap. P. 8.

o sif-Stokes Iier Desm. p. 111.

ozf wi - Corlie Brit. Desnu. p. 13 t. 17 f. 3.

z. - ๖. Jеnne i ibid.

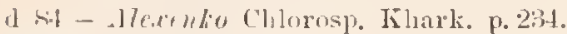

dzf $48 \mathrm{Cy}$. Mansy. Prods. Algenf. Böhm. ]. 17. f. 106 [e Je biary Conj.].

z - $\quad$ i Jenneri ibid.

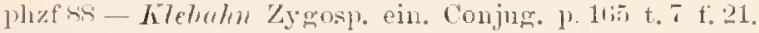

dzsS Pen. Tomi et Levi Fl. Alg. Tenez. 1).40.

msi-Iste. Jel. masriar al

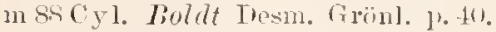

mztio - Nordst. Fr. wat. alg. N. Zeal. p. 72 .

dz S! - Toni syll, Alg. p.sii.

dz - v. Jennel० i ibil.

Su Penium Wret Fr, Alg. Nonth Yorksh. 1.2014 t.3.

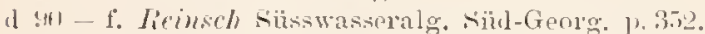

m!k - ('hmicl. in Tr. Soc. Nat. Khark. 23 1, $! 5$.

1) 91 - Kivden. Mikr. Pflanz. d. Süssw. m. 2 1) 23.

m $11 \mathrm{Cy}$. Heimerl Lesm. alp. 1, 5yl.

m!) - Gutw. Flor, alg. Leopol. p, : :

m 42 - Gute. Flor. olon. Galic, 3 p. 121

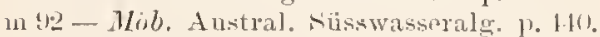

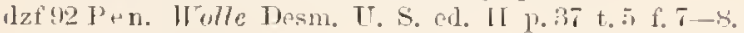

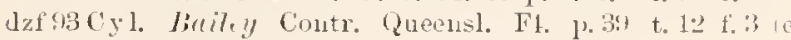
Coule').

m!13-_ Lätkemiäl. Desm. Attersees 1).511.

n! !3-Turuer Alg. lud. orient. p. 16.

ph 193 - Franzi in Usterr. bot. Zeitselur. p. Bst.

ple!1. - Lragerh. I'hyeoporph. 13.13.

maf!15-Eichle in Jamiet. Fizy. 13 p.os t. 1 f.e.

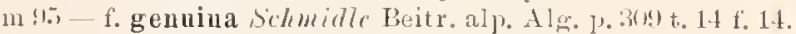

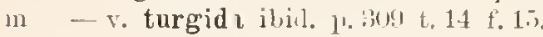

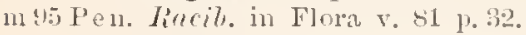

Cfr. Gyges bipartitus sec. Inmtar, Palmogloca Meneghinii, Peninu Palangula, 'Trichodictyon rupestre.

\section{Breloissomii}

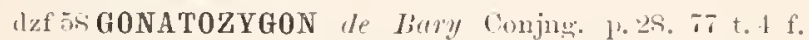
26, 27. (Tocill asperum Rrib. 18iti) [Cfi. Liitliem. [lesm. Attersees p, itil].

da 1;1 - Arch. in I'ritch. Inf. p. 722 (Leptouystinema Pertii). d 188 - liab. Flor. Eur. Alg. 3 p. 15i;.

m 84 - Gay Mon. loc. Conj. 1. 7\%.

d

4 - a. gallicum (Doe. arp. Ralt's Br. Desin. $27 \mathrm{f}, 1 ; c)$.

1) - b. vulgare ibit., t. 14 (sep), i) f. 11).

d - $\therefore$ tatricum ibic.. f. 4 .

d -- d. Kjellmanni ibid. 1. fis (ri. Kijell. Wille 1si!y).

dzf Sti - Coulie Drit. Desm. p. 2 t. 1 f. 2.

d si-? Iscmett Fr. Wat. Alg. Engl. Lake Dintr. 2 1.5 t. 1 f. 2.2 .

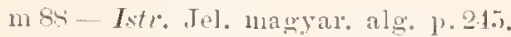

no 84 - Nordst. Fr. wat. alg. N. Zeal. p. To.

111 ? - West Fr, w. Alg. W. Irel. 1. 111 .

d ! 3 - f. gracillima Tumer Alg. Ind. orient. p. 24 t. 20 f. 7.

(1) - I'oy ficott. Desill. p. 250 (sep.p. 58) (inclus. G. laeve Ilitse).

\section{Jirebissomii}

4 (il STAURASTRUM Arch. in Priteh. 1nf, 1. Tis sit. pi-

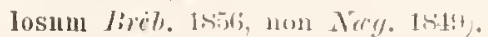

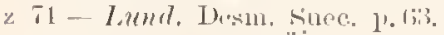

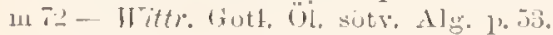

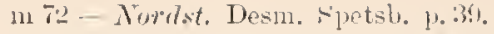

m 75 - Nordst. Desm. aret. p.31 (f. 3-5-gona).

d 81 - Wolle Desm. U. ㄷ. 1. 1.t1 t. 4i) f. $5-1$ )

mins - Broldt Sibir. Chloropls. 1) 113.

m si - Nordst. Desm. Grönl. p. 10 (f. minor).

a 81 - Stules liey Desm. P. 1lis.

dzs si - Coulie Brit. Desm. p. 1511 t. 52 f. 19.

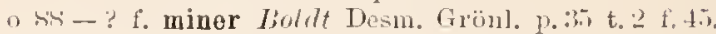

dz 8: - Tomi violl. alg. p. 1166.

m n1 - f. minor Crute. Ftol. alg. Leopol. 1. T:2.

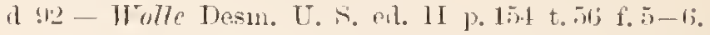

m 92 - Gutu. Flor. slon. Galic. 2 y. 134.

1t $52-\mathrm{v}$. brevispinum West Alg. Engl. Lake Distr. p. 731.

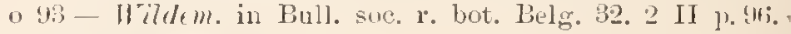

\section{Iirclissomii}

(1 4) CLOSTERIUM 21eneyh. Synops. Desm. 1) $2: 31$ (se1.p. 3i).

d It TEIMEMORUS linlfs in Ann. Nat. Hist. v. 14 p. 257 t. s f. 1 (et 184i, Trans. Bot. Soc. Elin. 1. 133 t. 12) (Clost. n:o 9 Iialty Amer. Bacill. p. 303 (sep.p. 22) t. 3 f. 33 i).

d 4.5-lluss. Brit. Alg. 1..37t t. 89 f. 5 [e Rulfs I. c. dolineat.].

d 18 - Kulf's, Brit. Desm. 1. 145 t. 24 f. 1 a, b. c. [fig. $f$. $/$, minor de $B a r^{\circ}$.] (Clost. munile Krïtz.).

1 - $\beta$ turgidus ibid. f. $d$ et $c$.

1) t:I PENIUM (Tetmenorus, hütz, sper. Alg. 1. 16. incl. T. laevis.

d 52 Tetm. I'ritch. Inf. 1.271 t. 13 f, 12 et 13 [e lialfs Br. Desm.].

d is - The lictr. Conjug. p. 78 .

o - $\beta$ miner ibict. p. 73 t. 5 f. $s$ (Rulfs fig. $1 f$.

o 51 - (monstr.) Arch. Abuom. Desm. in Dubl. Nat. Hist. soe, 2 1. 2 s t. 1 f. $11-15$; in Nat. IHist. Rer. 6 1\%

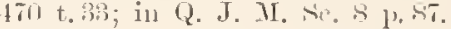

d bi - - lreh. in Priteh. Inf. l. Tfli; $\beta$ turgidus: $y e$ limy; t.2 f. 11-1:3 [e lialfs].

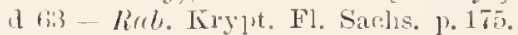

d fir - Reinsch Algenfl. Franli. p.18\%. Form. A ot B \& turgidus.

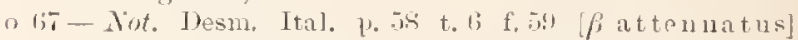
d lis - liab. Flor. Eur. Alg, :3 1) 13i'.

m - h. throilus ibid. p. 140) (Pen. striato-punctatum)

m - e. minor ibil.

z 7:3-Nordst. Norg. Desm. p. 34.

a $\mathrm{T}$ - Wood Fr. Alg. p. $116 \mathrm{f}$ t. 21 f. 3 ,

d 75-Microgr. Diet. 1). 77 .

d 7. Delponte Desm. subaly, p. 137 (sep.p. 2333 t. $15 \mathrm{f}$. 5.:3-51.

m 77 - Nordst. Alg. brasil. 1.16.

d 78 - Kirchn. Alg. ticliles. p. 145 .

m Ts-Jl'mpel Algent. Clemnitz. p. 112.

d 81 - Wulle Desm. U. S. p.91 t. 20 f. $1-2$ et t. 50 f.3i.

d - v. turgians ibià. p. 91 t. 20 f. $4-5$.

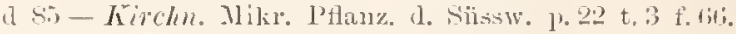

z bi- Bicm. Fr. w, Alg. Engl. Lake Distr. 1 p. Lik.

m 80 - Lagcrh. Amerik. Desm. 1. 2:0.

o sfi - Stokes liey Desm. 13. 1:30.

a si-Couke Brit. Desm. 1).t5 t. 18 f. 7 [e Ralfs 1848].

a - $\beta$ turgilus ibid. $p$. 49; et $y$.

o st - $\beta$ attenuatus Nordnt. Algolog. smaisal. it p. 163.

d ss-Jlansy. Prods. Algentl. Döhm. p. 188.

m - P minor ibid. f. 111 [e Je Lary].

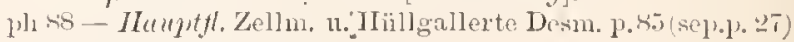
t. 2 f. $37,43-15$.

mis - Jate, Tel, magyar p. 237.

d sis-fi attenuatus Nordst. Fr. Wat. alg. N. \%eal. p. liti t.:3is. is. 


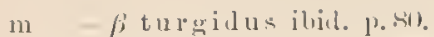

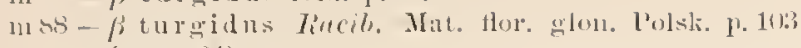
(sep.p. 21).

11 b. minol ibil.

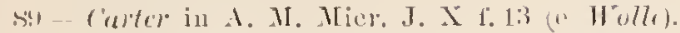

(I s!) - 7omi syll. Alg. postit.

แ1 - $\because$ minor ilsid. p. Mit.

III - v. thig gilus ilibl.

(1) r.eatenuatus ibid.

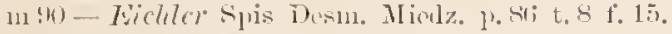

n! - Görg. Desm. Brasil. p. 2s.

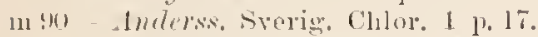

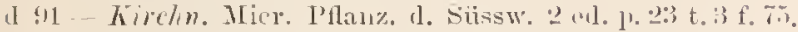

11:11 - Iste. Moteorpapir. p. 1.1:1.

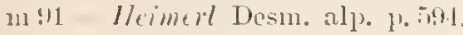

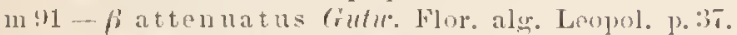

111 !2 Hiat Fr. W. Alsg. Wr. Irel. p. 1:31.

$m$ - r. mino ibid. 13. 13\%.

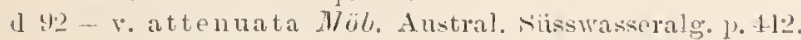

d - v. tenuissima ibil.. I. xyl. 15.

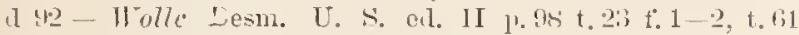
f.: $31 ;$.

1 - v. turgidus ibid.. t. $2 ?$ f. $1-5$.

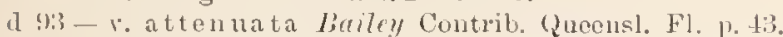

d - v. tenuissima ibil.

m 13 - Lillliemïll. Desm. Attersees p.515.

m !:3 - f. Turner Alg. Ind. orient. p. 25 t. 7 t. !.

o 55 - schmille Beitr. alp. Alg. 1).334, t. 14 f. 29 .

\section{Brebissomii}

a lis XANTHIDIUM lialf: Brit. Desm. p. 11:3 t. 1:4 t: 2 a et al (13in. aculeata Brib.).

(1) - b. varians ibil.. f. l, et $c$.

(1) 5.2 - Irilch. Inf. p. $25 \%$.

d lil- Lreh, in Pritch. Inf. p. 7:3;

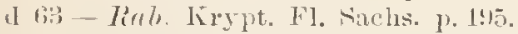

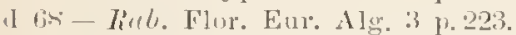

d st - Coulie Brit. Desm. 1) 1311.

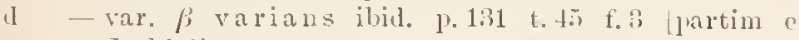
lialfis?.

1) की - $\beta$ basidentatum Foiry. Birr. Bornh. Desm. p. 118 t. (i) f, 11 .

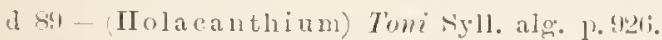

: 1 - t. Whest Fr. w. Alg. Nortl Wales p. 2.11 t.ti f. 38

o 13 -. t. punctata Eichl. et liuc. Yowe gat. zielen. 1) 125 1. 3 f. 30 ,

m! 4 - r. basidentatum Selmille Alg. Geb. Oberoheins 1.. $\div 2$. Cfr. Danth. aculeatum ot bisenarium.

\section{Iirefeldii}

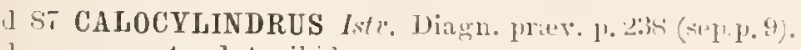
1 - v. rotundata ilul.

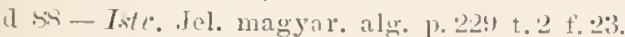

a - v. rotundata ibil.

d s:! DISPHINCTIUM Tomi sy-11. alg. 11. 88 i.

」 - v. rotundatum ibid.

\section{Brefeldii}

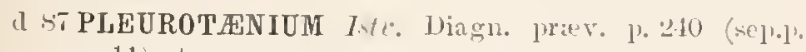
11) et

d ss - Iste. Jol, magyar. alor. p. 212 t. 2 f. 3. $\mid l^{2} 1$. truncatum $\beta$ crassum lioldt].

d sul - Toni siyll. als. y. s.9.

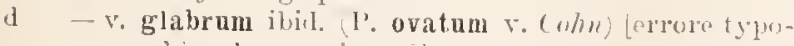
graphico huc pusitum "). arere

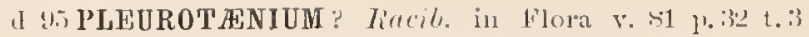
1.. 1 [11011 Hood].

\section{bieve}

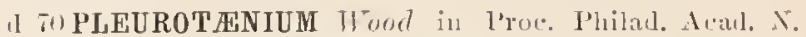
s. 1 inis? p. 18

at $7: 3$ - Wood Fr. Alg. p. 119 t. 21 t. 2 .

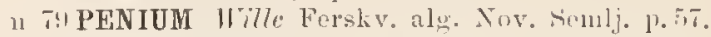

II $-\beta$ arcticun ibill., t. 11 f. it. [Alia sper.? ?.

1) SI DOCIDIUM (l']urotanium) lloll. Desm. U. s. 1. 15 .

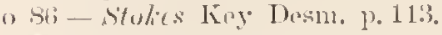

II s!! ? Tomi s.rll. Ale. p. nit.

a - $-v$ areticum ibid.

d 12 - Wolle Desm. U. ห่. ed. II p.5t.

\section{brevicelss}

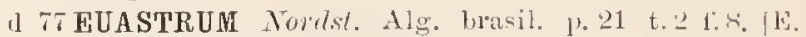
platycerum?].

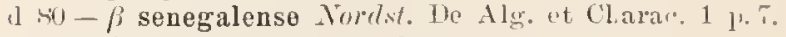

11 si- Toni syll. alcr. 1. 1052.

1 - $r$ sencoraleuse ibid. p. 108:3.

11 \% HELIERELIA Kuntze Rev, gen. pl. 1. S!s. Cfr. Eu. bellum Iire.

\section{brevicorne}

d !3 XANTHIDIUM Tumer Alg. Ind. orient. 1' 161 t. 13 f.?.

\section{brreirylindrirallu}

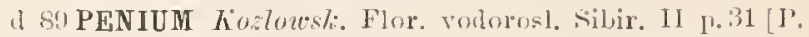
rufescens ('7re? ? ].

\section{Hirevisping}

n :39 BINATELLA Pril, in Chev. Mier. 1.272.

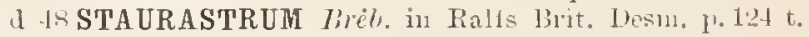
3.1 f. 7 .

d 52-1'ritch. Inf. p. 2ti2.

(1)

d li1-Arch. in Pritch. Inf. p. 737.

a fis-lial. Flor. Eur. Alg. 3 p. 202, cum 3 formis.

1 - b. Dickiei ibit. (Staur. Dickici Rirlfs).

d Ti- Tirchn. 1lg. Selles. p. 168.

d 7!) $\beta$ inerme Thille Ferskv. alg. Tov. Simmlj. 1. 5.2 t. 13 f. 102 . ("inarmatum" in explicatione figg.).

$\therefore 1$ - Cooke in Quekett Mier. T. (i t.16 f.3t

a 81 - Walle Desm. U. S. 1. 121 t. 40 f. $1-2$ (forma), to 53 f. $2-3$.

d - v. incrme ibil. p. 122 t. 40 f. $3-4$.

m sis - f. minor Isoldl sibir. Cllorophye. p.113; (f', minor Rab. ("brevispinum").

o - fo ibid. ot t. 5 t. 34 [ $\beta$ Boldtii Longerh. 18:13].

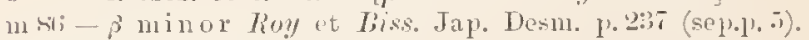

o s6-Stokes liey Iresm. p. 164.

(1) - (v.) inerme ibid.

mst - v. inerme Ifolle Fr. Alg. IT. ‥ A. 1.42 t.62 f. $\because-10$.

d 86 - Coole Brit. Desm. p. 14 ) t. 19 f. $1[\%, b . e$ a (indie 1.ss1. $b$ bis, $c \cdot d, f=$ e Ralfs 18 is].

1 $x$ - Mansg. Prodr. Algenfl. Bölnu. p. 211; ct pinerum.

un si-Iste. Jel. magyar. aIg. p. 231.

ll sil-Tomi Syll. alg: p. 1140.

1 - v. inerme ibil.

m! 0 - Eichler Sipis Desin. Miedz. p. !n!

11 !1 - West Adil. Frosliw. Alg. W. Yonksh. p, 2-17.

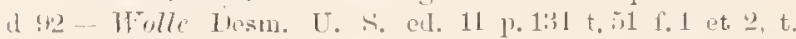
lit t: 2 ot 3 . 
d - r. inelme ilit., t. 16 f. 9 et 10 , t. is f. 3 et 1 .

11 (13) - $\beta$ Boldtii Layerh. Chlorophye. Alessin 1\% 1r:3 (f. Bolvet 1495.

m!:3 - Lü̈llemäll. Desm. Attersees p. iti?.

o 93 - f. Boldtii Twmer Alg. Ind. orient. p. 130 t. 16 f. 45 .

d $193-\beta$ retusum Dorge siissw. Chlor. Arehang. p : 1: t. 3 f. + to.

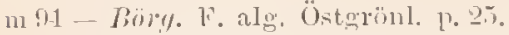

ก (3) - f. hoxagona Eichl. et Gutw. Spee. alw. nox. p. 17is

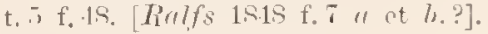
Cfr. Staur. laniatum.

\section{Broomei}

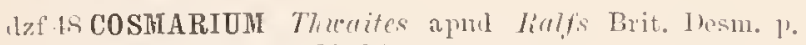
103 t. 16 f. 6. t. 32 f. 7 .

(1) $52-$ Hitch. Tnf. p. 251.

la lis - Alch. in Priteh. Inf. p. 731 t. 1 f. 7 .

il 1 (i) Relb. lirgpt. Fl. Sachs. p. 241.

u lis - Rab. Flor. Eur. Alg. 3 p. 171.

1) 71 - Imml. Desm. Suee. p. 2!?

11 73 - Irool Fr. Alg. p.133t.13 f.15.t.21 f..10 [C biretum]

11. 70 - Nordst. Desm. Ital. p. 41.

1) it Delponte Desmirl. subalp. p. 24 (sep.p. 12u) t.p; fo $11-19$.

1) TA-Kirchm. Alg. Sehles. p. 15.

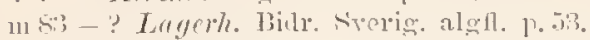

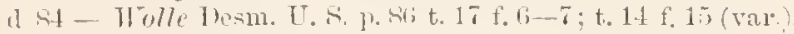

z. - r. f. s-9 ibil. [C. spinosporam Lalferh. 1Sit].

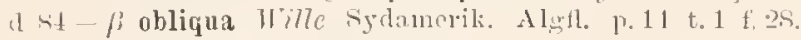
[C. Willei Lugerh. 1s,

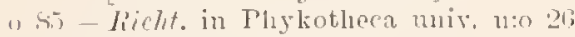

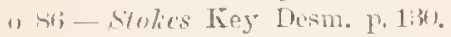

las - coolie Brit. Desm. p. 10 t. Ho f. 1.

d si - Hexemlu Chlorosp. Kihark. p. 2To.

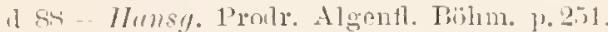

in Ra-Iste. Jol. maggar. als. p. 22.

0. s!) - Mark. Fr. Alo. Maine 11 p. 18ti.

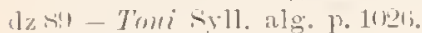

11 !1 URSINELLA Kunt: Rev, gen. pl. p. (2).

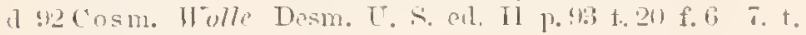
17 f. $1 \bar{i}$

uf - v. ibill. f. $8-\$$.

11 $11: 3$ - (Tetridiam) Tumer Alg, Ind. orient. p, 7.1.

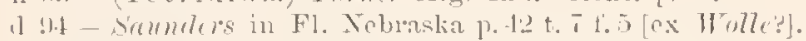

\section{Bryophilre}

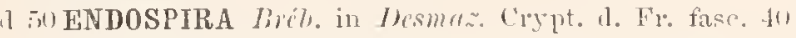
n:0 1:)5.1. eil. 2 n:o 14:5.1.

d th SPIROT P. 101 [e the liur. Conjug. Palmogloea endospira hïiz.).

11 7:) - Hund Fr. Alg. P. 122 t, 12 f. 10.

in 5 - Nortst. Desm. alet. p. 16.

a 84 - 11 on, Desn. U. S. p.33 t. 3 f. 20.

1) sti-stolies liey Desm. p. 111.

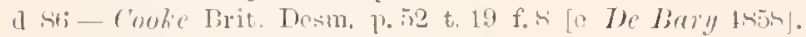

111 sit- Intr. Jol. magyar. alg. p. 2.13.

d sis - Toni syyll. alg. 1. sis.

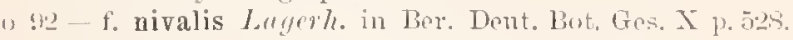

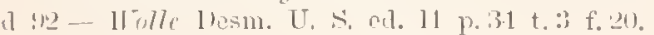
Crr. Ppirotenia muscicola.

\section{Tulbosum}

n :3T XANTHIDIUM khemb. in Abhand. Berlin. Mlat. 18:3; \%. 131 et t. 1 f. 7 (Fossile) [annon Spongia?].

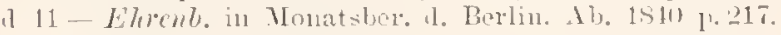
d 52 - I'ritch. Inf. p. 2.s.
51 - Etrent. Wicrogeol. t. 37 VII for

a 89 - Toni ry.11. nlen. p. 933.

\section{b1160smm}

n wi STAURASTRUM Benn. Fr. w. Alg. Engl, Lake Dista. 1 l. 11 t. 2 f. 18 - 2). [ (2uid ?].

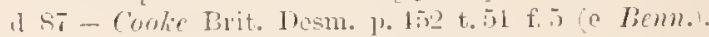

a s.1 - Tumi syll. alg. p. $117 \%$.

\section{limblueimiana.}

n 11 HELIERELLA Kumtze Rev. gen. pl. p. sos (Micr. Rabenlorstii Kivelun. 197s).

\section{Buluheimianmm}

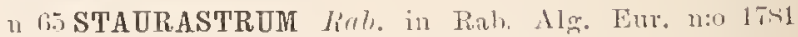
eum fig. a. et b. (sine deseriptione)

d to - Rall. Flor. Eur. Alu. 3 p. $245 ;$ h. (f, major).

a sa-Toni syll. alg. p. 1162.

\section{limluhrimii}

d S! ARTHRODESMUS liucit. Now. Desm. p. ก. (sep.p, 23)

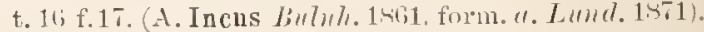
mon-Eichler spis Desm. Miedz. p. Ss.

\section{limmense}

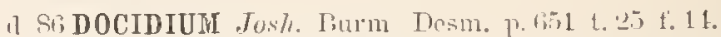

11 89 Tomi syll. al心. 11.5it.

n 93- Ocelematidinu Turner Alg. Tnt orient. p. :3.

\section{Burmenese}

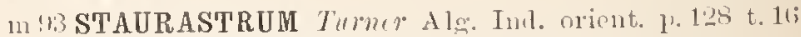
f. 13 St. bifurcum Josh. 1sti quoul fig. 27).

\section{corlutrme -11}

a ts COSMARIUHi Ralfs Brit. Desm. 1. 14 t. 17 t'. 1 .

17 52 - Iritch. Inf. p. $25+$ t. 13 f. 213 |e Ralfs

d 61 - Arch. in Pritch. Inf. p. 731 t. 2 f. 20 [e Rilfis].

11 be - Rul. Flor. Fur. Alg. :3 p.170.

o 11 Land. Desm. Sinec. p. 33.

o 73 - Nordst. Nory. Desm. p. 1t.

a 73 - Itood Fr. Alg. P. 13?.

o Ti - f spectabile Nondst. Desm. Ital. 1 . 40 (C. spectabile the Nut.j.

12 Ts-Kirchm. Alg. Seliles. p. 15i.

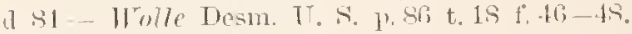

1) Si stokes king I lesm. 1. 12!

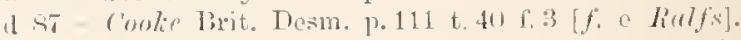

1) 87 - Wurtall in Ann. Inst. bot. lli Roma v. :3 jt. 1 p.li.

A 8 - Ilansy. Proilr. Algenh. Bülmm. 1.202.

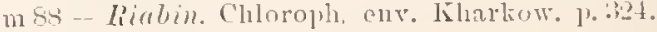

1) Si-Toni Sylt. alg. 1. 1007.

a - v. spectabile ibial. p. 1111 .

(1 8!) - v. bohemica Rucih. Now. Desin. p. !le t, is f. 21.

m - P spectabile f. minor Gutu. Fl. glon. Galic. $2 \mathrm{l}$. 15 t. 1 f. 13.

I - - triverracosum ibial.. t. 1 f. 1 t.

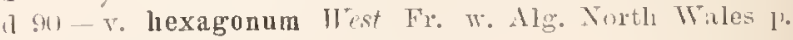
$20(1)$ t. 1 f. 30 .

m no - Eichler Spis Desm. Minila. p.87.

m:11 - Heimerl Desm. alp. 11. 505.

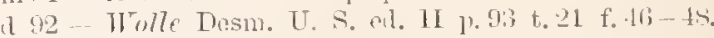

11 URSINELLA Kumtze Rov. gen. pl. p. m.t.

m 12 Cosm. v. speetabile f. elongata Gay Alg. Bagn. Rigorr. p.XXXi.

1) $9-\beta$ bolemienm Mlansg. Algent. Bïhm. eit. bohem. II p.175; ad. germ. II p. 2.84.

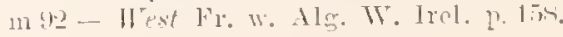




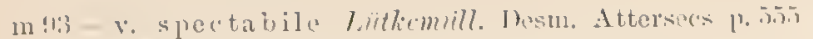
t.sit.s.

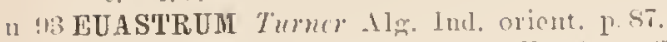

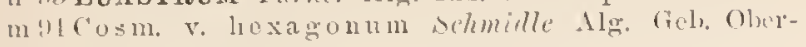
rheins 1. 531 .

m1 - v. spectabile 1ste. - Mlat. Roman. alw. 1. 155.

n! ! - lioryc süssw. Chlor. Arcliang. p. 2!!.

(fi. En. (Cosm.) decorum.

\section{(relatilm}

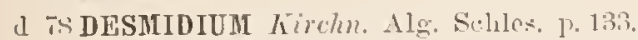

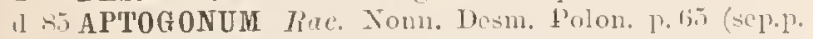
9). [D. Baileyi " eat at un Nordst. 14ris].

1 - r. diagonum ibis. Aptogonum Diagonum Delp. 1873 .

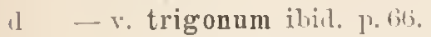

1 - f. italica ibil. (Apt. Bailey i $J_{(1)}$. 1473).

a - - f. polonica ibic.. t. 14 sep. is f. fi.

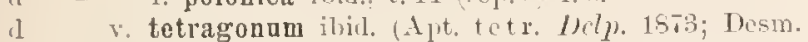
cate Tirche 1sis; D. Baileyi f. 1-gona Nordst. $1 \mathrm{isi1).}$

\section{relcorato-remleritum}

d 15 HOLACANTHUM Micron. in P'lanz, w, Ost-afrili. 17. 20.

\section{colculect}

d 55 PALMOGLEA Bonkom. Yotes r. 1 t. 1 f. 2 [Quir] est?]

\section{crilinerelli -}

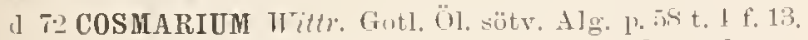

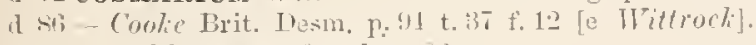

mis-Boldt Dosm. Grönl. ए. 23.

d Si - Tomi Srll. alg. p. 101\%.

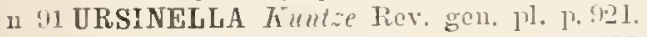

6 94 Cosm. Jolms. Rare Ilesm. U. s. p. $28 \mathrm{t}$ t. $211 \mathrm{f}, 13$. [Alia sper. sec. West in Joum. Bot. 189i p. bis].

\section{relcitropul}

d : $:$ BINATELLA Brit. Als. Falaise 1. $5 \%$. = Crystalli sec. Elurenb. 18:3-; Raphidium fasciculatum sec. hiitz.

\section{reldariorlum}

1 Ss MESOT ENIUM Hansg. I'roilr. Alerentl. Bilnm. p. 1it. 11. Endlicherianum $\beta$ cald a riornm Layorh, 1s\&(i)

d si Palmogloeal Tori viyll. Aleg. p. S1:3.

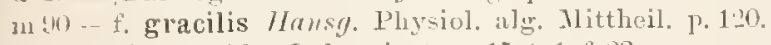

II 93 - Turmer Alg. Ind, orient. 1. 15 t. 1 f. 23.

\section{rerlatemese}

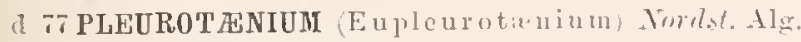
masil. 1. 17 t. 2 f. 2.

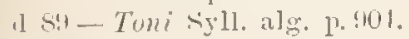

\section{CAI.OCYLINDRLS}

d 19 . Va\% einz, Alg. 1, 111. Subgen. Dysphinctii.

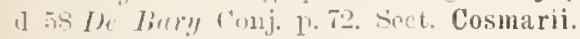

1 Tis Kirchn. Alw. Sehles. 1'.112. (renus.

¿1 S1 Tulle Desm. U. S. P. 51 .

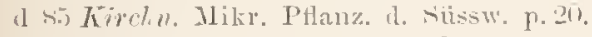

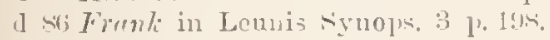

a sfistokes Tiey Desm. p. 10!.

d st Couke Prit. Desm. n. 12-2.

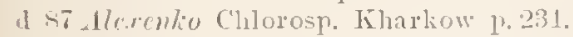

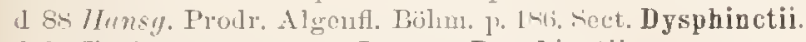

d S! Toni syll, Nlg. I. Ksit, Sect. Dysphinctii.

d s1 Kirchn. Mila. Ptlanz. r. Süssw. ed. "2 p. 21.

d i2 Wolle Jesn. C. S. et. 11 p. reatogermonm- -

l il EUASTRUM (Cosma rinm) (ray Mon. Loc. Conj. p. (i1 t. 2 f. 1; et Note Conj. 1]. 11. France 1).331;

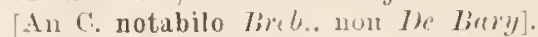

a 8: COSHARIUM Toni sill. alg. p. 3iit.

d si - p suecicum Nordsl. in Wittr. et Norist. Alin. cxs. 11:0 30 ; et fase. 21 p. 10.

n :11 URSINELLA Kuntze. Rev. gen. pl. p.921 ("calloderma").

\section{CATOOCASTRIDILY}

o 89 Toni syll. Alg. 1) 1611. Subsect. Gastrocosmarii (E ugastridium IInnsy. 18si'].

\section{c(170.51)0 $01111,-(1$}

daf to CLOSTERIUM IFitt. Skandin. Desm. p. 23 t. 1 f. 11. o 71 - Lumd. Desm. Suce. 13. S1.

o Tl-f. minor tfille Fersis. alg. Tor, Semlj. p. 60 t. 1.1 f. 45.5.

mz 81 - Iúcit. Iesı. okol. Kiraliowa p. S.

dzf 86 - Coule Brit. Desm. 1. 27 t. 1:3 f. 6 [e Witloek].

dzs. - Toni syll. Alg. 1. 812.

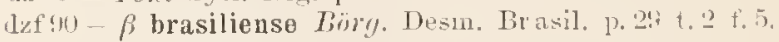

1791 ARTHRODIA Kinntze Rev. get. pl. p. s93.

m ytClost. Borye süssw. Chlor. Archang. p. 1h.

\section{"ulyeroilles}

d S5 STAURASTRUM Tulle Bull. 'Torr. bot. Clut, Lisis l'. a $\mathrm{t} .17$ f. $11-15$.

d $8 \overline{\mathbf{i}}$ - Holle Fr. Alg. T. S. A. P. 15 t. 57 f. 11-15 [icon. repetit.].

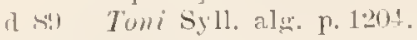

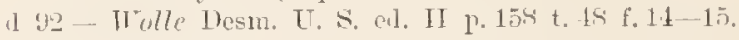

\section{rambiense}

o 93 EUASTRUM Taner Desm. Fotes p. 313 . et f. 1 p.31.

\section{c(l)lb):i("l)ll-}

a so Cosmarium rooke et Trills in rooke in Grevillea 9) 13.91. [C. venustum sec. Roy Scott. Desm. 1894 р. 17т; C. impressulum sec. HIrnsg.].

S1 - Coulie in Quekett Nicr. J. ti t. 13 f. A l).

d. 81 - Wills in Milland Natural. 4 p. 73 t. 5 f. 1.

n 85 a. typicum Ruc. Nonn. Desm. Polon. 1. 7!) sep.p. 23).

a b. dubium ibil., t. 11 (sep. 2) f. 10.

m si Lager\%. Amerik. Desm. p. 241.

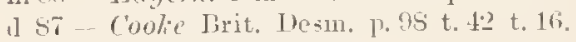

d s.! - Toni s.y11, aler. p. 957.

d - v. dubium ibid.

m!n URSINELLA Kunt:c Rev, wen. pl. 1) !r21.

o !3 Cosur. f. minor Twane Alg. Ind. orient. p. T6 t. 111 f. 15 .

o :11 - Willem. Obs. erit. Desm, 1.74.

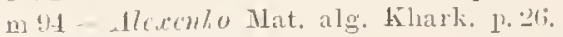

\section{CAMYLOCERAS}

(1 !3 Turuc Alg. Im\}, orient. 1) 20. Subgen. Closterii.

\author{
rallintull) -

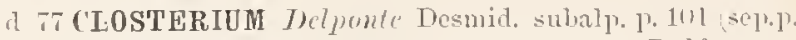 \\ 210! t. 17 f. $7-10$ (Cl. attenuatum Rulf: non \\ linelos.

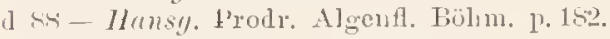 \\ d s.? -.. Tomi sivll. Alg. p. 830 .

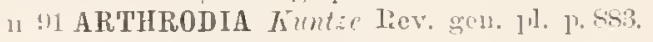

\section{cromdiamme - a}

d 75 COSMARIUM Jelponte Desnid. subalp. p. 17 sep.p. 113) t. \& f, 1-ti, 


\section{CANDIANUM}

o sil-f. Wille Norg. Ferskv, alg. I p. sis.

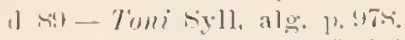

() -f. minus ("Wille") ilvil.

b) 1 URSINELLA Kumze Rev. gen, pl, p. 1.

m ! Cosm. Gule. Flor. alg. Jenpol. p. 51.

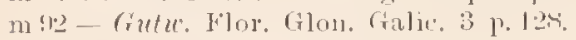

n !1-Gute. F1, alg. T'arnapol. p. S!?.

\section{remelirmmem - re}

d 73 EUASTRUM Dolponte Desmid. sulalp. p. 10t (sep.p. (4i) t. 6 f f. $11-1$.

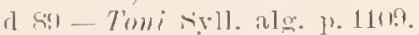

n !1 HELIERELLA himtac lies. gon. pl, p. Sor.

d 13 En. v. munitum Turuer Alg. Int, orient. P. 82 t. 10) $\mathrm{f}, 40$.

\section{Candirmmm}

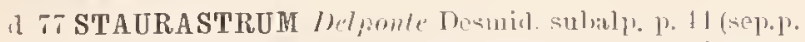

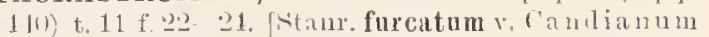
foule 1Mist].

d .

\section{(.)}

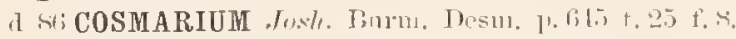

(1) PLEUROT $\mathrm{ENIOPSIS?} \mathrm{Tmi} \mathrm{syll,} \mathrm{alg.} \mathrm{1.} \mathrm{\{ 0! \%}$

\section{repemse}

a in CLOSTERIUM liabcul. Beitr. Trept. Güul-Afr. 1. 242.

\section{capense -is}

d S) COSMARIUM Toni syll. alg. p. Of? (C. pyramidatum

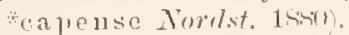

1) !1 URSINELLA Funtze Rev, gen. pl. p.121.

\section{rerlitlrove -is}

d 75 CLOSTERIUM I Hponte Desmil. subalp. p. 110 (scp.p. 201i) t. 1 is f. 15 -1!?

a 89 - Tmmi S.rll. Als. 1.51!?.

n "1 ARTHRODIA himtze Rev. gen. pl. p. sis.

\section{C"rpitulum}

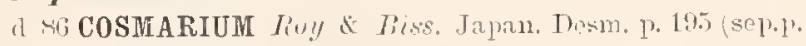
3) t. $268 \mathrm{f} 9$

d 89 - Tomi syll. alg. p. $43 ! !$

11 9 URSINELLA Kinlize Rev. gen. pr. I 921

m 11 Cosm. f. Gutw. Finr. Lenpol. p. 15 t 1 f. 21 .

1) $92-\mathrm{f}$. rectangularis Ruc. Desmillya ('iastoni. p. 372 it 3 i) 2 t. 7 f:. 20 .

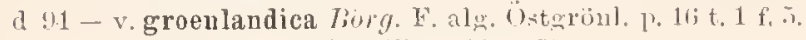
1205 - Eichler in Pamict. Fizy. 13 p. 54.

\section{Crepitulum}

d LSTAURASTRUM lirth, in linlfis Brit. Desin. p. $211 \mathrm{t}$.

\section{5 f. 25.}

d 52 - Iritch. Inf. 11. 2uis.

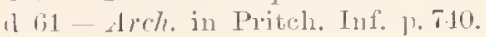

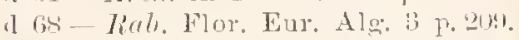

d - b. amoenum ibid. St. an ocn $11 \mathrm{~m}$ Mlilse) ihid.

1 72 b. amoentum f. spotsbergensis Vorlst. Desm. spotisl). p.34) et 11 t. 6 f. 2.5; (tig. 25 e. praullo incorrecta : forma: 2.

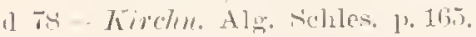

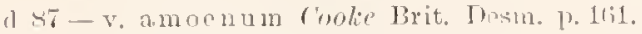

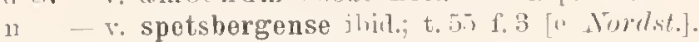

1) 8 - Toni tivll. al!

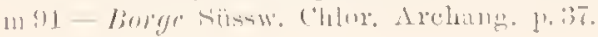

\section{roverlietum}

d 93 EUASTRUM Turnt) Alg. Ind, orient. p. Si t. 10 f. 60 [E11. spinulosum; subs]. inermins v. carductum [1/ll. ()bs. arit. p. (lli--)!!].

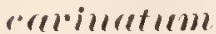

(1) 1:3UASTRUM Ehrenl. Mikr. Lob. sibd, u. N. Amm. p. (3:35. 33!1, 372 et) 413 (Euastr, sp. Ritlley Amer. Theill. t. 3 f. 24) [Descriptio mala. Cosmarium ovalo

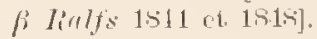

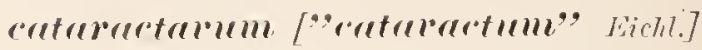

m 15 COSMARIUH Fichler in I’amiet. Fizy. 13 p. for [Cosm. viriolatum v. eataractarum linc. 18sey).

\section{Cretenutre}

d sĩ LEPTOzoSMA Tume New rare Desm. p. 331 (sep.p. 2) 1.16 f. 2 Dosuidim quadratnm sec. Wolle in

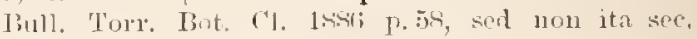
Turn. Alg, Tut, orient. p. 151\}.

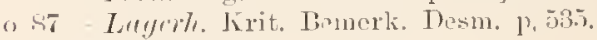

d sis! - Toni Syll. Alg. p. 799.

\section{erendretmon}

o 31 CLOSTERIUM cord" in Alm, d. Carlsh, 1835 p. 19m, 2u!!. 1. 5 f. lifi [C1. rostratum! sec. Whreub. in Wiegnn. Areh. $1830,1 \%$ sir]

o 111. - _ - 1810 p. 21:1: "Cette espuce se distingue dn Closterium rostratim Ehr. l. c. fig. X. par we euirasse unie".

\section{rolitum}

( si EUASTRUM (Cosmarium) Gay Mon. loc. Conj. p. in t. 1 f. 17. [E. humile Fay Not, Conj.].

\section{CENTRENTERILM}

d ss Bolll Desm. Grönl. 1.31. Sulbgen. Xanthidii.

(1) sil Tiucit. Now. Desm. p.97, sect, Arthrodesmi.

\section{rentrosphilletum.}

d 13 COSMARIUM Twner Alg. Tnd. orient. p. 51 t. s f. 1.

\section{CEPHA IASTRUM}

○ 93 Turne Alg. Ind. orient, p. 132. Snbgen. Staurastri.

\section{Cerrestes}

d 71 STAURASTRUM I.und. Dosm. Suec, p. 6.1 t. 1 f. 6.

o 71 - Arch. in Journ. Bot. 14ifl p. ?t Stanr. sp. Areh. in (2. J. М. Sc. $v, 12$ 1. 202 cum deseriptione).

si - Cooke in Quelsett Mier. J. is t. $15 \mathrm{f}$. $1 \mathrm{~s}-1$ \%

s1 - Wills in Midl Natural, 4 t. 5 f.. .

d 8.11 - Iolle leam. U. S. p. 133 t. 43 f.6-7.

in Si-Lagerll. Amerik. Desm. p. 2.1s.

o sti - Stokes key Desm. p. $16 \%$.

d si -Cuole Brit. Bosm. p. 173 t. 54 f. 3.

d.

d 12 - 11 olle Desm. U. S. ed. II p. 1.17 t. $51 \mathrm{f} .6-7$.

n $9: 3$ - Cyptastrum) Turner Alg. 1nd, orient. 1) 132.

\section{Cerretium.}

d 52 CLOSTERIUM Peity Tileinst. Lebenaf. 10.206 t. 16 f. 21.

d tim-Iiul). Flor, Eur, Alg. 3 p. 1:ss.

d sia-Tomi syll. Alg. p. 837.

n It ARTHRODIA humlic Rev. gen, pl. p. Mts?.

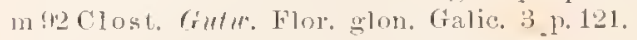

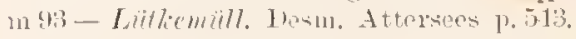

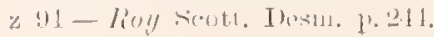




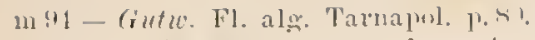

Cfr. ('lost. pronum b. acutum Klclse 1s7:?

\section{revertumbis}

d :13 STAURASTRUM Twmer Alg. Ind, orient. 1. 13: t. $1.1 \mathrm{f} .2 \mathrm{~s}$.

\section{revertojhorll}

d si MICRASTERIAS Josk. in Journ. Bot, v. $2: 3$ p.,31 t. 25 . f. 4 . "ceratofera".

d $8: 1$ - 7omi sill. alg. p. 1121.

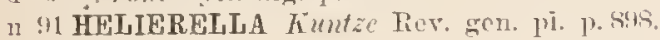

\section{(2evotoullorim}

1 iTSAURASTRUM Tortst. Ale. brasil. p. 21. f. xylogr. IHI.

d \$9-Tomi syll, alg. p. 11-16.

\section{Cerberils}

1) 51 DIDYMOCLADON? Bail. Micr, observ, p. 33t t. 1 f. 15 at 16 .

d $52-$ Pritch. Inf. p. 270

d 61 STAURASTRUM $1 \mathrm{rch}$, in Pritch. Inf. p. 711 .

A fis - Rabl. Flor. Enr. Alg. 3 p. 215.

d 73 - Wuod Fr. Alg. p. 15 t.

d 4 - Wolle Desm. U. S. P. 142 t. 15 f. T - S.

o 86-Stukes liey Desm. p.168.

d 89 - Tomi syll, alg. I. 1200.

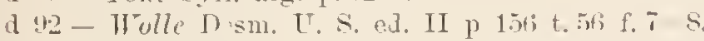

\section{Chatubinstiii}

d 93 XANTHIDIUM Eichl, et Rac. Nowe gat. zielen. p. 121 t. 3 1.'.24.

\section{[Chaorlinées]}

[1 23 Bury in Dict. class, hist. nat. v. 3 p. 13 Gen.: Chaos, Heterocarpella, Helierella].

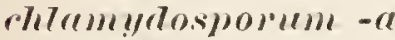

12 5f PALMOGLOEA Is Rar. in Rab. Alg. n:0 511.

z 5i- 7) liar. in Bot. Zeit. P. T6.

d J MESOT ÆNIUM De Dary Conjug. p. 75 t. 7 D.

dzfipl-v. $\beta$ Arch. Deseript. sep.p. 15 in Dubl. Nat. IIist. Soc. Pr. p. 2; t. 1 f. $1-19 ;$ in Q. Journ. Mier. Si. T. $121 \mathrm{t} .6 \mathrm{f}$

dzts Talmoglnea Rab. Fl. Eur. Alg. 3 p.117.

dz $-\beta$ Archori ibid. $\beta$ Arch. 1siti).

d\% TT - v. minor Reinsch Alg. Trom. Bon. Spec. p. 210.

mz 7!Mes. $f$ Aleheri f. minor Nordst. in Wittre et Fordst. Alg. exs. n:o 270 ; et in fase. 21 (18991) p. 1 .

$\mathrm{m} s \mathrm{~L}-\beta \mathrm{Archerif}$. Curumalensis Hille rydamerik. Algft. p. 19 t. 3 f. 92 .

tefsei-Coolie Brit. [Dan. p. 47 t. 18 f. 1 [ex Arch.]

dzsi l'almorlnea) Hansy. Prodl, Algent. Bijhm. p. 17l.

12 4! - Tomi sill. Alg. p. $\$ 12$.

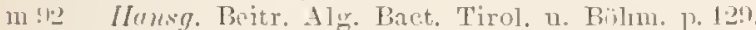

maf : -11 st Fr. w. Alg. W. Irel. p. 131 t. 21 f. 8 .

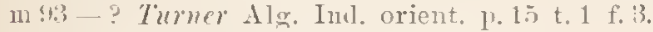

m s.] - West Fr. Alg. West Ind. p. 267.

m5 - Vichler in Pamiet. Fizy. 13 p. 5.

\section{rimstomii}

d !) EUASTRUM liac. Desmidya Cinstoni. p. 347 t. 7 f. 28

\section{(irlstollii}

d : PLEUROT

t. 6 f. 4 ;

Vimedsterit. Intex I'esnid.

\section{ritiutospinosum}

d 52 PHYCASTRUM 7 hly k leinst. Lelensf. p. 210 t. 16 f, a-s.

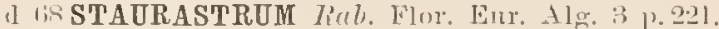

\section{rilintum!}

d) lis SH p. 119.

d 89? - Toni syll. Aler. 1). 7.5.

\section{rimetume}

d 63 EUASTRUM Grogn. Plant. Crypt. p. 263 [descript niala].

\section{rinctutum -re}

d T5 COSMARIUM Nortst. Desm. aret. 1. 27 t. 7 f. 20.

d 89 - Toni Syll. alg. p. 1033.

o 89 - Racib. Now. Desm. p. 81 (sep.p. 9).

n 91 URSINELLA Kuntze Rev, gen. pl, p.921.

\section{riventren -is}

l 6 G COSMARIUM Reinscl, Spec. Gen. Alg. p.113 t. 202 $0^{\circ}$ I. f. $1,2.3 .4$ (sсp.p. 5 t. 3 r. 1 f. $1,2,3.1$ ), non Initz.

d 67 DIDYMIDIUM (Cosmarium) Reinsch Algenfl. Frank. p. 109 t. 10 f. 2 a $-c$

it Cosm. Luml. Dism, Suee. p. $\$ 1$

85- Tolle Bull. Torr. loot. Club. v. 12 t. 47 f. 37.

d 85 - Rucib. Tonn. T ssm. Folon. p. 83 (sep.p. 27) [C. Raciborskiannm Tomi 1SS?].

- forma a. ibid. t. 11 (sep.p. 2) f. 1 a.

o - b. ibir. f. 1 a'.

d st - Tolle Fr. Alg. U. S. A. p. 28 t.5i f. 37 [Holle 1885 ?

d 97 - v. maculata Ist 2 . Diagn. prav. in Notar. p. 237 (sep p. A) Cfr infra 1888

d 87 - Alexemlio Chlorosp. Fliarl. n. 269

d. 89 - Hans\%. Proilr. Algenf. Bühm. p. 219.

d - $f$ minus ibid.

d 88 - $\mathrm{r}$. maculata Iste. Jel. marrar. ale p. 225 t. 1 f, 12 [C. obsoletum v. punctatum MIask. 18933].

d 89 - Toni Syll. alde. p.975.

1) $-r$, minus ibil

m 90 - Trest Fr. w. Alm. North Wales p. 289.

n 91 URSINELLA hunt:c Rer, gen, p1. p. 024.

m s1 Cosm. Gutw. Flni, alg. Lcopol, P. Lis.

m m - West Fr. w. Alo. Wr. Irel. 1) 111.

d .22 - Holle Desm. IT. S. ed. If p. 5.9 t. 19 f. 37.

m93-Turner Alg. InI. orient. p.51.

\section{rivelularer -is}

1) 45 EUASTRUM Tlass. Brit. Alg. p. 383 t. 90 f. 5 [Eu. ansatum see. Lumd. 1971]

d 18 - Ralfs Brit. Desm. p.85 a t. 14 f. 3 " es llass. delineata).

Pillil. (E. sinuosum "Lemorm. in herb." t. $13 \mathrm{f}$. $5 a, b, a$ et $t .11$ f. $3 b$ et $c$ [C. Falesiensis Breb.?

1 - $v$ ibid. E. Jenneri drel., t. $13 \mathrm{f.} 5$ c [Cfi. Lund. Desm. P. 2()?

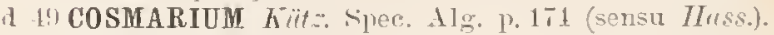

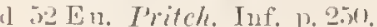

1) 5j-- B. Ralfsii lirib. Iist. P. 12.2 (Iealfs Br. Desm. f. 5 c)

C. Falesiensis ibil. (Tulfs l. e. f. 3 b

D. Hassallii ibir. (Fig. Mlass:i

$[A=\beta$ Tiralfs max. p.)

d $61-4 \mathrm{rch}$, in Pritch. Inf. 1, T.24.

d 63 - Kub. Kiypt. Fl. Sachs, p. 186, [scusu Hass:i] 


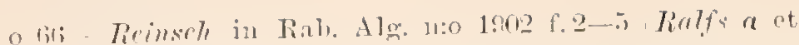
(i) [Forma?].

1iT. - Tot. 1hesm. ita]. p. 30 t. . f. 16i [E. sinnosnm].

ot his - a. Tialfsii. Tiul. Flor. Eur. Alg. 3 p. 1 k3.

d - b. Falesiensis ibil.

d - c. Hassallii ibicl.

d 73 Hood Fr. Ala. p. 139); a ed l, lialfsii.

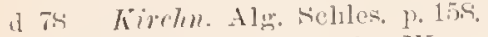

o s:3 (ubulski Mater. aler. Warszawa p. 241.

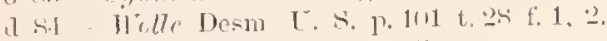

(1) sii-Stolir. Key Desm. p. 14 .

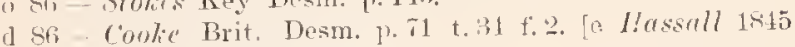
et lialfs 1 sis f. $\mathrm{f}$ "l]

a si Alexenko Chlorosp. Khark, p. 2l2.

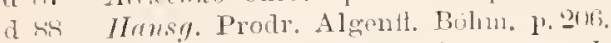

1 - $\beta$ sinuosum ihil. "Eu, sintosum Lemorm."

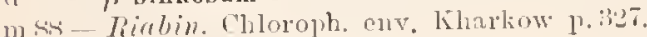

1) S.1 - Tomi isyll. alg. p. 1097.

m!1 - Gulw. Flor, als. Leopol. p. 73

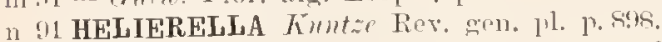

d. 12 Eu. Wolle Desm. U. S. al, II p. 112 t. 32 f. 1-2.

\section{riremlrre}

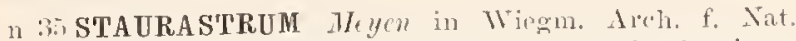
18:35 p. 218 (uomen tantum!) [An Erhiuella circularis fireville, Helicrella c. Meyen in Isis 1sim $\mathrm{p}$. 113. Mcrilion $\because$ A $y$ ? - An gonus poprium (Polyasterias) sec. Ehremb. Inf, p. 14:?!

\section{rofrudestimm}

1 15 CLOSTERIOM Küt. Phyeol. yorm. p. 132 [Cosm. Cucurbita sec. Kitz. in Rirlfs Brit. Desm. p. 11!n.

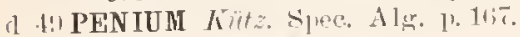

f!! DYSPHINCTIUM? Nory, einz, Alg. $\rceil .112$.

\section{rlovertum}

a knocIDIUM K̈̈̈z. in Ralfs Brit. D:sun. p.15li t. $26 \mathrm{f}$.

3. [Cost. truncatum Kill . 1515, nom Krib.].

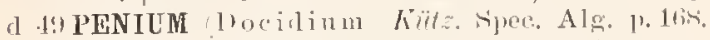

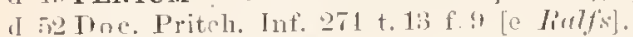

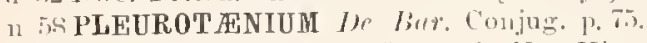

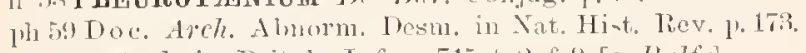

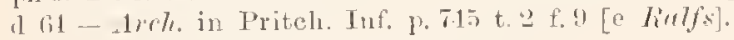

ก 157 - Not. Desm. Ital p. 59 t.5 f. sti.

(I tis Pleur. Rub. Flor. Eirr. Alg: 3 p. 141.

o 71 - Jumr. Desm. Sinec. 1). 84; forma.

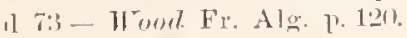

si3 Doe. Mask. N. ZeaI. Desm. Ade. p. 257 t. 25 f. 22, monstr.

d s.4-Whe Desm. U. S. P. Is t. a f.s.

o si - Stolies liey Desm. p. 113.

d 86 - Coolie Brit. Jesm. 1) 14 t. 15 f. ?.

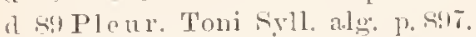

m 11 - Hest Thanish Alga lo. 119.

m! 12 - West Fr. W. Alg. W. Irel. 1'. 11!.

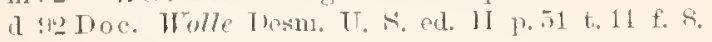
('tr. Pleur. 1. Doc. truncatum.

\section{rlorertirm}

d 13 EUASTRUM (Actinastrum) Thmer Alg. Ind. orient. p. 4.5 t. 11. f. 1s. [Eu. Turneri Hildm.].

\section{rloviferum}

" 1; XANTHIDIUM Hillinsm in lransart. Micr. Snes. 1 ]. 8 ! t. $1: 3$ f. 1 ( $\mathrm{X}$. tubiferum dilatatum). FFossile an Spongia:?.

\section{C7rpsydrem.}

d 77 COSMARIUM Thelponte Desmil. subal]. p. 8 (sep.p. 101) t. 7 f. 35-34; [non Nerdst. 1kitu; Cosm. integerrimum? see. Rinc, 188 !)!

d S9 DISPHINCTIUM? Tomi syll, alin. r. Sal.

\section{Clepsydren}

(1 To COSMARIUM Nordst. Desm. Trasil. p 212 (sep p. 17t). t. 3. f. 2!); 11011 Dell".

0 71 - Lumd. Desm. Suec, p.37 [C. tithophorum v. dissimile verisimiliter see. Rucib. 184\%. - An C. Bicardia?].

o 76 - Jucots. Desm. Danem. 1.:200.

d so-Tomi syll, alu. P. 1016.

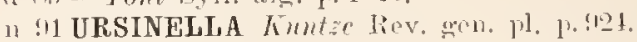

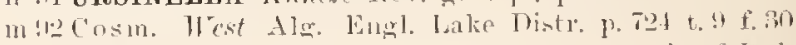
[sec. anct. in litt. fig. non bona est, partim falsa].

\section{rlepseghrou}

d 60EUASTRUM Wallich Desm. Low. Bengal p. 2.4 t. 14 f. $1: 1-21$.

(1 8.) Tomi syll. alg. n. 1076.

n \$1 HELIERELLA Kuntae Rev. gren. ple p.sis.

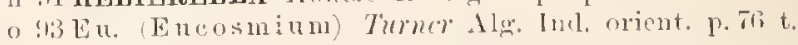
() f. 51 .

\section{clepsystro"}

d 71 PA

dzf 73 - Whod Fr. $\$$ lg. p. 105 t. 11 f. 4.

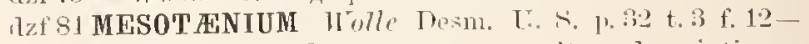
15 [Ex. Hood ? non exacte. saltem leseriptio ex Hood 1. e.].

o sh-Siolics Kiey Desm. P. 111.

Iz 89 _ I'almogloea) Toni Syll, Alg. P. 813.

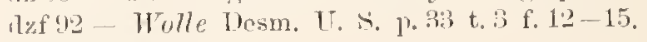

\section{Crepsydra}

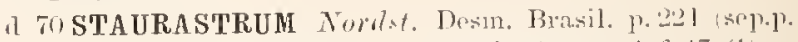
1.4i) a obtusnu, et $\beta$ acuminatum t. 4 f. $47(1 / 2$ a et $1 / 2$ fit. 1 f. ISt.

c 71 - a. Iaml. Desm. Suce poit [Nt. subpygmienm f. glabra llost 189t].

in 72 - Nortst. Iesm. Sietsb. p. 3s; a [st. Bienoanum sec. Nordst. in Desmi. Aret. 1, it2].

m St - - J J y

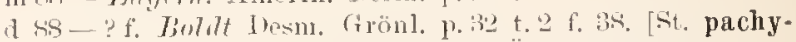

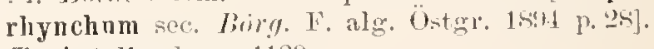

(1) 59 - Toni syll, alg. ]. 1139.

a - v. aculuinatum ibid.

m95- - Eichler in Pamiet. Fiz. 13 p. 62.

\section{rlepsymandm}

dzf $₫ 3$ STAURASTRUM Spencer in Mask. N. Z. Inesm. Adil. 1.21\%. t.21 f. 12. ISt. Spenceriaumm Musk in litt. ot in Furth. Not. 1ss?! ; St. connatum \& śpencerianum Nordst. 1848]; - rec. Novtst. 1stu.

\section{Clerei}

a 71 l'ENIUM I.tud. Desm. Suec p. si, t. in f. 11 . (P. Thwaitesii (lree, non linl/s).

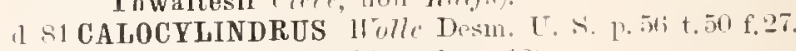
m só Pen. Buld Sibir. (hloroph. 1. 120.

o sic Cal. Stulies liey Desm. p.114.

11 . DISPHINCTIUM Toni Syll, alg. p. 84:\%.

m !ro l'en. Throt Fr. w. Alg. Wr. Irel. 1. 12!1.

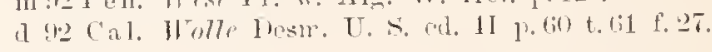




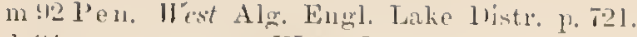

d ! $4-v$ crassum Irest New Brit. Alg. p. I t. 1 f. i.

\section{Clevei}

14!3 STAURASTRUM livy Scottisll Desm. p. 17!) (st. lavo fi clevei Tittr. 1siti!n.

\section{Clitorystis}

1) 93 Tum, Alg. lnd, orient. 1) 11: Anbgen. Cylindrocystilis.

\section{Closteriacer"}

d lit Givaly lirit. Alg. ]\% Tl Sect. Desmidiacoar. Genera: Tetmemorus. Penimm, Pocidium, Closterium, Spromtutuia, Aulistrodesmus.

\section{Closterien}

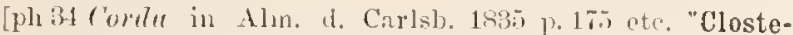
riées", fun, infus.].

[o.41) Curlle in Alm. d. Carlsb. 18n) p. 21\%. "Closteriées".]

[o 11 Imijurlin I1ist, nat. d. Zoophyt. p. 6ris. "Closteriées".

a t.2 Trevis. 1'rosp. d. Flor. Eugan. p. is. Subtrib. Micrasteriearum. Ge11.: Clost. Splaterastrum et 'lrochiscia.

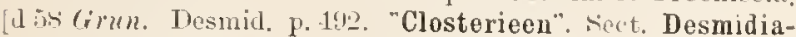
cearum. Gen.: Clost., Stanroceras, Docidium.

d 73 llierogr. Dict. eal. 3, p. 23. "l'rib, Desmidiac. Gen. Clost. Pen., Docid.. spirotenia.

n SG Toni Consp. gen. Chloroph. 1) 452. Trib. sulfamilite

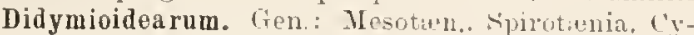
lintroe, ? Schizospora, Pen., Clost., Ineylonema.

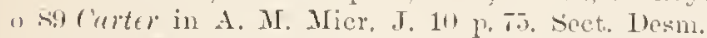

d Si Tomi ryll. alg. p. 806 et $81 \%$. Closter, it Penium. Cfr. Closteriacere, Closterina et Lesmil, interre.

\section{rlosteridin}

a ti ENTOSPIRA livét, in Kintz. Tab, phyce I p, tot. 3i f. 2 .

d 4! PALMOGLOEA (Crlindrocystis) hüt: sipec. Alg. 1). 20․․

o G1 Entospira Huntzch in Pab. Alg, no 10nt, f. a, b 1-I Raphidiam convolutum $\beta$ contortum sec. Rub. Flor. Eur. Alg. 3 p. th]

o 6.1 SPIR0TENIA $1 \mathrm{reh}$. Descript. sep.p. 5); in Thb. Nat. IList. Soc, 1" 16. Endospira truncorum Brib.).

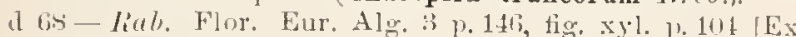
hiilz. 1;it].

(1) 59 -Toni S.r.11. Alg. p. 80\%.

d 41 - v. elongata Huns.y. Alo. u. bacter. Mittheil. 1.323. o $12-$ Latgerh. in $\mathrm{X}$. Notasis. III p. 34 (Gemts nov.?).

d 92 -Hansy. Prodr". Algenfl. Bülnn. ed. bohem. p. 173 (ril. grem. p. 21s).

d - $\beta$ elongata ibid. f. 6s, ell, german. 77. 215. f. (fi p

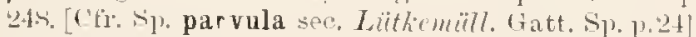

\section{CLOSTEIRTA}

d 32- Ehrent. Entw. d. Inf. 1,66. Fam. Polygastrica Anentera, Gymnicat.

d 38 Elerenb. Juf, $p=0$ et $8 \%$.

(d) Licess Breitr. Fauna Infus. p. 15.

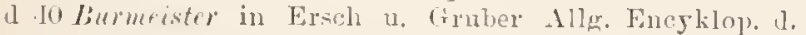
II. II, 18 1) 201\%.

o dis Sicbold Vergleich. Anatom. d. Wirbenlos. 'lihior. 1, T

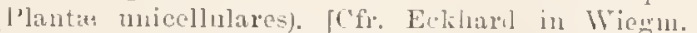

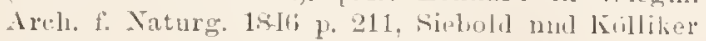
Teitsclur. f. wissensch, Zool. Bत, 1, 14l!, 1\%.270,

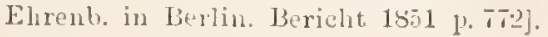

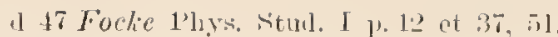

d is I'ritch. Infus. 1) 17!!

\section{rlosterioides}

1 1 PENIUM lialfs Irit. Lesn. 1, 1.iz t.31 f.4.

l 52 - Lritch. 1nt, ], 27:3.

d 61 - Arch. in Priteh. 1nf. p. Tis.

o 61 - f. [minor] Hamlased in liab. Alg. n:o 1:3es [1'. Xavieula sec. lírb. 1sisis.

If bis-liab. limpt. Sachs. p. 1tit.

oz $1 \mathrm{it}$ - Irch. in Q. J. N1. se. v. 7 p. 2.3.t.

o 6 - Not. Desm. Ital. po tis t. S r. Tis.

d tis-Jiab. Flor. Eur. Alg. 3 j. 121.

in 7o-Reinhord in Arbeit. Naturf. -g. Charkow I p. 11.

z 71 - Lund. Desm. Sinec. 1).81.

d 73 - ITood Fr. Alg. p. 10!1,

d TT Dhlponte Desusil. subalp. jo. 83 (sep.p. 17!) t. 1.j it. 19-2.2. [inclus. 1'. Naviculal.

mit - l'etit Desin. de Paris p. I (seppop. 28).

dz $78-\kappa r c h n$. Alg. Selles. 13. 135.

d T! - a typicuen Kllls Desm. Gstpreuss. p. 24 t. 2 f. $2 f$

d - b Navicnla ihil., t. 3 f. 2 g. (1. Navicula Mili.)

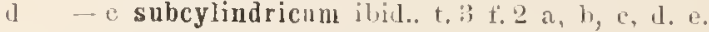

1) 84 - Wolle Desm. U. s.. p. 3. t. 5 f. 18 .

m81 - Wille sydanerils. Algfl, p. 22l.

in 81 - Artari List. a] r. Moscou p. 13is

d 85 - Kirchn. Milir. PHanz. 1. Niussw, p. 22,

o sij-stokes liey Desn. 1) 111.

dz sij-Cookir Brit. Desm. p. 4 I t. 16 f. :3.

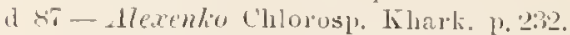

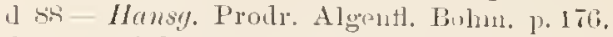

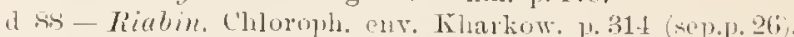

m Ss - Boldt Ilesm. Gï̈nl. p. 41.

phts - IIuntf. Zellu. n. Hiillerallerte Dosm. p. 101 (sep. 1. 43 .

m so - Iste. Jel. magyar. alg. 1.2-11.

m ss - Potent North Caroliua Desm. p. 2.

mis -- Nordet. Fr. wat. alg. N. Zeal. p. T1.

o - $\beta$ subcylindricum f. major ihid., t. т. f. 24.

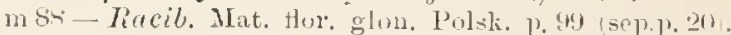

dzsi - Toni syll. Alug. p. stil.

6) M- West Fr. w. Alg. Tortl Wales p. 286.

m 90 - Borg. Desm. Brasil. 1. ㅇ․

m 30 - Eichler spis Desm. Miedz. p. 85.

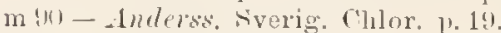

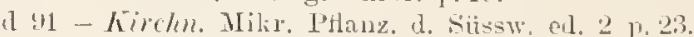

m!1 - f. minor Heimerl Desm, alpin. l', 590 t. 5 f.:3 $\mathrm{I}^{\prime}$ Heimerlianum simidle 1sit.

m!1 - Gulw. Flo1, alg. Loopol. [1.31

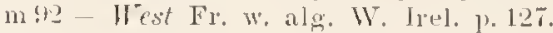

m 9.2 - Moud. Anstral. Silisswasseralg. p. 4 II.

d 92 - f. punctata like. Desmilya Cinstoni p.367 t. 1 f. 2. f. granulata ibiel., et fig. 1 .

d 92 - Wolle Dosm. U. . . ed. ll p.Bti t.5 f. lis

(1) f. fo interrupta 1 e'st Alg. Eingl. Lake Distr. p. 721.

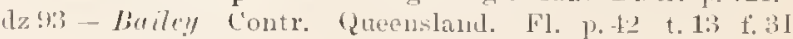
(e) Corstie.

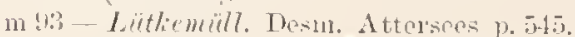

f. minns iluicl.

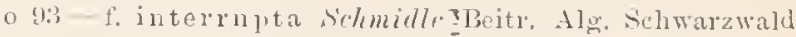
p. 8 it. 3 f. 7 .

o !4-f. minor schmille Alg. Geb. Oberrleins p.54.

o !1--f. tumida Istr. dint. Ruman. alu. p. 15i;

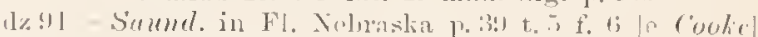

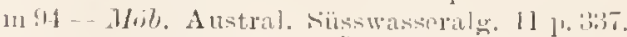

Inz!1 - Burges. F. aler. () stgrioul. 1)! t t. 1 f. 1.

Cfr. Clost. Ions $v$ intermedia Ju. 1s75, (1. Libellula, ('l. Penium licinorle. 


\section{CLOSTERIUM}

\section{CLOSTERII II}

o 17 Nitsech Beitr. z. Infus. p.60 et 6iT. (Vibrio Mäl. ex. p.). o 28 (:. $1 \%$. spee. Alg. 2. 1 p. XXXViII.

d 28 Ehrubery riyul. Phys.

o 30 - Teitr. z. lienut. d. Inf. p. 39.

1):31 Kül. sves. Diat. p. 591 (sep-p. 56).

034 Corda in Alm. d. Carlsb. 16.3 .5 p. 193 ete.

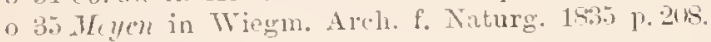

11 3. liveb. Alg. Falaise p. Ë.

o 35 Horren. Mem. $\therefore$. 1. Clost. in Bull. Ac. Belg. II p. 297 (genus Hrdroplyyt.) sec. Treificr Nom. bot.

o sti Horren IIem. s. 1. Clost. in An. d. se. nat. p.257 "c"Instrien"ies".

pho 37 Elrent. in Bericht. Prenss. Ak. THiss. II p. 133.

ph 36 עeych Deitr. z. PHanzenpliys. p. 125 t. 10 f. 2 [C]. monilifermm? et 7 . 4:32.

a 38 Etrent. Infus. p. 90 . Sulogenera: Closterium 1.90 et Toxotinm.

ph 3 A Meyen Syst. Pf. I'lysiol. 11 p. $24 \%$

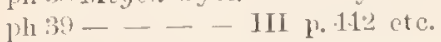

d 39 Brib. in (hev. Mier. p. 272.

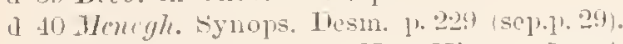

plitu Malrymple in Amm. Nat. I Iisto $v 5$ p. 115.

1) ph. 11 bail

d $\$ 1$ Wont. in Hist. Nat. d. ('allar. p. 1:t.

41 lieichend. Nom. p.19 [sec. P'eritr. Yom, bot. - n. v.].

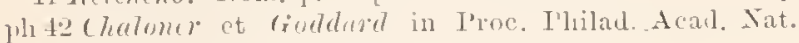
s.e. 1 1. 169 et $17: 2$.

143 hïtz. Phyce genex. p.16u.

d 11 Breb. in Dict, univ, list. nat. I p. 1 .

d 15 Mass. Brit. Alg. p. 367.

d 15 hï̈н. I'lye. germ. 1) 129.

ph to Erhihard in Wirgin. Areh. Naturg. X1I, 1 p. 211.

a 47 linb. Heut. kirgt. F1. II p. Vill et 52.

d ts lialfs Brit. Desm. 10. 1.s.

d $49 \mathrm{Kitt}$. spee. Alin. p. 16i:3.

d 49 Nog. cinz. Alg. P. 1th. Subgenera: Closterium et Xetrium.

d su Marisit. catal. esp. onis. 1?.31.

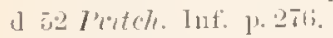

d 533 Huth. Fl. liclg. II p, is.5.

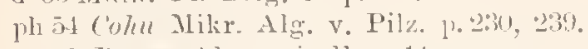

jhit 5.5 Brum Alg. micell. P. 11.

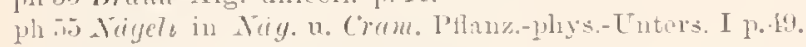

a Derlicl. Introul. Crypt. Bit. 1'21.

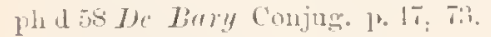

d 58 Gimn. Desmicl. p. 1!1.2.

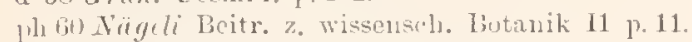

(1) 61 Areh, in Pritch. Inf. 1. T:20 ot 7 .1i;.

d $6: 3$ trognt. I'lant. Cryot. 1).26i:3.

a 63 liab. Firypt. Fl, Sachs. 1) 169.

d lit Gray Broit. Alg. 1. 72 .

d be Eyrich Alecn H. Mannl. p. 1:3.

d tï Not. Desm. Ital. 1. 22.

If tis Rub. Flor. Eur. Alg. 3 1. 12.3.

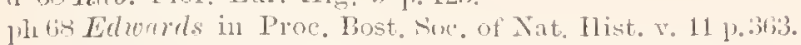

(1) Wit Wittr. Skandin. Wesm. 1. 21; suhgen. Asteroselene.

d 73 Hood Fr. Alg. 1) 109.

4 73 Delponte Desn. subalp. 1. 39 (sep..p 27\%

d 75 Microgr. Dict. 1) 2834 et 17.

o 7is Jacobs. Desni. Danem. p. 1tii.

d 7 Delponte Desmid. subalp. 1.9.3 (sep.p. 18\%).

d $7 \mathrm{Frank}$ in Lemis synops. p. 1633.

d Ts Kirchn. Alg. Sisles. p. 137.

u Tu hlebs Desm. Ostpreuse. 1\%.5.

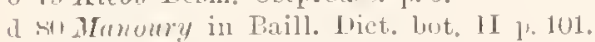

1.h s3 Fischer Zellth. ('loster. 202.). ph s. Fincher Gypskryst. Desm. p. 134 ete.

1] $5: 3$ ('ybulski Mater. alg. Warszaw. p. 260 (sep.p. 12).

d 81 Ciuy Monorr. loc. Conjug. p. 39.

d 81 Holle Desm. T. S. p. 37.

ph 81 Strusburg. bot. Pract. p. 337.

(1 si) Kirchn. Mikr. P'Hanz. d. Sïssm. P. 20.

ph 85 Ki7ebs Beweg. 11. Schleimbild. 1. Desm. p. 35 is ete.

d Bis Bulsumo Alghe del com. di Napoli p. 26 (et $\left.3 i^{3}\right)$.

d si Frank in Leunis synops. 3 p. 19.5.

o sf Stolies ling Desm. p. 109.

ph 86 Berth. Sturl. I'rotoplasmamech. p. 141. 11i2,

d sif Cooke Brit. Tesm. p.17.

d si Alexemke Chlorosp. Khark. p. 222.

d sis Klunsg. Prodr. Algenfl. Böhm. p. 175 (Shec. c: Stauroceras).

(i) 88 Toni et Levi Fl. Alg. Venez. p.22 et 27.

jh 88 Lundstrom in Bot. Not. 1888 p. 69.

d se Hauptfl. Zellm. n. IIḦllgall. Desm. p. 97 et 112 (sel'p. 39 et 54) t. 3 f. $38-40,43-47,50-50,58,59$.

d 89 \%oni syll. Alg. 1.817.

(1) Wille in Natür. PHanzenfam. p.9. Sect. 1. Euclosterium, If. Rostrata, III. Asteroselene.

plug1 Klebahe in Verh. d. Ges. deutsch. Naturf. u. Ärzt. in Bremen 1890 II p. 111.

1.1.!!1 \%. Zncharias ibid. N.122.

ph s1 Wildem. Recherch. temperatur. caryocin. p. Is t.2 f. $19-38$.

d 91 Lirchm. Mikr. Pflanz. d. Siissw. ed. 2 1. 21.

pl. 31 Hangernd in Le Bataniste 2 ser. fasc. 6 p. 250 -201 (parasit.) t. 1!t f. $5-15$.

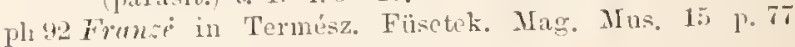
ct 159 .

1) 52 Holle Desm. U. S. ad. II p. 38.

a !3 liailey Contr. Queensl. Fl. p. 40.

o 13 Turner Alg. Int, orient. p. 23. Suligen.: Selenecras, (ampyloceras, Orthoceras, Stauroceras.

ph 93 Lithemiller in Verh. Zool. bot. Gis. Wien 1893 sitz. 月. p. 39.

ple!1 Lüthemïll. in (i)sterr. bot. Zeitseler. $1.1 \mathrm{p}$. 11.

1) 91 Samurl. in F1. Nebraska 1.39.

phat Ilemlletm in Pringsls. Jahrb. 26 p. 727 (scp.p. 5n).

\section{Closterillm}

¿11 POLYSOLENIA Ekenb. in Monatsber. d. Berlin. Ak. 1sil) p. 216 An Penium sp. cum fungo parasitico? fecundum Brebisson List. p. 1au et Dangeard 18s6 nihil aliud est quam Clostorium eujusdan ( $h y$. tridiaceis inquinatum].

\section{rocerctetem}

1 ! COSMARIOM West Alg. Engl. Lake Distr. 1. T2.1 t. 9 f. 11.

\section{rocerefutum}

o. S7 DESMIDIUM (Widymopinm) Norelst. Algolog. Surhsak. $11.155 \mathrm{ct}$

d 58 - Nordst. Fr. Alg. N. Zeal. 1.25 t.2 f. 3.

d 89 - Tomi Syll. Alg. P. Ts5.

1 $: 0$ - v. cambricum West Fr. W. Alg. Nortl Wales 1) $28: 3$ t. 5 f. 2.

\section{roarectatem}

d 5f STAURASTRUM Breb. Liste p. $14 \mathrm{t} .1 \mathrm{f} .29$.

d 61 - Areh. in Pritch. Inf. p. 740.

d bo-linb. Flor. Eur. Alg. :3 p 220

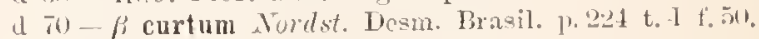

a 71 - Luud. Desm. Siner. J̈j; forma. 


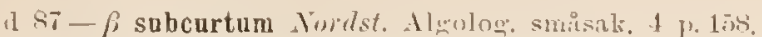

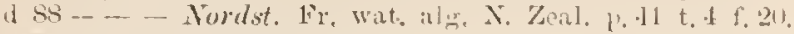

1 s!! - Tuni syll. nler. 1). 11si.

1 - r. subeutum ilid.

d $-r$. curtum ibil.

(M) - r. subeurtum IVest Fr. w. Alg. Nortl Wales t. $\therefore f .8$.

\section{coerulesiens}

d ta CYLINDROCYSTIS live apud Menegh. Mon, Nostoch. p. 9I = Pleurococcus coernlescens lireb. in Rab. Fil. Eul. Alg. III p. 29 (Stis).

\section{Colmii}

d TSCALOCYLINDRUS Kirchn. Alg. Sehles, p. 142 [Disphynet. tessellatum Ihell. 15.7 sece lion et lises. 1ssti; Cosmarilimm striolatum $\beta$ Ilonsg. 1854].

in 31 Rucit. Desm. okol. Kraknwa sep.p.!!

o so Cosmarium (Pleuroteniopsis' Rucib. Nonn Desin. Polon. p. 6! (sep.p. 1:3) t. 10 f. 3 .

m 90 Eichler Spis Desm. Miedz. ]3. sit.

(1) 13 DYSPHINCTIUM (spherosphinctinm) r. regulare Turner Als. Int, orient, 1). 41 t. 8 f. 39.

\section{roloritum}

d 193 COSMARIUM Turner Alg. Ind orient. p. 17 t. \& f. 11.

\section{roliferlem-r}

a ss COSMARIUM Lagerh. Bengal Desm. p. T t. 1 t. 5.

d 89 - Toni srll, ald p. 950.

11 "1 URSINELLA huntat Rev, gen, pl, p, !2.1.

\section{COHPGDASTRUM}

11 33 Turner Alg. Int. oriont. 1). s. Sulogen. Fuastui.

\section{COLPONEMA}

d 133 Turner Alg. Ind. orient. 13.110. Subgeu, Onychonematis.

\section{COLPOPELTA}

phi3t corde in Alman. d. Carlsb. 1s35) p. 179. 1s. 19.1 t. 2 f. 23 [una species (C. viridis; nulla deseriptio generis].

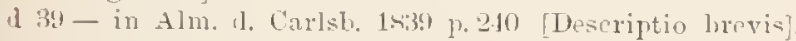

\section{Colpopelta}

d fil COSMARIUM Brib. apul Arch, in Tritch. Inf. p. 7031. [Cosm. Cordanum Brib. see, Rull, Isisis].

\section{columbirmum.}

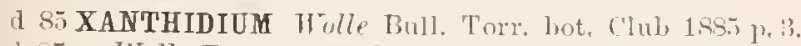

d 8. - Wolle Fr. Alg. U. S. A. n. 3t t. 2ar f. 10 \& 11 .

(1) - Holacauthium) Tumi syll, alg. p. spos.

d 12 - Wolle Desm. U. …․ II p. $1(k)$ t. $4 . j$ f. 10 et 11 ,

\section{commissurale -is}

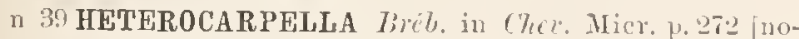
mell tantim].

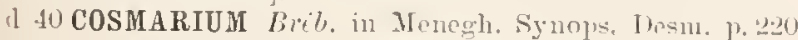
(sep).1. 20).

daf 4 Q $\rightarrow$ Kulfs Brit. Desm, p. 10:) t. 16i f. S

d $49-$ hütz. spee. Alg. 13. 17t.

d\%52-Priteh. Inf. p. 25-

$13 t$ - Rribl. List. p. 131.

d - r. acutum ibid.

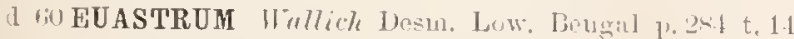
f. $12-13$.

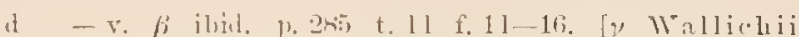
Tirn. 1s:3

1 (i1 Cosm. Arelt, in Pritel, Inf. T. T34; et $\beta$ acutum

in ti DLYMIDIUM Gosmarim licinsel Algentl. Frank. T. 120. A et li Cosm. ornatum Iinlfs:

d lis Cosm. Jiub. Flor. Eur. Agr, 3 p. 170.

d - re acutum ilid.

(1) $\beta$ crassum Nordst. Desm. 13rnsil, p. 213 t. 3 f. 1!.

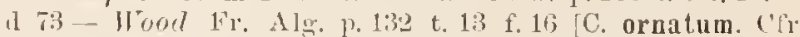
Holle 1). U. . . t. 18 f. 101 .

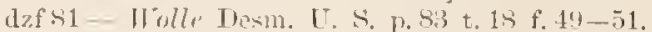

o sti - itolies hey Desm. p. 1:30.

dzf 87 - Cooke Brit. 1)esm, 10.113 t. 40 f. 5 [c Rulfs].

o $89-\mathrm{f}$. Ruteib. D.sm. Lithuan. p. 660.

1 89 - Toni syll. alor. 1) 1017.

o - r. acutum ibit.

11 91 URSINELLA himtžc lier, gen. pl. 1).921.

o 42 Cosm. T. crassum IT est Fr. W. Alg. W. Irel, 1. 158. Hzt:2 - Walle Desm. U. s. ed. II p.91 t. 21 f. $1 ! 9$-51.

m.93 Eu. Eucosuinm " typicum Turner Alg. Ind. orient P. 75 .

m - $\beta$ crassum f.? ibil., t. 11 f. 2 T.

d - $y$ Wallichii ibid. t. 11 f. 10 (v. P, Irall. 18(io)

1) od capitatum ibid.; t. 11 f. 11. Cfr. En. schizostauron Tum.

\section{rommune.}

1. s5 Cosmarium liacib. Tonn. Desm. Polon. p. 7.2 (sep.p. 11i).

a - 1. polonicum ibir. ('. polonicum lauc. Issi).

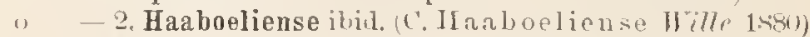
Nomen "commune" nly nuetere ipso lss"! in Now. Desm. p. 88 (sep.p. 16) supprimitur].

\section{rommututum}

a s9 COSMARIUM licht. in Phykotheca univ, is n:o 2sil, Cosm. punctulatam the Tot. 1867].

\section{rommutatum}

(1) 4? PHYCASTRUM Kïtz. Spec. Alg. 1\% 180 Phycastr. granulosum hälz. Phyeol. grerm., nee Desmid. gr. Elirenb.

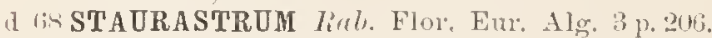

1 4 - Wolle Desm. U. S. p. 121 t. 40 f. 33- 3.t.

o sti-Ntokes Irey Tesm. p. 14is.

1) s!-Toni Syll, alg. 11. 11.19.

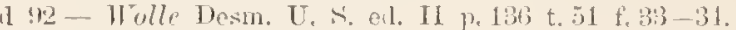

\section{rompactum-}

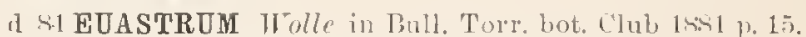

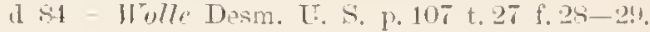

in Sij - $\beta$ major Latgerh. Amerik. Desm. p. 231.

o sif - Stokes liny Desm. p. 1.15.

d s! - Tomi sioll, aldr. 1. 110.5; ct 5 majus.

n !1 IIELIERELLA Kunta lies. gen, pl. p. s?

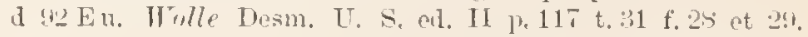

\section{comprectum -}

d 8 - CLOSTERIUM Tordst. Algolog. smisak, 4 p. 163.

a si - Nordst. Fr. Wat, alg. X. Zoal. p. 6s t. 3 f. 25).

d $x_{i}$-Tomi Syll. Alg. p. S?3.

n '11 ARTHRODIA hintze Rev. gen. pl. p. 883.

romblrmatem -re

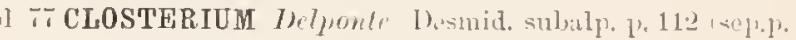
ons to ts t: $: 31-3: 3$. 


\section{COMPLANATUM}

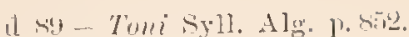

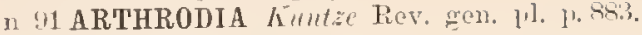

\section{complelertum}

d TSTAURASTRUM Thelponte Dosmid. subalp. p. 1tit. 11) $1 .: 26-36$.

d

\section{(1)}

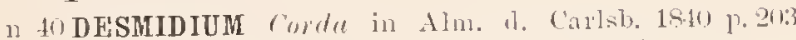
sep. 1. 1s see. liab.). (D. cylindricum Grev.).

d 42 - Iinlfs in Anm. Nat. l]ist. v. "1,253 [Sphrozosma vertebratum sec. Iialfs].

\section{comlmessum}

d 8. SPH 2 R0ZOSMA Mresk. Furtl. Not. X. Z. Desm. p. !) t. 1 i. 1.

\section{comptum}

d a) STAURASTRUM Wulle Bull. Torr. bot. Clul, 14so p..$\overline{4}$ t.5. t. $E^{2}$

1. 54 - Wulle Desm. U. S., p. 12!1 t. 12 f. 13-16.

o sij-Stolies liey Desm. p. 16ri.

d 8 - Toni syoll. aly. 1). 1.20!n.

d 92-Wulle Desm. [T. i. el. Il p. 113 t. 53 f. 43 - 40.

\section{concertemere}

a is PALMOGLOIA Grum. Desnid. P.191-2 Cosmocladium?]

\section{concentriculll}

1 93 COSMARIUM Turuer A]g. Ind, orient. p. 62 t. 9 f. 11.

\section{conrinnum}

a 62 EUASTRUM Rub, in Rab, Alg. Eur. n:0 1303 c. fig. [C. Meneghinii b. "oneinmum liub, 1868].

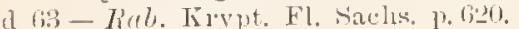

d fi cosmaRIUM Reinsch siper. tien. Alg. p. 1 to t. 22 It. I f. $1-7$ (sop.p.

a - f. A. majus ibid. 1. 111; f. $1-3.17$.

d - f. B. pygmanm ibid.: f. $4-5,111-11$. 15-1fi Cosm. plomaum llantzsch

d .... f. C. concinnum ibid.: f. fi-9, 12-14 (Rab. 18ri2). o (i) DIDYMIDIUM Cosmanium) Reinseh Algenfl. Frank. 1) 110 t. U f. B. Formet ut supra.

a sucosm. $p$ lave Wille Xorg. lerskr, alg. I p. 30 t.1

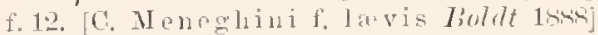

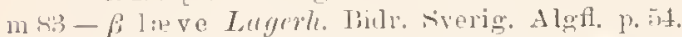

m 81 - $\beta$ lieve f. major Wille sidanerili. Algti. p. 31 .

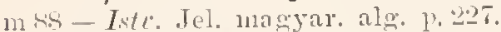

m so - p lave Nordst. Fr. Wat. alg. N. Zeal. p. 5s.

I $50-\beta$ lave f. major Gutu. Fl. grton, Galic. 2 ].12 f. 1 f. 8 .

m 91 - v, leve West Fr. w. Alg. W. [rel, p. 1.!!.

m ! - Iicte. Desmiclya Ciastoni. p. 371.

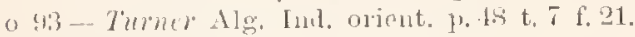

$m 55$ - Wrest Alg. Matag. p. is t. ? f. 23 .

\section{romrinmllu}

a s:3 XANTHIDIUM Areh, in Anu, Mag. Nat, Histo, jer. 11:0 61 p. $26 \%$.

a bi-rooke l3rit. Wesm. p. 1 - ry.

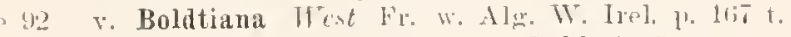

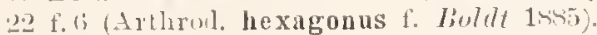

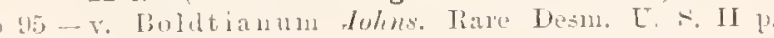
245 t. 233 f. 11.

\section{romalemsitu}

d IS SPIR0TENIA Jivéb. in Ralfs Brit. Desm. p. 17il t. 31 f. 1.

I i2 - Pritch. Inf. p. 28 . t. 13 f. 4 [e Ralfs].

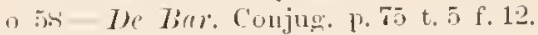

d til-Arch. in I'ritch. Inf. p. To1 t. 2 f.t [ex Malfs].

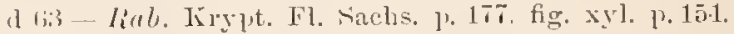

m rif - lieinsch in liab. A]g. n:0 1:00.

un fit-licinsch Algentl. Frank. p. 212.

ozlit Areh. Conjug. Sinrotien. p. 186 t. 8 f. s-11.

iti - Not. Desm. Ital, t.9 f. 82 .

m lis - Nordst. Bith. Averig. Desm. p. 11.

1 tis-liab. Flos. Eur, Alg. 3 p. 116. fig. xyl. p. 104 [E linb. 1863].

m 70 - Reinhurd in Arbeit. Natmif.-g. Charkow I p. 15.

1 $7: 3$ - Ifood Fr. Alg. 1. 122 t. 12 f. 11.

d 75.. Microgr. Dict. 13. 728 t. 16 f. 59 [e Ralfs].

m 75 - Nordst. Desm. Aret. p. 15

a 7 - Thlponte Desm. subalp. p. 141 (sep.p. 237) t. 20 f. 20,

a $\mathrm{is}-\mathrm{Kirchn}$. Alg. Sichles. p. 13i.

m $78-$ Mempel Algenf. Chemnitz p. 113.

m $7 !$ - Wille Ferskv. alg. Nov, remlj. p. js.

ll s1 - Hask. N. Z. Desm. p. 314.

m 84 - Cruy Mon. loc. Conj. 1. 75.

d si - Wolle Desm. U. S. p. 33 t. 3 f. 21 2.2.

m 81 - Arturi List. alg. Moseou 1? 138.

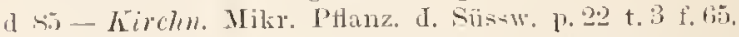

msi) -.. liacil. Xoun, Desm. Polon. p. 6.2 sep.p. f;

z 86 - Iirthold itud. Protoplasmanech. p. B1ti ete. [ime nomine sperificol.

o st - Stolies Key Desm. p. 111.

dyf sli - Cooke Brit. Wesur. p. 00 t. 14 f. 3.

d 57 - Alexemlo Chlorusp. Fhark. p. 220.

d 88 - IIansy. Prods, Algentl. Bühm. p, 17t f. 105.

m sis - Rivbin. Chloroph. env. Kliarkow p.320.

ms - Iste. Jel, magyar, alg. p. 213 ,

m 8 - Liacib. Mat. Hor. glon. Polsh. p. 100 (sep.p. 21).

s! Cruter in A. M. Micr. J. $10 \mathrm{f} .1 ;\left(\mathrm{ex} \|^{\prime}\right.$ olle $)$.

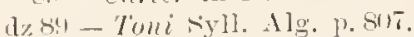

m 90 - Lichler spis Derm. Mielz. p. 85 t.8 f. 8.

m !n - Inderse. Siverig. Chlor. 1 p. 18.

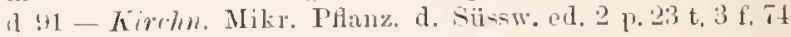

nn $\$ 1$ - Heimerl Desin. alp. p. 589.

m!1 - Gutw. Flor. aIg. Leopol. p. 30.

m! - Wret Fr. W. Alg. W. Irel, p. 133.

1] 1.2 - Wolle Desm. U. S. ed. I1 p. 33 t. 3 f. 21--2.2.

m!:3 - Lüthcmilll. Desm. Attersees p.jlu.

119 - Monotania) Turn. Alg. lum, orient. 11, 23.

m!t- Hedembe Mat, alg. Ishark, p. 1!.

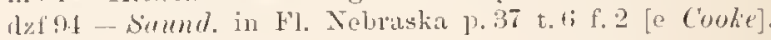

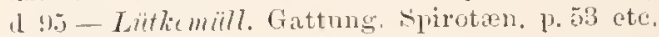

\section{coufertu}

1 il MICRASTERIAS I uml. Dorm. Anee. j. 14 t. 1 f. 5 M. papillifera f. Fuhluh. in IIeslw. 1 sti2 t. 10 quoad fig. 1). [Mic1. granulata Houd 1s73].

d $\$: 3$ - v. hamata Wolle in Bull. Turr, lut. C'lub v. 10 p. 1! t. 27 f. 1. [H. liamata Botry 18:\%)].

a s.t - Wolle Desm. U. S. p. 114 t. 53 f. 12 et 13 .

d - v. hamata ibid., t. 38 t: $3-1$.

sfi-Stolies Key Desm. 1. 147 .

1. sit;-Cove Brit. Desm. p. 50 t. 28 f. 2.

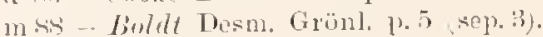

¿ 8 ! - Toni Syll, aly. 1) 1128.

1 - v. hamata ibid.

11 ! HELIERELLA Kimtze Rev. gen. pll. p.sis.

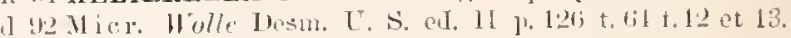

d v. luamata ibil. p. 1:27 t. 64 f. 3 -4. 
romforvoides

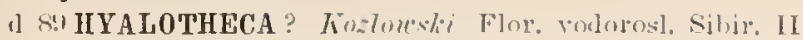
1. 1!) t. 1 f. T. [Oodogonium?].

\section{roll' $11.81111-$ -}

d st COSMARIUM ruotie Rrit. Desm. p. $110 \mathrm{t} .12 \mathrm{f} .9 \mathrm{C}$. Brebissonii f. genuina, latior et angustior Jacubs. $1 \rightarrow-i(i)$.

o 47 - $\beta$ regularins (ad intorin Nordst. Algolog. smilsak. $1 \mathrm{p.} 13$.

d se - - Nordst. Fr. wat. alg. X. Zeal. p. $7 \mathrm{t}$ if fot.

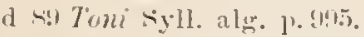

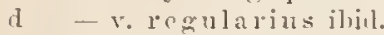

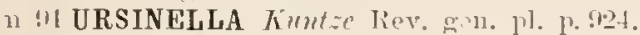

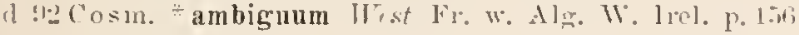
t. 21 f. 13. [C. subtholiforme see, sehmialle .tlug. Ober. 15!4].

\section{ronirmm}

d 95 COSMARIUM Ilest Alg. Madag. p. 71 t. 8 f. 12.

\section{romicum}

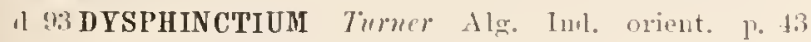
t. 1 f. 2 i.

\section{ronirmm}

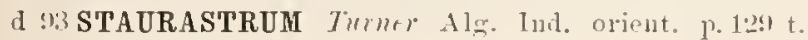
16 f. 38 .

\section{colijillirtm}

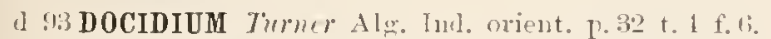

\section{roumutum}

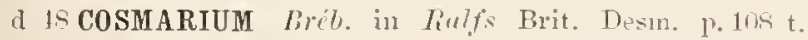
17 f. 10.

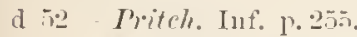

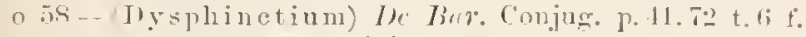
47. (Mysph. Meneginianum.

1) li1 - Lreh. in I'riteh. Inf. P. 735.

d] $1 ; 3$ - Trab. Krypt. Fl. Sachs. 1?:20?.

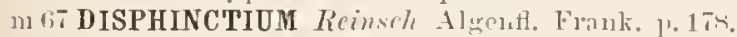

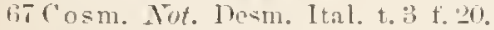

d 6r-Rril. Flor. Eur. Alg. 3 p. 16.

o - a. ibill. p. 17t;.

o - b. ibid. (Jiulfs)

o - c. ibicl. (DC Not.

d 73 - Wood Fr. Alg. p. 131.

Ti-Reinsch Contrib. t. 12 f. 5 .

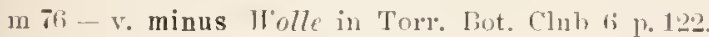

d 7 - Delponte Uesmid. subalp. p.31 (sep. p. 1.25 t. 9 f. $23-25$.

7 - Reinsch in Pringsll. Jahrh, v. 11 t. 17 f.fi et 12. m $7 s$ - Nortst. Alg. sanuvic. p. 1 \&.

d Tí CALOCYLINDRUS hirch. Alg. Sehles. p. 113.

m iscosm. Hempel Algenfl. Chemnitz p. 11 l.

d $7:$ - a typicum Klebs Desm. Ostpreuss. 1. 2?: a fi $\mathrm{t} .3 \mathrm{f} .21)-21$ [(Ruid?].

d - b psendoconnatum ibid. ('. pseudoc. Nordst.).

mine- Tordst. De Alg. ot Charac. 1) T.

1) HCal. Wulle Desm. L. S. P. 53 t. 1: f.s-! (s. "very. near to C. cllipticum [lelponte").

n - r. minor ibid.. t. 12 f. 10. t. ty f. 18 [Quil??

in 81 - Lopot Mater. alg. Warsza. 1). 203.

msl - Arturi Liste alg. Moscon p. 140.

o Si - Stulies Key Desm. p. 111.

d sí-Alesenlio Chlorosp. Kharl. p. 2031.

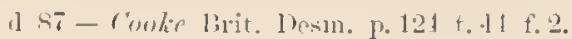

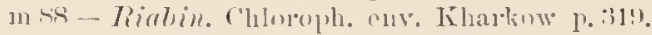

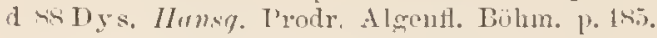

m - v, minus ibid.

m se Cal. Istr. Tel. magyar. aler. p. 2029.

1] S!l Disp. Tomi Syll. alg. p.sit.

m so Cosm. Anderss. Sverier. Chlor. 1 p. 15.

111 Iste. Fragn. $\$ 1$ lin. 1 p. 116\%.

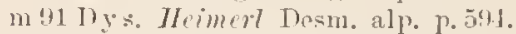

111 !) Cosin. Gutx. Flor. alg. 1,eopol, 1.39.

m !he - Jiorge ("liloropl. Xorsk. Fimm. p. 1:3.

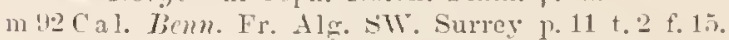

d $92 \operatorname{Cosm}$. v. truncatum West Fr. W. Mg. W. Irel. P. 161 t. 21 f. 11 .

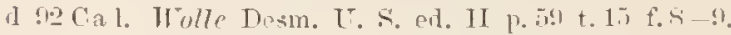

b - v. minor ibill. p. hill t. $15 \mathrm{f} .111$, t. (;) t. 18.

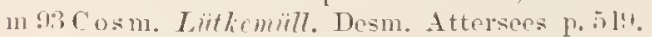

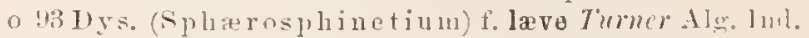
orient p. 11 t. 7 f. f.

m 91 Cosm. Gutw. F'. alg. Tarnapol. p. Ss.

m $94 \mathrm{Ca}$. Alerenko Mat. alg. Whark. P. $21 \%$.

d 95 Dys. f. sumatrana sichmidle Alg. Sumat. 1.20!1 t. 1 f. 6 .

\section{rommatum}

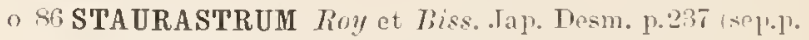
i) S. dejectım $\gamma$ connatum Limrl. $14 \bar{\gamma}$

d - rectangulum ihill. t. 21is f. 12.

m 89 - F rectangulam Fordst. Bornl. Desin. p. 2013.

nzfse - $\beta$ Spencerianum Hask, apul Nurilst. Ir]. wat. alg ․ Zeal. p. 40 t. 1 t. 18 (st. Clepsydra spener; now Nordst

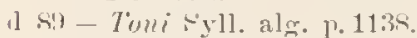

d - r. rectaugulum ibid.

mz - v. Npencerianum ibil. p. 11:3!!.

o !10 -- Dovo. Desm. Frasil. p. 14.

m!k - Richlor sivis Desm. Mlieiz. p.si.

m!n-Amderss. sverig. Chlor. 1 p.11.

m !12-- $\beta$ spencerianum f. Turge chloroph. Norsk. Finmark. T. т.

m!2- Ilest Fr. N. Alg. W. 1rel. p. 171.

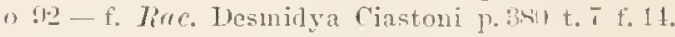

m! 15 - Fichler in Paniet. Fizy. 13 p.1;0.

- 95 - Tozlux ski in Pamietn. Fizyjogr. $13 \mathrm{p}$ p. 71

C'fr. Phycastrum cuspidatum "bilmulatum fïlz. 1819 (St. mncronatum Iirifs ex p.): Sitaur. corniculatum v. spinigerum; St. calyxoides; st. Ito jectum Jucols: 1sits.

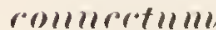

d (M) COSMARIUM Rinsch Sijswasteralg. Siad-Georg. I. $31+1$ selv.p. 16: t. 2 f. 1 .

\section{romspersmlll -}

d Is COSMARIUM Tirlys Brit. Desm. polit t. $11 \mathrm{f}$ f. 1.

1 50-I'ritch. Inf. p. 201.

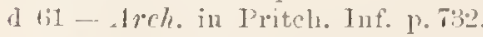

m 6it-. lifinsch in Rah. Alg. Eur. 11:0 1s:T.

n 6 T DIDYMIDIUM Cosmarium) Ricinsch Algenf. Frank. 1. 121 ; ff: a et $\mathrm{h}$.

o fir Cosm. Tot. Desun. Ital. p. 12 t. 3 f. 27.

d lis liul, Flor. Eur. Alg. 3 p. 1.i!.

d is $\beta$ rotundatum Witt. Skandin. Desin. p. 13 t. 1 f.l.

d 70 - Fi attenuatum Nordst. Desm. Brasil. 1). $2(18$ t. 310211.

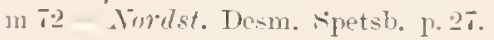

(1) 7!) - Protundatum Wille Ferskv, alw. Nov. Semulj. p.3.).

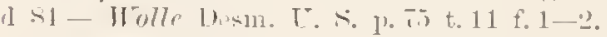

si - Jivelt sibir. Chloroph. ]. 106. 
m - f. ibid. (C. anomalum Delp. 1 kr7 ex p.).

n s.5 - a. Ralfsii liucib. Nonn. Desm. polon. p. 75 (sep.p. Lit).

m h. rotundatum ibil. 1. f. scandinavica.

2. f. intermedia ibid.

3. f. minor ibid.

d. elongatum ilid.. t. 11 (sop, -2) f. 1.1.

ค. Quadrum ibil. (

Sfi - Stokes liey Dism. 1, 1.28.

A 8 . - Coule Brit. Desm. p. 101 t. 39 f. 1.

o 87 - v. retusum Wolle Fr. Alg. T. . A. A. p 31 t. fi2 f, 5.

o $8:$ - $\beta$ lotundatum f. Tioldt Desm. Grönl. p. 26 (sep.p. 21) t. 2 f. 27 . [f. Boldti Tamer 18:B].

ms9-Harv. Fr. 1]g. Taine II p. 186.

d 89 - Toni syll. alg. p. 988.

d - v. elongatum iluil.

a - v, lotundatum ilid.

d - - v. attenuatun ibid.

m 90 - Eichler rpis Desm. Hieiz. p. Ss.

m 91 - v. rotundatum 1ste. Fragm. Alg. 1 p. 116s,

n 11 URSINELLA hiuntze Rev. gen. pl, p. !21.

mo1 Cosm. b. rotuntatum f. senndinaviea crutu. Elor. alg. Leopol, p. 53

$\mathrm{m}$ - - fointermelia ilid.

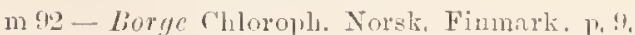

$m$ - f. minor ibid.

m - protunulatum ibiu.

d 92 - v. subrotundatum West Fr, W. Alg. W. Irel, p. 152 t. 21 f. 7 .

d 92 - Wolle Desm. U. s. al. II p.82 t. 17 f. 1-2.

d - v. retusum ilid., t. 16 f. 5 .

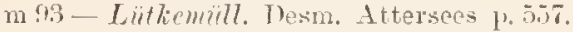

m -

n 93 - $\beta$ rotundatum f. Boldtii Tumer Alg. Int. orient. 1.67 form. Lioldt 1888).

n - Tetridium) ibid. p. T1.

r) 94 - Samd, in Fl. Nebraskia p. 11 t. 7 f. 1 [a et $b$ e Cooke: $e=$ C. undulatum?.

d 91 - F rotundatum liorg. F. als. Ötgrönd. p. 18.

m.1) - v. rotundatum Gutu. Fl. ales. Tarnapol. p. 95.

in 45 - Schmille Beitr. nlu. Alo. p. 151.

Cfr. Cosm, anomalum., Cosn, uargaritiferum 1.935.

\section{(0)m.suevismm}

a 72 PENIUM Writt. Gotl. Ö]. sät.v. Alg. p, 66.

o 73 - Nordst. Norg. Iesm. p. 15.

m 7.) - Nurlst. Desm. arcet. p. 14.

(1) - $f$ americanmm Norlst. Algolog. smitisak, 3 p. [r,

d $8:-T u n i$ siyll. Alm. 1. 8.5.

d - v. ameriean $11 \mathrm{~m}$ ilsid.

('fr. P'en. Cylindrus v, anunlatum et P. margaritaceum.

\section{Constrictere}

1 To Kirrhu. Alg. Sclules. 13. 112. Sect. P. Ir. Desmidiear.

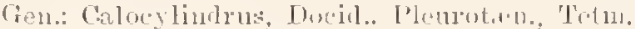

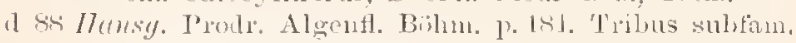
Didymiacear. Gen.: Dysphinctiun. Dor.id., Tetmen., Pleuroteruium.

\footnotetext{
comstrir.tum -

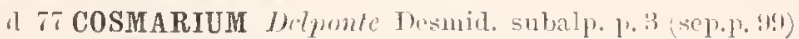
t. 7 f. $111-15$.

d s I Wolle Desm. U. s. p. Jít t. 5n f. L t.

o si- Shokes líey Desm. 1) 127.

d sis-Jansg. Prodr. Algentl. Böhm. J. 193

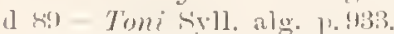

11 URSINELLA Kimläe Rev. gen. 11. 1). 1.

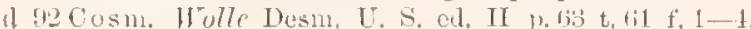

\section{comstrirtum}

[i] 6 DICTYOSPHARIUM sp. treh, in Q. J. II, Sc, v. 6 p. 127].

o 67-Arch. in Q. J. M. Se, v. $7 \mathrm{p}, 290$.

o 72 - Arch. in Q. J. M. Sc. v. 12 1. 422.

oz 75 (ad Cosmoclalium, nee ad Dictyosph, aceetens)

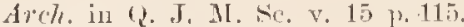

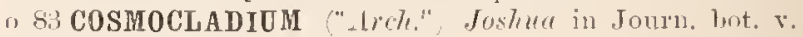
21 1. 2912.

d 86 - Cooke Brit. Ilesm. p. 79

d 89 - Tomi Svll. Alg. p. 805 .

11 COSMARIUM ("Areher") lioy Desin. of E. Fife in Am. Scott. N. Ilist. I p. 195 .

z 91 Cosmocladium lioy Scott, IJsin. p. 251 (sep.p, fi2) t. 2 f. 7 .

\section{comstrictume}

d ts D0CIDIUM liail. in Ralfs Brit. Desm. p. 218 t. 35 f. $\tau$.

(1) 52 - Jritch. Inf. p. 27 it.

d 61 - Arch, in Pritch, Inf. p. $7 \pm 5$.

d $68-$ Laab. Flnr. Eur. Alg. 3 p. 145 .

d T3 PLEUROT 尼NIUM TI vor Fr. Alg. p. 121.

d S1 Due. Wolle Desm. U. S. p. 5il t. 11 f. 2.

m 8i Pleur. Lagerh. Amerik. Desn. 1. 251.

o S6 Doe. Stolics liey Desm. p. 113.

d 83 P'enr, "coroniferum Largert, Bengal Desm, p. 11 t. 1 f. 9.

d 59 - Toni Syll. alg. p. 403.

d - v. coroniferum ibil.

d 92 Doc. Wolle Desm. U. S. ed. II p. 51 t. 1.1 f. 2.

\section{romstrictum}

o S6 SPHER0zosma stokes Finy Desm. p. 110 ["pulchrum var." verisinile est omissum].

\section{rompertum}

(1) 93 STAURASTRUM Tumer Alg. Ind. orient. P. 111 t. $15 \mathrm{f} .20$.

(1) - v. inevolntum ibil. t. 16 f. 2 , t. 2.2 f. 11.

\section{routor.tim}

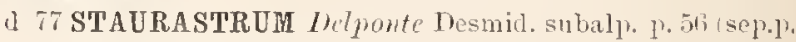
$152)$ t. 11 f. $53-5$

o 87 - $\beta$ pseudotetracerum Nordst. Algolog. smisak. 4 p. $15 \bar{i}$.

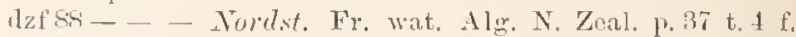
9. [Ntan. pseulot. West 1s95].

d 8.9 Toni syll, alm. 1) 1231.

d - v. psendotetracerim ibil.

\section{0mt)artum, $-x$}

d TócOSMARIUM hirchn. Alg, Schles, p. 117.

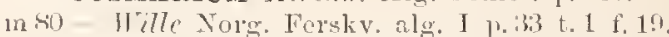

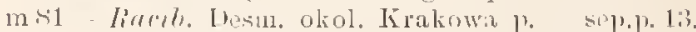

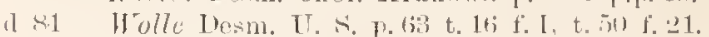

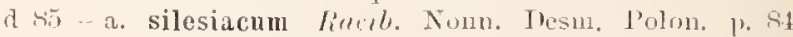

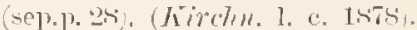

d). (?) n negicum ibid. (Wille l. c. 1880).

d c. cracoviense ilsil., t. 11 (sel 1 ) f. 10.

o sis-- Stolices liny Desm. p. 127.

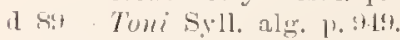

(1) v. clacoviense ibit. p. 9it.

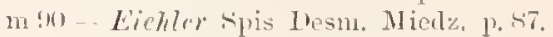

m - criscoviense ilit.

11 "1 URSINELLA Kimtze Rev, wen, pl, P. 12 I.

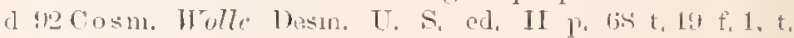
$1 ; 1 \mathrm{f}, 2 \mathrm{t}$. 
1n.93-Tumer Alg. Ind. orient. p. 4i t.7 f. 33. 31. 19. Colpopelta deplanata? Corla 153:).

o - $v$. punctatum ibid., t. 7 f. 38 , t. 9 t. 21 .

o 11 - schmidle in Flora is p. 5 b.

m95-v. minor Hicron. in PHanzenw. Ostafrik. p. 1!.

$m 95$ - West Alg. IIadag. P. 70 t. 8 f.

\section{controveresum}

d 90 COSMARIUM West Fr. w. Alg. North Wales p. 2 sin t. $13 \mathrm{f} .31$.

\section{comtrovelsim -}

1339 BINATELLA Brib. in Chev. Micr. p. 27.

d 10 STAURASTRUM Brib. in Menegh. Syn. Desm. 1).20S (sep.p. 2s).

dzf 48 - Ralfs Brit. Desm. p.111 t.23 f.3. [Nt. aculeatum Rulfs 1into; v. controvers. Rub.].

d 52 - Pritch. Inf. p. $26 i$.

d 61 - Arch. in Pritel. Inf. p. 712.

$6 \bar{\imath}-$ Not. Desm. Ital. t. 4 f. 39 .

d 84 - Wolle Desm. U. S. p. 1.43 t. 45 f. 24 - 25 .

o 86 - Stokes hey Desm. p. 167 .

dzf st - Cooke Brit. Desm. p. 173 t.60 f. 1 [e Kialfs?].

dzs - Tomi sryll. alg. p. 1216.

n 90 - v. West Fr. w. Alg. North Wales p. 295 t. 5 f. 22. n 30 - Eichter spis Desm. Miedz. p.90.

d 92 - Wolle Desm. L. S. ed. II p.15t t. 26 f. $24-25$.

$1193-($ Odontastrum) Turner Alg. Ind. orient. p. 133.

a $45-\mathrm{f}$. schminle in Hedwig. 34 p. 82 t. 1 f. 22.

d $96-\mathrm{f}$. schmidle Beitr. alp. Alg p.63 (sep.p. 35) et, 15.3. t. 17 f. $1-3$.

Cfr. Phycastrum trideus Kütz. 1849.

\section{controversin}

dz91 ARTHRODESMUS West New Brit. Alg. p.9 (A.? - glaucescens f. convexa West 1sid?.

\section{romery/gh:}

d 39 ARTHRODESMUS Ehrenb. p. 152 t. 10 f. XVIII. [Cfr. Jac. 1876$]$.

d 40 STAURASTRUM Menegh. Synops. Desm. p. 228 (sep. p. 26).

d 11 Arth. Pritch. Inf. p. 190 f. 112 et 113 [fig. Ehrenl:i repetita].

n 43 - Ehrenl. Mikr. Leb. Süd. u. 2. Amer. 1. $33 \pm$ (sep.p. 46) (Enastrum n:o 12 ex parte Bailey Amer. Bacill. p. $296^{\circ}$ (sep.p. 12 ) t. 3 f. 11).

n 13 SCENODESMUS Kütz. in Linnea 17 p. 74.

d tis Staur. Ralfs Ann. Yat. Hist. ₹. 15 p. 158 t. 12 f. 1 (et 181; Trans. Bot. Soc. Ediu. v. 2 p. 145 t. 15).

d 45 Arthr. Hass. Brit. Alg. p. 357 t. 85 f.9 [e Ralfs 1. c. delineate].

d t5 EUASTRUM Kütz. Phycol, germ. p. 136.

d $1 \bar{i}-\operatorname{Tinb}$. Deut. Frypt. Fl. p. 55.

d 48 Arthr. Thalfs Brit. Desm. p. 118 t. 20 f. 3.

I 49 - hïtz. Spec. Alg. p.176.

(1) $49 \mathrm{Eu}$. (Tetracanthinm) Nog. einz. Alg. p. 114 t. $;$ f. C. 1 .

d 52 Arthr. Pritch. Inf. p. 240 t. 2 f. 112 et 113 [Ex Elt$r e n b$.$] .$

52 - Kab. Bacillar. Sachs. fasc. 6 X:o j1: cum icone t. 6. o ju- (Manthidium) Focke Phys. stud. II p. 23 t. 4 f. 14.

n 5s CoSMARIUM (Ticrocosmarium, Arthrodesmus) de $\boldsymbol{B}$ ar. Conjug. 1. T2.

d 61 Arthr. Arch. in I'ritch. Inf. p. 737.

d 63 - Rirb. Tirypt. Fl. Siachs. p. 107 [ex Ehrenb.].

z ijt - clere Bidr. t. Srerg. Desm. p. tsos.

z 615 - Arch. in (2. J. M. ic. 6 p. 273.

Nordstedt, ludex Desmid. d 6 TIDYMIDIUM (Staur.) A. ellipticum Reinsch Algentl. Frank. p. 15 t.

d - B. trigonom St. Dickioi hinlfsi.

d 68 A th r. Rab. Flor. Eur. Alg. 3 p. 227: f. xyl. p. 110 [ut supra 1863]; et forma b.

d - e. (A. obsoletus Huntzseh) ibid.

d - I. subulatus (A. subulatus Kütz.) ibid.

4 $70-\beta$ pumila Norlst. Desin. Brasil. p. 282.

z 71 - Lund. Desm. suec. p. 54 .

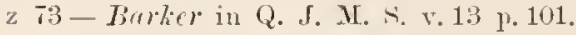

o 73 - Nordst. Norg. Desm. p. 25.

d $73-\|^{*}$ ood Fr. Alg. p. 15!.

d 75 - Mierogr. Diet. p. 73 t. 10 f. 27 [e I r 1 lfs].

zf 5 - Reinsch Contribut. 1\%.93 t. 1.5 f.?.

$1176 \mathrm{Stau}$ r. a armigera Jacobs. Desu. Danem. p. 203

$n \quad-$ f. inflata (Ralfs 3 a, b; f. attenuata Ralfs 3 d; Ehrent. 1838) ibid.

n $\quad \beta$ inermis ibid. (Eu. depressum Nog.).

dzf 7 XANTHIDIUM Delpunte Desm. subalp. p. if (sep.p. 172 ) .11 f. $13-23$.

dz 78 A r thr. Kirchn. Alg. Schles. p. 1515.

m 80 - Nordst. De Alg. et Charac. 1 p. 12.

81 - Cooke in Quekett Mier. J. 6 t. 13 f. B.

ms1-Hompel Algenf. Chemnitz Forts. p. (sep.p. 20).

o 83 - Masl. Add. X. Z. Desm. 1.243 [ $\beta$ divaricatus Mask. 18997.

m A Staur. Tacib. okol. Frakowa sep.p. 16; b. Rabenh.) t. 1 f. 8 .

d $84 \mathrm{Arthr}$. Wolle Desm. U. S. p. 95 t. 23 t. 19-21. rar. f. $22-23$.

m 84 - Artari Liste alg. Moscou p. 142.

d sõ-Kirchn. Mikr. Pfanz. d. Süssw. p. 25 t. 3 f. 74.

m 85- Boldt Sibir. Chloroph. p. 109.

d $S 6$ - Frank in Lemnis Synops. 3 p. 1916.

o 86 - Stokes Fey Desm. p. 131.

dzf 87 - Cooke Brit. Desm. p. 136 t. 47 f. 1. [ $a$ et $b$ e Ralfs. $c-e$ e Delp.].

d 87 - Alexcnko Chlorosp. Khark. p. 25i.

dz 88 - Hansg. Prodr. Algenfl. Böhm. p. 203 f. 117 et 251.

d ss-Hauptf. Zellm. u. Hüllgallerte Desm. p. 89 isep. p. $31^{\circ}$.

m $88-1$ - Iste. Jel. magyar. alg. p. 230.

in 88 - Nordst. Fr. wat, alg. N. Zeal. p. 15.

d $89-v$. divaricatum Masl. Furth. Note N. Z. Desm. p. $21 \mathrm{t} .4 \mathrm{f} .3 t$

dzs9-Toni sisll. alg. p. 10.5.

n 90 - Wille Natürl. Pflanzenfam. p. 12 f. 7 C. (e Nägeli).

ph $90-$ Camplell in Bull. Torr. bot. Cl. v. 17 p. $111 ;$ t. 102 f.! [sine nomine].

d $90-\beta$ incrassatos Gute. Wahr. d. Priorität. p. $\mathbf{i} 1$.

m 90 - Eirhler spis Desm. Miedz. p. 89 t. 8 f. 25.

m 90 - Auderss. Sverig. Chlor. 1 p. 13.

d $91-$ Kirchn. Nikr. Ptlanz. d. Süssw. ed. 2 p. 26 t. 3 f. 54.

m 91 - Heimerl Desm. alpin. p. 1343.

d $91-\beta$ incrassatus Gutw. Flol. alg. Leopol. p. 64 t. 3 f. 5.

1. 12 - Wolle Desm. U. S. ed. II p. 103 t. 26 f. $19-21$; r. f. $22-23$.

ph 93 - Lü̈themüll. Clılorophyllkörp. ein. Desm. p.9.

o 93 - Lütkemïll. Desm. Attersees 1) 059.

1 $93-v$ - ellipticum Weiss in Ber. Bayer. bot. Ges. p. 50. ozf 93 - Aplodesmus) a typica Tumer Alg. Ind, orient. p. 134 t. 11 f. 42. t. 12 f. 3 (f. 12 cum parasit. ?

d - $\beta$ corta ibid.; t. 11 f. 32 .

m - " minor ibid.; t. 11 f. $t 1$.

- 93 - Fichler Mat. Hor. Miedz. p. 164 (b. Rab. 1stris.

o 93 - Franze in Öster, bot. Zeitschr. p. 34 t. 13 f.?

m $94-1 s t c$. Adat. Roman. alg. p. 15 i. 
o 94 - West New Brit. Alg. p.9.

n $94-v$. Turneri Hildem. Obs, erit. Desm. p.111 (A. minor Tun. 1893).

d $94-$ f. Biorge Süssw. Chlor. Archang. 1, 32 t. 3 f. 34.

d - f. ibid., t. 3 f. 35 .

Cfr. Artlır, asper, curvatus, gangensis, senilis.

\section{romvergens:}

d to PHYCASTRUM (Pachyactinium) Perty in Bern. Mitth. 1819 p. 175.

d 52 - Perty kleinst. Lebensf. p. 210 t. 16 f. 34.

(1) 6S STAURASTRUM hiab. Flor. Eur. Alg. 3 11.221 [nom Menegh.J.

d 89 - Toni syll. alg. p. 1143 .

\section{roralloides}

a 86 EUASTRUM Josh. Burm. Desm, p. 63 t. 23 f. 10.

d $88-\beta$ trigibberum Lagerh. Bengal. Desm. p. 6.

d 89 - Toni Syll. alg. p. 110 s.

d - v. trigibberum ibid.

n 91 HELIERELLA Kumzc Rev, gen. pl. p. 898.

\section{Corbula}

d 56 COSMARIUM Bréb. List. p. 131, 303 (sep.p. 161) t. 1 f. 13 .

d $61-$ Arch. in Pritch. Inf. 1\% 734 .

d 87 -Cooke Brit. Desm. p. 107 t. 13 f. 9.

d 89 - Toni Syll. alg. p. 1054 .

d 90 - v. Pyreti Gutiv. Fl. Glon. Galic. 2 p. 15 t. 1 f. 12. dz 90 - - f. latior Gutw. Wahr. Priorität 1. 70.

n 91 URSINELLA Kuntzc Rev. gen. pl. p.92t.

dz91 Cosm. v. Pyretif. latior Gutw. Flor. alg. Leopol. p. 61 t. 2 f. 29.

zf $1 \pm$ - Roy Scottish Desm. p. \pm 1 (sep.p. 31 t. 2 f. 18.

d 94 -v. Pyreti f. podolica Gutw. Fl. alg. Tarnapol. 1. 102 t. 3 f. 39 .

\section{Corde}

n 55 MICRASTERIAS Braun Alg. unicell. p. 97 ("Stauridium Crux melitensis Corda Alm. de Carlsb. 1839 t. 1 f. 5 , al anctoribus ad Pediastrum Tetradem citatum, si figura nature congrua, Euastri (Micrasteriæ) speciem repræsentat, Micrasteria oscitanti Ralfsii affinem et M. Cordæ nomine numcupandam".).

\section{Cordan11m-11s}

d 68 COSMARIUM Bvéb. in Rab. Flor. Eur. Alg. 3 p. 17 T (Colpopelta viridis Corda).

o 85 - Turner New rare Desm. p.934 t. 15 f. 4 [sec, anet. fig. mala, efr corrigenda c. fig, xylograpluica].

a 86 - Stokes Kiey Desm. 1. 126.

a 85 CALOCYLINDRUS Wolle Fr. Alg. U. S. A. p. 27 t. 60) f. 28 [e Turner'].

(1) 88 DYSPHINCTIUM Hansy. Prodr. Algenf. Bölmm. p. 1si?. COSMARIUM West Massacl, Desm, t. 3 f. 23.

o $89-$ f. minor Mask. Furth. Note X. Z. Desm. p. 16 t. 2 f. 20.

1 92 Cal. Wolle Desm. U. S. e.]. II p. 54 t. 19 f. 28 [e Tumer]. m 91 Cosm. Borge Süssw. Chlor. Arehang. p. 23.

\section{rordatilm)}

d 37 EUASTRUM Rab. Dent. Kiypt. Fl. p.5t. (E. ventricosum hïtz?

\section{rordatmm}

(1) STAURASTRUM Giny Mon. loc. Conj. p. 65 t. 2 f. 7 ; et Tote Conj. d. m. France p. 338. [St. orbiculare f. punctata Gutw. 1890].

d su-Toni Syll. alg. 1. 1194

\section{ro)"uirulutum}

d il STAURASTRUM Luml. Desm. Hinec, p. 5 t t. 3 f. 23.

o 87 - $\beta$ variabile Norlst. Algolog. småsak. 4 p. 158.

d $88-\ldots$ Nordst. Fr. wat. alg. N. Zealand p. $39 \mathrm{t}$. 4 f. 17 .

d 59 - Toni Syll, alg. p. 1150.

d - v. variabile ibid.

d $12-\mathrm{v}$. spinigerum West Fr. w. Alg. W. Irel. p.171 t. 22 f. 1․ [st. connatum? sec. Borge in N. Yotar. 5 p. 514].

d $: 2$ - v. anstralis Rac. Desmidya Ciastoni, p. 3811 t. T f. 15 .

o - - f. granulata ibid.. f. 16. [Quid?].

" 93 - (Hectastrum) Tumer Alg. Ind. orient. p. 133.

Cfr. Stanr. spec. Reinsch Contrib. 1875 p. sil t. 1 ii f. 10 .

\section{Cormil}

in 30 CLOSTERIUM Ehren乙. Beitr. z. Kennt. d. Inf. p. $\{53$ et) 62 .

1 32-Ehrenl. Entw. d. Inf. p.67. [Descript. brevis].

d 38 - Elrenb. Inf, p.94 t. 6 f. V (Vibrio Lunnla Miül. 1786 f. s ?; Cl. tenne hiitz.)

d 40 - Menegh. Synops. Desm. p. 233 (sel.p. 33 ).

d 45 - Hass. Brit. Alg. p. 372 t. 88 f. 2 [ex Ehrenb.]

d $45-\hbar$ iüz. Phyc. germ. p. 131.

Izf 18 - Jirlfs Brit. Desm. p. 176 t. 30 f. $6 f$ et $g$. $\beta$ ibid.; fig. "-e. [Cl. tnmidum Johns. 1895].

d 19 - Kütz. Siec. Alg. p. 164.

d 52 -Jitch. Inf. p. 283.

o $56-$ Brel. List. p. 154.

n 5S STAUR0CERAS Grum. Desin. p. 497.

dz 51 Clost. Areh. in Pritch. Inf. p. 550 , $a$ et $\beta$.

d 68 - Rab. Flor. Eur. Alg. 3 p. 137.

d - b. f. tumida (Cl. teuse Kiutz) ibill.

d - c. f. olongata ibil.

o 70 -Nordst. Desm. Brasil. p. 204.

d 75 - Mierogr. Dict. 17. 176.

m 77 - Petit Desm, de Paris p.5 (sep.p.2s).

dz $78-h i v c h$. Alg. Schles, p. 140.

in 79 - Wille Ferskv. alg. Nov. Semlj. p. 59 t. 14 f. 80.

m - f. major ibid., t. 14 f. 81.

o 80 - f. Wille Norg. Ferskv. alg. I p. 59 t. 2 t. 38.

m st - Artari Liste Alg. Noseon l. 139.

m 84 - Schaurschm. Afghan. Alg. p. $24 \%$.

d 85 - Kirchn. Mikr. Pflanz, d. Süssw, p. 21.

(af) $S 6-f$. Lagerh. Algol, Bidr. 1. 47 c. fig. xy'. 2.

d 86 - Cooke Brit. Desm. 1) 35 t. 12 f. 4.

dzsi-Hansy. Prorlr. Algenf. Bohm. p.181.

dz bs - Toni et Leei Fl. Alg. Venez. 1?35.

in $88-J s t$. Jel, nagyar. alg. p. 240.

$\mathrm{dz} 89$ - Toni syll, Alg. p. 835 .

d - f. tumidnm ibid. p. 83b.

dz $b 9$ - $f$ upsaliense Norelst. in Wittr. et Nordst. alg. exs. 11:0 tsis; et in fasc. 21 (1589 p. 47.

m! - Gutw. Fl. glon. Galic. 2 p. 8.

Izf 90 - $\beta$ Brasiliense Börg. Desin. Brasil. p. 30 t. 2 f. 8.

m 50 - Eichler Spis Desm. Miedz. 1\%85.

1) 91 - Kinchn. Mikr. Pfanz. d. Süssw. ad. 2 p. 22.2.

m 91 - Heimerl Desm. alpin. p. 593.

1. 91 ARTHR0DIA Kuntze Rev. gen. pl. p. ss3.

m1 92Clost. Gutw. Flor. glon. Galie. 3 p. 121.

m 92 - West in Notaris. $T$ p. 1500.

m 4 - Borge siüsw. Chlor. Archangel p. 15. 
m 95 - Eichler in Pamiet. Fizy. 13 p. 58

Cfr. Clost, acutum et pronum varr.

\section{cormubiense}

d STSTAURASTRUM Didymocladon) Bem. Fr.w. Alge Nortl Cornw. 1. 18 (sep.p. 11) t. 4 f. 2ㄴ . Staur. furcigerum ?]

d 87 - Cooke Brit. Desm. p. 190 t. 6 is f. 6 (e Benn.t.

d 87 - Tomi Syll. alg. p. 115 .

\section{rovintate}

d sf MICRASTERIAS Benn. Fr.-wat. Alg. Engl. Lake Distr. 1 ]. 7 t. 1 f.6. [Helierella Bennettii Kuntze 1891; M. rotata l. denticnlata?].

o 86 - Stokes liey Desm. p. 14 .

d S6-Cooke Brit. Desm. p.5T t. 23 e Bennett).

d S9-Toni Srll. alg. p. 112T.

\section{cormutum.}

d 39 CosmaRIUM Corda in Alm. d. Carlsb. 1839 p. 243 t. 5 f. 30 [Enastrum verrucosum f. vel ralde affine].

\section{rormutum-r}

d 45 EUASTRUM Kütz. Plycol. germ. p. 135 (sec. Ralfs Brit. Desm. p. 211 habitu E. crassi, sed ut ridetur diversum].

d 45 - Ralfs Brit. Desm. p. 211 t. 35 f. 13.

d 49 - hüt $z$. Spec. Alg: p. 173.

d $52-I^{\prime} r \cdot t c h$. Inf. p. 251.

d 61 - Arch. in Priteh. Inf. p. 728 .

d 6r COSMARIUM liab. Flor. Eur. Alg. 3 p. 179 et 432.

d 89 Eu. Tumi sirll. alg. p. 108 \%

n 91 HELIERELLA Kuntze Rer. gen. pl. p. 898.

\section{rormutum}

o 81 STAURASTRUM Arch. in Ann. Mag. Nat. Hist. 5 ser. v. 8 p. 232.

o 8 - Cooke Brit. Desm. p. 190.

o 89 - Toni Syll. alg. p.1175.

d 93 - Roy Scottish Desm. p. 1.90) (et 1894) t. 3 f. 5 (sep.p. 18) (st. cornigerum" lapsu calami).

\section{romutum}

d s5 STAURASTRUM Irolle Bull. Torr. bot, Club 1885 p.t t. 4 f. 3 \& 4 , non Areh. 1881

d s7 - Wolle Fr. Alg. U. S. A. p.43 t. 57 f. 3-4 et t. 60 f. $11-12$, iterata icon) [Ex I'olle 1885].

d 92 - Wolle Desm. U. S. ed. II p. 158 t. 45 f. $3-4$ et t. 46 f. $11-12$.

Nomen specificum a De Toni 1889 in "snbcornutum" transmutatum.

\section{corouretum. - a}

d s1 COSMARIUM Cooke \& Wills in Cooke in Grevillea 9 ]. 90.

d 81 - Wills in Midland Natmralist 4 p. 74 t.5 f. 2.

d Si - Cooke Brit. Desm. p. 108 t. 41 f. 7 .

d S9-Toni Syll. alg. p. 1023.

1] 91 URSINELLA liuntze Rer. gen. pl. p. 124.

\section{rovorntum}

d Is DOCIDIUM Bréb, in Ralfs Brit. Desm. p. 217 t. 35 f. 6. [Pleur. nodulosum $\beta$ coronatum Boldt 1888]. d 52 - Pritch. Inf. p. 27.

d $61-A r \%$ in Pritch. Inf. p. 745 .

A fi PLEUR0TANIUM Rab. Flor. Eur. Alg. 3 p. 143.

o 71 - Lund. Desm. Snec. p. 90. forma.

d is - Kirchn. Alg. sichles. p. 11t. d 84 Doc. Wulle Desm. U. S. n. 4 t 11 f. 9-10.

in 84 Pleur. Artari Liste alg. Moseou 1. 140.

o 86 Doc. Stukes Fiey Desm. p. 113

d 8fi-Cooke Brit. Desm. p. 13 t. 7 f. 1.

d Ss Pleur. Hansy. Prodr. Algenfl. Böhm p. 19r,.

d 89 - Toni s.yll. alg. 1.901.

m 90 - Gutw. Fl. glon. Galic. 2 p. 9.

m 90 - Eichler spis Desm. Miedz. p. 86.

m90 Doc. West Fr. W. Alg. North Wales p. 284.

o 90 - hoy in Journ. of But. p. 335

- - $\beta$ nodulosum ibid. (D. nodul. Bréb. in Ralfs 1819). m 91 P len1. Gutw. Flor. alg. Leopol. p. 37.

m 92 - West Fr. w. Alg. W. Irel. p.118 t.19 f. S-10.

d - v. flactnatum ibid., t. 19 f. 11

- v. robustum ibid., t. 19 f. 12

- v. nodulosum ibid. p. 11?.

d 92 Doc. Wolle Desm. U. S. ed. II p. 53 t. 14 f. $9-10$ ph 93 Pleur. Frunzé in Österr. bot. Zeitschn. p. 383.

d $95 \mathrm{Doc}$. v. undulata Hieron, in Pflanzent. Ostafrik. p. 19.

\section{roromatmm-a}

d 85 EUASTRUM Turner New rare Desm. 1.935 (sep.p. 3) t. 15 f. ?. [E. simplex [E. integrum] f. sec. Wolle 1886].

d 85 - Toni syll. alg. p. 10 s6.

n 91 HELIERELLA Kuntze Rev. gen. pl. p. 898.

\section{rorountum}

d s2 STAURASTRUM Wolle in Bull. Torr. bot. Club 1892 p. 28 t. 13 f. 16 . non Rolfs [ab auctore ipso 1884 in "coronulatum" transmutatum].

\section{coromitim}

d 43 XANTHIDIUM Ehrenb. Mikr, Leb. Siid. u. N. Amer. 1) $(334,339,390$ et) 426 (sep.p. 46.51 et 138$)$ t. IV. I f. $2 \mathrm{t}$ [St. furcigerum quoad fig. et descript, excl. syn.].

d 18 STAURASTRUM Iialfs Brit. Desm. p. 216.

d 49 ASTER0XANTHIUM Kïtz. Spec. Alg. p. 183.

d 52 Staur. Pritch. Inf. 1. 269.

d $69 \mathrm{Xanth.} \mathrm{Rab.} \mathrm{Flor.} \mathrm{Eur.} \mathrm{Alg.} 3$ p. 224.

d 73 - Hood Fr. Alg. p. 157 .

\section{roroniferum}

d 93 STAURASTRUM Turner Alg. Ind. orient. p.114t 13 f. 21.

\section{Coromula}

d 39 MICRASTERIAS Ekremb. Inf. p. $156=$ Pediastrnm simplex.

\section{corommitum}

d 65 DOCIDIUM Grun. Ins. Bank. p. 13 t. 2 f. 20.

d $69-R a b$. Flo1. Eur. Alg. 3 p. 145.

d 81 - Wolle Desm. U. S. p. 19 t. 53 f. 16.

d $8 \pm$ PLEUROT扯IUM $\beta$ caldense Wille Sydamerik. Algt p. 22 t. 1 f. 43 .

o sf Doc. Jos7. Burm. Desm, p. 651 t. 25 f. 16 \& 17 [Pleurotwninm Warmingii $\beta$ birmense Lagerh. 1587].

m s6 - Stokes liey Desm. n.113.

m 86 Ple ur. $\beta$ Caldense Lagerh. Amerik. Desm. p. 251.

o $89 \mathrm{Doc}$. Wildem. s. flore alg. Conge p. 8.

d 89 - Toni syll. Alg. p. 572 .

d - v. caldense ibil.

- 90 P leur. Bärg. Desm. Brasil. p. 27.

d 92 Doc. Tholle Desm. U. S. ed. II p. 58 t. 64 f. 16.

m 93 - Turner Alg. Ind. orient. p. 3 s. 
- 94 - Möl. Anstral. Süsswasserale. II p. 338 t. 2 f. 17.

o 95 - Johns. Rare Dosm. U. S. II p. 2 !\%).

\section{roponmlitum}

1) 8 t STAURASTRUM Folle Desm. U. S. p. 135 t. 44 f. 11 -12. St. coronatum Wolle 1882. non Rulfi).

d - - v. Floridense ibid., t. 13 f. 12-14.

o 86 - Stokes Key Desm. p. 143 ; et v. Floridense.

d sy-Toni syll. alg. p. 1230.

d 92 - Wolle Desm. U. S. cd. If p. $145^{\circ}$ t. 55 f. 11-12.

d - v. Floridense ibid. p. 149 t. 5.1 f. $12-14$.

n 93 - (Trochastrum) Turner Alg. Ind. oricnt. p. 132.

\section{Corriense}

1) 4 COSMARIUM Bisset in Roy Scottish Desm. p. 41 (sep.p. 32) t. 2 f. 6.

\section{(.0)}

dzf 43 COSMARIUM Tmmer Alg. Ind. orient. p.51 t. 8 f. 2 d $94-$ f. minor Gutw. Fl. alg. Trinapol. p. 85 t. 3 f. 19.

\section{COSHARIASTRUM}

1. 13 Tumer Alg. Ind. orient. 1.87. Subgen. Euastri.

\section{COSMARTUTUM}

1] St Gay Mon. loc. Conj. p. 41. (Cosm. sect. Plenrotaniopsis Lund.); et Note Conj. d. m. France 1. 340.

(] So IIansy. Proulr. Algenfl. Böhn. p. 190. (Scet. 1 Pleurotrniopsis (Lund.) p. 245;2. Eucosmaridium p. 216.).

(1) 89 Toni ryll alg. p.910. Sect. Pleurotæniopsidis.

\section{Cosmariene}

[ph o (Cosmarièes) Corda in Alman. d. Carlsb. 1835 p. 173, 1839 p.210, Gen.: Colpopelta. Mesotrema. Stre phocystis, Cosmarium; 1810 p. 212, Gen.: Xanthidium et Cosm. - Famil. Bacillar.].

1 75 Microgr. Dict. ed. 3 p. 234 . Tribus.

o 89 Carter in A. M. Mier. J. X. p. 75. Tribus Desm.

o 89 Racil. Now. Desm. p.9s (sep.p.26), Gen.: Cosm., Arthrod.. Sttaur., Nothocosmarium.

o 94 IIaeckel Syst. Phylog. d. Prot. u. Pflanz. I p. 9r et 112. Famil. Conjugatar.

\section{rosmlluriforme}

d 93 XANTHIDIUM (Nicracanthum) Turner Alg. Ind. orient. p. 98 t. 12 f. 17.

o - f. evoluta ibid.; t. 9 f. 9.

\section{rosmurrioirles}

d 82 ARTHRODESMUS Ilantzsch in Rab. Alg. 1338.

\section{rosmorroioiden}

( 95 EUASTRUM West Alg. Madag. p.5.t t.6 f. 23 .

\section{rosmarioides}

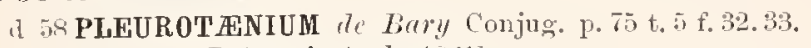
[Cosm. Debaryi Arch. 1sti1].

o $59-B u m h$. in Ifedw. II p.21 t.2 f. 8 .

d $193-K m b$. Firypt. Fl. Sachs. p. 17T; fig. xyl. 1. 153 [ex De bury].

d 69 - Rub. Flor. Eur. Alg. 3 p. 14t; fig. xyl. p. 104.

\section{rosmarloioirles}

193 SPH正R0Z0SMA Wallich (mser') aprul Tum. Alg. ind. orient. p. $11^{2}$ t. 21 f. 1.

\section{rosmrovioilles}

d 7o STAURASTRUM Tordst. Desm. Brasil. p. 223 (sep.p. 185) t. $\pm f .43$.

m 7 - Noretst. Alg. brasil. p. 23.

d 87 - subsp. Arvensis 1stv. Diagn. prav. p. 238 (sep.p. 9).

1] $88-\ldots$ - Iste. Jel. magyar, alg. p. 230 t. 2 f. 25 .

d 8: - Toni syll. alg. p. 1194

d - subsp, nrvensis ibid. p. 1195.

o 90 - Böry. Desnt. Brasil. p. 49 et 50 f. 1 - 6 (formie a-f) [Cfr. Lagerh. in N. Notaris. ser. 2 p. 411.].

\section{rosmurrioines}

75 STAURASTRUM Reinsch Contribut. t.9 f. 1 [non Nordst. 1870$]$ = St. Psendocosmarium ibid. p. 91.

d 8 - Wolle Fr. Alg. U. S. A. p. 42 t. 62 f. 7-8 [e Reinsch]. d 92 - Wolle Desm. U. S. ed. Il p. 139 t. 46 f. 7 -s.

\section{$\operatorname{COSM} M$ IRU UI}

ph 34 CORDA in Alm. d. Carlsb. 1835 ["los Cosmariées" in multis locis hujus operis; sine deseriptione generis, tantum spcciertum].

n 38 Menegh. Cenni s. organ. p. 358 (sep.p.34) (Cosmarium et Colpopelta Corda. -- Heterocarpella et Pandurellæ sp. Кӥtz. - Ursinellæ et Heterocarpellæ sp. Turp. Cymbellæ sp. Ay.).

d 3!) Corda in Aln. d. Carlsb. 1839 p. 242 [Cosmarinm, Eunstrum et Micrasterias auct. rocentior.].

d 40 Menegh. Synops. Desm. p. 217 (sep.p. 17). [Cosmar., Xantlidium ex p.. Euastr.).

d 4 Brib. in Dict, univ. list, nat. 4 p. 267 Cosm., Eu., Xantl.).

1] 44 Ralfs Ann. Nat. Hist. v. 14 p.391 (et 1846 in Trans. Bot. Soc. Elin. p. 147.

d 45 Hass. Brit. Alg. 1).361.

d 48 Ralfs Brit. Desm. p. 91.

d 49 Neg. einz. Alg. p. 114. Sect. Euastri.

d 4 hitit. Spec. Alg. p. 171.

- 50 Murissal Catal. esp. omis. p. 34.

d 52 Pritch. Inf. p. 251.

d 53 Math. Fl. Belg. II p.527.

z 57 the Bary in Bot. Zeit. p. 76i5.

d 58 De Bary Conjugat. p. (42, 47, 51,) 72 (sicet. 1 Encostnarium. 2. Microcosmarium (a. Arthrodesmus; b. Cosmariuus). 3. Dysphinctium. t. Calo,cylindrus).

o 58 Grun. Desm. p. 193.

d 61 Arch. in Pritch. Inf. p. 720 et 131.

d 63 Grogn. Plant. Cryplt. p. 262.

d 63 Limb. Irypt. Fl. Shehs. p. 198.

d fit Gray Brit. Alg. P. 6i.

d G6 Lyrich Algenfl. Manuh. p. 12.5.

6т Dulac Flore d. dép. d. Haute-Pyréné, 1si; = Adonis !

d 136 Remsch Algenft. Frank. 1. 106. (subgen. Didymidii).

d 67 Not. Desm. Ital. p. 21.

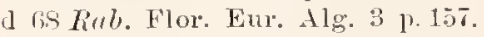

o 71 Lund. Desm. Suec. 1. 21 (Subgen.: Cosmarium 1. 24 et Pleurotaniopsis p.6 et 51.).

- 73 l'ferfier Yomencl. bot. 1. S91.

d 78 Jefponte Desm. subalp. p. 39 (scp.p. 26).

d 73 ITood Fr. Alg. P. 127.

If 75 Microgr. Diet. p. 2013 et 231.

11 7 Front in Lenuis Synops. p. 1633.

d 7 Delponte Desm. subalp. II p.1 (sep.p.97).

1) Tis Kirchn. Alg. Schles. p. 14 .

- $7 ! \mathrm{Kz}$ kus Desm. Ostprenss. 1. 20.

(l 81 Hunoury in Baill. Dict. Bot. If p. 23!9.

a sil Cooke in Quekett Micr. J. 6 p. 205.

d 83 Cybulski Mater. alg. Warszaw. p.240. 
ph 83 Jisclue Gypstryst. Desm. p. 151.

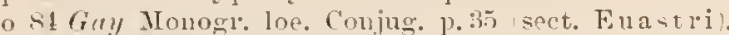

d sit Wolle Desm. L. . 1\%.r.

d) Sirchn. Mikr. Ptanz. A. Sïssw. 11. 20.

1) S5 Pulsamo Alghe dol com. di Tapoli p. 24; et 38).

phs si bivthuld Stnd. Protoplasinameeh. 1?.27.2 ete.

o sti Stokis Key Desm. p. 110.

it Sif Fank in Lemis symops. 3 p. $19 \%$.

1) Sli f'ooke Brit. Desm. 1. 79 .

I S7 Aledentio Chlorosp. Klatrk. r. 2.5s.

d 88 Hansg. Prodr. Algenfl. Bolm. 1) 192.

1 sect. Eucosmarium ampl.. ibil, p. 2-47.

1 subsect. Microcosmarium De Bar. ex p.. ibic.

-2 subsect. Eueosm. De Bar.. ex. p., ibil. 1. 2019.

2 sect. Gastrocosmarium ibid. p. 251.

3 subsect. Microgastrilitum ibid.

1 subsect. Engastridiun ibia. 1., 251.

su Tomi et Levi Fl. Alg. Venez. p. $4 \%$.

o 88 Ilıuptfl. Zellm. u. Hüllgallerte Desm. p. Sl; et 111 (sep.p. 2s et 52.

d 89 Toni Syll. alg. p. 131 (Sect. 1 Fucosmarium; subsect. I. Miclocosmaxium p.931. II. Eucosua ri um p. $46: 3$. Sect. 2 Gastrocosmariu un ]. 1000; subsect. 1. Microgastridium p. 10k0: II Calogastridium p. 1014.

o -9 Rucil. Now. Desm. p. $73-7 \pi$.

d 1. Eueosmarium. a. Microcosmarim. b. Eucosm.

2. Gastrid ium. a. Mierogastridium. b. Eugastr.

3. Bigastridium. a. Microbigastrid. b. Eubigastriıl.

ph sy Flf $x$. Ammärk. Desm. syst, p. Ts.

d 9n Wille in Natiurl. Pflanzenf. p.10.

ph 91 Klebuhn in Verh. d. Ges. deutsch. Naturf. in Bremen 1890 II D. 112.

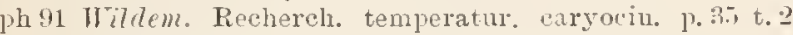
f. $1-18$.

d 91 - Kirchn. Mikr. Pflanz. d. Süssw. ed. 2 p. 21.

ph 92 Loew in Flora 1892 p. 375.

¿1 92 Wolle Desm. U. S. ed. II p.61.

d 93 Bailey Contr. Queensl. Fl. p. 413.

o 93 Tumer Alg. Ind. orient. P. 73. Subgen.: Sect. I. A. Cyclidium, B. Nephridium. C. Prramidium; Sect. II.: D. Sphre ridium. Seet. III.: E. Tetridium, F. Gouatidium. G. Teinidium.

(1) 44 Saund. in Fl. Nebraska 1. t1.

ph 94 Wellheim in Pringsh. Jahrb. 26 p. 730 (sep.p. 57).

\section{COSHOCLADIEE}

118.9 Nordst. apnd Toni Syll. Alg. p. S04. Subfan. Desmidiacear. Gen.: Cosmocladium.

\section{COSHOCLADIUII}

d 513 Brib. Liste p. 133.

d 58 De Bary Conjug. p. 7 .

d 61 Arch. in P'ritch. Inf. p. 721 et 752. Genus Palmellacear.

d 63 Rab. Krypt. Flor. Saehs. p. 119 et 132.

d 65 lle Bary in Flora p. 329.

o $6 \mathrm{~T}$ Arch. in Q. J. M. Sc. v. 7 p. 299.

d 6 S Rab. Fl. Eur. Alg. 3 p. 53.

d 75 Microgr. Dict. p. 2 .93.

it Ts Kirchn. Alg. Sichles. p. 105

d 81 Manoury in Baill. Dict. bot. II p. 14t).

d S5 hiveln. Mikr. Pflnuz. d. Süssw. p. 15.

d 8ij Coolie Brit. Desm. p. Ts.

o 8s Mungeard Rech. Alg. infer. 1. 162.

1) S9 Tumi s.ll. Alg. p. 804 .

1 no Wille in Natiirl. Pflanzenfam. p. 11.

191 Kirelın. Mikr. Pflanz. d. Süssw. ed. 2 p. 21.

oz 91 Goli Ueber ('issmoelad. p. 1r.

\section{Cosmosporre}

d sib Cookr Brit. Desn. 13.33. Sect B. Desmidiearum [= Glyptosporeæ stizenb. 1800. - sect. B. Rab. Fl. Exur. alg. 1 sis p. 1.5].

\section{costritum-11s}

1) 83 CALOCYLINDRUS Tulle in Bull. Torr. bot. Club v. 10) p. 16 t. 207 f. 206 .

1 St-Wolle Desm. U. S. p. 50 t. 1: f. 13.

o si-Stokes Kie y Desm. 1) 11 .

11 89 DISPHINCTIUM ? Tomi syll. alu. p. $88 \pi$.

1 $92 \mathrm{Cal}$. Wolle Desm. U. S. e.d. 11 j.111 t. 15 f. 13.

\section{rostretum -r}

om 34 CLOSTERIUM Corda in Aln. de Carlsb. $1835 \mathrm{p}$. 155,1 () (), 1!4. 20!!. t. 5 f. $61-63$. [C1. ruficeps! sec. Ekreul. in Wiegm. Arch. 1.534 p. 185].

$40-\ldots-0.180$ p. 214 (sep.p. 74 )

1z.5-Talfs Brit. Desur. 1. 170 t. 21 f. 1 incl. Cl. doliolatum et dilatatum).

d 19 - Kütz. sipec. Alg p. 166 .

d 52 - Pritch. Inf. 1. 281 .

d 56 - v. curtum Frél. List. p.1.18.

1 til-Arch. in Pritels. Inf. 1) 7.1 .

1) 63 - Rub. Firyt. Fl. Sachs. p. 173.

m tit-Reinseh Algent. Frank. p. 1s5.

o 6 T - Not. Desm. Ital. p. 62 t. 7 f. $61 \%$.

z $6 \mathrm{~s}-\mathrm{Arch}$. in Q. I. M. sic. 8 p. 118.

1 bi-Rab. Flor. Eur. Alg. 3 p. 12ti.

d -. b. turgidulum ibid. (Cl. t u $\mathrm{g}$. Kütz.).

- e. curtum ibia.

z $71-$ Lund. Desm. Snee. 1. T×.

d $75-$ Microgr. Dict. p. 176.

dz 78 - Kirchn. Alg. Schles. p. 139.

m $78-$ Hempel Alyenf. Chemnitz p. 112.

ph 83 - Fischer Gypskryst. Desm. p. 141 t. 9 f. 10.

dzst - Tolle Desm. U. S. p. 12 t. 6 f. 19.

d $85-$ Kirelun. Mikr. Pflanz. d. Süssw. p. 21.

m $\$ 5$ - Boldt sibir. Chloroplı. 1. 122.

d 55 - f. Tordst. Desm. Grönl. p. 1:.

m sti-Lagerle. Amerik. Desm. p. 254.

o $\$ 6$ - Stokes hiey Desm. 1. 112.

dz 83 - Cooke Brit. Alg. p. 28 t. 10 f. 3 .

d si-Alexento Clilorosp. Fibark. p. 22T.

dzss - Hans\%. Prodr. Algenfl. Bühm. p. 1 so.

ph sS-Hauptf. Zellm. u. Hüllgall. Desm. p. 99 (sep.p. 11 ) t. 3 f. 31 et 36.

mis - Inte. Tel. maryar. alg. 1. 238.

1) 89 - Toni ssll. Alg. 1) 833 .

i] - - turgidulum ibid.

(l) - v. curtum ibid.

i 89 - r. subtumidum liacil. Now. Desm. p. it t. 7 f. 18.

m 90 - Anderss. Averig. Chlor. 1 p. 18

d 91 - Kireh" Mikr. Pflanz. d. Siissw. ed. 20 p.22.

o 91 -? Heimerl Desm. alpin. p. 5033.

31 ARTHRodiA Kuntze Rev. gen. pI. p. 883.

$1119 \mathrm{Clost}$. West Fr. w. Alg. IV. Irel. p. 123.

dz92 - Wolle Desm. U. S. ed. Il p. 45 t. 7 f. 19.

o 98 - Lütkemall. Desm. Attersees 1) 543.

\section{(0)statum -}

l 75 COSMARIUM Nordst. Desm. aret. p. 25 t. 7 f. 17 (C. crenatum $\div$ costatum Nordst. 1872).

$111-\beta$ triquetrum ilid. 1 . $25 \quad r$ abnorme $\beta$ triqu. Tordst. 1si2).

ns $S$ - Boldt Desin. Grön1. 1). 21.

- f. minor ibid. 
o - f. major ibid.

o - $\beta$ triquetrum ihicl. p. 22 t. 1 f. 22.

d - $y$ subhexalobum ibid. t. 1 t. 23.

m 88 - Rucil. Nat. flor. glon. Polsk, p. 105 (sep.p, 26).

d $8: 1$ - Toni syrll. alg. p. 1012.

d - v. subhexalobum ibil. p. 1013.

n 11 URSINELLA Kimtze Rev, gen. pl. p.92.

d 2 Cosm. f. (intu. in Nuov. Notar. III p. 20.

d 6 -f. fiute. Flor. Glon. Galic. 3 p. 130 t. 3 f. $12[6$ Buldtiannm Gutw. 18:t].

o 95 - Jolms. Rare Desm. U. \&. II p. 293 t. 240 f.31. [C. pulcherrimua f.?].

\section{(ostutul)}

d St DoCIDIUM Wolle Desm. U. S. 10.53 t. 10 f. 2 (sp. dubia sec. anct.).

o 81 - Stuke Iiey Desm. p. 113.

d 89-Toni syll. Alg. p.siti.

a 92 - Wo7le Desm. U. S. ed. II p.5\% t. 13 f.2.

\section{(“)}

a St STAURASTRUM Racib. Desm. okol. Krakowa sep.p. 19 t. 1 f. 11 . [Mtaur:i megalonoti affine]

d 53 - Lincil. Nonn. Desm. Polon. p.90 (sep.p. 34).

d 8!-Toni Syll. nlg. 1). 1157.

\section{Cromeri}

1 s9 EUASTRUM liacib. Now. Desm. p.114 (sep.p. 32) t. if f.5. ("E. sprec. grö̈sser als elegans, ähnlich rostra. tum" ('. Cramer 1S63. in Rab. Alg. Eur. n:0 14t1) [Eu. octangulare sec. West 18t5].

in 94-Gutr. Fl. alg. Tarmajol. p. 104.

\section{"rospedoplen?um}

a 93 COSMARIUM Tumer Alg. Ind. orient. 1. 73 t. 23 f. 14.

\section{crocisa $-11 m$}

d 5s CYLINDROCYSTIS de Bary Conjug. p. 37, it t.7 f. $C .1-12$.

o 61-Arch. Descript. (1.564) sep.p.4; in Dubl. Nat. Hist. soc. Pr.p. 17.

o 72 - Wittr. Gotl. Öl. sötv. Alg. p. 6if.

z 7,1 - Nordst. in Wittr. et Nordst. Alg. ers. n:o 260; et in fase. $21(1899) 1$ 1. 49.

d st PENIUM Wolle Desm. U. S. p. 37 t. 5 f. 3.

o 86 - Stok's Kiey Desm. p. 111.

d $86 \mathrm{Cy} 1$. Cooke Erit. Desm. p. 46 t. 18 f. 2 [e de Bary].

$\mathrm{dz} 89-$ Hansg. Prodr. Algenfl. Böhm. p. $27 \overline{7}$

m s8 - Yurdst. Fr. wat, alg. N. Zeal. 1. 72.

m 88 - I'oteut North Carolina Desm. p. 2.

dz 89 - Toni Srll. Alg. p. 816.

90) - Wille in Natürl. Pflanzenfam. p.10 f. $1 ;$ D (e de Litry).

m 92 - West Fr. w. Alg. W. Trel. p. 131.

in 92 - Ruc. Desmidya Ciastoni. 11.390.

d 92 Pen. Wulle Desm. U. s, ed. Il p.37 t. 5 f. 3.

m $93 \mathrm{Cy}$ 1. Lithemiill. Desm. Attersees p.511.

n 93 - (Cyelocystis) Turner Alg. Ind. orient. l' 16.

m 91 - Stuchm. Nachtr. syst. Aufz. ()sterr. Krypt. p. 40.

o 95 - v. elliptica West Alg. Madag. 13. 48 t. 5 f. 27.

Cfr Coccochloris Brebissoni et Trichodictyon rupestre.

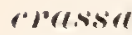

d 17 PALMOGLOEA Kintź, Tab. Phyc. I 1'. 19 t. 25 f. 1. [Quid?].

d 19-(Cylindrocystis) Kütz. spec. Alg. p. 229.

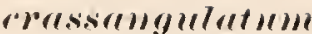

d 94 Cosmarium Borye Süssw. Chlor. Archang. p. $25 \mathrm{t}$. 2 f. 23.

Cfr. Cosm. crassipelle et C. taxichondriformo v. depressum.

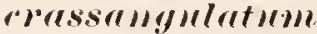

d 91 EUASTRUM Piory. Desm. Brasil. p. 37 t. 3 f. 25.

d $\$ 12-v$. ornatum II est Fr. w. Alg. W. Irel. p. 140 t. 20 f. 16. [Eu. binale f. Gay 18 sec. Bürg. F. alg. Ostgrönl. T.32].

\section{(r)(sisestriutum}

$\mathrm{dz}$ 7) CLOSTERIUM lrch. in Q. J. I. Sc, v. $19 \mathrm{n}: 0$ 73 p. 120.

d s9-Toni Syll. Alg, p. 858 .

n 91 ARTHRODIA humtze Rev, gen. pl. p. 8.83.

d $93 \mathrm{Clost}$ f.? Turner Alg. Ind. nrient. p. 167 t. 23 f. 8.

\section{crosiviolle -is}

d 71 EUASTRUM Lund. Desm. Suec. p. 23 t. 2 f. 8.

o 72 - Nordst. Desm. Spetsh. p. 37.

d 75 - $\beta$ dentiferum Nordst. Desm. aret. p. 31 t. 8 f. 32 .

o 79 -f. Wille Ferskv. olg. Nov, Semij. p. 33 t. 12 f. 9. [v. bicrenatum Tomi 188!1].

n $53-\beta$ nivale Wittr. Snöns o. isens $\mathrm{fl}$. p.213.

d 81 - Wolle Desm. U. s. p. 105 t. 27 f. $37-3$.

s5-Formis edentatæe Rracit. Nonn. Desm. polon. p. 91 (sep.p. 85$)$ :

11 - a. typicum ilil. (L tend. 1871).

o - b. F. ibill. (Hille 1s7(9).

$11-$ e. minor iloid., t. 13 (sep. 4 ) f. 15.

o 86 - stukes Key Desm. p. 146.

A si - $\beta$ dentiferum f. Boldt Desm. Grönl. p. 9 (sep.p. T).

d 89 - Tomi Syll. alg. p. $10 \% 2$.

d $-v$ bicrenatum ihid. p.1073 (f. Wille 1879).

m 91 - West Fr. w. Alg. North Wales p. 288.

n 91 HELIERELLA Kuntze Rev. gen. pl. 1. 898.

d $92 \mathrm{Eu}$. Wolle Lesm. U. S. ed, II 1).115 t.31 f. 37 et 38. o 93 - H. Turner Desm. Notes p. 343 et f. 5 p. 34.

m 14 - Burge siüssw. Chlor, Arehang. p. 33.

m 94 - Bärg. F. alg. Ostgrönl. p. 31.

\section{reassiperlle -is}

u 85 COSMARIUM Boldt Silir. Chloroph. p. 101 t. 5 f. 5.

d 89 - Tomi syll. alg. p. 948.

n 91 URSINELLA Kuntze Rev. gen, pl, p. 924. Cfr. Cosm. crassangulatnm.

\section{rorssipes}

d 14 XANTHIDIUM White in Transact, micr. soc. v. 1 p. 81 t. 8 f. 8 [Fossile, an Spongia?]. [Quoqne in Micr. Journ. v. 2. 1842, t.4. - n. v.].

m.16- Hillinson in T'ransact. micr. soc. v. 2 1\%.89 t. 13 f. 4 ("like X. crassipes").

a 52 - Pritch. Inf. p. 259.

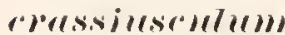

d 5s PENIUM de bary Conjug. p. 73 t. 5 f. 5 - 7 .

d s.3-Cybulski Mater. alg. Warszawa p. 260 (sep.p.12) t. 8 f. 22 [An Cosm. parvulum Lréb. ?].

d 86 - Cooke Brit. Desm. p. 44 t. 17 f. 7 (e De Bary).

d 89 - Toni syll. Alg. 1. 865 .

o 10 - f. Büry. Desm. Brasil. p. 26 t. 2 f'. 1.

z 94 - lioy ticott. Desm. p. 251.

o 95 - Schmidle Beitr. alpr. Alg. p. 311. Cfr. Peninm Brebissonii b., et P. polymorphum. 


\section{(")}

d $\because$ CLOSTERIUM b.7p. Desuil. subalp. l. 121 sep.p.

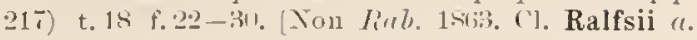
Delpontii K7els 1si!. Cl. Delpontii Wolle 1895 .

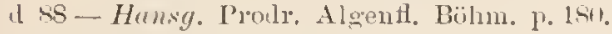

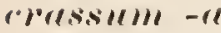

al 63 CLOSTERIUM liub. Krypt. Fl. Áarlis. p. 173,

il 6 s - Tiub. Flor. Eir. Alo. i3 1. 134.

a 89 - Toni r.y1l. Alg. p. 843 .

11 ARTHRODIA fiuntie Rer. gen. pl. p. S5:\%

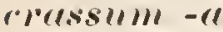

n 39 HETEROCARPELLA Trib. in Cher. Mier. p. 27: [nomen tantum!].

d 40 Cosma RIUM Hreb. in Menegh. Fynops. Desm. p. 222 (sep.p. 2.2.

(1) 45 EUASTRUM Kïtz. Plyycol, serm. 1" 135.

d $-\beta$ ibid.

d ts - Ralf:s Brit. Desin. 1. 81 t. 11 f. 3. (Eu. Pelta Rulfs. non Corkla).

d $49-K$ ïtz. Spec, Alg. p.172.

d $-\beta$ grande ibid. p. 173 .

d $52-13$ itcl. Int. 1).24\%.

d 56 - Bréb. List. p. 122.

d - $\beta$ appendiculatnm ibil. $=R a l f s$ Br. Desm. f. 3 ь.) [nulla varietas sec. Witdem. 1857).

- 61 - t. Bulmh. in Hedwigia p. 52 t.? f. 11).

a 61 - Arele in Pritch. Inf. p. 728 (et $\beta$;

1 63 - Ried. Firypt. Fl. Sachs. ]1 1855.

m 64-Rab. Alg. Eur. n:o 170s.

o 67 - Not. Desin. [ta]. t. 2 f. 12, p. 34.

d $68-R u$. Flor. Eur. Alg. 3 p. 1 si.

d - b. majus (" "halfs 1. c. F. 3 b") ibil. p. 182.

d 71 -Lund. Desm. Suec. p. 17 t. 1 f. 10.

d $-\beta$ scrobiculatum ibid. p. 18 t. 2 f. 1 .

o 73- $\beta$ scrobiculatum Nordst. Forg. Desnu. p.s.

d 73 - Wood Fr. Alg. p. $13 \overline{7}$.

1 75 - Microgr. Dict. p. 291.

o 75 - Reinsch Contribnt. p.93 t. 18 f. 12 ; monstr.

d 7 - Kirehn. Alg. Schles. p. $15 \overline{7}$.

m 81 - Gay Monogr. loc. Conj. p. jti.

d 84 - Wolle Desm. U. s. p.97 t. 25 f. 1 -3 (forma).

nu 85 - v. scrobiculatum Wolle in Bull. Torr. Bot. Club. 12 p. 3.

m S6- $\beta$ scrobiculatum Lagerh. Amerik. Desm. p. 232.

$118 t^{3}$ - - Wittre et Vordst. Alg. exs. no sill.

o $\$ 6$ - Stokes Key Desm. p. 145.

al 86 - Cooke Brit. Desm. p. his t. 32 f. 1 [partim e Ralfs].

n 87 - r. scrobicnlatum Wolle Fr. Alg. U.S. A. p. Bs t. 3 s f. $t$ \& $\mathrm{i}$.

187 - v. cornubiense Bem. Fr.-w. Als. Forth Cornw. 1'. 16 (sep.p.9) t. 19.

87 - r. colnubiense Cooke Brit. Desm. t. 65 f. 1 (e Benn.).

o si - Wildem. Observ. 1pu. Desm. p. 28t (sep.p. 1t) t. 1 f. 33-3.s formes).

d ss - Hansg. Prodr. Algenf. Bölım. 1. 20\%.

$m$ - $\beta$ ornatum ibid. Eu. ornatum Hord $^{r}$.

d 89 - Toni íyll. alg. p. 1058.

d- - v. scrobiculatum ibid

1 - v. cornubiense ibid.

d 89 - f. b. liacib. Now. Desm. p. 103 isep.p. 31 ) t. 1 f. 12.

- f. $c$. ibil.

- * scrobiculatum f. polonica ibid, et r. 112 t. 6 f. 11 .
$20-1$. crasso-humerosum Pem. Fr. Alg. Hampsh. t. 1 f. 14.

1) (m - Wert Fr. w. Alg. Nortl Wales p. 24: t.t; f.33.

In (1) - Anderss. Sverig. Chlor. 1 p. 10.

11 "1 HELIERELLA linutze Rev. gen, p]. p. k!

in $92 \mathrm{Eu}$. Thest Fr. w. Alg. Tr. Irel, p. L33:

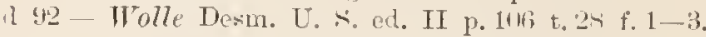

1 - - s. scrobiculatum ibid., t. 29 f. 1-i.

in 95 -Eich7er in Pamiet. Fizy. 13 1).61.

Cfr: Eu. magnificum $r$. rassioides, En. ornatum.

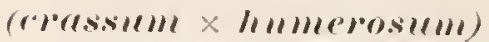

1 M EUASTRUM lienn. 11ybr. Desm. p.1il c. fig. xrl. 4. [Me julice nulla spec. hybrida! - Cti. Eu. crassom v. crasso-humerosum lienn. 1 relo]

\section{reverutu}

ll ts MiCRASTERIAS Bréb. in liulys Brit. Desm. p. 75 t. 7 f. 2. t. 10 f. 1. [YI. truncata f. Rirul. 1S65s] (Micr. rotata hulfs 1844 ex p.).

1 52 - Tritch. Inf. p. 245.

o 60 - v. lata Buhle. in Hedw. p. 52 t.! f. 12.

1) 61 - Arch. in Pritch Int. 1. 72 .

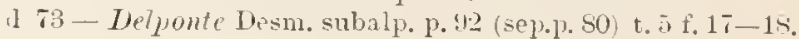

1 st - Wolle Desin. U. S. p. 113 t. 33 t. $\mathrm{i}$ - .

o 86 - Stolies Key Desm. p.147.

o 86-Cooke Brit. Desm. p. 61 t. 2i f. 1 [e Rulfs?].

o 5 - Wartel in Ann. Inst. bot. di Roma 3 1).9.

in S - Ruciz. IIat. flor. glon. Polsk. p. 111.

$1190-$ Bennett Fr. Alg. IIampsh. 1. T t. 1 f. 11 et 12 .

d 92 - Trolle Desm. U. S. ell. II p.126 t. 37 f. 7 - 5.

m 95 -Eichlo in Panniet. Fizy. 13 p. 131.

\section{(")ematil) -}

1) $4 \pm$ COSMARIUM Ralfs Amn. Nat. Hist. ro. 14 p. 394 t. 11 f. 6 (et 1846 in Trans. Bot. Soc. Edin. т. 2 p. 150 t. 16) [Fig. b. non satis bona; $a=$ alia spec.].

d 4.5 - Hass. Brit. Alg. p. 365 t. 6 [e Rulfs ]. c. delineata].

o 4 edastrum locke Plys. Stud. 1 p. 11 t. 1 f. 3 . [Cosm. orthogonnm sec. Delp. Desm. sub. II p. T.].

dzf ts Cosm. Kalfis Brit. Desm. p. 96 t. 15 f. 7.

u $49 \mathrm{Eu}$. (Cosmarium) Neg. Gatt. einz. Alg. p. 120 t. $\mathbf{i}$ A f.s [C. Nægeliaum Bréb.).

d $52 \operatorname{Cos} m$. Pritch. Int. p. 253.

1 5.2 Eu. Perty kileinst. Lebensf. p. 209 t. 16 f. 10 [Cosm. Pertyanum lícil. 1555; ? C. dovrense liac. 1859]. n is Cosm. (Microcosmarium) De Iitr. Conjug. 1. 72.

d 61 - Arch. in Pritch. Inf. p. 732.

d $63-R a b$. Krypt. Fl. Siachs. p. 19!.

d 67 - Tot. Desin, Ital, p. 47 t. 4 f. 34.

d tis-Liab. Flor. Eur. Alg. 3 p. 165.

1) - b. subcrenatum (Eu. Eenatum lerty 1-52) [C. Pertyanum líc 1.5-jo.

$6: 1$ - Witt. Shandin. Desm. p. 10.

i1-Lund. Desm. Suec. 1.34.

- $\beta$ subcrenatum ibid.

1 72 - Tordst. Desm. Spetsb. 1.2!; forma $1:$ t. 6 f. 7 . form. $2: t .6 \mathrm{f} . \mathrm{s}$.

a - costatnm ibil. p. 30 t. 6 f. 9 [C. costatum . Tordst. $1<-5]$.

$\beta$ bicrenatum ibid., t. is f., 10 . [C. bicrenatum Joshua 1-883].

$\mathrm{dz} 73$ - Wood Fr. Alg. 1. 131.

dz 75 - Microgr. Diet. p. 2(1) t. 10) f. 20 [e lialfis f. $T$ a

in 75 - Nordst. Desm. arct. p. 3s.

n 7 - $\beta$ bicrenatum Nordst. Desm. Ital. p.35.

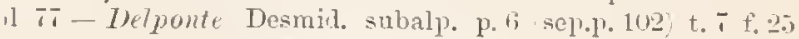
2-. [Cosm. Meneghinii sens, lat.]. 
m 78 - Norelst. Alg. sandvic. p. 12. [e, ma jnl linc. 18s5]. dz $78-K i r c h n$. Alg. Schles. p. 14!.

d $78-v$. Kerguelense Reinsch Freshw. Alg. Rerguel. p. 82 (sep.p. 18).

m 79 - Wille Ferskv. alg. Nov. Semlj. p. 40.

d $83-\beta$ nanum Wittr. in Wittr, et Nordst. Alg. exs. n:o 563 ; et in fasc. 21 (1S89) p. 11.

u 83 - Mask. N. Zenl. Desm. Add. p. 251 t. 24 f. 15 [C. Negelianum var. latum Mask. Furth. Not. 1889].

m 81 Eu. (Cosmarium) Gruy Mon. Ioc. Conj. p. 60, 11011 kütz. nee. $\mathrm{Nen}$.

dz 81 Cosm. Wulte Desm. U S. p. 67 t. 4.4 f. $31-32$.

d 85 - Kirrhn. Mikr. Pflanz. d. Süssw. p. 25.

m 85 - Dolit sibir. Chloroph. p. 105.

d - f. tricrenata ibill. p. $14 ;$ t. 5 f. 12 [C. Boldtiannm Gutw.? ?

m 85 - a. Ralfsianum Rac. Nonn. Desm. Polon. p. 76 (sep.1). 20).

o - b. suberenatum ibid. (Lund. 18i1, non Perty .

d - c. alpinum ibid., t. 11 (sep.2) f. 11 [C. alpinum Toni 1889 .

m - e. major ibid. C. cren. Kirchn. 1878).

u - f. minutum ibid. p. To (C. undulatum $y$ minutum Wittr. 186!t).

o 86 - Stokes Kiey Desm. P. 12 T.

dzf 86 - Cooke Brit. Desm. p. 95 t. 37 f. 13 [e Ralfs 181s?].

d 87 -Alexento Chlorosp. Khark. p. 262.

dzss - Murnsy. Prodr. Algenf. Böhm. p. 195.

d $\quad-\beta$ na $11 \mathrm{~m}$ ibid. 1 . 1iti.

m 88 - v. Riabin. Chloroph. env. Kilıarkow p. 324 t. 8 f. 5.

m 88 - f. a. b. c. Butdt Desin. Grönl. p. 18.

o - f. intermedia ibid.

$m-\beta$ bicrenatum ibid.

m ss - Iste. Jel. magyar alg. p. 224.

d 89 - Toni Syll. alg. p.941.

d - v. subcrenatum ibid.

d - - v. nanum ibid.

d - v. tricrenatum ibid.

o 10 - a. f. Gutw. Wahr. d. Priorität 10.67.

b. f. ilid.

c. f. ibid.

m 90 - Anderss. Sverig. Chlor. 1 p. 15.

m 11 - Ist $v$. Fragm. Alg. p. 1168.

d $91-$ Kirchn. Mikr. Pflanz. d. Süssw. ed. 2 p. 26.

d $91-\beta$ nan um Heimer Desm. alpin. p. 599 .

m 91 - Borge Bidr. Sibir. Chloroph. p. 11 (f. bi- et tricrenata).

n 91 URSINELLA Kuntzc Rev. gen. pl. p.921.

- 91 Cosm. f. a. Gutw. Flor. alg. Leopol. p. 41 t. 1 f. 12 [C. solidum?].

d - f. b. ibid. et t. 1 f. 13 .

d -f. c. ibid. et t. 1 f. 14.

n 92 - f. Borge Alg. notis $1-2$ p. 59 et 60 .

m 92 - Borge Cliloroph. Norsk Finm. 1. 10.

$\mathrm{dz} ! 2$ - Wolle Desm. U. s. ed. II p.73 t.60 f. 31-32.

m93 - Lüthemill. Desm. Attersees 1. 5ñ3.

m 13 - West in Notaris. 7 p. 1502.

m 93 - f. minuta Turner Alg. Ind. orient. p 50 t. 7 f. 28.

d $93-\mathrm{f}$. Nordst. in Wittr. et Tordst. Alg. exs. n:o $111 \overline{7}$ m 04 - Iste. Allat. Roman. Alg. 1\%:15t.

m 93 - Borge Süssw. Chlor. Archang. 1, 21.

m 94 - B̈̈ry. F. alg. Östgrönl. 1. 14.

m s. Gulw. Fl. alg. Tarnapol. p. so;

d 94 -f. Stockm. in Nachtr. Syst. Aufz. Österr. Krypt. p. 44.

m 94 - Hexenko Mater. alg. Khark. p. 26.

m55-Schmidle Beitr. alp. Alg. p.34s.

Cfr. Eu, sinuosm Kïtz. 1s49. Cosm. undulatum exp $\mathrm{p}$

\section{(*)entrill)}

d 45 EUASTRUM hïtz. Plȳcol. germ. p. 13. .

d 48 - Ralfs Brit. Desm, p. 211 t. 35 f. 13 (sec, Rulfs fortasse var. Eu. elegantis).

d 49 - hïtz. Spec. Alir. p. 17.

d 61 - Areh. in Priteh. Inf. p. 730.

A S6-Jenn. Fr.wat. Alg. Engl. Lake Distr. 1 p. i t. 1 f. 14 (cum descriptione Kützingii non congruit).

d Sf -Cooke Brit. Desm. p. 78 t. 35 f. 14 [e Bennct? ?]

\section{renrentlll.}

d 4 STAURASTRUM lialfs Brit. Desm. p. 210 t. 35 f. 17 .

d 52 - Iritch. Inf. p. $26 \%$ \%

d 61 - Arch. in Pritch. Inf. p. 711.

d 68 - liub. Flor. Eur. Alg. 33 p. 220.

d 73 - Trood Fr. Alg. p. 151.

a 81 - Wolle Desm. U. s.. p. 126 t. 11 f. 5-6 [E Ralfs].

o sfi-Stokes Key Desm. p. 167.

d so-Toni Syll. alg. p.118i.

d 92 - Wolle Desur. U. s. ed. Il p. 138 t. 52 f. 5-6.

n $93-(G$ lyptastrum) Twner Alg. Ind, orient. p. 133.

\section{(reniferllll}

d 93 COSMARIUM Thrner Alg. Ind, orient. p. 5 ; t. 8 f. $2 !$

\section{crencletull}

a 43 CLOSTERIUM Ehrenl. Mikr. Leb. siid. u. N. Amer. p. (335. 336. 338. 369 et) 111 (sep.p. 123) t. IT. I. f. 29. Clost. Trabecula Rail. 1841 . [Cfr Turn. 1893]

o 48 D0CIDIUM Rillss Brit. Desm. 1.219 (sec. Bailey in. litt. hae species cum Docidio noduloso identica est.).

a 49 PENIUM (Docidium) hï̈z. Spec. Alg. p. 169.

d Gs PLEUROT $\$$ NIUM Riab. Flor. Eur. Alg. 3 p. 142 inclus. Pl. nodnlosum).

d $73-$ Trood Fr. Alg. P. 119 t. 21 f. 1.

d S4 Doc. Wolle Desm. U. S. p. 47 t. 9 f. 1.

o Sti-Stokes Iiey Desm. p. 113.

d 86 - Roy et Biss. Jap. Desm. p. 211 (sep.p. 9. t. 268 f. 19.

m 99 - IIwr. Fr. Alg. Maine II p. 185.

d. 92 - Wolte Desin. U. s.. el. II p.51 t. 11 f. 1.

o 93 - Turner Alo. Ind. orient. p. 29.

\section{remmlutull -}

d s; EUASTRUM Iiem. Fr.-w. Alg. North Cornw. p. 17 (sep.p. 10) t. 4 f. 20, 21. [Non Ehrcnl. - Cosm. Regnesi ??

d 87 -Coule Brit. Desm. 1. 187 t. 65 f. 3 (e Benn.).

d 89-Toni Syll. alg. p. 10it.

11 !1 HeLIERELLA Kuntze Rev. gen. pl. p. 898.

\section{"reverlintume}

m 39 EUASTRUM Ehrenb. Meteorpap. p. 51 et 56 (sep.p. 7 et 12) t. 1 f. 1 fi, t. 2 f. 17.

a 41 - Elrenb. Berlin. Ionatsb. 1840 p. 208.

43 - Ehrend. Mikr. Leb. Siid. u. N. Amer. t. IV I f.14.

d 15 - Kitz. Phycol, germ. p. 135.

d 47 - Rab. Deut. Krypt. Fl. p. 51.

d 19 -(?) Kï̈z. Spec. Alg. 1. 174.

d 4:-(Cosmarium) Nag. einz. Alg. p. 120 t. 7 A f. 7 C. Menegh. f. crenulat a Iricliter 1583; fig. c. = C. biocul. b. crenulatum liab. $1868=$ C. II eneg. f. tricrenata Turn. $1893 ; 0$. nndulat. $\beta$ cren. H'itt. 1869].

d $52-$ Pritch. Inf. p. 251.

54 - Elrunb. Nicrogeol. t. 34 SiI B. f. 5 [e Meteorpap. 1839 delineata].

2. 56 COSMARIUM Brét. List. 1, 131. 


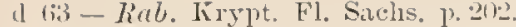

o tit-Not. Desin. Ital. 1) 11 t. 3 f. 2;) [C. Meneglinii f. Wordst. 18i3].

93 - Selemille Beitr. Alg. Selnwal"zald. p.ots t. 1 f. 9. v. Reinschii ibil.; t. 4 f. 10 (C. Menerhinii f. Roiuschii Borge 1891).

m (1) - Schmidle Beitr: alp. Alg. p. 388,

\section{r.rerumlitum}

(1) 19 PHYCASTRUM Stenactinimm) Nerg. einz. Alp. p. 12 ! t. $8 \mathrm{~B}$; a) triradiatum ("I'l, hoxaceros $\mathrm{E} h$ le 11 b. Iig.", b) mixtum, c) quadriradiatum, d) quinqueradiatum.

n 63 STENACTINIUM r. biradiatum Cramer in liab. Alg. Eur. n:o 1414 (Nt. tetracerum livitz.)

d 7 STAURASTRUM Delponte Desmid. subalp. I. $69 \mathrm{~s}$ (sep. 1. 1(i.1) t. 12 f. 1 - 11

I s. Wolle Desm. U. S. p. 126 t. 12 f. $26-29$ (figg. non exactio sec. auctor.).

o sil - Stokes liey Desm. p. 165.

m 90-Fichler spis Desm. Niedz. p. Sy (f. quinqueraliata!

1191 - Heimerl Desm. alpin. D. to6.

1) 52. Wolle Desm. U. S. ell. II p. 110 t. 53 f. $26-29$.

d ! 4 - Smund. in I'1. Nebraska p. $4 t$ t. 7 f. 20 [ex Itolle].

o !1i-Selemidle B Bitr. alp. Alg. p. 65 (sep.p. 3ij). Cfi. Staur. incisum

\section{(He)pellill}

d 95 CosmaRiUM West Alg. Madag. p. 19.3 t. 7 f. 11.

dzf - $r$. compressum ibid., t. 7 f. 33 .

\section{r)esrentum}

(1) (12 STAURASTRUM Hast. in Wolle Desm. U. S.ed. II 1. 153 t. 12 f.s -11 . [staur. forficulatum v. enoplon II est 1s91].

\section{rispula}

d 11 TESSARARTHRA Horren Recherch physiol. p. 12.2 t. 7 C. = plantulie germinales 0odogonii? sec. A. braun.

\section{(.)ispululle}

d 93 D0CIDIUM 'iuner Alg. Ind, orient p. 31 t. 1 f. 14 .

\section{ropisples}

1) 93 ARTHRODESMUS Twner Alg. Inul. orient. p. $13.1 \mathrm{t}$. 11 f. 30 [A. gibberulus sec. Wildem. in Notarisia 1593 p. 164 , sed probabiliter $110 n$ ita].

\section{r)istatum $-a$}

d 18 COSMARIUM Rulfs Brit. Desm, p. 105 t. 17 f. 2.

d) 52 - Priteh. Inf. p. 255.

(1) 61 - Arch. in Pritelı. Inf. p. 731 t. 1 f. 4 .

d GS-Rab. Flor. Eur. Alg. 3 p. 172

d 57 - Cooke Brit. Desm. p. 111 t. 40 f. 6 [e. e Rialfs].

d s9 - Toni Syll. alg. 1051.

n 91 URSINELLA Kuntre Rev, gen. pl. p. 921.

n 93 Cosm. (Cyclidium) Tumer Alg. Ind, orient. p. 73.

\section{(r) istatum}

d 93 D0CIDIUM Tumer Alg. Ind. orient, p. 32 t. 41 f. 7 .

\section{(r) istreterle.}

d 4 PHYCASTRUM (Pachyactinium) $\lambda$ ro. ein. $\mathrm{Alg}$.$\} .$ 127 t $8 \mathrm{C}$ f. 1. [Didymidium Nagelianum lieinseh $151 ; 6$.

o 52 - Perty kleinst. Lebensf. p. 210. Forma.

Vordscell, Index Desmid. d (il STAURAS'IRUM Arch. in t'ritch. Inf. p. 735 (incl. St. nitidum ?.

a $6.5-R a b$. Flor. Eur. Alg. 3 p. 215

d - Forma ibirl. p. 216.

m 72 - Nordst. Desm. Spetsb. p. 10.

- 76 - Tacols. Desm. Danem. 1. 208 t. 8 f. 25 .

d $78-K i r c h n$. Sichles. Alg. p, 170 .

un 87 - f. Roiuschii 1ste. Diarn. priev. p. 239 (sep.p. 16) (St, nitidum f. Reinsch 1875).

d 87 - Coole Br. Desm. p. 114 t. 50 t. 7 [ex Arch.?].

d 89 - Mansy. Proilr. Algenf. Bölin. p.215 et 255.

nis - Boldt Itesm. Grïnl. p. 36.

1189 - f. Reinsehii Istv. Jel.magyar. alg. p. 233 Reinsch Contrib. I 1875 r. 91 (Chlor.) t. 18 f. 3 a-b; St. acutum Brib.). [Staur. luuatum?].

d s9 Toni siyll, alu. 11.11s.

d - f. Reinseliii ibid. p. 1149.

1190 - Wille Natürl. Pflanzenfan. 1) 12 f. 7 F (e Nägrli),

m 90 -Eichler spis Tresm. Miedz. p. 90.

m (n) - Anderss. Sverig. Chlor. 1 p. 12.

m1 - Borge Bidr. Sibir. Chloroplı. p.10.

in 92 - Burge Chloropl. Norsk. Finnark. p. 8.

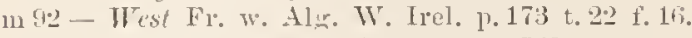

m 193 - Lüllemïll. Desin. Attersees 1) 563.

in 93 - ? f. Turnor 1lo. Ind. orient. p. 112 t. 16 f. 14

\section{roistatum}

d 18 XANTHIDIUM brib. in Rulfs Brit. Desm. p. 115 t. 19 f. 3 ; fig. a-c: $\boldsymbol{a}$.

d - $\beta$ uncinatum lireb. ibil. fig. d-f. [X. bisenarium Ehrent. 1813 sec. Tumer 18!3].

d 52-Iritch. Inf. p. 254 t. 13 f. 19 et 23 [e Ralfs].

d 61 - Arch, in Iritch. Inf, 1. 736 t. 2 f. 18 et 23 [e Ralfs].

d 63 - Rab. Irryt. Fl. Saclis. 1. 196.

d - b. wneinatum ibid.

d 66 -Eyrich Algenfl. Manuli. 1. 128.

m 67 DIDYMIDIUM ( $\mathrm{X}$ anth.) lieinsch Algenf. Frank, p. 127.

(1) 6s Ianth. Rub. Flor. Eur. Alg, 3 p. 224.

d - b. uncinatum ibid.

mz 71 - (Holacantlun ) I.und. Desm. Suec. p. 76.

d. 73 - Hood Fr. Alg. p. 157 .

zf 75 - Reinsch Contribut. p. 9 ? t. 16 f. 13

1] 76 -Delponte Desmid. subalp. p. 75 (sep.p. 1i1) t. 14 f. $1-12$ (f. 12 var. s. sp. nor.) $[1-11=\gamma \mathrm{Del}$. poutii Roy 1893].

dz 78 - Kirehn. Alg. Schles. p. 15 is.

(1) 81 - Wolle Desm. U. S. P.93 t.21 f.j-S (3 forma).

us - $\beta$ uncinatum Wille Sydanorils. Algf. p. 18.

d 86 - $\beta$ glabrum Lagerle. Amerik, Desm. 1.245. [X. glabrnm Lagerle. 18ST].

o S6 - Stokes Kiey Desin. 1). 130.

86 - Tumer in Loeds nat. clnb. transact. 1 t. 1 f. 13.

o 85 - Bem. Fr.-w. Alg. Nolth Colnw. p. 18 (sep.p. 11).

dzf 87 - Coohe Brit. Desm. p. 133 t. 16 f. 3 [ $d$ et $f$. e Lelp. 187\%; g e Keinsch 1875].

d - v. a reniforme ibid. ( 1 Ralfs 1818).

d $-v, \beta$ uneiuntum ibid.

d 87 - Alexenko Clilorosp. Thark. p. 250

m 88-(Euxanthidium) Bollt Desm. Grönl. p. 31.

d $85-$ Hauptf. Zellm. u. Hüllgallerte I)esm. p.90 (sep.p. 32) t. 2 f. 70.

n 85 - Istv. Jel. magyar. alg. p. $23 \overline{\text {. }}$.

d. 89 - v. truncatam Harr. F ${ }^{\circ}$. Alg. Maine II p. 186.

d 59 - Toni Syll. als. p. 923.

d - v. uncinatum ibid.

o - v. reniformo ibid. [ $=a$ ! .

d 8 ! v. depressum Iincib. Now. Desm. p. 107 t. 7 f. 24. 
d -f. irregularis ibid.. t. 7 f. 23.

n 10 HOLACANTHOM Tille Naturl. Pflanzenfam. p.11 et 12 f. 7 D [e Lelp.].

d 90 Xanth. v. spinnliferum West Fr. w. Alg. North Wales p. 291 t. 5 f. 21.

m 90 - $\beta$ uncinatum Börg. Desm. Brasil. p. 4 .

m 90 - Eichler Spis Desm. Miedz. p. 89.

m 91 - IIeimerl Desm. alp. p. 595.

d 91 - v. uncinatum f. mncronata West Freshw. alg. Naine II p.355 t. 315 f. 11 .

n $92-$ v. truncatum IIarv. Fr. Alg. Maine III t. 126 f. 23.

dz 92 - Ilansg. Prodr. Algenf. Böhm. ed. bohem. p. 174.

d $y_{2}-\mathrm{f}$. angnlatum West Fr. w. Alg. W. Irel. p. $165 \mathrm{t}$. 22 f. 3.

dz.92 - Mansg. Prodr. Algenf. Böhm. II p. 252.

d. 92 - Wolle Desm. U. S. ed. II p. 100 t. 21 f. 5 - 8.

o 93 - v. depressum Lïtlemüll. Desm. Attersees p. 548.

m 93 -- Turner Alg. Ind. orient. p.99 t. 12 f. 20.

d - f. inornata ibid.; f. 18.

m - v. leiodermum ibid.; f. 33 (X. leiodermum).

d - - f. irregnlaris ibid.; t. 12 f. 31 , t. 13 f. 3 .

d - f. inevoluta ibid.; t. 12 f. 27.

d -. v. erectum ibid.: t. 13 f. 5.

0 93- $\beta$ unciuatu in Roy Soottish Desm. p. 24 (sep.p. 27).

$11-\gamma$ Delpontii ibid. (TMClp. 185T).

n 94 - v. glabrum f. irregularis Wildem. Olus, crit. Desm. p. 121 (v. lei. f. irr. Turn. 1893).

$n$ - - f. inevoluta ibid. (Turn. 1893).

n - - f. ereetun ibid. (v. er. Tunner 1898).

o - v. uncinatum ilicl. p. 119 et 125.

- v. rotundatum ibil. (X. bisenar. v. rot. Tun, 1893).

- v. ornatum ibid. ( $\mathrm{X}$. bisen. v. oın. Tum. 1893).

1 $94-\mathrm{f}$. Borge Süssw. Chlor. Arcliang. p. 1 s t. 2 f. 11.

o $95-$ f. Ficller in Paniet. Fizy. 13 1. 60 t. 1 f. 11.

o - v. uncinatum f. ibid. T. 60 t. 1 f. 12.

Cfr. Xant], antilopæum.

\section{cruciata}

d 3i BINATELLA Bréb. Alg. Fal. p.5T t.8 [Phycastrum lexaceros $\beta$ eruciatum hïtr. 181:1].

\section{cruciata}

d 34 MICRASTERIAS Fütz. Syn. Diat. p.5yg (sep.p. 71 ) t. 19 f. 86 = crystalli see. Luitz. Pliyc. gener.

\section{cruciatu}

d 6) MICRASTERIAS Wallich Desm. Low. Bengal. p. 281 t. 13 f. 12. [Staurophanum cruciatum Turm. 1393].

d 89 - ? Toni Syll. alg. p. 113!;.

n 91 HELIERELLA Kunlive Rev. gen. pl. p. 89.9.

\section{cruciatum -re}

d 56 COSMARIUM Rréb. Liste p. 129 t. 1 f. 14.

d 68 - Rab. Flor. Eur. A.g. 3 p. 16s.

d $78-K i r c h n$. Alg. Schles. p. 153.

d 81 - Wolle Desm. U. S. p. 81 t. 18 f. 23 - 21.

o 86 - Stokes liey Desm. p. 128.

d 88-Hansg. Prodr. Algenf. Bölım. 1. 201 et 251.

m.98 - West Desm. of Maine p. 340.

d 89 - Toni Syll. alg. p. 1014.

n 91 URSINELLA limtze Rev. gen. pl. p.

a 92 Cosm. Wolle Desm. U. ... ed. II p. 8 !) t. 21 f. $23-24$.

\section{reveirutum.}

a is STACRASTRUM Wolle in Bull. Torr. bot. CIub v. 6 p. 123.

so - Wolle ibid. v. 8 t. 6 f. 18.

d 8. - Wolle Desm. U. S. p. 112 t. 45 f. 11-13 o 86 - Stolies Kiey Desm. p. 16is.

d 89 - Tomi syll. alg. p. 1171.

d 12 - Walle Desm. U. S. ed. II p. 156 t.56 f. $11-13$.

An revera planta Desmidiacea?

\section{rmeintum}

d 91 STAURASTRUM Ilimer Desm. alpin. p. 605 t. $5 \mathrm{f}$. 21. [St. Heimerlianum Lithemiill. 1893]; nee. IFlle 1.566 .

\section{cruciferum}

d 58 COSMARIUM? de fiary Conjug. p. 72 t. $7 \mathrm{G}$ f. $3-6$.

d 61 - Arch. in Pritch. Inf. p. 735.

d $68-$-Rab. Flor. Eur. Alg. 3 p. 1 iт.

m 75 - Nordst. Desm. Brasil. p. 215.

- 71 - Lund. Desm. Suec. 7. 51.

d 82 PENIUM $\beta$ pluriradians Wittr. in Wittr. et Nordst. Alg. Exs. n:0 182, et in fase. 21 (1589) p. 18.

pls $8 t$ - (Aphinetopenium) Gay Mon. loc. Conj. p. 70.

m 86 -- Iagerh. Amerik. Desm. p. 253.

d 87 - Wolle Fr. Alg. U. A. A. p.23 t.61 f. 9-11 [e De Bur: maje].

it s8 DYSPHINCTIUM Homag. Prolr. Algenfl. Biom. p. 185.

o 88 Pen. Nordst Fr. wat. alg. N. Zeal. p. 71 t. 7 f. 14.

d $89 \mathrm{Disp}$. Toni syli. alg. p. sis.

d - v. pluriradians ibid. p. 85 ง.

m 90 Cosm. Anderss. Sverig. ChIor. 1 p. 15.

d 92 Pen. Wolle Desm. U. S. ed. II p. 39 t. 10 f. 9-11.

\section{cruciforme}

d 93 EUASTRUM Tuner Alg. Ind, orient. 1. 76 t.11 f. 13.

\section{crucigenir}

d 34 MICRASTRRIAS Kutz. syn. Diat. p. 601 (sep.p. 13) = Crucigenia quadrata Morren.

\section{Cr.⿲丿丨土口}

a TOSTAURASTRUM limscow in Schrift. Fiew. Naturf. Ges. Vol. I. 1 p. 145 t. VI. 2 f. 4. ("St. parvum, distincte granulatum, senicellulis a latere introrsum ventricoso-globosis, a vertice (froutc) globoso-tetragonis, angulis in cornua quatuor elongata, liyalina, eruciatiun dispositis, crassa divergenti-recurva, apiee capitato-dilatata, aculeâ uniçẩ brevi instructa. productis. Magn. (cum cornub.) =0,105 mill.").

\section{Crux Africana}

o To MICRASTERIAS Cohn Florul. Desm. Bong. p.95.

d 79-Cohn Desm. Bung. 1. 268 (sep.1\%.10) t. 11 f. 3.

d 89 - Tomi syll. alg. 1) 1113. "Crux africana".

n :1 HELIERELJA himże Rev. gen. pl. p. Sys.

\section{Crux malthensis}

n 50 MICRASTERIAS Göpport et Cohu iu Jalıresbericht 1. Schlesisch. Ges. f. v. Cultur 1819 p.94 ["malthensis" verisimile $=$ "melitensis"].

\section{Crux melitensis}

d 32 EUASTRUM Elirenb. Entw. a. Inf. 1. 4.2.

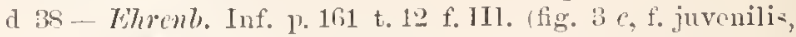
:= M. incisa l. Rab.).

n 39 CoSMARIUM Corda in Alm. d. Carlsb. p. 213 (Ehreub. ]. c. exclus, f. 3 c.).

41 En. Duiley Amer. Bacill. p. 299 (sep.p. 13) t. 3 f. 2 ?. d 41 - Yritch. Inf. p.146. f. 124 [ex Ehrenb.].

d 45 - Kithr. Plycol. germ. 1.131. 
o -15 MICRASTERIAS Hassull Brit. Alg. I p.3at, v. II p. 20 t. on f. T [ex Lihenb. 1. c. male delineata].

d 4 E Eu. Rab. Deut. Frypt. Fl. 1) ót.

d … b. incisum ibil. (Eu. incisum Brél.).

o 47 - Focke Phys. Stul. I p. 45 et (i1 t. 1 f. 13.

d 18 Micr. Ralfs Brit. Desm. 11. 73 t.9) f.3.

$49 \mathrm{Fu}$. (M i cr.) Na\%, ein\%. Alg. 1\% 128.

d 52 M icr. Pritch. Inf. 11.245 t. 2 t. $1: 21$ [ex Ehrenb.].

ph ös-De Bar. Conjug. p. 41.

d 61 - Arch. in Pritch. Inf. p. 726 t. 1 f. 22 [ $[$ lialfs].

o 62 - Iti. Bulnh. in Hedl. p. 5 t. 10, I t. 1.

a 63 - kib. Krypt. Fl. Sachs. p. 183.

ph 63 - Cramer in Hedwig. p. 65 t. 12 f.5.

d 66 - Eyrich Algenfl. Mannl. p. 121 (3 forma) t. 1 f, $1-3$.

d 68 - Reb. Flor. Eur. Alg. 3 p. 190.

d - b. furcata ibid. (Micr. fure. anct., nou $A$.

m 70 - Norlst. Desm. Brasil. p. 220.

m 70 - Reinhurd Arbeit. Naturt'-gh. Charkow I p. 16.

d(z) 73 -Delponte Desm. subalp. p. S7 (sep.p. 75 , t. 1 f. 7 -13. [Fig. 10 M. Janeiræ similis].

d 78 - Kirchn. Alg. Schles. p. 1 til.

83 - Turner Alga sitrensall f. 23.

d 84 - Wolle Desm. U. $\therefore$ p. 111 t. 35 f. 3.

d $85-$ Kirchn. Mikl. PHanz. d. Süssw. 1) 23.

o 85 - ff. a) et b) Riacil. Nonn. Desm. Polon. 1. 97.

d s5-f. superflua Turn. New raro Desm. 1.931; t. 15 f. 11 .

(11) 86-v. Josh. Burm. Desm. 1.636 t. 22 f. 10 \& 11 .

d 85 - Frank in Lounis Synops. 1) 195.

o St; - Stokes Key Desm. p. $1 \pm 7$.

o sf - Squinab. Catal. Desm. Genov. p. 5.

d sti-Cooke Brit. Desm. 13. 55 t. 21 f.2 [e Delyonte 1873].

87 - Holle Fr. Alo. U. A. A. 1) 40 t. 3 f f. $4-\overline{3}$.

d $8 \mathrm{i}$ - Alexenlio Chlorosp. lihark. p.248.

d ss-Hansy. Prodr. Algenfl. Bülim. p. 208 f. 118.

d SS - Toni et Levi Fl. Alg. Tenez. 1. 55.

m ss - Riabin. Chloroph. env. Kllark. p. 328.

m S8 - Hauptfl. Zellm. u. Hüllgallerte Desm. p. 93 (sep.p. 35) $t .3$ f. 25 et 21 .

J 89 -- Toni syll. alg. 1. 1113.

d - r. superflua ibil. p. 1114.

o $10-$ Benn. Fr. Alg. Hampsh. 1. 7 t. 1 f. 13.

m 90 - Eichler Spis Desm. Miedz. p.89 t.9 f. 33.

90 - f. monstrosa Anderss. Sverig. Chlor. 1 p. 9 t. 1 f. 1.

d 91 Kirchn. Micl. Planz. d. Siissw. ed. 2 p. 25.

in 91 - Heimerl Desm. alpin. p. 302.

o 91 HELIERELLA huntze Rev. gen. pl. p. 89\%.

o 12 Micr. a) typica Gutu. Flor, alg. Leopol. p. it (Ruc. form. a) 1885).

- f. monstrosa ibid.. t. 3 f. 28.

o - b) ibid. p. 75 t. 3 f. 29 [liac. 18s\% form. b); $\beta$ simplex Borge 1894].

n 12 - West Fr. w. Alg. W. Irel. p. 133.

m !2 - Rimmer Alg. St. Pülten p. 4.

192 - Wolle Desm. U. S. ou. II p. 123 t. 39 f. 3.

- 92 - f. punctulata West Alg. Engl. Lake Distr. 1. 702.

m 13 - Lü̈licmüll. Desm. Attersees p.5riz.

d 93 - $v$. ornatum schmidle Beitr. Alg. Sichwarzwald. p. 107 t.ti f. 11 .

o.93-(Aetinocystis) Turner Alg. Ind. orient. p. 92 t. 19 f. 17 [Cfr Hillem. in Totarisia 15:43 1. 170].

- f. typica ibid.; t. 5 fig. 4 a.

- f. compressa ibid.; fig. b.

- f. minor ibid.; fig. c.

- f. lata ibid of fig. d.

- f. robusta ibil.; tig.

- f. alata ibid; fig. f.

- f. gracilis ibid.; fig. $y$. o - f. ovoluta ibid.

d $91-\beta$ simplex Borye Süssw. Chlor. Arohang. p. 35 t. $3 \mathrm{f} .40$.

na 94 - Alexenko Mater. alg. Khark. p.29.

III5 - v. evoluta West Ag. Madag. p. 18 t. 6 f. 1.

Cfr. Micr. furcata, Crux malthensis, melitensis, Rabenhorsti, Rota.

\section{Crux Melitensis}

m 31 STAURIDIUM Cordu in Alm. d. Carlsb. 1835 p. 207 t. 3 f. $3 \pm$ [Micrasterias Cordat Al. Br.].

1 39 - Cordu in Aln. d. Carlsb. 1839 p. 238 t. 1 f. 5.

\section{ctenoilleum}

a 93 COSMARIUM Turner Alg. Ind. orient. p. 31 t. 7 f. 39 , t. $S$ f. 59

\section{Cucumis}

d 13 CLOSTERIUM Thenb. Mikr. Leb. Süd. nnd X. Amer. p. $(336.369$ et $)+11$ t. IV. I. f. 28.

d 4 s-Ralfs Brit. Wesm. 1.219.

d 19 Kütz. Spee. Alg. p. 163.

d 52 - Pritch. Inf. 1.283.

d hs-Ritb. Flor. Eur. Alg. 3 p. 138.

d 73 - Hood Fr. Alg. p. 113.

d 84 - Walle Desm. U. S. p. 40 t. 6 f. 17-18. [Cl. Eboracense Tum. 1886].

0 si Stokcs Key Desm. 1.113.

a sil-Toni syll. Alg. p. s2.t.

n 91 ARTHRODIA fintze. Rev, gen. pl. p. 883.

a 92 Clost. Wolle Desm, U. S. ed. II p. 12 t. 7 f. $17-18$.

\section{Cucumis}

m 54 COSMARIUM Corde in Alm. de Carlsb. 1835 j. 206 t. 2 f. 27 [non anct. reeentior.! An Cosnarium Cucurbita cum Seenedesmo quadrieauda fo inermi? - Euastrun lavo see. Ehrenb. in Wiegr. Arch. 1836 P. 185$]$.

d 40 - Menegh. Symops. Desm. p. 220 (sep.p. 20) (inclus. Eu. integerrimum Ehrb.].

d 44 - Ralfs Ann. Nat. Hist. v. 14 p. 395 t. 11 f. 8 (et 1816 in Trans. Bot. Soe. Edin. v. g p. 151 t. 16) [C. Ralfsii Breb.].

1] 45 - Ilass. Brit. Alg. p. 360 t. 86 f. 10 [e Rialfs l. e. male depicta].

1 48 - Kalfs Brit. Desm. p.93 t. 15 t..2 (incl. Pitlisens angulosus lï̈z.) [2 a $(a)=\mathrm{v}$. angliea Rac. 1885; 2 b $\beta=$ v. typicun hlebs 1s7:1.

d) $19-$ h

49 EUASTRUM (Cosmarium) Neg. einz. Alg. p. 114.

d 52 Cosm. Pritch. Inf. p. 252.

d 53 - Hath. Fl. Belg. II. p. 525 .

d 55 - v. lacustre Grun. Desm. p. 497

d fil - Areh. in Priteh. Inf. p. T31.

d 63 - Rub. Krypt. Fl. Saelss. p. 148, f. xyl. p. 15i) [e Rulfs].

m 6IDYMIDIUM (Cosmarium) Reinseh Algenfl. Frank. p. $10 \%$.

6. Cosm. Not. Desm. Ital. t. 3 f. 21.

d 68 - Rab. Flor. Eur. Alg. 3 p. 161; f. xyl. p. $108[0$ Ralfs].

d b. lacustre Grun. in litt. ibid. p. 162.

in it)- Vordst. Desm. Brasil. p. 210.

o 71 - (Pleuroteniopsis) Lund. Desm. Suee. T. 52. [v. sueeica Kiac. 1855].

m T:2 - Norilst. Desm. Spetsb. p. 36.

11 73 - Irood Fr. Alg. p. 130 t. 12 f. 15.

75 - It. Nordst. Wesm, arct. 1.2!) t. 8 f. 25 et 29 . [28 v. magna Rec. 1585̃]. 
n 76 - a f. rotundata Jucobs. Desm. Danem, p. 199 t. 8 f. 22 a. b.

a - $\beta$ f.quadrataibicl. f. 22 e, d. (C. quadratum $\operatorname{Iin} l f s$ ).

$n-y$ f. elongatu ibid. p. $20 \%$ f. $22 \mathrm{e}^{\prime \prime}$ : $\mathrm{e}^{\prime \prime}$.

$\mathrm{n}-\delta \mathrm{f}$. incisa ibir. 1 . $2(x)$ f. $22 \mathrm{f}$. [C. incisum Rrecib. 1885 ?].

d $78-$ Kirchn. Alg. Schles. p. $14 i$.

m 79 - Wille Ferskv. alg. Nov. Sirmlj. p. 48.

d 79 - a. typicum Klebs Desm. Ostprenss. p. 30 t. 3 f. 11, $12,15$.

o- - b. quadratum ibis., t. 3 f. 10, 13. 1.1.

d 50 - $\beta$ holveticum Norlst. in Wittr. et Nordst. alg. exs. n:0 378 ; et in fase. 21 (1.881) 1.43 (et forma trigoua).

d 82 - ? Speneer Fr. wat. Alg. X. Zeal. p. 296.

d 84 CosMaridiUM fruy ifon. loc. Conj. r. is t. 2 f. 19 (a $R(a l f s)$.

d St Cosm. Wolle Desm. U. S. p. 58 to 15 f. $6-9$.

m St - f. monstrosa Wille sydamerik, Algft. p. 32 t. 1 f. 4 .

d 85 - Kirchn. Mikr. Pfanz. d. Siissw. p. 24.

m 85 - Fordst. Grönl. Drsm. 1.9.

d $85-1$. typica Ruc. Tonn. Desm. polon. p. 69 (sep.p. 13).

1 - 2. anglica ibil. p. 70 Ralfs 1848 f. 2 \%).

d - 3. rotundata ibid. (Jacols. 1876).

(d) -5. magna ibin. (Nordst. 1855 p. 28).

(d) fi. suecica ibid. (Iund. 1si1).

d - T. polonica ibic.. t. 10 (sep. 5) f. 6 .

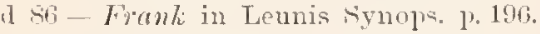

o s6-stolies Kiey Desm. p. 126 .

d 81:-C'noke Brit. Desm. p. 81 t. 36 f. 11.

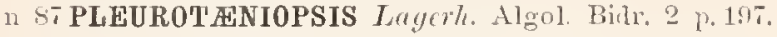

d 87 Cosn. Alrxentio Chlorosp. Th hark. p. 264 .

A SSCnsmaridium Mansg. Prorlr. Algenfl. Bölım. p. 190.

l $-\beta$ quadratum ibid. [Dysphinetium qu. ibirl. p. 244).

d $88 \mathrm{Cosm}$. Trmi et Leri Fl. Alg. T'enez. p. 4 .

n.sis-Riubin. Chloroph. env. Kharkow p. 326.

mss - Boldt Desm. Frïnl. p. 11; nt f. (Nordst. 18.5).

m $\$ 9$ - I'oteat North Carolina Desm. p. 3.

o $s$ - Nordst. Bornh. Desn. p. 202.

m St Cal. Iste. Jel. magyar. alg. 11. 22s.

m S9Cosm. f. Mory. Bidr. Borml. Desm. p. 146.

d s! Pleurotaniopsis (Cosmaridinm) Toni syll. alg. 1.910.

l - v. helvetica ibil.

- f. trigona ibid.

d - v. monstrosa ibid. 1.9!1.

m $90 \mathrm{Ca}$. Istounff. Rumel, alg. Frivald. p. t5.

m 60 Cosm. Eichler spis Desm. Miedz. p. 6 .

n - v. polonica ibirl; t. 8 f. 18.

m9o-Borq. Tesm. Brasil. p. 43.

o 01 - Reinseh susswasseralg. Siud-Georg p. 34 it t. 2 f. 15.

m.1 - Istr. Fragm. Alg. 1 p. 11 tis.

d 11 - Krrelm. Mikr. Pflanz. 1. Sǚsw. ell. 2 p. 2 is.

ma1 f. rotundata Borge Birlu. Sibir. Chloroplu. p. 11.

m!2 - Borge Chloroph. Norsk. Finm, n. 11.

z.2 - West Fr.w. Alg. W. Irol. p.16i3.

1) 92 - Wolle Desm. U. s. ell. II p. 62 t. 18 f. $6-9$.

m 92 - Wrest in Notaris. 7 p. 1502.

m 93 - L Lütlemiall. Desm. Attersees p.519.

n (3) - Neplerdinm) Tumer Aler. lnd. orient. p. 73.

m 94 - Alexenlio Nater. alg. Kihark. p. 24.

m 94 - Burg. F. alg. Ostgrönl. p.21.

m 91 - Gutw. Fl, alg. Tarmapol. p. k.1.

\section{cuenerbita}

11 41 CosmariUM Tréb. in Desmazières Pl. Crypt. France fasc, 2:3 n:o 1103, et icone; in elit. fase. 11 1511) $11: 0503 \mathrm{c}$. icon.
d.11-Rralfs in Ann. Nat. Hist. v. 11 p. 395 t. 11 f. 10 (et 1846 in Trans. Bot. Soe. Edin. v. 2 p. 151 t. 16). [Figura verisimile non bona].

d 45 - Mlass. Brit. Alg. p. 367 t. 86 f. 7 [et f. 12 b. sub nomine Cosm. quadrati] [e Ralfs 1 . c. verisimile sed non exacte depicta].

d 48 - Ralfs Brit. Desm. p. 108 t. 17 f. 7 (incl. Clost. clandestinum).

(t 52 - Jritch. Inf. p. 25.5.

o 56 - Bréb. List. 13.132.

n is - Calocylindrus) De Brar. Conjug. p. 72.

n 58 DYSPHINCTIUM Gmm. Desmil. p. 492.

d 61 Cosm. Arch. in Pritch. Inf. p. 735.

d $03-$ Tab. Tirypt. Fl. Sachs. p. 202.

om 66 - Reinsch in Rab. Alg. Eur. n:o 1898.

d 67 Dis. f. A. Reinsch Algenfl. Frank. p. 178 (Cosm. globosum Iizlnh..).

d - f. B. $\alpha$ et $\beta$ ibid. p. $17 !$.

d 69 Cosm. Rab. Flor. Eur. Alg. 3 p. 174.

0 $71-$ Inud. Desm. Suee. p. 51 .

d 55 -Microgr. Dict. p. 203.

76-Jacobs. Desm. Danem. p. 201 (inel. C. palangula).

d Ts CALOCYLINDRUS Kirchn. Alg. Schles. p. 143.

m 78Cosm. Hempel Algenfl. Chemnitz p. 114.

d 79 -a. typicum Klebs Desm. Ostpreuss. p. 28 t. 3 f. 8 a, e-g.

d b. Palangala ibid. p. 29 t. 3 f. 8 b-d.

z 81 - Elfv. Finsk. Desm. p. 14.

msi - Mempel Algenfl. Chemnitz Forts. p) - (sep.p. 20),

z 83 - Arch. in Ann. Mag. Nat. Hist, 5 ser. v. 12 p. 12\%.

d 84 Cal. Wolle Desm. U. S, p. 54 t. 12 f. 14.

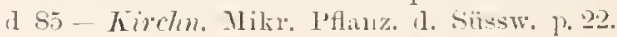

z 85 Cosm. Areh, in Ann. Mag. Nat. Hist. 5 ser. v. 16 1). 1.45

o sf Cal. Stokes Kér Desm. p. 111.

d $s t$ - Franti in Lemis rymops. $3 \mathrm{p} .1: 5$.

187 - Cooke Brit. Desm. 1. 1.25 t. 41 f. 7 [e Rerlfs].

1) si - Alexenko Chlorosp. Thark, p. 23.s.

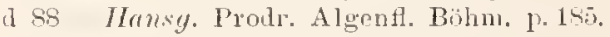

n 88 - Riabin. Chloroph. env. Kharkow p. 319 (sep.p. 31).

11 s8 - Istr. Jel. magyar a.lg. l. 224.

8!) - West Massachus. Desm. t. 3 t'. 15.

d $89 \mathrm{Dis}$. Toni Syll, alg. p. s81.

m $90 \mathrm{Cosm}$. Anderss. Sverig. Chlor. 1 p. 15.

n! 90 - Eichler spis Desm. Miedz. p. s6.

d 91 Ca l. Kirchn. Mikr. PHanz, d. Süssw. et. 2 p. 24.

z 91 Cosm. Wrest Add. Freshw. Alg. W. Torksh. p. 24h.

m 92 - f. major West Fr. w. Alg. W. Irel. r. 162 t. 24 f. 25.

in 92 - West Alg. Engl. Lake Distr. 1. 729.

1 92 Cal. Holle Desin. U. S. ed. II p. 59 t. $15 \mathrm{f} .14$.

in 930 osm. Liatliemüll. Desm. Attersees p. $\bar{y}+\%$.

1193 Dys. (Cylindrosplinetium) Turner Alg. Ind, orient. p. 14.

1 94-f.? Schmidle in Hedwig. 33 p. .99 t. 6 f. 3.

o $94-1 / 6 b$. Austral. Sïsswasseralg. II p. 338.

in 94 - West $\mathrm{Fr}^{2}$. Alg. West. Ind. p. 269.

ก 95 - schmille Beitr. alp. Alg. p. 847 t. 14 f. 16.

\section{"ucurbitinum}

d S4PENIUM liss. Desm. Winderm. p. 197 (sep.p. 6) t. 5 f. 7 (puncta false ordinata).

d 59 - $\beta$ subpolymorphum Nordst. Algolog. småsak. 4 p. 163. [Cosm. Thwaitesii Mask: 1883].

defss - - Nurdst. Fr. wat. alg. N. Zeal. p. 71 t. 7 f, 20.

m89- - D Mash. Furth Note N. Z. Desm. p. 27 t. 5 f. 50 .

d s9-Tomi syll. Alg. p. 856 .

d -v.subpolymorphum ibid. 
o 513 - v. subpolymorpli um Lilkem. Desm. Atters. p. 54t. m 91 - West Tew Brit. Desm. p. 4.

\section{rumbricum}

d 90 -STAURASTRUM Hest Fr. w. Alg. North Wales p. 2 . 2 t. 5 f. 5 et $t .6$ f. 36 i.

a - T. cambricum ibil. 1. 298 t. is fols et folm. minor. t. $6 \mathrm{f} .37$.

\section{cumentum-n}

d Sf COSMARIUM Josh. Burm. Desm, r. 6t: t. 21 f. 17 is 18.

n ss - Lagerh. Bengal. Desm. p. 7 t. 1 f. 4.

d sy-Tuni Syll. alg. p. 103i.

n 91 URSINELLA Kuntar Rev. gen. pl. p. 924.

d $93 \mathrm{Cosm}$ ? r. Indicam Tume Alg. Int. orient. p.152 t. if. 14 .

\section{cuneatum-n}

d IS EUASTRUM .tenner apud Ralfs Brit. Desm. ].90 t. 32 f. 3.

d $52-$ Jritch. 1 nf. p. 251 .

d 61 - Arch. in Priteh. Inf. p. 931.

d 63 - liab. Krypt. Fl. Saclss. p. $18 \%$.

d 68 - Ral. Flor. Eur. Alg. 3 ]. 18\%; form. a et b.

o 11 - Lund. Desm. Suec. 1.19, forma.

m 73 - Nordst. Norg. Desm. p. 9.

o is - Kirchn. Alg. Schles. p. 15R.

m si - Lagerh. Amerik. Desm. p. 283.

d sti-Cooke Brit. Desm. 17. 76 t. 34 f.o [e Ralfs].

o si-- 11 ulle Fr. Alg. U. S. A. p.37 t. 58 f. 12 \& 13.

ก si - $\beta$ solum Norelst. Algolog. småsak. 4 p. 15 fo.

m 88-Buldt Desm. Grünl. p. T t. 1 f. T form. b. Rab. $1<68$.

d - $\beta$ subansatum ibil., t. 1 i̊s [Amnon potius forma E. ansati??

d so-p solum Fordst. Fr. wat. alg. X. Zeal. p. 31 t. 3 f. 6.

d 89 - Toni syll. als. p. 1096.

f. majus et minus ibid. (Rab. 1869.

- r. solum ibid.

d - r. subansatum ibid.

o 89 - Racil. Now. Desm. p. 102 t. 6 f. . .

m 90 - Eichler Spis Desm. Miedz. p. 89 t.9 f. 32.

n 91 HELIERELLA Liuntre Rev. gen. pl. p. s.s.

m $92 \mathrm{Eu}$. Trest Fr. $\mathrm{W}$. Alo. W. Irel. p. 13\%.

m 12 - 1/ub. A ustral. Nïsswasseralg. p. 444.

m 92- - volum Rac. Desmidya Ciastoni. p. 378.

o 92 - Wolle Desm. U. S. el. 11 p. 108 t. 2! f. $12-13$.

d 93j-Bailey Contr. Queensl. Fl. p. 48 t 16 f. 44 (e Cooke).

m 91 - v. subansatum lärrg. F. alg. Östgrönl. p. 31.

o 95 - Schmidle in Hedwig. 34 p. 80.

\section{cunertum}

d S.5 STAURASTRUM Poldt Sibir. Chloropl2. p.114 t. పे f. 24, nec Wolle 1Siri st. Boldtii In Toni 1889?.

\section{rumeatum}

a if STAURASTRUM Wolle in Bull. Torr. bot. Club r. $6 \mathrm{p} .123$.

81 - Wolle ibid. v. 8 t. 6 f. 12.

d 84 - Wulle Desm. U. S. p. 148 t. 18 f. $T$ -.

o 86 - Stolies Fey Desm. ].16s.

d St - Toni Syll. alg. p. 1161.

d 92 - Wolle Desm. U. s. ed. II p. 162 t. 39 f. - - 8 ,

\section{curtum-11s}

n 38 CLOSTERIDM Brib. in Desmaz. Pl. erypt. de France fase. 19 n:o 901, nt ed. $=2$ fase. 5 n:o 201.
1 45 - Brib. apul Kütz. Phycol, germ. p. 132.

d 49 COSMARIUM kirlfs Brit. Desm. p. 109 t. 32 f. PENIUM c. Bribl. in litt.).

d 49 PENIUM Brel. in K̈̈̈tz. Spec. Alg. p. 167.

19 DYSPHINCTIUM ? Neg. cinz. $\Lambda$ lg. p. 112.

pll 511 P'en. Jircun Perjung. p. $21 \%$.

d $52 \mathrm{Cosm}$. Iritcle. Inf. ]. 250 .

i2 t'en. I'erty kleinst. Lebensf. t. 16 f. 17 a [?].

o $53 \mathrm{Cosm}$. Brib. list. p. 133.

o 5s - (Calocylindrus) We Bury Conjug. p. 45. 72.

1 28 Dys. Grun. Desmirl. p. 493.

d bi Cosm. Arch. in Pritch. Inf. p. 785 .

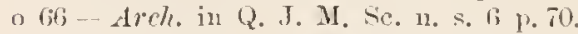

fit Dis. Reinsch Algenfl. Frank. p.17s.

d fos Cosm. Riab. Flor. Eur. Alg. 8 p. 17 it.

d - b. minus ilinl. p. 17 (Dysph. Reggelianum Voeg.).

- - c. majus ibid. Cosm. attenuatum Bréb.).

- 72 Pen. Nordst. Desm. Spetsh. p. 25, forma. f. major, f. minor.

m 75 - Nordst. Desm, arct. p. 15.

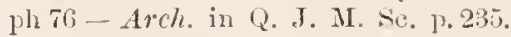

d 5 CALOCYLINDRUS Kivelen. Alg. Schles. p. 143.

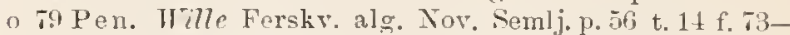
$75(73=$ f. in a jor $)$.

$m$ - f. intermedia ibid. f. $i t$.

o - f. minor ibid.; f. 75 .

d $\quad-\beta$ globosum ibid. p. 5 f t. 13 f. 72.

nz $90 \mathrm{Cal}$. b. ninor Kivelin. Beitr. Algenfl. Würtemb. p. $17 t$ (? Palmogloea sp. Reinsch Contrib. p. 80 t. 12 f. 14 ?).

m so Pen. f. intermedia Wille Xorg. Ferskv. alg. I p. 49.

o 81 - Siphinetopenium) Gry Mon. loc. Conj. p. 71.

d $81 \mathrm{Cal}$. Wolle Desm. U. S. p.51 t. 12 f. $15-16$.

d 86 - Frank in Leunis Symops. 3 p. 199.

o 81 - Stokes key Desm. p. 11.

msi Pen. f. Wille in Dijmplnn. Togt. Udb. p. 87 t. 13 f. 3.

d si Cal. Cooke Brit. Desm. p. 126 t. 43 f. 11 [e Ralfs].

d si- - llexenko Chlorosp. Kharkow p. 236.

n 5 - v. attenuatus lieck iu Verh. d. z. b. Ges. Wien p. 278 (Cosm. attenuatum).

n s. Dys. v. Regelianum Hansg. in Österr. bot. Zeitschr. v. 37 11:0 2 p. 5\%. (D. Regel. Norg. 1819)

n -.v. exiguum ibid.

d 88 - Jansg. Prorr. AlgenAl. Böhm. p. 1 st.

$\mathrm{dz}-\beta$ Regelianum ibid,

d $-y$ exiguum ibid.

m ss Pen. f. Boldt Desm. Gröul. \%. 10 (f. major et minol Nordst. 1872).

in - f major ibid. p.41 (Hille 18ig).

o soCosm. $\beta$ attenuatum Mask. Furth. Note N. Z. Desm. p. 15 t. 2 f. 16.

d s. Dis. Toni Syll. alg. p. 877 .

d - v. Regelianum jbid. p.8is.

d $-\mathrm{v}, \mathrm{majus}$ ibid.

v. exiguum ibid.

v. globosum ibid.

m 92 Pen. Rac. Desmidya Ciastoni. p. 3\%.

d $92 \mathrm{Ca}$ 1. Wolle Desm. U. S. ed. IT p. 59 t. 15 f. 15-16. m $92 \mathrm{Pen}$. f. minuta West Alg. Engl. Lake Distr. p. 721. m 93 - Turner Alg. Ind. orient. p. 18.

m94 Dis. v. exigum Schmidle Alg. Geb. Oberrheins 1. $51 \overline{\%}$.

(1) 9 Cosm. f. Borge Süssw. Chlor. Archang. p. 22.

o 94 Pen. Borges. F. alg. Östgrönl. p.9.

m - - globos a ibid. p. 10.

in $94 \mathrm{Cal}$. Alexcmio Mat. alg. Iiliark. p.27.

m $95 \mathrm{Dgs}$. f. minuta schmidle in Hedwig. 34 p. T2. 
m 05 - y exigu m schröler in 72 . Tahresb. Scliles. G. $f$. v. Cult. 1).35.

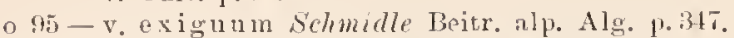
m 95 Pen. f. intermedia West Alg. Malag. p.47.

\section{curvertume.}

d 59 DESMIDIUM (Eudesmidium) Norlst. De Alg. et Clarne. 3 p. 1 t. 1 f. 4 b.

\section{rurvetume}

d 13 STAURASTRUM Twrner Alg. 1nd. orient. p.12s t.16 f. 9, non Trest 18!2. (Nomen specificum ab auctore ipso, Desm. Totes. 1893, p.347 in St, "involutum" transmutatum est.). [C p. 179].

\section{ruvelum}

d 92 STAURASTRUM W'est Frow. Alg. W. Irel. p $172 \mathrm{t}$. 22 f. 13.

\section{curvatus}

dzf 93 ARTHRODESMUS f. typica Turner Alg. Int. orient. ]. 135 t. 11 f. 31,$33 ;$ t. 12 f. $2,7.13,15$ et 11 [A gibberulus sec. Will. in Totaris. 1893 p. 169. sed verisimile non ital.

o - f. major ibid., t. 11 f. 35 , t. 12 f. 8.

\section{curvinostrum.}

d 43 STAURASTRUM Turner Alg. Ind, orient. l. 107 t. 17 f. 12 .

o - f. compressa ibid.

\section{cuspidatum.}

d 18 CLOSTRRIUM liniley in linlfs Brit. Desm. 1.21! t. 3ã f. 11. = 0phiocytinm cuspidatum Rabmh. 1868, Reinschiella? cuspidata be Toni syllog. alg. $\mathrm{p}$. 611 (18s?).

\section{euspirlatmm - a}

a 8.3 EUASTRUM Wolle in Bnll. Torr. bot. Club. 1853 p. 18 t. 27 f. 18.

d 8.1 - Wolle Desm. U. S. p. 105 t. 27 f. 32 .

o 8 - Stokes Kiey Desm. 1) 1.15.

d Sy - Tomi Syll. alg. p. 107s.

n 91 HELIERELLA huntze Rev. gen, pl. p. s9s.

1) Eu. Wolle Lesm. U. S. ed. II p.115 t. 31 f. 32 .

\section{chspidatum -a}

11 30 BINATELLA Wret, in Chev. Mirr. 1.272 [B. tricus pidata liréb. Alg. Fal. p. 5 i sec. auct.].

11 -10 STAURASTRUM Brib. in Wemegh. Synops. Desm. p $2: 26$ (sep.p. 26).

d 45 PHYCASTRUM hitz. Plyyeol. germ. p. 18 .

d 17 DESMIDIUM Riul. Deut. Krypt. Fl. 1.57.

dzf 48 Staur. Iinlfs Brit. Desm. p. 122 t. 21 f. 1, t. 33 f. 10. $4 \mathrm{z} 19 \mathrm{Pl}$ ycastrum Kütz. siec. Alg. p. 17!.

d $-\beta$ dejectum ibid. (St. dejec.)

d _, bilunulatum ibid. [St. mucron. Ralfs 1 sis figr. a super. dextra].

dz 52staur. I'riteh. Inf, 1.262.

dz 61 - Aveh. in Pritch. Inf. 10.737 t. 1 f. B1 - ist [e Rulfs].

d 63 - Rub. Krypt. Fi. Sachs. p. 18 !!

o 68 - Arch. in Q. J. M. Sc. 8 p. 289.

dzes-Tab. Flor. Eur. Alg. 3 p. 203 (incl. Phyc. spinulosum Nry.).

in 70 - Nordst. Desm. Brasil. p. 225.

d - $\beta$ divergens ibid., t. 1 f. 49.

1112 - Wittr. Gotl. ()l. sotv. Alg. p.54.

oz T2- Crowe in Q. J. Mier. Se. v. 12 p.s. n if " Ralfsiana Jaculs. Desm. Damem. p. 203. (Ralfs f. 1).

$11 \quad \beta$ De Baryaua ilicl. (Nt. dejectum De Rar. Conj.) [st. deject. $\beta$ Debaryanu in Norlst. 1893].

d $7 \tau$-Delponte Desmil. subalp. p.40 (sep.p. 136) t. 10 f. $26-393$.

a is - Tirchn. Alg. Nilles. 16!\%

d 84 - Wolle Desm. U. \&. P. 123 t. 40 f. $23-25$.

in 85 - Tioldt Sibir. Chloroph. p. 114.

o sf - Squimal). Catal. Desm. Genov. p. 11.

o sf; -. Stokte liey Desm. p. 164.

dzfit Coole Brit. Iosm. 1) 141 t. 49 f. 5 [fig. $e=\mathrm{e}$ lialfs 18ts?

m 87 - Alextuko Clilornsp. Khark. p. 256.

dzse - Ilaneg. Prodr. Algenfl. Böhm. p. 211.

dzso - Toni et Ler'i Fl. Alg. Venez. p, 43.

m 88 - Riabin. Chtoroph. onv. Kharkow p. 331.

inss-Iste. Jel. magyar. alg. p. 232.

m 88 - Nord.s. Fr. wat Alg. N. Zeal. p. 40.

dz 89 - Tomi syll. alg. p. 1140.

(1 89 - v. inflexum Racib. Now. Desm. p. 99 (sep.p. 27) t. 7 f.s.

a 90 - " coronulatom Gutw. Wahr. d. Prioritat p.71.

m 90 - Eichler Spis Desmid. Miedz. p.90.

$m$ ! $m$ - v. inflexmm ibiil

m 90 - Anderss. Sverig. Chlor. 1 n. 11.

m !1 - lleimerl Desn. alpin. p.604.

4 - $\mathrm{f}$. incurva ibid. et t $\overline{5}$ f. 19.

d $91-v$. maximum West Add. Freshw. Alg. W. Forksh. p. $24 \pi$.

ma - $\beta$ divergens Gutw. Flor. alg. Leopol. p.fí.

d - coronulatum ibil. p. 6 fi t. 3 f. 11.

$11 ! 2$ - v. divorgens West Fr w. Alg. W. Irel. p. 171.

d !2 - Wolle Desm. U. S. el. II p. 135 t. 51 f. $23-25$.

n 94 - Börg. F. alg. Ostgrönl. p. 27.

m95-f. incurva Eichler in Pamiet. Fizy. 13 p. 192

\section{ryumosperma}

d 93 CYLINDROCYSTIS Lagerh. apud Iittr.et Nordst. Alg. Exs. n:o 1150 .

\section{cyuthodes}

(i sh STAURASTRUM Josh. Burm. Desm. j. fit. t. 23 f. $22 \& 23$.

d 89 - Toni Syll. alg. p. 1160.

\section{rycludetum}

(1) 93 COSMARIUM Turner Alg. Ind. orient. p. it t. 8 f. 12.

ryclirume -

a 71 Cosmarium Lumd. Desm. Snec. p. 35 t. 3 f. 6.

d 72 - arcticum Vorlst. Desin. Spetsi) p. 31 t.6 f. 13.

d 7.5 - f. Reinsch Contrib. p. 89 t. 10 f. 10 [non liue sec. Nordst. in Hedwigia 1sif p. fi; ; efr C.pramorsum et C. Malinvernianum].

1176 - areticum Norelst. Desm. Ital. 1) 37.

s1 - Wills in Mirland Natural. 4 t.5 f.5.

a 83 - v. ampliatum .1 Lask. X. Zeal. Desin. Add. ]. 241 t. 21 f. 7 (mala) [C. subcyclicum Mask. Furth. Not. 1 1s89].

d ST-Cooke Brit. Desm. p.116 t. 40 f. 11 [e Lund. 1871 et Irills 1ss1].

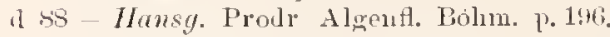

d - p subtruncatum ibid. [subsp. areticum sec. Nordst. il Alg. exs. 11:0 :17.1; 18597

6) 88 - a 1'eticum Boldt Desm. Grönl. 1"22.

m - f. minor ibid. p. 2:is.

d $-\beta$ subarcticum ibid., t. 1 f. 24. 
d 89 - Toni Syll. alg. p. 183.

d - v. subtruncatum ibid. p. !sil.

d - subsp. aretieum ibit.

d - v. subareticum ibir.

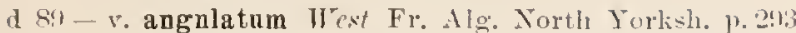
(sep.p. 5) t. 291 f. 2 [incl. v. truncatum Jiorye $18: 1$ et Cosm. Nordstedtianum licinsch sec. Wrest in Journ. Bot. 1805 p. (ii].

n II URSINELLA Runtze Rev. inn. pl, p. al.

m 92 Cosm. ช้, angulatnm Wrist Alg. Engl. Lake Pistr. 1). 729 t. 9 f. 1 ?

m 93 - Lïtkemilll. Desm. Attersees p. j5s.

of $\quad$ areticum Roy Scott. Desm. t. 2 f.?.

d $91-\beta$ truncatnm Tioryp silsw. Chlor. Archang. p. 21 [v. anguiatum West sec. West in Journ. Bot. $18,150.677$.

94 - Johns. Rare Desm. U. A. t. 211 f. J.

m 9.1 - areticum Biorg. F, alw. Ostorönl. p. 15.

$1 \%$ - v. maculatum Schmille in Helwig. 3.1 p. 76 t. 1 f.. .

m 95 - $a r c t$ f. minor Eichler in Pamict. Fizy. 13 p. 5!!. Cir Cosm. Turnerianum.

\section{CICLIDIUM}

1 93 Tumer Alg. Ind. orient. ?. 73. subgen. Cosmarii.

\section{CYCLOCYSTIS}

d 93 Tumer Alg. Ind, orient. p. 16. Subgen. Cylindrocy. stidis.

\section{CYLINDRIASTRU Y}

o 93 Tumer Alg. Ind. orient. p. 133, subgen. Stanrastri.

\section{Cylindrica}

d 5s Grum. Desm. p. 4!2. Trib. Desmidiacear. Gen.: Pen. Palmogloea, Dysphinet., Tessararthra, 'Tetm.. Hyaloth.. Spirotania et ommes Zygnonacure.

\section{ryliudricum}

d 41 COSMARIUM Ralfs Ann. Nat. IFist. v. 14 p. 392 t.11 f. 1 (et 1 st 15 in Trans. Bot. soc. Elin. v. 2 p. 118 t. 10). Pen. Ralfsii Küitz.l.

d t5-Huss. Brit. Alg. p. 345 t. 20 f. $t$ [e Ralfs 1. c. non exacte delincata?.

d 1S- hislfs Brit. Desm. p. $10 \mathrm{~g}$ t. 17 f. $t$.

I 52 Iritch. Inf. p. 255 .

d 61 -Arch. in Tritch. Inf. 1. 331 t. 3 f. 16-17. [e Rinlfs]. ph 65 - monstr. lieinsch M[orph. Fragm. p. 34 t. 2 f. 0.

o 67: DISPHINCTIUM Reinsch Algent. Frank. p. 181.

I bs Cosm. Rabl. Flor. Eur. Alg. 3 p. $17 \%$.

o St CALOCYLINDRUS a. typica Racil. Desm. okol. Krakowa p.?.

n - b. hexagona ibid. (Stanrastrum luexaonum Tiacil. 1645. Staur. Meriani f. Tiuc. 1868 sec. anct. ?

I 87 - Cooke Brit. Desm. p. 122 t. 13 f. 1-1 Te lialfs 1sts]. m RS - Riubin. Chloroph. env. Ki harkow p. 320 .

n 93 Dys. (Cylindrosphinetium) Turner Alg. Int. orient." p. 4 .t.

\section{rylindricume - 11.8}

d 27 DESMIDIUM Gree. Seot. Crypt. F]. v. is t. 293. [Didymoprium Grevillii Kittz.].

d $28-G r e v$ scot. erypt. Fl. r. 6 p. $3 \mathrm{~s}$

d $32-A g$. Consp. Diatom. p. 56 .

d 33 - Grer. in Hook. Br. Fl. II p. 4 res.

d 34-- Kïtz. Syn. Diat. p.61.t (sep.p. St)

d 35 - Erét. Alg. Falaise p. $25 \%$ (sep.13. 134) t. 2.

a 38 ARTHRODESMUS kirenl. Inf. p. 142 et 381.
(1) 10 Desm. Henegh. Synops. Desm. p. 201 (sep.p.4).

d $\$ 1$ - Horr. Man. Br. Alg. p. 196

(1) 11 Hyalotheca Firenb. in Berlin. Nonatsber. $1810 \mathrm{p}$. 212.

11 Desm. Desmazior. Pl. crvpt. Franec fasc. 23 n:0 1101 e. icon.; ed. 22 fase. 11 (1811) n:o 501 c. ieon.

(1 t:3 - liulf's Ann. Nat. Hist. v. 11 p. 373 t. 8 f. 1 (et $184 t$, Trans. Bot. Soc. Edinb. v. 2 p. $1 ;$ t. 2 f. 1). (Prima bona deseriptio].

d LODYMOPRIUM Rulfs Anm. Nat. Hist. v. 1ti p.10 t. 3 f. 1 (et 184 ; in Trans. Bot. Soe. Edlin. v. 2 p. 16.4 t. 1s)

d $45 \mathrm{Desm}$. Massull Brit. Alg. p. 312 t. 83 f. t. 2.

n T3- Didymoprium) Nordst. Norg. Desm. 1. t?.

(1) is - rivechn. Aler. Schles. p. 132

dzfst - Tolle Tesil. L. S. p. 25 t. 3 f. 1-1, t. 21 f. 25

m s - Litnri List. alg. Noseou 1. 138.

o sfi - Stokes liey Desm. D. 110.

dzf 86 - Coole Brit. Desm. p.! t. 1 f. 2 [e Je liury et liulfs, saltem $\mathrm{cx} p]$.

a 87 -Alexentio Chlorosp. Lhark. p. 217.

I ss - Hansg. Prolr. Algent. Böhm. p. 1 i2 f. 103 [e $t c$ liary conj.].

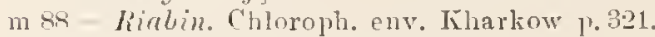

mse Nordst. in Gazell. Expedir. ps.

¿ 89 - Toni Syll. Alg. p. 783.

d 89 - 1. v. bidentula Kacib. Now. Desm. 1. Th.

l - 2. v. tridentula ibid., t. 7 f. 15.

m 90 - Jichler spis Desm. Miedz. p. St.

m M-Auderss. Sirerig. Chlor. 1 p.s.

in 12 - Thest Fr. w. Alg. W. Irel. p. 117.

dzf 4.2 - Wolle Desm. [. S. 1. 25 t. 3 f. 1-4.

m93 - Lütkemiill. Tesm. Attersros p. 53..

m93 Didymoprium Turner Alg. Ind, orient, 1. 15r.

m 9 Desm. Hexenko Mat. alg. Khark. P. 19.

dzys - ve elegans Tillcil. in Flora v. 81 p. 31 t. 1 f. 9.

m - f. media ibiu. p. 31 et 35 t. 4 f. 10.

\section{rylindricum}

(1) 93 DOCIDIUM Furner Alg. Ind, orient. p. 25 t. 2 f. 11.

\section{CILINIDROCISTIS}

o 35 . Tenegh. Cenni s. organ. p.32! et 310 (scp.p. ã et 2(i).

I 12 Menegh. Moungr. Nostuch. p. ss.

o 14 Jiél. in Ilict. univ. hist. nat. v. 1 p. 513.

d 4 H Hass. Brit. Alg. p. 361. Gonus Desmid.

d 58 7)e Hur. Conjug. p. 30, 3., Tt.

o (if flech. Descript. (sep.p. T) in Dubl. Nat. Hist. Soe. p. 18.

a 66 Arch. Obs. on Cylind. sep.p. 4 etce p. 205 ete.

il st Cray Monogr. loc. Conjug. p.34.

I S6 Cooke Brit. Desm. 1).4li.

d so Hansg. Prodr. Algenfl. Böhnn. p. 175.

o 88 Hauptyl. Zcllm. 11. Ifüllgall. Desm. p.125 (sep.p. 137).

a s9 Tome syll. Alg. 1. 815.

d 90 Wille in Natürl. Ptanzonfam. p. 9.

d 93 Bailey Contr. Qneensl. Fl. 1.39.

o 93 Tumer Alg. Ind. orient. p. 16. Subgen. Fyclocystis et Clitocystis.

ph to Lagerh. Phyeoporpti. ]. 4 .

\section{Cylindrorystis}

d 45 CLOSTERIUM Kïtž. Phyeol. germ. p. 132. [Cylindrocystis Brébissonii Mcnegli.].

\section{CYLIDROSPHIXC'ILI}

d 93 Twner Alg. Ind orient. p. 41 . subgenus Dysphinctii. 


\section{rylimdrosporren}

d 35 PALMELLA Breb. Alg. Fal. p. 15!’ (sep.p. 151). (Cylindrocystis Brebissonii. Ifenegh. 1838 see. Jenegh. 184?].

\section{Cylindrus}

d SSCLOSTERIUM? (Toxotium) Ehrenb: Huf. p. (5) t. is f. VI.

d 10-Menegh. Syuops. Desul. p. 236 (sep.p. 3i).

o 44 - Ralfs Aun. Nat. IIst. v. 1.1 p. 31 (et 1846 in Trans. Bot. Soc. Edis. 1. 1ti).

d 15-Kïtz. Phyenl, germ. p. 13!.

1 18 PENIUM Bréb, in Ralfs Brit. Desm. 13. 150 t. 25 f. 2.

d 19 -. Kiutz. Spece Alg. 17. 167.

o 19 D YSPHINCTIUM (Calneylindıus) Nóog. cinz. Alg. p. 111.

d 522 Pen. Pritch. Inf. p. 270.

oph ist - trech. Abnorm. Desm. sep.p. 17, in Nato Hist. Rev. 1. 17.

d hi - Arch. in Priteh. Inf. p. 3 .

o lis - Brib. in Rab. alg. n:o 1:351.

d $63-v$. annulatum Hentzsch in Rals. Alg. Eur. 11:0 1511 [Pen. conspersum? see Nordst. 1s:3].

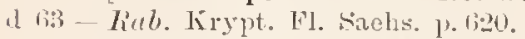

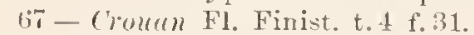

d bi CYLINDROCYSTIS limech Algent. Frank. p. 19k. Forma A.

1) - f. B. annulatum ibir.

o tiт Pen. Not. Desm. Ital. 1. To t. s f. si.

o 68 - Nordst. Bidr. Sverig. Desin. p. 14.

d $68-$ Rat. Flor. Eur. Alg. p. 12?.

oz 71 - Lund. Desm. Snec. p. 85.

o 73 Nurdst. Norg. Desm. p. 11.

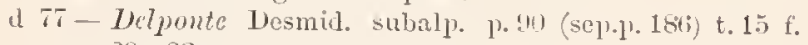
$29-33$.

dz Ts CALOCYLINDRUS Firch. Alg. Sehles. pro 112.

d - a. genuinus ibitl. p. 143.

d b. silesiacus ibid. $1,113[=a !]$.

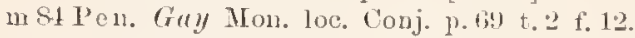

desi - Couke Brit. Desm. p. 39 t. 17 f. 2 [e Ralfs].

dz 88 Dys. Hansy. Prodr. Algenfl. Böhm. p. 186.

d $-\beta$ silesiacus ibid.

pla 88 Pon. Huuptf. Zellm. u. Hüllgallerte Desm. 13. 1109 (sep.p. 42) t. 3 f. $49,5 \pi$.

m 88 - Isto. Jel. magyar. alg. p. 211.

m 88 - Norelst. Fr. wat. Alg. N. Zeal. p, 71.

dz S'? Dis. Toni Syll. alg. p. S48.

d - v. silesiaeum ibil.

d 89 Pen. $\beta$ attenuatnm Racil. Now, Desm. p. 7 t. 7 f. 21. m (10 - Eichler Spis Desm. Miedz. 1. 85.

m 11 Lys. f. minor Heimerl Desm alp. 1. o.4.

ma1 Pen. b. attenuatum Gutu. Flor. algo. L.copol. 1.31.

un 92 - Borge Chloroph. Norsk. Finmark. p. 15.

oz: 12 - v. silesiaeum Rac. Desmilya Ciastoni. 1. 35t.

m 92 Dis. Mlob. Anstral. Süsswasscralg. p.412.

dz 93-Builey Contr. Quecnsl. Fl. p. 41 t. 13 f. 37 (e Coolie).

1n!3 l'en. v. silesiaeum Lülkcmull. Desm. Attersees p. 544.

o 93 - v. silesiacum schmidle Beitr. Alg. Schwarzwald. 1.. 87 t. 3 f. 6.

m 95 - v. Silesiacum dohns. Rare Nesm. U. S. II p. 291 t. 2:3!! f. . 2 .

$0.95-\mathrm{v}$, silesiaeum f. Schmidle Beitr. alp. Alg. p. 310 t. 14 f. 2 !?

d - v. subtruncatum ibit., t. 14 f. $2 i-2 \mathrm{r}$ (f. minor Heim. 1s:1?).

o - - f. colorata ibid,

\section{rymatimm}

d 93 EUASTRUM Tumer Alg. Ind. oriont. p. 80 t. 10 f. 19. (E. rostratum $\beta$ Wrall. verisimile).

\section{("ymatonotophorulm,}

d 2 COSMARIUM West Alg. Engl, Lake Distr. p. Teli t. 9 f. 23.

\section{c!)matopleunum -re}

d T2 COSMARIUM Lordst. Desm. spetsb. p. 24 t. 6 f. $\mathrm{f}$.

m 75 - Nordst. Desm. aret. 1) 18.

d 7i-p tyrolicum Tordst. Wesin. Ital. p. 30 t. 12 f. 5.

m 83 Lageth. Bidr. Sverigr. algfl. p. 万̃.

o s3 to Areh. in Ann. Mag. Nat. Hist. 5 ser. 11:0 $61 \mathrm{p}$. 281 et 285 .

d si-Cooke l3rit. Dosm. p. 188 t. 66 f. 3 (e Nurdst.).

d 89 - Toni syll, alg. p.9\%o.

d v. tyrolicum ibid. 1. sio.

d st f. polonica liecill. Now. Desm. 1, st t.j f. 31 .

n 91 URSINELLA Kuntze Rev. gen. pl. p. 4’at.

d ge Cosm. v. incrassata liorge Chloroph. Norsk Finmark. 1. 12 t. 1 f. 9.

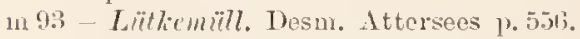

(fi): Dys. "an speciosum" Schmille in Hedwigia $18: 41$ [1. 45 t. $6 \mathrm{fot}$.

\section{CIMIBELLA}

(1) 30 Ag. Conspect, erit, Diat, 1. 1. Gen. Cymbellear. (Diatom.).

d 11 Hare. Man. Brit. Alg. 1. 16 et 215 .

\section{Cymthia}

d ii ClosteriUm Not. Desm. Ital. 10.65 t. 7 f. 71.

o 6 is - Areh. in (2. J. M. Se. 8 p. 11 s.

z $71-L$ zur. Desm. Suce. p. 78 .

o 75 -Jucobs. Desm. Danem. 1). 17 ti t. 7 f. 7.

4t $\$ 6$ - Couke Brit. Desm. p. 24 t. 13 f. ․․

m 88 - lste. Jel. magyas. alg. p. 238.

o st - Nurdst. F'. wat. alg. N. Zeal. 1. 6i!) (Cl. ruficeps Fitrent.).

11 -- $\mathrm{f}$. angustior itoid.

o 89 - f. MHask. Furtl. Not. N. Z. Desm. p. 29 t. 6 f. 57.

d 89 - Toni syll. alg. p. 841.

o - $\mathrm{f}$. a 11 gustius ibid. p. 812.

m90-West Fr. w. Alg. Aurth Wales p. 285.

m91 - f. angustior Heimert Desin. alpin. p. 593.

n!1 ARTHRODIA Kuntze Rev. gen. pl. p. S83.

m ! Clost. West Fr. W. Alg. W. Irel. p. 123.

o 92-Ruc. Ilesmidya Ciastoni p. 370 t. 6 f. 36.

in 93 - Jültkemïll. Desm. Attersces 1.513.

in 93 - Turner $A \lg _{\mathrm{g}}$. Ind. orient. 11. 22.

1185 -Jokns. Rare Desm. U. S. II p. 291 t. 239 f. 3.

m 95 - Vichler in Pamiet. Fizy. 13 p. 58 t. 1 f. 5.

m 95 - Schmidle Alg. Sumatr. 1. 294.

d 95 - v. subtilis Schröler Alg. II. Riesengeb. 1) 15. Cfr. Clost. Archerianum et ruficeps.

\section{CYPTASTRUM}

o 93 Tumer Alg. Ind. orient. p. 132. Subgenus Staurastri.

\section{cyrtocerume}

dz 15 STAURASTRUm lbik. apud Relfs Brit. Desm. p. 139 t. 22 f. 10.

d 49 PHYCASTRUM Kiit:. Spee. Alg. p. 180.

d 52 St a ur. Priteh. luf. p. 266.

d ti1-Areh. in I'ritel. Inf. p. T.t2.

d $63-R a b$. Líypt. Fl. Sachs. p. 181, 
m 70 - ? Norlst. Desm. Brasil. 1.228.

1n 72 - Mitlr. Gotl. Öl. Desm. 1). 51 .

In tis-Hempel Algenfl. Cluemnit: 1. 111.

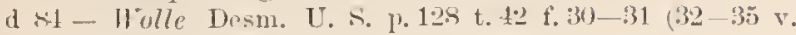
pentacladum).

m - $\mathrm{v}$ major ibil. 1. 129 t. 13 f. 1-2.

o so-Siolies licy Desm. 1) 165.

d\%st - Couke Brit. Desm. 1. 168 t. 25 f. 3 [ex parte e Iiulfs].

n st - Tordst. Borml. Desm. 1. 20ti.

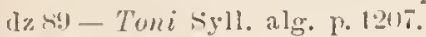

:10 - West Fr. w. alg. Nortl Wales t. 5 f. 16 (f. tetragona).

ma - Brirg. Desm. Brasil. p. 4h.

111 92 - kine. Desmidya Ciastoni. p. 381.

d s.2 - Holle Desm. U. s. eil. Il p 112 t. 53 f. 30 - 35 .

$n$-. vajor ibid., t. 5 [ f. 1-2.

m1-Borge süssw. Chlor. Archang. p. 38.

Cfr Didymidium polymorphum f. trigona livinseh 1 Set

\section{Cystula}

d-GYGES Eichwald in Beitrag z. Infusorienkunde Kusslands (in Bull. Soc. Nat. MLscou v. 17, 20, 2.2 1. 25) sec. Sitein Organ. d. Infus. III, 1 [n. v.].

\section{aluirull}

d 8. COSMARIUM IBarg. Bidr. Bornh. Desm. p. 1 to t. if f. 6. m 94-liorge siussn. Chlor. Archang. p. 26. Cfr. Cosm. substriatum.

\section{I) IIIlsollii}

d M COSMARIUM lioy et Biss. in Roy Scottish Desm. p. $-15(\operatorname{sep} . p .33)$ t. 1 f. 8 .

\section{Drbaryi}

d 61 COSHARIUM Areh, in Pritch. Inf. p. 735 (Plenrot. cosmarioides De Bar.). "De Baryi".

- 71 - (P'leurotaniopsis) Lund. Desm. Suec. 1. 52.

o 5 - f. spetsbergensis Tordst. Desm, arct. p. 29 t. 7 f. 27 [y spetsb. Jlansy. 1882].

d $78-K i v c h$. Alg. Sehles. p. 116.

d $79-\beta$ Novæ Semliæ Wille Ferskv. alg. Nov. Semlj. p. 45 t. 13 f. 47 (f. minor)

- - f. major ibil. 1) 18 et 73 t. 13 f. 48.

d 59 - a. typicum Klebs Desm. Ostpreuss. p. 2s; $и$.

- a. $\beta$ ibid.; t. 3 f. + b.

- b. inflatum ibid.

- $a$ ibid. (ofr Lomd. 1571). $\beta$ ibid. t. 3 f. 1 a.

d - c.turgidnm ibid. C. turgidnu liréb.).

o 80 - f. llille Norg. Fr.rsv. alg. I p. 3R.

d 84 - Wolle Desm. L. S. p. js t. 15 f.5 ["more like a form of C. Cueumis" sec, auct. 1857?.

o ri-Sitoles Key I lesm. p. 1245.

o sĩ CALOCYLINDRUS Wulle Fr. Alg. U. s. A. p. $2 \bar{t}$ t. f. 12.

d $s i$ - Cuolir Brit. Dosm. 1) 128 t. 11 f. $t$.

d šcosmaridiUM Hansy. Prodr. Alurnfl. Bölım. p. 246.

m $-\beta$ minns ilid.

111 - - s spetsbergense ibid. it. Nordst. 1575).

o s8Cosm. Mott in Norlst. Bornh. Desm. p. 202.

d s. PLEUROT ENIOPSIS Toni syll. alg. p. 106.

n. - - ninor ibid. p. 307.

in $-v$. spetsbergcnsis ibid.

d-v. Nova-Semlia ibil.

o (i) Cosur. liorg. Dism. Brasil. 13. 12 t. 1 f. B?.

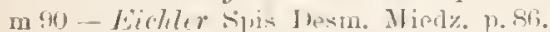

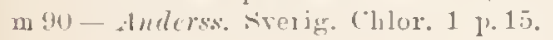

diordseted Index leesuid.
1191 Cosmarilium Iteimerl Desm. alp. p. 505.

m !2- $-\beta$ minus Mrensy. Prodr. Algenfl. Böhun. II Г. 252. m - $y$ spetsbergense ibirl.

o !2 Cal. Wolle lesm. U. S. ed. 11 p. 58 t. 15 f. 12. et t. is f. 5 [efr supra 1881, quoque sub Cosmario].

pla !:3 Pleurotun iopsis Lälkemüll. Chlorophyllsörp. ein. Desus. 1). 47 t. 3 f. 25.

m 93 - Lïllicmüll. Wesm. Attersees p. 5.19.

m !) Cosm. Pinflatum Barge sibissw. Chlor. A rchang. 1. 22. o 91-Jïrg. F. alk. Ostgrönl. 1.21.

Cfr. Cosm. Thwaitesii $\beta$ majns Witlr. 186\%.

Jebur!/i ["De Baryi"]

m 51 DYSPHINCTIUM Heimerl Desm. alpin. p. 593 (C. Palangula b. De Baryi liab. 1868).

\section{acear!lonllull -}

(1) 8i COSMARIUM lioy \& Jiss. Japan. Desm. p.19t (sep. 1. 4 t. 265 f. 15 . [C. taxichondrum $y$ decach. liae. 1859 .

d 89 - Toni syll. alg. p. 999.

n 91 URSINELLA liuntze Rev. gen. pl. p.924.

\section{derealens:}

n 83 EUASTRUM Roy in Sicott. Naturalist Jul. 1898 p. 38. (Cosin. plicatnm? C. decedens Reinsch 1865).

- sy CosmariuM a. sinuosum Racib. Now. Desm. 1. 8.9 (sep.p. 8) (C. sinuosum Lund.;.

d - b. carpaticum ibid, et t. 5 f. 1.

d - c. boreale ibil. (Nordst. 1875, non Tieinsch).

m 45 - b. carpaticum Eichler in Pamiet. Fizy. 13 p. 28. Cfr. Cosm. pyramidatum Not. 1867 ex p.

\section{decenderlutull $-\boldsymbol{a}$}

d 19 EUASTRUM (Iicrasterias) Neg. einz. Alg. p. 123 t. 6 II f. 2.

d 61 MICRASTERIAS Areh. in Pritch. Inf. p. 729.

o 6t-? f. Cleve Bidr. t. Srerg. Desm. p. $18 \mathrm{~s}$ t. $t$ f. 2 [sec. Lund. Desin. fsinec. p. $16=\mathrm{M}$. truocata var.).

m67 DIDYMIDIUM (Micrasterias) Reinseh Algenfl. Frank. p. 112.

d 69 Micr. Kiel. Flor, Eur, Alg. 3 p. 190.

- - forma ibid. MI. Itzigsohnii Br(eun).

d $71-\beta$ Upsaliensis Cleve apud Lund. Desm. Suec. p. 16 t. 1 f. 7 [M. Upsaliensis Arch. 1881].

d 73 - Jelyonte.Desm."subalp. p.91 (sep.1). 79) t. 5 f. 11 - 16.

d 81 - Wolle Desm. U. s. p. 113 t. 33 f. 5-6 [v. crassior Hunsy. 18:2].

o. .66 - Stulies Kiey Desm. p. 146.

d 88 -Hunsg. Prodr. Algenfl. Bölım. p. 909.

m 8s - Potentsionth Carolina Desm. p.t.

m si - Joni syll. alg. p. 1116.

d - v. angusta ibid. p. 1117 (M. Itzigsohnii 155̆

d - - o upsaliensis ibid.

o 89-Rucil. Now. Desm. p. 105 sep.p. 83).

m 90 - Eichler Fpis Desm. Mierlz. p. 89 t. 9 f. 35.

in $\$ 1$ - Heimerl Desm. alpin. p. $10: 2$.

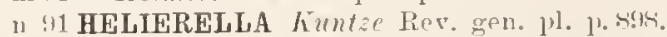

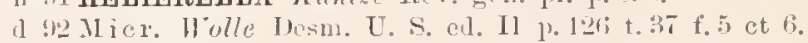

n!2-r. erassior Hensy. Proilr. Algenfl. Bühm. II p.

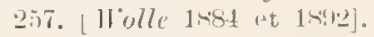

o 9.1- Hob. Austral. Siisswasacraler. II p. 341

Cfr. Holocystis incisa Mask. 1.851 et Micr. trnncats.

\section{areijlems}

a s.i STaURAstrum liacil. Tonn. Desm. Polon. 1's! t.

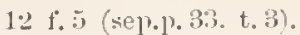

d si-Toni syll. alg. 1.1201. 


\section{reclive}

n 8f EUASTRUM Roy in Flora Lcicestersh. p. 35 (Eu. elegaus f. declivis leinsch 1867).

d - $\beta$ ornatum Twner Alg. Jur. oricnt. P. 83.

\section{(ecormm-a}

d 50 CLOSTERIUM Bréb. Liste \}. 151 t. 2 f. 39.

d 61 - Areh. in Pritch. Inf. p. 719.

d 93 - Rub. Kirypt. Fl. Sachs. p. 174.

d hs-liab. Flor. Eur. Alg. 3 p. $13 \pi$.

d $7 \bar{t}$-Delponte Desmid. subalp. p. 107 (sep.p. 203) t. $18 \mathrm{f}$ $1-2$.

dz $78-$ hirchn. Alg. Schles. p. 139.

d s.1 - Tolle Desm. U. S. p. 13 t. 7 f. 1.

o s6-Stokes Key Desm. p. 112.

dz 86 - Hunsg. Prodr. Algenfl. Böhn. p. 181.

o 8 - Turrat. Fr. wat. alg. N. Zcal. p. lit.

o 8. - f. gracilior Mask. Furth. Note X. Z. Desm. P. 30 t. 6 f. 5 .

dz 89 - Ton syll. Alg. p. 833 .

m 90 - Eichler Spis Desin. Miedz. p. $8 \%$.

n 91 ARTHR0DIA Kuntze Rev. gen. pl. p. 883.

d re Clost. Wolle Desm. U. s. ed. II p. $45 \mathrm{t} .8 \mathrm{f} .1$. Cfr. Clost. lineatum $\beta$ sandwicense.

\section{clecorritum}

d 95 COSMARIUM Thest Alg. Madag. p. 61 t. 7 f. 21.

\section{aeromm - a}

d 81 EUASTRUM (Cosmarium) Gay Mon. loc. Conj. p. 62 t. 2 f. 3; et Not. Conj. d. m. France p. 337. [Cosm. caelatum Ralfs].

d 89 COSMARIUM Tomi Syll, alg. p. 968.

n 91 URSINELLA Kuntze Rev. gen. p]. p. 924.

\section{acrussatum}

d 45 CLOSTERIUM Kïtz. Phyc. germ. ]. 131. [Clost. didymotocnm $\beta$ Liab. 186s].

d 48 -- Ralfs Brit. Desm. p. 220

d 49 - Kï̈tz. Spec. Alg. p. 165.

d 52 - Pritch. Inf. p.2st.

o 83 - Wo7le in Bull. Torr. bot. Club. v. 10 p. 15.

d 81 - Wolle Desm. U. S. p. 39 t. 15 f. 9-10 [Quid? Pe. ninm ?].

o 86 - Stokes Key Desm. p. 111

d 92 - Wolle Desm. U. S. ed. II P. 41 t. 7 f. $9-10$.

de Greyi - efr. Greyi.

\section{dejertum -r}

n 35 BINATELLA Bré7. Alg. Falaise p 269.

d 40 STAURASTRUM Brib. in Menegh. Synops. Desm. p. 227 (sep $) .27$ ).

dzf 18 - liulfs Brit. Desm. p.121 t. 20) f.5 a-m; $a=a$, $\beta$ et, (St. mucrouatum) $=$ fig. b-m [Fig.a-k et $m$ c lialfs in Ann. Nat. Hist. melius rlelineata]; $h-m$ zygosporte. $[a=a$ lunatum cooke 18si; $\beta=\beta$ directum Cooke].

dz 52 - Pritch. Inf. p.262= iden.

o $56-B r i b$. List. 1. 112 [sensu strictiore].

ph 57 - Hofmeist. Fortpllanz. p. 31 .

phaf $58-1$ the Bar. Conjug. p. $41, \pm 8,50$ t. 6 f. $25-32[\beta$ De Baryana Jucobs. 1876 .

o 59 - (monstr.) Areh. Abnorm. IJesm. in Dnbl. Nat. Hist. Soc. 2 p. 208 t. 1 f. 10, in Nat. Hist. Rev. v. 6 p. 470 t. 33 , in J. Nier. Sc. 8 p. 6.

dz $61-A r c h$. in Pritch. Inf. p. $737 ; a-g$.

d 63 - Rul. Jirypt. Fl. Sachs. P. 159 . d 60 - Eyrich Algenfl. Mannb. p. 129.

d 6 i DIDYMIDIUM (Stau1.) f. A. ellipticum Reinsch Algenf. Frank. p. 15r. (Arthrodesmus Incus.).

d - f. Is trigonum ibid.

67 Staur. Not. Desm. Ital. t. 5 f. 51 [efr. $\beta$ patens Nordst. $18 \mathrm{ir}$.

d $-\beta$ attennatum ibid. 1.55 t. 5 f. 51 bis.

dzes-Rab. Flor. Eur. Alg. 3 p. 203. a (St. mucrou. Rialfs).

d - b. ibil. (J) Not. 1867 fig. 51 a sinistr.; St. a piculatum].

d - c. ibid. (Phye. cuspidatum, bilunulatun fï̈tz.)

m $71-\beta$ spienlatum Lund. Desm. Suee. 1. 59 (St. ap. Biveb.).

d $\gamma$ connatum ibid. p. 60 t. 3 f. 2 s. [Stanr. connat.] m72 - Witir. Gotl. Ol. sötv. Alg. 1. 54 ; ct $\beta$ apiculatum

d 73 - Hood Fr. Alg. p. 118 t. 21 f. 1 s t. 13 f. !.

d 75 - Nierogr. Diet. p. 7.5 t. 10) f. 26 [e Rulfs fig. 5 a].

d 75 -f. Reinsch Contrib. p. 90 t. 13 f. 7 [st. mucrona$\mathrm{t} \mathrm{u} \mathrm{m}$.

n $66-a$ Jreols. Desm. Danem. p. 203 t. 8 f. 23 (St. dej. auct.; St. apiculatum Brél.); et f. intermedia ad v. comnatum.

o - $\beta$ Dickiei ibil p. 204 . (St, Dickici lialfs).

dz 78 - a. typicnm Kirchn. Alg. Sehles. p. 16 s.

d - b. macronatom ibirl. p. 169

d - c. sudeticnm ibia. p. 169.

d - d. depressum ibid. p. 169.

n 80 - a. genuinnm Kirchu. Beiträg. Algcnf. Würtcmb. p. 177.

o 80 - y' con1natum Wi77e Norg. Ferskv. alg. I p. 41.

83 - $\beta$ Debaryanum Nor lst. in Wittr. ct Norlst. Alg. exs. n:o 557 (St. cuspilatum $\beta$ De Baryanum Jacobs. 1stii) [st. mu uronat $\beta$ Debar. Tum. 1893].

n 83 - f. divergens Schuarschm. Magyar. Desm. p. 272 (Irood 1873 t. 13 f. .9).

83 - y connatum Thruer Algre Strensall f. 19 b.

m 84 - c.sudeticum Raeil. Desm. okol. Jirakowa sep.p. 16. dzf 81 - Wolle Desm. U. S. p. 121 t. 40 f. 7-11, 17-22 $[18-19=$ st. connatum].

- v. mucronatum ibid. f. 8 .

o - v. convergens Wolle ibid. p. 121, f. 7. 9-11.

mst - Arturi Liste alg. Moscon p. 111.

d 85 - Kirchn. Mikr. Pflmz. d. Sissw. p. 23.

in 5 is - Butdt Sibir. Chloroph. 1) 113.

m85- P Debaryanum Nordst. Grönl. Desm. p. 10.

m 85-v. Sudeticum Tumer New rare Desm. p. 939 t. 15 f. 23.

n 80 - Layerh. Amerik. Desm. 1.24i.

o si-Stokes Jiey Desm. p. 164.

o - (v.) sudeticum ibul. p. 165.

wh 86 - K7ebs Organisat. Gallerte b. Algen p. 393 t. 4 f. 16 .

daf 87 - Cooke Brit. Desm. p. 138 t. 49 f. 1 ( $u$ et $l=a$, ceteres $=\beta$, e Ralfs].

- a lunatum ibid. p. 13!) [a Rulfs 18ts].

- $\beta$ directum ibid. $[\beta$ Rialfs 18is].

- y un cronatum ibid., t. 5. f. T.

o 87 - $\beta$ patens Nordst. Algolog. småsak. 4 p. 15.

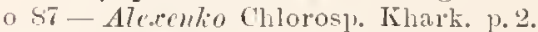

dz SS - Hansı. Prodr. Algenfl. Böhni. p. 211.

d $\quad-\beta$ mucronatum ibid.

- $y$ sudeticum ibid.

- $\delta$ lepressum ibid.

$-\varepsilon$ Debaryanum ibil.

y a piculatum ibid. et p. 255.

- 5 conver gens ibid. p. 255.

- connatum ibid. p. 255.

m88 - Riabin. Chloroph. env. K'harkow p. 329. 
d $-\beta$ patens Norlst. Fr, wat. alg. Y. Zenl, p. 39 t. 4 f. 16 .

ms?-r. mucronatum Harr. Fr. Alg. Maine II p. 1s.

d 89 - Toni Syll. alg. p. 113\%.

d - r. mucronatum ibiul.

- v. sudeticum ibid. p.1135.

v. depressum ibid.

- r. De-Baryanum ibid.

- v. convergens ibid.

- r. patens ibid.

nu (n) - v.typicum Fichler spis Desm. Miedz. p. 10 t.9 f. 12.

ni - v. mucronatum ibid., f. 11.

m - r. patens ibid.

$\mathrm{m}$ !n - Anderss. Siverig. Chlor. 1 p. 11

d :1 - Kirehn. Mikr. Pflanz. d. Süssw. ed. 2 p, 21.

m 91 - Heimerl Desin. alpin. p. 605.

o 91 - f. punctata West Add. Freshw. Alg. W. Iorksh. 1. $24 \overline{6}$.

m 91 - Borge Bidr. Sibir. Chloroph. p.?.

no $-\beta$ sudeticum Borge Chloroph. Norsk Finmark. p. $\mathbf{~}$.

d (1.2-v. inflatum West Fr.w. Alg. W. Trel. p. 170 t. 22 f. 11.

- 12-Hü. Austral. Süsswasseralg. p. 415 .

dzf 12-Wolle Desm. U. \&. ed. 2 p. 134 t.51 f. $7-11,17$ $-22$.

- v. mucronatum f. $S$.

o - - v. convergens f. $7,9-11$.

dzf 93 - Bailey Contr. Queensl. Fl. p. 90 t. 16 f. 4 .

m!3 - Lillkemïll. Desm. Attersees p.563.

- 93 - f. Selmidle Beitr. alg. Schwarzwald. p. 107 t. 5 f. 26 et 27.

n $93-$ - Acanthastrum) Tumer Alg. Ind. orient. P. 133.

ozf $-\beta$ apiculatum f. indica ibid. p. 100 t. $19 \mathrm{f} .14, \mathrm{t}$. 20 f. 14.

- - $y$ connatum ibid.

d 94 - Tellami West New Brit. Alg. p. 10 t. 2 f. 45 .

m 94 - B̈̈rg. F. alo. Ostgrönl. 1. 26.

m 95 - $\beta$ converous Eichler in Pamiet. Fizy. p. 62.

o 46 - tf. Schmidle Beitr. alp. Alg. p. 21 t. 16 f. 30 et 31 . Cfr. Dilymid. erectum heinsch, Staur. glabrum, inflexum et laniatum.

\section{areliratissima}

d 82 BAMBUSINA Wolle in Bull. Torr. bot. Chub 188? P. 27 .

d St - Wollc Desm. U. S. P. 2i t. 1 f. 22-2t.

m.it-Lagerh. Anerik. Desm. p. 228.

o s6-stukes Kiey Desm. p. 110.

n st GYMN0ZYGA Tordst. in Wittr. et Yordst. 11:o suB.

z 88 - Layer\%. in Notarisia III p. 59.1.

$\mathrm{dz} \times 9$ - Toni Syll. Alg. p. Tos.

d :2, Bamb. Wolle Desm. U. S. ed. II p. 2:5 t. 1 f. 22.2-24.

\section{drelifutulum -}

d 52 EUASTRUM I'my kleinst. Lebensf. p. 208 t. 16 f. 9.

d 6s COSMARIUM Rub. Flor. Eur. Alg. 3 p. 179.

1 89 - Toni Syll. alg. 1) 105.5.

1) 91 URSINELLA hiuntze Rer. gen. pl. p.924.

\section{relicretulum}

d si PENIUM Josh. Burm. Desm. p. 653 t. 25 f. y \& 10.

d $8.4-$ Toni syll, alg. p. 857 .

o 15 - v. minor Thest Alg. Madag. p. 17 t. 5 f. 36.

\section{arlitiense}

- 37 XANTHIDIUM Ehrent. in Bericht d. Vers, deut. Naturf. in Jena $1431 ;$ p. $71 ;$ [X. ramosum Elrent. Inf. p. 11s!.

\section{Drlpoutii}

11 só CLOSTERIUM Irolle in Bull. Torr. Bot. Clıb. v. 12 p. 2 Cl. Ralfsii a. Delpontii Klels 1879; Cl. crassum Delp., non Rilb.).

d 87 - Wolle Fr. Alg. U. S. A. p. 25 t. 55 f. 9.

a s!) - Tomi syll. Alg. p. 832 .

n 91 ARTHR0DIA Kuntze Rev. gen. pl. p. 883.

o 5 Clost. f. Rac. Desmidya Ciastoni. p. 369 t. $f$ f. 12.

(I !) - Wrolle Desm. U. S. e.I. II p. 45 t. $6 \mathrm{f}$ f.9.

o 92 - f. West in Notaris. 7 p. 1500.

o :1-f. glabra Gutw. Fl. alg. Tarnapol. p. 79 t. 2 f. 9 a', t. 3 f. ؛ . [Cl. Dianæ Rub. Bac. Sachs. t. 1 f. 2S?].

- 95-Schmidle Alg. Sumatr. p.298. Cfr. Clost. decorum 1s8\%.

\section{Jelpontei}

n si EUASTRUM Lagerh. Algol. Birlr. p. 46 (Eu. intermedium Delp. 18i3, non Clere 1864).

a 8s-Toni syll. alg. p.10:1.

d - v. Ralfsii ibid. (E. in term. $\beta$ Ralfsii Lelp. 1873). 1191 HELIERELLA Kuntze Rer. gen. pl. p. 898.

\section{deltoides}

o 31 COSMARIUM Corda in Alm. d. Carlsb. 183.5 p. 17s, 180, 1\%. 205 t. 2 f. 18. 19. Nulla diagnosis, sed varie observationes anatomice, physiologice etc. Euastr. margaritacenm sec. Whenb. in Wiegm. Arel. 1836 p. 185; Cos. Botrytis sec. Ralfs].

o 39 STREPHOCYSTIS Corda in Alm. d. Carlsb. 1839 p. $212=$ Idem.

\section{deltoirlentm -}

d 7 COSMARIUM Delponte Desmid. subalp. p. 21 (sepp. 117) t. 8 f. $28-30$.

d 89 - ? Toni Syll. alg. p. 996.

n 91 ? URSINELLA ("deltodea") Kuntzc Rev. gen. pl. p. 921.

\section{teltoiderm,}

d 10 XANTHIDIUM Corda in Alm. d. Carlsb. 1810 p. 214 (sep.p.2!) t.5 f.3s et 39. [Staurastrum muricatum sec. Ralfs. Staur. echinatum? sec. Hansg. 1898. staur. saxonicum Buluh.?].

\section{De Notarisii}

- 76 cosmariUM (Pleurotruiopsis?) Nordst. Desm. Ital. p.30. (C. tetrophth. "De Notarisii Wittr.).

A Tomi 1889 in "Notarisii" trausmutatun.

\section{rentutum-re}

d 7 cosmarium Wolle in Bull. Torr. bot. Club v. 6 p. 122 .

o 81 - Wolle ibid. v. 8 t. 6 f. 9.

d 81 - Wolle Desm. U. S. p. 76 t. 13 f. 15.

- S6-Stokes liey Desm. p. 128.

d $8: 1$ - Toni syll. alg. p. 10:30.

n 11 URSINELLA Kuntze Rev. gen. pl. p.

d 92 Cosm. Holle Desm. U. S. ed. II p. 83 t. 16 f. 15.

\section{dentirulate-ume}

d 35 MiCRASTERIAS Bréb, et God. Alyg. Falaise p.j1 t. s (Echinella rotata Gre'. sec. anct. ipsum in addend. 1. 269).

o 37 -Desmaz. Descr. esp. nouv. p. 211 t. 7 f. 4 [Fig. pessima! Fortasse non Micr, dentic. auctor. recent.].

dzf 18 - Relfs Brit. Desm. p, 70 t. 7 f. 1.

o 4i-Landsbor. Brit. Sea-TVeeds p. 317 t. 20 f. 80 [e Ralfs 1. c.]. 
o 51 - Bail. Micr. Obs, p. 47 t. 1 f. 20 [ $\beta$ Arch. 1861; M. triangularis Wolle 1881 ?].

dz 52-Pritch. Inf. p. 244 t. 2 f. $121-123$ [Eu. Rota ex Elrenl. Inf. delineata; f. $121-2=$ I. rotata; f. 123 = fimbriata], t. 13 f. 2 [fig. Ralfsii 1 e deminuata].

57 - Berliel. Introd. Crypt. Bot. 1. 120 f. 30 [e Ralfs].

o 5.5 - Tréb. in Rab. Alg. n:0 666.

pl 58 - De Bar. Conjug. p. 41.

o 60 - Wallich Desm. Low. Bengal. p. 280 (inclus. Mr. rotata).

pli 61 - Lolb Self-division P. 1-2 t. 1 f. $1-7$ [MT. rotata sec. Arch. 1862].

dzf 61 - Areh. in Priteh. Inf. p. 727 t. 2 f. 22 [e Tialfs].

d - $\beta$ ibid. (spec. Bail:i 1 $\$ 51$ ).

d 132 - Arch. New Micrast. (scp.p. 6); in Dubl. Nat. Hist. soc. Proc, p. 71 t. 2 f.6-8; Joum. M. S. p. 211 t. 12.

d 63 - Rab. Krypt. Fl. Sachs. p. 182 [et fig. a p. 157?] .

67- Crouan Fl. Finist. t. 4 f. 39 [e Breb.?; M. rotata]. z 67 - Areh. in Q. J. M. Se. v. 7 p. 296.

d 67 DIDYMIDIUM (Micr.) a. denticulatum Reinsch MIgenfl. Frauk. p. 147 .

I - b. crenulatum ibid.

o 67 Micr. Not. Desm. Ital. p. 31 t. 1 f. 7.

z lis-Areh. in Q. J. M. Se. 8 p. 294.

68-liab. Flor. Eur. Alg. 3 fig. xy1. p. 10 [e Ralfs 1844 ?].

z 70 - Lund. Desin. Suec. p. 12.

o 73 - Nordst. Norg. Desm. p. 5 .

1) 73 -? Wood Fr. Alg. p. 145 t. 13 f.6 [M. angulosa?].

dzf 65 -Microgr. Dict. p. 491 t. 10 f. 11 et 12 [e Riulfs].

o 75 -Jacobs. Desm. Danem. p. 186 t. 7 f. 11 (ff. 1 - ij pag. 187); t. 8 f. 1.

- - f. Thomasiana ibid. p. 187 (M. Thomasiana Arch. $1862)$.

dz $78-K i r c h n$. Alg. Schles. p. 162.

m 78- Hempel Algenfl. Chemnitz. p. 113.

d $80-\beta$ intermedia Nordst. in Wittr. et Nordst. Alg. exs. 1n:o 370; et (1889) in fase. 21 p. 35.

11 - * quadridentata ibid. n:o BT1.

o 81 - Mask. N. Zeal. Desm. p. 31:3 [Cfr. Arch. in Grevillea $10 \mathrm{p.} 29]$.

m 84 - Artrri Liste alg. Moscou p. 143.

o 84 - Fray Monogr. loc. Conjug. p. 52 t. 1 f. 2 -3.

d - $\beta$ angustosinuata ibid. p. 22 f. 1 ; et Note Conj. d. m. France 1. 33.t.

d $8 t$ - Wolle Desm. U. S. p. 109 t. 34 f. $4-8$ (formæ).

a $85-$ f. Minnesotensis Tumer New rare Desm. p.9:5 t. 16 f. 14.

o $\$ 6$ - Slokes Key Desm. p. 148.

o - (f. Minnesotensis) ibid. p.147.

dzf 86 - Coole Brit. Desm. p. 56 t. 22 [e Rulfs].

zfsi - Wulle Fr. Alg. U. S. A. t. 62 f.3. [Quid?].

o 87 - P notata Nordst. Algolog. småsak. 1 p. 155.

1 87 - Alexenko Chlorosp. Thark. p. 246.

dz 88 - Ilamsg. Prodr. Algenfl. Böhm. p. 2)!.

d $-\beta$ quadridentata ibid.

o 88 - Riabin. Chloroph. env. Kharkow p. 329 (v. denticulatum et crenulatum).

d 58 - f. Boldl Desm. Grönl. p.5 (sep.p. 3 ) t. 1 f. 2 [M. angulosa].

d 88 - Mauptfl.Zelln. u. Hiillgallerte Desm. p.94 (sep.p. 36) t. 3 f. 22.

o 88 - Nordst. Bornh. Desm. p. 187.

m $8 S$ - Istv. Jel. magyar alg. p. 219.

l . . $-\beta$ notata Nordst. F. wat. alo. p. 29 t. 2 f. 13.

n 89 - Curter in A. M. Mier. J. 10) f. 17 (ex Wolle).

dz 89 - Toni Syll, alg. p. 1130. d - v. intermedia ibid.

d - v. quadridentata ibid.

d - - v. minnesotensis ibid. p. 1131.

d - v. notata ibid.

d - v. angustisinuata ibicl.

ph $89-I I c l m$ in Joum. Now York Mier. Soc. V. p. $93(+$ 1 t.) [n. v.].

d 9 -v. intermedia Benn. Fr. Als. Hampls. p. 6 t. 1 f. 8 [MI. rotata].

m 90 - Eichler spis Desm. Micdz. p. 89.

n1 90 Anderss. Sverig. Chlor. 1 p. 9.

$\mathrm{m}-\beta$ notata ibil.

m 91 - Heimerl Desm. alpin. p. 603.

1191 HELIERELLA huntze Rev. gen. pl. p. S!Я.

m $92 \mathrm{Mic1}$. Borge Chloroph. Norsk Finm. p. 5.

m:12-West Fr. w. Alg. W. Irel. p. 134.

d 92-WTlle Desn. U. s.. ed. II p. 120 t. 38 f. $1-8$.

d 92 - v. subnotata $W^{r}$ est Alg. Engl. Lake Distr. 1\%.722 t. !) f. 5 .

Izf 93 - Breiley Contr. Queensl. Fl. p. 48 t. 17 f. 13 (e Cooke). m 93 - Lätliemïll. Tesm. Attersees 1.562.

o 93 - Turner Alg. Ind. orient. p.91.

1194 - Borge Süssw. Chlor. Archang. 1. 35.

m 94 - Alexenko Mater. alg. Khark. p. 29.

Cfr. Mier. cornuta, furcata, papillifera Hest. 1892, Rota et rotata.

\section{antirulatum}

d 65 D0CIDIUM Grum. Ins. Bank. p. 13 t. 2 f. $1 \%$.

il 68 - Rab. Flor. Eur. Alg. : p. 115.

d 89 - Toni Syll. Alg. p. 874 .

o 93 - Turner Alg. 1nd, orient, p.38.

\section{renticulatum}

d 84 EUASTRUM Gay Note Conj. d. m. France p. 335 (Eu. amænum Gay Mon. Conj., Eu. binale $\beta$ denticulatum Kirchn.) [Helierella Kirchneri Kuntzc).

o 87 - $\beta$ elongatum Nordst. Algolog. smìsak. \pm p. 164.

o 88 - a. f. Livldl Desm. Grön1. p. 8 (sep.l. (i).

d - b. f. ilid.. t. 1 f. 9. [Eu. Boldtii].

o se-Nordst. Fr. wat. alg. N. Zeal. p. 31 t. 3 f. 9 (forme).

o - P elongatum ibil. p. 79 t. 3 f. 10 .

o se-Masli. Furtl. Note Y. Z. Desm. 1. 18 t. 2 f. 11 . (Eu. ? binale Musk. 1ss1) [Eu. Turneri West].

d s! - Toni syll. alg. 1'. 1106.

d - v. elongatum ibid. p. 1107.

d $90-\beta$ stictum Büry. Desm. Prasil. 1. 34 t. 3 f. 19 [E. Turneri? $\mathrm{i}$ ?

m 90 - Eichler Spis Desm. Miedz. p. 89.

m 90-Anderss. Sverig. Chlor. 1 p. 11.

m 92 - Borge Chloroph. Norsk. Finmark. p.6.

m 92 - West Fr. w. Alg. W. Irel. p. 110.

d - v. granulatum ibid. p. 141 t.20 f. 17. [Quid ?].

m 92 - Iiac. Desmidya Ciastoni. p. 379.

m!12-Gutw. Flor. glon. Galic. I1I p. 133.

d $94-\beta$ rossicam Burge süissw. Chlor. Archang. 13.33 t. 3 f. 37. [Prouria spec.? Cfr. Eu. binale f. crassum Josh.].

m 91 - Dö̀g. F. alg. Östgrönl. p. 31.

m.9-Gutw. Fl. alg. 'Tarnapol. p. 101.

m195- Wrest Alg. Madag. p. 53 t.9 f. 15-16.

d - v. rectangalare ibid.; t. 6 f. 21 .

Cfr. Eu, elegans var. Wittr. 1872.

\section{dentivulrtum}

d 13 PHYCASTRUM Kütz. Spec. Alg. 17. 182 nec Norg. (Eu. Bailey Amer. Bac. 1841 t. 3 f.9 [Staur. rugulosum Brćb. 1818]). 


\section{Arutirulutum}

d 19 PHYCASTRUM (Paclugatinium) Norge winz. Alg. 1.12S t. S o f 3, nee Kätz. [Didymidinm Tign rinum Reinsch 18iti.

(1) 6I STAURASTRUM Arch in Priteh. Inf. 1. 73s.

1) ris-Rub. Flor. Fur. Alg. 3 p. 213.

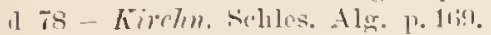

ms1 - ? Fiff. Finsk. Desm. p. \& t. 1 f. . [ [Est st. Avicula Bréb. sec. Nord.t. in Botan, Notis. 1882 p. 97 ; it. A v. r. subarcuatum ITest 18:4].

ph sfi - Berth. Stud. Protoplasmamech. p. 162 t. 3 fois (e Nirg.).

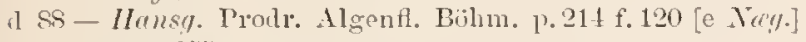
et p. 2.5 .

(l 89 - Tomi Syll. alg. p. 1163 .

(n)-West 1r. w. Alg. Xorth Wales t. 6 f. $2 \overline{-}$.

m 9 - Fïchler Spis Desm. Micd\%. p. 90.

o $93-$ f.? Turner Alo. Ind. orient. p. 112 t. 16 f. 3 .

m 9.4 - Ciutu. Fl, alg. Tarmapol. 1. 100.

\section{arutiferum}

a to COSMARIUM Corde in Alm. 1. Cartsb. 1stil p. $21 \mathrm{~s}$ t. (i) f. 41.

o ss - Mordst. Bornl. Desin. p. 192 t. 6 f. 1 et it.

\section{dentiferm}

d 93 EUASTRUM Turner Alg. Tnd, orient. p. 80 to ti) f. 39 .

\section{aleculperentu}

d To MICRASTERIAS Morr.t. Desm. Bramil. p. 2222 (sep.p. 181) c. f. xy.logiv.

m. S6 - Latgerh. Amerik. Desm. p. 231.

d 89 - Toni syll. alg. p. 112 s.

d 90 -f. Burr. Desm. Brasil. p. 32 t. 2 f. 12.

n 91 HELIFRELLA Kuntze Rer. gen. pl. p. Sos.

\section{deparperatum -a}

1 78 CosMarium Nordst. Alg. Fandric. p. 12 t. 1 f. 15 .

d s\$-Toni sirll. alg. p. 1020.

n !1 URSINELLA Kuntze Rev, gen. pl. p.924.

\section{deplanata}

d 3!) COLPOPELTA (orde in Alm. A. Carlsb). 1839 p. $241 \mathrm{t} .4 \mathrm{f}$. 24 [Quid est? Cosm. contractum? sec. Turner 189:3].

\section{appessers}

d 13 ? CYLINDROCYSTIS (Clitocystis) Tumer Alg. Int. orient. p. 16 t. 7 f. 11.

\section{(lepressum.}

d 51 CosMarium Rail. Micr. observ. p. 36 t. I f. 1 nee Kütz. 1s.19, nec Lumo. 1871. [C. Baileyi Wolle $18 S 4$ Dosm. U. S..

d is - I'ritch. Inf. p. 252.

d $61-A r c h$. in Priteh. Inf. p. T31.

1) 73 - Wood Fr. Alg. p. 130 .

\section{depressum}

d 19 COSMARIUM hït $z$. Spec, Alg. p. 166.

\section{armessum - a}

d 49 EUASTRUM (Tctracanthium) Neq. einz. Alg. p. 11.1 t. 7 C f. 2 [Cosm. Phaseolus sce. Rreb. List.; -Cosmarium depressum Naug." sec. IIontzseh 1hfiz in Rab. Alg. n:o $133 S=$ status evolnt. Arthro desmi convergentis. - Cosm, convergens $\beta$ inermis Jac. 1876.]. o 1 cosmariUM Lumd. Desm. Suce. p. 3s. nec Bril., nec Killz.

d $7 \mathrm{~s}-$ Kirchn. Alg. Sehles. 1. 14.

d sit- Woll: Desin. IT. H. p. 131 t. 50 f. 10-12.

o s6-Sitolits liey Dosm. 1. 127.

d 89 -- llansy. Prodr. Algenf. Bölım. p. 195.

d s! - Toni Syll aln. p. s.jo.

n1 90 - Jivhle\% Spis lesm. Mieiz. p.s.

o 91 - f. minuta Thimer Desm. alpin. p.50 t.5 f. 10.

1191 URSINELLA Kuntze Rev. gon pl. p. 924.

d 92 Cosm. Wulle Desm U. S. erl. II p. 69 t.61 f. $10-12$.

II $93-\mathrm{v}$. granulatum Twmer Alg. lnel, orient. 1\% 68 t. 10 t. 3 .

\section{6merssum}

1. 19 SPONDYLOSIUM Rrib. in hïtz. Spec. Aly. p. 189.

of - Mret). List. t. 1 f. 1 [Cfr De Bury in Beil. Bot. Zeit. 1859 1. 6.1].

d ri-Arch. in P'rit. Inf. p. 724 t. 3 f. 9 [e Brib.].

el 68 SPHER0Z0SMA Rub. Flor. Eur. Alg. 3 p. 151, fig. xyl. 1). 105 [e Bribl. $]$.

d Tsepondylosium Kirhur. Als. Scliles. p. 133.

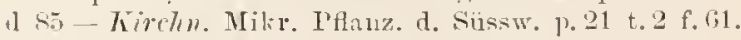

1 sesphar. Hamsg. Prodr. Algeufl. Bölum. p. 170.

d s! - Toni sivll. nlg. p. T!2.

m 90 - West Fr. w. Alg. North Wales p. 283.

m 90 spondylosium Fichler Spis Dosm. Mielz. p. St.

1 91 - Kirelm. Mikı. Pflanz. d. süssw. ell. 2 p. 22 t. 3 f. To. phe - Torre in Notaris. 7 p. 1 liz.

\section{Aepressimm.}

d 49 PHYCASTRUM (A mblyactininu) Norg. einz. Alg. p. 126, t. 8 f. A 1. [St. muticum fo minor Lumd. 1871; st. mut. $\beta$ ilepressum Nordst. 18Si].

d 93 STAURASTRUM f. aperta Tumer Alg. Ind, orient. 1. 11$) 4$ t. 13 f. 1 .

\section{DESWII)IACEA - (Cfr. "Desmillice").}

d 34 Kït. Syn. Diat. p.501 (sep.p.63. Divis. Diatomacearum. Series: D. libere (Gent.: Troelincia, Closterium, Hetcrocarplla, Micrasterias, Scenedesmus, Biddulpia), et D. inclusae P.611 (Gen.: Echinella, Geminella, Gilneonems, Desmidinm.

d 39 [Desmiliacea] Elront. Inf. p. 1to. Sect. Bacillar. Gen.: Desmilium. Staurastrum, Pentasterias, Tessararthra, Fpherastrum. Sintlidium, Arthrodesmus, Olonte]la. Micrasterias, Euastrum, Microtheca, Aptogonum (?).

d 40 bumeister in Erseh et Grub. Allg. Eneykl. Wiss. II, 1 s p. 201.

n 40 1/ont. in Hist. nat. Canar. IV p. 194. Trib. Phycear. Gen. C'losterium.

n 41 Builey Amex. Bacill. p. 2SS. Fam. Diat. (sensu Ehrenb:i + Closterium).

(1 49 Nrg. ein\%. Alg. 1.40 et 100. Ordo Algar. (Desmidiaceie 1. Desmicliex sonsu Ralfsii et auct. recent. inclus. Palmogloea ex p.. Pediastr. et Scenel. ex(elus.). Gen, nov.: Pleurotanium, Mesotitnium, Dysphinctium.

$p^{\mathrm{l}_{1}}$ 5ั1 $\%$ \%

d 52 I'ritch. Infus. p. 229 "Desmidiacea" sens. Ehrenb. incl. Closterium.

d 52 Perty kleinst. Lebensf. p.191 et 206.

d 54 Fuclie I'hys. Ftud. II p.23 (Desmidiacea) sect. Bacill. Gen.: Desmidium, Arthrodesmus. Odontella. Micrasterias, Euastrum, Tetmemonus, Closterium, Docilium, Penium. (Cfr. Xantidiea).

- 55 A. Braun Alg. unicell. p. 69. 
o 5 A. Araun Ueber Chytrid. p. 70.

d 57 Berkeley Introd. erypt. Bot. p. 113 et 121.

d 58 Havey $\mathrm{Ter}$, bor, aner. IlI p. T. Ordo Chlorospermear.

ph 59 Areh. Suppl. Cat. p. 73.

d $58 \mathrm{Grm}$. Desm. 1. 196 et 492. Tribus: a. "Closterieen" (Closter.. Stauroeeras, Doeid.); b. "Cylindriea" (Pentum. Palnogloia, Dysphinctiun, Tessalarthra, Tetmemorus; Hyalotheca; Zygnema et Zygogonium, et cetere Zygnenraees. Spirotænia. Spirogyra); e. "Euastreen" (Micrast., Euastr., Cosm., Arthrod., Xanth., Didymopl.. Isthmosira); d. "sta u rastreen" (ctaurastrum, Desmidium, Aptagonium).

ph 5. Arch. Alunorm. Desm. p. 207.

ph 60 Areh. Zoospor. in Desm. Nat. Hist. Kev. p. 350.

o (3) Wrallich Desm. Low. Beng. 1) 1.4t et 27:3. Gen. nov.: Leuronema, Onyehonema, Streptonema.

- 60 stitzenb. Inder Rab. Alg. p.27. Familia ordinis Zygophycearum. 'Tribus: a. Glyptosporea (Nier., Euastr., Staur., Phycastr., Didymocl.. Zyroxanthium, Tessararthra, Cosm.). b. Leiosporea: † Eremobiea (Pen., Clost.. Tetm., Palmogloea, Mesotien., Spirot., Doe.), † Filamentosa [11.25] (Hyal.. Didym., Gonatoz., Bambus., Desmid.)

d 61 Gray Arrang. Fam. et Gell. p.416. Fan. subordin is Callomorphæ (ordinis Maerosporarum).

(1) 61 Arch. in Priteh Inf. p. 71 .

d 63 liab. Krypt. Fl. Saehs. p. 166 (inel. Eremosphara De Bary.

d 65 Gray Brit. Alg. p.65. Fam. subord. Callomorphæ. Seet. I: A. Tanthidiere et B. Closteriacere. seet. II: Desmidiex.

d Ge Eyrich Algenf. Mannh. 1.117.

d 67 Notas. Desm. Ital. p. 17.

d bi Builey in Amer. Naturalist p, 19 (Desmids).

o 68 Harrop Desm. Tasman. p. IS.

plo dif Edwards Note on the Habits Diat, a, Desm. p.66.

d tis Rab. Flor. Eur. Alg, 3 p. 11 .

o 7 I Jund. Desm. Suce. 1). 2.

11 Ta Cohn in Hedwigia 1.17. Fam. Zygosporearum.

d 73 Wood Fr. Alg. p. 10 \%.

d 73 Delponte Desin. Subalp. p. 2T (sep.p. 15). Seet. I. Desm. aggregate p 35 (sep.p. 23) ("Colors" sep.p.t7); Gen.: Hyalotheea, Mixotanimm. Fidymonrim, Bantbusina, Desmidium, Aptogoumn. Spheroz., Xauthidiastrmm; sect. II liberie 1).37 (sep.17.25) ("Colrors" (sep.p. 70): cetera incl. Ankistrolesmo.

73 Ifeiffer Nomencl, bot. 1. 103: (Synonym.).

73 Microgr. Diet. ed. 3 p. 231. 'Trih.: I. Closteriex Gen.: Clost, P'en.. 'l'etm., Doc., Spiroten.). 1I. Cosmarite (Gen.: Mier.. Eu., Cosm. Xanth.. Arthr.. Staur.); III. Desmidiea; IY. Ankistrodesnea; Y. Pediastreze.

- 75 Jacubs Desn. Danem. 17. 14!

phit Hallich in Pop. Se. Rev. 1. 130-112.

o 7 g Klab Desm. Ostpreuss. 1. 1.

ph Fa Stahl Einfl. Licht 13eweg. d. Desn. p.21.

80 Coln in sichles. lahresle. f. v. Cult. 1sit p. 288.

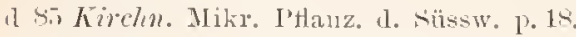

ph 85 K lebs Beweg. u. Scllleimb. d. Desm. p. 35t-36т.

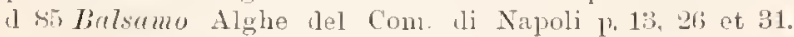

Fam. Zygocystearum isect. Zygosporearum).

jh si llitle Entw. a. Pollent. 1.21.

jh sif Klebs Organisat. Gallerte b. Algen 1.338 pte.

It si kanitz syst, vegret. janua P. 7.

d 88 llamsg. Prodr. Algenfl. Pöhm. p. 16r. Subfamil. 1. Eudesmidięu 1.167 (U. filiformes lïrehn.); 2. Didymiaced (Reinsch ex p.; D. integrat Delp.), cum seet: A. Integræ p. 172, B. Constrietæ p. 18.I, C. Incisa p. 190.

ph 88 Jayerh. Anwend. v. Milchsäure p. 59.

d SS Toni et Levi Fl. Alg. Venez. p. 21.

38.9 Toni Consp, sen. Chloroph. p. 452 . Familia Desmidioidearum. Subfamilia 1. Endesmidier, 2. Didymioilese (I. Closterieæ, II. Doeidieæ, III. II icrasterier).

pld 8 S Haupth. Zellm. n. Hillgallerte Desm. p. 1 cte. (Spirotenia, Mesotrenium, Cylindrocystis, sunt excludentia e fam. Desm.)

d 89 Curter in A. M. Micr. J. 10 p. 3.) et 37 . Seet.: Desminice, Closteriex, Cosmarier.

o 89 Racib. Now. Desm. p.9s (sep.p. 26). Seet.: Pleurotæniex et Centrotaniex.

a 89 Toni Syll. Alg. p. T7\%. Subfamiliæ: Endesmidieæ. Cosmoeladiere, Didymioidere.

d 10 Witle in Natürl. Pfanzenfam. I. 2 p. 1 ete. Gen. nova: Pleurenterium, Holaeanthum, Schizaeanthum,

d 91 Kirchmer Mikr. Pflanz. d. Sïssw. ed. 2 p. I9.

d 93 Eratley Contr. Queensl. Fl. p. 37.

d 94 Saund. in Fl. Nebraska p.36.

o 94 Hachel Syst. Phylog. 1. Prot. u, Pfl. I p.96, 97, I12 [Desm, filamentosæ stitzenb.].

\section{UESMIDIDA}

o 33 Bumett Outliu. Algol. p. 71 (Desmidica).

DESIIIDIE $\boldsymbol{E}$ (Drsmidiées, Desmidieen, Desmids - Cfr. "Desmidiaece").

d 33 Gree, in Hook Brit. Fl. II p. 401. Tribus Diatomacear. Gen: Meloseira et Desmidium.

d 35 ("Desmidiées") Bréb. et God. Alg. Falais, p. 9. Trib. Diatome. Gen.: Desmidium, Mierasterias. Heterocarpella, Binatella, Closterium, Seenedesmus, Trochiscia

o 36 Endl. Gen. plant. p.3. Subordo Diatomacear. Tribus: Micrasteriere. Eelinellere.

n 37 14ncuh. Consp. alg. Eugan. p. 16 sep.). Orulo alg. Gen.: Desmil.. Gleonema, Trochiseia, Closterium, Sconelesmus, Cosmarimn, Stamastrum, Micraster.ias, sphrrastrum, Pleuroeneeus.

o 38 Menry. Cenni S. organ. 1.339 et 3.58 (sep.p. 15 et 34). 'T'il. alg. Gen. ut supra 1837 exel. Gleon., add: Bitlinlplia. Spliæelodesmus, Geminella.

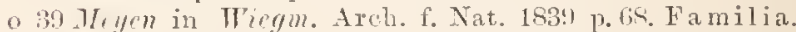
d J1 Memegh. Synops. Desm. 1.202 (sep.1) 2 ). Divis.: 1. incluse 1.202, gen.: A. Desmidium, Isthmia, B. Scenedesmus, Pediastrum, Gonilinm; Il. n ud $\mathrm{de}$. 214: A. Micrasterias. Cosmarinm, Xanthidium, Staurastrum; B. Closterinm, Spherastrum, 'Troehiseia. o 41 Fudl. Gen. plant. II p. I. ut supra 1836.

d 11 Hare. Nan. Br. Alg. 1) 75 et 194. Fa m. Diatomacear. (1).1!1: "Tribe"). Gen.: Meloseira et Desmidium.

6 41 mujurl. Hist. Nat. d. Zuoph. p.670.

1141 licichemb. Nomencl. gen. pl. I. I p. 19. Sectio Diatomearnm (trihus Confervaeear). Genera: Clostorinn, Cosmarium, Staurastrum, Spherastrum, Micrasterias. Scenedesmns, BiIdulphia, splierodesmus, Plenroeocens, Desmilium, Eehinella. Geminella.

11 42 Theris. Prosp. d. F1. Eugan. p. 57. Tritus Desmidioidearum. Gen.: Desmidium. Isthmia.

(1) 43 Kütz. P'hyo. gener. p. 15!'. Fam. Chamæphycear. Gen. Closterium, Mierotheca, Pentasterias, Euastrum, Santhidiun, Stanastrum. Crucigenia, Merismopoedia, Scenedesmus, Tessarthra, Nierasterias, Sphesrastrum, Gomphosphieria, Desmidium, Didymoprium. 
043 lialfs in Anu. Nat. Hist. r. 11 p. 4 ls.

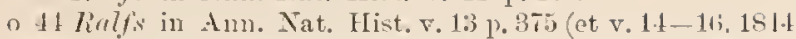
- j). Famil. Ger.: Euastrun, Tetmemorus. Mierasterias. Cosmarum, Xanthidium, Pediastrum, Staurastrum. Sceenelesmus, Desmidiun. Didymoprium, Glocoprimu, Spluxrozosina [et Closterium].

o 41 Trib. in Diet. nniv. hist. nat. v. -l p. T11). 'T'ribus alg. synsporear. Gen.: Hesmidium, Ilyalrtheca, Fipudylotium. Scenelesunts, AnJistroulesmus, l'ediastrum, Closterium. Penium, Spirotienia, Hocidium, 'l'ochiseia.

d 15 Küt:. Plyce germ. p. 12S. Gen.: Trochiscia, Teträdron, Pithiscus, Closterium, Stauroceras, Nicrotheca. Euastrum. Phycastrum, Scenodesmus, Grammatonema. Hyalotlieea, Bambusina, Isthmosira, Didymoprium, Desmidiun. Eucampia, Geminella, Merismopodia, Pediastrum, Splicuastr11m, Raphiclium, Sorastrum.

(1 45 Inssull Brit. Alg. p.338. Fam. nuica Alg. figuratar. Sect. I: Desmidium. Flacoprium. Spherozosma; sect. 11: Goniocystis, Artholesuus, Xanthidium, Cylindroeystis, Cosmarium, Clostcrium. Tetmemorus, Euastrum, Micrasterias, Holocystis, Perliastum, sicenedesmus.

ph fo Menegh. Sulla animalita p.58 et 212 .

047 Nreg. Neu. Algcnsyst. p. 123 (Sub Palmellac.).

d 47 Tiab. Dent. Firpt. Flo1. p. VIIl et 51. Fam. Schizophycear. Gen.: Lithodesmium, Amphitetras, sphæ. rastrum, Sorastrum. Raphidium, Merismopoedia, Closterium. Micrasterias. Euastrum, Xanthidium, Arthrolesmus, Tessararthra, Staurastrum, Pentasterias, Desmidium. Didymoprium. Geminella, Grammonema. Bambusina. Hyalotheca.

47 Lindl. Veg. Fingd. P. 13. Sub ord. Diatumacear. Gen.: Pentasterias. Xanth., Eu.. Odontella, Clost. Tetm., Micr.. Stanr.. Pediast. Sphreratrum. Selcnaca, Heliactis, Scencdesmus, Tcssarthra, Echinella, Desmilium.

d 48 Tree. Algh. coccot. p.99. Trib. Schimatothallar. Gen.: Gymnodesmus, Gymnozyga, Spherozosma, Desmidium.

1 48 Ralfs Brit. Desm. P. 49. Fam. Alg. Gen. nt supra 1814-5 excl. Glocopr., add.: Dilymocladon, Arthrodesmus. Spirotania. Penium. Docidium, Ankistrodesmus, Aptogonum. Hyalotheca.

d 49 Lrindsbor. Brit. Sea-Weeds p. 34 3.

d 49 K̈йz. Spec. Alg. p.162. Gen. ealem ne 1815 et: Pe nium, Polysolenia. Polyedrium, Nicrasterias. Cosmarium, Arthrodesmus. Xanthidium, Zygoxanthium, Asteroxanthiun, Stephanoxanthium, Spondylosium, Monactiuns?, Staurogenia, Coelastrum, Oocarlium. il 50 Mariss. Catalog. esp. omis. 1. 31.

ph 50 A. Inam Verjüng. p. 1.22 etc.

d 52 Perty kleinst. Lebensf. p. 194 et 206.

d 53 Math. Flor. Belg. II p. 521 ("Desmidiées. trib. alm.).

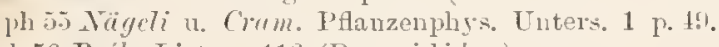

ll 56 Rréb. List. P. 116 (Desmidiées).

ph 5 - Mofmeister Fortptlanz. (Desmidiecm.

phat Jhe Bary in Bot. Keit. p. To5.

o 5 s 11 rallich in Trans, micr. soc. n. $\mathrm{s} .6 \mathrm{p} .81$.

d 58 the liary Conjug. P. 35. 67. 70. Sect. famil. Conjugatar. incl. Cylindrocystis, Mesotanium. Spirotrenia. Gonatozygon. Genicularia; spec dubic: Cos. mocladium et Aulistrodesums .

d 60 Haru. Index gen. alg. p. 16

1 63 Grogn. Plant. Crypt. 1) 2260. (Desmidices).

d 64 Gring. Brit. Alg. 1. Tt. sect. Desmidiacearum. Cien.: fionatozygon, Hyalotheca, Didymoprium. Desmidium, Ajutogonum, Nplitrozosma.

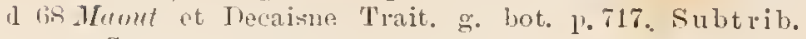
Synsporearum.

o 71 lyeiffer Syn. bot. loc. (Enmmeratio generum cum synolly1n.).

de it Oret. Lusporpl. p. 81.

it Ifeifle Nonenel. bot. 1\% 1030 (Syuonym.).

71 Mierogr. Dict. p. 2:3. Trib. Desmidiacearum. Gen.: Genicularia, Gonatozygon, Hy:al., Dirlymopu., Desm., A prog.. siphrer.

a 78 Kirehn. Alg. Sichles. p. 130. Section: A. Desm. fili fornes $l=$ Filanentose Stizenb. 1860] 1.131 ; B. 1. Des. integræ p. 134 (Gen.: Mesotinium. Penitum. Spirot., Clost.); I1. constricte P. 112 (Gen.: Calocylindrus, Docil.. Pleurot.. 'l'etm.); III. incise p. 14 (Gen.: Cosm., Xauth., Arthr.. Euastr. Micrast., stanr.).

phs so stall in Bot. Zeit. 38 p. 393.

o sil Cooke in Queck. Mier. J. 6 p. 203.

ph sl streher in Ann. Mag. Nat. Hist. 5 ser. v. 7 p. 341.

51 Hask. N. Zeal. Desm. p. 299.

d s2 Falkenberg in Selenk Handb. d. Bot. p. 292.

o 82 Frank in Leunis synops. (ed. 3) I p. 426 .

th th Schmitz Chromat. d. Alg. p.3 etc.

a 83 Manvury in Baill. Dict. bot. If p. 343 .

ph 83 Lundell in Bot. Not. 1883 p. 79.

ph 83 Fischer Gypskr. Desm. p. 133 ete.

a 83 Lemaire List. Desm. Vosges p. 3 .

a 81 Gay Monogr. loc. Conjug. p. 26 et 31. (Nov. gen.: Cosmaridium).

d st Wrolle Desm. U. s. p. 21 etc.

d st Coole Brit. Fr. wat. Alg. 1) 74.

ph 86 Berthold stul. Protoplasmamech. p. 15, 138. 161 ete. d 86 Cooke Brit. Desm. p. 1. Sec. A. Leiosporen, B. Cosmosporea.

ph 8 i Bem. in J. Linn. Soc. n:o 158 p. $5 \%$.

ph 8 t kioy in seott. Nat. p. 154.

d 87 Alerenko Chloroph. Kihark. p. $21 \%$.

o si Burgess in Americ. Naturalist $22 \mathrm{p} .673$.

o su Cartr A. M. Micr. J. X p. 75. Nect. Desmid.

ph si Elfi. Anmä1k. Desm. syst. p. 7 .

1190 Ardissone in Rend. R. Inst. Lomb. ser. 2 v. 29 p. 7 ("Desmidinee" : Class. "Ablefaritusee").

pha Richter in Flora 1892 p. 53.

d 9:2 Wulle Desm. U. s. ed. II p. 21.

o. 93 lioy Sicott. Desm. p. 106.

o 93 Tumer Alga Ind. orient. p.9.

o 94 Willem. Obs. crit. Desm. p. 57 et ser.

- 95 Thildem. Note algolog. I p.3 ete.

\section{DESTIDIOIDEA}

d 42 Trevisan I'rosp. d. Flor. Eugan. p.57 Subordo. Ulvacearum (Tribus: Desmidiex, Pediastrex et II icrasterieæ) = Desmidiaceæ.

n. SS Toni Consp. gen. Chloroph. in Notarisia p. 452. Ordo IV Chlorophycearum. Familie: Desmidiacex et Zyonemacea.

\section{DESMIDIUH}

U $24 A$. Nyst. Alg. pag. XV. Genus Diatomearum.

1. 25 Fries Plant. IInnonen. 1. 35t. Geun Fragilarinarum.

d $2 s$ (iver. Scot. erypt. Fl. 6 p. 38.

(1) $30 \mathrm{Ag}$. Consp. Diat. 1.56 et 66 sub Fragilaricis.

d 33 Wall: Fl. Cryp. Germ. II p.118. Genus Hydrophytozoorum.

(I) 333 Gree. in Hook. Ir. El. II p. 402. 
d 33 Sprengel in Ersch n. Gruber Allg. Encyklop. 1. Wiss. 1. 24 p. 264 .

d 34 hütz. syn. Diat. p.613 (sep.p. saj).

d 34 Ehronl. Organ. k. Raum. p. 211 sel. 147.

d 35 Brib. et God. Alg. Falaise p. 267 (sep.p. 53).

d 36 Endl. Gen. plant. p.3.

d 3s Ehrenb. Inf. p. 140 (inel. stanl.?

d 39 Bréb. in Chev. mier. p. 271 [inclus. Gymnozyga et Hyalotheca].

d 10 Merregh. Syn. Desm. p. 202 (sep.p. 2).

d 40 Cortu in Alm. d. Carlsb. 1910 p. 202 [sep.p. 17].

d 40 burmeister in Ersch 1. Gruber Allg. Encylitop. II. 18 p. 204.

d 11 Hare. Man. Br. Alg. p. 15 et 196.

d 41 Bailey Amer. Bacill. p. $28 s$ (sep.p. T).

o 12 liclfs Amn. nat. Hist. v. y p. 155 et 253.

d 13 kïtz. Plise. gener. p. 165 . [sensu strictione].

d 43 Rirlfs Ann. Nat. Hist. v. 11 p. 372 et Trans. Boc. Soc. Edinb. จ. 2 1). 5.

d 13 Ralf's Amn. Nat. Hist. v. 11 p. 418 (et 1846 in Trans. Bot. Soc. Edin, v. 2 p. 13.

d 4 Brib. in Dict. univ. hist. nat. 4 p. 710 ["Desmidia"] et 711 .

d 15 Rulfs Ann. Nat. Hist. v. 15 p. 40.j (et 1.86 in Trans. Bot. Soc. Edir. v. 2 p. 162).

d 4i) Ilussall Brit. Alg. p. 341 .

d 45 kitz. I'hycol. germ. p. 141.

d 4 R Rab. Deut. Krypt. Fl. p. TIII et 56.

d tis lialfs Brit. Desm. p. 60.

d 19 Kütz. Nive. Alg. p. 1 !h.

d 49 Noy. einz. Alg. p. 130.

d 52 Pritc\%. Inf. p 240.

pht

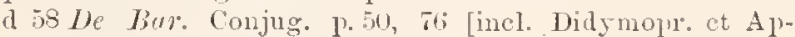
togon.].

o 58 Grum. Desm. p. 49.4.

1h 60 Niegeli Beitr. wiss. Bot. II p. 11.

a 60 Wrallich Desm. Low. Bengal. p. 1nt - 7 .

d 61 Arch. in Pritch. Inf. p. 719 et 723.

d 63 Grogn. Plant. Crypt. p. 261.

d tis Rab. Kiypt. Fl. Sachs. p. 180 .

d 64 Grory Brit. Alg. p. 7.

d 66 Eyrich Algenfl. Mannls. p. 117.

d 67 Jot. Desm. Ital. p. 20.

d 68 Rab. Flor. Eur. Alg. 3 p. 106 et 158.

d 73 Delyonte Desm. subalp. p. 36 et is (sep.p. 21 et 56).

n 73 Nordst. Norg. Desm. p. 19. Subgen. Dilymonrium, Desmilinm. Aptogonum.

d 73 Hood Fr. Alg. p. 126.

d 75 Microgr. Dict. p. 231 .

d if Fonk in Leunis smops. p. 163:3.

d Ts Kirelin. Alg. Schles. y. 13:2.

d 83 . Hunoury in Baill. Dict, bot. 1 1 1. 355.

d S.1 Guy Monowr. loc. Conjug. p. 44 sect 1 Eulesmidium: 2 Tirbmoprium; et in Note Conj. d. m. France 1. 341 ,

d st $11 \%$ lle Desm. U. S. P. 25.

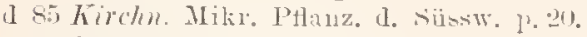

o sti Stolies key Desm. p. 10!.

d Sil Coule Brit. Desm. 1) ?

d st Alexentio Chlorosp. Khark p, 21 is.

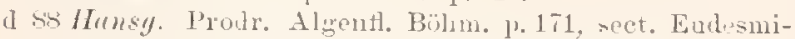
dium, Ajtogonum at p 172: Didymoprimm.

d ss Toni \& LA' Fl. Alg. Vene\%. p.21 et 21.

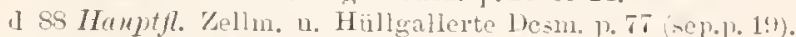

d sy Toui syll. Alg. P. T69.

d subger. 1. Eudesmidinn ihid. p. Ts(1).

d $\quad-\quad$ 2. Aptogonum ibid. 1. Ts1. d

Tille in Natïrl. Pflarzenfam. p. 14.

d s1 hirchl. Mikr. Pflauz. (1. Süssw. ed. 2 p. 21.

d t.2 Wolle Inesm. U. S. ed. II p. 25.

d (13 Ruiley Contr. Queens]. F1. 1).38.

- 98 Turuer Alg. Ind. orient. p. 149.

1) 9.1 buunt. in Fl. Nebraska p. 36.

$\mathrm{p}^{\text {ha }} 94$ II cllheim in Pringsh. Jahrb. $26 \mathrm{p} .726$ (sep.p. 53).

\section{Desmirlinm,}

d 3ऽ0DONTELLA lirenb. Inf. p. 153 t. 16 f. I V [Desm. aptogonum $\beta$ Ehrenbergii Kïtz.].

o 40-(Sect. II. Odontella) Corda in Alm. d. Carlsb. 1840 p. 208 .

41 - Protch. Inf. p. - f. 108 [fig. Ehr:i repetita].

i ts APTOGONUM Iialfs Brit. Desm. p. 61 t. 32 t. $1(a=$ Desmid. Aptog.; firg. $c-h_{:} \beta=$ Odont. Desmid.).

1. 52 - Pritch. Inf. 1.212 t. 2 f. 108 [fig. Ehrenb:i], et p. 243 sub nominc Od on tellæ.

d 69 - Eyrich Algenfl. Maunh. p. 119.

d 73 - Wilponte Desm. subalp. p. 73 (sep.p. 61 ) t. 3 f. $1-5$.

d 75 - Vicrogr. Dict. p. 63.

\section{Detoniane}

n 91 HELIERELLA Liuntze Rev. gen. pl. p. $\$ 93$ (Eu. Nordstedtianum Wolle 1ธ84).

Detorii [De-Tonii"]

d s4 STAURASTRUM Eichl. et Gutw. Spec. alg. nor. p. 17i; t. 5 f. 51. [Staur. furcatum (Ehb.) Bièb. see. Wist 1.592].

\section{diceruthume}

d SUSTAURASTRUM Lemuire in Bull. d. scéance. soe. se. Nancy 1 u:0 2 p. 17.

d $: 90$ - Lemaire in Bull. soc. sc. Nancy v. 10 p. 30 (scp.p). 4) f. 2.

\section{Diaclema}

d si COSMARIUM Josh. Burm. Desm. p. 616 t. 25 f. 7.

d S9 PLEUROT झNNIOPSIS? Toni Syll, alg. p. 913.

\section{diralematum- -}

d 83 COSMARIUM Schaurschm. Magyar. Desm. p. 267 t. 1 f. 8.

d sy-- Tomi syll. alg. p. 1004.

1. 11 URSINELLA huntze Rev. gen. pl. p.924.

\section{Diregomume}

d is APTOGONUM Dalmonte Desmil. subalp. p. $65 \cdot$ (sep.p. 64) t. 3 f. 6 -10. (A. Desmidinm $\beta$ hilfs $[$ Aptog. cælatum v. Wiagonum liec. 1s5a.

d 4 DESHIDIUM Wulle Desm. U. .. p. 159.

o sii-. Stolie's Kiey Desm. p. 110.

a 92 - Wolle Desin. U. S. ed. I p. 171.

\section{Jialle}

dzf CLOSTERIUM Ehthb. lif. p. 12 t. 5 f. XVII 1-6; Corpicetti a bacello Corti? O-serva. nicroscop. s. Tremella 17t 10.111 t.2 f. 17 ab, mm. Clost. ruficeps $E K, b$.) [ 1 et 3 alie spec?].

(1 10 - Mencyh. Sinops. Lesm. p. 232 isep.p. 32).

d 4is-Mriss. Brit. Alg. p. 371 t. $\$ 1$ f. 5.

d 15 - Kïtz. Ihyc. germ. p. 130 .

1 47 - Focke Phis. Stul. I p. 56 et 68 t. 3 f. 10 [(\%. striolatum?].

d Is-Lults Brit. Desm. P. $16 \mathrm{~g}$ t. 29 f. 5.

d $19-h u ̈ t z$ spec. Als. P. 163. 
50 - Limbenh. Bacill. t. 1 (f. 2- r) [Cl. Delpontei f. glabra Gute. 1:?1?].

a $52-$ Tritch. Inf. p. 281 .

in $5 \bar{t}$ - buring. Ols. Pliye. p. (il.

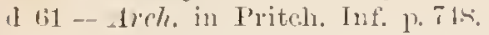

d $63-\operatorname{lin}$. Krypt. FI. $\because$ Sachs. P. 171 .

o 63 - f. Isulnh, in Rab. Alg. En1. 11:0 1432.

m 6 T heinsch Algentl. Frank. p. 191.

1 68 - Kint. Flor. Eur. Alg. 3 \%. 1:33.

(l) - 13. arcuatum ibicl. Cl. a reuntum Bréb.).

mo-heimlard in Arbeiten Naturfo-g. Charliow $1 \mathrm{p} .15$.

m 72 - Nordst. Desm. Sipetsb. 1. 2019.

d $33-N$ ood Fr. Alg. p, 114 t. 1ㄹ f. 1.

d 75 - Nierngr. Diet. p. 17 i.

o 75 -Jacols. Tesm. Danem. 1. 170 t.7 f. 3.

d 77 -Welponte Desmid. subalp. p. ey (sep.p. 1!5) t. 17 f. $45-51$.

m $78-$ Tordst. Alg. Sandv. p. 10.

dz Ti- Tirctm. Alo. siclales. p. 1.11.

o 79 - f. Wille Ferskv. alg. Nov. Semij. p. 54 t. 14 f. 52.

o $-1.1-f$. Wittr. in Wittr. et Nordst. Alg. exs, n:0 261.

(1) $79-$ a. typicnm Klebs Desm. Ostpreuss. p. 11 t. 1 f. 13 b. c, cl, e.f, g. 10 a (iuchus. Cl, areuatum et Cl. acuminatum

d - b. compressum ibil. 1. 11 t. 1 f. 10 b.

d - c. Jenneri ilid. p. 12 t. 1 f. 13 a et 12 b (Cl. Jenneri $\left.\operatorname{lillf:} 184)^{\prime}\right)$.

1 - a. Venus ibiu. p. 12 t. 1 f. 11 c. e Cl. Venus hütz in linlfs 1, 1 (s).

l - p. incurvum ibid. 1, 12 t. 1 f. 11 a et b. (Cl. incur

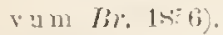

1h 83 - Fincher Gypskzyst. Desm. 1. 151 t. \& f. 4 .

1n 51 - Artari Liste alg. Moscou p. 134.

m 81 - Gay Mon, Ioe. Conj. 3. T2.

dzf 81 - Iulle Desm. U. S. p. 44 t. 7 f. S-G (incl. Cl. arcuatum); t.s f. 4 .

d 55 - Kirchn. Miks. Pflanz. d. Nüssw. 1. 21.

In 45 - Boldt sibir. Chloroph. p. 123.

d 85 - Bnlsumo Alghe del. Conn. di Napoli p. 37.

1. $86-$ Fomli in Lemis rjnops. 3 p. 198.

o s6-stolics Kiey lesm. 1\% 112.

1) 86 - f. rectior (Nordst. in Wittr. et Nordst. Alg. exs. 11:0 44 ; et in fiase. $21,1,899) \mathrm{p} .47$

dzf St - Coolue Brit. Desm. 1). 26 t. 13 f. 3.

8. - Wolle Fr. Alg. U. S. A. P. 25 t. 55 f. $1-2$.

d sí-Alexculo Clilorosp, Kinark. p.224.

dz 88 - Hansg. Prodr. Algenfl. Böhm. p. 151.

d $-\beta$ areuatum ibid, et 1 . 24 .

d s8-Tomi et Levi Fl. Alg. Venez. p. 34.

m Ss-Riabin. Chloroph. env. Kharkow p.316 (sep.p. 2s).

m SS- Tordst. Bornh. Desm. p. 184.

m. $\$ S-I s t r$. Jel. magyar. als. 1. 23!.

m.s - Nordst. Fr. wat. alg. N. Zeal. p. 69.

o . S9-v. aleuatum Mask. Furth. Note N. Z. Desm. p. 29 t. 6 f. 55.

dz

d - - a a reuatum ibit. p. Siss.

l) - re rectius ihid.

o so-Jury. Desm. Brasil. p. 31.

m 90 - Eichter spis Desm Miedz. p. sis.

1090 - ? Auders. sverig. Chlor. 1 p. 1 s.

o - f. ibid, et t. 1 f. 13.

n - f. compressa ibid.

d 91 - Kirden. Mik1. Pflanz. 1. Nïssw. ed. 2 p. 23.

m 51 - Heimerl Desm. alpin. 1, 593.

mes - Borge Bidx. Sibix. Chloroph. p.1t.

1191 ARTHR0DIA Kँuntze Rer. gen. pl. p. S\$3.

m th Clost. H'est Fr. W. Alg. Wr. Irel. p. 122.

Liredstede, Index Inesmit. o !2- Mobius Anstral. Süsswasseralg. p. 411.

dzf 92 - Holle Desm. U. S. ed. 11 1. 47 t. 4 f. s et ! (incl. Cl. ar ( u atum), t. 9 f. 4, t. 6 f. 1 - 2 .

111 !2 Rimmer Alg. St. Pölten I 1. 5.

d 93 - Bnilfy Contrib. Queensl. Fl. 1\%.11 t. 12 f. 33 (e Cuoke).

n 93 - Lüllitmïll. Desm. Attersees p. 113.

1198 - (Selenoceras) Tuner Alg. Ind, orient. 1. 23.

m a - $\beta$ compressum Lorye fïssw. Chlor. Arehang. p. 15.

nz!14 - Rürges. F゙. alg. Ostgxönl. p. 11.

m s.t - v, arcuatum Gutw. Fl. alg. Tarnapol. p. So.

dz 91 - Snumd, in Fl. Nebraska 1).38 t.f. f.! [e Cooke].

m 45 - v. minor Theron. in Pflanzenw. Ostafrik. 1. 19.

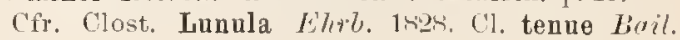
$18+1$.

\section{I) IATOMA}

(1) The Cundolle Flor. frane. 2 p. 49).

Apud auctores mica species hujus generis al Desmidiaceas pertinet; e gro:

a 17 Ag. Syn, alg. Nicant. r. XXXY. Gen. Confervoidearum. (l) 19 Lyngl. Ilydropl. Iran. p. 177. Gen, Homalogonator.

d 21 Groly Nat, arrang. Brit. plants I p. 27 et 295. Gen. Diatomidearum.

\section{DIATOMACET}

$1130 \mathrm{Ag}$. Consp, crit. Diat. p.1. Ordo Alg. Divis: Cymbelles. Styllariea, Fragilariea.

1136 Enll. Gen. plant. I p. 1. Subordines: Diatomere. Desmidiere.

o $\$ 2$ Emmll. Gen. plant. II p. I - - .

d 41 Enall. Enchir. bot. 12.2.

\section{DIATOHEE}

2.2 Jumort. Comm. bot. p. 71. Fam. Granuliniæ. [n. v.], d $24 \mathrm{Ag}$. Syst. Alg. p. Fll. Ordo Algar. Gen.: Desmidium. Diatoma ete.

d gs Grev. rieott. crypt. Fl. 6 p. 3 б.

d $31 \mathrm{~A} g$. Consp. crit. Diat. p. 43. Seriella Fragilariear.

\section{DIATOMIUEA}

d 21 Gray Nat. Arrang. Brit. Plants p. 27! et 2513. Sect. Hydrophyt. Gen.: Fragillaria. Biddulphia, Diatoma,

\section{dichomrloum}

d 95 Cosmarium West Alg. Madag. p. 65 t. 7 f. 12.

\section{richotomur}

d St MICRASTERIAS Walle in Bull. Torr. bot. Club $1 s 81$ 1. 11.

d 8. - Wolle Desm. U. A. 1). 111 t. 52 f. 2.

1186 - Lagerh. Amerik. Desm. 1. 231 t. 27 f. 1.

o 86 - Stokes Kiey Desm. p. 147.

d 89 -Toni syll. alg. p. 1117 .

n 91 HELIERELLA Fintze Rev. gen. pl. p. s!s.

1) $92 \mathrm{Mi}$ 1:. Holle Desu. U, S. ed, II p. 123 t. 13 f. 2.

\section{Dir\%:iri}

d 4 STAURASTRUM Ralfs Brit. Desin. p. 123 t. 21 f. 3.

d 52 - I'riteh. Inf. p. 262 .

d $61-4$ - reh. in Pritch. Inf. p. 737.

d 133 - Riut. Kirypt. F1. Sachs. p. 189.

() 79-f. Wille Fersist. alg. Xov. Semlj. p. 52 t. 13 f. 61. [Cfr st. Viugulmarkiæ].

81 - Wolle in I3ull. Torr. bot. Club. t. 14 f. 20-21.

nat - Gay Mon. loc. Conj. p.67.

181 - Woll Desm. U. S. p. 122 t. 10 f. $5-6$, t. 51 f. 20 $-21$. 
In 85 - Boldt sibir. Chloroph. p. 111.

o 86 - f. Nordst. in Wittr. et Nordst. Alg. exs. n:o 814; et (188.1) in fasc. 21 1..37.

d s6 - $\beta$ granulatum Roy et Biss.Jap. Desm. p.23R (sep.p.ti).

- 86 - Stokes kiey Desm. 1. 1 fit.

d 87 - Cuolie Brit. Desm. 11. 140 t. 14 f. 3.

o $8 \overline{-}-\beta$ parallelum hordst. Algolog. småsak. 4 \%. 158.

o 85 - f. Boldt Desm. Grönl. p. 36 t. 2 f. 4 .

d sq-- $\beta$ parallelum Nordst. Fr. wat. alg. X. Zeal. 1. 39 t. 4 f. 15 .

d 89 - Tuni Syll. alg. p. 1139.

d - v. granulatum ibid. p. 1140.

d - v. parallelum ibid.

o 90 - f. Rörg. Desm. Brasil. 1. 44 t. 4 f. 42.

m90-Anderss. sverig. Chlor. 1 p.11.

m. 91 - Heimenl Desm, alpin. p. 604.

m 92 - West Fl: w. Alg. W. Irel. p.171. f. punctata ibid.

m 92 - Lille. Desmidya Ciastoni. 1).350.

d 92 - Wolle Desm. U. s. ed. II p. 135 t. 51 f. J-6. t. 62 ft. $20-21$.

o 92 - West in Notaris. $T$ p. 1503.

m 93 - Lïtkemiall. Desm. Attersees p. 563.

d $93-v$ v. circulare Turner Alg. Ind. orient. p. 105 t. 16 f. 5. m _.. - f. major ibid.; t. 16 f. 25.

m 94-Borge sissw. Chlov. Arehang. p. 37 (Boldt 1s8s).

d $94-$ f. Groenlandica Böry. F, alg. Grönland. p. 25 t. 2 f. 2.

m 95 - Eichler in l'amiet. Fizy. 13 p. 132 (f. Nordst. 15915).

d 95 - f. parva schmidle Beitr. alp. Alọ. t. 16 f. 29 et, 18:16. 1.24 (sep.13.30).

d $95-\mathrm{v}$ - maximum West Alg. Madag. p. 72 t. 8 f. 19.

Cfi. Didymit. convergens B. Leinsch 1s6t, Staur. brevispina b. Ral. 1868; st. dejectum $\beta$. Jae. 1576; Staur. laniatum $\nu_{t} l_{p}$.

\section{Didelte}

d 28 HETEROCARPELLA Turp. Apere. organ, p. 315 t. 13 f. 16. Quid est? Cum Euastro Didelta Mullo modo identica est. Staurastrum sp. (f. tetragona) e vertice visum? - Cosmarium Turpinii Breb. teste Breb. in Liste Desm. p. 127.].

d 10 COSMARIUM Menegh. Siynops. Desm. p. 219 (sep.p. 19) (Heterocarpella polymorpha) [Descriptio mala!].

4 14 EUASTRUM Lulfs Ann. Nat. Hist. v. 14 p. 160 t. 7 f. 2 a et b; et 1846 ) Trans. Bot. Soe. Edin. v. $2 \% .127$ t. 11. Figg. r. d. e. f. = E. ansatum Focke, Rulfs].

d $45-H a s s$. Br. Alg. p. 381 t. 90 f. 8 et t. 91 f. 11 [e Rirlfs 1. c. deiineatum].

o $\pm 7-$ Focke Pliys. Stuul. I p. 43 et $6 \pm$ t. 1 f. 9.

lz 48 - Ralfs Brit. Desin. p. st t. 1.1 f. 1.

d $49 \mathrm{Cosm}$. Küitz. Npec. Alg. p. $17 t$ (sensu Thp.).

dz 52 Eu. I'ritch. Inf. p. $24 \%$.

m 52 - Ierty kleinst. Lebenf. p. 208.

o 59 - (monstr.) Areh. Abnorm. Desm. in Dubl. Nat. Hist. Soc. 2 p. 2 us t. 1 f. 12 in Nat. Hist. Rev, 15 p. 470 t. 33 ; in Q. J. M. Ace. 8 p.s.

z 60 - Wullich Desm. Low. Bengal p. 283.

2 - [ $\beta$ ansatum ibid. (Eu, ansatum).

o 61 - (monstr.) Bulnh. in Hedw. 3. 52 t.9 f. 1 .

$0 \quad-$ f. ibia.. f. 11.

dz b1 - Arch, in Pritch. Inf. p. 729 t. 1 f. $23-25$ [e Rulfis Br. Desur.); t. 3 f.ril [ex Arch. 155t].

d $693-$ Lab. liryjt. F1. Sachs, p. 1si?.

67 - Not. Desm. Ital. t. 3 f. 13.

z this - Crowe in Q. J. M. Sc. v. 8 11.60\%.

it ris - Línl. Flor. Emr. Alg. '3 p. 184.

m 70 - Livinherd in Arbeiten Naturfo-g. Charkow I p. 16. d 73-Delponte Desm. subalp. 1.105 (sep.p. (13) t.6 f. 2 .

dz 73 - f. scrobiculata Nordst. Noro. Desm. p. 9.

d 73 - Hood Fr. Alg. 1) 139 t. 21 f. 13.

d 75 - Microgr. Dict. p. 292 t 10 f. 16 et 17 [e Rulfs].

o 7 - Reinsel Contrib. p. 93 t. 18 f. 15 [E. humerosum sec. Wordst. in Hedwig. $18 \pi$; p. 1i ].

z $5 \overline{5}-(x$ humerosum $)$ 1ich. in Q. J. II. sic. p. $41 t$.

d is-Kirchn. Alg. Schles. 1. 15 .

m 81 - Gay Mon. loc. Conj. p. 51 .

d $-\beta$ sinuatum ibil.. t. 1 f. 11.

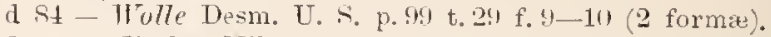

d $85-K i$ r chn. Mikl. PHanz, 1 . Silssw. p. 21.

o 85 - a. typicum Firc. Nonn. Desm. Polon. p. 92 (sep.p. 36).

d - b. tatricum ibial. t. $1: 3$ (sep. t) f. 3 .

d S6 Franti in Lemis Synops. 3 p. 196.

o si $-\beta$ tatricum f. Lagerh. in Wittr. et Nordst. Alg. exs. 11:0 812. et (1.889) in fase. 21 p. 35.

o 8 - Stokts key Iesm. 1) 14 .

lz 81 - Cooke Brit. Tresm. p. 69 t. 3 t. 1.

d 8 i - Alexenko Chlorosp. Kihark. p. 241 .

1 sis-IIrnsg. Prodr. Algenfl. Böhm. p. 205.

d $-\beta$ sinuatum ibid.

lzss - Toni et Leri Fl. Alg. Venez. 1. Ss.

m Ss - Roldt Grönl. Desm. 1. T.

d 88 - $\beta$ bengalicam Lagerh. Bengal: Desm. p. 13 t. 1 f. 3. m 85 - v. tatricum Rucit. Mat. flor. glon, Polsk. p.112. $n$ si-c'arter in A. Micr. M. J. $10 \mathrm{f}$. 16 (ex Wolle).

d si-Tomi syll. alg. p.1093.

d - v. sinuatum ibid. p. 1094.

d - v. tatricum ibid.

d - v. bengalienm ibid.

m90- Eichler spis Desm. Miedz. p.8s.

d 91 - Kirchn. Mikr. Pfanz. d. Sïssw. ed. 2 p. 25.

m 91 - Heimert Desm. alpin. p.60t.

n 91 HELIERELLA Kinntze Rev. gren. pl. p. S9S.

1) 91 URSINELLA Kuntze Rev, gen. p1. p. 923 (Cosm. Tur. pinii).

m 92 Eu. Borge Chloroph. Norsk. Finm. p. 6.

m 12 - West Fr.w. Alg. W. Irel. p. 137.

mzf 93 - Colpodastrum) Tumer Alg. Ind. orient. p. 77 t. 11 f. $\%$.

ilz - $\beta$ Bengalicum f. simplex ibil.

z 93 - Roy ricottish Desm. p. 175 (sep.p. 14.

m 94 - Jste. Adat. Roman. Alg. p. 154.

m94-Jorge süssw. Chlor. Archang. p. 32.

o 95 - lrildrm. Yote algolog. 1 p. 8 t. 1 f. 21 et 22 [ad E. Jumerosum paullo accedens].

o $y$ - f. Schmidle Beitr. alp. Alg. p. 22 et $(15 \% 5)$ t. 16 f. 6.

- f. sorobionlata ibid.; t. 17 f. 12-11.

Cfr. Eu. binale Kütz. 184\%, Eu. n:o 5े Bail. Amer. Bac. 1511, quond f. 27 a et $b$; Didymidium varians.

\section{didymurer(l)thrle - elm}

d t: EUASTRUM (Micrasterias) Nory. eiuz. Alg. p. 123 t. i H f. 1.

d (j1 TETRACHASTRUM Am. in Pritch. Inf. p. 725.

o THICRASTERIAS Nordst. Desm, Brasil. 1, 200.

o Su-Nordst. De Alg. et Charac, 1 p. 10.

n 90 - Wille in Natürl. Pfanzenfam. p. 13 f. 8 B (e Näg.). Cfr. Micr. oscitans et pinnatifida.

\section{aidymelle.}

a 39 STREPHOCYSTIS Corda in Alm. d. Carlsb. $1839 \mathrm{p}$. 242 t. 5 f. 27 . COsmarium Botrytis f. - Diagnosis irevis].

DIDI.WI ICEAE Cfr. Lidymidincea. 
DII YWIIACE

d tireinsch Algenfl. Frank. 1, 105. Fam. Conjugatarum. Desmidiacea cum appendice: Pamogloea. Spirota1ia et Eremosphera).

d se Didymiacea) Mansy. Prodr. Algenfl. Bohm. p. 172 subfamilia Desmidiacearum. Desnidiaced libera Delp.) Sect.: A. Integre. B. Constrietæ. C. In(c) is $: \mathrm{t}$.

n St Midymioidea, Toni Consp. Gen. Chloropl. p. 452. sub fan ilia). I. Closteriere. II. Mocidied. III. Micrasteriece.

d 49 (I) idymioidere Tomi syll. Alg, p. Tis et 803 Tertia subfamilia Desmidiacearum. Tribus: Spiroteniea p. Sm. Closteriez 1). Sin et 81\%. Docidieat. Micrasteriea).

(94 Didymioidede) Smmd. in Fl. Nebraska p. 37.

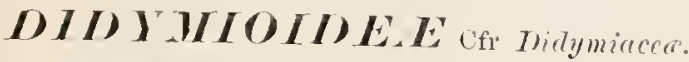

\section{DIDIMIDTLH}

d 6i Tieinsch Algenfl. Frank. p. 10h. Genus inelud.: Cosmarium Corda, Euastrum Ehrenb. Eueosmium Xito. Micrasterias Ag.. Staurastrum Meyen). Subgenera: Cosmarium, Eucosnim. Ianthi. dium, Euastrum. II icrasterias. Staurastrum.

\section{didymoraremm -a}

dzf 71 PENIUM L umd. Desm. Snec. p. $\$ 5$ t. 5 f. 9.

dzf 86 - Cooke Brit. Desm. p. 44 t. 16 f. 6 [e Lumdell].

n ss SCHIZOSPORA Tlansg. Prodr. Algenf. Bölnn. p. 165 ill nota. mz 88? Pen. Fordst. Fr. wat. alg. N. Zeal. p. i.) [forme
ineerta).

dz 89 - Tomi syll. Alg. 1.892.

$\mathrm{m}$ (iu - Gutw. Fl. glon. Galic. 2 p. т.

o 91 - ? Heimerl Desm. alpin. p. 591 t. 5 f.

mz? - West Alg. Engl. Lake Distr. 1. T21.

m 93 -- Lïthemïll. Desn. Attersees p. 545 .

d $95-\mathrm{r}$. alpinum schmille Beitr. alp. Alg. p. 311 t. 14 f. 17 .

Cfr. Pen. sp.: Areh. in Q. J. M. S. 1873 p. 423. Sehizospora minor Reinsch.

\section{didymorhomdrum -}

d if COSMARIUM Nordst. Desm. Ital. p. 36 t. 12 f. 11.

d 89 - Tomi syll. alg. p.972.

o s9-Racil. Desm. Now. p. si.

n 91 URSINELLA huntze Rev. gen. pl. p.924.

\section{DIDIHOCLAINON}

d 18 Rialfs Brit. Desm. p. 14.

d 52 Pritch. Inf. p. 270.

d fit Gray Brit. Alg. p. 71.

d 66 Eyrich Algenfl. Mannh. p. 131.

d 73 Lelponte Desiu. subalp. p. 37 (sep.p. 27 .

d 75 Microgx: Dict. p. 250.

d 7 Delponte Desmil. subalp. II p. is (sep.p. 1it).

o s1. Mrsh. 1. Zeal. Tesm. p. 30g [efr Arch. in Gievillen. พ. 10. 18si, p.30].

d 83. Henowry in Baill. Dict. bot. II p. 411.

\section{Didymomier}

d If Treris. Alghe Coccot. p. 19. = Trib. Schimatothallarnm, Didymoprium et (iloeopriun).

\section{DIDIHOPRICH}

n 43 hütz. in Linnar 17 p.st ("Didymopsium"). d 43 hüt:. Phice gener. p. 115.

d 1. Wont. in Dirt. unir. hist. nat. Y. 5 p. 10 (Didymoprion).

d 45 Rulfs in Anu. Nat. Hist. v. 16 p. 10 et 1846 in 'Trans. I Bot. Soe. Edin. r". 22 p. 16i3) (inclus. B a m. busina].

d 15 Kïtz. Plyeol. germ. p. 141.

i) 4 Tiab. Deut. Krypt. Fl. p. si et VIII.

d is Ralfs Brit. Desin. p. 55 .

d 4t hitz. spec. Alig. p. 189.

d 52 I'ritch. Int: p. 239.

o jo Grun. Desm. p. 493. (inel. Bambusina).

d $61 \mathrm{Arch}$. in I'riteh. Inf. p. 719 et $T \cdot 23$.

d tio Rab. Firypt. Fl. Sachs. p. 180.

d (i.t Groly Brit. Alg. 1). It.

d dir Not. Desm. Ital. p. 14.

d 68 Rab. Fl. Eur. Alg. 3 p. 106 et 153.

d TR thood Fr. Alg. p. 125.

o 73 Pfeiffer Nomencl. bot. p. 105t.

I 73 Ihelponte Desm. subalp. p. 35 et 54 (sep.p. 23 et 22 ).

1173 Nordst. Norg. Desm. p. 49. Subg. Desmidii.

d 75 Microgr. Diet. 1. 231 et 251 .

d 7 Frank in Lemis synops. p. 1633.

d 83 Munoury in I3aill. Dict. bot. II p. 415.

d st fruy Monogr. loe. Conj. 1).41 (Nect. Desmidii).

d 86 Frank in Leunis Synops. 3 p. 19\%.

d 88 Hansg. Prodr. Algenfl. Böhn. p. 1 i2 sect. Desmid ii).

d 89 Toni syll. Alg. 1. TSa (Nubg. Desmidii.

d 90 Wille in Natürl. Pflanzenfam. p. 15.

o 98 Tumer Alg. Ind, orient. p. 150 .

\section{ridymotor.um -r}

o $m 31$ CLOSTERIUM Corda in Alm. de Carlsb. 1835 p. 185. 190, 1!)? 209 t. 5 f. 61 -65 [Nulla deseriptio vera. Alia speeies quam Ralfsii].

(1) ts - a Ralfs Brit. Desm. p.168 a t. 29 f. 7 a et b. (Cl. subrectum Tivel. 1935 [?]). [Cl. fractnm Tum. 1893].

d $-\beta$ Baillyanum Brét. in Ralfs ibid. p. 169 t. 28 f. 7 e et d Cl. Baillyanum Breet. in litt.) $[\alpha$ et $\beta=$ Cl. Baillyanum Nordst. $1885 ; \beta=$ Cl. Ensis Focke ? sec. Rai, 1868].

d 52 - Iritch. Inf. 1. 2S1, et $\beta$.

ph 55 -Osborne in Q. J. M. S.e. v. 3 p. 58 fig. E.

ph 55 - Wright in Q. J. I. Se. $\therefore .3$ p. 172 c. fig. xylogr.

a 61 - Arch. in Priteh. Inf. p. 766 t. 3 f. 39 [e Ralfs, f. $\tau$ a].

d $63-R a b$. Iirspt. Fl. Sachs. p. 172.

d fis-Rab. Flor. Enr. Alg. 3 p. 125.

d - b. Brebissonianum ibid. (Cl. subrectum Brél.).

d -e. Baillyanum ["Baileyanum"] ibid. (inel. Cl. Ensis Focke?

d - d. decussatnm ibid. (Cl. decuss. Kïtz.)

n 70 - Teinhard Arbeiten Naturf.-g. Tharkow I p. 14.

- Boršcou in schrift. Kiew. Naturf. Ges. I. 1 p. 52 [et $\beta$ Brebissonianum?]. d $\overline{15}$ - Mierogr: Diet. 1.176 t. 10 f. 41 [e Ralfs Br. Desm.
f. T c diminut.].

d 75 -Juculs. Desm. Danem. p. 175 t. 7 f. 6 .

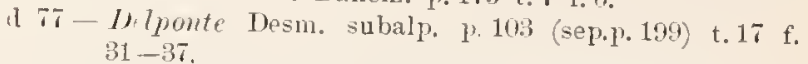

75 - Reinsch in Pringsh. Jahrb. v. 11 t. 17 f. 9.

- 5 - $\beta$ multinucleatum Nordst. Alg. Nandric. p.9.

d $78-K i n c l m$. Sclules. Alg. p. 138.

m is- Hempel Algent. Chemnitz 1.112.

o 83 - v. irregnlare Schnurschm. Magrar. Desm. p. 275.

d 54 - Wolle Desm. U. .- p.39 t. 8 f. $12-13$.

o 85 - Wolle in Bull. Torr. Bot. Club. 12 p. 1.

m sí-boldt vibir. Chloroph. p. 121.

ph 95 -- hlebs Bewer. u. Sehleimbild. d. Desm. p. 355 ete. 
o 80 - Stokes Key Desm. p.112.

a sti- $a$ Cooke Brit. Desm. p. 17 t. 8 f. 2 b. d.

d $-\beta$ Baileyanum ibid.; f. a, $c$, e.

ph 86 - Klebs Organisat. Gallerte b. Algen p. 382 t. $t$ f. $4-i$.

o st-f. Wolle Fr. Alg. U. S. A. p. 25 t. 55 t. 10.

d 5 - Alexenko Chlorosp. Khark. p. 2205.

o sis Hansg. Prodr. Algenfl. Bühm. p.179.

d - $-\beta$ Baileyann $\mathrm{m}$ ibid.

o 88 - Kiubin. Chloroph. env. Kharkow p.315 (sep.p. 27).

ph 88 -- Hurutfl. Zellm. u. Huillgallerte Desm. p. G9 (sep.p. 11) t. 3 f. 2 : et 37 .

n 88 - $\beta$ Hirudo Nordst. Bornh. Desm. p. 155 (Cl. II irudo)

m 88 - Iste. Jel. magyar. alg. p. 237.

n SS - f. Baileyana Racil. Mat. flor. glon. Polsk. p. 111.

3 - $\mathrm{f}$. genuina ibid.

I1 89 -- Toni Syll, Alg. 1.82.2.

a $-v$. Baileyanum ibid.

d-viregnlare ibid.

d -v. multinucleatum ibid. p. 823.

m 90 - West Fr. w. Alg. North Wales p. 28.

m (10-Eichler Spis Desm. Miedz. p. S.5.

m 90 - Anderss. Sverig. Chlor. 1 p. 17.

m91-Heimerl Desm. alp. p. 592.

n 91 ARTHRODIA Kintze Rev. gen. pl. p. 883.

d 92 Clost. f. Crutw. in Nuov. Notar. III p. 18 .

in 92 - West Fr. w. Alg. W. Irel, \%. 130.

d 92 - Wolle Desm. U. S. ed. II p. 411 t. 9 f. 12--13, t. I f. 11 .

○ 92 - Gutw. Flor. glon. Galic. 3 p. 120.

d - f. ibid. p. 121 (sej.p. 16) t. 3 f. 15.

o:13 - Lütlemüll. Desm. Attersees p. 511.

o 93 - Twrner Alg. Ind. orient. p.20 (sensu Corde non Ralfs

m 91 - Iste. Adat. Roman. alg. 1. 156.

m 94 - -1lexenko Mater. alg. Khark. p. 21.

m 94 -Johns. Rare Desm. U. S. p. $286 \%$

m 95 - v. Bailleyana Hieron. in I'flanzenw. Ostafrik. p. 19. $m$ - v. major ibid.

Cfr. Clost. acerosnm Mcnegh. 1810, Cl. turgidum v. kileles 1sig.

\section{dielymmm.}

m 31 DESMIDIUM forda in Alm. d. Carlsb. 1835 p. 208 t. 4 f. $43-44$ [D. bifidum sec. Ehrenl, in Wiegm. Arels. 1831 p. 185. - Desm. Swartzii f. didyma Toni et Levi 1sins].

d $15-K$ - Kitz. I'hycol. germ. 1) 141.

d ts-livlfs Brit. Desm. p. 207.

d t!-Kït s. spec. Alg. p. 190.

o 52 - Iriteh. Inf. p. 241 .

d 61 - Arch. in Priteh. Inf. p. T23.

d 63 - Kab. Krypt. Fl. Sachs. p. 181.

d 68 - Tial. Flor. Eur. Alg. 3 p. 154.

l ss-Hansy. Prodr. Algenf. Bohm. p. 171.

d bi - Tomi syll. Alg. p. Ts1.

\section{diftivile}

a 93 Cosmarium Ziitkcmïll. Desm. Attersees p. 551 t.

d - v. subleve ibid. 1. 5.2 t. 8 f. 4 .

Cir. Cosm. Meneghinii f. rotundata et C. angulosum. Cfr. Hest in Journ, Bot. 1845 p. 68.

\section{rlifiorme}

i 38 XANTHIDIUM? Ehrend. Inf., 1.149 t. 10 f. XXVI. [Ankistrodesmns sp.? see. Curdle in Alm, d. Carlsb. 18t1 p.211. Raphidium fascicnlatum hït: 1845. Rh. difforme Ral. 18t7].

52 -? Pritch. Iuf. t. 12 f. 513 et 511 ed. 3, 1Nii1 t. 17) [Fossile. Quid est?].

\section{Digitus.}

d 3. CLOSTERIUM Ehrend. Entw. d. Inf. p. 138.

d $38-E 7$ renb. Inf. p. 1 t. 6 f. III [III. $2=$ P. interrup. tum?] (incl. Plourosicyos myriopodus).

d 10 - Menegh. Hynops. Desm. p. 236 (sep.1. 26). [fuclus. Pen. lamellosum Breb.].

o 41 - Bailey Aner. Bacill. p. 302 (sep.p. 21) t. 3 f. 33.

d 45 - IIass. Brit. Alg. p. 376 to 85 f. 1 [ex Ehrenb. 1. c. fig. III, 1 delineati].

1 45 - Kütz. Phyeol. germ. 1. 132. [incl. P. la mell.].

d 47 - Focke Plyss. Stwil. I 1.57 et 68 t. 3 f. 22-27 [f. 22 Pen. lamellosum; f. 23 et 27 P. interuptum, 2.4 P. Navicula, 25 et 26 P. Nægelii?].

a 18 PENIUM Brebl. in Ralfs Brit. Desm. p. 151 t. 25 f. 3 [ $a=$ I'. oblongum].

d 49 Clost. (Netrium) Nag. einz. Alg. p. 107 t. 6 f. D. [P. Nitgelii Bril. 1s61].

d 52 Pen. I'ritch. Inf. 1, 273.

ph 5 , NETRIUM Itzigh,s, et Rothe in Rab. Alg. n:o 50.8.

d 61 Pen. Arch. in Priteh. Inf. p. 501 (incl. P. oblong nm)

d 63 - Tirb. Firypt. Fl. Wachs. 1) 168.

d 66 - Eyrich Algenfl. Mamnh. p. 132. [incl. P. lam.].

ph 6it-Areh. On Asteridia (sep.p. 1) in Q. J. M. Sc. p. 183 t. 8 f. 1.

o 67 Clost. Reinsch Algenf. Frank. p. 185.

o 67 Pen. Not. Desm. Ital. p.tit t. 8 f. 75.

z lis - Arch. in Q. J. M. Sc. 8 p. 68.

d $69-$ Rnb. Fl. Eur. Alg. p. $11 \%$.

m 70 - Nordst. Desm. Brasil. p. 202 (sep.p. 104).

d 73 - Wood Fin. Alg. 13, 105 t. 20 f.6.

d 77 - Delponte Desm. subalp. P.86 (sep.p. 182) t.15 f. i) - i1.

d is - Kirchn. Alg. Ruhles. p. 131.

m $78-$ Hempel Algenf. Chemnitz. p.111.

a 79 - a. typicnm Kicls Desm. Ostpreuss. p. 2t; $\alpha, \beta, \gamma$ (Pen. lamellosum Brib.), o (P.oblongum De Bury).

d - b. interraptum ibid. 1.25 (P. inter.rutum Bréb. $a$ t. 2 f. 3 a et b; $\beta$

phs3 - Fischer Gypsliryst. Desm. p. 14t, 16i t. 10 f. T a.

d 81 - Wolle Desm. U. S. p. 31 t. 53 f. 1.

o - v. ibit., t.5 f. 1-2.

m 84 - Wille sydamerik. Alofl. p. 21 .

d 85 - K̈̈rchn. Mikr. Pflanz, d, Siissw, p. 22.

m 86 - Layerle. Amerik. Desm. 1. 253.

o Si-Stolies Kiey Desm. 1.111.

d si - Cooke Brit. Desm. p. 40 t. 16 f. 1.

m si - Martel in Notarisia p. 338 bis.

d 8 it - Alexenko Chlorosp. Khark. p. 232.

d is - IIansg. Prodr. Algenfl, Bïhn. 1) 176.

m si-Riabin. Chloroph. env. Kharkow p.314 (sep.p.26).

1h 89 - Itur)tfl. Zellm. u. IIüllgallerte Desm. 1) 101 (sep. p. $43 ;$ t. 3 f. 62.

m 88 - Iste. Jel. magyar alg. 11.240.

m SS - Racib. Mat. flor. glon. I'olsk. 1).99 (sep.p. 20).

d sor-Tomi śyll. alg. p 860 .

o :10 - Wille in Natïrl. Pfanzenfam. p. 10 f. 60 [e Nägel.]

m 91 - Böry. Desm. Brasil. 1.26.

m 90 - Eicher Spis Desm. Miedz. p. 85 .

m 90 - Anderss. Siverig. Chlor. 1 p. 19.

m - f. curta ibid. et t. 1 f. 14 .

d 91 - Firchn. Mikr. Pflanz. d. süssw. ed. 2 p. 23.

m!l - Heimerl Desm. alpin. p. $5: 1$. 
m.2-Wcet Fr. w. Als. W. Irel, p 127.

a - v. constrictum ibid.

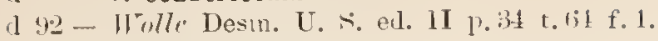

- v. ibid., t. i f. $1-2$.

m 93 - Lüthemïll. Desm. Attersees p. 044 .

1 93 - f. rectum Turner Alg. Ind. orient. p. 1.5 t. 1 f. 2 .

z $94-$ lioy Sicott. Desm. 1.251.

m S-Alecenko Mater, alg. Thark. p. 20.

ph:4 - P'alla in Ber, dentsch. bot. Ges. 12 p. 2030.

o 45 - West in Jouru. Bot. 33 \%.66 inclus. P. lanellosum et P. navigium.

m 45 - hiacil. in Flora v. 81 1).32.

m 95-schrüder Alg. II. Riesengel. 1. Lti.

\section{lilututume}

1 15 CLOSTERIUM Kä̈z. Phyc. germ. 13. 132. [C. costatum scc. liulfs Brit. Desm.].

\section{rizetretrum}

d s1 D0CIDIUM Wusk. N. Z. Desm. p.310 t. 11 f. 11-14; nec ('Teec) Tordst. [D. ovatum Nordst. see. Areh. in Frevillea $\%$. 10, 1581. p.30].

\section{ritututum}

1 6.t PLEUROT ENIUM Clece Birir. t. Siverig. Desm. p. 494 t. $t$ t.ti.

1 68 - Raib. Flor. Enr. Alg. 3 p. 142.

117 D0CIDIUM Nordst. in Rab. Alg. n.o 225.

o 71 - Lund. Desm. Suec. p. Ss t. 5 f. 12] [Doc. undulatum sec. Tumer $18 \% 3$.

1 is-Kirelen. Alg. Selules. p.14t.

d 81 - Wolle Desm. U. A. p.50 t.50 f. 32. Doc. undulatum sec. Tumner 1893].

m 86 - Lagerh. Anerik. Desm. p. 252.

o St-Stoker Kiey Desm. p.11t.

d $89-$ Toni Syll. Alg. 1. 873 .

10 - Wille Natiul. PHanzenfam. 1. $10 \mathrm{f}, 6 \mathrm{H}$ a' (e Lund.). m. W - West Fr. w. Alg. W. 1rel. p. 116 t. 19 f. 5.

o - f. ibil. t. 19 f. $1 ;$.

I - v. subundulatum ibid., t. 19 f. 7.

d 92 - Holle Desm. U. S. ed. Il p. 5. t.61 f.32.

Cfr. Pleurotienium nobile Richt.

\section{dilatretume-r}

a 38 STAURASTRUM Ehenb. 1nf. 1.143 t. 11) f. XIII (Descriptio et figg. e vertice malie?.

m 339-Ehrenl. Meteorp. p. 5i (scp.1\% 12) t. 1 f' $2+$ [e basi].

d $10-$ Menegl. Synops. Desm. p. 227 (sep.p. 27).

d 41 -lyitch. 1nf. P. $\$ 5$ f. 100 et 101 [ex Ehrenb.; n. v.].

1 1.5-Ralfs Ann. Nat. Hist. v. 15 p. 155 t. 11 f. 5 let Trans. Bot, Soc. Edin. v. 2 p. 143 t. 11).

d 4.5 GONIOCYSTIS (Staurastrum) IIass. Brit. Alg. 353 t. 8.5 f.5 [e lialfs 1. c. (male) delineata].

d 45 PHYCASTRUM Kintz. Plycol. germ. 1. 134.

d tistaur. líub. Kiryte F1. 1).56.

d 4 - Rulfs Brit. Desm. 1). 13:3 t. 21 f.s.

d 19 Pliycastrum hँ̈̈z. spec. Alg. p. 1 si.

$n$ 4! - Stenactininm) Verg. einz. Alg. p. 126.

d 52 staur. I'ritch. Inf. p. 2 t5 t. 22 f, 10, et 101 [ex klutul. $1 \times 35]$.

5.1 - Ehrend. Microgeol. t. 34 XII B f.17 [e Meteorp. 1 \$3! delineata]

a 61 - Arch. in Pritel. Inf. p. $\mathbf{i}+1$.

d $63-h a b$. Krypt. Fl. Áachs. p. 1.49. f. 1. p. 158 [e lialfs].

d 67 - v. obtusilobum Vot. Desm. Ital. p. 53 t. 4 f. 17.

a 68 - liab. Flor. Eur. Alg. :3 p. 207, fig. xyl. p. los [ut supra 1863].
1 - b. alternans ibil. (St. alternans Bred.

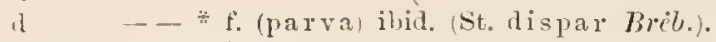

1 - c. tricorne ibid. (sit. tricorne Meneghe) cum forma 1.208 .

d 73 - Woorl Fy. Alg. 1) 1inl.

d - v. alternans ibil.

a - r.tricorne ibid.

n i6 - v. Wittrockii Jacols. Desm. Dunem, 1. 2013 Cosn. Wittrockii Lund.).

d 78 - Kirchn. Alg" Schles. 1) 16.5.

m.81 - Hempel Algenfl. Cheninitz Fort.s. p. 20.

o 84 - Lopot Mater. alg. Warszaw. p. 254.

1) 84 - Wrolle Desin. U. S. p. 12. t. i2 f. 32-33.

m $\mathrm{St}$ - Arturi Liste alg. Moscon p. 113.

d 8 õ - Kirchn. Mikr. Pflanz. d. Kiussw. 13. 2.2.

m Sis - Norrlst Desm. Grönl. p. 111.

d 86 - Frank in Leunis symops. 3 p. 1!t.

0 86 - Stukes Key Dosin. 1. 16i.

m 87 - Alexento Chlorosp. Khark. p.25t.

a 87 - Coole Brit. Desm. p. 162 t. jt t.s.

1) 88 - Ilansy. Prodr. Algent. Böhm. 1) 212.

d - $\beta$ tricorne ibid. p. 250.

d 88 - Toni et Levi F'. Alg. Venez. p. 45.

m 88 - Ist $i$. Jel. magyar. alg. p. 232 [sensu lat.].

o $88-\beta$ obtusilobum Norclst. Fr. wat. alg. N. Zeal. 1. 41 t. 4 f. 19.

ins - b. alternans Rucil. Iat. flor. glon. Polsk. p. 10!. d 89 - f. Mask. Furth. Not. X. Z. Desm, 1.21 t. 1 f. 35 [fig.. dubia].

d 8! - Tomi syll. alg. p. 1193.

d 90 - f. Gutio. Wahr. d. Priorität p. 71

m 10 - Hichler spis Desm. Mienz. 1?. S!t.

d 91 - Kirchn. Mils. Ptanz. d. Süssw. ed. 2 p. 21.

n1 91 - Gutw. Flor. alg. Lenpol. 1.4it.

d -f. ibid., t. 3 f. 1. .

d $92-v$. insignis Kac. Desmidya Ciastoni. p.388 t. 7 f. 13.

d 12 - Wolle Desw. U. S. ed. I1 p. 142 t. 63 f. $32-33$.

m 93 -- Lütlemilll. Desin. Attersees p.5fi.

d 43 - v. Indicum Tum $r$ Alg. Ind. orient. p. 109 t. 13 f. 1 .

zf 93 - hoy Scottish Desm. 1. 237 t. 4 (18.1) f. 1 (se 1.p. 19).

o $44-$ Möb. Austral. Süsswasseralg. II p. 342

o 45 - f. Schmidle in Hedwigia 34 p. 85.

Cfr. Staur. punctulatum lieinsele 1 ss et Phyonstrum rotundatum.

\section{rilatutum}

d s XANTHIDIUM Lordst. Algolog. smaisak. 4 p. 154.

d 59 - Nordst. Fr. wat. alg. X. Zeal. p. 13 t. 4 f. 25.

(1) s:1 - Holacantlium) Toni ryll. alo. p. 925.

\section{Jim,1\%)}

$125 \pm$ CLOSTERIOM Ehrent. Microgeol. 1, Bin.

\section{aimov)}

d 19 PALMOGLOEA Cylindrocystis) Kütz. Spec. dlg. 1. 2.2! [Coccochloris s]?.?].

o 51 - Watm. in Rab. Alg. n:0 349 (P. macrococca?).

\section{Jiorlon}

d 4! EUASTRUM Perty in Bern. Hitt1. 1819 p. 173 [Eu. binale Rulfis sec. auct. 1852. kl. Leb. 11. 218].

\section{riplrerenthrum.}

d 6. STAURASTRUM Not. Desm. Ital. p. 49 t. 4 f. 35 [St. vestitum b. dill. Rab. 1 sis; St. monticnlosum v. diplacanthum Nurdst. in Toni 1869).

A : 13-v. anglicum Thmer Desm. Totes p.315, et f. 10 p. $3+1$. 


\section{DTILOSI'HERILW}

n 62 Cormer in frortm. et Schenk Schweizer. Kryptog. fase. 3 snb n:o 13ti D. moniliforme]. [n. r. ipse. De cetero genus mihi plane ignotum].

aijlospora-n-m-n

dzf 71 CYLINDROCYSTIS Lmm. Desin. Sunc. p. 83 t. 5 f. 7. Nohizospora pachyderma Rrinsch 1875].

m 5 PENIUM Jucubs. Tesm. Danem. p. 161.

11 S2 CALOCYLINDRUS Wolle in Bull. Torr. bot. Club. ง. 103.15.

d 81 - Wulle Tlesin. U. S. p. 50 t. 12 f. 1s.

o 86-Stukes Key Desm. 1.114.

dzf sti Cy l. Coolie Brit. Desm. 1. 45 t. is f. 1 [e Lundell].

n 8s SCHIZ0SP0RA Hunsy. Prodr. Algenf. Böhm. p. 175 in 110 ta.

n 88 Cyl.? Nurdst. Fr. wat. alg. 1. Zeal. 1. T2 t. 7 f. 25.

dz 84 - ? Toni syll. Alg. 1. sifi.

o 91 - Staclimayer Algeng. Gloeotren. 12. 25.

m 91 - ? Borge Bidr. Sibir. Chloropl. p. 15 t. 1 f. 11.

119 GYGES Kuntze Rev. gen. pl. 1. S9i.

d $92 \mathrm{Cyl}$. major West Fr. W. Alg. W. Irel. p.131 t. 20) f. 5.

d 12 - Wolle Desm. U. S. ed. II 1)61 t.15 f. 18.

m 93-(Clitocystis) Twmer Alg. Ind. orient. 1.16 t. i f. $\mathrm{s}$.

In 93 - Eichle Mat. Hor. Miedz. 1). 1193 t. 10 f. 32.

d. $94-\mathrm{f}$. intermedia schmidle in Flora 1. 79 t. 7 f. $\$$

d 94 - sulsp. major f. constricta llest New Brit. Alg. p. 4 t. 1 f. 4 .

o 41 - - Roy Sicot. Desm. p. 25. (sep.p. 62).

\section{aiptillm}

d ToSTAURASTRUM Nordst. Desm. Brasil. p. 22 (sep.p. 189) t. 4 f. 5 i).

d 89 - Toni Syll. alg. 1. 1162.

\section{aivertum-ru}

1 6o CLOSTERIUM Arch. Xew Cosm. etc. sep.p.11), in Duibl. Nat. Itist. Foc. Pr. p. Si t. 2 f. $23-21$, Jonr. Mier. Ne. 1. 249 t. 12. [Cl. intermedium b. directum Kiteles 1sis. - CI. Ulnal.

d 68 - Tiub. Flor. Eur. Alg. 1. 127.

ph 73 - Norrlst. Norg. Desm. 1. 41.

o $80-\mathrm{f}$. Nordst. in Wittr. et Nordst. alg. exs, n:o 370; et in fase. 21 (18s9) 1). 4 .

o 85 - Kuci7. Nonn. Desm. Polon. 1).63 (sep.1. 7 .

d 86 - Cooke Brit. Desm. p. 18 t. 8 f. 3.

m s9 - Nordst. Fr. wat, alg. X. Zeal. 1.64.

a $89-$ - Tomi siyll. alg. p. 823 .

n 91 A RTHR0DIA Kuntze Rev. gen. 11. 1\%.853.

m 12 Clost. Thest Fr. w. Alg. WT. Irel. 1) 120.

m 91 - Iiorge Süssw. Chlor. Arehang. 1), 14.

\section{riseretum}

d si CoSMARIUM Sem. Frow. Alg. North Cornw. 1.17 (sel.j. 10, t. 4 f. 23.

o 87 - Cooke Jirit. Desm. 1\% 1Ss t. 6tj f. 2 (e Jenu.).

d si DISPHINCTIUM? Tomi ty.ll. alg. p.

\section{aispere}

d 56 STAURASTRUM Mrib. Liste 1\% 114 t. 1 f. 27. [Staur. dilatatum b. alteruans f. liab. 186i8].

n 63 PHYCASTRUM (irogn. Plant. Cry 1 t. 1) 262.

o sos sta ur. Nordst. Fr. wat. alg. N. Zeal. 1.11. rispersume

d gis Cosmarium Johns. Rale Desm. U. $\therefore$. II p. 297 t. 210 f. 1!.

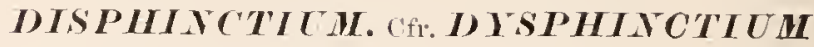
[false a dio nro bira derivatum].

\section{rlispututu}

d 73 MICRASTERIAS Hood Fr. Alg. 1). 142 t. 13 f. 4 (Tetracastrum americanum Arch.) [M. laticeps sec. Irolle 18S1].

n si HOLOCYSTIS Bennett F1.-wat. Alg. Eng- Lake Distr. 11.5

\section{dissiliens}

d or CONFERVA Will $u$. Br. Conf. Pl. 63 (c. descript.) et (1SO!n) 1.51 [Alia species quam Smithii sec. Ralfs Brit. Desm.].

d 12 - Smith Engl. Botan. vol. 35 t. 2464.

d 12 DIAT0MA? A\%. Dis1\% Alg. suec. 1, 34.

d 16 - Litjellad Sv. Flor. 1.596.

d 17 Conferva $A \mathscr{l}$. Syst. alg. seand. p.s1.

d 19-Lymgl. Tent. Hydr. Dan. H. 136 t. 45 f. E $1-3$.

d 21 - Gray Xat. Arrang. Brit. I'lants p. 311.

- 22 CADMUS Lory in Dict. class. hist. nat. I p. 597 (gen. zoocarrear.) [Ulothrix].

d 24 Conferva $d y$. Syst. Alg. 11. 90.

o 25 MYX0NEMA Fries Plant. Homon. p. 313.

d 2-Conferva Spreng. Syst. reg. IT, I p. 355.

d $30-$ Duby Botan. Gallic. II 1) 984 [ex 1\% Ulothrix] [Desm. limbatum v. mucosum Chrme, 1s37].

d 33 - Harre, in Hook. 13. Fl. 11.352.

d 33 - II allr. Fl. crypt. germ. II ]. 34.

d 35 - Irét. et God. Alg. Falais. 1) 20.

d 36 M yxonema Fries Flor. scan. p. 323.

d 11 Conferva Horr. Man. Br. Alg. 1\% 128.

n 45 OL æ⿸尸 RIUM Ber\%. in Jenn. Fl. Tnubr. Tells p. 192 (1. 919$)$.

d 45 - Jerk. apud Rulfs in Ann. Nat. Hist. т. 16 p. 11 t. is f. 2 let 1 sti in Trans. Bot. Soc. Edinb. v, 2 p. $161+2$.

d $45--M a s s$. Brit. Alg. 1).346 t. $\$ 3$ f. $3-1$.

d. 17 Myxonema Rab. Dentsch. Krylt. Fl. n:o 526 1 1.98. dzf is HYALOTHECA Bréb. in Ralfs Brit. Desm. p. 51 t. 1 f. 1 [sensu Smithii, non Willw.; Desm. mucosum Iive 1. 1835, Rulfs 1813].

o 49 - Lundsbor. Brit. Sea- Teeds p. 34s.

dz 52 - Iriteh. Inf. 1. 239 t. 13 f. 32 et 35 [fig. Ralfsii $1 b$. et $c$ diminutæ].

o 513 - Lirle. List. 10.11\%.

ph zf 5 - Hofm. Fortpfl. p. 35 t. 1 f. $5-8$.

ph 5s- De Bary Conjug. 1) 56.

d 60- Wallich Desm. Low. Bengal 1\%.187.

dz 61 - Arch. in I'riteh. Inf. 1). T22 t. 2 f. 32 et 35 [ex ed. 3 ].

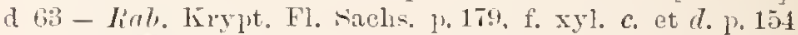
linlfis]

o tit - licinsch in Rab. Alg. Eur. n:o 1660.

o 67 - Reimsch Algenfl. Frank. 1. 203.

o fit-Not. Desm. Ital. p. 2 -j t. 1 f. 1.

d 6s-Rab. F'o1. Eur. Alg. 3 p. 152. f. xyl. p. 105 [e Ralfs]. m 70 - lieinherd in Arbeiten Naturf.-g. Clarkow I p.15.

m 70 - Nordst. Desm. Brasil. 1. 206.

d 73 - Hood Fr. Alg. 1, 124 t. 12 f. 12.

d 73 - Ielponte Desm. subalp. p. 59 (sep.p. 47).

dzf $-\beta$ major ibil. p.li1 t. 1 f. 1. 3, 4, T, 10, 11. 12.

d $-i$ minor ibid. p. 62 t. 1 f. $2,5,6,8,9$.

1 $73-a$ genuina Nordst. Noro. Desn. 1. 19.

d $-\beta$ bidentula ibid., t. 1 f. 2 ?. 
ll $-y$ tridentnla ilud., t. 1 f., 2.3.

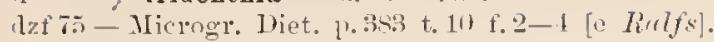

in 7 is - Nordst. Desm. aret. $\rho$. 11i $(\beta$ et $\mu \rho$.

A - o quadridentula ibid. p. 16 (et f. mixta).

m is - p birlentula et $y^{\prime}$ triclentula Nordst. Desm. Ital. 1) 2 .

(1) T - a circularis Jucobs. Desm. Danem. 1).212. cam f. punctata 1 . 213 .

d $-\beta$ triquetra ibil. 1.213 t.. t. 2 !!

d 78 Kirchu. Alu. Sehles. 1. 131.

mo -8 - Hempel Algentl. Chemnitz 1. 113.

o 79 - Will, Ferskv, alg. Nov, semlj. 1) 131 $(\alpha+\beta)$.

ni $\quad \beta$ bidentula t. major ibil. p. (ie.

o 82 - Joshue in Journ. Bot. v. 24 p. 301.

ph 83 - Fischer (ry pskrystall. Desm. 1) 161.

o $8 t$ - Gry Mon. loe. Conj. 1. 7.?.

m $8 t$ - Rircib. Desm. okol. Irakowa P. j.

m $8 t-4 r t u r i$ List. alw. Moseon p. 1:35.

Izf 84 - Wolle Desin. U. S. p. 22 t. 1 f. 3 -12, t. 24 t. 20.

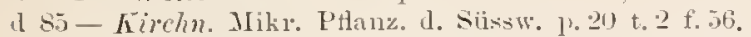

(1 ha - $\checkmark$. hians Wolle in Bull. Torr. Bot. Club. 12 p. 1.

phl s. - Klchs Beweg: u. Schleimb. d. Desm. 1. 361 .

185-v. tatrica " circularis 1 -2, $\beta$ bidentula (1 -2) Iiacil. Nonn. Desm. Polon. 11. (t) t. $14 \mathrm{f}$.j ise 1.S t. ti).

$m$ - ff. genuine, bidentula et tridentulæibid. p.6.

m S6 - Layerh. Amerik. Desm. p.22S.

m - $\beta$ bidentula ibid.

n Sti-Stakes Kiey Desm. p.110.

o si - B bidentula f. Lagerh. in Wittr. et Nordst. Alg. exs. n:o s0t. et 1 sit9 in fase. 21 1).33.

Izf 86 - Cooke Brit. Desm. p. T t. 3 f. 1 ( et $e$ (r.minor).

phsi-Klebs Organisat. Gallerte b. Algen 1.379 t. it f. 1.

d st - r. hians Wolle Fr. Alg. U. s. A. 1). 21 t. 51 f. $14-16$.

d 87 - v. annulosa Iste. Diagn. prev. ㄱ. 211 (sep.p. 12) [Cfr infra 1.s.5].

(1 st-Alexenlio Chloros]). Inhark. p. 218.

1 48 - IIansy. Prodr. Algenfl. Böhm. p. 168 fig. xyl. 100.

1 - $\beta$ bidentula et $\gamma^{\prime}$ tridentula ibid. et $1.27 \%$.

o s. - Rirbin. Chloropli. env. Kharkow p.321.

ozf s. - Bolalt Desm. Grönl. 1. 43 t. 2 f. 53.

$m$ - ff. bi.qninquedentula ibid.

ph $189-\beta$ bidentula f̈. minor Ilouptfl. Zellm. u. Hüll-

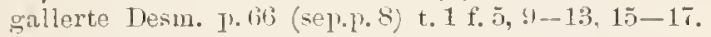

phd - f. major ibid. p. is et 1016 (sep.1). 10 et 4.5 ) t. 1 f. 1 1. $18,2.2 .23,26-30$.

m ss - Vordst. Borml. Desm. p. 20:

msis - Iste. Jel. magtar. alg. p. 214.

d - v. anulosa ibid. et t. 1 f.st [t. typlica].

ms $-f$. bidentula et tridentula Nordst. Fr. wat. alg. T. Zeal. 1]. 2 T.

n 89 - Curter in A. M. Micr. J. 10) f. 2 lex Wolle).

ms9-v. geunina Fucib. Desm. lithuan. 10.65\%.

11 - v. tridentula ibicl.

dz 59 - Toni Syll. Als. 1) T.5.

d $-v$. hians ibid. 1. Tsit.

d - v. anulosa ibid.

m - - v. major ibid.

m - v. minor ihid.

a - v. tatriea ibid.

d - v. triquetra ibid.

d - r. circularis ibik.

n 90 - Whlle in Natürl. Pflanzenf. p. $15 \mathrm{f} .9 \mathrm{~K}$ (e Delp.).

$10-$ Lagerheim in Hedwigia v. 29 t. 2 f. $1-7$ (cum patrasit.).

m90- Bürg. Desin. Brasil. p. 24.

m (1) - Eichler Spis. Desm. Miedz. 1. St. m (4) - Anderss. Sverig. Chlor. 1 j, s.

$m$ - $\mathrm{f}$. minor ibid.

m:1 - Iste. Fragm. Alg. 1 1\% 1168 .

d 91 - Kirchn. Mikr. Plimz. d. Süssm, ed. 2 p. 21 t. 3 f. 64.

m!11- Heimerl Desm. alpin. 11. 5x-s.

m:11-Borge Bidr. Sibir. Cluloroph. 13. S.

o 91 - Gutw. Flor, alg. Leolol. p. 2 - t. 1 f. 3.

m th - Borge Chloroph. Norsk. Finnark. 1.5.

mat - West Fr. w. Alg. W. Irel. 1. 11\%.

o !2- Möl. Austral. Süsswasseralg. p. 13!!.

m?2 - f. bidentula Ruc. Desmidya Ciastoni. 1) 353.

laf 92 - Wolle Dosm. T. .. exl. II 1.22 t. 1 f. $3-12$.

l) - v. hians ibid., t. 12 f. 14-11i.

m! - - v. tridentula Gutw. Flor. glon. Galie. 3 p. 119.

m $92-v$. tatriea West Alg. Eng. Jake Distr. p. T1s.

m ? 1 2- - limmer Alg. Nt. Polten I p. 5 .

dzf 93 - Batley Contr. Queensl. Fl. p. 39 t. 2 f. 2t: e Cooke).

o 13 - Lüthomilll. Desm. Attersees 1). iss.

10 - v. bidentula ihid.

o $(\%)$ - Tumer Alg. Ind, orient. p. 151.

in 93-Witt) et Nordst. Alg. exs. 11:0 1105.

m 94 - Iste. Adat. Roman. alg. p. 157.

o $14-v$. eircularis Filarszly in Fryptog. exs. n:0 it et in Ann. Naturhist. Hofmusenms 1.. 1 p. 139.

0 $94-$ Mob. Austral. Süsswasseralg. II 1.331\%.

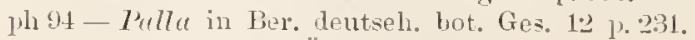

un 41 - Borg. F. alg. Gsturönl. 1.32.

m-v. tridentata ibid. p. 33.

m!1t-Alecentio Mat. alg. Khark. j) 1 s.

In 45 - v. tatriea schmidle Beitr. all'. 1]g. p.30s.

o 5 -v. bidentula Rucib. in Flora v. $\$ 1$ p. 30.

\section{listentum}

d s. STAURASTRUH Wulle Bull. in Torr. bot. Club 1ss? 1.. -9 t. 13 ז. $\tau$.

d st- Holle Desm. U. ‥ p. 14 ! t. 11 f. 15-16 [fig. 15 non bona].

o si-Stokes Iiey Desm. 1. 164.

d 59 - Toni syll. alo. p. 1231.

d 92 - Wollo Desm. U. S. e.l. II p.115.5 t.52 f. 15 et 16.

\section{elistich"lm -re}

o 87 COSMARIUM Norlst. Algolog. smisak. \pm 1) 160.

d s. - Vordst. Fr. wat. alg. X. Zeal. p. 51 t. 5 f. 16.

d s9-Tomi syll. alg. p. 10501 .

n !1 JRSINELLA Kuntze Rev. gen. 11. 1.:!24.

1) $12 \operatorname{Cos}_{0}$. v. heterochondrum hille. Desmidya Ciastoni. 1. 376 t. 6 f. 30 .

1 94-v. irregulare Eichl. et Gutw. sivec. alg. nov. p. $113 \mathrm{~s}$ t. $1 \mathrm{f}$ f. 1 s.

\section{divaricatum, -}

a 71 EUASTRUM Lamd. Desm. Snee, 11. 21 t. 2 f. 5. [Eu. elegans v. llivar. Jue. 1s75].

dz 83 - * tieteense Lufgr. et Nurdst. in Wittr. et Nordst.

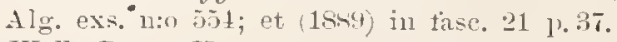

a 81 - Wulle Desin. U. S. 1. 114 t. 29 f. $18-19$.

n s.) - a. typicum Iircib. Xonn. Desm. Polon. 1. it (sep. 1 1. 38 ).

d - b. montanum ibid., t. 13 (sep. 4) f.. .

o si- Stokes liey Desm. 1). 145.

d 89 - Timi syll. alg. p. 1100.

$d z-v$, tieteense ibid.

d - v. montanum ibid. p. 1111.

1291 HELIERELLA Kuntze Rev. gen. 11. 1\%. s9s.

(1 92 En. Wolle Desm. U. s. ed. II 1).114 t. 34) f. 18-1!),

m 93 - Turner Alg. Ind. orient. 1) 81 t. 11 f. 22.2.

d $-\mathrm{v}$. inevolutum ibis.; t. 11 f. 20. 
d !4-f. miedzyrzecensis Eichl. et Gutu. Slec, alg. nov. 1. 173 t. 5 f. 3 .

d $-\mathrm{f}$. inermis ibid.; f. 40.

\section{diverirretum}

a 2 STAURASTRUM Wr/t: in BuIl. Torr, bot, Club 1852 1.28 t. 1:3 f. 12. [St frauconicum Reinsele sec. ITolle Desm. [T. S. p. 131].

\section{river!/}

d is ARTHRODESHUS liab. Iñyt. Fl, Sachs, 1197.

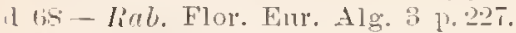

d . 9 - Tomi syll, alg. p. 10 in.

\section{diveryem.}

d 11 DESMIDIUM Ehrend. Berlin. Innatsber. 1810 p. $20 \%$. d 19 ASTER0XANTHIUM (?) Kitz. spec. Alg. p. 181.

d . 2 STAURASTRUM Pritch. Inf. p. 242.

\section{arieverymis}

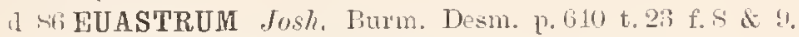
A $s_{1}$ - Toni sigll. alg. p, 1076.

n "11 HELIERELLA Kuntze Rev. gen, p. p. 8!s.

\section{Drerirlicer}

11 se Toni ronsp, gen. Chloroll. p, 452. Trib. Didymioidear. Gen, Drsplinet., Doc. Tetm., Pleurotien., Triploc. ?' Chianophila.

d St Toni syll, alg. P. SG, Trih. Desmidiacearum.

\section{DOCTDIOPSIS}

a 89 lincib. Nor. Desm. 1) 107 (sep.p. 35).

\section{D) OCI I I U H}

114 lirel, in Dict, univ, hist, nat, vol. 5 p. 12 (Clost. trabecula Ehrenb. Inf.

d 18 Bréb. apud Ralfs Brit. Desm. p.150.

d 19 Rreb. apud Fiitz. Spec. Alg. p.164, Sectio Penii.

d 5.2 Pritch. Inf. p. 27:3.

d 58 cirum. Desin. 1) 4 . 2 .

d lil Arele, in Pritcli. Inf. p. T.2n et T11.

d fod croul Brit. Alg. 1. T2.

d 66 Eyrich Algentl. Mamnh. 1. 1333.

d 6 T Not. Desm. Ital. 1) 21.

o lis Trittr. Sinantin. Desm. p. 20.

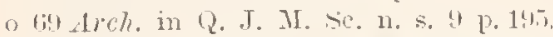

d 71 hund. Desm. Suec. p. S4 (sensu strictiore).

o 73 I'feiffer Nomencl. bot. I p.111t.

at 75 Microgr. Diet. p. 231 et 257.

o 5.5 wols. Desm, Danem. 1. 17 .

1 Tr Kirch". Alg. Sehles. p. 113.

d $\$ 3$ F

a st Manomy in Baill. Dict. Jot. Il p. 413.

d st Wolle Desur. T. S. p.17.

d 85 Kirchn. Mik1. PHanz, d. Süssw. p. 201.

o s6 Strlies Key Desm. p.10!n

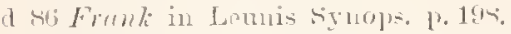

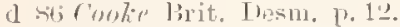

d ks IJunsy. I'roll'. Algenfl. Böhm, p. 1s.

d ss Toni et 1.evi F]. Alg. Penez. 17.3T.

d s.9 Tomi svll. Alg. 13.8i1

a !n Wille in Natiurl. Pflanzenfam. p." (Sect. 1. Eulocidium. II. Triplnceras (Bail.,

d sl Kirehn. Mikr. Pflanz. d. Silssw, ed. 2 p. 21.

d !2 Wfulle Desn. U. S. ed. II p. 50.

- 93 Tumar Alg. Ind. orient. [1, 39. Subgen,: Othidium. Pentidium, IJammatilium, Oedenatidium et Oontilium. [Cfr. Wildem. Ous, crit. Desin. 1844, p.62]. o 44 Whdem. Obs. crit. 1.65.

d 94 sound. in Fl. Nebraska p. 39.

\section{Ioliolretum}

n 39 CLOS'TERIUM bieb. in Chev. Mier. p. 272. [Cl. costatum sec. Palfs Prit. Desm.].

\section{Dommellii}

d s1 COSMARIUH Wolle in Bull. Torr, bot. Club 1881 p. 2 t. 6 f. 10 .

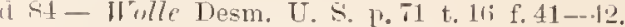

o 8 i - Stokes Kiey Tesm. ]. 128.

d 89 - Toni Syll. alg p. 1033.

11 91 URSINELLA kmtze Rer. gen. pl, p. grt.

d : 12 Cosm. Wulle Desm. U. S. ed. II p. 77 t. 1:4 f. 4 -12.

\section{lommellii}

d SOEUASTRUM lfolle Bull. Torr, bot. Club. v. 7 p. 45 t.5 A "Donnelli").

d 81 - Tolle Desm. U. A. p. 1113 t. 26 f. 6

o 86 - Stulies Kiey Desm. p. 114.

d s9-Toni rirll, alg. p. 107\%

in 91 HELIERELLA Kantze Rev, gen. pl. 1. 898.

d !' En. Tolle Desm. U. s. ed. II p. $11+$ t. 30 f. G.

\section{I)}

a S1 STAURASTRUM Wolle in Bull. Torr. bot. Club $18 s 1$ p. 3 t. 6 f. 15

d S.4 - Wulle Desm. U. S. p. 132 t. 52 f. 20

o s6- Stokes liey Desm. 1]. 165

d $8: 1$ - Toni syll, alg. 1) 115\%.

d 42 - Thulle Desm. U. S. ed. II p. 146 t. 63 f. 20 .

\section{"lom:suosim!}

d 5 T STAURASTRUM Tortst. Algolog. sme̊sak, 4 p. $15 \overline{7}$

d 88 - Torlst. F1. wat. alg. X. Zeal. p. 35 t. 4 f. 12 .

d sy-Toni Syll. alg. 1. 1180 .

(lov) 20 mse - is

d To CosmariuM Nordst. in Wittr. \& Nordst. Alg. exs, 2.:; et in fias. 21 p. 4h. [Cosm. Pertyanum hac. 1 1Sธ5].

d 89 - Tomi Syll, alg, p. (4).

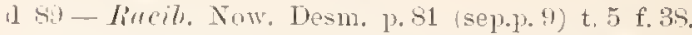

n. 91 URSINELLA Kuntze Rer, men. pl. p. 121,

แ 93 Cosm. Lüthiemïll. Desm. Attersees p. 555.

\section{allinil}

d 11 HYAL0THECA? Kitt. Phycol, grerm, p. 140 ,

1) 48 - ? Ralfs Brit. Desm. 1). 2ut t. 35 f. 16.

d th-(?) riitz. Spec. Alg. I. 18 s.

d 52 - lritelenel Inf. 11. 239.

d til-Areh, in I'ritcli, Inf. I. T22.

d $169-$ : Rirl. Frypt. Fl. Sachs. p. 17 .

d $65-$ ? If th, Wlor. Eur. Alg. 3 p. 152.

d 69 - $\beta$ litvis 11 ittr. Skandiu. Desm, p. 27 t. 1 f. 14.

d is-Kirchn. Alg. Schles. 1. 132.

d. 84 - Tolle Iesm. U. S. p. 21 t. 1 f. 14

o 86 - Stokts Tiey Desm. p.110.

d sit-Alexenko ('hlorosp. tihark, 1, 21s.

1 85 - Hunay. Prodr. Algenfl. Thöhn, p. 1b!!

a $-\beta$ subconstricta ibid. et $\rho^{2}, 27 \%$.

d 89 -? Toni Syll. Alg. 1). Ts.

d - v. subeoustricta ibid.

d- - r. lievis ibil.

d 12 - Wolle Desm. U. S. ed. Il p. 24 t. 1 f. 11. 


\section{dulium!}

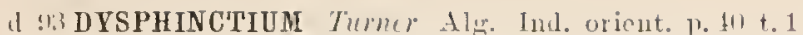
f. 1 - 2 [Cosm. moniliforme f. pandariformis Ilcim. 1.ny1 sec. Sichmialle tris?.

\section{llubillm}

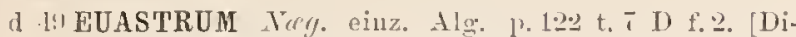
lyom. (En.) binale i " Iicinsch 1silii]

\section{"lllill"}

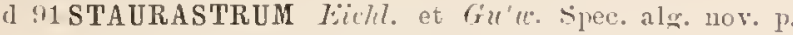

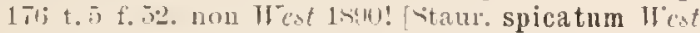
in Journ. Bot. 18!5].

\section{"llbill"}

1 : I STAURASTRUM West Fr. W. Alg. Nortl Wales 1 . 240 t. $15 \mathrm{f}, 0.2 \mathrm{~s}$.

\section{dulloif}

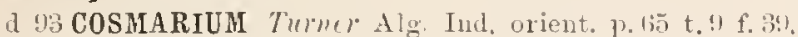

\section{"lilule.r}

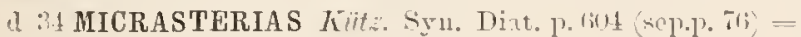
Pediastrum duplex Meyen.

\section{(lil)le.x}

A $\$ 3$ STAURASTRUM Wulle in Bull. Torr. bot. Club 1583 1. 19 t. 2 - f. 10 .

d 81 - Wulle Desm. U. S. p. 149 t. 53 f. 6-

o sto-stulies Key i $=11$. p. 469.

d 49 - Turi sill. alg. 1. 1162.

(1) 1.2 - Wulle lesm. U. S. ed. II jo. 164 t. 61 f.6-7.

\section{"luplirentu}

d 3.5 BINATELLA Brib. Alg. Fal. p.5 t. S. [Desmidium Swartzii sec. Ehrenl. 1\$34. - Staur. tricorne see.

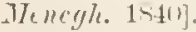

\section{D) ISPHINC'TIU.M}

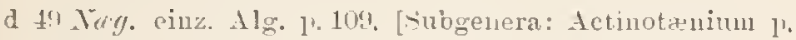

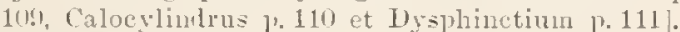

d 5s Gimu. Dermid. 11. 192.

त 5s De Bary Conjur. 1). T2. Sect. Cosmarii.

6i Iicinach Algent. Frank. p.17-. Hic et rariis loeis false Disphinctium scriptum]

d 73 Uelponte Desm. subal]. 1? 40 (sep.p. 24.

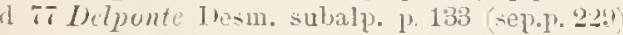

d st $G(u)$ Monogr. loc. Conjug. p. 37 .

d st IIanoury in Baill. Diet. bot. II p. 489.

d ss IIrang. Prodl. Algenf. Böhnn. p. $18 t$ (sect. 1. Actino-

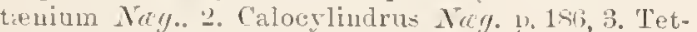
memoritiun p.1si)

d so Toni syll. Alg. p.87t seet. 1 Actinotenium (incl. Inisplinetio Nieg. ut sect. et sect. Penii "splninctopenio" Gay p. S7\%; sect. ㄹ Calocylindrus p.87. seet. :3 Tetmemoridium 1\%.\$3

11 13 Builu Contr. Queensl. Fl. p.4t.

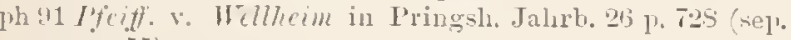
I. 55 ).

\section{Disermlstiii}

d 13 STAURASRTUM Eich. ot Rac. Jowe gat. ziclen. 1) 1.22 t. 3 f. 2 ij

m95-Hichler in l'auict. Fiz. 13 p.62.

\section{elot'mense}

(1) S: COSMARIUM West Fr. Alg. Torth Forksh. r. 2!n sep.1. 41 t. 251 f. 1

\section{ebovrermse - is}

1 Mi CLOSTERIUM Tumer in Couke Brit, Desm. p. 37 et (1ksi) t. (3\% f. 1. ('l. Cucumis Wolle non Ehr.).

Si - Twner in Leeds nat. club transaet. I t. 1 f. 16.

d 8 ! - Toni syll. Alg. 1. 814.

11 !I ARTHR0DIA kiuntze Rev, gen. pl. p. 893.

\section{eboveremse}

d !3 STAURASTRUM Tumer Desm. Notes p.315, et f. 11 p. $31 !$.

\section{"rollinatum,}

d IS STAURASTRUM Bril. in Lillfs Brit, Desm. p. 215 t. 35 f. $: 1$.

d 61 - Arch, in Pritch. Inf. 17. 735.

o liti-Milse in Iinl. Alg. Eur. n:o 1525 Nt. Saxonicum [iulule.].

d 6 - Lirrb. Flur. En1. Alg. 3 p. 213

d - b. Pecten ibil. (I'lyeastrum Pecten Jerty:

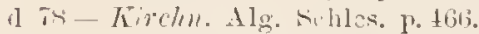

d 84 - Tulle Desin. T. S. 1. 141 t. 15 f. $31-32$.

$11 \mathrm{st}$ - Artari Linte alg. IInseou p. 14.

m 85-Bolitt sibir. Chloroph. 1. 113.

o stj- Stukes Tiey Desin. 1). 14s.

d sis-Hansy. Prodr. Algenfl. Buhm. p. 214.

in 88 - Irest Desm. of Maine p. 3t0.

d $89-$ Toni sill. alg. p.1171.

d - r. Tecten ibid

n 90 - Eichler spis Desm. Mielz. 1) 90.

1 II - Wulle Desm. T. s. ed. II p. 15I t. 56 f. $31-32$.

1h 93 - Lütkemilll. Chlorophyllkörp. ein. Desm. p.9.

m!13- (Raphidiastrum) Turner Alg. Iad. orient. 1.112 t. 16 f. 45 .

Cfi. Staur. gladiosum; Xantl. deltoidoum? sec. II ansy. 1588.

\section{ECIIINELLA}

d 10 Achar. in Weber it Mohr Beitr. z. Naturk. II p. 310 [Orula animaleul. sec. Ehrenl. - Closterium?]

12 Hy. Disp. Alg. suec. IIl 1, 45.

111 Vecs ab Escul. Alg. süss. Wassers 1. 28 0phrydium sec, EHenb.].

d 19 Lyngl. Hydroph. dau. p. 205 [Cfr. E. radiosa; alia sp. ad Diatomacear. pertinent?

d 21 A\%. Syst. Alg. 1. XVIII. Gell. Nostochinear.

d 2.5 Fries Plant. Homonem. 1 p.3\%. Gen. Eclinellear.

d 33 Hure. in Hook. Brit. F]. II 1). 262 et 398 [ex maxima parte Desmid.].

1 39 Ehrend. Inf. 1) 21!!. Gen. Bacillar.

Sreeies valide hujus generis, omnes Elvenbergi, sine dubio al Bacillarieas is. Viatom.) referenda. hic a me $n o 1$ enumerate sunt.

\section{Erllillellere}

[A 2.5 Fies Plant. Hononen. p.335. Trib. Diatomearum. Gen.: Echinella. Iferidium, Achuanthes, Frustulia.]

o 3i Endl. gen. pl. p.3. Trib. Desmidiear. Gen.: Eehinella, Gloionema. Desmirium, et 1810: Il I. I.

\section{Erllimls}

d 11 ZYGOXANTHIUM Ekrenl. Berl. Momatsb. 1940 p. 218 "Xanthidinm Echinus Berl. naturf. Gesellsch. 18 Juui 1839") [Xanth. armatum]

d 4!) - Kitiz. Spee. Al r. 1) 1is eum var. P.

d $52-$ I'ritch. Inf. 1.29!3.

\section{("("))'me}

d !3 STAURASTRUM Tumm Alg, Ind. orient. p. 187 t. 15 
f. 17 [Cfi. Willem. in Notnrisia 1893 1. 170; s. variabile v. eeorue Wilsl. 1s:4].

d $94-$ v. podlachicun Eichl. et Gutw. Spec. alg. nov. p. 174 t. 5 f. 47. [St. subpygmaum v. pod]. West 1se5].

\section{equetume $-a$}

d ss Cosmarium Rioy et lisset apud Nordst. Bormh. lesm. p. 118 t. 6 f. 8 .

(1) S. Toni Syll, alg. 1.952.

1) sil-v. tatricum Rac. Now. Desm. 13.82 t. 5 f. 17.

1. URSINELIA Kuntic Rev. gen, pl, p. 124.

m 11 Cosm. v. minor West Freshw. ale. Maine II p.355.

d $92-\mathrm{v}$. angustatum West Fr.w. Alg. W. Irel. p.113 t. 20 f. 20 .

n 93 - Roy Seottish Desm. t. 1 f. $\%$.

\section{egregimm}

d 13 D0CIDIUM Twmer Alg. Ind, orient. 1).34 t. 2 f. 14,15 ,

\section{Ehreubergiamum}

(1) PHYcastrum (Pacls yetininm) Nig. einz. Alg. p. 128 [Stane. furcatum b. Ral. 186s].

a 19 STAURASTRUM $A * c h$, in Pritch. Inf. p. 739.

( 68 - hat. Flor. Eur. Alg. 3 p. 215.

o 63 - Norilst. Norg. Desm. p. 33.

d 89 - Ton: Syll. alg. P. 1154.

\section{Ellrenbergii}

a 10 CLOSTERIUM Menegh. Synops. Desm, p. 232 (sep.T. 32). (Cl. Innala Ehronb. Inf, quoad t. 5 f. XY, 2).

d 15 - Iluss. Brit. Alg. p. 36!) t. 5 t f. 1 [ex Elurenb. Infus. t. $5 \mathrm{f}, \mathbf{X} V$ 2 delineata].

d $48-$ Ralfs Brit. Desm. p. 166 t. 24 f. 2.

A $49-K i i t z$. Spec. Alg. 1. 168 ,

plu zf 50 - Smith Conjug. of Clost. p. 1 t. 1.

II 52 - pritch. Inf. p. 200 .

d 53-Muth. Fl. Belg. II p. 525.

dz 61 - lich. in Pritch. Inf. 1. 715 t. 16 f. 10-11 [e Smith 1850], 15-19 [e Moren Mrunoir, s. 1. Clost.].

m62-Wurtm et Sehenk Schweizer. Kryptog. n:o 131.

1 63 - liab. Kivyt. Fl. Faehs. p. 171.

d 66-Eyrich Aigenf. Mamul. 17. 135.

(1 67 - Kickx Flore crypt. Flandr. 11 p. 141.

d $69-$ - Fab. Flor. Eur. Alg. 3 p. 1:il.

a - b.? Malinvernianum ibid. ('I. Malinv. $U_{c}$ Not.).

z 72 - Wïtr. Gotl. Öl. sötv. Alg. n. (;i3.

dz 73 - Thood Fr Alg. 1. 11:3 t, 12 f. '2.

d 5 - Microgr. Dict. 1. 176 .

d $7 T$-Delponte Desmid. subalp. p.93 (sep.p. 1s9) t. $16 \mathrm{f}$. $18-20$.

o 77 - Nordst. Alg. brasil. 1. 16.

d 78 - Kirchn. Alg. Selules. p. 111.

m is - Iempel Algenfl. Chennitz p. 111.

d sil- $\beta$ brasiliense Norlst. in Wittr. et Nordst. al s. exs. n:o :355; et in fuse. 21 (1-89) $\mathrm{p}, 17$.

in S2 - v. immaue IVolle in Bull. Torr. bot. Club. ? p. 24.

ph 83 -- Fischer Zellth. Clost. p. 235,257 t. 3 f. 13.

ph 83 Fischer Gypskr. Desin. 1) 139, 141 t. f f. 2, 3. 12, 13.

in 51 - Arturi List. alg. Moscou p. 13 !

m 84 - Gruy Mon. loe. Conj. 1'. $7 \pm$

d\% 81 - Wolle Ilesm. U. Ṡ. p. 45 t. 7 f. 16.

in - v. immane ibil. t. 7 f. 17.

d $55-$ Kirchn. Miki, Ptlanz, l. Süssw. p. 21.

- 86 - Stokes Key Desm. p. 112.

d $86-F r a n k$ in Lemis Synops. 3 p. 198 .

dz 86 - Coole Brit. Desm. 1. 23 t. 12 t'. 2.

d 88 - Mansy. Prorlr. Algenfl. Bölnm. 1. 18:2.

m. $\beta$ immane ibir. m s8 - 1ste. Jel. magyar. alg. p. 239.

m S8 - Nordst. Fr. wat. alg. N. Zeal. p. 69.

dz si-Tuni syll. Alg. p. St1

d -v. brasilieuse ibil. p. 845 .

n - v. immane ibid.

d 91 - Kirchn. Mikr. Pfanz. d. Sussw, ed. 2 p. 23.

n $\$ 1$ ARTHR0DIA Funtze Rev. gen. pl. p. s\$3.

m 91 Clost. Gutw. Fl, alg. Leopol. p. 36.

o 92 Mübins Austral. Süswasseralg. p.141 (inclun. Cl. Malinvernianum).

m 92- limmer Algen St. Pólten 1 p. 5.

1 5. Wulle Desm. T. S. ed. II 1. 48 t. 8 f: 16.

d $92-v$, intmane ibid., t. 8 f. 17 .

m 92 - West in Notaris. 7 1. 1499.

1h 92 - Torre in Notarisia 7 b.117'.

dz93-Bailey Contril, Queensl. F1. 1.42.

m93-- Lith miill. Desm. Attersees 1.513.

m 93 - Orthidium Turner Alg. Ind. orient, p. 19 t. 1 f. 16. o 91 - f. Borge Süssw. Chlor. A rehang. p. 16 t. 1 f. 11.

m 91 -... Alexenkio Mater. alg. Kilıark, p.21.

d $41-$ v. podolicum Gutw. Fl, alg. Tarnapol. p. 81 t. 3 f. 12. Cfr. Clost. Lnunla auct. nonuull.; Cl. moniliferum; Clost. sp. Hivyen Beitr. z. Pflanzenpliys. t. 10 f. 2 ?

\section{Ehrentergii}

n 14 DOCIDIUM Buct. in Diet. nuiv. hist, nat. tom. $5 \mathrm{p}$. 96) ('l. trabecula Ehronb. ex p.).

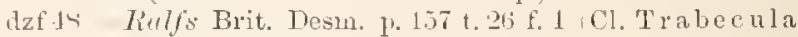
Firomb.

d - - p granulatum ibit. t. 33 f. 1.

d 49 PENIUM (Doeidium Kütz. Spee. Alg. p. 16r.

th 50 Duc, I'evty kleinst. Lebensf. 1. 207.

d is Iritch. Inf. p. 271 t. 13 f. $s$ et 11 le $R$ rlfs l. c. diminuata

n 58 PLEUROTANIUM De Bar. Conjug. p. 75.

ply (io Doc. Areh. Zoosp. in Desm. in Nat. Hist. Rev. P. 3 il t. 13; in Micr, Iolum. 1).227 t. 11 f. 1 -4.

dzf 61 - Aveh, in Initch. Inf. p. 745 t. 2 f. 8 et 11 e Ralfs];

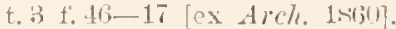

o 73 Pleur. Nordat. Norir. I Vesm. p. 16 ; forma p. 47.

$11 \quad-\beta$ crassum ibid. $p$. 17 (Pl. 'Trabeenla $\beta$ crassum Irittr.

d 75 -Delponte Desmid. subalp. p. 13\%2 (sep.p. 22s) t. 20 f. $1-\tau$.

m 80 - Nordst. Do Alg, et Clarane 1 p. 2.

d 8.3 - v. undulatum schaurschm. Mlagyar. Desm. p. 27s t. 1 f. 21 .

d St Doc. v. Floridense Wull, Desm. T. S. P. 159.

m sij Ple ux. Botdt Sibir. Chloropll. 1. 121.

m 85 - Layer\%. Anerik. Desm. 1. 250.

o 89 Doe. ( - v.) Floridense Stuker Tiey Desm. 20. 113.

dzf 86 - Cooke Brit. Insm. p. 11 t. 6 f. 1 u, b. d.

d - $\beta$ granulatum ibil., fig. C. [e Rirlfs?'].

1] S6 Pleur. Klebs Organisat. Gallerte b. Algen p. 3si t. $+\mathrm{f}$. $\mathrm{s}$.

d st Doc. Wulle Fr. Alg. U. S. A. p.337 $\beta$ granulat $u$ in)

dzsi Plenr. Hangy. Prohr. Algrent. Bünn. p, 1s:

d - $\quad$ granulatum ibid.

m ss - Nordst. Fr. wat alg. X. Keal. p. 6 ij et is.

d\%sit - Tomi syll. alg. p. sint.

d - - v. undnlatum ibid. p. $45 \%$.

o 10 Iooc. West Fr, w. Aleg. Nortl Wales p. Qsit

$\mathrm{n}$ - $\mathrm{v}$. elongatum ibid.

n !l P'leur. Borge Bidr, sihir. Chloroph. p. 13.

m:t1 - Gutw. Flor. alg. Leopol, p. 37.

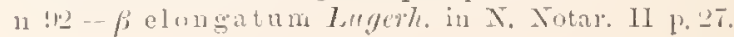




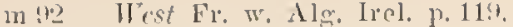

m - v. elongatum ilid.

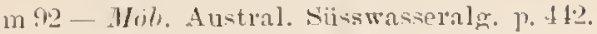

o: $: 2$ - Rac. Desmidya Ciastoni. p.37u.

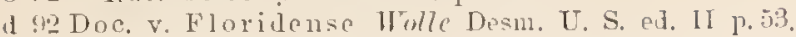

m93 Plenz. Baitey Contu. (2ueensl. Fl. p. 4.1 t. 13 f. 38 (e (uole)

d 9:3 Doe. $\beta$ tnnidum Tumer Alg. Ind. orient. P.:31 t. + f. 1 .

d 9t Plenrot.? Schmidle in IIndwig. 33 p. 93 t. fi f. 1 [P]. nodulosum.

m!4 - 1Wob). Austral. Ninsswasseralg. II p. 335.

m! Doc. lioy sicott. Desm. p. 241 (aеp.p. 1!n.

m st Plen. Gutu. Fl. alg. Tarmapol, p. S2.

m!5-Fichler in Pamiet. Fizy. 13 p. 5.

d $! 5-$ ? r. undulatum Schmidle Als. Sumatr. p. 300 c. fig.

0.95 f. IVest Alg. Madag. 1. 45 t. 5 f. 40 .

\section{Ehrembergii}

3! EUASTRUM rorda in Alm, ג, Carlsb. 1539 p. $138=$ Pediastrum E.7wenh.

\section{Ehrembergii}

a 40 XANTHIDIUM Curda in Alm. d. Carlsh. 1540 p. 214 (sep.p. 29) t. 5 f. 31; et 37. [Terisiniliter Staur. furcatum Elu:.

- 18 STAURASTRUM Tialfs Rrit. Desm. 1.211; st. spinnsum e froute?

(1) i.2 - ritch. Inf. 1.26!.

d $1 ; 1-A r c h$, in I'ritch. Inf. p. $T$ - 3 .

\section{Eichleri}

11 92 CosmaRIUn Rue. Desmidya Cinstoni, p. 384 t. i f. 7

\section{Eirleleri.}

1 93 STAURASTRUM Race in Eichl. et Rac. Nowe gat. rielen. p. 1.28 t. 3 f. 25

\section{clrboratum}

d 4 cosmARIUM West $\mathrm{Alg}$. Marlag. p. (69) t. 7 f. 15.

\section{elretum!}

d !13 DOCIDIUM Tumer Alg. Ind. nrient. p. 27 t. 2 f. 16 .

\section{plegrus}

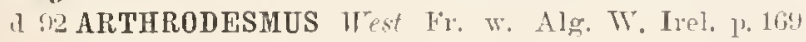
t. 22 f. $T$.

\section{ployrens}

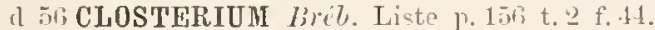

d (;1 - Areh, in Pritch. luf. p. tor).

d his - Lab. Flor. Eur. Alos. 3 p. 130.

d 89 - Toni Syll. Alg. 11. 853 .

n 91 ARTHRODIA fiuntive Rer. gen. pl, 13.85:3.

\section{elegam.}

d o. COSMARIUM hoy et biss. apud Roy siontish Desm. p. 100 (sep.p. 33) t. 2 f. .5. [Non Brit. 1:10]

\section{regrins}

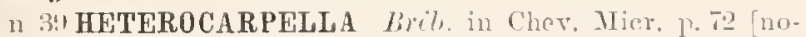
mon tantum!]

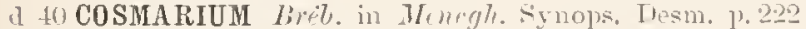
sep.]. 2.2).

d .15 EUASTRUM hitż. Phycol, germ. p.135,

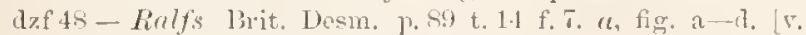
Lundellii Schaar. 1issa. d $\beta$ inermo ibia. t. 14 f. 7 o Fn. inerme Lund. $19 \div 1]$.

dzf - $y$ spinosum ibil., f. $T$ f-l. (Eu. spinosum R. 1811). [Fig. if et lo e Rulfs 1. e.].

d 49 - hätw. spec. Als. p. 173.

rl - P sinuosum ibil. (En. spinosum Ralfs 18.14 fig. a sinistra).

d - y armatum ibil. (linlfs l. r. fig. a lextra et ${ }^{\circ}$ ).

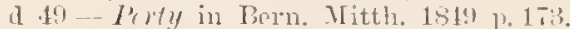

d 50 - I'ritch. Inf', p. 2.in) (sensu Rulfsii).

zf 37 - Rerliel. Introd. crypt. Bot. 1'. 120 f. $3: 3$ (e Ralfs)

d os - $\beta$ inerme Grun. Desm. p. ond.

d fil-Areh. in Pritch. Inf. p. T:30; et $\beta$ ct $\gamma$ (E. spino. S 11011 .

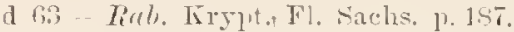

m 65 - Reinsele in Rah. Alg. n:o 19ok (f, minor) fig. 3-5.

d 136 . y spinosu in Eyrirh Algenf. Mannh. p.12t.

d lit - f. declivis Rrinseh spec. fien. $\lambda \mathrm{lg}$. p. $12.1 \mathrm{t} .20 \mathrm{f}$. D. IIT. 1 - 3 sep.p. 16 t. 1) [E. declive Roy then].

d tiT DIDYHIDIUM (Euastun) litinsch Alcenfl. Franl. 1. 1:3 : f. A. Bulnheimii ( $a$ minus et $\beta$ majus).

d - f. B, Brebissorii ibid. p, 187 ( $\alpha$ minus, $\beta$ medinm. $y$ majus).

o 67 Eı. v. incrme Not. Desm. Ital. p.37 t. 3 f. 17 , ( $\boldsymbol{t}$ et B). [E. bilobum Lïtlicmilll. 1sro3?.

dz6s - Kub. Flor. Eur. Alg. 3 p. 1אั.

d - b. rostratum ibil. 1) 1si (En. rostr. Ralfs).

d -c. spinnsum ilibl.; c. formâ (Focke Ph. Siturl. t.? f. 16

d - d. inerme ibil.

m 70 - Nordst. Desm. Brasil. p. $21 \%$.

ค 72 v. Wittr. Gotl. Öl. sïtr. Alg. p.15 t. 1 f. 1? [E. denticulatum f. ser. Boldt 18sis)

in 72 - Nordst. Desm. Nipetsb. 1, 37.

dz 73 - Hood Fr. Alo. p. 140 t. 21 f. 14 , t. 13 f. 2.

175 - Microgr. Dict. 1. 292.

m 75 - Tordst. Desm. n1et. 13.30.

7.) Juculs. Desn. Danem. p. 191 (incl. E. pulchellum Brib. et E. elegantulum P(rty).

n - v. bidentata ibid. E. bidentatum Näq.).

11 -.. v. lobulata ibicl. (En. lobulatum Breb.) [E. biuale sec. Wildem. 1s:17.

(o) - v. danica ibiul.. t. 7 f. 1.t. [E. binale f. secta Turner 1str?; E. ineme sec. Witelem. 18947.

dzis a. typicum hirelin. Alg. Schles. 1\% 159.

d - b. rostratum ibil.

d - c. suinosum ibid.

d - d, inerme ibid.

d 7 - Novæ Senliæ Wille Ferskr. alg. Nor. Seml. p. 32 t. 12 f. 5

m S-1 - Artari Liste alg. Mroscon p. 142.

m St - a Cray Mouogr. loc. Conjus. p.53.

d - $\beta$ cebennense ibil., t. 1 f. 6, et Not. Conj. d. m. France 11.335.

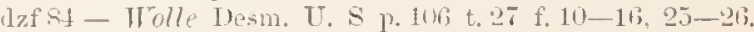

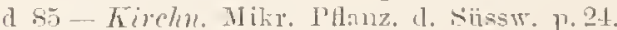

un - S.) - Boldt Sibir. Cliboph. p. 99.

o si itolits Key Desm. 1) 115.

def si - Coole Brit. Wesm. 1. It t. 3i, f. 3 [partim e Ralfs?]

d "spinosum ibid. p. 75 t. 35 f. 5 [e Rulfs]

si-Turme in Leeds nat. Club transact. 1 t. 1 f. 10.

d Si ... r. oculata lote. Diagn. prev. in Yotar. 1).230 isep. 1. 7) [An En. rostratum?].

ร. Lundellii ibial. [=a Tinlfs 184s!?

d si-v? Murtel in Ann. Inst. bot. di Roma $\vee .3$ pt. 1 p. 8 tig. xy]. 3 [An En, loostratum f.??]

I si - $\beta$ medianum Nordst. Algolog. småsal. 4 1 1 jti.

d si Alexento Chlorosp. Tihark. p. 310. 
dz SS - Howsy. Prodr. Algenf. Bilim. p. 206, f. 115 p. 206 [a lirgeri].

d - " "g"enuinm (Krch.)" ibil. [lapsn calani pro "t y. pic u m"].

d - prostratum ibil.

11 -, inerme ibill. p. $2(1 \%$.

(1 - - s spinosun ibin. p. 2.2.

m 88 - v. rostrata Riglin. Chlolrph, onv. T̈larkow p. 827. moss - fit. Boldt Desm. Grönl. J. ! (sмp.p. T).

d. $\beta$ speciosum jbia.. t. 1 f. 10 et 11 (monstr.) [? v. bidentata sec, Bün. 188!. An En, rostratnm f.?

m - ? " Xovat Semliz ibid.

r SS - v. oculata Iste. Jel, magrar, alg. p. 222 t. 1 f. 6. [E11, rostratum f.?].

m - v. I. unilellii ibial.

z 89 - r. bidentata Borg. Birlr. Bornh. Desm, p. 143 t. lif. 2.

l s. - P medianum Nortst. Fr. wat. alg. N. Zeal. p. 3H t. $:$ f., 8 .

dz 89 - Tomi Syll, alg. p. 1101.

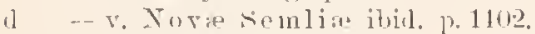

1) - v. cebennense ibirl.

d $-v$, medianum ibil.

d $\quad$ - v. speciosum ibicl.

d - v, oculatum ibir.

m - v. Lnudellii ibirs.

In 90 - Birg. Desm. Brasil. 1. ล\%.

m 90 - Eichter Spis Desm. Mirdz. p. 80.

un 90 - Antress. siverig. (ChIor. 1 p. 10.

$m$ - v. billentata ibid.

11 !1-Kirchn. Mikr. PHanz. 1. Siissw. ol. 2 1. 25.

m 91 - Heimerl Desm. alpin. 17. 102.

$m$ - f. Nova Semlixe ibid.

m.91 - Borge Bicls. Sibin. Chlorolh. p.s.

o - $\beta$ speciosum ibirl.

n!1 HELIERELLA Kuntze Rev, gem, pl. p. S!s.

m 5.2. En. Burge Clloropls. Yorsk. Finm. p.ti.

m - v. billentata ibill.

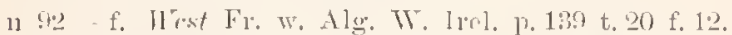

m!2- Rimmer Alg. it. Pölten I p. 1 u et $p$.

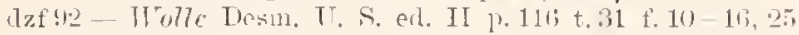
ot 21 .

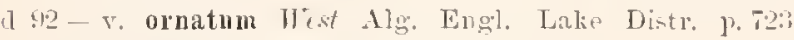
t. !) f.!!.

m93 - Tohlin Snöalg. Pit. Lappm. 1\% 16.

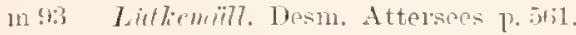

a - v. speciosum f. scrobiculatum ilsil.; t. \& fo 12 [E11. rostratum f??].

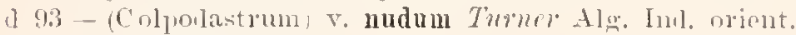
p. 81 t. 11 f. 11.

1 - $\mathrm{v}$. planum ibill.; t. 11 f. 16 .

z.93-Roy Scottish Desm. 1).17i (sep.p. 1.1).

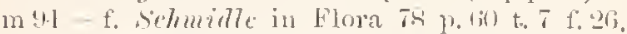

o !1 - Tizhem. Obs. crit. Desm, p. sij et ser.

จ. monodentatum ibil. p. sil et 4.1 .

- f. annulatum ibirl. Eur. annulatum et Eu. in:urvatum Turn. 181:3.

- f. exannulatum ibrl. Eur. subspinosum Twm. $16: 3)$

o - - f. ornatum ulid. Eu. pseudo-elegans Tum. 194i).

- vospinosum ibid.

prorum ilisl. 11.92 E. prorum Tirno).

- v. nudum ibid.

v. mediannm f. planum ilirl. (E. elegans v. planum Turm. 1.8:!:

- - - f. punctatum ibid. 10. !? E. bidentatum Väg. fig. a et $f$ tantmmi).

o :11-Bïrg. F. alg. Üstgrönl, p.:31 t. 2 f. :3:? m bidentata ibir.

phat-v. speciosum f. serobiculatum Strockm. in Nichtr. syst. Anf\%. Österr. Krypt. 1. 1 \%.

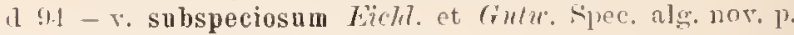
173 t. 5 f. 3 ..

o 9. -- Witrlem. Note algolog. 1 p. 10 t. 1 f. 23 -30.

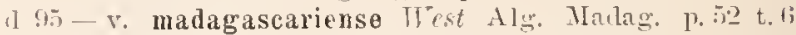
f. 18 .

m!5-v. latum Schröder dlg. H. Riesengeb. p. 21.

m!5- Borge Sverig. Chlor. II p. 22 t. 1 f. 12.

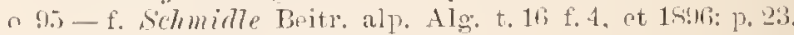
m! $1 \%$ r. speciosm ibir. p. 22.

m - .. fo serobiculata ibir.

Cfr. Cosm. bicuspidatum, Eu, crenatum K̈̈̈t... Eu. f. 10 aput Thomes Chieng. w. Sinppl. 15is.

\section{elegruss}

d 5 HYALOTHECA Racit. in Florn $v .81$ p. 31 t. 3 f. 1.

\section{elegrens}

m 34 SPH 207 t. 1 f. 37 . [Arthrodesmus (Aconellesmus)? sec. EKvent. in Wirgm. Areh. 1si3n p. 1s5. Spheroz. vortebratum sec. Rillf $s^{\circ}$.

(1 $10-\ldots-\ldots 1810$ P. 20 (sep.p. 21) t. 1 f. 30 .

(1 45-Mlrssan Brit. Alg. p.31.5 t. 81 f. 1 Jemur deliu.) [Qnill?].

1 19 Ticrlieley in Fingl. Fot. suppl. vol, \& t. 2!3!3 (Desm.

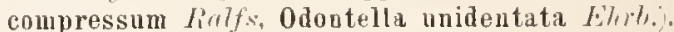

(1 4) ISTHMOSIRA? Kütz, silee. Alæ.. p. 1s!).

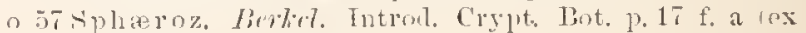
Engl. Bot, t 20139

\section{cle!}

1) 11 TESSARARTHRA Jlomen Fechereh, physiol, p. 122 t. 7 A. = Euglenæ irreculariter coarcelvat: et jassim Chytridio parasition obsita? sen. A. Brmm.

\section{clegnutissimum-}

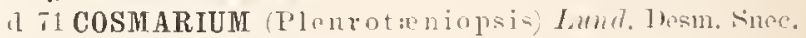
1.. 53 t. $: 2$ f. 21 .

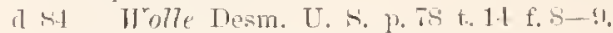

o 86 - blolies liey Desm. 1. 128.

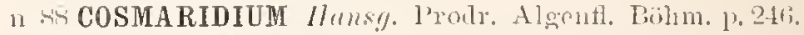

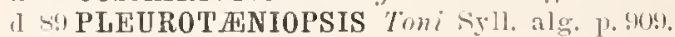

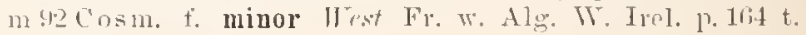
$21 \mathrm{f}, 10$.

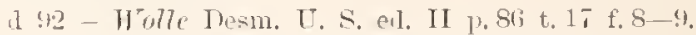

0 95 - Juhns. Rare Desm. U. S. II 1. 2!) t. 240 f. 2 T. Cfr. Cosm. annulatum $\beta$ elegans.

eleyrutissimmm

I !.! STAURASTRUM Joms. Rar Desm, U. \&. p. $290 \mathrm{t}$. 211 f. 11;.

Cfr. Staur. aculeatum fiornatum.

\section{elerrutulum-"}

17 52 EUASTRUM lert!l kleinst. Lobens. 10.208 t. 10 f. 7 (E. elegans in Berı. Mitth. 184! p. 173.

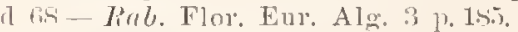

11 89 - Tomi syll. alg. 1\% 1111 .

n !1 HELIERELLA hamta Rev, gen, pl, p. sos.

\section{elepharentimum}

m 7o PLEUROT 列NIUM ('ohn Florul, Desm. Bong. p. 45.

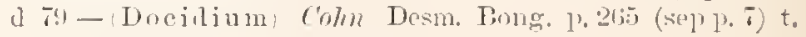
$11 \mathrm{f}, 1$.

a 


\section{Elfeillgii}

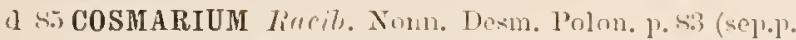
27) (C, hexagonum liffr. Insil.

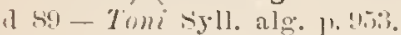

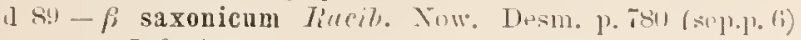
t. i) f. 1 .

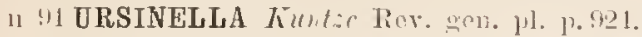

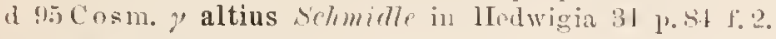

\section{pllipsoirlemm -re}

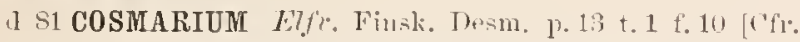
Nordst. in Bot. Notis. 18s? p. !T].

m Sij - Boldt Sibir. ('lalolopll. 1) 10:3; et forma ninor.

11 s.j - v. major Rereil. Xonn. Desm. Polon. p. St (selp.p. $2 x$.

a - v. minor ibil.. t. 10 sep. t. 1 ) f.?.

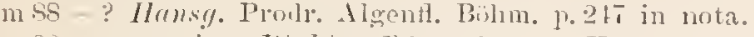

mSS - v. major Liabin. Chloroph. env. Kharlow p. 326; t. 8 f. 11.

d 8. - Tomi Syll. alg. p. !ni:;.

1) - v, minus ilinl.

(1) Sil - f. elliptica líucib. Xom. Desm. p. T. (C. moniliforme f.elliptica Nordat. 1873).

m so - v. minus Eichler sjuis lesm. Miedz. p. 87.

ms 90 - f. minor Awetess. Srerig. Chlor. 1 p. 16 t. 1 f.! (non Rac.).

n 91 URSINELLA huntž Rev. gen. 11. p.921.

d 92 Cosm. v. notatum Rec. Desmitya Ciastoni. p. 37:3 t. 7 f.. 2.

m!l - Lorge siissw. Chlor. Archang p. 25.

o - f ilvid.

mis to minor West Alg. Martag. p. ati t.9 f. $2 \pi$.

\section{elliptirel}

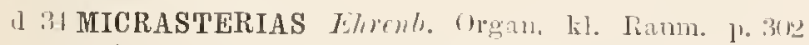
(sep.]. 1its) = Pediastrum Boryanum.

\section{rlliptirllm -}

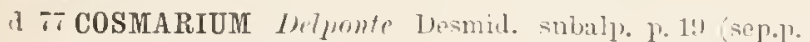
115) t. 8 t. $11-1: 3$.

d 8.9 - Tomi syll, alg. p. a7s.

n "1 URSINELLA Kumize Rev. gen. 11. p.924.

\section{"lliptirllu"}

dafst LUASTRUM ('osmarimu) Gray Mon. loc. Conj. p. 13.3 t. 2 t. 5 ; et Not. Conj. 1. 11. France p.337; 110e. J)etp. [C. Gayanum Ioni 1ss9\%.

\section{elliptirmm}

a 7 DISPHYNCTIUM Tetponte Desmil. subalp. p. 13.1 sep.p. 230) t. 21 t'. $1 . t$ [Cosm. counatum Ifolle 1SSH]. d s.t - Tomi syll. alo. 1. $88 \%$.

\section{elliptirmm}

d 92 STAURASTRUM Irist Alg:. Engl, Lake Dist1. 1\%.731 t. 9 f. 25. [Nt. muticnm \%. subspharica Birg. 1s!4],

\section{Eloiseallum -a}

a 83 COSMARIUM Wrolle in Bnll. Torr, bot. Club v. 10 p 10 t. 27 f. 7 .

$18 t$ - Tolle Desm. U. S. 1. s5 t. 1!) f. $1-2$ (non bonat.

o si- Stokes Kes Desm. p. 12!1.

o $.8 \mathrm{~T}$ - ITolle Fr. Alg. L.... A. p. 3?.

d $\$$ - Tomi Syll. alg: p. 1009.

n 91 URSINELLA Liuntie Rev, gen. pl. p.924.

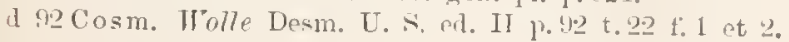

\section{Eloiserllll"le}

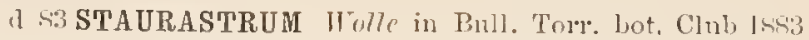
1. 2 (1) t. 27 f: ! :

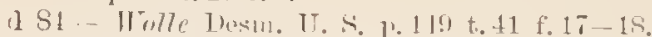

o sti-Stakes liey besm. p. 161.

a 8.1 - Tomi syll. alm. p. 1161.

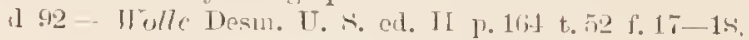
An stanr. Renardii lieinsch f.

\section{rlonegretum -}

d si CoSMarium (Pleurotioniopsis) Rucib. Nomn. Jesm.

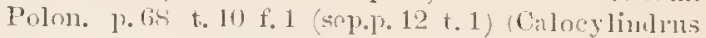
attenaatus line. 1rist.

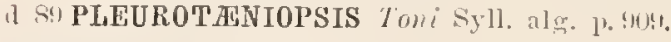

\section{rlongritum}

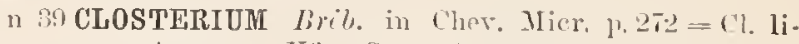
neatum sec. Kïtz. Spee. Alg. p. 165.

\section{elomiratume}

(1) E1DESMIDIUM Wolle in Bull. Torr. bot. Chu 1881 p. 15. - Al, anrtore ipso in Desm. U. S. all "louga. tum" transmntatum.

\section{clousectum}

d no Docidium Wist Fr. w. Alg. North Wales p. 294 t. 5. $f .17$.

\section{elongatum}

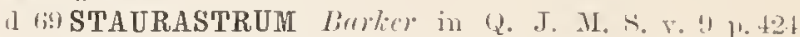
[itan?. terebrans Nords. 1873].

81 - Wolle in Bnll. Torr. bot. Chub. v. 11 p. $14 \mathrm{t} .4 \mathrm{f}$. B1 (v. tetragonum).

it $\mathrm{s} 1$ - Wolle Desm. U. S. p. 130 t. 16) f. 11-12.

I - v. tetragonnm ibill., t.jil f. 31 .

o sf - Stolics Kiey Desm. 1. 1tii.

o - (v.) tetragonum ibir.

1] Si - Caoke Brit. Losm. 1) 1 ie t. 59 f.2 [e Nordst. 15i:3]

d 1 - Tomi syll. alg. p. 1212.

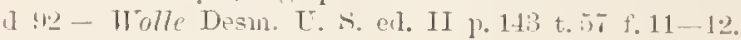

d - r. tetragonum ibill. p. 1.4. t. fi2 f. 31 .

\section{encrerginutu}

1 34 MICRASTERIAS Filrent. Organ. ki. Raum, 1, 311 sep.p. $15 \overline{7}$ - Pediastrum Rotula Ekr. $\beta$.

\section{emereginutum}

(1) 15 COSMARIUM West Alg. Madag. p.is t is f. 14.

\section{cmereginatum}

n 51EUASTRUM lihenh. Ticrogen]. p. 135. 245, 250.

\section{rmereginulum -r}

d 19. EUASTRUM (Cosmarium) Proty in Bern. Mitth. 1819 p. 173.

17. II - Ievty kleinst. Lebensf. p. 009 t. 16 f. 8 .

at wis COSMARIUM ["emarginatum"] Rorb. Fior. Eme. Aly. 3 p. 179.

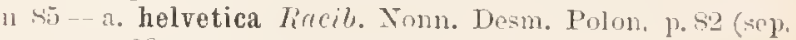
p. 26 ).

d - b. polonica ibit., t. 1 ) (sep. A, f. 12.

1 s. - Toni syll, alg. p. 1000.

1) - v. polonicum ibid. p. 1001.

11 91 URSINELLA Kuntzic Rer, gen. pl. p. 924.

\section{enchelioilles}

1) 34 GYGES Bory in Encyclop. meth. Hist, Xat. Zom h。 
II 2 p. 4.49 Enclelis similis Mii7l.). [Doxococeus? ser. Ehremb. in Isis 1::31 p.11:11].

\section{Endlicheriallum-a}

19 MESOT 19 NIUM No\% cinz. Alg. ]. 109 t. 6 B.

d GS PALMOQLOEA Rar. Fl. Eur. Alg. 3 p.11i.

a $78 \lambda \mathrm{es}$. Firelm. Alg. Selless. p. 131.

(1) 79 - $P$ grande Norrlst. in Wittr, et Nordst. Alg. pxs. 11:0 271; et in fise. 21 (1S8!1) p. 19 ,

o $83-$ Lager\%. Bill. Sverig. Algfl. p. is.

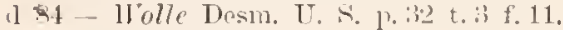

1 85 Kirchn. Milir. Pflanz, 11. Süs=w. p. 22 t. 2 f. $1: 3$ le Xiry.).

a 86 - $\beta$ caldariorum Lagc\%. Algol. Bide. 1 p. Ir fig. 4 xyloge. [M. caldatiorum Humsy. 1899].

o sti-Stolies kioy Desm. P. 111 .

r) 88 - (Eumesotxuium) Mansy. Prorly. Algenfl. Bihlum. P. 174 .

a - $\beta$ gande ibid.

1289 - Fruter in A. M. Micr. J. $10 \mathrm{f} . \overline{\mathrm{s}}$ (ex IFollc).

d 89 - Tomi Syll. Alg. p.811.

d - v. grande ibir.

o (1)-Hansg. Physinl. 13. alg. Hitth. p. 12().

o 90 - Eichler Apis Desm Miedz. p. 4\%.

d 41 - Kirchn. Nlikr. Pfanz, d. Silssw, eяt. 2 p. 2:3 t. 7 f. 72 (e Niigelis.

$1 n 91$ - ? P grande lleimer Desm. alpin. p. is!?.

m! - - Inc. Desmilya Ciastoni. p. 35\%?

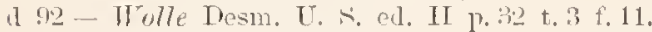

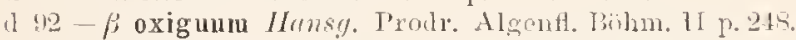

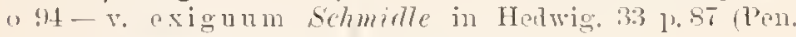
polymorphum I'erty tunoad f. 11;, non 15).

m 91 - A7crenko Mat. Alg. Iílark. p, 19.

zph 95 - $\beta$ grande Lagerh. Plycoporph. 10.21 etc.

\section{ENIDOSPIRA}

a so brob. in Desmariol. Pl, crypt. France fasc. 10 n:0 195.1 (et ed. 2 fase. $3+$ n:o 16int).

\section{emrosplitr"}

d 17 PALMOGLOEA Kütz. Tab. phyc. I p. 19 t. 24 f. i; ("Cyliudrocystis endospira Treb." in litt.).

(1) 4.1 - Cyliudrocystis) Küt. Siec. Alg. p. 22\%.

1) Gt SPIR0T届NIA Arch. Deseript. (sep.p.5), in Lah. Nat. Hist. \&. p. 15; in (2. J. 11. S. 1. 112.

Cfr. Spirot. bryophila et muscicola.

\section{enorme}

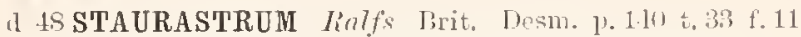
= Polyedrium (1. Tetraëdron) onorme auctor.

a 81 Wolle Desm. U. S. p. 151 t. 11 f. 19-25. [ex $]$. Staur?]

o sf-? Bemm. Fr.-w. Alg. Engl. Lake Distr. 1 p. 12 t. 2 f. 25.

o sfi-Stukes Tiey Desm. p. 105.

(I) - Wo7fe Desm. U. S. cl. 11 p. 166 t. 52 f. 19-2.

\section{ensifermm}

1. 93 STAURASTRUM Trmar Alg. Int. mient. p. 109 t. 14 f. 2 ?.

\section{Ensis}

d T CLOSTERIUM Detponte Desmid, snbalp. p. 123 sep.p. 21.1) t. 16 f. 14-17 nee Focke [Pen. Libollula f'sec. Tum.]; "ensis".

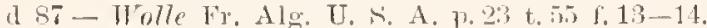

d 89 - Tomi syll. alg. p. S25.

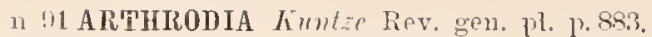

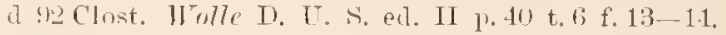

\section{Eusis}

1 17 Crosterium Forlie Plizs. Stul. I p. 59 t. 3 f. 31. [Cl. didymotocu: $\beta$ Baillyanum? see. Rub. 1868, et Turn. 1893! ].

\section{Entomon}

n it CLOSTERIUM Ehrmh. Mricrogeol. p. 355.

\section{ENTOSPIIAA}

47 Rrib) in Kätz. Tah. phyce. I p. 24 (E. closteridia, sine descriptione generis, tantum speciei).

\section{Eatersii.}

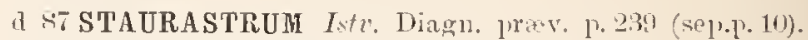
(1 ss - Iste. Jel. magyar, alg. 1).232 t. 2 f. 2 i.

(1) 89 - Tomi syll, alg. p. $11 \%$.

\section{er(1s)}

(1) is STAURASTRUM Irib. Liste p. 143 t. 1 f. 28

al 61 - Arch, in Pritch. Inf, r. 739.

1 b.s - Rrb. Flor. Fur. Alg. 3 p. 212.

1n 71 - f. espinulosa Luml. Desm. Sines p. 60.

8.j - f. espinulosa Ifolle in Bull. Torr. Bot. Club. 12 P. ¿) t. 47 f. $16-17$.

m.5 - ? Rollt sibir. Chloropls. p. 11?.

d. ST - v. espinulosa tholle Fr. Alo. U. S. A. p. 13 f.57 f. $16-17$ [ex Wolle 189i)].

(2. 89 - Tomi syll. alg. p. 1117.

4 1.2 - v. espinulasa Wrolle Desm. U. S. ed. II p. 139 t. ts f. $16-17$.

\section{erectilm}

d 67 DIDYMIDIUM (Stanu.) Reinsch Algenfl. Frank. p. 1.7- inclus. Cit. dejectum et Althrodesmus Incas a Ralfs). Forme A., B.. ? C. p. 158.

ozf 7 STAURASTRUM Remsch Contrib. p. 86 t. 15 f. 8 (St, dejectum liulfs f.5 a!

dzs! - Tom Syll. alg. p. 1115.

\section{ENemobial}

n 60. Sticent. Inlex Rab. Alg. p.27. Nubtrib. Leiosporear. Gen.: Prn.. ('lost., Tetm., Palmogl., Mesotien., Spirot., Doe.

\section{Evlougense}

a lï STAURASTRUM lirimsch sper. Gen. Alg. 1. 122 t. 23 f. () II. 1-6 (se 1.]. 14).

f. A. ibid. p. 12:3; f. 1 et 2 .

- f. B. ibid., t., $3-1$.

f. ('. ibil.. f. $\overline{0}-1$.

a 6 DIDYMIDIUM (Staur.) Reimsel Algonf. Frank. p. 15.5 t. 11 f. IV a-c. [St. acutum b. lave Rnb.].

d $-\mathrm{f}$. a. ibiri, f. b.

f. b. ibirl.; f. e. et d.

- f. $c$. ibid. p. 15r; f. a et e.

7 s stan r. Nordst. Norg. Desm. 1. 29.

mit - Wriltr. et Norkst. Alg. exs, 11:0 050, form. B; et 1.s.s!) in fase. 21 p. 37.

1) S8 - Homsg. l'rodr. Algenf. Bünm. p. 256

1) 89 - Toni syll. 1lg. 1, 1142.

\section{erosill}

m 13 COSMARIUM "Areher (Mser) non Delp." f. minor Tumer Alg. Ind. orient. p. 58 t. 8 f. 14. 
(j)ONIIII -

d T COSMARIUM Dhonte Desinid. subalp. p. 21 sepr. 117) $1.8 \mathrm{f} .21-27$

d 8:-Toni syll. alg. p. 9.58.

1191 URSINLLLA fintze Rev. gen. 1'] 1\%.21.

\section{crosIII) -}

d 71 EUASTRUM Lumd, Hesin, suee. 1) 22 t. 2 f.6. [Eu. sublubatum f. Teinseh 1sis].

7!) - Cohn Desull. Bong. t. 11 f. 12.

o 81 Holle Irem. U. S. p. 101.

o siti-. stukes liey Desn. 1. 145.

12 si-Cooke Brit. Desm. p. 75 t. 35 f. 12 [e Lundoll].

d s. Tomi syll. alg. p. 107?.

n "1 HFLIERELLA humtie Rev, gen, pl. p. sm:

1) En. Wulle lesm, U. \&. ed. II p.115.

d 5 - $-v$, notabile Hict Alg. Engl. Lake Distr. p. T23 t. (1) f, 17 .

In! 1 - Wtest in Notaris, 7 p. 1501.

d 93 - f. attonuata Turner Alg. Ind. orient, p. Tis t. $10 \mathrm{f}$. is et 21 .

d - f. undata ibisl.; t. 10 f. 23.

mot - Alcecnko Mater, alg. Kliark. 1. 23.

\section{erythroceplitulle.}

d òi SPIR0TRANA Itrigs. apud Brnum in Bot. Zeit. p. It. o 56 - Itzigs. in Bot. Zeit. p. $86 t^{2}$ (inelus. sp. minuta) d (i1 - Arch. in Pritch. Inf. p. 6 .

d 68 - Rab. Flor. Eur. Alg. 3 p. 1 16.

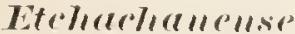

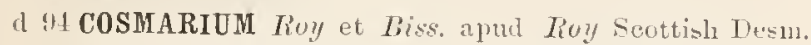
1. 101 (sep.p. 31 ) t. 1 f. 15.

\section{ELARTHROHESILS}

d 89 Thecib. Now, Desm. P. 67. Sect. Artbrodesmi.

\section{Enastrea (-ées, -een)}

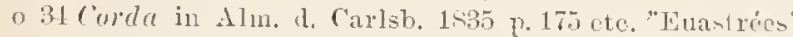
o 39 - in Aln, d. Callsb. 1533! p. 217. "Eunstries". Gen.: Asterieium, Stauridium, Tetrasoma. Euastrum, Mlicrasterias.

1) 40 - in Alm. d. Carlsbad 1840 p. 215. Gen.: Spluerastrum.

d 54 Grum. Desmid. p. 493. "Enastreen". Trib. Desmidiac. Gen.: a. Mier., Eu.. Cosm.. Althrod. Sintlı., p. Didymopr., Isthmosira.

o 94 Haceliel iystem. Phylogen, d. Protist, u. PHanz. p. 9 "Evastrea") et p. 112 "Evastreen". Fanil. Conjugatar.

\section{eurstuiforme}

d 90 COSHARIUM Gutw. Walır. d. Priorität p. To.

d :1 - Gulu. Flor, alg. Leopol. p. 57 t. 2 f. 19.

\section{eurcstroilles}

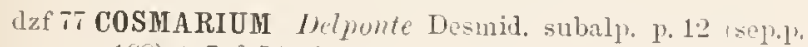
108) t. 7 f. 5:- 5.t.

m 80 - Wille Norg. Ferskv, alg. p. 27.

d 89 - Toni ígll. alg. p. 10Hs.

n 91 URSINELLA fiuntze Rev, gen. pl. 1.!?t.

\section{encest)oides}

d 95 HOLACANTHUM Hieron. in PHanz. w. Ostafrik. 17.21.

\section{curst)'oilles}

d S6 MICRASTERIAS Jush. Burm. Dosm. p. 637 t. 23.2 f. 14. o 87 - $\rho$ indivisa Nordst. Algolog. smisak, 1 p. 1is.
11 Ss - - Vorlst, Fl, wat, Alg. N. Zeal. p. 31 t. 2 f. 17. [M. tropica y indivisum Eichl. et Rue, 18:13]. 1. 8! Toni Syll. ale. p. 111!)

d - vo indivisa ibil.

1" HELIERELLA Kuntze liev, gen. pl. p. sas.

1) 9.5 Micr. v. producta liucib. in Flora v, 81 p. 31 t. $3-1$ f. 1 i:

\section{Eurstrou.}

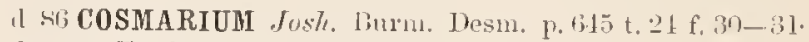

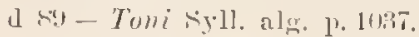

11 URSINELLA huntze liev. gen. pl. 1. !2 .

\section{EUASTIIU U}

12 32 Ehrenb. Futw, 1l. Inf. 1. 82. [Descriptio nimis hrevis $=$ Micrasterias, Enastrum et Cosmarim anct. lecent. - Cfr. Limtioe 18:11].

ph 31 khrenb. Or.gan. lil. Ranm. p. 31! sep.p. 175.

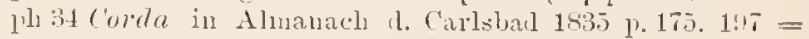
Pediastrum.

1h 3 i Meyen. Beitr. z. Pflanzenpluys. 1? 127.

il as Etroul. Inf. p, 160.

139 Corda in Alma1r. A. Cartsbal 1839 p. $236=$ Peliastrum.

ph 39 Meyen Nyst. P'll. Physiul. III p. tise t. 10 f. 31 [Cosm. $\mathrm{sp}$.].

d11 Burmeister in Ersch 4. Gruber Allg. Eneylilop. d. Wiss. It, 1is y. 2015.

a 11 Bailey Amer. Bacill. p. 2.13 (sep.p. 12).

d 13 Kïtz. Plyye. goner. 1. 163.

d 11 Rirlfs Anu, nat. llist. v. 11 p. 1st; et (1816) Thans. Bot. Sioc. Ellir. v. 2 1'. 1'21 [sensu strictiore].

a 15 Hhess. Brit. Alg. p. 37 !

d 15 Kï̈z: Plyyuol. gerne p. 133 .

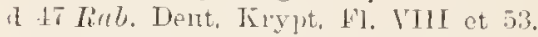

1) 1 Foeke Plays, situl. I p.3s d 41.

(1) 18 liolfs Brit. Tesm. 11. Ts.

(1) 19 Kiitz. Spee Alg. p, 171 .

d 1! Nor einz. Alg. p. 112. [Subgenera: Tetracanthium, Cosmariuı, Eucosmium, Euastrum ct Micrasterias].

d ig Iritch. Inf. p. 2-17.

d 53 Muth. F1. Belg. II p. 307.

pli 5 f Fuclie in Bot. Zeit. 18:T p. TT.

phat is De Dar!l Conjug. p 5u, 70-71.

o 5 is Grun. Desm. 1. 19.3.

- 39 Dixon On a new Genus (*e1.p. 9); in Nat. Hist. Rev. p. 468.

d 61 Areh. in Pritch. Inf. 1) 721 et 728.

1) lis Grogn. Plant. Crypt. 1). 219.2.

a $6: 3$ linb. Krypt. Fl. Naels. w. 181 .

d 64 Gray Brit. Alg. p. Bi;.

a 60 Fyrich Algeufl. Mamuls. p. 1202.

d $6 \pi$ (Subgen. Diulymidii Ieinsch Algenfl. Frank. p. 130.

d tit Not. Itesur. 1tal. 1. 2).

d lis liab. Flor. Eur. Alg. :3 p. 17 .

d 73 Delponte Jesm. subaln, p. 37 et 43 (sep.1).25 et 81 ).

d 73 Woorl Fr. Alg. 1. 135.

o 71 Iffiffer Tomencl. bot. p. 1268.

(1) is Viclogr. Diet. p. 234 et $2 ! 1$.

d 77 Frank in Leunis Synops. p. 1633.

d 78 kirehn. Alg. Sichles, p. 154 .

d si Cook' in Quekett Mier. J. if 1'.204.

ph 83 Fischer Gypshystall. Desm. 13, 160.

d is Cyulek. Hater. alg. Warszaw. p.26il.

d 81 linly Mouogr. loe. ('oujug. p.3.s (Eu., Cosmr, sens. strict. Luml. et A 1 tllod.) Sect. 1. Antenastrum; sect. 2. Cosmarinm; sect. 3 . Arthrodesmus. Etiam in Note Conj. d. 11. Firance p. 3:3.;. 


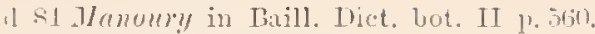

1) S1 Wulle Desm. U. s.. 1, \$T.

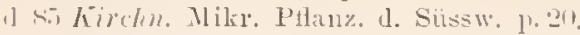

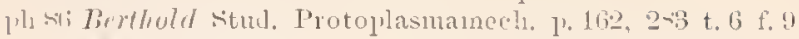
E. oblongum].

1] sit stukes Key Dosin. p. 10:1

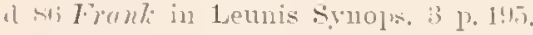

It Mi Coulie lirit. Desus. 1. 63.3.

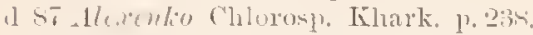

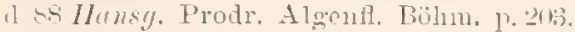

] sit Toni et Levi Fl, Mlg. Venez. 1, sti.

(1) Tumi sill. alg. p. 1615.

d) (10) Wille in Natürl. Pfanzenfum, 1. 11.

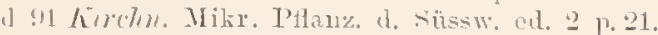

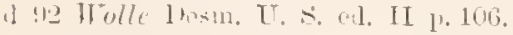

1) 93 Builey Contr. Queensl. Fl. p. IS.

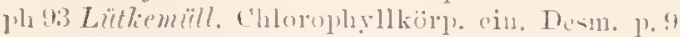

1) 93 Throer Alg. Ind. oricnt. 1, si. Seet. I. Euastrum. sulogen. A. Cosmariastrum, B. Colpodastrnm, C. Amblyastrum, 1). Actinastrum; see. II. Elacosminm.

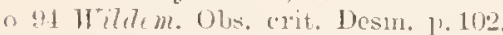

1) 44 Sunnd. in Fl. Nubraska 1). I2.

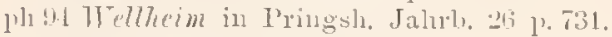

\section{ELIBITASTRIJIU IL}

d s9 lincil. Now. Desm. 1\% 7. sulsect. Bigastridii.

\section{ELCI,OSTERIUII}

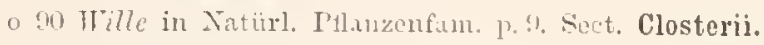

\section{EUCOSHARII)] U}

d si 7lansy. Prodr. Algenfl. Bülun. 11, 24i, sect. Cosmaridii.

\section{ELCOSHARIL M}

d 58 The Thary Conjug. p. i2. sect. Cosmarii.

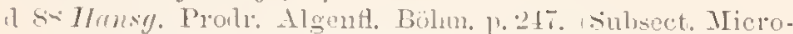

$$
\text { cosmarium et Eucosuarium lo lisury. }
$$

(1 S!) Toni sill, Al स. 1 1.931.

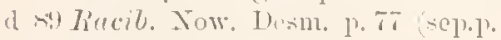

\section{ELCOSIIL.II}

d 49 Nog. cinz. Al p. p. 120. Sulgenus Euastri.

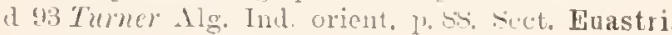

\section{Eudesmidice"}

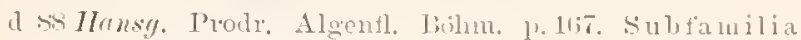
Desmidiacearmm Dosmidiacese angrematie Inelp.

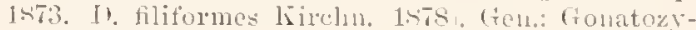
gon. Ilyalotheca, Gymuzyon, Nphatrozosma, Desmidium.

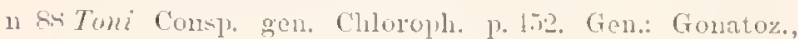
Fenicul., 1'lymat.. Leptozosma, Onychonema. Itraloth.. Frgmozy... Aplaeroz.. Desim,

d so \%oni syll. Alg. p. T-s, 1: Desmidim. Ilyalotheca, splielozosma, (nyychonema: B, irynozyga, Leptozosma, Plyyatolocis. Gonatozyon, Genicularia.

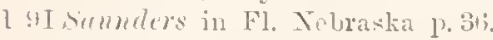

\section{EIDENMIDLU}

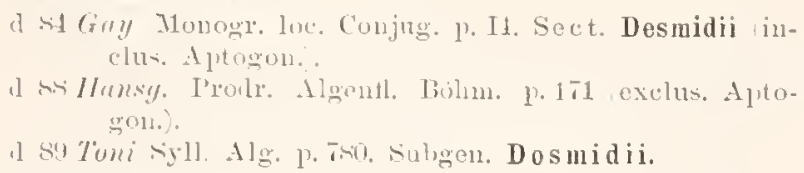

\section{EITHOTIOIT}

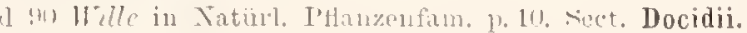

d !1 Wrildem. Obs. erit. Desm. p. (i:9. Sululivis: Integrae, Dentated. Coronulated.

\section{ELGASTIIDIUII}

d st IItusy. Prod1. Algenf. Bölum. p. 251. Rulsect. Gastrocosmarii.

d sy liucil. Now, Desm, p. Tr. Subsectio Gastridii.

\section{(1)!/}

1 93 D0CIDIUM Twmer Alg. Inl. orient. p. 30 t. 3 f. 3 .

\section{HOGYMNOZYGI}

o S? Turlst. Te Alg. et Clarac. 3 p. 1. Sect. Gymnozyga.

\section{EUMICRASTERIE}

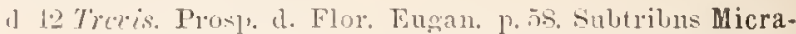
steriearum. Geucra: Micrasterias $A f$, Cosmarium Conde, Xanthidium Ehremb. Staurastrum Meyen.

\section{TET.PLELROTHNIOSPIS}

a s!l Tomi sill, alg. ]. Whi. Sect. Plouroteniopsidis.

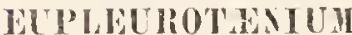

11 Ti Turtst. Alg. Prasij. p. 17. Sulogen. Plenrotænii.

\section{ELSPIIOTENIA}

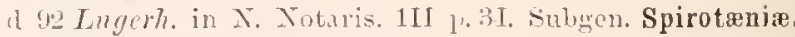

\section{('llstemllermum}

I 13 DESMIDIUM Ehrenh. Mikr. Leb. sül. n. X. Amer. P. (33-. 3:39, 371 et) $11: 2$ t. If f. 23. [Staur. furcigerum f. enstephana Wirlst. 1sss; st. psendofurcigornm]

d 4S STAURASTRUM linlfs Brit. 1)esm. p.215.

a t:। STEPHANOXAN'THIUM Kiitz. siec. Alg. p. $18 t$.

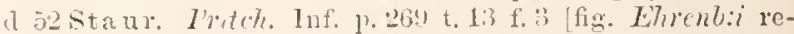
letita].

d 61 - lrel. in Iritch. Inf. ], Tt2 t. 2 f. 3 [ex el, 3. 18.

d $64-$ Rab. Flor. Enr. Als. 3 1. 200.

1) 73 - Hood Fr, Ale 11, 155.

$8: 3$ - v. omarginatum Musk. N. Keal. Desul, 1, 211 t. 24 f. 11. [Nitaur. fnocatum f.]

4. st Wolle Desm. U. \&. p. 117 t. 18 f. 9-10

o - r. a. ibid.. f. 11

0 - 1 ibid f $1-1$.

o 86 - Yolies liey Desul. 1. 165

(i) 8 - Cooke Brit. Desm. 1. 17 t. 1;2 f. ?.

8) - Mist Massaclius. Desm. t. i f. 18.

a

o (12) - ? Harr. Fr. Alg. Maine II1 p. 123 t. 126 f. 22 (mala),

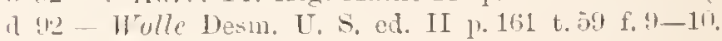

- v. a. ibik., f. 11 . v. b. ilid. f. 1-6.

\section{EUTOMLA}

a 11 Hlure. 1lan. Brit. Alg. P. 1.I et 1 si Nostochina spuria). Euastrmm et Micrasterias]

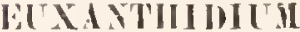

d și Boldt Desm. Grönl. p.31. sulggen. Xanthidii.

\section{Eirereflemse - is}

d s.i COSMARIUH Trolle in Bull. Torr. lot. Club $1883 \mathrm{p}$.

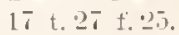

d. 84-Wulle Ilesm. T. S. 1. 85 t. 17 f. 10-12.

o si- Thele's liey Desnt. 1.12!t

d s! - Toni sirll. alg. p. 10ur.

$n$ (1) URSINELLA finut:e Rer. gnn. pl. 11.921.

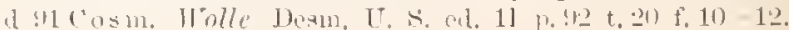




\section{Eververteme}

d sl EUASTRUM TFolle Desm. I. .. p. 102 t. 29 f. $5-7$.

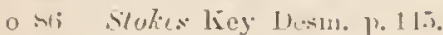

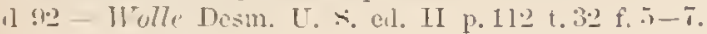

\section{corrsperutum -}

d wi Cosmariun Josh. Burm. Desm. p.649 t.2.) f. 1 \& 2. it si Tumi syll. als. p. 103\%.

n!1 URSINELLA Kimtzo Rer. gen. pl. p. 1.

\section{r.rorereterm}

d 70 COSMARIUM Fortst. Desm. Brasil. p. 211 t. 3 f. 25.

m il - f. Lund. Desm. suec. p. lli, (f. duplo major (C.

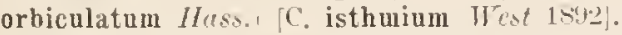

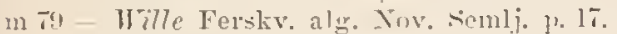

d $\quad \beta$ ellipticum ibil.. t. $13 \mathrm{f} .41$; [C. isthmium v. Willei West 1.t.: Dysp. Willei sirmidle 1Sil].

o so - f. Hille Jorg. Ferskv. alg. I p. 37.

If 4 - Wulle Desm. U. \&. p. 7 t. 53 f. 1t-15; f. duplo major Land.) [C. isthmium ITest 1s:t2].

m sij-Lengerh. Amerik, Desm. p. 23t. [C. istluminm Wtot $1-(1) 2]$.

d $-\beta$ trigounm iloid.; t. $2 \bar{i}$ f. $\bar{\imath}$. [? Stanr. sec. West $1 \mathrm{~S}^{(1,2)}$ ].

o 86 - Stukics Fey Desm. p.12.

I $\mathrm{si}$ - v. trigonum IIolle Fr. Alg. L. S. A. p. 30 t. 60 f. 21 -2; [e Lagerh. 1-.66].

m Ss - f. major Lioldt Desin. Grönl. p. 25 t. 2 f. $3 n$.

m-pellipticum ibiel.

a $\mathrm{xh}$ f. Yordst. Fr. wat. alg. X. Zeal. p. 52 t. 5 f. 18.

d Sy DISPHINCTIUM? Tuni syll. alg. p. $\$ 81$.

d - v. trigonum ibid.

d - v. ellipticum ibid.

d $92 \operatorname{Cosm}$. Wulle Desm. L'. S. ed. II p. sis t. lit f. 14-15.

I - v. trigonum ibit.. t. $4 ! 1$ t. $21-25$.

o $91-v$. elliptica bür. F. alg. Osturounl. p. 15.

\section{excuerefum -r}

n 15 SCHISTOCHILUB Rulfs in senu. Fl. Tumbr. Wells

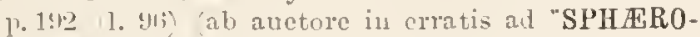
ZOSMA" cmendatum).

d 45 SPHÆROZOSHA Kulfs in Ann. Nat. Hist. v. $16 \mathrm{p}$. 15 t. 3 f.S 'et 1816 in Trans. Bot. Soc. Edinb. v. p. 168 t. $1 \mathrm{~s}$

d 4.5 - Intsisell Brit. Alg. p. 310 t. $\$ 1$ f. ‥ (Jenner delin.). [An spee. distineta see. hütz. 184"1].

dzf 18 - lialfs Brit. Desm. p. 97 t. $1 ;$ f. 2 .

d 19 ISTHMOSIRA fiutz. spec. $A \lg .1 \% .189$.

dz $52 \mathrm{Sph}$ we r. I'riteh. Inf. p. 213.

o .58- We Iurr. Conjug. 1. 45.

d 60 - Wallich Desm. Low. Bengal p. 192 t. 7 f. 18.

d Pibid.: f.15 [Nph. Wallichii Jucols. 1sitis].

d - $\quad$ iloil.; f. 16 [Sph. Indicum Tumer 1893].

1 - Sibid.; f. 17 [ด graulata f. major Tum.].

dztil - Arch. in P'ritul. Inf. p. T2t.

d 63 - Ful. Trypt. Fl. Sachs. 1. 17.

d - b. secedens ibil. sph. sec. Le Bury

m rilj- Krinsch in Rab. Alg. Eur. n:o 19!15 fig. 2-3.

n 660 - Eyrich Algenfl Mannl. p. 120.

m 6 - Meinweh Algenf. Frank. p. 19!

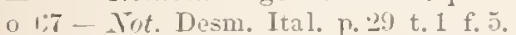

dzbr-Tirb. Flor. Eur. Alg. 3 p. 149; a. forma lævis.

- b. f. granulata ibi.l. [Pphar. spinulosum Wulle 1541 p. 311 .

m T0.- Nordst. Desin. Brasil. p. 205. ff. a. et $b$. Rab.

m 71 - limel. Desm. Suce. p. $(12$ ' $\beta$ Wrillich).

m 72 - Torlst. Desm. spetsb. p. 24: f. granulata.

dioristed?, Iulex Ilesmid. d 73 - Wuod Fr. Alg. 1, 1:23.

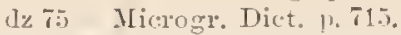

d to - Firchu. Alge. Sohles. P. 133

d $\neg:-\beta$ Novæ Semlix Withe Ferskv. alg. Nor. Semlj. p. (j)- t. 13 f. To.

n so- $\beta$ Wallichii Nisrlst. in Pointsf. Fianlin. Växt. 1 1.2.1. [Spher. Wallichii Jucols. 1sti].

d 80 - f. javanica Norlst. De Alg. et Charace. 1 p. 3 [spl. granulatum R. r. Is. 16563].

defsit - Wolle Desin. L. A. P. 2!) t. 1 f. S-12.

m sil - Lagerle. Amerili. Desm. p. 230.

o sij-Stokes Key Desin. 1). 110.

(tzf st-Cooke Erit. 1).sm. p. 1 t. 2 f. 2 [partim e Rirlfs $1 \mathrm{~s} 1 \mathrm{~s}]$.

It 5 - Alcuentio Chlorosp. Ih hark. p. 220.

o $89-$ Rialin. Chlorejh. cnv. Klharkuw p.321 (scp.p. 33).

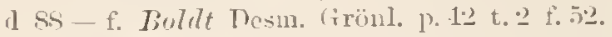

d 88 - Hansy. Proulr. Algenf. Bühn. 1'17).

d - $\beta$ spinulosum ibid. ( s sinulosum 1).lp..

$\mathrm{d}_{2} 59$ - Toni s.rll. Alg. p. 7!0.

d - v. Jova-šmlise ibid. p. Tyl.

d - $-r$ spinulosum ibid.

In 60 - f. Irevis I Röry. Desm. Brasil. p. 26.

$\mathrm{m}$ (A) - Eichlor spis Dism. Miedz. P.St.

dzf!2 - Holle Desm. [T. ‥ ed. II p.30 t. 1 f.s- 12 .

m ! ! - Futw. Flor. glu:1. ralic. 3 p. 11!.

m 93 - a typica Turnor Alug. Ind. orient. P. 140 t. 17 f. 1 ste.

- $\beta$ lieve ilbid.; fir. 19 d.

- "granulata" ibil.; fig. 1!) a. b (f. minor"

- f. major ibil. p. 141 t. 17 f. 19 e o Wull. 1stiol.

m9t-Burg. F. ale. Chtgrünl. p. 33.

mol - Alexenko Mat. alg. Khark. p.18.

\section{excreatum}

d 15 STAURASTRUM TVost Alg. Madag. p. is t. 8 f. 12.

\section{excelsum}

(1 93 DOCIDIUM Turner Alge lnd. orient. p. 31 t. 4 f. 2.

\section{exiguelu-}

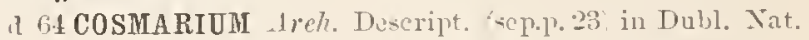
Hist. Soc. p. 19 t. 1 f. $32-33 ;$ in Q. J. M. Sc. p. 17 . t. 6 .

d 68 - Tul. Flor. Eur. Alg. 3 p. 16 t.

m 71 -- Lumel. Desm. Suec. 1. 13.

m 80 - Wille Norg. Furskv. alg. I p. 31 t. 1 f. 11 .

d st-Wolle Desm. U. S. p. bitj t. 16 f. $13-1 t$ [f. uninor Turn. 1S!13].

o 86 - Stokes Key Desm. p. 12i.

d 86 - Cuoke Brit. Desm. p. 92 t. 13 f. 1.

us 98 - Vordst. Fr. wat. alg. X. Zeal. p. 5r t. 6 f. 12.

- f. trigona ibill. t. $1 \mathrm{f}$ f. 13.

d 89 - Tomi syll. alg. 1.95l.

11 SI URSINELIA Timize Rev. gen. pl. p. nt.

m ge Cosm. West Fr. w. Alg. IT. Irel. p.11\%.

it a - Holle Desm. U. S. ch. Il p. T2 t. 15 1. 13-11.

111 (1) - Gutw. Flor. glon. Galic. 3 p. 121;.

m 93 - Schmidle Beitr. aly. Scliwarzmalu. p. 4.5.

(1) $9: 3$ - f. minor Tumcr Aln. Ind. orient. p. 5 s t. \& t. 1.

$\mathrm{n}: 11-\mathrm{v}$. norimbergense schmidle in Flora is p.jt $\mathrm{c}$ norimbergeuse Iifinsch $1.46 \mathrm{j}$.

d 94 - v. pressum West New Brit. $11 \mathrm{~g}$. p.1; t. 1 f. 1.

n. 91-Gutw. Fl, alg. Tarnapol. p. kilj.

m!5 - Eielker in Paniıt. Fizy. I. 5s.

\section{exiguentm}

d g2 PENIUM Wrest Fr. w. Alg. W. Irel. p. 124 t. 11 f. 17 et $1:$ : 


\section{EXIGUUM}

o 95 - f. Lewisii H cot in Journ. Bot. 33 p. 66 (P. Lewisi Turu. 1893 .

\section{exigll11m}

11 !3 SPIIAROzosma Tume Agr. Ind. orient. p.111 t. 18 f. 10 .

\section{exigll11m}

d T- STAURASTRUM himseh Contribut. Alg. Promont. Bun. sipei 1 . 213 toli f $15-11$.

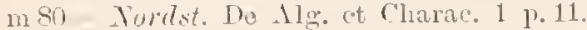

\section{exigflllm}

(1): STAURASTRUM Wolle in Bull. Torr. bot. Club. 1843 p. 19 t.27 l. 2:3, 23 a \& b [non Ririnsch 18Ti Ab auctore in Inosm. U.S. 1.481 in St. nanum tranis mutrtum.

d 89 - Toni syll. alg. 1. 1210.

exile

d 93 DYSPHINCTIUM Tumer Alg. Int, orient, p. 10 t. 1 f. $21^{*}$

exile-is

d s6 EUASTRUM Josh. Burm, Desm. p. 61 in t. 23 f. 1 ; 17 $\& 18$.

d 84 - Toni syll. alw. 1, 107i.

n 91 HELIERELLA huntze Rev. gen. p]. p). S!s.

exile

d g3 EUASTRUM Turner Desul. Notes p.346, et f. $21 \mathrm{p}$. 311; nec. Jos\%. 1sbii.

exile

d 9. STAURASTRUM West Alg. Madag. p. is t. 8 f. 35.

\section{eximilu}

1 95 cosmarium 11 cot $1 \mathrm{lg}$. Madag. p. $61 \mathrm{t} .7 \mathrm{f} .10$.

\section{eximium}

a 93 STAURASTRUM Tuner AIg. Ind. orient. p.131 t. 17 f. 6 .

\section{eximillm}

d $93 \times$ XNTHIDIUM Tuncr Alg. Ind, orient. p. $1 \mathrm{~m}$ t. $13 \mathrm{f}$. 12, t. 22 , f. 10

\section{exparesu}

(1) 1 MICRASTERIAS Tail. Micr. ubserv. p. 37 t. 1 f. 7. [M. a rcuata $\beta$ expansa Nordst. 157T]

d 52- Jritch. 1nf. 3. 217 .

$n 60$ - f arcuata Irullich Desm. Low. Bengal. 1. 2-27; Micr. areuta tomil. 1s51).

d - v. $y$ ibid. p. $27 ;$ t. 13 f. 3 . [M. tropica Nordst.].

a 61 - Arch. in L'itch. Inf. p. 725.

d 68 - Kub. Flor. Eur. Ale. 3 p. 1 s.

d 73 - Wrood Fr. Alg. p. 1.11.

d 81 - Holle Desm. T. S. p. 117 t. 37 f. 12.

o S6-Stokes Key Iesm. p. 117 .

d 89 - Toni svill. aler. p.1121.

n 91 IIELIERELLA Kuntise Rev. gen. pl. p. Sys

1 12 II icr. Nolle Desm. U. s. ed. II t. 11 f. 12.

m 93 - Atomocystis) Tumer Alg. Ind, orient. p. 30. m95- Rucib. in Flora v. \$1 p. 31 .

\section{(c.x)(1)}

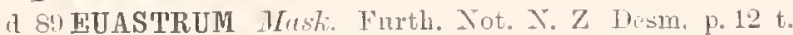
$1 \mathrm{f}, 10$.

\section{exsectum}

11 vit STAURASTRUM Clere in Rab. Alg. Eur. n:o 1925 [st. bifidum see. Lunkl.].

\section{fillecetr - 11$)$}

m 31 MICRASTERIAS (omli Alm. d. Carlsb. 153.) p. 206 t. 2 f.:2! = Raphidium f.?

n :5 STAURASTRUA Fhroub. in Wiegn. Areh. 1834 p. $185=$ Illem

1) 10 CLOSTERIUM Menegh. Synops. Desin. p. 2:33 (sep.p. $3: 3)=$ Idem.

11. 12 - C'cutor in Ann. Mag. Nat. Hist. v. p. 193 [sine nomine anctoris. Amnon eum viore i.lentieum].

\section{Furquhrorsomii}

a so DOCIDIUM Roy in Journ. of Bot. p. 335.

o y. R.oy scott. Desin. P. 211 (sep.p. 19) t. I f. 1 .

\section{I'rryuharsonii}

d !3 STAURASTRUM Roy Scottish Desm. p.237 (et 189.1) t. 4 f. 3 (se 1.1.20)

\section{fusciculatu}

d 11 TESSARARTHRA Worren Rechereh. physiol. p. 121 t.2 f. I - III. - Characium Sieboldii? see. 1. Limun Als. Unicell. p. 30 .

frescirulutum $-r \ell$

- TócLOSTERIUM Jucobs. Desm. Danem. p. 17t; non Rab. 1871.

(o) 89 - Tomi syll. alg. 1. 837 .

n I1 ARTHRODIA Kuntze Fev, gen. pl. p. Sis.

\section{fusciculatum}

d 70 CLOSTERIUM TRb. Alg. n:o 2163.

\section{fresciculatume}

d 3 S XANTHIDIUM Elwenl. Inf. p. 117 t. 10 f. 21 h. [fig. mala?.

- $\beta$ polygonum Ehrent. Inf. p.1 19 t. 10 f. 24 a [X. antilopieun]

11 - r'rith. Inf. 1. 1si [11, v.]

d 15 - Ralfs in Ann. Nat. Hist. v. 11 p. 1666 t. 12 f. 3 (et 1846 in Trans. Bot. Soc. Edinb. v. 2 p. Lī t.17) $a$ : fig. a. b. c. a rosm. acnleatnm Henegh.) [X. antilopien 12111 .

d - $\beta$ polygoum ibid. p.t67; f.3 e [X. fasciculat.un a Elweul)].

A 15 - Mass. Brit. Desm. p. 35? t. k:l f. 2 [ut videtur e fig. c. et i. Tulfsii l, e, delineate].

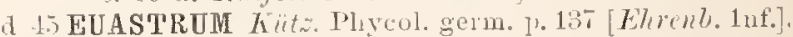

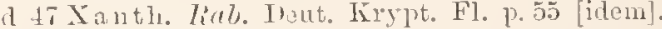

d IS-Kalfs Brit. Desm. p.114a [X. antilopaen n] t. 20 f. 1 . $[1 \mathrm{~b} .=\mathrm{X}$. antilupæum v. fascieuloides Litllem. 18937.

d - - p polygounin ibid. t. 19 f. 1.

d $49-K i t z$. sjec. Alg. 1\% 167. [Descriptio sat bona exclus. symonym.l.

d $52-$ Pritch. 1uf. 1.25s.

$05 b^{\circ}$ - brib. List. p. 131 (= Ralfs l. e. f, 1

d 61 - 1reh. ill Priteh. [nf. ]\%. $6315, a$ et $\beta$.

d $33-$ Rab. Krypt. Fl. Sachs. p. 1:6.

phli3 - crumer in Helwig. p.63 t. 12 f. 2 [X. antilop.]

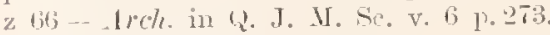

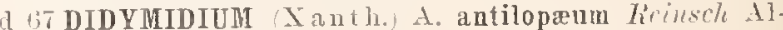
gentl. liank. p. 126.

d - B. pulygont1 ibid.

67 Xanth. Not. Desus. Ital. t. \pm f, 36 [X. antilopeum] 


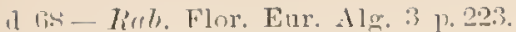

d - b. antilopitum ibil.

4. - e. polyogonum ibid.

n 7o- Tordst. Desm. Brisil. 11. 230 [X. an nilopanm].

71 - ll[n]acanthnm) Lumd. Desm. suec. 1) Tit.

1 33 - llwod Fr. Alg. p. 155.

11 i: - Microgr. Diet. p.sos (sensu Ehrenb.) t. 10) f. 25 [ Rolfs, X. antilopanm].

n in - r jolygona f. gomiuospinosa Jucols. Desm. Danent. 1.211 (hinlls. f. 4 .

o - -1 . cristatoides ibir. (X. cristatum Ralfs $\mathrm{Br}$. Desm. t. $1 ! 1$ f. 3 n. b, c).

o - - $\beta$ antilopea fimplex triquetra $\beta$ tric. Land.

17 7 - Dhlpoute Desmid. snbalp. 1. 72 (sep.]. 16s) inclus. antilnp.) t. 13 f. $211-26$ [r. subalpinum $1 H^{2}$ oll 1 s.iv; f. $20-23=r$ fascic n1 Inides Lïllem. 189:3].

d Tis-Kirchn. Alg. Schles. p. 1is.

s3-Tumer Alge strensall f, 12 [X, a ntiloperm].

mist - Arturi Liste alg. Mosenu p. 1.t?.

d st-liolle Dosm. U. S. p. as t. 2.2 f. 4 -is [X. antilop.?]

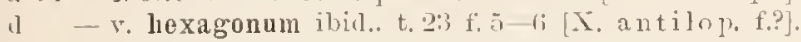

o - r. minor ibicl., t. 22 f. fi- $\bar{i}$ (monstr.). [X. a nt il.?].

o 8.j - r. subalpinum Wolle Bull. Torr. bot. Club. 12 p. 3 (Delp. 18:T). [X. Nordstedtianum Reinsch sec. llolle 1886; $\mathrm{X}$. hastiferum $\mathrm{v}$. javanicum soc. Witdcm. 1.i. -1.].

d sij-Kirchn. Mikr. Pflanz. d. Süssm. 1'25.

d 85 F ornatum Nordst. Desn. Grönl. p. 12 t. 7 f. 10 ,

msli-Lagerh. Amerik. Desm. 1).21\%.

o sti-stolies Key Desm. p. 130.

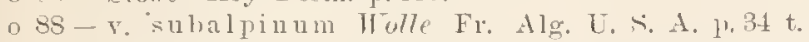
.;i f.?.

lasi - C'ooke Brit. Desm. 1\% 1.31 t. 41 f. $1 \mid b$ e Delp. 1sit]

d 8 - $\beta$ perornatum Nordst. Algolog. småsak. 4 p. 158.

d 87 - Alevenko Chlorosp. Kihark. p.251.

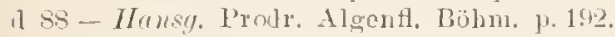

o - r. luexagonum et minus ibirt.

dzsS - Tomi et Leri Fl. Alg. Fenez. p. 53.

d 88 - IInuptf. Zellm. u. Hüllgallerte Desm. p. S9 (sep.p. 31) t. 1 f.5!-1;1. 72, 73. [- v. faseisnloides Lütlie'm. 1S:3].

0 to - v. pulchra Iste. Jel, nagyar, alg. 1, 2:36.

d so - P perornatum Yordst. Fr. mat. alg. X. Zeal. 1. 43.

d - - f. supernumeraria ibit, et t. 1 f. 23.

n s!) - (anter in A. M. Micr. J. 11 f. 14 (ex Wolle).

dz 85 - Tomi śyll. alg. p.918

- - r. minus ibid. 11. 11?.

d - v. ornatum ibid.

d - - v. jorolnatum ibil,

d - f. supexnumerarium ibid.

o - $\quad$ r. subalpinnm ibil.

m:0 Wichler spis Desm. Miedz. p. s6.

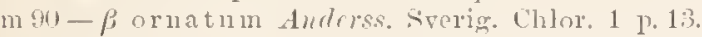

m !N - antilopieum ('hmider. in Tr. Soe, Khark, 23 1. 100 .

4 91 - Kirch. Mikr. Pflanz. d, Siissw, ed, 2 1), 223.

m!1 - Heimerl Desm. nl). 1, 595.

ms1 - Lorge Pille. vilir. Chloroph. 1. 10.

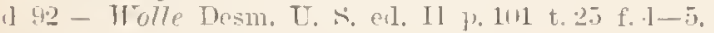

d - - . hexagoum ibil.. t. 2 ; i.

d - r. mincr ibid., t. 25 f, f,-i.

- v. subalpinum ibid. t. 4.5 f. ?.

o 93 - $P$ ornatum $\mathrm{f}$. longispina lichl. ot line. Nowe grat. zielen. 1. 12:5 t. 3 f. 2 !!

d $93-r$. ornatum Schmidle Beitr. Alg. Shwarzwald p. 4 t. 4 f.ti L. I. antilol. v. ornata Lurleres.

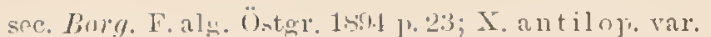
Schmidlei limege 18r5].

m 98 Twner Alg. In, oricut, 11, 14ij t. 12 f.:34.

ph 93 HOLACANTIIUM France in (i)trr. bot. Zeitschr. p. 381 c. fig. 2 A. et $B$.

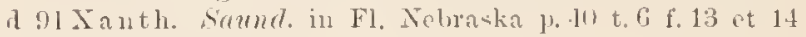
[ex Holle].

\section{fusciculoides}

¿ $\mathrm{sOSTAURASTRUNT}$ Wolle Bull. Torr. bot ćlub. 1880 p. 4 ti t. 5 f. f $^{\circ}$.

d 80 - Wolle Desin. T. S. 1. 13ij t. 49 f. $51-55$.

n sij - Stokes Key Desin. p. 105.

d 89 - Toni syll. alg. p. 115!)

d 92 - Wolle Desm. U. s. ed. II p. 11.4 t. 53 f. $5 \cdot 1-55$.

\section{follosum}

1) 5. EUASTRUM Ehrmb. Micrngeol. 1. 325.

\section{fenesturutur. - re}

o 3!) COSMARIUM ("Ord" in Alu. d. Carlsb. 1539 p. 243 t. 5 f. 29 [Euastam ausatum Foclie f. me jurlice!].

n 91 HELIERELLA Kumtze Ret. gen, pl. II p. Sns (En. Didelta Rolfs [Cfr. Nordst. in Hedrigria 15!? p. 151].

\section{festirme}

d 93 STAURASTRUM Turner Alg. Ind. orient. p. $129 \mathrm{t}$. ifi $\mathrm{f} .31$

\section{Filamentose}

n 60 Stizent. Index Rab. Alg. p. 28. Snbtrib. Leiosporear. Gen.: Hyal., Didymop.. Fronat., Hamb., Desm.

\section{filiforme}

d St ChoSTERIUM telicson in Proc. Canat. Inst. n. s. I 1. 417 ,

\section{filiforme -is}

38 TESSARARTHRA Ehrmb. Inf, t. 10 f. XXI. ["1S3:-" sec, anct.].

a 38 ODONTELLA? Ehrmh. Inf, p. 1it.

m 39 - Ehrent. Neteolpap. p. 5i (sep.p. 12) t. 1 f. 20.

( t 10) - Diplartum) Corda in Alm, d, Carlsb. 1940 p. 2015.

d 49 ISTHMIA Menegh. Sy.nops. Lesm. 1. 205 (sep.p. 万).

-110dontella Iritch. Inf. f. 107 [ex Ehrenb. - n. v.].

1 4. ISTHMOSIRA hïlz. Phycol, germ. $1,111$.

d 4 T TESSARARTHRA liab. Dent. Krypt. Fl. p. 5 ti.

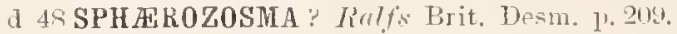

d 49 Istlmosira Kït s. Spec. Alg. 1) 1ss.

d 5zspluær. Pritch. Inf. p.213 (et sub genere Odontella 1. 2.93) t. 2 f. 10 i [ex Ekrenberg].

a $61-$ Arch, in Pritch. Inf. p. 724 .

d 69 - Rub. Flor. Eur. Alg. 3 p. 14?. fig. xyl. p. 11: [ex Ehrenb.]

o $69-$ Areh. in Q. J. M. Se. n. s. \& p. 195 .

m 71 -. Lund. Desm, siner. p. 91.

o it-Jucolss. Uesm. Iranem. p. 212. [Onych. Nordstedtia num sec. Turmer 184:3].

o 78 - Kirmu. Alg. Schles p. 133.

o $81-$ Hork. $\mathrm{x}$. Keal. Desm. 1. 303 et 315 t. 12 f. 25.

a 84 - Wolle Desm. [T. A. 1. 2!l t. 1 f. 5-6,

a sij-Siglies Tiey Dosm. p. 111.

(l Sf - Cooke Brit. Inesm. 1, j t. 2 f. f

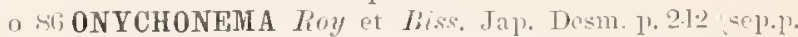
10) [0. Norilstedtianum sec. Tumb. 1sis?.

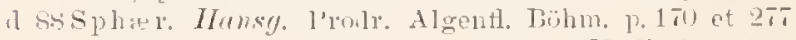
mosongehouema Nortst. Fr. wat, ald. N. Leal. p. gy t. 2 f. 10. [0. Nordsteitian. ser. Tum. 


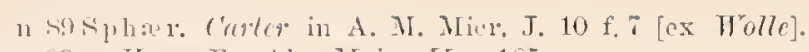
$n \mathrm{~s}$ - IIm\%. Fr. Alg. Inin If r.1si.

11 s!i Onychonema Tomi Syll. Alg. p. To6.

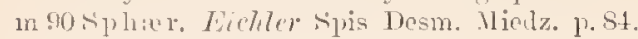

ms0ongeh. Amterss. Sverig. Chlor. 1 p.9.

m!1 - West Danish Algep p. bls.

no 91 - Rucit. Flor. alg. Leopol. 1\%30.

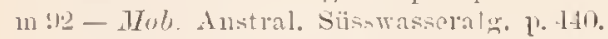

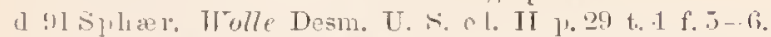

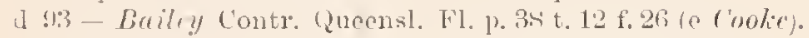

a Ongelonema ibid. p.33 t. 12 f. 29 (" Nordst.).

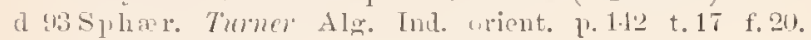
[Aph. Archeri see. Gute. 1.94].

d 9.40 Juclonema v. ornata selmidle in Flora 78 p. 49 t. 7 f. 6 .

d stsplute Samml. in Fl. Nebraska p. 37 t. 6 f. 3 [ex Holle].

\section{Filiformes}

d TS Kirchn. Alg. Schles. p. 1.11. Sectio Desmidienrum. Gen.: Gonatozyeg. Hyalot.l., Bambus.. Desm.. Sipheloz., Spontyl.

\section{fimbriata - 2m}

a $4 \times$ MICRASTERIAS Tatlss Brit. Desm. p. 61 t. 8 f. 2 (M. Rota Litul. Inf. t.12 f. l. [M. a piculata subsp fim Lr. Norrlst. 1sisi?.

1) 50 - Pritch. Inf. p. 215 [to. 2 f. 10:3].

4 $\mathrm{il}$ - v. ornata Bumle in Ifelwig. 1.21 t. 2 f.3.

d iil - Aveh. in Twitch. Inf. p. i2

d ti3-Ral. Krypt. Fl. Sachs. p. 152.

d bit-- v. ornata Postock in Ral. Alg. Enr. n:0 18:i) (M. aculeata Tostack ibil. in notal.

o 67 DIDYMIDIUM Mier., Femseh Alment. Frank. p. 149.

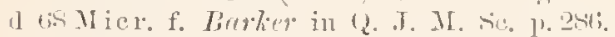

o tis-Areh. in Q. .T. M. S.e. S 1'. 230 et 296.

d bis - liab. Flor. Enr. Alg. : p. 19\%.

d 73 - Wood Fr. Alg. 1) 14\%.

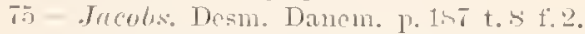

d is-Kinchn。 Alg. Nehles. [1. 16\%。

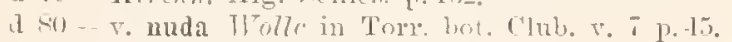

d 84 - Wolle Desm. U. F. 1. 10t t. 3 f. 1 -s.

f. geunina ibis. p. 110 f. 1.

f. ituda ilid.. f. 4 .

t. elephanta ibil.. f. 3 ["elephantina" infra 18!1?].

f. simplex ibik. f. 8 .

t. apiculata ibid. f. 2 (Nl. a pir ulata).

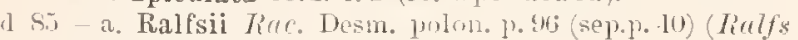
1515 .

d 1) obtusilobum ibil.: t. 14 f. 2 .

o bij-Stukes Iiey 1)esm. 1). 14ī.

(i) Sri - C'oolie Brit. Desm. ]. 50 t. 21: f. 1 .

sii-- Tumer in Leeds nat. elub. transact. 1 t. 1 f.s.

z sit- Wolle Fr. Alg. U. S. A. p.:33.

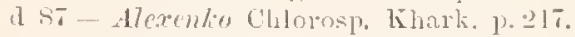

d sis-Honsy. Protr. Algenf. Bolm. P. 210.

mss - Joteret Forth Carolina Dosm. 1. 1.

(1) s.l - Tomi syll. alg. 1. 1131.

d - v. obtusiloba ibid.

$m$ - r.elephanta ibil. p. 1182

$0 \quad-f_{0}$ simplex ibil.

m 50 - Eichter Spis Dosm. Mirulz. p. S!\%.

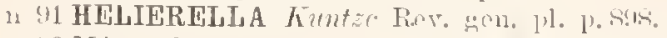

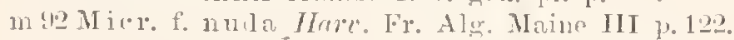

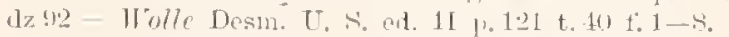

n - f. genuina f. 1 .

o - f. 11 mda f. 4 .

13 - f.elepliantina f.:3. o - apiculata f. 2.

d - simplex f.s.

d 93 P spiuosa Fisset in Ifoy Senttish Deam. \%.173 t.1 f. 3 (sep).p. 12).

mat-Alexenlio Mat, alg. Kliark. 1.29.

Cfr. Micr. denticulata 1852. M. furcata Wood.

\section{fimbrirtum}

d 14 XANTHIDIUM While in Micr. soc. transact. 1 1. Ti t. is f.2. Fossile, an syongin? [Quorue in Micr. Jol117. r. 2, 1842, t. 4. - n. v.].

\section{Finmarlice}

d 92 CosmariUm Iiorge Chlorople. Norsk. Finmark. p. 13 t. 1 f. 12 .

\section{firm}

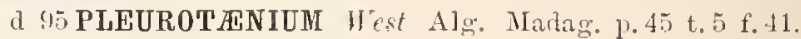

\section{fissume}

d 93 STAURASTRUH Twner Alg. Ind. orimt. p.110 t. 11 f. 21.

d 95 - v. perfissum West Alg. Mladag. p. 73 t. 8 f. 22-23.

\section{Herroillum -r}

d 7 CLOSTERIUM Delponte Desmirl. smbalp. p. 101 (sep.p. $1+17)$ t. 18 f. $31-86$.

d 89 - Toni syll. Alg: p. st!?

11 91 ARTHRODIA Kuntze Rev. gen. pl. 11. S83. Cfr. Clost. Luuula Focke $15 \mathrm{si}$ ex p.

\section{flrmmenm-r}

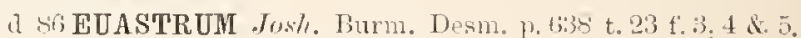
d Sil Tomi šyll. alg. 1\% 110\%.

11 \$1 HELIERELLA Kinntze Rev. gen. 11. 1\% 898.

\section{Hre.sum}

daf 9.1 COSMARIUM lioy ot Biss, in Roy Acottish Dosm. p. 101 , sep.p. 31) t. 2 f. 17.

\section{Floridromm -}

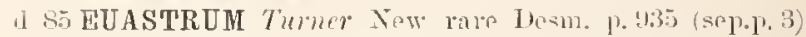
t. 15 f.. E. ventricosum L. sece. Wolle in Bull. Torr. Bnt. Club 158; p.58. E. veutr. v. Florida11 un Twm. 1893].

d si-Tomi sirll. alg. p. 1809.

11 !1 HEJIERELIA himtze Rer. gen. pl. p. sis.

\section{Flotomii}

1 52 DOCIDIUM Ral. Paeill. fase, 6 n:o $51 \mathrm{cam}$ icone t. 4. [Plenr. truneatum].

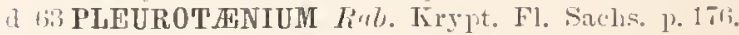

d tis - Lab. Flor. Eur. Alg. 3 p. 14 .

d Ts - Kirchn. Alo. hehles. p. 145.

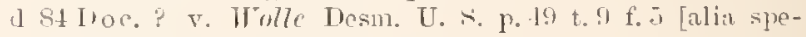
cies?].

0 so Iroc stoliex Key Desin. 1) 113.

1) 89 Plenr. Toni syll. alg. p. M2.

m!1 - Crutw. Flor. alg. Leopiol. 1. 38:

(1) 92 Doc.? *. Hulle Desm. U. S. ed. II p. 52 t. 11 f.

\section{Foersteri}

d 95 COSMARIUM sichmiale in I[edwig. 34 1. T. t. 1 f. 12.

\section{foliacen}

d 1 MICRASTERIAS Baitey in Ralts Brit. Desm. p. 210 t. $3.5 \mathrm{f} . \mathrm{i}$.

(1) 52-1'itch. lnf. 1, 216. 
defou-p. Wrallich Desn. Low. Thengal. p. 2.00 t. 1.1 f. 1 -. [-f, elongata Jum. 14:1:3].

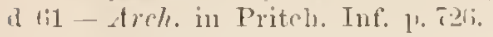

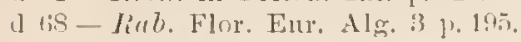

d\% $70-\gamma^{\prime}$ ornata Nordst. Desm. lirasil. 1'.221 t. 2 t. Li.

d $8: 3$ - TTond Fr. Alg. P. 117.

m sil- Nordst. De Alg. et Clasrac. 1 p. 111.

o 82 - Wolle in Bull. Torr. Lot. Club. 11 1. 27.

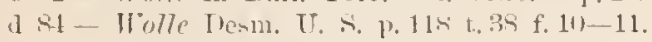

o 8 ; - Stolics lieg Desm. p. 1.17.

1) 89 - Trmi syll. alg. p. 1129.

dz - vornata ibid.

n 91 HELIERELLA Kunte Rer. wen. pl. p. sts.

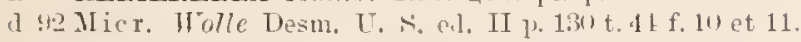

o (zf) $13-$ f. " typica Tumer Alg. Ind. orient. p.94 t. 1; f. $12-1.4$ (t. 15 zygospora. " l. $\beta$; $:$ ).

o - f. $\beta$ elongata ibid. $(\beta$ Hin.).

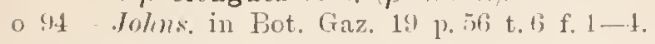

\section{foliutum}

d 93 STAURASTRUM Tmmer Alg. Ind. orient. p. $115 \mathrm{t}$. 13 f. 31 ).

\section{fontigenum - -}

1 Ts COSMARIUM Nordst, in Wittr. \& Norlst. Alg. nxs. n:c 171 f. xylogr. a. b. c; et in fase. 21,1859 ) p. 43.

a 7 - Arch. in Q. J. M. sic. v. 1!l n:0 73 p. 121 .

d $S 9$ - Tomi syll. alg. p. 1010 .

n 91 URSINELLA funtze Rev. gen. pl, p. 92t.

o 92 Cosm. Crutu. Flot, glon. Galic. 3 p. 129 t. 3 f. 4 .

d 45 f.? schmille Beitr. alp. Alg. 1. 45; t. 15 f. 26. Cfr. Cosm. pseudofontigonum.

\section{forciputum}

34 EUASTRUM Comle in Aim. U. Carlab. 1539 p. 23. 2 f. 7 - Pediastrnm f.

\section{forciputum.}

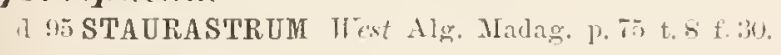

\section{forfirmlutum}

d il STAURASTRUM Lmat. Desm. Suec, p, 60 t. 1 f. is,

s1- Wolle in Pull. Torr. bot. Chub. 1, 14 t. 41 1. $16-19$.

1) st - Wolle Desm. U. S. p. 11.t t.51 f. 16-19. [Alia spee, sec. Il the 1895 .

o 86 - Stolifs Key Desm. p. 168.

d 89 - Toni Syll, alg. 1.117i.

d 1 - v. Americanum ti est Freshw. alg. Maine II p. 335 t. 31 \% f. 14 .

d - r. enoplon ibid. p. 356 t. 315 f. 15.

1192 - Wolle Desm. U. S. ed. II 1, $15 \mathrm{~s}$ t. 62 f. 16-19.

n 43 - (Schizastrum) Turner Alg. Inul. orient, ]. 132.

n $45-$ - . enoplon f. West in Jomin. Tot. $33 \mathrm{p}$. (5:) (Staur. crescentum Irastings $1 \mathrm{n}(12)$.

\section{formensw wm. -}

d SS COSHARIUM Hoft apud Nordst. Bornh. Desm. p. 194 t. if f. ij- 7 . (C. Quasillus $f$ quadrifera f. polycrenata. Jacobs.?

d 59 - Toni Syll. alg. p. 1 s.?.

n (11 URSINEIIA Fumlze Rev, gen. pl. p.92t.

m!1 Cosm. Gutu, Flo1, als. Lenpol. p. ril.

d $93-\beta$ xquatoriense Nimist. in Tittr. ct Fordst. Alg. exs. 11:0 111s.

d 9. - 5 depauperatum Gute. Fl. alo. Tarmapol. 11, 1:3 t. ; f. 25 .

o 95 - Borge siverig. Clalor. II j).201.

Cfr. C'osm. gradatom Roy. formosmm-

a so EUASTRUM $11 \%$ me in Bull. Torr. bot. (lub $1 \times 30$ 1). t5 t.5 R. non ciny.

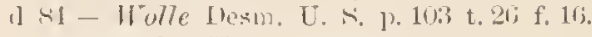

o sti-Stolics Key Desm. p. 144.

I s? - Tomi s.rll. olg: 11. 110-1.

n S1 HeLIERELIA Kuntze Rev. men. H. p. S9S.

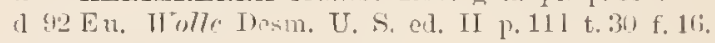

\section{formosmm}

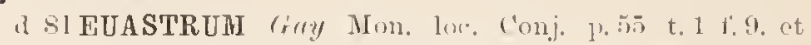
Sote Conj. d. m. France p.33\%. non llolle 1sso. [E. Gayann:n Tomi 1589].

\section{formosim}

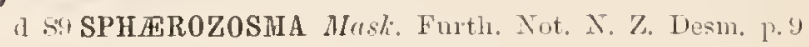
t. 1 f. 3.

\section{forte}

d 93 CoSAARIUM Tumer Alg. Ind, orient. p.61 t.s f. fif.

\section{fivereme}

(1) 93 CLOSTERIUM Turner Alg. Ind, orient. p. 20 Cl. didymotocum $h$ ialfs $(u)$ et auet, non ('ordu).

\section{Forgilarier"}

[22 "Fragillaries") Lwy in Dict. Class. I p.392; trib. Arthrodio].

4) 31 Ag. Consp. crit. Diat. 1.43. Divis. Diatomacearum. Seriellax: Diatnmese (eum genere Desmilio ete.) et Fragilarina

[18 40 Corda in Alman, 1. Carlsbad 1840 p. 186. "Fragillariées", fam. Bacillariar. fien.: Diatona. Gallionella, Actinnerelıs, Arthrotoma, Desmidium. splierozosma. Odontella. Arthrodesmus, Ankistrodesnus, Tessararthra].

\section{Fragilarime}

d 25 Frics Plant. IIomonem. 13. 3it. Tribus Diatomearum (Homalogonata Lỵng.). Gen.: Desmidinu. Melnsoira. Fragilaria, Diatoma.

n 25 leichenb. Con-1) regn, veg. I p, 24;. Dir. Conferveacear.

\section{firgile}

d a3 SPONDYLOSIUM Tuner Alg. Ind. orient. p. 44 t. 1.5 f. 4 .

\section{forrgilis}

l so ARTHRODESMUS Wolle in Mul]. Torr but. Club. $1880 \mathrm{p} .47 \mathrm{t.} 5 \mathrm{C}$.

d $81-$ Wolle Desm. L. S. 1. 45 t. 23 f. $14 ;-18$

o sf - Nitolies Key Desn. p. 131.

n. si-Carter in A. M. Micr. J. 10 f. 15.

(] 89 - Toni s.yll. alg. p. 104i).

d 92 - Wolle Desm. U. S. al, II p. 103 t. 26 f. 11 - $1 \mathrm{~s}$.

\section{forenromirum}

11 to COSMARIUM Gruke. Wahr. 1. Prioritit p. iss (C. intermedium Grry. non belp.) = transieus Gray 1881.

\section{firmronicum}

d misTAURASTRUM Reinsel, in Ral, Alg. Eur. n:o 1s!n fiæ. $1-3$.

d 07 - Remsch spen. Gen. Als. 1. 124 t. 23 B i. 1-1.t (sep). 1. 11; t. $1 ;$; 
d -f. A. ibid. p. 125; f. 1-! [5 = tig. fi lieinsch 1805]. i) -. f. B. ilsia; f. 101-11.

d Go DIDYMIDIUM (stanr.) lieimsel Algent. Frank. p. 138 t. 12 f. 3.

d - f. A. ibid. p. $159 ;$ f. $d-y$.

d - f. B. ibia; f. $a-c$.

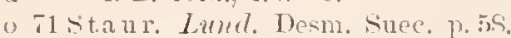

d 84 - Wolle Desm. U. S. p. 181 t. Hi f. 22 (forma) (St. divaricatum $\mathrm{WT} \cdot 1 \mathrm{ss} 2]$.

n 86 Stukes kiey Desm. p. 1606.

(1) S! - Tomi Ayll. alg. p. 1213.

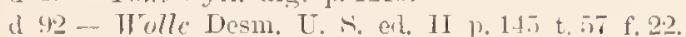
Cfr. Staur. sp. Reinsch Morlut. Fringm, 1865.

\section{Friburgense}

dzf os STAURASTRUM Millard, in Mémoir. Strasb, n. to f. $17-28$.

n 80 - Mille Norg. Ferskr. alg. I ], 13.

dz 8 - Toni Syll. alg. 1. 1186.

\section{Fridre}

$\mathrm{n}$ !s COSMARIUM schmille in Iledwig. $34 \mathrm{p}$. 7t $(\mathrm{Cosm}$. rectangulum Schmidle 1594: won lieinsch).

\section{finceatu-\|m}

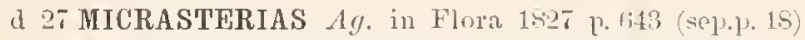
[Descriptio mala; Specimen orienale ad M. rotatam lirlys pertinet. Cfr. Al. I3r. Alg. unic. 1).64 et 10i, Nondst. Pormh. Desm. 1) 186].

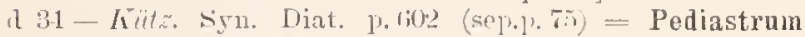
biradiatum Meyen see. anet. ipisum.

d 40-Menegh. Syn. Desm. P. 216 (sepip. 16). Tantum descriptio Agarthii repetita.

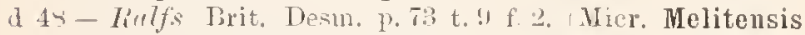

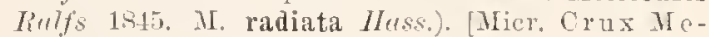
litensis b. fureata liab. 1806)

d 52 - Pritch. Inf. p. 245.

o fol - Irrtlick Desm. Low. liengal 1, 280.

a 61 - Arch, in Pritch. Inf. ] reri,

d 193 - Irab. Krypt. Fl. Aaclis. p. 183.

a 67 DIDYMIDIUM Misr., f. A. Crux Melitensis licinsch Algentl. Frank. polth. (Mier. (ir. Melit.).

d. I. iutermodium ibid.

1) - f. C. furcatam ibis.

d lis Micr, Rul, Flor, Eur. Alo, :3 p. 191. MI, rotata linlfs].

a - b. denticulata (M. Aent. Pirih. ibid. p. 1!2.

d -co capitulifera ibid. ("M. Rota f." IIontasch in liab. Alg. Eur. 1107 .

1) 70-Nordst. Desm. Brasil. 1, 2201 t. 2 1. 13; forma.

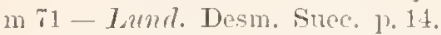

d 33 - Troor Fr. Alg. p. 111 t. 13 f. . . [M. fimbriata f.? sece. Nortst. Bornly. Desm. 1) 1!n]

it-riblons in Trans. F. Soe. Vietoria $\mathrm{I}$ in fig. plontogr. 2 et is.

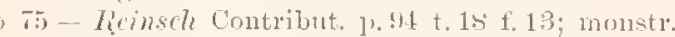

(1) 5 - Kirchn. Alg. Seliles. p. 161.

d st - Molle Desm. [. S. p. 111 t.835 f.5-6.

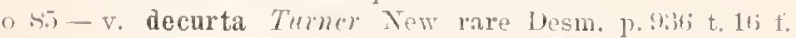
10 [forma tantum ser. Jolms. 1s:4]].

d 8.5 - v. simplex Irolle in Bull. Tonr. but. Cl. p. 1.2.s t. $51 \mathrm{f} .6$ et 7 forma tantum sec. Jolms. 1s! 4 .

m 86-Lagerh. Amerik. Desm, ], 231.

d si-Framli in Lemo. symops. ]. 19\%

o 8h-Stakes líey Desm. 13. 14\%.

- - vosimplex ibid.

d si-Couke Brit. Iesin. 13.5 t, 21 t: 1 . d 87 - r. simplex Holle Fr. Alg. U. S. A. p. 40 t. $69 t$ t.

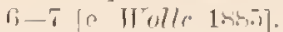

1] sti-Hansq. Trodr. Algenfl. Buhm. p. 2fr.

mse - ? Potert North ('arolina Desm. p.t.

phsa-r. capitulifern Houptl. Zelln. u. Hüllgallerte Desm. p. 91 (sep p. 36) t. 3 f. 23.

1) 89 - Tomi Syll. alg. p. 1114.

d - ? r. simplex ibir.

d - v. deen rta ibid.

m 90 - rmmiel. in Tr. Sis. Tat. Kiliark. 23 p. 101.

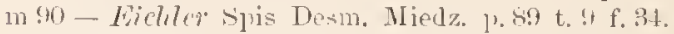

n 91 HELIERELLA hur.tze Rev. gen. pl. p. 898.

m 91 Mier. West Freslew. alg. Maine II p. Bivt.

m 92 - Mrst Fr. w. Alg. Wr. Trel. 13. 1333.

m 92 Holle Desm, [. S. er. II p. 122 t. 39 f. j-r.

d - v. simplex ibil. t. 4 f. $6-$ -

6) 93 - f. typica Tumer Alg. Ind.orient. 11.93 t. 5 f. i a (Relfs).

d - f. gracillima ibil, f, is b.

d - f. expansa ilicl. f. 5 r .

091 - Tulums. in Pot. liaz. 19 p. 5s t.1; f. 8-14 (incl. M. psendofurcata).

o 91-r. globulifera birh. ct Gutw. (in Kirakan Anzeig. 1. 241) et Spec, alg. nov. p. 17t t.5 f. 13).

\section{fureutospermum}

dzf 94 CosmariUM West Tew Brit. Alge p. 7 t. 1 f. 13.

\section{fureato-stellatum}

d "osTAURASTRUM licimsch Contribut. p. 55 t. 16 f. 1. [Nt. sexangulare (Bulnle) Land.].

\section{furertum}

d 31 XANTHIDIUM Ehrmb. Organ. kl, Raum, p. 318 (sep. 171) [rescriptio nimis brevis].

n :3;-Ehrent. in Berl. Monatsber. 1836 p. 114 [Fossile, nulla planta].

a 31;-Ehrent. in Amtl. Bor. d. Torsanml. d. deutseh. Taturf. in Jena 189,21 Sept. 1\% 76. Tdem.

:37 - Ehronl. in Abl. Berlin. Akad. 1836 t. 1 f. 14 (fossile) fanmon Spongia?]; f. 12.

d 39 -. Elrenl. Inf. p. 119 t. 10 f. XXi [fig. malat.

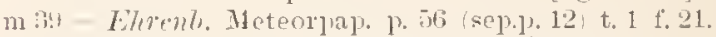

d 40)-Mencyh. Aynops. Desm p. 224 (sep.p. 24).

(1) 11 - Iritchered [nf. p. 18 ; f. 110 [n. v.].

(1) 1 - White in aricr. soe, transart. v. 1 p. 80 t. 8 f. 4 (fossile) [ripongin?].

d $15-$ I Inlfs in Ann. Nat. 11 ist. r. 11 p. 160 t. 12 f. 1 et r. 15 p. $40 \%$, et 1 sitli in Trans. Bot. Soc, Edinu. r. 2 p. 151 t. 17$)$. [N armatum].

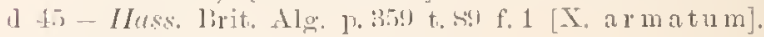

d 17 - liab. Dent. Firylut. Fl, p. 5.).

1 18 - Tialfs Brit. Desin. 1, 213.

d l! ASTEROXANTHIUM Kut spec. Alg. p. 183.

d 52 Xnutl. Iritch. Tuf. p. 255 t. 2 f, 110 [ex Ehront. Inf.]

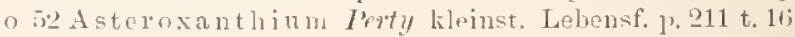
f. 27 [mala].

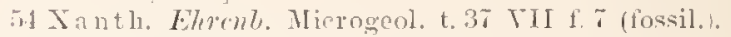

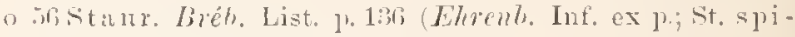
1u 0 \$11 11 Rirlfsit.

d dil - Areh, in Pritch. Inf. p. 713 .

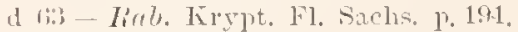

d - b. armigerum ibil. (At. a rm. Brét. 1sarb).

dz6 - Lint. Flor. Enr. Alg. 3 p.218; Forma:

a. (X. fureatum Eluenb.).

b. (Ast, fure. Terty l. c.).

c. (St, psendofurcigerum lieinseh Algent.)

d. X. Threnbergii ('mda).

e. st. armigerum birt.). 
d

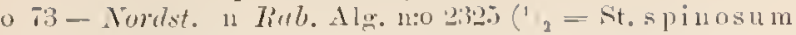
liulfs; 1/, = st. sonarium Ehrli.) liulfs's.

o 73 - Mordst. Noro. Desm. p. 3:3.

$7 s$ - f. spinosa Nordst. in Wittr. et Nordst. Alg. exs. 11:0 165 (st. spinosun $I_{1}^{2}, l f s$ ).

d Ts - hirehn. Alg. Sichlos. p. 17i).

n Ts-Hempel Algenfl. Clienuiliz p. 111.

11 So - $\beta$ senarinu Vordst. in Pointst. Skand. Växt. 1 P.

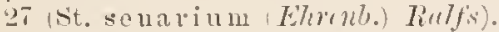

d st-Wolle Desm. U. s. p. 130 (iomiale, t. 40 f. $40-11$, t. 15 f. $15-11$, t. 52 f. 31.

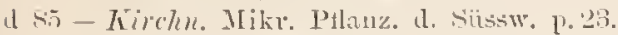

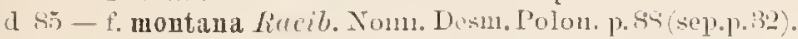

11 Si- $\beta$ senarium Josh. Burm. Drsm. p. 613 t. 21 f.ti

o si-Stulies Fiey Desm. p. 1lin.

087 - v. fissa lote. Diagri. pratv. p.21) (sep.p. 11).

dzsi-Cooke Brit. Deswl. p. 116.

dzt - v. armigorum ibil.; t. 51 f.1 [o Rulfs 18th].

d $-v$ candianum ibid. p. 117 t. 53 f.li (Ntaur, candia 11 u m $D_{i}(p)$ [?])

d s8 - Mansg. Prodr. Algft. Bölın. 1) 215.

u SS-f. a rmigera Boldt Desm. utbr. Nord. p. 6í.

11185 - Alexulu Chlorosp. Li hark. p. 2iT.

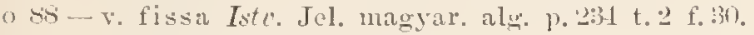

o sy-to? Mask. Furth. Not. N. Z. Desin. p. 2li t. 5 t. 17.

dz Si-Toni Syll. alg. p. 1153.

d - v. armigerum ibid. p. 1151.

o - v. fissum ibicl.

o 90 -v. West Fr. w. Alg. Nortl Wales p. 292 t. 5 f. 11.

m !0 - f. spinosa Auders. sverig. Clilor. 1 p. 1?.

o :1 - Kirclen. Mikr. Pllanz. d. Kïissw, ed. 2 1.2.1.

d 122 - Wolle Desm. U. s. ed. II p. 165 t. 51 f. 4 ll et $\downarrow 1$, t. 5 f. 15 et 16 , t. 1 i 13 f. 31 .

u93-Lïthemïlltr. Desin. Attersees p. ji3.

ul - f. spinosum ibil.

1 93 - f. Indica Tirne Alg. Ind. orient. p.116 t. 11 f.6. o 91 - ff. Schmialle $\mathrm{Agg}$. Geb. Oberilteins ].558.

in 94 - Iste. Adat. Roman. alg. p. $15 t$.

d. 1 - v. subsenarinm West New Brit, Aln. p. 10 t. 2 f. 53.

d 95 - v. aculeatum Sechmidle in Hedwig. 31 p. $\$ 1$ t. 1 f. 19.

Cfr. Asteroxanthium bisenariun Kiitz. 1849. Binatella furcellina, Staur. Detenii, Staur. Ehrenbergianum et Xanthilium Ehrenbergii, Janth. n:0 3 Buileng 1 ir11.

\section{furcellime}

u 39 BINATELLA Lréb. in Cliev. Nicr. p. $272=$ Xanthidium furcatam sec. Thnegh. Synops. Desm. p.204.

\section{fureigerum -}

n 39 BINATELLA Brib. in Chev. Mier. p. 272 .

1) 10 STAURASTRUM Brib, in Mcnegh. Synops. Desin. 1). 226 (sep.p. 26).

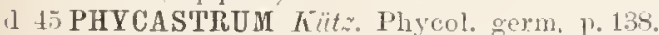

d is DIDYMOCLADON linlfs Brit. Desm. p. $14 t$ t. 33 f. 12.

d 1!! ASTER0XANTHIUM $h$ iitz. spee. Alg. 1 . 153.

11 1: F"ly castrum (A mblyactinium) Very. cinz. Alg, 1. 125.

d 52 Didymo. Pritch. Inf. p.200 f. xylogr. Ce Iialfs Br. Desm.1.

d lis sta ur. Arek in Pritel. Inf. p. 713 t. 3 f.32-33 [o Rulfs]. d 63 - Rull. Krypt. Fl, sachs. p. 194 f. 1 p. 15 s [ex Ricelfs] d titi-Eyrich. 1 lgent. Manul. 131 t. 1 f. 1 is et 7 .

mfit - Wartm. et Schenti Scluweizer. Kiryptog. fase. " 11:0 $13 \bar{\tau}$.

m67 DIDYMIDIUM (Staur.) Reinsche Algenfl, Frank, p. 17!. Form. 3-9-gоцим.
(1) 68stanu. Rub. Flor. Eur. Alg, 3 p.219, fig. xyl. p. $10 y$ [ut. supia 1:ibis].

y 71 - Ireh. in Q. .. II. S. v. 11 p. 95.

o 73 - Tartst. Nore. Desin. 1. 36.

d 73 - Wood Fr. Aly. p. 151.

d 75 Didyno. Nicrogr. Dict. p. 251 t. 10 f. 32 et 50 [e lialfsi.

- Fistaur. Jucobs. Desm. Danem. p. 20 (incl. St. a lntigerum Lirib.et sit. psendofurcigerum Reinsele).

d Ti Didymo. Dedronte Desmid. subalp. p. ts (sep.j. 17d) t. 1 f. $2.1-2 \pi$.

d 7s Staur. Kirehn. Alg. Sehles. p. 1tit.

m 80 - $\beta$ psendofurcigerum Nordst. in Pointsf. Slanuliu. Växt. p. 27 st. pisendof. Tieinsch 1sibi).

s1-Cooke in (Buekett Mier. J. 6 t. 11 f. 1.

o 83 - v. Wolle in linll. 'Torr, bot. (lul, v. 10 p. 20 t. 27 f. 5 .

o 53 - Task. N. Zeal. Desm. p. 21 ; t. 21 f. 13 [? St. sexangnlare $\beta$ productum Norlst.; $=$ st. sex. $\varepsilon$. attenuatum Turn. 1893.

83 - Turner Algae strensall. f. 13.

d 81 -- Wolle Desm. U. S. p. 113 t. 1 s f. $12-14$ (f. 14 var.); t. 52 f. $2: 3-24$.

d sõ-Kirchn. Mikr. Pflanz. d. Süssw. 1. 23 t. 3 f. 70

a 80 - Frunk in Leunis synops. 3 p. 198.

o sto-Stulies liey Desm. 17. 16 \%

d 87 - Coole brit. Desm. 1) 178 t. 62 2 f. 1 [partim e Delpont.].

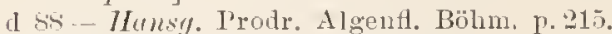

m 89 - livolalt Desm. Grönl. p. 10.

o st- Norlst. Bornh. Desm. p. 20\%.

- f. eustephana ibid. (Staur. eustephanum).

- f. armiger ibid. (Ntaur. armiger. et st. pseudo fureiger um).

in 89 I) id y mo. Iste. Jel. magyar. alg. p. 236.

I sel Staur. Toni Fyll. alg. p. 1221.

in (10)-Anderss. srerig. Chlor. 1 p. 13.

d 91 - Firchu. Jikr. I'llanz. d. Süssw. ed. 1 p. 21 t. 3 f. 7 !)

no 51 - Heimerl Desm. alp. P. 60 .

w1 11 Burge 13ikr. Sibir. Chloroph. p.10.

$11192-W c a t$ Fr. w. Alg. W. Irel. p. 186 .

d $9 \cdot 3$ - Wolle Desm. U. S. ed. 11 p. 161 t. 59 f. 12-11; t. 63 f. $23-21$.

m 93 - Lïtlicmäll. Desin. Attersees p.56.1.

¿ $93 \mathrm{Staur}$. Roy Scottish Desn. p. 23\% (sep.p. 20\%.

Cfr: Santh. articulatum et coronatum, Staur. cormubienso et montanum.

\section{fusifurlle -is}

a s1 ClosteriuM Guy Mon. loe. Conj. p. 71 t. 2 f. 16 ; et Note Conj. 1. 11. France p.33!.

(l 8) - Toni Syl1. Alg. p. 832.

11 ARTHRODIA Kunt:e Rev. gen. 1). 1). 583.

z11 90 Clost. Gutw. Fl. glon. Galic. 2 1.7.

\section{finsifurme}

a s.1 PENIUM (rily Mon. loc. Conj. p. 69 t. 2 f. 11 ; et Note Conj. d. m. Hrance 1.33s'.

d 84 - Tuni syll. Alg. 1. 857 .

\section{f'usiforme}

I 8.2 STAURASTRUM Tolle in Bnll. Torx. bot. Club 1.882 p. 2.4 t. 13 f. 8 .

d 81 - Wolle Desm. [T, S. p.137 t. 11 f. 20-21.

o sti- Stolies Key Desm. p. 166.

(1 8) - Toni śyll. alg. p. $1231 \%$

d 42 - Wolle Desin. U. S. ert. Il p. 150 t. 55 f. $20-21$. 
FUSIFORMIS

fusiformis

a :- ECHINELIA Corla in Stums Dentsehl. Fl. II. 18 t. 16. [An Clostorinm sp.?].

fusispora $-11 \mathrm{~m}$

d lit PALMOGLOEA counu Fl. Finint. p. 110 t. 1 f. 8 e et 1 .

d MES0T RSNIUM? (Palmogloea) Tumi syll. Alg. p. 813.

\section{fisullle $-\ell$}

a s6 COSMARIUM Roy \& Biss. Japan. Desm. p. 194 (sep.p. 3) t. ํㅡㄴ. f. 20.

d s9-Toui syll. alg. p.995.

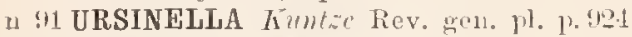
Cfr. Cosm. gomuifernm Irib.

\section{greleutume}

d !3 STAURASTRUM Twme Alg. Ind. orient. 1. 122 t. 11 f. $3, !, 10$.

\section{gralevitum -}

d 70 CoSMARIUM Nordst. Desm. Brasil. p. 2us (sep.p. 171) t. 3 f. 26 .

d $55-v$. minus lieilsele Contribut. 1. 85 t. 13 f. 6 [Non hue pertinet see. Nordst. in Iledwigia 1876 p. (ito].

a - f. ibick. 1. \&s t. 10 f. 4 [C. sexangulare Lmud. major sec. Nordst. in Hledw. 1s7i; p. 60. - ? C. subtumidum sec. II (u) 1858.

a $78-K i r c h . A l g$. schles. P.150. [C. Holmionse e. Kirchnorianum Fincib. 1s85; C. subtumidum sec. HI $14: \%$. 1585].

d 81 - Wolle Desm. U. S. p. 70 t. 16 f. $46,48$. - v. ibid. f. 17 .

o $1 ;$ minus Hille sydamerik. Algh. p.18 t. 2 f.S7.

o S6 - Stukics Key Desur. p.12\%.

m sti - $\beta$ minus hoy et Biss. Jap. Jism. p. 196 (sep.1. 1).

d 86 - Couke Brit. Desm. 1. 87 t. 12 f. 14.

(1) $89-$ Toni syll. alg. P. $67 \%$.

o- - v. minns ibid.

1180 - Rieil. Now. Desm. p. S6.

n 91 URSINELLA Kuntze Riev, gen. p1. p. 1

d g. Cosm. Wrol7e Dosm. U. s. ed. II p.75 t. 19 f. $16-1 \mathrm{k}$.

\section{Gangense}

a 93 COSMARIUM Thrner Alg. Ind. orient. p. 59 t. 8 f. 55 . [Cfr. C. jenisojenso v. rectangulum Gutw. 16y1].

\section{Gangense}

d 93 EUASTRUM Turner Alg. Ind. orient. p. 97 t. 11 t. 20.

\section{Gallgensis}

(1) 93 ARTHRODESMUS Turner Alg. Inl. orient. p.136 t. 12 f..1t, t.11 f. 35. [A. gibberulus see. Willem. 15.) 11 .

\section{rampolense}

1 4 COSMARIUM lioy ot biss, in Roy Scottish Desm. I.

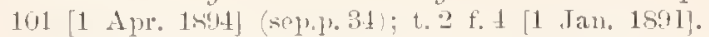
Cosin. alpinum v. helveticum Schmille $1 \bar{s} A_{1}{ }^{\circ}$. 1 s. 1 sec. ITest in Jouru. Bot. 1 so5 1.67; C. alpinu m see. Schmidle 1s:5̃].

\section{(4.ISTRTII) II H}

d s9 Rucib. Nom. Desm. p. 76. Seet. Cosumri. [Gastrocosmarium Hausg. ex l\%]. Fubsect. Microgastridium (1) Eingstrilium,

\section{GASTROCOSMARITU}

at sí Ilansg. I'rodr. Algenf. Böhm. p. 2.0. Seet, Cosmarii. Subsect.: Mierogastridium et Eugastridium.

(1) Sy Tomi syll. Alg. p. 1000 . Subsect.: Microgastridium et Calogastridium.

\section{rayanum -}

d S9 COSMARIUM Toni Syll. alg. p.904 (Enastrum ellipticun Guy 18st, uon Jictp. 1875). [C. Gayii Gutw. $18.10]$.

1) 11 URSINELIA Tuntze Rev. gen. pl. p. 924.

m 11 Cosm. Gutw. Flor. aler. Leopol. p. 53 .

m!4 - Gutw. Fl. ali.. Timapol. p.9.1.

\section{Gayamume - a}

d s9 EUASTRUM Tomi Syll, alg. p. 1075 (Eu, formosum Guy 18s1, non Holle 1880).

115 HELIERELLA Kuntze Rev, gen. pl. p. sus.

\section{Galgii}

o 10 COSMARIUM Gutu. Wahr. Priorität p. 60) (C. ellipticum Gay non Thly.) - [C. Gayanum Do Toni. $1,8: 1]$.

\section{gelidum}

n $\$ 3$ PENIUM Wittr. Suöns 0 . isens fl. p. 113 et 122 t. 3 f. 24.

d 8.1 - Toni syll. Alg. p. 85 s.

\section{gemellifrerum}

a 70 STAURASTRUM Nurelst. Dosm. Brasil. p. 290 t. 1 f, 54. d S9-Toni syll. alg. p. 1175.

\section{yeminatu}

d 25 HETER0CARPELLA Bory in Dict. class. list. nat. 8 1. 180) (Palmella rupestris $1 . y m g b$. ex p.; Arthrodia Riffinesq. 1813) [Tessararthra mouiliformis see. Ehrenl. ete.? Enastrum Ehrb. in Isis 1831].

o 45 - Turp. in Diet. se. wat. LIX p. $20^{\circ}$

\section{geminutume - a}

d 71 COSMARIUM Lund. Desm. Suce. p. 31 t. 6 f. 9 . m s. Wille Sydamerik. Algt. p. 15.

d si - Toni riyll, alg. 1.942.

o s! - f. berolinensis Recil. Now. Desm. p. 4.5 t. 5 f. 19. m! 10 - Eichler spis Desm. Miedz. p. ST.

n 1 URSINELLA huntze Rev. gen. pl. p. 924.

d 94 Cosm. v. berolinense f. polonica Eichl. et Gutw. in Irrakan Anzeig. p. 239 et Syee. als. nov. p. 166 t. 1 f. 12 .

\section{geminatum!}

m 13 SPONDYLOSIUM ? Turner Alg. Ind. orient. p. 47 t. 21 f. $1-5$.

\section{geminatum -}

d 73 STAURASTRUM Not 7 st. Nor.r. Desm. p.30 t. 1 f. 13.

d $55-\beta$ rotundatum Boldt Sibir. Chloroph. p. 119 t. 6 f. 3 .

d 57 v. supernumeraria Iste. Diagn. prev. p. 23!) (sep. 1. 10) et

d 88 - - Ist 2 . Jel. magyar. alg. 12.233 t. 2 f. 29.

d 89 - Tomi syll. alg. p. 1167.

d - v. supernumerarinm ibid. p.11tis.

d - v. rotundatum ibid.

n 933-(Rajhidiastrun) Tumer Alg. Ind. orient. p. 133. 


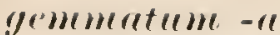

d 85 CosmaRIUM Tumer Xew rale Desm. p.935 sep.p.3) t. $16 \mathrm{f}$. J non Iirib. [C. triplicatum see. Holle 18si; won ita sec. Tum. in Alm. Ind. or. p.63. - C. occidentalo Turn, Is93].

d s!) Toni s.y.1l. alg. 1. 1030.

n 91 URSINELLA huntie Rev. gen. pl. p. 40

\section{yemmutum- -}

1 10 COSMARIUM Mrib. in IIenegh. Aym. Desm. 1.221 (sel'p.?.21)

d 14 EUASTRUM Tielfs Ann. Nat. Hist. v. 11 1).191 t.7 f. 1 ; et (1816) 'I'aus. Bot. śoc. Edinb. v. 2 1. 125 t. I1 [eum var. " $\beta "$, fig. f.] = E. pectinatum sec. Ralfs Brit. Desm. [fortasse fig. a. c (sinistra). d et e al E. gemmatum pertineant].

d 15-Mass. Brit. Alg. p. 3s'2 t. 51 f.6 [e Tialfs l, c. depictum].

d 15-Kütz. Phyeol. germ. P. 131 .

0 t 7 - Fucke Pliys. Stuil. p. 13 t. 1 f. T. [Quid?].

d 18 - Rulfs Brit. Desu. p. si t. 11 f. 1 (Eu. papnlesum Kïtz.).

d 1!-Kütz. Spee. Alg. p. 171 lsensu Rulfsii in An. X. Hist.].

19- (Euc asmium) Nag. einz. Alg. 1. 120.

d 52 - I'ritch. Inf. p. 250 .

d 53 - Wuth. Fl. Pelg. II p. 52-.

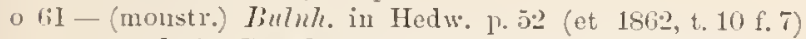

d 61 - 1rech. in Pritch. Inf. p. 730 (Eu. Hassallianum).

d $63-$ Rab. Krypt. Fl. siachs. 1\% 18\%.

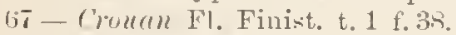

แn 6.7 DIDYMIDLUM Eucosuium) Reinsch Algenf. Frank. p. 124 .

d bs Eu. Tab. Flor. Eur. 1 lg. 3 p. 180 ().

d 73 - Delponte Lesm. subalp. p. 106 (sep.p. 94) t. 6 f.6- 6 .

d 73 - - Wood Fr. Alg. 1. 136.

d 85 - v. Reinsch Contribut. P.92 t. 10 f.S [aline sp. magis affine:|.

d 78 Kirchn. Alg. Scliles. p. 140.

d 81 - * mononcylum Nordst. De Alg. et Clarac. 1 p. 8 t. 1 f. 13. [E. mononcylum Riacib. 1885].

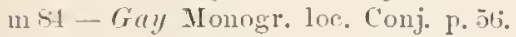

in 81 - Kucib. Desm. okol. Krakowa p. sep.p. 21.

m 81 - Lopot Mater. alw. Warszaw. 1).253.

d s 81 - Wolle Desin. U. s. p. 101 t. 28 f. 3-1.

u 85 - a. typicum Iiac. Tonn. Desm. Polon. p.91 (sep. p. 35).

a b. retusiformo ibid., t. 13 (sep. 1 ) f. T.

o Sb-Stokrs Key Desm. 1) 116.

a $\mathrm{Sij-Cooke} \mathrm{Brit.} \mathrm{Desm.} \mathrm{13.} 33$ t. 35 f. 1 [fig. a, b. e, f, f: e Ralf:s.

St- Tumer iu Leeds nat. club transact. 1 t. 1 f. 11.

d sit-Aleacuko Clilorosp, Kliark. p. 213.

d 89 - II amsy. Prodr. Algenfl. Böhm. p. 201.

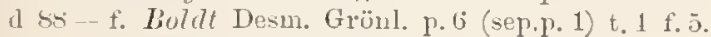

d 89 - Toni syll. alg. p. 1070 .

d - v. mononeylum ibid. p. 1071

d - v. minns ibird. Isolelt 1858.

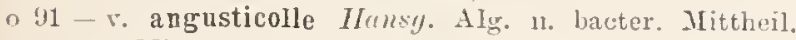
ए. 33.).

11 "1 HELIERELLA huntze Rer. gen. pl. 1. 8.18.

111 !' Eu. Borge Cliluropli. Norsk. Finmarli. p.6.

n! 10 - West Fr. W. Alg. W. Hel, p. 13s.

m !.- v. mononcylum Gutu. Flor. glon. Galic. 3 p. 132

o 11 -v. platycerum Wildem. Obs. crit. Desm. p. 101 Eu. platycerum\%.

Nordstedt, Index Desmid.
Cfr. Eu. 10:0 5 Lait. Amer. Bacill. p. 295 sep.p. 14) t. 3 quoad f.:27 $d$.

\section{gemmiferum-r}

d ari COSMARIUM Iirib. Listo p. 301 [Cosm. Botrytis r. sec. Nordst. 1sis; et 1sisi].

d $61-4$ ch. in Pritch. Inf. p. 733 .

d 63 - Iricb. in Rab. Nlg. Eur. 11:0 1585.

d tis-Rirb. Flor. Eur. Alg. 3 p. 15\%.

o it - Lund. Desm. Suec. p. 20i:

in 72 - Nordet. Desm. Nipetsb. 1.2T [C.snbspociosum Nordst.].

a 78 - Irittr, et Nordst. Alg. exs. 11:0 17\%.

m s2 - Nortst. Algolow. smăsali. 3 p. 4 s.

o 83 - Musli. X. Zeal. Desm. Add. p. 210 t. 21 f. 1 [C. magnificnm Tordst. 18Sir].

o 86 - Nordst. in Wittr. et Nordst. Alg. exs. n:o 826.

d S:I - Toui syll. alg. P. 4.

m 90 - Eichter s'pis Desm. Mied\%. p. s8.

11 URSINELLA humtzc Rev. gen. pl. 1.921.

\section{gemmelutum}

d 93 STAURASTRUM Timer Alg. Ind. orient. p.114 t. $13 \mathrm{f} .20$.

\section{GENICULARIA}

d as de Bary Conjug. n. $T$ it non Roussel Fl. du Calvad. (teste Drse. 1413) = Chantransia Fries, sec. Ifeifier].

d 61 Arch. in Pritch. Inf. p. 719 et 721.

d 6s Ful. Flor. Eur. AIg. 3 1) 107 et 156.

d 75 Microgr. Dict. p. 231 et 338.

d TTrunk in Leunis Synops. 1. 1632.

d 81 Gay Monogr. Ioc. Conjug. P. 42.

d sa Kirchn. Mikr. Pflanz. d. Süssw. 1) 20.

o s6 Stolies Key Desm. p. 109.

d si Frank in Leunis Synops. p. 195.

d 87 Cooke Brit. Desm. p. 181.

d sy Tomi syll. alg. p. $\$(13$.

d 90 Willc in Natürl. Pflanzenf. p. 13.

d 91 Kirchn. Mikr. Pflanz. d. Siissw. ed. 11 1. 21.

\section{yemuosum-"}

o si COSMARIUM Torlst. Algolog. småsat. 4 p. 161.

d 88 - Nordst. Fr. wat, alo N. Zeal. p. 5.5 t. ij f. $t$.

d so-Toni syll. alg. p. 9ht.

n 91 URSINELLA Kuntzc Rev. gen. 1, p. 1. 1.

d 9. Cosm. $\beta$ minus Gutw. in Nuov. Notar. Ill $p .19$.

(1) $92-\beta$ winus Gutu. Flor. glon. Galic. 3 p.127 t. 3 f. 8 .

\section{geometricum}

d 5 COSMARIUM TVest Alg. Madag. p. 59 t. 6 f. 32.

\section{Creoryir)m}

d 90 COSMARIUM licinech sïssmsseralg. Sild-Georg. $\mathrm{l}$. 350 t. 2 f. 8 .

\section{Georyicum}

a s6PLEUROTANIUM Layerh. Anerik. Desm. p. 250 t. $27 \mathrm{f.} .2 !$.

d s. DOCIDIUM Wolle Fr. Alg. U. S. A. p. 26 t.61 f. $16 \mathrm{i}$ [e Lugerh. 1. c. aucta].

4 89 Pleur. Toni syll. alg. 1. 102.

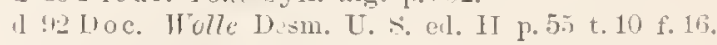

\section{Grerstenber!jii}

d 
635 cum icon. a-b; idem. in Hedwig. 1895 p. 23; fig. a-c p. 21.

o f. typica ibid, fig. $u, e, d, e, g, f$.

1 - f. trapeziformis ibid. fig. $h$ et $l$.

m - f. subreniformis ibid. fig. i et $k$.

\section{Ghibellina}

d 37 MICRASTERIAS Menegh. Conspect. alg. Eugan. p. 1! (Eu. hexagenum, Stauridium bicuspidatuu et St. Crux-Molitonsis $\operatorname{Cord}(\omega)=$ Podiastrum.

\section{yibberulus}

a 85 ARTHRODESMUS Josh, in Journ. of Bot. v. 23 p. 3.1 t. $25 \pm \mathrm{f} .6$

d 89 - Toni Syll. alg. p, 1062.

m93-(Aplodesmus) Turner Alg. Ind. orient. p. 137 t. 12 f. 5.

n 94 - Willem. Obs. crit. Desm. p. 106 et 111 (inclus. A. crispns, cnrvatns ot gangensis Tum. 1893).

Cfri. Arthr. Incus var. Grun, 1865.

\section{giganter.}

d 17 PALMOGLOEA Kutz. in Botan. Zeit. 1847 p. 221. Animal?

d 17 TRICHOCYSTIS Kütz. Tab. phyc. 1 p. 20 t. 26 f. 2. d 17 - Kütz. Spec. alg. p. 230.

\section{gigurteum}

d !3? MESOTENIUM Turner Alg. Ind. orient. p. 15 t. 1 f. 19 .

\section{gigunteus-um-a}

d 70 TETMEMORUS Tood in Ploc. Philad. Acal. $\mathrm{X}$. S. 1869 p. 19.

I 73 - Wood Fr. Alg. p. 117 t. 12 f. 7.

d 81 - Wulle Desm. U.S. p. 92 t. 20 f. 6.

o S6-Stokes liey Desm. p. 130.

o 87 - Wolle Fr. Alg. U. S. A. p. 31 t. 51 f. 1 ; forma.

d so EUASTRUM Nordst. in Toni syll. alg. p. 1106.

n 91 HELIERELLA Fintie Rev. gen. pl. 13.898.

d $92 \mathrm{Tetm}$. Wolle Desm. U. S. el. II p.99 t. 12 f. $1, \mathrm{t}$. 23 f. 6.

n $93 \mathrm{Eu}$. (Colpodastrum) Trmer Alg. Ind. orient. p. S7.

\section{grigles}

d 81 CLOSTERIUM G $G^{\prime}(y)$ Mon. loc. Conj. p. 73 t. 2 f. 15; Note Conj. d. 111. France p. Tr.

d 89 - Toni Syll. Alg. p. 832 .

n 11 ARTHR0DIA Kunt:e Rev. gen. pl. p. 883.

\section{ylabrum}

m 39 DESMIDIUM Ehrnb. Heteorpap. p. si et 56 (sep.p. 7 et 12) t. 1 f. 13 . [Staur. dejectum auctor. ex 1'.].

(1) 15 PHYCASTRUM Kütz. Pliycol, germ. 1\% 137.

d 47 Desm. Rab. Deut. Krypt. Fl. 1.57.

d 18 STAURASTRUM Ralfs Brit. Desm. 1.217.

d 19 Plyc. Kütz. Spec, Alg. p. 179.

n 49 - (Stenactinium) No\%. einz. Alg. p. 128

d $52 \mathrm{Stan1}$. Fritch. Inf. p. 269.

51 Desm. EThenl. Microgeol. t.31 XII B. f. 11 [e Meteorpap. 1839 delincata\}.

d 61 Staur. Areh. in Pritch. Inf. T. 738.

d 87 - Cooke Brit. Desm. p. 143 t. 50 f. \pm [e Builey 1811].

d 89 - Toni Syll. Alg. p. 1145.

oz 190 - Roy in Journ. of Bot, p. 337.

Cfr. Enastr. 11:0 1.t Briley Aner. Bacill., 1811. p. 297 t. 3 f. 1.1 (sec. Ehrenl. Mikr. Leb. Siid. u. N. Aner. p. 334).

\section{glabrum}

n 8т XANTHIDIUM Lregerh. Krit. Bemerk. Desm. p. 589

(X. cristatum $\beta$ glabrum Lager\%. 1896).

(1) 89 -- (Holacanthium) Toni syll. alg. p.980.

\section{gludiosum}

d S5 STAURASTRUM Tumer New rare Desm. 1. 138 (sep. p. b) t. 16 f. 21. [St. ochinatum sec. Wolle in Bull. Torr. Bot. Club 1886 p. 59].

d 89 - Tomi Syll. alo. p. 1172.

d 93 -? v. longispinum furner Alg. Int. orient. p. 112 t. 17 f. 2 (st. sagittiferum Bocry. 1890 ?).

Cfr. Thomas Chicag. wat. Suppl. f. $18-19$.

\section{GLAOPRIU H}

11 to Berlectey unss. in Jemn. Fl. Tunbr. Wells p. 192 (1. 96). d 45 Ber\%. (in litt.) in Rulfs in Am. Nat. Hist. v. 1i' p. 10 (et 1816 in Trans. Bot. Soc. Erlinb. v. 2 p. 16t). d 45 Ilass. Brit. Alg. 1\%346.

\section{gluphy)'um}

d 95 STAURASTRUM West Alg. Madag. p. 71 t. 8 f. 27.

\section{glacerescens}

d 72? ARTHRODESMUS Wittr. Gotl. Öl, sötv. Alg. p. 万ิ t. 1 f. 11 = Tetrapedia glancescens ( $W^{\top} i t r$. Arch. sec. Pointf. Skand. Växt. 4, 1880. 13.56. [Cfr. Boldt 1888j.

d 90 - v. papillifera Gutw. Fl. glon. Galic. 2 p. 16it. 1 f. 15.

d 92 - f. convexa West Fl. w. Alg. IV. Irel. 17.170 t.22 f. 10 [Arthr. controversus West 1s91.].

dzf 92 - f. convexa West Alg. Engl. Lake Distr. p. 730 t. !) $f .27$.

\section{Glaniovii}

d s4 COSMARIUM Wille Sydamrrik, Algfl. p. 17 t. 1 f. 3.;. 1 89 - Tomi syll. alg. 1. $\$ 39$.

n 11 URSINELLA Kuntže Rev. gen. pl. p. trat.

\section{Glaviovii}

d 90 EUASTRUM Borg. Desm. Brasil. p. 36 t. 3 f. 23.

d 95 - v. gujanense hiecil in Flora v. 81 p. 33 t. 4 f. 19.

\section{globos 11 m}

d 61 CosmariUM $B u l n h$. in Hedw. p. 52 t. 9 f. 8.

d 63 - Iiub. Kirypt. fl. Sachs. 1? fiz1.

d 68 - Rub. Flor. Eur. Alg. 3 p.17.

o 71 - Lund. Desm. Suec. p. 1.3.

o 5 - f. Nordst. Desm. arct, p. 29 t. 7 f. $25[\beta$ minus Hansy. 1588 sec. H.].

m 7 -f. major Wille Ferskv. Alg. Nov. Semlj. p. $45 \mathrm{t}$ 13 f. 12.

d $-\beta$ trigonum ibid. f. 11 .

d _ - compressum ibid. $\Gamma .45$ t. 13 f. 43 .

d 81 - fo Cooke in Grevillea s p. 31.

1) 83 - * subarctemm Lager\%. in Wittr. et Nordst. Alg. exs. 11:0 567 [C. subarctonm Ruc, 18\%?].

d s. - Wulle Desm. U. s. p. fio t. 19 f. $11-17$.

o - v. ibid., t. 15 f. 20.

m 81 - f. major Wille syorlamerik. Alyft. p. 17 t. 1 f. 36 . [ $\beta$ minus Hansg. 184s sec. H.].

13 _ t compressum f. major ibid. p. 18 t. 22 f. 88

m S5 - * subarctoum Tordst. Desm. Grönl. 1\%9 t. 7 f. 5. o 86-- Stules Key Desm. 1. 126.

d 8 - - Couke Brit. Desm. T. 121 t. 13 f. 6 .

d s DYSPHINCTIUM Hansy. Prodr. Algenfl. Bölnm. 1'. 213.

d $-\beta$ minus ibid. (inel. f. Nordst. 1. e. 1875, f. IItle 1879 et C moniliformo a Dely. 187i). 
a $88 \mathrm{Cosm}$. Bennett Fr. wat. Alg. Fingl. Lake Distr. 2 1). 5 t. 1 f. 14 [Quili?].

m 88 - f. minor Boldt Desm. Grönl. p. 46 .

d S9 Disp. Toni syll. alg. 1, 8s0.

d - $-\mathrm{r}$. minus ibid.

d - subsp. subaretoum ibid.

n - f. majus ibid. p. 991.

d - r trigon $\mathrm{tr} \mathrm{m}$ ibid.

1) - subsp. compressum ibid.

m Sy Cosm. " subaretoum f. minor (Norelst. in) Wittr. et Nordst. Alg. exs, n:n 9hif; et in fase. 21 (18sy) P. 45 .

m91 Dys. Heimerl Desm. alp. p. 593.

d 91 - v. perpnsillum Mansg. Alg. u. bact. Mittheil. p. 381.

m $92-\beta$ minus IItmsy. Beitr. Alg. Bact. Tirol. 11. Böhn. 1). 131 .

m $92 \mathrm{Cosm}$. IIest Fr. w. Alg. W. 1rel. p. 160.

o $92 \mathrm{Dys}$.. majus Rife. Desmilya Ciastoni. p.383 t. 7 f. 5.

d $92-\beta$ perprsillum Hansg. Irodx. Algent. Böhm. II 1. 251 .

d 92 Cosm. Wolle Desm. U. s. ed. II p. (ni) t. 60 f. 14-17.

o - r. ibil. t. 1 f f. 20.

n 93 v. subviride schmidle Reitr. Alg. Schwarzwald. 1. 91 t. 6 f. 13 (110n bona). |Cosm. moniliforme f. subviride sichm. 1894].

n 93 Dys. (Spherosplinetium) Turmer Alg. Ind. orient. 1) 4.

n $93 \operatorname{Cosm}$. (Splnapidium) ibid. p. 74.

o 9.1 - f. Borge siissw. Chlor. Arehang. 1. 23 t. 2 f. 20.

$\mathrm{m}-\mathrm{f}$ ? ibid.; f. 21.

$111-$ subarctoum ibid.

in $94-$ Borg. F. alg. Östgriul. p, 21 t. 1 f. 15 .

in 95 Dys. Sehmille Beitr. alp. Alg. p. 347 (Borge 1594. f. ibid.; t. 14 f. 2 is.

m 95 - Schröder Alg. H. Riesengeb. p. 17.

\section{globosim}

d sistaURAstrum Roy \& Biss. Japan. Desm. 1.237 (sep.p. 5) t. 268 f. 8.

d 89 - Toni Syll. alg. p. 1195.

d 91 - v. granulatum Hest Freshw. alg. Maine $\mathrm{Il}$ p.355 t. 315 f. 12 .

\section{globo.811m}

o 4 XANTHIDIUM Thite in Transact. Micr. sioc. v. 1 p. T7 t. 5 f. 12. [Fossile, an Spongia?]. [Qnoque in Micr. Journ. v. 2, 1842 t. 4 . - 11. v.].

\section{globulutum}

d 4 STAURASTRUM Iréb. in lialfs Brit. Desm. p.217 t. 35 f. 23. [Didymidium bacillaro b. Reinsch 1867].

1) 52 - Iritch. Inf. p. 269.

d 61 -Arch. in Pritch. Inf. p. T41 t. 3 f.24-27 [e Ralfs].

d $63-$ liali. Krypt. Fl. Sachs. p. 1s\%.

d 68 - liab. Flnr. Enr. Alg. 3 p. 221.

d $89-$ Tomi syll. alg. p. 1198.

n 93 - (Cephalastrum) Twner Alg. Ind. orient. p. 132.

\section{gloriosum}

d 93 DOCIDIUM Tumer Alg. Ind. orient. p. 30 t. 8 f. 5 .

\section{(ALTP'TASTRIII}

d 93 Turner Alg. Ind. orient. p. 133. Subgen. Staurastri.

\section{glyptorlermum}

a 95 COSMARIUM Weot Alg. Madag. p.69 t. 7 1. 23.

\section{Glyptosporea?}

n 60 Stizent. Index Rab. Alg. p, 27, Trib. Desmidiacear. Gen.: Micr., Enastr., Staur, Phyeastr., Didymocl., Zygoxanthium Tessararthra, Cosm.

\section{Goebelii}

d 95 SPHER0Z0SMA Racib, in Flora v. 81 p. 32 t. 3 f. 5 .

\section{(90NATIDILY}

d 93 Turner Alg. Ind. orient. p. 74. Subgen. Cosmarii.

\section{GONATOZIGON}

d 56 De Bary in Hedwigia p. 105.

n 5 t De Bury Copulationsproc. im PHanz. p. 340.

d 58 De Bury Conjug. p. $26,76$.

d 61 Arch. in Priteh. Inf. 1. 719 et 721.

1 63 Rath. Krrypt. Fl. Sachs. p. 181.

d) 64 Cray Brit. Alg. j. 74 .

d G.S Rab. Flor. Eur. Alg. 3 p. 107 et 155.

d 75 Mierogr. Dict. p. 234 et 34 .

d 77 Fromk in Leunis Synops. p. 1632.

a 78 Kirchn. Alg. sichles. p. 131.

d 84 Gay Monogr. loc. Conjug. p. 42.

d St Wolle Desm, U. S. p.22.

d S5̃ Kirrchn. Mikr. Pflanz. d. Süssw. p. 20.

o Sf Stokes Kiey Desm. p. 109.

d 8 Frank in Leunis Synops. 3 p. 195.

d 86 Coole Brit. Desm. p. 2.

a SS Hansy. Proilr. Algent. Böhm. p. 167.

d 89 Toni syll. alg. p. $\$(1)$.

d 90 Wille in Natürl. I'Hanz'nfam. p. 13.

d 91 Kirchn. Mikr. Pflanz. d. Süssw. ed. 2 p. 21.

d 92 Wolle Desm. U. S. ed. II p. 20.

ph@ Lütlicmüll. in Österr. bot. Zeitschr. 44 p. 53.

\section{GONIOCYSTIS}

d 45 Mlass. Brit. Aler. p.349. Sect.: Trigonocystis, staurastrum. Pentasterias.

\section{gomioides}

d 95 COSMARIUM West Alg. Madag. 1. 70 t. 8 f. 8.

\section{gotlandirnom}

a 72 COSMARIUM Trittr. Gotl. Öl. sötr. Alg. p. $60 \mathrm{t.} . \mathrm{f}$. 14. [C. rectangulare Grun.].

6) 73-Nordst. Norg. Desm. p. 19; forma.

d $80-\beta$ minns Wille Nolg. Ferskv. alg. I p.31 t. 1 f. 13. [C. rectangularo $\beta$ see. Boldt 1siss, non ita sec. Norelst. in Bot. Notis. 1882 p.97].

d St-C'oole Brit. Desm. p. 88 t. 37 f. 4 [verisimile e Wittr.].

m 93 - v. camhronso Tumer Desm. Notes p.315; et f. 7 1).34t.

o 95 -Johms. Rare Desm. U. S. II p. 293 t. 241 f. 26.

o 45 - r. eamblense Schmidle Britr. alp. Alg. p. 388.

\section{Goutrijevii}

d 91 Cosmaridm Alexentio Alg. Poltava p. 79 t. 3 f. 3.

\section{gracile -is}

n 39 CLOSTERIUM Brols. in Cliev. Micr. p. 272.

d 48-Bréb. apud Rialfs Brit. Desm. 11.2:1.

(1) 52 - I'ritch. Inf. p. 2.4.

d 5 li-Bréb. List. p. 155 t. 2 f. 45.

d fil-Arch. in Pritch. Inf. p. Tts,

d $63-$ Labb. Krypt. Fl. Sachs. p. 175. 
mit.t - Clere Billy. t. Sverg. Desm. p. 4.5 t. 4 f. 9.

z 69 - Arek, in (Q. J. M. S.e. 8 p. age.

zf 71 - Lwmrl. Desm. Suec. P. A2 t. 5 f. 15 [Cl. Inondellii Lagerh. 185:3].

oz 83 - Nordst. Norg. Desm. p.41.

m 75 -Jacols. Desm. Dinem. p. 172.

dz TS-Kirchn. Schles. Alg. p. 1:37.

o ms1-Kifl. Finsk. Desm. p. 11 t. 1 f. 12 [efr. Ileimerl $1.5 .11]$.

m 84 - Artriri List. alg. Moscon p. 13!!

dz 84 - Wolle Desm. U. S. p. 39 t. $1 \mathrm{f}$ f. $1-5$.

d 85-Kirchn. Mikr. Ptanz. d, Sïssw. p.21.

dz 86 - Coolie Brit. Desm. 1. 22 t. 13 f. 8 [e Bréb].

dz SS - Mumsg. Proulr. Algenfl. B̈̈lum. p. 17 s.

m 88 - Riabin. Chloroph. ent. Kharkow p.317 (zep.p. 29).

m S. - ? Nordst. Fr. wat. alg. X. Zeal. p.69.

m SS - ? Poteat North Carolina Itosm. p. 3.

dz 89 - Tomi Syll. Alg p. 818 .

n 0 - Eichler Spis Desm. Miedz. p. 8i, t. 8 f. 9.

nu so - Anderss. Sverig. Chlor. 1 p. 1 .

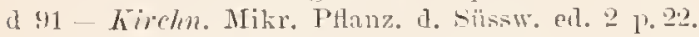

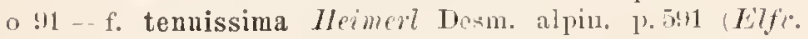
18.81; transit. ad Cl. bicurvatum).

m 91 - Borge Bich. Sibir. Chloroph. p. 13.

m!1 - Futw. Flor. alg. Leopol. n. 32.

n :1 - ARTHR0DIA Kuntze Rer. gen. p. p. 833.

m!2 - limge Chloropl. Norsk. Fimmarls. 1'14.

n - f. ibid.

d :12-f. gracillima West Frow. Alg. W. Irel. 1.122 t. 19 f. 15 .

$m: 12-$ Mijl. Austran. Süsswasseralg. p. 410.

4z:52 - T'olle Desm. U. S. ed. Il p.40 t. 7 f. 4-i.

1) 13 - Builey Contr. Queensl. Fl. 1. 11).

m 18 - Lintkemithl. Desm. Attersees p. i.11.

z 14 - Soy Scott. Desm. p.21] (sep.p. 52).

1315 - Selmidle Alg. Sumatr. p. pels.

C'fr. Clost. juncidum b. hab. 1siss; Cl. lineatum Ekrt. 1s.s ex p.

\section{grurite - is}

d 15 STAURASTRUM liulfs in Anu. Tat. Hist. Y. 15 1). 155 t. 11 f. 3 cet 1.84ti in Trans. Pot fior. Eiliub. v. 2 p. 142 t, 14). [Luastrum 1 : 19 Rritey Amer. Bacill

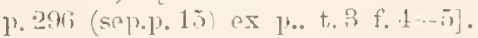

d 45 GONIOCYSTIS Trigonoeystis) Hass. Brit. Alg. p. 3.) t. \&5 f. 1 [Fig. e Ralfs 1. e. repict:1]

u IS sitanu Kalfs Brit. Desm. p. 139 t. 22 f. 12.

d 4! PHYCASTRUM hütz. Spee, Alg. p. 181.

1149 stencetinimm) Nro. einz. Alg. p. 12S.

d 52 stanl. Pritch. Inf. p. 266.

o bi1 - v. bicorno Puluh. in Hedwig. p. il t. 4 f. 2.

1) til - Arch. in Pritch. Inf. 17. 742 t. 3 f. 29 et 29 [e liulfs].

d 63 - Rab. Krypt. Fl. Sachs. p. 192.

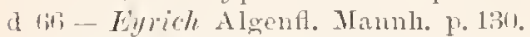

67 DIDYMIDIUM (Ntantr.) Remseh Algentl. Frank. p. 16if. A. bicolne. B. tricorne.

6istan 1. Not. Desm. Ital. t.5 1.49.

11 lis-linb. Flor. Eur. Alg. 3 1.211.

d - b, bicorne ibil.

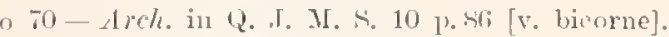

in 70 - Nordst. Desm. 13rasil. p. $22 !$.

d - $\beta$ curtum ibil., t. 4 f. 58.

6 73 - Novelst. Norg. Desm. p.34. form.

d 73 - Wrood Fr. Alg. 1, 152.

7.1 - Gibbons in Trans. R. Snc. Fictoria $\mathrm{X}$ in fig. pluotogre. 2.

a 75 - Micrugl. Dict, p. T.5 t. 10 f. 30 [e Iialfs]. d $7.5-\mathrm{r}$. lieinsch. Contribut, p.91 t. 15 f. 7 [St. pseadosebaldi?].

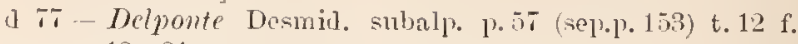
$12-21$.

d $78-$ Kivelm. Alg. schles. p. 167.

1) 80 - $\beta$ nanum Wille Norg. Ferskv. alg. I p. 46 t. 2 f. 31.

o . 33 - Mrssk. A. Zeal. Desm. Adl. 1. 25.8 t. 25 f. 17.

1) 84 - Wolle Desm. U. S. p. 133 t. 43 f. $16-17$.

m si) - $\beta$ nanum Dolelt Sibir. Chloroph. p. 116 t. 5 f. 29 ("rar. tennissima" p.12T).

d - $\gamma$ coronolatum ibil.. t. 5 f. 2 S.

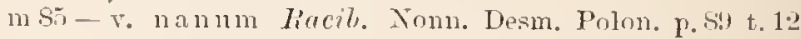
f. $t^{2}($ sep.p. 33 t. 3).

a st- Stolies Key Desm. p. 165.

d 8 . - Cooke Blit. Desm. p. 170 t. 58 f. f. [a super., e lialfs; a infera ex Ilassall].

a $8 \overline{6}$ - Mrritel in Notarisia p. 3-10 bis.

4) 88 - ILn

m s8 - Boldt Desm. Grönl. 13. 38.

m ss - Tordst. Bornl. Desm. 1. 200 (v. Reinsch 1sis).

m s8 - Iste. Tel. magyar. alg. 13. 23i.

d s? Tomi syll. alg. p. $120 \%$.

d - v. bienrne ibid.

m - v. nanum ibit.

d - v. coronulatum iluil.

d) - v. inconspicua ibit. P. 1210 (St. inconspicum De Notan: 1871, mon Nordst. 1si3).

m s9-Kozlownl. Flol. volorosl. Silir. II p. 33.

1) (10) $\beta$ subventricosum Bärg. Desm. Brasil. p. 47 t. 5 t. 50.

molo-Eichler spis Desm. Miedz. p. bll.

m! 10 - Ameterss. Siverig. Chlor. 1 p. 12.

m 52 Borge Chloroph. Norsk Finmatk. 1,S.

o ! $2-\mathrm{v}$. 11 num f. West Fr, w. Alg. Wr. Irel. p. 182.

1) -- bulbosum ibil. et t. 23 f. 11.

d !2 - Wrolle Desm. U. S. el. II p. 1.17 t. 51 f. 16-17.

o $12-v$. corounlatum W'est Alg. Engl. Lake Distr. P. 732 t. 9 f. 36 .

11 (13--v. imeonspienum Much in Bull. Inst. bet. parmens. p. 5!!!.

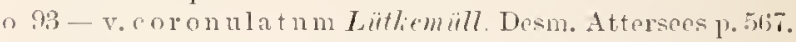

(1) 14 - Semud, in Fl. Nohraska 1. $4: 3$ t. 7 f. 17 [e Cooke].

d $95-v$. verrucosum West Aler. Madag. p. 75 t. $:$ f. 1 .

v. cyathiforme ibid.. f. '2.

- v. uniseriatum ibid., 1'. 3.

v. pusillum ibil.. f. 1.

$\checkmark$ convergeus ibid., f. ̌̀.

o $\%$ - f. Selmidle Beitr. alp. Alg. 1. St2 (sep.p. 38).

\section{grarile}

d 51 TRIPI,0CERAS Tiat. Mier. observ. 17.38 t. 1 f. 10. (Docil. verticillatum B. apud Ralfs Brit. Desm. glioasl fig. (1 $c_{0}$ ).

4) 52 - Pritch. Inf. p. 294.

d ril-ite inlPritch. Inf. p. 7 .

o 15:-Arch. Obs. on Micr. Maliab. (sep.p. 33) in Dubl. $\mathrm{N}$. H. Soc. Pr. 1. 83 t. 2 f. 1. in Q. J. Nicr. Sic. 1, 261 t. $T$ (incl. Doe. Pristidæ).

d lis - Rab. Flor. Em. Alg. 3 p.101. fig. 54 b. [Ex Lati. nou exacte].

d PLEUROT ANIUM ibil. p. 144.

(1) 6 DOCIDIUM ITittr. Skandin. Desm. p. 21 t. 1 f. 10.

o 71 Plenr. Land. Desm. Suec. p. x.

d $78 \mathrm{Triploceras}$ Wood. Fr. Alg. p. 122.

o so Plenl. Nordst. De Alg. et Clarac. p. 2.

1) 81 Doc. Wolle Desm. U. S. P. 53 t. $10 \mathrm{f} .3,6-8$.

m se Plenr. Lagerh. Amerik. Desm. p.252.

o so Triploceras stokes Key Desm. p. 114. 
1) 87 - - aculeatum Nordst. Algnlog. småsak. 1 p. 16i3.

a $\quad-{ }^{-}$bidentatum $\beta$ laticeps ibid.

" $\quad-\quad$ f. intermedia ibil.

m S8 - Norlst. Fr. wat. alg. X. Zeal. p. 6.1 t. 7 f. 1.2.

d _ - aculeatmm ibid. t. 7 f. $1: 3-14$.

n - $1.7 \%$.

d - - $\beta$ laticeps ibil., t. T f. $15-11$.

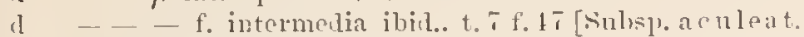
sec. [fildem. 1891].

a s. - Tomi syll. Alg. p. sio.

c - subsp. aculeatum ibit.

d - - bidentatum ibid. p.sit.

d _ - v. laticeps ibir.

d _ - - f. intermedimm ibil.

11 (M - - bidentatum Bör\%. Desin. Brasil. p. 2S.

m 92 - Mub. Austral. Siisswasseralg. p. 142 .

m !2 - a. genuinnm Rac. Desmillya Ciastoni. p.341.

a ! : - Wolle Desm. U. S. ed. II p. is t. 13 f. 3, 6. 7. 8.

m !3 - Briley Contr. Qnecusl. Fl. p.14 t. 13 f. 3 ri e Norelst.).

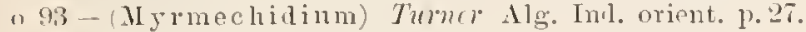

d - f. a. elongata ibil. p.2.; t. 2 f. 1 [* bident. r. laticeps sec. Wildem. 18.4].

a - f. b. gracillima ibid, 1, 26; t. 2 f. 2 [Cfr. Irildem. in Yotarisia 1893 p. 167 ; subsp. bilobat. see. Witll. 1894 .

(1) - f. c. quadrilobata ibid.; t. 2 f. 3.

d -+ bilobatum ibid.; t. 2 f. 4 [Cfr. Willem. Obs. crit. Desm. 1s!l p. 61].

a _ - billentatum f. depanperata ibid.

o !H Doc. (Triploceras) subsp. monodentatum Wrillem. Obs. crit. Desm. po fis et 73 (Triploc. occidentalo Tiหn. 19:13).

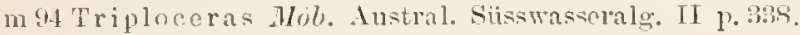

\section{merrileserms}

ozf ai BAMBUSINA $11 \%$ lle in Bull. Torr. Bot. Cl. 12 1 . 127 t. .1 f. 13 - 14 (Bambusina Borrevii $\beta$ wror. Nordst. 1S43.

ozf 57 - Wolle Fr. Alg. U. S. A. p. 21 t. งt? f. 13-14[ex Wolle 1855].

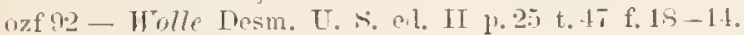

\section{greaticepus}

n S6 DESMIDIUM Iagerl. Amerik. Desm. 1.228 (D. quadratum $p$ graciliceps Hordst. 1880).

ozf -- f. major ibid., t. 27 f. 2 \& 3 . [D. majus Lagerh. 148?. exclus. f. 3 .

In s8 - Nordst. in Gazell. Expedit. p.3.

o $S S$ - Nordst. Fr. wat. alg. N. Zeal. p. 25.

in - f. intermedia ibid. (D. quadratum Jos/. 1sS(5).

dz 89 - Didymoprium, Toni Syll. Alg. p. Tst.

m 90 - Burg. Desm. Brasil. p. 25.

m 90 - Ekehler Spis Desm. Miedz. 1.84 t. 8 f. 4 .

m 93 DIDYMOPRIUM Turner Alg. Ind. orient. ㄱ. 150.

\section{grerillimer}

d T-SPIR0T in nota, t. 14; in Q. J. U. Re. v. 15 p. 116 t. B. [Annon S. tenerrima Arch. 1870? - Cfr. Lithemïll. 1.595 p.55].

\section{grarillimum.}

d 95 STAURASTRUM West Alg. Malag. p. 75 t. 8 f. 31 . et 32 (v. biradiatum)

\section{grerlatume}

d in) COSMARIUM|" Roy in Scott. Naturalist I p. 203 (C. formosulam Iloff' 1858:).

\section{"lvellatorillu}

1) Tostaurastrum Nomlst. Desm. Brasil. p. 228 (sep.1) 190) t. I f. i.

d st -. v. ungulatum Wolle in Bull. Torr. bot. Club. v. s P. 3 t. 6 f. 17 .

d 81 - Holle Desm. U. S. 13. 133 t. 11 f. 19.

f. t. $11 ;$ f. 21$)-21$. - [Cfr. infra 1s! ?]

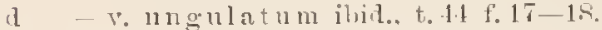

I sti- $P$ furcipigerum Lagerh. Ancrik. Uesm. p. 2.t? t. 27 f. 2 \%. [At. saltans fiforeipigerum Luger\%, 18st].

(1) Sti- Strukes Jicr Desin. 10. 105.

n - (v.) ungulatmm ibid.

d s. - Tomi syll. alg. p. 123.3.

d - r. $u n g$ on at $u m$ ibill.

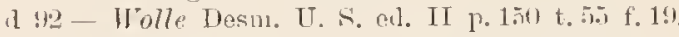

- f. ibid. t. 57 t. $20-21$ [Stamr. protractum Johms.].

d - v. ungulatum ibid., t. วิธ f. $17-18$.

m 93 - (Brachiastrum) Tumer Alg. Iul. mient. p. 123 t. 14 f. 15 .

o 93 - (r.) Eichler Mat. flor. Micdz. p. $16 t$ t. 10 f. 35. [?].

\section{(1)rmutoirles}

1) 14 CosmariuM Schmille in Flora is p. 52 t. 7 f. 12 C Meneghinii v, granatoiles 1s:33).

\section{(I)}

d 4 COSMARIUM Rulfs Brit. Desm. p. 9r; t. 32 f. 6. Cosm. Papilio Menegh.?)

a 52 - Priteh. 1nf. p. 252

o sf -. Breth. List. p. 126.

o วิ - ? Siming. Obs. phyce p. 5!?.

d fil-Areh. in Priteh. Tnf. p. T3:?

d 68 - Ralb. Krypt. Fl. Sachs. p. 1!!.

o 65 - - Grun. Ins. Bank. p.15 t. 2 f. 27 [p, Grunorii Roy 15!14].

m 6. DIDYMIDIUM Cosmarim) Licinsel Algenfl. Frank. 1). $10 !$.

d tis Cosm. Rat. Flor. Eur. Alg. 3 1) 162.

d $72-\beta$ elougatum Nordst. Desm. Sipetsb. p. 29 t. ti t. 6.

mo 75 Nordst. Desm. aret. 1\% 19.

и 76 - f. alata Jucols. Desm. Danem. P. 195 t. 8 f. 21 , $30=a$ monstr.).

0 6 - p elongatum Worlst. Desm. Ital. p. 30.

d $7 \bar{i}$ - Delponte Desmid. subalp. p.t (scpep. 100) t. T t. 16; -21 [o Delpontii rutu. 1891; C. Raneegungense Turm. 18!!??]

d to - $\beta$ subgranatum Nordst. Alg. sandric. p. 13 t. 2 f.s.

1 78 - Kirekn. Alg. Sehles. 11. 147.

d 7.t- $\beta$ elongatum f. latior Wille Ferskr. alg. Nor. Semlj. p. 38 t. 12 f. 25.

o - $y$ triagonale ibid. $p, 3 ! \%$

d 79 - a. typicum hlels Desm. Ostprenss. p. 32. a t. :3 f. $23-24$. $\beta$ t. 3 f. 20 .

d - b. hexagonum ibia, re t. 3 f. 22 c. pis t. 3 f. 22 a - b.

m 82 - Novdst. Aloolog. småsak. 3 p. 45 et 49

d 83 - f. Ricleter in Wittr. et Nordst. Alg. exs, n:0 $515 ;$ et in fasc. 21 p. 13.

m R1 EUASTRUM (Cosmarinm) (roy MLon. loc. Conj. p. is. d s1 Cosm. Tolle Desm. U. S. p.150 t. 50 f. 13.

- v. ibicl. t. 15 f. $14-15$.

m 84 - Scharaschm. Afghan. Alg. p.247.

mz - v. elongatum ibid.

d $8 . j$ - Kirchn. Mikr. Pflanz. 1. siisstr. p. 24

mo5 - Boldl Sibir. Chloroph. 1. 100.

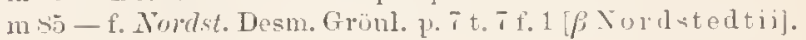


o si - ritolies liey Desm. p. 12li.

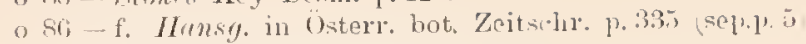
et. Plye, 17. Alg. Stud, p. 1 iff.

d 86 - 'oolie Brit. Desm. p. 83 t. 36 t'. 4 .

d st Alexemtio Chlorosp. Kihark. p. 2.5!

d Si-Hunsg. Prodr. Algenfl Bïhm. 1. 1:12.

d $\beta$ Nordstedtii ibicl. p. 1.43 (f. Nordst. 1885).

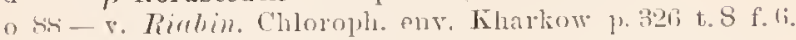

m $s s-$ Boldt Hesm. Grünl. p. 12.

m - $\beta$ elongatum ibid.

m xi - Nordst. Bornl. Desm. p. 19s; et f. al $p$, elongatum.

$\mathrm{m}$ SS - 1ste. Tel. magyar. alg. p. 220 .

"ss-Nurdst. Fr. wat. alg. N. Zeal. no sif ff.

d - B subgranatum f. ibid,; t. 6 t. 8 .

m s. Riacib. Mat flor. glon. Polsk. p. 107 (sep.p.25).

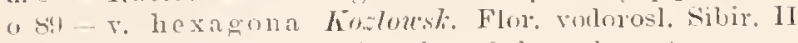
7. Bf t. 1 f. ৯ ( $\mathrm{a}$. a' major; [al r. elongatum aceedens]; 1. 21 et 36 f. b, b' minor).

d si- Tomi Syll, alg. p. 681

d - v. subgranatum ibid. p. 932.

d - - Nortstedtii ibid.

d - ve trigonale ibir.

(1) 94 - $\beta$ concavum Luger\%. Contrib, alg. Eeuarl p. 28?

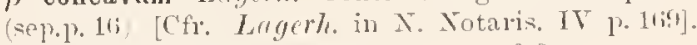

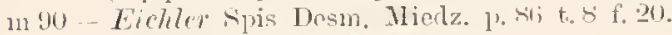

m 10 - Anderss. Sverig. Chlor. 1 p. 15.

m - $\beta$ hexagronum ibid. p. 16.

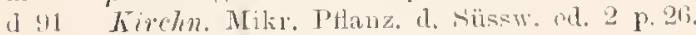

11191 - Heimert Desm. alpin. p. 5tt5.

m:1 - West Danish Alge p. 419.

m:1 - barge Bidr. Sibir. Chloropll. 1.12.

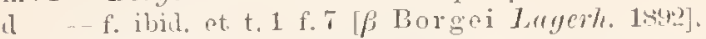

11 !1 URSINELLA humé Rer. gen. p1. p. (12t.

m !t Cosm. " typicum finte. Flor, alo. Leopol. p. If.

11 - Noristedti ibid.

m - is Delpontii ibil.; t. 1 f. 30 (Irely. 157T).

0. 42 - ff. Barge Subfoss. söty. alg. Gotl. p. 5e et is t. 1 f. $1-8$ [fig. 8 efr Lagerh. in N. Notaris. IT p. 169 ex p. = f, Borgei fintu. Istin].

o $12-\beta$ Borgei Lagerh. in $\mathrm{N}$. Notaris. II p. 25 iform. borye 1891\%.

m t2 - Burge Chlmoph. Norsk. Finm. 1, 12.

m - v. Nordstedtii ibid.

in 12 - West Fr: w. Alg. Wr. Irel, p, 143 .

() - f. ibid.

m -. r. subgranatum ibid.

1) 42 - Ruc. Desmilya Ciastoni. p. 385.

d - f. pentagona ibil., t. 6 f. 18 .

d s. - Wolle Desm. U. S. ed. II p. I.1 t. fil f. 13.

1) - v. ibill. t. 1 is f. $1+-15$,

o (t) - f. pentagona Nest in Notaris. 7 p. 1501.

13. - v. subgranatum Schmille Beitr. Alg. Schwarzwall. p. !lu t. 4 f. S ("v. crenulatum" lapsu calami).

m:93 - (Pyranidium) Tumer Alg. Tull. orient. p. T1.

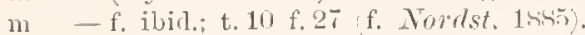

m193-v. subgranatum Test in Naturalist 1519 p. 213.

" 4.3 - $\beta$ subgranatum f. Nordst. in Wittr. ct Nordst. Alg. exs. 11:0 1119.

n (1.1 - Y Grunovii lioy Sentish Desm. p. 102 (sep.p. 35) (var. Gom. 186

d b.t-Samml. in Fl. Nebraska p. 10 t. 7 f. 7 [e Tlolle].

d $95-\mathrm{f}$. Schmelle in Iledwigia 84 p. 5.1 f. 1.

m th - v. sul,granatum Johts. Rare Desm. U. S. II p. 298 t. 2399 f. 1 is.

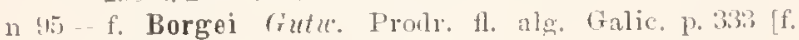
Borge 18.2 t. 1 f. 2. $4,5,5)$.

11] 9.i- Irest Alg. Marlag. p. 54.

d - t subangulare ibid, t. \& f. 4 .
Gfr. Cosm, tumidum f. minor; Eu. pygmaum 1.1.\%?. 18.10.

\section{"lirmre}

4 it DISPHYNCTIUM Ielponte Desmid. subalp. p. 135 (sep.p. 231) t. 21 f. !.

u SS CALOCYLINDRUS Dysplinetium) Iste. Jel, magyar. nlg. 1. 230.

d 89 Dis. Toni syll. alg. P. Shit.

d 93 Dys. v. cuneatum Turmer Alg. Ind. orient. p. 40 t. $7 \mathrm{f} .5$

\section{mrante}

1) t9 PHYCASRTUM Kiiiz. Spee, Alg. p.181. (Enastr. n.o 13 Briley Amerie. Bacill. 1s:81 qnoad fig. 7, tab. 3). [Staur. Ophiura?].

\section{gronde}

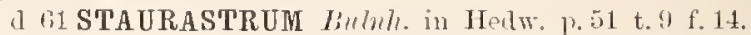

1) 71 -(Pleurnuterium) Jand. Desm. Snee. P. 72.

a - forma ibill.. t. 4 f. 11.

o 81 f. Coulie in Grevillen :) p. 91 t. 139 f. 4.

o s1-Conlie in Quekett Micr. J. 6 p. 200 t. 16 f. $2 \overline{6}$.

d sit - Wolle Iesm. L. \&. p. 120 t. 39 f.3-4.

o s6 -.-Stokes liey Desm. p. 1til.

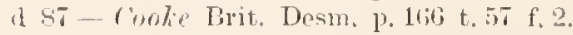

d 59 - Toni sill, nig. P. 1201.

n90 PLeURENTERIUM Wille Yatürl. P'flamzenfam. p.11 et 12 f. 7 G $(n$ Jarmel. $)$.

m gostanu: Biry. Desm. Brasil. p. 51.

m 90 - Eichler spis Desm. Mielz. p. 89 t.! f. 39.

(1)!2 - Wulle Desin. U. A. c4. II 1. 133 t. 50 f. $3-4$.

d :4 - t. parvmm Wrst New Brit. Alg. p.11 t.2 f.51. (Nt. Brevispina $\mathrm{v}$, inerme Wolle $18 \mathrm{~s}$, non Wille $18 \bar{y}$.

m 95 - dwhus. Rave Desm. U. S. II p. 294.

\section{grommis}

d TiSPIR0T AeNIA Delponte Desmic. subalp. p. 140 (sep.p. 23i t. 211 f. 23. [\$1]. obscura? sec. Juitkemill. Gatt. spirot. prin].

a 89 - Jomi syll. Alg. 1. 810

n 93-(Polytenia) Timer Alg. Ind. orient. p. 29. (Sp. obsenra?).

\section{Greantii}

a a COSMARIUM Roy et Biss. in Roy Scottish Desm. p. 10 ? (sep.p. 3is t. 1 f. 10.

\section{mercmulutu}

d 33 MICRASTERIaS Wrom $\mathrm{Fr}$. Alg. p. 14tit.21 f. 1\%. [M. conferta Lamel.].

\section{(fromelretum}

a sucosmarium West Fir. Alg. North Forksh. p. 292 (sep.p. 4) t. 2!) f. t.

\section{(romulatum}

d 5. DoCIDIUM Benn. Fr.-w. Alg. North Cornw, p. 15 (se p.p.s) t. 4 f. 17 .

d 87 - rooke lsrit. Desm. p. 18 t. 65 f. 2 (e licm.).

d 89 - Tomi Syll. Alg. p. 85 .5.

\section{gremulntum}

d sisPHÆROZoSMa liny a Biss. Japan. Desm, p. 24? (sep.p. 10) t. 2fis f. $1 \bar{i}$. (sphar. excavat. f. javanica Nordst.).

in S8-- Nordst. Fr. wat. nlg. N. Zeal. p.2S. 
d 89 - Toni s.yll. Alg. 1) 791.

\% !to lioy in Jomrn. of 13ot. 13. 235.

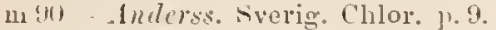

$111: 11$ - Heimerl Desm. alpin. 1).j.45.

m 91 - West Freshw. alg. Maine II p. 35\%.

in 91 - Gutu. Flor. alg. Leopol. p. 30.

1n 93 - Lïtkcmïll. Desin. Attersees p. 5:3:!.

\section{girmulutum}

d 7 STAURASTRUH Reinsel Cuntribut. 1). 55 t. 17 f.:3.

$1186-J o s h$. Burm. Desm. p. 613 t. 21 f. 4 d 5 .

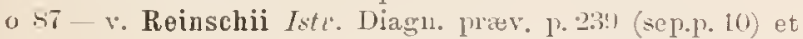

o 88 - - Istw. Jel. magyar. alg. p.231 t."2 f. 206 [Staur. angulatum West??]

d Si - Toni Syll. alg. p. 1173.

- - v. Reinsehii ibil.

\section{M"umlutus - 11$)$}

11 3.) CLOSTERTUM Rièd. in Chev. Micr. p. 27.2.

d 10 - Bréb. apud Itnegh. Synops. Desm. p. $0: 31$ (snp.p. 36).

1 11 TETMERORUS Ralfs in lun. Nat. Ifist. $\times 11$ l. 257 t. 8 f. 2 (et 1816 Trans. Bot. Soe. Elliı. vol. 2 p. 131 t. 12) ynoad figg. a, b, e [uron i, e, f, g, ']u世 figr. = T. lavis sec. Iinlfy 1his].

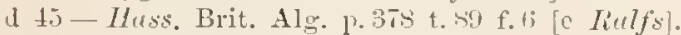

d t5 Clost. Títz. Plycol. germ. p. 132 .

dzf ts Tetm. Liulfs Brit. Desm. 1. 147 t. 24 f. 2, t. 33 f. 1.

d 49 PENIUM (Tetm.) Kïtz. spec. Alg. p. $11 i 7$.

d 52 Tetm. Priteh. Inf. p. 271.

dzf 5 S - De Bury Conjug. p. 29. 11, 51, 74, t.5 f. 11.

dz.61 - Arch. in Priteh. Inf. p. 7 \$6.

463 - Licl. Lirypt. Fl. Sachs. p. 175, f. xyl. p. 153 fe Rialfs 1S11].

m $6 \mathbf{i}$ - Reinseh Algenf. Frauk. p. 181.

67 - Not. Desm. Ital. t. 6 f. 5 \%.

d 6s-.-Tiab. Flor. Eur. Alg. 3 1. 110 , f. 50 p. 101 [ut supra 1863 .

m 70 - Nordst. Desm. Brasil. p. 204.

dz 73 - Wood Fr. Alg. p. 117 t. 1:2 f. S.

d 75 - Mierogr. Diet. p. 76 .

m 75 - v. minor Jucobs. Desm. Danem. p. 1 sil t. 7 f. 10 (T. lievis Ralfs); t. i f. 31 ( $a$ monstr.).

d 77 -Delponte Iesm. subalp. p.13S (sep.p. 231) t. $15 \mathrm{f}$. $5 \tilde{5}-56$.

m 78 - Nordst. Alg. sandivic. p. 10) (f. minor).

d is - Kirchn. Alg. Sehles. p. 1-1.5.

in 78 - Ilempel Algenfl. Cliemnitz p.112.

pli 83 - Fischer Gypskryst. Des1n. p. 16 t t. 10 f. 9-11.

m S1 Pen. (Tetm.) Gay Mon. loc. Conj. p. T.2.

d 81 Tetm. Wolle Desin. U. S. 1.91 t.50 f.33 et 34

d $85-$ Kirehn. Mikr. Pflanz. 1. Süssw. 1. oㅡ.

ph 85-Klebs Beweg. u. Sehleimbild. d. Desm. p. 351 ete.

m sib - Layerh. Amerik. Desm. 1. $24 \%$.

o 86 - Stolies Key Desin. p. 130 .

dzfs6-Ccoke Erit. Desm. p. 49 t. 18 f. 8, t. 1! f. 1. [e Iiulfs verisimile?.

1h 86 - Klcus Organisat. Gallerte b. Algen p. 353 t. 1 r. 6 et 1.1 .

d $8 \bar{i}$ - Hexenko Chlorosp. Kharkow p. 235.

(l sso-IIansg. Prodr. Algenf. Böhm. p. 159.

dz 88 - Toni et Leri F1. Alg. Venez. p. 37.

us $\$$ - Boldt Desw. Grönl. p. 11 .

ph ss - Hauptfl. Zellm. n. Hiillgallerte Desm. p sis (sep.p. -27) t. 2 f. $37.43-45$.

m Ss - Iste. Jel. magyar. alg. p. 237

m Ss - Rucil. Mat. flor. glon. Iolsk. p. 103 (sep.p. 2!).

m ss - f. ninor. Mask. Furth. Not. X. Z. Desm. p. 07 t. 5 f. L9. dz sio - Toni syll. Alg. p. $\$ 15 \%$. s9-- West Fr. Als. North Torksli. t. 2 n f. 5 .

m 90 - Eichler spis Desul. Miedz. p. 84 t. 8 f. 16.

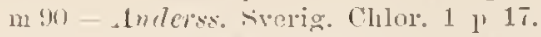

d !1-Kirelun. Milir. PHanz. d. Nissw, ad. 2 p. 23.

m 51 - Heimerl Desin. alp. p. 5:5.

m 32 - West Fr. W. Alg. W. Irel. 1. 132.

m - f: min or ibid.

d - v. attenuatus ibid. et t. 2 ! f. $\bar{\tau}$.

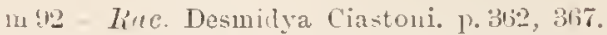

d 92-Wolle Desm. U. s. ed. II p 95 t.61 f.33 et :3.t.

m 93-Lütlemiill. Desm. Attersees p. 516.

d 15 - $f$. basichondra Schmillo Beitr. alp. Alg. 1 . S.1t; t. 14 f. 23 .

o - f. ibid.: f. ……

\section{gromulifermm}

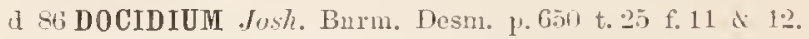
d S!) - Tomi śyll. Alg. p. 555 .

\section{grerulosum}

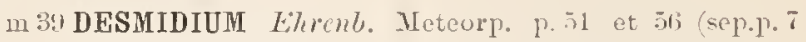
ct 12 ) t. 1 f. 12 .

d Lö PHYCASTRUR Kütz. I'hyeol. germ. p.13\%. [Phr commutatum?

d 17 Desm Rirl. Dent. Krypt. FI. 1.57.

11 IS STAURASTRUM Rilfs Brit. Desm. p. 21 .

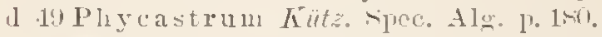

o 52 Perty lininst. Lebensf. p. 209 t. 11 f 2.29.

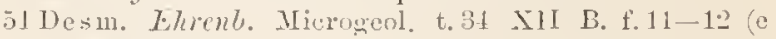
Meteorpap.

d 61 sitanr. Arch. in Pritel. Inf. p. 73s.

d bs-Rab. Flor. Eur. Alg. 3 p.enti.

d 89 - Tuni syll. alg. 1\% 111 .

m 52 - Gutw. Flor. glon. Galie. 3 p.134.

z $93-x_{n}, y$ scott. Desm. p. 23S, (ct 1S91) t. 3 f. i (sep.p. 20 ).

Cir. Staur. acntum Br. 1856? St. tunguscanum Gutu. 15:2.

\section{Grallulum!}

d 3 S GYGES Ehronb. Inf. p. 52 t. 2 f. 31 (Volvoox Giann$11 \mathrm{~m}$. Weill. Selranl; Gyges viridis Bory?. [Cfr Elucul. in Isis 1933 p. 241 ct 1931 p. 118\%]; Gyres bipartitus var. Ehrent. 1.531\%

\section{"Irrullusrulum}

d 9. Cosmarium lioy et Riss. in Roy Seottish Desm. p. 102 (sep.p. 25 ) t. 2 f.s.

\section{"regrillill}

d 37 CLOSTERIUM .17enegh. Consp. Alg. Eugan. 1'. 17 (sep.) $=$ Est Raphidium polymorphum Fresen. . $^{\text {. }}$

\section{Gregromii}

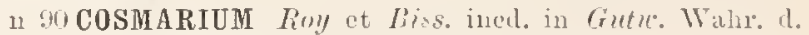
Prioritat P. 6\%.

d $\beta$ Janoviense (rutu: ibid.

d al - p janoviense Gutu. Flor. aly. Leopol. p. oti t. $2 \mathrm{f}, 16$.

d 92 - Roy et Liss. in Nuov. Notar. I1I p. 19.

d $92-$ Roy et Biss. in Gutu. Flor. glon. Galic, 3 p. 12! t. 3 f. 11.

III - $\beta$ Janoviense Gulu. ibict. p. 130.

d 91-Roy et Biss. apud lioy scottish Desul. p. 102 sep.p. (3i) t. 1 f. 11.

m:4-Gutw. Fl. alg. Tarnapol. p. M.

I - - papilliferum ibil., t.3 t.31. 


\section{Cirroillii}

11 43 DIDYMOPRIUM hiliz. in Limnira $17 \mathrm{p} .81$ (Tesmiclium cylindricum Grex.).

o 43 - Kïtz. Ply c. germu, p. Lliti.

d $45-k$ ïlz. I'hycol. germ. p. 141 .

d 47 - Rimb. Deut. Lirylt. Fl. p. 57 .

dzf 18 - Ralfs Brit, Desm, p. 57 t. 2 .

al 4. - Kiltz. Spec. Alg. p. 189.

d - $\beta$ Ralfsii ibid. 1. 110 (Desmid. cylindr. Rulfs 1si3 t.s f. 1, [dextra super, mala].

52 - Rab. Bacill. Sachs. fasce, 6 11:1 58 t.

dz 2 - I'ritch. Inf. p. 2.10.

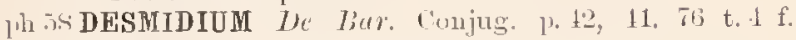
$30-31$.

lz 61 Didyn. Arch. in Iritch. Inf. p. 723.

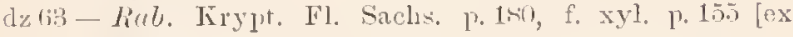
lialfs].

a - b. Inebnori ibid. Splatroprium Huebneri Rab.)

1i7 - Coucun Fl. Finist. t. 5 f. 12

o 67 - Reinseh Algentl. Frank. p. 207

o 1 it - Jot. Desm. Ttal. p. 27 t. 1 f. 3 .

d 64 -Rub. Flor. Eur. Alg. 3 p. 15\%, fig. xyl. p. 10 [ex Iillfs:

dzf 73-Delponte Desur. subalp. p. (it (sep.p. 52) t. 1 f. $211-28$.

dz 73 - Ilood Fr. Alg. p. 125 t. 12 f. 13.

d 7.)- llierogr. Dict, p. 251 t. 5 - i $[e R a l f s]$.

sit - berthold stul. Protoplasmamech. p. 1 (ing t.2 f. 11 (e De $B$ an? 1803 s).

m $50 \%$ - Frank in Leunis Synops. 3 1) 197.

d sis - Ilunpth. Zellm. u. Hullgallerte Desm. p. 76 et 10 . (sep.1. 11 i et 50 , t. 1 f. $3 ! 1-60$.

n sis GYMNOZYGA Riciz. Nat. flor. glon. Polsk. p. 18 (sep.p. 19).

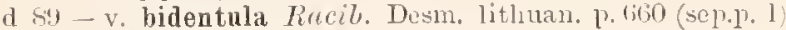

d - vo tridentula ibid.

n ! Didym. Wille Natürl. I'flanzenfam. p. 15 f. 9 H (e Uclp.).

d 91 Desm. Kirchn. Mikr. Planz. d. Süssw. ed. 2 p. 22.2.

o $11 \mathrm{Didym}$. f. minor Heim. Lesm. alpin. p.55!.

\section{Greyii}

d 56 MESOT玵IUM Turner Not. Fresliw. Alg. p.3t t. 1 f. 1. "de Greyii") [Jesotenium Braunii $\beta$ L Livy $1, \leqslant \leqslant 0]$.

d sto - [Greyi] Coole Brit. Desm. p. ts t. 18 f. 6 [e Turner].

d s!) - Eumesotanium) Toni syll. Alg. p. 814 .

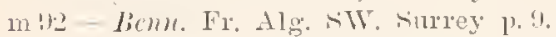

m 12 - v. breve West Fr. w. Alg. W. Irel. p. 131 t. $20 \mathrm{f}, 1)$

o :2-Rec. Desmidya ("iastoni. 1), 310.

\section{Griffithsienmm!}

d 19 PIIYCASTRUM (Pachyactinium) Nug. einz. Alg. p. 128 t. \& C f. 2 [Staur. spongiosum v.].

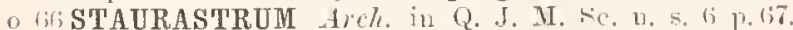

d $T-f$. Tordst. Als. Saudvic. 1, 11i.

I 87 - Couke Brit. Desm. p. 151 t. 53 f. 2 [e Neycli?]

\section{Griffithii}

d 5.1 CLOSTERIUM Tierled. in Anu. a. Mag. p. 2.46 t. 11 f. 2 , = Raphidinm sis.

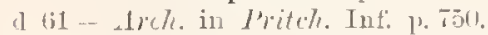

6 62 - lreh. On Ankistrod. (sep.p. 1s's in 1'x, 1)ubl. Nat. llist. Soe. p. $86=$ Ankistrodesmus acutissimus Am.? [ = liaphidinu].

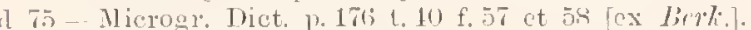

d sti-fooke brit, Iresm. p.it.

\section{(1)oenlumbirum-ls}

d Ss XANTHIDIUM (Contrenterium) Rollt Desm. Grönl. p. 31 t. 2 f. 37 .

d 5 - (lIolacanthiun, Toni Syll. alg. p, 9:39.

o 89 ARTHR0DESMUS kacib. Now. Desm. p. 97.

o 93 Ianth. Schizacanthum) Turn. Alg. Ind, orient. p. 103.

\section{guilllellse}

d 95 CosMARIUM lincil, in Flora v. 81 p.33 t. 3 f. 4.

Gurgeliense

d פi STAURASTRUM Schmidle Beitr. alp. Alg. p. 6t (sep. 1. 35) et, 189.5, t. 16 f. ․․ et et.

\section{Gllterilssii}

it (22 COSMARIUM linc. Desmidya Ciastoni. p. 396 t. 1 f. 25.

\section{G!y!ges}

(1) 26 Dory in Eneycloped. méth. Ilist. Nat. d. Zooph. II, 2 Vers (XeVIII liverais.) p. 419 Volvoc.)

(1) 20 liory Essai classif. anim. micr. p. 23.

a 31 Etucul. symb. pliys fol. d. a 2. Genus Cryptomonadinorum.

4 32 Ehmul. Entw. d. Infus. p. 61.

il 38 Ehenl. Infus, p 51. Genus Volvocinorum

d to Bumeister in Erech u. Gruber Allgem. Eucyclopal. d. Wiss. II, 1s p. 208.

(1) Flotow in Nov, act. Acad. Cets. Lcop. Carol. Natur. Cur. v, 20 p. 55 s etc. (Hæm a tococeus).

d 15 Vecaisue in Dict. univ, List, nat. v. 6 p. 433.

0 17 Focke Ploys. Nutud. I p. 29.

o 52 Perty lileinst. Lebensf. p, 17 .

o "11 Runtźc Ritw. gen. pl. II p. S913. Genus Desmid.

o 13 Nardstedt in Hedwigia 32 p. 118.

o 13 Kuntat Rev. gen. pl. III, 1 p. CCCXLY.

\section{GTMNOINSMUS}

11 t. Treris. Alghe Coccot. 17. (19.

\section{GIHXOZIGA}

(n) 41 Ehrent. Berlin. Nonatsber. $18 t 0$ p. 212 [tantum cum descriptione speciei "moailiformis"].

- 73.Jacols. Desm. Danent. p. 213.

¿Ls IIunsy. I'rodr. Algenfl. Bölın. p. 169.

o s! Nortst. Do Alg. et Charac. 23 1', 1 (Sect.: 1. Eugym $110 z y z a .2$. Ifoplozysa).

a su Toni Syll. Aly. P. T!T.

d 90 1Tille in Natiirl. PHanzenfan. p. 15.

(1) 91 Kirchn. Mikr. 1’hanz. d. Süssw, ed, 2 p. 21.

o 93 Turner $\mathrm{Alg}$. Ind. orient. p. 151.

phat Wellheim in Pringslı. Jahrb. 26 p. 727 (sep.p. 54).

\section{(I) IOU/ls}

d It STAURASTRUM Johns, Rare Desm. U. S. p. 290 t. 211 f. 1 .

\section{Herebocliense - is}

a 80 COSMARIUM Wille Norg. Ferskv, alg. 1 p. 25 t. 1 f. f. [C. polonicum $x$, II aab. Reac, 1sisi.

d so - Toui syll. ald. puss.

1191 URSINELLA humte Rer. gen. pl, p. 19: t.

\section{Harbocliensir}

1 so STAURASTRUM Norg. Ferskv. alg. I p. 12 t. 2 f. 27.

(1 81 - 1Folli Desm. U. \&. 1. 131 t. 12 1. $51-53$.

o sit-Stolies Kicy Desm. l’. 166). 
I S9 - Tuni syll. alg. p. 1211.

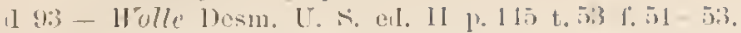

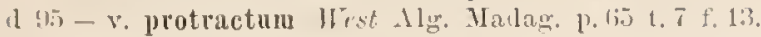

\section{IIulisis}

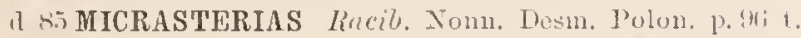
11 f. 1 (sep.]. 10 t. 5) [Micr. apiculata fi Norlst. 1S:

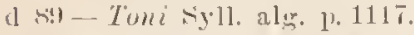

11 HELIERELIA finntic Rev. men. pl. p. Sis.

\section{Jiluntrin}

o sm MICRASTERIAS Böry. Desm. Brasil. 1.31 (M. conferta v, lismata Wolle 1s:3).

1. - f. Brasiliensis ibil. et t. '- f. 11 .

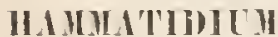

d 53 Tumer Alg. Ind, orient. p. 34. Subgen. Docidii.

\section{Irellumeri}

d wit COSMARIUM licinsch Spee. Gen. Alg. p. 115 t. 22 B. I f. 1 - 1 ! isep.p. 7 t. 3 ,

(1) - f. A. majus ibil.; f. 1 2.

(1) $-\mathrm{f}$. B. intermedium ibid.; f, $3-10$.

f. C. minus ibid.; f. $11-12$.

f. I. octogibbosum ibir.; f. 13-19. [Cosm. octog. lieinsile 18\%T.

(I BT DIDYMIDIUH Cosmarim, licinsch Algenfl. Frank. 1. 111 t. 10 f. 1 .

(1) - f. A. majus ibic.; f. a. fig. $b-e$ inter. A. et B.).

d - $\mathrm{f}, \mathrm{B}$. minus ibil. p. 11. ; $\mathrm{t}, h$ et $l$.

d - f. C. octogibbosum ibil.; f. $f$. g. $i . k$.

m 71 -Cosm. Luml. Desm. Suec. 1.37.

o 73 - croece in Q. Jouru. Micr. Sc. v, 13 p. 13j [v. hibernicum sec. ('ooke 1ssij).

o Ti . B. inteluedium Iieinseh Alg. Prom, Bon. Spei

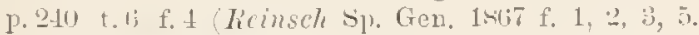
Cosm. homalodexmam Nordst.

11 î EUASTRUM ('uln Desm. Bong. p. 2-70 (sep.]. 12) t.11 f. 11 [Quid? Anv. octogibbosum?].

d 80 Cosm. $\beta$ retusiforme Wille Norg. Fersliv. alg. I y. 32 t. 1 f. 16 . [C. retusiforme Gutu. 18m].

dzf 81 - Wolle Desm. U. S. p. 7? t. 18 f. 27 (var. intermodium), $36-38$ (var.).

d $85-\beta$ subangustatum Lohlt silir. Chloroplı. p. 101 t. ร) $\mathrm{f} .3$.

d si f. Nordst. in Witt1. et Nordst. Alg. exs. n:0 s31; et in fase. 21 (1859) p. 13.

o s6 - Stukes her Lesm. 1. 127.

d Sij-C'oolie Brit. Desm. p. 81.

d - v. Hibernicnm ibil. t. 3 ii f.5 (C. inter C, Hammer et loomalodermum croue in Q.J. Mior. Sic. v. $17(15,7)$ p. 3ul)

.l RT - fisubbinale Nordst. Algolog. smisak. 1 1. 161.

d sit-Mlensag. Prodr. Algenf. Bölum, p. 191.

d $-\beta$ intermedium ibil. 1 ?-ix.

moss - f. rotundata Boldt Disn. Groul. p. 11 C. lownlodermum protundatum Wille 1875).

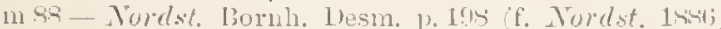

d sos = $\beta$ subbinale Nurdst. Fr. Wat. alg. X. Zeal. p. 5h t. if f. 7 crir. arl inter.) [C. subbinale Lugerh. 1s:!3].

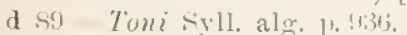

$11-$ ? v. subangustatum ibid.

d - ? v. letusiforme ibiul.

d - v. subbinale ihil. p.437.

(1 (M) - v. pachydermun lieins'th süsswasseralg. Siul-Georg. 1. 316 (sep.p. is t. 2 f. 2. inclus. Cosm. Nymann i n u $\mathrm{m}$

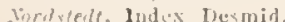

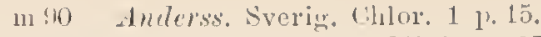

$m 90$ - Lichle Spis Desn. Miedz. p. ST.

m! - f. minor et intermedia /leimerl Desm. alp. p. s.s. 11 "1 URSINELLA l゙mutre Rev. ren, 1, p.921.

m 92 Cosm. Irest Fr, w. Alg. W. Irel. p. 1.le.

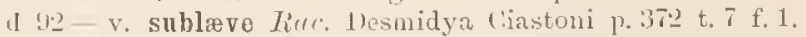
[Cfr Burge in X Notar. 5 p. 501 ).

Ixf (1.2- Wrolle Desil. U. S. el. II p.sis t.21 f. 27 (v. intermedium), 3i--35 (var.).

o 93 - f. acuta Turner $11 \mathrm{~g}$. Int. orient. 10.53 t. 8 f. 15.

111 - t. typica ibill, t.9 f. 31 ( . minus lieinsch).

o 91 - 1. mijus hory Scottisl Dosm. p. 103.

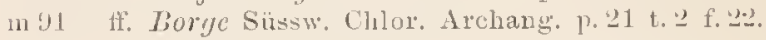

111 -. lotundatum ibil.

o 94 - v. subbinale t'. Gutw. Fl. alg. "Tarnapol. p. sis t. 3 f. 16 .

1129 -Alexenlio Mater. alg. Kiliarts. p. 26.

d :5i- f. abscissa behmidle Alg. sumatr. p. 302 t. 4 f. S. $111-$ f. actuta ibil.

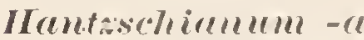

d os CLOSTERIUM Grum in Rub. Flor. Fur. Alg. : $\mathrm{p}$ 13: (specios dul,ia sec. Rub.).

d 89 - Toni syll. Aler. p. Sit.

1191 ARTHRODIA Kuntie Rev. gen. Il. p. 883.

\section{Mallisschii}

d 67 STAURASTRUM Ricinseh spec. Gon. Alg. p. 12!) t. 2:2 I II f. 1-6 (s.p.p. 21 t. 3).

d 86 - $\beta$ japonicnm Rou c.t Biss. Jap. Desm. p. 210 (sep.p. 17) t. 265 f.5. [st. Japonieum Turner 1593].

(1) 89 - Tumi Syll. alg. p. 1201.

d - - japonicum ibid.

d $11-\beta$ depauperatum Gutw. Flor. alg. Leopol. p. $i 1$ t. 3 f. 23 (st. intricat. $\beta$ Gutw. 1890.

m93 - v. depauperatum Liülicmïll. Desm. Attersecs р. $56 \overline{7}$.

n 93 - Turncr Alg. Ind. orient. p. 120. (St. intricatum Lelp. 1875 quoad f. $10,11,15,20$; non 11 ? 12, 13 , 16, 18, 21

m - v. cornutum ibid.; t. 15 f. 23.

\section{Hassulliallum}

d 1! EUASTRUM (E cosmium) Neg. einz. $1 \mathrm{lg}$. p. 121 t. 7 B. [E. gemmatum sec. Arch. 1861].

\section{mestifemem - us}

d s. XANTHIDIUM Tumer New rare Desm. p.939 (sep.p.

6) t. 15 f. 90.

o $5 \overline{1}$ - $\beta$ inevolutum Nordst. Algolog. smisak. 1 p. 159.

d so _ _ Nordst. Fr. wat. alg. N. Zeal. p. 13 t. $1 \mathrm{f}, 2.1$ d $5: 1$ - - - Toni syll, alg. 1. 92.2.

1 - a iluid n. n.21.

- 92 ARTHRODESMUS (Centranterium) Rinc. Desmidya Ciastoli p. 376 t. 7 f. 23

mis 13 anth. f. typica Twner Alg. Ind, orient. p, $100 \mathrm{t}$. 12 f. 25 (f. 22 moustr.).

$n$ - v, javanicum ibid, (X, antilopæum f, javanica Nordst. 184t).

f. plana ibil.; t. 12 f. $23 ;$ t. 13 f. 6 .

d f, plana ibil.; t. 12 f. 23 ; t.

o 94 - Wildem. Obs. crit. Desm. 1. 117.

v. javanicum ibid. inclus. f. angulata et $\mathbf{X}$. fascicul. v. subalpinum ITolle 1585).

v. reductum ilsid. p. 11s.

Cir. Xanth. antilopæum f. angulatum .Josh. 1886

X. heteracanthum?. $\mathbb{X}$. Bengalicum. 
HASTINGSII

\section{ITrstiugsii}

d !2 EUASTRUM Wulle Desm. T. S. ed. II p. 118 t. 12 f. 16 et 17 .

\section{Hrommalelii}

d si Cosmarium Schuarsetm. Mngyar. Desm. p. 267 t. 1 f. D. [Cosm, taxichondrum "II a ynaldii Rac. ISS9])

d sy-Toni syll. alg. p. $! 17$.

n U1 URSINGLLA fintze Rev, gen. pl. p. $92 \mathrm{I}$.

\section{Haymaldii}

d 83 PENIUM Seluerschm. Magrar. Desn. p. $27-7$ t. 1 f, 20.

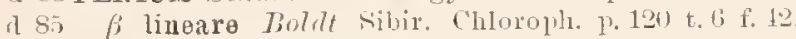
P. spirostriolatum: sec. Tиме 18!3].

d 85 -. Toni Syll, alg. p. 858 .

d v. lineare ibid. p. $85 \%$

\section{Hramurlalij}

a 83 STAURASTRUM sehaurschm. Magyar. Desm. p.272 t. 1 f. $t$ s.

mos Iste. Jel. magyar. alg. 1. 232.

a 89 - Ioni syll. alg. P. $118 \mathrm{I}$.

\section{HETTISTRU UI}

o 93 Tumer Alg. Ind, orient, p. 1:3. Snbgen. Staurastri.

\section{Heimerliamm}

o 01 PENIUM relmiale in lferwig. 33 p. 49 (Pen. closterioides v. minus Heim, 1s:11:

\section{IIeimerlialmm}

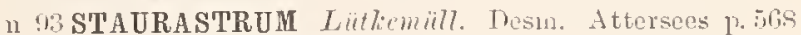
(st. cruciatum Ileimerl. 1s!1, non Wolle 18aj.

d $-v$. spinulosum ibid.; t. !) f. 17 .

\section{Heimerlii}

1195 COSMARIUn West in Jom of Bot, 33 p. 68 [Cosm. minutissimum Heim.. nun irch.].

\section{heleamgulare - is}

d s. COSMARIUM Nordst. Burnll. Desm. p. 190 t. 13 f. 16 $-10$

d sit - Toni syll. nlg. p. Mit.

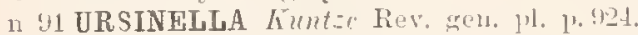

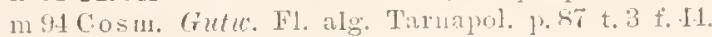

\section{Mrlemernum}

d s1 STAURASTRUM Iolle in Bul. Torr. Tot. Club. 1891 7. 3 t. 6 f.. $1 ?$

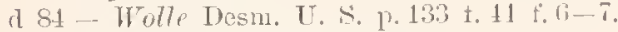

o 86 - Stokics Key Desm. j. Itil.

d 89 - Toni syll. alo. 1. 121:

1 92 - 11 olle Desm. U. S. e.l. II 1. 1412 t. 55 f. $6-7$.

\section{Heliactis}

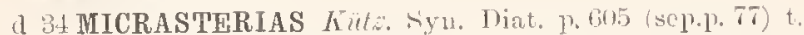

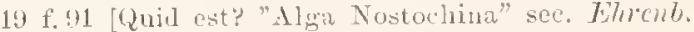
Inf. 1\%. 159.$]$.

\section{IIELINELELLA}

d 23 Lory in Dict, class, list. nat. v. 3 p. 13.

d 25 Tory in Tiect. class, luist. nat. v. s p. os /Echinella

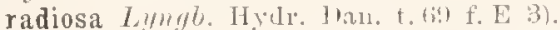

a 28 Tmpin in Nict, l. se. mat. t. 5!t 1. 24 [Pediastram].

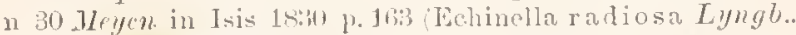
E. circularis Gree. Ursinella margaritifera Tup.) et in W'iegm. Arcli. 1835 i 1,217. o !1 Kuntie Pev. gen. pl. II p. 896 Euastrum ot Micrasterias anct.) Cfr. Tortst. in Bot. Tot. 1.922 1. . 4 . o 93 Norelst, in Hedwigia 32 p. 149.

o 13 humtze Rev. gen. plant. III' 1). CCCSLIV.

\section{heliospormm}

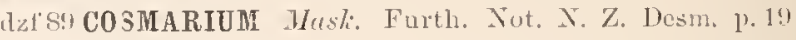
t. : 1.31 .

\section{berefretis}

d 31 MICRASTERIAS E7wemb. Organ. kl. Iaum. p. :(n)

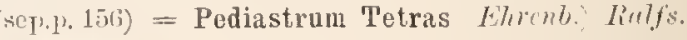

\section{heptregommm.}

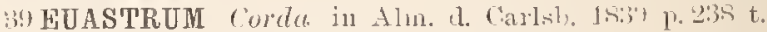
2. f. $10,11=$ Podiastrum forcipatum.

\section{Hermm.rmiremse - Hm}

d (iT MICRASTFRIAS Reinsele spee. Gen. Alg. 1) 1201.21 B f. 1-4 (sep.p. 1.2 t. 2) [Fig. now bonte sec. anct.].

d GT DIDYMIDIUM (Mierasterias) licinsch Algenfl. Frank. 1. 111 t. 8 t. 1.

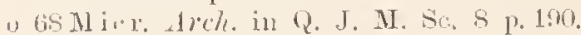

o 75 licinse/t Contrilunt. 1.93 t. 16 f. 11.

o s6-stules key Desm. 1. 116. Cifl. Micr. anericana v., M. Mahabuleshwarensis, M. Wallichii v. Tmm. 1s:11.

\section{heteroc(m)thmm}

a sl XAN'THIDIUN Lagerh. Amerili. Desn. p. 246 t. 27 f. ". I.

d 89 - Holacanthinm) Toni syll. alg. p. (1).S.

\section{IIETEROCARIELLA}

a 23 Jiny in Dict. class, d'1list. nat. v. 3 p. 13.

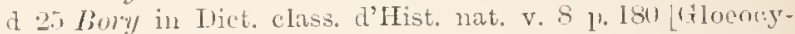
stis, sicenedesmus, Cosmarium etc. Genus delendun].

d's Till. Aperc. organ. 13. 311. [Euastrum? Descript. mala].

d 31 Kütz. Syn. Diat. p. 397 (sep.1. 69).

d 35 brib. Alg. Falaise p. 56.

1 39 Hicb, in Chev. Micr. p. 271 [Cosmarium. Euastrum, Xanthidium, Arthrodesmus?

o t.5 becuisne in Dict. univ. hist. nat. v. (f p). $59 \%$.

o yl Kuntie Rev. gen. pl. p.923 ("ist ein genus delemlum").

hetero(houdrum -

a su COSMARIUI Norlst. De Alg. et Charac. $1 \mathrm{p} .5 \mathrm{t}$. 1 f: 3.

(1) (4)-Toni syll, alg. I. 1038.

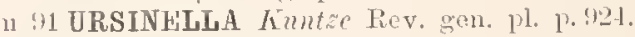

\section{heterorlo.x $m$ m. - -}

a 9: DYSPHINC'IUM Tmuner Alg. Ind, orient. 1\%. $41 \mathrm{t}$. 7 f. 15.

d - v. ornatum ibil.; t. 7 f. 1.1

11) PLEUROT 出NIOPSIS Hierom, in I'flumzenw, Ostafrik. 1. 20.

\section{IIenfleviomm}

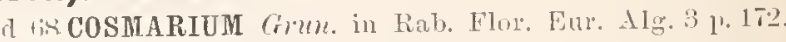
a $8: 1$ - Toni syll. alg. p. 1053.

\section{hexaromthum}

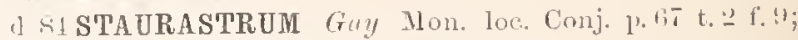
et Tote Conj. 1. 1n. France 12.33\%.

11. \%omi syll, alo. p. 1151.

o 11 - f. intermedia Fich. et frutu. Spec, alg. nox. 1'.

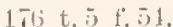




\section{hexelerellhmm}

1 :13 XANTHIDIUM Turner Als. Ind orient. p. 101 t. 1? f. 2 - 1 .

\section{hexarevos - zm}

d 34? DESMIDIUM Ehrent. Organ. kil. Ramm. p. 293 (s?p. 1. 1.1\%.

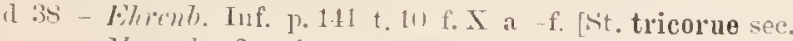

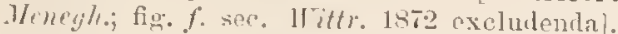

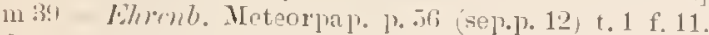

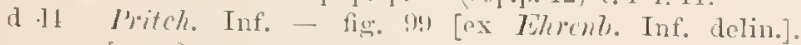
[11. $\because$.].

1143 - Ehmol. Mikr. Toh. sü̈, u. N. Amer, t. I. IT f. 11) 7. ot. IV. I f. 21. [Fir. 21 in explicatione tal. "D. tridens licxaceros" apjellatur"].

a tionIOCYSTIS Trigonocystis Hoss. Brit. Alg. 1. 352 t. 81 f. 11 [Fig. Sitriur:i tricornis in Ralfs An11. Nat. Hist. $\vee$. E (lepieta].

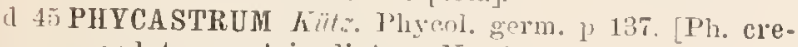
nulatum a. triradiatum $N$ Neg.?

11 49-Kütz. Spec. Alg. p. 180

d P cruciatum ibiel. (Binatella cluciata Rreb. 183i).

¿2STAURASTRUM With. Fotl. Ul. sötv. Alg. p.51 ct $\beta(R a l f s)$, "hexacernm".

d $y$ semilnnare ibil. p.52 t.t f.9 [St. tricorne v. scmil. Trest 1892].

ni 7 f. alternans Withe Ferskv. alg. Nor. Semlj. p. 52 t. $1: 3$ f. 63 .

m 85 - f. alternans Boldt Sibir. Cliloroph. p. 115 t. 5 f. 25.

mos Jivldt Desm. Grün]. 1]. 33.

dz 89 .. Toni syll. alg. p. 1206.

o - v. semicireulare ibil.

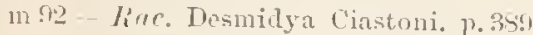

11193 Turur Alg. Incl. orient. P. 125

d 94 - v. subdilatatum schmidle Alg. Gel, Oberrleins p. 552 t. 28 f. 18 .

d It $\beta$ ornatum Borge siissw. Chlor. Arehang. p. 37 t. 3 f. 13 .

m 4.5- West Alg. Madag. p. is.

\section{herroctis}

n 36 MICRASTERIAS Ehrent. in Wiegm. Areh. fo Nat. $183 f^{2}$ p. 185 = Pediastrum Napoleouis.

\section{hexreyonre}

11 MICRASTERIAS Cuntor et Gront in Ann. Mas. Nat. Hist. Y. p. 4t? [M. hexactis? var. sec. Ehrenb. Microgeol. p.112; Cfr. $K \%$, in in Berlin. Bericht 1.917 [. 47. - Cfi Eu. hcxagonum].

\section{hexongonum}

a 81 CoSMARIUM E E fl. Finsk. Desm.p. 12 t. 1 f.s. [Cí Nordst. in Botan. Totis. 15\%2 p.97. - C. Elfvin. gii Rrac. 18so'].

m 92 Cosm. Harrsg. Beitr. Alg. Bact. Tirol. u. Lïhn. p.131.

\section{he.x"rgonmm -r"}

d io COSMARIUM Lordst. Desm. Brasil. p. 22/4 (sep.]1. 160 t. 3 f. 18 .

d s. - Tomi sir-11. nlg. p. 10:3\%.

n 91 URSINELLA huma Rev. gen. pl. p. 124.

\section{hexrgyonum}

m :1 EUASTRUM Forda in Alm, d. (ar]sl). 1830 p. 2uk t. : f.: [Mier. Ghibellina Henegh. = Pediastrum].

\section{hexregommm}

(1) S.) STAURASTRUM (1'murenterium) liarib). Nonu,
Desm. Polon. 1). 85 t. 12 f. 3 sep.p. 29) t. 3 (Calo-

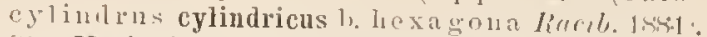
[st. Meriani f. lexagun sec. auct. in Mat. flor.

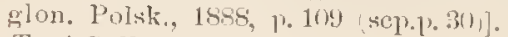

11 8 - Toni Syll. alu. p. 1105.

\section{hexagonum.}

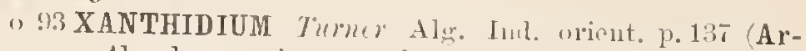
throdesmus lioxag. Lividt quoad fir. 11i. non forma fig. 17!

\section{lickergonus}

d 85 ARTHRODESMUS Iutht Sibir. Chloroph. p.109 t.5 f. 16 [X. coucinnum Areh. 18s:3 sec. Ifest 189.2; X. loexagnum Turner 184:3.

a - f. ibjil.; f. 17 [ty] pira forma sec, Tum. 1sy?; X. concin. v. Boldtiana llest 1892 ; $v$. polonica liac.

il 8 : - Tomi syll. alg. p. 1059 .

m $\sharp 1$ - Gutw. Flor. al@. Leopol. p. 31 t. 3 f.9.

d $93-v$ - polonica Lirhl. et linc. Nowe gat. zielen. 1) 122 t. 3 f.l; et 7 forma Boldt 18-io). [De fig. 6 efr Borye in Nuor. Notar. 6 1. 18j.

o 93 - Tumer Alg. Ind. orient. 1) 137 (forma Boldt 18s5). d 95 - v. tumida lincib. in Flor v. 81 p. 33.

\section{hexrlobum -r}

d 72 COSMARIUM Norlst. Desm. spetsb. p. 33 t. 7 f. 11 .

o 79 - ? Areh. in Q. J. M. Sc. vol. 19 p. 441 (nov. sp??).

d 5 - Cooke Brit. Desm. p. 116 t. 40 f. 10 [nou exacte e Nordst.?

ns - Boldt Desm. Fröul. p. 21.

d sis-Toni Syll. alg. 10.105\%.

1. 9 URSINELLA Lmize Rev. gen. 1]. p. g?t.

d 11 Cosm. P minor Tioy reottish Tesm. 1.103 (sep)p. 36 t. 1 f. 12 .

$0 \quad 91$ - f. Bonge Sïssw. Chlor. Areliang. p. 30.

d - ? $\beta$ rossicum ibid.. t. 3 f. 32.

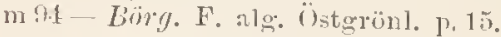

\section{hexastichum-r}

(1 71 COSMARIUM Lund. Desm. Snec. 1. 33 t. 3 f. 13 . [Cosm. quadrifarinm f. Norost. 18Ss].

o 73 - Nordst. Norg. Desm. p. 1t, 2 forma.

d $\beta$ octastichum ibid.

o 83 . f. Nordst. in Wittr. et Nordst. Alg. exs. n:o 530.

n $83-\beta$ Nordstedtii Witr. Snons och isens f. 1.113.

o sis Fordst. Grönl. Desn1, p. ?.

d si Cooke Frit. Desm. p.115 t. 10 f.s [e Lumerl.

msi-p octastichum Bolnt Desm. Grönl. 13. 23.

i - $\%$ polystichnm ibid.

(1) S!) - Toni Syll. alg. p. 1023

d - v, octastieln 1 ibid.

(l) - v. polysticlum ibid.

11 URSINELLA huntze Rev. gen. p). 1. 921.

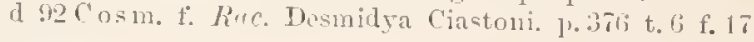

\section{hirms}

Si HYALOTHECA Nordst. Algolog. smaisal. 4 p. 15,

d 88 - Nordst. Fr. wat. alg. N. Zeal. p. 28 t. 2 f. 9.

( s.) Toni syll. Alg. p. T8s.

\section{hictuss}

1 9:3 ARTHRODESMUS Turner Alg. Int. orient. p.13.t.

II - f. major ibil.; t. 11 f. 10 ; t. 12 f. 1 .

in f. minor ibill.; t. $11 \mathrm{f} .3 \mathrm{H}$.

\section{hibermirmm}

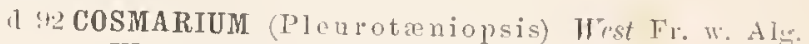
IT. Irel. 1. 163 t. 21 f. 1 ! 
HIBERNICUM

\section{hibermirum}

d 92 STAURASTRUM West Fr. w. Alg. W. Irel. p. 17 t. $23 \mathrm{f}$. fi [St. orbiculare $\mathrm{s}$, extensum $\mathrm{f}$. major schmille].

n 92 West Alg. Engl. Lake Distr. p. 7:31.

\section{lirsetwm,}

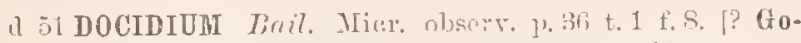
natozygon sec. Turuer Aler. Int. or. p. 341].

d $52-$ Pritch. Inf. 1.27\%.

d 61 Arch, in Priteh. Inf. p. Thf.

a ge Tiul. Flor. Eur. Alg. 3 p. 145.

d 73 FLEUROT midM Tum Fr. Alg. p. 121.

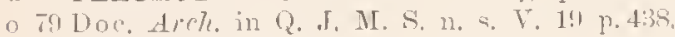

d S.t. - Wulle Desm. IV. S. p.51 t. 10 f. 13 [D. Wolleanum Turner 1:!n?

a 86 - Stolies Kiey Desm. p. 113.

1 81 - c conle Brit. Desm, p. 17 t. 7 f. 5.

d 89 - Tomi syll. Alg. 1. 867 .

a 92 - Wolle Desm. T. S. ell. Il y, if t. 13; f. 13.

\section{livisutum}

1) 3.1 XANTHIDIUM Jihnond. Orona. k1. Raum. p. 315 (sep,

a. 1, 17t) (roseriptio ninis hrevis?.

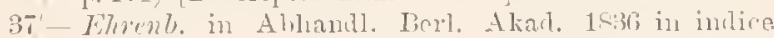
tabulari et t. 1 1. 10; et? 1. 13 (fossile) [Spongia?].

a 35 - Elerent. Tnf. p. 147 t. 10 f XXIT Xanth. pilosum E.r.ly, [fig. mala, anmon st. teliferi?].

il 10 COSMARIUH Mlenegh. Nymops. Desm. p. 223 (sep.p. 23).

6) $\$ 1$ antl. IV7ite in Mier. Soc. transac. v. 1 p. 79 t. 5 f. 3 [fossile, an spongia?'].

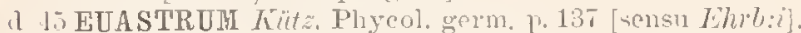

it 17 - liab. Dent. Firpt. Fl. p.5.s.

dzf 14 STAURASTRUM Rrib. in Rirlfs Tirit. Dosm. p. 127 t. 22 f. 3 (Timatella hispida Thro.; rit. muricatum Jirlfs 1S4.i). [1me spec.?]

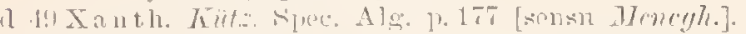

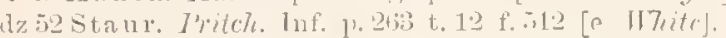

is $\mathrm{X} \Omega 11 \mathrm{tl}$. Elwewh. Microgeol, t. 37, FII f.

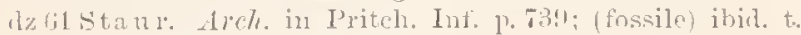
17 f. :12 (ex el. 3, 1952)

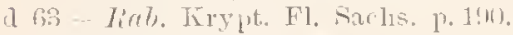

n 63 ATIBLYACTINIUM ('mmer in Iinb. Alg. Enr, 11:n 14.15.

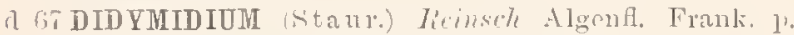
17.2. Format: A minus $a$ et $\beta$; B majus $a$, ? $\beta$. $\gamma$

lit stanr. Nut. Desm. Ital. t. 4 f. 11

d bo-lirb. Flor. Eur. Alg. 3 p. 2 - L.

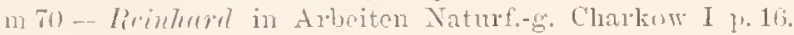

(1) 73 - ITood Fr. Alg. p. 153.

d $7 \mathrm{t}$ - Helpunte Tesmid. subalp. p. 5t (sep.]. $15(0)$ t. $11 \mathrm{f}$. $31-32$ [Quid!?.

d Ts- Kirchu. Alg. Sichles. 1, 1riti.

ms1 - Hempul Algenfl. Chemnitz Forts. 1) ?2).

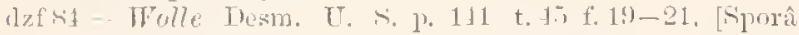
alia spec.].

d S., - Kivelm. Mikr. Pflanz. d. Sissw. 10.23.

1. 80 - Hormk in Lemis Synous. 3 r. 197.

o sfi-Stulies Kiny Desm. p. 168

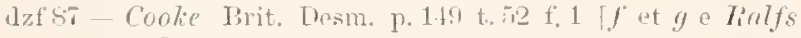
1.1 .1 .7$.

d s. - Mrnsy. Prolr. Algerff. Pulnm. p. 21t.

m $-p$ ninus ibid. p. 25i.

dz (si) - Toni syll, alu. 1) 1165.

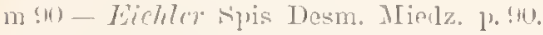

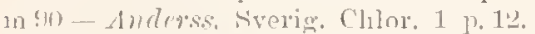

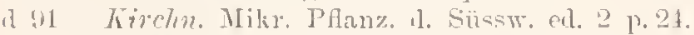

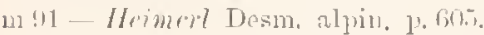

m!' - Borye Chloroph. Norsk. Finmark. p.

ก 92 - Rire. Desmidyn Ciastoni. p. 359.

aff:12 - Wolle Desm. U. S. eI. II p. 155 t. inf f. 19-21.

hirsultum

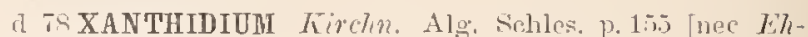
renl. 1891].

A Sa - (Holacanthium) Toni Syll, alg. p.927.

\section{hivelum}

n it XANTHIDIUH Ehrmb. Microgeol. p. 32.1.

\section{hiverlo}

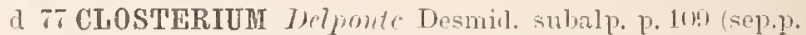
205) t. 18 f. 1;-8 [Cl. didymotocum \& H irndo Norelst. 1.89.

n !1 ARTHRODIA Funtze Rev, gen. pl. p. S83,

\section{hispidtr -nm}

d 35 BINATELLA Wrib. Alg. Fal. p.58 t. \&. [Figura maia. Staurastrum hirsutum sce, Jired. List. Desin. p. 141].

d 49 PHVCASTRUM Filz. Spee. Alg, 1, 182. (Phye, apiculosum Kïtz.) [Stnu. Brebissonii?].

\section{HOLACANTHUM}

(1 71 Lmol. Desn1, Snee. p. 75. Subgrn. Xanthidii.

o 73 Nuirlst. Norg. Desm. p.:37. Par.

d sit Guy Jonnorr. loe. Conjug. 1. It). Sect. Xanthidii. (Inelus. Stamrastri subg. Pleurenterimu).

I sh Honsy. Prodr. Algentl. Bölm. 1. 191. (Indacanthium). - Par.

d (M) Will, in Natiolich-PHanzenfam. I, 2 p. T et 11. Oenus proprium.

o st. Wildem. Whe crit. Desm. 1'. 122-121. - (sect.).

\section{Holmiense - is}

1 71 COSMARIUM Lmu. Desm. Sinee. p. 1! t. 2 f. 20.

1 - i iutegrum ibir.

त 73- Norlat. Hesm. Spetab. p.28, formia.

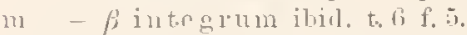

m 7: - Norlst. Noro. Desm. p. 2.1; a et fi.

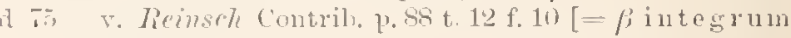
Ixund.].

11 7.) -. Norkst. Ilesm, aret. p. 15; f. maxima.

m $\pi$ ri-Norlst. Desm. Ital. p. 31.

d) - $\beta$ trigonum ibil., t. 12 f. 6.

if - f. A\%ch. in Q. J. M. S. p.31.1. [var. minor coolie 1.ssii.

mit-Nordst. Alg. sandvic. p. 13.

m T) - pintegrum Wille Ferskr. Alg. Nor, Semlj. p.37 t. 12 f. 19.

m 81 EUASTRUM (Cosmarium) Gry Mon. loc. Conj. 1. (3i).

d 8tCosm. Wolle Desm. U. ふ. p. 64 t. 16 f. 23 .

d -. v. int.e $17 \mathrm{~m}$ ibill. t, 16 f. $2 t-25$.

mst - Hitle Firlamerik. Algft. p.47.

a 8.5 a. Lundellit liacib. Nomn. Desm. Polom. p. S0 (scp.p. 2.1); f. 1, 2. 3 (maxima).

(1 - b. Nordstedtii ibia. 1. \$1. (Nordst. 1873 et 1876).

d …c. integrum ibir.

1 - 1. saxicolum ibir.. t. 11 (sep. 2) f. 16.

d - c. Kinchnerianam ibid. (C, galeritum Kirchn. 1sis). t. trigonum ibid. p. 82

o st - Stolics Key lesm. p. $12 \pi$.

$0 \quad$ - - integrum ibid.

I se-Coolis Brit. Desm. p. mi t. 35 f. 15 [e Lumdell].

n 87 -. v. minor ibid. p. 97 ["A very small form" Arch. $18.6]$. 
1] Si Hans:y. Prodr. Algenfl. Bailum. p. 197.

a $\quad B$ integram ibill.

4. - $;$ minus ibid. et p. 2.th.

m ss - Buldt Desm. Grönl, 1. 11.

in $-\beta$ integrum ilid.

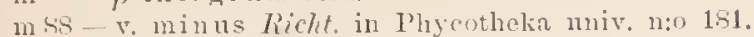

0 si $\therefore$. punctata Kirchn. Xachtr. Alg. Württ. P. 154.

ms! - f. minor Mask. Furth. Note X. Z. Desm. p. 17 t. 3) f. 2.ti。

d sig - Toni syll. aler. p. 911 .

1 $-v$. integrtum ibid. p. 145.

nu - r. minus ibid.

l $-v$, saxicolum ibil.

d - r. punctatum ibid.

(1) $90-\beta$ integrum f. constricta Gute. Walns. d. Prioritiit 1.67 .

1. - attenuatum ibic.

(1) - i? nanum ibil.

un - Eichler Spis Desm. Mieilz. p. SR.

m!1 - " minus Heimen Desm. alp, 1. 5!s.

n 91 URSINELLA Kuntze Rer. gen. pl. p.921.

(1) 1 Cosm. fintegum f. constricta Gutu. Flor. alg. Leopol, p. 42 t. 1 f. $\mathbf{1 7}$.

d $-\gamma$ attenutum ibill. p. 13 t. 1 f. 18.

(1) - ?) nanum ibid. et t. 1 f. 19.

d (12 $\beta$ integrum f. Rorge Subfoss. sötw. alg. Gotl. P. 5i t. 1 f. 10 . et Alg. Notis. p, 60.

1.92 - Wolle Desm. U. S. ed. II p. 71 t. 19 f. 23.

d - v. integram ibiu., t. 19 f. $21-25$.

(1) 92 - f. Ifest Alg. Engl. Lake Distr. p. 721 t.9 f. 12.

m 1:? - v. integrum Lïtlemill. Desm. Attersees p. sill.

ก $91-v$ - integrum sichmidle in Herwig. p. 95.

( - $\because$ hibernicam ibirl. (C. plicatum $r$ hibern. West 1 1.

1 ?. $\checkmark$. undatum West New Brit. Alg. p, 5 t. 1 f. 12.

m!4 P integrum lisirg. F. alg. Ötgrönl. p 20!.

m 55 - - Eichler in Pamiet. Fizy, 1; p.58.

n

1) - $v$. integram f. ibid.

\section{ITolmii}

a s6 COSMARIUM Wille in Dijmphn. togt. Uib, p. sit t. 13 f.. 2.

mss - f. minor Boldt Desm. (roönl. 1י. $2-$.

$\mathrm{m}$ - f. depamperata ibil.. t. 2 f. 2 ??

17. 59 - Tomi syll. alo. p. 1005.

11 !1 URSINELLA Kunt: Rev, men. 11. p.

\section{ITOLOCYSTIS}

a 4.5 Huss. Brit, Alo. p. $3 \mathrm{si}$.

1 tio Wrallich Desm. Low. Benaral. p.27-j.

d $9: 3$ Tam. Alg. Ind, orient. P. IS. Subgen. Micrasteria.

\section{ITolorystis}

d 4 EUASTRUM K̈̈̈t. Sper. Alg. p.173. [Inlocystis oscitans II a.s.s.].

\section{holorystoilles}

d si EUASTRUM Tordst. Algolng. smisak. 4 p. 15.5.

d $\times$ S - Forlst. Fr. wat. alg. X. Zeal. p. 32 t. 3 f. 1.

d 89 - Toni syll. alg. ?. 1181.

n 11 HELIFRELLA fiuntze Rev, gen. pl. p. sts.

\section{IIOLOPENICII}

d st Gay Monogr, Ine, Conjug. p. 38. Sinct. Penii. (Netrium กี้ถ. 151!).

d 93 Tumer Algr. 1nd. orient. p. 1s. Subgen. Penii. homalodermmm -

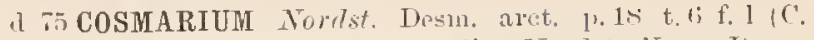
pyramidatum f. intormedia Nordst. Nor pr. Desm.

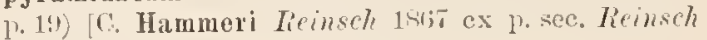
$187 \%$.

6) Ti- Norlst. Desm. Ital. p.:34,

6 76 ? (roue in Q. J. M. S. र., 17 j, :301.

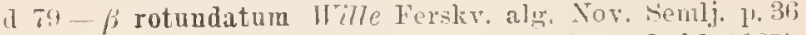
t. 12 f. 1s. 1'. Hammerif, rotnidata boldt 1885].

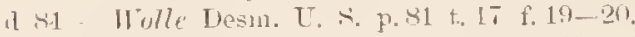

o st - Wille in Dijmphn, togt. Uitb. 11. 85 t. $13 \mathrm{f}$.

1) 8 - Stolies liey Desm. p. 128.

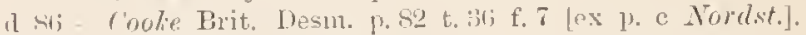

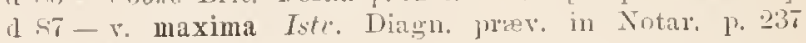
sep.p. 8 .

1) so - v. maxima Iste, fel. magyar. alg. p.2.26 t. 1 f. 13. [Quid est?'].

d 59 - Toni Syll, alg. p. 1043 .

o - -v. rotundatum ibid.

o - ? v. maximum ilis. p. 1012 (filse sub n:o 257 pro 260 positum).

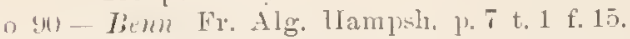

n :1 URSINELLA huntze Rev. gen. pl. p. 92.1.

d 92 Cosm. Wull Desm. U. S. ed. II p. 88 t. 20 f. 1! -2u. m 13 - f. typica Tumer Alg. Imd. orient. p. 53 t. 8 f. 62.

o - $\beta$ rotuudatum f. ibit.; t. 9 f. 23.

o 55 - v. rotundat $1 \mathrm{~m}$ schmille in Hedwig. 31 p. 78.

\section{IToolieri}

a 81 COSMARIUM schaurschm. Afghan. Alg. p. 246 t. is f. 21

(189-Tomi Syll. alg. 11.1002.

n 91 URSINELLA Kunt:e Rev. gen. pl. p. flet.

\section{Hoplivilii}

a 11 CYMBELLA Tuore in Harr. Man. Br. Alg. p. 215. [Closterium lanceolatum sec. Licalf's Br. Desm. Conferva ovalis sec. Houre, serl rix ita ser. Iialfs: 19481.

\section{HOPLASTRL'H}

o 93 Turner Alg. Ind. orient. p. 132. Subuenus Staurastri.

\section{horrometrum}

(1) 93 STAURASTRUM $I^{2} \circ y$ scottish Dosm. p. 238. (et 1sil) t. 3 f. 2 (sep.1. 21)

\section{horresrens}

a 8i STAURASTRUM fosh. Bum. Desm。 p. iit1 t. 24 f. 3. it 89 - Toni syll, alg. p. 11 ?2.

horviluem

d :1STAURASTRUM Tum, Alg. Ind, orient. $\jmath^{3 .} 11 \mathrm{~s}$ t. 1.4 f. 4.

\section{Huebneri}

dzf jl SPH尼OPRIUM Rub. lincill. exs, n:o $4: 4$ t. 3 f. 49 [Didymoprinm Grevillii b. Hubneri Rub. 1-63. - Desmidinn Swartzii eum zygosporis!].

\section{Hemerosum - r}

d 48 EUASTRUM lirelfs Brit. Desm, 1, 8. t. 13 i. 2.

a $i_{2} 2-J^{2}$ ritch. Inf. p. 249.

o 60 - $\beta$ ) aftine Wallich Desm. Low. Bengal 1. 253 (E. affine).

a $61-$ Arch. in I'ritch. Inf. p. T2!?

(1) is - liab. Flor. En1: Alg. 3 1, 15 ?2. 
a $7:$ f. scrobiculata Nordst. Norer. Desm. ]. \&.

z 75 - X Didelta Arch, in Q. J. M. Ac. 1\% 11.1.

a 84 - Wolle llesm. IT. S. p. 914 t. 24 f. $12-1 \%$.

n 85 - a, gezuinum Rucits. Yonn. Desmn. Polon. p. 93.

1 -. h. intermedium ibil., t. 18 (sef. 4) f. 5.

$11-$ a. affine ibid. (E. a fine liulfs $181 \%$

o st: - Stokirs Kiey Desm, 11. 145.

1] Si rooke Mrit. Desm, p. Gij t. 32 f. 3 [sa]tem partim e Fialfs.

rl so - Tomi syll, alg. p. 11900.

d - v, intermedium ibir.

m 901- $\beta$ iutermedium Anturs. Sverig. Clilor. 1 p. 1u.

1191 HELIERELLA Kumtre Rev, gen. pl. p. 848.

1091 Eu. Futu. Flor, alg. Leopol. 1) 7:?.

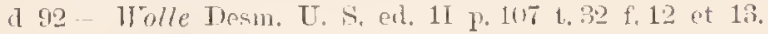

o 98-Lütliemill. Desm. Attersees 1, ittr.

d 13 - v. mammosa schmille Beitr. Alg. Schwarzwald. p. 106 t. 6 f. ? et 10 .

Cfr. Didymidium varians; Eu. crassum $\times$ humerosum, Eu. Didelta Reinsch 185.

\section{llumile-is}

a St EUASTRUM (Cosmarim) Gray Note ('onj. d. m. France 1. 33\%. (Eu. (Cosmarium) celatum Gruy. 1SSt, non Cosm. colatum Rirelfs.

a 8 COSMARIUM Tords\% in Toni Syll. alg. p.96i.

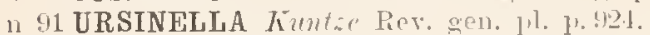

d 42 Cosm. v. glabrum Gutw. in Nuwv. Notar. $11 \mathrm{I}$ p. 21.

d $92-v, g l a l y m$ Grutw. Flor. glon. (talic, : p. 132 t. 3 f. 11. [C. substriatum f. see. Thest in Jonru. Tot. 1895 p. 6s. Non ita sec. Gutw. l'1. H. alg. galic., $1895, p .3407$.

n 45-v. striatum Schmidle Beitr. alp. Alg. 13. 35\% C. str. Boldt 1885)

u - v. subdanicum ibid. (Cosm. subl. TVest),

11 v. glabratum ibir. ( delendum].

n - r. dauicum ibid. (C. danicum Borg.).

n - v. substriatum ibid. (C. substr. Nordst. et f. minor).

n - v. Raciborskii ibir. (C. striatum r.glabratum Rne.) [nomen $S: i$ delendum?

n - v. lithaanicum ibia, (C. Blyttii f. Tith.)

11 - $v$. berolinenso ibill. (C. Blyttii f. ber.).

\section{IT"myradyammm-re}

a sis COSMARIUM Scharersch. Magyar. Desm. p. 2 lit t. 1 f. 1.

d S!1 - Tomi Sy+11. alg. ך. 1052.

i1 91 URSINELLA hunt:̈e Rev, gen, pl, p.921.

\section{IIntelinsomii}

a 13 D0CIDIUM Turner Desm. Notes p. 346. et f. 1li p. 3.14.

\section{IIyarinth:}

d 90 COSMARIUM Gute. Wahr, d. Prioritat p. 70.

d 91 - Gutw. Flor. alg. Leopol. 1. 0,2 t. 2 f. 30.

\section{YALOTHECA}

n 11 Ehrend, in Berlin. Menatsher. 1 s 10 p. 212 [Desmirl. mucosam lireb. 1835 et cylindricuus].

d 45 Kätr. Phycol, germ. p. 1.1\%.

d 47 liab. Dent. Irrpt. F1. p. 58.

d trilles Brit. Desmo 1, 51 .

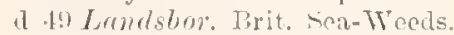

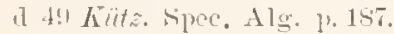

45 I'vitch. Infus. 1.238.

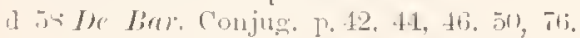

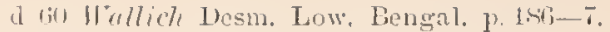

d $61 \mathrm{Arch}$. in Pritch. Inf. p. 719 et 722.

d 69 lidb. Frypt. Fl. Sachs. p. 179.

1) 61 Gray Brit. Alg. p. 71 .

11 67 s jot. Desin. Ital. p. 19.

a his hinl. Flor. Eur. Alg. 3 p. 10 . et 151.

o 72 Wittr. Gotl. (H. sötv. Alg. p. 47.

it 73 Helyoute Desm. subalp. p. 35 et in (sep.p. 23 et 47 .

(1 73 Wood Fr. Alg. p. 124.

d 7 is Microgr. Dict. p. 231 et 383.

d Ti Frenti in Lemuis Symops. p. 1633.

d TS Rirehn. Alg. Schles. p. 131.

d stray Honogr. loc. Conjug. p. l:3. sect. 1 Hyalotheca s. str.; sect. 2 Bambusina.

a 81 Wulle Desin. U. S. 1, 22.

a sj Kirrhn. Mikr. Pfanzenw, d, siussw, p. 20.

d si Frenti in Lennis Synops. 3 p. 197.

o sfistulies Key Desm. p. 109.

d sif Honowry in Baill. Dict. bot. Il p. 89.

d 86 Coole Frit. Desm. 1. 7 .

त si Alexemlio Chlorosp. Khark. p. 218.

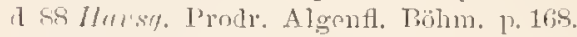

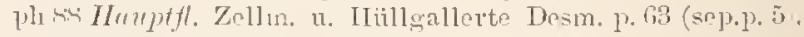
d s.9 Tomi syll. Alg. p. 685 .

1 : 10 Wille in Natül. Pilinzenfam. 1, 16.

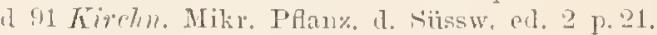

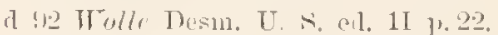

d 933 Finiley Contr. Q Zneensl. Fl. p. 33.

o 93 Twner Alg. mal. nient. p. 153. Subgenera: Mixotienium et If yalotheca sens. strict,

ph 9.4 Wcllheim in Pringsh. Tahrb. 26 p. 720; (sep.p. 5:3).

\section{hyporepherlophormm}

d 95 STAURASTRUM West Alg. Marlag. p. 71 t. \& f. 2.5.

\section{lyporthomblonirles}

d 95 EUASTRUM West Alg. Madag. p. 49 t. is f. $s$.

- $\vee$. irregalaris iliti.; f. 9.

hylpochonetrmm, -re

d so EUASTRUM Nordst. De Alg. et Clarace 1 p.s t. 1 f. 11.

d 89 - Toni syll. alg. 1) 1071.

n 91 HeLIERELLA Kuntze Rov. gen. pl. p. 898.

\section{IIystivin}

d 1 STAURASTRUM Rirlfs Brit. Desm. p. 124 t. $22 \mathrm{f} .5$.

th th- I'ritch. Inf. p. 261.

d $61-4$ rels. in Pritcli. Inf. p. 789.

mo 60 - Frimsch in Rrub. Alg. Eur. u:o 1s!s (f. trigona) 67 DID YMIDIUM (Staur.) f. A. minus a trigonum lieinsch Algenf). Frank. p. 171 (St. Hystrix

d - $\beta$ trigonum ibid. (St. quadrangulare).

d - B. majus ibich. (Nt. teliferum)

d Gistaur. Rab. Flor. Eur. Alg. 8 1, 213.

d 33 - Wood Fr. Al $\alpha$. T. 15t.

a 88 - $\beta$ tessulare Nordst. in Wittr. et Nordst. Alg. ex*. $11: 05.51$; et (1859) in fase. 21 p. 36.

a s. Wolle Desm. U. S. 1. 1.t2 t. th f. $14-16$.

o Sti - Stolks Key Desm. p. 10is.

d 5 - Cooke Brit. Desm. p. 151 t, 52 f. B.

in 48 Iste. Jel. magyar. alg. p. 233.

a ss-v, lithuanica liffeib. Desm. Lithnan. p. 6603 (sep.p. i).

d $89-$ Tomi syth. alg. 1. 116is.

d - v. lithunuienm ibil.

s. -. - - Racib. Now. Mesm. p. 100 t. 7 f. 7.

d $! 10$ - p polyspina Briry. Irom. Brasil. p. 4:4 t. 1 f. $4: 3$. 
m! - v. lithuanica bichler Spis Desm. Mindz. 1. (n).

d !ul Anderss. Sverig. Chlor. 1 p. 12.?

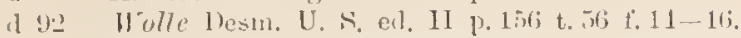

o 93 - Schmidle Beitr. Alg. Sehwarzwald. 1.105 t. 6 i. 5.

d - v. paucispiuosum ibid., t. li f. li.

m 6 - - - sehmille Deitr. alp. Alg. p.60 (sep.1. 32).

\section{igmotum}

1 !3 STAURASTRUM Turner Alw. Ind. orient. P. 130 1. lit f. 30 .

\section{imenessulum -n}

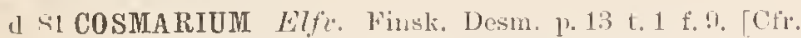
Nordst. in Bot. Notis. 1542 1,.97. C. Meneglizii f. latiuscula Jac, 187 ; sec. Boldt 18s8?.

m S1 EUASTRUM (Tosmarium) Gay Mon. loe. Conj. l. fil. sic Cosm. lioy et Jiss. Jap. Desm. p. 195 (sep.p. 1) t. glis f. 10.

1 ş- Kansy. Prodr. Algenfl. Bühn. p. 218.

d s! - Toni syll. alg. 1. Slu.

m !1 - Heimerl Desm. alpin. 1, 514!.

a f. integrata ibid. et t. $\vdots$ f. 12.

1. 91 URSINELLA Fumlze Rev. gen. pl. p. 425.

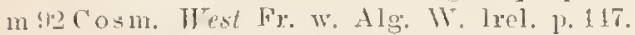

m!s f. minor Tumer Alw. Ind. orient. p. 60 t. ? f. 12.

a-1 Johns. liare Desm. U. S. t. 211 f. 6

m5.5 Schmidle Beitr. all. Alg. 1.38s.

1 - v. alpicola ibirl, et t. $15 \mathrm{f}, 11$.

1) - - f. ibil.; f. 13 .

\section{impressum}

39 EUASTRUM forde Alm. t. Carkh. 1839 1. 238 t. 2 f. 13 = Pediastrum forcipatum.

\section{inceruerele -is}

a 32 CLOSTERIUM? khrenb. Entw. d. Inf: p.67.

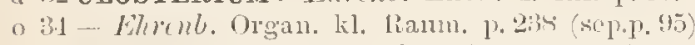

d 38 - Toxotium)? Ehrent. Inf. p.gs t. 6 f. XI.

d 14 - Thenegh. Synops. Desm. p. 235 (sep.p. 35).

11.15 hätz. Phyc. germ. p. 131.

d 1 . - liulfs Brit. Desm. 1) 221.

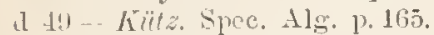

d $52-$ Pritrh. Inf. p. $25 \mathrm{~s}$.

(1) 1 - Heh. in Priteli. Inf. p. 7ts.

d bis-Rab. Flor. Eur. Alg. 3 p. 1:36.

1) 75 - fucols. Desm. Danem. p. $16 i 7$ "Le Clost. inturuale Ehrl, u'est nas une Desuidiacee".).

d si - Toni syll, Alg. p. Si.1.

" ! ARTHRODIA Kantze Rev. gen. pl. p. 883.

\section{inceryucre}

1 7 T STAURASTRUM Nordst. Alg. brasil. p.2.5 t. 2 f.9.

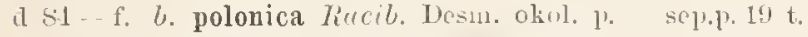
1 f. 12 .

n s. a brasiliense Racib. Nonn. Tesm. Polon. p. si (sep.p. 32).

a - b. polonicinm ibid.

1 SI - Toni syll. alg. p. 11 fi-1.

n - r. polonicum ibil.

\section{incerqualipellicume}

d 95 COSMARIUM West Alg. Iadag. p. j1 t.6 t: 28-29 et 30 (minor).

\section{irerene}

d 93 COSMARIUM Turner Alg. 1ul, orint. p. 57 t. $\mathrm{S}$ f. 11.

\section{increverterls}

a 93 COSMARIUM 7umer Algae Ind, orient. p. 55 t. 4 f. 17. (l) planum iliti.; t.22 f. 7 .

\section{ilrevetum- -}

d sl EUASTRUM Jush, et Nordst. in Wittr. \& Nortst. Alg. exs. 1957 f. xylogr. a, h, c, d; ot (1sia) in filse. 311 1. 36 .

d 55 - Jos\%. in Juturn. Bot. v. 23 p. 33 t. 251 [iterata icol1].

(1 89 - Tomi Syll. sh. p. 1075.

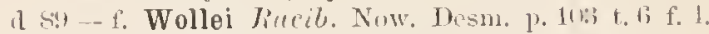

n 91 HELIERELLA Kunt:e Rev, gen, pl. p. sus.

\section{incovatus}

(1) 9 ARTHRODESMUS Twner Alg. Ind. orient. $1 \% 13 \bar{t}$. 11 f. 13 .

\section{incertume}

1 \% COSMARIUM schminh in Helwim. 31 1\%.78 t. 1 f. 8. ('fi. C. Meneghinii f. rotundata)

\section{inchoutum}

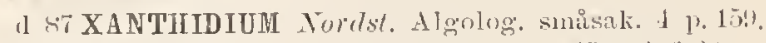

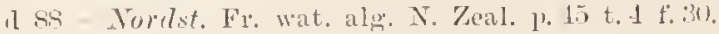

(l s!) (Holacanthium) Toni riyll, alo. 1).92..

\section{illeisu-um}

n 3:4 MICRASTRRIAS Prob. in Chev. Mier. p. 171 [nomen tantum]

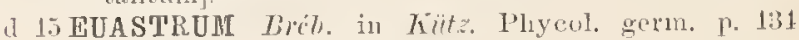
(Fhrent. luf. t. 12 f. III c).

d IS Micr. Brél. apul Rulfs Brit. Desm. 1).211.

(1) 1!) K Kütz. spee. Alg. p. 171.

$49 \mathrm{Eu}$. (1l i cr.) N Nog. einz. Alg. 13. 123.

ol Micr. Ibail. Mier. Obs, t. 1 f. 13 [Tetrachastrum americannm Arch. in Iritch. Inf. p. T25; $11 \mathrm{icr}$. laticeps f. minor Nordst. 1870].

d $52-$ Iritch. Inf. j. 247.

a bu HOLOCYSTIS Tullich Desn. Low. Bengal. p. 276 t. 13 f. $1-5$.

a - v. $\beta$ ibid.; f. $1 ;-7$ [ $\beta$ Wallichiana Tum. 1893].

d $61 \mathrm{Mi}$ er. Arch. in Priteh. Inf. p. 726.

a) 68 - liab. Flor. Eur. Alg. :3 p. 1s8: form. b. (Eu. crux melit. f. juvenilis threnb.).

d. $70 \beta$ excisa Nurdst. Desm. Brasil. p. 21 t. t. 2 f. 12.

o 71 - Lund. Desm. Suec. 1. 15.

o S1 Holocystis Musk. N. Zeal. Desul. p. 301; t. 12 f. 24 [M. Upsaliens.s sec. Arch. in Grevillea 10, 1:-s1. 1). 29].

0 5131 icr. Elfe. Finsk. Desm. 1.6 t. 1 t. 1 ("altera semicellula characteres M. pinnatifidæ, altera M. incisæ praliet").

s:3 TETRACHASTRUM (Ilolocystim) Must. N. Zeal. Dexil. Arld. 1. 257 t. 25 f. 21, mioustr.

d 58 Micr. LLansy. L'rendr. Algenfl. Böhm. 1. 207.

1 89 - Toni Syll, als. 1) 1110 .

d - v, excisa ibid.

"I HELIERELLA huntze Rev. gen. 11. p. S!S.

m $93 \mathrm{ll}$ icr. (Holoeystis) f. typica Turme Algr. Ind. orient. 1. Sy t. (; f. 8 et 10 .

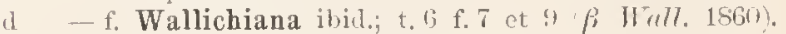

d - f. aculeata ibid.; t. 1 i f. 11.

\section{Inriste}

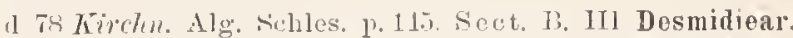
Geu,: Cosur., Xauth., Artlir., Euastr.. Micr., Staur 
d su Ilums. Troulr. Algenf. Böhm. p. 19u. Trii, subfam. Didymiacearum. Gen.: Cosmaridinm. et cetera ut supra.

\section{imrismlll -re}

a s.5 CosmariUM (Plen rotaniopsis) Racib. Nonn. Desm. Polon. p. To t. 10 f. 7 (sep.p. 1.I t. 1.) (? C. Cacumis o illc isum Jucols. 1 sinto).

n S\& COSMARIDIUM IIm,sy. Prodr. Algenfl, Bühm. p. 216. a S9 PLEUROT现NIOPSIS Tomi syll, aly. p. 91 .

m 9o- Cosm. Borye Chloroph. Norsk. Finmark. p.11.

o 95 - Richt. in I'hykotheca univ. XIII 11:0 6it b. (eum transit. al Cosm. holmiense $v$ integrum et Cosm. Cncumis)

m!5 - Borge sverig. Chlor. It p. 17.

\section{illeistlll $-r$.}

d si COSMARIUM Josh. Burm. Desu, p. 618 t. 24 f. 28 \& 29: nee liac. 1isso.

d so - Toni syll. alg. p. 930.

n !1 URSINELLA huntic Rev, gen. pl. 1? 3.s.

\section{incisum}

d st STAURASTRUM Wolle Desm. TT. $\curvearrowright$ p. 132 t. 11 f. $12-11$.

6) S6; - Stukes Key Desm. 1) 166.

d sy - Toni syll, alg. 1) 1.23!.

- $90-f$. convergens Gutw. Walı. d. Prioritid 1. 71.

d 91 - - Crutw. Flor. alg. Leopol. p. iti t. 3 f. 13.

d 92 - Holle Desm. U. S. ed. 2 p. 14ii t.52 f. 12-11.

m 92 - Twner Alg. Inl. orient. p. 115.

1 94-Johns. Rare Desm. U. S. p. $28 s$ (- St. crenulatum (Nerg.) Hely. .

\section{Incluse}

d 34 Kätz. Syn. Dia.t. 1) 611. Trib. Desmidiacenrum, Gen.: Echinella, Geminella, Gloeonema, Desmidium.

1140 Menegle. Synops. Desm. p. 202. 'T'rib. Desmidiearum. Gen.: A. Desnidium. Isthnia. B. Seenedesmus, Pediastrum, Gonidium.

\section{inconspir.mm}

d 9. PENIUM West New Brit. $11 \mathrm{~g}$. p. 4 t. 1 f. 6 et 7 .

\section{illeomspirmmm}

d 73 STAURASTRU Nordst. Norg. Tesm. p. 26 t. 1 f. 11. [St. minutissimnm Aucrsu, in Rub. Alg. Eur. n:0 112.2 ex p.]; nee. Not. 1871.

o $71-$ Arch. in Jourı. of Bot. 1874 1. 91 . [Staur. s]. Arel. in 12. J. M. Sc, 1 sito p. S\%].

d $81-\beta$ crassnm Guy Mon. loc. Conj. p. 68 t. 2 f. 10.

d 81 - Wolle Desm. U. S. p. 125 t. 53 f. 1-5.

m 85 - Boldt Sibir. Chloroph. p. 115.

n 85 - a. typicum Racib. Nomn. Desm. Polon. p, sí (sep. p. 31).

d - b. abbreviatum ibid., t. 12 f. ?

o s6-Stukes liey Desm. p. 165.

d 87 -Coolie Brit. Desm. p. 15s t. 51 f. 3 [d e Nordst.].

m 88 - f. mixta: pentagono $x$ tetragona lincib. Mat. flor. glou. Polsk. 1). 109 (sep.p. 30).

d so - f. gracilior Matk. Furth, Note N. Z. Desmı. 1. 26 t. 5 f. 46 .

d 89 - Tomi syll. alg. p. 1183.

a - v. erasisum ibid.

d - v. abbreviatum ibid.

(11) - v. vogesiacum Lemaire in 13ull. soe. sc. Xancy v. 12 p. 32 (sep.1.6) (Nt. subrefractum $L(m$.$) .$

$1 \mathrm{n}$ ! - Lichlo bis Desm. Mielz. p. $9 !$ ! m 91 - Heimerl Desin. alpin. p.606.

n1 12 - West Fr. w. Alg. W. Trel. p. 178 .

d !) Wolle Iresu. U. A. al. II p. 137 t. 6.1 f. 4 -

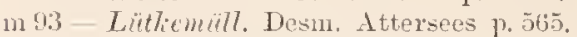

in - v. abbreviatuin ibil.

m 94 - v. crassum IIest New Brit. Alg. p. 11. Cfr. Staur. Haynaldii et St. refractum.

\section{incollsmirllmm}

d 7 STAURASTRUM Not. in Erb. critt. ital. ser. II fase. II 11:0 430. [Cfr Helwigia XI 1st2 p. 20, descript. iterata. - Stanr. gracilev, inconspicua Je Toni $1589]$.

\section{inceressatum - "l}

1) ST EUASTRUM Nordst. Algrologr. småsak. 1 p. 1.ri).

d ss - Norelst. Fr. wat. alg. X. Zeal. p. 35 t. 3 f. 12.

d sil-Toni syll. alg. 11. 107?.

11 91 HELIERELLA Kuntze Rev, gen. pl. p. 89.

1191 Eu. Gutu. Flor. alyg. Leopol. p. 71.

mit-Gutw. Flor, alg. Tarmapol. p. 108.

\section{incrersiatum}

1 59 PENIUM 21usk. ad inter. Furth. Not. X. \%. Desn. l'. $2 .+$ t. 5 f. 52 ; f. major et minor.

\section{increrssutus:}

d Sri ARTHR0DESMUS Lager, Amerik. Desin. p. 2.2.2 t. 27 f. 18 .

d $-\beta$ cycladatus ibil.. f. 1 1

d 87 - Wolle Fr. Alg. U. A. A. p. 35 t. 61 f. 6 [a Lugerh.].

o - - $\beta$ cycladatus ibil.

d s9-Toni syll. alg. 11. 1061

i v. eycladatus ibid.

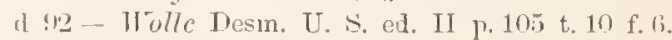

$0 \quad-$ v. cycladatus ibid.

\section{incurifiorme}

d ! EUASTRUM Ding. Desm. Brasil. p. 35 t. 3 f. 2.2.

\section{incurvatum.}

dzf 93 EUASTRUM Twmor Alg. Ind. orient. p. 83 t. 11 f. 1. [Eu. elegaus v. monodentatum f, annulatum WiTdem. 1894].

\section{inculrentume}

def) 93 SPONDYLOSIUM Turner Alg. Ind. orient. p. 5 t. is f. 8 (ff. major et ninor).

\section{inreneverum}

d 9.5 STAURASTRUM West Alg. Madag. p. 76 t. 8 f. 33 .

\section{inc:17?m!n}

1) 56 CLOSTERIUM Fred. Liste p. 150 t.2 f. 17. [Cl. Dians e. incurvm Kicles 1 sisid.

d $9: 1-A r c h$. in Pritch. Inf. p. T.1s.

d is - hab. Flor. Eur. Alg. 3 p. 135.

d i2 - $p$ majus Will. Gotl. Gl. sötv. Alg. p. 65 t. 4 f. 1!.

daf 75 .. Delumte Desmid. subalp. p. 102 (sep.p. 10.8) t. 17 f. $22-2-7$.

m S1 - Gray Mon, loc, Conj. p. T2.

d 85 - Prflamo Alghe del com. di Napoli p. 37.

d 89 - Toni s.rll. Alg. p. s1s.

o - v. majus ibirl.

\section{inr.11\%11}

(1) 
11 f. 28 ("Nonne Staur. Dickioi f. 2-gona?") [A. hiatus sec. Will. 1894 p.106].

\section{Incus}

11 3. BINATELLA Bréb. Aly. Falaise p. 269 (sep.j. (6). 139 HeTerocarPeLLA Bich. in Cliev. Micr. 1.272.

a 10 STAURASTRUH Mcnegh. Synops. Desm. p.228 (sep. p. 28).

1 $45-R a l f s$ in Am. Nat. Hist. v. 15 p. $15 \mathrm{~S} \mathrm{t.} 12 \mathrm{f.} 2$ (et 1 iff in 'Trans. Bot. Soc. Elliu. v. 2 p. 115 t. 15).

(1) 15 ARTHRODESMUS Ilass. Brit. Alg. p. 357 t. 55 f. 10 [firgo. fortasso e $R_{u}$ ulfs l. c. delinentie].

d t5 EUASTRUM Kütz. Phycol. germ. p. 13\%. - [Al'throdosmus minutus (Kütz.) Triéb.].

(1) 17 ... Rub. Deut. Firypt. Fl. p. 5n.

def 18 Arthr. Rulfs Brit. Desm. p. 119 t. 20 f. 1 a-d (Eu. retusuin hïtz.) [a divergens Cooke 1Ss7; Didymidium erectum Reinseh ex p.; $b=$ f. isthmosa Ilcim. 1891; $a$ et $d=$ f. typica ibid.].

o - $\beta$ ibid., f. $c-h[\beta$ convergens Cooke 1887; Arthr. Ralfsii West 1892; $f$ et $g=v$. vulgaris Eichl. et Roc. 1893].

d 19 - Kütz. spec. Alg. p. $17 \%$.

19 Eu. (Tetracathium?) Nog. Einz. Alg. p. 113.

d $52 \mathrm{Ar}$ tlir. Pritch. Inf. p. 260.

ph 5.1 - Osborne iu Q. J. M. Sc. v. 2 p. 237 c. fig. xyl.; p. 238 f. 5.

n 58 COSMARIUM (Microcosmarium, Arthrodesmus) De Bar. Conjug. p. 72 .

o 59 Arthr. (monstr.) Aveh. Abn. Desm. in Dubl. Nat. Hist. Soc. 2 p. 208 t. 1 f. 11 ; in Nat. Hist. Rev. 6 l. 170 t. 33 , Q. J. M. Sc. 8 p. 86 .

o 60 - (monstr.) Arch. in Nat. Hist. Rev. p.391 t. 13 f. 7 , ill Mier. Journ. p. 235 t. 11 f. 7 , in Dub. Nat. Hist. soc. p. 37 .

o 61 - (monstr.) Bulnh. in Hedw. p. 51 t. 9 f. 3 [A. Bulnheimii Ruc. 1889].

d $61-A \cdot c h$. in Iritch. Inf. p. 737 t. 3 f 36 [e Ralfs $\mathrm{Br}$. D. 1 e], f. 62 [ex Areh. 1859 ].

oz 61 - Mantzsch in Rab. Alg. 1:0 1201 (quoque f. trigona = Staurastrum).

$163-$ v.? Grun. Ins. Bank. p. 15 t. 2 f. 29 [A. gibberulus?].

d 69 - Rab. Flor. Eur. Alg. 3 p. 226 ; et form. b.

(1) $69-\beta$ intermedins $\|$ itt). Skandin. Desm. $p .15$ t. 1 f. 6 [St. Psendincns ex p. - st. 0'Mearii f. Arch. in Jou'n. Bot. 1874 p. 93; cfr. Nordst. Norg. Desm. 1873 p. 27 ].

1n 70 - Nurlst. Desm. Brasil. p. 231.

- 71 - a. Lund. Desm. Suec. p. 55; (Lulnh. 1561); [A. Bulnheimi i Racib. 18s9].

- - b. ibid. (Iialfs f. 4 d).

o 73 - Irood Fr. Alg. p. 158.

Tt-Gibbons in Trans. R. Soc. Victoria X in fig. plotogr. 2.

d 75 - Microgr. Diet. p. 73.

- Tf Staur. a Jacols. Desm. Dauem. p. 201 (iusel. Arthr. snbnlatns Kït $z$.).

- $\beta$ form. ibid. t. 8 f. 26 a.

$12-\gamma$ intermedia ibid. p. 205 t. 8 f. 26 b, e et 1 (f. 3 angular.) ( $\beta$ interm. Wittr. 1S63).

ple if Arthr. 1rch. in Q. J. M. se. p. 236 (monstr.).

d $78-$ hirchn. Alg. Schles. p. $15 t$.

81 - Cooke in Quekett Micr. J. 6 t. 13 f. C f.

daf 84 - Wolle Desm. U. S. p. 97 et 160 t. 21 f. $1-10$ forme) [Fig. $1=$ f. typica Ileim. 1s91, $1=\mathrm{f}$. depressa Eichl. et Ruc. 1893, $3=$ f. longispina ibid.].

m 85 - Boldt sibir. Chloroph. p. 109.

m $-\gamma$ intermedius ibia.

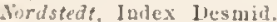

d 85 - v. Americanus 7urner New rare Desm. p. 937 t. 16 f. 17. [A. trianularis v. amer. Whest 1842; A. subulatus f. media Tumer 18!3].

d 850 - Balsamo Alghe lel com. di Kapoli p.40.

n $8 i^{i}$ - ff. Josh. Burm. Desm. p. \{ilt t. 21 f. 10-12 [f. Jos huse Gutw. 1S9t); f. 10) et 12 = f. simplex Eichl. et lire. 1893].

un 86 - ff. Lugerh. Amerik. Desm. p. 243.

o 86 - Stokes Riey Desm. p. 131.

86 - Turner in Leeds nat. elub transact. 1 t. 1 f. 9 [f. isthmosa sec. Fichl. et Rac. 1903].

dzf 87-Cooke Brit. D.sm. 1. 135 t. 17 f. $1[a$ et $b=\beta$; $c-i=a$.

$1 \quad-a$ divergens ibul. p. 136; $\left[\begin{array}{ll}\alpha & R a l f s\end{array}\right]$.

d $-\beta$ convergens ibil. $[\beta$ linlfs].

dz SS - Hansy. Prodr. Algenfl. B̈̈hm. p. $20 z$.

nı $\quad-\beta$ intermedius ibil. p. 203.

d 88 - Alexenko Chlolo-p. Tihark. p. 258.

m $8 \mathrm{~S}$ - Boldt Desm. Grünl. p. 30 .

in $-\beta$ ibid. $(\beta$ Rrelfs'.

in - ? ff. depanperatro ibid., t. 2 f. 35.

m 88 - Iste. Jel. magyar. alg. 1. 230).

m 88 - Nordst. Fr. wat, alg. N. Zeal. p. 45.

- $\quad-\beta$ intermedius ibid.

m 89 - v. depressa IInre. Fr. Alg. Maine II p. 195

da Si - Toni Syll. aleg. 1'. 1057.

d - v. divergens ibid.

d - v. convergens ibid.

d $\rightarrow$ v. intermedius ibid.

d $-v$, americanus ibid.

d 89 - f. Brebissonii Tuacil. Now. Desm. p. 96 t. 6 f. 15 ("var." p. 112).

d -f. rotundata ibil., f. 16.

o 89 - f. Nordst. in Wittr, et Nordst. Alg. exs. fase. 20 n:o 970 et fasc. 21 p. 38.

o - f. ibid. n:0 988.

n 90 - f. Joshna'ii Gutw. Walır. ł. Priorität p. 71 (Joslunt 1886 f. 10-12) [tantum quoad f. 11 Josh. sec. Eichl. et Rac. 1893 ; f. 10 et $12=$ f. simplex ibid ].

d $90-\beta$ sinuosa Börg. Desm. Brasil. p. 43 t. 1 f. 10 .

In 90 - Eichler Spis Hesm. Miedz. p. 88 t. 9 f. 26.

11190-Anderss. Sverig. Chlor. 1 p. 13.

m - $\beta$ intermedius ibid.

d $-y$ extensus ibid. et t. 1 f. 7 .

d 91 - f. typica Heimerl Desm. alp. p. 603 t. 5 f. 17 , Ralfs fig. 4 a et $(1)$.

d - f. isthmosa ibil. et t. 5 f. 18 (Iialfs fig. 4 b.) [Ex p. $=$ v. extensus sec. Rorge ill Nuov. Notar. 1593 p. 394].

m 91 - Gutw. Flor. alg. Leopol. p.64.

d - f. Joshure ibid., t. 3 f. 6 .

zf 92 - West Fr. w. Alø. W. Irel. p. 168 t. 21 f. 11 [a di vergens Coolec?.

- $-\mathrm{f}$. ibid.

m 92 - f. Røc. Desmidya Ciastoni. p. 377 t. 2 f. 25 [f. Saida Eichl. et Rac. 1893].

dzf 92 - Wolle Desm. U. S. ed. II p. 101 t. 27 f. $1-10$.

mz 92 - U'est Alg. Engl. Lake Distr. p. 730.

$1193-\mathrm{v}$. triangularis Lagerh. in N. Notaris. IV p. 182. A. triangularis L. 1S88).

m 93 - Lïthcmüll. Desm. Attersees p. 5อัเ

m - v. intermedius ibid.

o 93 - v. vulgaris Eichl. et hic. Nowe gat. zielen. p. 119 ( Ralfs 1818 fig. 1 f. ct $g$ ).

- - f. recta ibid. p. 120 t. 3 f. 22 et 21 (affin. f. 19 .

n $-v$. brasiliensis ibil. p. 120 (A. triangularis f. Bürg. 1590). 


\section{indirel}

11 93 HYALOTHECA Twrer Alg. Tul. orient. 1\% 152.

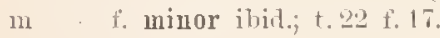

\section{illdicume}

d 13 COSMARIUM Tumer Alg. Ind. orient, p.67 t.9 t. in.

\section{indir.11m}

11 51 DESMIDIUM? Firemt. Mirrogeol. 1. 137.

\section{illdir.11me}

d 65 DOCIDIUM Grun. Ins. Bank. p. 13 t. 2 f. 1 s.

(i) 68 - líub. Flor. Fur. Alg. 3 p. 1.1.

(1) Nordst. Dosil. brasil. 1. 201.

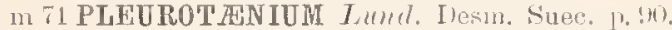

11 7 - Eupleulot:unum forlst. Aly. brasil. p. 17

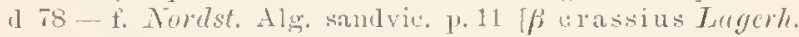
1857 .

d 79 - f. Nordst. in Wittr. ct Nurtst. Alg. exs. 11:0 260.

" so-Nordst. De Aler. et Cliarae. 1 p. 2.

1 - $\beta$ caracasanum ibid. p. 는 4.1 f. 22.

m. 96 - Lagerh. Anerik. Wesm. 1. 2.i1.

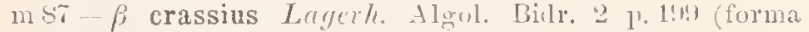
Tordst. 1sisi.

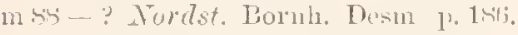

o 88 - $\beta$ саласа土аuиm Nordst. Fr. wat. alg. N. Zeal. 1. 66 .

d s9-Toni syll, als. p sol.

$1-$ v. caracasanum ibil.

u. crassius ibil.

m 90 - Burg. Destn. Brasil. 1. 27

d $93 \mathrm{Doc}$. f. major Thmer Alg. 1ut. orient. 1. 32 t. 1 f.s.

\section{Turlirull}

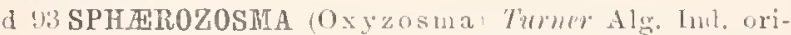
ent. p. $1+1$ t. 18 f. 2 (Nul. oxcavatun var. $\gamma$ Wall. 1860 .

\section{Intiventu}

d 93STAURASTRUM 1.1 f. 11.

\section{illaicllm.}

d 89 XANTHIDIUM Lagerh. Bengal. Desm. p.? t. 1 f. 6.

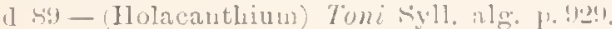

\section{Ludiress}

d 93 ARTIRODESMUS Tumer Algr. 1nu, orient. p. 135 t. 1.2 f. 10.

- f. minor ibid.

\section{imill10111116.}

d :U COSHARIUM Gutw. Wahr. d. l’riorität 11. 70.

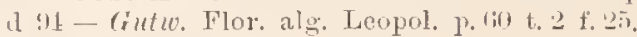

\section{incelitull}

1 93 STAURASTRUM Tumer Alg. Ind, orient. 1). 121 t. 1. f. 27 (St. intricatum $b / p .18 \%$ guoal f. 16 et 21 , ceter. exicl.)

\section{illeptllese.}

d $\%$ XANTHIDIU⿴囗 Twmer Alg. Int. orient. 1. 111 t. 12 f. 21 .

\section{illerence}

d 19 DOCIDIUM Turner Alg. Int, orient. p. 37 t. 7 f. $2 b$.

\section{illevme-is}

a 71 EUASTRUR Lund. Desm. Succ. p. 20 t. 2 f, 3 (b. elegans $\beta$ inerme Rilfs 1S1s.

d $8:$ - v. deprossun Holle in Bull. 'l'orr. bot. Club. v. 10) p. 1S.

1 sit - b. cracovienso Rucil. Desm. okol. Kirakowa 1. 20 t. 1 f. 13 Ent. bilobum Lithemiill. 1593].

1 81 - Wolle Desm. U. S. p. 104 t. 27 f. 31 et $3 t ;$, t. 29 f. 6 et is (formie) [S: cfr Eu, a boense].

1 5.5 - a. Ralfsii Ruc. Nom. Desm. Polon. 1. 42 (sej).1. 36).

$11-b$. Rabenhorstii ibil. (Eu. Rabenlorstii Lelp. 1873 :

1 - c. Lnndellii ibid.

4) - I. cracoviense ibid.

$n$ - e, aboonso ibia. (E. aboense Elfe.).

m sij-Lencrh. Anerik. Desm. p. 233.

o sti-stoles Key Desm. p. 116.

a si-Cooke Prit. Desm. p. 75 t. 35 f. t [o Rialfs 18Is].

18. - ilexentio Chlorosp. Iiliart. p. 212.

o SS - Poteat North Caroliua Desm. p. 4.

d 59 - Tuni Syll, alg. p. 1103.

d - v. eracoviense ibid.

11 - v. depressum ibid.

1) a a poltaviense Alexcula Alg. 1'oltava j. S2.

1191 HELIERELLA fintio Rev, gen. p1, p. S!s.

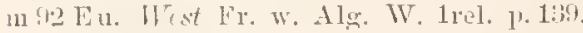

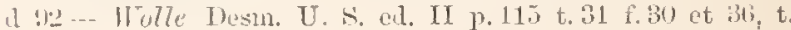
33 f. 6 i - is.

1 9.t Sannd. in Fl. Nebraska p. 12. t. 7 f. 1ii [ex Wolle].

d : 1 -f. hians Eichl. et Gulw. Spec, alg. 110v. p. 172 t. 5 f. 33 . Cfr. Eu. elegans v. danica Jac.

\section{il1?)IIr:}

1 93 STAURASTRUR Tumer Alg. Ind. orient. 12. $1: 31$ t. 17 f. 8. [Ufr Will. Obs. crit, Desnu, 1894, 1, 12! ].

\section{illerellills}

m93 EUASTRUM Tmmer Alg. Ind, orient, p.s6 (Eu, spinulosum *ै inermitus Nordst.) [= Eu. spinul. val. sec. Wildem. in Notarisia 1893 p. 1tis].

\section{infiry 1111 .}

1 193 DVSPHINCTIUM Twner Ale. Ind, orient. 1). 14 t. 1 f. 21. [Crsm. moniliforme f. pandurifors is J/cim. [s.)1 ser. Schmielle 1895]. 


\section{ilifristillil}

a (13 STAURASTRUM Twner Alg. Ind, orint. p. 1?() t. 15 f. 21. [St. lave $f$, (supermumeraria) Norlst. 1st3?]

\section{inflatum-r}

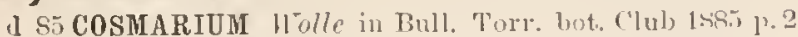
t. 17 f. $18-20$.

d 57 - Walle Fr. Alg. [. S. A. p. 27 t.5i f. 18-20.

d s. Toni s.rll, alg. p. 9. 92.

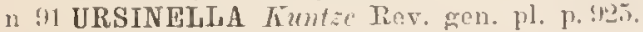

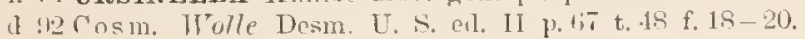

\section{infle.xum}

d in STAURASTRUM Rrit. Liste p.110 t. 1 f. 2.. [Nt, margaritaceum b. Rals. 1s68].

a til Arch. in Pritch. luf. p. 712.

81 Coolie in Quekett Mirr. J. (j) t. 3s.

s:3 - Turner Algan Strensall f. 14.

d so - Coolie Brit. Desm. p. 1fis t. 55 f. 5.

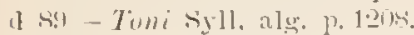

d si-f. Selmidle Beitr. alp. Alg. p. (33 (sep.p. 31) pt. 189i, t. 16 f. 11

\section{innotum}

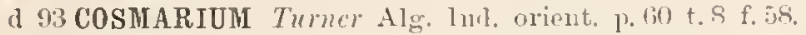

\section{inovinatlum -re}

d So COSMARIUM Josh. Burm. Desm, p. 64s t.21 f. 24 \& 27. [C. psoudamoeum Wille 1891 f. sne. Layer\%. 1887 .

(1 s!) - Toni srll, alo. p. 960.

n 91 URSINELLA Kuntie Rev, gen, p1. p. 12.\%.

\section{inomatum}

d 93 DocidiUM Tuner Alg. Ink. orient. p. 36 t. 1 f. 20.

\section{insingur}

a 93 COSMARIUM schmidle Beitr. Alg. Schwarzwall, p. 10 t. 6 f. 14. [non Turner].

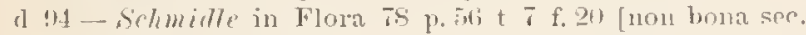
anct.].

\section{insigne}

d 93 COSMARIUM Turner Alg, Ind. orient. P. Ts t. 8 f. 16 i [now Setemille. An Cosm. paradoxum Tum.? spe. liorge in Nnov. Notar. 1845 p. 1833.

\section{insigne}

n 4.5 EUASTRUM Hass. Brit, Alg. ז. 2 p. 21 t. 91 f. 2.

ly.ls - kilfs Prit. Desm. p. 83 t. 13 f. f.

1) $52-13 r \cdot 1$. Inf. p. 219.

0 59- (monstr.) Arch'' Abnorm. Desm, in Dubl. Nat. Hist. Soc, 2 p. 209 t. 1 f. 13; in Nat. IIist. Rer. v. 6 p. 17i) t. 33 , in Q. J. M. s.c. p. 5 .

(1) $61-1 \mathrm{rch}$. in Pritch. Inf. p. 72 !) t. 3 f. 12 [e Ralfs].

d 1;:3-Rab. Krypt. Fl, Sachs, p. 18.s.

m67 DIDYMIDIUM Enastrum) lieinsch Algent. Fran. p. 130.

1 hS En. Ral,. Flor. Eur. Alg. 3 p. 181.

d - b. intermediam ibid. (F. interm. (7er

1) 73 - Wond:Fr. Alg. p. 189

(1) T- Kirchm. Alg. Sohles. p. 1:S.

d $81-$ Wolle Desm. U. S. p. 102 t. 27 f. 39-13 [? E. orientalo sec. Turner?.

d 8.5 - f. a. simplex Rac. Nomm, Desm. Polon. 1. (12 t. 1:3 f. 2 sep.p. 36 t. 4) (pag. 99: "var").

d - f. typicam ibid.

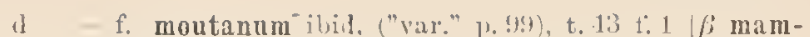
millosnm T31\%" 18:13\}.

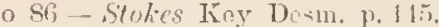

it si) - Coolie Brit. D.:sm. p. (19) t. 33 f. 1

d $5 \bar{t}-\mathrm{r}$. mastoidea $\mathrm{N}(\mathrm{r}$. Diagn, praer, in Totar. p. 20.; (sep.p.li et J'st: .Jel. magyar. alg. p. 222 t. 1 f.

d s9-Kansy. Prodr. Algenf. Bühm. p. 20r.

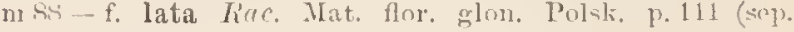
p. 32!

1) 89 - Toni syll. alm. p. 1052.

d - f. simplex ibill.

1) - f. montanum ibid.

d - v, mastoidenm ilhil]. p. 10!3,

m.90-Evichler spis 1)osm. Mierlz. p. s. t.9 f. 30

(t) $10-\mathrm{r}$. brevicollum Anderss, Sverig. ('hlor. 1 p. 10 t, 1 f. 3.

o 91 v. ? Ileimer 1)esm, alpin, p.601 t.j f. 15.

m 91 HeLIERELLA hutze linv. gen. pl. p. 898.

1 th Eu. $11 \%$ lle Desm. IJ. s. el. II p. $11: 3$ t. 31 f. $39-13$.

d 33 - v. elegans Schmiale Beitr. Alg. Sehwarzwaler. r. 105 t.fif. 7 et 8 .

o 13 P mammillosum Turner Alg. Incl. nrient. p. i!) : E. mammill. Wrille $1 s^{2} 13$.

m! 15 - Borge Sverig. Chlor. II p. 21 t. 1 f. 11.

Cfr. Zopf in Nov. act. v. 52. 188s, t. 19 f. 15-16.

\section{insigne}

d 7 STAURASTRUM Luml. Desm. Suec. p. 58 t. 3 f. 25.

msio-f. Nordst. Desm. Grünl. 1) 10.

m. S. - Boldt Desm. Griml. 1. 33.

$1188-I s t e$. Tel, magyar alg. p. 231.

I) 89 - Tomi Syll. alg. p. 1157.

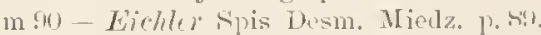

m 11 - Heimerl Desm. alpin. p.tint t. is f.21.

m 93 - Eichler Mat. for. Mied\%. 1) 161 t. 10 f. Bs.

m !4 - Borge Süssw. Chlnr. Archang. p. 3t.

d 91 -. f. Groenlandica Böry. F. alg. Oetgrionl. p. 25 t. 2 f. 24.

m 96 - Schmille Bcitr. Al 1 , Alg: p.fil.

\section{insulare}

n 83 EUASTRUM Roy in Sontt. Naturalist July 1 Rss (E) binale $\beta$ insulnu Thill). 18riz

o 84 - Wulle Desm. U. S. 1) 101.

n sfi-btolies kiey Desm. 1. 14 li.

o $! 2$ - Wolle Desm. U. ‥ ed. II p. 115.

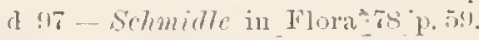

\section{integervimum -}

1) 3i EUASTRUM Emrnt. Inf. p. 1933 t. 12 f. $1 \mathrm{X}$. Cosm. Cucumis Corle et ?olpolelta viridis (orda).

n B STREPHOCYSTIS (woda in Alm, d. Carlsl, 153! 1. 212.

(1 4) En. Küt:-. Phyenl. germ. p. 136.

if 47 - Rab. Dent. limpt. Fl. p.5t.

(1) 490 CMARIUM!Kiil . Spec. Alg. p. 171 (incl. En, ansatum Ehreub. Verbr. Mikr. Leb., nou Tnfus.)

11 49? Eu. (Cosmarium) Ney. eiuz. Alg. p. 11 t t. T f. A. 1

I1 51 -- Rab. lineillar. Sachs, fase, 1 11:0 10 [Cosm. psendopsramidatum?] et fasc, 5 t. 3 n:n 10

"7 1 Cosm. Lmm. Desm. Suec. p. 50.

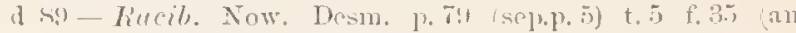
Neg. 1sin? non Filhenb. 1si3s; an Cosm. Clepsydra llelp.?; an nov. sp.?

man- Lichl, in 1'umiet. Fizy, 1:? pos.

\section{introrere}

d $: 3$ MICRASTERIAS tionelst. in $\|$ ittr. \& Tordst. Alg 
exs. 551 f. xylogr. a, b, c; et (1889) in fasc. 21 1. $3 \%$.

(1 89 - Toni Syll. alg. p. 1112.

n 11 HELIERELLA Kuntze Rer. gen. pl. p. 898

\section{Intry)}

d 7 S Kirchn. Alg. Schles. p. 134. sset. B. 1. Desmidiearum. Gen.: Mesoten., Pen., Spiroten., Clost.

1 89 IIansy. F'rodr. Algenf. Bölın. p. 172. 'Tribus sub. fam. Didymiacear. Gen. vt supra.

\section{interrmm}

d S6COSMARIUP Stokes Fiey Tresm. p.127. Ante Finteglum" est "IIolmiense $\beta$ " omissum.

\section{integrum}

o 57 झUASTRUH Wolle Fr. Alg. T. S. A. p.36 t. 27 f. $18-22$. (Eu. simplex Wolle majo 1884 , non Gay febr. 1884).

d 92 - Wolle Desm. U. s. ed. II 11. 117 t. 31 f. $18-22$.

\section{illevmerlinu-re}

1 48 CLOSTERIUM Ralfs Brit. Lism. p. 171 t. 29 f. 3.

(1) $52-$ Priteh. Inf. p. 282 .

(1) $61-A v c h$. in Pritel. Inf. p. 74\%

d $63-$ - Rab. Irrypt. Fl. Sachs. p. 172

d - b. regulare ibid. 1\%173 (Cl. regulare Brib.).

m 67 - Reinseh. Algenfl. Frank. 1'. 192.

z 71 - Lund. Desm. Suec. p. 7 .

d $75-1 l i c r o g 1$. Diet. p. 176.

m $7 T$ - Petit Desm. de Paris p. 1 (sep.p. 2S).

d 79 - a. typicnm lilebs Desn. Ostpreuss. p. 16 t. 2 f. 15 -16 [f. $16=$ v. Hibernicum West 1894].

d - b. directum ibid., t. 2 f. 17 (Cl. directum Areh.).

d - c. juncidum ibid., t. 2 f. 5 b (Cl. jumeidun Ralf $*$ ).

ph 81 - Sehareselim. in Magy. Xivv. Lap. p. 3.

m 85 - Boldt Sibir. Cliloroph. 1) 122.

di̊ 86 - Cooke Brit. Desn. p. 29 t. 11 f. 2, t. 15 f. 6 .

dzs: - Toni sill. Alg. p. 834 .

n 891 - a. v. rectostriatum Racib. Now. Desm. 1. 75 (Rulfs 1818).

(1) - b. v. sculptun ibil., t. 7 f. 19.

1 - c. v. spirostriolatum ibi.l., t. 7 f. 20.

m 40 - Eiehler Spis Desm. Miedz. p. S5.

0.90 -- Anderss. Sverig. ClıIor. 1 p. 18.

11 ARTHRODIA Kuntze R०v. gen. pl. p. 893.

m!1 Clost. Gutw. Flor. alg. Lenpol. 1. 3t.

m 92 - West in Notaris. p. 1499.

o 93 - v. sculptum f. eboracen:o Turner Desm. Notes p. 346 , et f. 17 p. 31 .

d s.1 v. Hibernicum West New Brit. Als. p.3 t. 1 f. 2.

z 94 - Roy Scottish Desm. p 24 (sep.p. 5:3).

m91 - Rorges. F. alg. Östgrönl. p, 10.

Cfr. Clost. striolatum r; Cl. Ulna.

\section{intermerlium -}

1. 7 COSMARIUM Delponte Desmid. subalp. 1.25 (sep.]. 121) t. 8 f. 7 - 10.

(1) 81 - Wolle Desm. U. S. p. 75 t. 13 f. 12.

o sf - Stules Key Desm. p. 128.

a Sit - Tomi Syll, alg. p.9.0ri.

1191 URSINELLA Kuntze Rev. gen. p]. p. 925.

1) 92 Cosm. Wolle Desm. U. S. er. II p. 83 t. 16 f. 12.

m 1:3 - f. minor Sehmidle Beitr. Algo. Selewarzwald. p. 101 t. 5 f. $t$.

\section{intermedimm - r}

a G1 EUASTRUM Cleve Bidr. t. Nverg. Desm, p. 184 t. 4 f. 1. [En. insigne 6 . I 4 ul. 18:8].
0 $70-$ Nordst. Desm. Brasil. p. 217.

- 71 - Lund. Desm. Snec. p. 21 t. 2 f.t.

d St - Wolle Desm. U. S. p. 102 t. 29 f. $1-2$.

d - v. cuspidatum ibid. p. 103 t. 29 f. $3-5$ [ $\alpha$ et $\beta=$ E. Wolloi Lagerh. 1886].

n 86 HoLOCYSTIS Benn. Fr.-wat. Alg. Engl. Lake Distr. 1 p. 8.

o 86 Lu. Stokes Key Desm. p.145 sensn Wolle.

d $89-$ Tomi Syll. alo. p. 1093.

1291 HELIERELLA Kuntze Rev. gen. pl. p. S.s.

m 9อ̃ Eu. Eiehler in Pamiet. Fizy. 13 p.61.

\section{intermedium}

d 73 EUASTRUM Delponte Desmid. subalp. p.97 (sep.p. 85) t. 6 f. $21-23$; non Cleve, nee Gay [L. Delpontei Lagerh. 1886].

d - v. Ralfsii ibid. p. 98 (sep.p. 86 ) t. 6 f. $24-25$.

\section{intermerlium}

(1) 84 EUATRUM (Cosmarium) Guy Mon. loe. Conj. p. 63 t. 2 f. 4, non Cleve. [E. transiens Guy Not. Conj. - Cosm. franconicum Gutzo. 1S90].

\section{internedium}

d 49 STAUROCERAS Kïtz. Spec, Alg. p. 166 [Cl. Kuetziagii Bréb. 1850].

\section{imtermerliume}

(I) XANTHIDIUH Musk. Furth. Not. N. Z, Desm. p. 20 t. 1 f. 33 .

\section{ilter)mutulu}

(1) 18 PENIUM Bréb. in Ralfs Brit. Desm. p. 151 t. $25 \mathrm{f.} 4$. d $52-P$ Priteh. Inf. p. 273.

ph 58 - De Rur. Conjug. p. $42-41,46,73$ t. is f. $1-4$.

d 61 - Arch, in Pritch. Inf. p. 651 t. 3 f. 45 [e Ralfs]

d $63-$ Rab. Kry lt Fl. Sinels. p. 10s.

mor CLOSTERIUM (Netrium) Reinseh Algenfl. Frank. p. 185.

d 68 Pen. Kub. Fl. Eur. Alg. 3 p. 114.

in 70 - Reinharel in Arbeiten Naturf.-g. Clarkow I p.14.

d 73 - Wood. Fr. Alg. p. 108.

d 77 - Delponte Desmid. subalp. 1. 79 (sep.l. 175) t. 15 f. 1 -9.

d $78-K$ irehn. Sehles. Alg. p. 135.

d St - Holle Desm. U. S. p. 35 t. 5 f. $14-15$.

m 84-Artari Liste alg. Moseou p. 138.

o 86 - Stokes liey Desm. p. 111.

d S6 - Cooke Brit. Desm. p.41 t.16 f. 2 [e De Bary 1s58].

d 8 i - Alexenko Chloroph. Kharkow p. 231.

d 88 - Mansg. Prodr. Algenfl. Böhm. p. 176.

d 58 - Riabin. Chlorosp, env. Kiharlow. p. 315 (sep.p. 26), ph 88 - Hantfl. Zellm. u. Ḧ̈llgallerte Desm. p. 101 (sep. p. 433 t. 3 f. 61.

m 88 - Istc. Jel. magyar. alg. p. 210.

d 89 - Toni syll. Alg. 1. 860 .

m:0-- Eichter Spis Desm. Miedz. p. 85.

m 91 - Heimert Desm. alpin. p. 590.

m :1 - Gutw. Flor. alg. Leopol, p. 31.

d 92 - Wolle Desm. U. S. ed. II p. 36 t. 5 f. 14-15.

m 42 - Gutw. Flor. glon. Galie. 3 p. 122.

d ! … v. sectum W'st Fr. W. Alg. W. Irel. p.127.

m 93 - Lüthemïll. Desm. Attersees p. 544.

m 93 - Sehmidle Beitr. Alg. Sehwarzwald. p. 88.

o 95 - Eichler in Pamiet. Fizy. 13 p.57. Cfr. Penium Digitus anet. nonnull. 


\section{interstitiale}

1] 15 EUASTRUM Kïtz. Phycol, germ. ]. 136 [Cosm. Botrytis sec. Kütz. in Rulfs Brit. Desm. P. XIX; C. Botrytis $\beta$ interstitinle Kütz. Spec. Alg. P. 175].

\section{intricatum}

(1) TSTAURASTRUM Delponte Desmid. subalp. p. 43 (sep. p. 133) t. 11 f. $10-21$. [figg. $10,1-1,1$ t et $20=s t$. Hantzschii Reinsch 180i ; figs. 16 et $21=$ St. iueditum Tun. 1S93; ex p. = St. Reuardii ? sec. Rac. 185.1].

m 83- Roldt Sibir. Chloroph. 1) 120.

d $10-\beta$ depauperatum Gutu. Wahr. d. Priorität p. 72 [St. I antzschii $\beta$ 1891].

m 10 - v. miuns Hansy. Nene Süss. n. Meeres-Alg. p.13,

d $y_{2}-H_{a}(n \times y$. Prodr. Algenf. Bölm. ed. bohem. II p. 176; el. germ. II p. 258.

m $\quad-\beta$ minus ibid.; ibid. p. 259.

m96-f. Schmidle Beitr. alp. Alg. p. 25 et (1S95) t. 16 f. 26 .

\section{innolutum}

n 93 STAURASTRUM Turner Desm. Totes p. 347 (St. curvatum Turn. 1842, non Tiest 1592).

\section{intrume}

d st STAURASTRUM Wolle in Bull. Torr. bot. Club 1881 p. 13 t. 41 f. 5 - 7 .

d 81 - Wolle Desm. U. S. p. 137 t. 51 f. $5-7$.

o S6-Stakes Key Desm. p. 166.

I $89-T o m i$ Syll. alg. p. 1117 .

o $: 0$ - Wret Fr. W. Alg. North Wales p. 296 t. 5 f. $9[\beta$ g l $l$ brum].

n $42-\beta$ glabrom Lagerh. in $\mathrm{X}$. Notar. II p.30 (West 1890 .

(1) 92 - Wolle Desm. U. S. ed. II p. 150 t. 62 f. $5-7$.

m 93 - 7urner Alg. Inl, orient. p. 132 t. 22 f. 12.

m 95 - Eichler in Pamiet. Fizy. 13 1. 62.

\section{irregulare}

a 7 COSMARIUM Tolle in Bnll. Torr. bot. Club v. $6157 \%$ p. 186. [C. Quasillas Lmol. 1 isi sec. Wollo in Desin. U. S. p. 8i).

81 - Wolle ibid. v. 8 t. 6 f. 6.

\section{irregulare}

d 93 D0CIDIUM Turner Algre Ind. orient. 10.33 t. 4 f. 9.

\section{irregulare}

a 89 EUASTRUM Mask. Furth. Fot. N. Z. Desm. 1. 14 t. 2 f. 14.

\section{irregulare}

d g4 STAURASTRUM West New Brit. Aler. 13.12 t.2 f. $49-50$.

m 91-Jolns. Rare Desm. U. S. p. $25 S$ t. 211 f. 10.

\section{Isidis}

d 79 CLOSTERIUM Cohn Desm. Bong. p.26.4 (sep.p.6) t. 11 f. 15

d. 89 - Toni Syll. Alg. r. 834.

n 91 ARTHRODIA liuntze Rev, gen. pl. p. 883 .

\section{ISTHMIA}

d 40 Menegh. Synops. Desm. p.205 (sep.p. 5) [ex parte $=$ Sphrrozosma], nou Agardle.

\section{isthmilm}

o 90 COSMARIUM West Fr. w. Alg. N. Wales p. $290 \mathrm{t} .5$ f. 19 C. excavatum v. duplo major Wolle 1894) [C. orbiculatum see. Pennett 1. c. p. 306. sed non ita sec. Wist 18.2; C. Portianum f.? sec. Schmidle 1891].

d 92 - f. hiberuica West Fr. Wr. Alg. W. Irel. p.159 t. 21 f. 15.

- - v. Willei ibid. p. 160 (C. exc. v. ellipticam Tille 1879 .

\section{isthmochondrum -}

d 73 COSMARIUM Nordst. Norg. Desm. p. 12 t. 1 f. 2 (Septembr.) [? (․ suborbiculare Wood Jan. 1873. Cosm. binodulum Reinsch 1875].

m 80 - Wille Nore. Fershv. alg. I p. 27.

o 81 - Arcle. in Ann. Mag. Nat. Hist. 5 ser. v. 7 p. 339

d 83 - f. Nordst. in Wittr. et Nordst. Alg. exs. n:o 561; et in fasc. 21 (1889) p. 41.

m 85 - Boldt Sibir. Chloroph. p. 106 .

d 8 - Cooke Brit. Desm. p. 114 t. 11 f. 9 [e Nordst.].

d 89 - Toni Syll. alg. p. 1015.

n. 91 URSINELLA Kuntzc Rev. gen. pl. p. 925.

d $93 \mathrm{Cosm}$. ? $\beta$ achondrum Turner Alg. Ind. orient. p. 53 t. 8 f. 10.

d 95 - - . biseriatum West Alg. Madag. p. 63 t. 7 f. 14.

\section{ISTHUOSTLA}

d 45 Kütz. Phyeol. germ. p. 140.

d 49 Kïtz. spec. Alg. p. 188.

o 58 Grun. Desm. p. 493.

d 88 Hansg. Prodr. Algenfl. Bühm. p. 170. Sect. Sphærozosm.

d 89 Tomi S5ll. alg. p. 789 . Sect. sphærozosm.

\section{It:igsohmii}

d 59 MICRASTERIAS Bram ajud Brebl. Liste p. 121 t. 1 f. 2.

- $62-B u l n h$. in Hedw. p. 57 t. 10, I f. 5 (status erolut. II. piunatifida).

m 84 - Racib. Desm. okol. Trrakowa p. sep.p. 22 t. 1 f. 14 [II. truncata snbsp. denticulata [st $\%$. 1887]. Cfr. Micr. decomdentata fir. et II. Neodamensis.

\section{Jacobsenii}

n 81 COSMARIUM Roy in Tiss. Desm. Winderm. p. 194 (sep.p. 3) (C. mouiliforme Jrcals. 1S70) [Cfr. C. monilif. f. Nordst. 18i3].

d 57 - Coolie Brit. Desm. p. 120 t. 43 f. 3 [e Jacobs. 187i]

o 88 - Nordst. Bormh. Desm. 1. 200.

o 93 - Nordst. apud Wittrock et Nordst. Alg. exs. n:o 1120 et 1125 .

ก 94 - Roy Scottish Desm. p. 16 s (sep.p. 39).

\section{juculiferum}

d 92 STAURASTRUM West Fr. $\pi$. Alg. W. Irel. 1. $172 \mathrm{t}$ 22 f. 14.

m 95 - Rucil. in Florn v. 81 p. 31.

\section{Jrmejora}

a S5 MICRASTERIAS Iiacil. Nonn. Desm. Polon. p. 47 t. 14 f. 4 (sep.1. 41 t. 5) [Annon M. Crux Melitensis $f$. ?].

d 89 - Toni syll. alg. p.111s.

n 91 HELIERELLA Kuntac Rev. gen. pl. p. 898.

\section{Japonirum -re}

d 70 CLOSTFriUM Sumg. Alg. Japon. p. 1 t. 2 f. 31. 
o 89 - Toni Syll. aldr. p. 835.

n 91 ARTHR0DIA Kuntze Rev. gen. pl. p.883.

\section{Jr) momicum}

d 93 STAURASTRUM Tumer Alg. 1md. orient. p. 121 t. 16 f. 21 (St. Hantzschii v. Japonicum Roy et Riss. 1856).

\section{javermirmm-a}

d sn COSMARIUM Nordst. De Alg. et Charac. p. 7 t. 1 f. 10. d 89 PLEUR0T他IOPSIS (Cosmaridium)? Toni Syll. alg. p. 912.

m $91-$ Mob. Austral. Suiscwasseralg. II p. 339.

o 95-Mobius apud Bailey Contrib. Queensl. Fl. XI p. 39 t. 10 f. 9.

\section{jenisejense -is}

d Sa COSMARIUM Boldt Sibir. Chloroplu. p. 107 t. 5 f. 13. d s. - Toni Syll, alg. 1) 1049.

n !I URSINELLA huntze Rev. gen. pl. p.924.

m 93 Cosm. f. Tuner Alg. Ind. oriont. p. 56 t. 8 f. 2. .

d $94-\mathrm{v}$. rectangulum Grete. Fl. alg. Tarnajol. p.101 t. 3 f. 3 S.

Cfr. Cosm. Gangense, punctulatum v. depressum, quadrans.

\section{Jemeri}

d 45 CLOSTERIUM Rulfs Brit. Desm. p. 167 t. 29 f. 6 (cl. moniliferum $E \% \cdot b$. Inf. t. 5 f. 16 , quoad n. 6, 7).

1 52 - Pritch. Inf. p. 281.

d 61 - Areh. in Pritch. Inf. p. Tits.

d $63-R a b$. Kineyt. F]. Sachs. 1. 170.

d $68-R a b$. Flor. Eur. Alg. 3 p. 134.

d 73 - Wood Fr. Alg. p. 115.

d 5 - Microgr. Diet. p. 176.

d 77 -Delponte Desmid. subalp. p.100 (sep.p. 196) t. 16 f. $52-53$.

d 78 - Kirchn. Alg. Schles. p. 140.

m 79 - Wr7le Ferskt. alg. Nov. Femlj. p. 60 t. 11 f. 83.

m 81 - Guy Mon, loc. Conj. P. T.t.

d 84 - Wolle Desm. U. S. p. 41 t. 7 f. 5.

o 8R - Stokes Kiey Desm. 1]. 113.

d Sf, - Cooke Brit. Desm. p. 24 t. 13 f. 4.

d 87 - Alexenko Chlorosp. Khark. p.228.

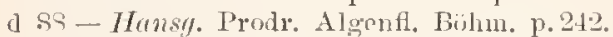

n. Ss - Riabin. Chloropll. env. Kharkow p. 317 (sep.]. $29 \%$

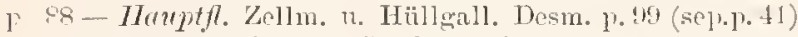
t. 3 f. 35 (inclus. Cl. Archerianum b. compressum et c. Cynthia in Klebs).

m SS - Lewin Span. Süssw,-alg. 1) 10.

d S.) - Toni Syll. Alg. p. $\$ 13$.

m 90 - Böry. Desm. Brasil. p. 30 t. 2 f. f.

m90-Andross. Sverig. Chlor. 1 p. 18.

m 91 - Heimerl Desm. alpin. p. 54!3.

$n$ II ARTHRODIA Kuntze Rev. gon. H. p. 883.

$\mathrm{m} ! 12 \mathrm{Cl}$ ost. West Fr, w. Alg. W. Irrl, p. 122.

m $512-R a c$. Desmidya Ciastoni. p. 390 .

d 52 - Wolle Desm. U. S. ed. 11 p. 47 t.s f.5.

ozf 01 - Burrges. Ostgrionl. E. alg. p.11 t. 1 f.2.

d 91 - Sruml. in FI. Nebraska p.38 t.6 f. 10 [e Cooke].

mo1-Alexenko Mater, alg. Khark. p. 21 .

C.fr. Clost. Dianæ, Lunula et spirale.

\section{elrmemi}

d b1 EUASTRUM Arek, in Pritcl. Inf. p. 73) (En. circulare " Rulfs; E. circe $v$ Ralfsii Treb. 18ati!) [Dirlymil. varians]. d 73 - Wuor Fr. Alg. 1) 130 .

d 86 - Cookic Brit. Desin. p. 72 t. 34 f. 4.

\section{Jenmeri}

d 45 MICRASTERIAS Rulfs Brit. Desm. 1.76 ( $\alpha$ et $\beta$ ) t. 11 f. 1.

d $52-$ Pritch. Inf. p. 216.

d 54 -- v. $y$ Areh. Abnorm. Desm. in Dubl. N. H. Soc. Pr. 2 1. 209 t. 1 f. $y$; in Nat. Hist. Rev. 6 1). 470 t. 33 ; in J. Hicr. Sc. 8 p. 86 .

o 61 - f. Bulmh. in 1 ledw, p. 52 t. 9 f. 13.

d $61-A r e l$. in Pritch. Inf. p. 727 (et $\beta \& \gamma^{\prime}$ ).

d $0.8-R a b$. Krypt. Fs. Sachs. p. 153.

d 68 - Rab. Flor. Eur. Alg. 3 p. 194.

d - b. angulosa ibid. (M. angulosa Hantzsch).

d $\rightarrow c$. ibid.

o 71 - f. Lund. Desm. Suec. p. 11 et 97 t. 1 f. 1.

o 73 - Nordst. Norg. Desm. p. 5.

d 73 - Woor Fr. Alg. p. 146 t. 13 f. 7.

d S4 - Wolle Desm. U. s. p. 115 t. 33 f. 1-2.

o 84 - Schroter X. Beitr. Alg. Schles. 1) 18 i (forma).

o 86 - Stolice liey Desm. 1) 14 f.

d 86 - Cooke Brit. Desm. p. 62 t. 29 f. 3 [snltem fig. $c e$ $R u l f s]$; et $\beta$ et $\%$

o 87 - $\beta$ subdenticulata Nordst. Algolog. smi̊sak. + p. 155.

d 85 - Jansg. Prodr. Algenf. Böhin. p. 209.

d - $\beta$ angulosa ibja.

m 88-Nordst. in Gazell. Exped. p. 4.

d $89-\beta$ sublentieulata Nordst. Fr. wat. alg. N. Zeal. 1. 30 t. 2 f. 15.

d 89 - Toni syll. alg. 1. 1125.

o (x) - v. simplex West Fr. W. Alg. North Wales p. 2st t. 6 f. 34 [efr. Lregerh. in N. Notar. 11 p. 27].

d] $90-$ f. Brasiliensis Rörg. Desm. Brasil. 1).32 t. 3 f. 13 [v. simplex Hest sec. Hest 18!1?].

n 91 HELIERELLA Kuntze Rev, ren. pl. p. Ris.

m $9 \mathrm{M} \mathrm{icr}$. West $\mathrm{Fr}$. W. $\mathrm{Alg}$. W. Irel. p. 135.

m-v, simplex ibir.

1) 92 - Holle Desm. U. S. ed. II p. 127 t. 37 f. 1 -2.

m. St) Scliroder $\mathrm{Alg}$. II. Riesengob. p. 21.

\section{Jemeri}

def 4s PENIUM Rulfs Brit. Desm. 1. 1.39 t. 33 f. 2. [Cyl. Brebissonii $\beta$ Hansg. 1889].

1. 52 - Pritr\%. lnf. 1). 273.

af 5i-Berlicl. Introrl. Crypt. Bot. p. 120 f. 31 (e liulfs;).

(1) $13: 3-R+b$. Krypt. Fl. Sachs. 1. 11i!.

dztis - hulb. Fl. Eur. Alg. 3 p. 120.

m 72 -. Wittr. Gotl. Öl. soitv. Alg. ]. (ii.

dz 73 - Wood Fr. Alg. 1. 108 .

m 78 - Hempel Algenfl. Cliemnitz 1. 111.

m 81 - Gray Mon. loc. Conj. p. fo.

1281 - Wulle Desm. U. S. p.36.

o 86 - Stokes Kiey Desm. p. 111.

1 8 - Riabin. Chloroph. env. liharkom. p.314 (sep.p. 26).

oz 89 - Rircib. Now. Desm. 13. T.

$\mathrm{dz} ! 2 \rightarrow$ Wolle Desm. U. S. ed. II p.37.

\section{Jemmeri.}

n tis STAURASTRUM linlfs in Jemer Fl. 'Tumbr. Wells 1. 191 (1. 1.97).

1] 45 - Tiulfs in Ann. Nat. I Tist. v. 15 p. $1.5 \mathrm{~s}$ t. 11 f. 8 (et $1841 ;$ in Trans. Bot. Soc. Edinb. v. 2 p. 114 t. 14 [St. sexcostatum Brietl.].

(] 45 GONIOCYSTIS (Pontasterias) IIrss. Brit. Alg. l\% 33i; t. Sis f.1; [e Rulfs 1. c. delineate, ut videtur, sed fig. " non exacte].

n 1! PHYCASTRUM (Stenactinin m) Nrg. einz. Alg. p.128. 


\section{Joshmre}

m 93 COSMARIUM Turner A]g. Ind. orient. 1).72 (C. Botrytis v. Indicum Jash. IRsilo.

\section{Joshurule}

n 91 HELIERELIA Kuntze Rev. gen. pl. p.898 (Eu. truncatum Josh., non H. truncata (Curdu) (JK).

\section{Joris}

11 12 EUASTRUM Cuntor et Gront in Ann. Mag. Nat. IFist. v. p. 193.

\section{jumillm-}

daf 18 CI,OSTERIUM Ralfs Brit. Desm. p. 172 t. 29 t. 1 .

ozt $-\beta$ ibid.; f. T.

d 32 - I'itch. Inf. p. 282.

o 56 - Bril. List. p. 153.

d $61-A \% c h$. in P'riteh. Inf. p. T.t?; $a$ et $\beta$.

o 61 - Muntasch in Rab. Alg. no 1113.

d 63 - Kiub. Krypt. Fl. Saclss. p. 173 (a et b).

d 67 - Reinsch Algenfl. Frank. p. 193, form. A et B.

o 67 - Not. Desm. Ital. p. 64 t. 7 f. 6i?.

d 1;5 - Rub. Flor. Eur. Alg. 3 p. 127.

o - b. f. brevior ibid.

o - c. (f. gracillima luvissima) ibil. (Cl. gracile liréb.?).

d $73-W^{+}$ood Fr. Alg. 1. 110 t, 12 f. 20.

III $\mathrm{it}$ - Richter in Rab. Alg. 11:0 2.101.

d 75 - Mierogr. Dict. p. 176.

d 77 -Delponte Desm. subalp. p. 115 (sejep.211) t. $17 \mathrm{f}$. $11-11$.

dz 78 - Kirchn. Alg. Sehles. p. 137.

m su - Wille Norg. Ferskv. alg. I p.55 ( $\beta$ Rulfs).

m 81 - Elfo. Finsk. Desm. p. 15.

ph 83 - F'ischer Gypskiyst. Desm. 1. 151 t.9 f.s.

def 81 - Wrolle Desm. U. S. p. 39 t. 6 f. $2-3$.

d 85 - Kirchn. Mikr. Ptanz. d. Sü̈ssw. p. 21.

m St - Lagerh. Amerik. Desm. p. 251.

o 86 -- Stokes Key Desm. p. 112.

dzf S: - Cooke Brit. Desm. p. 30 t. 13 f. 7 [e Rulfs].

d $8 \mathrm{i}$-f. gracillima-laevissima Wolle Fr. Alg. U. S. A. P. 23 t. 55 f. 21 (form. c. Kal. 18138).

d 8 T-Alexenlo Chlorosp. Fhark. p. 224.

dz 88 - II unsy. Prodr. Algenf. Böhum. p. 178.

m ss -- Riabin. Chloroph. env. Kliarkow p.315 (sep.p. 27).

nu 84 - Ist $c$. Jel. magyar. alg. p. 238.

dz $89-$ Toni siyll. Alg. p. 820.

n 90 - $\beta$ brevior Roy in Journ. of Bot. 1. 33t) (b. Rul. 1Slis).

1110 - Eichler Spis Desm. Miedz. p. S5.

d 91 - Kirchn. Milix. Pflanz. d. Silssw. 1. 21.

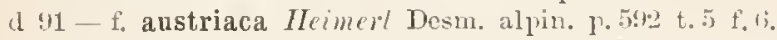

n 91 ARTHRODIA Kuntze Rev. gen. pl. p. 843.

mog Clost. t. brevior Borge Chloroph. Norsk. Finmarli. p. 11.

un 92 - Mol. Austral. Süsswasseralg. p. 110.

dzf 32 - Wolle Desm. U. S. el. II p. 39 t. 7 f. $2-3$.

d - f, gracillima-levissima ibid., t. 6 f. 21 .

In 92 - Gutu. Flor. glon, Galic, 3 p. 120.

dzf 93 - Builey Contr: Queensl. Fl. p. 10 t. 12 f. 31 (c ('oule).

11 $43-v$, gracile Weiss in Bayer. bot. Ges. 1.13 (Cl. gracile).

m 93 -- v. $\beta$ Lütkemiill. Desm. Attersees r. ̈̌l1.

d $93-$ Twiner Alg. Ind. orient. p. 21.

oz $11-R o y$ Scott. Desn. p. 245 (sep.p. 53i, a et $\beta$.

d $-y$ elongatum ibil.

in 91 - Börges. F. alg. Östgrönl. 1. 10.

\section{Jmmlaillii}

d 89 COSMARIUM lincil. Desm. Lituan. p.660 (sep.p.4). a 89 - Toni Syll. alg. 1.1036.

oz 89 - Racil. Now. Desin. p. 82 t. 5 t. 37.

n $y 1$ URSINELLA hinntze Rev. gen. pl. p. 925 .

d 94 Cosm. v. podlachicum Eichl. et Gutw. Spec. alg. nov. p. 167 t. 4 f. 17.

\section{Krenitwii}

d 83 COSMARIUM schureschm. Magyar. Desm. p. 265 t. $1 \mathrm{f.} 6$.

d 89 - Toni Syll. nlg. 1) 1011.

191 URSINELLA himize Rev. gen. pl. p. 925.

\section{Kremitaii}

d 83 STAURASTRUM Schuarschm. Magyar. Desm. p.273 t. 1 f. 16.

d 89 - Toni syll. alg. p. 1168.

\section{Kirlyei}

d 65 D0CIDIUM Arch. New Docid. (sep.p. 35 ) in Dubl. Nat. H. Soc. Pr. 1,81 t. 2 t. 2; Q. Journ. Mier. Sce. $\mathrm{P}$. 296 t. 7 f. 2.

d 65 - Rub. Flor. Eur. Alg. 3 p. 115.

n PLEUROT FNIUM ibid. p. 439.

o $71-$ Lund. Desm. Suec. 1?. 6.

d $8 S$ - f. Layc\%. Bengal. Desm. p. 10 t. 1 f. 8 [Forma? Lagerleinit a Toni in Notarisia 1888 p. 603 nominatur].

d 89 - Toni Syll. aly. p. 943.

- f. ? Lagerheimii ibid. 1.904.

\section{Kerguclense}

d 70 STAURASTRUM Reinsch in Journ. Linn. Soc. v. 15 1. $21 \pm$.

d 78 - Reinsch Freshw. Alg. Kerguel, p. 82 (sep.p. 18).

d 89 - Toni Syll. alg. p. $12 \$ 1$.

\section{Khorice}

d 93 MICRASTERIAS Tumer Alg. Ind. orient. p.97 t. 23 f. 2.

\section{Khrsirmum.}

a 93 CLOSTERIUM Tumer Alg. Ind. orient. p. 23.

\section{Kinahani}

d as LePTOCYSTINeMA Areh. Suppl. Cat. in Nat. Hist. Kev. v. 5 1. 213 et 250 t. 21 f. $1-1$; in Proc. Uubl. Univ. Zool. Bot. Assuc. v. 1 1) 105, 114 t. 11 f. 1-4; in J. Mier. Se. v. 7 p. 131.

d 61 - Arch. in Iritch. Inf. 1. 222 t. 3 f. 1 (ex Arch. Suppl. Cat.).

d 65 GONATOZYGON Rab. Flor. Eur. Alg. 3 p. 150.

d s6-Cooke Brit. Desm. 1. 3 t. 1 f. 3 [ex Archer?].

d 84 - Toni syll. aly. p. 802 .

m 91 - West Add. Freshw. Alg. W. Tork. p. 214.

m 92 - We'st Fr. w. Alg. W. Irel. p. 114.

o $94-$ Roy Seott. Desin. p. 250.

m 15 - Eichler in Pamiet. Fizy. 13 p. 57.

\section{Kirehreri}

d s9 Cosmaridm Borg. Bidr. Bornh. Desm. p. 113 t. 6 f. 3. Cosm. trachypleurum b. vorrncosum firchn. $1578)$

o 90 - Anderss. Sverig. Chlor. 1 p. 17.

m $94-$ Borge Süissw. Chlor. Archang. p. 29, 
m !1 - Borg. F. alg. Östgrönl. 1) 12.

d 95 - v. uniformo West Alg. Madag. p. 66 t. 7 f. 18.

\section{Kirchneri}

11 91 HELIERELLA Tiuntze Rev, gen. pl. p. 898 (Eu. denticulatum $G a y$, non Hel. dent. (Brib.) $O K$ ).

\section{Kitchelii}

d 82 CoSMARIUM Wolle in Bull. Tor". bot. Club 1882 p. 26 t. 13 f. 3.

a $8 t$ - Wolle Desm. U. S. p. 72 t. 18 f. 1-3.

o 86 - Stokes Fiey Desm. p. 128.

d 89 - Toni syll. alg. p. 958.

11 91 URSINELLA huntze Rev. gen. pl. p.925.

d 92 Cosm. Wolle Desm. U. S. ed. Il p. 79 t. 21 f. $1-3$.

\section{Kitchelii}

d SOMICRASTERIAS Wolle in Bull. Torr. bot. Clnb 1890 p. 45 t. 5 f. M.

d s1-Wolle Desm. U. S. p. 116 t. 37 f. 1-3. [Mier. dopanperata Nordst. 1870 sec. Turner 1880 et Lager\%. 1887; sed dubito].

n 86 H0L0CYSTIS Benn. Fr.-wat. Alg. Engl. Lake Distr. 1 p. 8.

- 86 Mier. Stokes Key Desm. p. 147.

o 87 - Lagerh. lïrit. Bemerk. Desm. 1.536.

o 87 - Will. Obs. qu. Desm. p. 281.

d 59 - Toni Syll. alg. p. 1133.

n 91 HELIERELLA Inutze Rev. gen. pl. p. 898.

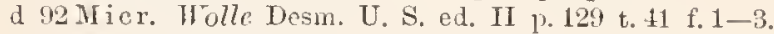

11 - v. ibill. t. 42 f. 2 .

d $94-$ f. polonica Eichl. et Gutw. Spee. alg. nov, p.173 t. 5 f. 41 [M. truncata f. moustr.? Cfr. Jucobs. 1875 et Wildem. 1887! - Mier. polonica W'est 1895].

\section{Kitchclii}

d S2 STAURASTRUM Folle in Bull. Torr. bot. Club 1882 1. 28 t. 13 f. 2.

d 84 - Wolle Desm. U. S. p. 150 t. 40 f. $35-36$.

o 86 - Stukes Key Desm. p. 168.

d 89 - Toni syll. alg. p. 1155.

d 92 - Wolle Desm. U. S. ed. II p. 165 t. 51 f. $35-36$.

\section{Kjellmani}

d 79 COSMARIUM Wille Ferskv. alg. Nov. Semlj. p. 42 t. 12 f. 31.

d $-\beta$ ornatum ibid. p. 42 t. 12 f. 32.

d - ${ }^{*}$ grando ibid. p. 13 t. 12 f. 33.

d 84 - Wolle Desm. U. S. p. 87 t. 49 f. $19-21$.

- 86 - Stolies Iiey Desm. p. 129.

d 87 - Cooke Brit. Desm. 1. 113 t. 42 f. 11.

o 88 - grande f. Boldt Desm. Grönl p.21.

d 89 - Tomi syll. alg. p. 1026.

d - subsp. grande ibid. P. 1027.

d - ? v. ornatum ibiul.

d 90 - $\beta$ Podolicum Gutw. Wahr, d. Priorität 1. 70.

in _ - grande f:" minor ibid.

m 91 - - grande Borge Bill. Sibir. Chloroph. p. 13.

1 91 URSINELLA Kuntze Rev. gen. p1. p. y25.

d 9l Cosm. v. podolieum Gutw. Flor. alg. Leopol. p.61 t. 2 f. 27 .

in - grande f. minor ibid., t. 2 f. 28.

d (1) $\quad \beta$ ornatum f. Borye Alg. notis. I p. 59.

o 52 - v. ornatum West Fr. w. Alg W. Irel. p. 15s.

4 ! t - Wolle Desm. U. S. ed. Il 1. 94 t. 60 f. $19-21$.

1) 31 ornatum f. Jorge süssw. Chlor. Arehatug. p. 30.

\section{Kjellmani}

d \%gONAT0ZYG0N Wille Ferskv. alg. Nov. Semlj. p. 59 t. 14 f. 75. [G. Brobissonii d. Kjellmanni Rice. 1885 ].

m 85 - Boldt Sibir. Chloroph. p. 123.

d 89 - Toni Syll. Alg. p. 802 .

o 92 - f. West Alg. Engl. Lake Dist1. 1.718.

\section{Kјellmani}

d 79 STAURASTRUM Wille Ferskv, alg. Nov. Semlj. p. 50 t. 13 f. $50-53$ (50 a, e = forma trigona major; $51 \mathrm{a}, \mathrm{c}=$ trigona miuor, $52 \mathrm{a}, \mathrm{e}=$ tetragona; 53 $=$ tetra- $\times$ pentagona) [St. punctulatum $\beta$ K jellman i Wille in Dijmphn. Togt. Udb. p. 86, 1856].

d 87 - Couke Brit. Desm. p. 163 t. 54 f. 9.

Cfr. Staur. Moriani f. Selmidle 1891.

\section{Klebsii}

d 92 COSMARIUM Gutio. in Nuov. Notar. III p.19.

d 92-Gutio. Flor. glon. Galie. 3 1. 127 t. 3 f.3. [Cosm, Phaseolns sec. Burge in N. Notar. 5 p.491].

in 94-Gutw. Fl. alg. Tarmapol. p. 87 t. 3 f. 18.

\section{Koslowstii}

d 92 STAURASTRUM like. Desmidya Ciastoni. p.387 t. 7 f. 9.

m $95-$ Racib. in Flora v. 81 p. 31.

\section{Kureirarum}

d 93 STAURASTRUM Turner Alg. Ind. orient. p. 106 t. 16 f. $3 \cdot 1,43$.

\section{Küt:ingianum -re}

d 67 EUCOSMIUM lieinsch spee. Gen. Alg.p. 118 t. 21 C, I f. $1-4$ (sep.p. 10 t. II).

d 67 DIDYMIDIUM (Eucosmium) Reinseh Algenfl. Frank. p. 123 t. 9 f. 3.

d 89 EUASTRUM ? Toni Syll. alg. p. 1070.

n 91 HELIERELLA Kuntze Rov. gen. p1. p. 898.

n 95 COSMARIUM Weiss in Bayer. bot. Ges. p. 47.

\section{Kütsingii}

d 56 CLOSTERIOM Brid. Liste p. 156 t. 2 f. 40 . (Stauroc. intermodium Kütz. 1819). [Cl. rostratum b. If uetzing ii 7 lezs 157:].

d $63-R a b$. Krypt. Fl. Sachs. p. 171.

d 78 - Kirelen. Alg. Schles. p. 141.

z 80 - Nordst. De Alg. et Clarae. 1 p. 1.

dzf $-\beta$ capense ibid. p. 1 t. 1 f. 1.

m af 8.1 - Rueit. Desm. okol. In rakowa p. 8 t. 1 f. 2.

a 81 - Wolle Desm. U. S. p. 17 t. 8 f. 8 .

m 81 - Artari Liste alg. Moscou p. 140.

o 86 - Stokes Fiey Desm. p. 113.

a 83 - Cuoke Brit. Desin. 1. 31 t. 5 f. 3.

o 87 - $\beta$ vittatum Nordst. Algolog. småsak. p. 163.

d 89 - IIansy. I'rodr. Algenfl. Bölum. p. 183.

m SS - Nordst. Fr. wat. alg. N. Zeal. 1).70 t. 3 f. 20.

d $-\beta$ vittatum ibid., t. 3 f. 21.

d 89 - Toni Syll. Alg. p. 850 .

d - v. vittatum ibid.

$\mathrm{dz}-\mathrm{v}$. capense ibid.

m 91 - Iiichler Spis Desm. Miedz. p. 86.

n 91 ARTHRODIA liuntze Rev. gen. pl. p.883.

m $92 \mathrm{Clost}$. MIrve. Fr. Alg. Maine III p. 122.

mz 92 - West Fr. w. Alg. W. Irel. p. 125.

14 \{1 - Mobius Austril. Süssmasseraler. p. 441. 
11 ! 2 - Wolle Desm. U. A. ed, II p. in t. ? f.s.

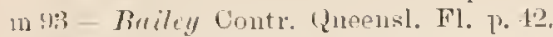

ozf $1: 3-\mathrm{f}$. ? Tmmer Alg. Ind. orient. p. 22 t. 1 f. 12.

\% !1 - Roy ficott. Desm. p. 21:.

m 91 - Börgr's. Ostgrönl. F. alg. p. 10.

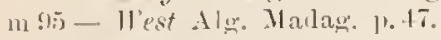

\section{Irurtaillyii}

n :I STAURASRTUM Ehreul. Organ. kl. Raum. p.:314

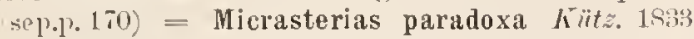
= crystalli.

\section{larerveretre}

(1) MICRASThRIAS Kïtä. Syn. Diat. p.lin1 (sep.p. 73) t. 1!) f.!n est crystalli see. Külz. Plyce, gener.

\section{Iner)}

"1 :3 STAURASTRUM Twmer Alg. Ind. orient. p. $126 \mathrm{t}$. ii) f. 11 .

\section{Irrimirtum}

1 13 COSHARIUM Tumer Alg Int. nrient. p. 5.) t. $\triangleleft$ f. 26.

\section{Ireteriverms}

1 . 11 CYMBELLA? Har\%. Maı. Br. Alg. p, 216 Peninm Brebissonii Mencgh. sec. Rirlfs Bl. Desm.].

\section{lore -is}

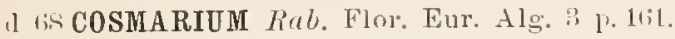

m it - Nordst. Desm. Ital. p. 2! t. 1? f. 1 .

$\circ 7 !-\beta$ septentrionale Ilille Ferskv, alg. Nov, Semlj. 1. 13 t. 12 f. 34 .

m st EUASTRUM ‘Cosmarim, fiay Monogr. loc. Conj. p. .)

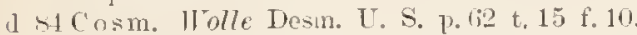

m 81 - Ilille syrtamerik. Alo H. p.31.

o si) - Wolle Bull. 'Torr. bot. C'lub 12 13. 3 t. 47 f. $35-33$.

0 ito-stokes key Lesin. 1.127.

(1) Si-Coolie Brit. Desm. 1).94.

o - roseptentrionale ibid.; t. 42 f, 17 [male ex Wille?].

87 - Wolle Fr. Alg. U. . A. t. it f. 35-31; [ex Holle 1S\$5].

(t sis-Ilunsy. Protr. Algentl. Bülnm. p. 1is.

d SS - v. hispanica Lexim Span. Süss.-Wass. Alg: poit t. 1 f. 13.

m So - v. septentrionale Hest Massachns, Desm. 1) 1s t. 3 f. 14 .

mos! - Harr. Fr. Alg. Maine II p.181.

d] 89 - "leve"। Toni Syll, alg. p.934.

$\circ \quad-r$. septentrionale ibid. 1).93\%.

o - v. hispanicum ibifl.

1191 URSINELLA Kuntze Rev. gen. pl. 1. 51.

m 11 Cosm. Gutw. Flor. Alg. Leopol. p.t.l.

m - $\beta$ septentrionale ibid.

m 92 -? Ilunsg. Beitr. Alg. Bact, Tirol. u. Bölım, p. 1:32.

o 92- f. Iirc. Desmidya Ciastoni. p. 361 t. 6 f. 1 ? et 20.

14 - Wolle Desm. U. S. ed. Il p. 72 A t. 18 f. 10.

11 - voseptentrionale ibil.. t. 43 f. 1.1 [e West]

zo 92 - Iste, in Magyar. Nör. Lapok. 15 1) $60 \mathrm{~s}$.

z 92 - West in Notaris. 7 p. 1 bu1.

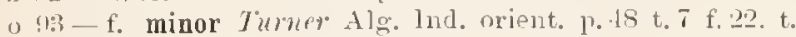
$S$ f. 21.

1) 14 - v. undulata Schmille Alg. Geb. Oberdheins p.5 Lit t. 2.5 f. 5 .

m yt-Borge süssw. Chlor. Arehang. 1.26.

d 11 -v. septentrionale Sauml. in Fl. Nebraska p. fu t. 7 f. 3 [e Cooke].

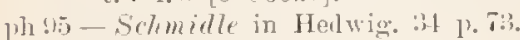

m95-Eichler in Pamiet. Pizy. 18 1. 5x.

Somsterit, indes Desmill m! ! Thest Alg. Malag. p. in.

Cfr. Cosm, lejodermum, Cosin. Meneghinii /luns!/. lisis at Ixo1 et Cosm. Gerstonbergii.

\section{lieve}

11 3i EUASTRUM Hhend, in Triegm. Arelt. 1si36 p. 16i (Cosmarium Cucumis r'orla! et? Colpopelta viridis rorda).

\section{Ire?e}

o titGONATOZYGON Hilse in Timl. Alg. Emr. n:0 1!m2. [G. Brebissonii sec. Roy 16!4]].

त 78 - ? Kivelin. Alg. Tichles. p. 131.

(1) S!) - ? Toni íyll. alg. p, 803.

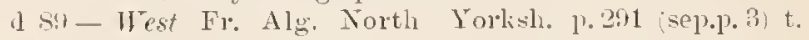
2!1 f. 6; ("G. lieve 11. sp.").

\section{lreve}

(1) 00 NYCHONEMA Nordst. Tesm. Brasil. p.211; (sep.p. 16i8) t. 3 f. 31.

m 75 - Reinsch Contribut. p.93 t. 15 f. 4 . [Cfr. Nordst. in Hedwigia $18 \pi t ;$ p. $6 \bar{i}]$.

d $50-\beta$ micracanthum Nordst. De $1 \mathrm{lg}$. et Cliarae. 1 p. 3. o sto- $\beta$ micracanth um f. Lager\%. Amer. Desm. 1? 2us. d s't) - Toni šyll. Alg. p. 796.

d $-\beta$ micracanthum ibid.

in 90 - Eichler sipis Desm. Miedz. 1. 8 . t. 5 f. 6.

m93--(Prionena) Tumer Alg. Ind. orient. p.13!) t.17 f. 15 a (inel, Xanthidiastrum paradoxum et Sphær. serratum)

m $-\gamma$ minus ibicl.; f. $15 \mathrm{~b}$.

0 94 - v. micracanthum Juhns. Rave Desm. l, 2x6 t. 211 f. 15.

m!1. - Racib. in Flora v. St p. 32.

\section{treve}

d 18 STAURASTRUM Livlfs Brit. Dism. p. 131 t. $2: 3$ f. 10.

d 52 - Prilch. Inf. p. 264.

d 61 - Arch. in Pritch. Inf. 1. 743.

l 193 - Jab. Krypt. Fl. Naclss. p. 193.

m lit-Cleve Bidr. t. Sverg. Desm. p. 4 inl (f. major) $\{f$ Clevei Wittrock 1879].

o $b 8$ - Nordst. Bidr. Sverig. Desn. p.4".

d fis - Rab. Flor. Eur. Alg. 3 13.206; b (f. alternans).

1 ts $\beta$ Clevei 1 ittr. Skandin. Desm. p. 18 t. 1 f.? [Nt. Clevei Roy 18033.

in 70 - Norelst. Desm. Brasil. p. 226;.

o 71 - $\beta$ Clevei Arch, in Q. J. M. A. v. 11 p. 93.

o $i_{2}$ - Wittr. Grotl. Ol. sötr. Alg. p.it.

d 7i-f. (snpernimeraria) Nordst. Norg, Desm. 1. 2s t. 1 f. 12. [Stau1, infestum Jurn. 1893?].

d 78 - Kivehn. Alg. Schles. p, 1tit.

d $\$ 7$ - Cooke Brit. Desm, p. 180 t. 6;3 f. 2 [e Rulfs? ?]

1) - v. Cievei ibid.; f. 3 [ex Wiltrock].

o sis - Hunsg. Prodr. Algenfl. Bölım. 1.212.

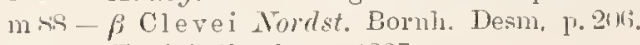

1 1 s. - Tomi syll. alg. p. 1227.

d - v. Clevei ilsil.

m. 92 - Hansy. Beitr. Alg. Bact. Tirol. u, Bohm. 13. 185.

nu - Rac. Desmidya Ciastoni. p. 3\%2.

m 95 - Johns. Rare Desm. U. S. Il p. 295 t. 240 f.:3t [Cfl. Stanx, fissnm].

$111.5--\beta$ Clevei Eichler in Pamiet. Firy 13 p.62.

\section{Ire'is -e}

1) 45 CLOSTERIUM Kït:- Pliycol. grerm. 1) 132.

drf ISTETMEMORUS halfs Brit. Desm, p. 146 t. 24 f. 3 (d, e. t, g e linlf: Ann. Nat, 18.1 melins delineatie). 


\section{LAGENARIOIDES}

dz 52 - Mritch. Iuf. p. 271.

o 58 - De Eury ronjug. 1. ¿1. T4.

dzof - Amp. in Pritell, Inf. p. Ttti.

1 63-Rab. Krypt. Fl. Sachs, po 17\%.

nn nit-Reinsch Algenft, Frank. p. 1 - 2

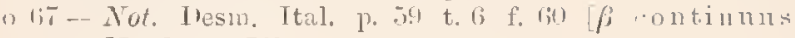
Nordst. 1878].

d 68 - Rab. Flor. Enur. Alg. 3 1? 140.

d 73 - Wood Fr. Alg. p. 118 .

o 73 - Norrlst. Norg. Tesm. p. 3i!.

daf 75 - Microgr. Dict. p. T76 t. 10 f. 3. [e lialfis].

mit - Nortst. Alg, brasil. p. 11i.

1) $7 \mathrm{~s}-\beta$ continuas Fortst. Alg. Sandvic. p. 10.

1 is - Kinchen. Alg. sichles. p. 1 to.

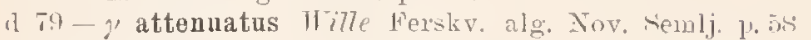
t. 14 f. 7 .

m St PENIUM Tetmemorns) Gry Mon. lor. Conj. 1. T1.

d sit Tetm. Wo77e Desm. U. s. p.!11 t.20 f. 3, t. 50 t. 35.

o 86 - Stoke's Iiey Desm. p. 130.

dzf to - Cooke Brit. Desm. p. 49 t. 1!) f. 2.

S6 - Timner in Leeds nat. club transact. 1 t. 1 f. 1.5.

d ss - Hunsy. l'rodr. Algenfl. Böhm. 1. 1s'.

m s 8 - $\beta$ attenuatus Boldt Tesm. Grönl. 1) 12.

m ss - Ist v. Jel, magyar. alg. P. 2:3\%.

m 88 - Nordst. Fr. wat. alg. X. Zeal, 1r.tit t. 3 f. 1!1

d\%s!) - Toni inyll. Alg. p. sis,

d - v. attenuatus ibid.

d - v. continuus ibid.

d $: 10$ - v. bifidus Gute. El. glon. Falic. 2 11.9 t. 1 f. 1 . [form. monstrosa see, Jagert. in Niwr. Notaris. $18: 1$ 1. 4.12].

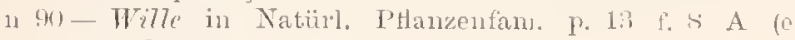
riulfs).

m $00-$ Bury. Desm. Brasil. p. 2s.

m : 10 - Anelerss. Sterig. Chlor. 1 11. 17.

n. $\quad$ in continu us iljill.

n191-Heimerl Desm. alp. 14.59.

m 92 - $\beta$ attenuatus Borge Chloroph. Norsk Finnark. 1. 14 .

112 - liac. Desmidya C'iastoni. 13.3\%2.

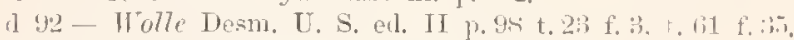

11198 - Lülliemä77. Desm. Attersees 1. 540.

11 9:3 - Schmidle Beitr. Alg. Schwar'zwalı!. 1).9\%.

in 94 Iste. Adat. Iioman. alg. p. L51;.

m ! - - Hexenlio Mater, alg. Iiliark, 1'.22.

m $9-1$ - West Fr. Alg. West Ind. p. 247.

(1) $\%$ - v. ornatus schmirlle Beitr. alp. Alg. p.31. t. 11 f. 24 .

('fr. Tetm. Brebissonii et granulatus.

\section{lagenrorioides}

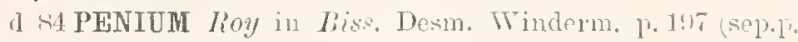
i. t.j f.ti puncta false ordinata.

m:St - C'ootip Brit. Desm. 13. 15

1) 8! - Toni syll, Alg. p. sisti.

d! - v. Sydneyense Ruc. Desmidya Ciastoni. p. 3tic t. (i) f. 3 .

\section{Tl1!rmarim}

m 3. COSMARIUM Corde in Alm. d. Carlsh. 1.435 1. 2116 t. 2- t'.21; [1ulla ilescrijtio. Fuastrum ansatum see.

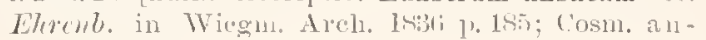
satum Ríb.j.

(1) 1s-Ralfs Brit. Desm. ]’.212.

(1) 52 - Iritch. 111f. 13. 2\%).

() $54-B r 67$. List. 13. 125,

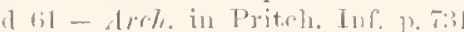

\section{Lregerheimirmm}

1) 1 D DSPHINCTIUM Turmer Alg. Int. nrient. $1.13 \mathrm{t}$. 22 f. 19.

\section{Irrgerhrimii}

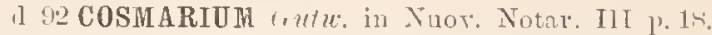

1) - Gutu. Flor, glon. (ralin. 3 p. 124 t. 3 f. 2.

\section{logoense -is}

d 70 CLOSTERIUM Yordst. Brasil. Desm. 12, 203 se p.p. 16.5) t. 2 f. 2.

ก $73-A x c h$ in 12. J. 11. \& . 1. 21:3.

d Sij-Cooke Brit. Desm. 1, 29 t. 12 f. 5 [e Nordlst.].

d $\rightarrow 9$-Toni Syll. Alg. p. S10.

o :n-Reinsch Stisswasseralg. Sïll.Georg. p. 3.1 t. 2 f. 13 (et t. 3 f. 4 crm parasito

n. 91 ARTHRODIA Kunt.e Rev. gen, pl. p. 483.

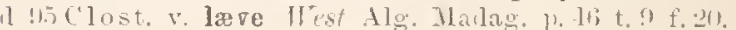

\section{Irygense -is}

n it COSMARIOM Tordst. Alg. hrasil. w.:0) (C. ornatum P lagoense Nordst. 1sio

1 - $\beta$ cornigerum ibil. $p$, 20 t. 2 f. 15 .

口 $x \bar{t}$-- Wolle Fr. Al Northt. ?].

1 S.1 - Toni sill. alg. p. 10.5.

d - v. rornigermin ibil.

11 :1 URSINEIIAA Kunt:c Rev. gen, pl. p. !25.

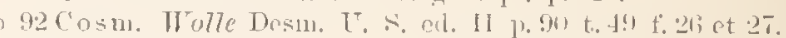

\section{Irmellifermm}

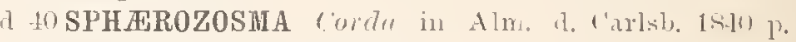
206 (se1.p. 21 ) t. 1 f. 29 .

a 1.i - Rulfs Brit. Hesm. p. 208.

d 52 - Pritch. 1ut, 13. 24:3.

d 11 - Arch. in Priteh. Inf. 11. 721 .

त sos- Rirb. Flor. Eur. Alg. 3 l. 1.1!.

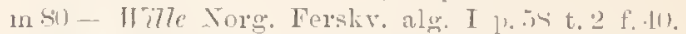

d si-Ilansy. Proulv, Algentl. Brilum. p. 17 .

d 8 ! - Tomi virll. Alg. p. T!n.

d :3 SPONDYLOSIUM v. attenuatam Tum. Alm. Ind. orient. p. 14 i t. 21 f. 2 .

\section{lamellosum}

d 35 CLOSTEPIUM Jind. Ale. Fal. 1, in t.s.

o :37-Desma.: Descr. esp. nouv. p. 214 t. 7 f. 3.

d 19 PENIUM Fïtz. Spee. Alg. p. 1 lí (incl. Digitus).

o $52-R a b c n h . A \lg$. n:0 241.

d 53 - Wath. Fl. Bolg. II p, 52 ti.

o oti-Jict. List. p. 14t.

1 (i1 - Arch. in Prituln. Inf. p. 751.

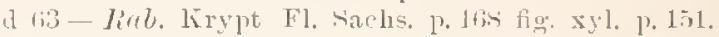

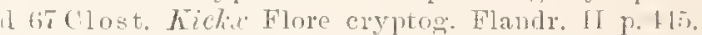

1 lis Pen. Rub. Fl. Enu. Alg. 3 p. 119. fin. xyl. 1. 102.

(1) 73 - TTood Fr. Alg. 1. $10 \pi$

d $7 T$ - Detponte Desmil. subalp. p.s1 (scp.[1. 17t) t. 15 f. 10-1S. [Cfr P. Nixgelii].

m 78 - Nortst. Alg. Sandvit. 11.

d $75-$ Kirchn. Alg. Schles. p. 13\%.

o 83 - f. Nordst. in Wittr. et Norist. Alu. exs. 11:0 539.

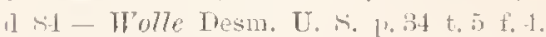

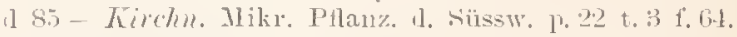

o si-stolies lier l)esm. 1\%, 111.

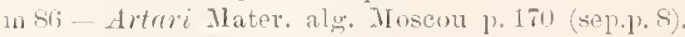

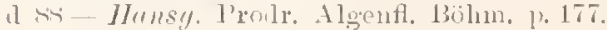

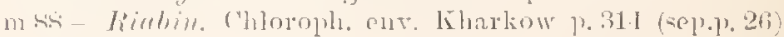


11 sis Iste. Jol. mangar. aly. 1, 2311.

(1) Sir- Tordst. Fin. wat, alg. N. Zeal. 1). Tu.

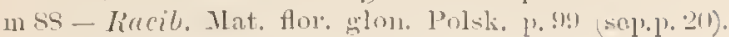

d 8 ! - Toni syll. Alg. p. sitit.

m!k - Eichter spis Desm. Miell\% n.

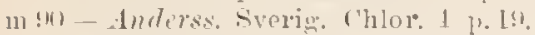

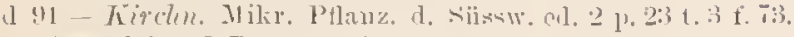

n!1-llcimerl Desm. alpin. p. jull.

III !1 - Gutu. Flor. alg. Teopol. n.:31.

m!12-Rinc. Desmidya riastoni. p. Bit.

1)!2-Wolle Desm. 1T. S. ed. II p.31 t. is f. 1 .

m!13-Tükemïll. Desm. Attersees p. 515.

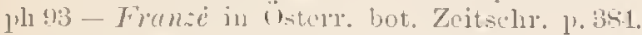

II! - Alexenlio Mater. alg. Kiliark. p. 20.

1 :1 - f. Borge siissw. Chlor. Alehang. ]) 17 t. 1 f., 12. Cfr. 1'en. bigitus nuct. mult.

\section{lecrepoleterul -re}

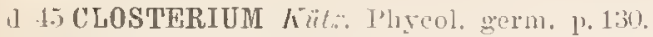

(1) Is - lielfs Brit. Desm. p. 16it t. 28 f. 1. Cymbella Hopkirkii; Clost. tenue Iinit. 1\$41?).

It $1 ! 1$ - Küt. siec, Ale. p. 165.

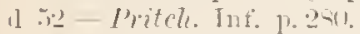

$1115 t-$ (?) liabenh. Alg. 11. 3ili [Cl. pragrande liab. Fl. Eur. Alo: 1, 12-1.

miti v. majus Rrib. Tist. 1, 102.

o 61 Arch. in P'itch. Inf. 1.747.

o tiis - Erb. Critt. It. 11:0 10:35.

d lis Rub. Kirylt. Fl. Sachs. p. 171.

o $1 ; 1-$ f. Clece Bidr. 1. Nverg. Desm. p. 19. t. 1 f. $千$ Cl. Pritchardianum Arch.].

I lis - Riab. Flor. Eur. Alg. p. 1.2! .

o ti!l - Mittr. tikanliu. Desun, p. 20.2.

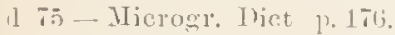

In T- P'tit Desm. de Paris p. 5 (sep.p. 2S

1117 - Ardiss et sitraftor. Alg. Ligur. p. 103.

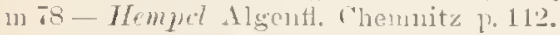

1 a:3-Cybulski Wat. aler. Warszaw. p. 260.

msi - Gay Mon, loc. Comj. p. т1.

d sit - Wolle Desin. U. S. p. 3is t. \& f. 11.

m sit - Wolle in Bull. Torr. Bot. Ciub, 12 1) 1.

o siti-stokes Key 1)esm. p. 112.

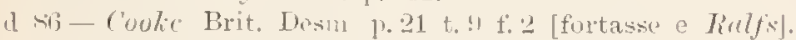

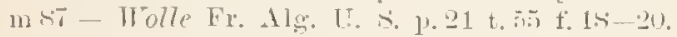

d SS - Tomi et Lrri Fl. Mlg. Tene\%. 1. 30.

d bi - Toni sirll. Alg. 1. A 29 .

m s! - Guter. Flor. glon. Polski p. ㄲ!4.

1n!1-Heimerl Desm. alpin, p. 5!r?.

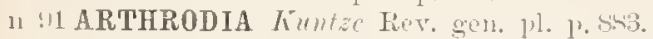

ma! clost. Gutu. Flor. aly. Leopol. p. 3่̧.

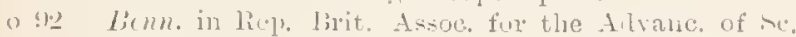
18.11 7.157 Fumg. parasit.?

o s.2 - Bem, in Aun ot Bot. 6 p. 1.) f. A (Fums. masit.).

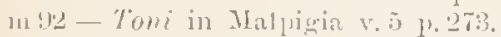

m $92-$ Rimmer Alg. Sit. P'ulten I p. 万.

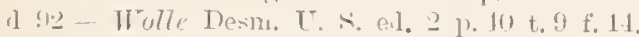

m! 12 - Hest in Notanis. 7 p. 14 tex?.

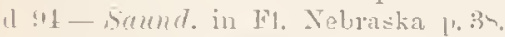

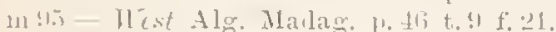

Cfr. r'lost. acerosum Ethenb. 1sise ex p. see. Livib. 1.ionti, etce.

\section{lemerentretille}

d !:3 PENIUM Turmet Alg. 1nd, orinat. 11. 1 t t. 1 f. 7.

\section{lulerelulutullu}

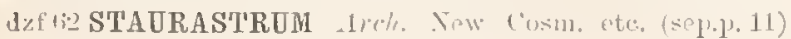

in Drols? Nat. llist. Soc. Pr. p. T! t."2 f. 1i-2.2. Inul: Mis*1. so, 1), 218 t. 12 .

dะlis-liab. Flor. kur. Alg. 3 p.21\%.

111 .2 - Nordst. Desm. Spetsb. 1, 3S.

1175 - Tordst. Desm, aret. p. 33 (3 formar.

m i! - Wille Ferskv. alg. Yov. Semlj. 1) il.

d 5 - perparvulum Nordst. Desm. Grönl. p. 111 t. 7 t. (i. laf $8 \bar{r}$ - Cooke Brit. Desm. p. 15 s t. $\overline{3}-1$ f. 2 [ex Alrcher].

dzs!! - Toni Syll, alg. 1. 1182.

d - subsp. perparvulum ibil. p, 11š3.

л!:3 - injlucicastrum) Turner Alg. Inu. orjent. P. 1:3:3.

(1) 4 - v. compressum West New Brit. Alg. f.11 t. 1 f. 2ㅡ. Cfr. Staur. orbicalare v. majus Not.

\section{L, II)!r?i}

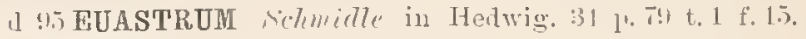

\section{lellintulll}

it TSTAURAS'TRUM Detponte Desmid. subalp. p. 34) (nep. 1. 135) t. 11 f. $13-25$ (inclus. Stau1: Dickiei [t, 17]. st. dejectum [f. 25], st. Brevispina [f.21]).

4. $\times !$ - Toni Syll. al@. p. 1112.

\section{(11siospyovill) -}

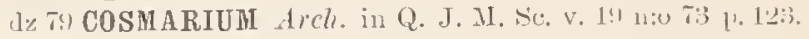
izsij-Coole Trit. Desm. p. 92.

dz s. - Tomi viyll. alg. p. 1033.

11 !1 URSINRLLA Kimtze Rev. gen. pl. p.:12.\%.

\section{luterale - is}

(1) - CloSTERIUH Nordst. in Wittr. \& Norist. Alg. ex.. n.o 393 ; et in fasc. 21 (15S!1) 13. 16.

(1) $\$ 9$ - Tomi syll. alg. 13.818.

1) 1 ARTHRODIA humze Rev. pl. p. ss:?.

\section{Iaticeples}

as COSMARIU⿴囗十 Gmon. apul hab. Flor. Eur. Alg. 3 p. 168.

os - Nordst. Fr. wat. alg. N. Zeal. p. 57 t. @ f. 10.

d s.

\section{leticeps}

a su DESHIDIUM (Didymoprinm) Norelst. in Witt. \&

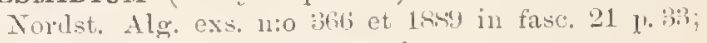
$a$ ellipticum et $\beta$ quadrangulare.

(1 S!) - Tomi syll. Alg. p. 784 .

!) - Rucib, in Flora $\nabla .81$ t. 1 f. 11.

\section{letireples}

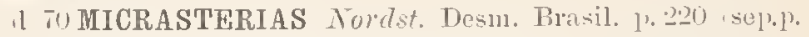
182) a. Forma major t. "- f. 11 .

- B. Forma minor ibid. Tetracastrum aumericanum Arch.1.

1 81 - Wolle Desm. U. S. p. 115 t. 37 f. t-5.

n. si ? HOLOCYSTIS Benn. Fr,- wat. Alg. Engl. Lake Distr. 1 p. $\varsigma$.

m sifi Micr. f. ma jor Lagerh. Amerik. Desm. p. 230.

o S6 - Stolies liey Desm. 1.147.

d S: - Toni syll. alg. 1. 1112; f. major et minor.

1191 HELIERELLA Funtse Rev. gen. 11. 11. s\%.

m!1 $\mathrm{Mi} \mathrm{i}$. West Freshw. alg. Maine II p.3.1.

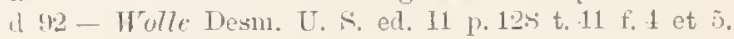

m 93 - f. minol Tumer Alg. Ind. orient. p. 8s. Ofr. Micr. disputata Hood 1s73, M. incisa Preil. 1857 , M. oscitaus Wild. 1887.

\section{letirollum -re}

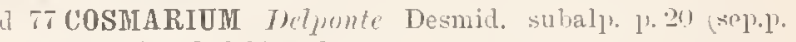
114i) t. 8 f. $20 .-23$. 


\section{LATIFRONS}

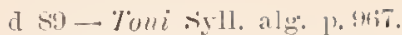

n "1 URSINELLA Funtze Rev. gen. 11. 1\%. (1).5.

\section{lutifiroms}

a 71 CoSMARIUM Luml. Desm. Suec. p. sil t. 3 f. 7 .

d s - Tomi Syll. alg. p. 1011.

d s1 - f. Borge Bidr. Sibir. Chlorople p. 13 [pisibirienm Layerh. 189:?].

11 U1 URSINELLA Kuntic Rev. gen. pl. p. 925.

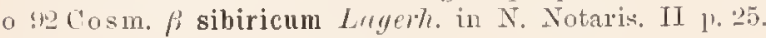
o !1 - - f. minor Borge Sïssw. Chlor. Areliang. p. 2u.

in - f. ibid. lionge 1891).

\section{latipes}

d T0 EUASTRUM Lordst. Desu. Brasil. 17.216 (se1.11. 178) t. 2 f.' 9.

d S! - Toni Syll, alg. 1. 1195.

\section{latiusculum}

a 4: CLosterium Perty in Bern. Mit.th. 18191 1.28.

d 52 PENIUM Porty lileinst. Lebensf., 1) $20 \%$ t. 16 f. Ist et 19. d 65. Lat. Flor. Eur. Alg. 3 p. 123.

d 89 - Toni Syll. Alg. p. 556.

\section{latuml -}

d 56 COSMARIUM Bré. Liste 1'. 128 t. 1 f. 11,

d 61 - Arch. in Pritcli. Inf. 13, 733.

o lis-richt. in Rab. Alg. Eur. n:0 2017

d is - Iiab. Flor. Eur. Alg. 3 j, 15s.

o (s) - Mittr. Skandin. Desm. 1) 12. [ $\beta$ L.mul.].

d 71 - $\beta$ margaritatum L.und. Desm. Suec. 17. 21). [C. mar garitatum Roy et Biss. 1SSib].

o $73-\beta$ margaritatum Nordst. Noro. Desm. 1\% 12.

d $84-\mathrm{f}$. Wolle Desm. U. .. p. 7 i t. 18 f. 11 .

o. Siti-stokes liey Desm. 1). 128.

a si -Couke Frit. Desm. p. 101 t. 11 f.s [e Bréb. ?].

$m$ s $-\beta$ margaritatum Bollt Desm. Grïnl. p. 21;.

$m$ - $f$. minor ilid.

d 89 - Toni Syll. alg. 1). (9)!

d - v. margaritatum ibid.

11 U1 URSINELLA Kwntice Rev. gen. pl. p. \25.

d !r Cosm. Wolle Desm. U. S. ad. Il p. 81 t. 16 f. 14 .

(1) - Roy Scott. Desm. t. 2 f. 10.

d - v. ninor ibil. p. 1115 (sep.p. 3.6) t. 2 f. 11.

Cfr. Cosm. anomalum, C. margaritiferum JaC. 1876, C. Pardalis Lag. 1884 i.

\section{Iretum}

1 $9: 3$ DOCIDIUM 7more Alg. Ind. orient. p. 3i t. 7 f. 1.

\section{Ieiblrimii}

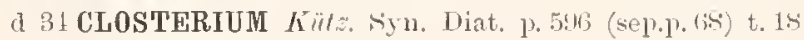
f. 7 !? (Cl. Lunula Leibl, et fortasse Vibrio Lunula Mïller").

1 35 - Tréb. Alg. Fal. 1\% 5. t. S.

o 34 - Breib. in Chev. Micr. 1) 272.

(1 40 - Mtncgh. synops. Desil. p. 232 (sep.1. 322).

d 15 - Kitiz. Phye. germ. p. 130.

dzf 4 sh-liulfs Brit. Desm. ]. 1lit t.2i f. 1. [a, b. c sec. Jacubs. $1875=$ ri1. moniliferum t". Leibleiniana; fig. e, d, g, lı, l = cl. Dianæ?

d $-p$ ibid.

A $1: 1-K u ̈ t z$. sipec. Alg. p. 113.

d 50 - DTurissel Catalog. esp. omis. 11, 32 t. 1 f. 2 (e Kïtz. Syn. Diatom.

d 52 - Pritch. Inf. 1, 2sil et $\beta$ t. $1: 3$ f. 1 et is [e liallys].

153 VIth. Fl. Belg. 1).525. plo

oz 56 - Itrigsolm et hothe in Rab. Alg. 11:0 507 Cl. calospornm littr.]

dz 1il - Arch, in Priteh. Inf. p. 718 t, 2 f. 1 et $\tilde{s}$ [c lialfs].

d 6:3-liub. Krylet. Fl. Sachs. 1) 171.

al lit;-Eyrich Algent. Manul. p. 137.

d 68 - Rab. Flor. Eur. Alg. 3 1. 132.

d - b. minus ibid. (Cl. incurvum Brèb.).

m 70 - Reinhurd in Arbeiten Natnrf.-g. Cliarliow. I 1\% 15.

d 73 - 11 ood Fr. Alg. p. 114 t. 12 f. 1 .

d 75 -Microgr. Mict. p. 176 .

d $7 \overline{-}$ - Detponte Desmid. subalp. p.as (sep.p. 194) t. $17 \mathrm{f}$. $1-6$.

d $78-$ Kirchn. Alg. Schles. p. 111.

m 75 - IIcmiel Algenf. Chemnitz p. 112.

o 79 -f. Wille Ferskv. alg. Tov. Semlj. 1, 5il t. 11 f. 7!.

m 8.1 - Gay Mon. loc. Conj. r. 79.

dyf $s t$ - Wolle Desin. U. S. p. 16 t. 7 f. 13-14 et ?0.

in 81 - Wille Sydamerik. Algh. 11.23 et 82.

o - f. ibid. p. 33.

$m$ - f. ibid. p. 49 t. 3 f. 93. [f. Wille i rutw. 1890].

d 85 - Kinclen. Mikr. Pflanz. d. Süissw. 1. 21.

d s.5--v.? angulatum Balsamo Alghe del com, di Napoli p. 37 t. 1 f. $15-17$.

m 810 - Iste, in Magyar. N. Lan, 10 1, 6.

ก 86 - Stolies Key Desm. 1).112.

dzf 5 f - Cooke Brit. Desm. 1. 25 t. 13 f. 1 [e Ralfs].

o $\quad \ldots p$ ibid.

d 8 - Alexenlio Chlorosp. Kiliar. p. 2311.

dzs8 - Toni et Levi Fl. Alg. Venez. p. S.:.

o 88 - f. Kinbin. Chloroph. env. Kharkow p.316 (sepr.p. 2.').

m ss-Iste. Jel. magyar. alg. 1. 239.

m ss - Lewin span. riussw,-alg. p. $!$

n - f. elatior ibid. t. 1 f. 1 T

d 85 - v. curtum West Massachus. Desm. 1) 17 t. 2 f.8.

dz 89 - Tumi sill. Alg. p. Sllo.

d - v. angulatum et f. elatius ibir. p. 817 .

m 30 - f. Willei Gutw. Fl. glon. Galic. 2 1.s (Wille 1sst f. 983$)$.

o so-b. winus Reinsch süsswassernlg. Sitd.Georg. 1. 303 t. 2 f. 11.

o (4) - f. Bür. Iesm. Brasi]. ], 31 t.2 f. т. [f., Boer gensenii Schmidle 1894].

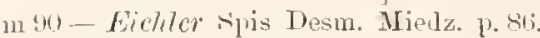

m91 - Anderss. śverig. Chlor. 1 p. 1 s.

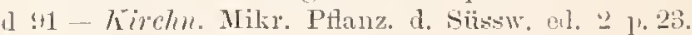

m!1 - West Danish Algee 1. 119.

In 41 - Torye Bidr. sibir. Chloroph. 1) 11.

d - f. ibil. et t. 1 f. 10.

11 91 ARTHR0DIA Tuntze Rev. gen. pl. 1) Mtrỏ.

11 ! Clost. West Fr. w. Alg. W. Irel. p. 122.

def 92 - Wolle Desm. U. S. ed. II 1'. 19 t. \& f. 13-14 et 90 .

o - v. cus:tum ibiu. t. 43 f. 22 [e $\|_{\text {cot }}$.

o :43-(Selenoceras) v, angulatum f. minor Tumer Alg. Ind, orient. 1\%. 19 t. 1 f. 18.

n - 2 typica f. parva ibid.; t. 23 f. 13.

11 ! f - f. Boergensenii Schmialle Alyg. Geb. Oberrheins 1). J) (f. Tirir\%. 1890).

d - v. minima ibil. et t. 2 s f. 1.

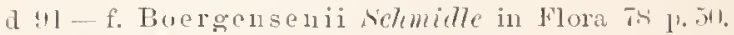

m 9. -f. Borge Suissw. Chlor. Arehang. p. 16 [f. Boerg.ens.].

f. illid. (Iorge 1s:1)

f.? ibid., 1. 1 f. ? et 10.

in 94 - Alexentio Natex. alg. Khaxk. p. 20.

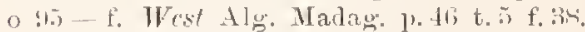

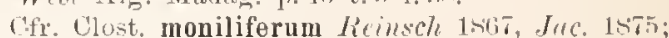
Echinella Luna r'ordu 1629. 
leiv)ler"111111- -

11 s1 EUASTRUM Cosmanium Gruy Mon. loc. Conj. 1).

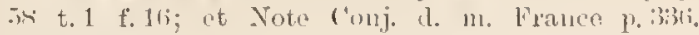

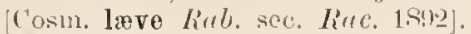

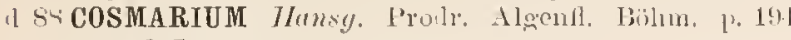
et 217 .

I 89 - Tomi syll, alg. p. 1437.

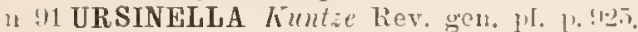

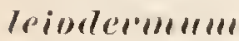

I ! GONAT0ZYGON Tumer Alg. Int. orient. p. 24 t. 24 f. $)$. Oedogonium su, verisimile see. Wist in , Tourn. of Bot. 1.95 1.65].

\section{Iriodlermillm}

4 sif XANTHIDIUM Roy \& liss. Japan. Desm. 1) 210 (se1.

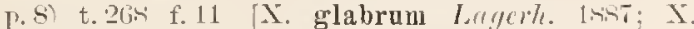
cristatum v. leioder mum Tirner lisi:3].

\section{Leiosporect}

11 to stizenl. Index Rab. Alg. 3. 27. Scetjo Desmidiacearum; subsection.: Erenobies et Filamentosi

d S6 Cooke Brit. Desm. p. 2 inclus. gren.: Splizerozosma, Cylindrocystis. Mesotænium]). [Rect. A liub. Fl. cur. 1 sitis 1 . 116].

\section{Teris}

(1) TíchosteriUM Juculs. Desm. Danen. p. 1ti ; v, major t. 7 f. 1 ('t. Libellula Foctie).

v. intermedia 1. e. 1. lis Pen. closterioides liclte. 11 - v. minor ibid. (['en. Navicula birib.)

\section{lepirllell!}

d 8. CosmariUM ITest Fr. Alg. Forth Forksh. p. 292 (sep.p. 4) t. 2.91 f. 1.1

\section{lelutrercuttullut}

d foSTAURASTRUM Nordst. Desm. Brasil. p. 22:1 (scp.p. 191) t. 4 f. $[6$.

( 73 - Nordst. Forg. Desin. 1. 32 (f. 'J-gona).

0 77 - Norelst. Alg. brasil. p. 24 f, !-gona major et minor)

o 82 - Nordst. in Wittr. et Nordst. Alæ. exs, 12:0 438.

d SI - v. tetroctocerum llolle in Bull. 'Forr. bot Club. 1. 13 t. 41 f. $29-30$.

d sit-v. tetroctocerum Wolle Desm. U. s. p. 151 t. 51 f. $2 ! 1-3$ !).

min-- Boldt sibir. Chloreple. p. $11 \%$

m sit - Layer\%. Amerik. Desm. p. 24 .

o sis- v. tetroctocerum Stokes Key Desm. p. 161

d sil - Toni Syll. alg. 1. 1205.

d 92 - v. tetroctocerum TTolle Desm, U. S. ed. II p. 16i; t. 62 f. $29-30$.

11 $1: 3$ - (Hoplastrum) Turm. Alg. Ind. oricut. T. 132.

\section{Irptorladum!}

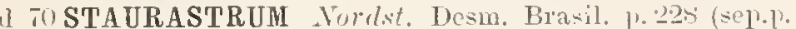
I.90) t. 1 f. 57 .

83 - v, sinuatum Wolle in Bull. Torr. hot. C'lnL, v'. 1). 2 (1) t. 27 f. 2 I.

I 81 - Wolle Desm. U. S. p. 136 t. 1 | f. 1 .

$11-$ v. divergens ibid, f.

i) 81 - $P$ cornutum Hille sydamerik, Algth, p. $1 ! 1$ t. 1 f. 3u.

o si - Stolies liey Desm, p. 165.

d $4 ! 1$ - Toni syll, alg. p. 12:33.

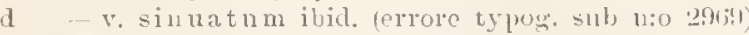

d - v, cornutum ibid. p. 1234.

o (n) - P cornutum Tiriry. Dosm. Brisil. p. 1,

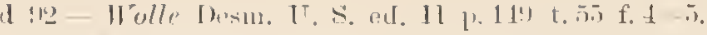

m193 - Bracliastrum) v. cornutum 7irner Alg. Lut. orient. p. $12: 3$ t. 11 f. 12 et 16 .

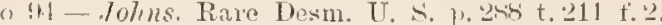

o - v. cornutum ihid. 1). 289 t. 211 f., 3 .

u $15-\ldots$ - West Alg. Madag. p. 7! t. ? f. 12-13.

\section{LEPTOCISTINEWA}

If 55 Areh. Suplol. Cat. in Nat. Ilist. Rev. p. 200 (in Pr. Tubl. Zoul. Bot, Ass, I 1, 111. in Q. ., M. Ác. 7 1. 133).

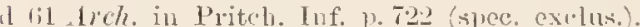

il si Munowy in Baill. Dict. bot. 11 I p, 226.

\section{leptoder"llum!}

11 !3 PENIUM Irittr. Snöns o. isens H. p. 11:3.

\section{IeptodernIIIIII}

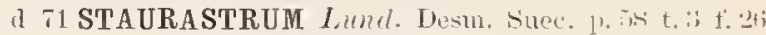

(t s!) - Toni śyll, alg. n. 1144.

u (13) - Hectastrum Tumer Alg. Int. orient. p. 1:3:3.

\section{LEITOKOSWA}

d sis Tume. New rare Thesin. 1.43I (sep.7?.2).

o s6 Stokis liey Desm. n. 10!

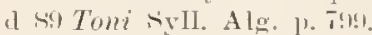

- 13 Tume Alg. Iud, orient, p. 1.is.

\section{LEURONEMA}

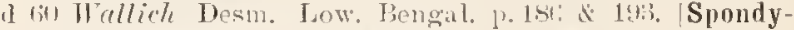

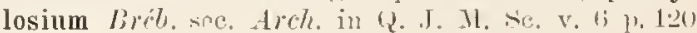
ct v. $11(15.1)$ 1). (2),

\section{frertull1}

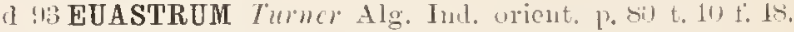

\section{levispinllu!}

mst STAURASTRUM Jiss. Desm. Wimlerm. p. 19.j (seprep. $t$ t. i f. 5

d sit-Cooke Brit. Desm. p. 143 t. in f. 3. ["levispinum"; figg. e Bisset? ?

I (8) - Toni syll. alg. 1. 1111.

1) 12 f. sydneyensis Ruc. Denuilya Cinstoni. p. 37 t t. Tf. 10.

\section{LPUPisillllm}

(1) 93 STAURASTRUM Tumer Dosm. Notes 1\%345. et fi.s P. 341

\section{Lereisii}

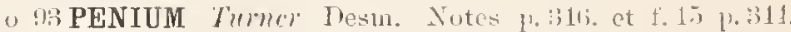
[P. exigunı f. Lewisii llest 1.5.5.7.

\section{Irerisii}

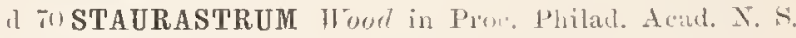
1 . 1601 p. Lis

73 - Wrod Fr. Algo p. 149 t. 21 t. 1:1, t. 13 f. 11

a 84 - Wolle Desm. U. A. I. 12: t. [0 f. $24-27$.

o si- Stolies Key Desm. p. 16 is.

d s. - Tomi syll, alg. p. 1112.

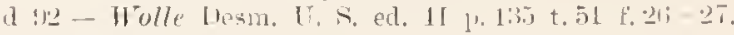

\section{Libellula}

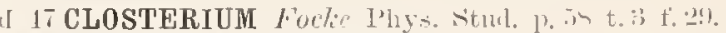

7:3 - Nordst. Norg. Desm. D. 11.

is PENIUM Norlat. Bornh. Wesin. p.191.

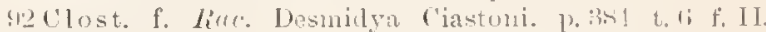
[Qnit? ?] 


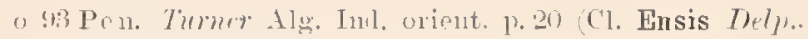
11011 Foeke).

m!1 - Borye *üssw. Chlor. Arehang. 1. 17.

m - $\beta$ subcylindricum ibid. (Pen. closterioides c. Klelis 1.479).

d !1. - $\beta$ intermedium Roy sicott. Desm. 1) 252 (sep.l. (i) (1). m:15- Kieven. in Pfanzentw. Ostafrik. p. 19.

Cf1. I'lost. Lunula Lob. 1\&10. Clost, Lens, Pen. closterioides.

\section{Lillellii}

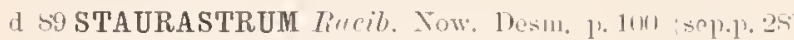
$t .7 .12$

\section{Lil)(Pe) (l)}

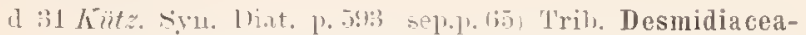
rum. Gen.: Trochischia. Closterium, Heterocarpella. Micrinsterias, Scenelpsmus. Biddulphia.

d 73 Thlyute Desm. subalp. sep.p. 25 et 71 . Rect. II Desmidiace arum. Gen.: Micrast.. Enastr., Cosm., Staur.. Santh., Dilymoclarl., Pen.. Clost., Pleurotanium. Tispluynct., Tetmem. Spirot. Ank.strodesmus.

\section{Lirlımull! - -}

a 89 COSMARIUM Rnelb. Desin. Tituan. p. 661 (sep'], 5).

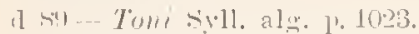

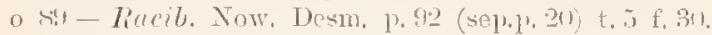

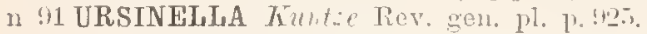

Cfr. Cosm. Botrytis r. emarginatocoustrictum Lemmerm. et C. Turpinii.

\section{ligretull!}

d 4.) PLEUR0T无NIUn West Alg. Mactag. 1. 1.1 t. 5 f. 1. .

\section{limbretum}

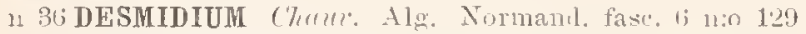

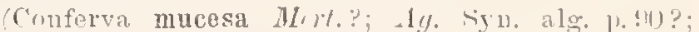
llook. Engl. Fl. 1.351?; Desinidium uz ucosum, Brib. in litt. [IIyalotheca dissiliens sec. Iinlf: $181 \%$.

$11: 3 \bar{t}-$ v. mucosum ibil. fase. $\bar{i}$ n:o 13.j ronfervo mucosa lmby Bot. gall. 1. Usit; Conte. C'lanvini 19 . in litteris)! | Hyal mucosa. ('fr. Jesmer.

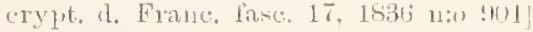

\section{limmonllillem,}

a 15 COSMARIUM Sichmidle Bnitr. all. Alg. 1. 157 t. $15 \mathrm{f}$. 20. Cosm. Reinschii Lreh. 18ti)

\section{Livere}

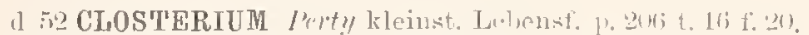

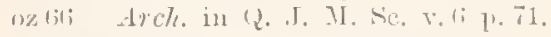

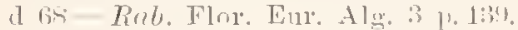

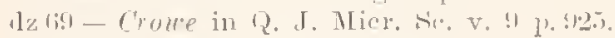

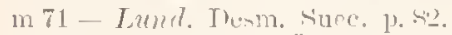

1172 - Iritlr. riotl. Öl. -ötr. 1l@. p. (i.).

de Sif-Coolic Bit. Dosm. p. :3i t. 15 f. - .

o 8 ! - Tomi sirll. Alin. p. sit.

11 !l ARTHRODIA Kuntze Rev. gen. 11. 1. Mt:"3.

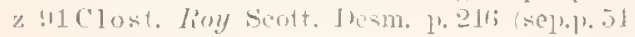

m 15 - Rarcib. in Flora $\mathrm{v} .81 \mathrm{p} .32$.

Cfr. ('lost, acutum et pronum.

\section{limerlis -}

1) 1:3 ARTHRODIA lifines\%. is Journ, lot, applic. 1 1, 235.5.

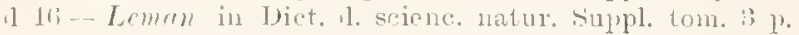
33. Bacillaria
11 15 CLOSTERIUM Trecis. Numenc.l. aler. 1.11. Cfr Arthrodia.

\section{limerers}

1) ty PENIUM (Hocidium?) Kït. Sirec. Alg. p. 16!l (losterinm lineare Nar. in litt.) [Pen, minntum b. lineare Rub. Litis. - Gonatozygon Brebissonii ut videtur].

\section{lineretem-re}

1) 34 CLOSTERIUM 77 wenb. Organ. lil. Raum. p. 2:36 (sep. 1). [1].

dat By-Ehrenl. Toxotinm Inf. 11. Tl6 to 6 f. VIII.

o $39-$ Heyen syst. Pf. Physiol. 111 p. 127.

1 $40-$ Menegh. Synops. Desn1. P. 231 (sep.p. 31).

(1) 11 - Iailey Amer. Bacill. p. 303 (sep.1).22) t. 3 f. 31 . [Cl. amblyonema Ehrub. 1813].

(1) 15) Hess. Brit. Alg. p.372 t. 48 f. 1 [snltem partim ex Ehronb. 1. c. delineatun, sal striis pancioribus].

(1) 15 - Fritz, ['hye, germ, p, 131

dzf 18 - liulfs Brit. Wesm. p. 173 t.3 3 f. 1.

d $-\beta$ ibid

d 49 - hï̈z. spee. Alg. 1. 105.

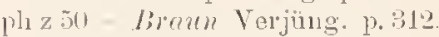

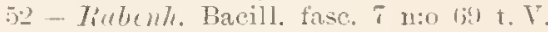

$\mathrm{d}_{\mathrm{z}} 52-$ - Priteh. Iuf. p. 282 ?

153 - Muth. Fl. Belg. II p.525.

d $3 i-$ v. sublævo Brib. List. 1). 252.

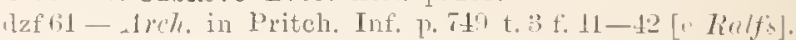
o 62 - v. tenue Biéb. in Rab. Alg. 11:0 1365.

lat 63 - liub. Krypt. Fu. Sachs. 1. 173 . fiv. 3 p. 152.

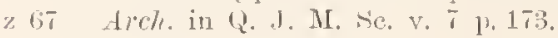

$16 \overline{-}$ - Reimeh Algenfl. Frank. 1. 192-3 Forme: A. tenuissimmm,

(1) - B. angustatum ibid, p. 193,

1 - C. angustrim ibil.

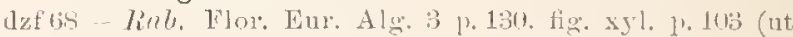
supra 18(t); ; formet b et ".

1 d. tenuis ibid.

(1) - Tordst. Desm. Brasil. 1. 201:, form.

* 71 - Lmud. Desm. suec. 1. 7!!

a tis Troorl Fr, Alg. 1. 112 t. 12 f.1.

11 $\%$ - Mirrogr. Dict. p. 176 .

d 7 - Lelponte Desm. subalp. 1. 11T (sej'1.213) t. 17 f. $2 \pi-30$.

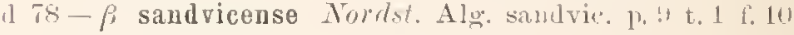
-12 .

1\% Tr-Kinchn. Alg. Rchles. 1. 13!3.

nus1-Lopot Mlater. alg. Warszitw. p. 252.

d 81 - Nolle Desm. U. s. p. 13 t. li f. lis.

- St-stolice Key 1esm. p. 112.

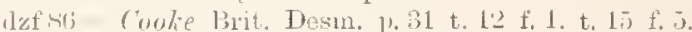

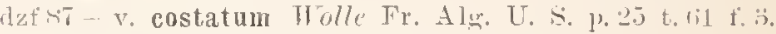

1) 87 - dexenko Chlorosip. Khark. 1) 22li,

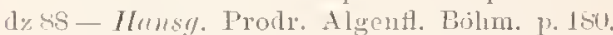

dz Mit-Toni et Levi Fl. Alg. Yenez. 1.32.

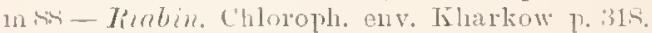

mits - v. sandvicense Nurtst. Fr. wat. alg. X. Zeal. p. lis.

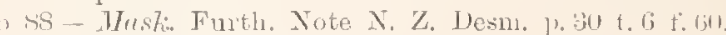

lz sil - Tomi ryll. alg. 1n. 83s.

i - v. sandricense ibil.

(1) (N) Böry. West1, Bras. 1).29 t. 2 f. 1.

m!

11 !1 ARTHR0DIA Kuntwe Rev, gen, 1). 13, s;.

m ! W Clost. West Fr, w. Alg. Wr. [rel. 1. 1:1.

o !.2 Nob. Austral. Susswasseralg. 1. 1.11.

(1) - v. sandvicense ibid. 


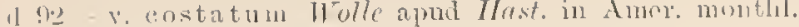
micr, .T. 1. 1 is t t. 1 t., 6 .

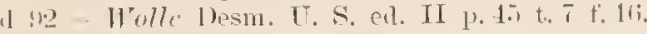

1 - . v. costatum ibid., t. 10 f. :3.

$111,-$ Gutu. Flor. glou, Falic. 3 1, 121.

d 9:3-Cably Contrib. Queensl. Fil. 1\% 11.

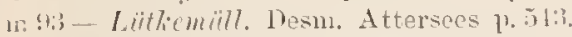

m! $1 ; 3$ - Turner Alg. Ind, nrient. p. 201).

m!l Bsandvicense Borge siissw. Clulor. Arolnng. p. L.

15-Jubius apul Briley Contrib. Queensl. Pl. Xl t. 11) f. 13 .

\section{tilleolutull}

1 1:3 CLOSTERIUM Ehrent. Tilir. Trh. Ninil. 17. N. Imer.

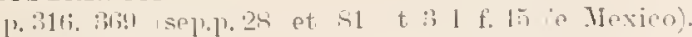
(Quit? \%

\section{limenlutum}

1) f! CLOSTERIUM Kütz. Spee. Alg. p.11\%) (ox Antillis)

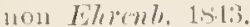

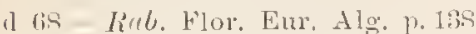

d k:! -. Tomi. Syll. Alg. p. Giul.

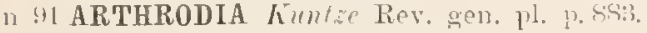

\section{tithurths}

1) 21 GYGES Burly in Eucyel. meth. Hist. Nat. (l. Zooplyyt. II 2 1. tho Paramecium narginatum Miill. [Ctr. Elerent. luf. p. 53; Vorticella?, Bursaria?. Spico-

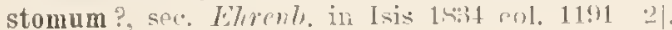

\section{littorule -is}

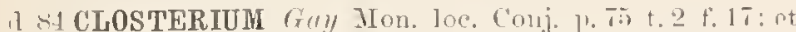
Note C'onj. d. m. France ]. 33s?.

1) 8 ! - Toni syll. alg. $11,84$.

n !1 ARTHRODIA Kuntze Pov. gen, pl. p. 48:3.

\section{(ot)ato.s/10)' 1111$)$}

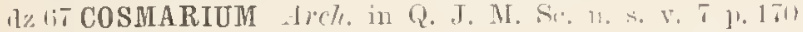
172

dy dis-Rab. Flor. Enr. Alg. : p. 17!.

l\%, 4 - Coule Brit. Desin. p. 121.

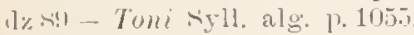

\section{loteltulum) -}

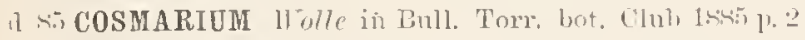
t. 17 f. 333 \& 3.4

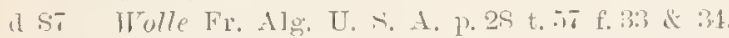

(1 S!) - Toni Syll. alg. p.1010.

1] !1 - URSINELLA huntze Rev, gen, 1)]. 1).925.

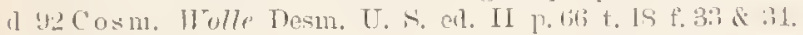

\section{lobritille}

1] !n) COSMARIUM Böry. Desm. brasil. 1\% 12 t. 4 [? :3:

\section{In) IIII(1)}

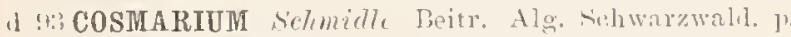
$1(1.1+5,5$ t. $1 !)-21$

\section{(o) letutull)}

1) is FUASTRUM lipel L ste p. 1.21 t. 1 f. 1 .

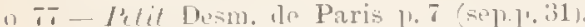

(fir. Eu, b nale $r$ rotundata $I s t r, 1$, sit. En, ele gans v. Jue. 15,5

\section{Lo!jichsp?}

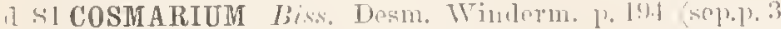

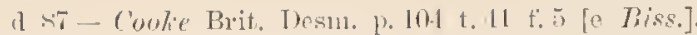

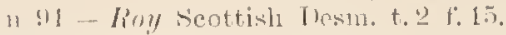

\section{$101191111-11+1$}

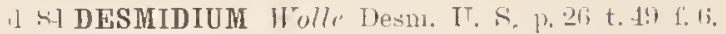

o st3-Stokes Riny Desm, 1. 1111.

11 si aYMNOZYGA Nmedst, in Wittr. et Nordst. 1lg. Exs. 11:0 81 (1).

11 89 - Timi sirll, alu. 11. 7!!!

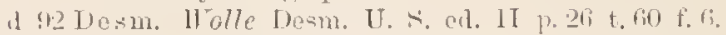

\section{longicolle -is}

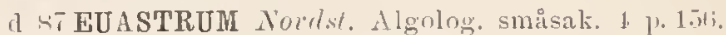

d SS - Nordst. Fr. wat. alg. N. Keal, po $3: 3$ t 3 f. i.

o 89 - Wask. Furtl. Not. N. \%. Desin. p. 12 t. 1 t.

a s! - Toni śr]l. 2lug. 3. [10!3.

1) (1 HELIERELLA hunta Jiev, gen. pl, p. 598 ,

(1) 13 Eu. v. Himalayense Turno Alw. Ind. orient. p. si t. 23 f. !)

\section{longirollis}

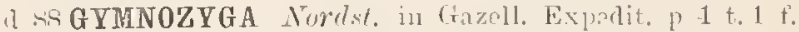
$11)-11$.

o $15-$ Racii). in Florn v. 41 j, 302.

\section{loughicomis}

11: 12 ARTHRODESMUS "lioy in litt." West Fr, w. Alg. WT. Irel, 1? 16!!

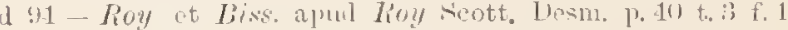
$(\div-3] \cdot] \cdot 24)$

\section{Iongifiroms}

1 9:3 EUASTRUM Twver Alg. 1ml, orient. 1. st t. 11 f. 3 a (major), a' et b (minos) [Cfr. Hillem. Obs, erit., 1,

\section{lom!jispill.16m.}

1) PHYCASTRUM I' :() Asterothrix pliycastroides A. Iirmm. - Polyedrium long. Iial. - Tetraëdron lung. IIrnsg. Cerasterias loug. Reinsch!.

\section{longivpillum}

(1) 5I DIDYMOCLAD0N? Bail Micr. observ. p.33 t. $1 \mathrm{f}, 17$.

d 5.2-Priteh. Inf. p. 271 .

1) 31 STAURASTRUM Are\%. in I'ritch. Inf. p. $74 \%$.

d ge-Rab. Flor. Fur. Als. 3 p. 221.

71 - Pleurenterinu) Lumd. Desm. Suen. P. T3. ISt. bidentatum 11 ittr:

ph 52 - Areh. in Q. J. Hicr. Sic. p. 1:19

1 73 - Hood Fr. Alu. p. 14.

phit - drek. in Journ. of Bot. p, 94

81 - Coole in Crrevillea \$ t. 141 f. f-g. [St, bidenta$\mathrm{tum}$.

6. 1 - Cooke in Queliett Micr. J. 13 p. 206 t. 16 f. $11-1$ ? [St. bidentat.]

1. 8 - Walle D.s.m. U. S. p. 1 t. t. 11 f. 7 [e Bail.

o si- Wulle in Bull. Tor'r. bot. ('lub. 12 p. 128.

un sfi-Lagerh. Amerils. Tesm. p. 24!) t. 27 f. 29 .

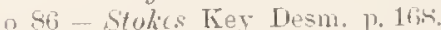

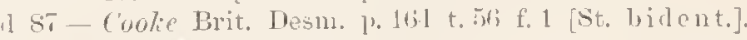

(1) s.) - Tomi syll, alg. 11. 11!!!.

m 12 - Wcst Fr. W. Alg. W. Ire]. p. 150.

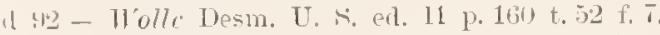

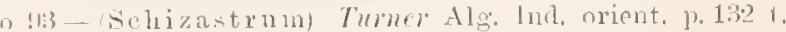
23 f. 12

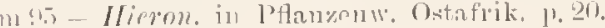


LONGIUSCULUM

\section{7on!finserllum}

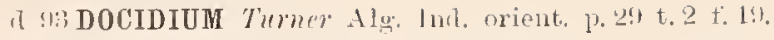

Lometirnullur. - r

(1) 199 COSMARIUM Retb. Alg. Enr, 13:0 $210 \%$.

(1 8:- Tomi svll, alg. p. $105 \mathrm{f}$.

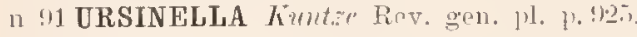

\section{I.nlle}

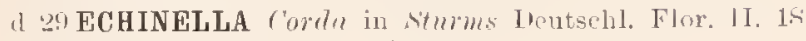
t. 11. Closterium Leibleinii?].

\section{Lumret"}

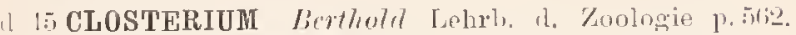
Aunm lapsu ralami l. errore typograpuien "Lunata" [ro "Lmula"? .

\section{I"1m!1!"1! - -11}

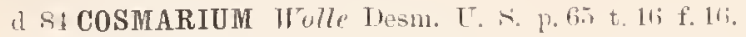

o si-siokes liey Desm. p. 12\%

A so-Tomi sitl. ale. p. 1031.

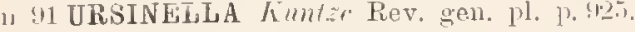

d 92 Cosm. Trulle Iesm. U. S. erd. Il p. 71 t. Lit f. 16 .

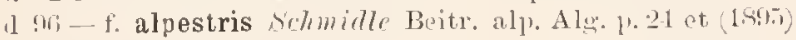
t. $11 ;$. . . $2-$.

\section{liluretull".}

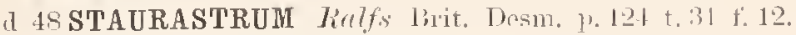

a 52 - J bitrle. Inf. p. 24 is.

I $61-$ Aveh. in Pritch. Inf. 1. 685.

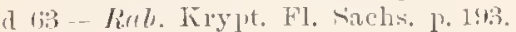

14 19-Rerb. Flor. Eur. Alg. :3 1.2:21.

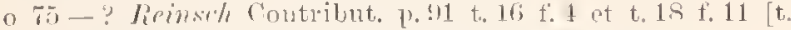
1s f.:3?, sul, nomine staur. nitidi $f_{0}$.

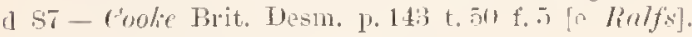

d 89 - Tomi sill, alo. 1).114t:

o 89 - f. Rircit. Now. Desm. 1.10\%.

o!n-Eichter s.is Desm. Miedz. 1, (n).

m.91 - West Add. Freshw. Alg. WV. Yorksh. p. 217.

1n 91 - Borge Bith. Sibir. Chlorozh. 13. ?.

m $5+2$ - West Fr. w. Alg. W. lrel, p. 173.

d 94 - v. subarmatum II'est New Brit. Alg. p. 11 t. 22 f. 4 .

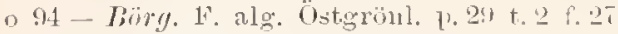

d - f. triangularis ibil., t. 2 f. 2 :

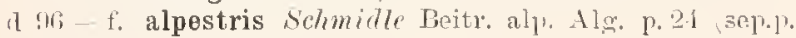
3i) et, 1895 , t. 16 f. 2 .

\section{Lumallii}

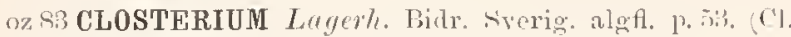

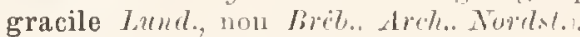

dz 89) - Toni syll. Alg. p. 818.

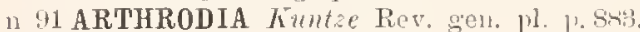

\section{Lundellii}

a Tr COSMARIUM Helponte Desmid. subalp. p. 13 (sop.l. 109 t. 7 f. 132-19. "Lnmlelii".

m 80 - Witle Norg. Ferskv. alg. I p. :3:

n 83 - f. Nordst. in Wittr. et Nortst. Ale. exs. nu: 5fil et in fase. 21 (LSSy) 1\% 13.

m St - f. minor Racit. Desm, okol. Krakowa p. sep.p. 1-I.

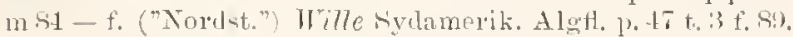
1. 45 - Toni syll, alg. 1r.956.

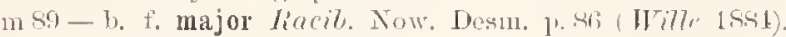

m (n) - f. minor Eichter spis Desm. 1. 8s.

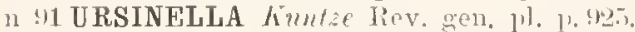

m 13 Cosm. Wrill. et Nordst. Alg. exs. 11:0 1122.

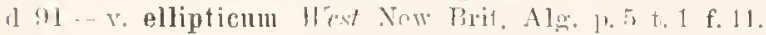

1 $45-$ - v. madagascariense West Alg. Madag. 1. 5.) t. in f. '. .

1) - v. suhangulare ibirl. 1.56 t. 8 f. 3.

\section{Lumrlellii}

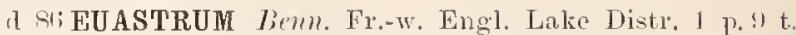
1 f. 13 . (E. binale y' elobatum Lund. Desin. Siter. sec. anct., sel ut villetur non ita).

o 86 - Stokes liey Desm. 1) 145.

d 89 - Tomi ryyll. alg. 1. 1080.

„91 HELIERELLA Komtze Rev, gen. pl. p. s!s.

\section{Lumallii.}

1) STAURASTRUM Twmer Alg. Inl, orient. p. 131. t. 16 f. 15

\section{Lu11!lu.}

ph 17.41 VIBRI0 Wiiller in Natmforsch. XX p. 112. et ph 1681 - Mermam ibid. p. 169 t. 3 f. 59 [non sensu anctor. recent.].

d 17 si - Mïller Auimal. Infus, p. XXXI et 55 t. $7 \mathrm{f} s-15$ ("Der halbe Mond" Eichorn kleinste Wasserthiere. $1781,1.15$ t. 5 f.C [- est Cl. Diande sec. Iacubs.] [sec. Bhrenb. Inf. f.s $=$ ('l. Corau?, f. 911 ( 1 . moniliferum, $f .12-\mathrm{Cl}$. acerosum, f. 13 ct 15 - Cl. Lunula, f. $14=$ Cl. tnrgidum? - Nes. Käl: 1831 arl Cl. Leibleiuii fortasse pertinens. Fig. (-1.) saltem 4 species ostendunt].

d 17:1 - Bory in Eneycl. méth. Planch. Vers ton. 1 pt. 1 p. 11 t. 3 f. 21-27 [figg. Mïlleri denuo dejicta!].

(r) MÜLLERIA? Leclere see, Ehrb. Inf. p. (n). - Lecler Mém. du II Is. I? sec. Wenegll. Isto Annon= Mulerina, efr Lemom in Dict. sci. nat. suppl. tom. 3 p. 1591.

$0: 3$ - Schromk Favna Boica IHI. 2 p. 47.

o 17 CLOSTERIUM Nilzsch Beitr. \% lufus. 1\% 160 et 67 [sensil Wïll.].

phe 21 Vibrio Grathuisen in Act. Nov, ('urios, X. 2 1) t.49 [efr. Cl. monilifer.].

plo 2:3 BACILLARIA schtrml Oscillat, in Nov, act. XI. '2 p. 533 .

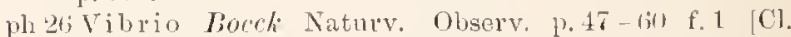
monilif. 1. Cl. L, eibleinit?

1) 28 c'lost, Ehrent, Symb, phye, Evertebr. I. Phytozoa t. II. IV f. 6 ['l. Lunula et Diauæ?].

m 29-Ehrend. in Abh. d. Berl. Akad. 1S23 p. 15.

d 2: Vibrio De Jilameille in Diet. Se. Nat. tom. 59 1. 7i;

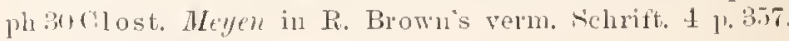
$35 \div, 117$.

ph $30-E h m m b$, in Isis 1\% 169.

mis-Lhrenb. Beitr. z. Kennt. d. Infus. 1)62 [‘' moniliferum sec. lialfs:

o 31 -Ehrent. Symb. 1'hysic. Fol, b. re. 2.

1 $32-$ Ehronb. Entw. 1. Tnf. p. 6 .

d 3:3-k Kül. Alg. ar. dule. Dee, III n:0 22 [verum].

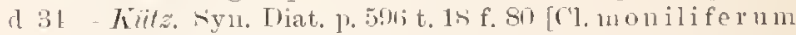
t. Kützingrana Jucobs. 187:

o 34 - Corde in Alm. d. Carlsb. 1435 1) 190, 192. 194. 248 t. 5 f $56-5$ s [f. 5 t $=$ C1. acerosum ser. Ehrent).

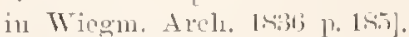

d 35 - Diel. Alg. Fal, 1, 58 t. 8 [C]. moniliferum].

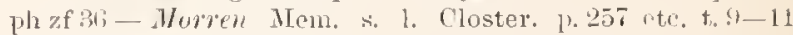
[Cl. Ehrenbergii 1), maxim, parte].

37 - Desmaz. Deser. esp. nour. 1.213 t. 6 f. 2 [Cl. Whrenl.].

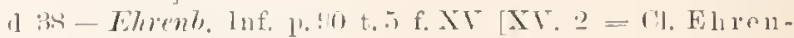

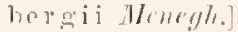


pho! - Meyn syst. P'H. l'hysiol. Ill p. 13:i ct 150 t. $10 \mathrm{f}$. $2.1-24 i$.

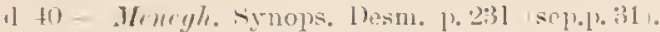

ph th-Loluarze $w$. Saftstr. t. T 1. 1-3 [Pen. Libellula?].

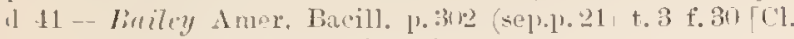

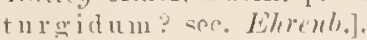

I $41-1 / 6 m t$. in Hist, nat. ('anas. p. 1\$1.

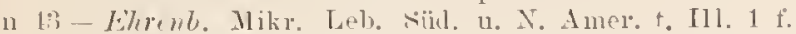

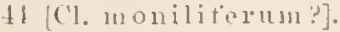

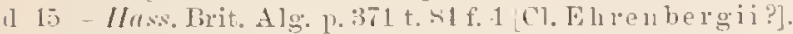

d t.i. Küts. Phye. germ. 1. 1:30 [Cl. Ehlenbergii].

I 17 - Finde Phys. Stul. I 1, il, 69 t. 3 t: 1-15. [See. Inly. 1, 6 : fire. 1, 2, 3. 1. 1; = ('l. flaccidum [s. Jenneri ? ; J [?] $7,111=$ Cl. monilifer.1111; $11=$

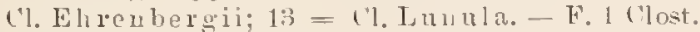
tetractinium Gay? ?.

It 4s - Riulfs Brit. Desm. p. 1 tis t. 27 f. 1.

1) 19 - Kütz. Nipec. Alg. 1) 163.

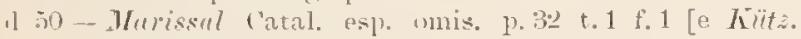
sym. Diat.].

.31 - hab. Bacill. saclsi, n:o t t. 2 ('l. Whrenbergii].

d $52-$ Jrilch. Inf: p. 2 sit.

d is - Math, Fl. Belg. II 1, 5.2.

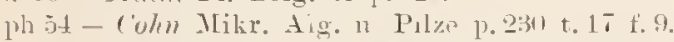

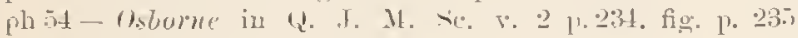
et $283-9$

ph $55-$ - ibill. v. 3 p. 1 î

50 - Bram über Chytrisl. t. i f. 21 .

m.t-Suring. ubs. plifool. jo (il [minor?

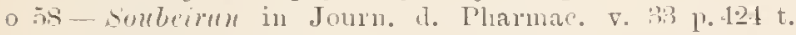
1 f. 1 i.

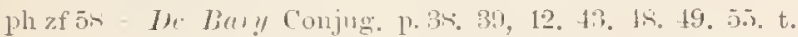
5 $\mathrm{f}, 24-25$.

phis- Ilenfr. in Anu. Mag. Nat. Hist. 3 ser., 1 p. 419.

phot - Areh. Ahnorn. Desm. sep.p. 14 in Nat. Hist. Rev. P. 17.2.

phlin - Arch. Zousp. in Desm. et Alonmm. Thesm. in Nat. Hist. Rer: 1). 34 s et 391 t. 13 f. 5 et (i.

di til Areh. in Yritch. Int. p. it

1 63 - lind. Frrpt. Fl. Saclss. 1. 169 , t.6 1. 152.

ph fi. - Reinsch Iorphol. liragu. p. 17 t. 1 f. $\mathrm{A}$.

mfit - heinsch Algent. Frank. y. 15 ?.

d 1j - Not. Hesm. Ital. p. 59 t. 6 f. 61.

(1 67 - Kickx Flore crypt. Flandr: II p. 411.

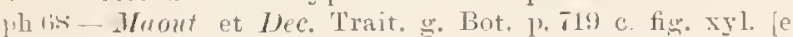
De Bury Conj.].

izf tis - Walz Zygosp. Cluster. Lanula p. 41 t. 2 f. 1 - ?.

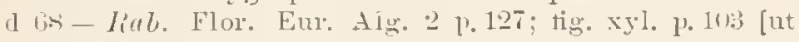
strpira 1863).

on 70 - Reimhard in Arbeit. 1. Naturf.-g. Charkow I p. 15.

d 73 - Woul Fr. Alg. 1\%.111.

o 7 - Nordst. Norg. Desm. 1.41.

4 75 - Microgr. Dict. p. 176 t. 10 f. 41 [e Riulf:s].

ph 5 - s - schumam in Flora 11.65 t.2.

o T-Jaculs. Desin. Danem. p. lis.

d 7 - Thelponte Desmicl. subalp. 1.45 (sep.p. 1!1) t. 16 f. $1-3$.

(1) 7 - Kirchn. Alg. ichles. p. 13a.

mis-Mempel Algent. Cluemnitz p. 111.

m to - Wille Ferski. algo. Nor. - hemlj. p is.

d $7 !$ - a typicnm lilebs losm. Ostpreuss. p. o t. 1 f. 1 b.

ab coloratum ibid.. tornı, $a=$ t. 1 a, $\beta=1$ il et $c$. sublanceolatum ibid. f. $\alpha$. et $\beta$ t. 1 fig. 1 f et. e.

d - cl submonilifornm ibil. p. $T$ t. 1 f. 4 a.

ph s1) - Wills in Midland Tatmalist r. :3 p. Lit.

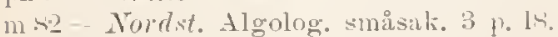

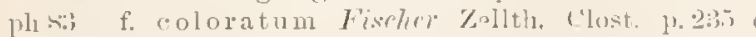
t. 3 f. 1 .

Shrdifed, Index Desmid.

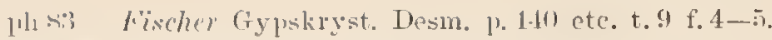

plu f. coloratum ibid. p. 141. t.!) f. (i.

in R- - Groy Mon. loc. Conj. p. Tt.

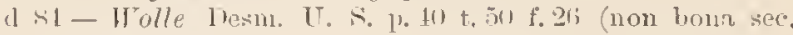
auct.).

m S1 - Wille sydamerik. AlgH. p.33.

(1 sis-Kirchn. Mikr. Pflanz. d. Niissw. 1'.21.

In 85 - Boldt silpir. ('bloroph. p. 122.

1 $\mathrm{xi}$ - Bulsamo Alghe del comm. di Napoli p. Br.

d sij- Framli in Leunis Synops. 3 p. 1:8.

msi - Laycrl. Amerik. Desm. p. 254.

ph wi- lierthold ritud. Protoplasmaneels. 1. il.

o sti - Ntukes liey Desm. p. 112.

1 kij-Cuokic Brit. Desm. p. 19 t. S f. 1.

si - Tumer in Leels nat. clnb transact. 1 t. 1 f.s (ex Areher).

ค. $.7-\mathrm{v}$ striatum $\|$ olle Fr. Alg. U. $\therefore$. A. 1.21 t.55 f. 12.

(1 4.7 - Alesentio Chlorosp. Kliark. p. 222.

d ss .. Hansy. Prodr. Algenf. Bühm. p. 17!.

11,88 - Toni et Ler. Fl, Alg. Venez. p.30.

o s. - Riabin. Chloroph. Env. Kiharkow p.31.) (sep.p. 27) t. 8 f. 13 (forma).

ph ss - IItuptfl. Zellm. u. Hüllgallerte Desm. p. ns (sep.p. (1) $t .3$ f. 11 et 12 .

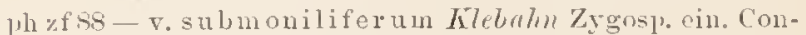
jug. 1. 16:1 t. 7 t:.17-20.

m 88 - Iste. Jel. magyar. alg. 1).23\%.

m Si-Nordst. Fr, wat, alg. N. Zeal. p. it et Ti.

o - ? b. eoloratum $\beta$ (Klebs ilid., t. 3 f. 24i.

m s! - West Aldit. West Torksh. p.s!?

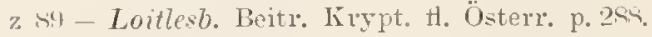

1t 89 - Toni syll. Alg. 1) 831 .

- - - coloratum ibil. p. 832 .

d !) - ce cuneatum crutw. Wahn. d. l'riorität. p, ft;.

ozf th-r, submoniliferum? Klebuhm sturl. ̈̈. Zygot. 1 3. 420 t. 13 f. $1-16$ (forsan propria spee. ser. auct. :

$m(n)$ - Eichler spis Desm. Miect\%. p. 45.

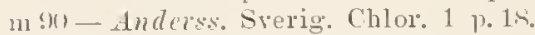

1) (1 - Kirchn. Mikr, Pflanz. 1. Siissw. ed. 2 1.22.

n 91 ARTHR0DiA fiuntze Rev. gen. pl. p. 883.

1) 91 Clost. v. cuneatum Gutw. Flor. alg. Leopol 1.82 t. 1 f. 6.

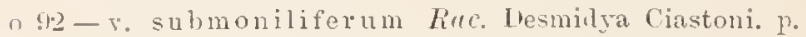
308 t. 6 f. 43.

1) 22 - $\Pi^{*}$ olle Desm. U. s. ed. II p. 12 t. 61 f. $21 \%$

(1) - v. striatum ibil.; t. 6 f. 12.

m! 12 - West in Notaris. 7 p. 1f!s.

m!13 - Lïtkemïll. Desm. Attersees p. 542.

o 93- Campyloceras) f. Tum. Alg. Ind. orient. p. 1! et 23 .

d $3:$ - f. Tordst. in Wittr. et Nordst. Alg. exs. 11:0 113T c. fig. xyl. $1-2$.

ph $1: 3$ - Klebs in Biol. Centralblatt 13 p. $0: 2$.

m! $4-f$. minor Borge silssw. Chlor. Arehang. p. 15.

n 94 - Heraentio Mater. alg. Khark. p. 20.

u1 y) Gutw. Fl. alg. Tarnapol. p. 69.

1) 4 - т. biconvexum schmille Beitr. alp. Alg. p. Bont. 1 f. 18 .

Cfr. (lost. acuminatum cmole. C1. Lnnata. Cl. moniliferum f. Mülleriana Jac. 1si,; Echinella radiosa Achur. 1sIu, Lunulina Mongeotii et vulgaris.

\section{lummlatum}

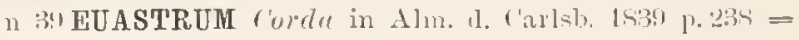
Pediastrum Selenæa. 


\section{LUNUIINA}

a $2.2 B 0 \% y$ in Dict. class, hist. nat, v. 2 p. 124 .

d 21 Trary in Encyclop. Méth. Histoir. Nat d. Hooplyyt. ₹. 2 p. 189 et B(ii).

1) 26 liowy in Dict, class. hist, nat, v. \$1 p.512.

29 Tump. in Irict. d. se. nat. Planeh. bot. Tég. arotyl. unilocul. Vesictl, t. I f.:3.

\section{Ineida}

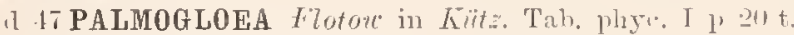
$25 \mathrm{f} .8$ ( I. rnpestris ex P. olim)

d th-Küt: spec. alg. ]), 22s.

o fit - Arch. Descript. (sep.p. 5 in Dubl. Nat. Hist. Sno. 1.1. 17 .

1 fos-Rub. Fl. Eur. Alg. '3 p. 11s.

Cfr. P. macrococca 1.803 ot P. violascens I/rmsiy. $1 \mathrm{~s} 8 \mathrm{~s}$.

\section{Lusitruirullu}

dz! 2 COSMARIUM Wret in Notaris. 7 p. 15412

\section{liteolulli!}

(1) a STAURASTRUM Lagr \%. Amerik. Desm. p. 247 t. 27 f.. 26.

1] si- lolle Fr. Alg. U. S. p. 13 t. 60 f. $22-23$ [e Lagrh non bene?.

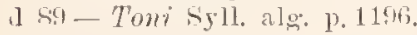

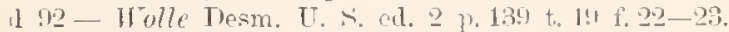

\section{1: $x^{\prime}$}

1 86 MICRASTERIAS .Josh. Durm. Desm. p. 631 t. 2.22 f. 12. (1) 8 - Tomi iryll. alg. 1) 111s.

n 41 HELIERELLA huntá Rev. gen. 11] p. s!s. m!BMicr. (Actinorgstis Thrme Alg. Inul. orient. p (I) t. B F. 1i.

$1 \quad-\beta$ Wallichii ibid, t, 2.2 f. 2

\section{Ly!u!blyi}

n 2.5 HELIERELLA Bury in Dict. class. hist. nat. v. \& p.

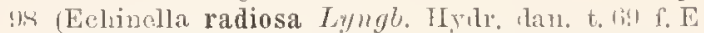

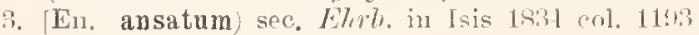
-1]. ( $\mathrm{fr}$ sil h) Helierella.

\section{murnllentse}

1) 6.) STAURASTRUM Am. in Q. J. M. Sc n. s. p. 200 [Ntanl. pseudocrenatum lawd. 1Si1 sece treh. in Jouru, of Bot, 1871 p. 987.

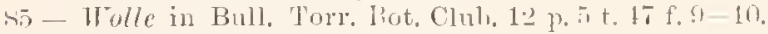

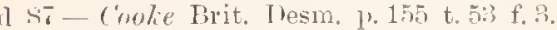

1) $89-$ - Toni iyll. alg. 3. 1175 .

$1 m$ st - Wey Fr. w. Alg. W. Irel. p. 17 ti.

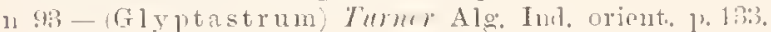

\section{mureitentume-n}

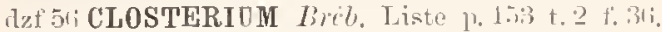

$1 \% t i 1-A ; c h$, in Pritch. Inf. 1) 117.

6 62 - Arch. ("lost. acic. 11. 32 .

a his-hat. Flor. Eur. A]g, 3 3, 131.

o 71 - Lumd. lesm. Snee. r. 7 .

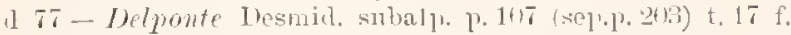
$60-1 ; 2$.

dz Ts Kirchu. Sclles. Alg. p. 137.

m st - Rucih, Desm. okol. Krakowa p, s

dz8.t - Walle Desm. T. S. p. 3. t. 6 foti.

lzas - Mansy. Proiln, Algenf. Bihm. 1. Lit.

mots-Istr. Tol, magyar. alg. 1, 2BS. m s!) -..- Hare, Fr. Alg. Maine 11 p. 18..

1 8 ? - Toni sivll. Alg. 11. \$21.

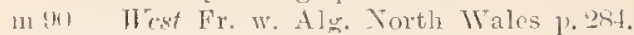

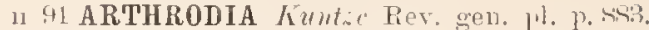

1) 92 Clost. $f$ substrigosum liar. Desmilyia ("iastuni j. 399 et $391 . t, 1 \mathrm{f}, 34$.

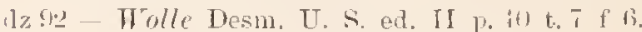

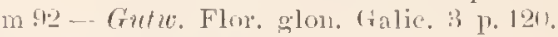

\section{merevorerllu}

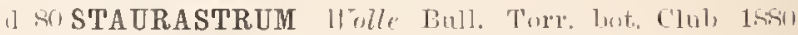
p. 4 is t. 5 f. i

d .4 - Wulle Desm. U. S. 1. 131 t. 13 f. 3-

o sti-Stutirs Key Desin. p. 16t.

11 .

11 $92-$ - Wolle Dosm. U. s. ed. II p. 1 ts t. if f.:3-1.

\section{merrenorocint}

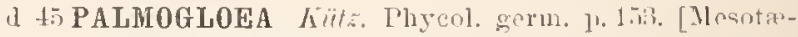
nitum chlamydosporum Do Bury (?) see, Llor. Teseripit. 1sint

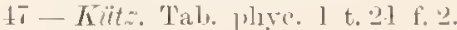

1] fil-Kït spec. Alg. p. 222.

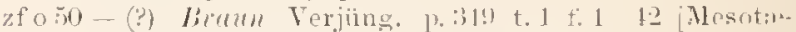
nium Braunii sec, De I'ent. Conjus.?

2 57 - De Bur. in But. \%eit. 1'. Tis.

o is - Heply in liab. Als. 11:0 tist.

15 - $\beta$ nigrescens (') (Yomer in Rab. Alg. n:0 60?

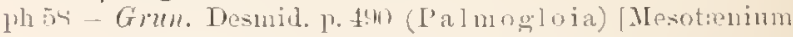
s].? sec. Alohu Descript. 1silt ], 2t].

1) 633 - laub. Krypt. Fl. Sachs. 167 (incl. I'. protuberans, vesiculosa, lurida et rupestris Kïti.., Mesotienium Branni i De Dat..Coccochtoris Brebissonii Therrit. . [Figr. xyl. a et $\mathrm{b} p .150=$ Mesotituium violascens,

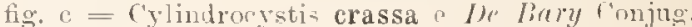
delineatre.

of fit - Arch. Descriplt. (sep.1\% 111) in Unbl. Nat. Hist. Noe, Pr. 1. 21: in Q. .1. M. . - 1. 10! ete.

o ot - riclis in t?. J. M. S. p. 353 .

o 66 - Arrh. Obs. on Cyliucts. (se].]. 2 ete. 201 atc.

m 67 - lítinsch Algent. Frank. P. $2 m$.

o phet-llicks in Q. I. M. Ne. VII p.t.

o 67 - 4 re\%. Conjug. Spiroten. 13. 192.

d\% ris - Rub. Fl. Eur. Alg. 3 1. 111;, sens, latior. lig. it 1.162 [e liry t. Fl. Riaclis.].

111 b. minor ibil, 1,117 Mesoten, Branuif $p$ minus lie liaryl.

(it) - Guppert in Abh. Sichles. Ges. v, Cultur lisin p. lil -iir t. 1 f. 8-13 (e I)e Bury).

nu- licinseh Alg. Prom. Bon. Spei 1.23:1. Cfr. l'almoglnea dimorpa.

\section{6\%0:0 11071111}

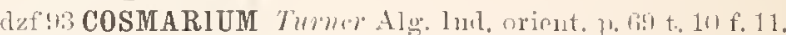

\section{murnlatiforme}

1) 4. (Plenroteniopsis) Swmille Alg. Sumatr. p. 301 t. + f. $3-1$.

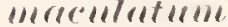

d :2 CLOSTERIUM Hast, in . Imer, monthl. mier. T. 13 l'. 15.1 t. 1 f. 5

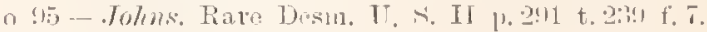
Cir. Clost, Brannii.

\section{0ulutum}

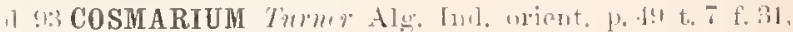
t. $S$ f., 6 S (forma). 


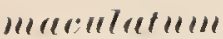

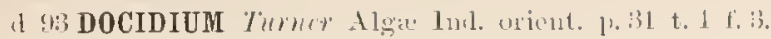

\section{m"1/r/lunirum}

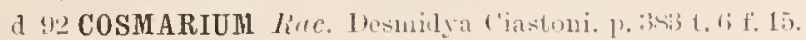

\section{"ll"!llifirllll -"l}

o it COSMARIUM Pleurotamiopsis Tordst Alunlog. smrisisal. $4 \mathrm{~T}, 162$.

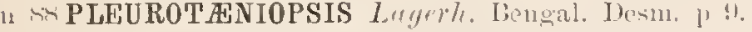

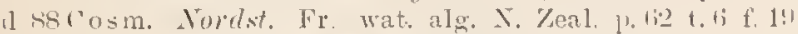
(C. gemmiferum Mast. 1siril.

ll s!l l'lenrotaniopsis Cosmarilium Toni syll. alg. 1. 31.5.

(1) s! Cosn. $\beta$ italicam lincil. Now. Desm. 1.933 (sep.p. 21) t. 6 f. 1 .

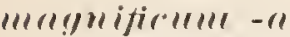

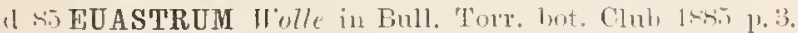

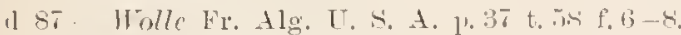

d sil - Toni syll. alg. p. llsi.

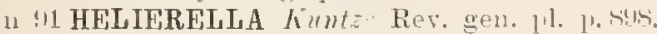

1) !2 Eur. $\%$ crassioides IInst. in Amer. monthl, micr. J. p. 1.33 t. 1 t. 1 . [E. crassum sec. Burge et Wist 189.5

1 !12- Wolle Desur. I. s. ed. II p. 10s t. 29 f. $15-4$

I - - v. ciassioides ibit.

\section{mI"!) $1111 !$}

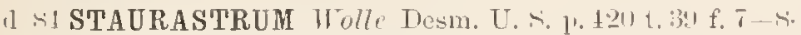

1) si - Stolifs Key Desm. 1. 161.

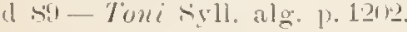

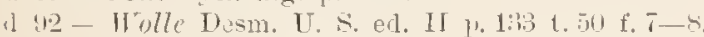

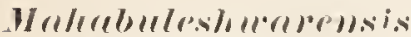

(1 b:3 MICRASTERIAS Ilobson Ind. Desm. p 168 - a. e. icone 1. $16 \mathrm{is}$.

(1). Areh. Oba, on Mier. Mahab. in Uubl N. H. S. H. p. 7!!; in (2. Jon1"n. M. Sc. p. 25.

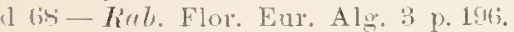

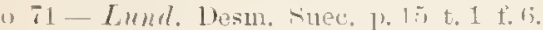

111 so - Nordst. De Alg et Charac. 13. 11!.

o $\mathrm{S1}$ - v. Americana Wolle in Bull. "lorw. Wut. "lub v. o 1.. 1 t. 1; f. 1.

$1: 4$ - Wolle Desm. L. . . p. 112 t. 37 f. 111

o sil-Stolies King Desin. 1'. 146.

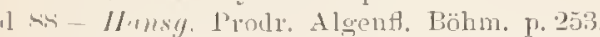

(1) Ast - fi surculifera Lagerh. Bengal. Desh. p. 5 l. 1 f. 1.

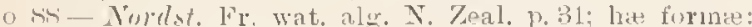

1. genuina. a. indica (incl. M. morsa of Frell. 1,isto, ‥ Wallichii (irme.

- h, enropæa cfr. Lund. Litil et M. Walli-

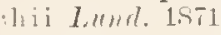

B. compacta. a. americana (Cfr. Wolle 1ists. et I. a merieana v. Hermanniana Wolle 1sst

1). enropæa M. Hernaniana. Reinsete c. novizelandica ihil. M. ampul la cea Morsti 1hisi lefr. intrich.

fi ampullacea ibil 1,:31) t. 2 f. 11 i

(1) s! - Tomi rivll. alg. p. 1122.

1) - v surulifera ibid.

d - r. ampullacea ibid: et forme a Turdst. supra 1ksi comnemorate 1. 1123.

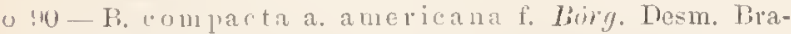
sil. 1. 3.2.

12 11 HELIERELIA huntze Fev, gen. pl. 1, 8!!!.

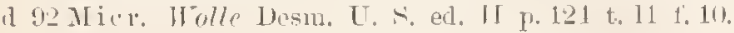

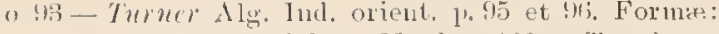

o - f. typica (Hobs.. Nordst. 1s81, Turn.) t. \& f. 1 (major).

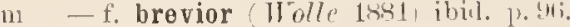

$m$ - f. Europiea (Lund. 1str) ibil. p. 919.

- f. Novizelandica (Nordst. ex 11.; quoad fig. Musk. t. 11 f. 7 ) iluid. p. 9.1 .

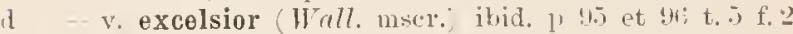
(1I. morsa of Hall. 1Stiol.

m!1! - Mob. Austral, süisswasselalg. 11 p. :311 [3. compacta c. novizelandica Norlst.l: et a juel Sirile! Contrib. Queensl. F1, X1. 1895,1 , 12 t. 10 1. 11.

(1) 15 - v. tetracera II est Alg. Malag. 1. 48 t. 6 f. $2-1$.

o 45 f. Rucil. in Flora v. 41 y. 35 t. $3-1$ f. 7. ('fr. Mier. americana fi. Mask. $18 s$ s.

\section{IIrejus}

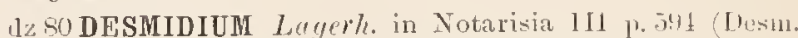
graciliceps f. major Lagerh. 1.88i).

dzs - (Didrmoprium) Toni syll, aly. 1\% Tsl.

$0.95-R a c i b$, in Flora v. 81 p. 31.

\section{Mrjusem/1m}

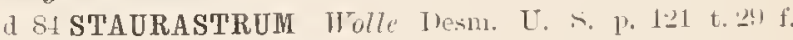
$5-1$

a wi - Stolies Tiny Desm. p. 164.

d $\$$ ! - Toni syll, alg. p. $121 \%$.

a 92 - Wolle Desm. U. S. ell. II p. 133 t. 50 t. 5 -6.

\section{Maliuveruirmmm -}

d 6.5 CLOSTERIUM lo Not. in Erl. urit. Ital. 11:0 1.51 [1. v.] [Cl. Ehrenbergii b.? Malin. liub. 1stis].

o $71-$ Land. Desm. Suec. p. 51 .

o 73 -? Lenz in Mecklenb. Areh. p. 5 s.

d s.1 - Toni Syll. Alg. p. 815 .

n 91 ARTHRODIA Kuntze Rev. gen. pl. p. 443.

o Yf Clost. Johns. Rare Desm. U. S. p. 2St5.

11 ! - Gutio. Fl. alg. Tarnapol. p.s1.

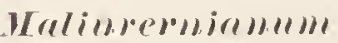

o ! 1 COSMARIUM schmille in Flora is p. 5s et bito subtholifurme v. Malinveruiauuu Rac. 188:4).

a - v. Badense ilid. 1.7 f. 21 (C. sulbtholiforme v. Badense ibid. P. 5ं') Cfr. Cosm. e yclicnm Reinsch 1570.

\section{"1)relleoferll"}

1) 14 XANTHIDIUM Thite in 'Transact. mier. soc. v. 1 1' S0 t. 8 f. fi [Fossile, an Spongia]. [Qnoyue in Micr. Journ, v. 2, 18.2. t. 4 - n. v.].

\section{niremillretre}

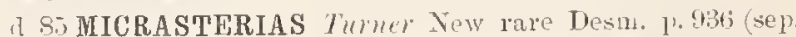
p. t) t. 16 f. 12 [M. apiculata f. sec. Wolle in Bull. Torr. Bot, Chn', 1856 13. 5y].

( 57 - Wolle Fr. Alg. U. S. A. p.3:1 t. 6.2 f. 2 [e Turner].

d 89 - Toni siyll. alg. 1) 112 .

11 "1 HELIERELLA huntä́ Rev. yen. 1) p. 89\%.

1) 12 Xicr. Wolle Desm. U. S. ed. II p. 125 t. 16 f. 2.

\section{mrellillatum}

d 93 DoCIDIUM Thrner Alg. Ind, orient. p. $2 \overline{7}$ t. 2 f.

\section{mamillatum}

a T STAURASTRUM Nordst. Desm. Brasil. p.22 (sep.]. 187) t. 1 f. 55.

71 - Lund. Desn. Suec. p. 1i1; forma.

(1 81) - Toni syll. alg. 1. 1152 . 


\section{mammatum.}

s:! EUASTRUM Musk. Furtl. Not. X. Z. [Mesm.

a - v. subcuneatum ibid, p. lit t. 1 t. 1.

d - v. ellipticnm ibir. p. 10 t. 1 f. 1 A.

\section{mamillifermm}

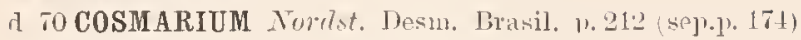
t. 3 f. 2 ? 2 .

d 73 - $\beta$ amazun Nordst. Norg. Desm. 11. 21.

त 8.1 -Toni Syll, alg. p.

d - - r. amazum ibid.

d $\% 5-v$. madagascuriense West Alo. Madaw. I. it t. 19 f. 35 .

\section{m(1)millosmm. -}

d 83 EUASTRUM Wo7le in Bull. 'Torr. bot. ('lub 1883 p. 1s t. 27 f. 21 [E. insigne $\beta$ nammillosum Turner 1893].

a 81 - Wolle Desm. U. S. 1. 11.2 t. 26 f. $14-15$.

o sij-Stolies Key Desm. 1. 115.

d 89 - Tomi Syll. alg. p.10is.

11 91 HELIERELLA Kunt" Rev. gen, 11. p. S:!!?

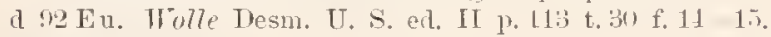

\section{Murifelrltii}

d TSTAURASTRUM Delponte Desmit. subalp. p. 6t (sep. p. $13(1)$ t. 13 f. $6-19$.

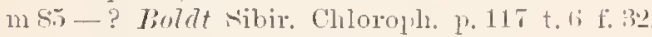

d S9-Tomi syll. alg. p. 1:214.

(n-Eichler spis Desin. Miedz. t. 9 f. 45.

m th - West Fr. W. Alu. W. 1rel. p. 155.

d $93-\beta$ bispinatum Turner Alg. Ind, orient. P. 12s t. 19; f. $11-12$.

d $-y$ pinnatum ibid.; t. 16 f. 10.

m 94 - rivte. Fl, alg. Tarnajol. p 10\%.

\section{Mrmmbrimm}

a 95 D0CIDIUM West Alg. Madag. 1. 1 t t. 5 f. 31 .

\section{mur!/uritureum}

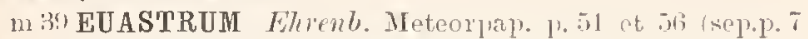
et 12) t. 1 f. 15 let partion B) t. 2 f. lit [la]stu calami pro "margaritiferum" verisimiliter].

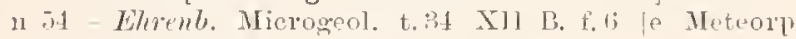
delineatic] et t. $15, \mathrm{~B}$ f. 48 .

\section{maregrituceum-}

a 3S CLOSTERIUM (Toxotium) Ehemb. Inf. 11. \% t. 1 ; f. XIII.

d 10-Monegh. Fynop. Desm. 11. 236 (sep.p. 3i)

d 1is-Ilass. Brit. Alg. 1.37ij t. 8s f, 5 [ex Ehremb. 1. c. delineatim].

d 45-Kütä. Phycol. germ. 1) 132.

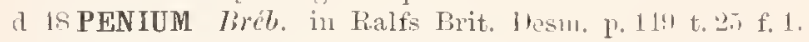
(a) a. h, c.

daf - $\beta$ ibid., t. 33 f. :3 [P. conspersum? see. Nordst. 18737.

dzt $-\gamma$ punctatum ilid. et t. 2.5 f. $1 \mathrm{~d}-\mathrm{h}$.

d 19 - Kï̈z. Spee. Alg. p. 167.

d 52 - Iritch. 1uf. p. 272 t. 13 f. 11 et 15 [e linlfs deliu.].

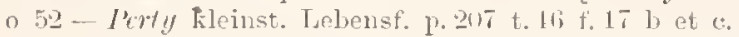

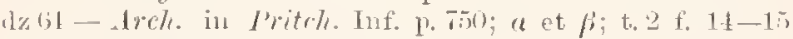
[e Tiulfs].

d 152-lired in Rab. Alg. 11:0 1:3:4.

d 133 - Rab. Kryut. Fl. Siaclis. 1. 169.

o 150 - Richter in Rab). Alg. Eur. nio 17.8 /1'. comspersum?]. n 67 CYLINDROCYSTIS Jiensch Algentl. Frank. 1. IGs.

o G7 Peuium Not. Desur. Ital. P. (i) t. 4 f. 73.

d 68 Reur. Flor. Enr. Alu. 3 p. 121.

(1) - b. punctatum ibid. p. 12:.

m 72 - Norlst. Desm. Spets. p. 25.

d 7 - $\mathrm{f}$. spiralis Nordst. Norg. Desm. p. 11.

d 73 - Hrod Fr. Ale. p. 107 .

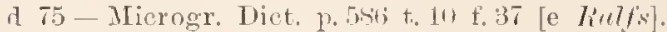

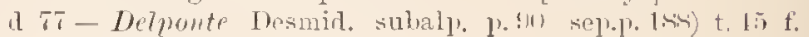
$43-50$.

d Ts-Kirchu, Fichles, Alg, 1. 135.

d 7)-a. typicum K7ebs Desm. Ostprenss. 1).21; $a$ et $\beta$.

d b. elongatum ibil., a $a 1, \beta ; 1, \gamma 1$ t. 2 f. $18 c ; \beta$ t. 2 f. 1 s a et 1 .

d - c. Cylindrus ibir., a t. ․ f. 18 e; $f ; \gamma ; \phi$ t. 2 f. 18 ، (Inclus. P. Paudurans Ite Not.).

unst - Cray Mon. loc. Couj. 13. 7).

m- $\beta$ punctatum ibid.

dzf 84 - ITolle Desm. U. S. 13.34 t. .j f. it-lj et 11 .

m 85 - Boldt Sibir. ('hloroplı. 1) 120).

d 8.5 - v. junctatum fo Lougior líe. Nonn. Dessu. Polon. p. 50 (sep.p. 3).

ns si - $\beta$ punctatum Laych. Anerik. Desm. p. 253.

o si- Stokes Key Desm. 1.111.

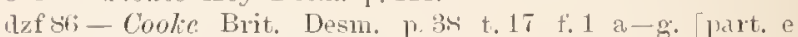
Ralfs]: $a$ et $p$.

1 -

m 87 - Mertell in Notarisia p.33 bis.

d $s \bar{\tau}$ - Alexpho Chlorosp. Kihark. 1, 2333.

d 88 - Uunsy. Prodr. Algenfl. Biilm. [) 176.

m 88 - Iiabin. Chloroph. env. Kharkow p. 31.t sep.1.26\%.

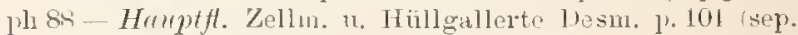
p. 43) t. 3 f. (13) et. (i3).

m xis - Istr. Jel. magyar, alg. p. 211.

z 89 - P punctatum Rory. Birr. Borul. Hesm. p. 1 12.

d sy - Toni syll. Alg. 10. kiss.

1 - - vo punctatum ibid.

ш 4 - Anterss. Fverig. ('hlor. 1 1. 1!).

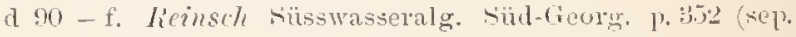
1. 24$)$.

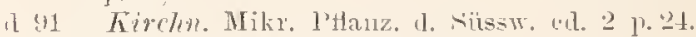

ms1 - Heimert Desm. alpin. p. non.

nı!) - Gutw. Flo1. als. Leopol. 1.31.

m - Borge Cliloropl. Norsk. Finmark. 1\% 15.

m n2-Rac. Desmidra Giastoni. 1, 3it.

dzf 1 - Wolle Desin. U. S. ed. II p. 3.5 t. 5 f. 5 - $6 \mathrm{ct} 11$.

m!3 - Thitlifmiln. Desm. Attersees p.511.

o 93 - v. punctatum Schmidle Beitr. Alg. Sichwarzald ]. 87 t. 3 f.. 1.

not-Iste. Adat, Romnn. alg p. $151 \%$

m! - Bürges. F, alg. Ötgrönl p.!.

in 91 - I7exenko Mat, als. Khark. p. 20.

\section{manemaitrremm -}

a 36 PENTASTERIAS Ehren?. in Abl. d. Berl, Al. 1.435 1. 173 [Descriptio mala].

d $38-$ Ehrenh. Inf. p. 14 t. 111 f. $\mathrm{XI}$ tantum semicellula e hasi visa).

n 39 - Elrinb. Meteor\%. 1.56 (sep.]. 12) t. 1 f. 25.

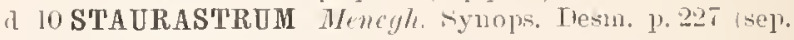
1. 27).

18 43 Pentasterias Ehrend. Mikr, Leb. Sürl. u. N. Amer.

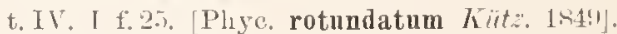

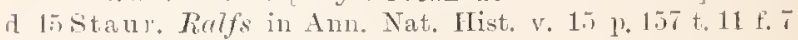
(et 1816 in 'Trans. Bot. Soc. Edin. v. 2 P. 11 t. 14) $[\ell, \beta, \gamma=$ f. 1-li-radiat. $]$.

1 15 G0NIOCYSTIS Pentasterias) IIass. Brit. Alg. p. :30̈ti t. 85 f. 7 [e liult's l. c. delineata]. 


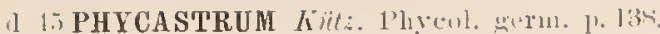

d IT Pentasterias liub. Deut. Krypt. Fl, p.ini

1. minus ibil. (1en. minol hül.

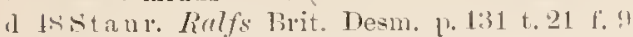

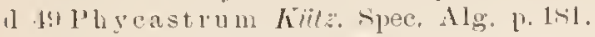

n t!) (Stenactinium) Nerg. ein\%. Aly. p, 12\%.

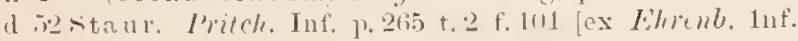
delin.].

il Pentasterias Ehrenl. Mierogent. t.31 XII I f. 15 [e Meteorpaj\% 1839, delineata?.

() D̈lititanu. Bréb. List. N.140.

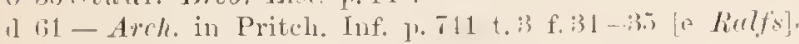

d 1 iz - liab. Krypt. Fl. Sachs. 1) 190.

n $1: 3$ - Inantzseh in Rab. Alg. Enr. n:0 1513.

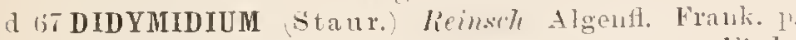
$11 ; 2$ (inchs. St, dilatatum, Desm, hexaceros, Ehrb. Pliycastr. crenulatum \% - Form. A.

d - f. B. re minimum ibid. lo. 1133 .

- $\beta$ intermedium ibid.

- $y$ alternaus ibil.

- os subglabrum ibia.

- $\%$ decedens ibid.

- 5 bidentatum ibid.

y margaritaceum ibicl.

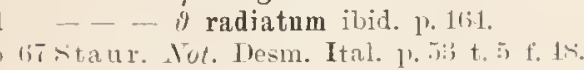

d 6 s- Rab. Flor. Eur. Alg. 3 p. $21 \%$.

d - b. inflexum ibid. p.

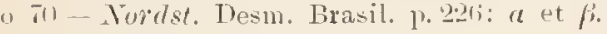

o 73 - Nordst. Xorg. Desm, 1. 28.

d 7 Houd Fr. Alg. p. 150.

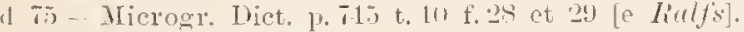

o in-heinsch rontribut. p. 91 t. 1i f. 11); monstr. [magis ad St. polymorphum accedens sec. Tordst. in Hedwigia 19.60 p. $6.5^{3}$.

1175 - Nordst. Desm. aret. p. 33.

o $\pi$-. licinseh Alg. Prom. Bon, spei p. 213 t.6 t., 13 et 14. [Quid?].

111 is - Turdst. Alg. Sandvic. 1) 16i

1) 78 - Kivelm. Alg. Schles. p. 16f.

d sil - $\beta$ hirtam Nordst. Te Alg. et Charac, 1 l., 11 t. 1 f. $1 \stackrel{2}{\circ}$.

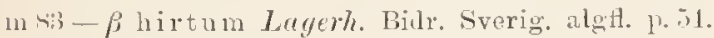

s3 - Tumer Algie Strensall f. 15.

11 st - Gay Mon, loc. Conj. t. 1 is.

at 81 - Holl Desin. U. \&. p. 12.5 t. 11 t. 31 - 35.

d 85 - Kirehr. Mikr. Ptanz. d. Sïissw. P. 23.

mis - Boldt sibir. Chlorouh. 1. 11\%.

$1 \quad-\beta$ subtile ibid., t, 5 f. 24 ,

l - - f. ornata ihis. p.116 t.j f.2- st. orluatum Turver 1893].

o kili-Stulies Key Desm. p. 16it.

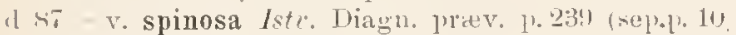

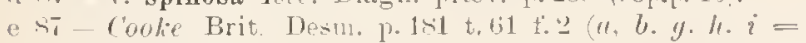
linlfs

- v. ibill. tig. $c, d, e, f$

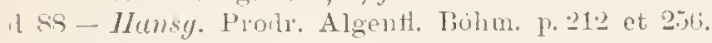

11 Ss - Euldt 1)esn. Grünl. 1. 37.

1 $-\beta$ trnncatum ibid, t. 2 f. 1 s.

111 th- Iste. Jel. mugvar, alg. p. 2:30.

d - $\mathrm{r}$. spinosa ibid.. et t. 2 f. $26 \mathrm{~s}$.

d

i - v. truncatum ibid. p. 1224.

v. subtile ibid.

- f. ornatum ibiu.

- - f. ornatum inosum ibid.

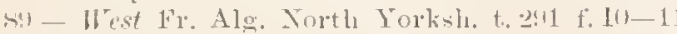
gona.

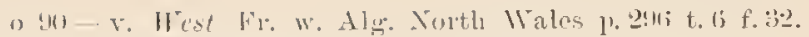
$11-r$. coronnlatum ibil., t. 5 f. 3.

m!n Fichler suis Desm. Mied\%. p. (n.

(1) (1) - $\beta$ hirtum f. Bärg. Desm. Brasil. p. Hi.

m!n - Lnderses Niverig. Chlor. 1 p. 11.

$0: 11$ - f minor /lcimerl Desm. alpin. 1) f6rli,

m 52 - Burge Sibir. Chtoroph. 1. 10.

111 92 - Rorgc Chloropl. Nursk. Finmark. 1s.

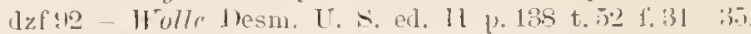

o! 12- West Alg. Engl. Lake Distr. 1. 73:3.

d 9:3- (Trochastrum) vo inornatum Thrm. Aly. Int. orient. p. 113 t. 13 f. 22.

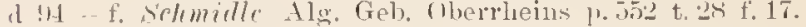

d 5 - v. alpinum, selmille in Helwig. 11.!1 t.li f. s.

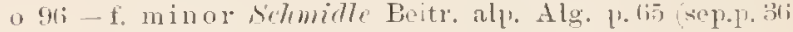
et, 1.995 . t. $16 ;$ f. 28 .

\section{mal'!gritutum}

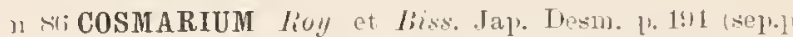
3) Cosm. latum $\beta$ maratitatum Lund. Niti).

:11 - - ITest Freshw, alg. Maine 11 t. 315 f. 16

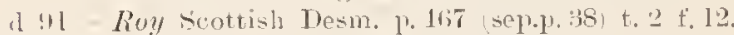

o (5) - Jokns, Rare Desm. T. S. 11 p, 29t t. 210 f. 32.

\section{maryuritifin)um -}

פO URSINELIA Turp. in llict, sc. nat. planch. bot. vém. acot, vésicul, f. 2:3 et $a, b, c$. [Figurir malex: mixtmo compositum].

(1) 24 - in Dict. sc. nat. ton1. 30 1.375 [Lito].

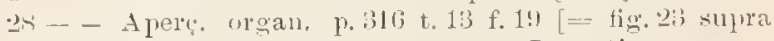
citata, sefl magis ancta]. ['osm. Botrytis v. emarginatım Hansg.?].

11 on HELIERELJA ? 1/eyen in lsis $1830 \mathrm{p}$. 16i:.

( 31 EUASTRUM Ehenb. Organ. k1. Raum. p. 216 et 3:(rep.p. 102 et 17\%).

a 3 i MICRASTERIAS Bréb. et God. Alg. Halais. 1) 55 t. 7.

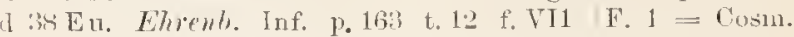
ochthodes ?; 2 = C quadrifa rinm? (3, e lat.. iden. ?); $4=\mathrm{C}$. conspersum $\mathrm{f}_{\mathrm{i}}$ all speciosnm ?; 5 et $i=\mathrm{C}$. margaritifurnm auct, recent.?].

d 11) Cosm. ALnegh. Synops. Desm. 1).21!) (sep.1. 1!).

o 41 Eu. Builen Amer. Bacill. p. 245 (sej.r. 11) t. 3 f.s [C. ron iforme?].

11 - Dujard. IList, nat. A. Zooph. t, 2ul f. 17

d 11 - Pritch. Tnf. ed. 11 \%. 11 1i, ti. 120;

1) 13-Ehremb. Mikr. Leb. Nind. 11. N. Amer. t.3 f. VI. 1: t. 4 f. 1.19.

d 11 Cosm. Rulfs in Am. Nat. Hist, v. 14 p. 349 t. 11 f. 1 (et 1816 in Trans. Bot, soc. Elinb. v. "u. 14!) t. 16).

1) 4 - Hass. Brit. Alg. p. Bfiz t. si t. 1 [e Rirlfs I. c. non exacte delineata].

d 1.) Eu. Kütz. Phycol. germ, 1. 1:3f.

d 17 - liub. Dent. Kirypt. Ft. 1, הl.

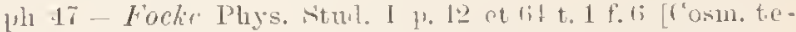
troplithilmum?], t. 2 f. 17 et 19 [an l'osis. Botrytis?], f. 21 [Cosm. siper. uov, ?], f. 20),

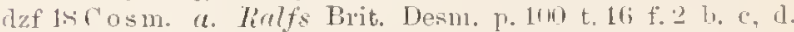

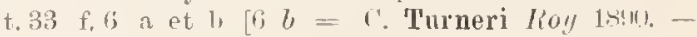
i) $a=$ ? .

$\beta$ reniformis ibid. 1 . 100 t. 16 t. 2 a $[$ Cosm, reniforme].

1 19-Kïtz. Spec. Alg. p. Titi.

(1) I! Eu. Cosmariun) Na\%. ein\%, Alg. p. 119

d 5 Cosm. Marise. Catal. esp. umis. p. 35 t. 2 f. 27 (Heterocarpella Ursinella e Imjurd. Olserv. microse.). lakb. Bacill. t. 3. (n:0 10).

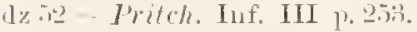


(15i3- Muth. I'1. Belo. 11 1.502.

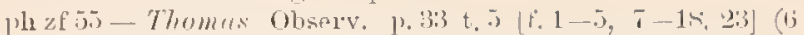
('osm. Ralfsii [31-33=?; $21=$ Broomei (2f.): 2.3 $-2 \bar{T}=$ C. bioculatum c. zyonsp. sec. freh. in I'ritcle. Inf'].

1,

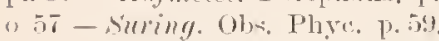

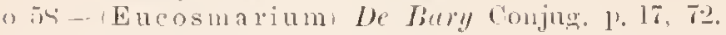

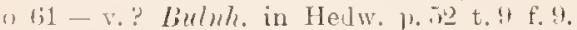

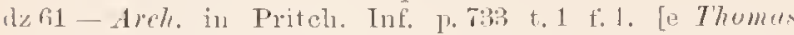
1855. lelineat. $1=1.2=3 ; 3=5 ; 1=11 ; 5=13$ i $=14 ; 7=2 ! ; x=25 ; 1=27 ; 11-12=2 ! ; 13-14$ $=31-333 \times 1 \%$

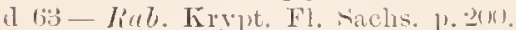

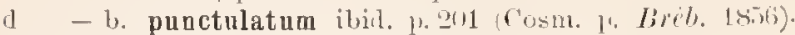

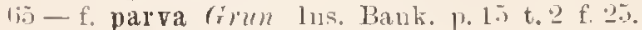

fh Gis-Reinsch Morpl, Fragm, p. 35 t. 2 f. 1.

d 60 - Eymich Algenfl. Mamm. p. 126 “ $r$ C. semiorbiculare" [nomen tantim] et $\beta$ reniforme.

\& bit;- 1 rech, in () J. M. Ác. v, is p. 271 .

m 137 DID YMIDIUM (Cosmarinm) Reinsch Algenfl. Frauk. 1. 118 a minus, fi medium, "majus.

o lit Cosm. Not. Desm. Itik1. 1. $4 t$ t. 4 t. 2! !

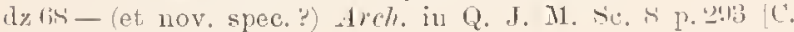
reniforme.

d 6 - liab. Flor. Eur. Alg. 3 p. 157.

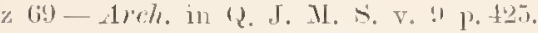

m 70 - Nords'. Desm. Brasil. p. 20T.

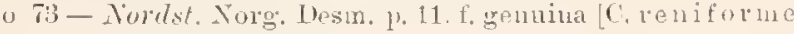
A.clt, 1sit]

(1 73- 11 ood Fr. Alg. 1'. 129 t. 21 f..

o 71 - irch. in Journ. of Bot. 1).93.

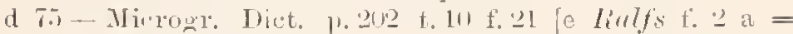
(. reniforme].

73 - f. lata Jarubs. Desin. Danem. 1. 1!1! C. latum livéb.'.

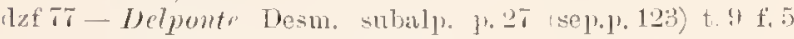
-9. Cosm. reniforme].

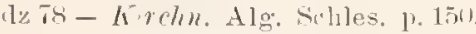

1) -... n. genuinum ibil. p. 1.i.

d - b. incisnm ibil.

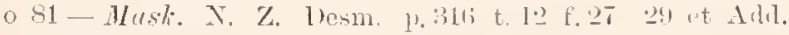

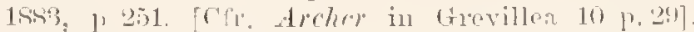

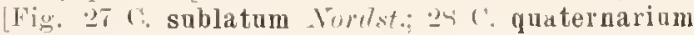

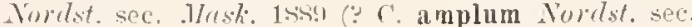

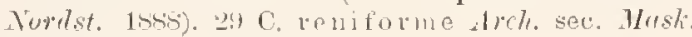
1 [ST:!].

un Sit-Arari Liste aly, Moscou p. 111

m. S-- Guy Monngr loe, Couj. p. 1;1.

nit - Lopot Nater. alo. Warszaw p.2.3.

laf 84 - Wolle [hom. U. \&. p. 7 l t 13 t, L - ;

It si-Kirchn. Mikr. I'tlonz. Al. Sissw. 1. 21.

In tho diullt Sibir. Chlorople p. 10,

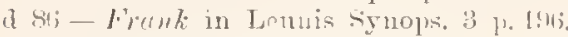

o siti - Stoker kiey Desul. P. I2S.

ph 87 - \%ouf Untersuch. ii. Parasit. a. Gr. Monaliu, t. 1 t $2-5$.

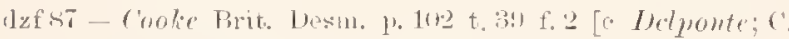
xeniforme

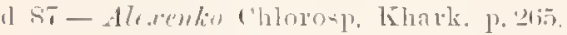

dz 85 - Hansg. Prodr. Aluentt. Bölnn. 1. 19s.

1) - $p$ incisum ivil.

dyss-Joni et Leei lil. Alg. Venez. 14.51?.

$118 \mathrm{~s}$ - livuldt Desm. Griml. 1.2.24.

o - f. ibid.

b. incisum f. ibiul. t. 2 f.' 2 s.

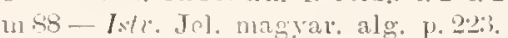

n $8: 3-$ r'nter iu A. M. Micr.J. 11! f. 12 ex Wolle

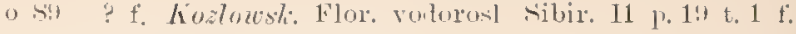
9. [Cosm. Portianum].

dz $S: 1$ - Toni Syll. alo. p. $\$ 7 ! 1$

o - v. incisum ibir.

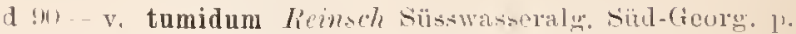
3.17 t. 2 f. 7 . [Quid? Longe alia spme.].

m! - Lür\%. Desm. Brasil. 1. 33.

in 90 - Eicliler spis Desn. Miedz. p. si.

1190 - Anderss. Sverio. Chlor. 1 p. 11

m-f, minor ibid.

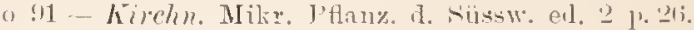

u\$1 - Meimeri Desm. alpin, p.545.

mal - Borge Pidn. Sibir. Chloroph. p. 11.

o "1 URSINELLA limtre Fiev. gen. pll. p. 123.

m 91 Cosm. f. Gutw. Flor, alg. Leopol, 1, 5l t.2 t. .

m 92-Borge Chloroph. Norsk Fimmatk. p.9.

m92 Limmer Algen sit. Pölten I j.4.

dzf (1) - Wolle Desm. U. A. ed. II p. 81 t. $11 ;$ f. $1-3$.

m! !2 Cruw. Flol. glon. Galic. B p. 128.

m 13-Jïtipmill. Dism. Attersees 1.5.si.

ma 93 - Gutu. Glon. staw. Z/hrnezn 1. 29.

1193 - (Nephridinm) Trmer Alg. Inr. orient. 13. 73 .

m 41 - Iste. Allat. Roman. alg. p. 155.

o !1 - f Porye Siissw. Chlor. Arehang. p. 211 t. 2 t. 15.

m 14 - Böry. F, alg. ̈̈stgrönl. p. 13.

1n: 1 -- Alexenko Mater. alg. Khark. 1'.2\%.

o 9.) - Schrodter Alg. Riesengeb. p. 19.

m95 -- f. Borge Sverig. Chlor. II p. 11 ( Burge 9). Cfr. En. margaritaceum.

\section{ully"lvitum, -}

diff'1 COSMARIUM Wolle in Bull, live. bot. ('lub, 1stit p. 1 t. is f. 7 .

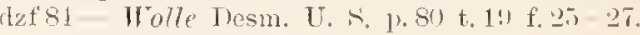

o Si - Stokes lier Desm. 1'. 129.

(1) si-Toni Syll, alg. 1) 1112

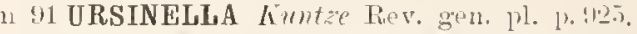

m 31 C'osm. Wrest lreshw, alo. Maine Il w.351.

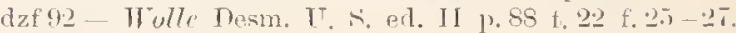

\section{Murlinsmisliyi}

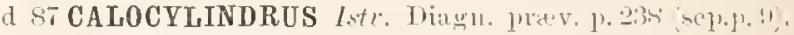

d sis-Istr. Jel. magvar. alg. p. 22 ! t. 2 f. 21.

d 8 DISPHINCTIUM Toni syll alg. p. 85. .

\section{Mreslirllii}

1 !3 STAURASTRUM Tumer Alg. [nul. orient. 1.131 t. If: f. 21.

\section{mexillum}

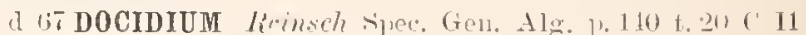
f. 1 -? (sep.p. 3i2 1.1 C II

l) bit . livinsch Algenfl, Frank, l. lsid t. 12 f.t.

n 71 PLEUR0T कNIUM Lund. Tesm. Snee. 1).

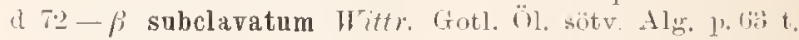
1 f. 16 .

msilide. $\beta$ subelavatum Roy et liss. Jap. [lesur. 1. -41 (sep.p."

1) 89 Pleur. Tuni tryll, alg. 1) 8m.

d - v. subclavatum ibid, 1. (xus.

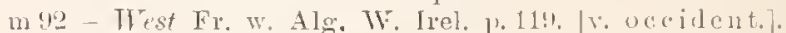

m 1.2 - vo occidentale West Alg. Eugl, Lake 1)istr. p. 71!.

\section{medioglublamem}

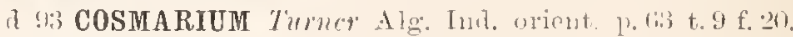

\section{mediolreve -is}

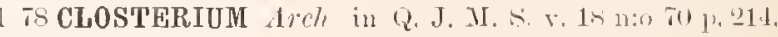


(1) s!! - Tomi syll, Alg. p. s.i3.

" " ARTHRODIA kumtze Rev, gen. pl p.st:3.

\section{mediolaner ("mratiolere"e)}

o !l COSMARIUM Firhl, et crutre. in linakau in\%ig. 1..2:3?.

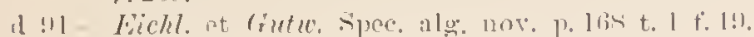

\section{mediollere}

n s.t STAURASTRUM limy apud Arch. in Am Mas. Nat. llist. v. 1:3 1.115 forma suceira itam, oligacanthii Norlst. non Brels.1. Ifor nomen sine Irseriptione est deleurlum.

\section{mr!/lrath"lm}

1) 7 STAURASTRUM Lmil. Desm, sines. p.lit t. 1 f. 1.

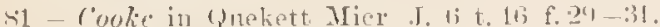

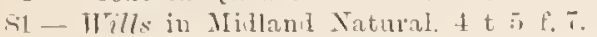

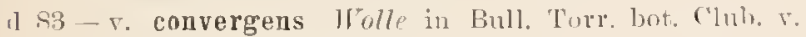
10 1. 2 (1) t. 27 f. 13 .

\$3 - Turner Alge Sitrensall f. 10.

si - Wolle in Bull. Torr, bot. ('luh, t. If f. 10)-I?.

1) st - Holle Desm. U. S. p. 121 t.

o sil Nolies Key Desin. p. 1tit.

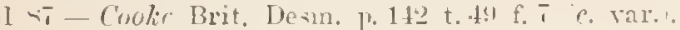

1 ห) - Tomi syll. alg. p. $11+1$

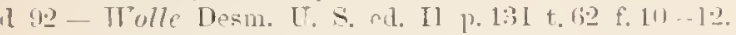

1) 93-. A canthastrum r. depressum Fumr Aler. Iut. orient. p. 133 et 106 t. $11 \mathrm{f}$..!.?.

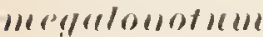

(1 TSTAURASTRUM Norkt. Desm. aret. p. 35 t. 8 f. 34 .

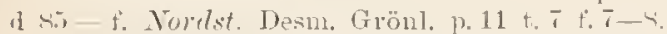

m 4 - Roldt lesin. Grönl. p.39.

11 s!1 - 7oni syll, alg. 13. 122.2.

o. .2 - f. Wrst Fr. w. Alg. W. Irel, p. 17:3 t. 2:s f. 1.

d (1.2- - r. obtusum IIrst, in Amer. montlil, micr. J. $1: 3$ p. 1.it t. 1 f., 3 mala).

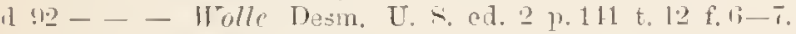

1) 13 - f. hastatum rietkemill. Desm. Attersees p. ifs 1. () f. 18 .

u :1:3-O.loutastrum, Turme Alg. Tnt, orient. p. 1:3:3.

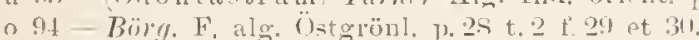

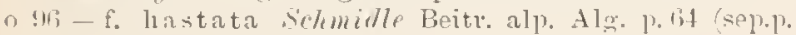
33 et, $1.5 \%$, t. 17 f. 6 et 7 .

\section{melluts)}

z. A3 COSMARIUM archer et Roy) in Ann. Mag. Nat, Ilist. 5 ser. v. 12 n 11 r 65 p. 124.

z si-Coole Brit. Desm. D. 18 .

z. so - Toni Syll. alg. p. 10.5.

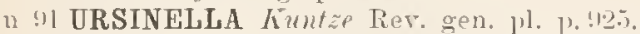

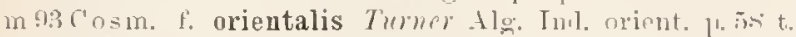
- t. $4: 3$.

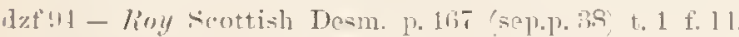

\section{meliteusis}

110 MICRASTERIAS Henegh. Symops. Desm. 13. -2li sep. 1. 11; Enantrum Crux melitensis Iflerenle.

(1) - junior ibil. I lihenb. f. (c)

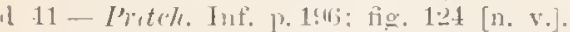

141 - Itrlfs in Alul, Yat. Mist. v. 14 p. $21 \%$ t. 1; t. 2 (ot

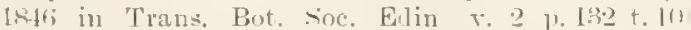
[mala!] [M. furcata sec, liolfs lBi. Desm.].

1) 15) Kït: sper. Alg. 1) 170.

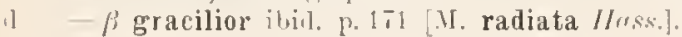

\section{Henrallinirmum}

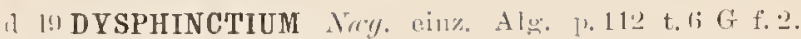
(?. connatum $\mathrm{Br}$.]

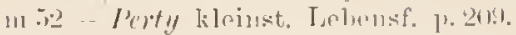

\section{Weneghinii}

1 ts COSMARIUM Rib. apul linlfis Bit. Desm. p. Mi t. I.) t. (i Cosm. bioculatum Menryh. 1,337.

1 i2 - Pritch. Int? 13. 25:3,

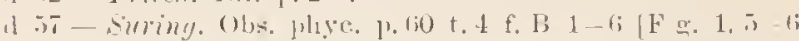
$=($. trilobalatum, an ('. angustatum?; 5 Eu. rotun datom (roy?; 1 forma latiuseula Jreobs. 1sori:?.

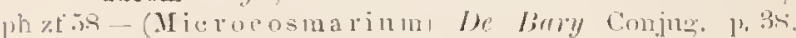

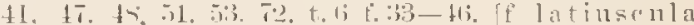
Jaculs. 1:itil.

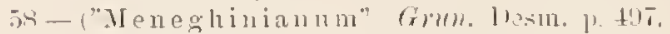

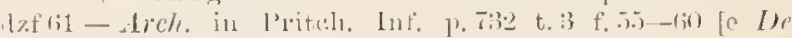
Iirre. 1sistis

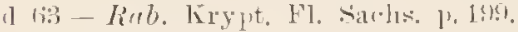

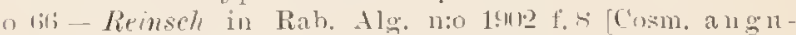
statum??.

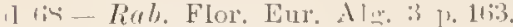

d - b. concinoum i,il. En conciunun fiul.).

1) - c. angulosum ibil. Cosm, a $10 \mathrm{gul}$, Bréb.).

o 68 - Norrlst. Birlu. Siverig. Desm. 1. 3!!

o 1 iी - $\beta$ coneinnum Wittr. Skanlin. Desm. p. 12.

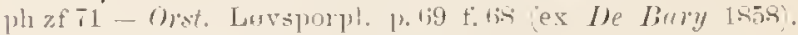

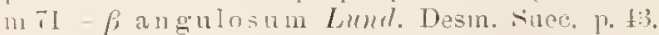

19 - " conciunum a. majus (limsing et c. eoncin-

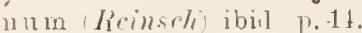

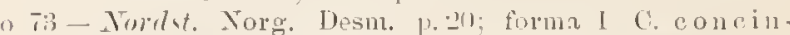
num): 2 . nndulatum $\beta$ crennlatum Wittr. : :3 a [v, vaIgraris Jacols.]. 3 b [v. Intiuseula Jucobs.],

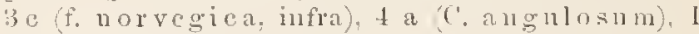
b (C. erenlatum lle Not. Eu. angulatum I'prty? 1 c $\mathrm{f}$ trigona.

f. norvegica iłid. 1).20.

1 78- Hood liv. Alw. p. 131 t. 12 f. 18.

zf 7.$)$ Reinsch Contrils. t. 16 f. 5 .

Izf - f. ibit. p. As t. 1.i f. li.

I - f. 1 a et $\beta$ ibild. p. ․s t. 12 f. 12 a et b: [f. Reinsch ii Iste. 184i]

- f. 2. ibi.t. f. 12 c,

n iti-f. latia-cula Jacolss. Desm. Danen. p. 197; De Pary 1sis).

f. vulgaris ilin. (Kulf: Br. Desm. .

- f. intersepta ibit. p. $198 \mathrm{~s}$ t. 8 f. 18 .

1. - f. rotundata ibil. p. 198 t. i f. 211.

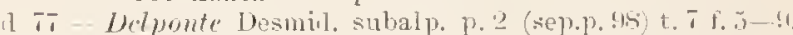

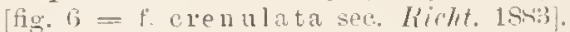

$1 \%, \pi$ - a. grenuinum Kirchr. Alg. Schles. p. 1 tr.

1 - b. angulosum ibid.

1) -c.concinum in ibid.

o 7 - f. octangnlaris Trille Ferskv. alg. Tov. TemIj. p. 43 t. 12 f. 35 .

1) - $\beta$ nannm ibil. 1) 13 t. 13 f. 37 (De Bary Conjing. 18.\%. t, ti f. $11 i$.

1) (5) $\beta$ simplicissimum ["singlicimnm"] Tille Nor@. Ferskr. alo. I p.30 t. 1 t. 11.

n - - a gugusun ihil.

S:3 - f. crenulata Kichter in Wittr. et Tordst. Alg. cxs. 11:0 jffi Eu. crenulatum Xäg. einz. Alu. 1849.

pla s:3 Fischer Gypskrystall. Desm, t.! f. 15-16,

m 81-Lopot Mat. ale. Warszaw. 11. $25: 3$.

m $\$ 1$ - Artari Liste alug. Inscon p. $1+1$.

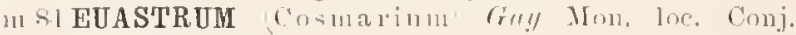
r. is. 


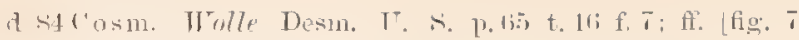
sibistra superior = P Wolle i Layrth. Rsist].

$11 \mathrm{~S} 1$ - Sehatarsehm. Afg. Alg. p. 247.

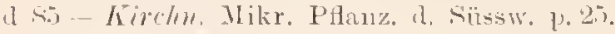

m sis - Roldt sibir. 'bloropl. p. 10.3.

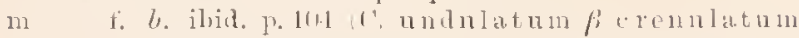
Irittr: Listis.

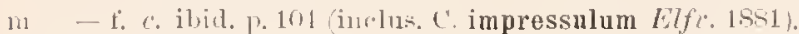

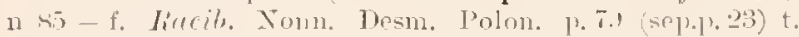
$11 \mathrm{f} . \mathrm{i}$.

A sõ - linlsamo Alghe del com. di Nippoli p.:3

m.81-f. Lagerlh. Amerik. Desm. p. 211.

$m$ - f. ihil. [f. latiuseula Ireobs. 14iti].

o sitj-stokes ling Desin. 1. 12t.

sif- I mor in Leeds nat. club malsact. 1 t. 1 f. l2.

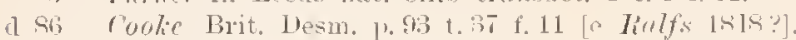

d si - Alexento Glorusp. Khark. I'24il.

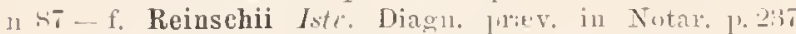
(sep.p. 8) Reinsch Contrit) t. 12 t. 12 n et 1, 1.5.)

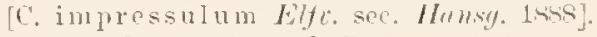

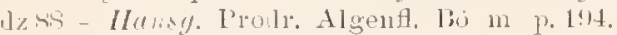

d - gen11 gum ibicl. p. 15s.

1 - $\beta$ angulosm ibicl.

d $\quad$ - crenulatum ibid.

d - d conciununs ibil.

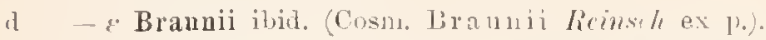

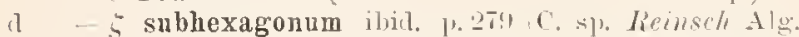
Prom. Bon. Spei t. 13 f. 10-11. ('. læve sere, Iirre. 1812.

11 su- Tomi et Leri Fl. Alg. Venez. p, I!!

m is - Riabin. Chloroph. env. K'harliow J.32t.

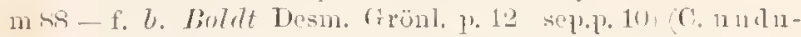
latum $\beta$ creututum Wittr.

m - f. \%. ibid. p. 18. (C. impressulum Elf\%).

in - foctangutaris ibid.

$0 \quad-f_{0}$ g. ibid., t. 1 f. 14 arl t. in terseptam Jacols.

$0 \quad-\mathrm{t}$. h. ibill. t. 1 f. 15 [f. Boldtii Wtest 1 .S! $;$; subreinschii v. Boldtiana schmille 1s:-1?

1 -? f. i. ibid.. t. 1 f. 16 [f. minuta Jimrg. 1siff].

n St-f. lavis Jolll Desm. ntbr. Nord. p. 31 (Nep.]. T;

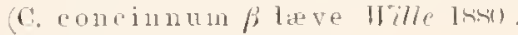

- f. angulosa ibid. p. 32.

-f. simplicissima ibir.

- f. $11 \Omega 11 \mathrm{a}$ ibid.

o Ss - f. erenulata Koff in Norrls. Bornlı, Desm p. L!T.

- f. latiusenla ibit.

- f. 110 orvegica ibid. p. 1 is

111 - f. angulosa ibid.

11 s. $\beta$ Wollei Layerh. Bengal. Jusm. pes iforma Whalle Desn. T. S., 1851, t. 16 t' T sinistrn superint

mish-Iste. Jel. magyar. alg. 1.22\%

11 - f. Reinsehii ibid. et t. 1 f. 1s.

msí- $\beta$ simplicissimum Norlst. Fx. wat. alg. X. Zeal. p. 2.5.

mot - West Desm. of Maine 1. Bas.

so- $\beta$ simplicissimum II ext Mastinchus. Thesm. t. 2 t. 7.

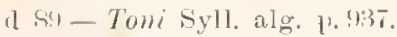

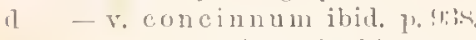

d -v. liteve ["leve"] ibid.

f. majus ibicl.

- v. angulosum ibirl.

v. 112111111 ibicl.

v. simplieissimn m ihril

ร. Brauni i ibil.

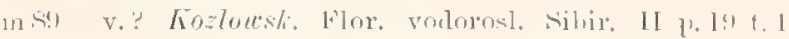
f. 11 .

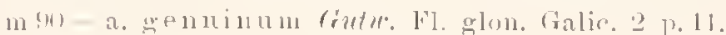

m c, Reinschii ibid. p. 12.

a - l. v. octangulariforme ibid, t, 1 f. 6 .

m s0 - v. angulosum et concinum Eichler sisis Desm. Miedz. p. 8 .

11 ! 0 - f. vulgaris dnders. Sverig. Chlor. 1 p. 11;.

11 - f. ibid. Iiar. 1s.5

1 f. ibid. et t. 1 f. 10 [v. Anderssonii iufra].

$m$ - f. latiuseula ibiul.

10.90 Reinsch süsswasseralg. Nïid-Georg. 1, 347 t. 2 f. i.

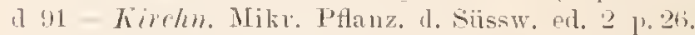

() 91 - Meimen Lesm. alpin. p. 59!\%

(1) 91 v. creulutum Hansg. Alg. u. bact. Mittheil. p. 332. [v. undulata schmidle 1sist.

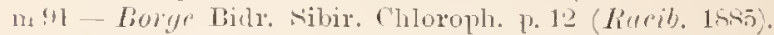

11 - f, Reinschii ibid., t. 1 f.s [C. crenulatum v. Reinschii sclmidle 1 s.t3].

11 - f. ibid, f. 9.

n - f. ilbit. Boldt $18 \mathrm{sit}$ form. i.

1! !) URSINELLA fimtie Rev. gen. pl. p. (12).

m.91 Cosm. f. Gutw. Flor. alg. Leopol, j. tis t, 1 f. 22. [f. leopoliense 189.).

111 - $\mathrm{f}^{*}$ polonica Gutw. in Nuov. Totar. p. 1ঙ.

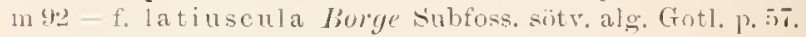

o - f. ibid., t. 1 f.!!

m!2 - Borye Cliloroph. Aorsli, Finmarts. p. 12.

1 ? f. ibid, et t. 1 f. 11.

m92-v. Wollei IIest. Fr. W. Alg. W. Irel. p. 14:4 t. 24 f. 18.

1119- $-\beta$ concinnum Rimmer Alg. St. Poiten I j. 4 .

m! - - Rre. Desmidya Ciastoni. p. 3!m.

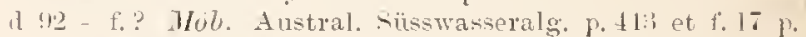
411. Cfr. Borge in Nuov, Notar, (i p, 22.

d 12 - Whlle lesm. U. S. ed. II p. 70 t. 19 f. T (ff.).

$n-$ v. simplicissimum ibir. p. 71 t. 13 f. $11-1$,

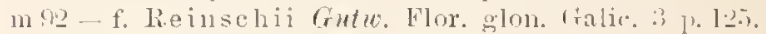

m - r. Braunii ibid.

$m-v$. simplicissimum ilid.

m - f. polonica ibil.. t.s f. ?)

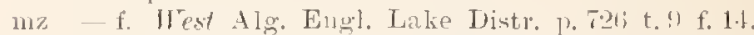

$11-$ f. Boldtii ibill. (f. /. livelelt 1s8s).

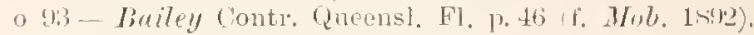

m 93 - f. Lü̈tkemäll. Desm. Attersees p. 550.

11 - f. ibid. Gute. 18il).

d (1:) - v. granatoides Schmelle Beitr. Alg. Schwarzwalul. p. ? t. 6 f. 15 [C. granatoides sich. 1:44].

m93 Gonatidium) f. typica Turme Alg. Ind. or ient. 1. 71 (Iillfs fig. i;

11 - t. trierenata ibil.; t. \& f. 25 [Eu. erenulatum Nag. f. 5 c).

m 93 - v. Branni Eichler Mat. flor. Miedz. p. 164 t. 10 f. 33.

(2) 4 - f. rotundata schmille Alg. Geb. Oherrlieins p. $5.1 !$ t. 2 . 4 f. 1 .

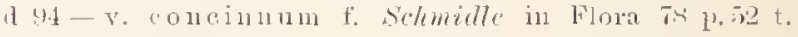
7 f. 1 .

3 9.t - f. Borge siissw, Chlor. Archang. 1. 21; t. 2 1. 21.

fi Brauni i ibid.

11 - 1 ranatoides f. ibid., t. 2 f. 25.

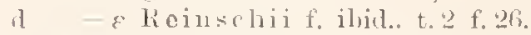

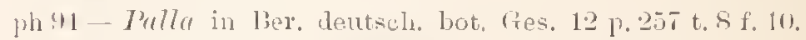

1) !1-v. angulosum sumat. in Fl, Nebraska 1. 11 t. 7 1. 12 [12 " et e e Cooke. 12 1 ex 11 olle].

o 9.1 f. Dimg. F. alg. Ö.tgrinl. p. 16 t. 1 f.9.

m - f. Reinsclii ibirl.

$m-1$. angulosa ilisl. p. 17.

11 - t. minuta ibil. t. i fiollt $188 \mathrm{~s}$

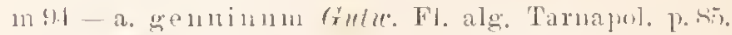

m 4. - Molves in Hedwigia :31 p. 17. 


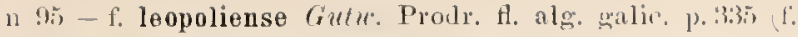
frutw. Flor. alg. Leopol, 1sili).

m 95 - IIest Alg. Madag. p. 59 t. if f. $t 1$.

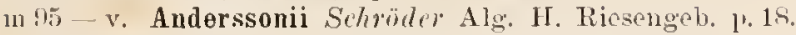

m 15 - Borae Sverig. Chlor. II p. 19 t. 1 f. 10.

Cfr. Cosm, difficile, incertum, nracrosporum, octogonum, suiatyniense et umbonatum.

\section{Hrueghinii}

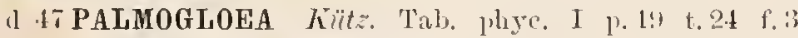
('ylimtroeystis Brebissonii Menryh.).

(1) 19- Cylindroerstis Küt: spee. Alg. 1. 231).

\section{mentiens}

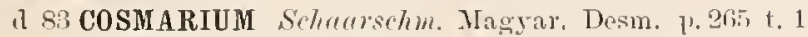
f. i1.

1) 8s - Tomi syll, ald. p, 10:31.

11 91 URSINELLA huntze Rev. gen. pl. p. 2.

\section{Meviurni}

a 6 i STAURASTRUM Reinsch sipee. Gen. Alg. p. 125. t. 23 D I t. $1-11$ (sep.p. 17 t. 4) Formie: $A$, minus $a, \beta$ et $\%$. B. mitusus a et $\beta$.

a 67 DIDYMIDIUM (Ataur.) Reinsch Algenfl. Frank. p. 160 t. 12 f. 1. Forme (ut supra p. 161.

m 73 St a 11 . Nordst. Noro. Desm. 1. 29.

11 Ti, - Nordst. Desm. Ital. p. 42.

1) sl llolle Desm. L. \&. p. 132 t. 40 f. $17-1 ! 1$.

ma - Mor - Nordst. Desm. Grönl, p. 10.

o st-Stokes Key Desm. p. 167.

d $\mathrm{sit}$ - Cooke Brit. Ilesm. p. 161 t. 5.; f. 2.

89 - Irest Massachus. Desm. t, 3 f. 22.

d s' - Tomi syll, alg. p. 1192.

(1) 92 f. rotuudata Borge Chloroph. Norsk. Fimmark. p. F t. 1 f. 1.

d 92-IIan*o. Prodr. Algent. Bühm. el. boh. If p. Lis; el, nerm, II p. 25\%.

m 92 - West Fr. w. Alg. Wr. Irel. p. 179.

d : 92 - M'olle Desm. U. S, ed. II p.14t t. 57 f. 17-19.

n 93 - Cylindrastrum) Tumer Alg. Ind. orient, p. 1:33.

d 9.3 - f. schmille in Ifedwig. 33 p.91 t.6 f. is. [Statu. Kjellmanni sec. ITest $18 \%$ ].

Cfr. Staul. hexagonum liac. 1885.

\section{mesoleimm}

o S4 STAURASTRUM dreher in Am. Mag. Nat, Hist ser. 11:0 7$]$ p. 145.

n ST-Conke Brit. Desm. p. 190.

\section{MESOTENIUM}

it 49 Nreg. einz, Alg. p. 40.

d 58 le Pary Conjug, p, 20, 30, 74.

d bit drel. Deseript. (sep.p. 9) in Dubl. Nat. Ilist. Sor. Proc, p. 20.

o bif Arrh. Obs. on Cylindr. (sep.p. 9 ete.) p. 213 ete.

d is Kirchn. Alg. Schles. p. 13 .

d st fiay Monogr. loe. Conjug. p. 34.

l sit Tolle Desm. L. s. p. B1.

1 55 Kirhm. Mikr. PHanz. d. Siissw. p. 20.

o sils stolies hey Desm. 1. 1111.

a sif Cooke Brit. Desm. 1. 47

(1) st Alexphk Chlorosp. Thark. p. 221

d sis Mlansg. Yrodx. Algenfl. Bühm. p. 172. (Sect. 1 Pa lmo gloea Kütz), p.173. 2 Eumesotanium p. 174).

a sitoni et Leri F'l. Alg. Tenez. p.39.

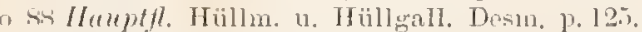

d sit Tomi Syll. Alg. p.811.

d s. MLnowy in Baill. Dict, bot, Ill p.348.

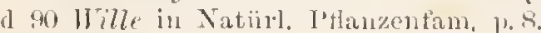
Nisidstedt, Inilex Itesmid.
1 "1 Kirelm. Mik1. Pflanz, d, siissw. ed. 2 p. 21.

I ste Tolle Desin. U, si, ed. II p, 32

ph 95 lagerh. Phycenprph. p. 3 etr.

\section{LSOTHEMA}

1 39 Corda in $1 \mathrm{~lm}$. 4. Carlsh) 1839 P. 211 [M. undulatum $=$ Cosmarium sil??

\section{messorhomdrimll}

d 95 COSMARIUM sclmidle in IJelwigia $34 \mathrm{p.} .85 \mathrm{f} .3$.

\section{Meterler}

d 86 PLEUROT ËNIUM Lagerh. Amerik. Desm, p. 251 t. 27 f. 30 . [Fig. non reeta ?].

(1) Si-Tomi Syll, alg. p. (4)4.

Michiganensis

a 65 ARTHRODESMUS .Iohm. Rare Desm. U. s. II p. $29 \%$ t. 239 f. 12 .

\section{MIC'RAC'AN'T'IL M}

d 98 Turner Alg. Ind, orient. p. 108. Subgen. Xanthidii.

\section{mirver(er)mthum}

a 13 EUASTRUM Turmer Als. Ind. orient. p. 82 t. 111 f. 33.

\section{Mirrosterier"}

○ 3 Em Ell. Gen. 11. 1 1. 3. Tribus Desmidiear. Genera: Micr.. Scenndesmns, Biddulphia.

1 12 Trevis. Prosp. d. Flor. Eugan. p. is. Tribus Desmidioidearum. Subtribus sunt: Eumierasteria et closteriex.

1? 12 Trevis, in Att, IV Riun. Ital. p. 335 [sec. Trevis.]. Tribus Schimatothallarum [n. v.].

11 4 Trecis. Alghe Coccot. 1.98. 'T'ribus Schimatothallarum. Gen: Troulischia, 'T'eträ̈dron, Pithiseus, Clost. Staurnceras, Tetmemorus, Microphycus, Holocystis, Mier, Euastrum, Cosm., Arthrodesmus, Nanth, et Staul:

189 Tomi Consp. gen. Chloroph. p. 152. Trib. Didymioidearum. Gen.: Cosmarilium, Plenroteniopsis, Xanthidiun. Cosm., Arthrod., Euastr.. Mier, Staur.

1) 59 Toni Syll. alg. 1, sol et $90 \mathrm{~s}$ (nt supra, Cosmaridium in Plenvotæniops. incl.).

\section{MICRASTERIAS}

d 27 A $\%$. in Flora 1827 p. 1.12 (sep.p. 18). [Descriptio mala, sed speeimen originale hue pertinet. Cfr. Mr. furcata].

a 34 Küt. Syn. Diat. p. $5(1: 1$ sep.p. 71) [tantum ex parte]

a 31 Ehrent. Organ. kl. Ranm p. 298 (sep.p. 15it) [= Pediastrum. Cfr. Mteyen in Wiegm. Arch, f. Nat. $1635 \mathrm{p} \cdot 247 \mathrm{~T}$

d 35 Bréb. et Crod. Alg. Falaiso p.51. [= Mier., Tediastrum, Cosmarium, Euastrum, Crystalli].

d 36 Encll. Gen. plant. 1. 3 [ = Pediastrum, Staurastrum ete.]

(1) Butb. in Chev. Micr. 1), 271.

1 1) Menegh. Synops. Desm. 1. 21.1 (sep.p. 1)

1) fll Burneister in Ersch. u. Gruber. Allg. Eneyklop, 1. IV. 11, 18 1, 2015.

d 4:3 Kütz. Plyye, gener. p. 164 [= Pediastrum ?].

1) 14 Ralfs in Ann. Nat. Hist. r. 11 p. 259 (et 1816 Trans. Bot. Foc. Elliub. v. 2 p. 131)

145 Mass. Frit. Alg. p. 395.

14 Palfs Brit. Desm. p. 48.

11 4!) Tey, einz. Alg. 1\% 12.2. Sulogen, Euastri.

1 49 ["Microsterias"] Lamdsbar. Brit. Sea-TVeeds p. 34.

(1) 19 Pretb. in Dict, miv, hist, nat, v. 8 p. 144.

d 49 Kïtz, suee Als. p. 17\%. 
1 511 Wurissal Catal. esp. onis. 1.33.

11 52 l'ritch. Inf. p, 244.

1] is Mnth. Fl. Belg. II p.5\%25.

d phos De Bar. (onjing. 1. 3!), fo, t7, 50, 71).

n 28 Grun. Desn. P. 193.

o 5y Dixun On a new Genus (sep.p. 9) in Nat. Hist. Rev. 1. $14 \mathrm{is.}$

d 60 Tall. Desm. Low. Bengal p. 27.t et 276 .

d 61 Arch. in Priteh. Inf. p. 720 et 725 .

d 63 limb. Krypt. Fl. sachs. p. 1s2.

d $6 \pm$ Fraly Brit. Alg. p. 65.

d fo; Eyricle Algenfl. Maunh. 1) 121.

1] dir lieinsch Algenfl. Frank. p, 140. Subgen. Didymidii.

d 67 Not. Desm. 1tal. 1. 20.

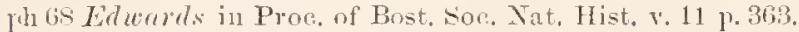

A th Liab. Flor. Eur. Alg. 3 p. 185.

d 73 Delponte Desm. subalp. p. 35 et 82 sep.p. 25 et. 70).

1] 731 trool Fr. Alg. p. 141.

d Th Microgr. Dict. p. 234 et 4.8.

d T5.Jacobs. Desm. Danem. p. 181.

1) To Frank in Leunis sirnops. p. 10:33.

d is kirchn. Alg. Selales. p. 160.

o s1 Colie in Quekett Micr. J. f p. 201.

ph 53 Fischer Gypskrstall. Thesm. p. 1 is.

d Sil Guy Monogr. loc. Conjug. p. 3 t.

d sit Wulle Desm. U. S. p. 10 s.

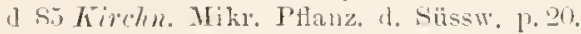

ph 86 berthold Stud. P'ojoplasmamech, 1. 273 t.6 f. 10) [M. papillifera?].

n Si; Stolies Key Desm. p. 10!.

a si Frank in Leunis Symops. p. 195.

d S6 Coolie Prit. Desm. p. 53 . (Mubuen. I. Tetracastrum (Jiron); II. Eumicrasterias, 1, 55).

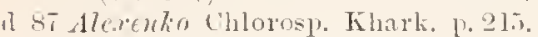

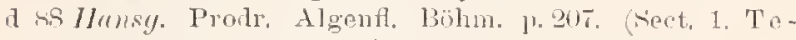
tracastr., 2. Eumicrasterias.

1) 89 Toni et Leri Fl. Alg. Vinez. 1.:11 et 111.

o so Nordst. Bormh. Desm. p. 1 sici.

1 88 Haupth. Hïllm, u. Hiillgall. Desin. 1, 91 et 111 (sep.p $33: 3$ et 5.3 .

d 89 Manowy in Baill. Dict. bot. III 1.352.

a so Tomi Syll. alg. 1) 1114 Seet. 1. Tetrachastrum p. 1110,3 . Eumicrasterias p. 1113).

1 s) Wille in Natürl. Pflanzenfan. p. 13.

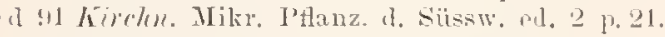

(1) Wolle Desm. U. S. el. II p.11.8.

fl 98 Baitey Contr, (queensl. Fl, p. 4s.

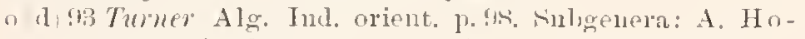
locystis, I). Atomoeystis, ('A Actinoeystis, D. sohizorystis.

1) 91 Sinumd. in Fl. Nebraslia p. 13.

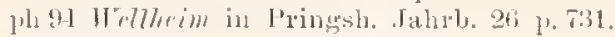

\section{MITROBIGASTRIIIUM}

1] 89 liuriz. Now. Desm. p. 77. subsect. Bigastridii.

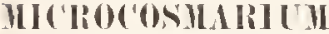

I bis lle Bary Conjug. 1. T2. Soetio Cosmarii. Subsect. Arthrodesinus et Cosmarimm.

1] 58 Hansg. Proill. Algenil. Bihlul. 1. 217. Anbsectio Eucosmarii.

1) s!! Toni Syll. alg. p.953. Snlyect. Eucosmarii.

1] Sit Lacib. Now. Desin. p. Tт. - Par.

\section{mir.mor.or.enm-n}

.1 47 PALMOGLOEA Kït $\approx$. in Botan. Zeit. 1S.4 1. 221.

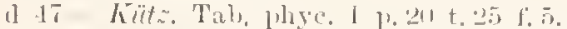

d tu - Cylimboegstis) hütz. spec, Alg. 1.22!1.
1 68 - Lial. Fil. Eur. Alg. 3 1\% 110.

o 7 - Arch, in Q. J. M. S. v. 10 P. 202 ("an interesting condition of a minute seytonematous plant"!

1) TR MESOT Braunii $\beta$ minus].

d 81 - Wrulle Desm. U. S. p. 32 t. 3 f. 11.

o sif-Stokes Kiey Desm. p. 111.

phs6 Palmogloea IIansy. Einzell. Bild. Moosvork, p. 299 (sep.p. (1).

d 88 Mesotinum (Palmogloea) Hansg. Prodr. Algent. Böhm, p. 173.

d 39 - Toni Syll, alg. p. 811 .

m $:$ - Ereher Spis Desm. Miedz. p. 85.

m 91 - Leimerl Desm. alpin. p. 58s.

m 12 - West Fr. w. Alg. W. lrel. p. 131.

d 92 - Wolle Desm. U. S. ell. II p. 32 t. 3 f. 10.

1n93-Lütkemiell. Desm. Attersees p. כ.lo.

ma4- Wist Fr. Alg. West Ind. p. 26 .

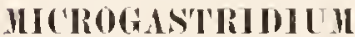

d ss Ilunsy. Prodl: Algenft. Bölm. p. 250!. Sulsect. Qastrocosmarii.

189 Toni Syll. Alg. p. 1000.

d Sy liucib. Now. Desm. p. ir. Snbsectio Gastridii.

\section{IICROPIIICUS}

n th Tivevis. Algh. Corcot. p.98 = Microtheca (animal?.

\section{mirmoscopirimer}

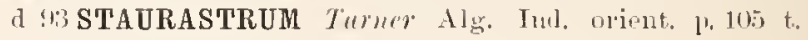
11 f. 23 .

\section{micuosphimetum -r}

dof if COSMARIUM Norlst. Desm. Ital. p, 33 t. 12 f. 9 (C. psendopyramidatum f. Sordst. Wesm. aret. p. 191).

"I - $\beta$ crispnlum Norlst. Desm. Ital. p.3t (C. ps.p y. $\beta$ erisp. Nordst. Desm. al'et. p. 19).

m 7 : - f. parvula Wille Ferskv. alg. Nov. Senlj. p. 34 t. 12 f. 22.?

d $-\beta$ crispulnm fo ibid. p.3s t. 12 f. 23.3 .

o - - f. intermedia ibil. p. $3 s$ et 72 t. 12 f. 2.

st - Wolle Fr. Alg. U. S. A. t. 60 t. 21) \& 31 [male e Norlst.].

iz - v. parvula ibid. p. 32.

o ss- boldt lesm. Grünl. p. 11.

dz 89 - Toni syll, alg. p. 10115.

d - v. erispulum ibid. p. 1006.

d - v. parvulum ibid.

21 91 URSINELLA Kuntze Rev, gen, pl, p.92.

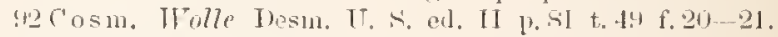
i - v. parvula ibil.

1n : 2 - West Alg. Engl. Lake Distr. p. i2t t.! f. 32.

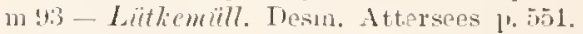

o 43 -? f. parvula Turner Alg. lud, orient. p. 52 t. 8 f.5. m $: 1$ - v. majus Ruy Seottish Desm. 1. 16is (sep.p. 34) t. 1 f. $\mathrm{t}$.

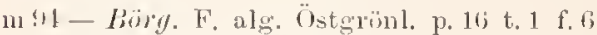

m DXSPHINCTIUM simmalle Beitr, alp. Alg. p. 34!。

o $\quad \cdots$ v. crispulum ibid.

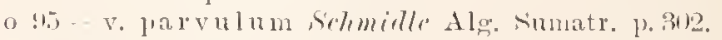

\section{ICIOTHECA}

d 39 Ehrent. Inf. p. 1fit [et alii] - animal? [Cfr. Microphycns]

\section{mirrtelyaremere}

o :1 COSMARIUM Eichl, et Gutu, in Frakan Anzeig. p. 238.

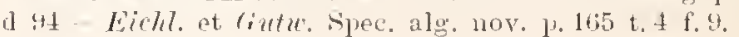


millilll!

d !13 НУАLОТНЕСA Turner Alg. Ind. orient. p. 153 t. 22: f. 16 .

\section{minimum}

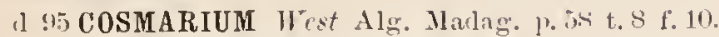

d v. subrotundatum ibid. 1).59 t. 8 f. 11.

\section{Himmerpoliense}

a sTAURASTRUM Wolle in Bull. 'T'on" hot. "lub 1885 p. 5 t. 17 f. $11-13$.

d 8. - 11 olle Fr. Alg. U. S. A. 1. 15 t. 57 f. $11-13$ [ex Wolle 1895].

a 89 - Tomi syll. alg. p. 1147.

d !2 - Wolle Desn. U. S. or. II 1. 141 t. 18 f. $11-13$.

\section{minneapolitumum -}

d s. CosmariUm Mansg. Prodı. Algenfl. Bühm, p. 203 (C. protuberans $\mathrm{v}$. granulatum $11 \% 7 \mathrm{lc} 1884$.

d 89 - Tomi Syll. alg. p. 100 .

n!1 URSINELLA Kuntre Rev. gen. pl. p. 92.

m 95 Cosm. Johns. Rare Desm. U. S. Il p. 2!n.

\section{limmesotense}

(1) ST STARASTRUM Wolle in Bull. Torr. bot. Club 18k5 p. li t. 17 f. 7 \& 8 .

d 87 - Wolle Fr. Alg. U. \&. A. p. 43 t. 57 f. $7 \&$ \& iterata icon].

d sis - Toni syll, alg. p. 1152.

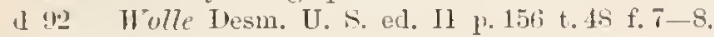

\section{minol}

d 93 ARTHRODESMUS Tuma Alg. Ind. orient p. $131 \mathrm{t}$. 11 f. 29. [A. convergens v. Turneri Witdem. 1834 ].

\section{millo"}

izf 75 SCHIZ0SP0RA Rinsch Contribut. 1.87 t. 17 f. 2. [Penium didymocarpum Lund. sec. Nordst. in Hedwisria 1876 p. 66$]$.

\section{minon- -}

d 13 PENTASTERIAS Kütz. Phyc. gener. p. 11:2. Descriptio inala. Pen. margaritacenm b. minus Rab. 1817].

d 45 PHYCASTRUM" Kä̈z. Phycol. germ. p. 13!.

d Is STAURASTRUM: lialf's Brit. Desm. p.217 t. 35 f. 18.

1) 49 Phyeastrum (?) Kïtz. Spec. Alg. 19, 183.

d 52 Staunatrum Pritch. Inf. p. 269.

d 61 - 1rch. in Pritch. Inf. p. 738.

d $68-$ Riub. Flur. Eur. Alg. 3 p. 2200.

\section{minns}

n $\$ 2$ COSMARIUM ["minor"] Ruc. Desmidya Ciastoni. p. 374 (C. trachypleurum v. mino liac. 1851).

d - f. australis ibid., t. if f. 27.

n $\$ 13$ - ["minus"] Gutu. Glon. staw. "/b1uezu p. 28.

mb - $t$. schmidle Beitr. alp. Alg. 1.92 (sep.p.37), et, 18:3. t. 15 f. 20

\section{minllserlllum}

d 85 STAURASTRUM .Josh. in Joum of Bot. p. 34 t. $25.1 \mathrm{f} .7$.

1 89 - Tuni syll. alg. p. 1230 (nomen specif. ementatum: "minntuIum"

\section{milllte}

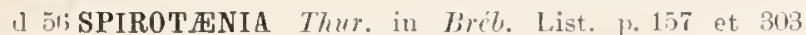
(sep.p. 165) t.1 f. 30. [Sp. erythrocophala see. It zigs: 1556]. o st) - Itzigs. in Bot. Zeit. $1856 \mathrm{p}$. 8406.

o 58 - De Jirr. Conjug. 1) 75.

(1) 63 - Monotienia) hab. Krypt. Fl. Sachs. p. 16 i.

d 68 -Rub. Flor. Eur. Alg. 3 p. 117.

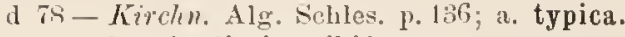

$m$ - b. minutissima ibid.

o $83-\beta$ minutissima $f$, orythropunctata $L a g c \cdot h$. Bidr. Sverig, Algft. p. 5?

d 86 - roolic Brit. Wesm. p.51 t. 19 f. 7.

m si-Racil. Mat. flor, glon. Tolsk. p. 1 - Mo (sep.p.21).

¿ 59 - Tomi syll. Alg. p. Bil!?.

m - v. minutissima ibid.

d - v.erythopunctata ibid.

m 90-Eichler Spis Desm. Miedz. 1. 45.

pl. 14 - hoy ricott. Desm. p. 25\%.

m94-Alexentio Mat, alg. Kílark. p. 20.

o 55 - Lüthemïll. Gatt. Spirotien. p. 54 t. 1 f. 21.

\section{minutissimn.}

d 93? CYLINDROCYSTIS Turner Alg. 1nd. orient. p. 16 t. 1 f. 24.

\section{mimutissimum.}

oz 7 COSMARIUM Areh. in Q. J. M. S. v. 17 p. 194 et 301. oz 810 -Cooke Brit. Desm. p. 91.

\section{minutissimum.}

(1) 91 COSMARIUM lleimerl Desm. alpin. p. 600 t. 5 f. 1 t, nee Arch. [Cosm. Heimerlii W'est 1895].

\section{mimutissimum}

dzf 73 PENIUM Nordst. Nolg. Desm. p. 16 t. 1 f. 21.

m 84 - f. major Wille Nylannerik. Algft. p. 18 t. 3 f. 11.

dzf 86 - Cooke Brit. Desm. p. 15 t. 17 f. 10 [ex parte e Nordst.?].

$\mathrm{dz} 89$ - Toni syll. Alg. p. 863.

1195 - West Alg. Madag. p. 47.

\section{minutissimum}

n 63 STAURASTRUM Auersm. in limb. Alg. Enr. n:o 1128 e. icone [Saltem $\mathrm{ex}$ parte $=\mathrm{st}$. inconspicnum Norlst. see. Norlst. in Mesmid. spetsb. p. 3s'].

d 67 -Reinsch Fipe. Gen. Alg. p. 1.10 t. 23 i II f. $1-8$ (sep.p. 32 t. 1)

d 67 DIDYMIDIJM (Staur.) Reinsch Algenf. Frank. p. $15 \mathrm{~s}$ t. 13 f. 1.

d Gosta ur. Rab. Flor. Eur. Aly. 3 1, 201.

o 72 -f. Notdst. Desm. Nietsb. 1. 34.

o Ti-Reinsch Contribut. p. 91 t. 16 f. 3 (forma).

m 75 - Nordst. Desm. arct. p. 33 t. 7 f. 36 (f. tetragona).

o 79 - Wi7le Ferskv, alg. Nov. Semlj. p.52 t. 13 f. 59 (f. trigona major) et lio (f. miuor).

o 89 - f. a. Bolrlt Desm. Grönt. 1. 33.

-? f. b. ibid.. t. 2 f. 10.

o - f. c. ibid.

m - f. i. ibid. t. 2 f. 11

d 89 - Toni syll. alg. 1. 1181.

(1) $12-v$. constrictum West Fr. w. Alg. W. Irel, p. 172 t. 24 f. 14 .

m 94 - Bäry. F. alg. Östgrönl. p. 25.

milltullll - Cfr. minusculum!

\section{minutum}

mo2 COSMARIUM IBem. Fr. Alg. ‥ W. Surrey p. 10 t.2 f. 11. non Delp. [C. truncatellum? Cfr. Luyerh. in Nuov. Notar. 1893 1. 168. - C. polygonum f.? West in Journ. of Bot. 1895 1. 64']. 
"11 illtull -

d TT COSMARIUM Delponte Desmil. subalp. p.9 (sep.p. 105) $1.7 \mathrm{f} .37-39$.

m 84 - Schererschem. Afghan. Alu. p. 24 .

Il $85^{\circ}$ Hlunsy. Prodr. Algenf. Böhm. p. 1!\%.

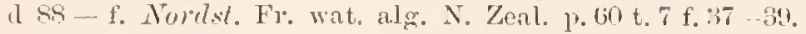

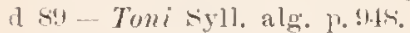

11 URSINELLA huntze Rev. gen. 1) p. 925.

o 95 Cosm. Sclmidle Beitr. alp. Alg. 1. 38.1 t. 15 f. 12. [Quil.?].

Cfr. Cosm. Wittrockii Bcnu. 1ho6, 'Tessararthra moniliformis $k h \cdot b$. 183 .

\section{$\|1\|\|t\| m-\|t-\| s$}

d 4 DOCIDIUM Rirlfs Brit. Desin. 13. $1581.24 \mathrm{f} .5$

5l - Bait. Mier. Obs. t. 1 f.

d $52-$ l'ritch. Inf. n. $2 \pi t$.

o (i1-f. Luhluh. in Hedw. p.51 t.? f. 1 [f. ma jor Lumd. 1871].

d $61-1 r c h$. in Pritch. Inf. p. 745.

11 1il PENIUM Clece Bills. t. Sverg. Desm. l'. 193 (inel, P'en. Ralfsii.

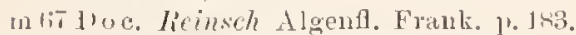

d $15 \overline{7}$ - Not. Desm. Ital. 1. $5 \overline{7}$ t. 5 f. 57 .

d 68 Pen. Rab. Fl. Eur. Alg. p. 12:.

d - b. lineare ibid. (Penium lin. Külta.).

m 70 - Tordst. Desm. Brasil. p. 2002,

- 71 -Lind. Desm. sues. p. 8T; forma major (f. Iiulnh. 18601

(1) 73 - Thuod Fr: Alg. p. 107.

o 75 Doe. Jacubs. Desm. Janen. 10. 162 t. 7 f. !.

4 TI PLEUROTANIUM Dilponte Desm. subalp. p. 131 (sค1.1. 227) t. 20 f. $17-21$.

I Ts CALOCYLINDRUS Firch. Alg. Sichles. 1'. 14.2.

d so Pen. $\beta$ gracile Wille Nurg. Ferskv. alg. I p.51 t. 2 f. 33.

(l - $v$ tumidum ibid., t. 2 f. $: 31$.

d 84 - Wulle Desm. U. ×. p. 35 t. 5 f. $19-20$.

(l 84 cal. ibid. p.5t t. 5 t. 19 et 20, t. 12 f. 1.2.

a st Doc, ibid. p. 52 t. 10 f. 9, t. 50 f. $29-31$.

n 81 l'en. Wizle Sylamerik. Algh. p.22.

1385 - Schuruschm. Magy. növ. Lap. p. 7.

a 85 - a. gracile lincib. Nonn. Desm. Polon. p. (30) sep. 1.4)

d - b. minor ibid.

d c. majol ibid. 1.til (sep.1. 5) (buluh. 1861).

1) - d. genuinum ibick. t. 11 (sep.5) f. 11 .

\& - e. alpinum ibid.

1. - f. tumidum ibicl.

nn si-Lagorh. Anerik. Desm. p. 253.

(1) sto-stokes Key Desin. n.111.

Ca l. ibid. p. 114.

Doc. ilid. p. 113 .

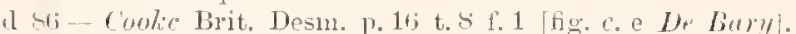

n 87 DISPHINCTIUM Hang. in Österr.bot. Zeitsehr. v. 37 11:0: $: 11.99 \%$

d sis-Mansy. Irouln. Algenfl. Bölnm. 1) 1 t55 (Dor. minutum a) genuinum p.24t et 27 .

in Doe. ibid. p. 188 f. 110 (e Dely) ?].

m 8s Dys. Istr. Jel. magyar. alg. p.211.

m $\gamma$ tumidum ibiel. 1. 212.

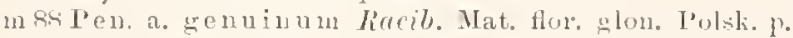
$100($ ke]r.p. 21)

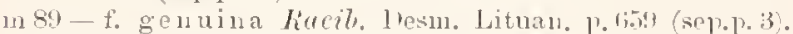

d S9 I'leur. Tom: syll. alg. p. a04.

v. gracile jbid. 1. w.

v. tumidum ibil. na 90 Pen. Hichter spis Desm. Miedz. p. 85 t. 8 f. 7.

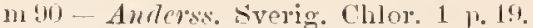

m no Doc. v. gracile West Fr. w. alg. North Wales P. 281.

m!1 - Heimerl Desm. alu. p. on!1.

m 91-Gutur. Filor. aly. Leopol. p. 37.

in 42 Fen. f. genuiua West Fr. w. Alg. W. lrel. 1' 12!.

$m$-f. major ibil.

mo - f. minor ibil.

n - v. gracile ibid.

m -. v. tumidum ibil.

m - - v. alpinum ibid. p.13n.

- v. polonicum ibid. (Pen. polonienm Ruc. 1895). - v. crassum ibid., t. 20 f. 1.

- f. punctata ibid., f. 2.

- - f. inflata ibil.. f. 3.

- v. undulatum ibic.. f. $t$.

A ! 2 - Wolle Desm. U. ‥ el. II p.36 t.5 f. 1! 20).

Doc. ibid. p. 57 t. 13 f. 9, t. 61 f. $24-31$

Cal. ibid. p. 59 t. 5 f. $19-20$. t. 15 f. 12.

11 @13 Pen. Lüllicmiall. Desm. Atterseses 1.545.

- 95 - Wrest in Jonrn. of Pot. 33 p. 65 Horidium BacuIum Liatliemiill. 1s:13).

119.5 - Recib. in Flora v. 81 1.32.

Cfr. Doe, Baculum.

Verisimiliter, ut mihi videtn1,2 $(-3)$ sjecies existunt. una ad genns Penium, altera ad Pleurotanium pertinens, sod investigandum est, an revera ita ist. Species Pleurotienii, ut mihi viletur, wricipue ab his auctoribus descripta

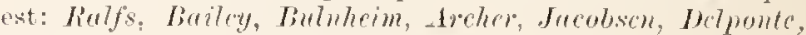
ajul alios auctores lua species ad mnan conjuntes sunt; alii anetores tantum ad Penium Ralfsii Je bar. spectant.

\section{minlll!}

1 47 EUASTRUM Focle Plyys. Fitud. I 1. 11 t. 1 f. 1. [Cosmarium ad ('. snbcrenatom aceetens?!

n 52 - Pevty liteinst. Lebensf. r. 20y.

\section{milltum}

1) MGONATOZYGON W'ot Fr. W. Ale. North Wales p.

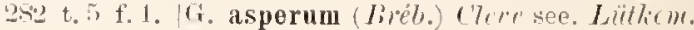
Desin, Atters.).

$1192-$ West Fr. w. Alg. W. Irel. p.111.

\section{"IIIUt\|s}

11 is ARTHRODESMUS lirit, in Ralfs Brit. lesm. 1'.213 t. 55 f. 15. Euastr. Incus Kït. Plyce, germ. Eu. minut, hïti. in litt.

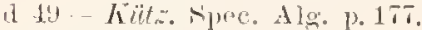

(l) Iritch. lnf. 1. 26i).

il 1;1 - Arch. in Priteh. lnf. 1. 737.

d (is - Rub. Flor. Enr. Alg. 3 p. 227.

7.5 - Mierogr. Dict. p. 73 t. 13 [e Ralfs.

13 si - Luyerh. Amerik. Desin. p. 215.

d s? Tomi syll. alg. 1\% 10it!.

\section{IIIIIIIs}

1) 5. TETMEMORUS de liary Conjug. 1. 11 et $71 \mathrm{t} .5 \mathrm{f} .10$.

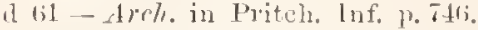

d riz-Krob. Krypt. Flox. Saels, p. 175.

d 68 - Rub. Flor. Eur. Alg. :3 p. 160.

at 58 - Kirchn. Algo. sehles. p. 115.

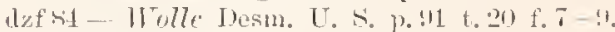

a sio-stokes key lesim. p. 13m.

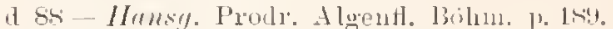

d 89 - Tomi syll. Aler. 11. 868 .

m 90 - Eichler spis Desm. Mindz. p. 8i.

m 20 - Anderss. Sverig. Clalor. 1 p. 17. 


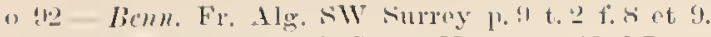

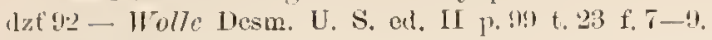

\section{milifir."1m-a}

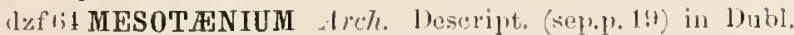

Nat. Hist. Soe: F'1. 1, 30 t. 1 f. $: 0-31$, in (2. Jonl.

Mic.r. sis. r. 130 t. 1;.

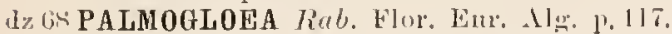

def sti Mes. Cooke Brit. Besm. p. ti t, 1s f. 3 [ex Archer]. dz 89 - (Palmogloea) Toni syll. Alg. P. 813 .

\section{MINOTINIUM}

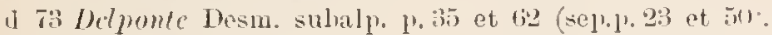
o 193 Tymer Alg. Ind oriont. 1. 153. Anbgenus Hyalotheca.

\section{Hoerlintull}

(1) COSMARIUM Lïthmüll. Desm. Attersees 1. 3.it t. 8 f. 7 .

\section{Moprlirmes}

d. is ARTHRODESMUS Grm, in Rilb. Flor, Eur. Alg. 3 1). $20 \%$.

d s!1 -. Tomi Syll, alg. p. 1065.

\section{molur.ruse}

(1) 6 ARTHR0RHABDIUM kihenb. in Abl. d. Berlin. Akar. 1869. 2 1) 1 t t. 2 f. 1 II. 13.

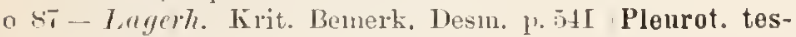
sellatum 1. verrucosum?

\section{monrelime}

d 25 HETEROCARPELLA bory in Uict. class. \& p. 1 so (I'almella rupestris Lyngb. ex lo.).

\section{monile}

11 3! CLOSTERIUM Breb. in Chev. Nicr, 1. 27\%.

d 15 - brib. in hitz. Phycol, germ. 1. 13\%. [Tetm. Brebissonii ser. Rulfs 18ts.

d 1") PENIUM Kïl. Spec. Alg. 1. 11\%. Idem.

\section{monile}

d :3DYSPHINCTIUM Twner Alg. Int. orient, p. 11 t. 7 f. 13.

\section{monile}

0 1:3 SPONDYLOSIUM Turner Desin. Nites 11.316, et t: 1:1 1. BI1 [fig. non bona sec. auct. in litt.].

\section{momilifemum-r}

1 21 LUNULINA ["moniliplura"] Bory Encycl. meth. Hist. T. d. Zooph. 11 p. 501 t. 3 f.2.2, 25.27 (Vibrio Lu nula Wiiller Inf. t. 7 t. 9- [2, [f. Borya $11 \mathrm{um}$ Finsch 1887].

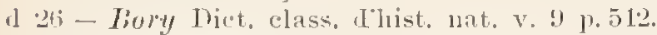

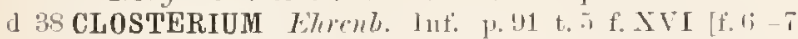
$=$ Cl. Jenneri; f. $1-5=$ ?; f. $1-\$=$ ('l. monil. f. Iülleriana Jucobs. Lrizo. F. Boryanum lirinsch 1 isiji].

d 10 - Menegh. Syn. Desin. 1.2:32 (sep.1. :32)

(1 11 - Builey Amer, Bacill. 1).3r) (sep.1, 21, t. 3 f.:3l.

d 15 -llass. Brit. Alg. 1. 370 t. 8 f. f. [ex Ihrenl. 1. f. $3,4$.

d 45 -Kütz. Phy». germ. p. 130.

d IS - Rolfs Brit. Desur. 13. 16itj t. 29 f. 3.

d $19-K^{\prime}$ ïtz. spec. Alg. 1), $16: 3$

d $-\beta$ minus ibid. [(1) ornatum Rub. Krypt. Fl. Sarlıs. $186 ; 3$ p. 171]

ก 19 - Ney, einz. Alg. p. 106 t. ti, c f. 1.
4. 5 - Irilch. Inf. 11.25il.

ph 52 - Perty kleinst. Lebensf. p. 2200.

(1 53 - Math. Fl. Belg. II p. 395.

d 5fi-v. Thureti lirib. List. 1) 119 . [Cl. Thureti 1818. Status divisionis see. Rab. 1868].

if ti - Arch. in Priteh. Iut', p. 718.

(1) 63 - Reb. Krypt. F1. Sachs. 1. 171.

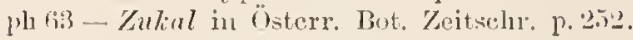

n 6.) - ? v. Grum. Ins. Banka t. 2 f. 1T.

(1) 6 - Eyrich Algenf. Mamnh, P. 13i;.

o $m 67-f$. A. Leibleinii lieinsch Algentl. Fraul. 1. 1!u. $a$ (Cl. parvulum $\left.N_{(\%)}\right), f$ ('l. Leil,l. Kïls.).

d - f. B. angulatum ibis. (Cl. angulatum I/ontźsch).

l) - f. r. Boryanum ibill. 1. 1:1, a et $f$.

d - f. T). Ehronbergianum ibid.; a Cl. E luenbergii), $\rho, \gamma$.

67 - Not. Desm. Ital. t. li f. 62

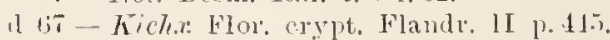

o 68-Reinsch in Ral. Alg. Eur. 11:0 2070.

(1) 68 - Rab. Elor. Eur. Alg. 3 p. $131 ;$ a, 1.

$-\beta$ min us ibicl. p. 132.

$4 \quad-y$ angulatum ibid.

m los - Nordst. Tesm. Brasil. 1. 203 .

zf 71 - Lumd. Desm. Suec, p. 80 t, is f. 11 .

d 73 - Wood Fr. Alg. p. 11:3.

1 i.) - Mierngr. Diet. p. 17 i t. 10 f. 43 [e Kulf: Br. Desu.].

n 75 - t. Ehrenbergiana Jacols. Desm. Danem. p. 170.

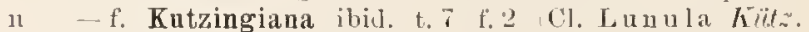
Syn.)

n - f. Miilleriana ibil. Vibrio Loula Mïller; ril. non il if. R(my).

n - $\mathfrak{f}$. Loibleiniana ibid. (U. Loilleinii hïtz.).

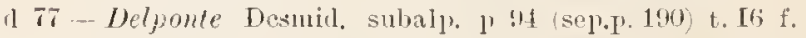
$21-23$.

o Ts- Nordst. Alg. sandv. 1. 10.

a 78 - a. genuinum Kirchn. Alg. Selles. p. 1 tl, et b. mi 11 us. m 78 - Hempel Algenf. Fhemnitz p. 11 .

d is-a. typicum hlels Desm. Oitpreuss. p. U t. 1; $a=$ f. $b$ b; $\beta=$ f. 1 e et $1, \gamma=1,8$ a.

I - b. Leibleinii ibid.. f. T.

d - - Ehrenbergii ibil. p. 10. $a=f .1$ a, $\beta=$ f. 4 b. If - 11. concavum ibid. 1. 11. $a=f .5 \mathrm{a}, \beta=\mathrm{f} .5 \mathrm{~b}$.

ph 79 - Stahl Einf. Licht. Beweg. 4. Desm. p. 25 (sep.p. 2). jh sit - - in Bot. Zeit. 34 1. 394.

nu 82 - Nordst. Algolog. smàn. 3 p. 1"l et 51 .

o $\$ 3$ - ('ybulski Mater. alg. Warszaw. 1. 240 +. 8 f. 13.

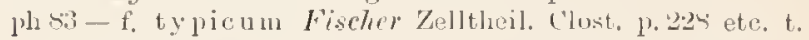
3 t. $3,5,6,9 .[?]$

ns 84 - hopot Mater. alg. Warszaw. 1. 253.

m 84 - a.e et b. angulatum Arturi Liste alg. Moscou p. 140.

a si-Wolle Desin. U. S. p. 4i t. 7 t. 15.

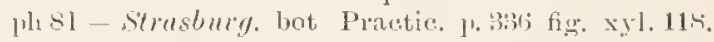

1) 85 - Giveln. Mikr. Pflanz. t. Süssw. p. 21.

m 45 - Boldt sibir. Clıloroph. p. 12:2.

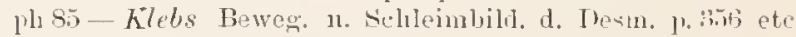

o 813 - Stoliex hey Desm. P. 112.

1) St - Coole Brit. Dessn. 1.2I t. 12 f. 3.

o. .6 - v. Syuimul. Catal. Desin. Fenov. 1' 15.

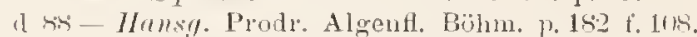

B L ribleinii ibil. P. 183.

ass-Toni et Levi l'l. Ale. Vene\%. 1, 3:3.

1u 8. - v. minus hinbin. Chloroph. env. Kharkow ip. 317

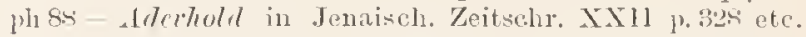

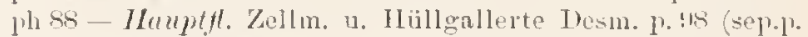
40) t. 3 f. 4 s.

m 88 - Iste. .Jel. magyar. alg. p. 23:.

m 88 - Nordst. Fr. wat. alg. N. Zeal. 1.65. 


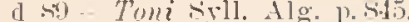

o - v. minus ibicl. 1\%.8.16.

d - $\quad$ angulatum ibill.

m! -- Eichler S̈pis Desm. Miedz. 1) 81;.

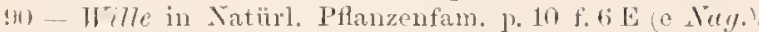

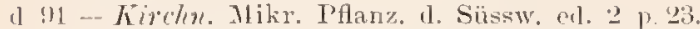

n! ARTHR0DIA hunt:e Rev. gen. j]. 1. \$s:3.

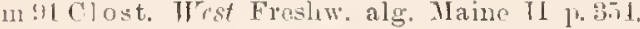

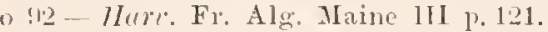

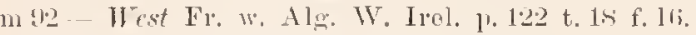

o ! H - f. linc. Desmidya Ciastoni. p. 381 t. $1 ;$ f. 37.

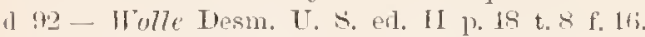

m! - Lithemiill. Desm, Attersees [. 543.

(33-v. concavum Sclunidle Beitr. Alg. Sieluwarywald. 1. $\$ 1$ t. 3 f. 11.

1, !1. - I'alla in Ber, lent. bot. Ges, 12 p. 157 t. 8 f.s.

1 11 f. intermedia Gutu, Fl. alg. Taruapol. p.is t. 3 f. 13 .

In 91 - Alerpulio Mater. alg. Lluatk. 1.20.

d !1 - Sumul, in Fl. Nebraska. 1) 39 t. 5 f. 2 [0 Cooler].

1n95-v. minus Mieron. in PHanzenw. Ostafik. 1. 19.

m.5 - $\beta$ concavum Lorge sverig. Clulor. II 1. 13.

Cfr. C'lost. Lunula ex j. (partiul apul Nitzseh?. livenb. Küz. Breb.. Fuche, et

"Conferve inedite" Girod Chustrus Reclrelch. chim. et microsco11. p. 234; t. 39 17:0 77, et

"Pflanzenthier", Grwithuisen, Beitr. \%. Ihysiog

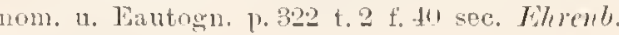

monififellm-r

175 COSMARIUM linincele Cuntribut. 1). 81 t. 13 f. 11. [C.

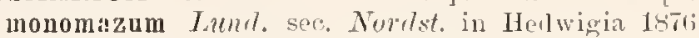
]. $61 \%$.

77 - lieinsel in Pringsh. Jalur, v. 11 t. 17 f. 7.

(1) Sil-Tomi sirll. aly. 1) $111 \%$.

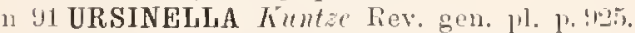

\section{monilif'llm}

1 9.5 PLEUROTANIUM West $11 \mathrm{~g}$. Malag. 1. 1.1 t 5 t :2.

\section{momiliforme}

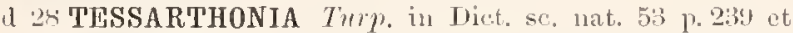
Pl. bot. Véget, acotyl. plaut, vésicul. f. 1 [1s20]; et A per;. organ. p.:3li t. 13 f. 16. [Hace planta multo minor est (lomg. 20 \%, erass. 5 \%) quam f'osmariun monilifolue anct, lecent.e et scenudum descriptionem, ut mili videtur, al lesmiliaceas non pertineat. ( $\mathrm{fr}$. Kumta 1s:!1]

33 - Jimnett Outlines Algol. 1". Th fig. xylogr. i [e Tum.]. (] 31 SCENEDESMUS h Idem.

(1) 35 - Iirib. Iler. Falaise p. vin t.8. Tdem.

11 30 TESSARARTHRA Ghrb. in Ablı, l. Pollin. Alial. $183 ; \div, 173$.

1137 TROCHISCIA Mrnegh. ('onsp. Aly. Eug. p. 1i.

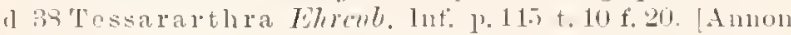
C. minntum $/ \mathrm{l} / \mathrm{l}$.?

II 3"I 'Trocliscia $f$ duplex breb. in Chev. Micr. p. 273

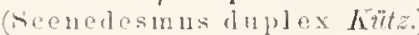

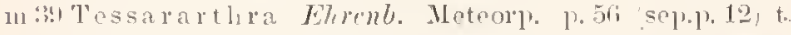

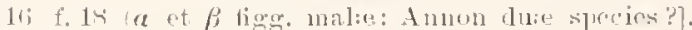

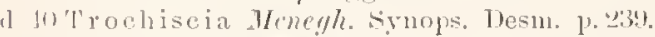

d 11 'Tessar. Morren lieclierch. plysiol, 1.!3"sep.]1. 121).

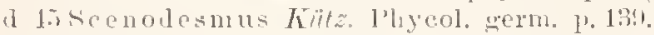

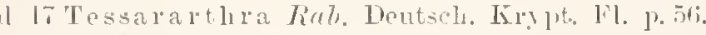

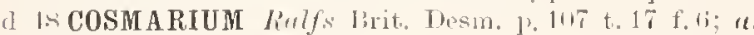

$\beta$ ibil.

1 5i2-Iritch. luf. 11.25\%.

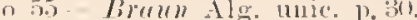

pliss-(Dysphinctium) He Bary Conjug. p.11.72 t. $6 \mathrm{f} .4 \mathrm{~s}$.

o 5s Tessararthra Grum. Desm. ], 4!33.

I) 1 il Cosm. Arch. in Priteh. Inf. p.735.

n 6.) DIPloSPHARIUM Cramer in Wartu. et Selienk Schwei\%. Krypt. fase, 3 sub 11:0 136, [lue?].

oph fiticosm. Arele. in (2. J. MI. Se. v. li p. 120.

1) $1 ; 7$ Ścenodesmus Kichx Flore crypt. Flandr. Il p. 14ti.

d tit DISPHINCTIUM Reinseh Algenf. Frank. 1), 180; A $a$ et $\beta, \mathrm{B}$.

d lis Cosm. Tint. Flor. Eur. Alg. 3 p. 173

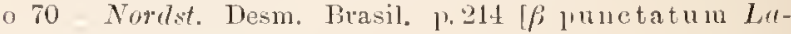
gem. 15isi].

ozf 71 - Lumd. Desm. Silec. 1) 11 t. 3 f. 1.5.

n 73 - (f. elliptica) Nordst. Norg. Mesm. p. 22 [Cfr. Novedst. in Bot. Notis. 18-2 1.97; C. Iacobsenii Foy see. Fordst. Bornh. Desm. p. 2oon.

in 55 - Riviscle Contrib. p. 8\%3 t. 12 f. 1 b. Cfr. Nortst. Bornh. Desin. 1).21k. Quid??.

o 76 -Jacols. Desm. Danem. 1). 240 t. 8 f. 21 [C. Jacobsenii lioy 184:37.

16 77 - Delpontc Desm. subalp. 17. 10 (sep.p. 1(16) t. 7 f. 10 - 11. (val, a.) [C. globosum $\beta$ minus $/ 16 m .5 \%$. 1589]. (l $-v$. b. ibid. et t. 7 f. $42-45$.

dz 7 - Finden. Alg. Achles. 1. 117.

d 5 - a. typienm Klels Mesin. Ostprenss. 1, 36.

d - b. ellipticum ibid.

o 80 v. Wi77, Norg. Ferskw. alg. I p. 37 (Itelp. 187\%).

m 81 - Jife. Finsk. Desun. p. 13 .

lyfit - Wolle Desm. U. S. p.60 t. 1.5 f. 14;-19 [Fig. 19 şırâ aculeatâ alia spec:.

m s6 - f. elliptica Lagrh. Amerik. Desm. p. 2to t. 27 f. 13.

d 80 - Frank in Leuris b́ynops. 3 p. 13.

o sif- Stukes Key Desm. n. 126.

laf $\$ 7$ - ('ooki Brit. Desm, 1. 11!) t. 13 f. 2. [ $d$ fortasse e Lund. 1871, cetere firg. now houre, partime Rulfs?.

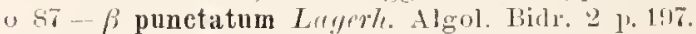

n 87 - f. elliptica Lryorh. Kirit. Brmerh. Desm. 13.539. lzsiti- Mrysy. Prolr. Algenfl. Bolm. 1) 193

dzsi-Toni et T.eri Fl. alg. Venez. p. $4 \%$

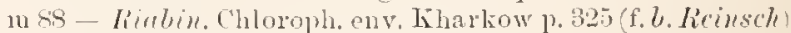

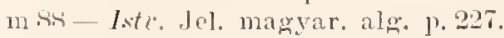

m sis-t. elliptica Nortst. 1r. wat. slg N. Zeal. p.61.

1189 - liarit. Desm. Litna11. 1. G61.

dz sis - Tomi"iyll. alg. 1.932.

d - v. punetatum ibil. 1. \$33.

in - ve ellipticum ibid.

m 10 - Riv?. Mesm. Brasil. 1. 12.

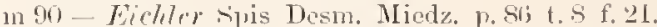

m 10 - Inderss. Siverig. Chlur. 1 1. 16.

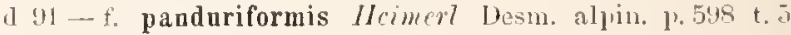
f. 11. [Qunid?]

11 !1 URSINELLA Kuntie Rev. gen. 11. 1. \%25.

11] Gosur. West Fr, w. Mlg. W. Irel, p. 1iil. f. ibid.

dzf 13 - Wolle Desin. U. S. ed. Il p.6.j t. 1i f. 16-19.

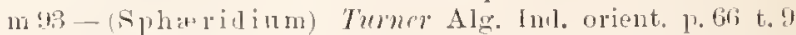
f. 11 et 45

113 913 - f. panduriform is Thest in Naturalist $14: 13$ p. 211.

1) 11 - f. suboiride sehmille in Flora is 1.51 t. 7 f. 1)isple. glohosum f. subviride srlem. 16ib3.

oz!1 - lloy Scottish Desm. ]. 1 lin (se].].3!).

11 \$1 Alerenlin Mater. alg. Khark. 12.26.

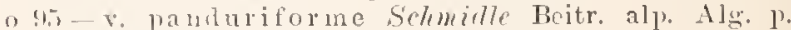
387 (incl. 1) dubium at inferam $T w \mu_{\text {.). }}$

In 45 - Wrest Alg. Madag. 1?. il) t. ! f. $3($ ).

m - v. punctatuu ibid.. f. 31 . 


\section{momilifurme}

a 11 SPONDYLOSIUM I.und. Desm. Sinere p.92 t.is folf.

m 85 SPHÆROZOSMA Wolle in Hull, 'Tur'l. lot, Cl. 12 p. 127 t. 51 f. 11

o sli-Stolic's Ker Desm. p. 111.

d 87 - Wolle Fr. Alg. [T. S. A. 1. 2.2 t. 59 f. 11 [ex Holle $1895]$.

d 89 - Tomi syll. Alg. p. Tims.

d ir - Wolle Desm. [T. S. ed. II ].30 t. 4 f. 11.

\section{moniliformis}

(1 41 GYMNOZYGA Ehrenb. Berlin. Monatsber. 18!0 1, 212. [Desm. Borrori, Bambnsinn Brebissonil],

d .i2 - Pritch. Int". 1). 2413.

m 48 - $\beta$ gracilescens Fordst. in Gazell. Expedit. 1) 4. (Bambusina Borreri foracilescens Nordst. 1s4(1).

o sS - Nordst. Bornh. Desm. p, 20 !.

m SA - Wordst. Fr. wat, alg. N. Zeal, p. 2.R.

in - v, gracilescens liacib. Desm. Lituan, p. Giil.

d) 89 - Tumi syll. Alg. 1) T:1.

dz - v. gracilescens ibid, p, Tis.

m 9 - Anderss. Sverig. Chlor. 1 p. ?.

m 1 - W - West Fr. w. Alg. W. Irel. 11.117.

m 12- Mib. Austral. S̈̈sswasseralg. p. 410.

m 13 - Bailey Contr. (2neensl. Fl. 1).3:4.

m !13-7urnor Alg. Ind. orient. p. 151.

m 94-Börg. F. alg. Östgrönl. p.32.

(5) - Builey Contrit. Queens]. Fl. XI t. 10 f. 3.

oz 95 - r. gracilescens Racil, in Flor:a v. sil p.31. o - - majus ibil.

\section{monitimhorre}

21 LUNULINA limy Cfr. L. monilifera.

\section{monochomalmem - -}

d 73 COSMARIUM Jordst. Norg. Desm. 17. 17 t. 1 f. 6.

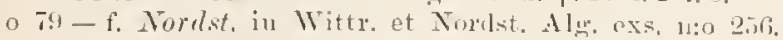

d 89 - Toni Sy'll. alg. p. 16kr.

n !1 URSINELLA Kuntze Rer. gen. 11. p. 92i.

\section{momororren}

I .1:) PALMOGL0EA (yliwlrocytis) hät. Sipec. Alg. p. 22!!, $\iota$ æruginea et $\beta$ mollea $=$ Alooothece et Pleurococcus sip.

\section{momororer $11 m$}

(1) cLOSTERIUM Fresenins ar inter. in Rossm. Nachtr. Wetter. Alg. 1\%. 7 Cl:o Loibleinii aflime

\section{monorlentutum}

o 93 EUASTRUM Tmmer Alg. Inl, ngent, p. is t. S fost (Cosm. Aitchisouii iliju.

\section{monomrantem -}

a 71 COSMARIUM Lmml. Desin. Silec, p. 32 t. 3 f. 11.

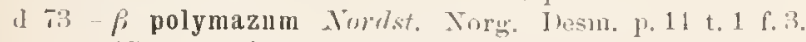

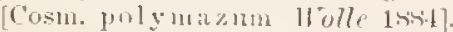

o $\$ 2$ - t. Wolle in Bull. Torr. bot. Club, a p. 26 t. 13 f. 1 . [C. prolyma\%. II olle]

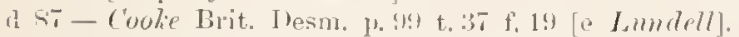

1) 5 !) - Toni syll. aler. p. 1015.

I - v. polymazum ibit. p. 1616.

1) s9 - va amazum lincib. Now. lesm, p. si t. 5 f. 18

11 URSINELLA Kunt: Rev, gen, pl. p. 12.5.

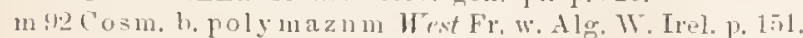

\section{monom}

n sis EUASTRUM lincib. Xonn. Desm. Polon. p. 9.t snp.p. 35). (E. gemmatum * mononcylum Nordst. 1,isil).

n - a. capenso ibiel

il - b. polonicum ibil.. t. 13 sep. 3) f. 6.

m!1 - r. polonicum Gutw. Flor. alg. Leopol. p. T3.

(1) (4) - v germanicum sclemille in 1Ielwig. $34 \mathrm{p} .80 \mathrm{t}$. 1 f. 17 .

m5-v. polonicum Hest Alg. Madag. p, il.

a - r. æquilobnm ibid., t. of fi. 14 . Cfr. Eu, spicatum Tmm. 1898.

\section{MONOTIENTA -IE}

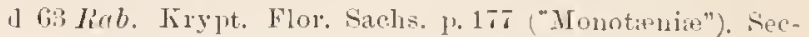
tio Spirotaniæ.

d !n Twrn. Alg. tud. orient. p. 23 ("Momotienia"). Subren. Spirotan.

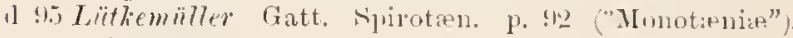
silbgenus.

\section{monotrmillm-ire}

a if CLOSTERIUM Arch. in Q .T. M. . . v. 10 1) 415 .

d S6-Cooke Brit. Desin. p. 25.

d 89 - Tomi sill, alg. p. slis.

" "I ARTHRODIA Kuntze Rer. gen. pl. p. s8:3.

\section{monotaminm}

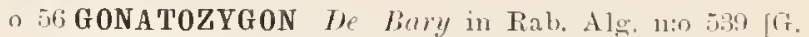
Ralfsii $H_{6}$ l?. 1858 ?

d si; - De Tiary in Helwigia I p. 106.

o $5 \overline{-}$ - Ihe Bury Copnlationsproc. im Ptanz. p. 340.

z 57 - De Rariy in Bot. Zeit. p. 735.

ค 72 - Hittr. Gotl. (3). sütv. Alg. l', 633 .

If .96 - $\beta$ pilosellum Nordst. in Wittr, ot Norlst. Alg. oxs. n:o 75). (G. Ralfsii f. Archer 18(it); ot (1.sin) in fase. $21 \mathrm{p} .1 \mathrm{~s}$

\section{montrmum}

1 85 STAURASTRUM Racil. Nonn. Desm. Tolon. p.m t. 12 f. 11 (sep.p. 34 t. B.) [An Stan. furcigerum f.?] d so - Tomi şrll. alg. 1. 1226.

\section{montirulosum-r}

1) 3!) BINATELLA Brib. in Ches. Mier, 1. 272.

1) th STAURASTRUM Biell, in Wenegh, Symops. Desm. p. 226 (sep.p. $2(i)$

1) h PHYCASTRUM hätz. Phycol. germ. p. lis.

¿ 17 DESMIDIUM Jiub. Dent, Krypt. Fl. p. 57.

1 fostaurastrum lialfs Brit. Desm. p. 1:30 t 34 f.9.

1) 19 STEPHANOXANTHIUM hï̈. spec, Alg. p. $18 t$.

1) is sitaux. Iritel. Int. p. 264.

"5s-Arch. Suppl. Cat. in Dubl. Zool. Tot. Ass. Pr. I P. 123 t. 11 f. 16, in Nat. Hist. Rer, 5 p. 257 t. 21 f. tetragona); in J. Micr. Sc. T p. 138.

1) (i1 - Arele. in Pritch. Inf. p. 739.

a 69 hab. Tirypt. Fl. Sachs. p. 1 s.

d lis linb. Flos. Eux. Alg. 3 p. 214.

m 71 - Lurnd. Desm. Sinec. p. (ii.).

1) 73 - P bifarium Nordst. Nor.g. Desm. 1,31 1.1 f. 1.t.

o 71 -Jucols. Dosm. Danen. 1) 2019.9.

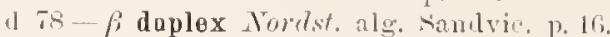

1) $4: 3$ - r. Sanctx Anna Schunrselem. Magyar. Desm, 1, 2-3 t. 1 f. 17 .

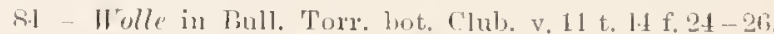

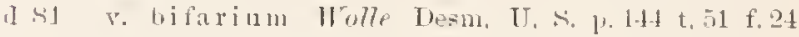
gii 
m81 - $\beta$ lifarium f. hirsuta Norlst. in Trith. et. Nordst. Alg. exs. n:0 6.on; et (18s?) in fasc. 21 1). 35 .

m S5 - P bifarium Boldt sibir. Claloroplu. p. 11s.

a - " rhomboideum ibid. p.119 t. if f. 39 .

o si- itokes Key Desm. 1) 168.

d 87 - Fuoke Brit. Desm. p. 147 t. 50 f. $10 \mathrm{ll}, b, c=e$ lialfs 18t8; $c=$ ex Arch. 1858].

in sis - P Lifarium Boldt Desm. Grünt. p. 10.

o st-p lifarium Tordst. Bornl. Desm. p. 200,

a 89 - Toni syll. alg. 11. 1150 .

d -.v. duplex ibill.

d - v. bifarium ibid. 1. 115 .

l $-v$. sanct:e-Ann:e ibid.

d - v. rlomboideum ibid.

d - v. diplacanthom Nurrst. (in litt.) iliul. St, dipla(cantlıum Not. 18tiT).

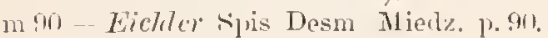

m (n) Auderss. Siverig. Chlor. 1 p. 13.

1) 12-v. Lifarium Irolle Desm. U. S. ल. II p. 159 t. 62 f. $24-26$.

44 - Roy Seott. Desm. t. 3 f. 4 .

o :41 - $\beta$ Lifarium Bürg. F. alg. Östgrönl. p. 29 t. 2 f. 25. m!s - - - West Alg. Malag. p. 78 t. 8 f. 21.

\section{Hoorerem!m}

dofit PENIUM Ach. Descript. (se].p. 24) in Dubl. Nat. Hist. Soc. p. to t. 1 f. 31-11: in (2. T. M. Sic. p. 179 t. 6 .

dz 68 - Lirb. Fl. Eur. Alg. 3 p. 123.

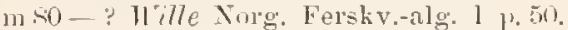

dzf wi-Cooke Brit. Wesm. P. 14 t. 17 1.5 (ex Areher).

dzsi - Tomi syll, alg. p. $\$ 19$.

mz:12 - Ifest Fr. W. Alg. W. lmel. 1. 128.

o 53 Sechidle Boitr. Alg. Solwarzwald. 1, sis t.3 f.8 et !.

- v. constricta ibid., t. 3 f. ll at 11 .

\section{mordan}

11 93 COSMARIUM Turwer Alg. Tus, oriput. p. 50 t. 7 f. 29 , t. 4 f. 7 .

\section{morsce - IIm}

48 MICRASTERIAS ["Fol" M. morsa read americana, Ehrb." lialfs in Brit. Desm. p. XIX.].

11 ro v. Baileyi Wrallich Desin. Low. Bongal. p. 27T (M. Baileyi lialfsi).

n - v. riugens ibid. (M, r. Inailry 1sid

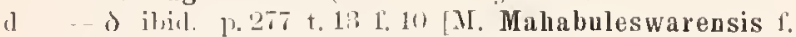
gelluina, indica Nordst. 18sis ex $\mathrm{p}$; v. excelsior IYall. in 7inne 1s93!.

mot DIDYMIDIUM Miorasterias limsel Algent. Frank. 1, 113.

f. inerme ibil.

(1) - f. cornutum ibil.

\section{"1101:SIII}

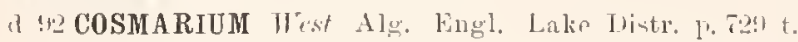
() f. 10.

\section{9:411.5}

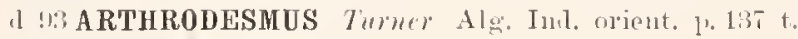
$161: 33$.

\section{Mongeotii}

1 24 LUNULINA Bory in Eneycl. Metl. Hist. Tat. d.

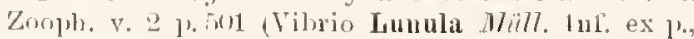

t. 7 f. S; Ene. Meth. Planel. Vers, 17!1. t. 3 f. 21) [Cl. Loibleinii quoad fig. ser. Henegh. 1840].

n 31 Rory in Dict. class. hist, nat. (1821 1. 1824?) v. 17 1. 41 t. 2 f. 8 [Clost, acerosim mortum et Synella lunaris sec. Fllrenb. in Isis $1834 \mathrm{col} .1197-8 ; \mathrm{Sy}-$ neilua lunaris? sec. Ehrenb. Inf. p.92 et 21:3].

\section{mucosile - mm}

d on CONFERVA Dillw. Brit. Conf. p. ti t. F [mala] [Specimina niginalia a Ralfs. Brit.' Desm. 11. 55, visa!].

(1) 21 - Gay Natur. Arrang. Brit. Plants 1.311.

4] 21-Ag. Syst. Alg. p. !n.

d 27 - Simeng. Syst. veget. IV. I 1. 355 .

d 30 - Juby Botan. Gallic. Il p. 184.

d 33 - Ilare, apnd Hook. Brit, Fl. II p.351.

1 33 - Wullv. Fl. crypt. germ. p. 33.

135 - Bréb. et God. Alg. Falais, 1\% 19.

d DESMIDIUM ilid. p. 268 (sep-10.65) t.2 [11yaloth, dissiliens see. Brieb. List.].

1) 10-Menegh. Syn. Desm. p. 201 (sep.p. 4) (Desm. limbatum incl.) [Item ae prior.].

141 -. Mare. Man. Br. Alg. p. 128 (t observatio rarmich:i).

n 11 HYALOTHECA Ehrent, in Berlin. Bericht, 1810 p. 212 lireb. 183. |H. dissiliens]; et Actinocyclus variabilis Corla 1840 .

143 besm. Iirlfs in Anm. Tat. Hist. v. 11 p. 374 t. 8 f. 2 (et 18tr Trans. Bot. see. Erlinb, v. 2 1. 7 t. 2 I. 2 \%. [II. dissiliens sec. liulfs 181s].

11 4. GLOEOPRIUM linlfs in .Jemn. Fl, Tumbr. Wells p. 1 1.2 1. 1. $11 \%$.

1) 45 - H11 ss. Brit. Alg. p. 347 t. 83 f. 5 o.

It 45 - Ralfs in Am. Nat. Hist. v. $14 i \mathrm{p} .11 \mathrm{t} .3 \mathrm{f} . \mathrm{f}$ (et

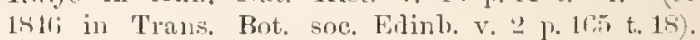
[Ilyal. Ralfsii hïtz. 18t!)].

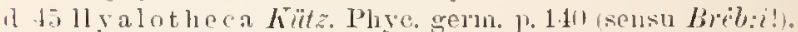

(1) 18 - Kirlfs Prit. Desm. p. 53 t. 1 f. 2.

1) 49 - Kütz. spec. Alg. p. 1si [H. dissiliens].

1) $52-P^{2}$ ritch. Inf. p. 2:39.

ph 58 -Itrighs. in Bot. Zeit. 1453 p. 485.

d in-p Wrallich Desm. Low. Beng. p. $187[=a]$.

a hi- Arch. in Pritch. Inf. 11. 720.

o fi: Desm. " limbatum Groyn. Mlant. Crypt, p. 2 fil (D. limb. ('lecure).

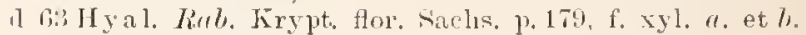
p. 1.4 [ [ Ralfs].

o (i) - hirinsch Algenfl. Frank. p. 2Ht.

137 - Croman El. Finist. t. 5 f. 40.

n $1 ; i$ - Not. Desm. Ital. p. 20i t, 1 f. 2.

d is - liab. Flor. Eur. Alu. 3 p. 150. fo xylogu, p. 14. [e lirilfs].

m 71 - Nordst. Desm. Brasil. p. 20r.

o 7 - Nordst. Norir. Desm. p. 4 S.

d 73 - 11 ood Fr. Alg. p. 124.

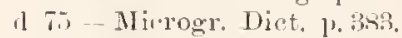

d 7 - Kirchn. Alg. Sichles. p. 181.

in Sil - Nortst. De Alo. et Cliarae, 1 p. 3.

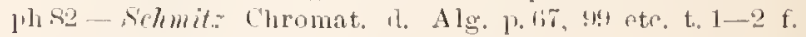
$221-8$,

7. 83 - Layerh. Birls. Averig. algh, 1. 54.

o 81 - Gu!y Mon. loe. Conj. ]. 7.9 t. 8 f. 2.

1] 81 - Wolle Desm. U. A. 1). 23 t. 1 f. 13.

o Si - a. Ralfsii liucib. Tonn. Desm. Polon, 1. 6.1 (sep.p. s).

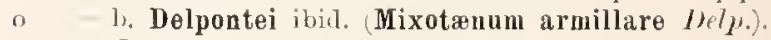

m.si Lugerh. Amerik. Desm. p.22S.

o sti-stolies Kiey Desm. 13. 110.

() $84 ;-f$. Lusperh, in Wittr, et Nordsi. Alg. exs, n:0 805 pt (18si, in faso. 21 ]. 33. 
d st Coole Brit. Desm. p. 8 t. 3 f. 2 [e Delp. ex p.].

o 86 - v. irregulare Iste. Diagn. prav. p. 241 (sep.p. 12).

87-Gobi Perion. Hyalotlı. t. 1 f. 1.

dzss - Jansig. Prodr. Alggenf. Böhm. p.16s.

m SS - likbim. Chloroph. ent. Kharkow. p. 3221.

ph 85 - Ilauptf. Zellm. u. Hiillgallerte Desin. p.63 et 104 (sep.p. $\overline{\text { si }}$ et 16 ) t. 1 f., $1-1,6-8$.

ms8 - 1ste. Jel. magyar, alg. p. 244.

$0 \quad-r$ irregularis ibid.

d $89-$ Toni Syll. Alg. p. TSi.

d - r. irregularis ibid. p. Tss.

1n 90- Fichler Spis Desm. Miedz. p.s1.

m 90 - Anderss. Sverig. Chlor. 1 p. S.

d 92 - Wolle Desm. U. S. ed. II p. 23 t. 1 f. 13.

m 93 - Lïtliemüll. Desm. Attersees 1.539.

m 93 - Turmer Alg. Ind. oxient. 1\% 152.

in - r. elongata ibid.

m.93 - $\beta$ minor hoy Scottish Desm. p. 170 (sep.1.9).

m 45 - Tiacib. in Flora v. 81 p. 30 .

\section{muct.omatu- -}

d 59 TETRACHASTRUM Hixom On a new Genns (sep.p. 7 ) in Nat. Hist. Noc. Dubl. p. 204 t. 1 f. 5-8; in Dubl. Nat. Hist. Rev. 1.466, t. 33 ; in Q. J. Micr. Sc. 1. 81 t. T. [Nicr. oscitans $\beta$ mueronata Hille 1850].

d 61 - Arch. in Pritch. Inf. P. i25.

d 68 MICRASTERIAS Rab. Flor. Eur. Alg. 3 p. 1st, fig. xyl. p. 109 [e Dixon].

o 73 - crove in Q. J. M. S. v. 13 11.212 (N. oscitans Linlfs?

d 73 -f. intermedia Norkst. Norg. Desm. 11.6.

d $78-$ Kirrlm. Alg. Schles. p. 163.

o 81 - Coole in Frevillea 9 p.s9 t. 141 f. 2 a-d $/=$ T. oscitans sec. anct. ips.).

d 86 - (Tetrachastrum) Cooke Brit. Desm. p. 53 t. 20 f. 1 [ex Thixon].

d 89 - Tomi risll. alg. p. 1112.

d $-\mathrm{f}$. intermedia ibid.

n 91 HELIERELLA Kuntze Rev. gen. pl. p. 899.

\section{mucromutum}

d 45TAURASTRUM Ralfs in Jemer Fl. 'Tunbr. Wells P. 192 1. $96 \%$ :

dzf $45-$ Lalfs in Am. Nat. Hist. p. 152 t. 10 f. 5 et 6 (et 1,113 in Trans. Wot. Soe. Edinb. v. 2 p. 139 t. 13) $\alpha, \beta, \gamma$. [Fig. 5 " inferior dextra (actleis convergentilus), et " supera sinistra ( $\gamma$ recta Tum. 1s93), et $b$, et fig. $b=$ St. nucronatum sensu Brib., Lund. ete. - Fig. 5 a inferior sinistra = st. dejectum Breb. - Fig. 5 a superior dextra (in lialfs Br. Desm. non depicta) fortasse = St. dejectum $\beta$ connatum Lnol. (vel $a$ obliq. vis.) $=$ Ihyc. cuspidatum , bilunulatum Kïtz.].

d 45 GONIOCYSTIS (Trigonocystis) Hassall Brit. Alg. p. 3511 t. 81 f. 8 [e Rnlfs]. $\alpha, \beta . \%$

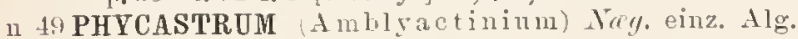
1. 125.

o 56 staur. Tréb. List. p.112.

d 63 - Rub. Krypt. Fl. Sachs. p. 189

m 72 - Norlst. Term. Spetsh. 1. 38.

m.2- Hemprl Algenf. Chennitz p.11t.

m $8 t$ - Gay MLon. loc. Conj. 1.67; $a$ et $\beta$.

msij-Boldt sibir. Chloropls. 1. 113; et f. minor.

o 93 - $\beta$ Debaryana Turner Alg. Ind. orient. 1\% 105 t. 16 f. 20. (St. dejectum $\beta$ Debarianum Tordst. 1s83).

n - $-y$ recta ibid. (Iinlfs 1845 f. 5 " super. sinistr.

o - - - f. Indica (minor) ibid. t. 19 f. 15 (monstr.). Tordstedt. Inder Desmid.

\section{minciomulutus}

d 70 ARTHRODESMUS Nordst. Desm. Brasil. p. 232 (sep.p. 194) t. 4 f. 58 .

d 89 - (Octacanthinm) Toni Syll. alg. p. 1064.

o 95 - f. West Alg. Madag. 1. 72 t. 8 f. 16.

$0-v$. robustum ibid. t. $8 \mathrm{f} .17$.

\section{MULLERIA}

02? Leclere sec, Ehrenb. Inf. p. 90 (II. Lunula). [Annon = Mullerina.

\section{MULLERINA}

- 16 Leclere de Bazoches sec. Leman in Dict. seiene. nat. suppl. tom. 3 p. 159 (Vibrio Innula). [Cfr. Muilleria].

\section{multiconve}

n 70 STAURASTRUM Grm. in Rab. Alg. n:o 2165, nomen tantum [St. brasiliense Nordst. (f. suecica) sec. Nordst. Norg. Desm. p. 37].

\section{melltifill}

d 76 MICRASTERIAS Wolle in Bull. 'lor. bot. Club. 6 p. 12:2.

d 89 - Tomi syll. alg. p. 1125 .

n 91 HELIERELLA Kuntze Rev. gen. pl. p. 894.

\section{multigibleremll -ll}

d 87 FUASTRUM Nordst. Algolog. småsak. 4 p. 155.

1 88 - Nordst. Fr. wat. alg. N. Zeal. p. 32 t. 3 f. 2.

d 59 - Toni syll. alg. p. 1069.

n 91 HELIERELLA Kinntze Rev. gen. pl. p.899.

multilobretume-a

d 70 EUASTRUM Wood in Proc. Philad. Ac. N. \$. 1869 p. 16 .

d 73 - Wood Fr. Alg. p. 135 t. 12 f. 16.

1 81 - Wolle Desm. U. S. p. 98 t. 53 f. 11 [Ex IVood].

o 86 - Benn. Fr.-wat. Alg. Engl. Lake Distr. 1 p. 8 t. 1 f. 11 :

o 8ti-Stukes Kies Desm. p. 111.

d 86 -Couke Brit. Desm. p.67 t. 35 f. 15 [e Bennett].

d s9-Toni syll. alg. p. 1082.

11 91 HFLIERELLA Fintse Rev, gen, pl. p.899.

d $19 \mathrm{Eu}$. Wolle Desm. U. S. ed. II p. 107 t. 6.1 f. 11.

n 93 - Amblyastrum) Turner Alg. Ind. orient. p. 88.

\section{multistuirtull -}

n 28 BACILLARIA Whrenb. Symb. phys. Phytozoa t. II sinaitica f.9 [in contextu tantum "Synonym." Closterii acerosi?.

m 32 [separ. 1828-29?] CLOSTERIUM Elrenb. in Abh. d. Berl. Akad. 1899 p. 11 et 20 [nomen tantum et mensura].

Cfr. Clost. acerosum v. maximum Wood.

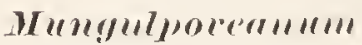

1.93 SPONDYLOSIUM Tumer Alg. 1nd. orient. p. 46 t. 18 f. 11.

\section{1 it 1111,}

19 93 COSMARIUM Tumer Alg. Ind. orient. 1).56 t. 8 f. 30 .

\section{"lumitul"}

d ToSTAURASTRUM Wood in Proc. Plilad. Acarl. N. s. $1569 \% 1 \%$.

d 73 - Wuod Fr. Alg. p. 154 t. 13 f. 13 [St. Aretiscon]. 


\section{merircetr - $11 m$.}

d 46 EUASTRUM Bait. Catsk. Desm. p. 126 fig. xylogr. $1-2$.

d 18 MICRASTERIAS Rirlfs Brit. Desm. p. 210.

d $52-$ Pritch. Inf. p. 216.

d 61 - Arch. in Priteh. Inf. p. 726.

d 68 - Íab. Flor. Eur. Alg. 3 p. 195.

d 84 -- Wolle Desur. U. S. p. 118 t. 31 f. t-7 (formæ).

m S6 - Lagerh. Amerik. Desm. p. 232.

o S6-Stokes Kiey Desm. p. 116.

d 89 - Toni íyll. alg. 1) 1121.

1. 91 HELIERELLA Kuntze Rev. gen. pl. p. .99.

d $92 \mathrm{Miex}$. Wolle Desm. U. S. ed. II p. 130 t. 35 f. $4-7$.

n 93-(Sehizocysti.) Twmer Alg. Ind. orient. p.98.

\section{muriratiforme}

d 96 STAURASTRUM Schmialle Beitr. alp. Alg. P. 162 (sep.p. 33 ) et, 1895, t. 16 f. $14-15$.

\section{muriverume - $\ell$}

n 35 BINATELLA Bret. Alg. Fal, p. 269 (sep.p. 66).

d 10 STAURASTRUM Bréb. in Mencgl. Synops. Desm. p. 226 (sep.j. 26). (incl. Desm. apicnlosum Elrb.).

d $45-\beta$ Ralfs in Ann. Nat. Hist. T. 15 p. 151 t. 11 f. 1 d, e

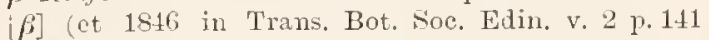
t. 11) (Xanth. deltoideum Corda).

d - a ibid. fig. a, a. b, e (in eopul.) [St. hirsutum].

d 45 GONIOCYSTIS (Trigonocystis) Hass. Br. Alg. p. 351 t. 81 f. 9. [E. Rialfs. - St. hirsutum].

- $\quad \beta$ rugosa ibit. p. 351 et vol. II p. 19 (in explicatione icon.) t. st f. 10. [E Ralfs?].

1) 4 S Staur. Lialfs Brit. Desm. p. 126 t. 22 f. 2 . [Prima bona descriptin!].

d 19 PHYCASTRUM Kiüz. Spec. Alg. 1. 182.

n 49 - (A mblyactinium) Nreg. einz. Alg. p. 125.

d 52Staur. Pritch. Inf. p. 263.

d 53 P'lyeastrum Math. Fl. Belg. 1 I p.528.

o 56 stiaur. $\beta$ denudatum Bréb. List. p. 141.

d 61 - Arch. in Priteh. Inf. p. 740.

d 63 -Rab. Krypt. Fl. Saelıs, p. 19 \%.

o 67 - Not. Desm. Ital. p. 50 t. 4 f. 42.

d $68-R a b$. Flor. Eur. Alg. 3 p. 218.

o - f. ibir. (Not. I. c.).

o 73 - Norilst. Norg. Desm. 1. 29.

d 7 - Detponte Desmid. sulualp. I.55 (sep.p. 151) t. 11 f. $51-52$.

11 $78-$ Kirchn. Alg. Sehles. 1. 164.

d 84 - Wulle Desm. U. S. p. 127 t. 42 f. $3-6$.

o s6- Stolics Key Desn. 1. 167.

d $8 \overline{8}$ - C'oulic Brit. Desm. p. 159 t. 54 f. 5 [e R'alfs 1818?].

o $8 \mathrm{~S}-$ Halls. Prodr. Algenfl. Böhm. 1) 213 et 254.

d $88-$ Toni et Levi Fl. Alg. Venez. p.44.

d 88 - Nordst. Bornh. Desm. p. 203 t. 6 f $19-22$ (inelus. Rtaur. silesiacum).

d 89 -Toni Syll. alg. p. 118 \%.

o 89 - f. West Fr. Alg. North Yorksh. p. 293 [v. aeutum 18901 .

d 90 - v. acutum West Fr. w. Alg. North Wales p. 294 t. 5 f. 14 [St pyramidatum West 1892].

n $90-\beta$ Bornholmieuse Gutw. Wahr. d. Priorität I. 71. (st. mur. Nordst. 1899 fig. 19-20) [u].

d $-y$ trapezicum ibid. 13.72 .

m 90 - Eichler Spis Desm. Mieiz. p. 89.

o 91 - Heimerl Desm. alpin. 1.605.

d 91 - $\gamma$ trapezicum Gutw. Flor, alg. Leopol. p. 6 t t. 3 f. 15 . d $92-$ v. australis Rac. Desmidya Ciastoni. p. 383 t. 7 f. 19 [Quid?].

d 92 - Wolle Desm. U. S. ed. II p. 141 t. 53 f. $3-6$.

o 93 - Liêtliemiill. Desm. Attersees p. $5 i j 6$.

d $94-v$. subturgescens Schmidle $\mathrm{Alg}$. Geb. Oberrheins 1. 554 t. 28 f. 20 .

d $95-\ldots-$ f. Sclmidlc in Hedwig. 34 p. 81 t. 1 f. 23. Cfr. Staur. trapezicum.

\section{miscicola}

d 5S SPIR0T无NIA de Bury Conjug. p. 75 t. 7 F. (Palmogloea oudospira Brèb.)?) [Spirotania bryophila].

d 61 - Arch. in Pritch. Inf. 1. 751 .

d 63 - Monotinia) Tub. Krypt. Fl. Saehs. 1.177, fig. a-d p. 154 [e Iirlfsj.

o 64 - Areh. Descript. (sep.p.5); in Dubl. Nat. Hist. Soe. 1. 16.

90 - Wille in Natürl. Pflanzenfam. p. 10) f.6 F (e de $\operatorname{Bary})$.

\section{mutchile}

d 93 STAURASTRUM Twmer Alg. Ind. orient. p. 129 t. 16 f. 42.

\section{muticum -}

d 35 BINATELLA Bréb. Alg. Fal. p. 57 t. 8.

I 40 STAURASTRUM Breb. apud Menegle. Synops. Desm. p. 228 (sep.p.28 (st. trilobum Menegh. 1837 [an recte ?]).

Izf 48 - Iiulfs Brit. Desm, p. 125 t. 21 f. 4. t. 34 f. 13 .

d 49 PHYCASTRUM hiitz. Spec. Alg. 1. 179.

d 52 Stan r. I'ritch. Inf. p. 263.

d $61-A r c h$, in Pritch. Inf. p. $7 \pm 0$.

a 63 - Tiub. Krypt. Fl. Saehs. p. 18s; f. 3 p. 158 [e Ralfs].

d 6 T DIDYMIDIUM (Mierasterias) fo an utieum Reinsch Algenfl. Frank. p. 151.

d - f. b. alteruans ibid.

I - f. e. Bieneanum ibid. (st. Bien.).

d - f. d. minus ibid.

d $-f$. e. decedeus ibid.

m67 staur. Not. Desm. Ital. p. 55 t. 5 f. 53.

dz 68 - Rab. Flor. Eur. Alg. B p. 200 ; Fig. xy]. p. 109 [ut supia 1863].

(1) - f. minor ibid.

d 71 -f. minor Lund. Desm. Suee. 1. 56; (Phye. depressum Nüg.

dz 73 -- Tirood F1. Alg. p. 148.

n $76-\beta$ brevispina Jacabs. Desm. Danem. P. 202 (St. brevispina Bréb.).

m 78 - Nordst. alg. Sandvie. 1. 15.

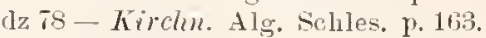

m 78 - Thempel Algenfl. Chennitz. p. 114.

11 so- $\beta$ depressum Nordst. in Pointsf. Skandin. Växt. 1 p. 27 ['llye. depressum Nag.].

m 84 - Gruy Mon. loe. Conj. p. 64.

m 84 - Artari Liste alg. Moscou p. 143.

d 84 - Wolle Desm. U. S. p. 119 t. 39 f. 11-12.

m - v. minor ibid., f. 1t-15.

o - v. ellipticum ibid., f. 13.

d 85 - Krivelun. Mikr. Pflanz. d. Sïssw. p. 23.

in s5-f. minor Boldt sibir. Chloroph. p. 110.

d 86 - Frank in Leunis synops. 3 p. 197.

o 86 - Stokes liey Desn. p. 161.

o - r. minor ibid.

1) 86 - v. ellipticnm Wolle Fr. Alg. U. S. A. p. 41 t. 60 f. $41-43$. 
dzst - Cooke Brit. Desm. 1. 156 t. 51 t. 6 [*iltem partim e Rirlfs:.

d 87 - Alexento Chlorosp. Khark. p. 253.

1 ss-Hansg. Prodr. Algenf. Böhm. 1.210, et $\beta$ ellipticum.

o - - " minus ibid. p. 255 (Phycastr. depressum Nory.). 1z 88 - Toui et Levi Fl. Alg. Venez. 1'. 42.

n 89 - a. typicum Riabin. Chloropl. env. Filarkow p. 329. m - c. lieneanum ibil.

ux s8-Iste. Jel. magyar. ales. 1. 231.

la 89 - Tomi srll. al@. p. 117\%.

1) - v. lepressum ibicl. 1.117s.

I $8.7-$ - substriolatum Fincil. Now. Desm. 1.99 t. 7 f. 13.

m !0-Jichler spis Desm. Mied\%. 1.89 t.8 f. 37.

m90 - Auderss. Sverig. Chlor. I p. 11.

d $90-\mathrm{r}$. Bien anum f. Reinseh Sinsswasseralg. SïdGeor. p. 3.30 (sep.p. 2.2) t. 2 f. 14 (et t. 3 f. 3 cum larasito; [non haec var.].

d s1-Kirchn. Mikr. Pflanz. d. Stissw. ed. 2 p. 21

m!1 - Heimerl Desm. alpin. p. 6its.

m $t_{2}-$ Dorge Chlosoph. Forsk. Finmarli. p. 7 .

o : 12 - linc. Desmidya Ciastoui. p. 37!!

$192-$ ITolle Desm. L. S. ed. 2 p. 131 t. 50 f'. 11-12.

$11-\checkmark$ minus ibil. f. 14 et 15 .

l) - r. ellipticum ibir. 1) 132 t. 50 f. 13, t. 49 f. $41-42$.

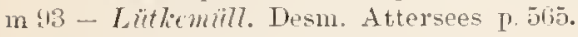

m -.v. depressum ibid.

m? 13 - r. lepressum schmille Beitr. Alg. Schwarzwald. p. 109 et in Flora 78 p.60.

m 94 - Iste. Alat. Roman. alg. p. 156.

m 94- Mil. Anstral. Süsswasseralg. Il p. 311.

m 14-B̈̈ry. F. als. Ostorönl. p.2t.

1. - $r$ subsphærica ibid.. t. 2 f. 18 [st. ellipticum ITest?]. mat-Gutu. Fil. alg. 'Tarnapol. p. liki.

d. 15 - Jiriley Contrib. Queensl. Fl. XI p. 42 t. 10 f. 10 Mobius del. :

\section{mutirum.}

d 52 PHYCASTRUM Terty kleinst. Lebensf. 1, 210 t. 16 f. 28. [Staur. Bieneanum liub.?].

d bis STAURASTUM Rab. Flor. Eur. Alg. 3 p. 221 [non

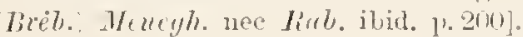

o 91 - Ihel Torre in Rivist. Ital. d. sc. nat. XI p.130.

\section{$m\|t i\| t m m$}

d is STAUrastrum l'jeurenterium) Lund. Desm. suec. D. 74 t. $5 \mathrm{f}, 3$.

d 59 - Tomi syll. alg. p. 117i.

\section{migrioperdm.s}

ph in 34 PLEURosicyos Cordu in Alm. d. Carlsb. 1835 P. 17R, 1R2, 209 (sep.p. 125) t. כू f.68 et 69 [Penitum lamellosum Brib? - Closteriun digitus $L / W r$ sec. Wiegm. Arch. f. X. 18336 Jahrg. II Bd. II p.186. et $E / 1 \%$. Inf: p. 94].

\section{MYRUETHIJU}

d 13 Turne Alg. Lnd. ori n1t. p. 2-. Subgen. Triplocerat.

\section{Y IO NEWA}

d 25 Frims l'lant, homon. 1. 343 ex 1\%. yuoad sp. dissilientem [Htal. dissil.?]. Gen. Batrachos permear.

d 3 Frics Flor. Senu. 11.329. Gen. Cunfervear.

d 43 Endl. Gener. plant. Suppl. Ill p. 15 n:o 33.

d th Rab. Deut. Kirypt. Fl. p. k,

\section{IIegplianmm. -}

17 5l) COSMARIUM Rreb. List, 13. 127. Eu. crenatum Nog.
1St9) [Cosm, orthogonum sec. Delp. Desm. subalp. II $\mathrm{p}, \mathrm{T}$.

n $58-(M \mathrm{icrocosmarium})$ De Iirk. Conjug. p. 72.

d 61 - Arch. in Priteh. Inf. 1. 732.

d 67 - Not Desm. Ital. p. 45 t. 1 f. 32.

d $68-$ Rab. Flor. Eur. Alg. 3 p 164.

- to Nordst. Desm. Brasil. 1. 211.

1n 70 - Reimliar in Arbeit. Naturf.-g. Charkow 1 p, 16.

m 81 EUASTRUM (Cosmarium) Gray Mon. loc. Conj. p. fil.

d $81 \mathrm{Cosm}$. Wolle Desm. U. S. p.6it t. 50 f. 21.

d 85 - hirclen. Nikr. Pfanz. d. Süussw. p. 25.

o 86-Stoke Key Desm. 1. 127.

d ss-Hansy. Prodr. Algenf. Böhm. p. 191;

oz SS - Kivelun. Nachtr. Alg. Wïrtt. p. 1ist.

dzf $89-v$. latum Mush. Furth. Note X. Z. Desm. p. 17 t. 3 f. 27 . (C. crenatum Musk. 1853).

d 89 - Toni syll. alg. 1. 912 .

d 91 - Kiechu. Miks. Phanz. d. Siissw. ed. 2 p. 26.

m 91 - Heimert Desm. alpin. p.

n 91 URSINELLA Kuntze Rer, gen, pl. p, 925.

m 92 Cosm. liac. Desmidya Ciastoni. p. 360 .

d ! 2 - Woll, Desm. U. A. el. II 1. 73 t.61 f. 21.

n 93 - Lïthemïll. Desin. Attersees p. 553.

d 93 - v. crenulatum Schmidle Beitr. Alg. Sehwarzwald. p. $: 17$ t. \pm f. 16 ; et 17 .

m 9.5 - f. Schmidle lieitr. alp. Alg. p. 92 (sep.p. 37 ) et, 1895, t. 15 f. 10 .

o 95 - f. Sorge sverig. Chlor. II 13. 16.

\section{Nregelianmm,}

m67 DIDYMIDIUM (Staun.) Reinsch Algenfl. p. 167 (Pbycastrum cristatum Nicg.

n 9 STAURASTRUM Treiss in Ber. Bayer. bot. Ges. p. 50.

\section{Niegelii}

d 61 PENIUM Brél. apud Arch. in Pritch. Inf. p. 751. Clost. (Tetrimm) Digitus Nor.). [Cfr. Pen. lamellosum Help. 1sit].

d 68 - Rab. Fl. Eur. Alg. 3 p. 119

m 70 - Notrtst Desm. Brasil. p. 212; f. minor.

m $7 \tau-$ Tordst. Alg. brasil. 1. 15; f. major.

mSt - Gay Mon. loc. Conj. y. 69.

186 -Cooke brit. Desm. 1) 42 t 16 f. 4 [e Nageli].

o 88 - Nordst. Fr. wat. alg. N. Zeal. p. 71.

d S9-Toni šll. Alg. p. \&ist.

o 90 -- Börg. Tresm. Brasil. p. 26.

o 95 - schmille Beitr. alp. Alg. p.311 t. 14 f. 31.

\section{"u\|"\|"}

d S4 STAURASRTUM Tolle Desm. T. S. p. 135 t. 11 f. S -10. [At. exiguum Irolle, non Reiusch).

o 86 - Stokes Key Desm. p. 166.

189 - Tomi syll, alg. p. 1159 "crassum" elrore typographico).

o 92 - IIwre. Fr. Alg. Maine III p. 128.

1) 92 - Wolle Desm. [T. ‥ ed. II p 151 t. 55 f. 8-10.

\section{Norpoleonis}

(1) "S HELIERELLA Tup. Apere. organ. p.319 t.13 f. 21 [Pediast um N.].

1) 3 t MICRASTERIAS Küt. Syn. Diat. p.602 (sep.p. Tt) [ilem].

\section{$\| r s u t m m-r$}

(1) 81 CLOSTERIUM Tolle Desm. T. S. 1.11 t. 6 f. 12.

o 8 is-Sioks key Desm. p. 112.

o 8 - - Wolle Fr. Alg. T. s.. A. p.338.

o 88 - Poteal Forth Caroliua Desm. p. 3. 
d. 89 - Toni Syll. Alg. p. 825 .

n 91 ARTHRODIA Kuntze Rer. gen. pl. p. 893.

d 92 Clost. Wolle Desm. U. S. ed. II p. 43 t. 7 f. 12.

\section{musmtmm-}

d T2 COSMARIUM Nordst. Desin. Spetsb. p. 33 t. 7 f. 17 .

d - f. grannlata ibid. P. 34.

m 7 - f. grannlata Wille Fershv. alg. Nov, Semlj. 1. 42 t. 12 f. 30 .

d St- Wolle Desm. U. S. p. 89 t. 19 f. 19; form. $\beta \beta$ Wollei Lagerh. 1887].

o si- - Stokes Key Desm. p. 129.

d $8 \overline{-}-\mathrm{v}$. simplex Istv. Diagn. prev. in Notar. p. 286 (sep.p. T).

o $57-\beta$ Wollei Lagerh. Frit. Bemerk. p. 53s (f. Wolle 1884).

un Sh - Boldt Desm. Grönl. p. 24.

- - f. graulutata ibil.

d $8 \delta-\mathrm{r}$. simplex Ist $c$. Jel. magyar. Alg. P. $22+$ t. 1 f. 10.

d $s 8-\beta$ subnasutam f. Nordst. Fr. wat. alg. N. Zeal. p. 50 et 79 t. 5 f.11. (C. subnasutum Ruc. 1885).

d 89 - Toni syll. alg. p. 1048.

d - v. simplex ibid.

n 91 URSINELLA Kuntze Rev. gen. pl. 1\%.925.

m 92 Cosm. Borge Chloroph. Norsk. Finmark. p. 13.

d 92 - Tholle Desm. U. S. ed. II p.96 t. 22 f. 19.

m 92 - f. granulatum Lithemüll. Desm. Attersees p. 555.

o 94 - f. Borge Süssw. C'blor. Archang. p. 30.

m - $\beta$ Wollei ibid.

m94-f. granulata Börg. F. alg. Östgrönl. p. 14.

m 95 - v. simplex Eichler in Pamiet. Fizy. 13 1. 59 t. 1 f. 7.

d $95-\mathrm{v}$. enastriforme Schmidle Beitr. alp. Alg. p. 459 t. 16 f. 2. [Quid ?].

o 95 - Schröar Alg. H. Riesengeb. p. 20.

Cfr. Cosm. ornatissimum et Eu. scutum.

\section{matator"}

d 92 STAURASTRUM TVest Fr: w. Alg. Tr. Irel. p. 183 t. 23 f. 14.

\section{Nathoristij}

a Ss CoSMARIUM Boldt Desm. Grönl. p. 2u (sep.p. 18) t. 1 f. 21.

d 89 - Tomi syll. alg. D. 1021.

d $90-\beta$ trinotatam Gutw. Walur. d. Priorität p. To.

n 11 URSINELLA Kuntze Rev. gen. pl. p. 925.

m 91 Cosm. Gutw. Flor. alg. Leopol. p. 5?.

d $-\beta$ trinotatum ibid., t. 2 f. 2.2.

\section{Natho(o):stij}

rl 98 STAURASTRUM Tume Alg. Ind. rient. p. $12 \tau$ t. 16 f. 8 .

\section{Nrevicula}

d 56 PENIUM Tréb. Liste p. 146 t. 2 f. 37.

1) 61 - Arch. in Priteh. Int. p. 751.

o ij - Not. Desm. Ital. p. Gis t. \& f. T.

d $6 s-$ liab. Flor. Eur. Alg. 1, 121.

m 70 - Rrimhurl in Arbeit. Naturf.-g. Charkow. I p.11.

zf 71 - Luml. Desm. Suee. p. 81 t. i f. 8.

o 73 - Lenz in Mecklenb. Arch. 13.57.

m $\mathrm{tr}-$ Nordst. Alg. Sandvic. 1. ؛.

dz $7 s-K i r c h$. Alg. Silles. T. 135.

o 80 - f. Wille Norg. Ferskv, alg. I p. 49 t. 느 f. 32.

ph 5.3 - Fischer Gypskryst. Desm. 1. 16 in t. 10 f. 8.

un 81 - Gryy Mon. loc. Conj. P. 6.

d $8 t-$ Wolle Desur. U. s. p. 35 t. 5 f. 16

m 81-Arturi Liste alg. Moscou p. 138. o 86 - Stakes Key Desm. 1. 111.

dz 86 - Cooke Brit. Desm. p. 12 t. 110 f. 5.

d 87 - Alexenko Chlorosp. Khark. p. 232

dz $8 s-$ Hansg. Prodr. Algenf. Böhn. p. 176.

m s8 - Kiabin. Chloroph. env. Kharkiow p. 315 (sep.p. 27). m 88 - Iste. magyar. alg. P. 241.

11 89-Carter in A. M. IIicr. J. $10 \mathrm{f.s}$ (ex Wolle).

ozf 89 - Musk. Furth. Note X. Z. Desm. p. 28 t. 5 f. 51 a.

d 89 - Tomi Syll. Alg. p. 861 .

m90-- Eichler spis Desm. Miedz. p. 85.

m 90-Anderss. Sverig. Chlor. 1 p. 11.

- 91 - f. Heimerl Desm. alpin. p. 590 t. 5 f.. .

m 92 - West Fr. w. Alg. W. Irel. p. 12T.

- $92-$ R r e. Desmidya Ciastoni. p. 367 .

dz 92 - ITolle Desm. U. F. ed. II p. 37 t. 5 f. 16.

m93-Lütlicmüll. Desm. Attersees p. 545.

in 93 - Turner Alg. Ind. orient. p. 18.

mot-Alexenko Mat. alg. Kihark. p. 20.

Cfr. Pen. Berginii, Pen. closterioides var., Clost.

Lens v. minor Jaculs. 1 ing.

\section{navirmloides}

d 80 CLOSTERIUM Wizhe Norg. Ferskv, alg. I p.53 t. 2 f. 36 .

d 89 - Toni Syll. Alg. p. 824 .

n 91 ARTHRODIA Kuntze Rev. gen. pl. p. 883.

\section{navigium}

d 93 PENIUM Tumer Alg. Ind. orient. p. 17 t. 1 f.9. [Pen. digitus f. sec. West 1895].

\section{nerpolit(u)mm-}

d 85 CosMariUM Bulsamo Alghe del com. di Napoli p. 220 (sep.p. 3y) t. 2 f. $1--4$.

d 86 -. Balsumo in de Toni et Leri Phycotheca italica fase. 2 12:0 it.

d 89 - Tomi syll. alg. p. 1129.

11 91 URSINELLA funtze Rev, gen. pl. 11.925,

Cfr. Cosm. sp. ("Probably a variety of Cosm. Teapolitanum Buls.") Tum. Alg. Ind. or. p. T2 t. 23 f. 111

\section{neglerta}

1) 95 HYALOTHECA Rucil, in Flora v. 81 p. 30 t. 3 f. 2 et 3 .

\section{meglertmm}

m SS MESOT正NIUM "Reinhard in litt." apud Riabin. Chloroph. env. Kliarkow 13.313 (sep.p. 25).

dz $85189 ?,-$ Reimleard in Alexentio Chlorosp. Thark. p. 221. 1189 - Tomi syll. Alg. p. sit.

\section{meglertmm}

d 94 SPHAROZOSMA Schmille Alg. Geb. Oberrheins P. 541 t. 28 f. 13.

o 9 SPONDYLOSIUM West in Journ, of Bot. 33 p. 6.5.

\section{mematodes}

11 56 CLOSTERIDM .Josh. Burm. Desm. 1. 652 t. 22 f. 7-9. Il 89 - Tom Syll. Alg. p.840.

1. 91 ARTHRODIA liuntze Rev. gen. pl. p. s83.

d 98 Clost. $\beta$ probosciden Timer Alg. Ind. orient. p. 21 t. 22 f. 13.

\section{Teodamemsis}

n 56 MICRASTERIAS A. $\mathrm{Tr}$. in Rab. Alg. n:o 508 [M. Itzigsohnii Iraxn in Brél. List. sec. Itzigs. in Bot. Zeit. $18513 \mathrm{p}$. 81 iij].

d 63 - liab. Krypt Fl. Sachs. p. $18 t$. 


\section{NEPHRIOIUII}

d 43 Tumer Alg. Ind. orient. 1). Ts. Subgen. Cosmarii.

\section{mel $1 \%$ wirlenm}

m 1 COSMARIUM koy et Risset soottish Desm. p. 1ria et (1s!13) t. 2 f. 3 (sep.p. 4(1). (Cosn. Portiannm $\beta$ nepln roileum Wittr. 1siz).

\section{NETRII II}

d 19) Norg. einz. Alir. p. 107. Subgen. Closterii.

n 56 Itzighs. et Rothe in Rub. Alg. n:0 508 sine descriptione. Genns. [Verisinile "Clnsterium subgen." omissum est].

\section{Netserirm!lm}

1) 95 COSMARIUM Schmidle Beitr. alp. Alg. p. 390 (sep.l). 20) t. 15 f. $1 !$.

\section{Nignere Silvere}

d 9.2 STAURASTRUM Schmidle Yeue einz. Alg. 1.207 t. 11 f. 3 -!

a 95 - schmidle Beitr. Alg. Schwarzwalel p. 107 t. 6 f. $1-1$. o 94 - Schmidle Alg. Geb. Oberrheins 1, 553. Cfr. Staur. Simonyi v. gracile Lïth. 1893.

\section{nigrorimerturm}

d 13 COSMARIUM Turner Alg. Ind. orient. p.57 t. f f. 34 .

\section{Nilssonii}

d sscosMaRIUM Lewin Span. Süssw.-alg. p.S t. 1 f. 12. d 89 - Toni syll. alg. p. 966.

n 1 URSINELLA Luntzc Rev. gen. pl. p. tris.

\section{nitens}

d 60 LEURONEMA Wrallich Desm. Low. Bengal p. 193 t. 7 f. $10-11$.

d(zf) - $\beta$ ibill. f. 12-14. et p. $194 \quad \beta$ triangul. f. producta et f. tensa Turuer].

d $-\gamma$ ihid., t. 8 f. $12-13$ [ $\beta$ triangulare Turn. ex p.]. o his SPONDYLOSIUM Arch. in Q. J. M. Sc. n. S. ז. 6 (1.i(i) p. 120.

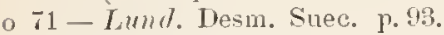

m 8 s - Lugerh. Amer. Desm. p. 220.

d 89 SPH年R0Z0SMA? (spondylosium) Toni. Syll. Alg. p. $T$. 4.

óz) 13 Spondylosium Tumer Alg. Tnd. orient. l. 44.

$\mathrm{m}(\mathrm{z})$ - r typica ibid.; t. $19 \mathrm{f.li}$ (minor) et $T$ (major).

$m-\beta$ triangulare ibid.; f. 17 a et $c$.

11 - . . . f. producta ibil. p. 45 t. 18 f. 17 b.

m - f. tensa ibid., t. 18 f. 10 et 11 .

\section{mitilulum, $-\ell$}

1) 1 i7 Cosmarium Tot. Desm. Ital. p. t.2 t. 3 f. 26.

d bs - Lub. Flor. Eur. Alg. 3 p. 169.

o 70 - Nordst. Desm. Brasil. p. 211.

o $\mathbf{1}$-Lund. Desm. Suec. p. 35; a. f. genuina et b. major 1. 3i;.

1] if -? f. Nordst. Desm. Ital. r. 31 t. 12 f. 10. [Cfr. C. rectosporum Tum. 1893].

m S1 --? f. Elf $\ell^{\circ}$. Finsk. Desm. p. 12 t. 1 f. 7 [C. subtumidom sec. Norrst. in Bot. Not. 1saz p. y.

mat EUASTRUM (Cosmarinm) f. genuina Gry Mon. loc. Conj. 1) 59 .

1) 81 Cosm. Wolle Desm. T. ‥ p. 62 t. 18 f. 16-18 (16-17 non bonce sec. auct.). t. 52 f. $1-10$.

in 80 - Iste. in Jagrar. X. Lap. 10 p. 6 (et f. monstr.).

o s6-Sitolies liey Desm. 1. 12 T. m 87 - Murtel in Ann Inst. hot. di Roma v. 3 pt. 1 p. (i. d ss-Hansy. Prodr. Algenfl. Böhm. p. 19t.

m 88 - Iste. Jel. maøyar. alg. 13. 225.

mss-Nordst. Fr. Wat. alg. X. Zeal. p. 5!l (et formæ?),

d 85 - Toni Syll. als. p.93i).

o s9-Möb. in Hedwigia 2s p. 314

d (N) - f. punctulata Gutw. Fl. glon. Galic. ? p. 14 t. 1 f. 11.

d ( $)-\beta$ mezotumidulum Gutu. Wahr. d. Priorität p. 69

d $90-\mathrm{f}$. Reinsch Süsswasseralg. Niid-Georg. p. $3+1$ t. 2 f. 1 [alia spece? Cfr. Cosm. microsphinctum f. Börg. $189.1]$.

- 90 - f. Borg. Desm. Brasil. p. 41 t. 4 f. 36.

n1 90 - Anderss. Sverig. Chlor. 1 p. 16.

n 91 URSINELLA huntze Rev. gen. 11. 1.925.

d a Cosm. $\beta$ mezotumidulum Gutw. Flor. alg. Leopol. 13.5t t. "2 f. 16 [f. 11011 bona].

d 12 - Wolle Desm. U. s. el. II 1.72 A t. 21 f. $16-18, \mathrm{t}$. 63 t.. $1-10$.

m93 - Lütliemïll. Desm. Attersees p. $5 \pm 9$.

193 - f. Schmidle Beitr. Alg. Sichwarzwald. p.98 t. 4 f. 1s (Borg. 1690).

d - v. subundulata ibil.; f. 19 .

m94-Istv. Arat. Roman. alg. p. $15 t$.

d $94-$ f. Borge silissw. Chlor. Archaug. p. 28 t. 2 f. 28.

us $94-$ v. mezotumidulum Gutev. Fl. alg. Tarnapol. p. 85.

d 94 - Suund. in Fl. Nebraska p. 11 t. $T$ f. 13 [e Cooke].

m95- Borge siverig. Chlor. II p. 18.

\section{nifillul}

d 59 STAURASTRUM Arch. Descr. in Dubl. I. H. Sac. p. 201 t. 1 t: $3-4$; in Nat. Hist. Rev. 6 r. 463 t. 33; in Q. J. M. Sc. 8 p. is t. 7 f. 3-1 [St. cristatum Arch. sec. auct. ipsum 1861].

d $63-$ Kub. Kry 1 t. Fl. Sachs. p. 193.

d $75-f$. Tieinsch Contrib. p. 91 t. 18 f.3 [St. crist. f. Reinschii Iste. 18s7. - Staur. lunatum?].

\section{6 ile}

d 93 EUASTRUM (Eucosminm) Turner Alg. Ind. orient. p. 76 t. 19) f. 2 .

\section{nobile}

d 65 PLEUROT正NIUM Richt. in Hedw. 1865 p. 129 f. 1 -3 Yl. verticillatum Richt., non Bril.) [Docid. undulatum sec. Turner 18:13].

d $68-$ Ral. Flor. Eur. Alg. 3 p. 142.

- 71 D0CIDIUM Lund. Lesm. siuec. p. 88.

d sif-- Cooke Brit. Desm. 1. 13 t. 7 f.3 [e Richter.

o 89 - f. genuina Rucib. Desm. Lituan. p. 659 (sep.p. 3).

o $-\mathrm{f}$. ibid.

1 $89-$ Toni syll. Alg. 1). 573 .

o 89 - Iícilb. Now. Desm. p. 55 t. 7 f. 17 (monstr.).

m90-Eichler Spis Desm. Miedz. p. S6 t.s f. 13. Cfi. Loc. dilatatum r'leve!

\section{norlifer"m}

d !3 STAURASTRUM Tirner Alg. Ind. orient. p.130 t. $1 \pm$ f. 26 .

\section{"10dosilm!}

11 (1) COSMARIUM Anderss. Siverio. Chlor. 1 p. 14 t. 1 f. 8 .

d 98 - v. stellata Eichl. et Iiuc. Towe gat. zielen. p. 119 t. 3 f.' 1.

m 94 - Borge Sïssw. Chlor. Archang. 1. 20.

1n65 - v. stellata Eichle in Pamiet. Fizy. 13 1. 60.

m 95 - Borge Siverig. Chlor. II p.16. 


\section{m.0rlosill1}

d $\$ 6$ CLOSTERIUM Rriley Catsk. Desm. p. $12-$ fig. $x y$ $\log _{1} 1 .: 3$

d 4 D0CIDIUM Riril. in Rulf's Brit. Desm. 1. 218 t. 35 f. 8.

d 51 -Intit. Mier. ols. t. 1 f. 4.

d 52 - Iritch. Inf. p, 275.

d 61 - Areh. in Iritele. Inf. p. Thi.

d 69 - Rath. Flor. Eur. Alw. 3 p. 145 .

- 71 PLEUR0T'

o 72 Doc. Arch, in Q. J. M. Sc. v. 12 P. 1913, forma ("our Irish").

d is Pleur. Wood Fr. Alg. p. 120.

m 77 - Eupleurotienium) Sordst. Alg. brasil. p. 17.

S1 Doc. Coule in Grevillea! t. 141 f. 1.

d 84 - Wolle lesm. U. \&. 1. 50 t. 11 f. $11-12$, t. 12 f. 20 .

o sij-Stolies hey Desnı. p. 11:3.

d s6-Cookc Brit. Desm. p. 12 t. 7 f. 2. "r. Hibernicnm Archer 1852) [Cfr. supra 1:7:2].

o s8 pleur. Wordst. Fr. wat. alg. N. Z Desm. p. 6.5.

m s9 Doc. Mask. Furth. Not. X. Z. Desm. p. 28 t. 5 f. 53.

d Si Plon r. Tomi sill. alg. p. 901

m 84 D0CIDI0psis hach. Xow. Desn, p. 107 (sep.p. 35) t. 7 f. 22 [y dentatun f. polonica Tum. 1893).

m ๒

1 92 Doc. Wralle Desm. U. S. ell. II p. 54 t. 14 f. 11 et 1?. t. 15 f. 20 .

af 93 Pleur. Briley Contr. Queens!. Fl. p. 11 t. 15 f. 35 bis (e Cuolie).

d 98 Docidiun (Hammatidiun) a typica Turuer Alg. Ind. orient. p. 35 et 39.

d $-\beta$ Anglicum ibid,; t. 3 f. 7 l.

d $-g$ dentatum f. Indice ibid; t. $3 f^{\prime} .7 \mathrm{a}$.

d - - - f. polonica ibil. (Ruc. I. c. $185 \%$.

o 95 - Johns. Rare Desm. U. S. Il p. 2yu.

\section{morllifrrmm}

d 93 COSMARIUM Twmer Alg. Ind, orient. p. 50 t. 7 f. 27.

\section{morlutosem}

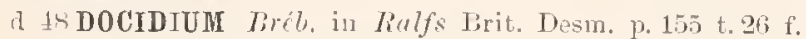
1 Clost. trabecula Linit. 1s41? [Doc. coronatnm finodulosum lioy 15:00].

d 52 - Pritch. Inf. 1, $27 t$.

o in- Buluh, in Rabenl, Aler. 11:0 105.

n SS PLEUROT ENIUA It Rar. Conjug. p. T5.

d 61 Doe. Areh. in I'ritch. Inf. p. 745.

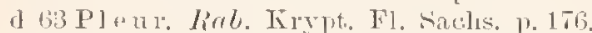

d 66 Doc. Eyrirle Alganfl. Mamnl. p. 133 t. 1 f.s-s.

mfi-heinseh Algentl. Frank. p. 1sit.

o $6 \bar{T}-$ Not. Desin. Ital. p. 5 f t. 5 f. $54-5.5$.

o 69 - Hrittr. Skandin. Desm. p. 20.

m i1) - Norrlst. Desn. Brasil. 1). 201.

d 7.- Microgr. Liet. p. 25\%.

(I 7 l'leur. Delponte Desm. subalp. p. 126 (rep.p. 222) t. 1!) f. $1-6$.

m $7 T$ - Eupleurotieniumj Nortst. Alg. brasil. p. 1T.

in Tis-Nordst. Alg. sandvic. 1. 11.

it Ti-kimhl. Alg. Schles. 1. 14.

mis - Hemprl Algentl Chemuitz p. 112.

d $7 y-v$ a. tenuior Colm Desin. Bong. p. 266 (sep.p. s) t 11 t. $\%$.

I - v. b. latior ibid. f. fi.

ph 83 - Fischer Griskrystall. Desm. p. 161 t. 10 f. $2-5$

in 8.1 - Artwri Liste alg. Moscou p. 140.

d 85 - Kirrlin. Mlikr. Pfanz. d. Niïsw. n. 22 t. 3 f. 69.

d sis Doc. Cooke Brit. Desm. 11. 15 t.li f. 3. d 57 - II wlle Fr. Alg. U. S. A. 1.26 t. 54 f. 3.

if $57-\gamma$ labiatum Tumer Not. alg. Gormire p. 275 et 290.

d 88 Pleur. Hansy. Prodr. Algentl. Böhm. p. 189 f. 112.

1188 - $\beta$ coronatum f. suecica Boldt Desm. ntbred. Nord. 1).5:4 (sep.p. 10:3) (P. coronatum Lund. f.).

m 88 - Riabin. Ghloroph. env. Kiharkow p.s1s.

ph 88 - Hunptfl. Zellu, u. Hüllgallerte Desm. p. 81 et $111)$ (se 1.11.23 et 52) t 2 f. 24. 29. 32, 33.

d ss - Mexphlo ('hlorosp. Khark. p. 2:it.

d 89 - Toni syll, alg. p.900.

m 90 - Bory. Desur. Brasil. 1. 2 .

m 90 - Eichler Spis Desm. Nierlz. Y. 86.

d 91 - Kirchn. Mikr. Pflanz. Siissw. ed. 2 p. 24 t. 3 f. 78.

m.91- Keimert Desm. alp. 13. 595.

- 91 -- Torve in Rivista Ita?. d. sc. nat. XI p. 129. [Parasit.?].

ph 92 - Torre in Notarisia 7 p. 1473.

d 93 Doc. f. undata Turue Alg. Ind. orient. p. 28.

d 44 Pleur. Sumul. in Fl. Nebrislia p. 39 t, 5 f. 5 [e Coolie]. m 95 - f. wudata Borge Sverig. Chlor. II \%. 14.

Cfr. c'lost. crenulatum et Trabecula, Pleur. Ehrenbergii f.? schmille 1 sist.

\section{$m 0 m 11 m m m$}

d 93 STAURASTRUM Tumer Alg. Ind, orient, p.119 t. 15 f. 14 ; f. minor ibir. t. 15 f. 15 et 21 , t. 16 f. 1 . [Staur. Tohopekaligense f.].

\section{Tordemsliviolltii}

1 71 ANCYLONEMA Iierggr, in Öfrers. Tet. Akad. Fürh. p. 293 | sin. $110 \mathrm{~m}$.] et 865 t. 5 f. 1 . 11 [tig. if $\beta$ Berggreuii; Mesot. Berggr. Lagerh. 189z].

o 1 - Tordenskiold in Ö'vers. Vet. Akad. Förh. $18 \pi 0 \mathrm{p}$. 309 et 1081.

phz 83 - Wittr, in Bot. Notis. p. TS.

1 - $\beta$ Berggreni ibid, p. TT Fig. 6 Berga:i).

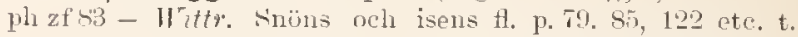
3 f. 1:-2.2 [Fortasse non alice figg. lne pertineant].

$n(0)-\beta$ Berggreni ibid. $\% .113$ et 122 t. ; f. 18 [Mesot. Bergoren i Layerh. 1,ir?].

dz s9 - Tumi SyH. Alg. p. 81T.

11 - v. Bermenii ibid.

(9) - Wille in Natürl. J'Planenfam. 1) $10 \mathrm{f}, 6 ; \mathrm{B}$ (e Nordst. niser).

ph 15 - Lagerh. I'hycoporph. p. 11 ete.

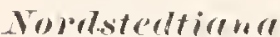

(1) 15 MICRASTERIAS Hieron. in Pflanzenw. Ostafrik. p. 21 (1). Torreyi f. Norlst., non Bail.), non Wolle $187 t$.

\section{Normstertiomer.}

1. S1 MICRASTERIAS Wolle in Bull. T'orr. bot. Club $18 \mathrm{~s} 4$ 1. 15.

A 4 - Wulle Nosu. U. ‥ H. 113 t. 52 f.3-5.

o 86 - Sitokes Kiey Desm. 1) 116.

"l s9-Tomi syll. alg. 1. 111?.

91 HELIERELLA Funtze Rev. gen. pl. p. sig.

d tz Mier. Wulle Desm. U. \&. ed. II 1) 125 to 63 f. $3-5$.

1193 - Schizocystis) fumer Alg. Ind. orient. p. 98.

o $\$ 9$ - Jolms. Rare Desu. U. A. II p. 292 t. 239 f. 14.

\section{Nomerlsterttimm!}

d S4 PHY MATODOCIS Wolle in Bull. Torr. bot. Club $188 \pm$ 1.15.

d st - Holle lesm. U. S. p. 2a t. 4 ! f. 1-t.

o 87 - $\beta$ novizelandica Nordst. Algol. småsak. 4 p. 155. 
d $8 S-\frac{-}{1-2}$ Nordst. Fr. wat. alg. X. Zeal. 1. 21 t. 2 f. 11 8! - Corter in A. M. Micr. J. 10 f. 1! (e Molle).

d $811-T o n i s y l 1$. Als. p. 814 .

d - - novizelandicum ibicl. p. s01.

d (x)-t. miuor Borg. Desm. Brasil. p. 2.) figg. $x y^{\circ} \log$.

1) 9.2 - Wulle Desm. U. s. ed. II p. $2 x$ t. hit if $1-4$.

\section{Fordsted inmu}

I s. SPIR0T quadrata rerisimile sec. Liitlicmïll. Gatt, spirotien. p. .). 3].

\section{Findstratian!m -}

A To Cosmarium Reinset Contribut. p. s. t. 10 f. 11 [C. cyclicum Land. f. sec. Tordst. in lledwigria tusti [i. $6 i \bar{i}]$.

d. 89 - Toni syll. alg. p. 1030 .

n! URSINELLA Kuntze Rer. gen. 11. p. 925.

\section{Soredstratimnum}

d S1 EUASTRUM Wo7le in Bull. Tor', bot. Club 18:4 1'. 16: [Helierella Detoniana Kuntze 1s01].

d St - Walle Desm. U. S. p. 105 t. 24 f. $7,9-13$ l. $=\mathrm{v}$. minor t. 52 f. 13-15. [Cfr. Witrlem. Obs. erit. Desm. p. 91].

o sf-stulies liey Desm. p. 14.

d $\rightarrow$ - Toni srll. alg. 1. 1105.

d :12 - Wolle Desm. U. S. ed. II p. 116 t. 30 f. T--13. t.63 f. $13-15$.

d 93 - v. elegans Turner Alg. Ind. orient. p. 8.j t. 11 f. 17 [Cfi. Eu. 'Turneri].

129:3-(Actinastrum) ibid. p. 98 .

\section{Nordstedtimmm!}

d S5̃ ONYCHONEMA Tumer New rare Desm. p. 934 (sep.p. 2 t. 15 f. 3 [O. filiforme sec. Roy et Riss. 1886].

o st - Stokes Ker Desm. p.111.

a 86 - Cooke Brit. Desm. p.6 t. 2 f. 7 [e Thrner].

o 88 - Nordst. Bormh. Desm. p. 208.

d 89 - Toni syll. Alg. p. 795 .

m 90 - Eichler spis Desm. Miedz. p. S5.

- 92 SPH玨R0Z0SMA Wulle Desm. U. s. er. II p. 31 t. 13 f. ? - 11).

m 930 onchonemn (Colponema) Tumer Alg. Ind. orient. 1. 139 t. 17 f. 17 a et b.

- $\quad-\beta$ compressum ibid.; f. 17 c.

\section{Nordstedtiammm -re}

1 5 XANTHIDIUM lieinseh Contribut. 1. 92 t. 10 f. 6 [X. fasciculatum v. subalpinum sec. Wolle 1s\$6].

d. 89 - Holacanthium Toni Syll, alg. p. 923.

\section{Nordstedtii}

d it COSMARIUM Detponte Desmid. subalp. 13.16 (sep.j. 1113) t. 7 f. $65-68$.

o 5.5 - Wolle Bull. Tor1. Bot. Club. 12 p. 2 t. 17 f. $23-25$. [C. stichochondram Largerh. 1897].

d s. Holle Fr. Alg. U. S. A. p. 30 t. 57 f. $23-25$ [ Tolle $18 \div 5]$.

1 $\$$ - ? Tuni Sirll. alg. p. 997.

n aI URSINELLA Kintze Rer. gen. pl. p.925.

d $\{2$ Cosm. Wüle Tesm. U. S. ed. II p. 80 t. 4 f. 23-25.

\section{Fordstedtii}

4 si COSMARIUM Racib. Desm. okol. Krakow p. 14 t. 1 f. T [C. Raciborskii Lagerh. 18sT].

11 sis - Kucib. Yonn. Desm. Polon. p. TS (sep.p. 22).

\section{Nordstedtii}

d (M) STAURASTRUM Gntw. Wahr. d. Priorität p. T2. d 11 - Gutw. Flor. alo. Leopol. 1) it t. 3 f. 22.

\section{Norimbergense}

d tji COSMARIUM licinsel spec. Gen. Alg. p.117 t.22 A IV f. 1-11 (sep.1. ? t. 3 A IT). Formi A majns et $B$ minus [C. exiguum v. norinberg. Sehmirle 1894].

d 67 DIDYMIDIUM (Cosmariun) Reinsele Alg. Flor. Frank. 1) 113 t.!) t.: 2 .

m 71 Cosm. Lnnd. Desm. Suec. 1. 43.

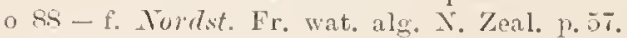

IL 89 - Toni ryll. alg. ]). 360.

1] 91 URSINELLA Kint:e Rev. gen. pl. 1. 125.

- $93 \operatorname{Cosm}$. v. microscopicum Thmer Alg. Ind orient. p.

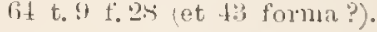

o 93 - Eichler Mat. flor. Miedz. 1). 164 t. 10 f. 34. Cri. Cosm. bigranulatum et Meneghinii ff.

\section{notrbile}

1) 56 COSMARIUM liéb. Liste p. 129 t. 1 f. 15 .

phaf 58 - Caloegliulrus) De Rur. Conjug. p. 38. 47, i.2. t. 1i f. 5 - $5+$ [Alia spec. quam Breb:i].

dz 61 - Areh. in I'ritch. Inf. p. 733.

ozf 61 -.. Hantzscle in Rab. Alg. Eur. 11:0 1111, fig. a-g.

1) 63 - Rab. Frypt. Fl. Saclss. p. 194).

o tit - Richt. in Rab. Alg. Eur. n!o 1941.

o 67 DIDYMIDIUM (cosmarium) Reinsel Aloenfl. Frank. p. 117. Forme A, B a et $\beta$ p. 118 .

d tos Cosm. Kab. Flor. Enr. Alg. 3 p. 173.

d $76-f$. ornata Nordst. Desm. Ital. y. 11 t. 13 f. 16 . [C. tumens sec. IJunsg. 15ss.

[ $78-$ Kirelur. Alg. Schles. p. 152.

d 79 -f. minor IIille Fersliv, alg. Nov. Semlj. p. 36 t. 12 f. 17 .

o 84 PENIUM (sphinctopenium) f. latior Gay Mon. loc. Co11j. p. 7 .

a $8 \pm$ Cosm. Wolle Desm. U. S. p. 6 t et 79 t. 16 f. 11.

o 86 -Stukes hey Desm. 1. 12h. 127.

dz 87 - v. minor (uoke Brit. Desm. p.118 t. 42 f. 12 [c. et $d$ ex Irit7e; $a$. et $b$. ??.

n 8 DYSPHYNCTIUM Jlans\%, in Tisterr. bot. Zeitschr. v. 37 n.r 2 p. 5 .

1 88 - IIansg. Prodr. Algenfl. Böhm. p. 156.

d - $\beta$ pseudospeciosum ibił. p. 187 et 289 [C. speciosum v. ps. spec. Nordst. 1889.

o - subsp. speciosum ibid. p. 290 Cosm. speciosum Lund.).

- 88Cosm. f. ornata Boldt Desm. Grönl. p. 22.

in 88 - Poteat North Carolina Desm. p. 3.

d 89 D ysp. Toni Syll. alg. p. 89 .

d - f. ornatum ibid.

d -v. pseudospeciosum ibid.

d-f. minus ibid. p. 890 .

in $89 \mathrm{Cosm}$. f. minor Nordst. in Wittr. et Nordst. alg. exs. sub n:o 97.

d $-\beta$ ornation f. ibirl. 11:0 980, in fasc. 21 p. 10.

o 90 - f. minor Gutw. Fl. glon. Galic. 2 p. 14.

d (6) - f. media Gnte. Wahr. d. Priorität p.66.

a $91-\ldots$ - Flor. alg. Leopoi. p. 39 t. 1 f. 10.

n $91-$ West Freshm. alg Maine II p. 355.

d $92-$ f. minor West Fr. w. Alg. W. Irel. p. 159.

d 92 - Wolle Desm. U. S. ed. II p. T2 et 86 t. 19 f. 11.

m $92-G u t w$. Flor. glon. Galic. 3 p. 123. Cfl. Cosm. calodermum. 


\section{Noterrisii}

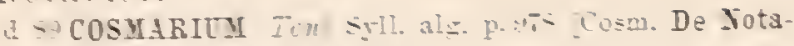
risii Mrar. Nirist.

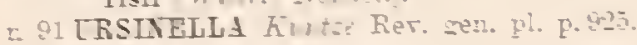

\section{Voterivii}

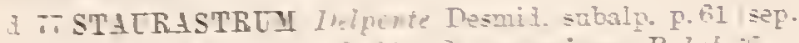
T. 15: - 13:1-2. An St. saronicum Bulnha

\section{notoehomatrum}

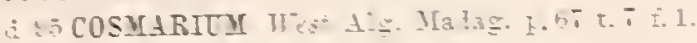

\section{notorhomelnes}

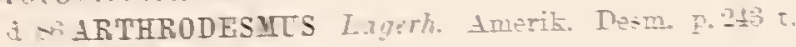
$\therefore-\therefore 1$.

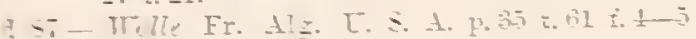
werh. no: exacie

F $\cdots$ - Teni -rll, alz. P. Itw

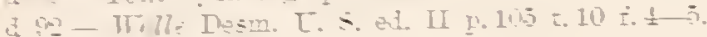

\section{SOTHOCOSUARTL}

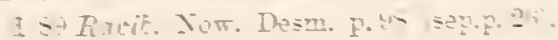

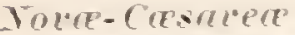

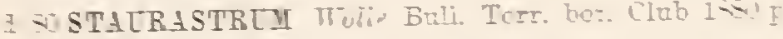

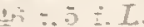

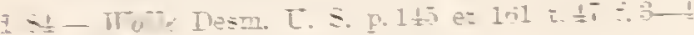

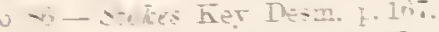

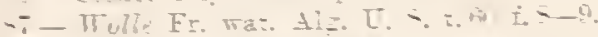

3 - I - In - ril. alz. p. 113 .

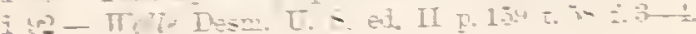

\section{Torer semliex}

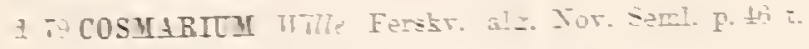
$13 \div \div 5$.

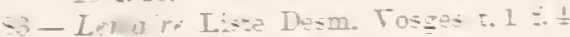

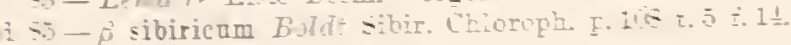

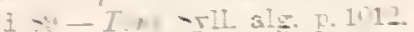

3. $-r_{0}=$ irieum ibiz.

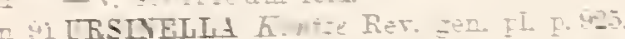

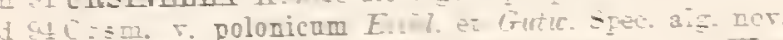
F.1. L

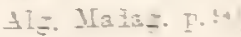

\section{Foret semline}

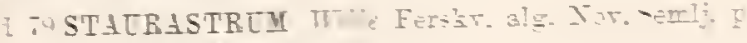
$+19=3-$

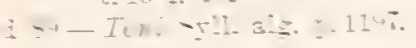

\section{Nueler}

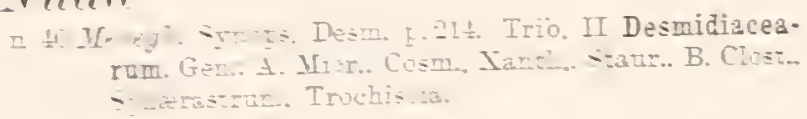

mudireme

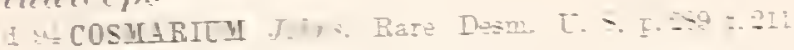

$\therefore \div$

mummularium -

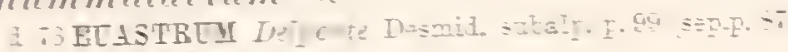

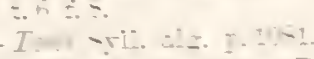

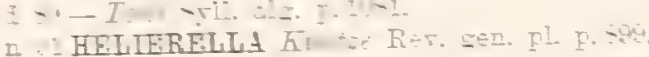

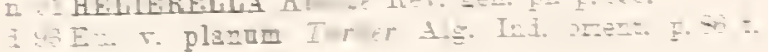

\section{Iittullii}

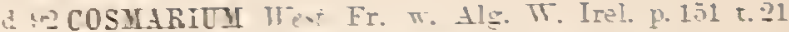
t. ․ Cir. C. subundulatum sec. Burge 15:4?.

\section{Vymannianmm -}

A as COSMARICM hith. Flor. Eur. Als. 3 p. 1 hib.

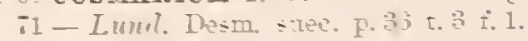

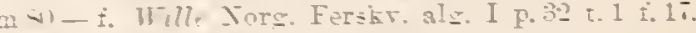

$-3-W_{0} \cdots r .5$.

at - Woll. Desm. L. - p. . .

过

su - Tuni SrII. aIg. p. mit.

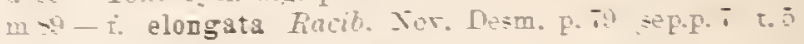
$\therefore 13$.

- i. brevior ibil. p. . . .

1 TRSIVELIA huntse Rer. gen. pl. p. trat

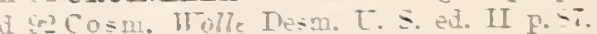

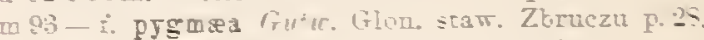

mot - theres tu Mater. alg. hinark. p. 2n?

mo3-Eichler in Pamier. Fizr. 13 Fo. 39

\section{obrumeatume}

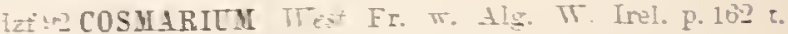
-1. $\mathrm{f}_{0} 1 \mathrm{x}$

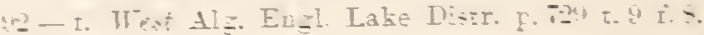

\section{obevim-a}

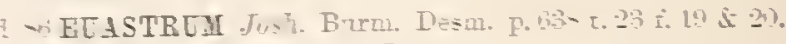

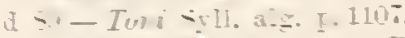

11 HELIERELLA hintze Rer. gen. pl. p. - no

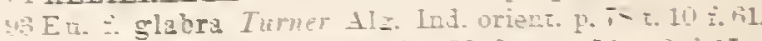
3.5-r. subangalare Wes Alg. Mada fo. 50 t. 6 i. 15.

oblipleneme-re

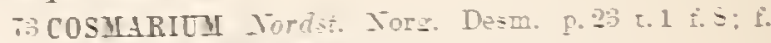
minor. media. major.

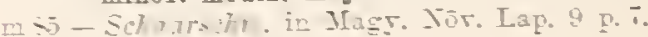

- i. monstrosa ibiz

-i. daplex ibii.

a $-r$. Csatoi ibia.

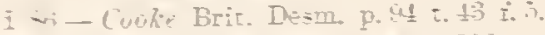

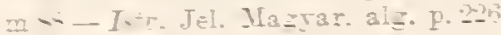

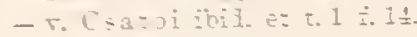

- 1 inplex ibia er t. 1 i. 13 .

L -

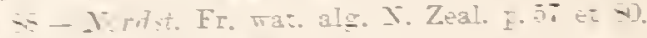

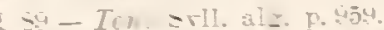

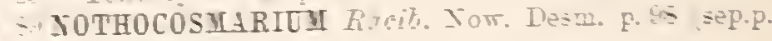

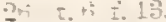
Cosm. Huirerl Desz. alpin. F rin.

LRSINELLA hum Rer. gen pl. p. w-

a gosm. r. trigonam Test. Fr. Als. W. Irel. p. $1 \pm 9$ $=21 \div 15$

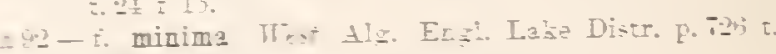
1.

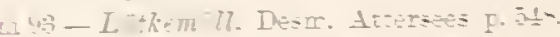

on $4 \frac{1}{5}-B$ rig -

IIS

"blon!liorme

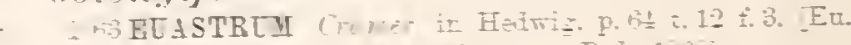
oblongam b. otioncificme Rab. lwat.

oblon!!l!

- $\$$ MICR 1 STERIAS E/ Tent. Mierogeol. p. $9.5=$ Pediastrum. 


\section{oblon!/mm a-}

d sic COSMARIUM Benn. Fr.-wat. Alg. Engl. Lake Distr. 1 1. 10 t. 1 f. 16 (Cosm. sp. Reinsch Contrib. p. 82 t. XII f. 3); now Bréb. 1810.

o sti-Stokes Key Desin. p. 126.

(1) St CALOCYLINDRUS Cooke Brit. Desm. 1). 123 t. 14 f. 8 (e Benutt).

d st DISPHINCTIUM Toni syll. alg. p. $\$ \$ 1$.

\section{ob7om!/mm - -}

d 33 ECHINELLA Grev, in Hook. Br. Fl. v. 2 \%.398.

d 10 COSMARIUM Breb. in Menegh. Symops. Desm, 1. 221

d - v. junius (Heterocarpella [sinuata $\beta$ ] Lyngbyei liréb.).

o 41 EUTOMIA IIare. Man. Br. Alg. p. 188.

d 14 EUASTRUM Ralfs in Ann. Nat. Hist, v. 14 p. 189 t. 6 f. 4 ; et (1846) Trans. Bot. Soc. Edinb. 2 p. 126 t. 10 f. t. (Eu. Pecten Ehrenü.).

d 45 - Ilass. Brit. Alg. p. 380 t. 91 f. 1 [e Ralfs].

dzf 18 - Ralfs Brit. Desm. p. 80 t. 12 (Cosm. sinuosum Corda. Dicr. sinuata Brib.)

dz 52 - Pritch. Int. p. 248.

$\mathrm{dz} 61$ - Areh. in Pritch. Inf. p. 728 t. 3 f. 11. [e Ralfs].

d 63-kab. Krypt. Fl Sachs. p. 185, f. xyl. p. 159 [e Rolfs 1814?].

m 67 DIDYMIDIUM (Euastrum] Reinsch Algenfl. Frank. p. 136 .

$67 \mathrm{E}$ u. Not. Desm. Ital. t. 2 f., 11

d 68-hub. Flo1. Eur. Alg. 3 p. 1 s1 [e Rab. 1863].

d - b. oblongiforme ibid. (Eu. oblong. (ramer).

m 70 - Reimhard in Arbeiten Naturf:g. Charkow I p. 16.

dz 73 -Delponte Desm. subalp. p. 99 (sep.p. 87 ) t. 6 f. 26 -30 .

dz $73-b$, oblongiforme f. scrobiculata Nordst. Norg. Desm. 1. T.

dz 73 - Wood Fr. Alg. p. 136.

d 55 - Microgr. Dict. p. 291 t. 10 f. 15 [e Ralfs].

$\mathrm{dz} 78-$ Kirehn. Alg. Schles. p. 157.

in is-Ilempel Algenfl. Chemnitz p. 113.

d 83 - . trigibberum Schaarschm. Nagyar. Desm. p. 262 t. 1 f. 2. [? f. scrobiculata 1873 sec. Nordst. Bornh. Desur. p. 190]. ("trigibbum").

m 81 - Artari Liste alg. Moscou p. 142.

m St - Gay Monogr. loc. Conj. p. 56.

d 81 - Wolle Desm. U. S. p. 98 t. 25 f. 5-7 (forma) [f. 6 = v. cephalophorum forma West 1894).

d $85-$ Kirchu. Mikr. PHanz. d. Sïssw. p. 21 t. 3 f. 72.

- 85 - a. ff. genu inæ Racib. Desm. nonn, polon, p.93 (sep.p.37)

d - - 1. typicum ibid. (Ralfs $1818 \mathrm{f}$. $a$ ct $b$ ).

d - - 2. subcylindricam ibid.. t. 13 (sep.4) f. 14.

n - - 3. elongatum ibid. (Ralfs fig. c.).

$-\mathrm{b}$.

n - - 1. oblongiforme ibid.

d - - 2. - ihid.. f. 13.

d $86-$ Frank in Leunis synops. p. 194.

- $80^{\circ}$ - Stokes Key Desin. p. 145.

dzf 86 - Coole Brit. Dosm. p. 61 t. 31 f. 2 [e Ralfs et Focke].

d 87 - v. ocellata $1 s t c$. Diagn. præv. in Notaris. p. 235 (sep. p. $(i$.

d 87 - v. integrum Benn. Fr.-w. Alg. North Cornw. p. 16 (sep.p.9) t. 1 f. 18.

87 - v. integram Cooke Brit. Desm. t. 66 f. 1 (e Benn.).

dz 87 - Alexenko Chlorosp. Khark. 1. 239.

dz 88 - Hansq. Prodr. Algenfl. Bühm. p. 204.

dz 88 - Toni et Levi Fl. Alg. Venez. 1.57.

m 88 - Riubin. Chloroph. env. Khark. p. 327.

Sordstedt, Index Desmid. m 88 - a. typicum Boldt Desm. Grinl. p. 7 (sep.p. 5).

$m$ - b. oblongiforme f. scrobiculata ibid.

d $-f$. depressa ibid., t. 1 f. 6.

m 89 - Iste. Jel magyar. alg. 1. 221.

d - v. ocellata ibid.

m 88 - Potent North Carolina Desm. p. 4.

$\mathrm{dz} 89$ - Toni Syll. alg. p. 1086.

d - v. oblongiforme ibid. p. 108i.

d - f. depressum ibid.

d - v. integrum ibid. p. 1088.

d -v. trigibbum ibid.

d - v. ocellatum ibid.

in 90 - Büry. Desm. Brasil. p. 33 .

m 90 - Eichler Spis Desm. Micdz. p. 88 t. 9 f. 29.

in 90 - Anderss. Sverig. Chlol. 1 p. 10.

d 91 - Kirehn. Mikr. Pflanz. 1. Süssw. el. 2 p. 25 t. 3 f. 81.

ph $91-C h$ mielev. in Tr. Soe. Nat. Ihark. p. 161.

in 91 - Heimerl Desm. alpin. p. 601.

m 92 - West Fr. w. Alg. W. Irel. p. 136.

d 92 - Wolle Desm. U. S. ed. II p. 106 t. 28 f. $5-7$.

m 92 - Gutw. Flor. glon. Galic. 3 p. 133.

m 93 - v. oblongiforme f. scrobiculatum Lütkemüll. Desm. Attersces p. $5 \nmid 0$.

n 93 - (Amblyastrum) Turner Alg. Ind, orient. p. 88.

m 91 - Alexenko Mater. alg. Khark. p. 22.

d 94 - v. cephalophorum West New Brit. Alg. p. 1 (Wolle 1884 quoarl fig. 6) [Cfr. Eu. Pecten Ehrenb. 1858 !].

o 95 - Witdem. Note algolog. I p. 5 t. 1 f. $1-20$.

m 95 - Eichler in Pamiet. Fizy. 13 p. 61 t. 1 f. 13 (monstr.).

Cfr. Euastrum n:o 5 Bailey Amer. Bacill. p. 295 (sep.p. 14) t. 3 quoad f. 26, non 27; Eu. Berthold 1886 t. 6 f. 9 ; Eu. Thomas Chicag. IV. Suppl. p. 16 ?

\section{oblongmm}

d 58 PENIUM de Briry Conjug. p. 42, 73 t. 7 G f. 1, 2.

$63-R a b$. Krypt. Fl. Sachs. p. 151 fig. xyl. a et b $[e$ De Bary].

d $68-R a b$. Fl. Eur. Alg. 3 p. 119, fig. xyl, p. 102 [e De Bary]

m 70 - Nordst. Desm. Brasil. p. 202.

d 77 -Delponte Desmid. subalp. p. 86 (sep.p. 182) t. 15 f. $40-42$.

d $78-$ Kirchn. Schles. Alg. p. 135.

m 84 - Gay Mon. loc. Conj. p. 69.

dz 84 - Wolle Desm. U. S. p. 34 t. 5 f. 17. [Quid est?].

m 85 - Schaurschm. Hagy. Növ. Lap. 9 p. 8.

m 86 - Lragerh. Amerik. Desm. p. 253.

o 86 - Stulies Key Desm. p. 111.

d $88-$ Hansq. Prodr. Algenfl. Böhm. p. 177 f. 107 e de Bary].

in 88 - Iste. Jel. inagyar. alg. p. 240.

d 89 - Toni Syll. Alg. p. 861.

in 90 - Anderss. Sverig. Chlor, 1 p. 19.

o 91 - Heimerl Desm. alpin. p. 591.

dz 92 - Wolle Desm. U. S. ed. II p. 35 t. 5 f. 17.

m 93 - Lütkemäll. Desm. Attersees p. 545.

o 13 - f. major Turner Alg. Ind. orient. p. 18 t. 1 f. 22.

m 91 - Iste. Adat. Roman. alg. p. 157.

ph 95 - Lagerh. Phycoporphyr. p. 3 et $\pi$.

m 95 - Schmidle in Beitr. alp. Alg. p. 311.

m 95-Schroder Alg. H. Ricsengeb. p. 16. Cfr Penium Digitus 1818, 1879.

\section{$0670 m: / 1 m$}

d 7 STAURASTRUM Delponte Desmid. subalp. p. 70 (sep. p. 166 t. 12 f. $30-35$

d 89 - Tomi syll. al 1163.

1131 - Gutw. Flor. alg. Leopol. p. 68. 


\section{obsi०m?}

d 4 SPIR0T

d 52 - Pritch. Inf. p. 245.

o 56 - Bril. List. 1. 157.

( $59-D_{c}$ Liary Conjugat. p. 75.

d 5 - Fresen. in Act. Senckenb. II p. 240 sep.1. 32) t. 11 f. $21-26$.

d $61-4$ - Areh. in Pritch. Inf. 1. 752.

(1) 63 - Polytenia) Rab. Krypt. Fl. Sachs. 1.17s.

d 68 - Fial. Flor. Eur. Alg. 3 p. $11 \%$.

d 7 - Rimhurd in Arbeiten Naturf.-g. Charkow I p. 15.

n 71 - Luml. Desm. Suec. 1.91; f. major et minor.

o 73 - Wurlst. Norg. Desm. p. 47.

d 75 - Microgr. Dict. 1. 72S.

m 75 - Nordst. Desm. aret. p. 16 (f. minor).

o 71 - Areh. in Q. J. II. S. 1.33S.

d 7 - Delponte Desm. subalp. p. 140 (sep.p. 236) t. $20 \mathrm{f}$. $21-2 \%$

d 78 - Kirlen. Alg. Schles. P. 136.

m 79 - Hille Ferskv. alg. Nov. Semlj. p. 58 (t. media).

ns) - f, intermedia Norlst. in Pointsf. Skandin. Väst. 4 p. $3 t$.

d 51 - Tolle Desm. U. S. 1. 39 t. 3 f. 16-19.

o s6-Stolies Kiey Desm. 1. 11.

d 86-Cooke Brit. Desm. p. 52 t. 19 f. 6 [e Delpont.?].

ph st - Kilebs Organisat. Gallerte b. Algen p. 381.

d 5 - Alexentio Clilorosp. Khark. p. 221.

d 89 - Joni et Leri Fl. Alg. Venez. p. 39.

n 88 - Riubin. Chloroph. env. Kharkow p. 320.

ms8 - Rucit. Nat. flor. glow. Polsk. I. 100 (sep.p. 21).

a 89 - Toni S̈rll. Alg. p.s19.

d 92 - 1 olle Desm. U. s. ed. II 1. 33 t. 3 f. 16-19.

0 93 - Lüthemüll. Desm. Attersees 1.540.

ph93 - - in Verh. zool. bot. Ges. Wien 1893, sitz. 3 p. 38. m 94-Johns. Rare Desm. U. S. p. 286.

dz:95-Eiüliemüll. Gatt. Spirotæn. p.2, 93 t. 1 f.1-13, 15 $-1 !$.

Cfr. Spirot. bispiralis, grandis et rectispira.

\section{obsculemlu}

d S3 MES0TANIUM Luger. B. Bidr. Sverig. Algtl. p. ô [M. Berggrenii : Wittr.) Lagerh.].

d 8.--(Eumesotanium) Tomi syll. Alg. p. 814 .

\section{obsoletus $-\pi,-\| u$}

(1) 62 ARTHRODESMUS Fluntzsch in Rab. Alg. n:o 1407.

65 - Grm. Ins. Banls. p. 1 5 t. 2 f. 25

d Gr CosMARIUM Reinsch spec. Gen. Alg. p. 142 t. 22 D. I t. 1 -.t (sep.p. 34 t. 3).

d 6 T DIDYMIDIUM (Cosmarium) Reinsch Algenfl. Frank. 1. 110 t. 9 f.. 5 .

71 Cosm. Lund. Thesm. Suec. p.8.

m 80 - Nordst. De Alg. et Charae. 1 p. 7 t. 1 f. 9.

a 83 - v. punctatum Mast. N. Zeal. Wesm. Add. 1.2.10 t. 2.1 t. 5.

d 5.1 - v. tinecense Raciz. Desm. okol. Krakowa sep.p. 1.1 t. 1 f. 3.

d 81 - v. major Wolle Desm. U. s. p. 64 t. 49 f. 12

m 81 - Wille sydamerik. Algfl. p. 16 t. 1 f. 33.

m 81 - Thille sydameris Racib. Nonn. Desn. Tolon. p. St (sep.p. 28)

84- Stulies Kiey Desm. p. 127.

d 89 - Ilrnsg. Prodr. Algenfl. Böhm. p. 251.

d si- $\beta$ punctatum f. Nordst. Fr. wat. alg. N. Zeal. I. $5 \pm$ t. 5 f. 21.

$0 \quad$ - f. ? ibid. f. 22 .

d 8 - Toni syll. alg. p.971. d- - v, tinecense ibid.

d - v. punetatum ibirl.

o 8 - f. tinecensis Ruc. Now. Desm. p.s\%.

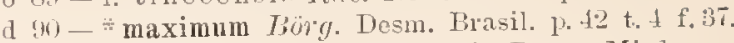

m90-v. tinecense Fichter Spis Desm. Miedz. p.St t. 8 f. 23.

1191 URSINELLA Fintze Rev. gen. pl. p. 125.

(1) 92 Cosm. v. angustatum West Fr. w. Alg. W. Irel. P. 141 t. 24 f. 22 [C. smolandicum sec. Borge in $\mathrm{N}$. Not. 1894 1. 509 ; propria spec.??.

a $\$ 2$ - Moh. A ustral. Süsswassernlg. p. 44 .

o 92 - Rac. Desmidya Ciastoni. p. 373.

il 92 -v. major 11 olle Desm. U. S. ed. II p. 70 t. 60 f. 12.

d $93-$ Britey Contr. Qupeusl. Fl. p.t7.

m93 - Lï̈liemüll. Desm. Attersees p.

6 93 - f. major Turner Alg. Ind. orient. p. 60 t. 8 f. 63.

95 - Hotius apml Bailey Contrib. Queensl. Fl. XI t. 11) f. 23 .

Ofi. Cosm. circulare v. maculata Ist 2 . et Cosm. tetracanthum. - Cosm. obsoletum auctor., nou IIantzsch) Tieinsch nec Lundell = Cosm. palustre sec. Tum.

\section{obtusu- - uाu}

a 41 PENTASTERIAS Ehrent. in Berlin. Nonatsber. 1840 I. 212.

d 49 (?) PHYCASTRUM Kütz. Spec. Alg. p. 182.

\section{obtusalugulume - a}

a 40 CLOSTERIUM Cordo in Alm. d. Carlsb. 1840 p. 220 (sep.p. 35 ) t. 6 f. 12 et 43 .

d to-Relfs Brit, Desm. p. 221.

d 52 - Pritch. Inf. p. 281.

d 61 - Arch. in Iritch. Inf. p. 748 .

d BS- hul. Flor. Eur. Alg. 3 p. 139.

d 89 - Toni 5511. Alg. 1.85t.

1) ARTHRODIA Tumtze Rev. gen. pl. p. sst.

\section{obtesmill -}

a 84 EUASTRUM Wolle in Bull. Torr. bot. Club 1881 1. 15.

d 81 - Hrolle Desm. U. S. p. 10 t. 27 f. 31.

o 86 - Stolies Kiey Desn. p. 146.

d s9-Toni Syll. alg. P. 1106.

n 1 HELIERELLA Kuntze Rev. gen. pl. p. 899.

d 92 Er. Holle Iesm. U. S. ed. II p.117 t. 31 f..31.

\section{obtusullu. -}

d 56 CLOSTERIUM Brid. Liste p. $15 \mathrm{t} \mathrm{t.} 2$ f. 46.

a 61 - Arch. in I'ritch. Inf. p. 746.

o 62- Mantzseh in Kab. Alg. Eur. Dec, 129-130 in nota.

d $63-K u l$. Krypt. Fl. Sachs. p. 170 (inclus. Cl. pusillum IIa). fig. 4 c-e xyl. 1\%. 152. [Fig. $c$ et $d$ e Brib.].

d 65 - Rab. Flor. Eur. Alg. 3 p. 121, fig. xyl. p. 103 (ut supra).

m 71 - Land. Desm. Snee. p. 77.

$\circ 76-A r c h$. in Q. J. M. S. p. 33ss.

d 78 - Kirclin. Alg. Sehles. p. 137.

m 78 - Hempel Algenfl. Chemnitz p. 111.

d 79 - a. typicum Klebs Desm. Ostpreuss. 1. 8 t. 1 f. 2 a et b.

1) - b. pusillum ibid.; f. 2 e (Cl. pusillum Hantzsch. 1851).

z 80 - Kirclen. Beitr. Algenf. Würtemb. 1. 173.

m 80 - Wille Norg. Ferskv. alg. I p. 58.

o 83 - ? Arch in Ann. Mag. Nat. Hist. ser. 5 v. 12 p. 124.

d st - Wolle Desm. U. ... p. 38 t. 6 f. 1.

a 84 - f. Schröter N. Beitr. Alg. Schles. p. 181. 


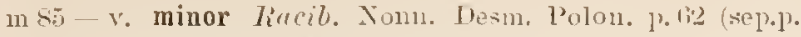
(i) Lumel. 1.811.

12 - v. major ibid. p. 13 (Rub. Lingis).

a 81 - Stolies kiey Desn. 1. 112.

I sti-Coolie Brit. Desm. p. 1!l t. 10 t. 4.

1 87 - Alexentio Chlorosp. Fihark. 1.2.25.

d Sis-Mansg. Proll. Algenfl. BöLm. p. 178.

m St-Kiubiu. Chloroph. ens. Kharkow 11.35 (sep.p. 25),

d si! - Tomi syll. Alg. 1. si?.

m - v. minns ibid.

m-v. majus ibid.

m 90 - West Fr. W. Alg. North Wales p. 281.

m 11 - Eichler spis Desm. Miedz. p. 85.

m 11 - Heimerl Desm. alpin. p. 5!l-2.

n :I ARTHRODIA huntze Rev, gen. pl. p. Ans.

"m 920lost. West Fr. W. Alg. W. Irel. 1\%121.

a ! 1.2 - Wolle Desm. U. S. erl. II 1.35 t. 7 f. 1 .

o 92-f. Thest Alg. Engl. Lake Distr. p. 719 t. 9 f. 13.

A $95-\mathrm{v}$. incisum schröder Alg. H. Riesengeb. 1) 15

\section{ocreidentule}

n m CosmaRIUM Tumer Alg. Ind. orient. p. 69 (C. gemmatum Turn. non Bréb.).

d - r. ornatum ibil.; t. 10 f. 5.

d 91 - v. intermedium Gute. Fl. alg. Tarnapol. p.91 t. 3 f. 22.

\section{oreidemtrle}

d si DoCIDIUM ( $\mathrm{T}$ iploceras Jumer New rare Desm. 1. 939 (sep.1. 5 ) t. 15 f. 25 [D. gracile sec. Wolle 1nsi; itlen v. monodentatum Wildem. 1891].

a si - Toni sivll. Alg. p.si1.

\section{orellatum}

d $\$$ COSMARIUM Eich. et Gutw. Spec. alg. nov. 1. 161 t. \pm f. .

\section{OCLACANTIITII}

d Ss Hamay. Prodr Algenfl. Böhm. p. 203. Sect. Arthrodesmi.

o su Toni s.rll. Alg. p. 11163.

\section{oretrerelethellme}

d 19 EUASTRUM (Micrasterias) Perty in Bern. Mittl. 1319 p. 171 (Arthrodesmus octocomis sec. anct. ipsum in kiennt. klein. Lebensf. 15i2. p. 208).

\section{ochthorles:}

d 75 CosMARIUM Nordst. Desm. aret. p. 17 t.6 f. 3 [C. Botrytis r. K7ehs 18797.

m 76 - Nordst. Desm. Ital. p. 28

m 7. - Wille Ferskt. alg. Nov. Semlj. p. 35.

d $50-\beta$ subcirculare Wille Norg. Ferskv. alg. 1 p. 26 t. 1 f. 8 .

4 81 - Wolle Desm. U. S. n. 66 t. 14 f. 3-1: form.

o 86 - wtokts liey Desm. P. 128.

d $4 \bar{\tau}$ - (oolie Brit. Desm. p. 109 t. 41 f. 3 [c. et d. e Tordst.].

ms9-Boldt Desin. Grönl. p. 29.

$0 \quad-\mathrm{f}, b$. ibill.

- f. c. ibicl. t. 2 f. 32 .

d $89-\beta$ inesoleium Kucil. Desm. Lituan. p. 660 (sep.p.4).

d S4 - Tomi s.'ll. alg. p.992.

d - r. subcirculare ibil. p. 993.

a - $\mathrm{r}$. mesoleium ibil.

d 90 - b. abtusatum Gute. Wahr. d. Priorität p. 68. m90 - v. mesoleium Eichler Spis Desm. Miedz. p. Si. m 90 - Auderss. Sverig. Chlor. 1 p. 14.

n 91 URSINELLA Kuntze Rev. gen. pl. p. 125. d 91 Cosm. v. obtusatun Gutw. Flor. alg. Leopol. 1).51 t. 2 f. 3.

m 92 - Borye sulsfoss. sïtv. alg. Gotl. p. jo et $5 \overline{5}$.

at 6 - Ifolle Desm. U. S. ed. II p. 81 t. 17 f. $3-4$.

1] $12-\mathrm{v}$. amoebum West $\mathrm{Alg}$. Engl. Lake Distr. p. $728 \mathrm{t}$. () f. 31 [inclus. f. granulosum $L$. et f. amoebogranulosa schm. sec. W'est in Joturn. of Bot. 1895 p. $67 ;$ C. speciosum $\beta$ austral. f. Gutu. 1890 sec. Gutw. 1895].

d 93 ... f. granulosum Lïtimülll. Desm. Attersees p. 557 t. 8 f. 9.

m 94 - Borge Chlor. Arehang. p. 19.

d $94-\mathrm{f}$. amoebogranulosa Schmidle in Hedwig. $33 \mathrm{p}$. 92 t. 6 f. 3.

m 9t-Bory. F. alg. Östgrönl. p. 13.

Cfr.? Cosm. Butrytis r. squamosa Schacer,? Cosm. psendospeciosum Iste.; Eu. margaritiferum Ehrenb. 1835 ex p.

\section{orhthodes}

d 93 STAURASTRUM Tumer Alg. Ind. orient. p.105 t. 16 f. 22 .

\section{octumenelreve}

d 4 EUASTRUM Rorge Süssw. Chlor. Arehang. p. 31 t. 3 f. 34. [Eu. Crauteri, sec. West in Journ. of Bot. 1895 1. 60 ; sed non plane identicum esse mihi videtur].

\section{ortoresers.s}

d 38 MICROTHECA Elwenh. Inf. p. 161 t. 11 f. $\mathbf{X}=\mathrm{A}$ imaleul.

n 48 MICROPHYCUS Theris Alghe Coccot. p.98.

\section{actororme -is}

d 38 ARTHRODESMUS Ehrenb. Inf. p. 15?.

d 40 MICRASTERIAS Ilenegh, synops. Desm. p. 216 (sep. P. 16).

d I5 STAURASTRUM? Rilfs in Ann. Nat. Hist. v. $15 \mathrm{p}$. 159 t. 12 f. 8 (et 1816 in Trans. Bot. Soc. Edin. v. 2 p. 145 t. 1 j).

a 45 A rthrodesmus Mass. Brit. Alg. p. 357 t. 85 f. 11 [e Relfs].

a 4 EUASTRUM Kütz. Phycol. germ. n. 134.

d 18 XANTHIDIUM ? Iialfs Brit. Desm. p. 116 t. 20 f. 2 a-e.

d $-\beta$ major ibid.. fig. $f-i$.

d suicr. ?? Hütr. Spec. Alg. p. 171.

d 52 Xanth. (?) 7ritch. Inf. p. 258.

o 58 - Areh. Catalog. p. 75. (Arthr.).

d 61 Arthr. Areh. in Pritch. Inf. p. $730 ; a$ t. 1 f. $30, \beta$ f. 2 !' [e Ralfs 181S].

d $63-R a b$. Krypt. Fl. Sachs. p. 197.

o 63 Iantl. f. Richter in Rab. Als. Eur. n:o 1570 f. B e.

m 67 DIDYMIDIUM (Xauthidium! Reinsch Algenfl. Frank. 1. 127 .

165 Arthr. Rab. Flor. Eur, Alg. 3 p. 225.

d - b. major ibid.

z $69 \mathrm{Xanth}$. Arch. in Q. J. M. S. ธ. 9 p. 423.

oz 71 Arthr. Lund. Thesm. Suec. p. 0.

(1 73 - Wwael Fr. Alg. p. $15 \mathrm{~s}$.

n fi Xanth. Jucobs. Desm. Danem. p. 211, f. minor (Ralfs a).

1 - f. impar ibid. p. 211 t. 8 f. 28 .

1 is $-\beta$ majus f. havaiensis Nordst. Alg. Sandvic. p. 17 t. 2 f. $3-5$.

dz Ts Arthr. Kirchu. Als. Sichles. p. $15 \%$.

S3Xanth. Turner Alwae Strensall f. $T$.

m St-(Holacanthum) a Gay Mon. loc. Conj. p. TT.

d 81 Arthr. Wolle Desm. U. s. p. 97 t. 21 f. 19 -23 (forma). in 86 - f. Lagerh. Amerik. Desm. 1. 241. 
o 86 - Stolies Kiey Desm. p. 131.

dz87-Cooke Brit. Desm. p. 134 t. 47 f. $2[d, c, y=a$; a. b. e, f,g (bis) $=\beta$ ].

d - a simplex ibid. (a Ralfs 18tS).

d $-\beta$ major ibid.

dr 88 - (Sectio 2 Octacanthium) Hansg. Prodr. Algenf. Böhn. p. 208.

z $89-$ Tomi et Leri Fl. Alg. Venez. p. 55.

m 88 - Boldt Desm. Grönl. p. 30.

d - ? P trigonus ibid., t. 2 f. 36 .

dz 89 - Tom syll. alg. p. 1063.

o-v. simplex ibid.

o - v, majus ibid.

d - v. havaieuse ibil.

d - v. trigonum ibid.

o 90 - v. West Fr. w. Alg. North Wales p. 291 t. 6 f. 41. m 9 - Eichler śpis Desm. Miedz. p. 88 t. 9 f. 27.

m -. v. impar ibid.; f. 28.

m 50 - Anderss. Srerig. Chlor. 1 p. 13.

m91 - Gutw. Flor. alg. Leopol. p. 6.

in $92-W_{\text {est }} \mathrm{F}_{1}$. w. Alg. W. Irel. p. 167.

- 92 - Rac. Desmidya Ciastoni. p.37.

d 12.- Wolle Desm. U. S. ed. II p. 104 t. 2 - f. $19-23$.

d $93-\mathrm{v}$. inermis Eichl. et Rac. Nowe gat. zielen. 1.122 t. 3 f. 13.

ozf 94 - $\beta$ major Roy Scottish Desm. p. 11 t. 2 f. 20 .

dz 94 - Sunnd. in Fi. Nebraska p. 12 t. 6 f. 12 [ex Wolle]. m95-v, majus Eichler in Pamiet. Fizy. 13 p.60.

Cfi. Fu. octacanthum Perty 1819, Staur. sp. Rcinsch Contrib. 1875 t. 12 f.9, Xanth. aculeatum Elrenb. 1839 ex $1 ., \mathrm{X}$. bicornutum Reinsch.

\section{octogibbosum!}

1) 7 CoSMaridm Reinseh Alg. Prom. Bon. Sp. p. 210 (C. Hammeri D. octogibbosum Reinsch).

d $98-\beta$ Indica Turnc Alg. Ind. orient. p.52 t. 8 f. 8 et t. 10 f. $1 t$ (form. minor).

\section{orto!fon"11!}

a 93 COSMARIUM Turmer Alg. Ind. orient. p. 159 et 182 t. 10 f. 12.

\section{octolobum}

d 40 EUASTRUM Ehrenb. Berlin. Monatsuer. 1840 p. 20s. [Quid?].

d 52 - Pritch. Inf. p. 251 .

\section{octomraimm}

d s7 XANTHIDIUM Nordst. Algolng. småsak. 4 p. 15 .

d 88 - Norist. Fr. wat. alg. N. Zeal. p. 42 t. $t$ f. 22.

d 89 - (Holacanthium) Toni Syll. alg. p. 927.

\section{oculatum}

d 90 EUASTRUM Tury. Desm. Brasil. p. 36 t. 3 f. 24.

\section{oculifermm -a}

d 86 Cosmaridm Lugerh. Amerik. Desin. p. 234 t. 27 f. 12 ,

d 87 - Wulle Fr. Alg. U. S. A. p. 30 t. 61 f. 7 et 8 [e Lugerh].

d 89 - Tomi syll. alg. p.953.

n :1 URSINELLA Kuntse Rev. gen. pl. p.925.

d ic Cosm. Tulle Desm. U. S. ed. 11 p. Th t. $X$ f. 7 et 8.

\section{(OJONTASTRLM}

o 13 Turner Alg. Ind. orient. p. 133. Subgen. Staurastri.

\section{odomtritum}

a 81 STAURASTRUM Wolle in Bull. 'Torr. bot. Club $18 s 1$ 1. 2 t. 6 f. 11. d 81 ... Wolle Desm U. S. p. 134 t. 43 f. 8 -9.

o 86 - Stokes Irey Iresm. p. 165.

it 8 - Tomi syll. alg. p. 1233.

d 92 - Wolle Desm. U. S ed. II P. 148 t. 54 f. 8 -9.

\section{OJONTELLA}

a 35 Ehrend. Inf. p. 153, non Agardh (1832) = Desmidinm sp. et Onychonema?

d 40 Corda in Aln. d. Carlsb. 1840 p. 207. Sect. = Diplarthrum et Odontella p. 208.

\section{odoutorleurum}

dzfol COSMARIOM Areher in Roy Scottish Desm. p. 169 et (1893) t. 2 f. 13 (sep.p. 40 \%

\section{(IEI)EMTIIIUM}

a 93 Turner Alg. Ind. orient. 1, 39. Snbgen. Docidii.

\section{oedematum}

d $n 3$ D0CIDIUM Tumer Alg. Ind. orient. p. 34 t. 2 f. 7 .

\section{oligucrathum}

n 66 STAURASTRUM "Bréb." dreh. in Q. J. M. Se. 6 p. 67. o 66 - Arch. in Q. J. M. S. 6 p. 189.

o 73 - Nordst. Norg. Desm. p.31. [Staur. mediolave Roy?].

m 75 - Nordst. Desm. aret. p. 36 t. 8 f. 39 .

d 87 - Cooke Brit. Desm. p. 145 t. 50 f. 8 [e Nordst. 1.c.]: d s9-Toni Syll. alg. 10. 1149.

d $91-v$. Incisum $W^{\prime}$ est Fr. w. Alg. W. Irel. p. 173 t. 22 o 95 - v. podlachicum West in Journ. of Bot. 33 p. 70. (Staur. podl. Eich. et Gutw. 1sy1).

\section{Orimogom!roms}

d 75 COSMARIUM Reinsch Contribut. p. 84 t. 16 f. 6 [C. ungerianum f. sec. Nordst. in IIedwigia 1sth p. 66].

d s9-Tum syll. alg. p. 1041.

n 91 URSINELIA Kuntze Rev. gen. pl. 1.925.

\section{Oliveri}

d st CoSMARIUM Schearschm. A fghan. Alg. p. $246 \quad$ t. 5 f. 22.

o ss - Nordst. Fr. wat. alg. N. Zeal. p. 51.

d 8. - Tuni Syll. alg. 1. 1005.

n 91 URSINELLA Kuntze Rev. gen. pl. 1.925.

\section{O.Herrii}

dzf 5 STAURASTRUM Areh. Siuppl. Cat. in Nat. Hist. Rov. 5 1. 254 t. 21 f. 8 - 13 (in Pr. Dithl. Zool. Bot. Ass. I p.11s t.11 f.s-13, J. Micr. Nic. 7 p. 137).

$\mathrm{dz} 61$ - Areh. in Priteh. Inf. p.738.

dz 68 - Tiab. Flor. Eur. Alg. 3 p. 204.

- 73 - Norilst. Norg. Desm. 1. 27.

- 74 - A rch. in Journ. of Bot. 3 p.93 inclus. Arthr. Incus $\beta$ intermedius Wittr.).

m 81 - Gay $11 \mathrm{nn.} \mathrm{loc.} \mathrm{Conj.} \mathrm{1 \%} \mathrm{6t.}$

dzf 87 - Coole Brit. Desuı. p. 142 t. 50 f. 1 [ex Arch.].

dz so-Toni śyll. alg. p. 1143.

d 52 - v. ninutum West Fr, w. Alg. W. Irel. p. 172 t. 22 f. 15 .

m 93 - Lültemüll. Desm. Attersees p. 548.

\section{omcospormm -}

1) 7 CLOSTERIUM Nordst. Alg. brasil. p. 16 t. 2 f. 1.

it 89 - Twni syll. Alg. p. 852.

11 91 ARTHR0DIA Kuntze Rev, gen. pl. p. 853.

\section{ONICIIONEMA}

a 60 Wrallich Desm. Low. Bengal. p. 186 \& 194. 
o 86 Stokes Key Desm. 1. 109.

d Si Cooke Brit. Desm. 1, 6.

d 89 Toni syll. Alg. p. T95.

d so Wille Natïr. T'lanzenfam. p. 14.

d 93 Builry Contr. Queensl. Fl. 1. B!?

d 93 Turner Alg. Ind. orient. P. 138. et 140. Nubgen.: Prionema et Colponema.

\section{On!r/homrmile}

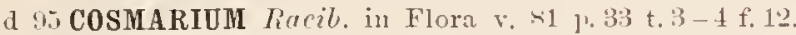

\section{NTIIIIII}

d 93 Turner Alg. Inl. orient. p.34. Subg. Docidii.

\section{Ophill,}

d is STAURASTRUM Lund. Desm. Suec, p. 6i) t. 4 f. 7.

o 73- Nurdst. Norg. Desm. p. 35.

80 - rooke in Grevillea 9 t. $140 \mathrm{f}$. a-c [v. Cambricum II. 1 . 294 .

o 81 - ('uulie in Quekett Micr. J. ti p. 247 (sej).1. 5) t. 11 f. $10-11$ [v. Cambricum W. 1s:4]].

82 - Wolle in Bull. Torr. bot. Club p. $2 \mathrm{~s}$ t. $1: 3 \mathrm{f}, 4$ (v. tetracerum et $\mathrm{v}$. pentacerum).

d st - Wolle Desm. U. S. P. 134 t. 43 f. $10-11$; v. tetracervm t. 14 f. 1 -2, pentacerum t. 14 f. 3.

o S6 - Stokes liey Desm. p. 165-6.

d 87 - Cuoke Brit. Desm. p. 172 t. 59 f. 1 [v. cambricum, quoad figg.'.

d S.1 - Tomi sirll. alo p. 1212.

o 10 - Wrst Fr. w. Alg. North Wales p. 294 t. 5 f. 15 (et Bemett ibid. 20306$)$.

d (12-Wolle Desn. U. S. ed. II p. 147 t. 54 f. $10-11$. t. 5.) $t .1-3$

d 94-v. Cambricum IIest New Brit. Alg. p. 12 Cooke $1 \mathrm{~s}$ so, et $188 \mathrm{~s}$ ex $\mathrm{p}$.)

Cfr. Phycasti: grande Kïtz. 1849 (Eu. 11:0 13 Bail. Amer. Bacill. 1541 quoad f. $\%$ t. 31.

\section{olimmm}

d 93 STAURASTRUM Twmer Alg. Ind. orient. p. $129 \mathrm{t}$ 16 f.: 35 .

\section{orbirmlare -is}

d 60 EUASTRUM Wullich Desm. Low. Bengal, p. 292 t. 14 f. $8-11$.

d $65-\beta$ Grun. Ins. Bank. p. 14 t. 2 f. 23 . [Quid? Spec. ad E. quadratum 1. spinulosum acceleus?

1) 89 - 7oni syll, alg. p. 1094.

11 "1 HELIERELLA huntze Rev. gen. pl. p. 8.19.

m!3 Eu. Cosmariastrum Turner A]g. Ind. orient. p. si) t. 11 f. 1: [E. spinulosam africanum Tordst. sec. Wildem. in Totarisia 15:13 p.14i!, idem. var. orb. IIild, 1siti?.

\section{orbirmlune -is}

d 31? DESMIDIUM Ehrenb. Organ. k1. Ram. 1.29-2 (sep. P. 1.t.

d 39 - Elerenb. Int. 13. 141 t. 10 f. IT

d to STAURASTRUM Henegh. Synops. Desm. p.225 (sep. 1). 25 [Exclus, syn, Lreeb.].

.11 - I'ritch. Inf, ]. 183 [n. r.].

d 15 - hulfs in Ann. Nat. Hist. v. 15 p. 152 t. 10 t. 4 (et 1s.i in Trans. Bot. Soc. Edin, v. 2 p. 13s t. 13 .

(1) 5 G0NI0CYSTIS (Trigonocystis) Hass. Brit. Alg. 1. $34 ! 1$ t. 84 f. 7 [e Rulfs].

d 45 PHYCASTRUM Kiütz. Phycol. germ. p. 137.

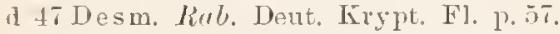

dzf 15 staur. Ralfs Brit. Desm. p. 125 t. 21 f. 5 . [Tres forma. Fig. 5 le et $i=$ st. muticum sec. Jucobs. 18.67.

d 49 Phycastrum Kürz. sipec. alg. p.178.

$1149-($ Amblyactinium) Norg. einz. Alg. P. 125.

dz 52 Staur. Pritch. Inf. 1'. 233.

o 5s-De Eur. Conjug. 1. 34.

d 61 - Areh. in Pritch. Inf. ]. T 10 .

1 $63-$ Rab. Rirglt. Fl. Saclss. p. 18s.

- 67 DIDYMIDIUM (standastrum) Feinsch Algenfl. Frank. p. 15:?

d - f. a. minns ihid.

d $-b$, intermedium ibil.

d -c. majus ibid.

d 67 Staul. Y. majus Not. Desm. Ital. p. 55 t. 5 f. 52 [Staur. lanceolatum $\mathrm{f}$.??].

1\%68 - Rul. Flor. Enr. Alg. :3 p. 2 \%).

d -. b. Bieneanum ilid, (Et. Bienean m Rub.

(1) 70-Norlst. Desm. Brasil. 11.221, forma.

d $-\beta$ denticulatum ibid. t. 4 f. 12.

o 71 - Lund. Desm. Supe. p. 56 .

d 73 - $\beta$ extensum Torelst. Norg. Desm. p. 26 t. 1 f. 10.

7.t-Gibbons in Trans. R. Soe. Victoria $\mathrm{I}$ in fig. photogr. 2.

dz 73 - Wuod Fr. Alg. p. 14 t. 21 f. 1 \%, t. 13 f. 8.

d 75 - f. elliptica lieinscle Contrib. t. 10 f.5 et p. 81 sub nowine ('osm. s].).

m 7.5 - Tordst. Desm. aret. 1.32.

m $76-\beta$ extemsum Norlst. Desm. Ital. 1) 12.

d T- Delpunte Desmicl. subalp. p. 37 (sep.p. 133) t. 10 f. $5-12$.

o is - f. Nordst. in Wittr. et Nordat. Alg. exs. n:o 16i; et $(1,8.9)$ in fasc. $21 \mathrm{p} .36$.

dz TS- Kirchn. Alg. Schles. p. 164.

in 7 - Ilempel Algent. Chennitz p. 113.

m 79 - Wille Ferskv. alg. Nov. Semlj. p. 19.

d $s 0-\beta$ verrucosum Wille Norg. Ferskv. alg. I p. 40 t. 2 f. 26.

m 81 - Artari Liste alg. Moscon p. 14:.

ns. St - Guy Monogr. loc. Conj. p. his.

d 84 - Tolle Desm. [. S. p. 120 t. 39 f. 9-10.

ın $\$ 4$ - Wille Sylamerik. Algfl. 1.1S.

d Sij-Frank in Lemnis sinops. 3 p. 197.

d si - y depressnm Roy et Biss. Jap. Desm. p. 237 sep. 1. ㅎ t. 21 is f. 11.

o s6 -- Stolics Key Desm. p. 164 .

o $8 \mathrm{i}$ - r. Wolle Fr. Alg. U. ‥ A. p. 41 t. 601 f. $36-38$.

dzf $s$ - Cuolie Brit. Desin. p. 156 t. 51 f. $\tau$ [ $f$ et $g$ e Ralfs $1 s i s$

m - $\beta$ extensum ibid. $1.15 \%$.

d si - Aleituko Chlorosp. Khark. 1. 253.

¿ S. - Hansg. Proilr. Algenf. Bölım. p. 254.

dzas - Tuni et Levi F1. Alg. Venez. p. 43.

ms. - Riabir. Chloroph. env. Kharkow 1. 329.

m 88 - Boldt Desm. Grönl. p. 32.

m - $\beta$ rerrucosum ibid.

m $s 8-7 . t r$. Jel. magyar. alg. 1. 2:31.

in SS - $\beta$ depressum Norlst. Fr. wat. alg. N. Zeal. p. 42.

dz s9-Toni syll. alg. 1) 1180.

d - v. extensun ibid. p. 11si.

- $r$. denticulatum ibid.

- r. lepressum ibid.

- v. verucosmm ibid.

-v. 12 a jus ibid.

m S9-- Ko:lowsli Flor. volorosl. Sibir. II p. 20.

m - b. minor ibid.

1190 -f. punctata Gutu. Waln. d. Priorität p. T1 (St. cordatnm Gay 1ns1).

m 90 - Eichle' Spis Desm. Miedz. 1) 89. 
mo - Andess. Sverig. Chloroph. 1 p. 11.

1n 51 - Hemerl Desm. alpin. p.605.

m 91 -f. punctata Gutu. Flor. alg. Leopol. p. 65 t. 3 f. 10 .

1392 - West Er. W. Alg. IV. Irel. p. 176 .

m - v. Injesesum ibil. p. 17T.

o 92 - . depressum Rue. Desmidya Ciastoni. p.370 t. \% f. $1 \%$.

d 92 - Wolle Desm. U. \&. ell. 11 p. 132 t. 50 f. $9-10$.

m 92 - f. major Itest Alg. Engl. Lake Distr. r. 631 .

in - - v. extensum ibid.

in 93 - Lütlicmïll. Desm. Attersees \}. 565.

o v. extensum ibil.

o 93 - Sphærieastrum) Twner Alg. Ind. orient. p. 104 t. $16 \mathrm{f} .40$.

zf 91 - f.? Roy seott. Desm. t. 3 f. 7. [Sporî alia speeies quam liculfsi l. c. fig. $5 \mathrm{~g}$, sed fortasse typica forma].

m $44-\beta$ depressum Irorge sïssw, Chlor. Archang. 1. 36. m 94 - Burg. F. aly. Östgronl. 1. 21.

$m$ (i.) - r. depressum Wist Alg. Marlag. p. 73.

in - v. denticulatum f. miuor ibid. p. 74 t. 8 f. $40-41$,

in 19 - f. Schmidle Beitr. alp. Alg. p.61 (sep.p. 32).

m - v. extensum f. major ibid. St. hibernicum). Cfr. St. muticum.

\section{ovbirmbruis}

a S3 ARTHRODESMUS Wulle in Bull. Torr. bot. Club 1853 ए. 18 t. 27 f. 20.2.

d 84 - II

o 86 - Stokes Key Desm. p. 131.

d 89 - Tomi syll. alg. p. 105s

d 92 - Trolle Desm. C. S. ed. II p. 104 t. 27 f. $15-16$.

\section{orbiculutum -r}

a 14 COSMARIUM Ralfs in Am. Nat. Hist. v. 14 p. 342 t. 11 f. 2 let $1811 \mathrm{j}$ in Trans. Bot. Soe. Edin. v. 2 p. 14 . t. 16).

1. 45-Hass. Brit. Alg. p. 364 t. 86 f.5 [e Rulfs non exacte delineata? - C excavatum forma Lund.].

dzf ts - Mulfs Brit. Desm. p. 107 t. 17 f. 5. t. 33 f. $\%$

d 19 PENIUM hïl. Spec. Alg. p. 167.

d $52 \mathrm{Cosm}$. Jritch. Inf. p, 255.

ozf $58-($ Dymphinctium) The Brov. Conjug. 1.41, 72 t.6 f. 49 -50. (C. Portianum Arch. 1 sho sec. A., non ita sec. A. in (?. J. M. S. $18 \pi 6$ p. 100].

- 5S TESSARARTHRA Grm. Desm. p. 493.

dzcil c'osm. Areh. in Pritch. Inf. 1). 731.

n 67 DISPHINCTIUM Reinsch Algenft. Frank. p. 181.

is 68 Cosm. líub. Flor. Eur. Aler. 3 1. 173.

o $73-$ Nordst. Norg. Desin. p. 22.

d 7 - Thetponte Desmid. suball' p. 11 (sep.p. 107) t. 7 f. 1fi-1s.

$\mathrm{dz}$ is - Kirchn. Alg. Sichles. p. 152.

o 6 - K7ebs Desm. Ostrueuss. 1. 40 t. 3 f. $78-79$.

dzst - Holle Desm. T. S. p. 77 t. 11 f. $20-21$.

an 855 - Bolnt Sibir. Chloroph. p. 168.

o sli-Stokes Key Desm. D. 12s.

dafs 8 - C'colie Brit. Desm. p. 119 t. 43 f. 1 [fig. f. e De Tory 1s5s; ceterce fortasse non exaete e Ralfs 1814.

Izss - Hansy. Protr. Algenf. Bühn. p. 24!!.

m 88 - Ist . Jel. magyar. alg. 1.227.

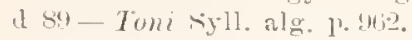

(1)-Wost Fr. W. Alg. North Wales t. 5 f. 18 .

m (1) - Eichly spis Wesm. Mielz. 1.57.

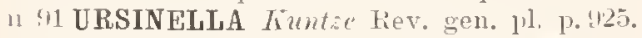

in il cosm. Frutu. Flor. alg. Leopol. 1) 40. m 92 - Porge Chloroph. Norsk. Finmark. p. 9.

m 92 - Writ Fr. W. Alg. W. Irel. p. 154 .

d.92 - Wolle Desin. U. S. er. II p. 85 t. 17 f. $20-21$.

oveliutum

d 93 STAURASTRUM Twrner Alg. Ind. oriont. p.126 t. 15 f. 9.

\section{oricutule}

d 933 CosmaRIUM Turne Alg. 1nd. orient. 1. 65 t. 9 f. 35.

\section{orientule}

d 93 D0CIDIUM Thmer Alg. Ind, orient. p. 31 t. 4 f. 1 .

\section{orientrle}

d 93 EUASTRUM Twmer Alg. Ind. orient. 1. 69 t. 10 f. 34 , t.11 f. 26. (? E. insigne Tiulle, non lialfs).

\section{orientale.}

I !3 STAURASTRUM Tumer A]g. Ind. orient. p. 123 t. $14 \mathrm{f.j}$.

$m-\mathrm{f}$. minor ilıil.

\section{ormatisisimum}

d 4 CoSMARIUM Schminle in Hedwig. 33 p.90 t. 6 f. 12. [An Cosm. nasutum?].

\section{ormutum}

a 63 CLOSTERIUM hul. Firypt. Fl. Sachs. p. 171 (C. moniliferum $f i$ minus hit $\approx$. 1849).

\section{ormatum- -}

.14 Cosmarium Ralfs in Anm. Nat. Hist. v. 14 p. 392 t. 11 f. 3 (et 1846 in Trans. Bot. Soe. Edinb. v. 2 p. 14t t.16). Fig. :3 b verisimile non bona].

d 45 -Ilass. Brit. Alg. p. 364 t. $\$ 6$ f. 3 [e Ralfs].

d 4 t EUASTRUM Focle Phys, Stuid. I p. 41 t. 1 f. 2. [Cosm. psendoormatum Eichl, et crutw.??]

Taf 48 Cosm. Ralfs Brit. Desm. p. 104 t. 16 f. T. (Cosm. Sportella livelu. mser.).

d 49 - hïtz. Sipes. Alg. 1\%. 176.

dz 52 - Pritch. Inf. p.2it.

m 101 - Suring. Kruitlk. Arch. p. 27t.

dz 61 - Arch. in I'ritel. Inf. 1\% 731.

d 63 - Rub. Krypt. Fl. Sachs. p. 201

d o. - Lub. Flor. Eur. Alg. 3 1. 169.

d 70 - $\beta$ Lagoense Nordst. Desm. Brasil. 1. 213 t. 3 f. 32. [C. layoense Nordst.].

oz 71 - Lund. Desn. Sinee. p. $2 \mathrm{~s}$.

d 73 - Trood Fr. Alg. p. 132.

d 75 - Microgr. Diet. 1). 202.

o 76 -Jurobs. Desm. Danem. 1'. 195 (forma).

d - f. depauperata ibid. p. 195 t. 7 f. 16. [Quid ?].

dz $\mathrm{S}$ - Firelin. Alg. tichles. p. 158.

d 51 - Wolle Desm. U. S. 10. 2 2.t. 18 f. $39-12$, t. 49 f. 23 - 2.1 .

- v. ibid. v. 21 f. $43-15$.

o- - v. protractum ilid., t. 19 f. 2.2 (et v. minor t. 17 f. 2!!).

11 (d) 85 - a. suecica Racib. Nonn. Desm. Polon. p. 72 (sep. 1. 16 .

- - b. Anglica ibic. Rulfs 1\$1s).

d - e. lithuanica ibid., t. 11 (sep. 2) f. 2.

1 - d. polonica ibid.. f. 3.

m sti-Lugerh. Amerik. Desm. p. 234.

o si stolits liey Desm. 1. 12!.

dzs - Coulie Brit. Desmll. 1. 112 t. 40 f. 4 [partim e Ralfs].

d 8 - Alexentie Chlorosp. Khark. p. 270. 


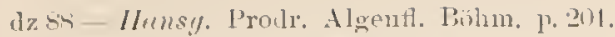

ms:1- IIrr. Fr. Alg. Maine II p. 1si.

d 891 - Tomi śrll. alun. 1\% 11).25.

d - - r. lithunnicum ibid.

l - v. polonieum ibid.

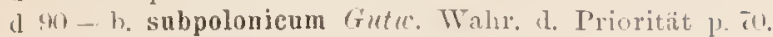

m(n)-Líry. Desm. Brasil. 1. 38.

- t. major ibid. p. 39 t. \& f. 2 !!

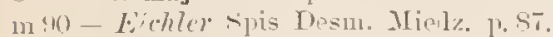

m91-Anderss. sverigr. Chlor. 1 P. 17.

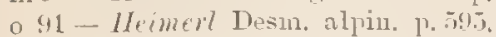

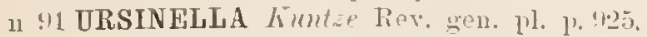

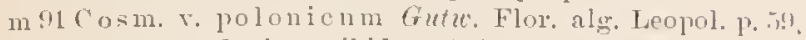

d - 1 subpolonicam ibic., t. 2 f. 24 .

d 92 - Wulle Desm. U. A. ed. II 1. 8. t. 21 f. $31-42$, t. 60 t. 2321 .

r. ibic. t. 21 f. $13-15$.

1 - r. protractum ibill. p. 90 t. 130 f. 2.3.

o - т. minor ibid. t. 20 f. 2 (protractum?).

m 14 - 1lexenlo Mater. alg. Ǩhark. p. 25.

o 91-v. polonicum Gutu. Fl. alg. Tarnapol. p. 9:.

m.95-Eichler in Pamiet. Fizy. 1:3 lo, 1in.

m?5-F protractum Borye Sverig. Chlor. II 1. 20.

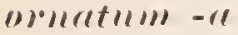

17 ऑEUASTRUM $\|^{\circ}$ ood in Proc. Plilad. Acad. X. S. 1869 1. 17 .

d 7:3- Wood Fr. Als. p. 137 t. 21 f. 12.

d 81 -? Wolle Desm. U. S. p.97 t. 25 f. \& [e Wuorl; for tasse forma E. crassi sec. Holle; E. crassum $p$ ornatum Hunsy. 1sss].

o sti-ntokes lier Desm. p. 14 .

d Sa - Tumi Sril. alg. P. 1058 .

n "1 HELIERELLA Kuntze Rev. gen. pl. p. 594.

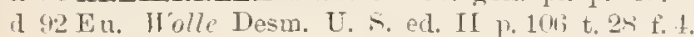

\section{(1)'uritum.}

m!3 STAURASTRUM Twner Alg. Ink. orient. p. $115 \mathrm{t} .13$ f. $28^{-} \rightarrow$ t. margaritaceum $\beta$ subtile t. olnata Boldt 1585).

d 9 - v. asperum schmidle Beitr. alp. Alg. p. 65 isep.p. 3i) et, 1805, t. 16 f, 22 Pliycastrum asperum Ierty.

\section{"rmithorephlialum-re}

d sf EUASTRUM Bem. Fr.-w. Aly. Engl, Lake Dirtr. 1 p. 1 t. 1 f. 12.

o 86 - stokes liey Desm. p. 145.

d 86 - Cooke Brit. Desm. p. Ts t. 35 (e Bemett).

d $89-\%$ mi syll. alg. p. 110\%.

n 11 HELIERELLA Kuntze Rer, gen, pl. p. 85.

\section{morthorephrelum}

d $ง$ STAURASTRUM Test Alg. Madag. p. 38 t. 5 f. 24.

\section{(OR'THIJ) I II}

d 93 Turner Alg. Ind, orient. p. 39. Subgen. Docidii.

\section{OR'THOC'ERAS}

d 98 Tumes Alg. Ind. orient, p. 23. Subgen. Closterii.

\section{orthogomem $-a$}

d TC COSMARIUM Delponte Desmid. subalp. p. 8 (sep.p. 101) t. 7 f. 49-51. E 1., crenatum Nog. et Foche). ("ortogonum")

d 81 - $\beta$ constrictum Lagerh. Amerik. Desm. p. 241 t. 27 f. 15 .
A $8 T-v$. constrietum Wwe Fr. Alg. T. S. d. p. 33 t. (j) f. 31 - 35 [e langrrh. male].

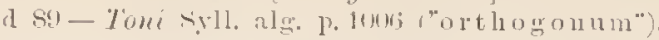

d - veconstrictum ibil.

is $s$ - $\beta$ concinnum liacit. Now. Desm. $]^{1}, 4$ t. 5 f. 12.

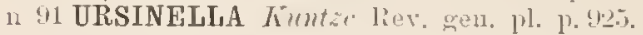

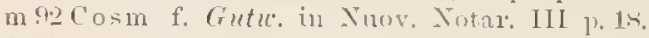

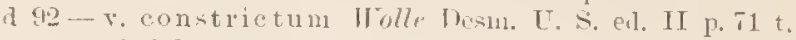
49 f. 31 et 33 .

o $92-\mathrm{f}$. Gutu. Flor. slon. Galie. 3 p. 125 t. 3 f. 16 .

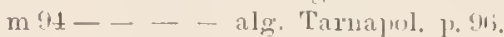

$\mathrm{m} ! 50$ - Eichler in Pamiet. Fizy. 13 p. 60 t. 1 f. 10.

\section{(1) + thoj)/rurum -}

d sf Cosmarium lioy a biss. Japan. Desm. p. 194 (sey. p. 2 t. 268 f. $11 \%$.

d 89 - Toni syll. alg. 11.990.

n 91 URSINELLA himtze liev. gen. pl. p. y25.

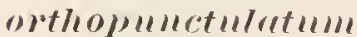

195 COSMARIUM sichmidle Beitr. alp. Alg. p. 389 (sep.p. 19 t. 15 fo. 1 is.

\section{olthostirhllu- -}

d 7 cosmariUM Lund. Desm. suec, p. 24 t. 2 f. ?.

$1-\beta$ pumilum ibia. p. 25 t. 2 f. 10 .

d 84 - Holle Desm. U. s. p. Ts t. 18 f. 4-5.

m S5-fi pumilum Boldt sibir. Chloroph. p. 108.

$\mathrm{m}$ Sij-Lagerh. Amerik. Jesm. p. 235.

- $\beta$ trigonum ibial.

o s6- Stokit Key Tesm, n. 12A.

I š̄-Cootic Brit. Desm. p. 10.5 t. 42 f. 3 [e Lund.?]

d so-Toni syll. alg. p. 963.

11 URSINELLA Kuntze Rev, gen, pl. p. 925.

a 12 Cosm. Wolle Desm. U. S. ed. II p. 81 t. 21 f. $1-5$.

m t.2 - v. pumilum West Alg. Engl. Lake Distr. 1.727.

d 94 - v. rectaggulum Lich, et Gutio. Spec. alg. nov. p. 167 t. 4 f. 15.

\section{oscitrus:}

n 45 MICRASTERIAS? I'ulfs in Jenner Fl. Tunbr. Wells p. 198 , 1.99

d 45 HOLOCYSTIS Uase. Brit, Alg. p. 387 t. 9 f. 4, et cum "?" f. 3 (in indice vol. II p. 20) [M. incisa forma b. Rub. Fl. Eur. III p. 158. - Eu. Holocystis Kütz. 1st!?.

14 Micr. Ralfs Brit. Tesm. p. it t. A f. 2 .

19 FUASTRUM Micrasterias) N'(ey, einz. Alg. p. 128.

o $51 \mathrm{Micr}$. Buil. Mier. Obs, p. 17 t. 1 f. 19.

d 52 - Pritch. Inf. p. 246 t. 13 f, 25 -2! [e Ralfs].

a 59 TETRACHASTRUM Vixm On a new Genus sep.p.8; in Dubl. Nat. Hist. Soc. p. 205; in Dubl. Nat. Hist. Rev. p.tfit; in Q. J. Micr. Sic. p. 83.

d 60Holocystis Wrallich Desm. Low: Bengal p. 275 t. 13 f. 1-3 [M. pinnatificla a typica Tumer 1893].

- vo ibid. Micraster. quadrata Puiley 1851).

d 61 Tetracliastrum Arch. in Pritcli. Inf. P. 725 t. 2 f. 28-29 [e Rulfs].

d 63 Micr. Rab. Lirst. Fl, Sachs, p. 1 st.

d 68 - Rub. Flor. Eur. Alo. 3 p. 1s?.

d - b. pinnatifida (I. pin 12. Kütz.; Eu. didymac. Nog.).

d 73 - Wrood Fr. Alg. p. 142.

$76-\mathrm{v}$. inflata Wrolle in Bull. Torr. Bot. Club. 15 p. 122. [M. pinnatif. v. 1881].

so-f. Wille Norg. Ferskv. alg. p. 21 t. 1 f. $4-5$.

- $\beta$ mucronata ibid. p. 21 t. 1 f. 3 (Tetrachastrum mucronatum Dixon 185\%). 
o 81 - Cooke in Grevillea 9 p. 89 t. 141 f. 2 incl. Tetrac. mucro 11.).

d st - Wrolle Desm. U. S. p. 116 t. 33 f. 3-4.

d 85 - Kirchn. Mikr. Pflanz. d. Süssw. P. 23.

o 86 Holocystis Benn. Fr.-Alg. Engl. Lake Distr. 1 p. 7 t. 1 f. T-10 (incl. Tetrachastr. mucronatum).

- 86 Micr. Stokes Key Desm. p.147.

d 86 - (Tetrachastrum) C'volie Brit. Desm. p. 54 t. 20 f. 2 [e Rirlfs 1848].

o 87 -. Wildem. Observ. (1u. Desm. p. 290 (sep.p. 10) t. 1 f. 27-32 (inclus. M. laticeps et dispntata).

o - - . pinnatifida ibid. p. 281 (inclus. v. inflata Holle 1876).

d $S s-\beta$ pinnatifida Hansy. Prodr. Algent. Böhm. p. 208.

n $88-\beta$ mucronata $f$. intermedia Boldt Desm. utbr. Nord. p. 55 (M. mucr. f. interm. Nordst. 1873).

d 89 - Tomi Syll. alg. p. 1110.

d $-v$. pinnatifira ibid. p. 1111.

d $-\mathrm{v}$. inflata ibid.

d 91 - Firchn. Mikr. Pflanz. d. Süissw. ed. 2 p. 25.

n 91 HELIERELLA Kuntze Rev. gen. pl. p. 899.

d 92 Micr. Wolle Desm. U. S. ed. II p. 129 t. 37 f. $3-4$.

in 93 - v. pinna tifida Lïtlemiill. Desm. Attersees p. 562.

m93-(Holocystis) a typica Turner Alg. Ind. orient. p. 86.

m - $\beta$ intermedia ibid. (Cooke 1881 fig. 2 e et e).

$m-y$ mucronata ibid.

Cfr. Euastrum Holocystis et Micr. adscendens.

\section{osteommu}

d 90 STAURASTRUM West Fr. w. Alg. North Wales p. 293 t. 5 f. 7 [Cfr. Lagerh. in N. Notal. I1 p. 29].

\section{Osteri}

d 95 COSMARIUM Schmidle Beitr. alp. Alg. p. 455 (sep.p. 24 t. 15 f. 32. [Cosm. vogesiacnm Lem. 1853].

\section{ovale -is}

d 44 COSMARIUM halfs in Ann. Nat. Hist. v. 14 p. 394 t. 11 f. 7 tet 1816 in Trans. Bot. Soc. Edin. v. 2 p. 150 t. 16).

o - $a$ ibid.; fig. $: a, b, c$ [C. pseudopyramidatum * stenonotnm?.

- $\quad-\beta$ ibid.; t. 11 f. $7 d$ et $e$. (Euastrum n:o 6 Bailey Amer. Bacill. p. 295 (sep.p. 14) t. 3) [Eu. carinatum Ehrb. 1813].

d 45-Mlessall Brit. Alg. 1). 866 сum $\beta$ (=Fig. Baiteyi), t. $86 \mathrm{f}$. 8 et 9 [e lialfs?

- 47 EUASTRUM Focke Phys. Stud. I p.41 et 64 t. $1 \mathrm{f}$. 5. [Cosm. pyramidatum verisimile].

d $48 \mathrm{Cosm}$. Rialfs Brit. Desm, p. 98 t. 15 f. 9.

d $49-K u ̈ t z$. Spec. Alg. p. $1 \% 5$.

49 Eu. (Cosinarium) Neg. einz. Alg. 1. 114.

d 52 Cosm. Pritch. Inf. p. 253.

o $52 \mathrm{Eu}$. Porty kleinst. Lebensf. p. $20 \mathrm{~s}$ t. 16 f. 14 [mala, cfr. descript.; alia spec. ?'].

d $61 \mathrm{Cosm}$. Arch. in Priteh. Inf. p. 733.

I $63-R a b$. Krypt. Fl. Sacls. p. 200 .

d 69 - Rrub. Forlor. Eur. Alg. 3 p. 158; a I'erty 1s52; b, c (Focke 1847).

- 71 - (Pleuroteniopsis) Lund. Desm. Suec. p.53.

d 73 - Wood Fr. Alg. 1.128.

(1 77 -Delponte Desmicl. suhalp. p.31 (sep.p. 130) t. 10 f. $1-4$.

d 78 - Kirchn. Alg. Sichles. p 14ti.

d 81 - Wolle Desm. U. . . p.57 t. 13 f.s-9 o 86 - Stukes Kiey Desm. p. 124.

d 87 - Cooke Brit. Desm. 1\%.100 t.39 f.3 [e Ralfs $181 \mathrm{~S}$ verisimile.

○ 88 - ? I'oteret Nortlı Carolina Desm. p. 3.

d ss CoSmaridium Hansø. Prodr. Algent. Böhm. p. 191 f. 113 [e Detp.].

m89 Cosm. Hurv. Fr. Alg. Maine II p. 186.

d S9 PLEUR0T AnIOPSIS (Cosmaridium) Toni Syll. alg. p. 912.

d 8. Cosm. $\beta$ excisum Racib. Now. Desm. p. 91 (sep.p. 19) t. 6 f. 2.

d 90 - f. Börq. Desm. Brasil. p. 43.

m 92 - Hest Fr. W. Alg. W. Irel. p. 164.

d 92 - Wolle Desm. U. S. ed. II p. 62 t. 16 f. S-

n 93-(P'y ramidium) Turner Alg. Ind. orient. p. 73.

\section{ovale}

d 93 SPONDYLOSIUM Turner Alg. Ind. orient. p. 44 t. 18 f. 3 et 9.

\section{oreclis.}

d 83 ARTHRODESMUS Wolle in Bull. Torr. bot. Club 1853 p. 18.

d 84 - Wolle Desm. U. S. p. 96 t. 24 f. $13-14$.

o 86 - Stokes Kiey Desm. p. 131.

d $88-$ L Kunsy. Prodr. Algenfl. Böhm. p. 203.

d 89 - Toni syll. alg. p. 1059.

d 92 - Wolle Desm. U. S. ed. Il p. 103 t. 27 f. 13 \& 14. Cfr. Arthrodesmus subulatus.

\section{ovalis}

d 13 CONFERVA Hopkirk Flor. Glottiana p. 153. [Sec. Moore in Hare. Man. Br. Alg. p. $215=$ Cymbella Hopkirkii [= Clost. lanceolatum], sed vix ita sec. Ralfs Br. Desm. p. 164].

\section{ovalis}

d 93 CYLINDROCYSTIS (Cyclocystis) Turner Alg. Ind. orient. p. 16 t. 1 f. 5 . [0ocystis sp. sec. West in Journ. of Bot. 1895 p. 66].

\section{ovatum.}

d 70 D0CIDIUM Nordst. Desm. Brasil. p. 205 (sep. 167) t. 3 f. 37.

o 7 PLEUR0T ÆNIUM (Eupleurotanium) Nordst. Alg. brasil. p. 18.

d $79-$ (Docidium) v. glabra Cohn Desm. Bong. p. 265 (sep.p. 7 ) t. 11 f. 5.

m 80 - Norlst. De Alg. et Charac. 1 p. 1.

$\mathrm{m} 88$ - Nordst. Fr. wat. alg. N. Zeal. p. 65.

o Si Doc. Mask. Furtl. Note N. Z. Desm. p. 29.

d - v. tumidnm ibid. t. 6 f. 54.

d 89 Pleur. Toni syll, alg. p. $89 s$.

d 93 - Railey Contr. Queensl. Fl. p. 45 t. 15 f. 39 bis (e Norelst.).

n 93 Doc. (Oontidinm) Tumer Alg. Ind. orient. p. 39.

d $91-$ v. inermius Mub. Austral. Sïsswasseralg. I1 p. 339 t. 2 f. $18-19$.

- 95- - v. inermius Bailey Contrib. Queensl. F1. XI p. 39 t. $10 \mathrm{f.5}$ (e Möb.); et $a$ (cum nota a Th. L. Bancroft .

Cfr. Doc. dilatatnm Mask., non Cleve; Pleur. Schweinfurthii, Pleur. trnncatum? Gibl. 1874.

\section{Oxyaramthra}

d 59 STAURASTRUM Areh. Descript. in Dubl. N. H. Soc. 1). 200 t. 1 f. 1 et 2 ; in Nat. Hist. Rev. 6 p. 462 t. 33; in Q. Jour. Mier. Se. 8 p. 78 t. 7 f. $1-2$ ). 
A $61-4 \%$. in Pritch. Tuf. p. T12.

d 63 - liab. Kiypt. Fl. Sachs. p. 193.

1) bis-liab. Flor. Lur. Alm. 3 p.219 ("oxyacantlum").

1! $71-\beta$ bicorne Lumb. Desm. Snee. 1) 67.

o $7.2-$ Archer in (2. J. Micr. sic. $v .12$ p. s! (2-4 rad.).

d sis- - sibiricum Boldt Sibir. Chloroph. p. 119 t. f f. 41 .

o - - f. ibil., t.1i f. 41 .

d 5.5 - $\beta$ polyacantham Nordst. Desm. Grönl. p. 11 t. 7 f. 4.

d 87 -Cuole Brit. Desm. 1. 175 t. 60 f. 4.

ก 89 - Bürg. Biılr. Bolnlı. Desm. p. 147.

d s:1 - Tomi Srll. alı. p. 1219.

d. - r. bicorne ilid.

- r. polyacanthum ibid

- vibiricum ibid. p. 12-20.

uf $0-\beta$ polyacantlum Anderss, sverig. Chloroph, 1 p. 12.

m?1-Heimerl Desm. alpin. p.60\%.

in $42-W$ est Fr. w. Alg. W. Irel. p. 184.

m 94 - sibiricum Borge Sussw. Chlor. Archang. p. 39. m95 - - Eichler in Pamiet. Fizy. 13 p. 62.

m 95 - f. Borye sverig. Chlor. II p. 25 t. 1 f. 16.

Cfr. Staur. rostratum liac. et Sitaur. scorpioideum Delp.

\section{$0 . x \cdot y \cdot h y m+h \| m$}

d sf STAURASTRUM fioy \& Biss. Japan. Desm. 1).238 sep.p. it) t. 2 tis f. 6

d 89 - Toni syll. alg. p. 1146.

\section{OXYZOSML}

o 93 Turner Alg. Ind. orient. p. 144. Aubgen. Sphærososm.

\section{PACHYACISILII}

d 49 Nirg. einz. Alg. P. 126. Subgen. Phycastri.

d \&s IJans\%. Prodr. Algenfl. Bühm. p. 255. Sect. Staurastri.

\section{purhyremis}

d St ARTHRODESMUS Lagerh. Amerik. Desm. p. 244 t. 27 f. 23.

d 87 ... Wolle Fr. Alg. U. S. A. p. 36 t. 61 f. $13 \& 1 \pm[\mathrm{e}$ Lagerh.]. ("rachyceros").

d 89 - Tomi syll. alg. p. 1061.

d 5.2-Wolle Desm. U. S. ed. II p. 105 t. 10 f. 12-13.

\section{parhyllevma}

dzf 75 SCHIZOSP0RA lieinsch Contribut. p.si t. 17 f. 1. [Cylindrocystis? diplospora Lund. sec. Norlst. in Hedwigia 157 p. $\left.6 t^{\prime}\right]$.

\section{pachydermmm}

d 95 CLOSTERIUM West Alg. Madag. p. 46 t. 5 f. 37 .

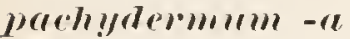

d 71 COSMARIUM $L$ umd. Desm. Suec, 1. 39 t. 2 f. 15.

d 73 - $\beta$ minus Nordst. Norg. Desm. p. 18 t. 1 f. 7 .

d 75 -Reinsch Contribut. p. 8? t. 9 f. 7 .

d $\mathrm{Ts}$ - Kirchn. Alg. Schles. p. 149.

d 7 - a typicum Klebs Desm. Ostpreuss. p. 34 t. 3 f. 34 ; 38 f. $3 s=$ f. transitoria Heim. 18!1]

d - b latum ibid.. t. 3 f. $39,40,49,4 ![3.1=$ f. transitoria Heim. 15! 1 ]

d sol $-\beta$ minus f. crassior Wille Norg. Ferskv. alg. I l) 33 t. 1 f. 20 .

d si - Wolle Desm. L. S. p. 71 t. 15 f. $2-4$.

m 8.i - Boldt Sibir. Cliloroph. p. 102.

o si-f. Lagerh. Amerik. Desm. p. 23?.

o 86 - Stokes Key Desn. p. 127.

d st - Coolip Brit. Desm. 1. 85 t. 37 f. 1 [e Lundell].

Sordstede, Index Ilesmid. d $87-v$ octodiformis Iste. Diagrt. plave in Notar. p. 237 (sep.p. 8) et

d $88--$ - Iste. Jel. magyar. alg. 1. 227 t. 1 f. 1!) [fig. jerploxa].

d ss - Mrinsy. Prodr. Algenfl. Inölım. p. 14s.

m SS - Rirbin. Chloroph. envir. Klharkow p.324.

o 89 - f. intermedia M"sk. Furth. Note N. Z. Desm. P. 15 t. 2 f. 1 s.

d 89 - Tomi syll. ale. p. 57.

ll - v. minus ibid.

d - r. crassius ibid.

d - v. latum ibirl.

d - v. octodiforme iloid.

in 90 - Gutw. Fl. Glon. Galic. 2 p. 13.

d 9 - $\beta$ hexagonum Gutw. Wahr. d. Priorität p.68.

m 90-Eichlor Spis Desm. Miedz. p.87 t. 5 f. 22.

$\mathrm{m}: 10$ - Anderss. Sverig. Chlor. 1 p. 15.

m 91 - Iste. Fragm. Alg. 1 p. 1168 .

m91-f. typica Heimerl Desm. alpin. p. 546.

-- f. transitoria ibid. (K/ebs 1874 f. 35 et 39 ) (transit. ad C. py $\mathbf{r}^{\circ}$ a midat $\left.11 \mathrm{~m}\right)$.

1191 URSINELLA huntze Rev. gen. pl. p. 925.

d 91 Cosm. $p$ hexagonum Gutu. Flor: alg. Leopol. p. 18 t. 1 f. 31

m 92 - Rirc. Desmidra Ciastoni. 1. 386.

d $92-$ Wollc Desm. T. S. ed. II p. 75 t. 18 f. $2-4$.

m .93 - Liitlemüll. Desm. Attersees 13. 5506 .

o 94 - ?. minus Iriory. F. alg. Ostgrönl. p. 24.

m $91-G u t u$. Fl. alg. Tarnapol. 1.88.

int - $\beta$ liexagonum ibid.

d 95 - f. Schmidle Beitl. alp. Alg. p. 390 t. 15 f. 16.

o $95-\mathrm{f}$. Schmille Alg. Sumatr. p. 308.

\section{parhyו'hymchmm.}

1 5 STAURASTRUM Nordst. Desm. aret. p. 32 t. 8 f. 34.

84 - Wolle in Bull. Torr. bot. Club, r, 11 t. 44 f. 32 35. [St. pseudopachyrhynchum].

m 85 - Boldt Sibir. Chloropl. p. 111.

o 88 -? f. Roldt Desm. Grönl. 1. 32 (sep.p.30) t. 2 f. 39 .

d 89 - Toni Syll. alg. p. 1185.

d $84-v$. convergens fícil. Now. Desm. p. 95 (sep.p. 26) t. 7 f. 1 t.

m $90-v$. conrergens Eichler Spis Desm. Miedz. p. 89 t. (3. 41 .

o 91 - v. convergens Heimerl Desm. alpin. p. f305.

m 91 - Borge Bidr. Sibir. Chloroph. p. 9 t. 1 f. 5.

и1 93 - (Spliericastrum) Tuner Alg. Ind. orieut. p. 133.

o 91-Bürg. F. alg. Ustgrönl. p. 24 t. 2 f. 19 et 20 (formae) inclus. Nt. Clepsyara f. Boldt 18s8).

\section{Parificum,}

a 5 COSMARIUM Johns. Rare Desm. U. S. Il p. $296 \mathrm{t}$. 240 f. 25 (cfr. C. inflatum).

\section{PAGETOPHILA}

11 83 Wittr. Snöns o, isens fl. p. 113.

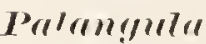

14 PENIUM Frél. in Dict. univ. hist. nat. v. 4 p. 513 Cylindrocystis Brebissonii Meneyh.

14 COSMARIUM Breil. ajnd Ralfs Brit. Desm. p. 212.

d 513 - Bréb. List. p. 132 t. 1 f. 21.

n 5s-(Calocylindrus) Te $B(t)$. Conjug. p. 72 t. 6 f. 5l.

d fil-Arrlo in Pritch. Inf. 1) 785.

di3-Kab. Kiryt. Fl. sachs. 1\% 202.

ก $f \overline{-}$ - Not. Desm. Ital. p. 11 t. 3 f. 24.

$169-T i a b$. Flor. Eur. Alg. 3 p. 174.

(1) - a. genuinum ibid. 1\% 175 . 
d - b. De Baryi ihil. Do Bary l. c.) [Dysphinctium lhe Baryi lleimerl 1s:11].

d - c. Notarisii (Not. 1. c.).

m $78-$ Nordst. Alg. saulvic. p. 13.

1. TA CALOCYLINDRUS hirchn. Alg. Siehles. 1. 143.

msocosm. $\beta$ De Bary i Wille Norg. Ferskr. alg. I p.37.

ms1 pen. (Sphinctopenium) $\beta$ We Baryi Gay Ion. loc. ('onj. p. II.

1 85 Cal. Kirchner Mikr. Pfan\%. d. Süssw. p.22.

plostcosm. Klebs Oryanisat. Gallerte b. Algen. 1.355 t. 1 i. 15.

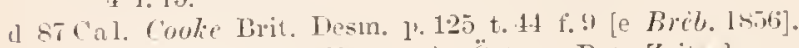

na 8 DISPHINCTIUM Hansg. in Österr. Bot. Zeitschr. v. 37 n:0 3 p.99.

d siti-Man:g. Prodr. Algent. Bühm. p.18t.

1 $-\beta$ De Baryi ibid. 1.15\%.

mascal. $\beta$ de Baryi Iste. Jel. magyar. alg. p. 22s.

d - v. rotundata jste. Jel. magyar. alg. P. 228 t. 1 f. $21-22$.

d 6 o Tisp. Tone syll. alg. 1\% 879.

(1) - v. De-Baryi ibid.

in 10 Cosm. Inders.s. Sverig. Chlor. 1 p.15.

m9n-Eichler sipis Desm. Miedz. p. sti.

d s1 C'a l. Kirchn. Mikr. Pftanz. d. Süssw. el. 2 p. 24.

un 41 ? Dys. Ileimer Desm. alp. p. 391.

1) - ? i. ibile et t, 5 f. 7 .

in 92 Consm. De-Baryi Hest Fr. W. Ale. W. Irel. p. 162. n 93 - Lïlliemiill. Iresm. Attersees p. 048.

in - v. We Baryi ibid. 1\% jt!.

m 45 - Schoider in 72 Jahr. schles. f. $\checkmark$ Cult. p. 35.

m 45-Rucib. in Flora v. 81 p. 33.

Cfr Cosm. Cucurbita.

\section{julmatr}

n sileterocarPELLA Brib. in Chev. Micr. p. 27.2. [Arthrodesmus octocornis lireb. List. p.130)].

\section{PALMOGLOEA}

d 13 Kütz. l'lyce. gener. 1) 166. [Descriptio mala].

d 45 kïtz. I'liyeol. germ. 1. 153 [sensu latior.].

d Is Tiecis. Alghe encent. p. lis.

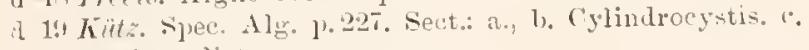
Ijimnolictron.

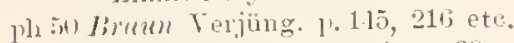

1) 51 Mariss. Catal. esp. omis. p.39.

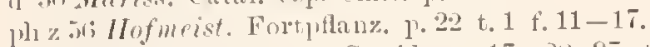

phat llichs Developm. Gonid. P. 17-241, 97 t. 2 f. $12-$ 1.1. 17.

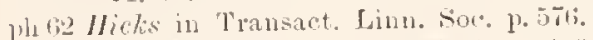

1) fil Arch. Descript. in Q. J. M. Ne. 1. 1199; in Dubl. Nat. Hist. Foc. 1\%. 12.

1) til Mickir in 12. .5. .1. Se. p. 2533.

o bi, Jlicks in Pop. Sie. Rev. v. 4 p. 311 t.11 f. 11.

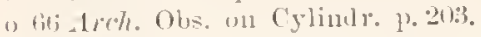

\% tit livinsch Algenft Frank. p. 2112.

a tis Rab. Fl. Eur. Alg. lo. Lli.

d $7311 \%$ ood Fr. Alg. 1. 1115 .

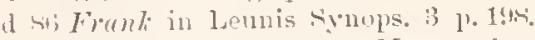

hth sll Mansy. Einzell. Bill. Moosvork. p. 249 (sep.p. 9).

d ss /lumsg. Prodr. Algenfl. Böln. 11. 173. Sect. Mesotrenii.

d (10) Lanowry in Baill. Dict, bot. II 1.502.

\section{P.I L HOCLOEITES}

d hisfiopert Algenart. Einselnl. in Dianant. in Able.

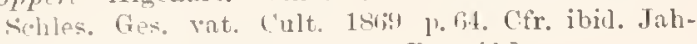
resh. 1stit 1\%.3:\%. [Certe nulla Desmill.]

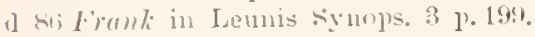

julustre

๑ 93 Cosmarium Turme Alg. Ind. orient. p. 60. Cosm. obsoletum anct, nou H(untzsch) Reinsch. nec Lauldell).

m - " circulare f. major ihid. 1.61 t. 8 f. 65 . f. minor t. 9 f. $2 \mathrm{~g}$. m- - Fovale ibid.; t $9 \mathrm{f}$. $t$.

\section{jumdurums}

4 67 PENIUM Tot. Desm. Ital. p. 70 t. 8 f. 80 .

o 5 - ? Ifucols. Desm. Danem. p. 163.

11 89 - Toni syll. Alळ. p. 858 .

Cfo. I'en. margaritaceam c. Cylindrus ḱlebs 167.?

\section{pundurutum-}

d 7 COSMARIUM Delponte Desniil. subalp. p.15 (sep.p. 111) t. 9 f. 1 .

d 89 - Toni ryll. alg. 1.9\%5.

n 91 URSINELLA huntze Rev. gen. pl. p. 125.

\section{punduriforme}

d 93 COSMARIUM Tumer $1 \mathrm{gg}$. Ind. orient. p. 4 ! t. 9 f. 3.

\section{pumirmlosum}

a sis STAURASTRUM Wolle in Bull. "Torr. lot. Club 1893 p. 1 is t. 27 f. 3.

d st - Holle Desm. U. s. 11. 124 t. 11 f. 39-411.

o sij-Stukes Key Desm. 1. 16.

d sit - Toni syll. alg. p. 11st.

d!2-Wolle Desm. U. \&. el. II p. 137 t. 52 f. $39 \ldots 4$ ! .

\section{Hensum}

a 93 STAURASTRUM Turner Alg. Ind. orient, p. $117 \mathrm{t}$. 13 f. 3:?

\section{Provilin}

d 37 CoSMARIUM Mencyh. Consp. ale. Engan. sep.p.1A. [Quid est? Descriptio nimis brevis! - Cosm. granatum: sec. Iiulfs].

(1) to Wenegh. Symops. Desm. p. 2.23 (sep.]?.23).

1 4h-liulfs Brit. Desm. 17.212.

1) ty EUASTRUM ?) Kït: spee. Alg. p. 17t.

1 52 Cosm. Pritch. Infus. p. 255.

1] 61 - Areh, in Pritel. Inf. 1) 732.

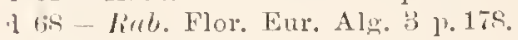

d ss - Tomi et Leei Fl. Aly. Venez. p. 52.

a 89 - Tomi sroll. alg. p. 1155.

11 91 URSINELLA himtäe Rev. gen. pl. 1). [2.

\section{Papilio}

1) 45 EUASTRUM liarib. Nom. Desm. Polon. 1.95 t. 13 f. 9 (sep.l 39 t. 1) [non hiitz.].

d so - Toni sivll. alg. 1. 116 .

n 1 HELIERELLA Kuntze Rev. gen. pl. p. sis.

\section{pal)illiferele - $11 m$}

dzf Is MICRASTERIAS Brib. in liulfs Brit. Desm. p. i2 t.? f. 1 .

dz $52-$ rritch. Inf. p. 215.

dzf ri1 - - rech. in l'ritel. Inf'. 1. T26 t. 1 f. 18-19 [e Rulfs].

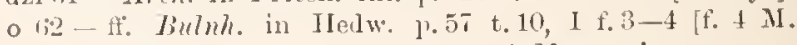
conferta sec. laum.; f. 3 al M. speciosam recedens].

(1) (ii) - Linb. Frypt. Fl. Sachs p. 182.

o lï DIDYMIDIUM (Micrasterias) Iicinsch Algenfl. Frank. 1\% 1.66.

o bi Mlirr. Wot. Desm. Ital. 1).31 t. 2 f.s.

d 6 - Lub. Flor. Eur. Alg. 3 p. 19l.

a 73 - Wood Fr. Alg. 1\% 1.th.

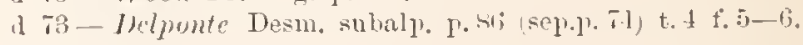


7. 1 - Arch. in Q. I. M. S. p. 213 .

dz is - Kirchn. Alg. Schles. 1. $16: 3$.

a x.2- $\beta$ glabra Nordst. in Wittr. et Norlst. Alg. exs. 11:0 4 tili; et $(18,0,1)$ in fasc. 21 1. 33.

83 - Twmer Alga Stronsall f., 2.2.

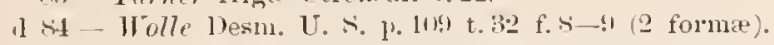

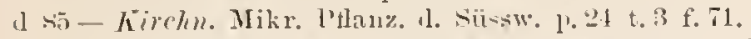

d sis-v. Novm-Scotix Tumer New rave Desm. p.937 t. 15 to 16 .

d sto-Frank: in Leunis syops. 3 p. 16t.

o sti-Stokes key Desm. p. 11s.

- - v. Nova seotial ibid.

dz 81 ; - Cooke Brit. Desur. p. 601 t. 27 f. 2 [d et e e halfs].

o $8 \overline{-}$ - $\beta$ evoluta Norelst. Algrolog. snits. 1 p. 155.

d 87 -Alexentio Chlorosp. Klark. 1.2.tr.

d 48 - Mansy. Prodr. Algenfl. Böhm. P. 210.

o Si-Rerunett Fr. wat. Alg. Engl. Lake Distr. 2 p. 5.

o . . S-IJcilen Beitr. Alg. Mecklenb. p. 10.

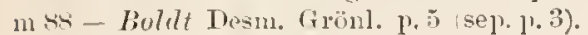

d wa - $\beta$ evoluta Nomlst. Fr. Wat. alg. N. Zeal. p. 29 t. 2. f. 14.

o sı- Börg. Bidr. Bornl. Desm. p. 142.

dz S! - Toni syll. alg. 1. 1132.

d -r. Norke-Scotice ibid.

d - v.evoluta ibid.

d - r. gla bra ibil.

m 90 - Eirhter Sipis Desm. Miedz. ]. \&!.

$\mathrm{m}$ :0-Auders. siverig. Clilor. 1 p.

d 91-Kirchn. Mikr. Iflanz. d. Süssw. ed. 2 p. 2 t t. 3 f. SH

n1 91 - Heimerl Desm. alpin. p. 603.

n 9l HELIERELLA huntze Rev. gen. pl. p. 8,1,.

m 9.2 Micr. Borge Chloroph. Norkk. Fimmark, p.6.

m ! 1 - Wrest Fr. W. Alg. W. luel. p.135.

d - v. glabra f. inflata ibid., t. 20 f. 10 [M. denticulata f. notata minor?].

d (12- Wolle Desm. U. A. el. II p. 120 t. 34 f. 8 et 9.

m 93 - Lïlliemïll. Desm. Attersees 1. 563.

o !13- v. varvicensis Turner Desm. Notes 1.345, et f. 13 1.31..

m 94 - $\beta$ glabra liorge süssw. Chlor. Arehang. p. 35.

d $96-$ r. verrucosa Schmille Beitr. alp. Alg. p. 23 c. fig. (se].p, 29). Cfr. Micr. Berthold 1ssti.

\section{parillosilu}

d 95 SPONDYLOSIUM W'est Aly. Madag. 1. 13 t. 9 f. 19.

\section{p(1)illosmm}

d is STAURASTRUM Kirchn. sichles. Alg. p.170.

m Si - Boldt sibir. Chloroph. p. 114 t. 5 f. 23.

m ss- Nordst. Borul. Desm. p. 206.

d 89 - Toni syll. alg. p. 1198.

m (x) - lichler spis Desm. Miedz. p. 90.

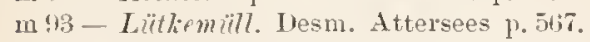

m 93 - f. Thmer Alg. Ind. orient, p. 112 t. 13 fo. 18.

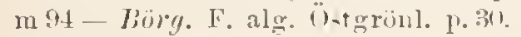

\section{p(1)}

d 45 EUASTRUM Kätz. I'hye. germ. p. 13i [E. gemmatum sec. Ijieb. et livlfs in Ralfs Brit. Tesm. p. 88].

d $49-$ Kittz. spec. Alg. P. 172 "E. verrucosum" Ralf: 1811, [Descri]tio nimis brevis].

\section{merudo.re}

d 33 MICRASTERIAS hït. Syn. Diat. p. 60 (sep.p. 72 ) t. $1 !$ f. $8 ! 1=$ crystalli sec. Kütz. Phyc. gener.

Cfr Stanrastrum Knetzingii khenb.

\author{
lurerlo.rmm-r \\ laf so CLOSTERIUM Wille Norg. Ferskv. alg. I p.56 t. \\ 2 f. 3 . \\ dz 89 - 7oni ky.ll. Alg. p. 840. \\ n !1 ARTHRODIA Kinutze Rer. gen. 11. 1\% 884.
}

\section{melertormm}

1) 93 COSMARIUM Twmer Alg. Ind. orient. p. 64 t.9 f. 22.

\section{maracto.rmm}

d !3 EUASTRUM Turner Alg. Ind, orient. p. $8 * 3$ t. 14 f. 4.

\section{Jureclo.xum}

d 29STAURASTRUM Meyen in Nov. act. p. 76 t. $13 \mathrm{f}$. $3 \overline{-}-3 R$. [Descript, et figig. nalde].

o 34 - Ehrub. Or.gan. kl. Raum. p. 314 (sep.p. 170).

o 35- Neyen in Wiegm. Arch. 1835 p. 24.

d 38 - Ehrenb. Inf. p. 143 t. 10 f. XIV (Micr. tetracera et $\beta$ didicera, M. tricera, M. Stanrastrum hütz.).

m 39 - Ehrenb. Meteorp. p. 56 sep.p. 12) t. 1 f. 23 [St. totracer.].

1) 4h-Menegh. iyn. Desm. p. 22T (sep.p. 27).

d 11 - Pritch. Inf. p. 185 f. 112 et 103 [ex Ehrenb. - n. v.].

a $45-$ Rerlfs in Anu. Nat. Hist. v. 15 p. 151 t. 10 f. 2 (et 1846 in Transact. Bot. Soc. Edinb. 1. 136 t. 13).

o 43 - Knitz. Phycol. gener. 1) 163.

1) 45 GONIOCYSTIS (Staur.) Hess. Brit, Alg. 11, 35 t t 85 f. 3 [e livelfs].

11 t5 PHYCASTRUM Kütz. Plyycol. germ. P. 135.

d t7 staur. Riab. Deut. Frypt. Fl. 155.

d 48 - Ralfs Brit. Desm. p. 138 t. 23 f. 8 .

1) 49 Pycastıum kïtz. Spec. Alg. p.180 [St. tetrace$\mathrm{r} n \mathrm{~m}]$.

n $4 !$ - (Stenactinium) Ney. einz. Alg. p. 128.

1) 50 - Marissal Catal, espec. nmis. p. 35.

d $52 \mathrm{Staur}$ Pritch. Inf. p. 266 t. 2 f. 102 et 103 [ex $\boldsymbol{E} h$ renb.].

d 53 Phycantrum Math. Fl. Belg. II p.528.

54 staur. Ekronb. Microgeol. t. 34 f. XII. 16 (e Meteorp.).

d fil-Arch. in Pritch. Inf. p. 742.

d 63 - liab. Krypt. Fl. Sachs. p. 1:1.

m 67 DIDYMIDIUM (Sta ur.) Teimsch Algenfl. Frank. p. 164.

d $-\mathrm{tr}$. $A$, tetracerum a cruciforme, $\beta$ alternans, $B$. trigouum, C. tetragonum. D. mixtum ibid. p. 163.

d 6s staur. Rab. Flor. Eur. Alg. 3 p. 210.

d -1 , tetracerum ibid. (Staur. tetrac.)

d $73-\beta$ longipes Nordst. Norg. Desm. p. 35 t. 1 f. 17. [Cfr. A Nele in Journ. of Bot. 1874 1.92].

a 73 - Wood Fr. Alg. p. 152 t. 21 f. 20 et 21 b.

$74-$ Gibbons in Trans. R. Soc. Victoria $\mathrm{X}$ in fig. photogr. 2 et 5 .

1 77 -Delponte Desmid. subalp. p. 5ij (sep.p. 152) t. 11 f. $63-65$.

d Ts-Kirchm. Alg. Schles. p. 1tit.

81 - r. longipes Cooke in Quekett Micr. J. 6 t. $15 \mathrm{f}$. $16-17$.

d 81 - Wolle Thesm. U. S. p. 129 t. 12 f. 36-37.

o 4 - - . parvalum Seleroter N. Beitr. Alg. Schles. p. 182.

d 85 - $\beta$ fu-iforme Bolst sibir. Chloroph. p, 11 s t. f; f. 37 .

o 85 - $r$. Osceolense Tolle in Bull. Torr. bot. Club r. 12 1. 128 t. 51 f. S-?.

o sit-Stoles Key Desm. p. 160; et r. Osceolense.

o si - v. Osceolense Wolle Fr. Alig. U.S. A. p.45t t.59 l is is [ex 1\%olle 1885].

ma - B. longipes f. minor Iste. Diagn. prinv. p. 24u (app.1. 11: 


\section{PARADOXUM}

d 87 - Cooke Brit. Desm. p. 171 t. 59 f. 4 [e Ralfs?]. o - P longipes ibid.: f. 5 .

d ss - Toni et Jcri Fl. Alg. Venez. p. 45.

m 88 - Risbin. Cliloroph, env. Kharkow p. 330.

m 88 - $\beta$ longipes fo minor Ist v. Jel, magyar. alg. p. 235.

088 - f. Norlst. Fr. wat. alg. N. Zeal. p.38 t. \pm f. 10.

o - f. ibid. f. 11.

d 89 - Toni syll. alg. 1. 1211.

d - v. fusiforme ibil.

d - v. longipes ibid. p.1212.

d $-\mathrm{v}$ osceolense ibid.

o $90-\nabla .10 n g i p e s$ West Fr. w. Alg. North Wales p. -291.

m 40 - Eirhl His Desm. Miedz, p. 90 (f. biradiata).

o 91 - f. minutissima Heimerl Desm. alpin. p. 607.

m 92 - f. parva West $F_{1}$. w. Alg. W. Irel. p. 182 t. 23 f. 12.

( - v. nodnlosum ibid., t. 23 f. 13.

d 92 - Wolle Desm. U. S. ed. II p. 143 t. 58 f. $36-3 \overline{6}$.

a - r. Osceolense ibid. t. ti f.s-9.

m93-f. minutissimum Lïtkemäll. Desm. Attersees p. 36,8 .

m 93 - Tumer Alg. Ind, orient. p. 125 t. $15 \mathrm{f} .4$ a. b, d. e.

dzf $-\beta$ longipes ibid.; t. 15 f. 4 c et $f$.

- - $\gamma$, depressum ibid.; t. 15 f. 5 .

z 63 - Tion Scottish Desm. p. 241.

- 90 - Mobius in Herwigia 34 p. 178 t. 2 f. 14.

m $96-f$. minutissima Schmidle Beitr. alp. Alg. p. his (sep.p. 36 ) et, 1895, t. $11 ;$ f. 16 .

$\mathrm{m}$

- f. ibid.

Cfr. Eustr. n:o 13 Bailey Amer. Bacill. 1. 29i; sep.p. 15 ) ex p.? t. 3 f. 2 et 3.

\section{Jurceloxum}

d 73 XANTHIDIASTRUM Delyonte Desmid. subalp. 1. 81 (sep.1. 65) t. 3 f. 27 -33. [Onychonema læve sec. Ticm. 1863].

n 85 ONYCHONEMA Hans\%. Prodr. Algenfi. Böhn. p. 171 in nota.

a 89 - Tomi Syll. Alg. p. $79 \overline{\text { f }}$.

\section{1)}

d 4) TRICERAS Lubnrew Diat. Ostk. Arriat. Meer p. 273 t. 5 f. 3 a. b. [Fpongia?].

\section{parallelum}

d 95 PLEUR0T歪NIUM Test Alg. Madag. p.45 t.5 f. 34 .

\section{prercesitirlem}

d 37? CLOSTERIUM Menegh. Consp. alg. Eugan. p.335 sep 1.17). QQuid est? Characium sp.? - "primor. hia Confervæ sistit" Meneyh. šsn. Desm. p. 237].

\section{$\mu(1) \times m$}

d st STAURASTRUM Hille sylamerik. Alght. p. 20 t. 1 1. 4 .

1 8 - Toui syll. alg. p. 114 .

\section{Prevelalis}

d i) COSMARIUM Cuhu Desm. Bong. p. 267 (sep.p.9) t.

11 t.. 8.

11 Si - f. minor Jush. Burm. Desm. p. tits t. 24 f. 20.

$\mathrm{m}$ si - f. major Lagerh. Amerik. Desm. 1).236 [C. latum fi margaritatam Lund. sec. Lagerh. 1885!].

d si - Wolle Fr. Alg. U. S. A. p. 31 t.64 f.3-5 (e Cohu).

a s!! - Tomi syll. alg. p. 1183.

1191 URSINELLA Kuntze Rev, gen. pl. p. 925.

ozfol Cosur. West Freshw. alg. Maine II p. 35.5 t. 31\% f. 10 .

d 92 - Wolle Desm. U. S. ed. II p. 83 t. th f.3-5.

\section{urrevla}

d 62 SPIR0T开NIA 1reh. New. Cosm. (sep.p. 16), in Dubl. Nat. Hist. Soc. I'r. p. $\$ 1$ t. 2 f. $32-43$, in .Jour. Micr. Sic. r. 251 t. 12.

o 60 - Arch. in Q. J. I. Ric. v, 6 p. 191.

d Gs - Rab. Flor. Eur. Alg. 3 p. 147.

m 71 - Lund. Desm. Snec. 1. 91.

d sfi-Coole Brit. Desn. 1.51 t. 1s f. 5.

d si - Toni Syll. Aler. p. sos.

m 93 - Liatlicmäll. Desm. Attersees p.540.

o 95 - Lütiemüll. Gatt. Spirotæn. p.5t (sep.p. 11). Cfr. Spir. closteridia v. elongata.

\section{nurulum -}

(1) 4i) CLOSTERIUM Noy. einz. Alg. p. 106 t. if C f. 2.

z ph 57-De Inryy Copulationsproc. in Pfanz. p.333.

z ph 57 - De Bury in Bot. Zeit. 1\%. 765 .

ph zf 58 - De Briry Conjug. 1. 11. 42, 44-51 t.5 f. $14-23$.

d 13 - liub. Kry

d 6.8-Rub. Flol. Eur. Alg. 3 p. 134.

ozfig - Millard in Mémoir. Strasb. p. 35 t. 1 f. 1-16.

d 73 - Hood Fr. 1 le. 11.115 t. 12 f. 5 .

n $7 T$ - I'etit Desm. de Paris p. 5 (sep.p. 2S\%

m 7 -f. minor Torlst. Als. sandvic. p. 10 t. 1 f. 8 .

a is - Kirchn. Alg. Sehles. p. 141.

ก T. - f. Wille Ferskv, alg. Nov, Semij. 1. 60 t. 14 f. 84.

ph 82 -Falkenb. in rehenk Handb. d. Iot. p. $25 s$ f. 22 T-VII lex the Bar. 1850].

o $\$ 3$ - Cybulski Mater. alg. Warszaw. p. 12.

dzf 84 - Wolle Desm. [. S. p. 45 t. T f. T. t. 8 f. 1 i.

m st-Lopot Mater. alg. Warszaw p. 253.

m 81 - Arteri Liste alg. Moscon p. 139.

o 81 - Acheson in Procel. Canal Instit. ‥ s. I p. $\$ 17$.

d 85 - Kireln. Mikr. Ptanz. d. Sïssw. p. 21.

m 85 - Boldt Sibir. Chlmoph. p. 123.

0 sti - Stokes key lesm. 1. 113.

1 si - Alexento Chlorosp. Khark. p. 22s.

d ss - Hansy. Proll. Algent. Böhm. p. 18*.

m s. - Riabin. Chloroph. env. Tharkow. p.316 (sep.p. 28).

s - Iiollt D ssm. Grönl. p. 42.

mst - Iste. Tel. magyar. alg. p. 24!.

n 88 - Lewin span. Siissw.-aler. p. 10.

1] 4 - Tomi syll. Als. p. $4 \$ 1$.

o 10 - f. minor Reinsch Nüsswasseralg. Süd Georg. 1'. 358 (sep.p. 25 t. 2 f. 10.

$m$ ! 10 - Eichter Spis Wesm. Miedz. p, s6 tos f. 11 [?]

n (4) - Anderss. Niverig. Chlor. $1 \mathrm{p.} 18$.

d 91 - Kirchen. Mikr. Iflanz. d. Süssw. ed. 2 p. 23.

n!1- Keimer Desm. al pin. 1.593 (incl. Cl. Venas.

ms - Borge Bidr. sibir. Chloroph. p. 14.

in 11 ARTHRODIA Kuntźe Rer. gen. pl. p.s81.

m 42 Clost. Borge Chloroph. Norsk. Finmark. P.1.1.

m 1 - Mub. Austral. Süsswasseralg. 1. 411.

o 32 - f. Rac. Desmitya Ciastoni p. 362 t. if f. 35 .

dzf 92 - Wolle Desm. U. ‥ ed. II p. 4 t.s f. T. t.9 f. 16.

m 53 - Briley Contr. Qneensl. Fl. 1'4?.

m 93 -- Lïtlemaill. Desm. Attersees p. 543.

o 51 -f. Dorge Süssw. Chlor. Archang. p. 16 t. 1 f. 8 .

dzf 94 - Smund. in Fl. Neluaska p.38 t.5 f. 8 [ex 1 olle].

o 95 - f. Selemille Alg. Sumatr. p. 299 t. 4 f. 1.

Cfr. Clost. moniliferam f. Feinsch 1867. Vibrio sp. Boeck Naturw. Obs. p. B1 f. 2?

\section{prevelum - $\ell$}

d Fi Cosmarium Pril. Liste p. 133 t. 1 f. 18.

d 61 - Arch. in Pritch. Inf. p. 735.

a bs-Rab. Flor. Eur. Alg. 3 p. 177. 
o To-Nordst. Desn. Brasil. p. 215.

d $71-L u n d$. Desm. Suec. p. 50; forma.

d 75 -f. Norlst. Desm. aret. 1. 27 t. 7 f. 21.

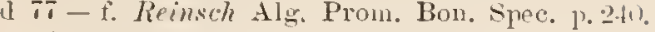

m 78 - Nordst. Alg. sandvic. p. 13.

o 79 - Wille Ferskv. alg. Nov. Semlj. p. 3! t. 12 t. 21\%.

m 81 - rray Mon. loc. Conj. p. 72.

I st - Wolle Desn. U. S. p. is t. Is f. 12-13.

ma k Lagerh. Amerik. Desm. 1' 241.

o -6 - Stokes Ley Desm. p. 1:26.

d 87 - Cooke Brit. Desin. p. 120 t. 13 f.. .

mss-Boldt Lesin. Grönl. 1) 11

o $\quad \ldots$ f. ibil.

$m$ - f. ibid. (f. Nordst. 1575.

त si - Toni sivll. alg. p.95s.

n 11 URSINELLA Fintze Rev. gen. pl. p. 19:.

m 12 Cosm. Hansg. Beitr. Alg. Bact. Tirol. u. Buhm. p. 1:32. d 12 - Wulle Desm. U. s. ed. II p. bt t. 21 f. 12-13.

m. 94 - Rorge siissw. Chlor. Areliang. p. 22 .

d 95 DYSPHINCTIUM v. undulatam Schmidle Beitr. alp. Alg. 1.34h (sep.1. 15) t. 15 t. T. [An Corm, auceps t. crispula].

Cfi. Pen. crassiusculum Cyb. 1 S83.

\section{$1101 \% 1111$}

d 93 D0CIDIUAI Thrner $A l g$. Ind. orient p. 3f t. \pm f. 1 .

\section{patems}

d 13 STAURASTRUH Tumer Alg. Inl. orient. p.108 t. $1+\mathrm{t}, 21$.

\section{prucideutatum}

d s9 STAURASRTUM Lemaire in Bull. d séance soc. sc. Nancy 1 11:0 ?2 p. 17.

d 40 - Lemaire in Bull. Sors. sc. Nincy v. 10 p. 33 sep.p. i) t. 1 f. 3 .

\section{Pauleuse}

d co COSMARIUM IBorg. Desm. Brasil. 1, 3: t. 4 f. 30 .

\section{Paulense}

- 95 Cosmarium Johns. Rare liesm. U. \&. II p. $29: 3$ t. 240) f. 17 (C. polymorphum subsp. l'aulense Borg.

Prellense non Borg. 1.'M!

a gi EUASTRUH Büry. Desm. Iirnsil. 1.33 t. 3 f. 17.

\section{Pauleuse}

d anSTAURASTRUM Birg. Desm. Brasil. p. 11i t. 5 f. 17.

\section{paxillosullu}

d 93 DYSPHINCTIUN Tum Aly. Ind. orient. p. $13 \mathrm{t}$. 2.2 .5

\section{Perten}

d 32 EUASTRUM Ehrenb. Entw. d. Inf. 1. 82) [Descriptio nimis brevis: est Echinella oblouga Grex. 1833 sec. Ehrent. 1835].

d 38 - Ekenb. Inf. p. 16? t. 12 f.IT. Cosm. sinuosum ('orda) [Echinella oblonga Gree. 1s33].

d 11 - Pritch. Inf. p. 16k. [1, r.].

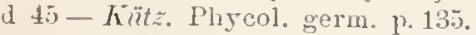

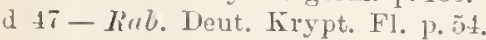

0.7 -Focke Pligs. stud. I p.4t. 14, (36. t. 1 f. 10. t. 2 f. siet 9.

d 49 - Kïtz. spec. Alg. p. 172.

o "1 HELIERELLA finntze Rev. gen. p]. p. s97. [Cfr. Hordst. in Hedwigia 1598 p. 150).

\section{Perten}

d 52 PHYCASTRUH (Amblyactinium) T'erty kleinst. Lebersf. P.2.10 t. 16, f. 32 [mala]. STtaur. echinatum b. Lial. 1869].

d St STAURASTRUM Wolle lesm. U. S. p. 141 t.4.j f. $35-31 \%$.

- 80 - stokes Rey Desn. p. 115.

d 92 - Wulle Desm. U. S. ed. II p. 15 is t. 36 f. 35 --36.

\section{pectillutum-re}

n 39 HETEROCARPELLA lirib. in Chov. Micr. ]). 27: [1]0men taitum!].

d 50 COSMARIUM Bréb. in Menegh. Synops. Deam. p. 222 (sep.p. 2.2).

dzf 48 EUASTRUM brèb. in lialfs Brit. Desm. 13. si t. 14 f. 5 a, b, $l . r, f$. (Eu. gemmatum lialfs 184t, non Breth.

a $-\beta$ ibil.; t. $5 c$.

d 49 - hintz. Spec. Alg. p. 17.2.

dzf $52-$ Pritch. Inf. p. 250 t. 13 f. 10 et 30 fe Tulfs 1. c.? dzf 131 - Areh. in I'ritch. Inf. p. 630 t. 2 t. 10 et 30 [e Rirlfs].

dzf 63 - hub. Krypt. Fl. Sachs. p. 186. f. xyl. 1) $155[\mathrm{e}$ Rullis].

o) (7 DIDYMIDIUM (Eucosminm) A. rotundatnm Reinsch Alventi. Frank. 1) 123.

d - B. Brebissonii $a$ et $\beta$ ibid.

o 67 En. Not. Desm. Ital. p. 3 t. 3 f. 15.

d 68 - Rub. Flor. Eux. Aler. 3 p. 19u, fig. xyl. 67 a p. 10 s [e Tiulfs].

o ibil. (Not. 1.867)

171 - f. Lund. Desm. Nizec. p. 17 t. 1 f. 9.

d 72 - $\beta$ brachylobum Witt. Gotl. Ö. sötv. Alg. p. 48 t. $4 \mathrm{f} 5$.

D 75 - f. depauperata .Facols. ]. 189 t. 7 f. 13.

d 78 - Kirchn. Alg. Schles, p. 160.

o $\mathrm{S} 4$ - f. Gay IIon. loc. Conj. p. 5 t t. 1 f. 12.

d $85-v$. Wolle Bull. Torr. Bot. Cluh. 12 p.t.

dzf 86 - Cooke Brit. Desm. p. i2 t. $3 \pm$ f. 5 [e Ralfs?].

si - v. Wolle Fr. Alg. U. S. A. p. 31 t. it f. $10-12$.

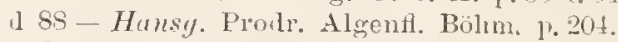

In 85 - f. typica lioldt Grönl. Desm. p.6 (sep.p. 4).

d - $t$ : intermedia ibid.. t. 1 f. 3.

d $-\beta$ lagenale ibid.. t. 1 f. 4 .

dz 89 - Toni syll. alg. P. 106s.

l) - v. brachylobum ibid.

1) - v. interinedium ibid. r. 1069.

d - v. lagenale ibid.

m 90 - Anderss. riverig. Chlor. 1 p. 111.

n "1 HELIERELLA Kuntze Rev. gen. pl. p. syc.

m zf $92 \mathrm{Eu}$. West Fr.w. Alg. W. 1rel. p. 13s t.2t f, 7 .

d $92-\mathrm{v}$. Wolle Desm. U. $\therefore$. ed. II p. 109 t. 12 f. 10-12.

\section{pertillatus}

(1) ARTHR0DESMUS Ehrend. Inf. 17.151 = Scenedesmus 1 .

\section{pertilloides}

d 7 COSMARIUM Wolle in Bull. Torr. bot. Club is p. 122.

o 81 - TVulle in Bull. Torr. bot. Club. v. 1 \%. 2 t. $4 \mathrm{f} .8$.

d 81 - Wulle Desm. U. S. p.si t. 19 f. $12-13$.

o sii-Stokes Key Desm. p. 124.

d 89 - Toni Syll. alg. p. 1029.

n 91 URSINELLA ("pectinodes") Kuntze Rev. gen. $\mathrm{pl}$ 1. 325.

d 92 Cosm. Wolle Desm. U. S. ed. II p. 96 t. 22 f. $12-1.3$.

\section{Pelta}

m $3 \pm$ COSMARIUM cordle in Alm. A. Carlsb. 1 s35 p. 205 
(sep.p. 121 t t. 2 f. 25 [Euastrun verracosum? sec. Ehronb. in Wiegn. Arch. 1836 p. 185. - Zygospora Mesotenii ? - Cfr. Staur. Capitulum Iialfs Br. Desm. t. 35 fig. 25 sec. Kuntze Rev. gen. pl. p. 923; verisimiliter non ita].

d 40 - Wenegh. Synops. Vesm. p. 222 (sep.p.22).

(1) 14 EUASTRUM Rialfs in Am. Nat. Hist. v. 14 p. $190 \mathrm{t}$. T f. 1 (et (1846) Trans. Bot. Soc. Edinb. T. 2 p. 126 t. 11) [F. crassum [r. appendiculatum Bréb.?'] sec. lialfs 18tin.

d 45 - Hass. Brit. Desm. p.380 t. 91 f. 3. [e Ralfs l. c. male].

d 45 - Kïtz. Phycol. germ. p. 13̄) ("E. verracosum Elirenb. quoal f. 3").

1) 49 - hialfs Brit. Desm. p. 211 (sensu (ord.).

1) 49 -- Kütz. Spec. Alg. p.173.

(1) 52 - Pritch. Inf. 1. 251 .

d 61 -Arch. in Pritch. Inf. p. 731.

r) 68 Cosm. Líal. Flor. Eur. Alg. 3 p. 178.

d 89 - Tomi Syll. alg. p. 1050.

1191 URSINELLA Funtze Rev. gen. pl. 1. 125.

\section{Penireen}

o 95 Ilacekel System. Pliylog. der Protist. u. Pflanz. p. 47. et 112 ("Peniaceen"). Fanil. Conjugatar. Gen.: Mesotanium. Penium, Cylindrocystis. Spirotenia.

\section{penivillutull}

n 43 XANTHIDIUM Ehrenl, in Bericht. Berlin. Akad. 1843 p. 62. [Fossile].

n 54-Ehrenb. Microgeol. t. 37 f. VIII. 3. [Spongia?].

\section{penioirles}

d 86 TETMEMORUS Bem. Fr.-w. Alg. Engl. Lake Distr. 1 p. 13 t. 2 f. 26.

o sf - Stokes Key Desm. p. 130.

d 86 - Cooke Brit. Desm. p. 5t) t. 19 f. 9. t. 26 f. 2 (e Bennett).

d Sel - Toni Syll. Alg. p. stos.

\section{PENIU M}

(1 44 Rreb. in Dict. miv. hist. nat. v. 4 p. 513 Cylindrocystis Meneyh.).

d ts Préb. apud Rialfs Brit. Desm. p. 148.

d 49 Kitz. Spec. Alg. P. 167 Sect.: 'Tetmemorus. Penium et Docidium

d 52 l'ritch. Inf. p. 272.

d 53 Mith. Fl. Belg. II p. 526.

(I) 58 t)e liar. Conjug. p. 50, 73.

d 58 ( $\mathrm{mm}$. Desmid. p. 492.

d 61 Arch. in Pritch. Inf. 1. 7201 et 500 .

\& 63 Grogn. I'lant. Crypt. p. 263.

d 63 Rab. Krypt. Fl. Sachs. p. 165.

d bit Groy Brit. Alg. p. 71 .

d 66 Eyrich Algentl. Manuh. p. 13:.

d 6 T Not. Desm. Ital. p. 2.2.

d fis Rub. Fl. Eur. Alg. : p p.11s.

d 11 Lund. Desm. Snec. p.st.

d 73 Helponte Desm. subalp. 39 (sep.p. 27

d 73 Wood Fr. Alg. p. 105.

4) 75 Microgr. Dict. p. 586.

o 75 Jaculs. Desm. Danem. p. 16it.

d 76 Delponte Desmid. subalp. 1. 7o (se1.1\% 175).

1 7 Frank in Leunis Sruops. p. 1633.

d to Firclin. Alg. Sehles. 1. 134.

o 79 hicles Desm. Ostpreuss. p. 21).

ph 93 Fischer Gypriryst. Desm. p. 165. d 83 ('ybulski Mater. alo. WVarszaw. p.260.

d 51 Gay Monogr. loc. Conjug. p.38: Sect. 1. Holopenium, 2. Sphinctopenium, 3 Tetmemorus. Et in Note Conj. d. 1n. France p. 338.

d 81 Wolle Desm. U. S. p. 33.

d 85 Framk in Leunis synops. 3 p. 198.

d 85 Kirchn. Mikr. Pflanz. d. Sïissw, p. 20.

o 86 Stokes Key Desm. 1) 110.

d $86 \mathrm{Fromk}$ in Lounis Symops. 3 p. 195.

d si (Yooke Brit. Desur. p. 38.

d 87 Alexenko Chlorosp. Kihark. p. 231.

d 88 Hansy. Prodr. Algenfl. Bölim. p. 175.

d 88 Toni et Leri Fl. Alg. Tenez. p. 40.

ph Se IIouptfl. Zellm. u. Hïllgallerte Desm. 10i) et 121 (sep. 1. 12 et 633 .

d S5Toni Syll. Alg. p. 855 .

d 90 Wille in Natïrl. Ptlanzenfam. p. 8.

d 91 Manowry in Baill. Dict. bot. III p.530.

d 91 Kinchn. Miks. PHanz. d. Süssw. ed. 2 p. 21.

ph thacharias in Verh. d. Ges. d. Naturf, ut. Aerzte Bremen 1890 II p. 122.

d 92 Wrolle Desm. U. S. ed. II p. 34.

d 93 Bailey Contr. Queensl. Fl. p.42.

o 93 Tumer Alg. Ind. orient. p. 18.

ph !3 Lrithemüler in Terh. Zool, bot. Ges. Wien 1 S9B Sitz. Bericht. p. 38 .

d $9+4$ Saund. in Fi. Nebraska p. 39.

ph 44 I'feiffer v. Wellheim in Pringsh. Jahrb. 26j p. 728 (sep.p. 55).

\section{Penillm}

m 67 CLOSTERIUM (Netrium) Reinsth Algenfl. Frank. p. 1st Penium closterioides Ralfs'.

\section{pentarhomalum}

d 90 CosmariUM Börg. Desm. Brasil. p. 39 t. 4 f. 31 .

\section{pentartariume.}

d s1 STAURASTRUM Wolle in Bull. Torr. bot. Club. 1881 p. 3 t. 6 f. 16.

d 84 - Wolle Desm. U. S. p. 130 t. 43 f. 15 . t. 14 f. 15-16.

o si -- Stukes Key Desm. p. 16iti.

(1) 89 - Tomi Syll. alg. p. 1230.

d 92 - Wolle Desm. U. S. ell. II p. 14 t. 54 f. 15. t. 55 f. $15-16$.

\section{pentanymlare}

m 34 EUASTRUM Corda in Alm. de Carlsb. 1835 p. 206 t. 3 f. 32 = Pediastrum.

\section{PENTASTERIAS}

d 36 Ehenb. in Abl. d. Berl. Ak. 1835 p. 173 [non the Bluime. 1834 in Dict. Se. Nat. LX, Eehinodermata, Asteridea].

d 40 Ehroul. Inf. p. 14.

d 43 Kïtz. Phye, gener. p.163.

d 45 Hlass. Brit. Alg. p. 355. Sect. Goniocystillis.

d 47 kab. Dent. Trivt. Fl. p. ali.

\section{peracerosum. -}

d 84 CLOSTERIUM Gay Mon. loc. Conj. 1\%.75 t. 2 f. 1s; et Note Conj. d. m. France p. 839.

d $89-T$ Th syll. Alg. p.825.

n 91 ARTHRODIA Kuntze Rev. gen. pl. p. Sat.

\section{neveyrinmm}

d 90 COSMARIUM Turner Alg. Ind. orient. p. 60 t. 8 f. 56. 


\section{perforitum -}

d il COSMARIUM Lund. Desm, suec. 1).40 t. 2 f. 1 li.

$8 \overline{3}$ - Wolle Bull. Torr. bot. C'ub. v. 12 t. 47 f.32.

m s5 - Boldt sibir. Cliloroph. p. 102.

1 si - Wolle Fr. Alg. U. S. A. p. 24 t. 37 f. 32 [ 11 olle 18.55 .

d ss - f. Boldt Desm. Grönl. 1\% 14 (sejp.p. 12) t. 1 i $1 \overline{7}$.

d 59 - Toni syll. aly. 1.9 9 T.

d $90-b$. porosum Gutw. Wahr. d. Priorität p. 6s.

m 90 - Eichler Spis Desm. Miedz. p. 88 t. 8 f. 24.

n 91 URSINELLA huntze Rer. gren. pl. p. 925.

m s1 Cosm. a. typicum Crulw. Flor. alg. Leopol. p. 1s.

d - b. porosum ibid et t. 1 f. 32 .

m 193 - Trest Fr.w. Alg. W. Irel. p. 114 .

d 92 - Wolle Desm. U. S. ed. II ].65 t. 49 f. 32.

m 93 - Lütliemuill. Desm. Attersees p. $55 \%$.

m 94 - Borge süssw. Chlor. Archang. 1. 25.

0 - f. ibid.

m 94-Alexenko Mater. alg. Kihark. p. 25.

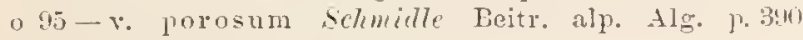
(sep.1. 19).

\section{pevirymatimm - a}

a 75 COSMARIUM Norlst. Desm. arct. p. 29 t. 7 f. 24 .

d 89 - Toni syll. alg. p. 1135.

o $\$ 9$ - Nordst. in Wittr. et Nordst. Alg. exs. sub. n:o 9sy.

n 91 URSINELLA huntze Rev. gen. pl. p. 92.\%.

o $95 \mathrm{Cosm}$. Johns. Rare Desm. [T. S. II 1. 29:3 t. 240 f. 28. m95 DYSPHINCTIUM sclemidle Beitr. alp. Alg. p 345 (sep.1. 14).

\section{perissum}

dzf 9. COSMOCLADIUM lio! et His.s sicott. Desm. p. 254. (sep.13.1;2) t. 2 (15.13i f. 11.

\section{perisosmum}

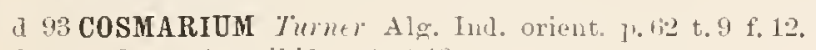
d $-\beta$ ornatum ibic; t il $\mathrm{f}$. 8 .

\section{perlace}

d 93 DOCIDIUM Turner Alg. Iud. orient. p. 27 t. 2 f. 1?.

\section{perpastum}

d 13 Cosmarium Timer Aig. Ind. mient p. 18 t. 7 f. 23.

\section{nerpusillum}

d 4. COSMARIUM West Fr. w. alg. Tr. Irel. p. $14 \mathrm{t}$ t. 21 f. 2.

[Cfr Borge in N. Notaris. 18,4 p.510].

\section{perplusillum}

d 1 EUASTRUM Gichl. et fiute. spec. alg. nov. p. 178 t. 5 f. 39 .

\section{personcturm}

d 95 EUASTRUM West Alg . Marag. P. 5.2 t. $1 ;$ f. 19.

\section{Pertyanum}

d s. COSMARIUM Racib. Nonn. Desm. Polon. $1 \%$. 7 sep. $]^{\text {. }}$ 21. Eu. crenatum Perty 185:; C. rrenatum $\beta$ subcrenatum Rial. 1868;. [C. dovrense sec. auct. $1 \neg 89]$.

o 89-Rucil. Nat. flor. glon. Polsk. p. 10t (sep.p. 2s;.

\section{Pertyi?}

o so STAURASTRUM Toni \& Leri in Notarisia 1 p.911
(Phyc, asperum Ierty 185. non Staur. asperum Breb.; verisimile Stanr. brachiatum var.).

\section{phacodermum.}

d S3 PLEUROT t. 1 f. 22.

d 8: - Toni Syll. alg. 1. 102 .

\section{Phaseolus.}

1) 39 HETEROCARPELLA Whit, in Chev. Micr. p. 272 (Achnanthes stomatomorpha).

d to CoSMARIUM Bréb. in Jenegh. Synops. Desm. p. 2:20 (sep.p.20) [Descript. mala].

d 18 - Kirlf's Brit. Desm. p. 106 t. 32 f.5.

d 49 - Kï̈z. spee. Alo. p. 176 .

d $52=$ Pritch. Inf. 1. 255 .

o jif-Brit. List. p. 131.

n 5s-(Microcosmarium) dr Bur. Conj. p. T.2.

d 61 - Areh. in Pritch. Inf. 1. 732.

d $63-$ Rab. Krypt. Fl. Sachs. p. 20?2.

d fis-Rob. Flor. Eur. Alg. 3 p. 160.

d 73 - $\beta$ elevatum Nordst. Norg. Desm. p. 17 t. 1 f. t.

n 75 - $\beta$ elevatum Tordst. Desm. aret. 1). 24.

d $75-$ Kirchu. Alg. Sichles. p. 153.

d 5 - a. typicum Klebs Lesm. Ostpreuss. 13. 35.

$$
\text { a }
$$

$-a^{1}$

$-\beta^{1}$ t. 3 f. 12.

$\beta \beta$ elevatuin Nordst.).

$-a^{1}$

$\beta^{2}$ t. 3 f. 41

- b. bioculatum ibid. (Cosm. bioculatum). a t. 3 f. 14.413.

(i) t. 3 f. 53 a et b. $\$ 7$.

m st EUASTRDM (Cosmarium) (ruy Mon. loc. Conj. P. 59 .

daf $8 \pm$ Cosm. Wolle Desm. U. S. p. 81 t. 18 t:.24-32.

o $84-\beta$ elevatum Wille sydamerik. Algtl. p. 31.

d 85 -- Kivelin. Mikr. Pflanz. d. Süssw. 13. 25.

m 85 - Boldt Sibir. Chloroph. p. 10?.

n - f. minor ibil.

in $-\beta$ elevatum ibid.

d -y achondrum ibid. 1.103 t. 5 f. 7.

m sij-Lagerl. Amerik. Desm. p. 239.

.1 86 - Frumk in Leunis Synops. 3 p. 196.

o S6-Stolies Kiey Desn. p. 129.

1 86 - Coole Brit. Desm. p. s8 t. 37 f. 3.

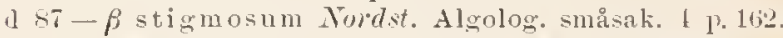

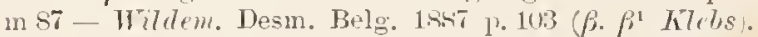

d $8 \mathrm{i}$ - Alecentio Chloroph. Fihark. p. 26 i.

1) ss-Hansg. Prodr. Algenfl. Böhm. p. 201.

d $-\beta$ elevatum ibid. p. 251.

inss-f. minor Boldt Desm. Grinl. p. 15.

m - $\beta$ elevatum ibid.

d Ss - Huwptf7. Zellm. u. Höllgallerte Desm. p. ST et 111 (sep.p. 29 et 53 . t. 2 f. $48-50,52-55,5 \overline{7}, 62,63$.

o 88 - f. Nordst. Desm. Bormin. 1.201, t. if f. 12-14 (C. bioculatun Bréb. ex 1.).

- $\beta$ elevatum ibil.

d — ̈ notatum ibid. t. 6 f. $4-11$.

dzf $88-\beta$ stigmosum Nordst. Fr. wat. alg. X. Zeal. p. 59 t. 3 f. 1. (C. tetraophthalmum $\beta$ Musk. 1843 ex 1. [Cfr Tumer Alg. Ind. orient p. 51$]$.

m 89 - f. minor lícil. Desm. Lituan. 1) Bril.

d 89 - Toni Syll. alg. p. 1001.

- v. elevatum ibil.

d - v. stigmosum ibid.

d -v. acliondrum ibid. p. 1002. 
d - subsp. notatum ibid.

d 89 - v. minus Lucib. Now. Desm. p. 43 t. 5 f. 5 (aus Botat?).

d - v. subbireme (subbiremum") ibic. p. 83 t. 5 f. 4. m 90 - v. minus Eichler Spis Desm. Miedz. p.si.

d $: 1$ - Kirchn. Mikr. Pfanz. d. Süssw. ed. 2 p. 26.

m 91 - West Add. Fresliw. Alg. W. York. p. 245.

1n 91 - Borge Bistr. Sibir. Chloroph. p. 13.

m - $-\beta$ aclondrum f. major ibid.

n 91 URSINELLA Tuntze Rer. gen. pl, p.925.

m 91 Cosm. Grutu. Flor. alg. Leopol. p.

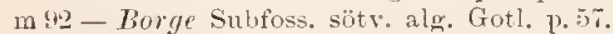

o $32-\mathrm{v}$. elevatum Schmidle Neue einz. Alg. p. 210 t. 11 f. 15 et 16 .

o - r. achondrum ibid.; f. 17 et 14 .

d w - f. punctulata Rac. Desmidya Ciastoni. 11.383 t. 1 f. 23 .

dzf 92 - Wolle Desm. U. ‥ ed. II p. s: t. 21 f. $2 .-32$.

m 12 - Gutu. Flor. glon. Galic. 3. p. 130.

n $4: 3$ - Bohlin sniralg. Pit. Lappm. p.4h.

un 13 - v. achond 1.um schmille Beitr. Alg. ichwar\%wald. p. 102 t. 5 f. 11.

o - v. elevatum ibid.; t. 5 f. 12.

m:3 - Gatw. Glon. staw. Zhruezu p. 29.

m.3-Turner Alg. Ind. orient. p. 73.

m 91-Böy. F. alg. Östgrönl. p. 1\%.

m - re elevata ibid.

o - v. achondra ibid., t. 1 f. 13.

d $94-v$, elevata f. maior Gute. Fl. alg. Tarmapol p. 65 t.3 f. 27 .

m $14-$ Alexemtio Mater. alg. Khark. p. 25.

m 95 - Eichler in Pamiet. Fizy. 13 p. 59.

o 95 - v. elevatum Gute. Prodr. At, alg. Galic. p.346 in nota.

m 15 - v, elevatum Schmille Beitr. alp. Alg. p. 156.

Cfr. Cosm. bioculatum vo omphalum; Cosm. Klebsii. Eu. depressnm Tog.

\section{Jhimels}

d !3 ARTHRODESMUS Twmer Alg. Ind. orient p. $136 \mathrm{t}$. 12 f.?

\section{PHICASTRUM}

d 4.5 Kïtz. Phycol. germ. p. 137 .

d 49 Kitz. spee. Alg. p. 178.

d 19 Nerg. ein\%, Alg. 1, 121. Subg. a. Amblyactinium p. 125. b. Pacluactiniun p. 126, c. Stenactinium 1). 128 .

d 50 Marissal Catal. esp. omis. 1', 35.

1 53 Mlath. Fl. Belor. II w. 525.

d 63 Grogn. Plant. Crypt. p. 262.

\section{PIITHATOUOCIS}

d $7 T$ Nordst. Alg. brasil p 18

d st Wolle Desm. U. S. 1. 28.

o so stokes lier l)esm. 1\%. 10.

d 89 c'arter in A. M. Mier. J. 10 1. T.

d 84 Toni syll. Alg. p. Tuts

d 10 thithe in Natiurl. Pflanzenfani. p. 14.

d y2 Wolle vesnu. U. r. ed. II p. 24.

\section{ph!molospolmm}

daf 76 PENIUM Nordst. Desm. Ital. p. 26 t. 12 f. 1.

an $79-\beta$ majus Nordst, in Wittr. et Nordst Alg exs. 11:0 265.

o $\$ 1$ - f. Wi7le Sydamerik. Algfl. 1. 48 t. 3 f. 9\%.

o 85 - .7osk. in Journ. of Bot. v. 23 p. 35 t. 254 f. 11. m 86--?f. Wille in Dijmphn. Togt. Udb. 1. 87 t. 13 f. 4.

daf 8 - Cooke Brit. Desm. p. 40 t. 17 f. 8.

dz 8 i - Joni siyll. Alg. 1.859.

m-v. majus ihid.

m 5 - Sclirïler Alg. H. Riesengeb. p. 16.

\section{lirtull}

1) 90 EUASTRUM Burg. Desm. brasil. p. 34 t. 3 f. 19.

\section{lilertum}

1 77 STAURASTRUM Jetponte Desmic. subalp. p. 71 (sep.p 167) t. 12 f. $36-38$.

d $89--$ v. inflatum Mask. Furth. Fote X. Z. Desm. p. 24 t. 1 f. 42

d $\delta^{\prime \prime}-$ Tomi syll. alg. p. 1163.

\section{pileigerum-re}

d 86 COSMARIUM Lager . Amerik. Desm. p 238 t. 27 f. 11.

1 89 - Toni Syll. alg. p. 997 .

n :1 URSINELLA Kuntze Rev. gen. p1. p. 425.

n 93 Cosm. (Teinidium) Tumer Alg. Jnd. orient. p. Tt. Cfr. pseudotaxichondrum tholle 188 .

\section{jileolutum}

d 48 STAURASTRUM Brèb. in Ralfs Brit. Desm. p. 215 t. 35 f. 22 .

d 52 - Iritel. Inf. p. 20 .

d 61 - Arch, in Pritch. Inf. P. 740.

1 68 - Lab. Flor. Eur. Alg. 3 p. 200.

o St - Schröter N. Beitr. Alg. Sehles, 1. 180.

d 87 - Cooke Brit. Desm. p. 160 t. 55 f. 1 [e Rulfs].

d 88 - Mansy. Prodr. Algenfl. Bohni. 1).211.

d 89 - Toni syll. alg. p. 1194.

d 93 - r. cristatum Lïtlemïll. Desm. Attersees p. 566 t. y f. 1 it.

$1193-(C y l i n d r i a s t r u m)$ Timer Aly. Inu. orient. P. 133.

z 93 - Roy Scottish Desm. p. 241. Cf1. Staur. amoenum $\beta$ brasiliense.

\section{pilo.ill}

d 82 GONATOZYGON Wolle in Bull. Torr, bot. Club 1882 P. 27 t. 13 f. 16

d 84 - Wolle Desm. U. S. 1. 22 t. 1 f. 2.

o 86 - Stokes Fiey Desm. r. 110.

d 89 - Toni syli. Alg. p. 803 .

m 90 - West Fr.w. Alg. North Wales p. 282.

d 91 - Wolle Desm. U. S. el. II p.20 t. 1 f. 2.

m93-f. minor Turner Alg. Int. orient. 1. 25 t. 20 f. 1.

$m$ - f. evolnta ibid., t. 20 f. 2.

\section{pilosum}

d 49 PHYCASTRUM (Amblyactinium) Neg. einz. Alg. i). 126 t. 8 A f. 4

d 5i STAURASTRUM Brob. list p. 141 t. 2 f. 4 ! [cum priori sec. auct. non identicum. Est. St, Brebissoni i Arch.]

d $61-A r c h$. in Pritch. Inf. 1. 73:1.

dzf 63 - Clere Bidr. t. Sverg. 1tesm. p. 490 t. 4 f. 3 [= St. Brebissonii].

dz 68 - Jiab. Flor. Eur. Alg. 3 7. 212.

d - h. Brebissonii (St. Brebissonii Arch.).

dzf 69 - Wittr. Skandin. Desm. W.17 t. 1 f. S.

m 75 - Nordst. Desm. aret. p. 31.

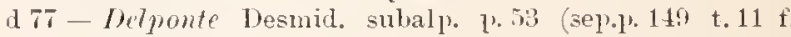
$24-30$.

m82 - f. minor Nurdst, in Wittr. et Nordst. Alg. exs. 11:0 169: et (188:1) in fasc. 21 13.37.

83 - Turner Algat strensall f. 11. 
mist-Fun Mon. loc. Conj. p. tis.

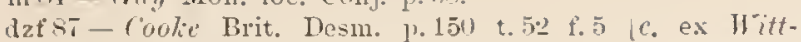
rock 18ti, ?].

dzs - Tomi syll. alg. p. 1160.

in $\$$ - Eichler spis Desm. Mieilz. 1. 90.

In (n) - Andevs. Nuerig. Chlor. 1 p. 12.

m 1 - Borge Bidr. Sibir. Chloroph. p. 10.

z.m 92 - West in Notaris. T p.1503.

m!93 - Lütlirmüll. Desm. Attersees 1).561.

m 44 - Iste. Adat. Roman. alg. p. 15 r.

mit - Buirg. F. alg. Östgrönl. 1.2T.

\section{lilosill}

n 36 XANTHIDIUM Ekrend. Berlin Monatsber. 1836 p. 114. [X. hirsutam sec. Ehrenb. [nf. ]\% 147].

nอ̆t-Ehtenb. Microgeol. t. 37 f. VIII 4.

\section{pingue -is}

d 81 EUASTRUM Elfe. Finsk. Desm. p. 7 t. 1 f. 3 [Cfr. Nordst. in Botan. Notis, 1st2 p.97. - Eu. Armstrougianum Arch. 1s९3].

d s- Wolle Desm. U. S. p. 105 t. 27 f. 1-3.

o sf-situlies Kiey Desm. p. 144.

d 89 -Toui syll. alg. p. 1098.

m "1 HELIERELLA Kuntze Rer. gen. pl. 1) s9!,

d $92 \mathrm{Eu}$. Wolle Desm. U. S. ed. II p. 116 t. $31 \mathrm{f} .1-3$.

d $94-r$. depauperatum Eichl. et Gutu. spec. alg. nor. 1). 172 t. 5 f. 34 .

\section{pinmatifiela -11 m}

d 45 EUASTRUM Kïts. Plycol. germ. p.131 Eu. n:o T Briley Amer. Bacill. 1811) t.3 f. 29 \%

d $4 \bar{\imath}-R a b$. Deut. Krypt. Fi. p. 54 .

d 48 MICRASTERIAS Ralfs Erit. Desm. p. 7 t. 10 f. 3.

d $19-h u ̈ t z$. spec. Alg. p. 171.

51 - Bail. Micr. Obs. t. 1 f. 12.

d $52-$ Pritch. Inf. p. 246.

$\mathrm{m} 5^{2}-I^{2} r$ ty Kleinst. Lebensf. p. $20 \mathrm{~s}$.

d 5:T TETRACHASTRUM Dixon On a new Genus (sep.p. 8 , in Nat, Hist. Rew. p. 4n-, in Micr. Journ p. 83.

d 61 - Areh. in Pritch Inf. p. 725 .

- 62 MI icr. Bulnh. in Hedw. p. 5 t t. 10 f. fi.

d $63-$ Rab. Krypt. Fl. Sachs. p. 1s4.

m67DIDYMIDIUM Micrasterias, Reinsch Algenf. Frank. P. 111 .

it Micr. Gibbons in Transact. F. Soe. Victoria $x$ in fig. fotogr. 2 .

81 - v. inflata Wulle in Torr. bot. Club. 8 t. 6 f. 5 M. oscitans $r$. inflata Wulle 1sib).

s1 - Elfe. Finsk. Desm. t. 1 f. 1 ("altera semicellula characteres M. pinnatifida. altera XI, iucisæ præbet").

d 84 - Wulle Desm. L. S. p.116 t. 37 f. T-S.

- $-v$. inflata ibid. f. 9.

n Si HOLOCYSTIS Beun. Fr. Alg. Engl. Lake Distr. 1 p.8. o S6 Iicr. Stokes Key Desm. p.117.

d 86 - (Tetrachastrum Cooke Brit. Desm. p. 54 t. 20 f. 3.

d Ss-Hruptfl. Zellm. u. Hüllgallerte Desm. p. 42 (sep.p. 31 t. 3 f. 4-6. T-9. 14, 16-1s.

o 48 - Worlst. Bornh. Desm. p. 18\%.

m sy - Rucib. Desm. Lituan. po 663.

d $59-r$. trigona West Freshw.-alg. Maine p. 206. t. 2ø1 (in Journ. of Bot.) f. 15.

$\mathrm{m}(0)$ - Bör\%. Desm. Brasil. p. \$1.

m90 - Eichler syis Desm. Miedz. p. so t.9 f. 36

m 90-Anderss. siverig. Chlor. 1 p. 9.

一 f. monstrosa ibid. t. 1 f. 2.

m91- Heimerl Desm. alpin. p.602.

m 91 - r. inflata West Freshw, alg. Maine II p. 354.

voristedt, Index lesmid. d - $r$ dirisa ibid, et t. 315 f. 8 .

o 92 -f. West Fr. w. Alg. W. Irel. p. 133 t. 20 f. 9.

d 92 - Wolle Desm. U. ․ ed. II p. 128 t. 41 t. 7 -s.

o - - v. infllata ibid., f. 9.

m93- Holocystis) "t typica Turner Alg. Ind. orient. p. ss t. 5 f. 3 a. et e. (f. et g. monstros.).

d - $\beta$ quadrata ibid. p. 8 t. 5 f. 3 b.

d - $y$ expausa ibid.; f. 3 c.

d - in inflata ibid.; f. 3 d.

o $94-J o h n s$. in Bot. Gaz. 19 ]. ¿s t. 6 f. $5-6$.

d $95-\mathrm{s}$. incudiformis Trest $A$ lg. Madag. p. 48 t. 6 f. 5 . Cfr. Eu. bifidum Focke; Eu. didymacanthum, Micr. Itzigsohuii, M. oscitans b. Rab. 1868.

\section{lilluatull -}

d 18 EUASTRUM Ralfs Brit. Desm. p. 81 t. 13 f. 1 .

d 52 - Pretch. Inf. p. $24 ! 9$

d 31 - Arch. in Pritch. Inf. 1. T2S.

d 65 - Rub. Flor. Eur. Alg. 3 p. 18?.

- 71 - Lund. Desm. Suec. p. 19, forma.

- 73 - f. scrobiculata Nordst. Norg. Desm. p. S.

d s1 - Wolle Desm. U. S. p. Is t. 28 f. $14-16$.

o 55 - a. typicum Racib. Nonu. Desm. Polon. p.93 (sep. 1. 35 ).

d - b. iutermediam ibid.. t. 13 (sep. 4) f. 1.

o S6-Stokes Key Desm. p. 145.

d sti-Cooke Brit. Desin. 13. 66 t. 32 f. 2 [verisimile e Ralfs.

m 88 - Racib. Mat. flor. glon. Polsk. p. 112

d S9-Toni Syll. alg. T. 1089.

d - r. intermedium ibid. p. 1090.

I 91 HELIERELLA Kuntze Rev. gell. pl. p. 899.

m $12 \mathrm{E}$ n. Thest Fr. w. Alg. W. Irel, p. 137.

d 92 - Irulle Desm. U. S. ed. II p. 107 t. 32 f. 14-16.

in 94 - Alexento Matel. alg. Iihark. p. 23.

\section{pimnatull}

d 9 STAURASTRUM Tumes Alg. Ind, orient, p. 115 t. 13 f. 27.

d - r. simplex ibid.; t. 13 f. 29.

\section{pisciforme}

d 93 STAURASTRUM Tume Alg. Ind. orient. p.118 t. 14 f. 7 .

\section{PITHISCUS}

d 45 Kütz. Phycol. germ. p. 129.

1) 49 Kïtz. Spec. Alg. p. 162.

\section{Pittarillm}

d 5 EUASTRUM Bréb. Liste p. 125 t. 1 f. 6.

d 61 ARTHRODESMUS Arch, in Pritch. Inf. p. 731.

d $68-R a b$. Flor. Eur. Alg. 3 p. 226.

d 89 - Toni s.jll. alg. p. 1060 .

\section{plaremen}

d 95 COSMARIUM West Alg. Madag. p. 59 t. 8 f. 9 .

\section{plutyrerum-a}

d 5 EUASTRUM Reinsch. Contribut. 1). 85 t. 12 f. 6 [Eu. gemmatum v. plat5cerum Wild. 1894].

d 84 - Toni syll. alg. p. 1083.

1191 HELIERELLA huntze Rer. gen. pl. p. 899.

I $93 \mathrm{Eu}$. v. pulchrum Turner Alg. Ind. orient. p. 75 t. 10 f. 11. [ = a sec. Wildem. 1s94?.

Cfr. Eu. bellnm r. italicum et Eu. breviceps. 


\section{platyrermul}

is is STAURASTRUM Josh. Burm. Desm. p. fit3 t. 24 f. 1 it 2. Annon forma kt. aspinosi Wolle 1sst?].

(1) \$:1 - Tomi syll. alg. 1) 1203.

\section{plethyisthmuln - "l}

dz 83 COSMARIUM Arch, in Amm, Mag. Nat. Hist. ser. 5 11:0 633 1. 215.

d $8 \overline{-}$-Cooke Brit. Desm. p.1si.

(1) 89 - Toni Syll. alg. p. 1034 .

1191 URSINELLA Kuntze Rev. gen. 1'1. 1.925.

\section{lilatypterre}

d Sf MICRASTERIAS Tumer Not. Freshw. Alg. p. 34 t. 1 f. 5 .

d S4-Toni syll. alg. p.1124.

11 91 HELIEREIIA Kuntze Rev. gen. 11. p. Sa!.

\section{PLETRENTERIIU}

d 71 Lund. Desm, snee, 1. 72. Subgen. Staurastri

d 9o Wille in Natiorl. Phanzenfam. 1. 11. Genus.

\section{PLEUROSICYOS}

o 34 Cordu in Alns. d. Car]sb. 1835 p. 178, 182. 209 [Penium lamellosum Breb.?]

14 Ehrenl, in Berl. Monatsber. 1840 p. 216 "Pleurosycios").

\section{PLEUIOTENIOHSIS}

d 71 Lund. Desm. Sinee. 11.51. Sect. Cosmarii.

1) si Layerheim Algol. Bidr. 2 p. 197. [Gemus tantmn in connexione cum specie.

d ss Hansy. Prodr. Algenfl. Bölım. 1. 245. Sect. Cosmaridii. d S! Toni Syll. alg. p.9ns et 906 (Sect. 1. En-Pleurotaniopsis Lumd.) P.906.2. Cosmaridium (Guy) p. 910).

d 90 Irille in Naturr. Ptianzenf. 1. 11.

d 93 Builey Contr. Queensl. Fl. p. 15.

ph 43 Lüthemiller Chlorophyllkorl. ein. Desm. p.t1.

d $4 \pm$ Saund. in Fl. Nebraska p. 40.

phot Wellheim in Pringsh. Jahrb. 20 p. 72 (sep.p. 5t).

\section{PLEUIOTENIUH}

d 4 ก Nay. einz. Alg. 1. 104.

is 5 t)e Berr. Conjug. p. 10, 45, is (incl. Docidium et Cosmarii spree.

d 63 liab. Frrpt. Fl Sachs. 1, 176.

(1) Ra Rab. Flor, Eur. Alg. 3 p. 14\%.

o 69 Arch. in (2. J. M. šc. 11. s. v. 9 p.195. 123.

o 71 Lumar. Desm. Snee. 11. S4.

ph $72 A r$. in Q. J. M. S.e. v. 12 1). 200.

1) 73 Wood Fr. Alg. p.11s.

173 Detponte Desm. subalp. 1..39 (sep.1).27).

fh 7.4 Leidly in Proc. Plilad, Ac. Nat. Sc. p. 15.

1 T- Delponte Desmil, subalp. 1.123 (sep.p. 219).

a it Fromli in Lemis rynops. p. 1633.

$n$ it Norlst. Alg. brasil. p.17. Subg.: Eupleurotan inm et Triploceras.

1) Tis Kirch. Alg. Sichles. p. 144 .

lh 80 Stall in Bot. Zeit. 35 p. 394.

d $8 \pm$ Guy Monogx. loc. Conjug. p. 41 .

d 85 Kirchn. Mikr. 1'flanz. d. Süssw. p. 20.

ph sis klels Peweg. n. Schleimb. d. Desm. p.36.5.

d sti Fromk in Leunis synops. 3 p. 198.

a 57 Alevento Chlorosp. Kharkow 1?.236.

1) s. Ilansy. Prodr. Algenfl. Bölım. p. 15?. d Sॄ Hauptfl. \%ellm. u. Hüllgallerte Desm. p.S1 et 119 (sep.p. 23) et 51 .

1) S4 Tomi Syll, alg. p. s.s.

o se Racib. Now. Desm. p. 106 (sep p. 34).

1) 90 Wille in Natïrl. Ptlanzenfam. 1.9 inclus. Arthror.abdium).

II 91 Manoury in Baill. Dict. bot. III p. 616 .

d 91 Kirehm. Mikr. Pfanz. d. Süssw. ed. 2 p. 21.

d 93 Builey Contr. Queensl. Fl. p. 4.

d 94 Samud. in Fl. Tebraska p. 39.

th 94 Wellheim in Iringsh. Jahrb. 26 p. 729.

\section{plicatum}

d 67 COSMARIUM Reinsch spec. Gen. Alg. 1). 114 t. 22 f. C. II. (rep.p. 6 t. 3 ); form. A. majus fig. 10 ; form. 13. minus $f, 1-l$.

1) - f. C. decedens ibid. f. $7-9$ Cosm. sinuosum $\beta$ Turdst. 1875, Eu. decedens Roy 1,433].

d 67 DIDYMIDIUM (Cosmarium) Reinsch Algenfl. Frank. j. 109 t. 9 f. 1 a-d $[\mathrm{d}=\mathrm{f}$. decedens supra].

o 77 Cosm. B. minus Reinsch Alg. Prom. Bon. Spec, p. $2+11$ (C. sinuosum Lund.)

o st-f. majus $M$ Nab in Ann. Mag. Nat, Hist. 5 ser. 11:0 74 p. 141.

d $86-$ Cooke Brit. Desm. p. si t. 36 f, 3 [e Reinsch?].

d - v. sinuosum ibid., f.4 (Cosm. sinuosum Lund. 1871). m 91 - Heimer Desm. alpin. p. 54t.

d 42 - v. hibernicum West Fr. w. Alg. W. Irel. p. 142 t. 24 f.! [C. holmiense v. hib. Schmidle 1894; cfr. infra].

m 44 - v. majus? Roy Ścottish Desm. p. 171 (sep.p. 42) et (18.3) t. 2 f. 1 .

d - v. Scoticum Roy et Biss. ibil. et t. 2 f. $2 .[=\mathrm{v}$. hibcruicum 18:2 see. West in Jonru. of Bot. 1895 1. 67 ].

\section{pluciale}

d 61 CoSMARIUM Bréb. in Pritch. Infus. 1. 784.

t 64 - Biplb. in Rab. Alg. Eur, n:0 1642.

a 67 DISPHINCTIUM heinsch Spec. Ge11. Alg. p. 139 t. 21 f. A II $1-5$ sep.p31 t. 2) [fig. mon bona].

d 68Cosm. Rab. Flor. Eur. Alg. 3 p. 176.

73 - Vordst. Norg. Desm. 1.22?.

a 49 Dis. Tom syll. alg. p. s8t.

\section{Porllarlliar}

1 y. COSMARIUM Eichl. et Gutu. Spec. alo. nov. p. 160 t. 4 f. 13 .

\section{1morllarhirnm}

1) 94 STAURASTRUM Eichl. et liutw. Spec. alg. nov. p. 175 t. 5 f. 19. [St. oligacanthum v. podl. West 1.49)].

\section{IokOr"ly"llmm}

d IS EUASTRUM Rub. Flor. Eur. Alg. 3 p. 185. [A 4 Cosmarium valde accedens, precipue ad C, angustatum et trilobulatam

d st- Hollc Desm. U. S. 1. 104 t. 27 f. $333-35$. [An alia species, ineisura angusta lobi polaris distineta?].

o siti-Stokes Key Desn. p. 145.

d s! - Tomi syll. alg. p. 1073 .

d 42 - Ilansg. Prodr. Algenfl. Bölım. ed. bohem. II p. 175; erl. german. II 1.257.

d 12 - Holle Desm. U. s. el. II 1, 114 t. 31 f. 33-35.

d $y .1$ - v. subcrassicolle Gutw. Fl. alg. Tarnayol. p. 103 t. $3 \mathrm{f} .40$. 
nollere

1] T2 EUASTRUM Nordst. Desm. Spetsb. p. 37 t. 7 f.2.t. [Comm. angustatum (Wittr.) Nordst. 1855].

\section{jolomirore}

(o) 11 CYLINDROCXSTIS Eichl, et Gut . in lirakau Anzeig. l. 20:3s.

daf 4.4 - Eichl, et Gutw. Spec. alg. 110v. 1\% 163 t. 4 f. 2.

\section{jolomir.r}

n $(15$ MICRASTERIAS West in Journ. of Bot. 33 p. 66 (Micr. Kitchelii f. polonica Eichl. et (rutu. 1844).

nolomir.mm-

d st CosmariuM liacib. Desm. okol. Krakowa ]' - (se [']' 12) t. 1 f. 1 [C. commune 1. polonicum líce. 1k85].

d 8.1 - Toni Syll. alg. 13. 1009.

m 90 - Fichler. Spis Desm. Miedz. P. Ss.

d (n) $-x$. quadrigrauulatum Gnte. Wahr. d. Priorität 1). 71 .

(1) 91 - - Gutu. Flor. alg. Leopol. p. 62 t. 2 f. 31.

n 91 URSINELLA Kuntze Rev. gen. pl. p. \$25.

d 9. Cosm. x. intermedinm Gutw. Fl. alg. Tarnapol. p. 96 t. 3 f. 3 !).

o - $\quad$ f. ibil. t. 3 f. 31

(1 $95-r$. alpinum Sclmidle Beitr. alp. Alg. p.457 (sep.p. 23) t. 15 f. 21 .

Cfr. C'osm. subpunctulatum sichmidle 18.13.

\section{jolomirnll1}

d $s 5$ PenIUM (Docidium?) Racil. Nomn. Desm. Polon. 1. bi t. 1.1 f. 12. (se].p. 5 t. 5) [P. minutum v. polonicum llest [1892].

d si-7omi śtll. Alg. 1\% 863 .

\section{polomiv11m}

d sistAURASTRUM Racib. Desm. okol. Firakowa sep.p. 17 t. 1 t. 10

d să-Pleurenterium hacil. Nonn. Desmid. Polon. 1). S.5 sej.p. 29\%.

d 89 - Toni syll. alg. p.118t.

\section{poly!gommm- -}

d 49 EUASTRUM (Cosnarium) Nerg. einz. Alg. 1) 120 t. 7 A f. 9.

d fil CoSMARIUM Arch. in Priteh. Inf. p. 73\%.

d $63-R a l$. Krypt. Fl Sachs. p.199.

m67 DIDYMIDIUM Cosmarium) Reinsch Firpt. Flor Frank. 1) 111.

d $68 \mathrm{Cosm}$. Rirl. Flor. Eur. Alg. 3 p. $16 \pi$.

d 75 - ? f. Reinseh Contrib. p. 89 t. 9 f.5 [C. pseudoprotuberans firchn. 18787.

d s.t - Tolle Desm. U. S. p. ha t. 16 f. 30

o 86 - Stolies Key Desm. p. 126.

d $\mathrm{x}$ - Ilansg. Prodr. Algentl. Böhm. 1. 145.

m 85 - Trest Desm. of Maine T. 310 (se].1. 2).

d s9-Toni syll. alg. p.94!).

m.1 - Heimerl Desm. alpin. p.1000.

n 91 URSINELLA Kimntze Rev. gen. pl. p. 495.

d 92 Cosm. Wolle llesm. [. S. ed. II p.71. t. 19 f. 30. m 45 - v. minns Hieran. in Pflanzenw. Ostafrik. p. 20. Cfr. Cosm. minutam Bem. 1892.

\section{polyg/unll11}

d 45 XANTHIDIUM IJass. Brit. Alg. p. 360 t. 89 f. 4 [e Jarlfs in Ann. Xat. Hist. $\mathrm{r}, 11$ delineatæ; est $\mathrm{X}$ fasciculatum Rialfs $r$, non $\beta$ polygoum Rolfs, sed $\beta$ polygoum liherl. $=\mathrm{X}$. antilopauml.

d 49-Kütz. Spec. Alg. 10.17\%.

o 50 - Bril. List. 13i.

d as-Rab. Lrypt. Fl. Sachs. p. 19 .

67 - Croman Fl. Finist. t. 1 f. 31 . [Quid est?].

\section{1)}

a s 1 COSMARIUM $\|$ olle Desm. U. s. p. 70 t. $16 \mathrm{f} .38-40)$ Ex Wolle 1.riz). (C. monomazum $\beta$ polymazum Nordst. 1503 .

o 86 - Stokes Key Desm. 1.12-.

d ( 2 - Holle Desm. U. S. el. II p. is t. 19 f. $38-4 n$.

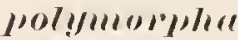

n 39 BINATELLA live. in Chev. Micr. p.20, cum var.: $\beta$ retusa, , tricera Micrast. Kütz.), $\delta$ iucurvata, $\varepsilon$ tetracera (Strur. paradoxum Meyen). s didicera (Micrast. Kütz.).

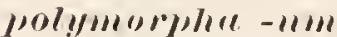

d 31 HETER0CARPELLA K̈̈̈. Ny'n. Diat. p. 598 (sep.p. (1) t. 1! f. $x$ ] Hixtum compositum? "Cosmarium ansatum" sec. Kütz. iyst Alg.; Cosmarium didelta ex p. see. Wen ghini xisn. Desm,].

d 35 - brél. Alg. Falaise 1) 56 , t. 7 .

n 3 T COSMARIUM (polimorphum) 1/enegh. Consp. alg. Eug. p. 18 isep.).

polymory!llm- -

dz 70 COSMARIUM Norlst. Desm. Brasil, p. $20 !$ (sep.p. 171) t.3 f. 31, non Menegh. nee Jacols

o s. -f. Nordst. in Wittr. et Nordst. Alg. exs. n:o 471; et (1889) in fase. 21 p. 41.

m 86 - Lagerh. Anerik. Desm. 1. 239.

d 5 - Wolle Fr. Alg. U. S. A. p. 31 t. 60 f. $31-33$ [e Nordst.1.

dz 89 - Tomi syll. alg. p. $19 \%$.

o 90 - Bürg. Desm. Brasil. p. 35 t. 4 f. $2 \pi$.

d - Paulense ibid. et t. + f. 24 Cosm. Paulense Johns. 1s95; non Börg. 18(W).

" 91 URSINELLA humtze Rev, gen. pl. p. 925.

d 92 Cosm. Tolle Desm. U. S. ed. II p. 81 t. 49 f. $31-33$.

\section{polymorp)/11"1}

d 93 DoCIDIUM Turner Alg. Ind. Orient. p. 29 t. 2 f. 13 et 17. t. 4 f. 13. Cfr. Wildem. in Totarisia 1593 p. 160. et Obs. crit. Desm., 1894, p, 63.

\section{pol!/morphlmm}

d 19 CLOSTERIUM Ierty in Bern. Mitth. p, 28.

d 52 PENIUM I'rty Ǩleinst. Lebensf. p. 207 t. 16 f. $15-16$. [f. 16 = Mesot. Endlicheriauum sec. Schmidle in Hedw. 18947

d 68 - Rab. Flor. Eur. Alg. 3 p. 123 (Inclus. P. crassins. culum the Bar.)

o for - Wittr. Skandiu. Desin. p. 20.

d $7 \mathrm{l}$ - Lmal. Desn. Suec. p. S6 t.5 f. 10 (Jerty 1852 quoad f. 15

- 73 - Nordst. Nor.o. Desm. p. 45

m 75 - Nordst. Desm, aret. p. 15.

o 75 - Juculs. Desm. Danem. p. 161.

- 6 COSMARIUM Jacols. Desm. Danem. 1) 201 (non Henegh.. nee. Nordst.)

d 84 Pen. Wholle Desm. U. . . p.36 t. 5 f. 12 [non bona].

o 86 -. Stukes Key Desm. 11. 111.

m $88-$ Norelst. Fr. wat. alg. N. Zeal. p. 71.

o 89 - f. Mask. Furth. Not. N. Z. Desm. p. 29 t. 5 f. 51. 
d 89 Toni Syll. Alg. 1\%. พอ̄9.

d 91 - f. alpicola Heimerl Desm. alp. p. 590 t. 5 t.4. [est forma typica sec. Schmille in Hedw. 169t].

d 92 - Wolle Desm. U. S. ed. II p. 37 t. 5 f. 12.

d 93-f. obesum Tumer Alg. Ind. orient. p. 17 t. 7 t. T [?].

d 94 - schmidle in Hedwig. 33 p.89 (f. alpicola Heim. 1891 ; I'erty 1852 quoad tigg. 15 sinistre).

d - v. Lundellii ibid. (I mand. 1871).

\section{polymorphume}

dzf 45 STAURASTRUM Brib, apud Ralfs Brit, Desm. p. 135 t. 2.2 f. 9, t. 34 f. 6.

dzf 52 - Pritch. Inf. 11.266 t. 13 f. $20,21,24.25,31$ [e Ralfs].

dzf 61 - Arch. in Pritch. Inf. p. 742. t. 2 f. 20, 21, 24, 25, :31 [e Ralfs].

d $63-R a b$. Krypt. Fl. Sachs. p. 192.

m67 DIDYMIDIUM (Staur.) Reinsch Algenfl. Frank. p. 165 inclus. St. cyrtocerum et proboscideum. Format: $3-\bar{\imath}-$ gonum.

67 Staur. Not. Desm. Ital. t. 4 f. 46 .

d 68 - Rab. Flor. Eur. Ale. 3 p. 24!!.

d - b. cyrtoceram ibid. p. 210 (St. eyrtoc. Brél.).

d - c. brachycerum ibid. (St. brachyc. Bréb.).

o 70- Tordst. Desm. Brasil. 1. 228, forma.

d $72-\beta$ subgracile Wittr. Gotl. Öl. sötv. Alg. 1.57 (Ralfs f. 9 $y$ ? Phycastr. crenulatum Nay. cquoad figg. H. $v, p ?)$.

m 72 - Tordst. Desm. spets. p. 39.

dz 73 - Truod F1. Alg. p. 151.

d - v. eyutocerum ibid.

d 7 - Welponte Desmid. subalp. p. 44 (sep.p.162) t. $11 \mathrm{f}$. ati-6?.

d $78-$ Kirchn. Alg. Schles. p. 167.

m 78 - Mempel Algenf. Chemnitz p.114.

m 79 - Wille Ferskw. alg. Nov. Semlj. p. 53.

d - f. intermedia ibid., t. 13 f. 64.

m - f. montrosa ibic. p. 54, t. 13 f. 65.

dz 84 - Wolle Desm. U. S., p. 126 t. 12 f. 9-10, 24-25.

d 85 - Kivelen. Mikr. Pflanz. d. Süissw. p. 23.

m 85 - Boldt sibir. Chloropl. p. 116.

$\mathrm{m}-\beta \mathrm{subgracilcibid.}$

o Sf - Stokes Key Desm. p. 166.

ph 86 - Klebs Organisat. Gallerte b. Algen p. 417 t. 4 f. $t$.

dzf 87 - Cooke Brit. Desm. p. 169 t. 56 f. $t$ [e Rulfs pro max. p.)

o Si - Murtel in Ann. Inst. bot. di Roma 3 p. 10.

d 87 - Ale.enko Chlorosp. Kihark. p. 255.

d 88 - Mansq. Prodr: Algenf. Böhm. p. 213 et 2̇s?.

no 88 - Riabine Chloroplr. env. Charkow P. 330.

m 88 - Roldt Desm. Grönl. p. 38.

m 58 - Jste. Jel. magyar. alg. p. 234.

m 89 - Harey Er. Alg. Maine p.18s.

dzsy - Toni syll. alg. p. 120 s.

d - v. intermedium ibid.

d - v. subgracile ibil. p. 1204.

In 90 -- Eichler this Desm. Miedz. p. 40.

m 50 - Anderss. Sverig. Chlor. 1 p. 12.

d !1 - Kirch. Mikr. Pflanz. d. Süssw. ed. 2 p. 21.

d 51 - f. obesa Heimer Desm. alpin. p. 60 t. 5 f. 22.

m $\$ 1$-.. Burge Eibir. Chloroph. p. 10.

in 91 - Gutic. Flor, alg. Leopol. p. 6 is.

d 92 - Mare. Fr. Alg. Maine:3 p. 122 t. 126 f. $1 . t$ et 15 (leutagnia) [Xon hece spec. sec. West 1545].

m 92 - Borge Chloropli. Norsk. Fimmark. p.s.

dz:12- Wolle Desm. U. S. ed. II p. 139 1. 53 f. 9, 10, $24,25$.

m 92 - Gutw. Flor. glon. Galic. 3 p. 135. d :2 - v. munitum West Alg. Engl. Lake Distr. p. 732 t. m93-Lütlemïll. Desm. Attersees p. Бит.

$m-v$ sulogacile ibid.

dz 94 - Sumed. in Fl. Nebraska p. 43 t. 7 f. 19 [e Cooke].

o 44 - f. intermedia Burg. F. alg. Ötgrönl. p. 27.

\section{POL YSOLENTA}

41 Elronb. in Berlin. Monatsber. 1840 p.216 [Cfr. P. Closterium ! = Penium 1. Closterium cum Chytridiis]. Tantum descriptio speciei.

\section{POIIT ITNIA - I E}

d 63 Kab. Krypt. Flor. Sachs. p. 1 is ("Polytaniæ") Sect. Spirotæniæ.

d 93 Tum. Alg. Iud, orient. P. 23 ("Polytenia") subgen.

d 95 Liithemull. Gatt. Spirotien. P. "2. "Polytæniæ" subgen.

\section{jolyt)ichume}

(1) 52 PHYCASTRUM J'evty KJeinst. Lebensf. p. 210 t. 16; f. 24.

I GS STAURASTRUM Rab. Flor. Eur. Alg. 3 p. 214.

o 71 - Lund. Desm. Suec. p.63. [Cfr. St. senticosum].

o 73 - Nordst. Norg. Desm. p. 30.

1 73 - Wood Fr. Alg. p. 153 t. 13 f. 12, t. 21 f. 23 .

ns 84 - liacib. Desm. okol. Krakowa p. sep.p.1s.

m 8.5 - Riabin. Chtoroph. env. Kharkow p. 332 t.s f. 11 [Staur. subpygmæum].

\89-7oni syll. alg. p. 1169 .

m $92-$ West Fr, w. alg. W. Irel, p. 175 t. 22 f. 18 .

n 92 - Iiue. Desmidya Ciastoni. p. 389.

o 13 - Twrner Alg. Ind. orient. 1\%.113 t. 13 f. 16.

o 93 - hoy sicottish Desm. p. 241 (et 1sy4) t. 3 f. .

m.94-Schmidle Alg. Geb. Oberrheins p.554.

d 95 - v. alpinum Schmidle in Hedwig. 34 1. 81 t. 1 f. 20. [Ntaur. teliferum?]. Cfr. Staur. Pringsheimii.

\section{$\mu 0 \nu \cdot e c t u m-11$}

d To CLOSTERIUM Nurdst. Desm. Brasil. p. 203 (sep. 165) t. 2 f.. 1.

in $7 \mathrm{t}$ - Nordst. Alg. brasil. p. 16.

1) s9-Toni syll. Alg. 1. $\$ 33$.

in (0)- Hery. Desm. Brasil. 1.2^.

11 91 ARTHRODIA Kuntź Rev, gen. pl. 1. 881.

\section{pojerectum -}

a 70 COSMARIUM Nordst. Desm. Brasil. p. 207 (sep.p. 169) t. 3 f. 28.

o 81 - Nordst. De Alg. et Charae. 1 p. 4 (forme).

it s! - Tomi syll. alg. p. 487.

11 "11 URSINGLLA Kuntze Rev. gen. pl. p.925.

n 93 Cosm. (Teinidium) Thmer Alg. Ind. orient. p. T. ny - Johns. Rare Desm. U. S. II 1. 29:3 t. 241 f. 30.

\section{Portianum -}

d bo cosmariUM Areh. Deser. New spree, in Dubl. Nat. Hist. Soe. Pr. v. 3 p. 49 t. 1 f. $8-9$, in Nat. Hist. Rer. v. 7 p. 103. t. 13 f. 8 -9, in Q. J. Micr. Sc. v. 1. 235 t. 11.

d 61 - Arch. in l'ritch. Inf. p. 733.

d lis-lirb. Flor. Eur. Alg. 3 p. 160, f. xyl. b. et c. p. 108 [ex Archer?.

o 71 - Lumd. Desm. suec. 1. 46.

d 72 - $\beta$ nephroideum IVttr. Gotl. Öl. sötv. Alg. p. 57.

o 75-Norlst. Desm, arct. 1) 18; forma.

o if-Nordst. Desm. Ital. 1'2s. 
m 79 - Wille Ferskw. alg. Nor. Semlj. p.31.

11 s.t-Racil. Desun. okol. Krakowa P. 10.

daf 81 - Tolle Desm. T. S. T.T- t. It t. $12-1 t$.

$181-\beta$ brasiliense Willo Sirdanerik. Algf. p.14 t. 1 i. 20 ( 1 Blonskii Rucib.. sed non ita see. Rarye in 1. Notar. is 1. 199 .

m si- $\beta$ brasiliense Lagerh. Anerik. Desm. 1.2035.

(1) St- vitulics liey Desm. 1) 128.

1) 8 - C'oule Brit. Desm. P. 1113 t. 39 t. 3 [fig. $f$. e De bury 185in].

o se - $\beta$ nepluroidenm Nordst. Bormh. Desm. p. 19:3 t. 6. f. 1 .

lz 89 - Tuni s.rll, alg. 1. 4rst;.

d - r. nepliroidenu ibid.

o 89- (?) Kosluxest. Flo1. vodorosl. vibir. II 11.32.

m 91 - $\beta$ nephroideum Heimerl Desm. alpin. I. 593.

1191 URSINELLA huntze Rev. wen. pl. p.925.

in 92 Cosm. Borge Chloroph. Norsk. Finmark. 1.9.

m 12 - Wat Fr. w. Alg. W. Irel. p. 152.

daf 92 - Wolle Desm. U. S. ed. II p. st t 17 t. 12-1t.

m 92 - v. nephroideum Gutu. Flor. glon Galic, 3 p. 129.

1n $93-$ L ïthemïll. Desm. Attersees p. 555

d 93 - f. attenuata Turner Alg. Ind. orient. p. 59 t. 8 f. 51.

o. 84 - Schmidle Alg. Geb. Oberoheins p. 50 t. 25 f. 8 .

1 $-v$ orthostichnm ibisl. p. $54 !$ t. 28 f. T. et in Flora is p. 5 i; t. T f. 11.

m 94 - Borges. F. alg. Ostgrünl. p. 1?.

1 1 95 - v. orthostichum Schmidle Beitr. alp. Alg. p.3!n.

d $-\mathrm{v}$-caleum ibid.; t. 15 f. 17.

Cfr. Cosn. isthminm, orbiculatum, margaritifernm Ko:l. 15s4. psendomargaritifernm lieinsch $18 \%$.

\section{Portii}

d 5s LEPTOCYSTINEMA Arch. Suppl. Cat. in Tat. Hist. Rer. P. 251 t. 21 f. 6 (in Pr. Dubl. Zool, Bot. Assoc. r. 1 1.115 t. \& f. 1; in J. Mier. Sc. ₹. 7 p. 13t). [Gonatozygon Brebissonii De Bur. see. Arch. 1861].

\section{rottsii}

I 8t STAURASTRUM Wolle in Bull. Torl. hot. Club 1894. 1 1. 16 t. 41 f. 8 \& ! .

d 84 - Wolle Desm. U. S. p. 151 t.51 f. s-:?

o 8i-Stoke Key Desm. p.168.

11 89 - Toni rirll. alo. p. 1265.

d 52 - Wolle Desm. L. S. ed. 2 p. 163 t. 19 f. 8-4.

\section{"10(ecelsulll}

d 93 CoSMARIUM Tume Alg. Ind, orient. p.61 t. 9 f. 2.

\section{preglomele -is}

d 63 CLOSTERIUM Rub. Krypt. Fl. Sachs. y. $170 \mathrm{Cl}$. lanceolatnm? Rab. in Rab. Alg. Sachs. n:0 366).

It is - Rab. Flor. Eur. Alg. 3 p. 12 .

d $89-$ Toni syll. Alg. p. 825 .

n 91 ARTHRODIA Kintie Rev. gen. pl. p.sst.

o 93 C'lost. Tordst. in Wittr. et Yordst. Alg. exs. n:o 1137 et 1139 .

\section{premprumale-is}

d 7 CoSMARIUM Pleurototeniopsis) Lund. Desm. inec. 1. 51 t. 3 f. 21.

n ss CoSMARIDIUM Ifunsy. Prodr. Algent. Böhm. p. 2ti. m 89 Cosm. Boldt Desm. Grönl. T. 25.

o 89 - Bury. Bidr. Bornh. Desm. p. 14 t. $1 \mathrm{f}$ f. $\tau$.

o \$9 PLEUROT ENIOPSIS Cosmaridium, Toni syll. alg. 1. 913.
- 10 Cosm. $\beta$ sphæricum ad inter.) Lagcrh. in Ninov. Notar. p. 133! C. spluericum Reun. 1885).

u 93 - (Ypliariliuus) Furner Alg. Iul. orient. p. Tt.

mat-borye siism. C!llor. Areliang. 1. 19.

\section{H)(elon!/um -}

d jo CLOSTERIUM Wib. liste. 1. 15.2 t. 2 f. \pm 1 .

d 61 - Areh. in Pritch. Int. 1r. ît.

d lis - Lab. Flor. Eur. Alg. :3 p. 1:30.

d 7 - Delpunte Desin. subalp. p.12h (sep.p. 216) t. $19 \mathrm{f}$. 9-11.

m $81-$ EVlfi. Finsk. Desm. 1. 15.

4) 56 - roole Brit. Desm. 1). 2.2 t. 10 f. 2 [fig. 2 e verisimiliter" ad Cl. Pritchardiannm pertineat].

1 87 - Wolle Fr. Alg. U. S. A. p. 24 t. 53 t. 15 -16 .

o 88 - f. Nordst. Fr. wat. alg. X. Zeal. p. 15 t. 3 f. 22 -2 1.

o $89-$ Musk. Furth. Sot. N. Z. Desm. 1) 30 t. 6 f. 54.

11 89 - Toni syll. Alg. p. 830 .

in 91 - f. brevior ITest Add. Freshw. Alg. W. York. 1). 244 .

n 91 ARTHRODIA Kuntze Rev. gen. pl. p. sst.

d. 92 Clost. Holle Desm. IT. S. ed. II p. 13 t. 6 f. 15 et $11 \%$ in 92 - West in Notaris. 7 p. 1199.

m 94-Gutec. Fl. alu. Tarnapol. p. 79.

\section{J'Remorst}

1235 BINATELLA Brib. Alg. Fal. p. 269 (sep.p. 613) [ab auctore teste Menegh. Synops. Desm. p. 229 suppress:t].

\section{promorsum - $\boldsymbol{l}$}

d 5t COSMARIUM Breb. Liste p. 1.2s t. $1 \mathrm{f} . \mathrm{m}$.

1) $61-A v c h$. in Pritch. Inf. p. 733.

d his-Linb. Flos. Eur. Alg. 3 p. 190.

m 73 - Nordst. Norg. Desm. p. 12 t. 1 f. 1.

m 84 - Rucil. Desm. okol. Kirakowa p. 11.

d 8 - Cooke Brit. Desm. p. 107 t. 12 t. "2.

d 89 - Toni syll. alg. p. 100k).

d s9-a. gallicum Racib. Nok. Desm. p. 89.

d - b. scandinavicnm ibid. (Nordst. 1873).

d - e. germanicum ibid.. t. 5 f. 34t.

1] 91 URSINELLA Kuntze Rev, gen. pl. p. 125.

ph 13 Cosm. Lütlemüll. Chlorophyll. ein. Desin. p.?.

m 43 - f. germanicum Lütkem. Desm. Attersees p. 55 .

o 93 - Schmidle Beitr. Alg. Schwàzwald. p. 101.

o 94 - Roy Scottish Desm. p. 171 (sep.p. 42)

o 95 - ft. Selmialle Beiti. alp. Aly. 1. 154 t. 15 f. $22-25$. Cfr. Cosm. cyclicnm lieinseh 1875.

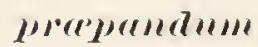

d 93 EUASTRUM Thener Alg. Ink. orient. p. 93 t. 10 f.57.

\section{Hoillylei}

d 81 STAURASTRUM Wolle in Bull. Torr. bot. Club. 1sis p. 2 t. 6 f. 11 .

1) 54 - Wulle Desm. U. S. p. 132 t. 50 f. 25.

o 86-Stokes Key Desm. 1\%. 167.

d s. -- Toni syll. alg. 1. 1171 .

d 92 - Walle Desm. U. S. ed. Il p. 145 t. 131 t. 25

\section{I"⿵ill!stleimii}

d Gi STAURASTRUM lieinsel sipee. Gen. Alg. p. 130 t. 2t t. A et B. Il. $1-S$ (sep.p. 2.2 t. 5). SSt. polytrichum Perty ser. Arch. in Journ. of Bot. 1hit p. 98 et Roy 1,137 .

- f. A. minns " ellipticum ilid. P. $1: 31$; t. $7-9$.

- $\mathrm{f}_{\mathrm{f}}--\beta$ trigonum ibid.; f. $4-1 \mathrm{j}$.

- t. B. franconicnm ilid.; f. 2 et 3 . 
d - f.? C. subcordatum ibid.; f. 1.

d 67DIDYMIDIUM (stausastrum Feinsch Algenfl. Frank. 1) 172.

d -f. A. minus a elliptienm ibid.

d $-\mathrm{f} .-\beta$ trigon $\mathrm{um}$.

d - f. B. franconicum ibil.; t. 10 f.t.

d -f. C. subcordatum ibid.

o 75 staur. Fieinsch Contrib. 1. 50 t. $10 \mathrm{f} .4$.

81-Cooke in quekett Wier. J. 6 t. 16 f. 36-40.

m 85 - Turner Xew rare Desm. p. $43 ! 1$ t. 16 f. 21 (v. duplomajor).

d 87 - Cooke Brit. Desm. p. 152 t. 52 f. 1.

\section{PRIONEUA}

d 93 Turner Alg. Ind. orient. 1) 1 to. Subgen. Onychonematis.

\section{Pristirla}

63 D0CIDIUM Holson Ind. Desm. p. 169 c. icone [Triploceras gracile Brwil. sec. Arch. Obs. on Micr. Mahab. (sep.1. 2k) in Tuhl. Nat. Hist. Soc. Pr.v. 1 pt. 2 1. 79 ; in Q J. Micr. Sc. 1865 p. 261].

\section{Pritehredirnmm -n}

dzf 62 Closterium Arch. New Cosm, etc. (sep.p. 13), in Dubl. Nat. Hist. Soc. Pr. p.81 t. 22 f. 25-27; Journ. Micr. sic. 1). 250, t, 12.

d 62 - v. Juntzseh in Rab. Alg. Eur. 11:0 1409.

d 69 - Linb. Flor. Eur. Alg. 8 1) 129.

m - b. ibid. (ral. Muntzsch. 1962).

o $7 \mathrm{~T}$ - f. maxima Nordst. Alg. brasil. 1. 16.

o 78 - Wittr. et Nordst. Alg. exs. n:0 170 (f. = C. acerosum?).

m 78 - Norlst. in Alg. samdvic. 1. 10.

pli z 81 - Ilempel Algenfl. Chemu. Forts. 1\%.- (sep.p: 17)

m $8 t$ - Wi7t, sydamerik. Algfl. p. 49.

m 85 - Boldt sibir. Chloropls. p. 122 (b. Rab.).

dzf 86 - Cooke Brit. Desm. p. 22 t. 10 f. 1, t. 15 f. T.

d $89-$ Toni Syll. Alg. 1. $\$ 30$.

o - f. maxinum ibid. 1) 831.

oz 8 - Richer in Plyyeoth. miv. It n:o 284.

11 !1 ARTHRodIA Kintze Rer. gen. pl. p. 881.

o !2 Clost. $\because$ minus West Fr. W. Alg. W. Irel. 1.121 t. 19 f. 13. [Quid est?]

m 93 - Lütkeminll. Desm. Attersees 17.542.

d 45 - $\mathrm{s}$. alpinum schmille Beitr. alp. Alg. p. sur (sep.p. 10. t. 14 f. 19.

C'fr. rlost. attenuatum 1sit, lanceolatum Clere 1silt, pronum lieinseh 1.517 .

\section{probosrirleum}

d 61 STAURASTRUM Aich. in J'riteh. Inf. P. 742 (Staur. asperum $\beta$ proboscideum $($ ire $b$. $)$.

o 76 -J Jacols. Desm. Danem. 1.206.

d so-t. javanica Nordst. De Alg. et Charace 1 p.11 t. 1 f. $1 !$.

d 82 - v. Americanum Wolle in 7ull. 'Torr. bot. Chub. 9 1). 2 ! t. 18 f. 111

d $85-\beta$ altum Thult Sibir. Chloroph. p. 117 t. if f. 31.

d 87 - v. furcata Iste. Diagn. prov. p. 210 (sep.p. 11).

d 87 - Couke Brit. Desm. p. 173 t. 59 f. 6 [e lialfs?].

o si- $\beta$ a ltum f. Nordst. Algolog. smås. 4 p. 157.

d 8 - f. intermedia Bollt Desm. Grönl. 1) 38 .

d 88 - v. furcata Iste. Jel. magrar. alg. p. 235 t. 2 f. 33.

d $88-\beta$ altum f. Nordst. Fr. wat, alg. N. Zeal. p. 36 t. 4 f. 5 .

d 89 - Toni sirll. alg. p. 1215.

d - v. javanicum ibir.

d $-v$. altum ilijl. d - v. internedium ibit. p. 12lo.

d - r. furcatum ibil.

d 10 - v. subglabrau Il'est Fr. W. Alg. Nortli Walos p. $2 ! 5$ t. 1 i f. 35 .

d $90-\beta$ Brasiliense Birg. Desm. Brasil. 1 . 46 t. is f. $1 ! 1$.

m 98 - $\beta$ a ltum Turnev Alg. Ind. orient. 1. 125 t. 11; f. 16 , t. 21 f. 6 .

\section{1"Ojertum}

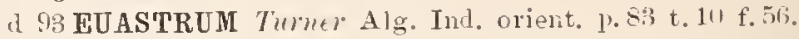

\section{l"rominems}

1 (13 COSMARIUM Twrner Alg. Ind, orient 1. 70 t. 10 f. 7.

mominmllm-r

d 85 Cosmarium liacib. Nom. Desm. Polon. p. T!t t. 11 f. 7 isep.p. 23, t. 2 \%

त $89-T$ - Tomi syll. alg. p. 1004.

॥ 91 URSINELLA Kuntze Rev. gen. pl. p.

in! Cosm. Lüllirmüll. Desm. Attersees p. 500.

d 94 r. subundulatum West New Brit. Alg. 1.6 t. 1 f. 16.

\section{fromontorillm.}

a ot CosmariUM West New Brit. Alg. p. T t. 1 f. 14.

\section{H"OM"111-}

d 5i CLOSTERIUM Iireb. Liste p. 15 t. 2 f. 42.

d 61 - Areh, in Pritch. Inf. p. 750.

d $63-$ Rol. Frypt. Fl. Sachs. p. 175.

d 63 - Fresur. in Rab. Alg. Eur. n:o 1133 c. icon. 1-3.

64 - Clece Bidr.t. Sver. Desm. p. 495 t. 4 f. 8.

d 67 - f. A. tenerrimum Reinsch Algenfl, Frank. p. Is8.

(l - f. B. Brebissonii ibid. (Cl. pronum Brele).

d - f. C. Pritchardianum ibid. Cl. Prit. Archer.

d 68 - Rab. Flor. Eur. Alg. 3 p. 136.

a - b. Fresenii ibid. (Cl. promum Fresen. 18633).

m 71 - Luml. Desm. Suec. p. 81 .

m $\tau_{2}$ - Wittr. Gotl. Öl. sötr. Alg. p.65.

d 79 - a. typicum klebs Desm. Ostpreuss. p. 19 t. 2 f. 12 a.

d - b. acutum ibid. t. 2 f. 12 b, 13 c. (C!. a eutum liril. et Cl. Ceratinm Perty).

- c. Cornu ibil., t. 2 f. 13 b. (Cl. Cornu Ralfs Bu. Desm.

d - d. Linea ibid. t. 2 f. 14 b. ('l. Linea J'erty).

o 85 - Wolle in Bull. Torr. Bot. Club. 12 p. 2.

d si - Wolle Fr. AJg. U. S. A. p. 25 t. 55 f. 22.

I 89 - Toni syll. Alg. p.852.

- v. Fresenii ibid.

I) 91 ARTHRODIA Limtze Rev, gen. 1,1. p.894.

- 12 Clost. Firc. Desmidya Ciastoni. p. 369 t. 6 f. 40.

f. hyalina ilid. 1).362 t.6 f. 39.

d 42 - Wolle Desm. U. . . ed. II p. 50 t. 6 f. 22.

1n 94 - Borye süssw. Chlor. Archang. p. 17.

- f. ibid.

d $45-\mathrm{v}$ longissima Lemmermann in Forschungsb. Biol. Station Plön 3 1.5.

m 95 - Fecib. in Flora v, 81 1. 32 .

\section{1"10011111}

1 93 EUASTRUM Turner Alg. Ind, orient. p. 85 t. 11 f. 23. [Eu. elegans v. prorum Wildem. 18:4].

\section{proteiforme}

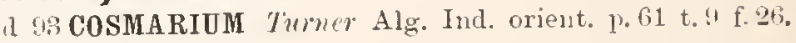
- - v. Wallichii ibid.

\section{metrortum}

d 49 EUASTRUM Cosmarium) Nag. einz. Alg. 1. 119 t. 7 A f. 4 . 
n th COSMARIUM (Eucosmarium) De linr. Conjug. P. T2 1) 61 - Arch, in P'ritch. Int', p. T:3 3 .

d fis Eu.? [errole trpogr. "puostratum"] Tiub. Kirypt. Fl. Sachss. p. 1sh.

m ti DIDYMIDIUM ( Cosmarinm) Feinech Algenfl. Flank. 1. 1'20. a majus et $\beta$ minus.

d foc Cosm. Iiab. Flor. Eur. Alg. 8 p. 17.2; torma a et l. nis - Nordst. Algolog. smasak. 3 1'.48.

d 84 - Wolle lesin. [. S. p. \$8:3 t. 17 f, $27-25$.

o s6 - stokics key Desm. 1) 120!.

o s. - Heidm Beitr. Alg. Jlecklenb. Il p. 101.

d s.9-Tuni syll. alg. 1) 1028.

mat Anders.s. siverig. Chlor. 1 p. 17.

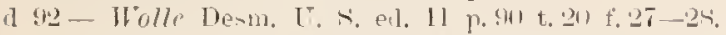

1298 - Gouatidiun Tumer Alg. Ind. crient. p. 74.

Cfr. Cosm. Botrytis Jac. 187\%, Cosm. ornatum v. minor Hulle.

\section{l1)ot)(artum}

d 9. STAURASTRUM Johms. Rnve Desm. U. -. Il p. 2!15 t. 240 f. 35 (it. grallatorinm forma Holle Desm. L. S. [188t et] $18 ! 12$ t. 57 f. 291-21).

\section{H'ot)ertull}

d 15 STAURASTRUM Rucib, in Flora v. 81 p.34 t.3-t f. 14 , non .lolens.

\section{0tuberrus.}

4 71 CosmaridM Lund. Desm. Suee, p. 37 t. 33 f. 17

1 $8 t$ - v. granulatum Holle in Bull. Torr. bot. r'lub. p. 1i; t. 14 f. $13-15$.

m s1-Racib. Desm, okol. Krakowa ]. se]. p. 13 [toglab) um liac. 18857 .

، 81 - v. granulatum Wolle Desm. U. S, p.st t. 51 f. 13-15. [C. minneapolitanum Ilonsy. 1898].

o $\$ 5-a_{1}$ subgranulatum Racib. Nonn. Desm. Polon. p. S2 (sej.p. 2ii).

I) b. glabrum ibid. líce. 1set).

o St-vitukes Kiey Desm. P. 129

d s9-Tuni syll. alg. p. 1kk\%.

d - v, glabrum ibid. p. 1007 .

m 90 - Eichler sis Desm. Miedz. p.ss.

(1) $92-v$. granulatum Wolle Desm. U. s. el. II p. 11 t. 62 f. $13-1$ 万.

d 13 -f. elevata Eichl. et Rrce. Nowe gat. zielen. p. 118 t. 3 f. $t$.

1 51 - $\mathrm{s}$. minor Sichmidle in Flora is p.5.5 t. 7 f. 2.2 [2.2 a $110 u$ bona sec. auct.].

('fi. C. pseudoprotuberans Wille 1sino.

\section{Wotuber(t).s}

d 14 ULVA smith Engl. Bot. vol. 313 t. 2593.

d 24 PALMELLA Ag. Syst. Al@. 1\% 11.

d 24 - Gree. Fl. Edinen. p. 323.

d 27 - Greet Seot. Crypt. Fl. Yol, 5 m:0 243 f. 1 et v. is p. $3 \%$

1 27 COCCOCHIORIS Sirrengel Syst. veg. v. 4 pt. I p. 373.

1 $33 \mathrm{Palmella} / \mathrm{H} r \mathrm{r}$. in Hook. Br. Fl. v. II p. 396 .

n 33 - Burnott Outlin. Algol. p.67 fig. a. b. c et $\mathrm{k}$ [e (i)eville].

d :35-Brib. Alg. Fal. 1.39.

4 $11-\| 7 n \%$. Brit. Alg. P. $27 \%$

d t2 Coceocliloris Menegh. Monogr. Nostoch. p), 59 t. - f. 1.

1) t3 Palinogloea Kütz. Phyce gener. P. 176.

d 15 Coecochloris Hass. Brit. Alg. p. 312 t. 70 f. т. t. 82 t. 4i-11] [f.6 e Gree. 1827. T-10 e Menryh. - Mesotænium chlamydosporum? sec. [reh, 1864].
(1) to T’almoglnea Roem. Alg. Deutuchl. 101:1 t. 10 f. 250).

d 45 - Kï̈ts. Phycol, rerm. 1'153.

" 47 - Kitz: Taib. phye, 1 t. 2.4 t. 1.

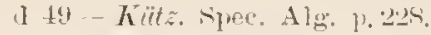

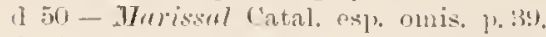

d 53 Palmella Muth. Flor. Bely. II 1.522. Cfr. Palmogloea macrococea Tirb.

\section{protumialme}

d i2 CosmaRIUM Nordst. I resin. spetsb. p. 31 . " ellipticum t. 7 f. 18 .

a $-\beta$ triquetrum ilill. 1 1. 35 t. 7 f. 19.

d $-\gamma$ evolutum ibil.. f. 20.

A - $\delta$ intermedium ivil., f.: 1.

d - subplanum ili,I.. 1. 22 .

o

il 89 - Tuni syll. alg. 1). 1111 .

l - v. subplatu $12 \mathrm{~m}$ ibil. p. 1012.

\section{Meselem}

d 81 COSMARIUM Wille Sydamerik. Algfi. p. 18 t. 1 f. 37. [Cosm. inornatum .Josh. 1886;].

1 s. - $\beta$ basilare Torlst. Algolıg. småsak. 1 p. 160.

11 88 - - Norelst. Fr. wat, als. N. Zeal. p. 50 t. 5 f. 11. m $\$ 9$ - Racib. Desm. Litu:11. p. tili. "pseudoamoenum" ".

1) 89 - Tomi ivil. aly. p. «!

d - v. basilale ibil.

m $91-\beta$ basilate Heimerl Desm. alpin. 1) 595.

11 91 URSINELLA Kumtzc Rev. gen. pl. p. \$2.

1 93 DISPHINCTIUM sehmidle Beitr. Alo. schwarzwald p. 4.2 t. 4 f. $4-5$.

un 94 Cosm. Borge sissw, Chlor. Archang. p. 19.

\section{piseudreretoum}

d 79 COSMARIUM Norlst. in Wittr. d Xordst. Alg. exs. n:o 257 cum t. xylogr. a, a', b, c, d; et (1889) in fase. $21 \% .7 \%$

1 57 CALOCYLINDRUS Cowke Brit. Wesm. 1. 129 t. 41 f. 1. un Sic Cosm. Boldt Desm. Groinl. p. 17.

ma Cal. West Addit. West Torksh. 1). 9.2.

d sy DISPHINCTIUM Tomi syll. alg. p. sis.

12 Cosm. West Alg. Engl. Lakie Distr. t. 9 1. 16.

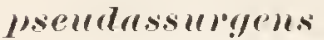

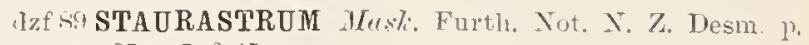
25 t. 5 f. 15.

\section{pesendrthutoirleum}

d.92 COSMARIUM llest Alg. Engl. Lake Distr. p. 725 t. 9 f. 21 .

\section{psemalelegrus}

d 95 EUASTRUM Twne New rare Desm. p. 930 (sep.p. 3) t. 15 f.s [En. elegans f. ornatum Writdem. 1891].

I 89 - Tomi syll, alg. p. 1112 "psendo-elegans"

o 90 - West Fr. w. Alg. North Wales 1). $25 \%$.

n 91 HELIERELLA Lintze Rev. gen. pl, p. S:19.

\section{Psemdinems}

d. Gi STAURASTRUM Heinsch Finee. Gen. Alg. P. 123 t. 24 C II t. $1-5$ (sep.p. 15 t, i). [Waltem ex $\mathrm{p}$. = Althrot. Incus $\beta$ intermedius Irittr. 181; ; quoad $\mathrm{t}$. $3=A$. Incus f. Reinschii Turner 16:33).

\section{psendistmorhomdrum -}

1 ic COSMARIUM Wille Ferskv. alg. Nov. Semlj. p. 34 t. 12 f. 13. 
d 89 - Toni sy-11. alg. 1. \$nif ("pseudoisthmochondrum"). n 91 URSINELLA huntze Rer. gen. pl. p.925.

\section{peseudobiorulatume}

d "o COSMARIUM Gute. Wahr. d. Prioritat p. 68. d 91 - Gutw. Flor. alg. Leopol. 1. $41 ;$ t. 1 f. 27.

\section{psevelobireme -is}

I sí COSMARIUM Eoldt Sibir. Chloropl. p. 102 t. 5 f. 6 . d 85 - f. Boldt Desm. Grönl. p. 15.

I 89-Toni sirll. alg. p. 1042.

n 91 URSINELLA Funtze Rev, gen. pl. p. 925.

m 91 Cosin. Gutu. Flor. alg. Leopol. p. $5 \%$.

\section{Pseulobotrytis}

dzf si EUASTRUM (Cosmarimm) Gay Mon. loc. Conj. p. 61 t. 1 f. 19 ; et Note Conj. d. M. France 1.336. ph sf CosmaridM squinub. Catal. Desm. Genor. p.9. d Ss-Hansy. Prodr. Algenfl. Böhm. p. 200.

d 89 - Tomi Syll. alg. 1. 962.

d $\%-\mathrm{v}$. minor Gutw. Fl. glon. Galic. 2 p. 13 t. 1 f. 5 .

n 91 URSINELLA Kuntze Rev. gen. pl. p.925.

d 92 Cosm. f. pyrenaica Gay Alg. Bagn. Bigolr. p. XXXI. mat - Iimmer Alg. St. Pölten I p. 4.

m 92 - Gutw. Flor. glon. Galic. 3 p. $12 \tau$.

ph 13 - Lütlimüll. Chlorophyllkörp. eiı. Desm. 1).8.

- 93 - Liitkemüll. Desm. Attersees 1).555.

o 91 - Sehmidle Alg. Geb. Oberrheins p. 550.

\section{Pseulobroomei}

d 84 Cosmarium Tolle in Bull. Torr. bot. Club $18 \mathrm{~s} 4 \mathrm{p}$. 16 t. 44 f. $36 \& 37$

d 84 - Urolle Desm. IT. S. I. Sit t. 51 f. 36 - 37.

o 86 - Stolies Key Desm. 1).12.

o 89 - " Tomi syll. alg. p, 1055.

d .92 - Wolle Desm. U. S. ed. II r. 93 t. 62 f. $36-37$.

d 93 -? Schmidle Beitr. Alg. Sehwarzwall. p.100 t.5 f. $2-3$.

d 93 -Tumer Alg. Ind, orient. p. 66 t. 1 f. 11.

d $95-v$ madagascariense West Alg. Malag. p.63 t. 7 f. 31 .

d - v. elegans ibid., t. 6 f. 2.

\section{Pseurlortosterillu}

d (4.4 CLOSTERIUM Roy Scott. Desm. p. 247 (sep.p. 55)

\section{psemdoromuretum-us - a}

d To COSMARIUM Tordst. Desm. Brasil. p.214 (sep.p. 176) t. 3 f. 17. [Cosm. connatum b. pseudoc. Klebs 187g]

m 11 - Lund. Desn. Sinec. p. 15.

o 73 - (Pleurotaniopis) Nordst. Norg. Desm. p. 24.

o 81 - Cooke in Grev. 9 1).90 t. 140 fig. $\mathrm{l}$.

n 81 CALOCYLINDRUS Wolle in Bull. Torr. bot. Club. v.

\section{8. $1.3 . \%$}

a 84 - Woll Desm. U. S. p. 5.; t. 12 f. 11 t. 45 f. $10-11$.

m stCosm. Tille Sydamerik. Algfl. p. 17 .

$m-$ f. major ibid. 1). 18 .

10 so-Lagurh. Amerik. Desm. 1.242.

o 86 C a l. Stokes Kiey Desm. 1. 111.

d 87 - Coole Brit. Desm. p. 124 t. 44 f. 3 [Quid est $3 e$ ?]

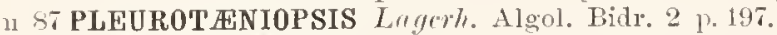

n ss COSMARIDIUM Hansg. Prodr. Algenf. Böhm. 1. 245 in 110 ta.

11 sacal. Carter in A. M. Mier. J. 10 f. 11 (ex Wolle).

d S9 Plenrotin nopsis Toni Sirll. alg. p. Gro.

m de Cosm. Hent Fr. W. Alg. W. IreL P. 161.

d $-v$, constrictum ibid. t. 21 f. 17. d !m Cal. Wolle Desm. U. S. ed. 11 p. 60 t. 15 f. $11 . t .60 \mathrm{f}$. $10-11$.

o 19 Cosm. Lïtlermill. Desm. Attersees p. $54 !$.

in $93 \mathrm{Dysp}$. Tumer Alg. Ind. orient. p. 43.

m 95 Cosm. West Alg. Madag. p. 71 .

\section{pseudororoucutum}

d 93 COSMARIUM Tumer Alg. Ind. orient. p.5s t.s f. 45.

\section{Pseudo-Cosmurium}

d 5 STAURASTRUM Reinseh Contribnt. p. 91 t. 9 f. 1.

o $76^{\circ}$-Nurelst. in Hedwigia p. 67.

Cfr. Stanr. cosmarioides Reinscle 1875 et Wolle 1587, non Norlst. 1870.

\section{pseudoreenutum}

d 90 COSMARIUM Gutu. Wahr. d. Priorität p. 70.

m 91 - Gutu. Flor. alg. Leopol. p.5s t. 2 f. 20.

\section{pseudocreuretum}

d 71 STAURASTRUM Lund. Desm. Suec. p. 65 t. 4 f. 4. Thtaur. maamense Areh. 1869.

d 87 - Wulle Fr. Alg. U. S. A. p.42 t.57 f. 4 \& 10.

d 8 -Alerentio Chlorosp. Khark. p. 255.

d 92 - Wolle U. S. ed. II p. 139 t. 48 f. 9 et 10.

\section{pseullorenspirlaterm}

d si STAURASTRUM Roy \& Bis.s. Japan. Desm. p. 237 sep.p. ह) t. 269 f. 3 .

d 89 - Tomi syll. alg. p. 1146.

m 95 - Test Alg. Madag. p. 73 t. 8 f. 44 .

\section{Psendodesmidiarea}

d gn IHasy. Neue Süssw. u. Meer. Alg. p.11. Familia Chlorophycearum inter Palmellaceas et Desmidiaceas. Hect.: Gloeotænier (ad Pleurococcaceas s. Nephrocytieas sec. Stoehmayr 1891 ) et spirotæniew Dr Toni

\section{Psendodirma}

d 90 CLOSTERIUM $I^{*}$ oy in Scott. Naturalist $\mathrm{X}$ p. 201. d $94-$ Koy Scott. Desm. p. 248 t. 1 (1.893) f. 4 (sep.p. 56)

\section{pisendoexigutum -}

d s5 cosmarium Pleuroteniopis) Racib. Nonn. Desm. Polon. p. 71 t. 10 f.s (sep.p. 15 t. 1) [in tabula: C. "subexiguum"]

n. Si PLEUROT

11 88 CoSMARIDIUM Hansq. Prodr. Algenft. Bölım. p. 246 in nota.

d S9 Pleurot:eniopsis Toni Syll. alg. p.914.

1n 95 Cosm. Schröder Alg. H. Riesengeb. p. 18.

\section{pseudofontigenum}

d 90 COSMARIUM Gutw. Walir. d. Priorität p.67. et

d 91 - Flor. alg. Leopol. p. 10 t. 1 f. 11

\section{p.seurlofucroretr}

d SI MICRASTERIAS Wolle in Bull. 'Torr. bot. Club v. 8 p. 1 t. 6 f. 3.

m 83 - v. minor Wolle in Bull. Torr. bot. Club v. 10 p. 19.

If 84 - Trolle Desin. U. S. p.111 t. 35 f. 4 .

- v. minor ibid. t. 37 f. 11.

m s6 - Layerh. Amerik. Desm. p. 231.

o 86 - Stulies her Desm. p. 147.

d 89 - Toni syll. alg. p. 1124.

in - r minor ibid.

n 91 HELIERELLA huntzc Rev. gूen. pl. p. 899. 
d $12 \mathrm{Micl}$. Wolle Desm. U. s. ed. II p. 122. t. $39 \mathrm{f}$. $t$.

o - r. minor ibid. t. 41 f. 11.

Cfr. M. furcata Johns, 1Si1.

pseulof mreiger"llm

I GT STAURASTRUM Reinsch spec. Gen. Alg. p.128 t. 23 C. I f. $1-4$ (sep.p. 20 t. 4) [s. furcigernm f. sec. Arch. in Journ. of Bot. 1874 p. (13].

d 6.TDIDYMIDIUM Staul.) Reinsch Algent. Frank, p. 169 t. 11 f. 2. [Nt. fur i igerum sec. Iacobs. 1569; sit. furcatum c. $R_{i} b$.; st. furoigerum f. armigera Nordst. 1888].

o 71.Staur. Lund. Desm. Suee. 1. 71 (Desm. enstephanum? ?

o $73-$ Nordst. Norg. Iresm. p.36

81 - Couke in Qnekett Micr. J. i; t. 1+ f. 1-3.

s1 - IFills in Nidl. Natural. 4 t. 5 f. 10.

o 83 - Turner Alga Strensall p. 20.

a 84 - Wolle Desm. U. S. p. $1+7$ t. 52 f. $27-2$ s.

o 85 - Rícib. Yonn, Desm. Polon. p. 84 t. 12 f.4 (sep.p. :33 t. 3).

o sfi-Stokes lier Desm. p. 168.

d 87 - Cooke Brit. Desm. p. 147 t. 61 f. 4 .

d 89 - Harsg. Prodr. Algentl. Böhm. p. 216.

d 89 - Toni Syll. aly. p. 1155.

d 92 - Wolle Desm. T. S. ed. II p. 162 t. 63 f. 27 et 28 .

o $93-\mathrm{f}$. Turner Alg. Ind. orient. p. 122 t. 17 f. 5 .

\section{psemlogl) (1)}

I To COSMARIUM Norlst. Desm. Brasil. p. 211 (sep.p. 1i3) t. 3 f. $2 \overline{7}$; f. minor, media. major.

m 71 - Lund. Desm. Suec. 1.42, f. media.

d 81 - Wolle Desm. U. S. p. 155 t. 17 f. 21-23. [C. Wolleanum Lagerh. 1886].

- $86^{\circ}$ - Stokes Key Desm. p. 129.

d 89 - Toni Syll. alg. p. 1045.

1191 URSINELLA humtze Rev. gen. pl. p.925.

m 91 Cosm. Gutu. Flor. alg. Leopol. p. 47 t. 1 f. 29 [C. granatnm? sec. Layerle. in Nuov. Notaris. 1893 p. 186].

d 92 - Hansg. Prodl. Algenft. Böhm. ed. bohem. II p. 155 ed. gel'm. II p. 256 .

m 93 - Turntr Alg. Ind. orient. p. 73.

\section{psemloman!garififermm -a}

dzf 75 COSMARIUM Reinseh Contribut. p. 84 t. 16 f. 12 [C. Portianum sec. Arch. in Q. J. M. Sic. v. $16,1576$. p. 100 et 416 .

dz 89- Toni syll. alg. p. 1040.

n 91 URSINELLA Kuntze Rer. gen. pl. p.925.

\section{psemrlomitidnlum -}

d 73 Cosmarium Norlst. Norg. Desm. p. 16 t. 1 f. $t$.

d 75 - v. majns heins h Contribut. p. 85 t. 12 f. 7 [C. tnmidum Lund. sec. Nordst. in Hedwigia 1576 p.67].

7 - Reinseh in Pringsh. Jahrb. v. 11 t. 17 f. 5.

d in-v. Reinsch Freshw. Alg. Kerguel. p. 82 (sep.p. 15).

s1-Foole in Quekett Mier. J. 6 t. 13 f. A. a. [Quid?].

81 - Wills in Midland Taturalist 4 t.5 f.6. [Quid?].

d st - Wolle Desm. U. S. p. 1 i2 t. 18 f. 19.

o 86 - Stakes Key Desm. p. 107.

d 86 - Coolie Brit. Desin. posi t. 12 f. 15 [an $\alpha$, an $\beta$ ?].

d - vo obsoletnm ibil. p. 88 [Coole et Wills 1S81?]

d 89 - Toni s.yll. alg. 1. 1173.

n 91 URSINELLA huntze Rev. geu. pl, p. 925.

d 12 Cosm. Holle Desm. U. \&. ed. II p. T2 A t. 21 f. 19.

d $94-v$. levissima Schmidle in Flora $i s$ p. 57 t. 7 f. 15.

m95-Eichler in Paniet. Fizy. 13 p. 54 t. 1 f.6.

kiralstedt. Inder Itesmid. psemrloligraranthum

d Si STAURASTRUM Musk. Furth Not. К. Z. Desm. 1. 21 t. 5 f. 43 .

\section{jwe 11 toom}

(1) 94 COSMARIUM Eichl, et Gutw. Slyec. Alg. nor. p. 170 t. 5 f. 25 .

Cfr. Eu. ornatom Focke 1817.

\section{psembloparhyrlermmm -re}

If si COSMARIUM Norlst. Algolog. småsak. 4 p. 161.

d 88 - Nordst. Fr. wat. alg. N. Zeal, p. 53 t. 5 f. 20 (Cosm. Ralfsii Musk. 1883?).

d s9? PLEUROT ÆENIOPSIS Toni syll. alg. p.?15.

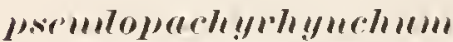

d st STAURASTRUM Wulle Desm. U. s. p. 125 t. 51 f. 32 - 35 [St. pachyrhynchum Holle, non Norlst.].

o 81 - Stokes Key Desin. 1. 164.

d 89 - Tomi Syll. alg. p. 1185.

d 92 - Holle Desm. U. S. ed. II p. 137 t. 62 f. $32-35$.

d 91 -Sunnd. in Fl. Nebraska p. 14 t.6 f.8 [ex Wolle].

d 94 - v. polonicum Eichl. et Gutw. Spec. alg. nov. p. 174 t.5 f. 4 ii.

\section{prevelopertimoides}

d st COSMARIUM Wolle Desm. U. A. p. Sil t. 19 f. $16-15$. o 86 - Stokes Key Desm. p. 129.

${ }_{111} 89$ - Harr. Fr. Alg. Maine II p. 186.

Il 89 - Toni syll. alg. p. 1054.

11 "1 URSINELLA huntze Rev. gen. pl. p.925 ("pseudopectinodes").

d 92 Cosm. Wolle Desm. U. s. ed. II p. af t. 22 f. 16-18.

\section{psemdopisciforme}

d 94 STAURASTRUM Eichl. et Gute. Spec. alg. nov, p. 175 t. 5 f. 5\%. [Tar. Stanr. arcuati sec. West; sed non ita, ut milhi videture.

\section{piseudoprotuberaus}

d 78 COSMARIUM Kireth. Alg. Sichles. p.150. (C. polygonum forma Reinsch Contrib.. 1875, t. 9 f.5).

d 90 -f. W'ille Norg. Ferskv, alg. I p. 33 t. 1 f. 18 [C. protuberans f. major verisinile sec. Nordst. in Grönl. Desin. p. 8].

d s s - $\beta$ trigonum Nordst. Desm. Grönl. p. 7 t. $\overline{\text { f. }} 2$.

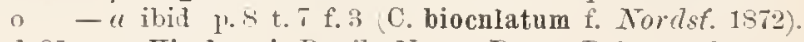

d 85 - a. Kirchneri Rucib. Nonn. Desm. Polon. p. 82 (sep. p. 26).

a - b. minor ibil. Witle 1880 \%

d - c. alpinum ibid. p. 83 t. 10 f. 11 (sep.p. 27 t. 1).

d $8 \bar{i}-\beta$ angustius Nordst. Algolog. småsak, 4 p. 162.

o 88 - - - Nordst. Fr. wat. alg. N. Zeal. p. 58 t. 6 f. 15 et $16 \%$

d 89 - Toni syll. alg. p. 951 .

a $-\mathrm{f}$, nin in us ibid.

d - v. alpilum ibid.

d - r. trigonum ibid.

d - v. angustius ibid.

(19)-y pygmæum Giutu. Wahr. d. Priorität p.69.

1191 URSINELLA Kuntze Rev. gen. pl. p.925.

mo1 (cosm. Gastridium) $\beta$ angustius f. leopolieuse Gutw. Flor, alg. Leopol. p. 54 t. 2 f. 8.

d - y pygmanm ibid. et t. 2 f.s. [Quid :].

d y2-f. Worge Chloroph. Norsk. Finmark, p. 12 t. 1 f. 10.

pli 93 --Luitlemeill. Chlorophyllkörp. ein. Desm. p.S t. 3 f, 16-1s [C. ellipsoideum see. Borge in N. Notar. 5 
p. 495. - quoad f. 16 afr Cosm. contractum sec.

West in Journ. of Bot. 1895 p. 366].

m:13 - Twrue Alg. Ind, orient. p. 54 t. 10 f. 15.

$\mathrm{m}$ - f. ibid. t. 5 t. 49 .

o $94-B \ddot{r}$ \%. F. alg. Ostg1ünl. p. 18 t. 1 f. 12.

m 95 -Joluns. Rare Desm. U. ᄂ. II p. 2913 t. 240 f. 24 .

m 45 - Eichler in Inmiet. Fizy. p. 60.

$m$ - f. trigona ibid.

m 45 - Sclimille bejtr. alp. Alg. p. 369.

m 95 - v. angustius West Alg. Malag. 1, 5n t. s f. 22 .

\section{psentopymaminatum. - a}

d 71 Cosmarium Luml. Desm. Suec. p. 41 t. 2 f. 18 (C. pyramid. $\beta$ minns lieinsch); et f. major ( $\therefore p \mathrm{y}$ ram. Tialfs ex parte t. 15 f. 4 d. e, f).

m 72 - Writtr. Gotl. Öl, süty. Alg. p. 60.

m 72 - Nordst. Desm. Nipetsb. 1) 29; f. major et minor.

o 73 - f. excavata Norlst. Norg. Desin. p. 19.

o 75 - Nordst. Desm. aret. 1. 19 [C. microsphinctnm Nordst. 1876.

$1-\beta$ crispulum ibid. 1 19 t. 6 f. 5 [C. micr. $\beta$ Norelst. $1876]$.

d $76 \ldots$ stenonotum Nordst. Desm. Ital. p. 32 t. 12 f. 8. m 82-Norlst. Algolog. småsak. 3 p.4!.

m St EUASTRUM (Cosmarium) $\beta$ stenonotum Guy Won. loe, Conj. p. 60.

ozf st Cosm. Wolle Desm. U. S. p. 69 t. 15 f. $11-13$, t. 16 f. 5 et 6 ;

$\mathrm{m} \& 4$ - f. minor Wille Sydamerik. Algft. p. 16 t. 1 f. 32.

o m 85 - Bollt sibir. Chloroph. p. 1no; f. inajor Land. 187 et minor Nordst. 1 sir.

n 813-Lagerh. Amerik. Desm. p. 240; et f. minor.

o 86 - Stokes Key Desm. 1) 12ti.

d 86 - Cooke Brit. Desm. p. 815 t. 37 f. 2 [e Lund.?].

d 87 - * umbonolatum Nivdst. Algolog. småsak. 4 p. 161.

d S8-IItusy. Prodl. Algenfl. Böhm. 1. 198.

d - $\beta$ variolatum ibid. (C. variolntum Lund.).

m - y minus ibid. p.24s (t. Wille 1894).

o ss- Nordst. Fr. wat. alg. N. Zeal. p. 54 (f. Nordst. 1873).

d —umbonulatum ibid. p.5t t. $f$ f. 2.

d 89 - Toni siyll alg. p. !46.

$m$ - f. minus ihid.

d - subsp. stenonotum ibid.

d - subsp. umhonulatum ibid. p. 94i.

d 89 - $\beta$ subtumidum Facil. Now. Desm. 1) 7!) t. 5 1.2.

m 90 - Bory. Desm. Brasil. 1. 12.

m 90 - Anderss. sverig. Chlor. 1 p. 15.

m91-Heimerl Desm. alpin. p. 597.

n 91 URSINELLA Kuntze Rev. gen. 11. p.925.

m G Cosm. Wrest Fr. w. Alg. W. Irel. p.14t.

d - f. subrectangularis ibid. p. $14 ;$ t. 2) f. $2 \mathrm{l}$.

n 92 - *tenonotum f. minor lícc. Desmidya Ciastoni. p. 33.1 t. 6 f. 32 .

12 - ibid. p. 373; f. major.

1) - f. ibid.i t. 13 f. 31 .

ozf 92 - Wolle Desm. U. S. ed. Il 1. 65 t. 18 f. 11 et $1:$, t. 1 : f. 5 et 6 .

m 93 - Lïtliemilll. Desm. Attersees 1) 551.

m 94 - ITest Fr. Ale. West lud. p. $20 ;.$

In - - stenonotum f. minor ibil., t. 1 f. 25.

in 95 - $\beta$ subtumidum Eichler in l'amiet. Fizy. 13 r. 29.

o 95 - Schmidle Beitr. al p. Alg. p. 395 .

m!5- West Alg. Madag. P. 5i.

Cfr. Eu. ansatum 183, Cosm. pyramidatum ex p.

\section{Psemroveryesio}

a 95 COSMARIUM West Alg. Madag. p. $5: 1$ et 40 t. $15 \mathrm{f} .12$ -43 (Cosm. Nova-Semlia v. polonicnm)

\section{Psentosebulli}

4 So STAURASTRUM Wille Norg. Ferskv. alg. I p. 45 t. 2 f. 30 .

d 4 - Wolle Desm. U. S. p. 139 t. 46 f. 8 -9.

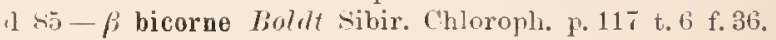

d 85 - b. gostynie ose Racib. Noun. Desm. Polon. p. 89 t. 12 f. 10 (sep.p. 33 t. 3 ).

o 86 - stalies Key Desm. 1.165.

o 87 - tonsum Nordst. Algolog. småsak. p. 157.

a $8.9-J l a n s y$. Proilr. Algenfl. Böhm. p. 256.

a $88-t u n s u m$ Nordst. Fr. w, alg. N. Zeal. p. 3i t. 4 f. 4.

d 89 - Toni syll. alg. p. 117 .

d - v. gostyniense ibid. p. 1179.

d - v. bicorne ibid.

1) - subsp. tonsum ibir.

d 92 - dnacense W'est Fr. w. Alg. W. Irel. p. 184 t. 24 f. 1.

o $92-v$. bicornis MLU. Austral. Suisswasseralg. p. 445.

a 92 - Trolle Desm. U. S. el. II 1). 152 t. 57 f. 8 -y.

d $12-v$ - simplicins West Alg. Engl. Lake Distr. p. 733 t. 3 f.:37.

o 93 - v. bicornis Bailey Austral. Siisswasseralg. p.50. o 93 - F bicolne Tumer Alg. Ind. orient. p. 123 t. 14 f. 14.

d - $\gamma$ pulchellum ibid,; t. $11 ;$ f. 14.

$\mathrm{m}-$ - typica ibid.

m 94 - Borge Sïssw. Chlor. Arehang. 1.38. Cfr. Staur. gracile v. Reinsel 1875.

\section{Jsendosproiosum}

d 12 COSMARIUM Rac. Desmilya Ciastoni p. 364 t. 13 f. 21.

\section{jesertostenonotum.}

d 14 COSMARIUM Eichl. et Gutw. Spee. alg. nov. p.170 t. 5 f. 2!!

\section{psemetetexirhourtmum -}

(1 7 COSMARIUM Yordst. Alg. brasil. p. 20 t. 2 f. 5.

181 - Wolle Desm. U. S. p. 71 t. 50 f. $22-23[\beta$ hians Lagerh. 1s87.

1 _ trichondrum Lagerh. Amerik. Desm, p. 238 t. 27 f. 9 .

1 _ - $\beta$ quadridentulnm ibid.. f. 10.

0 sio-Stakcs Key Desm. 1). 12s.

o 87 - Wohle Fr. Alg. U. ‥ p. 32 (inclus. C. pileigerum).

o. 87 - $\beta$ hians Lagerh. Krit. Bemerk. p. 539 a Wolle 1884. non Nordst. 1875.

it s9- Tomi Syll, alg. P. 1032.

l - v. quadridentulam ibil. p. 1eb:s.

a - v. trichondrum ihil.

m! 11 - trichondrum $\beta$ quadridentulum Bory. Desm. Brasil. 1).4n.

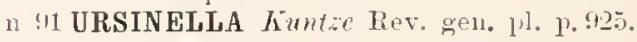

1 92 Cosm. Walle Desm. T. ‥ ed. II p. 7 t. 4 4 f. 22 et 23 .

\section{jesemdotetrarement"}

d 95 STAURASTRUM West Alg. Madag. p. 79 t. s f. 39 (sit. contortum $\beta$ psendot. Norkst.).

\section{Psevelotorreyi}

a 83 MICRASTERIAS Wolle in Bull. Torr. bot. Club 1883 1. 1 . t. 27 f. 2 .

184 - Wolle Desin. U. A. 1. 105 t. 32 f. 1.

o 86 - Sitolies liey Desm. p. 14.

d sil-Toni syll. alg. p. 1127.

n 91 HELIERELLA Kuntze Rev. gen. pl. 1) S:M.

1192 Micr. Wulle Desm. U. s. ad. II \%.11' t. 36 f. 1.

\section{pisilospormis}

dz 93 STAURASTRUM (A $\mathrm{r}^{\mathrm{t}}$ hlodesmus) Nordst. et $L a ̈ f g r$. 
in Wittr. et Nordst. Ale. exs. n:0 $559 r^{\circ}$. fig. xylogr. a. b. c.

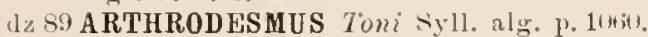

dz 89 - Wittr. et Tortst. Alg. exs. fase. 21 p. 39 c. fig. (ut supra).

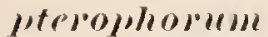

d 29 OPLARIUM Losana Nemor. A. Torino vol. 83 (secundum imaginem apud oken. Isis 1832. p. ibs t. 14 f. 2.5 redditam. [Euastr. Pecten sec. EHrend. Inf. p. 160. sed certissime nulla alga desmidiacea].

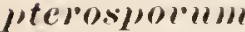

dzf 71 STA URASTRUM l.and. Desm. Sues. p. (6) t. 3 f. 29.

oz 81 - f. Areh. in Aun. Mag. Nat. Hist. 5 ser. v. \$ p. 233; f. elliptica.

dzf Si - Conke Brit. Desm. p. 113 t. 00 f. 2 [e Lund.].

m s. - B Bulet Desm. Grönl. p. अ;.

in 84 - ? Fortst. Fr. wat. alg. N. Zeal. p. 10.

d si-Toni syll. alg. p. 1143.

nis - Gutu. Flor. alg. Leopol. p. 65.

\section{jetilotim!}

d 93 COSMIARIUM Tumer $\mathrm{Al}$ g. Ind. orient. p. 62 t. 9 f. 17

\section{pulchellum}

1) 93 COSMARIUM Tumer Alg. Ind orient. p. 46 t. 9 f. 16.

\section{pulewellum}

d 5i COSMOCLADIUM Bréb. Liste p. 133 t. 1 f. 20.

A ss - De Bary Conjug. p. T.

d 41 - Arch. in Pritch. Inf. p. 752 t. 3 f. 63 [e $B v \cdot$ b.]

d 63 - Kinb. Krypt. Fl. Sachs. p. 132 [C. saxonicum de Bury - quoad citat. Rab. Alg.] fig. xyl. p. 619 [e lireb. List.?].

d $65-$ Le Bary in Flora 1). 329.

d 68 - Rab. Fl. Eur. Alg. 3 p. 54 . f. 28 p. 103 [e Krypt. Fl. sachs. 14037.

d $\div$ - Microgr. Dict. p. 203 t. 42 f. 35 [rerisimile e $R a$ ben $\%$. libere delineata].

d Ti- Kirchn. Alg. Schles. p. 105.

d 85 - Kivelm. Mikr. Pflanz. d. Sïssw. p. 16 t. 2 f. 33 (e Breb.).

d 89 - Tomi syll. Alg. p. 804.

d 91 - Kirchn. Mikr. Pflanz. d. Süssw. ed. 2 p. 26 t. 3 f. s2 (e Brib)

\section{pulehellum-u.}

d 56 EUASTRUM Brib. Liste p. $12 t$ t. 1 f. 5 . [Eu. elegans Jacobs. 1875].

d 61 -Arch. in Pritch. Inf. p. T30

d $68-$ Rab. Flor. Eur. Alg. 3 p. 186.

d 89 - Toni syll. alg. p. 1106.

n 91 HELIERELLA Kuntze Rev. gen. pl. p. 899.

\section{pulehrllmm.}

d 5is SP瓜R0Z0SMA Arch. Suppl. Cat. in Nat. Hist. Rer. ษ๋. 5 p. $25: 3$ t. 21 f. $T$ in I"r. Dabl. Zool. Bot. Ass. I p.117 t.11 f. 7 ; in J. Micr. Sce. 7 r. 136). [Sphær. secedens $\beta$ pulehellum Hunsg. 1858].

d 61 SPONDYLOSIUM dreh, in Priteh. Inf. p. 724 t. $3 \mathrm{f}$. 10 [figura minus bene delineata].

o tit;-Arch. in Q. J. M. Sc. 6 N. 120.

U GS Sphær. Rab. Flor. Eur. Alg. 3 p. 150 . fig. xyl. p. 105. [Ex Arelecr.

o ilspondylosium $\beta$ bambusinoides Lund. Desm. Suec. p. y2 (sipher. bamb. Writtr.)

o 73 - Nordst. Xorg. Desm. p. 47 . d 75 - f. gracilius Reinsch ('ontribut. p. 77 t. 6 f. 6 [fig. non hona? sec. Norlst. in Hedwig. 1870 p. S5].

ก 77 - Arch. in Q. J. M. S. V. 17 p. 191.

d $78-$ Kirchn. Alg. Schles. 1. 131.

un S1 splax r. [Spondy̆losium] f. minor Gay MIon. loc. Conj. 1. 7.t t. 3 f. 1. [siponl. tetragonum West 189?].

d si-Cooke Brit. Desm. p.ti t."2 t". 4.

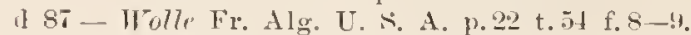

o sispontylosinm B. bambusinoides f. doplex Ist? Diagn. pripr. p. 211 (scp.p. 12, [monstrosa!].

m 88 - Boldt Desm. Grönl. p. 4:?.

m $85-\beta$ bambusinoides Istc. Jel. magyar. alg. p. 243.

a - f. duplex ilid. et t.2 f. 36 imonstr. .

m 88 - $\beta$ bambusinoides Nordst. Fr. wat. alg. N. Zeal. p. 28 t. 2 f. 11.

o $89 \mathrm{sph}$ r. Mrisk. Furth. Not. N. Z. Desm. p. U t. 1 f.

d $89-$ Toni Syll. Alg. p. 732 .

mospondylos. $\beta$ bambus. Wille in Natïrl. Pflanzen fam. p. 15 f.9 A (e Wittr. 1.4691.

In 90 -Anderss, Fiverig. Chlor. 1 p. 9.

n gosiphær. Eichler Spis Desm. Miedz. p. s1

m 91 - Heimer7 Desm. alpin. 1. 5s:.

m 91 sipondy 1os. $\because$ bambusin. West Freshw. alg. Maine II P. 35:\%.

d 92 spher. Wolle Desm. U. ‥ ed. II p. 24 t. 12 f. 8 -?.

d $93-$-. austriacum Lüthemilll. Desm. Attersees p.539 t. 8 t. 1.

- 98spondylos. Roy Senttish Desm. p. 171.

d 94 - v. pyramidatum West New Brit. Alg. p. 3 t. 1 f.s. o st Spher. Schmiale Alg. Geh. Oberrheins p.516.

m. 94 - Alexenko MIat. alg. Khark. p.18.

\section{"ul.hervimum-a}

(l) 0 CosmaRIUM Nordst. Desm. Brasil. p. 213 (sep.p. 17.j) t. 3 f. 21 [a typica Turn.].

d 71 - Lund. Desm. Suec. p. 34; forma. [ $\beta$ 1872?].

d 72 - $\beta$ boreale Nordst. Desm. Spets. p. 32 t. 6 f. 14 .

m $75-\beta$ boreale Nordst. Desm. aret. I. 23.

○ 7 - Reinsch Alg. Prom. Bon. S̈pei p. 241.

d -? f. ibid. p. 241 t. 6 f. s. [An Cosm. quadrifarium f. ??]

d so-f. senegalensis Nordst. De Alg. et Charac. 1 p. 5. msi - $\beta$ boreale Elf $i$. Finska Desm. p.11.

d. 81 - Wolle Desm. U. S. p. 90 t. 49 f. $23-27$; v. minor. [Quid?].

m 84 - Schararschm. Afghan. Alg. p. 246.

0 sfj-Stokes Kiey Desm. p. 129.

d as-Hansy. Prodr. Algenf. Böhm. p. 201.

m 88 - $\beta$ boreale Boldt Desm. Grönl. p. 20.

d 89 - Tomi Srll. alg. p. 101ti,

d $90-\beta$ truncatum Gutie. Wahr. d. Priorität p.70.

- 90 - Börg. Desm. Brasil. p. 38.

d $90-\beta$ majus Reinsch Süsswasseralg. Süd-Georg. p. 349 t. 1 f. 14 (et t. 3 f. 2 cum parasit.). [Annon Cosm. quadrifarium f.? Cfr. var. gemmulatum Mask.].

n 91 URSINELLA huntze Rev. gen. pl. p. 125.

d 1 Cosm. $\beta$ truncatum Gutu. Flor. alg. Leopol. p. 58 t. 2 f. 21 .

d 92 - Wolle Desm. U. S. el. Il p. 57 t. 60 f. $25-27$.

in 93 - a typica Truner Alg. Ind. orient. 1. 73 .

d. m 9.1 -- $\beta$ boreale Rörg. F. alg. Ostgrönl. 1. 14.

m 95 - r. truneatum Sclemille Alg. Sumatr. p. 301 t. 4 f. 11.

Cfr. Cosm. costatum.

\section{muleh)}

d 25 HETEROCARPELLA Bory in Dict. class. hist. nat. 8 
1. 180. Enastrum? sec Elrenl. in Isis $1834 \mathrm{col}$. $1193-4]$.

\section{mich}

d 1S SPH EROZ0SMA Bailey in Ralfs Brit. Desm. p.209 t. 35 f. 2.

d 52 - Hritch. Inf. p. 243.

o 58-Arch. Suppl. Cat. p. 116 (in Nat. Hist. Rev. p. 252).

d 61 SPONDYI,OSIUM Arch. in Iritch. Inf. p. T24.

d 6SSphier. Ral. Flor. Enr. Alg. 3 p. 151.

o 71 Spondylosium Lund. Desm. Suec. p. 92 t.5 f. 17 forma.

d $-\beta$ triquetrun ibid.

d 73 sphxer. Detponte Desm. subalp. p. 77 (sep.p. 65) t. 3 f. $11-1 \overline{1}$.

d 73 - Wood Fr. Alg. 1. 123.

d $80-\beta$ brasiliense Nordst. in Wittr. et Nordst. Alg.exs. n:o 36!) ; et (1Ss! i) in fase. 21 p. 34.

m 80Spondylos. Wille Noro. Ferskv. alg. I p.54.

d 84 Sphær. Wolle Desm. U. S. p. 29 t. 4 f. 1 -2.

d - v. plannm ibid.. t. 4 f. $3-4$.

1 - v. inflatnm ibid., t. 49 f.s.

o 85 -. v. constrictnm Wolle in Bull. Torr. Bot. Club. 12 p. 127 t. 51 f. 12.

a $86-\beta$ trilobnm Josh. Burm. Desm. p. 635 t. 22 f. $1 \& 2$. [Alia sp.?].

o 86 - Stokes Key Desm. p.110.

- - (v.) constrictum ibid.

o 87 - v. constrictum Wolle Fr. Alg. U. S. p. 22 t. 59 f. 12 [ex Wolle 18s5].

d 89 -. Toni syll. alø. p. 793 .

d $-v$. trilobrm ibid.

d - v. brasiliense ibid.

d - v. triquetrum ibil. p. 794 .

- v. constrietum ibil.

- v. planum ibid.

-v. inflatum ibirl.

m92 Spondylosium v. triquetrum West Fr.w. Alg. IV. Irel. p. 116 t. 19 f. 3.

d 92 strier. Holle Desm. U. S. ed. Il p. 29 t. 4 f. 1-2.

d - v. planum ibill. t. 4 f. $3-4$.

d - v. intlatum ibid., t. 4 f. 8.

o - v. coustrictum ibid. p. 172 t. 47 f. 1.2.

m 05 - f. pusilla lincib. in Flora v. \$1 P. 32.

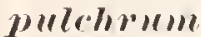

d 80 STAURASTRUM Wrolle in Bull. 'Torr. bot. Club 18s0) p. 46 t. $5 \mathrm{f} . \mathrm{H}$.

o 84 - Wolle Desm. U. S. p. 132 t. 41 f. 10 et $11 \mathrm{cum}$ nota in explicatione tabule.

\section{pull}

d 93 XANTHIDIUM Tuner Alg. Ind. orient. p. 102 t. 13 f'. 10 .

\section{1"1rim(t)m}

d 95 COSMARIUM West Alg. Madag. 13.64 t. 6 f. 24

\section{junrtuletum}

d 56 COSMARIUM Biéb. Liste p. 129 t. 1 f. 1 .

d 67 - Not. Desm. 1tal. p. 46 t. 4 f. 33. [Cosm. commntatum Richt. 1s.94]

d $69-R a 7$. Flor. Eur. Alg. 3 p. $15 \%$.

9 - b. ibid. (Not. 186it).

z 71 - Lumd. Desm. Suec. 1).30.

m 72 - Wittr. Grotl. Oll. sötv. Alg. p. 57 .

m 72 - Norist. Desm. Npetsb. P. 26 t. 6 f. 1. [C. solidnm Sordst. 15.47.
(1) $\beta$ triquetrum ibid. f, 2

73-? Aich. in Q. J. H. S. v. 13 p. 100 (non Luend. 1871).

- 73 - Nordst. Norg. Desm. p. 14 (f. trigona).

o 77 - Ricinsch Alg. Prom. Bon. Spei p. 241 t. 6 f. 7.

dz $78-$ Kirchu. Alg. Sehles. 1. 148.

in 79 - Wille Ferskv. alg. Nov. Semlj. p. 33 t. 12 f. 10-11. [C. solidum].

d $-\beta$ bidentnlatum ibil. p. 34 t. 12 f. 12. [Cosm. bidentulatum Boldt].

d 79 - a.typicnm Klels Desm. Ostpreuss. p. 37 t. 3 f. 50 -51.

d - b. rotundatnm ibid.:

o $\quad-$ a t. 3 f. 60 .

o - - $\beta$ t.3 f. 52.54 .56 [f. 52 v. Klebsianum Tum. 1843 .

1) - c. elongatmm ibid.. t. 3 f. 53.

dz 82 - * brasiliense Nordst. in Wittr. et Nordst. Alg. exs. n: 171 ; et 1859 in fase. 21 p. 41.

m $8 t-$ Artari Liste alg. Moscou p. 141.

(1) 84 - Wolle Desm. U. S. 17. 44 t. 13 f. 4 .

m 85 - Botdt Sibir. Chloroph. p. 108.

o s6-stolies Key Desm. p. 127.

dz 87 - Cooke Brit. De-m. p. 104 t. 42 f. 7.

87 - v. ornata Iste. Diagn. prev. in Notar. p. 237 (sej. P. 8).

dz8s - Hansy. Prodr. Algenf. Böhm. p. 199 et 27\%.

m $88-$ Buldt Desin. Grönl. p. 27 t. 2 f. 33.

m - f. ibid. (f. Wille 1879 ex $\mathrm{p}$.)

o 8 - $\beta$ elongatum Nordst. Bornh. Desm. p. 193.

d 88 - v. ornata Iste. Tel. magsar. alg. p. 225 t. 1 f. 11.

d 88 - f. malagensis Lewin span. Süssw.-alg. p. 8 t. 1 f. 14.

a $-\mathrm{f}$. circnlaris ibid., t. 1 f. 15 .

d 89 -- Tuni siyll. alg." p. 961.

a - v. ornatum ibid. p. $\$ 2$.

d - f. malagense ihid.

d - f. cirenlare ibil.

d - vo elongatum ibid.

d - subsp.? brasiliense ibid.

d - v. lotundatum ibid.

a 59 -v. mesoleinm Rrcib. Now. Desm. p. St (sep.p. 15) t. $5 \mathrm{f} .2 \mathrm{i}$.

d v. rhomboidenm ibik.. f. 28

m 90 - Eichter spis Desur. Mielz. p. 87.

maj-Gutw. Fl. glon. Cralic. 2 p. 14.

m: $10-v$. rotundation West Fr. w. Alg. North Wales 1. $28: 1$.

m :1 - West Danish Algat p. 119.

d - v. danicnm ibid.

m :11 - Borge Bidr. Sibin. Chloroph. p.11.

n 91 URSINELI,A Kuntac Rev. gen. pl. p.925.

In !l Cosm. Pimplex Gutw. Flor. alg. Leoprol. p. 53 t. 2 f. 5. m! 2 - Borge Chloroph. Norsk. Fiumark. 1) 10 t. 1 f. 7.

nu 42 - Rimmer Alg. St. Fólten p. 4.

a 92 - Wo77c Desm. U. S. ed. II p. 81 t. 16 f. 4 .

m.12-Gutu. Flor. glon. Galic. 3 p.127.

d 93 - v. depressum Tumer Alo. Ind. orient. p. 34 t. 8 f. 1i. [Cfr. C. jenisejense v. rectangnlum Gutw. $1,4.4]$.

- $\quad-\beta$ rotundatum ibid., t. 8 f. 58.

d - v. Klebsiannm ibid. t. 7 f. $3 t$ (b. rotundatum f. K7eb" 1879 quoal fig. 52; "Cosm. Klebsianum Tiem.?" in nota?

m 94 - Koy Sicottish Desm. p. 172 (sep.p. 43).

o 54 - v. perforatum Eich7. et Gutw. in Krakan Anzeig. p. 239.

o $94-$ Borgrs. F. alg. Ostarünl. p. 11.

d - f. ibil. p. 12 to 1 t.. 3.

o - $v$. subpunctulatnm ibid. (C. subpunctulatum Norist. 188T). 
in 94 - Alexenko Mater. alę. Khark. 1.25.

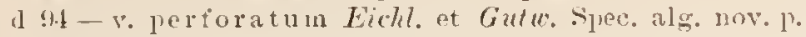
1iii) t. 4 f. 10. [Quid?].

m 95 - vo or $11 \mathrm{tum}$ West Alg. Madig. 1. 133 t.7 f. 23.

Cti. margaritiferum b. Ii (1). 196:3 et Cusm. polonicum.

\section{mumrtulutum}

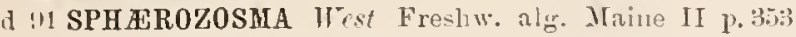
t. 315 f. 1 -?.

\section{1)urtulutum}

d 4s STAURASTRUM Brib. in Ralt's Brit. Desm. p.133 t. 2.) f. 1 .

a $52-$ Pritch. Inf. 1). 24:5

58 - Cufliseh in Ber. d. Naturhistom. Ver. Anguburg 185. t. 1 f. 21.

1) 61 - Areh, in Pritch. Inf. 1'. 740 .

1 63 - hab. Krypt. Fl. Sachs. p. 1ss.

m67DIDYMIDIUM (Staur.) Finsch Algenfl. Frauk. I). 159 (inclus. St. dilutatum, alternans, striolatum it rugulosum.

- f. A. minus ibid. p. 110 ( $a$ trigonum et $\beta$ tetragon um . $y$ alternans ibid. Staus. alternans.

- f. B. majus ibid.

o 6T Staur. Not. Desm. Ital. p.jl t. $t$ f. 44 .

oz 137 - Brmun in sitz. Ber. naturt. Freund. 1867 13. 31.

d 69 - Rub. Flor. Eur. Alg. 3 1. 208.

1 - b. turgescens ihid. (Staur. turgescens Not.!

o $6 s$-Itzigs. ill Bot. Zeit. p. th.

m 70-Reinharl in Arbeiten Naturt.-g. Charkow I p.119.

z 71 - Lund. Desm. Snec. 1.63.

m $72-$ Nordst. Desm. Spetsb. p. 39.

a 73 - Tordst. Norg. Desm. 1.29.

d 73 - Wood Fr. Alg. p. 151 t. 13 f. 11 .

(1) $75-$ Reunsch Contrib. p.9() t. 10 f. 14. [st. pygmænm Witt: 1872 sec. Nordst. in Hedwigia 187i p.67].

m 75 - Nordst. Desm. arct. p. 34 .

11 7 - Delponte Desmid. subalp. p. 16 (sep?]. 142) t. $11 \mathrm{f}$. 33 -34. [st. Friburgense ex p. ?].

dz $7 s-K i r c h n$. Alg. Fichles. p. 164.

m 78 - Hempel Algentl. Chemnitz p. 114.

m St-Arturi Liste alg. Moscou l'143.

m 84 - ritay Mon. loc. Couj. p. tits.

I 84 - Wolle Desm. U. S. 1. 127 t. 41 f. $43-45$.

d 55 - Kirchn. Mikr. Ptanz. d. Siussw. p. 23.

m 85- Buldt vibir. Chloroph. p. 111; ft:

m 85 - Nordst. Desm. Grönland. p. 10.

(1 8.5 - v. subrugalosnm Racil. Nomn. Desm. Polon. 1, 83 t. 1으. f. 13 (sep.p. Bu t. 3).

o sit- $\beta$ Kjellmani Wille in Dijmphn. Togt. Udb. p. $86^{3}$ ist. Kjellmani Wille 1sis.

o 86 - Stokes Key Brit. Desm. p. 167.

uf 86 - Tumer in Leeds nat. club transact. 1 t. 1 f. 14.

dzsi-C'uole Brit. Desm. p. 160 t. 54 f. 6.

msi - Alexenko Chlorosp. Khark. p. 254.

dzhs-Mansg. Prodr. Algenfl. Bühm. p.212 et 251.

m 89 - Boldt Desm. Grönl. p. 34 (sep.p. 82).

$m$ - f. ibid. Hourl 1873 .

d -f. ibil. p. 3; t. 2 f. 43.

$-\beta$ Kjellmanni form. 1-t ibid.. form. t: t. 2 f. 14.

m ss - Novrlst. Fr. wat. alg. X. Zeal. p. 41 (ff.).

m 89 - Lewin Span. Siissw.-alg. p.9.

l) - f. elliptica ibid.. t. 1 f. 16 .

1z 89 - Toni syll. alg. 13. 1190.

1 - v. Kjellmani ibid.

l - v. ellipticum ibil.

m 90 - Lichler spis Desm. Miedz. p. \$?. m 10 - Anderse. Sver. Chlor. 1 p. l?.

d 91 - Kirclen. Mikr. PHanz. d. Siizsw. ed. 2 p. 21.

m 91 - Heimerl Desm. alpin. 1. 1itis.

Izf ! $-t$. crassa Griy Alg. Bigorr. p. XXXII c. figg. [Cfr. Borge in Ninov. Notar. 6 p. 201].

m 92 - Forge Alg. Xot. 1 13. 59.

m 92 - Borge Chloropls. Norsk. Finmark. P. T.

n 92-Kimmer Alg. St. Pölten I 1. 4.

m 12 - like. Desmidya Ciastoni. p. Bso et 385.

d 42-Wolle Lesm. U. \&. ent. II p. 141 t. 22 f. $48-45$.

in 92 - Gutu. Flor. glon. Fralic. :" p. 134.

n 93 - Lïtliemull. Desm. Attersees p. 566.

o. 93 - Twrner Alog. Ind. orient. p. 10.4 t. 16 f. 4 .

m 94 - Iste. Adat. Roman. alg. p. 156.

m 94- - K Kellmani Schmidle in Hedwig. 33 p. 96.

n. 94 - v. Kjellmani Bürg. F. alg. Gstgrönl. p. 26.

o. 9 - Schmille Beitr. alp. Alg. 1.62 et 92 isep.p.38).

- - f. contorta ibid.

\section{1'1111yems}

d tisTAURASTRUM Brib. in Ralfs Brit. Desm. p. 130 t. 34 f. 10.

132 - Pritch. Int. p. 201.

o äß-Brel. List. 1) 137.

d 61 - Arch. in Pritch. Inf. p. 738.

d 63 - Rab. Krypt. Fl. Sachs. p. 143 .

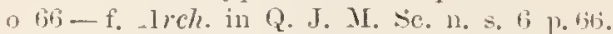

A 58 - Rab. Flor. Eur. Alg. 3 p.214.

d $71-L$ Lul. Desn. Suec. p. 64; forma.

A si-Cooke Brit. Desm. ].14t t. 00 f.li [non exacte e Ralfs? ?].

1. SS - Hansg. Prods. Algenfl. Böhm. p.214.

(1) Sy - Toni syll. alg. p.1148.

m 91 - Heimerl Desm. alpin. 1) 606.

m 94 - Burge Süissw. Chlor. Archang. p. 39.

\section{$\mu\|1\| m-\ell$}

1

1 87 - Wolle Fr. Alg. U. S. A. 1. 87 t. 58 f.9-11.

1. 89 - Toni syll. alg. p. $11 \mathrm{~kb}$.

n 91 HELIERELLA Kuntze Rev. gen. pl. p. sos.

II $92 \mathrm{Eu}$. Wolle Desm. U. S. er. II p. 1111 t. 29 f. 9-11.

\section{jusille}

1 (6) MICRASTERIAS Wullich Desm. Low. Bengal p.281 t. 1: f. 13. [Staurophanum pusillum Tum. 1893].

d s3-? Toni vill, alg. 1).1131;.

n $\$ 1$ ? HELIERELLA huntse Rev. gen. pl. p. sy9.

\section{")*illum-r}

1 1,1 CuOSTERIUM Hantzsch in Rab. Alg. Eur. n:o 1008, fig. a-e. [Cl. obtusum Brèb. sec. Kab. in Alg. Eur. Dec. 10:-110 "Berichtigune". Cl. obt. b. pusillum Klels 157!!].

- 1i2-Huntzsch iu Rub. Alg. Eur. Decad. 129-130 in nota.

dz67-Ficinseh Algentl. Frank. 1. 1st.

d is - Rulb. Flox. Eus. Alg. 3 1. 125.

mS5-a. minor Racil. Xonn. Desm. Polon. p.1:3 sep.p. T) Rul. 1sisis)

d. - b. major ibil.

a sh-p monolithum Wittr. in Wittre tordst. Alg.exs. n:o 935 . cum figg. xylogr.; et in fase. 21 r. $4 \overline{\boldsymbol{\tau}}$.

m s. a. minor fícil. Mat. Hur. glon. Polsk. p. 102 sep.r. 23.

d $59-70 \mathrm{mi}$ - syll. Alg. 1). \$ㅇ․

1) - v. monolithum ibil. 
a - vomajus ibil.

n 11 ARTHRODIA kuntse Rev, gen. pl. p. 8 si.

- $91 \mathrm{Clost} \beta$ inajor lioy et Biss. Scott. Desm. p. 248 (sep.p. 56).

m 55 - Eich7. in Pamiet. Fizy. 13 1. 58.

m95 - f. Selmid7e Beitr. alp. Alg. p. 3u!.

\section{mIsillum-}

A 56 EUASTRUM liril. Liste p. 125 t. 1 f. 7 .

d 61 COSMARIUM dreh. in Pritch. Inf. p. 731.

d 6s-Tílb. Flor. Eur. Alg. 3 p. 169.

o 71) - Nordst. Desm. Brasil. p. 211.

d $78-$ Kirchn. Alg. Schles. p. 153.

o 83 - Mask. N. Zeal. Desm. Add. p. 234 t. 24 f. 3.

d 8s - Homsg. Prodr'. Algent. Böhm. p. 201.

o 88 - Boldt Desm. Grö̀l. p. 17.

d 89 - Tomi viyll. alg. p. 1045.

m90-Fich7er spis Desm. Miedz. p. $8 \%$.

11 URSINELLA Kuntze Rer. gen. pl. 1. 125.

o $93 \mathrm{Cosm}$. v. retusum Tumer Alg. Ind. orient. p. 71 t. 11) $f .25$ et 26 (forma?

d 94 - - f. iutermedia cutu. Fl, alg. 'Tarnapol. p. 100 t. 3 f. 37 .

\section{lusillum.}

d 6ti COSMOCLADIUM Hitse in Ber. d. sehles. Ges. 1865 p. 117 .

d 67 - Ili7se in Rab. Alg. Eur n:o 1963 c. icone.

d $6 s-K u b$. Fl. Eur. Alg. 3 1. 54.

d $78-$ Kirchn. Alg. Schles. p. 105.

d 89 - Toni syll. Alg. p. $80 \%$.

\section{pusillum}

d S8 DYSPHINCTIUM Hansg. Prodr. Algenfl. Böhm. p. 1 it f. $109 .=$ D. anceps $\beta$ pusillum ibid. p. 278.

\section{fusillum}

d 7 PENIUM Delponte Desmid. subalp. p. 6.9 (sep.p. 185) t. 15 f. 3436 .

4 59 - Toni syll. Alg. p. 862.

\section{lllsillum}

d suSTAURASTRUM Wolle in Bull. Torr, bot. Club 1880 p. 47 t. 5 f. $F$

d 81 - Wolle Desm. U. S. p. 1330 t. 12 f. $47-50$.

o 86 - Stokes Key Desm. p. 165.

d 89 - Tomi syll. alg. p. 1213.

d 92-Hansy. Prodr. Algent. Böhm. II p. 259; ed. bohem. II p. 17 h.

d $y 2$ - Wolle Desm. U. S. ed. II p.14t t. 53 f. 47-50.

\section{putrinle}

d 93 COSMARIUM Tumer Alg. Ind. orient. p. 71 t. 8 f. 31. d -f. munita ibirl.; t. 22 f.?

\section{nyrnochondrum -}

d 73 COSMARIUM Torlst. Desm. aret. 1. 29 t. 6 f. 14 .

d s.l - Wolle Desm. U. S. p. 89 t. 19 f. 10-11.

o sf - Stoles Key Derm. p. 12!.

m 84- Rioldt Desm. Grint. 1.21.

d 8. - Toni syll. alg. p. 1021.

n 91 URSINELLA humtze Rev. gen. pl. p. 52.

d 92 Cosm. Wolle Desin. U. s. ed. II j.97 t. 22 f, 10-11.

\section{l)y!m,}

dzf 14 COSMARIUM Arch. Descript. (sep.p. 27); in Dubl. Nat. Hist. Hoe. p. $61 ;$ t. 1 ; in Q. J. Mier. S. p. 174 t. 1 f f. $45-49$.
Iz fir SPH列R0ZOSMA Rab. Flor. Eur, Alg. 3 p. 150 .

o 69 - Wittr. skandin. Jesm. p. 26 .

in 86 Cos m. Lagerh. Amerik. Desm. 1. 242.

dzf si- Cooke Brit. Desm. 1.91 t.37 f.8 [tnala, partim ex Arch.].

o 88 - Boldt Desm. Frönl. p. 17.

a 88 Splıxi. Hauptfl. Zellm. u. Hibllgallerte Desm. p. 81 (sep.p. 23) t. 2 f. $21-26 ;$, 30. [s] ph. secedens?]

o 8s? Cosm. Wist Massachus. Desm. p. 18 t. 2 f. 6 .

dz 89-Toni Syll. alg. p. 1046.

n 91 URSINELLA Kumtac Rev. gen. pl. p. 925.

mzf 92 Cosm. West Fr. w. Alg. W. Irel. p. 146 t. 20 f. 24. In 93 - Lütkemiï7. Desm. Atterisees p. 550.

m 93 - Turner Alg. Ind. orient. p.51) t. 8 f. 17 et 20.

n $94-$ Cutu. Fl. alg. Tarnapol. p. 101.

m 95 - Eichler in Pamiet. Fizy. 13 p. 5! Cfr. Cosm. Schliephackeanum.

\section{"y!ma"mm}

d 61 COSMARIUM Hantssch in Rab. Alg. n:o 1204. [Cosm. concinuum var. sec. Reinsch 1867].

\section{1"1/!) (1) $11 m$}

d 90 CLOSTERIUM Gutu. Wahr. d. Priorität p.66.

1) 91 - Gutw. Flor. alg. Leopol. p. 32 t. 1 f. 5.

\section{"y!ma'm}

d 41 ? EUASTRUM Elerenb. Monatsb. d. Berlin. Ak. 1810 p.20\%. [Specimina IIoffm:i = Cosmariam sp. sec. Heiberg Consp. crit. Diat. Danie. 1. 16; = C. granatum brèb. sec. Jacobs. Desm. Wanen. p. 19S].

\section{HIIIIt)}

- So SPONDYLOSIUM Coole in Grevillea v. 9 p. 39. [Sp h rozosma pygmam Kabenh.. 1868, non Cosm. pygm. Arch. see. Cooke; sed non ita. quoniam species Rabenhorstii secundum descriptionem et citationem apud $R a b$. nihil alind ac spec. Archeri est].

d si SPH Rozosma (ooke Brit. Desm. p. 5 t. 2 f. 5 ("Rab.") [sel non "Rub."; cfr. supra].

o grpondyl. West Fr. w. Alg. W. Irel. p. 116 [efr. Borge in $\mathrm{N}$. Notar. 5 p.518].

d 92 - v. compressum West Alg. Eng. Lake Dist1. p. 718 t. 9 f. 4.

o 95 - West in Journ. of Bot. 33 p. 65.

\section{"yyma'm}

dzf 48 STAURASTRUM Bréb. in Ralfs Brit. Desm. p. 213 t. 35 f $24 ;$

dz 52- Pritch. Inf. p. 26\%.

dz 61 - Arch. in Priteh. Inf. 1. 740.

o 67 - Not. Desm. Ital. 1. 52 t. 4 f. 45 . [?].

d 68 - Rab. Flor. Eur. Aig. 3 p.220.

o 72 - Wittr. Gotl. Ol. sitv. Alg. p. 53 t. 1 f. 10.

o T5-Nortst. Desin. aret. p.34; et f. ad s. luuatum accedens.

m Ty - f. major Iitle Ferskv. alg. Nov. Semlj. p.51 t. 13 f. 54-5n.

d $-\beta$ obtusum ilsil., f. 56

d 80 -f. minor Wille Norg. Ferskv. alg. I j. 42 t. 2 f. 28.

d St - Wolle Desm. U. S. p. 128 t. 12 f. 14-21.

f. genuina f. $14-15$.

- f. truncata ibid., f. 16-19.

- f. rhomboides ibid., f. $20-21$.

m 85 - Isoldt sibir. Chloroph. p. 112; et f. minor.

d $-\beta$ subglabrum ibid., t. 5 f. 20. [St. varians sec. Sichmidle]. 
m.5 - f. Raclb. Nonn. Desm. Polon. p. Si t. 122 f. 12 sep. p. 31 t.3) [St. subpygmæum ITe-t].

o s6 - Stokes liey Desm. p. liji; et r. truucata.

d $8 \mathrm{t}$-Cooke Brit. Desm. 1. 1.it t. 54 f. 1. Se Rulfs:??

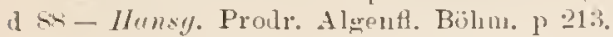

ms -- Bennelt Fr. wat. Alg. Engl. Lake Distr. '2 p. 1 .

o $8 s-f$. Boldt Desn. Grönl. p. $3+$ t. 2 f. t2. [St. vatians sec. Schmille].

o 88 - Whet Desm. of Maine p. 3339.

d 89 - Tomi syll. alü. p.11-1.

d - f. majus ibill. p. 11s?.

1 - 1 . minus ibil.

d - r. ohtusum ibil.

1 - $1.5 \mathrm{~s}$ gilabrum ibiu.

mS. - Ko:lousk. Flor. vodorosl. sibir. Il p.21.

1) 90 - f. minor Jeinsch Silsswasseralg. Sill-Georo. p. 351 (sep.p. 23 ) t.:3 1.1 ". l, (forma $1^{\circ}$, et $c$ forma 2 [Figs. malit].

m (m) - Eichler Spis 1)esm. Miedz. p. (1).

m $91-$ f. Gutu. Hlor. alg. Leopol, p. lis t. 3 f. 17

m $92-v$. trilineatum West Fr.w. Alg. W. Irel. p. 177 t. 23 f. $\mathrm{T}$.

d $92-$ Wolle Desm. [. S. cl. 2 p. 141 t. 53 f. 11-21.

n - f. genuina f. 1415.

$n-f$. truncata f. 1 il-1!!.

n - f. rhonboices t. 20 (1)-21.

zd 10 - Went in Notaris. T p. 15 (13.

m (13) - Lïtlemïll. Desm. Attersees p. .6.5.

$\mathrm{m}$ - r. subglabrum ibid.

o 93 - Tordst in Wittr. et Nordst. AIg. exs. n:0 1113.

m.4-Burg. F. alë. Ütgroinl. p. 26.

d 15 - v. apiculatum Wist Alg. Madag. p. it t. \& f.26.

o $15-\mathrm{s}$. obtusum Schmelle Alg. Sumatr. p. 306, t. 4 f. 16.

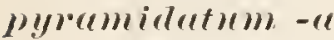

dz 4 COSMARIUM live in lialfs Brit, Desm. p.94 t.15 f. \pm [fig. $t$ l, c. $f=$ C. pseudopyramidatum].

dz $52-$ Pritch. Inf. p. 20.2.

dz 61 - Areh, in Pritel. Int. p. 131 t. 3 f. 14 et 15 [e Rrlfs. f. $t$ e et $f=$ ps.psi.].

a $138-R u b$. Firpt. Fl. Sachs. p. 198.

d lif - a minor Feinsch in Pab, Alg. 1n:0 19ir? f. f $[\mathrm{C}$. pseudopyramilatum]. f. T if. typica)

d $3 h^{2}-$ Eyrich Algenfl. Mannh. p. 125.

m67 DIDYM1DIUM ('osmariul Reinsch Algenfl. Frank. p. 107 ; a. Francunicum, b. Brebissonii, C. Bulnheimii.

o lit Cosm. Wot. Desm. Ital. p. 411 t. 3 f. 22 et 23 [2.2 Cosm. psendopyranidatum ?; $23 \mathrm{C}$. sinuosum $\beta$ decedeus sec, Nordst. 18T6].

d ijs - R थb. Flor. Eur. Alg. 3 p. 1132.

m - b. minus ibid. Reinsel 1560

m 70- Vortst. Deim. Rrasil. 1'210 [C. pseudopyramida t $13 \mathrm{~m}$ ].

o 71 - Lund. Desm. Stuec. P. 41.

(1) 73 - f. excavata Nordst. Norg. Wesm. p. 18.

1 - f. intermedia ibil. p. 19. C. homalodermum Nordst. 19.5. C. Hammeri fipinseh ex p.].

11 $7: 3$ - Wood Fr. Alg. 1. 131 t. 13 f. 14 .

a 75 - Microgr. Diet. p. 202 t. 10 f. 18 et 19 [e Rulfs Br. Desw. f. 4 a et b].

1) $T$-Delponte Desinic. subalp. p.33 (sep.p. 129) t.9 f. $30-33$.

(1) TS-Kirchn. Alg, schles. P. 14!.

m is - Hempel Algrenfl. Chemnitz p. 114

t 6 - a. pseudocacumis Klebs Desm. Ditpreusa. p. 30 t. 3 t. $11 ;-1 \overline{7}$.

1) - b. typicam ibil. 1.:31 t. 3 f. $19,19,31$.
1) - c. stenonotum ibid.. t. 3 f. 2s-30] [C. psendopyr. * tenon. Tordst. 1siti.

1 - 1. subgranatum ibil., t. 3 ז. 2.5. 2-2.

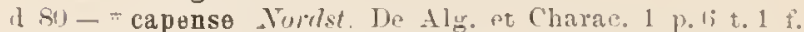
8. [C. capense Toni 1Misi!].

msil - Wille Norm. Ferskv. Alg. I p. 34. Not. Desm. Ital. $\mathrm{t}^{2} \cdot 2.2$.

phs1-Areh. in Ann. Mag. Nat, Hist. v. T p.341.

m s2- Nordst. Algolog. suăsak. 3 n. $\$ 9$.

o 83 - " stenonotum f. minor schauschm. Magyar. Desm. 1. 26s.

d At-Wolle Desm. U. S. p 13!l t. 14 f. $16-17$ fig. $17=$ pseudolyr. f. major sec. Honle.

d - т.. stenonotum ibil.. f. 1s-19.

mst - Schansechm. Afgahn. Alg. p.247.

m $\$ 4$ - Wille sydanierik. Algft. p. $4 \overline{7}$.

d 85 - Kirchn. Mikr. Pllanz. d. Sïssw. p. 24 .

o s6-Stokes Fiey Desm. p. 126.

ph $86-K 7$ ebs Organisat. Fallerte b. Algen. p. 3\$2 t. 4 f. 13 .

dzsti-Coolie Brit. Nesm. p. sf t. 36 f. 13 [partim e Delp. 187 ? ?].

.187 - Alexento Chlorosp. Kihark. p. 203.

a 88 - Hansy. Prodr. Algent. Bülım. p. 197.

ms-t. Brebissonii Rimbin. Chloroph. env, Kharkow p. 32.3

m Si-1sti. Jel. magyar. alg. 1.205.

d sy-Toni syll, alg. 1.915?.

$\mathrm{m} 90$ - Chmiel. in Tr. Soc. Nat. Khark. $23 \mathrm{p} .99$.

d 90 - b. gypsorum Gutw. Wahr. 12. Priorität p.6\%.

$m$ (1) - Eichler Spis Desm. Miedz. p. ST.

m $10-$ Anders. Sverig. Chlor. 1 p. 15.

1) 91 - hirchn. Mikr. Ptlanz. d. Sïissw. ed. 2 p. 21 .

m\$1 - Heimerl Desm. alpin. p.596.

11 91 URSINELLA Ḱuntze Rev. gen. pl. p.925.

d 91 Cosm. v. gypsorum Gutu. Flor. alg. Leopol. p. 19 t. 1 f. 34.

m 92 Cosm. Borge Chloroph. Torsk. Finmark. p. 12.

m 92 - West F1. W. Alg. W. Irel. p. 14 .

1392 - Wone Desm. U. $\therefore$. el. II p. it t. 17 f. 16 et 17.

d - r stenouotum ibid., f. 1s- 19 .

ph 93 - Lütkemül. Chlorophyllkörp. ein. Desm. p.6 t.2 f. $1-8[1-\bar{T}=\mathrm{C}$. pseudopyramidatum ?].

1) 93 - subsp. abnorme Liithem. Desm, Attersees p. 53 ij.

m 13 - Turner Alg. Ind. orient. p. 73.

m 94 - Ist $v$. Adat. Roman. alg. p. 15\%.

m94-Alexenko Nat. alg. Kliark. p. 25.

$194-\mathrm{v}$. angustatum 11 est New Brit. Alg. p.5 t. 1 f. 18. Cfi. Cosm. pachydermum Heim. 1s91, Eu. ovale Foche 18ti; Hithiseus angulosus.

\section{1"yramidatum}

d 92 EUASTRUM W'est Fr. w. Alg. W. Irel. 1. 139 t. 20 t. 13 .

1 $45-\mathrm{r}$. incrassatum West $\mathrm{Alg}$. Wadag. p. 53 t. 1; f. 20 .

\section{l"yramidntum}

a 2 STAURASTRUM West Fr. W. Alg. W. Irel. p. 17!) (st. muricatum v. acutum West 1mak,.

m 42 - I'est in Notaris. 7 p. $1511: 3$.

d $41-5$. coilon West New Brit. Alg. p. 11 t. 2 f. 45.

n - ? v. spinosissimum ibil. St. spinos. Tum. 1843).

\section{PYRAMII)IUII}

d 93 Tumer Alg. Ind orient. P. 7:3 subgen, Cosmarii.

\section{lyyiforme-re}

d i) CoSMARIUM Vort.st. Jerm. Brasil. p. 214 (sem.p. 17 
PYRIFORME

d 89 - ("piriforme"; Tomi syll. alg. p. 1031.

n 91 URSINELLA Kuntze Rev. gen. pl. p. 925.

\section{lyyiforme}

d 93 D0CIDIUM Dontidium) Tumer Alg. Ind. orient. p. 35 t. 5 f. 3 .

\section{Pyrite}

n 3 XANTHIDIUM Chetotgrhla?) Ehrenb. in Abl. Berlin. Akad. 1636 tab. synopt. ad p, 132. [Fossile, annon Spongia??.

\section{IIyxirliemlum}

49 XANTHIDIUM Jeane in Transact. Micr. Soc. of Lond. rol. 2 p.iT. [An ab alio descriptum, mihi imnotum est. - Fossile, an Spongia?].

\section{gurarlougies-cuspidutum -a}

d 40 COSMARIUM Corda in Alm. d. Carlsb. H. 215 (sep.p. 30) t. 6 f. 40 Mricrasterias trnncata $\beta$ quadragies. cuspidatum Hansg. 15ss. - Cfr. Micr. semiradiata].

d 48 MICRASTERIAS Rialfs Brit. Desm. p. 209.

d $52-$ Pritch. Inf. p. $241 \%$.

d $61-A r c h$. in Pritch. Inf. p. 727 .

d $68-R u b$. Flor. Eur. Alg. 3 p. 195.

\section{quadromgulare -is}

d to CLOSTERIUM Corda in Alm. d. Carlsb. 1840 p. 221 (sep.p. 35) t. 4 f. 46 et 47.

d 48 - Rulfs Brit. Desm. 1. 221.

d 52 - Pritch. Inf. p. 284.

d 61 - Arch. in Pritcls. Inf. p. 747 .

n 91 ARTHR0DIA huntze Rev. gen. pl. p. 881.

\section{quarlorengutre}

d 39 COSMARIUM Corde in Alm. d. Carlsb. $183 y$ p. 243 t. 6 f. 32 [Tuastram verrucosum oblique e latere?].

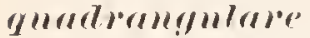

a t5 DESMIDIUM Kit $z$. Pliycol. germ. p. 1.11. [D. quadrangnlatum $R_{i}(i l f s]$.

d 19 - kitz. Snec. Alg. p. 191.

d $63-$ kith. Krypt. Fl. Sachs. p. 181.

o $6 \bar{i}-$ Reinsch Algenfl. Frank. p. 2066.

d si-Alexenko Clitoropli. Khark. p. 218.

d 89 - Toni syllog. Alg. p. T89).

1n 92 - 1706 . Austral. süsswasseralg. p. 43!!

\section{yuadromgulare}

d 4s STAURASTRUM Brib. in Ralfs Brit. Desm. p. 128 t. 34 f. 11 [specim. majus e Brebissom.]; t. 22 f. 7 . [Didymil. Hystrix A $\beta$ Reinseh 1.sid].

(1) $52-$ Pritch. Inf. p. 264 .

o 56 - Mreib. List. p. 138. Forma.

d 61 - Lrch. in l'rituh. Inf', p. $7 \pm 1$ t. 3 t. $24-25$ [e Rulfs].

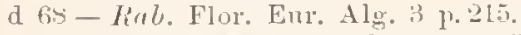

d $79-\beta$ attenutum Kordst. Desm. Brasil. 1.229 t. 4 f. 4 t.

d To-? forma Iieinseh Contribut. p.91 t.12 f. 11.

d $7 s-f i r c h . s e h l e s, ~ A l g . p .170$.

a 84 - Wolle Desm. U. S. 1. 145 t. 41 f. 1-t.

d s.t- $\beta$ alatum Wille sydamerik. Algfl. p. 21 t. 1 f. 41 .

o 86-Slutes Key Desm. p. 16t.

d si-Cooke Brit. Desm. p.16.1 t. 55 f. 4 [e Ihalfs??].

d - $P$ unajor ibid. (Rulfs 1. c. f. 11)

o sy - Borg. Bidr. Bornh. Desm. p. 146 t. 6 f. 10.

d 89 - Toni syll. alo. p. 1199.

d - va alatum ibill. d $90-\beta$ longispina Birg. Desm. Brasil. p. 49 t. 5 f. 55 .

d 62 - r. americana lift. Desmidya Ciastoni. p.358 t. 7 f. 11.

d 92 - Wolle Desm. U. S. ed. 1 I p. 160 t. 52 f. $1-4$.

m 92 - West Alg. Engl. Lake Distr. p. 732.

m 93 - Eichler in Pamiet. Fizy. 13 p. 62.

\section{quredromegularis}

f. 39 ARTHRODESMUS Corde in Alm. d. Carlsh. $1839 \mathrm{p}$. 244 t. 6 f. $36=$ Scenedesmus denticnlatus Lager h. (?)

\section{queradramgulatume-re}

dzf 60 COSMARIUM IIantzsch in Rab. Alg. Sachs. n:o 969 c. fig. 1-5 [C. biretnm linlfs sec. Hantzsch in Rab. Alg. 12:0 $569 l$ in Dec. 121 122 (1861].

d $68-R a b$. Flor. Eur. Alg. 3 p. 170.

d $89-$ Tomi syll. alg. p. 1052.

1191 URSINELLA hientze Rev. gen. pl. p. 925.

\section{querelermguelatum}

d 45 DESMIDIUM Rulfs in Ann. Nat. Hist. v. 15 p. 405 t. 12 f. @) (et 1s4t; in Trans. Bot. Soc. Edin. v. 2 p. 163 t. 15) [D. quadrangulare Kütz;; Desun. Swartzii $a$ Brebissonii quadrangnlare C'rem. 1.863; D. Swartzi i fi quadr. Roy 18!13].

d 45 - Huss. Brit. Alg. p. 345 t. 44 f. 3 [e Ralfs?].

d 19 -lialfs Brit. Desm. 13. 62 t. á [v. obtusilobun Ruce. $1 \leftrightarrow 5$.

d 52 - Pritch. Inf. p. 241 t. 13 f. 37 et th [e Iialfs 1. c. delineata].

d $61-$ Arch. in Pritelı Inf. p. 723 t. 2 f. 37 et 40 [e Ralfs .

d $65-$ Rab. Flor. Eur. Alg. 3 p. 155.

m 70-Nordst. Desm. Brasil. p. 207.

d 73 - Delyonte Desin. subalp. p. 72 (sep.p. 60) t. 2 f. 21 $-2 \%$.

d $73-$ Wood Fr. Alg. p. 126.

a 75 - Mierogr. Dict. p. 231.

d 84 - Wolle Desin. U. S. p. 27 t. 2 f. $13-11$.

o 45 - a. obtusilobum Rucib. Nonn. Desm. Polon. p. 66 sep.p. 11).

d - b. acutilobnm ibill., t. 14 (sep. 5) f. 7 .

o 86 - Stokes Key Desm. p. 110.

d sij-Cooke Brit. Desm. p. 11 t. 5 f. 3.

m 8s - Rickin. Chloroph. env. Kharkow p. 322.

m 88 - Iste. Jel. magyar. alg. p. 245.

m 91 - Iste. Fragm. Alg. 1 p. 1168.

d 92 - Wolle Desm. U. S. ed. II p. 27 t. 2 f. 13-1t.

d $43-$ Briley Contr. Queensl. F1. p. 38 t. 11 f. 27 [e Cooke].

\section{quardronsis}

d 93 COSMARIUM Tumer Alg. Ind. orient. p. 52 t. 8 f. 6. [Cfr. je aisejense r. quadrangulum Gutw. 1s94].

\section{quratratu - $11 m$}

d 51 MICRASTERIAS Duil. Micr. observ. p. 37 t. 1 f. 5 .

a 52 - I'ritch. Inf. p. $24 i$.

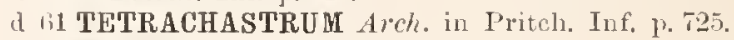

d $69 \mathrm{H}$ icr. Ral. Flor. Eur. Alg. 3 p. 18\%.

d st-Wolle Desm. U. S. p. 117 et 161.

o 86 - Stukes Key Desm. p. 147.

d $89-$ Toni syll. alg. p. 1121.

11 91 HELIERELLA Kuntze Rev. gen. pl1. p. 899.

o 52 Mier. Wulle Desm. U. S. ed. II 13. 129.

\section{quaralratulum -}

a St EUASTRUM (Cosinarium) Guy Mon. loc. Conj. p. 58 t. 1 f. 15 ; et Note Conj. d. m. France p. 336. 
d 8! Cosm, Toni syll, alg. 1. 134.

d (n)-f. h. Gute. Wahr. Priorität 1. 1it.

11 91 URSINELLA kuntze Rev. gen, pl. 1. 1..5.

1) 11 cosm. f. Gutw, Flor, alg. Leopol. p, 45 t. 1 f. 23.

11 !5-t: leopoliense Guhe. Prodr. fl, alg. galic. p. 333 if. 1591.

\section{y"uイrルtum}

1) 14 COSMARIUM Relfs in Ann, Nat. Hist. ‥ 11 p. 39is t. 11 f. 9 (et 1Sti in Trans. Bot. Soc. Elinb. v 2 p. 151 t. 16 [Fig. " siuistra (et $b)-$ C. sinuosum Lund., fig. " dextra $=$ ? C. binerve Lund. teste Lumdell. sed verisimiln uon recte. qua fig. fortasse male exsecuta est. I. tantum figuram Mussullii e Rulfsio 1. c. depictam citar.].

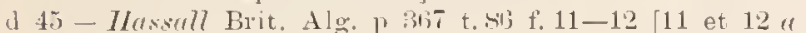
e Iinlfs l. c. lepieta. sed fig. $12 b=$ C. Cucurbita liulfis l. e.].

a 45 - Rulfs Brit. Desin. p. a t t. 15 f. $1[c$ at $b=a$ sinistra et $b$ in Rulfs l. e. supra].

d 4 - Kïtz. sipee. Alg. p. 175.

19 EUASTRUM Cosmarium) Nag. einz, $A l g, p .114$.

d $52 \mathrm{Cosm}$. Pritch. Inf. p. 252.

a 61 - Areh, in Priteh. $\operatorname{lnf}$. p. 731 .

a $6 ; 3-$ Rub. Firypt. Fl, sachs. p. 19s.

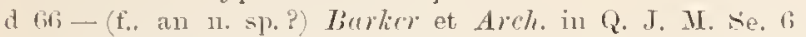
1. 129. [Cosin, decedens??].

m 1; DIDYMIDIUM ('osmarium) Teinsch Trigpt. Fl. Frank. 1. 11:3.

d 68 Cosm. Rab. Flor. Eur. Alg. 3 1) 16?.

1 - b. minus Gmm. (in litt.) ibid. [Cosm. decedens?]

c 71 - Lmmd. Desm. Suee. p. $4 \bar{T}$.

ni 72 - Nordst. Desnu. Spetsb. p. 29.

- 73 - f. excavata Norist. Norg. Desin. 1). 23.

in 75 - Nordst. Desm. arct. 1. 14.

4) 78 - a. genuinum hirchu. Alg. Shales. p. 146.

d - b. maius ["Lundell"] ibid.

o 79- Wille Ferskv. aln. Nor. Senilj. 17. 37 t. 12 f. 20; [v. Wille i schmidle 18013].

○ -f. major ibid. f. 21.

d StE 1. $\beta$ microsphinctum Gay Mon, loe. Conj. p, 64.

d 84 Cosm. Wrolle Desm. U. S. p. 59 t. 18 f. $8-10$.

d 85 - Kirelm. Mikr. Pflanz. d. Süssw. p. 24.

m. Si - f. suecica Boldt Silir. Chloropls. 1) 100.

$m$ - $t$, iloid. Wille liszit).

o 8ti-Sitakes Kiey Desm. 1) 127.

d sfi-Cook Brit, Desm. 1). sic t. 3t; f. '2.

d 87 -Alexentio Chlornip. Kiluark, p. 2601.

d S8 DYSPHINCTIUM Mums\%. Prodr. Algenf. Böhm. p. 241.

mit Cosm. v. genuinum Tiabin. Chloroph, env. Kinarkow p. 325 .

m 8s-f, suecica Boldt Desm. Grönl. p. 10.

$m$ - $\mathrm{ff}$. ibid. (ff. ITille 1sĩg).

m 88- Tordst. Bornh. Desin. p. 19s.

o 88 - Nordst. Fr, wat. alg. N. Zeal. 1. 5.j t. 6 f. 5 form. Luml. 1sit et aliar tro.

d 49 Dis Toni syll. alw. 1\% Sint.

d r. mierosphincetum ibid. p. 4.9. v. elongatum, ilid. la psu commemoratum, ad Cosm. grauatum pertinet!

ms - Wist Fr. w. alg. North Wales p. 288

m !n-Eichler spis Desm. Miedz. p. 80 t. 8 f. 19.

m 90 - Anderss. Sverig. ('hlor. 1 p. 1 万.

d !1-Kirchn. Mikx. Pflanz. d. Süissw. ed. 22 p, 26.

m:11 - Heimerl Desm. alpin. p. 5t31;.

d 51 - f. Borge Bilr. Sibir. Cluloroph, 13, 12 t. 1 f, f.

m itz-Borge Chloropl. Norsk. Fimuark. p. 11.

wordstedt, Itudex luesmid. il f. major ihid.

in tr. ilitil.

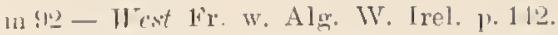

(1) 92 - Wolle Desm. U. S. ed. Il p.63 t.21 f. 8 - 10.

11193 - Liitlirmulll. Desm. Attersees 1.555.

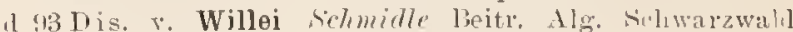
1. 91 t. 4 to. 1 et 2 , Wille 1s69). [Forma tautum sec. [3i)r\%. 18:11].

d - f. ibill.. t. 4 f. 3.

m?4 Cosm. f. major Iste. Ailat, Roman. alg. 11. 1s.

m $14-\mathrm{f}$. Borge Siissw. Chlor. Arehang. p.2: it: Wille 1879 .

12 - ff. ibid. liorge 1891 et Nordst. 1sats).

o ! - f. major liory. F. alg. istorönl. p. 20.

m 95 - Borye strerig. Chlor. II p. 17.

o $95 \mathrm{Dis} . v$. punctulatum schröler Alg. H. Riseng..., 1. 17.

Clip. Gosm. Cucumis.

\section{muraritum}

d 73 DESMIDIUM (Didymoprium) Nordst. Nong. Desm. p. $4:$ t. 1 f. 24 .

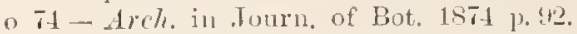

d $80-\beta$ graciliceps Nondst. in Wittr. et Nordst. Aler. exs, n:0 337 et in fase. 21 1.33 (184!1. [D. graciliceps Lagerh. 18si3].

z 43 - $\beta$ ginciliceps Nordst. in Wittr. et Nordst. Aly. exs, 12:0 5.5 ; et $(1989)$ in fase. 21 p. 33.

1] $8 t$ - Wolle Desm. U. S. p. 2 t. 19 f. 5. [v. eonstrietum Nordst. 1s8s].

In 85 - Bollt Sibir. Chloroph. p. 124.

n ș DIDYMOPRIUM Facil. Nonn. Desm. Polon. p. 69 sel.p. 11).

11 S6 Desun. Josh. Burm. Desm. p. 63is t. 22 f. 3 [D. grae ilieens f', intermedia Nordst. 1888].

zf 86 - Layerh. Amerik. Desm. p. 22.27 t. 27 f. 1.

o 80 - Stukes liey Desm. p. 110).

ก SS-v. constrictum Nordst. Fr. wat. alg. N. Zeal. p. 25 (Wolle 1.84t).

d 89 - Tomi sisll, Alg. p. 784

d 12 -- Wulle Desm. U. S. er. II p. 26 t. 60 f. 5 .

\section{gucurberatum}

11 TuEUASTRUM Norlst. Desm. Brasil. p. 215 (sep.p. 175) t. 2 f. 10 won Neq. Eu. spinulosum subsp. q ฉ. Wild. 1s91].

d $80-\beta$ javanicum Nordst. De Alg. et Charac, 1 p. 9 t. 1 f. 15.

d 89 - Toni syll. alg. p. 1079 .

d --v. javauicum ibid.

\section{yurerlrutum}

d 19 STAURASTRUM Turner Aig. Ind. orient. p. 104 t. 14 f. 1 !?

\section{mercilvirenurlutus}

1136 ARTilRodesmus Elroul, in Hiegm. Areh. f. Nat, 183 is p. 153 - Scenedesmus caudatus.

\section{yurealnir.ros}

d T0 EUASTRUM Nordst. Desm. Frasil. p.216 (sep.p. 178) t. 2 fi. is.

ค $九-$ Nordst. Alg. brasil. p. 21

a $8: 1$ - Toni śrll alg. p. 10\%5.

1 91 HELIERELLA Kuntze Rev. gen. pl. p. Sy9.

o $92 \mathrm{E}$ u. f. Réc. Desmidra Ciastoni. 13.37!) t. 7 f. 30.

1 - v. dideltoides ibid., t. 7 f. 31. 


\section{reurliviromentulue}

it si STAURASTRUM Foy de Rise. Japan. Desm. p. 241 (sep.p. s) t. 268 f. 4.

d 89 - Toni syll, alg. p. 1205.

ozf 13 - f. Thomer Alg. Int. orient. p. 110 t. 14 f. 2.

nt - f. typica ibid.; t. 16 f. 1:!

a _ - f. divergens ibid.; p. 111 t. 17 f. 4 .

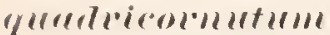

d 93 XANTHIDIUM Roy et Bisset in Roy Scottish Desm. p. 215 , (et 1894) t. 4 f. 5 (sep.p. 25 ).

\section{quarloiderus}

1) 6 ARthrodesmus Wood in Proe. Philad. Ae, N. s. 1869 p. 17

$173-$ Wood Fr. Alg. p. 158 t. 20 f. 2.

a sit-Wolle Desm U. S. p. $9 i$ t. 24 f. 17-1s [Ex Wood 110 bene delineat.].

1 sib- $\beta$ æqualis Lagerh. Amerik. Desm, 1. 243 t. 27 f. 20 ?

o sili - Stokes Key Desm. p. 1:31.

1) 8 - Tomi syll, alg. p. 105?.

- - v. itqualis ibid.

1 92 - Iolle Desin. U. S. ed. If p. 104 t. 27 f. 17 - 1 s.

\section{qundlifurillur. - "}

def 71 CoSMarium $L$ Luml. Desm, suec. p. 32 t. 3 f. 12.

1 s st - Wolle Desm. U. S. 1. st t. 17 f. 16-18.

$18 t-\beta$ brasiliense Witle sydamerik. Algft. p. 15 t. 1 f. 31.

in sh - Layerh. Anerik. Desin. p. 236.

(1) sij-Stoke's liey Iesin. p. 129.

itas Cooke Brit. Lesm. p. 115 t. 4! f. s [e Lund. !].

un s'- Boldt Desm. Crönl. p. 23.

ozAs - f. hexasticha Nordst. Fr. wat. alg. N. Zeal. p. 49

C. hexastiehum Lund. 1571).

o - f. octasticha ilid. (C. hexast. $\beta$ oetastiehum Tordst. 1573).

d $8: 7$ - v. gemnulatum Mwsk. Furth. Note X. Z. Desm. p. 19 t. 3 f. 32

dz 81 - Toni sy Hl. alg. p, 102.2.

d - v. brasilieuse ibid.

m 59 Racil. Now. I'esm. p, 89.

1191 URSINELLA Kuntz: Rev. gen. nl. p. 12;

m 92 rosm. We'st Fr. w. Alg. W. 1rel. 1. 155.

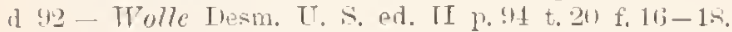

Cfr. Cosm. gemmulatnm, pulcherrimum v. Reinsch $187-$ et 1sim. supraspeciosum v. emarginnlnm II'est. Eu. margaritiferum Litrbg $183 \%$.

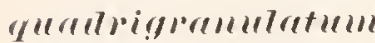

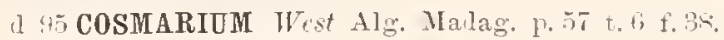

\section{reeredrispincterle}

a st STAURASTRUM Tumer Not. Freslaw. Alg. p. 35 t. $1 \mathrm{f}, 4$.

d si -- ("quadrispinum") Cooke Brit. Desm, p. 164 t. 5í f. 5 (e Turn.).

d s:3-Toni syll, alg. p. 11:n

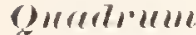

a 71 Cosmarium Land. Desin. Suec. p. 25 t. 2 f. 11. [Cosm. conspersum v. Quadrum liue. 1545].

at 78 - P minus Nordst. Norg. Wesm. P. 11.

ma-Bolit Sibir. Chloroph. p. 10t.

d s 5 -Cooke Brit. Desm, 11. 102 t. 42 f. 1.

m 89 - Boldt Thesm. Grönl. P. 26.

o ch-? Nurdst. Borruh. Desm. p. 19?.

in 85 - Ist 2. Jel, magyar, alg. p. 223. d $89-$ - Toni Syll. alg. p.985.

o - v. minus ibid.

m 90 - Anderss. Sverig. Chlor. 1 p. 14.

11 1 URSINBLLA huntre Rev. gen. pl. 1.925,

m 92 Cosm. West Alg. Engl, Lake Distr. p. 726

m 93 - v. minus selmidle Beitr. Alg. Sehwarzwald p. 101.

n 93 - Twner Alg. Int, orient. p. 73.

m94 - f. minor Schmidle in Flora is p.5s.

o $94-$ v. minor Böry. F. alg. Östgrönl. p. 1.t.

o 95 - f. Johns. Rare Desin. U. S. II p. 244 t. 240 f. 22 [?]. m95-Erchler in Paniet. Fizs. 13 1. 59.

o 95 - Selumidle. Alg. Sumatr. p. 304.

\section{qure7urm}

d 93 DYSPHINCTIUM Tumer Alg. Ind. orient. p. 42 t. 10 t.?.

\section{rencutillume}

1 93 DocidiUM Turn. Alg. Ind, orient. p. 28 t. 2 f. 9. t. 1 f. 12. [Cfr. Wildem. in Notarisia 1893 p. 166; et Ohs. crit. Desm1.. 1.s.t 1),63].

1] 95 PLEUR0T ASNIUM Wret Alg. Madas. 17, 45.

\section{Quersillus.s}

a 11 COSMARIUM $L$ und. Desm, Suee, p. 29 t. 3 f. 10.

n $12-$ Norlst. Desm. spetsb. 1. 32. forma.

o 7 - f. quadrifera Jacols. Desm. Danem. p, 196.

o - - v. polycrenata ibid.; t. 7 f. 17 a [C. formosninm verisimiliter sce. Nordst. Boruh. Desm. p. 195].

o - - v. tricrenata ibid, p. 196 t. 7 f. 17 b. [Quid.?]

o - - vo bicrenata ibill.; f. 17 e. [Quid. ?].

d st Wolle Desm. U. S. p. 8.1 t. 17 f. 13-15 (C. irregulare Wolle 1877.

o si-Stokes liey Desm. p. 124.

d 89 - Tomi syll. alg. 1. 1020.

m 90 - Eichler sipis Desm. Miedz. p. 87.

n 91 URSINELLA Kuntze Rev. gen. pl. p. 925.

(1) $92 \mathrm{Cosm}$. v. depressa Rine. Desmidya Ciastoni. 1. 26 t. fi f. 9 .

d 92 - Woll, Desm. U. S. ed. II p. 42 t. 20 f. 13-15.

In 94 - liarge sïssw. Clator. Archang. p. 29.

m 94 - Gutw. Fl, alg. 'Tarnapol. 1\%.95.

d $95-v$, alpinum sectmialle Beitr. alp. Alg. p. 459 t. 16 f. 1 .

\section{querterureriume -}

1 50 COSMARIUM Nordst. in Wittr. \& Nordst. Alg. exs, 11:0 363 ; et in fase. 21 p. 40 .

1 si-Conke Brit. Desm. p. 102 to 42 f. 5 [t. 12 Deeembr. 188ij. Quid est f. 5? ?.

I si - $\beta$ tumefactum Nordst. Algolog. snlasak. 4 p. 163.

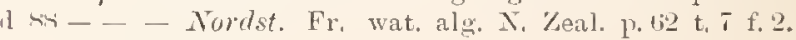
(var. all inter.

a ilid. f. 1.

1 89 PLEUR0T 佂NIOPSIS Toni syll, alg. p.914.

d - v. tumefactum ibid. p. 915.

\section{guatemiume}

a si STAURASTRUM Wolle in Bull. '1orr. bot. Club 1881 1. 13 .

if 84 - V'olle Desm. U. S. p. 144 t. 52 f. $17-19$.

o 86 - Stolies Key Desm. p. 168.

d 89 - Toni syll. alg. 1. 1151.

d) 82 - Wolle Desm. U. S. ed. II p. 158 t. 68 f., 17-19.

\section{Quimbyii}

a 73 CosmariUM Wood Fr. Alg. pr. 134 t. 1 f. 9.

d 84 - Wolle Desm. U. S. p. 61.

o 81-Stokes Key Desm. 1.12i. 
1 so COSMOCLADIUM (Nordst. in litt.) Timi syll. Alg. 1. 8(5).

d 92 Cosm. Wolle Desm. U. S. ed. II potiti.

quimarimm-re

a 71 CosmaridM Lund. Desm sinec. p. 28 t. 2 f. 14 .

d $73-\mathrm{f}$. irregnlaris Norlst. Nor.o. Desm. p. 13.

d 8i) $-\beta$ circulare Nordst. De Aly. et Charace 1 l. $4 \mathrm{t}$. 1 f. 2.

m S6--Iagerh. Amerik. Desm. p. 236,

d 8 - Wolle Fr. Alg. U. S. A. p. \$2 t. t. 60 f. 10 \& 11 [male e Lund? ?

d $8 \mathbf{i}$ - Cooke Brit. Desm. p. 114 t. 4h to í [male e Lund.].

d 89-Toni Syll. alg. p. 1014.

d - ? r. eirenlare ibid. p. 1015.

d - f. irregulare ibid.

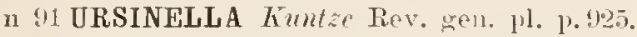

d 92 Cosm. Holle Desm. U. i el. Il p. Ts t. 49 f. 10 et 11.

quinelurirer

d 93 EUASTRUM Tumer Alg. Ind. orient. p. 85 t.11 f. 21.

\section{quintrullu}

d 13 EUASTRUM Turner Alg. Ind, orient. 1\%.81 t. 10 f. 4?.

\section{Ralbenhorstii}

d T3EUASTRUM Intponte Desmid. subalp. p. 145 (sep.p. 93 t. 6 f. 5 . [Eu. inerme b. $R$ abenhorstii Racil). 1.5\%5].

1 89 - Toni siyll. alg. p. 1085.

n 91 HELIERELLA Kuntze Rev. gen. pl. p. 890.

\section{Rabenhorstii}

d is MICRASTERIAS Kirchn. Alg. Sichles. p. 163 [Helierella Bulnheimiana Kunte 1s!1. Videtur M. Crux melitensis f. monstrosa esse. Cfr. Gutw. Fl. alor. Leop. t. 3 f. 28 .

d st-Wolle Ihesm. U. S. p. 118 t. 52 f. 6.

o st - Stoke's Kiey Desm. p. 147.

d 87 - Wolle Fr. Alg. U. S. A. p. 40 t, 56 f. 6; forma [Cfr. Micr. decemdentata].

mss - ? I'otent. Torth Carolina Desm. 1) 3.

d 89 - Toni syll. alg. p. 112!).

d 89 - v. tatricum Racib. Now. Desm. p. 106 et 113 t. 7 f. 2 .

d 92 - 11 olle Thesn. U. S. लl. 2 j. 1331 t. 45 f. 6 (var.), t. 63 f. 6 .

m 93 - Eichler Mat. flor. Miedz. p. 161 t. 10 f. 36 . Cfr. Micr. stauromorpha vo inermis.

\section{Raribor:slici}

d 95 COSMARIUM Koztowsli in Pamietn. Fizyjograt. 13 p. it C. sp. Racib. Nonn. Desm. Polon. p. To t. 11 f. 15, Cosm. lati affine), non Lagerh. $185 \%$.

\section{Raciborslieinum -}

d s. COSMARIUM Toni śyll. alg. p. 75 C. circnlare Rarll. 14\%5. non hïtz̈. see Rrinsch sec. De Toni. sed cum specie heinschil ilenticum est].

"91 URSINELLA limtze Rev. gen. 11. 1. 425.

\section{leariliolrsliti}

118 T COSMARIUM Laycrh. Firit. Lemerk. Desm. p. 53 (C.

Nordstedtii Rac. 1584, 1on alion'um).

d $\$ 9$ - Toni śyll. alg. p. 9.56.

m (4) - Eichler Spis Desm. Miedz. 1. 8T.

1191 URSINELLA Kuntze Rev. gen. j1. 1’.92.

o (12) Cosm. liac. Desmidya Ciastoni. p. 345.

o 93 - Lütliemuill. Nesn. Attersees p. 5.55 t. 8 f. 10. m !1 - Borgr süusw. Chlor. Archang. 11.25.

m 85 - Gutu. 11. alg. Tarmajol. 1. [12.

o 95 -Johns. Rare Desm. U. S. II 1.2.14 t. 2.10 f. 20.

\section{rediums}

1) 93 MICRASTERIAS Tumer Alg. Ink. orient. 1\%!).

- f. typica ibil. p. 12 t. 5 f. 6 a.

- f. dentata ibill f f. $j$ b.

o 94 - Wildem. Obs, crit. Desm. 1) 130.

\section{rediretume}

d 93 EUASTRUM Turuer Alg. Ind. orient. 1, $8: 3$ t. 10 f. it, 55. [Eu. Turneri Wildem. 1s:4].

\section{rellicetr- - llil.}

d 11 PENTASTERIAS Ehrenb. in Berlin. Nonatsb. 1s.10 1. 216.

d 49 PHYCASTRUM hï̈z. špee. Alw. 13. 18..

\section{rellintu- $\|$ )}

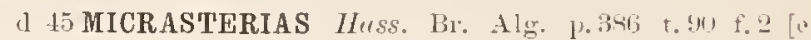
fig. mala Mirr. molitensis hulfsii in Ann. Xit. Hist. ‥ 14 t.li f. 2 delineata. - M. melitensis $\beta$ gracilis hïtz. - M. furcata sec. Riulfs 1848].

n 19 EUASTRUM (Micrasterias) Noy. einz. Alg. p. 123

\section{rellintum}

d 66 COSMARIUM 1.066 in Q. J. Micr. Se. 11 . s. v. 6 p. 5 ;. c. icone $\mathrm{p}$. of $[\operatorname{Cosm}$. sp. in nuco involutum; efr. Areler in Q. J. M. Se. 11. s. v. 16, 185ti, p. 105].

d 68 - Kirb. Flor. Eur. Alg. 3 p. 178.

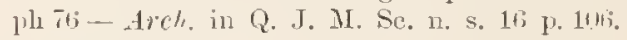

o s9 - Toni syll. alg. p. 1056

\section{rectioser}

1) 10 ECHINELI,A Acharius in Weber et Moler Beitr. Naturk. 2 p. 340 t. 4 f. $4-15$ [Vorticella [0phrydium] versatilis 17 ill. sec. 19 . Syn. alg. Scand., 1817 l. XL. Echinella Acharii A $y$. Ovula animal. sec. Ehrenb. Int. p. 2020. - Closterium Lunula?].

d $19-L y n g b$. Hydroph. Dan. p. 208 t. 69 f. E [Ech. Ricciæformis Ay. Syst. Alg. p. 15. - sec. Jacubs. Desm. Danem. 13. 181 hee speeies apnd Lyngbye ex variis Desmidiaceis in muco involutis compleetitur. - Quoad fig. E $3=$ Helierella Lyngbyi Bory. - Qnoad fig. E $2 \Rightarrow$ Heterocarpella siuuata $\beta$ Lyngbyei $B$ réb.

n 27 MICRASTERIAS $A y$. in Flora 1807 p. 643 [sine deserip)tione et tautum "Echinella radiosa Lyngb." - Ex 1. Cosm. Botrytis sec. Ehrenb.].

d 48 - Rulfs Brit. Desu. p. 72 t. 8 f. 3. [Euastrum Sol Ehrenb.].

d 52 - Pritch. Inf. p. 2.5.

1) 61 -Arch. in I'ritch. Inf. 1. 727 t. 1 f. 21 [e Ralfs].

(1) 68 - Kab. Flor. Eur. Alg. 3 p. 192.

d $70-\beta$ ornata Nordst. Desm. Prasil. p. 223 t. 2 f. 11.

- 71 - Poruata Lumd. Desm. Suec. p. 13.

1) 73 - Delponte Desm. subalp. p. 85 (sep.1. 73) t. 1 f. $2 .-4$.

l 73 - Wood Fr. Alg. p. 145 .

184 - Wolle Desm. U. S. p. 109 t. 31 f. 1-8 forma.

o sfi-Stake's Key Desm. p. 147.

a 86 - Cooke Brit. Desm. p. 59 t. 27 f. 1 [e lialfs].

d $s$ - v. punctata TVest Massachus. Desm. p. 20 t. 2 f. 12. [Quid, est? M. angulosa?].

l) 89 Tomi Syll. alor. 1) 1138.

11 : 1 - West Fr. w. Alg. Wr. Irel. p. 134.

d 92 - Wolle Desm. U. S. ed. II p. 119 t. 35 f. $1-3$,

d - r. prinetata ibil.. t. 43 f. 1 e Mest 1sis!. 


\section{valiosulll-}

1 it COSMARIUM Wolle Desin. U. A. p. 90 t. 19 f. 21 -22.

o si- Stokes Key Desm. 13. 12!

1) - Tomi sisll. alir. p. 11152.

n !1 URSINELLA Kuntzo Rev. gen. pl. p.925.

m ! 2 Cosm. West Fr. w. Alg. Wr. Irel, p.15!.

d $42-$ Wolle Destn. T. S. ed. II 11.4 t. 22 f. $21-22$.

\section{Ralfsii}

1) S2 ARTHRODESMUS Wrot Fr. w. Alg. W. Irel. p. 16s A. Incus $\beta R \cdot l f s$ 1.45).

\section{Ralfisii}

n 15 CLOSTERIUM lireb. in Jemer Fl. 'l'unbr. Wells p.x.

1 th-Bréb. in linlfs Brit. Desm. p. 174 t.30 f. 2 .

152 - Jritch. Inf. p. 28?.

1 is - Arch. in Pritch. Inf. p. 749 .

1) (1;) - Rab. Kirypt. Fl. Sarhs. p. 171.

1 - b. hybridum Rab. ibil. 1. 17t.

l] 6 s - Rab. Flor. Eur. Al

a - b. hybridum ibid.

mi1- Luml. Desm. Suec. 1. 81 .

1) 75 - Microgr. Diet. 13. 17ii.

miti - v. major? Cohn Florul. Desm. Bong. 1)!n.

d 7 - ? v. (o/h, Desm. Bong. p. 26;3 (sep.\}) b) t.11 f.t.

d 79 - a. Delpontii hlebs Desur. Ostpreuss. 1\% 17 (Cl. crassum Doln. 157\%. non Kab. 1863). [C1. Delpontii Ilolle 1s:ioj.

$1 \quad-\alpha$ iloil., t. 2 f.5 a. 6 a. $\beta$ ibid. p. 18 t. 2 f. 5 c.

d - i. typicum ibid. p. 18. a t. 2 f. 1 , c, $\beta$.

ph 8:3-f. Lelponti Fischer Zelltheil. Clost. p. 22, ete. t. 3 t.. 1. 2. .

ph $x_{0}$-t. Delpontii Fiscleer Gyliskryst. Desm. p. 151 t. if. 7 .

d st-Wolle Desm. U. s. p. 46 t. 7 f. 10.

ph 85 - K7tls Beweg. u. Schleimb. d. Desm. p. 315.5.

o sio-Stokes Key Desm. 1. 11:2.

l si-Cooke Brit. Inesm. P. 32 t. 14 f. 2 , t. 15 f.s.

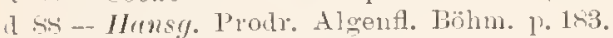

d - $;$ hybris um ibil.

m. S - Bary. Bidr. Buruh. Desm. p. 1.2.

d $x 9$ - Tomi Syll. Aly. 10.847.

1) - v. hy bridum ibid. 1). sts.

m (M) - Bory. Desm. Brasil. 17. 2!\%

$m s 0$ - Eichler Spis Desin. Mienz. p. 86 .

ng1- Borge Bidr. Sibir. Chloroph. p. 14.

11 !l ARTHRODIA Kuntar Rev. gen. pl p. St.

m!ll Clost. v. ly brillum Ifest Frow. Alg. Wr. Irel. 1. 124 .

d 42 - Wolle Desm. U. S. eil. II p.49 t. 8 f. 10.

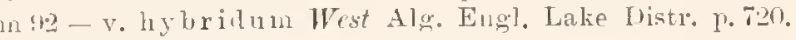

\section{lirtfisii}

d lis COSMARIUM Breb, in Ralf's Brit. Desm. p.93 t. $15 \mathrm{f}$. :) Cosm. Cucumis Rulfs 1841$)$.

d $52-$ Iritrl. Int: P. 205.?.

jh $55-$ - (?) Thomus ubserv. p. $3+$ t. 5 f. 6 .

ph 58-Areh. Suppl. Cat. in Dubl. Zool. Bot. Ass. p. \&s;

in Nat. Hist. Rev. p. 23 s.

1 lil - dreh. in priteh. Inf. p. T:31.

d $43: 3$ - Rub. Krypt. Fl. sachs. 1. 1:1

1\% DIDYMIDIUM (Cosma inm) Reinsch Algenf. Frank, 1. 11 ৫:

d diveosm. Rub. Flor. Enr. Alg. 3 p. 161.

71 - Plenroteniousis) Luml. Desm. Nuec. 1) 52.

9 7:3 - Tombt. Norg. Desm. p. 25.

9.5 - Reinseh ('ontribut. 1. $9: 3$ t. 18 f. 11; monstr. o 7!) a. typicum Klebs Desm. Ostpreuss. p. 33 t. 3 f. 33 $-35.37$.

d - b. perforatum ibid., $\alpha$ t. 3 f. $32, \beta$ C. perforatum Lunel.

o 81 - Must: T. Z. Desm. p. 314; t. 12 f. 31). [? C. pseudopachydermum Vordst. 18s8; ef r. Mask. Furth. Note $18: 12 \mathrm{p}, 5]$.

o 83 - fi Uask. N. Z. Desm. A अa. p. 239 t. 24 f. 1. [? C. pachydermun f. sec. Mash. Furth. Yot. 1892 1. 16].

a 84 - b. angulosa Tiuc. Desm. okol. Krakowa p. sep.p. 15 t. 1 f. $(i$.

d 84 - Wolle Desm. U. S. p. 69 t. 15 f. 1.

o 54 - Sclwöter N. Beitr. Alg. Schles, p. $1.8 t$ (forma).

d 5.5 - a. typicum Liuc. Yonn. Desm. Polon. 1. Th sep. 1. 11).

d - b. alpinum ibil. 1. 1 1, t. 10 (se1. 1) f. ..

d - c. montanum ibid., f. 4.

d - d. angulosum ibid.

d 8 f - Tronli in Leunis Synops. 3 p. 196.

o siti-stokes liey Desm. n.127.

d st - Coolie Brit. Desm. 13.85 t. 31 f. 12 [f. c. e Ralfs].

a 8. - v. depressa Iste. Diagu. prev. in Notar. p. 238 sel'p. !).

d 88 - - Iste. Jel. magyar. alg. 1. 22s t. 1 f. 20.

d sis-IIrnsy. Prodr. Algenfl. Liohm. p. 193.

COSMARIDIUM Hunsy. ibiu. 1. 2413.

m s8 Cosm. Liabin. Chloroph. env. Tharkow p. 325.

d SG PLEUROT无NIOPSIS (Cosmaridium) Toni syll. alg. 1.911.

d $-\mathrm{v}$. alpina ibil.

d -..v. muntana ibid.

d $\quad-$ v. angulosa ibid.

d - v. dejuessa ibil.

ma1 Cosm. Gutw. Flor, alo. Leopol. 1) 51.

d 92 - 11 olle Desm. U. s. ed. II p. 75 t. 18 f. 1.

n $9: 3$ - Cyelidium Timer Alg. Iml. orient. 1). 73.

d 9.1-Plenrotaniopsis Somnd. in Fl. Nobraska p.40 t. 7 f. fi [e rinolir?.

o !) Cosm. Sehröte Alg. H. Riesengeb, p. 18.

\section{lirrlfisii}

d 4t EUASTROM Kïtz. Spec. Alg. 1.173 Eu. binale Ralfs 1811); a inflatum ( $R$ alf: l. c. fig. " sinistr.).

d - $\beta$ emarginatum (1. c. fig. a dextra) ibid.

d - y truncatum (Rirlfs 1. c. fig. b) ibid.

\section{linlfisii}

d ris EUASTRUM $h$ hub. Flor. Eur. Alg. 3 p. 1.91 (E. ansatum Rinlfs, Fucke. non Eilienb.) [non Kitt. 1849].

o bi! - Wittr. Skaudin. Desm. 1) 1\%.

o 61 - Wood in 1'r. Phil. Ac. 11. s. 1\% 16.

d 73 -- Hoor Fr. Alg. p. 1339 t. 13 f. 1.

m 89 - Riabin. ('bloroph. env. Kharkow p 328.

\section{Ralfsii}

dzf DS GONATOZYGON he Bary Conjug. p. Ti t.t f. $23-$ 2.. (G. monotæniam $D_{e} B a r$. 1956. Doeid. aspernm Ralfs Br. Desm. ex p.e non Bréb.).

deffil - Arch. in Pritch. Inf. 1. 721 t. 3 f. 1-2 Leptocyst. aspernm Aveh. 1siss).

zf 63 - Mab. Krypt. Fl. Sachs, p. 1引t fig. xyl. [e Pritch. Inf:. 1861 ].

o bi-Arch. in Q. J. M. Sc. v. 6 p. 181 [a. lavis Turmer $18: 137$.

o in 67 - Ricinseh in Rab. Alg. Eur. 11:0 1919.

zf 69 - Rab. Flor. Eur. Alg. 3 p. 107 fig. xyl. [ut supra $1863]$. 
o 69 t. Areh. in Q. J. Y. Ric. 11. s. !l p. lis [f. monotiplum fi pilosellum Nordst. 14ai; G. R. l.

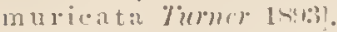

m

a is kirhn. Aly. Xiclules. p. 131.

daf S6-C'oulie Brit Desm. 1.20 1. 1 f. 1 [e Irritchurd.

d Sa - Ilonsg. Prodr. Alerenfl. Böhm. p. 27 ti.

mz sos - Iste. Jel. maryar. alw. 1). -.45.

(1 8!) - Tomi syll. Alo. p. *i)L.

(1) - $\because$ pilosellum ibid. Ci. monoten ium $\beta$ pil. Tordst. 1siviti.

oz. S: - Richter in Plyykothera univ. TII n:o 343.

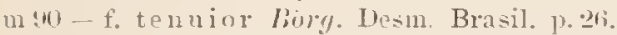

in :1] - Gutu. Flo1. alu. Leopol. 1.2:

d $1: 3$ - fo a. lavis Turue Aler. In l, orient p. 24 -1 reher supra 1siti.

d - fo b. municata ibil. f. trele. $1 \mathrm{sin}$

d - f. e. depauperata ilinl.; t. 20 f. $t$.

l $-\mathrm{f}$. d. crassa ilid.; t. 20 fo t;.

o $91-$ Mol. Anstial. silsswasseralg. Il p. 339.

o !4-Roy sectt. Desm. p. 050 .

m.1-Bir\%. F. alg. Ostgroul. p. 32.

m 15 - v. brevior Schmille in Hedwig. 31 p. il.

m 4.5 - Schmidle Alg. Sumatr. p. 299.

\section{Rerlfisii}

1 t9 HYALOTHECA Kütz. spec. Alg. p. 1s. Gloeoprinm mucosnu lirlfs. non Desmidinm mucosnm Biéb.).

\section{Ralfisii}

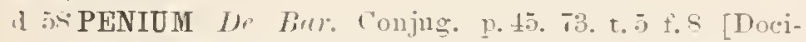
dium minutum Rulfs 18t sec. auct. ipsum; sed propria species verisimiliter sitj: non hït:. 1849.

\section{Rinlfisii}

1 1. PENIUM hütz. Spec. A]g. p.14i. [Cosm. cylindricum Rirlfs 14497.

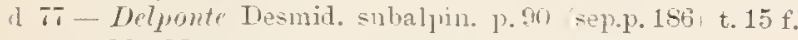
$26-2.9$.

d îCALOCYLINDRUS Fivehn. Alg. Schles. p. 142.

d st - Wolle Desm. U. S. T. 34 t. 12 f. 17 [mala].

o Sti-stolies Fier Itesm. p. 114.

n $\rightarrow$ DISPHINCTIUM Men: $\mathrm{g}$. in Österr. bot. Zeitsehr. v. 3 i $12: 03$ n.

d sos-Ilan:y. Prodr. Algent. Bülnm, p. 1, sis:

d sy - Tomi syll. alg. p. xss.

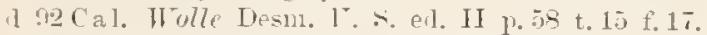

m $4 t$ - Alewnlio Mater. alg. Khark. p. 27.

d 94 Dis. v. hexagonum schmille in Hedwig. 33 lo.?.2.

\section{lialfisii}

1. 19 PHYCASTRUM hütz. Syer. Alg. p.1S1 stam, bif$\mathrm{dnm}$ Ralfs in Ann. Mag. X. H. 1S45. nec alior., st brachiatum.

\section{lialfisii}

11 4! PHYCASTRUM Fag. einz. Alg. p. 125 Stamx. tricorne lirlfs. non livel.) [st. alternans Breb. 1stí].

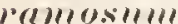

11 11 DESMIDIUM Ekrenl. in Berlin. Monatsher. 1410 p. 207. [Staurastrum spongiosum fortasse].

n 43 - Ehrenl. Mikr. Leb. siid. u. X. Aner. t. IV. f.21. $=$ ideun?

1 49 ASTEROXANTHIUM h̆ütz. sipec. Alg. p. $184=$ idem.

\section{"(l) mosil)!}

n 3) XANTHIDIUM Ehrent, in Berlin. Monatib, 1mbl; 1. 114.
37 - Lhrmb. in Abl. Berlin. Akad. 1831; t. 1 f. 15.

d 34- Ehrenb. Inf. 1. $11 \mathrm{~S}$ [. . delitiense Ekrent. 15:37].

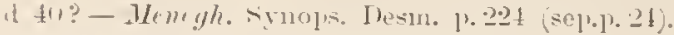

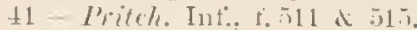

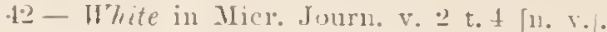

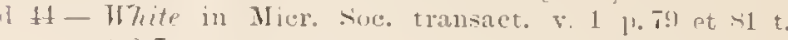
s. f.

() - v. ibil. 1 . $81 ;$ t. $1: 3$.

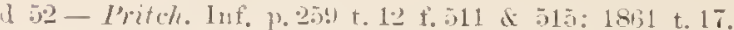

$54-E h r e n t$. Microgeol. t. 33 VII fog et 11. t.30 f. 43.

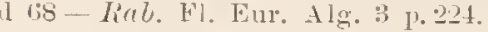
Fossile, an Spongia?

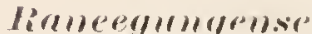

laf:43 COSMARIUM Twner Alg. Ind, orient. 1. (6it t. 10 t. 13 forsan C. granatum Delp.. non lirè . - $\beta$ ornatum ilid.

\section{Ricumeegmugensse}

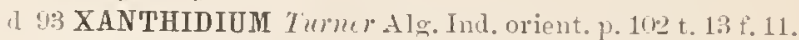

\section{RAPHIIINTRIM}

o 93 Tumer Alg. ind. orient. p. 133. Anbgen. Staurastri.

\section{Rélllii}

1. 59 ARTHRODESMUS Wolle in Bull. Torr. bot. Club. $18+3$ p. 17 t. 27 f. 17

1) 84 - Wulle Desin. L. S. p. 45 t. 23 f. 13-15.

o st - Stokes liey Desm. p. 131.

1. Si - Octacantlium; Toni Syll. alg. p.10tit.

1 12- Wulle Ilesm. L. ... ed. II p. 103 t. 20 f. $13-15$.

o:4-Tetracantlinu, Wildem. Obs. crit. Desm. J. 109 et 111 .

\section{hervenrlii}

d 73 STAURASTRUM Wood Fr. Alg. p. 153 t. 21 f. 22.

d sit-Wulle Desm. L. S. p. 143 t. 45 f. 17 -1s (non vera sec. auct. . t. 52 1:. T-4.

o si -- btoke Key Desm. p. 14is.

189 - Tuni syll. alg. 1. 1172.

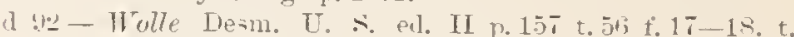
$1 i 3$ f. 7 - $\bar{c}$.

o 94 - Johus. Rnve Desm. U. $\rightarrow$. P. 259. Cir. Staur. sparsiaculeatum.

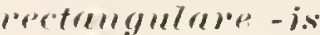

d rs COSMARIUM Grun. in Lal. Flor. Eur. 3 p. 16ir. [Cosm. gotlandicum Hitts. 14.2]

a 82- Nordst. in Bot. Notis. p. 8T.

1 ss-f. Boldt Desm. Grönl. p. 15 (sep.p. 13 ) t. 1 f. 18

n $4 \$-\beta$ minus Buldt Thesm. ntbr. Nord. p.39 (sep.]. \$3) C. gotlandicum $\beta$ minus Irille.

1) 59 - Tom syll. alg. 1\%.987.

(1) - v. ninus ibid. p. 94.

$89-\mathrm{v}$. Kozlowsh. Flor. vollorosl. Sibir. II 1\% 19 et $32 \mathrm{t}$. 1 f. 12 et 1:. [quil ?].

n

m 91 Cosm. Gutu. Flor. alg. Leopol. 1. 11.

0) 1 - f. Borge Alo. notis. 1 p. 59 t. 1 f. 11 form. Boldt 1888 [C. subrectangulare Gutw. 1894].

in :12-Giute. Flor. glun. Galic. 3 p. 124.

it it-Saund. in Fl. Nebiaska p. 41 t. 7 f. t. [Qnid??

m 94-Gutu. Flor. alg. Tarmapol. p. $\$ 2$.

m $4.5-E i c h l e r$ in Paniet. Fizy. 13 p. 59 t. 1 f.s.

\section{rertrugmlrim}

in :3 EUASTRUM Forla in Alm. d. Carlsb. 14.35 $\mathrm{p} .20 \mathrm{~m}, \mathrm{t}$. 3 f. 3()$=$ Pediastrum. 


\section{rectumgulare}

d \&4 SPH两R0ZOSMA Tolle Desm. U. \&. p. 31 t.4! f.s.

o si-stokes Kiey Desm. p.110.

d 89 - Toni syll. alg. 1) 7!4.

(1) 92 .. Holle Desm. U. S. ed. Il p.31 t. 160 f. ?. [Cfr. Tur$n \in r^{\text {in }} \mathrm{Alg}$. Ind. orient. p. 141].

\section{rertulumulum! - -}

d 5 COSMARIUM li inseh Contribut. p. 89 t. 10 f. 9.

d 89-? Toni Syll. alg. 1\%1041\%.

11 URSINELIA Timize Rev. gen. pl. p.

\section{rectru!nulum}

d 94 CosmaridM setmille in Flora $7 \mathrm{~s}$ 1.57 t. 7 f. 23. [Cosm. Schmidlei TTest mart. 1895; Cosm. Frida schmidle april. 1895 !.

\section{liertispilol}

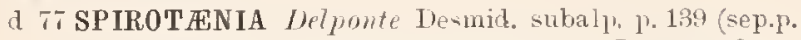
235, t. 20 f. 22 [Spirot. obscura sec. Lütlicm. Gatt. sprirotan. 1. 50].

1 89 - Toni sill. alg p. 811 .

$1193-$ Holytenia Twner Alg. Ind orient. p. 23.

\section{rectorormutum}

12 83 XANTHIDIUM Wrolle in Bull. Torr. bot. Cluh. 1883 p. 17 t. 27 f 6.

d 84 - Wolle Desn. U. S. p. of t. 22 f. $10-11$.

o 86 - Stulies Fiey Desm. 1. 130.

d S! Holacanthium Tomi Syll. alg. p.922.

a $42-7$ tolle Desm. U. s. ed. II p. 102 t. 25 f. $10-11$.

\section{rectosyormm}

dzf 93 COSMARIUM Twm Alg. Ind orient. p. $69 \mathrm{t}$. $10 \mathrm{f} .16$. C $\mathrm{fr}$. Cosm. nitidulum Nordst.

\section{rectum}

d 77 PLEUR0T FNIUM Th ponte Desmid. subalp. p. 12, (se1.1. 22i') t. 20 f. $8-11$.

in 80 - f. Writ7e Jorg. Ferskv. alg. 11.51.

in 84 PENIUM t: minor lfille sirlanerik, Algf, p. 22 t. 1 i. 4.2.

o 55 D0CIDIUM Wulle in Bull. Torr. bot. Club. 12 p. 2.

d 87 - Wulle Fr. Alg. U. \&. A. p. 26 t. 61 t. $211-21$.

o ss Pleur. f. minor Nordst. Fr. Wat. alg. N. Zeal. p. bit t. 7 f. 15 .

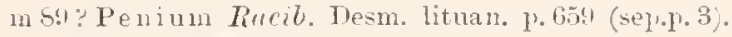

d sty Pletr. Toni Syll, alg. p. S96.

m - f. minus ibid.

o si-Ruc. Now. Desn. P. 10\%.

o - f. punctata ibid. 1\%. 107 t. 7 f. 16.

m(t) - f. in inor Biry. Desm. Brasil. 1, 27

m

o 92 - f. australis hor. Desmilya Ciastoni. 1. 370 t. 6 f. 4. d !1 Doc. Holle Desm. T. S. ed. Il p. 52 t. 10 f. 20-21.

m!13 Plen r. Lïllicmäl. Desin. Attersees p. 516. f. tenuius ibial.

o 9:3 Doc. Twmer Alg Im, orient. 1.38.

\section{rectull}

1) $1:$ SPONDYLOSIUM Twmer Alg. Ind. orient. 1) 46 t. 1si $\mathrm{f}^{\prime}, 20$ \%

\section{rer.1110 (1)}

1 :3 STAURASTRUM Tmmor Alg. Ind. vrient. 1\%128 t. 1 if f. 16.

"refinrtmu-

i 7 CLOSTERIUM It lunte Desmid. subalp. p. 120 (sep.p. 21: $t$ is t: $12-11$. d 8! Toni Syrll. Alg. 1. 831.

n "1 ARTHR0DIA kuntale Rev. gen. pl. p.884.

\section{refirutum}

1 7 STAURASTRUM Delponte Desmid. subalp. p. 42 (sep. ]. 138) t. 11 f. 7 - ?. [St. inconspicuum Nordst. 1sis sec. Lagerh. 1siri.].

\section{regale}

d 9 DOCIDIUM Tumer Ale. Ind. orient. p. 30 t. 3 f. 6.

\section{Regelinmum}

d 4!) DYSPHINCTIUM (Actinotanium) $N$ rag. einz. Alg. P. 110 t. 6 f. E.

n 56 COSMARIUM Brét. List. 1\% 126.

n 55 - (Ca]ocylindrus) de Liar. Conj. p. 72.

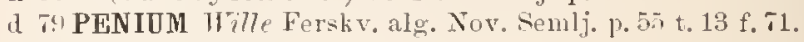

m sis - f. a. Buldt Desm. Grönl. p. 41.

f. 1. ibid.

ma - Birges. F. alg. Östgrönl. p. 10.

Cfr. Cosm. curtum et Thwaitesii.

\section{liegruellij}

d st COSMARIUM Withe Sydnmerik. Algft. p.16 t. 1 f.s. m 85 - f. minor 7boldt Sibir. Chloroph. l. 103 t. 5 f. 8 [dubir sec. anct. in Desm. utbred. Nord. p. 12].

m 88 - ? f. minor Boldt Desm. Groml. p. 14.

d si-Tomi syll. alg. p. 93!.

m 10 - f. minor Gute. Fl. glon. Galic. 2 p. 11.

"1 URSINELIA Kuntze Rev. gen. 11. 1.925.

o 92 Cosm. f. minor Gutu. Flor. glou. Galic. 3 p. 125.

m 12 f. West Alg. Engl. Lake Distr. p. 725 t. 9 f. 20.

- 93-1umer Alg. Ind. orient. p. 49 t. 7 f. 25 (minor) et 21 (major).

m 94 - Dirge Siissw. Chlor. Archang, p.28.

194-v. minimum Eichl. et Gutw. Spec. alg. nov. p. 164 t. 1 f. 6 .

mns-f. minor Schmalle in Hedwig. 34 17. 74.

d 95 - v. madagascariense Hest Alg. Madag. p.58 t.6 f. $n 9$.

Cfr. Cosm. Capitulum.

\section{liegllesi}

d 67 COSMARIUM licinsch Spec. Gen. Alg. p. 116 t. 22 A IIl f. 1-i, sep.p. 8 t. 3 \%

d 6 - DIDYMIDIUM (Cosmarium) Reinsch Algenfl. Frank. p. 112 t. 7 f.s.

d 7 T Cosm. Fiemseh contrib. p. 49 t. 10 f. 12.

Si-Tum. Not. Fresluw. A]g. p. 34 t. 1 f. 10.

d sfi Cuole Brit. Desm. p.95 t. 12 f. 19.

o s8-Nordst. Bornl. Desm. p. 19\%.

d si - v. ornatnm Masli. Furth. Note N. Z. Desm. p. 17 t. 2 f. 25.

4 $89-T$ - Tomi syll. alg. p. (n) 1 .

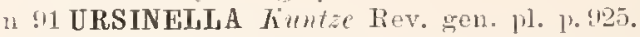

d th Cosm. Hang. Prolr. Alweufl. Bölm. ell. Wohem. p. $17 t$. $\checkmark$ trigonnm ibid.

m: W- West Fr: w. Alg. W. Irel. W.149.

o - v. tritum ibill, et t. 21 f. 3.

1 [1'2-IIansig. l'rodr. Algent. Bühm. II p. 252.

d - $\beta$ trigonum ibil.

o [12-Wrolle Lesm. U. S. ed. II p. 70 t. $43 \mathrm{fo} 4$.

m 93 - West in Naturalist 1893 1.213.

d $55-v$. montanum Schmidle in Hedwig. 34 p. 7.1 t. 1 f. 4 ,

m95- - Beitr. all. Alg. p. 389 t. 15 f. 11.

m 5. - v. tritum líest A]g. Madag. p. 5 ! t. 9 f. 24. Cfr. En. crenulatum Benn.? 
renulure-is

a micLOSTRRIUM Brib. Liste 1. 118 t 2 1.3\%. [Clost. intermedium b. Rub. 1sis, striulatum b. " klels $187 ! 1$.

o 68 - Rirb. Flur. Eur. .11m. 3 1. 121;.

0 $71-$ Jamd. Mesm. Suec. 13. 7 .

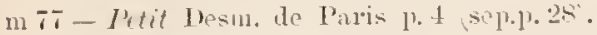

mss - Hordst. Fr. wat. alg. X. Zeal. 1. Th.

o 84 - Tuni sirll. Aler. 11. Mißsl.

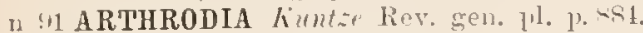

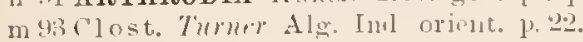

regulare

11 9 COSHARIUM Schminle in Flora is 1) is t. 7 f. 16.

\section{rec!lulurep}

a Tu XaNTHIDIUM Vordst. De-n. Brasil. 1, 231 (sel.ep. (1:3) c. $t^{\circ}$. xylog.

1. T- Tordst. Alg. bresil. 1. 27 t.2 f․ 10 .

d .4 - (IIolacanthium) Tomi syll. alg. p.42\%.

\section{heinhurlii}

a 91 CosmariUm Aleremleo Alg. Poltava p. T t.3 f.2.

\section{Reinsthirlum - "}

1. So COSMARIUM Tomi Fryll, alg. p. $10: 33$ (C. Reinschii

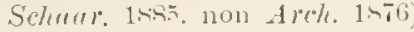

n 91 URSINETIA huntie liev. gen. 11. p.

\section{Reinsrlhii}

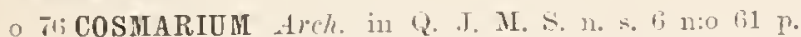
104. (C. s]. lieinsch Contribut, t. 14 f. 4) CCosm. limnophilum sechidle?

d st - Woll Desm. U. ‥ p. tis t. 16 s.. 12.

o 813 - stokes Key Desm. p. 126.

a $8 b^{3}$ - cooke Brit. Desm. p. anj t. 37 t.. 14. [An fig. Reinselii male repicta?].

d 89 - Toni syll, alg. 1. 1045.

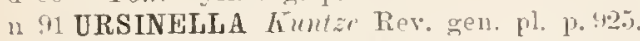

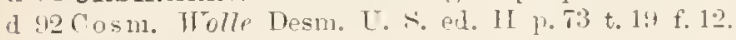

\section{Ririmshllii}

n s. COSMARIUM schacesehm. in Bull. Torr. bot. Club. v. 12 p. 51 Cosin. sp. Reinsch Contrib.. 18i5: r. St t. 1il f. 6 . non Areh. 18Ti. [C. Reinschianum the Toni syll. alg. 1ins! 1. 1181i]

\section{Reimsrllii}

11 S3 STAURASTRUM foy in soott. Naturalist July $188:$ p. 344 Staur. sp. Reinsch (outuih.. 1-í, p. 86 t. $17 \mathrm{f}, \mathrm{s})$.

d $8 \pi$ - (woke Brit. Desin. 1. 1tit t. 51 f.t e Rrinsth).

d s8-Jlunsg. Prolr. Algenfl. Bölım. 1, 2213.

d s. - Toni syll, alg. 1\% $115 \mathrm{~s}$.

o 45 - Johns. Rare Desm. L. S. Il p. 245 t. 239 f. 15 .

\section{lienrullii}

d 1:- STAURASTRUM lieinsch spec. Gen, Alg. 1) 127 t. 23 f. A 1 sep.13. 19 t. 4 . Forma A ot B.

1) t) DIDYMIDIUM stanr. Ieinsch Algent. Frank. p. 16is t. 7 t.9 form. A

o ssitaur. Tordst. Fr. wat, alg. N. Zeal. p. 34 t. 4 f. 2

c] $89-T o n i$ Syll. alg. 1. 115 \&.

1) $89-v$. cornifrons Racil. Now. Desm. p. 1ul (sep.p.2! t. $;$ f. 10 .

d - congram ibił.. t. 7 f. 11

m S12 - v. cornifrons liuc. Desmilya Ciastoni. p. 382 in 43 - Twruer Alg. Iml. orient. p. 102 t 17 f.:3.

m 94 - v. congroum cutw. Fl. alg. Tarnapol. p. 14. (ti. staur. intricatum $/ 1.7 \%$. et st. truncatulum léersch ret it. Eloiseanum.

\section{lenicorrma}

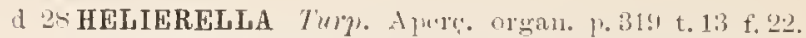

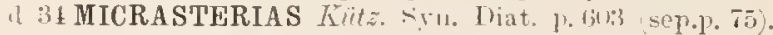
- Pediastrum Tetras EHrenl.) Sinlts?

\section{reniformm -is}

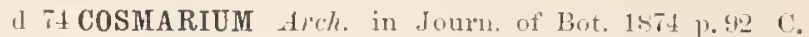
margaritiferum f. genuina Nordst. 1873; C. inarg. B reniformis Rirlys Br. Desun, [non Cymbella re-

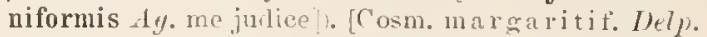

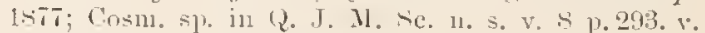
() $\mathrm{pe}+425]$.

1375 - Nordst. Desin, aret. 1. 10.

o :2 - f. Murdst. Algolog. smeksak. 3 p. 1!.

it 84 - Wwile Lesm. I. S. p. Tij t. 11 f. In - H1

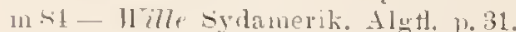

o sij-Stolirs liey Mesul. p. 1.2.-

d $8 T$ - Cooke Brit. Desin. p. 104 t. 42 f. 111.

m 87 - Hansg. Plyys. u. Al r. Stuil. p. 156

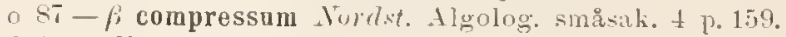

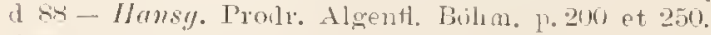

d so- $\beta$ compressum Norlst. Fr. Wat, alg. Y. Zeal. p. 16 t. 5 it. 5 .

$12+9$ - Tomi Syll. alg. 1.952.

d - v. compressum ibid. p. !k3.

m (1) - Eichle spois Thesm. Miedz. p.88.

¿.90-Tioy in Journ. of Bot. p. 33\%.

m 91 - Borge Bidr. Sibir. Chloroph. p. 11.

11. 1 URSINELIA Kumtä Rev. gen. pl. p.925.

m $91 \mathrm{Cosm}$. Cintw. Flox: alg. Leopol. p. \%3.

o 12 - Schmidle Neve einz. Alg. 1'. 211 t. 11 f. 19.

o- $-r$ compressum ibid., f. 20 .

ก - v. retusum ibil. et f. 21 et 22 .

m 92 - West Fr. w. Alu. Wr. Irel. 1. 153.

192 - Holle Lesm. L. S. ell. II p. 44 t. 17 f. 10-11.

o 92 - v. coupressa Mol. Austral sisswraseralg. p. 114.

$12-v$ con pressum Grutu. Flor, glon. Galic. 3 p. 128.

1192 - - Thest Alg. Engl. Lake Distr. p. T27.

- 93 - Divilry Contr. Qupensl. Fl. 1) 47.

- v. coupressum ibid., t. 15 f. 42 (e Nordst.).

1n.93-Lütlicminll. Desm. Attersees 1).55\%.

$493-x$ retu 4 m Schmidle Beitr. Alg. Schnarzwall p. $100 \mathrm{t}, \mathrm{j} \mathrm{f} .1$.

m $98-\beta$ compressum Turner $A$ lg. Ind. orient. p. T3.

n 91 - Bory. F. alg. Österinl. p. 13.

1114 - Gute. El. alo. Tarmapol. 1.!1.

1n 95 - Sichmialle Beitr. alp. Alg. 1) 391 .

n. - f. ibiel.i t. 15 f. $1 \mathrm{~s}$.

$1195-\beta$ compressum Racib, in Flora r. si p.33.

\section{reniforme"}

d 13 SPONDYLOSIUM Jurner Aler. Ind. orisnt. p. lit t. $19 \pm 1 \%$.

\section{$r$ ruiformis}

1 31) CYMBELIA Ay. Consp. Diaton. p. 11" Planta sinm nomine a Leibl. in Flura 1830 descripta r.315, et t. 1 f. 2 [male] pieta). (Descriptio mala. imutilis; non $=$ Cosmarium margaritiferum $\beta$ ren iform is Tirlys. - = Heterocarpella tetrophthalma sec. Kitt. Syı. Tiat. 1. 5y.].

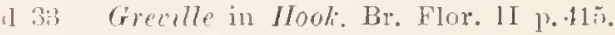

( $41-M r r$. Man. Br. Alg. P. 21\%. 


\section{rellifullis}

d 2t HETEROCARPELLA Bory in Dict. cl. hist. nat. 8 13. 1 so [Micrasterias hepactis?' sec, Elmenb. in Isis $1831 \mathrm{col} .1193-94]$.

\section{repullum}

d 87 COSMARIUM Norlst. Algolog. småsak. 4 p. 162.

d 88 - Tordst. Fr. wat. alg. 1. Zeal. p.5s t. 6 f. 14.

o 89 - Mast. Furth. Note N. Z. Desm. 1) 16 t. 2 f. 21.

d 89 - Tomi Srll, alo. 1\%971.

n g1 URSINELLA Krntze Rer. gen. pl. p. (125\%.

\section{rejumallu!}

a 41 Docinidm Wo7le Desim. U. s.. p.50 t. 11 f. 1.

o si - Stolieg Key Desm. 1) 113

d so-Tomi syll. Alg: 1. 873

d 92 - Iolle Desm. U. S. erl. II p. 54 t. $1+$ f. 1 .

\section{"epurlutluा"}

d 49 PHYCASTRUM (Pachractinium) Jerty in Bern. Mitth. 181! 1) 175

d 52 - I'erty lileinst. Lebensf. p. 210 t. 16 f. 26 .

d 68 STAURASTRUM Rul. Flni. Eur. Alg. 3 p. 221.

d 89 - Toni syll. alg. p. 1143.

\section{vesulluillm}

d 93 STAURASTRUM Twmet Alg. Ind. orient. p, 126 t. 15 f. 1․․

\section{retienlutum}

d USGONAT0ZYGON Tumer Alg. Ind orient. 1.24 t. 24 f. : . Oedogonium punctatostriatum the liury sec. IVest in Jomrn. of Bot. 1895 [?.65].

\section{retror:sIIII - -}

d si EUASTRUM Josh. Bum. Desm. p. 638 t. 23 f. 11 \& 15. d 89 - Tomi Syll, alg. p, 1107.

13 91 HELIERELLA huntze Rev. gen. pl, p. 8s.

\section{retusiformll?}

n 9o COSMARIUM Gute. Wahr. a. Priorität 1) 69 (C. Hammeri $\beta$ retusiforme litle.

d - $\beta$ incrassatum ibil.

m91 - Gutw. Flor. alg. Leopol, p. 55 t. 2 f. 1?.

d $-\beta$ incrassotum ibid. t. 2 f. 13.

d $62-\mathrm{f}$. majus Gutw, in Nuov. Notar. III 1, 2(1.

d ! 2 f. major Flor. glon. Galic. 3 p. 130 t. 3 f. 6 .

m 45 - Eichler in Paniet. Fizy. 1:3 p.59.

d 45 - v. alpinum selmmill Beitr. alp. Alg. p. 456 t. 1 5 f. 27.

\section{"rtusull}

d 1u CLOSTERIUM Mencyh. Synops. Desm. 1.236 (sep.p. 3ti) [Pleurotenio truncato et Trabeculæ froximum ser. anct. ips.]

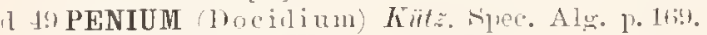

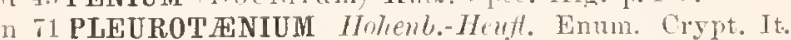
Yenet. 3. 321.

\section{vetursll11}

a :B DYSPHINCTIUM Thme Alg. Ind. orient. 1.41 t. i t. 10.

\section{letusull1.}

(1) 45 EUASTRUM Kïlz. I'hyeo]. germ. p. 13ij [Arthrodesmus Incus ser. Kiitz. in Rulfs Br. Desm. 1, 118].

d 17 - Fub. Deut. Frylut, Fl. 13.55. n 49- Tetracanthiun) Norg. einz. Alg. p. 113.

in 61 COSMARIUM Rossm. Nachtr. Wetter Alg. 1. T

\section{Hetusull1 -}

d 49 EUASTRUM (Cosmarium) Perty in Bern. Mitth. 18.19 p. 17: [10n Kitz. 1845].

a 52 - I'rty kleinst. Lebensf. p. 209 t. $16 \mathrm{f}$. 12.

d 68 cosmariUm Rab, Flor. Eur. Alg. $3 \% 1 \%$.

11 71 -Lumd. Desm. Snec. p. 3 t t. 3 f. 3 ; et f. minor.

a 73 - Nordst. Norg. Desm. 1) 16.

o 76 - Jucols. Desm. Danem. 1. 195.

a 80 - $\beta$ vagans Nordst. Te Alg. et Charac. 1 p. 5 t. 1 f. 5 .

1 st - Fucib. Desm. okol. Krakowa p. - (sep.1.13).

d 84 -. Tolle Desm. U. S. p. 40 t. 18 f. 25 - 26.

o S6-Ntulies Kiey Desm. 1. 129.

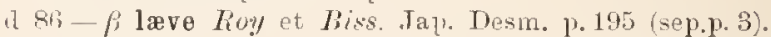

o 8:-v. Ine Musl. Furth. Note X. Z. Desm. 1\%15 t. 2 f. 17.

d s.7-Tomi syll. alo. p. 1018.

a - vo vagans ibid.

n - $-\mathrm{v}$. lieve ibil.

n !l URSINELLA Kumtz' Rov. gen. pl. p.920.

o !2 Cosm. Bigastridium) Rac. Desmidya Ciastoni. p. 3.37 .

1 92 -.. Wo7lp Desm. U. S. el. II p. 88 t. 21 f. $25-25$.

\section{ietusulu}

a $1:$ STAURASTRUM Turner Alg. Ind. orient. p. 104 t. 13 f. 13.

d $91-$ v. punctulatum Eichl. et Gutw. (in Krakau Aureig. 3). 241 et sipec, alg. nov, 1). 17 t. 5 f. 41.

o - - f. hians ibil.. et ilee. alg. nov, p. 174 t. 5 f. 4 . .

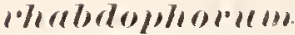

d 5 STAURASTRUM Nordst. Desm. aret. p. 36 t. 8 f. $\neq 0$. it 89 - Toni siyll. alg. p. 1179.

n 98 - (Rutidiastrum) Twner Alg. Fud. orient. J. 133.

\section{rhomb1rsoides}

a si COSMARIUM Tolle Fr. Alg. U. S. A. p. 28 t.60 f. (i) 5 . 7 .

o 87 - ITolle Desm. Pacif. Coast p. $4: 35$.

il 89 - Tomi syll. alg. p. 10li.

n :11 URSINELLA Kuntž Rer. gen. ph. p.925 "rhombus'oides")

\section{"rhomI)/remm}

d 93 D0CIDIUM 7mmer Alg. 1nd. orient. p. 29 t. 2 f. 18.

\section{Rirroirformolllis}

121 ECHINELLA Ag. Srst. Alg. 1\% 15 (Ech. radiosa Lyngl. 1819. nee fehar. 1810). [Ex $]$. = En. Botrytis Ehrenl. 1-35]

\section{rireitrformis}

n $2 i$ ? MICRASTERIAS A $\%$ in Flon 1827 p.613 "Rivularia riccixformis ter Engl. Bot."). (Lapsus memorize. "uwm nulla species " $\boldsymbol{R}$. ricciæformis" in Engl. Bot. exstat, sed R. "echinulata" t. 137s. Cfr. A\%. Frst. Alg. 17. 15 et 16: Echinella Ricciæformis E. radiosa Lyngl.) et $\mathbf{E}$. articulata ( $R$. echinata [!] E. B. t, 137s)].

\section{liirhtrei}

d (1). EUASTRUM Schmidle in Flora 78 1).60 t. 7 f. 25 Euastropsis Richteri (Gen. Hydrodictyac.) Lager\%. iu Tromsoe Nus. Aarsh. 17. 189.1 p. 12 et 20 . Cfi. Sethmille in Hedwigia 1,49t p. (153).J. 


\section{rimgens}

d 51 MICRASTERIAS Buil. Micr. obserr. p. 37 t. 1 f. 11.

1) 52 - Yritch. Inf. p. 247.

d 61 - Areh. in Pritch. Inf. p. 726.

d $68-R a b$. Flor. Eur. Alg. 3 p. 195.

d 73 - Wood Fr. Alg. r. 143.

d St - Wolle Desm. U. s. p. 112 t. 35 f. 1-2.

o 8 - . serrulata Wolle in Bull. Torr. bot. C1. 12 p. 129 t. 51 f. 15 .

o 86 - Stulies Key Desm. p. 146.

o - - v.) serulata ibid.

o $8 T$ - r. serrulata Wolle Fr. Alg. U. S. A. p. 41 t, ล. f. 15.

d Si - Toni Syll. alg. p. 1120.

o - r. serrulata ibid. p.1121.

1. "1 HELIERELLA Kuntze Rev, gen. pl. p. $\$ 89$.

d $.2 \mathrm{Mier}$. Wolle Desm. U. S. ed. II p. 123 t. 39 f. 1-2.

d - v. servulata ibid., t. 47 f. 15.

\section{Robinsaniamm}

dz 80 XANTHIDIUM Arch. in Crowe in Q. J. I. Sc. 11. s. rol. 22 n:o 7 p. p. 114 et 116.

z 83 - Joshull in Journ. of Bot. v. 21 p. 291.

d si-Coole Brit. Desm. p. 134.

d 89 - (Holacanthium) Toni Syll, alg. p. 924.

\section{robustum}

d 5 CLOSTERIUM Hast. in Amer. monthl. micr. J. 13 1. 1.04 t. 1 f. 4 . $\mid \mathrm{Cl}$. Ehrenbergii sec. West in Journ. of Bot. 1895 p. 207.

d 92-Woll' Desm. U. S. ed. II p. 48 .

\section{robustum}

d 93 D0CIDIUM Turner Alg. Ind, orient. p. 27 t. 2 f. 8 .

\section{robustum}

d TSTAURASTRUM Delponte Desmid. subalp. p. 50 (sep. p. 11 ii) t. 10 f. $34-35$.

d 89 - Toni Srll. alg. p. 1151.

\section{Rïmerianre}

d 45 PALMIOGL0EA Kütz. Phyeol. germ. p.153=Limnodictyon Römerianum.

\section{roseola}

- 93 CYLINDR0CYSTIS Turner Desm. Notes p.346 et f. 18 p.3.1.

\section{Rostrifiusliti}

d a) COSMARIUM Gutx. Wahr. d. Priorität p. fi.

d 91 - Gutu. Flor. alg. Leopol. p. 41 t. 1 f. 15.

\section{liostrifillshii}

d 9) STAURASTRUM Fintu. Wahr. đ. Priorität 1'72.

d 91 -Gute. Flor. alg. Leopol. p. 37 t. 3 f. 16.

\section{rostellmmin}

d 95 CosMARIUM $W^{2}$ st Alg. Madag. p. 65 t. 7 f. 19, et 20 f. $\operatorname{lninor^{\circ }}$.

\section{rostellum}

d 93 STAURASTRUM Roy Seottish Desm. p. 212 (et 1894 t. 3 f. 3 (sep.1. 2 )

\section{ROSTRATA}

- 90 Wille in Natiorl. Pflanzenfam p.9. Sect. Closterii. dovetedt. Index liesmid.

\section{lostrutum. -}

d 32 CLOSTERIUH Ehrent. Entw. d. Inf. p. 67. [Deseript. brevis].

(1 31 - E7hul. Organ. kl, Raum. p. 240 isep.p. 96).

d 38 - Toxotium) Elrevib. Inf. p. 97 t. 6 f. X. (Cl. Acus in fütz. Syı. D.. Frustulia subtilis et subulata? Kïtz. I. c., Cl. caudatum Comln 1835).

d $40-$ Menergh. Srnops. Desm. p. 234 (sep.p. 34).

o 41 - Builey Amer. Pacill. 1, 303 sep.1. 22) t. 3 f. 36. [C. setaceum.

d 45 -Hass. Brit. Alg. p. 373 t. 87 f.6 [ex Ekrunb. l. c. delineat .

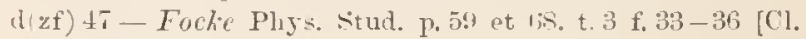
Kützingii ?!.

Izf 48 - Ralfs Brit. Desm. p. 175 t. 30 f. 3.

$149-$ hitz. spec. Alg. p. 173.

d 52 - Pritch. Inf. 13. 253 .

o 56 - v. lævigatum Brib. List. 13. 156.

z $5 \bar{T}-$ De Bury in Bot. Zeit. p. T6if.

zf 58 - De Bury Conjug. 1. 50. 5t, t. 5 f. 24i-30.

Iz 61 - Arem, in Pritch. Inf. p. 719 t. 3 f. 44 [ex Ralfs].

o 61-f. Hantzacle in Rab. Alg. n:o 1330 et 1337 (f. ad Cl. de corum accedens.

l) 63 - Rul. Kryjt. Fl. Sachs. p. 174.

in 67 - Reinseh Algenf. Frank. p. 191.

o $6 \pi$ - Not. Desm. Ital. p. 66 t. i f. 73.

il 68 - Rub. Flor. Eur. Alg. 3 p. 135, f. xyl. 51 b p. 103.

o - b. lævigatum ibid. p.13t;.

an 70 - Reinhard in Arbeiten Naturf.-g. Charkow I p. 15.

i 73 - Wood Fr. Alg. p. 115 t. 12 f. 3.

d 75 - Microgl. Dict. p. $17 \%$.

Ilaf 7 -Delponte Desm. subalp. p.11s (sep.p. 211; t.17 f. ti3-6s:

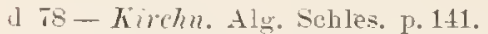

m 78 - Himpel Alwenfl. Chemnitz p.112.

a 79 - a. typicum Klebs Desm. Ostrueuss. p. 1s, a et $\beta$ (v. lievigatnm Bréb.).

a - b. Kuetzingii. a et $\beta$ ibid. Cl. I ïtzing ii Brid. List.). d - c. setaceum ibid. Cl. setaceum Ehrd.।.

- 81 - Musk. N. Zeal. Desm. p. 314 t. 12 f. 34.

ph zf 53 - Fischer Gypskrsstall. Desm. p. 151,173 t. 9 f. 11. t. 10 f. 14.

o 81-Gay Mon. loc. Conj. p. 76.

mst - Arturi Liste alg. Moscou p. 110.

dzf 84 - Wolle Desm. T. S. p. 46 t. \& f. $1-3$.

d so-Kirchu. Mikr. Pfanz, d. Süssw. p. 21.

In Sā-Buldt Sibir. Chloroph. p. 123.

m S5̆ - Racil. Nonn. Desm. Polon. 1. 633 (sep.1) T.

r $86-F r a n k$ in Leunis Synops. 3 p. 119.

zf o $86-$ Lagerh. Algol. Bidr. 1 p. 48 , fig. $3 \times 5 \log r$.

o 86 - Stokes Key Desm. p. 113.

dzf 86 - Cooke Brit. Destr. p. 33 t. 14 f. 3 (e De Bary 1s5s).

d sí-Alexentio Chlorosp. Kliark. p. 229.

d 88 - Hnnsy. Prodr. Algenfl. Böhm. p. 183 et 243.

dz 88 - Toni et Leri Fl. Alg. Tenez. p. 35.

m SA - Riabin. Chloroph. eur. Kliarliow T.317.

m Sho- Boldt Desm. Grönl. p. 42.

d 89 - v. hrevirostratum West Massachus. Desm, p. 17 t. 2 f $!$.

dz 89 - Toni syll. alg. 11. 851 .

n - v. lievigatum ibid. p. 852.

n 89 - Kozlousk. Flor. vodorosl. Nibir. II 1) 32.

12 to - Eichler śpis Desm. Miedz. T. 86.

m (n) - Anders: Sverig. Chlos. 1 p. 18.

d 91 - Kirchn. Mikr. Pflanz. d. siissw. el, 2 p. 2 .

n 91 ARTHRODIA Kuntiv Rer. gen. pl. p. 884.

m 21 Clost. Gutu. Flor. alg. Leopol. 1. 37. 
m 92 - Borge Chloroph. Norsk. Finmark. p. 15.

$m \quad-\beta$ lidvigatum ibil.

m 92 - Rimmer Alg. St. Poilten I p. is.

dyf 92 - Wolle Desm. U. s. ed. II p. 19 t.! f. 1-3.

d - v. breviustratum ibid.. t. 13 f. 21.

1392 - West in Notar. 7 p. 150 !

n!13-Lütliemïll. Desm. Attersees 1) 544 .

\section{rostrutum -}

a S5 COSMARIUM Turner New rare Desm. p. (335 (sep.p. 3) t. 1i, f. fi. [C, aculeatum Holle sec. Holle 18sij].

o 57 - Layerh. Iirit. Benerk. Desm. 1). 537.

d 89 - Toni syll, alg. p. 1032.

11 11 URSINELLA Kuntze hev. gen. pl. 1. (25.

\section{nostrutum -}

a 14 EUASTRUM Rulfs in Ann. Nat. Hist. v. 14 p. 192 t. 7 f. $\bar{j}$ (et 1846 in Trans. Bot. Soc. Edin. v. 2 p. 12! f. 11 ).

a 15 - Ilass. Brit. Als. p. 383 t. 91 f. 8 [e Rulfs 1. c. depictum].

dz.ts - Ralfs Brit. Desm. p. 88 t. 14 f. 0.

dz 52 - Pritch. Inf. p. 25 !.

o 60 - v. $\beta$ Wrallich Desm. Low. Bengal p. 2S3. [v. bengalicum Toni 1889; Eur. cymatium? Tum. 1893]

l 61 - Areh, in Pritel. Inf. p. 730 t. 1 t. 20 [e Ralfs].

d $193-$ Rab. Frypt. Fl. Saclis. p. 18\%.

m 70 - Nordst. lesm. Brasil. p. 217.

m 72 - Nordst. Desm. Spetsb. p. 37.

0.44 - Wolle Desm. U. S. 1. 106 t. 27 f. 8-9. [?].

o $\$ 6$ - stokes fiey Desm. 1, 145.

dz 66 - Coulie Brit. Desm. p. 73 t. 35 f. 2 a-f. [c. et d. e Ralfs 1,48].

o $8 T$ - $\beta$ præmorsum Nordst. Algolog. småsak. 4 p. 156 .

d $8 S$ - v. cumbricum Bemett Fr. wat. Alg. Eng. Lake Distr. 2 p. 5 t. 1 t. 13.

o 89 - f. Nordst. Bornl. Desm. p. 191.

d $s s-\beta$ premorsum Norlst. Fr. wat. alg. N. Zeal. p. 34 t. 3 f. 7. [Eu. umbonatum Schmidle 189fi].

m 89 - Rucil. Mat. Hor. glon. Polsk. p. 113 (sep.p. 34).

d S9-Toni Syll. alg. p. 1099.

d - vepremorsin ibid.

d - v. cambricum ibid. p. 1100.

d ... v. bengalienm ibil.

n (1 HELIERELLA Kuntze Rev. gen, pl. p. An!.

m@1 Eu. Gutu. Flor. alg. Leopol. p. 73.

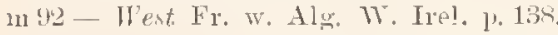

o 12 - Wolle 1esm. U. - . ed. 11 p.116 t. 31 f. is et 9.

in 92 - Gutw. Flor. glon. Gralic. 3 p. $13 \%$.

d 93 - f. Nordst. in Wittr. et Nortst. Alg. Exs. n:o 1109 cum f. xylogr.

o 94 - Wildem. Obs. erit. Desm. p. 85.

n 95 - $\beta$ priemors um Kieron. in PHanzenw. (stafrik. p. 21.

1] 15 - umbonatum West Alg. Madag. p. 51 t. 6 f. 16 [Eu. unbonatum Schmidle 189i3].

1 $\quad$ - v. ornatum ibid. 1). 52 t. 6 f. 17. Cfr. Eu. elegans b. Rab. 1s6s. Eu. Crameri.

\section{rostrutum}

(l s5 STAURASTRUM Rucil. Nonn. Desm. Polon. 1).91 t. 12 f. s (sep.1. 35 t. 3) [Stanr. Oxyacantha Arch.t.?]. d 89 - Toni tryll. alg. p. 1164.

1n! 10 - Eichler spis Desm. Miedz. 1.90.

\section{Rosula}

d 31 MICRASTRRIAS Kut syn. Diat. p. 1300 (sep.p. 72) t. $19 \mathrm{f} .98=$ Botryocystis Morum Kütz. sec. Kïztz. Phy g.en.

\section{Potre}

1) 32 EUASTRUM Ehrenb. Entw. 11. Inf. p. 82. [Deseript. mala. nimis brevisl.

o 3.t-Ehrenb. Organ, kl. Raum. p. 215-6.

1) 3.3 - Elerenb. Inf. p. 1 iil t. 12 f. 1. [F. a et $e=$ Micr. rotata; $d($ et $e$ ?) = fimbriata; $y$ et $l=$ truncata .

II 39 COSMARIUM Corde in Alm. d. Carlsb. 1\%:39 p. 24:3 Eher. l. c. f. I g. h. Eu. Crux melit. l. c. f. III c.).

d to MICRASTeRIAS Menegh. Synops Desm. p. 215 (sep. p. 15\%. - junior ibid. C. trulleat un Cortu).

d 41 Eu. Tirilry Amer. Bacill. 1. 294 (sep.p. 13) t. 3 f. 22 [I. denticulata Breb. Fig. 22 ab Ehrenh, 1813 Euastrum Sol nominata est] et ? Euastr. n:o 3 f. 21 [M. truncata].

1) 41 - Hotch. Inf. p. 195, f. 121-123 [ex Ehrent. Inf. delineate: $121-122=$ I. rotata; f. $123=$ M. fim briata].

1) 45 Kütä. Phycol. germ. p. 131.

d $t \bar{\imath}-$ Tiab. Dent. Lirypt. Fl. p. 53.

pht7 - Foclie Phys. Stud. I 10.16. 64, 66, t. 1 f. $15 ;$ t. 2 f. $1-7$ [N. Thomasiana?].

d 49 Micr. Kitz. spec. AIg. p. 1Ti, sensu latiore.

o - $\beta$ ibid. Mier. truneata Bréb. $[$ fortasse $=$ M. denticulata Rulfs.

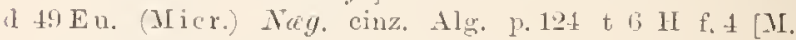
rotata].

d 50 Micr. MLrissal Catal. espo omis. p. 3t.

51 - Rul. Baeill. Sachs. f. 5 t. 8 (sine 11:0) [fig. mala].

ph 5\% Eu. Focke in Bot. Zeit. 15.5 p. Tr1. [Cfr. Le Bary in Beil. Bot. Zeit. 1858 1.641.

o 62 Micr. f. Hantzsch in Rab. Alg. no 140 [M. farcata "C. capitulifera" Rab. Flor. Eur. 3 p. 192].

d 67 -.- Kiclix Flore cryptog. Flanulr. p. 146 .

phz 69 Eu. Focke in Bot. Zeit. p. T.51 [Micr. denticulata]. phso Micr. Stull in Bot. Zeit. 34 p. 3!!!.

\section{rotritu- - $11 \|$}

1 33 ECHINELLA Grev. in Hook. Br. Fl, v. 2 p. 398.

o $\$ 1$ EUT0MIA Herr. Man. Br. Fl. p. 157.

44 MICRASTERIAS linlfs in Ann. Nat. Hist. v. 1.t p. 259 t. 6 f. 1 (et $15+1 ;$ in Trans. Bot. Soc. Edin. v. 2 p.131 t. 10) [quoar fig. $c$ (et $/$ ?) sensu auct, recent.; fig. a 2 forne) $=$ M. denticulata?; fig. b superior $=$ M. crenata; fig. $b$ inficrior $=M$. truncata].

d 45 -IIass. Frit. Alg. 1).385 t. (1) f. I [e Fialfs delineata].

1] th- I ialfs Brit. Desm. p. 71 t. 8 f. 1 [fig. $1 b$ alia spec.?].

(1) is - Iritch. Inf. 1.21t.

ph 5 - The Bury Conj. p. 11 .

pho 5 - Areh. Suppl. Cat. in Nat. Hist. Rev. p. 239.

d 61 - Areh, in Pritch. Inf. p. 72 T t. 1 f. 20 [e Iirlfs Br. Desin.].

162 - Arch. New Micrast. (sep.p. 6); in Proc. Nat. Hist. soc. Dubl. p. it t. 2 f. 9-10; in Jour. Micr. Sc. l'. 3*1. t. 12.

d 03 - liab. Frypt. Fl. Sachs. p. 182, fig. xyl. p. 157 [e lialfs 1841 pro maxima parte].

63- licinsch in Rab. Alg. Eur. 11:0 19M1 (f. dentibus capitellatis).

z 67 - Areh. in Q. J. M. Sc. v. 7 p. 2 m.

(1) 67 DIDYMIDIUM (Micr.) Reinsch Algent. Frank, form. a. b et c. p. 14\%

- 6 T Micr. Not. Desm. Ital. p. 30 t. 1 t. 6.

o 68 - (monstr.) Arch. in Q. J. M. Sc. 8 p. 291.

z 6s - Areh, in Q. T. M. Sc. v. 8 p. 294.

68 - liub. Flor. Eur. Alg. 3 1. 118 fig. xyl, [nt supra $1.563]$. 
() tis- With. Slandin. Desm. p.s.

$1170-$ Nordst. Desn. Mrasil. p. 223.

oz $: 1$ - Land. Desm. Snec. 1\% 12 t. 1 f. 2.

Iz 73 Dilponte Desw. subalp. r.

(1) 75 - Microgr. Dict. p. 494 t. 16 f. 13 [e Rralf. $]$.

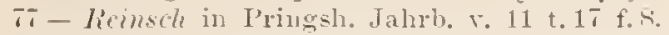

dz $\mathbf{x}-$ Kirchr. Alg. Fichles. p. Itiz.

ul ts Hempel Algenf. Chemnitz p. 113.

pl 7! - Stahl Einf. Licht. Beweg. d. Desm. p. g! seprp. (i),

o 81 - Mask. X. Zeal. Desm. p.303 t. 11 f. 5 [M. Schwoin furthii.

1, sis-Fischer Gypskrystall. Desm. p. 15!) t. lu f. 1.

1) 83 - Musk. X. Zeal. Desm. Adu. p. 24! t. 25 f. 1li a $[=$ M. Schweinfurthii] et b [= M. angulosa Hantzsch see. Mask. Furth. Wot. 1ssit.

m 81 - Gray Mon. loc. Conjug. p. 53 t. 1 f. 5.

m st - Arfuri Liste alg. Moscou p. 143.

1 81 - 11 olle Desm. [T. S. p, 109 t. 31 f. 1 -2 (2 formie).

$11-r$. simplex ibid. f.. 3 .

o. S1- $t$. depauperata Tille sydamerik. Algf. p. 12 t. 1 f. 21 i.

1) s5-Mirden. Mikr. Pflanz. d. Süssw. p.23.

o ș - í. monstrosa Fiacil. Non11. Desm. Polon. p.4n (sep. p. 39 ) t. 1.1 f. 3 .

o wi-stuks Tiey Thesm. 1) 14\%.

drtati-- Couke Brit. Desm. p. 5 t t. 24 [fig. d e Lamd. 1siti].

If $s \bar{t}-\mathrm{v}$. depressa Iste. Diag. prows. in Notax. 1. 234 sep. 1).

d si-Alexentio Chlorosp. Nhark. 11. 26.

1) .

ms - Rimbin. Chloroph. ent. Kharkow p.32...

d St- lianpth. Zelln. u. Hüllgallerte Desm. p.:4 et 112 (sel1.p. 36 et 54 t t. 3 f. $15,14.2(1$.

In sit - Norilst Bornh. Desm. 1'. 1nis.

phist- Ademold in Tenaiseh. Zeitsehr. 22- p.339-340.

in Si Iste. Jel. magryar. alg. p. 219.

a - v. le pressa ibil. p. 220.

$m$ - f. duplex ibil. et t. 1 f. 1 [nonstr.].

$n-f$. monstrosa ibid. et $t$ f. 2 .

lizs!-Tuni sirll. alg. p. 1126 .

a - r. le pressa ibid.

d $-r$. subdenticulata ihid. [11. Jenneri v. Tordst.-Hic errore trpographico?

d. m (*) - bichler sjis Desm. Miedr. p.s9.

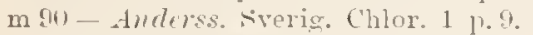

d :1- hirelm. Mikr. Pflanz. d. Sissw ed. 2 p. 20.

o 91 - Hrimerl Desm. alpin. p. 603.

n 91 HELIERELLA limtzi Rer. gen. pl. p. 899 .

m 91 M icr. Gutu. Flor, alg. Leopol, p. 75

d $92-$ r. acotidentata Bem. Fr. Alg. W. Surres p. $t$ t. 2 f. 11 .

m 42 - West Fr. w. Alg. W. Irel. p.134.

d - f. granulata ibid.

d 92 - llulle Desm. U. S. ed. II p. 120 t. 38 f. $1-2$.

n $-v^{*}$. simplex ibil. f. 3 .

m! 13 - Lirtlifmull. Desm. Attersees p. 562.

n 93 - A tomoeystis) Tumer Alg. Ind. orient. 1. 0.

d - fo evoluta ibid. 1. 167 t. 23 f. 1.

in 94 - Alea+mio Mat. alg. Khark. p.29.

ph 14 - J'alla in Ber. deutseh. bot. Ges. 12 p. 231.

o 95 - f. punctata Schmidle in Hedwig. 34 p. 80.

d 95 - v. papillifera liacil. in Flora $\mathrm{v} .81$ p. 34 t. 4 f. 1 \%. Cfr. Cosm. stellinum Eu. Rota, Mier. denticnlata et furcata.

\section{lintula}

a 38 MICRASTERIAS Ehrent. inf. p. $158=$ Pediastrum.

\section{Riotule}

d To STAURASTRUM Nordst. Desm. Brasil. p. 227 (sep.p. 18:1) t. 4 f. 34 .

8. - Wrolle in Bull. Torr. bot. C'lub. 9 t. 13 f. 9.

d it-Wolle Desm. U. is 1. 135 t. 11 f. $13-14$.

o 86 - Sitoles Key Tesm. p. 1ti5.

d s:-Toni syll. alg. 1. 1230 .

d 12 - Wolle Desm. TT. S. el. 11 p. 14 t. 55 f. 13 et 14.

11 13 - (Troclustrum', Turner Alg. Ind. orient. p. 132.

\section{rotmelerter}

n 35 BINATELLA Trèt. Alg. Fal. p. 2(3.) (sep.p. 66; ab) auctore teste Menegh. Symops. Desm. supprimitur).

\section{rotmedotmm -re}

a st EUASTRUM (Cosmariun) Gay Mon. loc. Conj. p. jos t. 1 f. 1t; et Tote Conj. d. m. France p. 336 . [Cosm. Meneghinii suriny. 1857 ex p.?].

d so COSMARIUM Toui syll, alg. p. 139.

11 91 URSINELLA huntze Rev. gen. pl. 1.925.

\section{rotmingtmm}

d 93 Docidium Tumer Alg. Ind, orie ut p. 37 t. 7 f. 2 n.

\section{rotumatiotmm}

a 19 PHYCASTRUM Kütz. spec. Alg. p. 152 (Pentast. margaritacea Elerenb. Mikr. Leb. in Amer. t. IV. 1. f. 25. nec alibi) [At. dilatatum r. obtusilobam ?].

\section{rotumdotum}

d 93 STAURASTRUM Twner Alg. Ind. orient. p. $105 \mathrm{t}$. 16 t. 3!?

\section{rotmnderm}

d 93 COSMARIUM Twmer Algre Ind, orient. p. $58 \mathrm{t}, \mathrm{s} \mathrm{f} .4 \mathrm{~s}$.

\section{rotmmenm?}

d s9 EUASTRUM Mask. Furth. Not. N. Z. Desm. p. 12 t. 1 f. $\therefore$.

\section{rotemalum}

d 93 PENIUM Twiner Alg. Ind. orient. p. 18 t. 7 f. 12.

\section{Rogy $(m) \cdots$,}

d 93 PENIUM Tumer Alg. Ind. orieut. p. 165 t. 23 f..

\section{lio! 1 (e)mm}

I TISTAURASTRUM Areh. in Q. J. M. S. v. 17 p. 103. [St. setigerum Cleve $1 \mathrm{~s} 64 \mathrm{sec}$. Roy 1893].

I st - Couke Brit. Desm. 1) 152.

\section{Royii}

(I) 93 STAURASTRUM Tumer Alg. Ind. orient. p. 120 t. 15 f. 25.

\section{rubescens}

d 35 Palmelia Treeb. Alg. Falais. p. 133 (Microcystis Henchh. Palmogloea huitz.); species delenda teste Tribissonio sec. Rabent. Flor. europ. aly. III p. 118.

\section{mefescems}

1) tit PENIUM r'tere Bidr. t. Srerg. Desm. p. 493 t. 4 f. j. [Pen. rufopellitam Roy 157]

d bs-- Rab. Flor. Eur. Alg. p. 123.

o 71 - Lund. Desm. Śuec. p. Sร̃.

in 80 - Wille Norg. Ferskw. alg. 1 1. 5o. 


\section{RUFICEPS}

d SS- Ilansy. Prodr. algent. Böhm. p. 241.

d 89 - Tomi syll. Alg. P. 856 .

\section{ruficeps:}

d 32 CLOSTERIUM Ehronb. Entw. d. Inf. p. 8 .

o 34 - Ehrenb. Oreran. kl. Raum. p. 234 (sep.p. 94) [C]. Dianæ et Cl. tnrgidnm sec. Ehrenu. Inf. 1938. p. 99. - Cfr. Nordst. Fr. wat. Alg. N. Zeal., 18s8, p. 1991.

n SS - Bollt Desm. utbredn. Nord. 1\% 19 sep.p.63) Cl. Diande EFrly. 1838?.

n - f. major ibid. (Cl. I f. Wille 1879 .

$n$ - f. rectior ibid. (Wittr. et Nordst. Alg. exs. 1879). Cfr. Clost. costatum (sec. Ehrenb. 1536) et Cl, Cynthia.

\section{info-pellitum}

d 7 PENIUM Roy Desm. of Perthsh. p. 73. [P. rnfescens Crer sec. Roy Scott. Desm. 1594 17.253]

o 84 - Areler in Amn. Mag. Nat. Hist. 5 ser. n:o 74 p. 140.

d 8 - Cooke Erit. Desm. p. 185.

d $89-T o n i$ Syll, Alg. p. $\$ 64$.

m 92 - West Fr. w. Alg. IV. Irel. 1. 126.

\section{vilyosilll}

d 93 COSMARIUM Twner Alg. Ind, orient. p. 61 t. 8 f. 67 .

\section{rugulosum.}

a 48 STAURASTRUM Bréb. in Ralfs Brit. Desm. p. 214 t. 35 f. 19. (Euastrum 11:0 9 Dailey Amerik. Bacill. 1811. p. 2.9.5 (sep.p. 15) t. 3 f. 9.) - [Phycastrum denticulatum 1849. - Didym. dilatatnm Reinsch 181ii].

त $52-M$ ritch. Inf. p. 265

d 61 - Arch, in Pritch. Inf. p. 740.

d $69-$ R.ab. Flor. Eur. Alg. 3 p. 20 .

d $78-$ Kirchn. Alg. Schles. p. 16t.

d 81 - Wolle Desm. U. S. p. 127 t. 11 f. $11-22$.

o s6-Stukes Kiey Desm. p.167.

d $89-T o n i$ syll. alg. p. 1170.

m 91 - Heimerl Desm. alpin. p. 605.

d 92 - llolle Desm. U. S. ed. II p. 140 t. 52 f. $\$ 1$ - 42.

n 93 - (Sph terichastrum) Tumer Alg. Ind. orient. p. 133.

o 95 - f. 11 est Alg. Madag. p. 74.

\section{rupestie}

dzf 49 EUASTRUM Cosmarium Ney. einz. Alg. p. 11! t. 7 \& f. 6 .

1. 61 COSMARIUM Areh, in Pritch. Inf. p. 731 .

d 63 - $h a b$. lirypt. Fl. Sachs. p. 199.

- 64-Wartm. et Schenk Schweizer. Kryptog. fasc. "1 n:o $131 \%$.

\section{ilpestivis -e}

(1) 45 PALMOGLOEA Kütz. Phycol. germ. p. 153.

d 47 - Kritz. Tab. Plyyc. I p. 19 t. 25 f. 2.

1) +9 - hutz. Spee. Alg. p. 228.

o 64 - Areh. Deseript. (sep.1.5); in Dubl. Nat. Hist. Soc. l'r. p. 16.

d 65 - Rub. Fl. Eur. Alg. p. 118 .

in PENIUM Reinseh Alg. Prom. Bon. Spei p. 240 (incl. Trichodict, rnpestr.

d St - Wolle Desm. U. S. p. 37 t. 5 f. 13.

o 86 - Stokes Kiey Desm. p. 111.

d 92 - 11 ulle Desm. U. S. ed. II p. 38 t. 5 f. 13. Cfr. Palmog. lurida, macrococca 1863 et violascens 188 s. ilpestris -

d 45 TRICHODICTYON hätz. Phyc. germ. p. 153.

47 - Kütz. Tab. phyc. I t. 26 f. 1. [Cylindrocystis crassa We Bur. sec. Arch. Descript. (1564) sep.p.6, in Dubl. Nat. Hist. Soc. Pr. p. 17; in Q. J. M. Sc. p. 114].

1 4. Thevis. Alge coccot. p. Bs

d 19 - Kiïtz. spec. Alg. 1. 230.

4) 63 - Rab. Krypt. Ft. Sachs. p. 74.

m 7 PENIUM Reinsch Alg. Prom. Bon. Spei p. 240,

n 11 GYGES Kunt:e Rev. gen. pl. p. S96.

\section{pusticull}

1) 93STAURASTRUM Tumer Alg. Ind. orient. p.121 t. 16 f. 2 .

\section{RUTIIISTRUU}

- 93 Tumer Alg. Ind, orient. p. 133. Subgen. Stanrastri.

\section{RUTIIILII}

d 93 Tumer Alg. Ind. orient. p. 39. Subgen. Docidii.

\section{sugittr.rillu}

lz 87 STAURASTRUM Nordst. Algolog. smăsak. 4 p. 157. dzf $85-$ Nordst. Fr. wat. alg. N. Zeal. p. 37 t. 4 f. $6-7$.

$\mathrm{dz} 89$ - Toni Syll. alg. p. 1214.

n12-Ruc. Desmidya Ciastoni. p. 381 t. 7 f. 18.

o $y 2$ - ? Mobius Austral. Süsswasseralg. p. $44 t \mathrm{t}$ t. 18.

o :13-Bailey Contr. Queensl. Fl. p.50.

\section{sugittifelut}

(1) 9 STAURASTRUM Bärg. Desm. Brasil. p. 45 t. 5 f. 46 [St. gladiosum? v. longispinum Turn. 1s93?].

\section{suleblosum}

d 93 D0CIDIUM (Rutidium) Tumer Alg. Ind. orient. p. 34 t. 2 f. 12.

\section{saliullu, $-r$}

d 5f COSMARIUM Hrensy. in Osterr. bot. Zeitschr. p.385 (sep.p. 5.

d 87 - Honsg. Pliys, u. Alg. stu.l. p. 156 t. 4 f. 26.

d so'-Ilansg. Prodr. Algentl. Böhm. p. 194 f. 115.

d 89-Toni syll. Alg. p.936.

n 91 URSIN ELLA Kuntre Rev. gen. pl. p. 925.

\section{steltalls.s}

d si STAURASTRUM Jush. Burm. Desm. p. 641 t. 23 f. 21.

o $s i$ - $\beta$ forcipigerum Lagerh. Krit. Bemerk. Desm. p. 539 ist. grallatorinm $\beta$ Lagerh. 1856).

d 89 - Toni syll. alg. p. 1234 .

l - v. forcipigerum ibid.

o 93 - Twmer Alg. Ind. orient. p. 122 t. 14 f. 8.

\section{Suncti Sebalali Cfi. Sebaldi.}

\section{sullguineus}

d 40 GYGES Shuttleworth in Bibliotl. univers. Genève 1840 1.347 Hamatococcus nivalis sec. Flotow in Nov. Act. Acad. Cæes. Leop. Car. Nat. cur. 20 p.560].

\section{samsibarense}

d 95 CosmariUM Hieron. in Pflanz. w. Ostafrik. p. 19.

\section{sansiburense}

d 95 HOLACANTHUM Hieron. in Pflanz. w. Ostafrik. p. 20. 


\section{Stotrii}

a 94 EUASTRUM Gutu. Fl. alg. Tarnapol. 1'. 104 t. 3 t. to [Cosm. asperulum licinsch f:? sec. West in Journ.

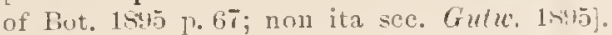

o 95 - Gutw. Prodr. Al. algo. Galic. p.35i in nota.

\section{shexomir. 1111}

d ris COSMOCLADIUM De Bary in Flora 13.321-9 t. 1 f. $1-3$.

d tis - Rub. Fl. Eur. Alg. 3 p. $5 t$.

m 72 - Arch. in Q. J. Micr. Se. v. 12 p. 195.

o 71 - Arch. in Q. J. M. S. 1.212 (C. pulchellum?)

d 86 - Couke Brit. Desm. 1. 78 t. 35 f. 16 .

d th - Dangeurd Rech. Alg. infer. T. 1ti?

d 89 - Toni syll. Alg. p. 804 .

n 90 - Wille Xatürl. Phanzenfam. 12.12 f. 7 A (c de Bary).

\section{slexollirllll}

d 63 STAURASTRUM Bulnh. in Rab. Krypt. Fl. Sachs. p. 190. St. sp. in Hedw. II. 1859. t. 2 f. '̄. mala\%

d 6 -Richter in Rab. Alg. Eur. n:o 19f0) c. icm. (st. echinatum IIilse).

o $67-A r c h$. in Q. J. I. Sc. v. T p.29k.

1 68 - Rirl. Flow. Eur. Alg. 3 p. 213.

m 2 - Nordst. Desm. Spetsb. p.40.

o 75 - Tordst. Desm. arct. p. 35 ( $\mathrm{f} .3-1$-gona).

n 78 - Hempel Algentl. Chemnitz p. 114.

o 79 - Tille Ferskv. alg. Nov. Semlj. p. jut.

d S. - Wolle Desm. U. S. P. 141 t. 45 f. 33-31. [Quid ?].

o $\$$ - Stokes Key Desm. 1. 165.

m. $\$$ - Bullt Desin. Grönl. p. 36.

m 88 - Inrr. Fr. Alg. Iaine I p. 161 v. pentagonum,

d $89-$ Toni syll. alg. p. 1173.

- 90 - Böry. Desm. Brasil. 1. 41.

n $92-$ Har?. Fr. Alg. Maine III t. 126 f. $26-27$ (f. pentagona) [Cfr West in Jonrn. of Bot. 189.5 p. 70 ].

d 92 - Wolle Desm. U. S. ed. Il p. 154 t. 56 f. $33-34 . t$. 42 f. $14-15$ v. pentagonum).

o 93 - Roy sicottish Desm. 1. 211, (et 1st.t t. 3 f. 10.

n 91 - Jürg. F. alg. Östgrönl. p. 27.

Cfr. Staur. Notarisii Delp:- Aantl. deltoideum.

\section{saxomirum}

d 67 STAURASTRUM Reinsch Spec. Gen. Alg: p. $127 \mathrm{t}$ 21 C I f. $1-1$ (sep.p. 19 t. J) [St. trachynotum West 1892 ; St. aculeatum f.? sec. lioy 1s93] nee Buluk. 1863.

o T)-lieinsch Contribut. p.90 t. 10 f. 1.

$\mathrm{m}$ - f. minor ibid. p. 90 t. 10 f. 2 [Cfr Tordst. in Hedwigia $1876 \mathrm{p} .6 \overline{7}$.

81 -? f. Cooke in Quekett Micr. J. 6 t. 15 f. $21-2.1$.

o 81 - Wills in Midland Natural. 4 p. 73.

d 87 - Cuoke Brit. Desm. 1). 155 t. 53 f. ว.

\section{scabiertulum}

d 9: COSMARIUM W'est Alg. Madag. 1. 04 t. 6 f. 27.

\section{scabrolutulu}

I 93 COSMARIUM Turner Alg. Ind. orient. p. 59 t. $\mathrm{S}$ f. 51 .

\section{scabinu}

d 93 CosmaRIUM Tumer Alg. Ind. orient. p. 6.5 t.9 f. 3.2.

\section{scab) $* 1, m$}

d 18 STAURASTRUM Brele in Ralfs Brit. Desm. p. 214 t. 35 f. 201).

1) 52 - I'ritch. Inf. p. $26 s$. d $61-4 r c h$, in Priteh. Inf. 1. TIII.

d $68-$ Rub. Fl. Eur. alg. Il! p. 217 .

ni $71-L u$ d. Desm. Suec. p. 1 is.

$m 75-$ ?ordst. Desm. aret. 1.37.

d 81 - Wulle Desm. IT. ‥ p. 130 t. 11 f. 2!! 30 .

in s8-Foldt Desm. Grünl. p.3!.

m - f. ibid.: t. 2 f. 50).

il 89 - Toni Fyll. alg. 1. 1170.

m 5 - Aulerss. Sierig. Chlor. 1 p. 12.

d 92 - Wolle Desm. U. S. ed. II p. 144 t. 52 f. 29! 30.

o $4+3$ - Litheminl. Desm. Attersees 1) Orj.

z 93 - Roy scottish Desm. 1.212.

93 - Burgesen in Wittr. et Nordst. Alg. exs. n:o 1114 c. fig. $x y \operatorname{lng} 1$.

o 916 - f. Schmialle Beitı. alp. Alg. p. 60 sep.p. 32) et 159.) t. 16 f. 21

\section{screlare}

dzf 93 COSMARIUM Twner Alg. Ind. orient. p. 68 (cfr. p. $167)$ t. 16 f. 1.

\section{Sermudinavir"l"!}

d 93 PENIUM Turner Alg. Ind. orient. p. 166 t. 23 f. 6 (P. spirostriolatum Tum. 1855. non Bark.).

\section{Sicenedesmms}

A TCOSMARIUM Delponte Desmid. subalp. p.5 (sep.p. 101 t. 7 f. $28-34$.

d 81 - Wollc Desm. U. S. p. 59 t. 50 f. $7-9$.

o 86 - Stokes liey Desm. p. 126.

o $8 \mathbf{i}-\beta$ dorsitruncatum Nordst. Algolog. småsak. 4 p. 162.

d Se - - Nordst. Fr. wat. alg. X. Zeal. p. 59 t. 3 f. 1 i.

o SS - Boldt Desm. Grönl. 1) 15.

d 89 - Tuni Syll. alg. 1.96.

d - v. dorsitruncatum ibil.

d 90 - b. intermedium Gutu. Wahr. d. Priorität p. 69.

m 91 - West Ald. Freshw. Alg. W. Torksh. 13. 246.

11.91 URSINELLA huntze Rev. gen. pl. 17.925.

d s1 Cosm. r. intermedium Gutw. Flor. alg. Leopol. p. 4 ti t. 1 f. 2 .

n 5.2 - f. punctata West Fr. W. Alg. W. Irel. 1. 145.

d $92-\beta$ dorsitruncatum Rac. Desmidya Ciastoni.p. 373.

d 92 - Wolle Desm. U. s. ert. II p. 63 t. 61 f. 7 -9.

o 93 - . intermedium f. glabra Schmidle Beitr. Alg. sclewarzwald. p. 98 t. 15 f. 16.

d $93-\beta$ punctatum Turuer Alg. Inl. orient. p.50 t $S$ f. 61 .

m94 - v. intermedium Schmidle in Flora is p.51.

o $44-B \ddot{r} r$. F. alg. Östgrönl. p. 20 t. 1 f. 14 .

o 4 - v.dorsitruncatum Gutw. Fl. alg. Tarnapol. p. Si.

\section{Sceptrull}

d 45 CLOSTERIUM Kütz. Phycol, germ, p. 133. [Doc. Baculum Ralfs 1848, sed recte?].

19 PENIUM (Docidium) Killz. spec. Alg. p.168.

n 49 PLEUR0T 㕞IUM ? Ner. Gatt. einz. Alg. p. 104.

- 69 DOCIDIUM Areher in Q J. II. se. v. 9 p. 195 (Cfr. Burker ibid. 1) 1!).

1) 83 - Foy in sientt. Naturalist Jul. 1883 p. 39 [Doc. tridentulum Wolle 18\$1.

n :13-(Ortlidium) Turner Alg. linl. nrient. p. 39.

\section{schimatothallew}

1? 42 Treris. Att. IV Riun. [tal. 13.33\%. Subordo Ulvacearum [sec. Treris, 1sH. - n.

n 4 S Treris. Alghe Coceot. 1. IS (Desmidiere Auct.) Subord. Ulvac. Tribus: 1. Micrasterieæ, 2. Pediastrex, 3. Dcsmidiex. 4. Dillyoprier. 


\section{SCHISTOCHILIUAI}

n 15 linlfs in denn. Fl. 'Tunbr. Wells p. 192 (1. 96) [in Erratis ab ipso auctore ad "Sphærozosma" emendatinm.].

\section{SCHIZACANTHUV}

d 71 Lmel. Desm. Snee p. Tt. Subgen. Xauthidii.

1) G Guy Monogr. Ine. Conjug. p. 40. Sect. Xanthudii.

d SS Ilrusy. Prodr. Algenf. Böhm. p. 191 ("Schizacan * tlium"), sect. Xanth.

d (ll) 1Ville in Natior. Pfanzenfam. p.11. Genus proprium.

\section{SCHIZANTHLII}

o 13 Thener Alg. Inel orient. p. 132. Suhgen. Staurastri.

\section{SCHIZOCINTIS}

d 13 Tumer Alg. Ind. orient. p. 9h. Subgen. Micraster.

\section{S(HIZOI)ESHLS}

o 93 Turner Alg. lnd, orient, p. 13\%. Subgen. Arthrodesmi.

\section{SCHIZOSPORA}

d 55 Reinsch Costrils, p. sit

\section{sroisost 111$) \cdot 11 / 1$}

d 93 EUASTRUM Tumer Ale. Ind. orient. 11. 76 t. 11 f. 12. ("fr. ('osn. commissurale of capitatum Turn.

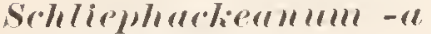

a Gs COSMARIUM Knb. Flor. Eur. Alg, 3 1r. 16: [Cosm. pygmæum ?].

def is - if. spetsbergensis) Nordst. Desm. aret. p. 24 t. 7 1. 15 [Cosm. asphærosporum Nurlst. in Wittr. et

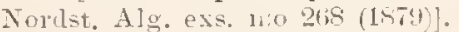

z itj-Arrh.in Q. J. M. S. p. 33s.

d is - Kirclen. Alg. Schles. 1. 153.

it 81 - Wolle Desm. [T. \&. p. 82 t. 1 is t. 14-15 [?].

o 86 - Situkes Key Desm. 1. 129.

d 86 -Coolie Brit. Desm. p.!r?.

nzf - v. spetsbergensic ibid. t. 37 f. 10 [e Nordst. 1875].

m ss - I'utert Nonth Carolina Desm. p. 3.

d s!l - Tomi syll. alg. 1\%1041i.

o st-Tícib. Now. Desn. ]. 81 t. 5 f.6 [C. silesiacum a milnor Gutw. 1s!tu].

o:11 -? Reimerl IJesm. alpin. 1.610 t.5 f. 13. [Cfr Torge in Nuov. Notar. 1 in:13 p. 3!5].

n 91 URSINELLA huntžc Rev. gen, pl. p. 425.

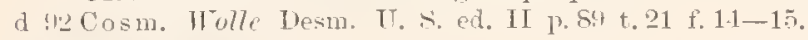

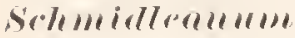

a s4 EUASTRUM Eich. at Gutu, in Krakan Anzeiger

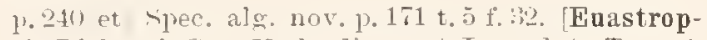
sis Richteri Gen. Hyclrodictyac.) Lager\%. in Tromsö Mus. Aarsh. 17. 1894, p. 12 et 20].

\section{Schmidlei}

315 COSMARIUM 17 est in Jomm. of Bot. 393 1\% fis. [1) 111 . rectangulam Sichmille $159 t$, won Reinseh 1 1.

\section{schueinleri}

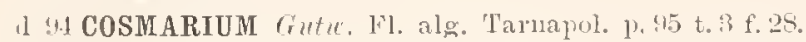

\section{selliibelevii}

(l) sucosmarium wille Norg. Ferskv. alg. I p.31 t. 2

d $8 ! 1-$ Toni syll, alg. 1. 1148.

n.) URSINELLA huntze hev. gen. pl. p.925.

\section{Schlleinfurtlii}

o 76 MICRASTERIAS Cohn Flonul. Desm. Bong. p. 45.

(1) 70 (ohn Desm. Bong. p. 26s (sep.p. 10) t. 11 f. 2.

m 8 - Tordst. Fr. wat, alg. I. Zeal. p. 29 t. 2 f. 12.

d 89 -. Toni Syll, alg. 1'.1125.

12 HELIERELLA huntze Rev. gen. pl. p. 899. Cfr. Nier. rotata Mask. 1853.

\section{Schurilluthii}

n 76 PLEUR0T层 Cohn Florul. Desm. Bong. p. 96. [1']. ovatum Nordst. sec. Colm in Desm. Bong.

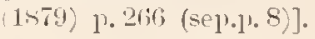

\section{scitull!}

(l) 95 Cosmarium West A]g. Madag. p. 64 t. 7 f. 29.

\section{scitum!}

d 92 EUASTRUM West Fr. W. Alg. W. Irel. p. 141 t. $24 \mathrm{f}$. 13. [Amon Cosm. nasntum?].

\section{srolojur(illlll}

d 93 STAURASTRUM Tmmer Alg. Ind. orient. p. 14 t. 17 t. 11] [Cfr: Wildem. in Notarisia 1893 p. 170 ; St. variabile r. scol. Wilit. 1894].

\section{scorplinidemm}

d Ti STAURASTRUM Delponte Desmid. subalp. p. 59 (sep. ]. 155) t. 12 f. 12-45. [St. oxyacantha Areh. $1859 \mathrm{f}$.] 11 $\$ 9$ - Toni syll. alg. p. 1214.

d $90-v$ brevius Gutw. Wahr. d. Priorität 1. 72.

1) :1 - - F For. alg. Leopol. p.6! t. 3 f. 14.

\section{scotir.111!}

d 93 CLOSTERIUM Turner Desm. Notes p. 347.

l $-\beta$ fusiforme ibicl.

1) 94-Timer apud lioy Scott. Desm. p. 245 t. 4 f.s (sep. ].

1 ... v. fousiforme ibid. p. 249 t. 4 f.?.

\section{sroticulll}

11 94 Cosmarium West New Brit. Alg. 1.6 t. 1 f. 23.

\section{semlptum}

a 94 COSMARIUM Fichl. et Gutw. Spec. alg. nov. p. 169 t. 4 f. $2: 2$.

\section{s. 11$)+11 \|$}

d 13 EUASTRUM Tumer Alg. Ind. orient. p. 87 t. 8 f. 32; "n. sp."." [E. spinulosum subsp. Africanum f. scalptum Hilkem. 18:4].

\section{scutellum!}

tl 93 COSMARIUM Tumer Alg. Ind. nrient. p. 60 t. 9 f. 35.

\section{Scutull.}

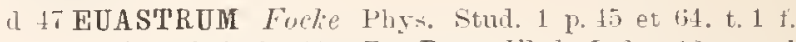
14, t. 2 f. 10-11. Eu. Rota Elhb. Inf. t. 12 quoad f. $1 \mathrm{~g}$ et $\mathrm{h}$, [Micrasterias truncata; figg. $10-11=$ b. Scutum Richter].

\section{searsolemse}

(1) 93 XANTHIDIUM Tinner Alg. Ind. orient. p. 101 t. 13 f. 8.

\section{seballi}

d 67 STAURASTRUM Feinsch spee. Gen. Alg. 1. 133 t. 24 D I f. $1-3$ (sep.p. 25 t. 5 D I).

d 67DIDYMIDIUM (Ntaurastrum) Reinsch Algenfl. Frank. 1. 175 t. 11 f. 1. ("Sancti Sebaldi"). 
d 7istatur. Norlst. Norg. Desm. 1. 33:3.

d $-\beta$ ornatum ibid. p.31 t. 1 f. 15.

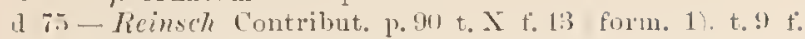
1 form. 2.

S1-r, Cooke in Quekett Micr. J. if t. 15 f. 11. [v. Coolieii Gutw. 18no].

S1-f. Cooke in Grevillea 9 to 139 fo. 万. [Tlem ac prior].

o . .3 - r. spinosum tholle in Bull. Torr. bot. ('iub. v. 10) 1. 2. (1) t. 27 f. 11.

83 - Tumer Alwie Strensall f. 4 .

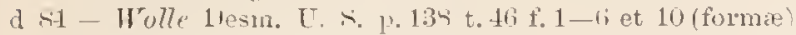
v. spinosum ibid. 1. 133 t) t. fi f. 7 .

(1 8.5 - $\beta$ depauperatum Roldt Sibir. Chloroph. p. 117 t. ti t' 33.

o 86 - Stokes liey Desm. p. 165.

o - (v.) spinosum ibid.

d sit-v. elegans Ist

o - v. superornata ibicl.

d Si-Cooke Brit. Desm. p.17t t. lil f. 1 [ealem forma ac $18 \Omega 1$ ].

d - $\beta$ oriatum ibid.

o - T- $\beta$ ornatum f. novizelandica Nordst. Algolog. småsak. \pm p. 1.57 .

d is - v. elegans Istr. Jel. magyar, alg. 1). 234 t. 2 f. 31.

it - v. superornata ibil. p. 235 t. 2 f. 32 .

d ss - $\beta$ ornatum f. novizelandica Vordst. Fr. wat. alg. 1 Zeal. p. 3 ; t. 4 f. 3.

o 89 - West. Massach. Desm. p. 20 t. 3 f. 17.

o 89 - Miri. Birlr. Bornh. Desm. p.14s.

d 89 - Tum sill. alg. p. 1220.

d - r. oruatum ibid.

1 - f. novizelandicum ibil. p. 1221.

d $-v$. elegn us ibid.

d -v. smperornatum ibit.

d - vo depaupatum ibid.

d - v, spinosum ibid.

n $90-v$. Cookeii Gutw. Wahr. d. Prioritüt 1. 12 Cooke in Quek. M. J. L8s1.

d - p) Jarynæ ibid.

d $90-\beta$ Brasiliense Förg. Desm. Brasil. p. 17 t. 5 f.j.

m 91- $\boldsymbol{1}$ Cookei Gutw. Flor. alg. Leopol. p. (39.

d - Jarynæ ibid., t. 3 f. 18.

d $92-v$ quaternum Ilare. Fr. Alg. Maine 3 p. 123 t. 12 h f. 16-17 Quid est? Cfr. Burge in Nuov. Notar. $1893 \mathrm{p} .342$ et West 1895].

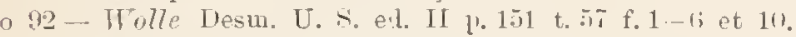
o - - s. spinosum ibid. p. 152 t. 57 f. 7.

m $92-f$. novizelanileum Gutw. Flor. glon. Galic. 3 p. 185 (quoque birarliatum)

m9: - $\beta$ ornatum Turner Alg. Tnd. orient. p. 132.

1 94 - f. Groenlandica Büry. F. alg. Ostgrönl. 1).30 t.2 f. 31 .

m 95 - Eichler in Pamiet. Fizy. 13 p. 63.

\section{sererlen.}

a js SPH [Spll. excaratum b. seced. Rab. 1s68].

a 61 SPONDYLOSIUM Arch. in Pritch. Inf. p. T19 et 72t. a fossphier. Rrub. Flor. Eur. Alg. 3 p. 15).

o T1 Spond. Areh. in Q. J. M. S. p. St.

111.80 - Artari Mater. alg. Moscou p. 171) (sep.p. 8).

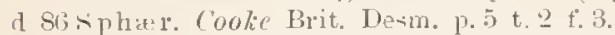

d $89-$ Hansy. Prodr. Algentl. Bülım. p. 170.

d $\quad-\beta$ pulchellnm ibid. (Sph. pulchellum Arch. 185.9).

d - bambusinoides ibid. p. 276. (sph. bambus.)

d S - Tumi íyll. Alg. p. 792.

m $90 \mathrm{~s}$ pornl. Eichler spis Desm. Miedz. 1. St m 95 - Wichter in Pamiet. Fizy. 13 p. ז̈.

Ctr. Spluær. pygmæum Hanptf. 18.rit.

\section{Sipelyallum-}

d s:3 COSMARím Wolle in T3ull. Torr. bot. Club v. 10 p. 16 t. 27 f, 11 \& 11 a.

d st - 11 ulle Desm. U. \&. 1. 73 t. 18 f. 33 - 35.

o 86 - Nitulies hiey Desm. 1) 1.28.

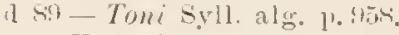

u !1 URSINELLA Kuntie Rev. gen. pl, p. 19.

o 42 Cosm. Mob. Austral. Siisswasseralg. p. 413.

d 42 - Wolle Jlesm. I. S. ed. II p. 80 t. 21 f. $33-35$.

If 93 - Bwitey Contr. Qneensl. Fl. p. 11.

95 - Mobrus apul Bailey Contrib. (queenst. F1. XI t. 10 t. 20.

\section{sejullutum -re}

d st COSMARIUM Wolle in Bull. Torr. bot. Club. 1884 P. 14.

d $8 t$ - Wolle Desm. U. s. p. 1i2 t.50 f. 18-20.

o Sij-Stakes Fiey Desm. 1. 127.

ms -1 ste. Jel. magyar. alg. p. 225.

a 89 - Tomi ryll. alg. 11. I1830.

n 91 URSINELLA Lunté Rev. gen, pl. p.925.

(1) 92 Cosm. Wulle [lesm. U. . . ed. I1 p. 69 t. 151 f. $18-20$.

\section{selencere}

l 34 MICRASTERIAS K̈̈tz. Syn. Diat. n. 604 (sep.p. 7t $j$ ) t. 1! f. $^{\prime \prime 2}=$ Pediastrum $\mathrm{S}$.

\section{selem(enm)-}

4 81 CLOSTERIUM Mask. X. Z. Desm. p. 312 t. 11 f. $15,16$. o .81 - Areh, in Grevillea v. 10 p. 30 .

oz 53 - Mask. in X. Z. Desm. Ad, p. 255 t. 2.5 f. 19.

d $59-$ Toni syll. Alw. 1. $\$ 53$.

u 91 ARTHRODIA Kuntze Rev. geu. pl. p. 854.

\section{SELENOCERAS}

d 93 Turner Alg. 1nd. orient. p. 23. Subiren. Closterii.

\section{seminadiutum. - -}

1) tuEUASTRUM Brëb. in litt. apul Menegh. Syn. Desm. 1. 215

d 45 - Kütz. Phycol, germ, 1. 131.

d 17 - Rub. Dent. Kirypt. Fl. 1, isi.

d 49 MICRASTERIAS Kätz. sjec. Alg. p. 170.

d 49 E $u$. Micrasterias) Nog. einz, Alg. 1\%.123 t.6 H f. 3. al Mier. Rub. Bacill. fase. 5 t. 3 (sine n:o).

ph 53 -Itzigs. in Bot. Zeit. 1.553 p. 4 isti.

il 63 - Kab. Fiypt. Fl. Sachs. p. 183.

Cfr. II. truncata et Cosm. quadragies-cnspidatum.

\section{sellurir}

d 43 MICRASTERIAS $k h r e n b$, Hikr. Leb. Siid. n. N. Amer. p. $417=$ Pediastrum

\section{senuriull}

1 43 DESMIDIUM threnl. Mikr. Leb. süd. u. . Amer. p. (337. 389, 371 et) 11.3 (sep.p. 1.2t) t. IV. I f. 22. [it. furcatum].

1 48 STAURASTRUM Rialfs Brit. Dein. p. $21 \%$.

d 49 STEPHANOXANTHIUM Kitz. spec. Alg. p. 184.

1) $52 \mathrm{Staur}$. Pritch. Inf, 13. 269 t. 13 f. 7 [fig. Whrenb. repetita].

d 61 - Arch. in Pritch. Inf. 1. 712 t. 2 f. 7.

d 68 - Kab. Flor. Eur. Alg. 3 l, 22001.

1 71 -Luml. Desm. Suer. 1) 19\%. 
o 72 - Wittr. Gotl. Öl. sütr. Alg. 1. 50.

o 72 - Nordst. Desm. Spetisb. p. 41.

d 73 - Toorl Fr. Alg. p. 155.

o 73 - Nordst. in Rab. Alg. Eur. n:o 2325 (St. spinosum

o 73 - Nordst. Norg. Desin. p. 33.

d 81 - Wulle Desm. U. S. 1). 14 t t. 52 f. 1.

d 85 - f. tatrica in descript.) liac. Nonn. Desm. polon. p. .s (sep.p. 32); in inlice et tab. 12 (sep.t. 3) f. 7 appellatur "var. alpinom" [St. monticulosum $\beta$ bifarium sec. Tordst. Bornh. Desm.. 1888; p. 206].

o 86 - Stokes liey Desm. p. 16!\%

A 89 - Tomi sroll. alg. p. 1155.

d 92 - Wulle Desm. U.S. ed. 11 p. 162 t. 198 f. 1.

m 13 - Tumer Alg. Ind. orient. p.119 t. 15 f. 13.

d $94-\nabla$. Nigra silva Schmidle Alg. Geb. Oberrheins p. 553 t. 29 f. 19 [staur. monticulosum?].

\section{Seudtueriamume -}

4 6i EUASTRUM Remsch Spec. Gen. Alg. p. 119 t. 21 f. C II 1 - 6 (sep.p. 11 t. 2).

a 67 DIDYMIDIUM (Euastıun) Reinsch Algenfl. Frank. p. 135 t. 9 f. 4 .

0 75 Eu. f. Reinsch Contribut. p. 92 t. 9 f. 6.

- 55 COSMARIUM (Euastrum) Wolle in Bull. Torr. bot. Club. 12 p. 3 t. 4 i f. $30-31$.

d $s \bar{t}-\prod^{\top} u 7 l e$ Fr. Alg. T. S. A. P. 29 t. 57 f. $30-31$ [ex Trolle 18-5̃.

d S9Eu. Toni syll. alg. p. 1079.

1191 HELIERELLA Kumtze Rev. gen. pl. p. st9.

ma1 Cosm. Gutw. Flor. alg. Leopol. p.40.

a 92 - Wolle Desm. U. S. ed. Il p. 22 A t. 48 f. $30-31$.

o 93 Eu. $\beta$ latius Roy Scottish Desm. p. 17 (sep.p. 15).

\section{semilis}

1 39 ARTHROdesMUS Carda in Alm. d. Carlsb. $1839 \mathrm{p}$. 244 t. 6 f. 33 . [verisimiliter A. convergens].

\section{sentirosum}

d TT STAURASTRUM Delyonte Desmid. subalp. p. 51 (sep.p. 147) t. 10 f. 39-3!. [An titaur. polytrichnm f. Lund.].

1) 89 - Tomi Fyll. alg. p. 1173 .

o 13 -Lütlicmïll. Desm. Attersees p. if6t.

\section{septeurerium}

d at cosmarium Eich. et Gutw. Spec. alg. nor. p. 1 ti t. \pm f. 16.

\section{sevelutum}

d 93 COSMARIUM Tumer A]gee Ind. orient. p. 4 t. 7 f. 18.

\section{severtum-le}

a s6 EUASTRUM Jash. Burm. Desm. p. 1339 t. 23 f. 1 \& 2. d so-Tomi syll. alg. 1). 1118.

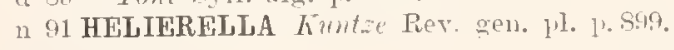

\section{selvertullu}

151 SPH砍OZOSMA Iinil. Micr. observ. p. 37 t. 1 f. 14. [Onychonema linve sec. Thm.].

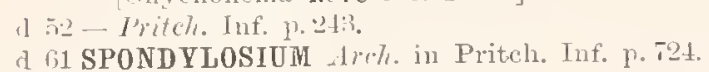

d T3Splere Hour Fr. Alg. 1. 121.

d .4 - Wolle Desm. U. S. p.30 t. 4 f. 7 .

, st ONYCHONEMA Stokes Kcy Desm. p.111.

d. S9?-Toni syll. Alg. p. T.7.

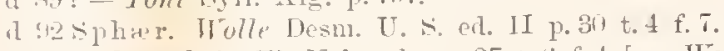

a 14 - Sammd. iu Fl. Tebraska p. 37 t.1i f. 4 [ex Wolle]

\section{sevinatis:}

d 39 ARTHRODESMUS Cordr in Alm. d. Carlsb. 1839 p. 244 t. 4 ; .35 , = Scenedesmus Hystrix Lagerh. (?)

\section{serviformo}

a ToSTAURASTRUM Börg. Desm. Brasil. p. 45 t. 4 f. 45.

\section{setaceum. - re}

d 34 CLOSTERIUM Ehrenb. Organ. kl. Raum. p.239 (sep. 1. 15$)$.

dzf 38 - Tnxotiuns) Ehrenb. Inf. p. 9 t. 6 f. IX.

d 40 - Menegh. Synops. Desm. p. 235 (sep.p. 35).

dzf 41 - Pritch. Inf. f. 67 [ex Ehrenb.].

d 45 -Huss. Brit. Alg. p. 373 t. ST f. 7 [ex Ehrenz.].

o 47 - Focke Phys. Stud. I p.59 t. 3 f. 32 [Cl. pronum sec. Reinsch 1:iliz].

dzf $4 S$ - lialfs Brit. Desm. p. 176 t. 30 f. 4.

dzf 52 - Pritch. Inf. ]. 283 t. 1 f. 67 [ex Ehrenb.].

o 50 - Errib. List. p. 156.

d 61 - Arch. in Pritch. Inf. p. 750.

d 63 -liab. Krypt. Fl. Sachs. p. 174.

oz $6 \overline{0}$ - Reinsch Algenf. Frank. p. 195.

o 67 - Not. Desm. Ital. p. 67 t. 8 f. 74.

1) 6 - Rab. Flor. Eur. Alg. 3 p. 136.

1 - b. intermedium ibid. Stamoceras intermedium kiitz).

1 73 - Wood F1. Alg. p. 116.

dzf 75 - Nicrogr. Dict. 1. 17 t. 10 f. 45 et 46 [ex Rrelfs Br. Desm.].

1 7 - Delponte Desmid. subalp. p. 105 (sep.p. 201) t. 17 f. 41-.41. [C]. Kützingii ?].

m TR-Nordst. Alg. Sandvic. p. 11.

d $\mathrm{s}$ - firehn. Alg. Sehles. p. 142.

o 80 - Wusk. N. Z. Desm. p. 316 t. 12 f. 35 . [Cl. Kïut. zi is gi i ?].

Izf 84 - Wull Desm. U. S. p. 47 t. 8 f. 6-7. 9-11.

o 86 - stulies Key Desm. p. 111.

atz st-Cooke Erit. Desm. p. 34 t. 14 f. 4 [e Ralfs?]

d 87 - Alexenlio Chlorosp. Flark. p. 230 .

a ss-Ilunsg. I'rodr. Algenfl. Bühm. p. 184 .

las 8 - Toni et Leri Fl. Alg. Tenez. p.313.

m ss - Rirubin. Chloropl. env, Kharkow 1.317 (sep.p. 29).

m 88 - Nortst. Fr. wat. alg. X. Zeal. p. 194.

dz S:3 - Toni sirll. Alg. p. sõo.

m 90 - Rorg. Desm. Brasil. 1.29.

m 90 - Eichler spis Desm. Viedz. p. 56 t. 8 f. 12.

m on-Anderse. Sverig. (hlor. 1 p. 18.

n :1 ARTHRODIA Kuntze Rev. gen. pl. p. $88 t$.

o 12 Clost. Rac. Desmidya Ciastoni. p. 369 t. 6 f. 11.

dzf 9o - Wolle Desm. T. S. ed. II p. 50 t. it f. $6-7.9-11$.

dz 93 - Bailey Contr. Queensl. Fl. p. 42 t. 14 f. 33 bis.

m 14 - Borge süssw. Chlor. Alchang. p.17.

- 94 - Mvb. Austral. Nuisewasseralg. II p. 337 .

95 - Brilay Contrib. Qneensl. Fl. XI p. 37. (1i. clost. rostratum et subulatum.

\section{setigerem}

il 93 DocIDIUM Tumer Alg. Ind. orient. p. 33 t. 4 f. 5 .

\section{setigerum}

d ot STAURASTRUM Cleve Birls. t. Srerg. Desm. p. 4.10 t. 4 t. 4. [St. Royanum Arch. 15it].

d 58 - Riml. Fhor. Eur. Alg. 3 p. 216.

71 - Lmin. Desm. Suev, t. 1 f. 3.

o 73 - Nordst. Norg. Desin. p.31.

d 84 - Wulle nosm. U. S. p. 141 t. 45 f. $26-27$.

o sh-Stokrs Iney Desm. p.16T. 
d $8: 1$ - Tomi sirll. alg. p.116i.

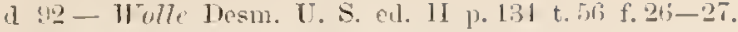

o 93 - lioy Seottisl I Iesm. 11. ㄲ.3 et 1.494 t. 3 f. 9 .

m 95 - Ficleler in Pamint. Fizy. 13 lo tio.

\section{serrem!fulurer-is}

1] 61 COSMARIUM l.mud. Desm. sinee. 1\%35 t.2 f.23.

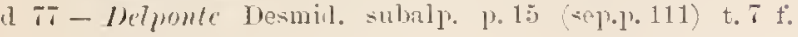
(0) -73

d s.t-Wulle Desin. U. S. P. 63 t.16 f. S-: [10m hona see. anct.]. t. 4 ! f. 13 .

o si - Stulics liey Desm. m, 121\%.

m $86-f i$ minor lioy et Biss. Ta]. Desm. p. 195 sep.p. 3

a 87 - Hexenke Chloroph. Kliarkow p. Dit.

d 5 - f. minima Tortst. Algolog. smaisak. 4 p. 160.

d ss- - Nurdst. Fr. wat. alg. X. Zenl. p. 60 t. 6 f. 26 -26 (-

d $89-T u n i$ syll. ale. 1\%. (1.54.

in - צ. minns ibill.

1 - 1 . minimum inul.

1191 URSINELLA himtie Rev. geu. pl. 1).925.

m 91 Cosm. f. minima Guter. Flor. alg. Leopol. p. th.

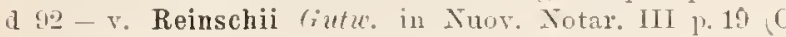
galeritum f. Reinsel contrib. t. 10 for'?)

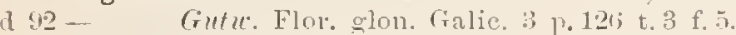

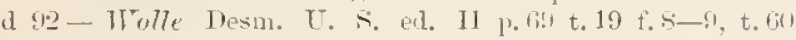
f. 13.

d 13 -- Gouatidium $\backsim$ Bengalense Tumer Alg. Ind. oricut. port to $\$$ t. 30 .

m 44 - t. minima Borge Fibsw. Chlor. Arhang. 1). 29 t. - f. f.

o 94 - Mill. Austral. Silsswasseralg. II p. 340.

in:4-f. miuima rutu. Fl. alg. Taruanol. p. 87.

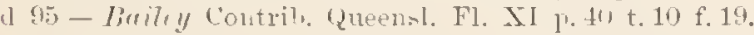

\section{sexron!m}

31 EUASTRUML Corla in Alm. d. Carlsl. 1.535 p. 206 t. 3 f. $30=$ Pediastrum Rotula.

\section{sexull!mlare - is}

d 61 DIDYHOCIADON bulul, in Helwig. p. 51 t. a A f. 1.

d 63 STAURASTRUM Tinl. Trypt. Flor. Sachs, p. 621.

d 71 -Lund. Desm. Suec. 1) 71 t. 4 f. 9.

m So - Nordst. De Alg. et Charae. I p.11.

81 - Cooke in Quekett Mier. J.6 t. 11 f. s et y [e Lund.?].

n $813-\gamma$. Jus7. Burm. Desm. 1.64t2 t. 23 f. 24 .

d si-P lave lioul et Ihise. Jaj. Desm. 1. 239 (sep.p. T).

d si-Coule Brit. Desul. p. 17 s t. 10 f. 3 et t. 64 f. 1 [ut videtur e Lumal.. sed non exacte].

o 87 - $\beta$ productum Nordst. Algolog. småsak. 4 p. 156.

Ss - - - Wordst. Fr. wat. alg. N. Zeal. p. 35 t. 4 f. 1.

d 84 - Tuni Sirll. alg. p. 1221

d - r. productum ibid. $\% 1225$.

d - ז. Iave ibid.

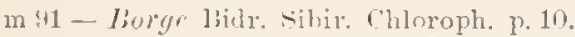

o $92-\beta$ productum líc. Ilesmidya Ciastoni. 1).381 t.

d 13 - Hoplastrum " crassum Twmer Alg. Ind. orient. p.117 t. 15) f. 1 a et $b$ form. "glabrum", c et d dentato-serratum".

d $-d$ intermedinm ibid.: t. 15 f. 2.

- - F attenuatum ibid.; t. 15 f. 3 St. fnrcigerum Mask. $1 \times-\div 3)$.

m - f. triangularis et 5 compressa ibid.; t. 14 f. 1. Cfr. Didymocladon Stella Mask. Staur. furcatostellatum lieinsch.

inrdstede, Index Iresmil.

\section{surenstutum - r}

n 3!! BINATELLA Brib, in Chev, Nlicr. 1) $2 \%$.

(1) IOSTAURASTRUM Rrit. in Jenegh. Synops. Desm. ]. 2.2s (sel.j. - gs). [Descript. mala].

d 49 - hinlfs luit. Desm. p. 129 t. 23 f. 5 Staur. Jenneri $1 \mathrm{int5}$

d 1: STEPHANOXANTHIUM hälz. sipec. Alg. p. 1.54.

d 52sitaur. Pritch. Inf. 1.26il.

d li1-.treh. in P'ritch. Inf. p. TH.

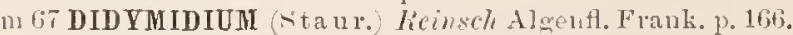

d 6stitaur. Lal. Flnx. Eur. Alg. 3 p. 216.

o 71 - Plenrenterium) Limd. Desu. inec. p. 71.

o 73 - Nordst. Norg. Desin. p. 37.

In 75 - hordst. Desm. aret. p. 3i.

d tit-Kirmo. Alg. Schles. p. 16.).

1184 - Racib. Desm. okol. Tírakowa p. sep'op. 18.

o S5-a. typicum liacil. Nonn. Desm. Polon. p. S5 (sep. 1. 2ul lialfs 1stis.

d - 1. truncatum ibid.. t. 12 (sep.3) f. 14.

o Si-Coolie Brit. Desm. 1. 1 sic t. 61 f. 1 [e lialfs].

d $84-T o n i$ syll. alg. p. 1232.

d - r., truneatum ihil.

d 12 - subsp. productum IVest Alg. Engl. Lake Distr. 1. 733 t. 9 f. 34

ms -- ฯ. productum schmidle Beitr. Alg. Sclwarzwald. 1. 1111.

1.94-v. jroductum schmidle Alg. Geb. Oberrheins 1. 5ั52.

m 44 - Borge süssw. Chlor. Arehang. 1. 34.

\section{sexmotritum}

d 92 COSMARIUH Gule, in Nuov. Notar. Ill p. 19

1) 92 - Gutw. Flor. glon. Galie. 3 1. 125 t. 3 f. 7 .

194 - r. triomphalum Gutu. Fl. alg. Tarnapol. 1'. 3 f. $2 !$ !

n 95 - v. tristriatum simidle Beitr. alp. Alg. 13. 45 Cosm. Blyttii f. tristr. Laitlem.).

(1) - r. subtriomphalum ibid. p. $45 \overline{\text { t. }} 15$ f. 2 s. [Quid?].

\section{ser-spinifer'llm}

d 85 GONAT0ZYG0N Tirner New rare Lesm. 13.440 (sep. 1. 8 t. 16 f. 27 . [ = partes auimaleuli verisimiliter

n sif-Stolies Key Desm. 1).110.

d 87 - Wolle Fr. Alg. U. A. A. 1. 21.

d sy - Tomi sivll. Alg. posin.

d 42 - Wolle Ilesm. L.S. el. 2 p. 1 T2 t. 43 f. 15 [e Tumer]

\section{sibirirllm -re}

a 85 EUASTRUM Buld sibir. Chloroplı. p. 99 t. 5 f. 2.

d S:t - Toni Syll. alg. p. 1075 .

n 91 HELIERELLA Kuntze Rer. gen. pl. 1. 899.

m 95 Eu. Johns. Rare Desm. U. 8. II p. 29? t. 239 f. 13.

\section{sibirirmm}

dzf 85 PENIUM? Buldt Sil,ir. Chloroph. p. 120 t. 6 f. 43. dz 89 - ? Toni Sr 11. Alg. 11.857.

\section{sibirirllm}

I 91 STAURASTRUM f. ovalis Rorge Bidr. Sibir. Chloroply. ]. ? t. 1 f. $t$ [Cfr. Latgerle in 1․ Notaris. II 1.25; - et II est 1sin].

d (1) - v. crassiangulata lior\%. F. alo. Grönland. p. 2i t. 2 f. 22. (st. sp. Boldt Gröıl. Desm. 1. 34 t. 2 f. 51 ).

1) 93 CosMARIUM Tumer Alg. Ind. orient. p. T.2 t. 23 f. 11. 


\section{silllloillem}

1 93 CLOSTERIUM Larr $h$ et Nordst. in Wittr. et Nordst. Alg. exs, 11:0 1138 e. figg. 1-3.

\section{Silihimenve}

(1) 13 COSMARIUM Tumer Alg. Ind. orient. p.li1 t.9 f. 4 et : 50 .

\section{sillatutum.}

d st STAURASTRUM Wolle Desm. U. . . p. 125 t. 4.2 f. 22 -2: "Fortasse St. dilatatum" Nordst. in litt. 15:13 ad IIolle. - Figg. malee. Quid?].

a 86 - Stules Key Desm. P. 161\%.

d 92 - Wulle Desm. U. S. cil. 2 p. 142 t. 53 f. $22-23$.

\section{silesincell1}

d 90 COS MARIUM Gutw, Wahr. d. Priorität p. 69.

n - $\quad$ minor ibid. (C. Schliephackeanum Rac. 1say).

d - $\beta$ major ibid.

d 91 - Gutw. Flor. alg. Leopol. p. 55 .

d - v. major ibid. p. 51 t. 2 f. 14.

\section{silesill")lll}

d 61; STAURASTRUM Hise in Rab. Alg. Eur. n:0 1820. 1 19 - Milse in Ber. d. schles. Ges. v. Cult. 1515 p. 123.

d 7 - Kirchn. Alg. Solles. p. 165.

Est Staur. muricatum sec. Nordst. in Bornl. Desm. 18s9.

\section{Sillii}

a 9t COSMARIUM Roy ot Bis. Scottisl Desm. p. 1it (sep. 1. 15) (1893) t. 2 f. 11 .

\section{simen!yi}

a 9 STAURASTRUM IJeimenl Desmo alyin. p. 61 t t. 5 f. 23. d 93 - v. gracile Jü̈liemiill. Desm. Attersees p. 563 t. 4 f. 14 [St. Nigrat silva Schmidle 1S!r]

\section{sillulex}

a 84 (febr.) EUASTRUM (Cosmarium) Gry Mon. loe. Conj. p. 62 t. 2 f. 2 ; et Not. Conj. d. m. Fratuce 1. 333.

a s. COSMARIUM Toni syll, alg. p. 40 .

11 URSINELLA Kuntze Rev. gelı. pl, p.925.

\section{simplex}

f) 8. (maj.) EUASTRUM Holle Desm. T. S. p. 10 t. t. 2 f. 18-2.2, nou Giny [Eu, coronatum Tum. 1895; E. integrnm Wolle 18si, E. binale is simplex IIansy. $14 \mathrm{~s} \mathrm{~s}^{\circ}$.

o S6-stolies Key Desm. p. 14 .

\section{simllex}

d somicRASTERIAS Bïr\%. Desm. Brasil. p.31 t. 2 f. 10, $110 n$ Kütz.

\section{silliller}

d 31 MICRASTERIAS Kïtz. Syn. Diat. p.602 (sep.p. T) = Pediastrum simplex Meyen.

\section{simplex}

o 84 MICRASTERIAS Wolle Desm. U. S. in explicatione tabule 36 f. S, que l. 110 M. fimbriata forma simplex appellatur.

\section{silleplesen}

d 93 PENIUM Tuner Alg. Ind, orient. p. 17 t. 3 f. 9.

\section{simplivills}

d 93 EUASTRUM Turner $\mathrm{Alg}$. Ind, orient. 1.81 t. 10 f. 31 et 11 .

\section{simplievills}

d si XANTHIDIUM Nordst. Algolog. småcak. 1 p. 154.

1 8i - Nordst. Fr. wat. alq. 1. Keal. 1. 11 t. 1 f. 26.

1] $89-$ Holacanthinm) Toni Fyll. alge. 1\%924.

\section{simostros}

1 83 COSMARIUM schurrechm. Magyar. Desm. 1'. 266 t. $1 \mathrm{f} 1 \cdot 2$.

d 89 - ("synostegos"), Tomi syll, alg, p. 1113.

n il URSINELLA Kuntäe Rev. gen, pl, p. 9.5.

d 2 Cosm. v. obtusius Gutu. in Nuov. Notar. III p. 21.

1 12 - - C Cute. Flor. glon, ralie. 3 p. 131 t. 3 f. 13.

n 93 - (rouatidium) Thmer Alg. Ind. orient. p) Tt.

o $95-J o h n$. . Fare Desm. T. ‥ If p. 201 t. 241 t. 24 .

o $95-v$. olitusius f. Ilest Alg. Marlag. 1. is t. 6 f'. 33.

\section{singullare}

d 93 EUASTRUM Tumor Alg. In1. orient. p. 79 t. 10 f. 45.

\section{sillurt!}

1] 35 MICRASTERIAS Brib, et God. Alg. F. laise 1). 55 t. i Echinella oblonga Grte. sec. aucturem ipsum in addenda p. 26 .

n 39 HETEROCARPELLA Wieb in Chev. Micr. p. 2.2.

n 39 - $\beta$ Lyngbyei ibil. Echinella radiosa Lyngb. Hylr. [ran, t.199 E f. 2 [Cosmarium oblongum junius in Henegh. synops. Desm. p. ․ㅡㄴ]

\section{sin.110.}

o $3 \pm$ COSMARIUM Cordr. in Alm. 1. Carlsb. 1835 p. 100 et '2145 (sep.1). 1.21) t. 2 f. 21 [Euastrum Pecten sec. Eherenb. in Wiegm. Areh. 1.3315 l. $185=$ E. oblonguin : iree.)].

\section{sillovillm}

a 71 COSMARIUM Luml. Dsim. Siec. p. 47. C. quadratum var. liulfs Brit. Desin. t. 15 f. 1 c.. Dilym. plicatum lieinsch Alg. Fl. ex 1. t. 9 f. 1 d.) Cosm. plicatum v. simuos. Cooke 1856].

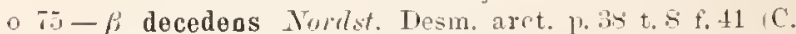
plicatum? c decedeus Reinsch 1s67) [Cosm. decellens c. boreale Rac. 1859 .

m 76 - p decelens Nordst. Desm. Ital. p. 31.

d 84 - Wrolle Desm. U. S. p.tis t. 16 t.2.

o. 56 - Stohes Rey Desim. p. $12 \%$.

o sis DYSPHINCTIUM IJungg. Proh. Algenf. Bühm. 1. 211.

d s. Toni syll. alg. p. Silt.

d $\quad-\beta$ decedens ibid

a 92 Cosm. Wolle Desm. U. ‥ ed. 2 p. 70 t. 1:4 f. 2.

m94- $\beta$ ilecedens Borge Nïssw. Chlor. Archang. p.22. m.94-Alecenko Mater. alin. Khark. p.24.

\section{simllostlm}

d s. DOCIDIUM Wolle Desm U. s. p.51 t. 11 f. 6 et $S$. d - v. breve ibil. p.51 t. 11 f. 7

o $\$ 6$ - Stulies key Desm. p. 113.

d sy-Toni Frell, alg. 1. sir.

d - v. breve ilid.

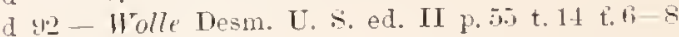

d - v. breve ibil.; f. $T$. 


\section{sill10smll}

d 1! EUASTRUMI? Kütz. sipe. Alg. ].17t Cosmocrenatum Tialfos, non aliormu.

\section{sill $11,+1111-11$}

[n th EUASTRUM "Lenormand, in lerb," Ralfs Brit. Desm. p. S. (E. circulare $\beta$ R Ralfs". Tomen "sinuosum" a Relfivio non aceeptatun!?.

1 61 - Arch, in Pritch. Int. p, T2y Eu, ciuc, Falesiensis Trib.).

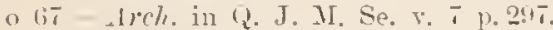

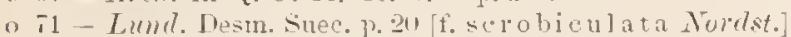

n 73 - 1 . scrobiculata Fordst. Norg. Desm. 1.9.

m is- Vordat. Alg. sandrie. p. 14.

in 85 - Jiolelt wihir. Chloroph. l'. as.

d sili-Coulie Brit. Desm. 1. 11 t. 34 f. 3 [e lialfs].

m Ss - Vordet. F1. wat, alg. N. Zeal. p.33.

d s9- - vemmulosum Mask. Furtl. Not. X. Z. Desm. P $10 \mathrm{t} 1 \mathrm{f} . \mathrm{s}$.

dzf $-\mathrm{y}$. simplex ibid. p. 11 t. 1 f. ?.

(1) 89 - Toni syll. alo. p. 1049 .

(1) sh - $\mathrm{v}$. Jenneri f. polonica Rurib. Xon. Desm. p. $103 \mathrm{t}$. (i) 1.: [Eu. Jenner.i Arch.].

d - f germanica ibid.; t. ti f. 10 .

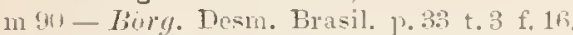

110 9) - Andros. Srerig. Chlor: 1 p. 10.

11 91 HELIERELLA Kuntzf Rev. gen. p]. p. S!1

m E Eu. West Fr. w. Alg. W. He]. p. 13s;

o 62 - live. Desmitlya Ciastoni, 3.37?.

d 93 - Builey Contr. Queens]. F]. l'. is t. 1s f. 14 bis $[\mathrm{e}$ (cuolis.

m 93 - v. Jenueri f. polonicum Lïtkemüll. Desm. Attersees p. mil.

m (1;3-Colpodastum Tmmer Alg. Inı]. orient. p. so

m 45 - f. polonica Eichler in Pamiet. Fizy. 13 p.61. Cfi. Dielsmidium variass Pitinsch.

\section{s7eredrumbense}

dz 90 CosmaRIUM Roy in seott. Naturalist X p.204.

zf 93 - Roy Scottish I iesm. t. 2 f. 19

\section{smirieregliumll}

dzf 9: STAURASTRUM Turner Alg. Ind. orient. p.103 t. 1.i. f. 14 .

\section{simithii}

( i) XANTHIDIUM Areh. Deserizt. New ripec. in Dubl. Tat. Hist. Soc. Proc. v. 3 p. 51 t. 1 f. $10-12$ in Nat. Hist. Rev. p. 105 t. 13 f. $10-12$; in Q. J. Mier. sc. 1. 239 t. 11

d $61-$ drch. in Pritch. Inf. p. 736

d 68 - Iinb. Flor. Eur. Alg. 3 p. 22 t.

d 8 - Cooke Brit. Desm. p. 133 t. 45 f.t.

d $s \overline{-}-p$ variabile Fordst. Algolog. småsak. 1\% 15y.

d s8 - - - Nordst. F. wat. alg. X. Zeal. 1. 44 t. 4 f. 27-29,

d s!- Holacanthim, Tomi Syll. alg. p.t2t.

d- $-v$ variabile ibid.

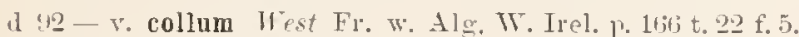
$m$ - r. variabile ibid.

o 4 - v. variabile Wrb. Anstral. süsswasseralg. II 3. 389.

$0.5-1$ - Mub. in Railey Contrib. Queensl. Fl, XI p. 40 t. 10 fi. 15 ; et $a$ )

d $45-r$ variabile f. Racib. in Flora v. 81 p. 33 t. 3 -4 f.s.

\section{Smolamdirame -r}

a 71 CosmariUM Lund. Desm. Suee. p. 39 t. 2 f. 17 . d $7 S$ - a. genuinnm firchn. Alg. Pichles. p. 150.

d - b. angolosum ibil.

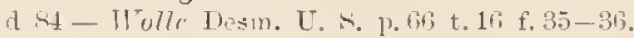

m sij-Laryerl. Amerik. Desm. 1, 239.

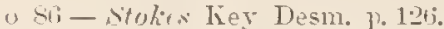

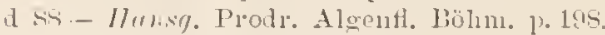

1) - $\beta$ angulosum ibil.

1)

d - v. angulosum ibit.

11 ¿1 URSINELLA kuntac Rev. gen. pl, p. 125.

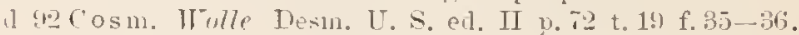
Cfr. Cosm. obsoletum rar. angustatum et Cosm. palustre.

\section{sllirtyllense}

1) (t) COSMARIUM Gutu. Flor glon. Galic. 2 p. 12 t. 1 f. 7. ('fr. Cosm. impressulum].

(] !2- - v. sydneyensis Kac. Desnidya Ciastoni, p. 37: t. 7 f. 3.

1355 - - Eichler in Paniet, Fizy. 13 p. 50.

\section{smomeromienser}

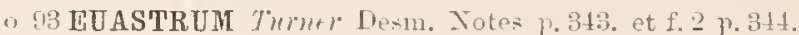

\section{sorintulu}

a st STAURASTRUM Wolle Desm. T. S. p. 112 t. $45 \mathrm{f}$. 2.2-2-23.

o s6- Stukes Kiey Desm. p. 164

1 89 - Tumi sirll. alg. p. $116 \%$

1 t. - Wolle Iesm. U. S. ed. II p. 155 t. 55 f. 22-23.

1h 93 - Thmer Alg. Ind. orient. p. 113 t. 17 f, 13.

\section{Sol}

a 43 EUASTRUM Lhrub. Miki. Leb. Sizd. u. X. Aner. p. (334, 337. 372 et 413 sep.1. 125) t. T. I f. 16 [Exclus. syum. Briteyi]. [Micr. radiosa $T_{i}$ lfs].

d 19 MICRASTERIAS Kiin. suee. Alg. p.171.

- To-Jacabs. Desm. Dunew. 1) 1ss.

$m 80-\beta$ ornata Norlst. in Pointstör. Skand. Väst. $4 p$. 25 [M. radiosa $\beta$ olnata Tordst. 1870].

- 91 HELIERELLA Fimutze Rev. gen. j1. p. $89 \%$.

\section{solidull, -re}

msi CoSMARIUM Norlst. Algolog. måsak. 4 p.160 C. punctulatum Norlst. Desm. - pets. 18i2, non Breb.).

m SS-Doldt Desm. Grönl. 1.27.

d 88 - Wordst. Fr. wat, alg. X. Zeal. p. 4x.

a $89-$ Tomi syll. alg. 3. (n).

11 :1 URSINELIA huntze Rev. gen. jl. p. "us. Cfr. Cosm, crenatum form. "Gutu. 16ri??

\section{Sonthatianum}

a 93 D0CIDIUM Twner Alg. Inul. orient. p. 33 t. 3 f. 8.

\section{Sonthreliamum}

dzf 93 STAURASTRUM Tumer Alg. Fnd. orient. p. 124 t. $14 \mathrm{f} .27$.

\section{Springbergiena}

n $\$ 3$ PAGET0PHILA Wittr. Snöns o. isens fl. p. 113.

\section{sprersicueleretum}

d 1 STAURASTRUM Schmidle Eeitr. alp. Alg. p. 60 (sep. p. 31) et, 1885, t. 16 f. 20 St. Ravenelii? see. Hest $1894 i]$.

11 95 DYSPHINCTIUM schmillc Beitr. alp. Alg. p. 318 t. 
15 f.1-6. "sparsepunctatum") [Cfr. Pen. cruciferium].

\section{s)(t)s}

dzf 93 COSMARIUM Tuner Alg. Ind. orient. p. 69 t. 19 f. $13,16 \%$

\section{speriosa}

d s.s MICRASTERIAS Wolle in Bull. Tor $x$ bot. Club 12 p.4.

a $5 \%$ - 11 olle Fr. Alg. U. S. A. p. 38 t. 56 f. 1--2.

d sy-Tomi ivil. alg. p. 1124.

n 11 HELIERELLA Kunze Rev. gen. pl. p. 899.

d 92 IL ic 1. TFolle Desm. U. S. el. II p. 119 t. 45 f. 1 -2.

d $44-$ Samml. in Fl. Nebraska p. 43 t. 7 f. 2.2 [es Wolle].

\section{speciusissill 111}

1 y5 COSMARIUM schmidle Beitr. alp. Alg. p. $45 \mathrm{~s}$ t. 15 f. $30-31$.

\section{speriosum!}

11 s6 CLOSTERIUM Tumer in Leeds Nat. Club transact. 1 p. 10 t. 1 f. 17 . [Cl. angustatum f.? Cflo v. subrectum schmidle 1.593$]$.

\section{speriostim!}

1) 71 CosmariUM Lund. Desm. Suec. 1. 34 t. 3 f. 5 [Dysp]. notabile subsp. speciosum Hansg. 18ss].

a 72 - $\ell$ biforme Norlst. Desm. Spetsb. 1.30 t. f f. 11.

d $-\beta$ sinplex ibid. $\% 31$ t. 6 f. 12.

0 - forma ibil.

o $75-\beta$ simplex Tordst. Desm. aret. p. 22.

m $7 \hat{6}-\beta$ simplex Tordst. Desm. Ital. 1.37.

m 78 - $\beta$ simplex Nordst. Alg. samlvice p. 12.

m 79 - a biforme Wille Ferskv. aly. Tov. Semlj. p.t1.

m $-\beta$ simplex ibid.

m - f. minor ibic. t. 12 f. 28.

$m$ - - $\mathrm{f}$. intermedia ibil. f. 29.

A 83 - v. inflatum Wasl: N. Zeal. Desm. Aill. p. 240 t.24 1. li. [C. subspeciosum $\beta$ validius Nordst. 1sit; cofr. Mask. 18!) p.4\%.

n St EUASTRUM (Cosmarinm) Gay Mom. loe. Conj. p. 6\%. m $\quad-\beta \operatorname{simplex}$ ibil.

d $81 \mathrm{Cosm}$. Wrolle Desm. U. S. p. si to 19 f. 7 - $8(9,14$, 15 var.).

- 86-Stolies Key Desm. p. 12!?.

‘ 8 - Cooke Brit. Desm. P. 117 t. 41 f. 1. [e et d. e Lundell; a et $b$ ? ?

A 87 - $\beta$ australianum Nomlst. Algolog. smasak. 4 p. 161 . msi - v. abbreviatum Wolle Desm. Minnesita p.3s.

n ss DYSPHINCTIUM Hansy. Prodr. Algent. Johm. p. 1si in nota efr. r. 1!(1).

m SSCosm. Follt. Desm. Grönl. p. 19.

m - fo ibill.

m - a liforme ibid. p. 2t).

$$
\text { f. minor ibil. }
$$

n - p simplex ilis.

11 - $-\mathrm{f}$. intermedia ibid.

o 8 - $\beta$ australiaunu Nordst. Fr. wat. alg. X. Zeal. 1. 5 t. t. 5 f. 9.

moth- Intent Forth Carolina Desm. p.3.

nu s. liacib. Mat. Hor. glon. Polsk. p. 104 (sep.p. 25).

m s. - fo genuina Mask. Finth. Tote X. Z. Desm. p. 1t; t. 2 f. 20.2 .

$0 \quad-$ v. simplex ibid. p. 16 t. 2 f. $2: 3$.

1 sy Lis.? Toni Syll. alg. P. \$:11.

1 - v. bifolme ibil.

1 - 1 . simplex ibia. p. s92.

1. - v, anstralianum ibisl. d 89 Cosm. $\beta$ simplex f. Wordst. in Wittr. et Nordst. Alg. exs. n:o 13 is et in fase. 21 p.39.

d - $y$ psendospeciosum ibil. 110 97t (Dysph. notabile (P) pendospeciosum Hunsg. 1siss).

(1 - $\$$ lapponicum ibir. 11:0 $9 \%$

d $90-\beta$ Anstralianum f. Gutw. Walır. d. Priorität p. 65 .

$191-$ - f. Gutw. Flor. alg. Leopol. p. 50 t. 1 f. 35 a, t. 2 f. 35 b. [cir Lïlliem. Desm. Atters. 1. 557; f. leopoliensis Gutıo. 1894; C. ochthodes r. amoobum ser. Gutw. in Pr. A. alg. Galic. 12.34j].

m $92-B n g e$ Alg. notis. 2 p. 60.

m - $p$ simplex ihid.

w92 - Borge Chloroph. Torsk. Finmark. p. 10.

m - p rimplex fo intermedia ibil.

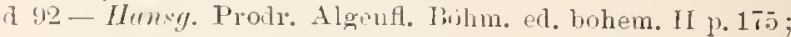
ed. germ. II 1.25j.

m $92-$ Línc. Desmidya Ciastoni. p. 386 t.tj fi. 13.

dzf - v. difficilis ibit. p.35 t. i f 16 .

1 92 - Wolle Nesm. U. S. ed. IJ p.95 t. 22 f. T- !. 14-15. m Dis. f. Gutw. Flor. glon. Galic. 3 p. 123.

1ht 43 Cosm. Lïliemill. Chlorophyllkörp. ein. Desm. p. in 93 - Lütlemüll. Desm. Attersees p. ist.

o - v. biforme ilvil.

m $94-\mathrm{v}$. simplex Iste. Roman. alg. 1\%. 15\%.

o - - . ornatum ibid

m - v. biforme ibir

d 94 bis.? v. Schmidle in Hedw. 33 p. 95 t. 1 f f.4.

1) 94 Cosm. ' rossicum Purge Süssw. Chlor. Archarg. p. 21 .

d - i) rectangulare ibil.. t. 2 f. 12.

o 94 - r. simplex Bory. F. alg. Gstgrönl. p. 15.

$m$ - v. bifolm is ibil.

m 94 - Alcoenlio Mater. alg. Tihark. 1.25.

m91-v. australiaum f. leopolionsis futu. Fl, alg. Tarna.jol. p. 81 (f. Gutw. smpre 1S91).

m 94 - Storlim. in Xachtr. syst. Anfz. Österr. Kry pt. p. t5.

1 95 - v. tumidum Schmille Beitr. alp. Alg. p.317 t. 11 f. 31 .

\section{s)ertabile}

1] 6 - Cosmarium Not. Desm. Ital. p. 4.5 t. 1 f. 31 Cosm. calatum $\beta$ s spect. Nordst. 1sir6].

1 69-Riul. Flo1. Eur. Als. 3 p. 170.

4 EUASTRUM (Cosma r.in m) Giny Non. loc. Conj. p. $6^{\circ 2}$.

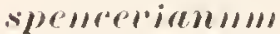

n se STAURASTRUM Irast: in litt. apul Xordst. Fro-wat. alg. X. Zeal. p. 4) (st. connatum $\beta$ stpenc. ibid.).

o 89 - Mrsti. Furth. Not. Y. Z. Desm. p. (5 et 2T.

\section{spetsluevegense -is}

(1) T. Cosmarium Korlst. Desm. Spetsh. p. 27 t. 6 f. 3.

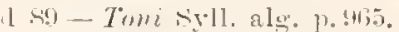

n 91 URSINELLA Kuntie Rev. gen. pl. 1. D2.

\section{sullevelestillu}

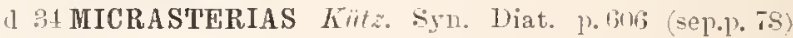
$=$ Sphærastrum pictum עeyen.

\section{SPHARICISTRUII}

o 93 Turner Alg. Iuk, orieut. p. 133. Rubgen. Staurastri.

\section{sphrmirom, - -}

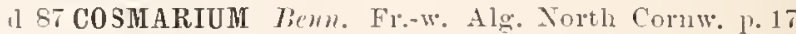
(aep.p. 1ii) t. 4 f. 22 [C. pregraude see. auct. 1890 in Fr. Alg. Hanıpli. p.9; - - pi splurericum Lagerh. 1890].

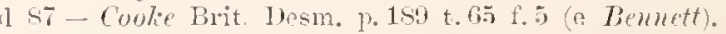

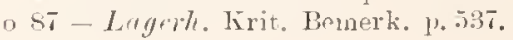


d S9 PLEUROTÆNIOPSIS ? Tomi sivll. alg. p.913.

o s9 Cosm. Bueryes. Bornh. Desm. p. 14i.

\section{SPIL ERIIIUII}

d 93 Turner Alg. Inl. orient. 1) T.t. Subgen. Cosmarii.

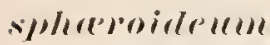

d !.2 COSMARIUM If est Fr. w. Alg. W. Irel. p. 153 t. 211.8 .

\section{SPILEROIIIUN}

d 51 liab. Bacill. exs. fasc. 5 n:o 19.

\section{SPILEROSPIIITETLII}

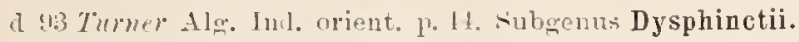

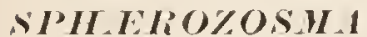

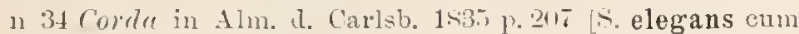
explicatione iconis, sel sine lescriptione generis!?.

n 411 - ibicl. 1840 1. 205.

d fis Rulfs in Ann. Nat. Hist. r. (1) 1. 13 'et 154ri in Trans. Bot. Soc. Elint?. 1. 167.

d t.3 Mrawall Brit. Alg. p.34s.

(1) thelfs Brit, Desm. p. 60 .

(1) 52 I'ritch. Inf. p. 243.

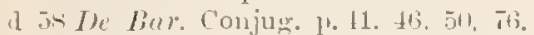

It to Wallich Desm. Low. Bengal. 13. 186 et 1:2.

a 51 Archer in Pritch. Inf. p. T2:

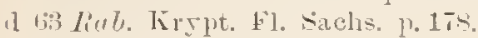

d $5 \pm$ forny Brit. Alg. p. Tis.

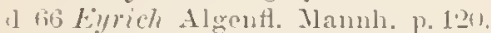

d lit Not. Desin. Ital. 11.20).

d his Rab. Flor. Eur. Alg. 3 p. 10 , et $14 \mathrm{~s}$.

(1) 7 Milponte Desmid. subalp. 13.36 et 7 (sep.p. 24 et 65

d 73 Trood Fr. Alge. p. 123.

d 75 Microne. Diet. 13. 23.I et 715 .

1 Tit Frank in Lewmis Synops. p. 1633.

a to hirchn. Alg. richles. 1\%133.

1 St Gray Monogr. loc. Conjug. 1. 12. Sect. 1. Sph. s. str. 2. Spondylosium.

d St Tholle Desm. U. s. p.2s

1) 85 hirehn. Miku. PHanz. d. Siissw. p. 20.

o slistokes Key Desm. p. 109.

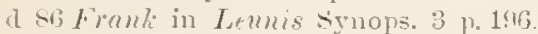

1] Si Coule Prit. Desm. 13.3.

it Si Alexenlio Chloroph, Khark. p. 219.

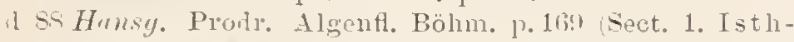
nosira hiltz..?. S. pondylosium limb

4 ks Toni et Leri Fl. Alu. Venez. 1. 21 et 25.

1) 8.8 Ilnmpll. Zellm. u. Hüllgallerte Lesm. 1'. 9 (sep.p. 21 .

1 . 9 Tomi vill. Alg. p. Ts4 et io sect. 1. Isthmosira

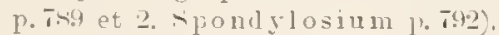

a so Winle in Natür. Ptlanzenfam. p. 1t.

1) 91 Kirchn. Mikn. Ptanz. d. Süssw. al. 2 n. 21

a 82 Tolle Desm. T. S. e.t. II p. 28 .

1 !13 Britey Contr. (queensl. Fl. p. 3s.

o 9.3 Tuner Alg. Ind. orient. p. 1.13. Subgenern: A. Spharozosma. B. 'Temmozosma. C. Oxyzosma.

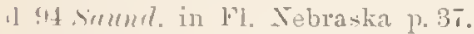

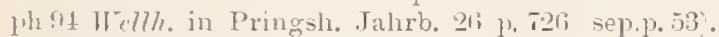

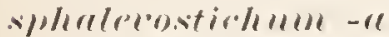

1\% if COSMARIUM Tord.t. Jesm. Ital, p. 29 t. 12 f. 3.

1 $81-\beta$ brasiliense Thlle Sydamerik. Algfl. 1\% 15 t. 1 i. (3n) $\mathrm{C}$ brasiliense Mordst. Isiri.

"4.j - ITolle in Bull. Torr. Bot. Club. 12 p. 2 t. 47 f. 21;-27.

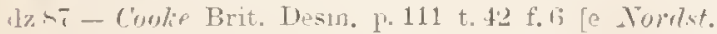

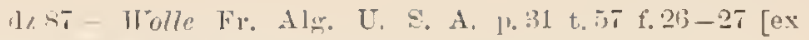

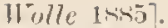

m ss - Roldt lresm. Frönl. p. ㅈ․

lzs - Jomi syll. alu. p. 108\%.

n s1 URSINELLA hunt:e Rev. gen, pl. p. t...5.

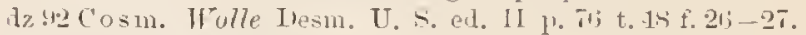

\section{SPHISTTOIPEILII}

d 84 Gruy Monogr. loc. Conjug. 1) 35 / Dysphinctium suhgen. Calocylindrus et Actinotanium Näg. rect. Penii.

d 93 Fum . Alg. Tnu, orient. 1. 1s. Subgen. Penii.

\section{spllymoirles}

(l) Si EUASTRUM Tarlst. Algolog. smaisak. p. 1:it.

d si- Torlst. Fu. wat. alg. X. Zeal. p. 32 t. 3 t. 3.

1 89 - Toni ryll. alg. 1) 11171 .

"9 91 HeLIERELLA "Wphyoles"; Kuntze Rer. gen. Il. 1. S.r.'.

\section{spiretull}

il :13 EUASTRUM Tuner Alg. Int. orient. p. 87 t. 11 f. 13.

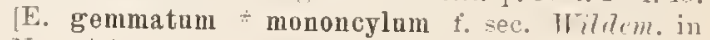
Totarisia 15!:3 p. 11j!; ammon potius E, substellatum f.?.

\section{spirutur}

n 15 STAURASTRUM 11 est in Journ. of Bot. 33 p. Tn Stan. dubium Eichl. et Gutw. 1s:4. non thest 18:40).

\section{spireters}

a :3 ARTHRODESMUS Tumer Alg. Ind. orient. p. 13f t. 1 is $f .1 ?$.

\section{spiculiferum}

I 93 COSMARIUM Turner Alg. Ind. orient. p.tit t.9 f. 1?.

\section{spillifelell}

4 g STAURASTRUM West Fr. w. Alg. Torth Wales 1. 2!1.2 t. .5 f. 20 .

o 91 - West Freshw. Alg. Waine Il p. 35.

\section{जHinOsis.simum}

1) 93 STAURASTRUM Tumer Alg. Ind. orient. p. 113 t. 13 f. $\tau$ [? St. pyramidatum v. see. West Ten Brit. Als. P. 11].

\section{spinospe)"mull}

Iz S3 PENIUM Cylindrocystis). Jushue in Journo of Bot. ง. 21 1. 20.12.

laf 95 -Josh. in Journ. of Bot. v. 23 p. 35 t. 254 f. 10.

lzf ali-Cooke Brit. Desm. 1. 45 t. 17 f.9 [ex Josh ua?].

lz 89 - Toni syll. Alg. 1). 868 .

\section{spinosporllm- $\ell$}

oz 87 COSMARIUM Lnger\%. Krit. Bemerk. p. j:3s (C. Broomei v. Wolle Desm. U. A. t.17 f. S- 1891).

Iz 89 - Toni syll. alg. 1\% 1020i.

n 91 URSINELIA huntze Rev, gen. pll. p.92\%.

\section{spillosilll -r}

I 813 COSMARIUM Jush. Burm. Desm. 1. 447 t. 25 f. 3 \& 1.

I sit - Tuni syll, alg. n. 97.

in y1 URSINELIA huntze Rev. gen. pl. p. (1.25,

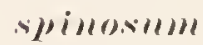

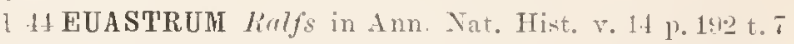


f. 1 i et 1 silj in Trans. bot. Soc, Ellin. v. 9 p. 129 t. 11). [Eu elegans "spinosum lirilys 1S18].

d 45 - Hass. Frit. Alg. j. 351 t. 1 f. 9 re Ralfs 1. e. deli. neatum?.

1 47 -Forlie Phss. Stud. I p. 41 \& 64 t. 1 f. 1 , et t. 2 f. $1.1-16^{2} \quad$ F. 4. 1-1.5 Fu, elegans sec. Rerinsch, 14i Thism. Eu.) binale A. corviculatum "Reinsch].

o 81 - Wulle Desm. L. S. p. 1613 t. 27 f. $1-7$ et 17 . [ifig. (i) Eu. quiucunciale Tum. 1843 sec. Witdem. 18:4].

o sij-Stukes Kies Desm. p. 111.

- 92 - Wolle Ilesn. U. S. ed. II P. $116 \mathrm{t} .31 \mathrm{f} .1-\mathrm{T}$ et $1 \mathrm{~T}$.

m 93 - Tumer Alw. Imi. orient. p.it.

m195-f. Rucil, in Flom v. 41 p. 33 t. 1 f. 15.

('fr. Eu longifrons et Nordstedtianum.

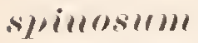

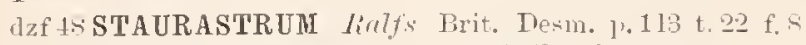

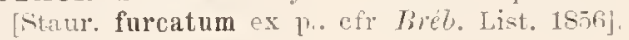

al $52-T$ rotch. Inf. p. 2isi.

phot - Je Jiur. Conjug. p. 4.1.

o 194 - Reinseh in Rab. Alg. Eur. 11:0 1st9 figg. 1 -5.

m 6i DIDYMIDIUM (Staur. Reinseh Algenfl. Frank. 1. 10s. o Tostaur. Reinsch Contribut. p. a

m 41 - Fichler Spis Desm. Miedz. p. «

m 91 - Heimert Desm. alpin. p. 60\%.

('tr. Staur. armigerum, furcatum et Ehrenbergii Tiulfs.

\section{siluox"m}

DOCIDIUN - vile spinulosum!

\section{sipillosill}

d 11 XANTHIDIUM White in Micr. soe. transact. $\mathrm{x} .1 \mathrm{l}$. sil) t. 's f, 5 [Fossile. an Spougia?]. [Quorue in Micr. .Tourn, v. 2, 1412 t.4. - n. r.].

o 4f - Wi7kinson in Mier. Soc. transact. 1.2 13. 89 t. 18 f. 2 f. 3 "like $\mathrm{X}$. spinosun".

\section{spimlliferllm}

as STAURASTRUM Mrsk. Furth. Tot. X. Z. Desm. ?. 25 t. 5 f. 41.

\section{sim}

d 81 D0CIDIUM Wolle in Bull. Torr, hot. Clul, v. S. 1 rs1, p. 1 t. 6 f. 21.

A St-"spinosum", Wolle Thesm T. S. 1.51 t.10 f. 12.

o si- Dtulips Iiey Desm. 1. 113.

d 89 - Tomi syll. alg. p. s76.

d 93 - Wulle Desm. U. S. ed. II 1.5n t. 13 f. 12 .

\section{s)illlosim-}

d T3EUASTRUM Letponte Desnid. subalp. 1, th sep.r. 85) $1.1 ;$ f. 17. 1s:

d si - "africanum Tordst. We Alg. et Charace 1 p. 9 t. 1 f. 16 [E. orbiculare Hz77.. Twm. sec. Hitdem. in Notarisia 1893 p. 16:9].

11 - $\beta$ minus ibid.

d -

d at - suhsp. inermins var. Oliveri Schuarsch. A fohan. Alg. 3. 24is t.5 f: 15 .

mit - inermius fo major tille sydamerik. AIgtl. p. 15 t. 1 f., 27.

d. s:1-Toni syoll. alg. p. $11 \cdots 0$.

d - subsp. africanum ibid.

m - - v. minus ibill.

d - subsp. inermius ibil.

d - v. Oliveri ilid. 1'. 1081. dzf 89 - subsp. africanum f. italica Racib. Now. Desm. p. 104 t. 6 f. 7 .

d - f. Bulnheimii ibid.. t.2 f. 6.

11 91 HELIERELLA fimtze Rev. gen. pl. n. sı!!.

1194 Eu. subsp. africanum f. scnlptom Wildem. Ols. erit. Desm. 1. 99 (E. se u I ptun Twm. 1sis).

n - - v. orbiculare ibid, n, 9.-5 E. orbiculare Tum.l.

o - subsp. inermins $r$, carductum ibir. E. carductum firm.).

- -- subsp. quadratum ibil. 1.: : , et v. javanicum E. quadratum c. var. Nordst.

1) 95 - $v$. duplo-miuor Hist Alg. Madag. p. 31 t. 6 f. 13.

o - - f. ibil.. t.6 f. 1? Eu. seulptum Tum.).

\section{spinUlOsUm}

d 40 PHYcastrom Amblyactinimm) Nay. einz. Alg. 1. 126 t. \& A f. 2 [St. cnspidatum].

m 67 DIDYMIDIUM sta ur., Femsch Algent. Frank. p. 156.

\section{"pimllosmme}

1 7 S SPH 2 R0Z0SMA Delponte Desmir. sutalp. p. is /sep.p. (bii) t. 3 f. 24 -2f. [sphrer. excavatum $\beta$ spin. Honsg. inimis?.

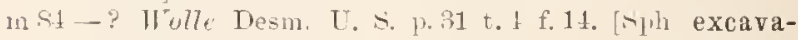
tum f. granulata see. Tumm 1.483! ; et 1 . 159 (recte). o Sij-- Stolies liey Desm. p. 110.

o.

\section{slimmlosmm!}

a Si XANTHIDIUM Tiem. Fr.- Alg. Engl. Lake Mistr. 1 \%. 10 t. 2 f. 17. [X. fasciculatum sec. Bem. Fr. AIg. Hampsh. 1.60, p.!1. X. antilopæum].

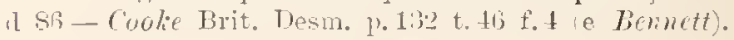

d 89 -. (Holacanthium' Toni syll. alg. p. 928.

\section{spirmle - is}

d $3+$ CLOSTERIUH Corta in Kivtr. Sym. Diat. p. 5. (sep. 1. $69 \%$.

o 34 -- rorda in Alm. d. Car]s1. 1.33 p. 194 t. 5 f. fir "tube intestinal spiral ? " . [CI. Jenneri?: Cl. striolatum (?) sec. Kiitz. spec. Alg.].

d 41) - Mcmegh. Symops. Desin. 1.2037 (sep.p. 37).

d 6u-Fat. Flor. Eur. Alg. 3 1. 139.

d sis - Trmi risll. Alg. p. t.5t.

I1 t1? ARTHRODIA fimtze Rev. gen. 11. p. Sat.

\section{slivalifermm}

a 7 .5 CLOSTERIUM Jacobs. Desm. Danem. p. 17 t. 7 f. 8. [Penium spirostriolatum sec. Timner 1s93].

\section{spiveostriolatum}

d ho PENIUM Jierleer in (?. J. M. Sc. 11. s. v. " p. 194.

o 64 - Archer in Q. J. M. sc. n. . . r. 9 p. 194.

o 71 -Arch. in Jour. of Jiot. p.94.

S:3 - Mittr. in Wittr. et Fordst. Alg. exs. n:o jot et 1 wsen, in fase. $21 \mathrm{pot}$.

(1) 8. - Tumer New rare Desm. p. 939 t. 16 f. 20. [P. scandinavicum].

d 86 - Couke Brit. Desn. 1.3! t. 15 f. 3.

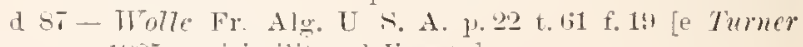
1.sis verisiuiliter lelineata].

o - v. ibill. P. 23 t. 61 f. 17.

d 8. - Toni Syll. Alg. p. 858 .

d 50 - Lemarive in Bull. Soc. se. Naney v. 10) p.31 (sep.p. 5) $\mathrm{f} 1$.

o 90 - West Fr: w. AIg. North Wales 1. 255 t. 6 f 24.

m 90 - Eichler Sipis Desm. Miedz. 1'.85. 
o 911 - f. Borye Cliloroph. Norsk. Fimmark. p. 1 is t. 1 f. 13.

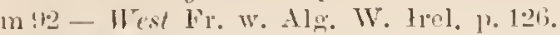

d! 12 - Wulle Desm. [. S. ect. II p.35 t. 10 f. 19 .

1) - $\because$ ibirl. f. 17 .

$m$ m - West in Yotaris. 7 p. 1500.

4 93-- Tumer Alg. Ind. orient. l. 140 t.23 f.3-5. (Cl. spiraliferum Jac; P. Haynaldii p lineare fioldl? (l 93 - Lichlev Mat. flor. Miedz. p. 14:3 (var:).

\section{SIIROT.ISIA}

n +1 hivel. in Dict. un. hist, nat. v. .l p. 711 .

it tis Brit. in Ralfs Brit. Tesm. p. 17t:

d 45 Brit, in Dict. miv, hist. nat. v. 11 p. 77.

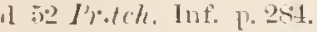

o sti liomm in Bot. Zeit. p. 46 .

o 50 Mzigs. in Bot. Zeit. p. Stits.

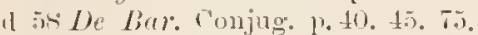

a dil Arch. in Pritch. Inf. p. Toll et Tis.

a 63 kab. Lirpt. Fl. Sachs. p. 17t. (Sect. a. II notania, b. Polytaniæ).

a 64 Groy lirit. Alg. p. it.

o lit fieinseh Algenti. Frank. p. 20:3.

d 6 i Not. Desm. Ital. p. 22.

d lis Rab. Flor: Eur. Alg. 3 p. 115.

d $7: 3$ Lrlponte Desm. subalp. p. to) (sep.p. 2-4).

d 73 Wood Fr. Alg. p. 122.

d 75 Microgr. Diet. p. 234 et 72.

d Ti Delponte Desm. subalp. p. 139 (sep.p. 235)

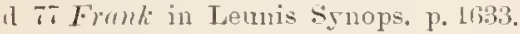

d iskirchn. Alg. schles. p. 131\%.

is Arehe in Q. J. M. Sc. v. 19 p. 121.

d in Gray Mlonoga'. loc. Conjug. p. $\$ 1$.

I) 41 Wolle Desin. U. S. p. 3․․

d s5 Kirchn. Mikr. Ptanz. d. Süssw. p. 20.

ph zasliberlhold stud. Irotoplasmamecl. p.316 ete.

o sti Stokes Kiey Desm. p. 109.

I 86 Franli in Leunis symops. 3 p. 198.

d sij Cuoke Brit. Desm. p. 50.

d si Alexenko Chtorosp. Khark. p, 220.

d sS Hansy. Prodr. Algenfl. Böhm. p. 1it.

d 88 Toni et Leri Fl. Alg. Tenez, p. 39.

I s. Tomi s.y.l. Alg. p. 807 .

d 91 Kirchn. Mikr. Pflanz. d. Süssw. ell. 2 1. 21.

- 92 Layerh. in Notaris. III p. 34. Subgen: Euspir rotania S. condensata). 2. Spirotiniopsis (S. truncata)

d 1.2 Wolle Desm. U. \&. ed. II p.33.

- 93 \%umer Alm. Ind. orient. p. 23. Subgen.: Monotænia et Polytenia.

d 94 sicund. in Fl. Nebraska p. 37.

ph 94 Wellheim. in Pringsh. Jahrb. 20 p. 727 (sep.p. 51).

d 95 Lüllemüll. Gatt. Spirotren. p.92. etc.

\section{spirotenire -inm.}

156 GONATOZYGON De Bur. in Hedwig. I p. 10h.

o $5 \overline{-}-$ De Bary Copulationsproc. in P'lanz. p. 340.

z 57 - De Bar. in Bot. Zeit. p. 765.

diffos GENICULARIA De Bar. Conjug. p. 26, 29, it t. 1 f. 1 - 2 .2.

d $131-A r c h$. in Prith. Inf. p. 721 t. 3 f. 3 [e De Bury].

d 36 -liub. Flor. Eur. Alg. 3 p. 156 .

d 55 - Nierogr. Dict. p. 335 .

d si-kirchn. Mikr. Ptlanz. d. Süssw. p. 20.

o sti-Stakes liny Desm. p. 110.

dats - ('ooke Brit. Desm. p. 18 t. 6t f.6 (e De Bury).

dz 89 - Joni s.yll. Alg. p. Sill3.

n sh - Wille in Natürl. Pflanzenfam. 13.13 f.s D (e de Pury).

d 91 - Kivelm. Mikr. Pflanz. d. sïissw. ed. 2 p. 22 t. 3 f. (ii) (e de Birry)

\section{Spirotermirere}

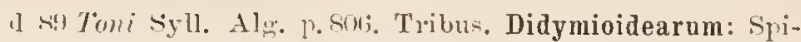
rotania. Mesot:uinu. Cylinulrocystis.? Aneylonema.

1 sut thithe un Natürl. P'flanzenfan. p. 4.

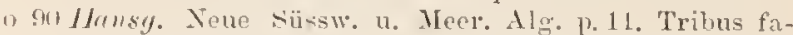
milise Pseudodesmidiacearum, inclus. Gloeotænier [Gloent:enimm].

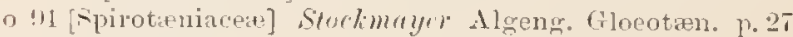
(sep.p. 3)

\section{SPIRO'THIOPSIS}

d. 12 Lagerh. in X. Notaris. III p. 3.t. Subqen. Spirotanix.

\section{splemdirlull}

a si STAURASTRUM Musk. Furth. Not. X. Z. Desm. p. 23 t. 4 f. 11

\section{SPONDILONIUH}

n +1 Brit. in Dict. univ. list. nat. 4 p. 111 . "spondyIntiuin").

d 4 Brit. in Kïtz. spec. Alg. p. 1 s!.

d 58 the Tiar. Conjug. 1. it) (Uiamos. Breb:i .

d 61 dich. in Pritel. Inf. p. 719 et 721 .

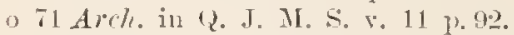

d Ts firchn. Alu. ichles. p. 133.

o St Guy Monogr. loc. Conjug. p. 13. Sect. Spherozosm.

11 s.5 Kirchm. Mikr. Pflanz. il. Sïusw. p. 201).

a sij Frank in Leunis synops. 3 p. 197.

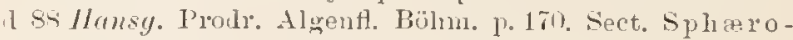
zosm.

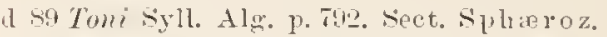

d 90 Wrille in Natiurl. Pflanzenfam. p. 14

d 91 Kirchn. Miks. Pflanz. d. Sïssw, ed. 2 p. 21.

o 13 Turuer Alg. Ind orient. p. 47.

\section{spollgioselle -re}

n 39 BINATELLA Brèb. in Chev. Micr. p. 27.2 .

a 4 STAURASTRUM Breb. in Rilfs lirit. Desm. p. 141 t. 23 f. 4. [Desmilium ramosnm Ehrenb. ?].

d 52 - Pritch. Inf. p. 267 .

d $131-$ Arch. in Pritch. Inf. p. 73 t. 3 f. $22-23$ [e Kulfs].

1 (i3-Jiab. Lirypt. Fl. Sarhs. p. 193.

m 67 DIDYMIDIUM (stau 1.) Feinsch Algentl. Frank. p. 175. o 67 stan $u$. Nol. Desm. Ital. p. th t. 1 f. 37 .

d GS-Rab. Fl. Eur. Alg. 3 p.21т.

z $71-$ Lund. Desin. Snec. 1) 65.

o 73 - Nordst. Yorg. Desm. p.3..

m 75 - Nordst. Desm. arct. 13.37.

dz 78 - Kivehn. Alg. Schles. p. 166.

m $84-$ Artari Liste alg. Moseou p. 14t.

d 81 - Wolle Desm. U. . . p. 148 t. 17 f. 5 - S (forma).

d sō-Kirchn. Mikr. Pflanz. d. Süssw. p. 23.

m S.5 - Boldt Sibir. Chloroph. p. 118 t. 6 f. 31 .

o \$5-Turuer New rare Desm. p. 938 t. 15 f. 22 a et b.

d $81 ;-F r a n k$ in Leunis Fynops. 3 p. 197.

n S6 - $\beta$ Griffithianum Legerh. in Wittr. et Nordst. Alg. exs. 11:0 821 (Phycastrum Griff. Nreg. .

o sij-Stokes Kiey Desm. P. 16\%.

dzst - rooke Brĭt. Nesm. 1. 1533 t. 53 f. 1 .

dziti-Mansy. Proulı. Algenfl. Böhm. p. 215 et 255.

(1) - $\beta$ Griftithianum ibil.

d $A 9$ - v. cumbricum Bennell Fi: wat. Alg. Engl. Lake Distr. :2 1.6 t. 1 f. 15-16.

n 8.9 - Boldt Desm. Grönl. p.3!!.

m 89 - Iste. Jel. magyar. alg. 1.231.

se - Wrest Massachus. Desin. t. 3 f. 21.

dzsit - Toni syll. alg. P. 117 . 
d - v. Griffithianum ibid.

d - re cumbricum ibil.

d s9-f. Rircil. Now. Desm. p. 101 (sep.p. 2!) t. 7 f. 5 (f. gallica = Phycast. Griffith.

l - f. depauperata ibil. 1. 11 t. $t .7$ f. 4.

in 90 - Eichler sipis Desın. Mierlz 1). 90.

in 90 - Anderss. Srerig. Chlor. 1 p. 12.

11 91 - hïrth. Mikr. Phanz. d. Süssw. ed. 2 p. 24.

m 91 - $\mathrm{f}$. Griffithiana Hemert Desin. alpin. p. 606.

m 91-Gute. Flor. alg. Leopol. 1. 61.

d $92-\mathrm{v}$, perbifidum $\mathrm{H}^{\mathrm{e}} \mathrm{est} \mathrm{Fr}$. w. Alg. W. Trel, p. 175 t. 23 t. 3.

0 92 - Ruc. Desmily Ciastoni. p. 39?.

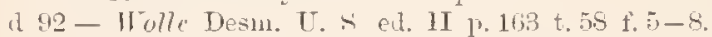

ma3-v. Griffitlianum Lïtlemï7. Desm. Attersees 1. 501.

$m$ - v. perbifidum ibil. p.565 t. 9 f. 15.

n 93-Rutidiastrum) Turner Alo. Ind, orient. p. 133.

n! 16 - ? v. cumbrieun? Schmille Beitr. alı. Alg. p. 61 (sep.1\%, 32) et. $15 \% 5$. t. 17 f.5.

\section{Sportella}

d 19 COSMARIUM Breb. in Kütz. Spec, Alg. 1. 176. [Deseriptio mala].

d 56 - Breb. List, p. 130 et 164 t. 1 f. 12.

d 131 - Arch, in Pritch, Inf. p. 734 .

d 69-Timb. Flor. Eur. Alg. 3 p. 16\%.

d - b. Corbnla ibid. C. Corbula Lréb.

if - Nordst. Desm. Ital. p. 29.

z TT-Norlst, in Wittr, et Nordst. Alg. exs, n:0 Ts; et 1886) in fase. 21 p. 41.

d 81 - Wolle Iesm. [T. S. p. 83 t. 19 f. 25-30.

n Sh-Stokirs Key Tesin, p. 12!.

1 8. - Coulic Brit. Desm. p. 107 t. 41 f. 6 [saltem ex p. ex Wolle].

d $89-$ Tomi syll, a]g. p. 111.53.

n!) URSINELLA Kuntä Rev. gen. 11. p. 925.

d [12 Cosm. Wolle Thesm. U. S. ell. II p.90 t. 60 f. $28-30$. Cfr. Cosm. Botrytis f. Nordst. 1sss.

\section{spyrialion}

195 CoSMARIUM West. Alg. Madag. p. 64 t. 7 f. 24.

\section{squamritmm.}

o $5 \pm$ CLOSTERIUM? Ehrenb. Microgeol. p. 25.

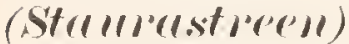

o ji Grun. Desm. 1. 494. Sect. Desmidiac. Gen.: Staur. Desmit. Aptogonium.

\section{starrastruirles}

d 14 COSMARIUM Eichl. et Gutr. Syec. als. nov. p. 171 t. $\overline{\text { f }}$ f. 30 .

\section{STALRASTIRLII}

a 29 Mey/ry in Nov. act. 14. 2 1" 7T. [Descriptio mala].

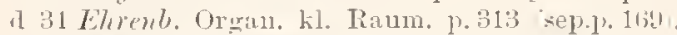

o 35 Meym in Wirgm. Areh. t. Nat. 1835 p. 20!n.

a 3athend. Inf. 1. 112.

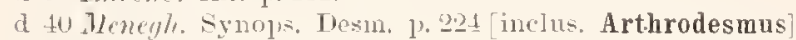

d 4i Timmister in Ersch. u. Gruber Allg. Encykloperl. II, is 11, 204.

d 43 Küts. Plive, gener. 1) 163.

a 45 linlfs in Ann. Nat. Hist. v. 15 p. 149 (et 1846 Trans. Bot, Soc. Edin. v. 2 1, 135 ?.

d 15 Mlr.s. Pr. Alg. 1). 353; sectio generis Goniocystidis.

d 47 Tinb. Deut. Jiryt. Fl, 1. 56.

a 18 livelys Brit. Desm. p. 119. d 19 Lred in Diet. univ. hist. nat. v. p. po6.

d 52 Tritch. Inf. p. 2 iil.

o 56 linet. List. 1) 133 .

(1) 58 The Iin: Conjug. 1.41. 45, 47. 51), 71.

o 5 s Grum. Desm. p. 494.

d 61 Arch. in Pritch. Inf. p. 721 et 737 .

d 63 Rab. Frypt. Fl. Sachs. p. 188.

d 61 Gray Brit. Alg. p. 1iis.

d tif Eyrich Algenfl. Tannh. p. 12r.

d 6r heirsch Algenfl. Frank. 1, 150. Subg. Didymidii.

d 67 Not. Desm. Ital. p. 21.

d lis Riab. Flor. Eur. Alg. 3 p 1 gif.

- 71 Lund. Desm. Suec. 1. T. Subspec.: Staurastrum p. 56, Pleurenterium 1\%. 2.

d 73 Delponte Desm. subalp. 1'.38 (sep.p. 26).

d 73 Hrool Fr. Alg. p. 14i.

d T5 Microgr. Diet. p. 231 et 7.15 .

d 7 Delponte Desmid. snbalp. p. 36 (sep.p. 132)

d F Fromt: in Teunis synops. p. 1633.

d To Kirchn. Alg. Schles. p. 163.

o S1 ronlip in Quekett Hicr. J. 6 p. 205.

ph sis Fischer Gypskryst. Desm. p. 161.

d st Gay Monogr. loe. Conjug. 1'sit.

d sit Wolle Desm. U. S. p. 119.

d n.j Kirchn. Mikr. Pfanz. d. Süssw. p. 21.

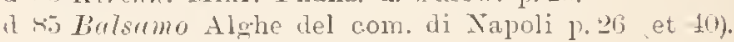

d sef Fremti in Lemuis synops. 3 p. $19 \%$.

o sis stoks Tier hesm. n. 10 .

A 8 r Coolir Brit. Desm. p. 134.

d si Alexentio Chlorosp. Thark. 1. 258

d sit Hunsy. Proll. Algenfl. Böhm. p. 210:

1 Sect. 1. Amblyactinium (Neg.) p. 254 .

d - 2. Pachyactinium Nog.) p. 255.

d - 3. Stenactinim ( Wog.) p. 25r?.

d ss Toni et Levi Fl. Alg. Venez. p. 11.

d si Huuptfl. Zellm, u. Hïllgallerte Lesm. p. 14 (sep.p. 36).

d sy Toni srll, alg. p. 1136 .

jhe Elfir. Anmärk. Tesin. system. p. so.

a (1) Wince in Natiurl. PHanzenfam. p. 11.

1) 91 Kirchm. Mikr. I'flanz. d. Süssw. ed. 2 p. 21.

d 92 Trone Desm. L'. S. ed. Il H. 131.

d 93 Bailey Contr. Queensl. F1. p. 50 .

93 Turnc Alg. Inu, orient. 1, 132. Subgenera: A, Sehiz astrum. B. Trochastrum, C. Hoplastrum, D. Cystastrum, E. Cephalastrum, F. Hectastrum, G. Cylindriastrun. H. Glyptastrum. I. Brachiastrum. J. Rutidiastrum, K. Raphidiastrum. L. Acanthastrum. MI. Spharicastum, Y. Odoutastrum.

d s Samml. in Fl. Nebraska p. 43 .

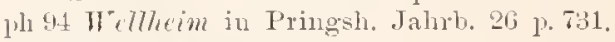

\section{Stall'(1st)m}

a 34 MICRASTERIAS Kütz. Syn. Diat. p.599 (sep.p. .1) itaurastrum paradoxum $\mathbf{H}(y e n)$.

\section{STA I R IDI I I}

1134 Corlu in Alm. 1. Car]sb. 1535 p. 20\%. [Quoad St. Crux melitense efr Micr. Cordx 1. Br.! Alia spec, certissime est Pediastrom?

1 39 - in Alm. d. Carlsh. 1839 1. 235. Genus Enastr. [Pro maxim. $1 .=$ Pediastrum].

\section{STTATIOCERAS}

1 15 Kintz. Phycol. serm. p. 133. [Sect. 1. subgen. Closterii]. d 49 Kïts. spee. Alo. p. 166.

d 50 Marissul Catal. esp. omis, 1. 33.

d 53 Muth. F1. Belg. It p. 52ii. 
d Is Gron. Desmid. P. 192.

(1 ti3 Grogn. Plant. Crypt. p. 253.

\section{Streelrorlemelrum - re}

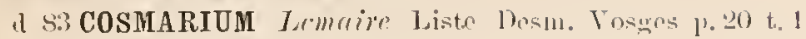

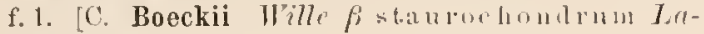
yerh. 1897].

il s. - Tomi syoll. alg. p. 10in.

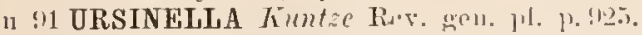

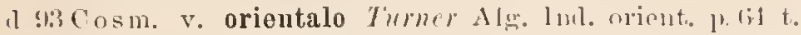
9 f. 23. [stel aliam speriom pretineat].

\section{strumomovilha}

a 13 MICRASTERIAS (Atomorstis) Tume Aly. In]. oricut. p. if to t. $f$ f. $1(;-1$ s.

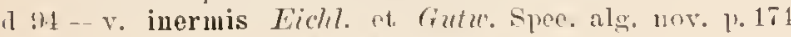
t. 5 f. 7 .2. [Cfi. M. Rabenhorsti].

\section{Stella}

a S1 DIDYMOCLADON Mask. N. Z. Desm. p. Sis to 11 f.!. 10. [Ntaur. sexangulare Jimlul,. sece. Areh. in Girevillea $\{0,1851$.$] . 3(0)$.

o Sis STAURASTRUM Merst. N. Z. Deam. Adi. 14.257.

\section{stellatum -a}

d TOEUASTRUM Nordst. Desm. 13rasil. p. 21!1 (scp.p. 1s1) t. 2 f. 7 .

1891 - Toni siyll. alø. p. 1082.

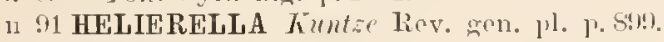

\section{stellatulu}

d @STAURASTRUM Böry. Derm. Brasil. p. 18 t. is t'. i3. [St. Boergesenii Rricil, 18:12].

\section{stellatille}

d it STAURASTRUM Jicinscle spec. Gen. Als. p. 130 t. 23 D. II f. $1-4$ (sep,p. 2.2 t. 4 ).

d 93 - v. pulchellam Trmn. $\Lambda$ g. Int. orient. P. 113 t. 13 f. 21. [Longe alia s]ecies ac Reinscliti, ut mihi vidletur].

\section{stellimum}

d 34 CosMLRIUM forda in Alm. de Carlsb, 1sist p. 180, 200 et $20 \%$ t. 2 f. 2.2. [Euastrum Rota sece Ehroub. in Wregm. Areln. 1s:5, p.155; Mier. rotata].

\section{stellimum}

d 93TAURASTRUM Troner AIg. Ind. nrient. j. 119 t. 1 ij f. 6 .

\section{S'PEXICIIIIIII}

d 4! Je\% cinz. Alo. 1) 12S. Subgen. Plyycastri.

11 (33 ('remer in Riul. Alg. Eur. 11:n 1114 [Genus. "Pliscastrum subgen." omissum esse virletur].

r ss JIansy. Prodr. Algenfl. Iöhm. p. 2ar. Rect. Slaur.

\section{STEPIIANONANTHIUM}

d 19 Kütz. spece. Alg. p. $181=$ spee. Stanrastri.

\section{stivhochomlrum $-a$}

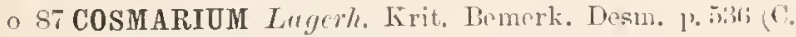
Nordstedtii W"olle 1s85, nou Jelp. 187T)

d 8 - Toni iyl]. alg. ?. 1010.

n 11 URSINELLA Kuntze Rev. gen. pl. p. 125.

\section{stigmosim!}

d I: EUASTRUM Turner Aler. Ind. wient. p. 45 ᄂ. 11 f.2.

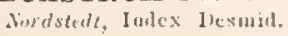

stomatomor)hmm - $-11 \mathrm{~s}$

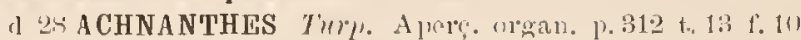
["stomatimnrplia"]; et in l)ict. se. nat. Pl. Viog. acot. Vesionlin. f. 11 [sine nomine] 1820 [Heterocarpella Phascolus sec. Trib. 183:!!

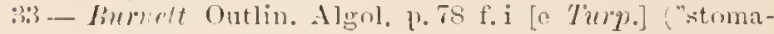
tomorplia").

1 :31 SCENEDESMUS Kälz. Syn. Diat. p. $60 \mathrm{~s}$ (scp.].80).

it 3.5-Divel\%. Alg. Fal. 1\% 60 t. s.

a 10 ISTHMTA? Mh negh. synops. Desm. p. 205 (sep.p. 5).

¿1! SPONDYLOSIUM Kïtz. Spec. Alg. p. 18?.

1 li1-irh. in Priteh. lnf. p. 721.

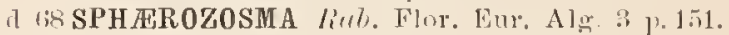

It sis-Tomi ct Leti Fl. Nlo. Yencz. p. 21;.

d s. ? - Toni syll, Alo. p. T!5.

\section{strumglatus}

it st CALOCYLINDRUS Coole \& Hills in Conke Brit. I)esin. 1. 1.2. t. t. H R. 10.

d so DISPHINCTIUM Tomi syll, alg. p. sst.

\section{strensullouse}

1 13 STAURASTRUM Turner Alg. Ind. nrient, p. 113 t. 17 f. 1 .

\section{STREPIIOCISTIS}

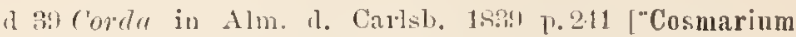
parte Corel., Euastrum jart. Elr.t.. Heterocarpella hiitz:"].

\section{STIREPTONEMA}

(1) (i) Wrallich Desur. Low. Tengal p. ISG \& $19 \%$.

1) set Tomi rigll. Als. p. Tse in nota.

d! !O Wille in Natürl. Pflanzenfam. p. 1.4.

d (13 Turneg Alg. Ind, orient, p. 1.14.

\section{striato-pumctatum}

(1) 4: PENIUM Küt:. Spec. Alir. p. 16is. [Tetmemorus Brcbissonii b. targidns sece fiab. 18fis].

\section{strictulus}

o 41 ARTHR0DESMUS Ehromb. Berlin. Monatsh. 18:0 p. 205 = Grammatonema striatulum $\beta$ diatomoides Kütz. (Diatomete).

\section{strictum -}

d 8.5 COSMARIUM foldt Sibir. Chloropls. p.101 t. 5 f.9. [Cosm. humble v. str. Schminle 1s!)

in 88 - Boldt Desin. Grönl. p. 1.1.

11 89 - Toni Syll. alg. p. .10.

1 89 - v. glabratum Rircil. Now. Desm. $1 \% .81$ t.5 f.:31 [Cosm. In mile v. Raciborskii Ślimirllt].

D 8! - f. Nordst. et Boldt in Wittr. et Nortst. alg. exs. n:o 178 et fase 21 p. 4 ?.

(1) 30 - $\beta$ galiciense Gutu. Fl. glon. Galir. 2 p.11 t. 1 f. 5 [Cosin. substriatnm $\beta$ Jagerh. 15:11].

m 90 - intross. Sverig. Chlor. 1 p. 15.

n 41 URSINELLA himtze Riev. gen. pl. p. 125 . m 93 Cosm. Lütliemilll. Desm. Attersecs p. $55: 3$.

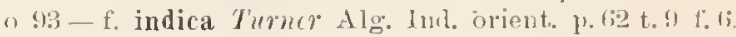
n! - v. galicicuse Gutw. Fl. alg. Tarmapol. p.sti. o 95 - f. Pinrye sverig. Chlor. II p. 19 t. 1 f. 9.

\section{strigosum -a}

d כิ CLOSTERIUM Rréb. Linte p. 153 t. 2 f. 13.

n fil-Arch. in P'riteh. Inf. 1. 717 .

d $69-$ Tiab. Flor. Eur. Alg. 3 p. 130 . 
m $71-$ Lund. Desm. Snec. 1. 7 .

d TT-Delponte Desn. subalp. p. 108 (spp.p. 204 t. 18 f. 3. -

d is - Kirchn. Alg. Schles. p. 1:39.

n $79-\pi$ typicum K7ebs Desm. Ostprense. P.S.

d - b. elongatum ibid.. t, 1 f. 3.

dafst - Irolle Desm. U. S, F, 12 t. 6 f. $18-44$. t. 53 f. $9-10$.

m 85 - Buldt Sibir. Chloroph. p. 122.

o se-Stukes Iiey Desm. p. 112.

d $88-$ Llansy. Prodr: Algenfl. Böhm. p.180.

d s:! - Joni syll. Alg. p. 82!!.

ms.9-Gutu. Flor. glon, Polski 1, 29t.

11 91 ARTHRODIA Kuntze Rev. gen, pl. p. sisl.

dzf (Ylost. Wolle Desm. U. S. el. I1 p. 11 t. . f. 13-14. t. f.1 f. 9-10.

m. 93 - Lïtkemiill. Desm. Atterapes p. r.12.

m 94 - sclumidle Alo. Geb. Oberrheins p.51s.

m (1) Gutw. Fl. alg. Tarnapol. p. 79.

m 15 - Eichler in Pamiet. Fizy, 13 p. is.

\section{stviolatum -a}

a 32 CLOSTERIUM Ehrnb. Entw. ג. Inf, p. ris. [Teseriptio brevis].

o 84 - Eltrenb. Organ. kl. Raun. p. 239 (scp.p. 91.

daf 3s-(Toxotinm) Ehrenb. Inf. p. 96 t.6 f. All.

o 10 - Menegh. Synops. Desm. p. 234 (sep.p.3.4.

o 41 - Brilley Amer. Bacill. p. 303 (sep.p. 22) t. 3 f. 35. [Cl. costatum?].

n 13 - Ehrenb. Nikr. Leb. Siih. n. N. Amer. t. $1 \mathrm{Y}$. I f. 30.

1 45-ILess. Brit. Alg. 1.371 t. $9 \overline{6}$ f. 1 [ex Ehrents. Inf. fig. 12. 1 male depicta?.

d $15-$ Kïtz. Phyc, germ. p. 131.

daf 4 - Ralfs Brit. Desm. 1. 170 t. 20 f. 2 . ( $g$ et $f=$ a. typicum Klels 1sig; $b$ et $f=\beta$ orthonotnm Roy 1 som; $d$ et $c=$ v. tumidum Rab. 186s; $g=$

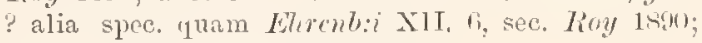
$c$ et $h$ huc dubie: sec. Tioy 18,0].

d 49 - Kïtz̈. spee, Alg. p. 165.

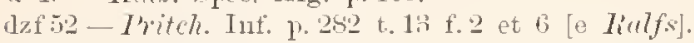

d 57 -v. procernm Bricb, in Rab. Alg. n:o 667.

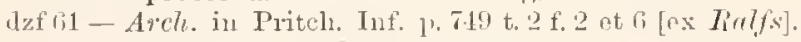

1] 63 - likb. Kiy ht. Fl, saclss. 17. 172.

1113 - Ricleter in Rab. Alg. Eur. 11:0 1570, f. xyl. 1.

ph (j) - Leinsch Morph. Fragm. 1). 13 t. 2 f. 7.

m

o 67 - Not. Desm. Ital. 1\% 633 t. 7 f. 67.

o dis-croup et Arch. in (2. J. M. Sc. S p. 2SS-y (monstr.

o 68 - H'rrop Desm. 'T'asm. 1. 21.

d bis-Iab. Nlor. Eur. Alg. 1. 125.

d - b. elongatum ibid. 1) 12t; (Cl. intermed ium Lialfs)

त - $c$ tumidum ibid. Cl. striol. Tialfs 1. 1: f., $d$ et $e$ )

m 7 ()-Nortst. Desm. Brasil. 1. 2(1); f: Mininos.

m 70 - Lirinherl in Arbeiten Naturf.-g. Charkow I p. 1 j.

m $72-$ Nordst. Desm. Spetsb. p. 25.

d 73 - Wroud Fr. Alg. p. $10 \%$.

d 75 - Microgr. Dict. 1\% 176.

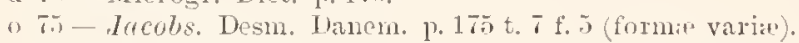

- a ibid. 1\% 1 'iri.

$\beta$ v. intermedia ibil. (Cl. intermedium Rulfs).

y. ve Una ibicl. (Cl. Ulna Focke: Cl. directum Arele.).

$n-\delta$ v. subjuncida ibid. (Cl. subjuncidum In' Not.).

d $77-$ Dedponte Desmil. sulealp. 1' 117 (sep.p. 213; t. $17 \mathrm{f}$. 3is-11).

d Tis-Kirchu. Alg. Sehles, p, 1:34.

(l - a. genuinum ibid.

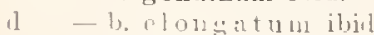

m 7 s - Hempel Algenfl. Chemnitz p. 112.

m 79 - Wille Ferskv. alg. Nov. Semlj. p. 61.

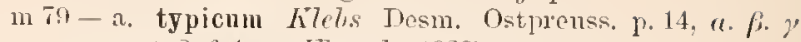
$=$ t.2 f. 4 a (E7rmub. 19838).

(1) - b. costatum ibid. (CI. costat $\mathrm{nm}$ (ord.).

1) - - " (\%. regulare Iirtb.) ibil.; t. 2 f. 2 .

i $-\quad \beta-\sigma^{\prime} ; \beta^{\prime}$ t. 2 f. $11 ; \gamma^{\prime}$.

1) $-\mathrm{a}$ e erectum ibicl. $a=$ t. 2 f. 4 b. $\beta=$ t. 2 f. $10 \mathrm{nt}$ B; $\gamma=$ t. 2 f. 1 c.

mzs1 - Elfi. Fiusk. Desm. 1. 15.

phs 83 - f. r rectum Fischer Zelltheil. Clost, p. 202 ete. t. 3 f. 11 et 12.

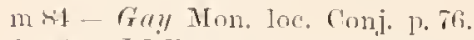

dzst - Wolle Dosm. T. S. p. 42 t. f f.s in 20.

dz S1 - v. plongatum Artari List. alg. MIoseon p. 13:t.

d si - Kirelm. Mikr. Pflanz. d. Süssw. p.21.

m sio - Boldt Sibir. Chloroph. p. 122.

mas5-Racit. Nonn. Desm. Polon. p. Ri3 (sep.p. 7).

o sij-Stolies liey Desm. p. 112.

o Sri-f. Wittrock in Wittroek et Nordst. Alg. exs, n:o A4; et (1SR9) in fase. 21 p. 46.

dzfsi-Coole Brit. Desm. 1. 29 t. 11 f. 1 [e Rolfs].

0.87 - Wrille Fr. Alg. U. S. A. D. 21 t. 55 f. $5-8$.

d si - Alexentio Chlorosp. Iihark. p. 22\%.

dzs - Hansg. Trodr. Algenfl. Böhm. p. 180 et 212.

d $-\beta$ elougatum ilid.

las - Tomi et Leri 1Fl. Alg. Vene\% p. 29.

mss-v. gen n in n Riabin. Chloroph. env. Sharkow p. 316 (sep.p. 2s).

m 88 - Tioldt Desm. Grönl. 11. 42.

1h sh - Ilauptfl. Zellm, u. Hüllgallerte Desm, p. ag (sep.p. 41) t. 3 f. 28 .

ph. S8 - Aderlold in Jenaisch, Zeitschr. f. Naturw. 22 p. 332.

m 88 - Iste. Jel. magyar. alg. p. 23-.

m sis - Nordst. Fr. wat. alg. N. Zeal. p. fir.

n 89 - Carter in A. M. Mier, T. 10 f. 9 (ex Holle).

d s. -Toni syll. Alg. 1. \$20.

d $-v$. t $12 \mathrm{mid} u \mathrm{~m}$ ibid.

d 5 -f. recta West Fr. w. Alg. North Wales p. 255 t. 5 f. 23. [Cfr. Lugerh. in $\mathrm{X}$. Totar. I1 p. 30. Penium sp. ?].

m! 10 - Borg. Desm. Brasil. p. 2!.

$m-f$, minor ibil.

m 10 - Lichter Spis Desm. Miedz. p. Si.

d $90-\beta$ orthonotum Lioy in Journ, of Botany p. 336 (lialfs $\mathrm{Br}$. Desm. figm, $2 b$ et $2 f$. nt viletur).

m.n)-Anderss. Nierig. Chlor. 1 p. 17.

m - Prectum ibid. p.19.

d !1--Kirclen. Mikr. Pflanz. d. Süssw. ed. 2 p. 22.

m.91 - Heimerl Desm. alp. p. at?.

In!1 - Borge Bill. Sibir, Chloroph. p. 14.

11.) A RTHR0DIA Limtze Rev, gen. pl. p. s81.

ph sl Clost. Wel Torre in Rivista Ital. d. se. nat. XI p. 129.

d $92-y$ spirostriolatum Ilansy. Prodr, Algenf. Böhm. ed. bohem. p. 17-1; ed. groman. I1 p. 251 (life. 1559).

d - $r$ sculptum ihid. (C). intermed. $v$. Ruc, 1SS!) .

o. 12 - Demett in Amn. of Bot. (f p. 151 f. B (fung. parasit.)

m! $92-v, o x$ thonotun West Fr. w. Alg. W. Irel. p. 124. in $92-y$ tumidnm límmer Alg. St. Pölten I p.5.

mose- Rirc. Desmidya Ciastoni p. 368.

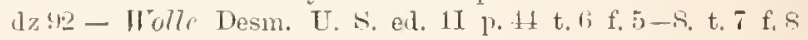
et 20 (v, intermedium, elongatum et tumi(li m).

o 93 - Lätliemüll. Desm. Attersees p. 5.t1.

d 93 - v. cronulatum Weiss in Bayer. bot. Gesellsch. 2 1) 43.

93-Wizdem. Not, mycolog. IT t. 6 f. 1 et 2.

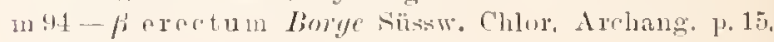




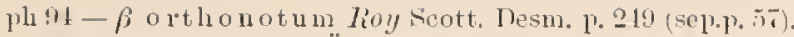
n! ! - Büryes. F. alg. Ostgrünl. p. 10.

mat - " typicum et $\beta$ orectum Gutw. Fl. alg. 'Tarua1301. 1. 79.

111 9.1 - Hexenko Mater. alu. Kinark. p. 21.

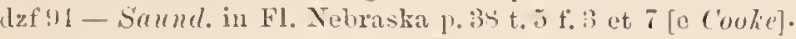

1n $15-\beta$ crectum $f$. Borye srerig. Chlor. II p. 12 t. 1 f. $t$.

Cir. Clost. Diane Focke. Cl. spirale.

st)iolutullt -

1) 19 DYSPHINCTIUM Nog. einz. Alg. p. 112 t. 6 (f f. $\mathrm{f}$.

1) til COSMARIUM $1 \% \mathrm{ch}$. in Priteh. Inf. 1). 731.

0 if Dis. lirinseh Algonfl. Frank. 11. 179 [Cfr. Arch. in Aml. Mag. Nat. Ilist. 1884 v. 11 p. 205; nov. spee.?]

d is Cosm. Riab. Elor. Eur. Alg. 3 p. 17 it.

0 7 - (Plourotaniopsis) 1.mud. Dosm. Finec. p. 53.

un - Noy et liss. Jap. Desm. p. 1int (sep.p. i).

d si COSMARIDIUM Ilans\%. Prodr. Algenh. Böhn. p. 2.11;.

d $-\beta$ Cohnii ibid. Calocylmas Cohni Kircho.).

d Su PLEUROT

d - v. Coln ij ibid.

\section{st)iolutull}

a 19 PHYCASTRUM (Ambly actinium) Tery. vinz. Alg. 1. 126 t. 8 A f. 3.

d hil STAURASTRUM Areh, in Priteh. Inf. p. T.10.

1) lin - Rab. Flor. Eur. Alg. 3 p. 2011; et form. 1.

o Tl- Nurdst. Desm. Brasil. p. 225 t. 1 f. 15 [f. Brasilic11sis Tum. 1893].

m i.2 Hittr. Grotl. Ö. söty. Alg. p. 52.

I $z-f$ oelandicum ibid.

d Ts-Kirchn. Alg. Schles. p. 16it.

st - $11 \%$ olle in Bull. Torr, bot. Club. v. $11 \mathrm{t} .11 \mathrm{f} .27-2 \mathrm{~s}$.

d s 1 - Wolle Desm. U. S. p. 126 t. 51 f. $27-28$.

1186 - Lagerh. Amerik. Desin. p. 216.

o 46 - stokes Key Desm. p. 16T.

d 8 T - Coulic Brit. Desm. p. 158 t. 51 f. $t$.

d 59 - v. acutius Mask. Furth. Note X.Z. Desni. p. 23 t. 1 f.M.

d S9-Toni Srll. alg. p.118.

d's - v. oelandicum ibid.

In (in)-Eichler spis Desm. Miedz. I. 89.

m 12 - West. Fr. w. AIg. W. Irol. p. 175.

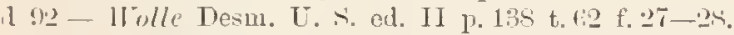

m 93 - f. Brasiliensis Turner Alg. Ind. orieut. 1. 109 t. 13 f. 15 Nordat. 1870).

\section{stiomelylotorehmm}

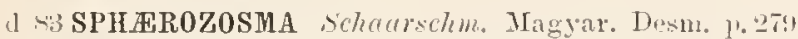
t. 1 f. 11 .

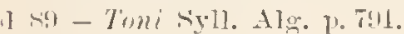

\section{stuhlmammii}

a) (5) COSMARIUM Kirron. in PHanz. w, Ostafrili. 1. 19,

\section{Stmhlmannii}

1 95 DoCIDIUM Hicron. in Planzenw. ()stafrik. p. 19.

\section{stuhlmammii}

()

\section{stuhlmummii}

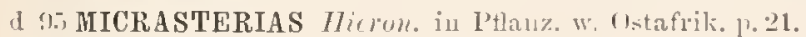

\section{Stuhlmanmi;}

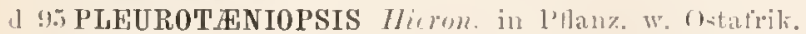
p. 20 .

\section{sulurlutum}

d 95 COSMARIUM 16 est Ag. Madag. 1). 133 t. 7 f. 31 .

\section{subrmoenmm}

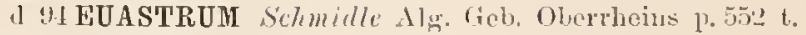
281.11.

\section{sulumoenulu}

a so STAURASTRUM 1/rkl. Furtl. Not. N. Z. Desu. 1). 22 t. 1 f.; 37 .

\section{subum!nstatmm}

a S1 CLOSTERIUM Went Freshw, alg. Maine II posid t. 315 f. $3-4$.

\section{subrictortm}

5 COSMARIUM Iine. Desinidya Ciastuni p.355 t. 6 f. 21. C. globosum : subaretoum lergerh. 185:3.

d - f. australis ibid. 11.343 t. if f.2.2. [C. globosn m " comprossum? sec. liorge 18!11].

\section{subar)u(utum}

d sisTAURASTRUM Woll in Bull. Torr. bot. Club lsiso I. L6 t. is f. D. [Nt. Avicula v. subareuat, West 1ssi]

d st - 11 olle Desm. U. s. p. 110 t. 16 t. $15-16$.

o Sij-Stokes Key Desm. p. liti.

d sil-7oni syll. alg. P. 1140.

d 12 - Tolle Desm. U. $s$. cl. II p. 153 t. 57 f. $15-10$. Cfr. Strur. subcruciatum.

\section{subarmitgerum}

d st STAURASTRUM lioy it Biss. Japan. Desm. p. 239 (ser.p. T) t. 268 f. 2 .

d sel-Toni syll. alg. p. 1205.

m 42 - Rac, Desmidya Ciastoni. p. 382.

1) 93 - Tuner Alg. Ind. orient. 13. 120 t. 18 f. 31 .

\section{subalvirulutulu}

d 95 COSMARIUM TTest Alg. Madag. p. 5.5 t. 6 f. 31.

subarirulu

d ! STAURASTRUM Thest New Brit. Alg. 1. 1? (ht. archatum subsp. subaricula test 1,502 .

Cfr. Sit. vastum.

subbibrechiatum

4 sy STAURASTRUM Toni syll, alg. p. 1ons (st. bibrachiatum llolle 1s70, non leinsch 1si5). [St. tetracerum sec. Wolle in litt.].

\section{subbinale}

11 9:; COSMARIUM larerl. Chlorophyce. Abessin. p. $161 \mathrm{r}$ Hammeri $\beta$ subbinale Nordst. 1siss.

(I) - $\beta$; abyssinicum ibid.

\section{sublimale}

(1) 1 EUASTRUM Gutw. Flor. alg. Tarnapol. p. 101 t. 3 f. 11.

\section{subbotrytis}

o !) COSMARIUM Schmille in ITerwig. 35 1.93 C. Bo trytis v. tomidum 11 olle lisit et sehm. 1st2:-

\section{subbrebissomii}

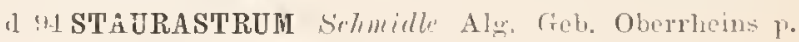
5.1 t. - -4 t'. 1 .

\section{$\therefore$ slburoomei}

11 !:) COSMARIUM Sehmille lieitr. Alg. schwarzalel. p. 1111 t, 5 t. $2: 2-21$. 
o 94 -v. retusum Eichl. et Gutw. in Krakau Auzeig. 1). 239 .

a 91 - v. retusum Fichl. et Gutw. Sipec. alg. nov. 1) 168 t. 1 f. 20 .

\section{subrupitulutu}

d !w COSMARIUM W'st Alg. Engl, Lalie Distr. p. 725 t. () f. 20 .

\section{subcirculare}

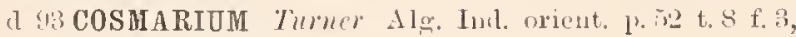
t. 9 f. 27,37 .

m $\quad-\beta$ rugosum ibil. t. 8 f. 7 .

\section{subromentull}

d 93 DYSPHINCTIUM Turner Alg. 1ne. orient. 1. 12.

\section{subro) mutum}

1 so STAURASTRUM Tuni śyll. alin. p.11ll (St. cornutum Wolle 1sis, nec Arehcr LSSL).

\section{subcovountatume.}

4) 93 DOCIDIUM Turner Alo. Tud. orient. p. 2.) t. 3 f. 1.

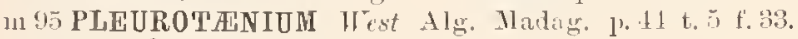

\section{subrosmurioides}

a y STAURASTRUM liac. Desmidyr Ciastoni. p.38t t. 7 f. 21.

\section{subrostutull -}

d su CLOSTERIUM Nordst. in Wittr. \& Norlst. Aly. exs. 11:0 370 ; et $(1859)$ in fase, $21 \mathrm{p} .16$.

at 87 - Wolle Fr. Alg. U. S.. A. p. 21 t. 55 f. 11.

d sil - Toni syll. A] pr. 1. 831 .

n"l ARTHR0DIA fiuntze Rev. gen, j!. p. Stit.

d Clust. Wolle Desm. U. S. ed. II p. 4 t. 6 f. 11.

\section{subrostretume-u}

it if COSMARIUM Norlst. Desm. ltal, p. 37 t. 12 f. 13.

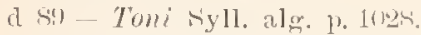

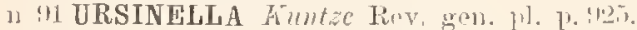

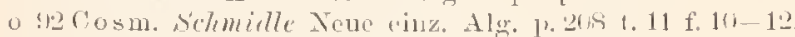
- 91-Böryes. F. alu. Ostgrönl. 1. 12 t. 1 f. l.

\section{subremsilll}

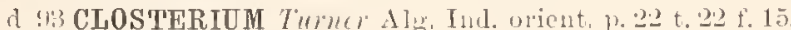

\section{sub(r)enutull. -}

d (i1 COSMARIUM Hantsch in Rah. Hir. 11:0 121:3.

d lis - Ríb). Flor. Eur. Alg. : 3 p. 16 t.

d 75 - Nordst. Desme aret. 1.21 t.li f. 10 et 11.

i $-\beta$ triquetrum ibid. $p .21$ t. $f$ f 12.

o $76-$ Norlst. Desm. 1 tal. p.35.

nu 79 - Wille Ferskv. alg. Nov. Semuj. p. Jo.

In - f. minor ibid.

(1) $-\rho$, divaricatam ibicl. p. 40 t. 12 f. 27.

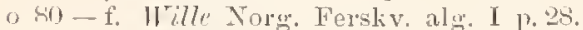

o $8: 3$ - f. Nordst. in Wittr. et Nordst. Ais. exs. 11:0 5i:2; et $(18 \mathrm{~s}(4)$ in fasc. $21 \% .11$.

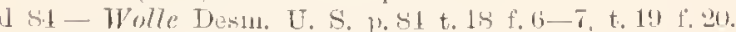

111 si-Wille Sydamerik. Alwt. p.31.

m 85 - liveldt sibir. Chloroph. p. Ini.

- Sti-Stakes liey Desm. \%, 129.

d 58 - Iluns.sg. Prodr. Algenfl. Bühns. p.己̈n1.

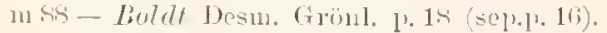

- - Pitriquetrum f. ibid. j. 1!?

su - o divaricatum ibil.

i - i rotundatum ibil.., t. 1 f. 1!. d $-\varepsilon$ subsolidum ibic.. t. 1 f. 20.

o 88 - Nordst. Bormlı. Desm. p. 196.

11 SS - Levin Span. Süssw.-alg. 1). 7.

d 89 - Tuni syll, alg. 1\% 1000 .

d $-v$, divaricatum ibid.

d - v. triquetrum ibid. 1) 1001.

d - v. lotundatum iljil.

(1) - v. subsolidum ibid.

d\%f 90 - v. subdivaricatum Gutw. Fl. slon. Galic. 2 p.11 t. 1 f. 10.

m 90 - Fichler Spis Desm. Mielz. p. 8 .

d $90--$ f. 1. Re'insch Sïiswasseralg. Süd-Georg. 1. 318 (sep). p. 20$)$ t. 2 f. 3 a, e, $d$ [Quid ?].

d - f, '2, ibit.

1 - f. 3. ibist. p. 319 t. 2 f. 3 \& [Quid ?].

1390 - Anderss. Siverig. Chloroph. 1 w. 15.

m :11- liorge Birly. Sibir. Chloroph. 1'. 11.

11 91 URSINELLA Kunt:e Rev, gen. pl. p.925.

m sl Cosm. Gutw. Flor. alg. Leopol. 1, is.

m - $y$ divaricatum ibicl.

m 12 - Lurge Chloropl. Norsk. Finmark. P. 10.

d - t'. ibid

(1 92 -- Wolle Desm. U. S. ed. II 1). 94 t. 21 f. (6 et 7, t. 22 f. 20.

mi 92 - $W^{\top}$ est Fr. w. Alg. W. trel, p. 150 .

o- $-\mathrm{v}$, divaricatum ibid.

d $13-\mathrm{f}$. Nordst. in Witts et Nordst. Alg. exs. 11:0 1127.

def $93-v$. Nordstedtii Schmille Beitr. Alg. Schwarzwald. p. 102 t. 5 t. 7 - 9.

d $94-v$. Norlsterltii f. Schmidle $\mathrm{Alg}$. Geb. Oberrleins 1. 551 t. 28 f. 9.

o 94 - v. divaricatum f. Schmidle in Inelwig. 33 p.91 t. 6 f. 10 .

4 94 - Sramd. in Fl. Nebraska p. 11 t. 7 f. 8 [ex Wolle].

1) 91-Lïry. F. alı. Ötgrönl. p. 11.

u 91 - Gutw. Fl. Alg. 'l'arnapul. 1). 45.

\section{subrulueilum.}

d st STAURASTRUM Coole et Wills in Coohe Brit. Dosm. 1. 1 th t. 51 f. 3 .

18 S) Toni Kyll. alg. p. 11 äs.

1104 - Schmidle Alg reb, Oherrlupins p. 053 (? inchus, st. subarcnatum Wolle 1 sist et it. avicula verrucosum ilest 1birte

subrumerfoume -is

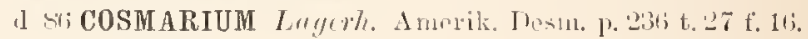

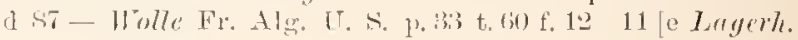
male?.

(1) si - Tumi sirll. alur. p. 1011\%

1) "1 URSINELLA Kuntze Rov. gen. pl. p. מoz.

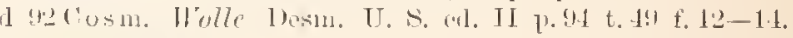

\section{sllorlluls}

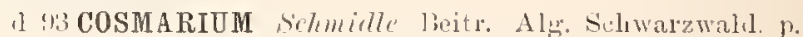

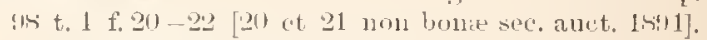
(Cosm. Cucnmis nuct ( $x$ parte).

\section{subculleutull}

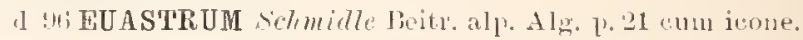
[Cosm. plicatum f. verisimiliter see. We'st in lonrs. of Bot. 1kin).

\section{stlor!lulivelut.}

a sil COSMARIUM Musk. Furth. Not. X. Z. Desm, P. 1s t.

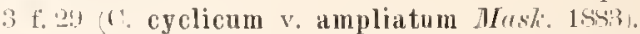

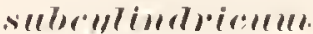

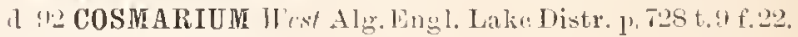


sublumirum)

1) 13 COSMARIUM West Fr, w. Alg. W. Ir.l. 1, 150 t. 21 f. 1 [Cfr. Cosm. substriatum; C. humilo v. subu. Schmidle].

\section{subdeutivulutum}

4

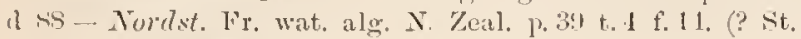
avicula Mask.).

1 83 - Toni syll. alg. p. 116I.

\section{sublivertum-a}

1) 8n CLOSTERIUM West Massachus. Desm. p. 17 (sep.p. 2) t. 2 f. 10. t. 3 f. 16

1.

n!) ARTHRODIA Kumtze Rev. gen. 11. 1. SSI.

d 92 Clost. Wulle Desm. U. S ed. II 1\% 16 t. 13 f. 20 [ex $\left.W_{c} s t\right]$.

\section{sublistichum}

d 9 COSMARIUM Íac. Desmillya Ciastoni. p. 376 t. $4 \mathrm{f}$ f. 29.

\section{subeluetum}

a 90 COSMARIUM Gutw. Wahr. d. Priorität p.48.

(1) $91-$ Gutw. Flor. alg. Leopol. p. 19 t. 1 f́. 33.

\section{subcrigumu,}

Sõ Cosmaridu liacib. Desm. Xomn. Polnn. tantum in inliee et tałula = "psendoexiganm" in deseriptione.

\section{subfubriatu}

o SIMICRASTERIAS Wulle Desm. U. S. in explieatione tabilie $34^{\circ}$ f. 7 , que fig. plag. 109 M. fimbriatae alnumeratux. [Cfr. Nordst. Bornl. Desn. p. is:1].

\section{subgemmmlutum}

¿ 5 STAURASTRUM West Alg. Madag. 1. 70 t. \& f. 31.

d - v. gracilins ibil. t. 8 f. 35.

\section{sub!lobosum}

d TACOSMARIUM Nordst. Alg. sanelvic. p. 11 t. 1 f. 13.

m 80 - Tille Norg. Ferskv. alg. I p.37.

d s! DISPHINCTIUM Toni Syll. alg. p. 851.

m 12 - IImmsy. Beitr. Alg. Bact. Tirol. u. Bólnn. p. 131. m!1 Cosm. Johns, Rare Desm. U. S. p. 247 t. 211 f. 7.

m!5-Iiecib, in Florn v. 81 p. 33 .

o !s - f. Schmialle Alg. Sumatr. p. $3(0)$ t. 1 f. t.

\section{subhastifinum}

d I2 XANTHIDIUM Weat Fr. w. Alg. W. Irel. p. 16it; t. 2.2. F. T.

\section{subhumite}

d m COSMARIUM Gutw. Wahr, d. Priorität p. 6s.

d 91 - Gutio. Hlor. alg. Loopol, p. 50 t. 2 f. 1. Cfr. Cusin. substriatum].

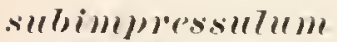

d "l COSMARIUH Borge süssw. Chlor. Arehang. 11. 27 t. 2 f. 27

\section{subiurismm-n}

d it EUASTRUM lieinseh Costribut. Alg. Promont. 13, si. p. 212 t. 6 i f. 12.

d sil-Toni syll. aly. p. 117

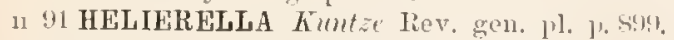

d y. Eu. Jac. Desinilya Ciastoni. 10.3liti t, 7 f. :-T.

\section{subintr!lum -}

d 70 eUASTRUM Nordst. Desir. Brasil. p. 210 (sep.p. 178) t. 2 f. 8 .

d 89 .. Toui syll, alg. 1) 107 (1).

n 91 HELIFRELLA Kintze hev, gen. pl. p 899.

d $93 \mathrm{Eu}$. v. Indicnm Twner Alg. Ind. orient. p. il t. Tf. 17.

\section{subjumcidum -}

d 67 CLOSTERIUM Not. Desm. Ita]. 13.63 t. 7 f. $1 \mathrm{is}$. [Cl. striolatum of subjullcida Jacobs, 1575. - Cfr. Cl. Ulna]

A 89 - Tomi syll. Aly. 1) 822.

o $90-$ f. Böry. Dosm. Prasil. 11. 29 t. 2 f. 3.

1191 A RTHRoDIA himtze Rev. gen. pl. p. sat.

o :2 Clost. f. minor Ifuc. Desinilya Ciastoni. p. 36.

In 95-Eichler in Panict. Fixy. 13 p. 58.

\section{sublamellosum}

d 93 PENIUM Tuncr Alg. Ind, orient, p. 17 t. 1 t.s.

\section{sublateriludatum}

d 95 COSMARIUM Wrat Alw. Madag. p. 60 t. 5 f. 1.

\section{sublutum -r}

d Si COSMARIUM Norelst. Algolow. smisak. 4 p. 159 .

d Ss- Nordst. Fr. wat. alg. N. Zeal. p. 15 t. 5 t. $1-4$ (Cosm. margaritifermm Mask. N. Z. D. 1581 quoal f. 27$)$.

d si-Toni syll. alg. p. 993.

n 11 URSINELLA himtze fiev. gen. pl. p. 425.

d 93 Cosm. v. minus Lïthemïll. Desin. Attcrsees p. ons. m : 1 - Gutw. Fl. als. 'Tarinajol. p.91.

\section{sublobctum -}

a 18 EUASTRUM ? Bril, in Ralfs Brit. Desm. p.91 t. 32 f. 1 .

d 52 - Pritch. Inf, p. 251.

d $5 ;$ - B. pileelatum Tréb. List. p. 124.

d il COSMARIUM Arch. in Pritch. lıf. p. 731.

1 $63 \mathrm{Eu}$ : Fab. Krypt. Fl. Sachs. l'158.

d Gs Cosm. Iial. Flor. Eur. Alg. 3 p. 165 .

d - b. pileolatum Breb. ibid.

d 73 - Woud Fr. Alg. 13. 132.

$173 \mathrm{Eu}$. $\beta$ crispulum Norlst. Norg. Desm. j. 10 t. 1 f. ?.

d 5 - f. Reinsch Contrils. p. 12 t. 13 f. t. [Eu. erosnm f. sec. Tumer 1ni3j.

d $76 \mathrm{Cosm}$. * dissimile Vordst, Desm. Ital, p. 39 t. 12 f. 15. d is-hivelun. Alg. Schles. 1. 152.

m o Ts Eu. Hempel Algenfl. Chemutz p, 113.

in St Cosm. Racit. Desm. okol. lirakowa p. sep.p. 13.

d 81 - Wolle Desin. U. S. p. 80 t. 1 s f. 21 - 2.2.

o sti-Stules Key Desm p. 128.

d stj-Coole Brit. Desm. p. Ti t. 36 f. 1 [saltem partin e Tialfs

d st - Alcuculio Chlorosp. Kiliark. p. 206\%.

¿ si - $\beta$ brevisiuuosum Nordst. Al polog. småsak. 4 1. 1til.

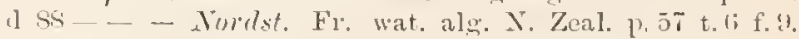

o so Eu. Mask. Furtl. Tute X. Z. Desml, p. 12 t. 1 f. a.

d sit Cosm. Toni syll. alg. p. 1041.

l - v. pileolatum ibid.

d - subsp. dissimile ibil.

d - v. brevisinuosum ibid. p. 1042.

d -.v. crispulum ibid.

1) 10 - v. miuntum Gutw. Fl. glon. Galie. 2 p. 10 t. 1 \&. 3. n 91 URSINELLA Kuntzc Rov. gen. pl. p. 925.

a $12 \cos 1 \mathrm{n}$. Wulle Desill. U. s. erl. Il p. 87 t. 21 f. 21-22. 
m93-v. brevisinuosum Lïtlemüll. Desm. Attersees P. 550 .

m !1 - dissimile bory. F. alg. Ötgrönl. p. 17 t. 1 f. 11.

\section{submumillntum}

d 9.5 COSMARIUM West Alg. Malag. p.51 t. 6 1. 31.

\section{submonticulosull}

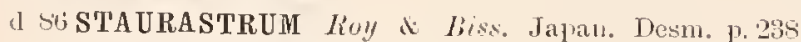
(sep.p. 1i) t. 20 is f. 7.

d 89 - Toni syll. a]g. 1).1176.

\section{subulsutull -}

a si cosmaridm Rucit. Nomn. Desm. Polon. p. 75 t. 11 f. 1 (sep.]. 21 t. 2). [Cosin. nasutmm $\beta$ sil buasutum Nordst. 18ss].

l s. - Toni syoll. als. p. atil.

n !1 URSINELLA huntae Rev. gen. p]. 1.925.

\section{subuotubile -is}

d Ty COSMARIUM Wille Ferskv. aleg. Nov. Semlj. ], 36 t. 1. f'. 16.

d s3-Toni sirll. a] n. p. 9416.

11 91 URSINELLA huntie Rer. gen. pl. ]’. !25.

\section{suboblomgute}

(1) 8 i MICRASTERIAS Nordst. Algolog. smitisal. 4 p. lit.

d st- Nortst. Fr. wat, aler. N. Zeal. 1, 78 t. 2' f. 18.

d su-Tomi syll. alw. 1\% 1111 .

11 !1 HELIERELLA Kminte Rev. gren. 11. 11. 84!).

\section{suborlithodes}

1 95 COSMARIUM Schmille in Iledwig. 31 1. 75 fig. 20. [Cosm. cymatopleurnm $\beta$ tyrolicum $t$. sec. anct. in litt., saltem ex parte].

d - v. luteum ibid. 1).71; et fig. 27 p. 75.

\section{suboctum!lulare}

dzf y2 PENIUM West Fr. w. Alg. W. Irel. p. 128 t. 21 f. 201.

\section{suborbirulate -is}

d 7o COSMARIUM Wood in I'roc. l'hilat. Acarl. N. S. Januar. 18199 p. Is. [Cosm. isthmochoudrum Nortst. Sept. 1sis?.

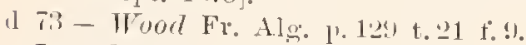

o $7 j$ - Nordst. in Hedwigia p. 1;.;.

d 81 - Holle Desm. U. A่. ]. is t. 21 f. 21 .

o sij-Sluke's Iiey Hesm. 1. 1.28.

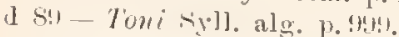

1191 URSINELLA Kuntar Rev. gen. p]. 1. 40.5.

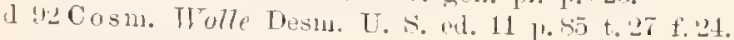

\section{suborthosticlellut}

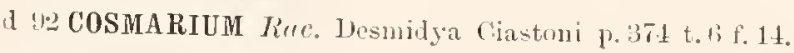

\section{selbortherfonllume}

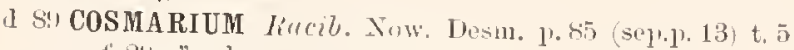
f. 2!!: "snbortugonu un",

\section{subpurluguevullu.}

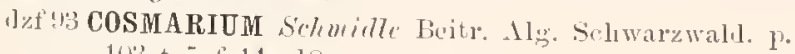
$10: 3$ to it f. $11-18$.

\section{subpulallgulu}

If 1 COSMARIUM Elfe. Finst. Tesm, 1. 11 t. 1 f. 11.

o si - f depanperata Lugerh. Algul. Piilr. P. 17.

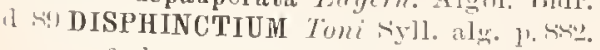

o - f. depanperatum ibid.

\section{subjmonlll}

d 1 CLOSTERIUM IVist New Brit. Alg. p. 3 t. 1 f. 3.

\section{subjurutuber(e)s}

d 95 CosmariUM Jest $1 \mathrm{lg}$. Madag. p. 57 t. 6 f. 10.

\section{sub)100tumirlum -u.}

a it cosmarium Norlst. Desm. Ital. p. 38 t. 12 f. 11.

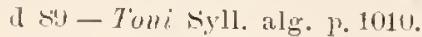

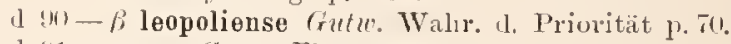

d $91-$ - Cintw. Flor. alg. Leopol. 11.59 t. 22 f'. $2: 3$.

o 11 - West. Janish Alge p.120.

1191 URSINELLA Kumtä Rev. gen. pl. p. 205.

m (12) Cosm. f. West Fr. w. Alg. W. Irel. p. 157 t. 21 f, 21 m- Crutw. Flor. glon. Galic. 3 p. 131.

48 - Schmidle Beitr. Alg. Schwarewald. p. 110 t. 5 f. 13. m93- Wittr. pt Nortst. Alg. exs. n:o 1124.

d $95-v$ - simplicius Schmidle in Hedwig. 34 p. 7 t. 1 f. 10

\section{subpumetulatum -}

d si CosMaRIUM Nortst. Algolog. smăsak. 1 p. 1ij1. [Cusm.

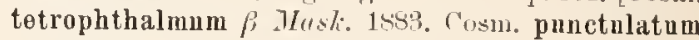
v. subpunct. Focrg. 1.81].

d SS - Norlst. Fr. wat. alg. X'. Zeal. p. 4 t t. 5 f. 8.

o s!l-f. Dar\%. Bidr. bornh. Desnr. l. 111 t. 6 f. 4 [v. 13oergesenii 1892].

d si - Tuni syll. alg. p. 1119.

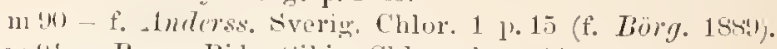

n1:11 - Borge Biar. Sibir. Chloroph. p. 11.

"

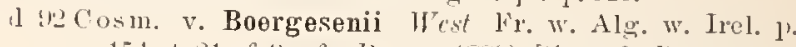
154 t. 21 f.!) (f. lioery. 158\%) [run f. Boerg. non plane identicun sec. Borge in X. Notar. 5 p. 511$]$.

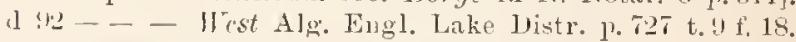
In (12) - Job. Anstral. Nusswasseralg. p. 141.

d $43-\checkmark$. Boergesenii Schmille in Helwig. v. 32 p. 109. f. 1-11 1). 11 \%.

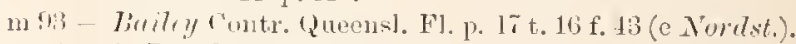

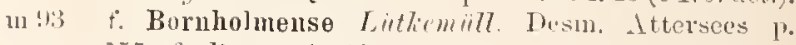

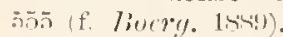

1 91 to. Schmidle in Flora $7 \mathrm{~s}$ j. 39 t. $\mathrm{T}$ f. 19.

l !l - f. Borge süssw, Chlor. Arehang. p. 20.

\section{stl)}

d si STAURASTRUM Gay Mon. loc. Conj. p. liti t.2 f.s; e't Not. Conj. d. un. France 1) 338 .

(1)

\section{: 11$) ! ! ! l 116 \| 1)$}

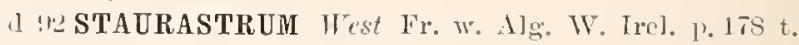
23 f. . . [st. polytrichum liab.].

"!2 - f. glabra II est New Prit. Ale. 1. 11 t. 2 f. 43. [Stan. Clepsydra L.und., non Tordst.].

$4.5-$ - v. podlachicum ITest in Journ. Bot. 3:3 p. pi?. [St. ecorue v. poill. Eichl, et Gutw. 1stl].

\section{s(l))(l) iforme}

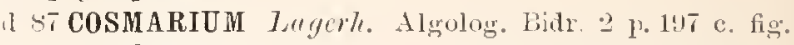
$x y \log x^{\circ}$.

d s. DISPHINCTIUM ["subpiriforme"] Tonisyl], alg. $1^{2}, 490$.

\section{sululludiellul-}

a 7i COSMARIUM Nordst. Desin. Ital. 1) 32 t. 12 f. 7 .

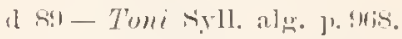

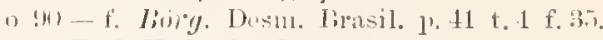

n 11 URSINELLA Krmitze Rev. gen. pl. p. 125.

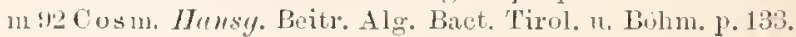




\section{subrursillus}

d SSCOSMARIUM Rolil Desm. Gronl. p. 25 t. 1 f. 25.

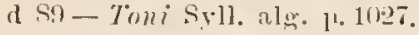

n 91 URSINELLA huntar liov. gen. pl. p.92.).

n!1 Cosm. Gutu, l’hor. alg. Tonpol. p. fil t. 2 f. 2 f.

(I 93 - v. tropicum Turner $A$ ]g. Ind. orinnt. p. 6.3 t. 9 f. 15.

\section{simbramosum}

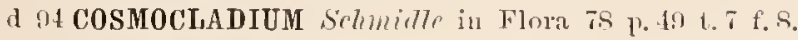

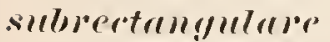

(1)! COSMARIUM (rutu. Flor. alg, Tarnapol. 1.92.

11 - f. " glabra ibil.. t. 3 f. 23 (C. rectangularo f. Borge 1sine).

$m$ - f. piornata ibid.; t. 3 f. 24 . [Propria spec.?].

\section{subrectum}

1 3. CLOSTERIUM Prit. Alg. Fal. p.5i t. $[$ Cl. didymotocum a sice. Firlfs; $\mathrm{Cl}$ did 5 . $\beta$ Brebissonianum Rirluentr.].

d tó-hütz. l'lyуe. germ. P. 131.

d f 19 - Krïts. Spec. Alg. 1. 16is.

\section{subrefinctum,}

1 sis STAURASTRUM Lemuir Liste Desm. Tosgrs. p. 2:3 t. 1 f.:3 [St. inconspicuum Nordst., non the Not.].

\section{sulbreillsthii}

d 94 COSMARIUM Sechmidle in Flore is p. in to. 7 f. 2.1 .

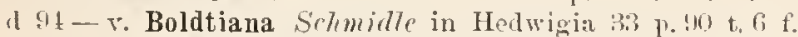
s (C. Meneghinii form. h. Boldt 1sss) [roptins "f. Boldtii (Hest)" sec. anct. in Hedw, 185 s. p. 78].

\section{subreniforme -is}

d 75 COSMARIUM Nordst. Desm. aret. p. 21 t. 7 f. 16 .

m st-Racib. Desn. okol, Krakntra sep.p. 11.

m 85 - Doldt Sibir. Desin. P. 105.

l) 89 - Toni Syll. alg. p. 1050 .

n 91 URSINELIA Kantre Rer. gen. pl. p. m5.

\section{subretusiforme}

a 4 COSMARIUM West Ňew Brit. Alg. p.5 t. 1 f. 20.

\section{subrostratume}

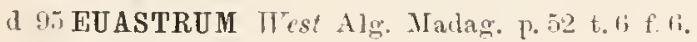

\section{subrotula}

d 93 STAURASTRUM Turner Alg. Ind, orient. 10.195 t. 15 f. $\pi$.

\section{subrotumalum}

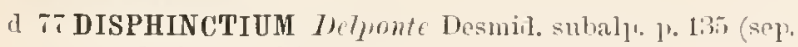
p. 231) t. 21 f. T. 8 .

d se - Toni isyll. alg. 1. Sall.

\section{sulbschlbum}

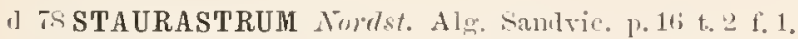

d 89 - Tomi syll. alg. p. $117 \%$.

ก 12 - f. scabrior West Fr. w. Alg. Ir. Irel. p. 176 t. 23 f. 1 .

\section{subsperiosum -}

(I is COSMARIUM Nortst. Desin, aret. p. 22 t. if f. 13.

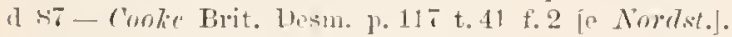

d $8 \bar{s}$ - $\beta$ validins Nortst. Algolng. smisak. 4 p. Hin.

m 89-Bolit Desm. Grïnl. p. 21 .

d ss - F ralidius Nordst. Fr. wat. alg. N. Zeal. p. 19 to 5 f. 10 1? C. speciosum $\beta$ inflatum Mhesk. 1sisi). o $89--$ Musk. Furth. Note N. Z, Desm. p. 16 t. 2 f. 2.1 [non bona].

d So-Tomi riyll. alg. 1. sRf.

1) - v. validins ibirl. p. s.s7.

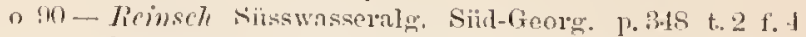
[fig. mala. ant alia sjee.].

11 URSINELLA Kuitie Rev. gen. pl. p. In.

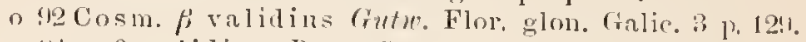
no!1 - $\beta$ validius liorge Siissw. Chlor. A rolang. p. 31.

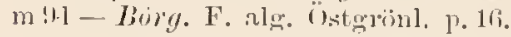

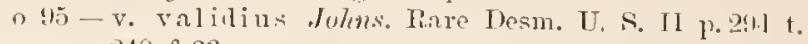
240 f. 33.

d $95-v$. truncatum Wrst Alg. Madag. P. fiel t. 7 f. 22.

d - r. effigiatum ibid., t. 7 f. 1 is.

\section{subsphrericum}

d To STAURASTRUM Nortst. Desm. aret. p.31 t.\& f. 33. d $89-T o n i$ s.oll. alg. p. 119S.

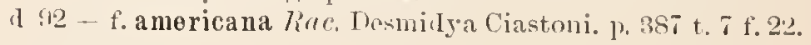

\section{subspinosum}

d 93 EUASTRUM Timer Als. Ind. nrient. p.St t. 10 f. 17 (f. typica) et f. 37 (f. tumida). [En. elegans v. monodentatum f. oxanmulatmm Iri7d. 18:1\%.

\section{substellatum. -r}

d So EUASTRUM Nordst. De Alg. et Charae. 1 p.s t. 1 f. 12 .

त so-Tomi sioll. alg. p.107:?.

11 HELIERELIA Kuntze Rev. gen. pl. p. \$!).

m!13 Eu. Tum Alg. Inrl. orient. p. 82.

(I -f. Bengalensis ibid.; t. 10 f. 32. Cfr. Eu. spicatum.

\section{substrirtum}

d 89 CosmariUm Nomst, in Wittr. \& Norist. Alg. exs. 11:0 $75 \mathrm{f}$. xylogr 1 .. et in fase. $21 \mathrm{p} .42$. [Cosm humile v. substr. sec. Schmidle].

n $11-\because$ galiciense Lagerh, in N. Notaris, sel. 2 p. 14? (C. striatum $P$ gal. (rufw. 1590).

n - v. berolinense ibik, (C. Blyttii f. berol. Rac. 18s! ). o 12 - West Fr. w. Alg. Wr. Trel. T. 14!!.

m1 18 - r. minus schmille Beitr. Alg. Sohwarzwall. p. 102 t. 5 f. 10 .

o 91 - ff, Schmille in Finra 78 p. 53 (inclus: \%. humilo (Gay) 1sit), subdanicum, danicum, subhumile, striatum, Blyttii ex p.).

m $5 \%$ - v, minus Borge sverig. Chlor. II p. 16.

\section{subtelifemum}

1 Si STAURASTRUM Roy \& Tiss. Japan. Desm. p. 2:s (sep.p. (i) t. 26 f. 1.

I 89 - Tomi srell, a]g. p.1100.

m.91 - f.? Grutu. Flor. ald. Jeopol. p. 72 t. 3 f. 24.

\section{subtetragomum -}

If is EUASTRUM Jetponte Desmil. sulalp. p. (Hi (sep.p. S.1) to fi to 1 !! -2 2 .

1. Sh-Toni syll. alg. 10.106R.

12 11 HELIERELLA huntze Rnv. gen. pl. p. Sin.

subtholiforme -is

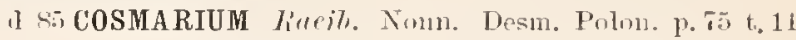
f. is (sep.p. 1? t. 2).

o - h. verrucosum ibid, 1 . 76 (C. trachyplenrum b. verr. Kivelm. 1sts).

1) s!l-Toni syll. alg. 1. tho. 
v. Malinvernianum Tirecil. Now. Desm. 1.91 t.5 f. 41) [C. Malinv. Sichm. 18!1]

n 9 URSINELLA Kuntze Rev. gen. pil. p.!25.

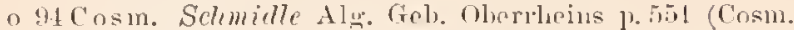
confusum subsp. ambigunm If est).

d 9.1 - v. Badense sichmulle in Fima os poss t. 5 f. 21

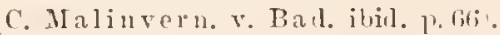

mo. - Gutu. Fl. alı. Tarnapol. 1. !3.

$\mathrm{m} 95-\mathrm{f}$. minor schmidle in Itedwig. $3.1 \mathrm{p} .7$.

\section{sultile -is}

1 5 CLOSTERIUM Brit, Liste p. $1 \%$ t. 2 f. 4s.

(1) 12 - Areh. On Ankistrol. 'sep.p. 181. in P'r. lunlul. Nat. Hist. Soc. p. $80=$ Ankistrodesmus acutissimus Areh.

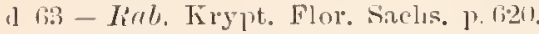

11 18 - Rub. Flor. Enx. Alg. 3 p. 135 .

o 72 - Wittr. Gintl. Öl. sistv. Alg. p. fiti.

d $78-$ Kirchm. Alg. Fehles. p. 1.10.

d 8.1 - Wolle Desm. U. S. p. 1 is t. 7 f. 2.

zo 81 - Josh. Burm. Desm. p. 1552.

o sij - Stoles Kiey Desm. p.112.

d 87 - Alexenlon Clilorosp. Khark. p.227.

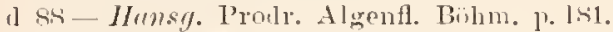

m 83 - Rircib. Mat. flor. glon. Polsk. p. Hor (sep.p. 23).

(1 8!) - Tomi syoll. Alg. 1. 830.

m 90 - Lishler Spis Desm. Mielz. 1). 85.

n 91 ARTHRODIA Kuntze Rev. gen. pl. p.8 84.

m $92 \mathrm{Clnst}$. Hare. F. Alg. Maine III p.121.

m 92 - f. Wrest Fr. $w$. Alg. W. Irel. p. 126 t. 19 f. 16 .

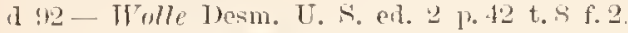

m 94 - Alexenko Mater. alg. Iilark. p.21.

Hare sprecies saltem pro maxima parte Raphidium (1. Ankistrodesmus) spee. est; tanen efr. Closterium spec. Hoffmeist. Fortpflanz. t. 1 f. $9 \mathrm{cum} \mathrm{zy}$ gosporis!

\section{subtile}

d is STAURASTRUM Nordst. Alir. Santvic. p. 1t; t. 2 f. 2. (l s. - Tomi syll. alg. p. 1161.

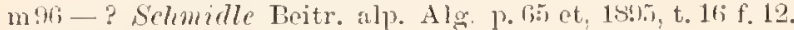

\section{subtilis}

d 31 FRUSTULIA Kïtz. Sym. Diat, p. $3 i$ (sep.p. (9) t. 13 f. 2 [C]. rostratum juv. sec. Ehrent. Inf. p.98].

\section{smbtumilmm - -}

1] 78 COSMARIUM Nordst, in Wiltr. \& Norlst. Alg. nxs.

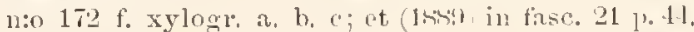

(1) So- $\beta$ platydesmium Aordst. De Als. et Charac, ir 6 t. $1 \mathrm{f} .7$.

z 83 - Nordst. in Wittr. et Nordst. Aly exs. n:0 517; ot (1sis!) in fase. 21 p. 44.

msi-lioldt Sibir. Chloropl. p. 10:;.

In $81 \mathrm{i}$ - $\mathrm{f}$. Nordst. in Wittr. ot Norist. Aler. exs. 11:0 \$32.

d SS-Ilansg. Frodr. Algenfl. Bïlnm. 1).2l!?.

m 88 - Boldt I Desm. Griml. p. 16.

m - f. ibid. (C. nitidalum Elfe. 1871)

d 85 - Tomi syoll. alg. p. 150.

1) - v. platydesmium ibirl.

m mo - West Fr.w. Alg. North Wales p. 24t.

1) ?1 URSINELLA limtio Rov. gon. pl. p.s?.

0 !l Cosm. Schmille in Florn 78 1.52 t. 7 f. 1:3.

(1) - r. rotundata ibil, et t. 7 f. 11.

Cfr. Cosm. galeritum.

\section{smbtrl/illm, -}

4 80 CLOSTERIUM Nordst. in Wittr. \& Norlst. Alu. exs.

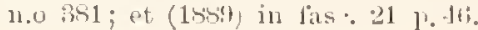

18.9-Tmi syll. Alo. p.839.

n 11 ARTHRODIA Kuntze Rev. gen. 11. p. Ssi.

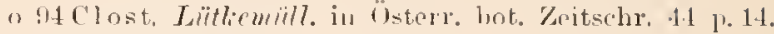

\section{s"Itルl"yidm!}

(1) 98 DSPHINCTIUM Twmer Alg. Int. oriont. 1) 40 t. 7 f. 4 .

1) (1) COSMARIUM (Plenlotioniopsis, fominor Selmidlo Aln. Snmatr. 1. 300 t. 4 f. 2.

\section{subulatum -r}

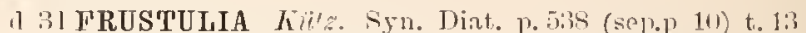
f.1. [Firnre al Raphidium spectant ("ross. vire. 2 11. long. 90--135 "1 ; teseriptio fortasse quoque all Closterium. (1. rostratum juv. sec. Ehrenl). Inf. p. 98. Est Closterinm setacenm Ehrb. ser. Ǩitz. Phye. gener. Cl. acutum $\beta$ linlfs 1sis].

n 34 - Kitta. Ale. Arru. llule. germ. dec. IS n:n st. [Hic Raplillium sp. (erass. $4-5 / 1$, loug. 120 /) et Closterinm setacelum (crass. 11 11. long. 2411 il) vilii].

11 39) CLOSTERIUM Brih. in (her. Micr. 1.272.

1. $-\beta$ cuntroversum ibil.

145 STAUROCERAS Kïtz. Plyeol. germ. p. 183 (C1. setacenm $E$.)

d 49 - Kïtz. Spec. Alo. p. 166 .

o 5iclost. Pre?. List. p.151. [Cl. a eutum ser. Areh. 1862].

o 137 - Not. Desm. Ttal. p. 02 t. 6 f.6.1.

d 86 - Cooke Brit. Dosm. 1. 36, t. 15 f. 1.

m:2- Hest Fr. w. Alg. W. lrel. pr.12\%.

m:13 - Lällemüll. Desm. Attersees p. isls.

\section{submlatus}

d 49 ARTHRODESMUS Kïtz. spec. Alg.p.17\%,

a $-\beta$ gracilis ibid. $1.17 \%$.

d 63 - Rirb. Krspt. Fl. Sacls. p. 197.

in 70 - Nordst. Desm. Prasil. p. 232. f. major t. 4 f. 59 , merlia (Lu. n:n 12 Lath. Amer, Bacill. p.enk (sepl. 1. 15) t. 1 'fuoad f. 12, non 11) et minor (Kïtz. I.c.).

d 84 - Wolle Desm. U. S. p.96 t. 21 f. $11-12$

1) 86 - v. gracilis Josh. Burm, Desm. 1. 044 t. 24 f. 13.

o 81; - stolies liey Desm. 1. 131.

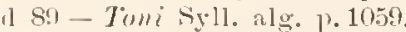

oz 90 - f. major Bärg. Desm. Brasil. p.43 t. 5 f. 57.

(1) 92 - Hansq. Prollr. Algentl. Brihm. ed. bohem. p. 175,

1) 92 - Wolle Desm U. S. ed. II p. 1114 t. 27 f. $11-12$.

m!3 - Eirhl, et liac. Nowe gat. zielen. p. 124 t.:3 f. 14.

() $93-(A$ plodesmus) f. media Turner Alg. Ind. orient. l. 133 t. 11 f. 34 et 37, t. 12 f. 1 .

$m$ - f. minor ilid.; t. 11 f. 39.

o 91- Withm. Olss. erit. Desm. p. 108 (inclus. A. ovalis) o .4 - West Alg. Madag. p. i2 t.9 f. 32-33.

(fr. Arthrolesmus convergens et Incus.

\section{submmalnlatmm -}

1) Su COSMARIUM Wille Norg. Fersliv. alg. I p. 27 t. $1 \mathrm{f}$ ؛. [C. undulatum v. subundulata Ibor\%. 15!1. Cfr. C. Nuttalli?

msil- Bublt Desm. Grionl. 1) 17

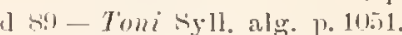

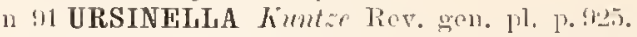

1) $1 \mathrm{Cosm}$. v. Beanlandii thest New lirit. Alg. 11. $\mathrm{T}$ t. 1 f. 10 .

\section{surisum}

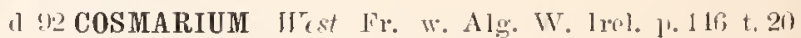
I. 23 at 23 
sulectum- -

d is CosMARIUM Nordst. Alg. Nandvic. p. 13 t. 1 f. 1 s.

4. 89 - Toni syll. al@. 1. $54 !$.

o 8. - lincib. Xow. Desm. p. S2.

1191 URSINELLA Kuntre Rev. gen, p1. p. (125).

m :11 Cosm. Gutu". Flor. alo. Leopol. 1) 55.

m !) -..Johns. Rare Desm. T. S. p. 247 t. 211 f. 11.

d $95-r$ sumatranum Schmille Alg. Sumatr. n. 302 t. 1 f. 10.

m5-West Alg. Madag. 1.5 t. 9 f. $28-20$.

\section{Sumaterbundense}

dzf 03 STAURASTRUM Tumer Alg. Ind, orient. p. $124 \mathrm{t}$. $1 \pm$ f. 1 is:

m 9.5 - sclimidle Alg. Sumatr. p. 30 ri.

\section{sil) erbllm}

d S1 XANTHIDIUM Elfi. Finsk. Desin. 1). 10 t. 1 f. 6.

d sa-Holacantlium. Toni syll. alg. 1, 906s.

\section{s"l)ergrumatum}

d 93 COSMARIUM Tumer Alg. Ind. orient, p. 57.

- f. minor ibid.: t. i f. 37 .

- f. media ibid: t. 8 f. 3. .

- f. pulchrum ibid.; t. 9 f. 24.

\section{sil) rurollutum,}

d 13 DYSPHINCTIUM Tumer Alg. Ind. orient. p.42 t. !) f. 5 .

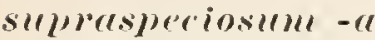

d st Cosmarium Wolle Desm. T. s. p. his t. 50 f. $5-6$.

o. Sib-Stokes liey Desm. p. 12u.

d $89-T o n i$ - ivll. alg. p. 1113.

11 !I URSINELLA Kuntze Rev. gen. 1.1. p. 925.

o 92 Cosm. Ruc. Desmilya Ciastoni. p. 330 t. 6 f. 8 .

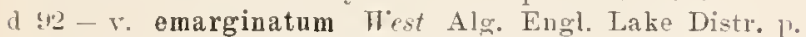
7.2! t. 9 f.21. [Cosm. quadrifarium $\mathrm{r}$. (C. hexastichum " polystichum foldt 1sis')].

m $95-$ schmedle Alg. Sumatr. p. 305.

\section{Surainei}

d 92 MICRASTERIAS Thast. in Tolle Desm. U. G. ed. II 1.11! t. 12 f.1. [1I. radiosa Thalfs sec. Borge in Nuov, Notar. 1893 p. 397].

\section{Sururtii}

d 12 DIATOMA Ag. Disp. Alg. suec. p. 31.

d 12 - Ay. Aloar. Dec. I p. 13.

def 1 à -- Ag. in Sr. Bot. t. $4: 1$ f. $1-3$.

d 17-Ay. Syn. alg. Scand. p.11s.

a 19-Lyngb. 'Tent. Hydr. Dan, J. 1 i t.61 f. A. 1-5.

$20-T m \%$ Dict. d. se. nat. Pl. [20] Véget. acotyl. Vesicul. Arthrorl. f. 2. Fortasse non omnes figures hue pertineant].

d 21 - Greny Nat. arrang. Brit. I'lants II p. 25.

d 21 DESMIDIUM A\%. Srst. Alg. 1.!.

d $26 \mathrm{Diat}$. Wahlrnb. Fl. Suec. p. 13.

d 27 - Siprengel syst. veget. $\because$. TV. 1 p. 374.

d 27 Desm. Frovill. Sicot. Crypt. Fl. r. is t. 292, v. 6 p. 32.

d $32-A \%$. Consp. Diatom. p. 5 ;

d 33 - Wulls. Fl. eryet. Germ. II p. $11 \mathrm{~s}$

d 33 Diat. Wahlenb. Fl. Suec. ed. II p. 533.

d 33 Desm. Gree. in Hook. Br. Fl. v. 1. 102.

d 33 - Sprengel in Ersch u. Grub. Allo. Encyklop. d. II iss. I. 21 p. 201.

d $34-$ Kütz. Syn. Diat. 1.613 sep.p. 55 .

Nordstedh, Index lesmid. d 34 - Elirenb. Organ. ki. Raum. 1. 241 (sep.p. 117 ).

- 34 - Corla in Alm. d. Carlsb. 1s35 p.17T (sep.p.15) t. 4 f. 44 .

d 35 - Brèl. Alg. Falaise p. 53 et 267 t. 2 [a Brebissonii hütz. 1,it! $]$ et t.: [non bona].

ph 36 Diat. Lamr. in Compt. rent. II p. 167.

d SSDesm. Ehrend. 1nf. p. 140 t. 10 f. VII1 [a Brebisso11 i Kïtr. 18lis

m $39-k 7$ renl. Mleteorpap. p. 56 (sep.p. 12) t. 1 f. 10 [non lona].

d 10 - Menegl. Synous. Desm. p. 203 (sep.p. 3).

d 11 - Tiniley Aner. Bacill. p. 2 . s (sep.p. 7 ) t. 3 f. 1.

11 - Have. Han. Tir. Alg. p. $19 \%$.

d 43 - Ralfs in An11. Nlag. Nat. Hist. v. 11 r. 375 t. 8 t. 8 et in Trans. Bot. Soc. Eilin. v. 2 1) 7 t. 2 f. 3.

d $45-$ Rrelfs in Ann. Mag. Nat. Hist. v. 15 p. 405 let 1846 in 'rans. Bot. Noc. Elinb. p. 1621.

d 45 - Hass. Brit. Alg. p. 341 t. 83 f. 7 -S.

d 45 - hï̈z. Pliycol. germ. 1. 141.

d 47 - Tiub. Feut. Kigpt. Fl. p. 5i.

dzf 48 - Jialfs Brit. Desm. p. fil t. 4 .

d $19-a$ Brebissonii Küt. Spec. Alg. p. 100; Brib. 1835 et Ehrl, 1538).

d - $\beta$ Ralfsii ilid. (Iiulfs 1st3).

a 49 - Na\% einz. Alg. p. 130 t. 8 I1.

z $51-$ Brewn Verjüng. p. 316.

51 - $R$ ub. Bacill. taclus fase. 4 t. 3 f. 41.

d $52-$ Mritch. Inf. 1. $2 \pm 1$.

phist - The Isary Conjug. p. 42. 44, is t.6 f. 5 .

dzftit) - Wallich Desm. Lom. Bengal p. 1 se t. 7 f. 1 et 4 [D. aptogonum].

d $-v \beta$ ibill. 1.189 et 191 t. $\tilde{\mathrm{f}}$. 2 et $3[\mathrm{D}$. Bengalicum Timm.

d 61 - Arch. in Pritch. Inf. p. 723 .

o (i2 - Imb. Alg. Eur. n:o 1256. f. dentibus obtusis. (D. a mblyollon $I t z$. .

dzf $63-$ Thl. Krypt. Fl. Sachs. p. 1sy, f. xyl. a-c p. 15 ; [ex Tiralfs 1-ts].

d - a Brebissonii ibil.

d - b. amblyodon (It $z$, ibid. p. 1 S1.

-c. Ralfsi i ibid.

(i3- - Erebissonii, quadrangulare Crumer in Rab. Alg. Eur. 1:0 1.143 (D. guadrang. Tielfs),

I 6 if - Eyrich Algenf. Mannl. p. 11T.

6it-Crourn F1. Finist. t. 5 f. 11

d 67 - Iicinsch Algenf. Frank. p. 205: a. Brebissonii, b. Ralfsii.

zolit-Arch. in Q. T. M. Sc. v. T n. 290.

67 - Nut. Desm. Ital. t. 1 f. $t$.

daftis - a. Brebissonii Rul. Flor. Eur. Alg. 3 p. 1.t, fig. xyl. y. 16\%

d - b. amlilyodon ibid. p. 154.

d $-c$. Ralfsii ibid. (Rulfs 1sts fig. f.).

d 73 - Hood Fr. Alg. 1. 126 .

daf 74 - Delponte Desm. subalp. p. (is (sep.p. 56) t. 2 f. $8-20$.

z 71 - Croue in Q T. M. S. p. 105.

dz T5-Microgr. Lict. p. 231 t. 10 f. $T$ et 8 [e Rolfs].

d 6 - hivehu. Alg. Schles. p. 132.

in ts - Hempel Algenfl. Chemnit: p. 113.

o 7 - Coln Desm. Bong. p. 263 (sep.p. 5) t. 11 f. 1 [Quid ?].

ozf 80 - Hitchc, et Wolle in Amer. Mier. Journ. v. 1 p. $7 \mathrm{fig} . \overline{\mathrm{T}}$.

ph 8. - Fischer Givishytall. Desm. p. 1 fil.

m St - Artari List. alg. Moseou p. 13\%.

n 81 - Guy Mon. loc. Conj. p. 80 t. 3 f. 3.

m st - Incib. Desm. okol. Krakowa 1, 5.

daf.t-Wolle Desm. U. S. p. 26 t. 2 f. 1 -5. 
d 85 - Kirchn. Mikr. Pflanz. d. Süssw. p. 21 t. 2 f. 59.

o R6-Siokes Kiey Desm. p.110.

msti - Frank in Leunis synops. 3 p. 197

dzf.S6 - Coole Brit. Desm. 1) 10 t. 5 f. 2.

ph 86 - Filels Organisat. Gallerte b. Alıen p.379 t. 4 f. 2.

a 87 -Alexentio Chloroph. Khark. p.217.

d 88 - Hunsy. Prodr. Algenfl. Böhm. p.171.

d - f a mblyodon et $\gamma$ Ralfsii ibid.

—? v. ibid. p. 172 in nota (Tesm. bispinosum (orda).

d 88 - Toni et Levi Fl. Alg. Venez. p. 24.

- - f. didyma ibid. p. 25 (Desmidium didymum Corel $a$ ).

o ss - Kiabin. Chtoroph. ens. Charkow p. 322.

d 88 - Huuptf. Zelim. u. Hüllgallerte Desm. p. Tt sep.p. 19) t. 2 f. $1-5.7-1$.

m so - Ist . Jel. magyar. alg. p. 245.

m(z) ss- Fordst. Fr. wat. alg. X. Zeal p. 25.

n 89 - Curter in A. M. Mier. J. 11) f. $t$.

dz $89-$ Toni s.yll. Alg. 1. 780.

d - a. Brebissonii ibid.

d - b. Amblyodon ihid.

d - c. Kalfsii ibid.

ph 90 - Bittner Gerbsäure-react. lebend. Pfanzenz. p. S3. 1190 - Wille in Natiill. PHanzenf. p. 15 f. 9 F (e Delp.).

m 90 - Eichler spis Desm. Miedz. p. 54.

in (10) - - Huderss. sverig. Chlor. 1 p.s.

m 91 - Istc. Fragm. Alg. 1 j. 1198.

d 91 - Kirchn. Nikr. Pflanz. d. Silssw, erl. 2 p. 22 t. 3 f.67. m:1 - Heimerl Desm. alpiu. p. 5ng.

o 91 - l)el Tome in Revista Ital. ג. sc, nat. XI p. 12 ?

dzf 92 - Wolle Desm. U. .. ed. II p. 26 t. 2 f. 1 - 2.

m 93 - Lüthemill. Desm. Attersees 1.534.

dzf 93 - a. typica Thrne Alg. Inu. orient. P. 115 t. 19 f. 8 [e Wall. 18tio].

d - b. minor ibid.

- - c. Erebissonii? ibid. t. 19 f. 7.

n 93 - Pr quadrangulatum Fioy Scott. Desm. p. 170 (Desm. 4th. Lirelfs!

93 - Wildeman Not. mycolog. t. 7 f.t.

m94-Alexenlig Mat. alg. Khark. p.19.

dzf 14 - Saund. in Fi. Nebraska p. 313 t. 6 f. 7 ["fo" errore typographico. - Ex Wolle].

ph 94 - Pulla in Ber. deutsch. bot. Ges. p. 231.

o 95 - va anblyodon West Alg. Madag. p. 43 t. 9 f. 3.i [Г. aptogonum].

o - v. 'quadragulatum ibil., t. 9 f.34. IIdem. excl. s.rn.].

Cfr. Spheroz. vertebratam $18 x 3$.

\section{:}

d 55 EUASTRUM West Alg. Marlag. 1).60 t. 6 f. 11.

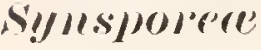

d 4:2 Therrisule in Ann. se. nat. ser. '2 t. 17 p. 305 et 32.9 . Divis. algar. Gen.: Mougeotia. Tyndaridea, $Z y^{-g}-$ nema. Closterium.

o 42 Chmon Rechereh. s. lorg. fruct.. class. p. .

d 68. Hrout et Decris. 'Trait. gen. bot. 1. 71\%. Subtrib.: Desmidieæ.

\section{sylltibomemull}

d so CosmariUM Hest Fr. w. Alg. IV. Irel, p 154 t. 21 f. 11.

\section{Treniel}

n 41 ARTHRODESMUS Filerent. in Ber. d. Berlin. Akal. 1841 1).2013 ["Falklanks Inseln"].

d 13 - Ehrenb. Mikr. Leb. süd. u. X. Amer. p. 410 t.I f. I $\perp S=$ Grammatonema sp.

\section{tateicer}

dzf 55 CPLINDROCYSTIS Rac. Nonn. Desm. Polon. 1. 54 (sep.p. 3) t. 14 (sep. 5) f.

dz.s!) - Toni syll. Alg. p. 81i.

1191 GYGES Kuntze Rev. gen. pl. 1). S96.

\section{tat)}

d 85 Cosmarium Fiacil. Fonn. Desm. Polon. p. Ts t. 10 f. 12 (sep.p. 2 .2 t. 1 .

d 57 - $\beta$ novizelandicum Fordst. Algolog. Smăsak. 41 161. d $88-$ - Norlst. Fr. wat. alg. X. Zeal. p. 56 t. 6 f. 6. d s. - Toni syll. alg. p. 1035.

a - v. novizelandienm ibid.

n 91 URSINELLA Kuntze Rev. gen. pl. p. 925.

1] 92 Cosm. v. spheraliferum West Fr. w. Alg. W. Irel. p. 1.2 t. 20 f. 19.

in $92-v$ - novizelandieum Test Alg. Engl. Lake Distr. p. 723 .

\section{trenirhourleiforme}

1 11 COSMARIUM Eichl. et Gutw. spee. alg. nov. p. 16! t. \pm f. 23 .

d - v. depressum ibid.; t. 4 f. 24. [Cfr. Cosm. crassangulatum].

\section{tex:irhomalem- -r}

d 71 COSMARIUM Lund. Desm. Snee. 1. $3 !$ t. 2 f. 13.

(l $73-\mathrm{f}$. irregularis Nordst. Norg. Desm. 1. 1..

mso- Wille Norg. Ferskv. alg. 1 p. 32.

d st - Wolle Desm. U. S. p. 71 t. 16 f. 32-34.

d si- $\beta$ subundulatum Bollt Sibir. Chloroph. p. 101 t. 5 f. $t$.

m sij - Lugerh. Amerik. Desm. 1.237.

a - $\beta$ bidentulam ibid.; t. 27 f. 8 .

o .96 - Stokes key Desm. p. 128.

1 $87-v$. bidentulum Wolle Fr. Alg. U. A. A. p. 32 t. 60 f. 17 \& 18 [e Laggerh. 185io].

1) s - Hunsg. Prorlr. Algentl. Bölım. p. 197.

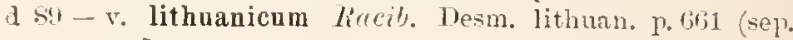
1..5).

d so - Toni siyll. alo. P. (1)

1 - v. bidentulum ibid. p.9!1.

$1-v$. subumdatum ibid.

1) - v. lithuanieum ibid.

1. 89 - " genuina Racil. Now. Desm. 1.88.

- $\beta$ subundata ibid.

- y decachondrum ibid. (C. deeaehondrum Roy et Biss. 1896 ?

i lithuanicum ibil., t. 5 f. 16 .

1 - Hayualdi ibil.. t. ¿) f. 15 (C. Haynaldii Schear.). m 60 - v. decaehond un Eichler Spis Desm. Miedz. p. 87 . 11 "1 URSINELLA finntze Rev. gen. pl. p.925.

d 52 Cosm. Wolle Desm. U. S. erl. Il p. TT t. 19 f. $32-34$. I - v. bidentulum ibid.. t. 49 f. $17-18$.

d 43 - f. abyssinica Lagerh. Clilorophye. Abysin. p. 16i.

19.3 -- v. nudum Thrner Alg. Ind, orient. p. 60 t. 8 f. 64.

m 94 - Borge Süssw. Chlor. Arehang. 1.31.

d -f. ibid.

m $95-W^{2}$ est Alg. Madag. p. 66 t. 5 f. 2.

1) - v. emarginatum ibid. t. 7 f. 3.

d - v. subundulatum f. subdenticulatam ibir. p. fit t. 7 f. 4.

d - v. dentatum ibil.. t. 7 f. 5 .

a - v. compressum ibill., t. $T$ f. $d$.

\section{TEINIIIUII}

11 98 Tumer Aig. Ind. orient. p. 7. Snbgen. Cosmarii. 


\section{telifer"lm}

dzf.18 STAURASTRUM Rulfs Brit. Desm. p. 1.2t t. 22 f. 1, t. 34 t. 1 t.

d $52-$ Iritch. Inf. p. 263.

1 $61--4 r c h$. in Pritel. 1uf. p. T34 t. 3 f. $20-21$ [e Ialfs].

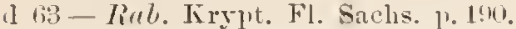

a $6.1-$ f. Clere Bidr. t. Srerg. Desm. p. 490.

d bit-- Fyrich Algenfl. M[annh. ]. 12!l t. 1 f.t-5.

o 67 - lot. Desm. ltal. 1). 00 t. 4 f. 40.

dztis-liub. Flor. Eur. Alg. :3 1, 21:.

o 68 - Norlst. Bidr. Nrerig. Desm. p.10.

o 73 - Nordst. Norg. Aler. p. 30.

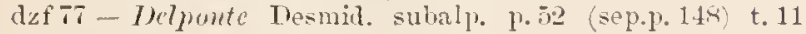
f. $1-1$.

dz Ts-Kirchn. Alg. Schles. p. 17̈.

n Ts- Kempel Algenfl. Chesnuit\% p. 114.

m $S t-G r ! !$ Mon. loc. Conj. 1. fit.

d 81 - Wolle Desm. U. S. 13, 110 t. $45 \mathrm{f} .4$.

o s. - f. Lagoensis Wille sydamerik. Algfl. p. 1:4 t. 1 f. 3 .

111.45 - f. minor Roldt Nibir. Chloroph. 1) 113.

d $81-v$. convexum liem. Fr. wat. Alg. Engl. Lake Distr. 1. 11 t. 2 f. $21-23$.

o Sli-Situkes Key Desm. p. 16\%.

dzfst - Cuoke Brit. Desn. p. 151 t. ה.2 f. 2 [e, e lialfs].

d - $\beta$ eonvexum ibil.

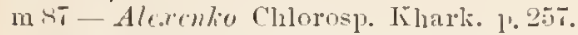

mis-Riubin. Clıloroph. env. Tiharkow p.331.

msis- Buldt Desm. Grönl. p.3i;.

m Si - Iste. Tel. magyar. alg. r. 233 .

iz 8:1 - Tomi Syll. alg. p. $116 \pi$.

d $-r$ convexum ibid.

1 - v. lagoense ibid.

m 9)-Anderse. Strerig. Chlor. 1 l. 12.

ph $: 0$ - liem. Reprod. Lower forms p. 100 t. 2 f. 5.

o 91 - f. minor Heimerl Desin. alpin. 1.605.

zf 92 - West Fr. W. Alg. W. lrel. 1. 175 t. 24 f. 5 .

d - f. ubtusa ibia. et t. 24 f. $f$.

d $[$ - W - Whe Desm. U. $\therefore$. ed. II p. 154 t. $56 \mathrm{f} .1$.

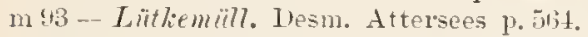

n $63-($ Raphidiastrum) Tmmer. Alg. Ind. orient. p. 133.

$94-\mathrm{v}$. ordinata liorg. F. alg. Ustorönl. 1. 2 t t. 2 f. 23. Cfr: Binatella hispida, Didyrin. Hystrix B. Reinsch, Staur. polytrichmm $\because$ alpinum, Xantl. hirsutum 1 s.8.

\section{T'EMTO\%OSILA}

d 93 Turuer Alg. Ind. orient. 1. 143. Sulggen. Sphierozosmat.

\section{temax}

d 24 DESHIDIUM $A g$. syst. Alg. p. \%. "An potius Gloionema?" sec. $A g$. !

d $32-A \%$. Consp. cr. Diat. p. 57 ["species inquirenda" $A \mathrm{~g}$.]

d $31-k$ ïtz. Syn. Diat. p. li1t (sep.p. 86).

\section{temervimu}

d TOSPIROTENIA Arch. in Q. T. M. S. v. 10 p. 203.

d 86 - Coule Brit. Desm. 13.52.

d 89 - Tomi sioll. Alg. p. $80 \%$.

n 93 - Monotienia) Tumm Alg. Ind. orient. p. 22?.

o (1)-- Lïtliemill. Gatt. Spirotien. 1.51.

('f: Spir. gracillima.

\section{temer.imllm}

d 45 CLOSTERIUM Kïtz. Ihyc. germ. p. 130.

o $45-h$ - hitz. apud Rulfs Brit. Desin. 1.222 t. 35 f. 10. Cl. acutum sec. Rilfs). [Cl. acutum $\beta$ tenerrina sichatar: 1853]. d $1 ! 1$ - Kütz. Spec. Alg. p. 164.

d 69-Rieb. Krypt. Fl. Sachs. p. 170.

\section{tener $11 m$}

1 5 B COSMARIUM Tumo Alg. Ind, nrient. p. 55 t. 8 f. 27.

\section{teme}

d 31 CLOSTERIUM Kït. Syn. Wiat. p. 545 (sep.p. (16) t. 18

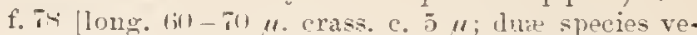
risinniliter $=\mathrm{Cl}$. Cornn et acutum f. ?]. [Cl. cornu sec. Ellrent. Inf. p. 4 is].

d 35 - Tirit. Alg. Falaise p.5y t.i [e kïtz.].

o 41 - Diviley Amer. Bacill. p. 303 (sep.1. 2.2) t. 3 f. 3 [Cl. lanceolatum sec. liulfs Brit. Desm.; for'san non ita. - Cl. Dianæ sec. Küt:. Spec. Alg. - Cl. acerosum r. maximum II vod $1573(!)]$.

d 45 - Kïtz. Phyce germ. p. 139. ["1/140" bleit". Annon $1 / 210^{\prime \prime \prime ?]}$ ?

d 4 - Kïts. spec. Alg. 11. 164

1) 50 - Murissul Catalog. esp. onnis. p. 32 t. 1 f. 3 (e Kütz.).

d $53-$ Huth. F1. Belo. II p. 525 .

\section{ternlle}

dz 68 COSMARIUM Areh. in (2. J. M. Sc. v. 8 1. 248.

dz si - Cooke Broit. Desm. p. 92.

uzf 92 - West Fr. W. Alg. W. Irel. p. 117 t. 20 f. 25.

ozot-Jolms. Rare Desm. U. S. p.2si (C. bioculatam Holle [?]?

d $41-f$. strusoviensis Gutu. F1. alg. Tarnapol. p. 45 t. 3 f. 15.

\section{teille}

d 83 CosmaRIUM Mush. N. Z. Desm. Adu. 1\%.213 t. 24 f. 10. [Cosin. bioculatum?]; nec. Arch.

\section{tenuissimus - $\| m$}

(l) 6.1 ARTHRODESMUS Arch. Descript. (sej.p. 2n), in Dub. Nat. Hist. Soc. p. 68 t. 1 f. $50-5 \tilde{5} ;$ in Q. J. Micr. Sic. 1 . 175 t. 6 .

d fis-Rirb. Flor. Enr. Alg. 3 p. 2026.

d 57 - Cooke Frit. Desm. p. 137 t. 17 f. 3 [ex Arch.].

ms - Racit. Mat. flor. glon. Polsk. 1. 110 (sep.p.31).

d $\$ 9$ - Toni syll. alg. 1' 1058.

90 - West Fr. W. Alg. North Wales t. 5 f. 10

m 90 - Anderss. Sverig. Chlor. 1 p. 13.

m 93 - West Fr. w. Alg. W. Irel. p. 170 t. 22 f. 9.

o 93 XANTHIDIUM 7ime Alg. Ind, orient. 11. 137.

11196 Arthr. Sichmille Beitr. alp. Alg. p 20.

\section{temissimllm}

d 95 STAURASTRUH Itest Alg. IIadag. 1. is t. s f. 43.

\section{tevebrams}

d 73 STAURASTRUM Nordst. Jorg. Desm. 1. 34 t. 1 f. 16. [Staur. elongatum I Barker sec. Archer in Jonr. of Bot. 1874 p. s.2.

nu Si-Lagerh. Amerik. Desm. p. 24s.

\section{TESSARARTIIRA}

n 36 Ehrenber!" in Abl. d. Berl. Akad. 15is p.173 Tessarthonia Timp.); "Tessarathra".

(1) Ss Elrend. Inf. 1. 114.

(1) 40 Bumeister in Ersch 12. Gruber Encycloped. II. 18 1. 211.

at 41 Horren Rechereh. physiol. 1, 120.

n 43 ("Tessarthra Fhrby.") Küts. in Linnata 17 p. S4.

a $13-K$ Kït. Phycol. gener. 1.161. 
d 47 liab. Ilent. Krypt. Fl. 1\%56. (Tessarthonia, Scenedesmus, Isthmosira?

o 5i, Braun Alg. unicell. p. 30.

o is $\mathrm{rrmm}$. Desmid. 1. 493.

\section{TESSARTHONIA}

n 25 Trup. in Dict. se. nat, tom, is p. 289 [sine descriptione generis, tantum speciei mouiliformis]. [Tessarartlira?.

o "1 Huntze Fev. gen. pl. p. "2:3 genus delendum).

\section{TESSARTHIA Cr. TESSARATTHRA.}

\section{tessellatum - a}

d 7i DISPHINCTIUM Delponte Desmil. subalp p. p. 136 (sep). n. 232? t. 21 f. $10-13$.

o so Cosmarium Nordst. De Alg. et Charac. 1 p. T.

o sh I is. lioy et Biss. Jap. Desm. p. 196 (sep.p.jo).

n Ss CALOCYLINDRUS (Dysplinetium) Iste. Jel, maहुvar. alg: 1\%.23n.

d 89 PLEUROT \#ENIOPSIS? Toni srll. alg. 11.908.

m.1 Dis. Iste. Fragm. Alg. 1 p. 116is.

1 92 Pleurotæniopsis v. Nordstedtii Möb. Austral. Susswasceralg. 1?. 41 ; f. 16.

d 93 - - Eailey Contr. Qmeensl. Fl. p.45.

ph 93 - Liitlemïll. Chlorophyllkörp. ein. Desm. p.41 (sep. 1). 7) t. 3 f. $19-2 t$.

m 98 - Lïliemiill. Desm. Attersees p.54.

phri3 - Lïthem. in Terh. zool. bot. Ges. 1843 sitz. p. 38. m 94 Cosm. Johns. Rare Desm. U. S. p. 285 t. 211 f. 17. Cfr. Calocylindrus Cohnii.

\section{tessellatum}

d so DOCIDIUM .Josh. Burm. Desm. ], 6i50 t, 25 f. 15.

o 87 PLEUR0T ANIUM Largerl. Frit. Bemerk. Desm. p. 541. d 89 Doc. Toni Syll. alg. p. 87 .

Cfr. Arthrorhabdium moluccense et Doc. verrucosum.

\section{'TETMEM(ORIDI II}

d ss Ilansg. Prour. Algentl. Böhn. n. $15 \mathrm{i}$ et 214. Sect. Dysphinctii.

d 89 Toni Syrll. Alg. p. Si3.

\section{TETMEMORUS}

d 44 hiulfs in Ann. Yat. Hist. v. 14 p. 251 set 154 ; Trans. Bot. Soc. Edin. p. 133).

d 45 Hass. Brit. Als. p. 375.

d 4 S liulfs Brit. Desm. p.115.

d 49 Kintz. Spec. Alg. 1). 167. Sect. Penii.

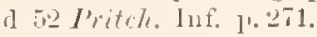

d 5 s be Brar. Conjugat. 1). 73.

d 58 Grmn. Desmit. 1, 493.

d fildrech. in Pritch. Inf. p. 220 et 716 .

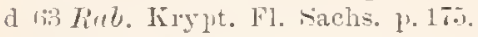

d lif Grall Brit. Alg. 1. il.

d $1 ; 7$ Not. Desm. Ital. p. 2:?.

d tis Tirb. Flor. Eur. Alg. 3 p. 139.

d 73 Hood Fr. Als. 1. 116 .

d 73 Jifunte Desm. subalp. p.40 isep.p. 28).

d Ta Microgr. Dict. p. 284 et Tio.

d 7 trelyonte Iesmid. subalp. 1) 131; (sep.p. 232).

d TT Frumk in Leunis tronops. p. 14i33.

d Ts Kirche. Alg. Schles. p. 145.

d st frmy Monngr. low. Conjug. P. 38. Rectio Penii.

d 84 Wolle Jesin. U. S. p. 90.

d s.i kirclen. Mikr. I'Hanz. d. Süssw, p. 20.

d Sf Fronk in Lennis Synops. 3 p. 19 s. o Si3 Stokes Key Desm. p. 109.

d st Aleventio Chlorosp, Khark. p. 28s.

d ss Cooke Brit. Desm. p. 48.

d s8 IIunsy. Prodr. Algenfl. Bühm. p. 188.

d Ss Toni et Lori F'. Alg. Venez. p.22 et 36 .

d 8.9 IJuntfl. Zellm. u. Hiullgallerte p.st (sep.p. 26).

ph 89 fderhold in Jenaiseh. Zeitschr. f. Nat. 20 p. 336 ete.

d s. Tone syll. Alg: p. siro.

d so thille in Naturl. P'flanzenfam. p. 13.

d 91 Manowry in Baill. Dict, bot. IV 1.164.

d 91 Kinchn. Mikr. Pflanz. d. Sï̈ssw. e 1. 2 p. 21.

d 92 TTolle Desm. U. S. ed. It p. 19.

d 92 Brailey Contr. Queensl. F1. 1).42.

plist Whllheim in Pringsh. Jahrb. 26 p. $72 \mathrm{~S}$ (sep.p. 55).

\section{tetrocercuthe}

n 35 BINATELLA Brib. Alg. Fal. p. 269 (sep.p. fir) (ab anctore teste 7 kuegh. Symops. Desm. 1.209 suplirimitur).

\section{TETRMANTHUM}

149 Nay. einz. Alg. p. 113. Aubgen. Euastri.

o so Hansg. Prodr. Algenfi. Böhm. p. 24r. Sect. Arthrodesmi.

o 89 Toni Fiyll. Alg. p. 1057.

\section{tetrueruthum-a}

d TCOSMARIUM Delponte Desmid. subalp. p. 16 (sep.p. 112) t. 7 f. $74-76$. [Cfr. Arthrodesmus obsoletus].

4l sy - Toni Srll. alg. p. 97 s.

n 11 URSINELLA Kimtze Rev. gen, p1. p.925.

\section{tetroreathum}

d 93 XANTHIDIUM Tumer Alg. Ind, orient. P. 101 t. 12 f. 29.

\section{tetrocelpre}

1 25 HETEROCARPELLA Bory in Dict. class. \& 1.180 (Palmella rupestris Lyngb. ex p.).

\section{tetraremt)otum}

a 82 XANTHIDIUM Tolle in Bull. Torr. bot. Club 1582 p. 29 t. 13 f. 14 .

d 81 - Wolle Desm. U. A. p. 4.) t. 22 f.S-9.

o 86 - Stokes Key Desm. 1. 130.

d 89 - (Holacanthim) Tomi syll. alg. 17.923.

d y2 -- Wolle Desm, L. S. ed. II 1. 10.2 t. 25 f. S-5.

\section{tetruevum, -}

d 31 MICRASTERIAS Kiitz. Syn. Diat. p.602 isep.n. 71) t. 19 f. $s 3$ le vertice?] et $\beta$ didicera f. St [Stanrastrum paradoxum Meycn sec. Kïtz. Plyc. gen. ete.].

n 35 BINATELLA Breb. Alg. Falaise p. 269.

1. t. STAURASTRUM liulfs in Ann. Nat. Hist. v. 15 p. 150 t. 10 f. 1 (et 1846 in Trans. Bot. Soc. Edin. v. 2 p. 137 t. 13 .

a 45 G0NI0CYSTIS (itaurastrum?) Ilass. Brit. Alg. p. $35+$ t. $\$ 5$ f. 4 [e Ralfs 1. c. (male) delineata].

a 4s Staur. Rulfs Brit. Desm. p. 137 t. 23 f. 7 .

152 - I'ritch. Inf. p. 266 t. 2 f. 102, 103. [ex Ithenb. Inf. delineat.].

o is - Le liar. Conjug. p. 71 .

1) 61 - Arel, in Pritch. Iuf. P. 741.

d 63 - liab. Frypt. Fl. rachs. p. 191.

d 66 - Eyrich Algenfl. Mamnh. p. 130 .

m î - Nordst. Desm. Brasil. 11.228.

\& 71 - Lunl. Desm. Suec. p. 6s.

0 is- Tordst. Norg. Desm. p. 35.

d TT-Detponte Desm. subalp. p. hi. (sep.p. 16il) t. 11 f. $25-29$. 
d\% $\mathrm{is}-$ Kirchn. Alin. Fichles. p. 16s.

m St - Arturi Liste alg. Museon p. 14.

m 85- Buldt silur. Chloropls. p. 118.

dzsi-Cuoke Brit. Desm. 1. 1s? t. 193 f. s [partime Jillfs?].

o sS - Riubin. Chloroph. env. Kharkow p.33i.

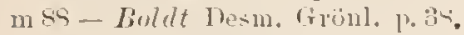

dz. 49 - Tuni syll. alg. p. 123:2.

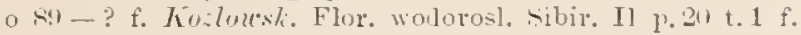
14 [St. iuconspicuum Nurelst.].

m 92 - West Fr. "A. Alg. W. lrel. p.157.

ma2-Ruc. Desmilya Ciastoni. p. 381.

m 94 - B̈̈̈ry. F. alg. Ostgrönl. P. 3!.

in 45 - West Alg. Marlag. p. sit.

d - $-v$. undulatum ibid. t. :! fo 1 ?.

Crir. Stanl. Arachne v. Jacobs. 1his et ritenactinium crenulatam $v$. biradiatum Crem. 1 ito.

\section{TETRACHASTRU.H}

d ig Jixon On a new Genus sep.p. I) in Nat. Hist. Rev. 1. 465 ; in Micr. Journ. P. 1 ; in Dubl. Nat. Hi-t. Soc. r. 203 .

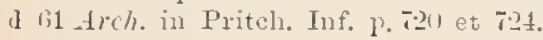

d sf Cooke Brit. Desm. 1.53. subgen. Micrasteriæ.

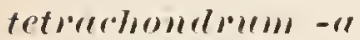

1 71 COSMARIUM Lund. Desm. suec. r. 39 t. : f. 2.

o 73 - Fordst. Torg. Desm. p. 17.

o Ti-Jaculs. Desm. Danem. p. 195.

d 81; - Cooke Brit. Desm. p.s9 t.37 f.5 [e Lundell].

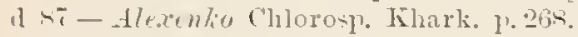

d. s. - Tomi -yll. alg. p.956.

n 91 URSINELLA kut:e her. gen. pl. p. p..

z 24 Cosm. Roy Scottish Lesm. p. 17ij.

o (1.) - t. compressa Fichler in Pamiet. Fizy. 13 p. wo t. 1 f. 9.

o 95-Tiorge Sverig. Chlor. II p. 18.

\section{tetrertinimll- -}

d 84 CLOSTERIUM Guy Mon. loc. Conj. p. 73 t. 2 f. 1 ; p t Tote Conj. d. n. France P. 383?.

d $89-$ Toni Srrll. Alo. p.st.

n 91 ARTHRODIA Kuntie Rev. gen. pl. p.sst. Cfr. Clost. Lanula Focke 1sti quoad fig. 1?

\section{tetrel!(u) 1111$)$}

d i3 APTOGONUM Delponte Desmid. subalp. T. is (sep.p. (3) t. 3 f. 201)-23. [Desm. Baileyi. - Aptog. calatum v. tetragonum liae. 1s-5].

d S4 DESMIDIUM [lapsu memoriw: "D. quadratum"] v. excavatum Schurschm. Afghan. Alg. p. 247 t.5 f. 25 [D. Baileyi $\beta$, bengalense Nordst. 1588?].

\section{fretragom $11111-a$}

d 19 EUASTRUM (Cosmarium) Trey. einz. Alg. r. 119 t. 7 A f. 5 .

1) coSMLARIUM Areh, in Pritch. Inf. p. 732.

d is - lirb. Flor. Eur. Alg. 3 p. 1tit.

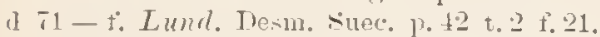

o $\because-4$ - 1 che in (Q. J. M. . 17 P. 102 form. Lund:i).

d $83-r$. euastroides tichurerschm. Magsar. Desm. p. 269 t. 1 f. $\bar{t}$.

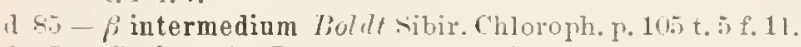

d st-Cooke Brit. Ilesm. p. 18 t. 37 f. 17 e Togele].

(l - - Lundellii Cuoke ilis.; t. 37 f. 18 male e Lmdell 18.1 .

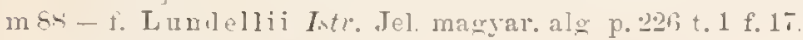

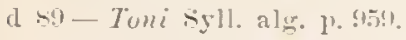

d - $\mathrm{v}$. Lundellii ibil. d - reuastroides ihid.

d $-v$, intermelium ibirl.

1 s!l- $\beta$ Lumlellit f. tatrica Ruciu. Now. Desm. p. sil t. 5 t. 11

1) $30-\%$ granulatum Crutu. Wahr, d. Priorität 1)65.

d - is subintegrum iliil.

m

m!1 - v. Lundellii lleimerl Desm. al1\% 1). 598.

n ؛1 URSINELLA Kuntie Rev. „2en. pl. 1. 12.5.

d 91 Cosm. y' granulatum frutw. Flor. alg. Leo]ol. p. \pm t. 1 f. 20. [Alia spec.].

a $-\delta$ subintermedium ibiel. et t. 1 f. 21.

m!13-v. Lundelli I Juthemäl. Desm. Attersees p. 5̃on.

d $91-v$. Lundellii f. Schmille Alg. Greb. Obermeins l. 5.19 t. 2 si t. $1 \%$.

d $14-v$. pumilum West New Brit. Alg. p.5 t. 1 f. $1 ! 1$. [Qnid \%?].

ma - $\beta$ intermedium lorge Sissw. Chlor. Archang. 1. 24 .

d 94-P intermedium fo polonica Eichl. et Gutw. Hiec. alg. $110 \mathrm{r} \cdot \mathrm{p}^{3} .171$ t. 5 f. 25.

m95-v. Lundellii Jokns. Rare Desm. U. S. II p. 231 t. 240 f. 21 .

Cfr. Cosm. Bigorrense.

\section{tetingoull11!}

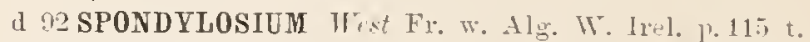
$1 ! 1$ f.?

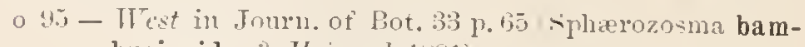
businoides? Heimerl lsil Cir. Spher: pulchellum róly last.

tetioloblin- -

d 75 EUASTRUM Nordst. Desm. arct. 1. 39 t. 5 f. 30 .

d 89 - Toni s.r11. alg. p. 1105 .

1291 HELIERELLA Funtze Rev. gen. pl. p. su?.

\section{triecorlon}

n 39 EUASTRUM Corela in Aln. 1. Carlsb. 1839 p. 238 t. 2 f. $!=$ Pediastrum.

\section{tetrecorlon}

d 11 : ODONTELLA Lhrmb. in Berlin. Monatsber. 1810 1.212. Bacillaria!?.

(1) 4!? - Kutz. Spec. Aig. p. 1 s9 (descript. Ehrenbi).

d 89? SPHÆR0Z0SMA Toni syll. alg. p. î5.

\section{Tetires}

d 3s MICRASTERIAS Fhrub. Infus. r. $155=$ Pediastrum $T$.

\section{TETRIDIU}

d 93 Timur Ale. Ind. orient. p. it. Áubgen. Cosmarii.

\section{tetrolnthulmull -}

d 31 HETEROCARPELLA Fiitz. Syn. Diat. p.597 (sep.p).

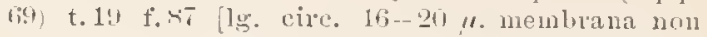
verucosa. Quil est? - Euastrum angulosum Ehrenb. sec. Kïtz. Phyce gener.].

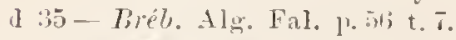

n 37 COSMARIUM Wenegh. Consp. alg. Eug. p.1s; "tetraoplithalm um".

1] 41) - Mentgh. Srutops. Desin. p. 220 (sep.p. 2 - [Descriptio mala; alia species].

I 45EUASTRUM Kïtz. Phyenl. germ. 1) 13k; "E. margaritiferum Fhenb. Infus."

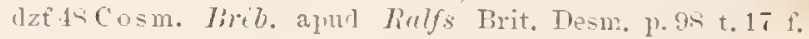
11. t. .8:3 f.s. 
d 49 - Küt: spec. Alg. p. 175.

d - $\beta$ rupestre Nro, in litt. ibid. (Eu. rupestre Norg.)

d 50 - Muressul Catal. esp. omis. p. 35 t. 1 t.9 (En. margaritiferum e thijarl. observ. microse.).

d $52-$ Pritch. Inf. p. 253.

d 53 - Wath. Fl. Belg. II p.527.

ph zf.it-Hofmcist. Fortpflanz. p. 1.8 t. 1 f. $1-4$.

in วั - P rupestre "Nog. Mspt." Wartm. in Rab. Alg. Sachs. n:0 ti31 h.

o 54-- De Bury Conjug. p.5t.

dz 61 - Arch. in Pritch. Inf. 11. 732.

d $63-$-Ruz. Krypt. Fl. Sachs. H. 2ur.

n 67 DIDYMIDIUM (Cosmarium) Reinsch Algent. Frank. 1. 121 .

o 67 Cosm. Not. Desm. Ital. 1.34 t. 3 f. 19 [r. De Notarisic Wittr. 1si2].

d is - Rab. Flor. Eur. Alg. 3 p. 150.

o - b. rupestre ibid.

o $71-$ L.mol. Desm. suec. 1. 27; forma. [ $\beta$ Lundellii Hittr. 1si2].

(1 $72-\beta$ Lundellii With. Gotl. sötr. Alo. p. 56 f. Lamd.).

m …, De Notarisii ibicl. (C. tetrophth. De Not. 1865 [C. De Not. Nordst. 18Ti].

m73- 7 De Notarisii Nordst. Norg. Desm. p. 12 .

d 73 - Wood Fr. Alg. p. 102! t. 21 f. T.

d $75-M i e r o g 1$. Dict. 1) 202 t. 11 f. 2.2 [e Iinlfi]

m $75-\beta$ Lumdelli i Nortst. I'esm. arct. p. 17 et 40 .

d 75 - Melpunte Desmid. subalp. p. 20 (sep.p. 122) t.9 f. $1-4$.

- 79 - Kitelus Ijesm. Ostpreuss. p. 41.

o 83 - Cybulshi Mater. alg. Warszaw. p. 261.

d $83-\beta$ Mroli. 2 . Zeal. Desm. Aid. p. 212 t. 24 f.s [C. subpunctulatum Nordst. sec. Mask. Furth. Not.].

d 84 - Wolle Hesm. U. - . . 1. 5 t. 13 f. 13.

m 85 - Boldt sibir. Cluloroph. p. 10s.

m 85 - $\beta$ Lundelli Nordst. Desm. Grönl. p.7.

m 86 - f. minor Josh. in Wittr. et Noritst. Alg. exs. n:o 82 .

o 86 - sitolies Kiey Desm. p. 1:-

dzsi-Cooke Brit. Desm. p. 19 t. 28 f. 1.

d sí-Hans: Prodr. Algenfl. Bühm. 1) 200)

1 - $\beta$ rupestre ibil.

$m-y \operatorname{minus}$ ibid.

d s8-T'Tomi et Leti Fl. Alg. Venez. 1,50.

m 88 - Bolat I lesm. riünl. 1.2s.

n - P L mulellii ibid.

dz 89 - Toni syll. alg. p.981.

o - - r rupestre ilid. pous.

$m$ - r. minll $\mathrm{s}$ ibid.

d. - - v. Lumallii ibid.

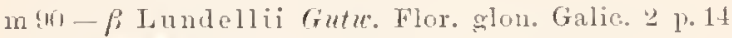

o (x) - Heat Fr.w. alg. North Wales p. 25\%.

d - v. subrotundum ibic., t. if f. 2...

o 90 - Rür\%. Desm. Brasil. 1) 37.

m s) $-\beta$ Linulelii Anders. Sverig. Chlor. 1 p. 14.

n 41 URSINELLA humtze Rer.gen. pl. p.92.

in 41 Cosm. Gutu*. Flor. alg. Leoprol. 3.51.

in 5 - P L undelli Borge Chloroph. Norsk. Fimuark. p. 9. in 12 - Wrat Fr. W. Alg. W. Irel. p.1.is.

d 19 - Wull besm. U. S. ed. 1 p p.S.2 t.16 f. 13.

m! 13-Linticmill. Desm. Attersees 1\%506.

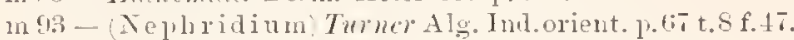

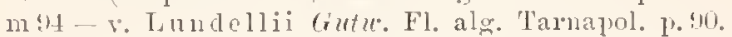

d - - f. minor ibid.. t. 3 f. 21.

Cir. Cosm. Botrytis Jucols. 1siti, Eu. margari. tiferum Focle $141 \%$.

tholiforme -is

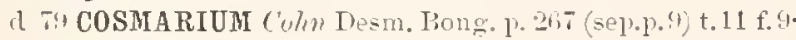

d $89-$ Tomi syll. alg. p. 1037.

n 91 URSINELLA Funtze Rev. gen. 13. p. .25.

\section{Thomresirnu}

d. 62 MICRASTERIAS Arch. New Micrast. (sep.p. 3), in Dubl. Nat. Hist. Soc. Pr. p. 72 t. 2 f. $1-5$, Mier. Journ. p. 239. t. 12. [M. denticulata f. Thomas. dac. $15 ; 67$.

d 69 - liab. Flor. Eur. Alg. 3 p. 192

o 71 - Lama. Iresm. Suec. 1) 11.

o S1 - ? Mask. X. Zeal. Desm. p.301.

z 82 - Joshun in Journ. of Bot. r. 20 p, 301.

n 85 - Racit. Noun. Desm. I'olon. p. 45 (sep.p. 39).

d Sci-Cooke Brit. Desm. p. is t. 2j f. 1 a-c [ex Archer 1. et $f .=$ M. denticulata; $\%$. M. rotata !].

m ss - hucil. Mat. Hor. glon. P'olsk. p. 111 (sep.p. 32).

d 89 - Tomi Syll. alg. p. 1134.

m 90 - Eicleler :ipis Desm. Miedz. 1\%.89.

12. 9 HELIERELLA himtie Rer. gren. pl. 1. say.

in Mier. f. major West Fr. w. Alg. W. Irel. p.134.

\section{Thureti}

d 48 CLOSTERIUM tivet). in Lialfs Brit. Desm. p. $219=$ (l. moniliferum $v$. Thureti Frét. List, Desm. 1856. d 52 - I'ritch. Inf. p. 2x:3.

\section{THuratesii}

d ticoSMARIUM lialfs Brit. Desm. p. 109 t. 17 f.

d $52-I$ ritch. Inf. p. 255 .

phe 5 - Thomas Observ. p. 35 t. is f. 21.

d $61-$ Arch. in Pritch. Inf. p. 735.

d 63 - I ind. Krypt. Fl. Sachs. 1. 2 2.

o 64 PENIUM Clere Bich. t. Srerg. Desm. p. 492 [P. Clevei Lumd.].

1n 67 DISPHINCTIUM Reinseh Algenf. Frank. p.17\%.

d 68 Cosm. Iial). Flor. Eur. Alg. 3 p. 175.

d - b. majus ibil.

o 69 - h. majus Wittr. Skandin. Desm. p. It t. 1 f. 5 [C. (Plenroteniopsis) De Baryi Arel. sec. Lundell].

o 71 - Lamd. Desm. suec. p. 47 et 52.

d 73 - Trood Fr. Alq. 1. 134.

75 - Teinscle Contrib. t. 12 f. 2.

7. - Leinsch in Pringsh. Jahrb. v. 11 t. 17 f. 1 t.

m Ti- Itempel Algenfl. Chemnitz p. 111.

d 79 - a. typicum hlels Iesm. Ostpreuss. 1.26.

a $-b$. penioides ibil.. t. 3 f. $5-7$.

d - c. rotundatum ibid. p. 2 t t. 3 f. 5.

d - d. curtum ibid. C. curtum Ireb), $a ; \beta$ (Dysph. Regelianum Nig.. $\gamma$ ( $:$ attenuatum Rolfs).

d $80-\beta$ incrassata Thille Ferskr. alg. I p. 37 t. 2 f. 24.

8. CALOCYLINDRUS Schertrechm. in Magrar. Xör. Lap. (; 3. 3.3 .

o 83Cosm. Mask. N. Zeal. Desm. Add. p. 239 t. 24 f. 2 [Pen. cucurbitinnm fi subpolymorphum Nordst. 1857 see. Mask. Furth. Not,, 185\% 1\%6].

inst Cal. Linc. lesmo okol. Frakowa p, 4.

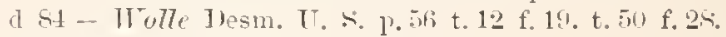

o sil- Nolies liey Tosm. p. 11 t.

d si-Cooke Ir. Desm. p. 126 t. 41 f. 5 .

d 87 - Alerenlio Chlorosp. Ǩliarkom 1?.235.

11 so -- ? I'otent Fortl Carolina Desm. 1.3.

d 89 Iris. Tomi sifll. alg. p. serl.

d - r. incrassatum ibid. 1) S41.

d si Cosm. f. Rincit. Now. Desin. 1). sto

d 90 - $y$ subiucrassatum Gute. Walur. d. Prioritä p. 66. in 90 - Eich7er sipis Desm. Mierlz. 1. 96 .

d 91 - r. subiucrassatum crutu. Flor. alg. Leopol. p. 34 t. 1 t. 3 . 
m 91 Dys. v. peuioides Heimerl Desin. al]. p. 5:3].

o !2 Cosm. fi penioides f. Morye Clloropl. Norsk. Finmark. p. 11.

d 92 c al. Wolle Desm. U. A. mi. Il p.130 t. 15 f. 19. t.151 f. 29 .

m!3 Cosm. v. penioiles Lütkmïl. Newm. Attersees P. 35.5 .

d $: 4-v$. Scoticum West New Brit. Alg. p. T t. 1 f. 15.

m 94-P penioides Borge siinsw. Chlor. Arohang. p. 20.

d 94 - Ilcoulio Mater. alg. Khark, 1.20.

m 94 - rrutu. Fl. alg. Tarnapol. p.si.

1195 - Fichler in Paniet. Fizy. 1:3 p. 8.8.

in 45 - burge siverig. Chlor. If $p .1 \%$.

\section{Tiguri)แm}

1;- DIDYMIDIUM (staur.) Jeinseh Al rentl. Frank. p. 161 ('liycenstrum deoticulatnm Nigg.).

al - t. A. a et $\beta$. B. ibid. p. 16i2.

\section{tinctullt -rl}

def ts COSMARIUM Rulfs Brit. Desm. p. 95 t. 32 f. 7 .

dz 52 - Pritch. Inf. 1.252.

o 5 th-B. aggregatom Brél. List. 1) 127.

o is - He Briz. Conjug. 1.73 (Sphirozosma?).

dzb1 - Lreh. in Priteh. Inf. p. 731.

d 65 - Richt. in Rab. alg. Eur. n:o 1787.

dz 64 SPHÆR0Z0SMA hill. F'lor. Eur. Alg. 3 p. 15).

rlz is Cosm. Kirchn. Alg. Sichles. p. 14s.

m 79- Wille Ferskr. alg. Nor. Semlj. p.4t.

d - Parctoiforme ibil. p. 11 t. 13 f. 10

o 79 - Klelus Desm. Ostpreuss. 13. 36 t. 3 f. 45.

mso- lille Norg. Ferskv. als. I p.36.

0 - f. ibid., t. 1 f. 22.

d) 84 - Holle Desm. U. S.. 1).131 t. 16 f., 31 .

o st - Stules Kiey Desm. p. 127.

dzf 86 - Coolie Brit. Desm. p.90 t. 3 f. 7 [e Rulf $s$ ].

d $s \bar{i}-\beta$ intermedinm Nordst. Algolog. smisak. 1 p. 162.

Iz $\times 8$ - Hansy. Prodr. Algenfl. Böhm. p. 248.

in is - Boldt Desm. Grönl. p. 11;.

111 - $\mathrm{f}$. ibid. (f. Wille 1simil).

m ss - Nordst. Fr. wat. alg. N. Zeal. p. 11.

d - f. trigona ibid.. t. 3 f. 16.

\& - pintermedium ibil.., t. 3 f. 17.

m 89 - Horley Fr. Alg. Maine II p. $18 \%$.

dz 89 - Toni syll. alg. p. 912 .

a - - v. arctoiforme ibid. 1.943.

d - f. trigonum ibid.

d - v. intermedinm ibir.

m (n)-Eichler spis Desm. Miedz. pr. 87.

m 90 - Anderss. Sverig. Chlor. 1 p. 16.

m 91 - Heimer? Desm. alpin. p. 598.

1191 URSINELLA Kuntze Rev. gen. pl. p. 925.

o cosm. fi intermedium f. Borge Chloroph. Norsk. Finmark. p. 13 .

mz 92 - West Fr. w. Aly. WT. Irel. 1. $14 t^{\circ}$

def 12 - v. excisum Ruc. Desmidya Ciastoni. p. 371 t. 7 f. 17. dz 9.2 - Wolle Iesm. U. S. ell. II p.67 t. 19 f. 31.

m $92-v$. intermedium IVest Alg. Engl. Lake Distr. 1. .2.5.

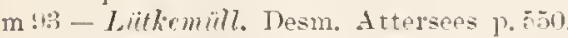

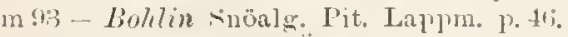

in 94 - Jierq. F. alg. Cietgrönl. p. 1s.

dzf 94 - Smuml, in Fl. Nebraska p. 11 t. 7 f. 10 [e Cooke].

\section{titholllollllt -}

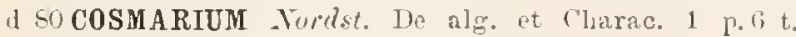
$1 \mathrm{f} .4$;

d 8.1 - Wolle Desin. U. S. p. so t. 1! f. $29-30$.
0. 86 - Stakes Key Desm. p. 129.

d 89 - Toni iyll. aler. po 1942.

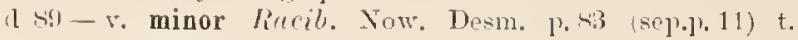
i) f. 8 .

il - v. major ilitl. t. is f. $\$$.

(l) - v. dissimile ibil, p. st t.j) f. 7 .

11 "1 URSINELLA huntze Rev. gen. pl. 1. 425.

d 42 Cosm. Wolle Desm. T. s. ed. II p.sit. 2.2 f. 2s-30.

(l) $\$ 3-f$. irregularis Tumer Als. Inıl. orient. P. th t. f. 20 .

d $91--\mathrm{f}$. internedia Fichl. et Gutw. Finc. alg. nov. p. 171 t. 5 f. : : 1 .

o (15) - f. W'est Alg. Marlag. p. if t. 9 f. 26 ,

o 45 - r. dissimile Schmille Beitr. alp. Alg. p. toti.

\section{Titta!glemensis}

izf 93 COSMARIUM Turner Alg. In]. orient. 1. 133 t. 9 f. 1!.

\section{Tolopelartigense}

cl 85 STAURASTRUM liolle in Bull. Torr. bot. Clnb las. p. $12 \%$ to i i 1 f. 1 \& 5 .

o si-Stulies liey Desm. ]. 168.

d 87 - Wolle Fr. Alg. U. ‥ A. p. 15 t. 39 f. 4 \& 5 (ex Wolle 1s85).

"l x"t - Toni syll. alg. p. 1162; "tohopecaligense".

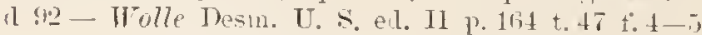

d $5 \%-v$. trifurcatum llest Alw. Mardag. p.sil t.9 f.s (inclus. Nit. nonanum)

d - v. quadrangnlare ibid., f. $y$.

\section{tol"yeletulu}

d :3 XANTHIDIUM (Mieracanthum) Tumer Alo. Ind. orient. 1\%.10 t. 22 f. 8 .

\section{Torveni}

d ts MICRASTERIAS Bril in Ralfs Brit. Desm. p. 210 t. $35 f .5$.

A 52 - Pritch. $\ln$ f. 10. 246 .

d 61 - Arche, in Pritel. Inf., p. 727.

d $68-$ Kab. Flor. Eur. Alg. 3 p. 195.

il 7 - Irood Fr. Alg. 1. 147.

1) 81 - Wolle Desm. T. A. p. 108 t. 30 f. 1-s.

o 83 - Stukes Key besm. p. 11s.

o sis-f. Norlst. in Gazell. Expedit. p.t t. 1 f. 12 et 13. [M. Nordstedtiana Hieron. 1s95. mon Wolle 1,sst].

d 8.9 - Toni syll. alg. p. 1127.

n 91 HELIERELLA Kuntze Rev. gen. pl. 1. Ro!.

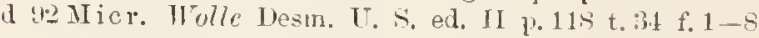

Tor)?!Ii

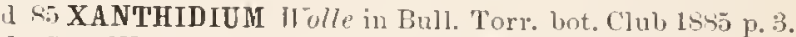
d si - Wolle Fr. Alg. U. S. A. ¥. 3.5 t. 05 f. 13 \& 14.

l syl-(Holacautliun) Toni syll, alg. po!r?!

\section{tol:still}

d (13) STAURASTRUM Tume Alg. Iml, orient. p. 115 t. 13 f. 2 .

\section{to.xoll}

d MZCLOSTERIUM West Fr, w. Alg. W. Irel, p.121 t. 1! t: 1 !

\section{TOXOTIEX}

o 35 Ehrenl\%. Inf. 1. 3) et !5. - subgen. Closterii.

\section{Truberulu}

m: 30 CLOSTERIUM Ehrenb. Beitr. z. Tenut, il. Infus. p. $5 ; 3$ et $1 ; 2$ et 70 [sine descriptione !] 
d $32-$ Ehrend. Entw, d. Inf. p.64.

d 38 - Ehronb. Iof. 7.92 t.6 f. I1. [Sec. Turner in Als. Int. or. 1873 p.3 figg. 1 et $T=$ f. genuina?; f. 1 $=$ Doc. truncatum; 2 et $5=\mathrm{D}$. clavatum hït $\%$ ? i? et $6=$ D. nodulosum Rreb.? (3 D. crenulatum?); $8=$ D. Elirenbergii Ralfs? ?.

ph $3 ! 1-$ Meyen šrst. I'f. I'lysiol. III p. 115 .

m 39 - Ehrent. Mleteorpap. 1. ar isep.1. 12, t. 1 f.9.

d to- Menegh. Symops. Desm. p. 2.i5 (sep.p. 35),

1h 41 - Tivitey Amer. Bacill. 1.302 (sep.j.21) t. 3 f. 32 ? [Pleurotanium nodulosum? - Closterinm crenulatum Lhrenb. sec. Ehrmb. 1si3].

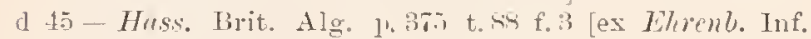
t. $1,5.8$.

d $45-$ hit: Plyeol. germ. 13. 18 sis.

d 4 - Focke Phys. Stmul. p. 5t; et tif t. 3 f. 1 i-21 120 Pl. nod $n$ ] osum].

d 49 PLEUROT ENIUM Nom. einz. Alg. 7.104 t. 6 f. A.

In 49 Clost. I'vty in Beru. Mittheil. 1st! p. 163.

54 - Elwomb. Microgeol. t.31 XII B f.21 ex "Meteorpap." delineata].

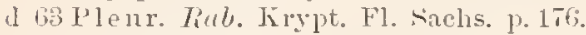

d - b. granulatum ibid. (Tocid. Eluen bergi b. gran. Iinlfs:.

d 67 DOCIDIUM f. A. Ehrenbergii Teinsch AlgenA. Frank. p. 18: Doc. Ehrenbergii Korlfs). $t$ minus et $\beta$ majus.

d - f. B. clavatum ibid. (Toc. clavatum).

d $-\mathrm{f}$. C coronatum ibict.

d 68 Plenr. Rab. Flor. Eur. Alg. 3 p. $1 \pm 1$.

- - b. granulatum ibict.

o 60 Doc. Wittr. Skandin. Desin. p. 21.

- 11 Pleur. Luml. Desm. Suec. p. $4 \%$

dz $72-\beta$ crassum Wittr. Grotl. Ö. sötr. Alg. 1.62 t.4 f. 17 .

d 73 - Wood Fr. Alg. 1. 11 s t. 12 f. 9

d 7 - Delponte Desmid. subalp. p. 124 (sep.p. 220) t. 8 f. $4 \cdot 2-19$.

no is - Nordst. Alg. Sandvic. 1. 11.

dz 5 s - Kirchn. A]g. Sichles. 1) 14.

m Tx-Hempd Algenfl. Chemnitz 1. 112.

mi - $\beta$ classum Wille Ferskr. Alg. Nor. Semlj. 1. Zu, ns 81 - Gray Mon. loe. Conj. p. Ts.

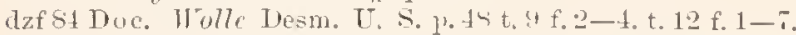
m StPlenr. f. minor Magn. et trille in Wille Sylanerik. Aigt. 1. 32 t. 1 f. 48.

m 84 - Lopot Mater. alg. Warszan. p. 253.

in 81 - Arturi Liste alg. Moscon 1) 140.

(1) $85-$ Kirchn. Mikr. I’flanz. d. Siissw. 1) 22.

msti-Franti in Lemis rinops. 3 p. 14.

o 86 Doc, stokes Fiey Desin. p. 113.

ph sij Pleur. Klebs: Organisat. Gallerte b. Algen p. $350 \mathrm{t}$. 4 f. 11.

dzst - Alexenko CHoroph. Filark. p. 2sit.

d ss-Mnusy. Prodr. AlgenA. Böhm. 1) 190 et $2 \pm 5$.

mss - Riubin. Chloroph. env. Ǩharkow p.318.

d SiDor. Tomi et leeri Fl. Alg. Venez. p. 3í.

m Sa Pleur. Tioldt Desm. Grönl. p. 41.

m -... perassum ibid.

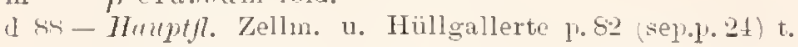
$2 \mathrm{f}, 31,34-36,3 \times, 39$.

un 6 's - Istr. Jel. magyar. alg. p. 212.

o si - Hest Massachus. Iesm. p. 17 t. 2 f. 11.

d sit-Tomi syll. aly. p. \$45.

d -r. erranulatum ibid. 1. 896.

dz $-v$ verassum ibil.

$111-\mathrm{f}$. minus ibid.

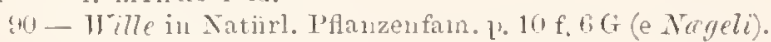

in 90 - Eichler Spis Desn. Miedz. p.86.

m 90 - Anderss. Sverig. Chlor. 1 p. 17.

in $91-1$ ste. Fragm. Alg. 1 p. 1168.

d 91 - Firchn. Mikr. Pfanz. d. Süssw. ed. 2 p. 24.

m 91 - $\beta$ erassum Heimel Desm. alp. p.595.

m 91 - Gutu. Flor. alg. Leopol. p.35.

in $92-$ limge Chloroph. Forsk. Fimmark. p. 13.

$m-\beta$ crassum ibid. p. 14.

mosm - Linc. Desmidya Ciastoni. 1. 351.

m $-\beta$ granulatum ibid. 1.370 t. 6 f.5.

dzf.93 - Trolle Desm. U. S. ed. II 1. 51 t. 11 f. $2-4$, t. 15 f. $1-7$.

m 6:3-Lïtliemilll. Desm. Attersees p. 546.

- 93 Doc. Tumer Als. Ind. orient. p.3s.

phas Plenr. Fransi in Österr. bot. Zeitschr. p.383 t. 13 f. $:-t$.

m 94 - Alexemlo Mater. alg. Khark. p.22.

m 94-Trirges. F. alg. Ötgrönl. p.11.

$m-\beta \cos u m$ ibid.

Cfr. Clost. retusum.

\section{trabeculata}

d 5t; SPIR0T不NIA A. Br. in Rab. Alg. n:o 543.

a $58-$ De $B$ (ury Conjug. p. 55 .

d $63-$ Rab. lirypt. F1. Sachs. 1) 17s. (Wect. Polytan.).

d $6 \mathrm{~s}-$ Tinb. Flor. Eur. Alg. 3 p. 14.s.

d - s- Kivelm. schles. Als. 1. 137.

ms S - Rracil. Mat. flor. glon. Polsk. 1) 100 (sep.p. 21).

d so-Toni syll. Alg. n. S10.

d 95-Lïtlemilll. Gatt. Spirotin. 1.5 et 95 t. 1 f. 20.

\section{traberntoides}

d 10 CLOSTERIUM Corda in Alm. d. Carlsb. $14 t 0$ p. 218 t. 6 f. 14 et 45 . [Plenrotænium maximum? - Doc Baculum sec. Ralfs sel rerisimile non ita].

\section{trachyrytum -a}

d 75 COSMARIUM Tieinsch Contribut. 1. 83 t. 18 f. 1.

d 89 -? Toni syll. alg. p.1039.

14.11 URSINELLA Kunt: Rev. gen. pl. p.

\section{trarhystermem}

d. 95 COSMARIUM West Alg. Mranlag. p. 64 t. 6 f. 26.

\section{trarllyatrimmm}

d 93 STAURASTRUM Tumer Alg. Ind. orient. p. $129 \mathrm{t}$. 16 f. 23.

f. minor ibil.. f. 47 .

\section{trelchly!lom!m!}

d 62 STAURASTRUM West Fr. w. Alg. Wr. Irel. $1.176 \mathrm{t}$. 23 f. $\overline{\mathrm{B}}$.

\section{torerom!notum}

d STAURASTRUM Wist Frow. Alg. W. Irel. p. 176. (St. saxonicum Jirinseh 19t5, non Tulnh.).

d $-\mathrm{r}$. annulatum ibid. et t. 24 f. 16 .

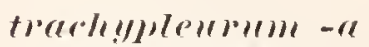

d 71 COSMARIUM Lumd. Tlesm. Suec. p. 27 t. 2 f. 12

d. 8 - a. genuinum Firireh. Alg. Solnles. p. 151 .

d - b. verrucosum ibid. p. 152. [C. Kirchneri Börg. 1.5\%. (\% snbtholiforme b. ver rucosum Riac. 1885].

mat-b. minor Racib. Desm, okol. Irrakowa sep.p. 11 t. 1 f. 5. [C. minor Rire. 18.2].

d st- Tolle Desm. U. S. 1. 73 t. 16 f. $26-29$.

d 85 - b. minor Racit. Nonn. Desm. Polon. 1.73 (sej. 1). 17). 
o S6 - Stukes Kiey Desm. p. 12r

d) 89 - Tuni syll. alg. 1.973.

d - r. milus ibid. p, 97t.

d - ? v. ver rucosum ibil.

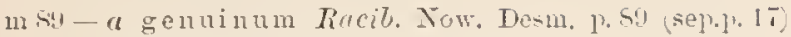

d - $\beta$ ellipticum ibid. p, 10 t. 5 f. 23.

d - $\mathrm{r}$. stellatum ibid.. t. o f. 2.1 .

$m 90-\checkmark$. minus Eichler. spis Desm. Niedz. 1\% $8 \overline{\%}$.

12 11 URSINELLA huntze Rev. ger. 11, 1).

d m Cosm. Wolle Desm. L. S. ed. II p. 79 t. 1! f. $20-2$ ?.

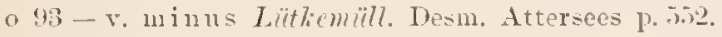

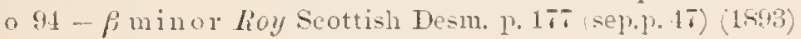
t. 1 f. 13 .

d $94-\beta$ minor f. Lorge sitssw. Chlor. Arehaug. p. 28 t. 2 f. 311.

d - $-y$ corutum ibid. 1'. 29 t. 2 f. 31.

d $94-v$ distichiforme Gutu, Fl, alg. Tarnapol. p. S8 t. 3 f. 20 .

m $91-\beta$ ellipticnm Eichler in Panict. Fizy. p. (in.

d $95-\mathrm{r}$ - spinosum Thest Alg. Madag. 7.66 t. 7 f. 17.

mas - $\beta$ minor Borge Sverig. Chlor. II 1.21)

\section{traful!nrerir+mm-re}

d 7 COSMARIUM Thittr. in Wittr. \& Nordst. Alg. exs. n:o s1.

d 86 - Cuoke Brit. Desm. p. 89 t. 43 f. T [male sec. Nurdst. in Jouln. of Bot, 1ss. 13. 35.4.

d $\$ 9-T o m i$ sroll. alg. 1) 1054.

d si-Wittr. in Wittr. et Jordst. Alg. exs, fasc. '21 1 4tc. fig. $x y \log \mathrm{u}^{2}$.

11 91 URSINELLA Kuntze Rer. gen. 11. 1. 12\%.

\section{tremsiems}

d St EUASTRUM Cosmarium) Gray Note Conj. d. In France 1).33i Eu. intermedium Griy. now Cleve). [Cosm. franconicum Gute.. non Feinsch].

1 so CoSMARIUM Toni syll. alg. p. 976.

1191 URSINELLA Funtze Rer. gen. 11. 1. 12\%.

$1791 \mathrm{Cosm}$. Gutw. Flor, alg. Leopol. 1) 51 t. 2 f. 2.

\section{trimsturiele}

d 2+ GYGES Bory in Encyclop. méth. Hist. Nat. d. Zoophyt. II. 1 . 149 . Cyclidiuu fluitans Mïl. Inf. p. 80 t. 11 f. 4-5. [Cyclidium glaucoma sec. E7rb. Inf. 1. . ว3].

\section{trajericull!}

d 90 EUASTRUM Dör. Desm. Brasil. 1. 32 t. 3 f. 1 t.

\section{tranraramm}

d sS STAURASTRUM Bollt Desm. Grönl. p.35 (sep.p. 33) t. 2- f. 46 . [Annon Staur. mnricatum?]

d 85 - Toni syll, alg. p. 1172.

d 9ij-r. campylospinum Schmidle in Hedwig. $34 \mathrm{p}, 81$ t. 1 f. 25. [Nt. pyramidatum f. sec. West 1sig].

\section{Trellerliense}

d 13 STAURASTRUM Tumer Desm. Notes 1'.315, et f. 12 1. 311 .

\section{trirermeretmm}

d 10 STAURASTRUM Gute. Talr. d. Priorität p. i2.

d 11 -Gutu. Flor. alg. Leopol. p. 50 t. 3 f. 20.

\section{t)irm! $/ m+r) \mathrm{C}$}

d 93 STAURASTRUM Tumer Alg. Inc. orient, p.116 t. 13 f. 3 is.

\section{trirm!lutrlvis}

d S6 ARTHRODESMUS Lager\%. Amerik. Desm. p. $244 \mathrm{t}$.
27 f. 22 [A. Iucus v. sec. auct, iusum in X. Totaris. IV, 1 . 913 p. 152].

d 87 - Wolle Fr. Alg. U. A. A. p. 34 t. 61 f. 11 \& 15 [e Latererle.].

o 69 - f. Lugcrh. Bengal. Desm. ]. ؛

d $59-$ Toni Srll. alo. p. 1rtil.

n 6 -f. Lagerheimii Gutu. Walır. d. Priorität r. il (I. agert. 18xis).

o 40 - f. Lui\%. Desu. Brasi]. 1. 43 t. 4 f. 41 [A. Incus v. brasiliensis Eichl. et lifec. 15087.

m $\$ 1$ f. Lagerhciuij Gutu. Flor. alg. Leopol. p. 64 t. 3 f. 7 .

n 52 - f. West Fr. w. Als. W. Irel. p. 168 t. 24 f. 19.

o - v. Americana ibid, 1) 11;!) (A. Incus r", A merica. uns Tuner 15\%3,

(1) 12 -- Ilolle Desm. U. S. ed. II 1. 105 t. 10 f. 14-15.

li 98-(Aplodesmus) Tumer Alg. Ind. orient. p. 137.

1095 - liacib. in Flora r. 81 p. 33.

\section{trirmemtretis}

1) \$1 MICRASTERIAS Wolle in Bull. "Turr. bot. Club 1851 l. 1 t. 6 f. \pm [MI. denticulata Rail. 1aj1].

d $8 \pm$ - Wolle Desm. [T. S. H. 115 t. 38 f. 1-2.

o Sij-Stolies Ficy Desm. 1. 14T.

d 89 - Toni syll, alg. 11. 111\%.

11 91 HELIFRELLA Ǩmtze Rev. gen, pl. 1, 509

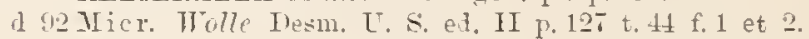

\section{triceps}

d $93 \operatorname{COS}$ MARIUM Twmer Alg. Ind. orient. p. 59 t. 8 f. 52.

\section{trirerere}

d 34 MICRASTERIAS hïtz. Syn. Diat. 13.602 (se1.j, it) t. 19 f. 55 [Staurastrum paradoxum (abnorin.) Meyen sec. Kït:. Pliyc. gelı, p.163. Staur. tetracerum sec. Iirlf: 1515

\section{TRICELAS}

d 40 Lobarzew. Diat. Ostk. Adriat. Meer. 1.272 Gen. dubium Desmidiacear.) (Phycastrum hïtz? sec. Pfeiff. Noul. bot.]. Terisimilter $=$ Partes Spongiæ.

\section{THICHOCISTIS}

d ti hüz. 'Tab. 1,hyc. I p. 20. Tantum dingnosis speciei. Palmogloea gigantea.

d 40 Tï̈t. Spec. aly. 12. 23!. Genus Palmellear. - Animal?

\section{TRICHOIICTION}

d t5 Fïtz. Phycol, germ. p. 153 [Cylindrocystis crassa sec. Areh.].

d 45 Trevis. Alghe coccot. p. 64\%

d 49 Kütz. spec. Alg. p. 230.

d 63 Rad. Kiypt. Fl. Sachs, 1, T4.

\section{trirome -is}

d 35 BINATELLA Brib. Alg. Fal, p. 57 t. 8.

d 40 STAURASTRUM Menegl. Synops. Desm. p. 225 (sep. 1.25 [ince\}s. Binatella duplicata Brét. et Desmid. hexaceros Elit. Inf.).

d 45 - Rolf's in An1. Nat. Hist. v. 15 p. 155 t. 11 f. 2 Cet $1 s t$ ti in Traus, Bot, Soc. Edin, r. 2 p. 141 t. 14. [St. alternans Bret. 1518. - Phscastrum trilobatum Kütz. 1819. - Phyc. Ralfsii X'og. 184!].

d 45 PHYCASTRUM hilt. Phycol. germ. p. 137 .

d 47DESMIDIUM Rub. Neut. Kiypt. Fl. p.57.

dzf 18 Staur. Lialfs Brit. Desm. p. 134 t. 22 f. 11, t. 34 f. 8 a. d $-\beta$ ibid.; f. 8 b, c, d.

d 49 Phye. Küt. Syec. Alg. p. 179. 
- $\beta$ pygmæum ibirl. (rit. rygm um).

n 19 - Pachyactinium) N(ry. cinz. Alo. 1, 120.

$51-R a b$. Bacill. Sachs. fasc.5 t. 3 (sine 10:0).

dz 52 Staur. P'ritch. Inf. p 215 ; $\beta$ t. 2 f. 99 [ex Ehemb. delin.].

dz61 - Areh. in Priteh. Inf. 1. $7+1$.

d 63 - Rnb. Irry"pt. Fl Sachs. p. 191.

6it-Croum Fl. Finist. t. 1 f. 35 [e Brib.]

un 7:2 - Tordst. Desm. Apetsb. p. 38 .

d $77-$ Delponte Desmił. subalp. p. 19 (sep.p. 145) t. $11 \mathrm{f}$. $48-50$.

d Ts-Kirchn. Alg. Sehles. p. 135.

d 81 - Wulle Desm. U. S. p. 126 t. 41 f. $36-38$.

m sij-Lagerh. Desm. Amerik. p. 21\%.

o s6-stalies Kiey Desm. p. 16is.

d 5 - C wole Brit. Desm. 1. 167 t. is f. 2.

daf - v. $p$ ibid. p. 165 t. 191 f. 2 [e Rilfs].

m $88-$ Noldst. Fr. wat. alg. X. Zeal. p. 41 .

n $92-\mathrm{v}$. semicirculare West Fr. w. Alg. W. Irel. p. 180 it. hexacerum $\Rightarrow$ With. 1572)

d 92 - Wolle Desm. U. S. ed. II p. 135 t. is2 f. 30 - 35.

\section{tricorllutull}

a so STAURASTRUM Wolle in Bull. Torr. bot. Club 1san p. 4 ti t. 5 f. II

d 84 - Wolle Desm. U. S. 1. 115 t. 47 f. 1-2.

o st - rtolies liey Desm. p. 169.

d 89 - Toni syll. alg. p. 1151.

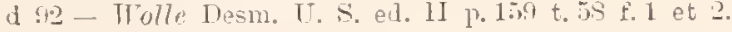

\section{tirivenertull}

n 95 Coshariug Gutw. Prodr. Al. alg. Galic. p. 351 Cosm crenatum f. tricrenta Boldt, Cosm. Boldtianum Gutw. 1892).

\section{tricrenrtum}

o 4 EUASTRUM Eichl. et Gulw. in Trakan Anzeig. 1. 210. d 94 - Eichl. et Gutw. spee, alg. nov. p. 172 t. is f. 35.

\section{tricespidetu}

d 35 BINATELIA Lirib. Alis. Fal. 1\%57 to (nomen specificum ab ipso auctore (in Chev. Micr. p.272) art "euspidata" transmutatum est?.

\section{triryrliat}

d 34 MICRASTERIAS Ehrenl. Organ. kl. Raum. p. 301 (E) 1 . 15T) $=$ Pediastrum Boryanum.

\section{fividems}

a 41 DESMIDIUM Whenb. Monatsb. d. Berlin. Ak. 184 p. 207 .

n 13 - v. hexaceros Lhrmb. Milkr. Leb. Süd. u. N. Amer. 1.372 ("D. (tridens) hexaceros" in explicatione icon. p. 14 t. IV I f. 24 ).

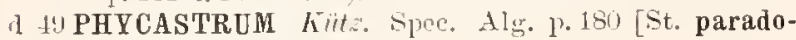
xum et controversum].

d 52 STAURASTRUM l'ritch. Inf. 1r.242.

\section{frideututume}

d s1 TRIPLOCERAS Wask. N. Z. Desm. p. 311 t. 12 f. 21 $-29$.

o S3 - v. cylindricum Mask. X. Z. Desm. Add. p. 247.

I si - $v$. superbam Mask. in Trans. N. Z. Inst. v. 1 s $\mathrm{l}$. 325 c. fig. xylogr. [Triploceras verticillatum * superbum Nordst. 1sisic

89 - c. varr. Mask. Furth. Xot. X. Z. Desm, p. T.

\section{tridentifintm}

a se STAURASTRUM Wolle in Bull. Torr. bot. Club $1 \leqslant 82$ 1.2. 2 ! t. 13 t: 13 .

1) 8.1 - Thulle Desm. U. S. p. 142 t. 45 f. 9 --10.

o st - vitukes Irey Desm. p. 168.

d 8 - Toni syoll. alg. p. 1150 .

a 92 - Wolle Desm. U. . . ell. II p. 15h t. Jf f. 9-10.

\section{tridentulum}

il st Docidiun llolle in Bull. Torr. bot. Club 1nst p. 14.

a 81 - Wolle Desm. U. S. p.52 t. 10 f. 10.

o sti-itoles Liey Desm. p.113.

(1) - - Toni syll. Alg. p. \$it.

a! PLEUR0T ENIUM West Fr. w, Alg. W. Irel. p. 120 (et v. granulatum).

$1-v$, capitatum ibid.. t. 21 f. 12.

18 Dos. Holle D.sm. U. S. ed. 11 p. 57 t. 13 f. 10.

ozf 23 PENIUM Eichl. et Ruc. Nowe gat. zielen. p.11s t. 3 f. 3.

o. 91 Doc. Roy reott. Desin. 1.242 (sep.p.50) (Doc. Sceptrum lioy 1893

m 95 Pen. Eichler in Pamiet. Fizs. 13 p. 57.

\section{triforsireterme}

1] it COSMARIUM Nordst. Desm. Ital. p. 11 t. 13 f. 17

d S9 DISPHINCTIUM? Toni syll, alg. p. 890.

\section{trifirlllm}

a in STAURaSTrum Mordst. Desm. Brasil. p. 226 (seprep. 1 sif $\mathrm{t}, 4$ f. 51.

1 st - Wolle Desn. U. S. p. 123 t. 40 f. 15 - 29.

o $=6$ - P glabrum Laycrh. Amerik. Desm. 1.247.

o si - Stolies Kiey Desm. p. 165.

18 - Itaseg. Prodr. Algenf. Böhm. 1.25t.

d 89 - T'oni syll. alg' p. 1158.

1 - v. gabrum ibil. p.1159.

(f) $90-\beta$ glabrum f. torta Bürg. Desm. Brasil. 1) 49 t. is f. $31 \%$.

1) 2 - Wolle Desm. U. S. ed. II p. 136 t. 51 f. $29-29$.

(1) 93 - f. reversa Turner Aly. Fnd orient. p. 10.5 t. 15 f. 10.

\section{Trifilium}

(1) BI EUASTRDM Cohn Desm. Bong. p. 11 t. 11 f. 13 .

(a) 89 - Toni sirll. alg. p. 10 it.

11 91 HELIERELLA Kuntze Rev. gen. pl. p. .99.

\section{'rifolium}

1 !) STAURASTRUM Fl. alg. Tarrapol. p. 71 t. 2 f.t (An Tetraëdron spee, ? sec. allet.)

\section{trifurertum}

1) 93 STAURASTRUM Tumu Alg. Ind. orient. p, 110.

il $-\beta$ reversum ibid. t. 17 f. $\%$.

\section{trigemmatum-re}

1) it Cosmarium Detponte Desmid. subalp. 1. 13 (sep.p. 10!1) t. 7 f. $59-1 j 1$.

(1)

12 91 URSINELLA huntze Rev. gen. pl. p.92\%.

\section{trigibbrellm,}

(4) EUASTRUM West Alg. Madag. p. 53 t. 6 f. 2?.

\section{'TRIGONOCINIIS}

it 45 Ilass. Brit. Alg. 1.349. Sect. Aoniocystidis.

\section{trilerdrate}

(t s3 STAURASTRUM Wolle in Bull. Torr. bot. Club 1is: P. 20 t. $27 \mathrm{f} .20$. 
d 5.1 - Wolle Desm. [T. S. p. 123 t. 40 f. 12-13.

o St; - Stolics Key Desm. p. $16 t$.

d St - Toni Syll, alg. p. 1 L9.1.

d 92 - Wolle Desm. U. S. ed. II p.13ti t. 51 i. 12 -it.

o $45-J o h n s$. Rare Thesm. U. S. II P. 294

\section{trilobutulu}

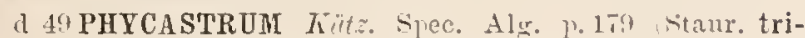
corno linlfs 1815. [Staur, altervans livel.].

\section{t)ilobretum}

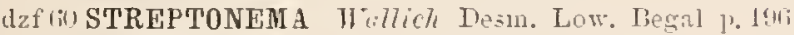
t. 8 f. $1-1 i$.

$11 \mathrm{S9}-$ Toni Syll. Alg. p. 399 in nota.

1190 - Wille Natiul. PAnuzenfam. 1.15 f.s D (e Wall.).

dzf 93 - Tumo Alg. Ind. orient. 1. 144 t. 18 f. 15 (1-li ex 11 (177.).

\section{trilobulutum -}

a 07 cosmaridm Meinsch Spee. Gen. Alg. 1\%.11s t. $22 \mathrm{~A}$ II f. 1 -6 isep. 1.10 t. 3 \%.

(1) 6. DIDYMIDIUM Cosmarium) Reinech Algent. Frank. 1. 116 t. 4 f. 6 .

- 71 Cosm. I.und. Desn. Suec. 1.42.

d so-f. minor Wille Norg. Ferskr. alm. I 1. 32 t. 1 f. 1 i

o si- $\beta$ basichondrum Nordst. Algolog. smăsak. \& p 1fi1.

o 88 - - Nurlist. Fr. wat. alg. X. Zeal. p. ot t. i f. 11.

m.

d si-Toni Syll. alg. p. [160.

d - v. basielondrum ibi.t. p. afil.

d - f. ? minus ibid.

(1) 90 - f. elongatum Gute. Fl. glon. Galic. 2 1. $10 \mathrm{t} .1 \mathrm{f} .4$. A $90-r$. minus Hunsy. X゙ene Süss. mud. Meer. Alg. 1) 12. m go-Aurless. Sverig. Chlor. 1 p. 1li.

1191 URSINELLA huntze Rer. gen. 11. p.925.

1291 Cosm. f. retusa Gutw. Fler. alg. Leopol. 1. 12. t. 1 f. 1 f.

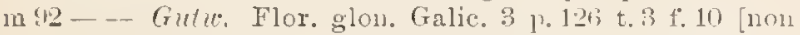
hue pertinet see. Borge in X. Notar. 5 n. $1: 11$.

d 92-Hansy. Prodr. Algenfl. Bühn. ed. bohem. p.17t; ed. germ. Il 13. 254 .

$m-\beta$ minus jlid.: ibid.

m:12 - West Alg. Engl. Lake Dintr. 1, T2!.

m 94 - Lorge siissw. Chlor. A reliang. 1. 21 .

d $91-\mathrm{v}$. excavatum Eichl. et Gutu. in Krakau Anzeig. p. 238. et siec. alg. not. p. 165 t. 1 f. S. [Cosm. venustum v. excatatun Wist 1sib].

12 (4) - Eichler in Pamiet. Fizy. 13 1. js.

Cfr. Eu. ansatom Ehrl. 1 sas et Eu. Pokornyanum.

\section{trilobum}

d 10 EUASTRUM IBor $\%$. Desm. Brasil. 1. 34 t. .8 f. 20.

\section{trilobum!}

d 37 STAURASTRUM Menegh. Cons]. alg. Eugan. p. 1s sep.) [St. muticum Brib. see. Muncgh. Syrops. Desill. 1.2.24. - St. orbiculare?].

\section{trilolum)}

d ToXANiHIDIUB Nordst. Wesm. Brasil. 1.230 (sep.]. 152, t. 3 t..35.

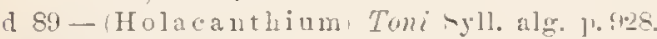

\section{trimodiferem}

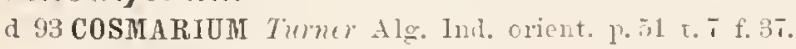

\section{trinodulum- -}

a so COSMARIUBI Norlst. De Alg. et Charae. 1 p. 5 t. 1 f. 4 . a 80 - Toni Syl]. alg. 1). 1021.

n 11 URSINELLA fimtic Rev. gen. 1\%, p. מ2:

\section{trimotrtem}

d a COSMARIOM Fichler et crutu, spee. alg. now p, 166 t. \pm f. 11 .

\section{triomerimetum}

d 95 COSMARIUM Wcest Alg. Malag. 1.66 t. 7 f. 27.

\section{tripuluillutulu}

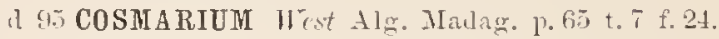

o - r. alastrenso ibia. 1]. 60 เ. 7 f. 25.

\section{trijes}

1) 7o STAURASTRUM Nordst. Desm. Brasil. 1.226 (sep.1). 1 s't t. $t$ f. 11

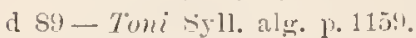

\section{triplicellllt. -}

d Si COSMARIUM Holle in Bull. Torr. bot. Club v. 10 1. 16i t. 27 f. 8 [Cosm. gemmatum Immer 155].

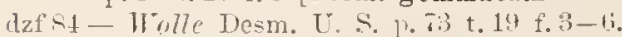

o sib-stakes hey Tesn1. 13. 12s.

$08 T-\beta$ pancius Nordst. Algolog. småsak. 4 p. 1 ljt.

1 58 _... - Tordst. Fr. wat. Alg. X. Zeal. 1\%. 6 t. 5 f. 15.

d s. - Toni syll. alg. p. tho.

d - - vaneius ihid.

n! 10 - Eichler sis Desm. Miedz. 1.

n 41 URSINELLA huntäe Rev. gen. pl. p. 425.

dizf 12 Cosm. Wolle Desm. U. S. ed. II 1, Th t. 22 f. $3-6$.

\section{TITPLOCERAS}

d $5 \mathrm{~L}$ Li7. Mier. ouserv. 1. 37.

d 52 Iritch. Inf. p. 29.1 .

d G1 Arch. in Pritel. Inf. 1\%. 720 et 74t.

173 Hood Fr. Alg. 1\% 121.

() TT Fordat. Alg. Brasil. r.18. Subgen. Pleurotænii.

o S1 Musli. X. Zeal. Lesn, 1. 311 .

- slistulics Iier Desm. p. 104.

o Si hordst. Fresh. wat. Alg. X. Zeal. 1. 65.

d 8! Toni syll. Alg. 1) S6!.

o Set Racil. Xow. Desm. p. 104 (sep.p. 35).

(t) (10) Wille in Notür. PHanzenfam. 1.9. sect. Docidii.

d 93 Rrriluy Contrits. Queensl. Fl. p.42.

(13 Tumer Alg. Ind. orient. p. 27. Subgen.: Mgrmechidium et Bacteridium. [Cir. Wildem. in Notaris. 1593 p. 167 et Obs. crit. Desm., 1s64. p.64].

\section{tripuenctretum-les}

d 17\$6 VIBRI0 37ith. Animal. infusor. p. 52 t. 7 f. 2.

n 17 CrOSTERIUM Nitzsch Peitr. z. Infus. p. 60.

o $31-$ - in Kït. syn. Diat. 1.595 (sep.p. 6i) [Navicula (? Bac. Palea) see. Ltucul. Organ. kl. Raum. 1). 210) (sep?.1. 16.$]$.

tristichume

d 81 STdURASTRUM Elfin. Finsk. Desm. 1.8 t. 1 f.4.

\section{trisulcatum}

d 13 STAURASTRUM Tumer Al Ind. orient. P.111 t.17 f. 7 . t. 16 f. 17 f. minor

\section{Thoororestorlme}

o 93 Tumer Alg. Ind. orient. 1. 182. Subgenus Staurastri.

\section{Torrtiscin}

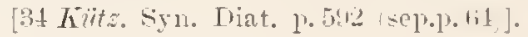


n 37 . Menegh. Consp. Alg. Eugan. 1. 16 [tantum quoad T. moniliformem?.

1) 39 Bril, in Cliev. Ticr. p.273.

o 4 Bréb. in Dict. univ. list. nat. v. 12 p.-. Sec. Brib. hoc genus ad Protococcoideas pertiuet.

\section{t)opire}

"ToMiCRasterias Tomst. Desm. Brasil. p. 219 (sep.p. 1S1 t. 22 f. 15. (M. expansa \& Trallicle.

o 80 - f. Nordst. De Alg. et Charac. p. 10.

d $-\beta$ senegalensis ibid.

d $s 9-$ Tomi syll. alg. r. 1111.

1) - $\mathrm{r}$. senegalensis ibil.

n 91 HELIERELLA funtze Rev. gen. 11. p. sts?.

1193 \icr. a Wallichii Eicht. et Rac. Nowe gat. zielen. p. 124 (y Till.).

d $-\beta$ polonicum ibid.; t. 3 f. 3 .

o - $y$ indivisum ibid. (M. enastroides $\beta$ indivisa Nordst. .

- 93-(Atomocystis) Tumer Alo. Ind. orient. p. 30 t.5 f. $1 \beta$ minor.

d $94-\beta$ polonica f. Borge Silssw. Chlor. Archang. l. 36 t. 3 f. 41.

d 95 - v. gujanense Racil. in Flora v. 81 p. $3+$ t. $3-4$ f. 15.

\section{t)Opir.tm}

0 91 STAURASTRUM Lager\%. in X. Totaris. ser. 2 p. 411 s alpinum $\beta$ trol'. Lagerh. 1\&S!?

\section{trumratre-tlm}

m ph 34 COSMARIUM Cortu in Alm. d. Cartsb. $1835 \mathrm{p}$. $14(1,201 ;$ t. 2 f. 23,24 . Nulla descriptio. - Euastrum Rota juvenile sec. Fhrent. in Wiegm. Areh. $183 \mathrm{~s}$ P. 181].

(1) 4 MICRASTERIAS Brib. in Pralfs Brit. Desm. p. To t.

8. f. t. 10 f. 5. (Euastrum 11:0 3 Iinitey Amer. Bacill. 1.2ut (sep.p. 13) t. 3 f. 24. Eu. Rota Ehrl. ex 1?.: Eur. semiradiatum Bréb; Hicr. rotata Ralf's $1+14$ ex 1 . .

d $52-7$ ritch. Iuf. p. 245 .

d $59-$ v. quadrata Bulwh. in Hedwig. I. 21 t. 2 f. 2.

o 51 - - quadrata Bulmh. in Hedwig. p. 52 t.9 f. 5.

d $b 1$ - Arch, in I'ritch. Inf. 1. 727.

d 63 - liab. Krypt. Fl. Sachs. p. 183 [et p. 157 f. b.? e Tinlfs $1 \times 44$.

plo $63-\mathrm{cmm}$. in Hedwig. p. 61 t. 12 f. 4.

64- semiradiata Clere Bidr. t. Sverg. Desn. p.45. (Eu. s. Nieg.

o 615 - Reinsch in Rab. Alg. n:o 1902 f. 1.

d 6TDIDYMIDIUM Micr. f. a. crenatum Reinscle dlgenfl. Frank. 1. 143. Nicr. crenata).

d f. b. dentatum ibil. p. 114.

o 67 Micr. Not. Desm. Ital. p. 32 t. 2 f. 9

1 65 - Jinl. Flor. Eur. Alg. 3 ]1. 191 ; f. 62 b p. 109 [o Ralfs].

d - f. b. (Eu. sicutum Fiocke)

d - f. c. Micr. crenata Tirb.).

d $69-\beta$ Bahusiensis Wittr. Skandin. Desm. 1.9 t. 1 f.2.

- 70 - Tordst. Desm. Brasil. 1. 221, $a$ et $\beta$.

I - $y$ Lagroensis ibid. p.22L, fig. xyl. p. 22.2 [M. tr. subsp. denticulat a Iste. 1887].

d $-\delta$ ibill. [P excavata Nordst. 1850].

o 71 - f. Lumd. Desm. Suec. 1. 16.

(1 73-Thelponte Desm. subalp. 1. S! (sep.p. 7T) t. 5 f. (5-10. [MI. semiladiata sec. Wildem. $1.45 \%$ p.27].

o 73 - Nordst. Norg. Desm. p. 7, form.

1 73 - Irood Fr. Alg. 1. 144 t. 21 f. 15.

o 75 - Reinsch Contribut. p. 14 t. 19 f. 9 ; monstr. [subslece radiosa Iste. 1ss.]. ph 75一 Jacols. Desm. Danem. p. 152 t. 8 f. $2-8$.

77-Tieinsch in Pringsh. Jahrb. v. 11 t. 17 f. 13.

o 79 -- Nordst. Alo. Samdvic. T. 15.

d 6 s - Kirchn. Alg. Scliles. 13. 16\%.

d sol- $\beta$ excavata Nordst, in Wittr. et Nordst. Alg. exs. n:o 374 M. truncata $\delta$ Nordst. in Desin. Bras.. 1 1:7(1).

m 82 - Wolle in Bull. Torr. bot. Club. \& p. 27.

ph S3 - Fischer Gspskrystall. Desm. p. 160 t. 10 f. 6 .

d 81 - Wolle Desm. U. S. p. 114 t. 39 f. $6(-9)$.

- r. semiradiata ibil. f. $\bar{\tau}$.

o - v. concatenata ibir. f. $s$.

n - v. minor ibid. f. 9. [M. semiradiata Witem. 1587.

d 85 - Kirelur. Mikr. Pflanz. d. Siissm. p. 23.

ph sij-kitels Beweg. n. Sehleimbild. d. Desm. p. 366.

m. 41 - Lugerh. Anerik. Desm. p, 230.

m $-\beta$ minor ibid.

d sc- Franli in Lennis Synops. p. 195.

o St - Stolies Key lesm. p. 14.

d sf - Cuole Brit. Desm. p. 60 t. 25 f. $2[2 d=$ II. denticulata. $\mathrm{a}-\mathrm{c}=$ II. semiradiata sec. Wildem. 1887 p. 273].

phsi - h7ebs Organisat. Gallerte b. Algen p. $3 s 1$.

d $8 \overline{-}$ - subsp. radiosa Iste. Diagn. prev. in Notar. p. 231 sep.p. 5) Eu. semiradiatum! Teg.) ( $\beta$ quadragies-cuspidata sec, IIansy.].

d - subsp. denticnlata Iste. ibid. r. 235 (selp.1. 6) (M. trunc. T. lagoensis Torrst. 1sio, M. Itzigsohnii Tiuc. 18st;

d 8 - - v. Murtel in Ann. Inst. bot, di Roma r. 3 p.9 f. xyl, 5 .

o $8 \mathrm{r}-\mathrm{v}$. Martel in Totarisin p. 310 bis.

1 8 - Alerenlio Clulorosj. Kliark. p. 249.

d 87 - Witdem. Observ. (1u. Desm. p. 272 (sep.p. 2) t. 1 f. $1-26$ forme).

1 S.5-- IJ insy. Proulr. Algenfl. Bühm. p. 20 s et 253 .

$1-\beta$ quadragies-cuspidata ibic. C. qu.-cus. Corlu 1810; Eu. semiradiatum).

d 8 - Toni et Levi FI. Alg. Venez. P. 55.

d ss-Junptr. Zellm. u. Hiillgallerte p. 91 (sep.p. 33) t. 2 f. . . . 1.1 -99, t. 3 f. $1-3,10$.

ph $88-$ dilerhold in Jenaisch. Zeitschn. 22 p. 338.

in 88 - Jste. Jel. magyar. alg. 17. 220.

d - + xadiosa ibid.

d - denticulata ibid. (chr. supra 1ssi et Wolle 1nst f. (1. S, $)$.

m 89) - f. punctata Recil. Desm. Lithuan. 1) 4633.

ms. - Hare. Fr. Alg. Maine II p. 18i.

d s. - Tomi Syll, alg. y. 111.

l -v. quadragies-cuspidata ibid.

d - v. excavata ibid.

d - v. bahusiensis ibid. p.1116.

i - v. enastroides ibil. [a Nordst. 15ito!?.

d $-\mathrm{f}$. incisa ibid. [ $\beta$ Norlst. 1870!].

ll - f. lagoensis ibid.

1 - $t$. Nordstedtiana ibid. [= ipsa r. excavata supra!].

1) 59 - f. granulata Racib. Кow. Desm. p. 10 t. 7 f. 1 .

o 90 - v. tridentata Tem. Fr. Alg. Hampsl. 1'. ' t. 1 f. 10.

o 90 - West Fr. w. Alg. Aorth Wales p. 287.

m 4 - Dürg. Desm. Brasil. p. 32.

$m$ - $\mathrm{f}$. Nordstedtiana Rörg. Desm. Brasil. P. 32.

m 90 -. Eichter spis Desm. Mierlz. 13.89.

in - v. granulata ibid.

m!o-Anderss. Sverig. Chlor. 1 p. \%.

d $91-$ Kirchn. Mikr. Pflanz. d. Süssw, ed. 2 p. 25.

1) 91 - f. Heimer Desm. alpin, p. 002 t. 5 f. 16 .

o ! HELIERELLA Kuntze Rev. gen. pl. p. s97. 


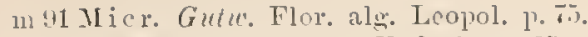

w. 6 - Weyt Fr. W. Alg. W. lrel. p.135.

- f. junctata ibil.

192 - Holle Desm. U. S. el. Il p. 120; t. 44 t. 13 - 19

- v. semirarliata ibid. f. T.

- v. concatenata ibid. f. $\$$.

- v. minar ihill. f.".

(3) - b. Scutum Richter in Pliykotheca univ. Xil 11:0 5.t1 Eu. Seutum Focke 1sti t.2 1. (1)-11).

m 93-Liithemüll. Desm. Attersces 1. alio.

m 93 - 1Iolocystis) Tumer Alg. Ind. orient. l. s.

a 93 - Tumer Desm. Notes p. 34 ti et f. 11 p.344 C. qua. dragies-cuspidata Corla!

m 95 - f. lata Eichlo in Pamiet. Fizy. 13 p. fil t. 1 f. 15. m95-Schröler $\$ 1 \mathrm{~g}$. H. Riesengeb. p. 21.

Cfr. Mici. decemdentata et Kitchelii.

\section{trimerenter}

1) 6. SPIR0T开NIA Arch. New Cosu. ete. (sep.p.15); in Dubl. Nat. Hist. Soc. Pr. p.83 t. 2 f. 25 -31; in Jour. Mier. Se. 1. 253 t. 12 .

aztit-Aich. Conjug. Spirotien. p.191 t.s f. 12 (sep.l. fi).

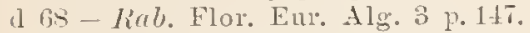

z 72 - Arch. in Q. J. Micr. Se. 12 ].SJ

n 79 - Wille Ferskv, alg. Nor. Semlj. p. .9.

dzf St-Cooke Brit. Desm. p. 51 t. 19 f. 4 .

d s:t-Toni syll. Alg. p. Sus.

m 10 - Anderss. Strerig. C'hlor. 1 p. 1 s.

o 93 - f. rotundata Turne $)^{\circ}$ Alg. Mul. orient. p. 23 t. 1 f. 11.

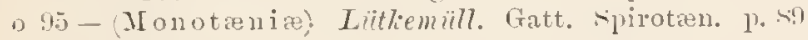
et $!$ ! 3 .

\section{trumatellum - a}

(1) 19 EUASTRUM (Cosmarium) Puty in Bern. Mith. $1-1.917 .173$.

1) 52 - Ituty kleinst. Lebensf. p. 2ug t. 16 f. 13.

4] 6. COSMARIUM $h u b$. Flor. Eur. Alg. 3 p. 165.

¿ 73 - Arch. in Q. J. М. Se. r. 13 p. 99.

o 73 - Vordst. Norg. Desm. p.17; forma.

z 82 - Vosture in Journ. of Bot. จ. 20 p. 301.

( 85 - liuc. Jonn. Desm. Polon. p. to sep.p. 21).

dzf sh-Cuoke Brit. Desm. p. 91 t. 3 i f. st

dz 89 - Tuni siyll. alg. p. 1017.

n :1 URSINELIA Kuntze Rev. gen, p]. 1?. 1203.

\section{t)"ur(t)lum}

(1) 93 DOCIDIUM Tumer $\mathrm{Ag}$. In 1 orient. 1. 32 t. 1 f. 19.

\section{trmuratulum}

is STAURASTRUM Reinsch Contribut. p. 91 t. 9 f. 3 Sec. auctorem = St. Ronardii Reinsch, lapsu calami vel typograplico: "Benadii"].

\section{t) $\|1\| \cdot n t u m)$}

(1) CLOSTERIUM Toner Alg. Inl. orient. 1).2.2 t. 2.2 f. 14.

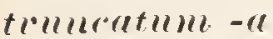

(1) CoSMARIUM Fordst. Desm. Brasil. p. 210 (sep.p. 172) t. 3 f. 23.

d 8 - Toni sill. alg. p. $95 \%$.

n 91 URSINELIA Kuntze Rev. gen. pl, p. \%ol\%.

\section{t)'llur(t)}

n 3!) CLOSTERIUM Live. in Cher. Nier. 13.27.

140 - Breb. in Mtnegh. Synops. Desm. p. 235 (sep.p. 35).

1 45- Kïtz. Phyeol. germ. 1) 133. [Docid. clavatum Kütz. in Ralfs Brit. Desm.].
1) 4s DOCIDIUM Brib. in lialfs Brit. Desm. 1. 15; t. 20 t. 2 .

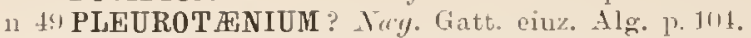

1 49 PENIUM Docidium) hütz. spec. Algo p.16s [nec Jivèb. in lialfs Br. Desm.?

d 52 Doc. Mritch. Int. 1).274.

5. - lab. Bacill. Sachsens fasc. 6 n1:0 j1 c.t. 6 f.j1 c.

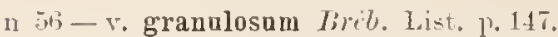

1, ha - Hofmeist. Fortptlanz. 1.30 t. 1 f. $23-25$.

$n$ is Plenx. The Bur. Conjug. p. T..

d 61 Doc. Areh. in Priteli, Int. p. $74 \%$

m 67 - Reinsch Algenfl. Frank. 1. 183.

l Gs Pleur. Rnd. Flor. Eur. Alg. 3 p. 142.

d - b. Forma. ibid. p. 113.

m 0 - Reinhurel in Naturf.-g. Charkow 1 p. 15.

m 7 Doc. Nordst. Desm. Hirasil. p. 204.

m 72 Pleur. Nordst. Desm. Spetsh. 1.20.

TtDoe. Criblons in 1'ras. R. Soc. Victoria $\mathrm{X}$ in fig. photogr. 2. [An Pl. ovatum?].

(1) 75 - Microgr. Diet. 11.257 t. 10 f. 38 [e Rulfs].

d TTPleur. Delponte Desm. subalp. p.127 (sep.p. 2.23) t. 1 i) f. $\bar{\tau}-11$.

m 7 - Eupleurotauium) Torelst. Alg. brasil. p. 1s.

m 79 - f. angustata Irille Ferskv. alg. Nor. Semlj. 1. 5T.

(1) So- $\beta$ constrictum Wille Norg. Ferskv. alg. I p. 52 t. $2 \mathrm{f}, 35$.

n 52 - f. gracilior Richter in Wittr. et Nordst, Alg. exs. Il o titi.

d St Doc. Wolle Desm. U. S. p. ts t.9 f. $6-7$.

$\mathrm{m}$ s. Pleur. f. gracilior lioldt sibir. Chloroph. p. 121.

$m \quad-\beta$ crassum ibil.; t. $13 \mathrm{f} .14$.

o $86 \mathrm{D}$ oc. Stalies Key Desm. 11. 113.

o 81 - Cooke Brit. Desm. p. 1 é t. 5 f. 4.

ph sif Plenr. Syminab. Catal. Desm. Genor. p. 18.

phsi - Klebs Organisat. Gallerte h. Algen p. 381 t. 4 f. 10 .

o $\leftarrow$ Doc. " emarginatum Tumer Not. alg. Gormire p. 290.

d so Pleur. Mtonsy. Prodr. Algent. Bohm. p. 190.

m SS - Rinbin. Chloroph. env. İharkow p. 31 S.

m ss - Istr. Jel. magyar. alg. p. 212.

m SS - Nordst. Fr. wat. alg. X. Zeal. p. 1;ir.

1] 89 - Toni syli. alg. p. $\$ \%$.

d $-\mathrm{r}$. constrictum iluil. p.sis.

m - v. crassum ibid.

m - f. gracilins ibiel.

m 90 - Eichler spis Desm. Mielz. p. si t. s f. 14.

m 91 - Iste. Fragm. Alg. 1 p. $116 \mathrm{~s}$.

m 92 - Trest Fr. w. Alg. W. Irel. p. 119

m 92 - Kimmer Alg. St. Pölten l l.t.

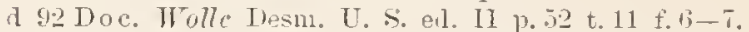

m 93 Pleur. Lütliemüll. Desm. Attersees p. 54 tr.

m 63 Doc. (Ortlidium) Tumer Alg. Ind. orient. p. 36 et 39.

d 94 Plen1. v. grannlatum Hest Xew Brit. Alg. p. 3 ,

1) 94-f. Boryf Siissw. Cllor. Areliang. p. 19 t. 1 f. 13.

m.9-f. graeilins Gutw. Fl. alg. Tarnapol. p. 83. Cfr. Clost. retusum, Trabecula, Doc. Flotowii, Pleur. Brefeldii.

\section{tivur(utmu)}

a si EUASTRUM Josh. Burm. Desm. 1.639 t. $2: 3$ f. 5 \& 7 . Helierella Joshnana Kuntre 1s91].

.1 89 - Toni Syll. alg. p.111.

\section{ti"llite(t)il)}

dzt LA PENIUM Brib. in Rulfs Brit. Desm. p. 1522 t. 25 f. 2. dz 52 - Jritch. Inf. p.ำ 3 .

dz\$1 - Arch. in Priteh. Inf. p. T.j.

dzis-Kab. Irypt. Flor. Sachs. p. 1199.

a 6 T - Tot. Desm. Ital. 1. 139 t. \& f. TS.

dzGS-Rab. Fl. Eur. Alg. 1.121. 
d 7 - Detponte Desmid. snbalp. 1.85 (sep.p 1S1) t. $15 \mathrm{f}$. 3i-3!.

dz 78 - Kirchn. Alg. Schles. 1. 136.

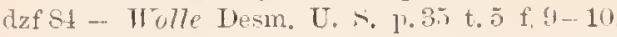

zf $-v$. ibil. f. $21-22$.

o s6-Stukes Iier Desm. 1) 111.

dıf S6 - Cuolie Brit. Desm. 1. 41 t. 1 f f. 1 [e Riulfs?].

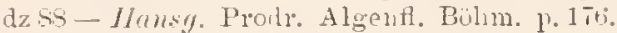

dz $\$ 9-$ Toni syll. Alg. p. 862 .

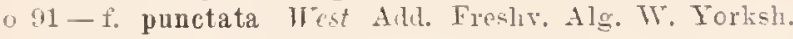
1. 245 .

m 12-Went Fr. w. Als. Wr. Irel. 1.12 -

dzf 52 - Wolle Desm. T. S. ell. II 1).3ri t. $5.9-10$.

zf $-\mathrm{r}$. ibid. f. $21-2 \mathrm{~g}$.

m 93 - Lütliemtill. Desm. Attersees p. 515 .

\section{trintratum.}

a 13 STAURASTRUM Tumor Alg. Ind. orient. p. 116 t. 13 f. 20 .

\section{t)"ucatum}

d 2 XANTHIDIUM Hast. in Amer. montlıl, micr. J. 13 p. $15 \pm$ t. 1 f. 2 (X. antilopetum $r$. truncatum Hast. in "a lacal newspaper" Oct. 20 , "hir sec. auct. ipsum. X. Tylerianum Hest 1hat Cfr Eorge in Nuor, Notar. 6 p.2n et liest in Journ. of Botany $33 \mathrm{l} \cdot 6 \mathrm{~s}]$.

\section{trumeatus $-i t m)$}

d 39 ARTHR0DESMUS Ehrmb. Inf. l, 152. Quid est?

d 10 STAURASTRUM? Homegh. Syuop). Desm. p. 220 (sel. P. 2:1\%.

1 45 PHYCASTRUM? Kütz. Plig"col. germ. p. 189.

d $45 \mathrm{Arthr}$. Rialfs Brit. Desm. p. 213.

d 49 - Kintz. Spec. Alg. 1.17\%.

d $52-$ ? Jritch. Iuf 13.261.

d 68 - Ral. Flor. Eur. Alg. 3 1.2.2s.

d 59 -? Toni Sylt. alg. 1). 1015.

\section{trumcontlm}

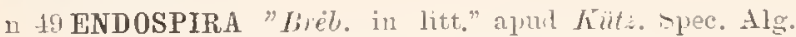
T. 2.29 sub Palmogloea endospira [Cfr. Areher Descript. (Gep),p.5\% in Dubl. Nat. Hist. S. 1'.16].

\section{tuberentritum-}

a 62 COSMARIUM Arch. New Cosm. etc. (sepep. 10) in Dubl. Nat. Soe. Pr. 1) is t.2 f.11-15: Jour. Vicr. Sic. p. $2 \pm 5$ t. 12 f. $11-15$.

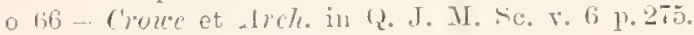

d so-Rrub. Flor. Eur. Alg. 3 p. 1T.

d s. CALOCYLINDRUS (owle Brit. Desm, p. 123 t. 43 f. 13 [ex $1 \mathrm{rch} \mathrm{r}^{\circ}$.

it so DISPHINCTIUM Tom syll. alg. 1) s.r.

\section{tubereulutum}

d Sij STAURASTRUM $I ; m$. Fr.1 1. 12 t. 2 f. 21.

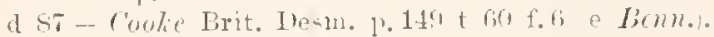

d so-Toni Syll. alg. l'. 116 t.

\section{tubifirellu}

" 3 XANTHIDIUM Elmenl, in Ah. Berlin. Akad. 1835 1. 134 t. 1 f. 16.

rt 41 - Ehrend. in Berlin. Beric lit 1 stu p. 21\%.

d 14 - White in Transat. Micr. Noc. v. 1 1 8.2 t. 8 f. 9 (simplex, 10 complex p. 83 ), 11 (recurvatum 1.

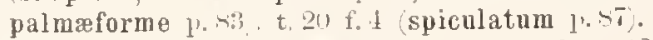

an 41j- Withinson in Trans. Micr. Sue. v. 2 p. 90 t. 13 f. "like X. tul, recur vatum" d 52 - ? Pritch. Inf. 1.25t,

54 - Elremb. Nicrogeol. t. 3 T VII f. 11, t. 20 f. 48.

d si-Toni Svrll, alg. p. 930. Fossile, annon Spongia?

\section{tumems}

d 72 COSMARIUM Nordst. Desm. Spetsb. p. 3 t t. 7 f. 23.

d s. DYSPHINCTIUM Hansq. Prodr. Algenf. Bühm. p. 27 inclus. C. ornatum fornata $N u d^{2} t$. $156 \%$.

d. $-\beta$ minus ibil

1) 89 - Toni šll. alg. 13. S42.

d - $\beta$ minus ibilt.

m.10-v. minus IIansg. Physiol, alg. Mittheil. 1, 121.

\section{timesirems}

d 98 COSHARIUM Tumer Alg. Ind. orient. p.49 t. 7 f. 32.

\section{tumilu- $11 \mathrm{~s}-\| m$}

a S1 CYLINDR0CYSTIS Gay Mon. loc. Conj. 1.52 t. 1 f. l. et Note Conj. d. m. France 1).33t.

n Sร̃ PENIUM Trolle in Eull. Torm. bot. Clnb 12 p. 1.

d si- $11 \% l l e$ Fr. Alg. U. S. A. p. 28 t. 50 f. T-S

d $89 \mathrm{Cy}$ 1. Tomi syl]. Alg. 1. 816 .

11 GYGES Kuntze Rev. gen. pl. p. 896.

d 12 Pen. Tolle Desm. U. S. ed. II p. 38 t. 45 f. $7-8$.

o $95 \mathrm{Cy}$. Thest Alg. Madag. p. 4 .

\section{tumidulum-e}

a si CLOSTeriUM Gay Mon. loc. Conj. 1). 72 t. 2 f. 13; et Not. Conj. d. m. France 17.33\%.

d 89 - Toni syll. Alg. p. 539 .

n. 11 ARTHRODIA Kuntze Rev. gen. 13. 1. Sot.

o 13 Clost. Tumer Alg. Ind. orient. 1'. 1: t. 1 f. 20.

\section{fumillllum}

d SASTAURASTRUM Gay Mon. loc. Conj. p.65 t. 2 f.6; et Note Conj. d. n. France. p. 33\%.

1) 89 - Toni syll. alg. 1.1196.

\section{tumidlum}

m 15 CLOSTERIUM Julms. Rare Desm. U. S. II 1\%.2.1 t.

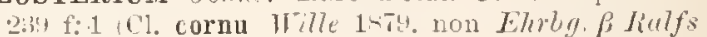
listis fit a et $l$.

\section{tumillum-"l}

d 71 Cosmarium Lund. Desm. Suec. p. 45 t. 3 f. 16 [non bona.

a 5 - a genninum firchn. Alg. Schles. 1. 11 .

d - b. subtile ibid.

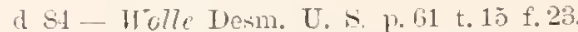

o - v. ibia., t. 1 . f. 20 [alia species !].

m 81 - Arturi List. alg. Moscou p. $1 \pm 1$.

o 86 - Stokes liey Thesm p.127.

niss-Jiollt Desm. Grünl. p. 1 ò.

d 89 - Toni sirll, alu. 1\%. 450.

d - r.subtile ibid.

In (11) - Went Fr. w. Alg. North Wales p. 2-s.

mon-Eichler spis Denm. Miedz. p.si.

o

o 91 - f. subtilis Meimerl Desm. alpin. p. วิ4.

a - f. ventricosa ihid. et t.5 f. S. [Quid?].

n URSINELLA Kuntie Rev. gen pl. 1. 1 .

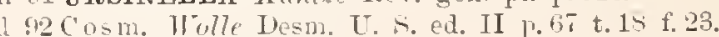

- r. ilid., t. 21 f 20 .

d. 93-f. minor Eichl. et Iiac. Fowe Gat. zielen. p.119t. 3 f. 27 [ 1 i. C. granatum 5 . Delpontei].

m 65 - E Eichler in Pamiet. Fizy. 13 1\%60. 
95 - Burge Srerix. Chlor. II p. 20. Cf1. Cosm. pseudonitidnlum $\mathrm{r}$. majus Reinsch 1.5ij.

\section{tilmidlum.}

(1) 9.5 COSMOCLADIUM Johns. Rave D.sm. U. ‥ 11 p. 2913 t. 2 -41) f.:2:

\section{tullillull-"}

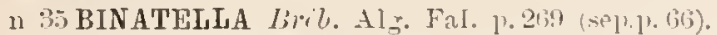

it ts STAURASTRUH Brib. apul lialfs Brit. Desm. P. 121; t. 21 f. 6 .

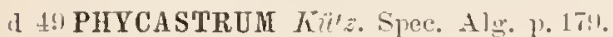

d 52stanu. Mritch. Inf. 1).263.

d bI - Areh. in Priteh. Inf. p. $\mathbf{t}+1$.

1) 65 - Ral,. Flor. Eur. Alg. 3 1).201.

$169-$ Hech. in Q. J. M. Se. n. s. 9 p. 195.

or. T1 - Plenrentelinm) Lund. Desm. Suce. p. T2 t.l f. 10 .

ph 72 - Areh. in Q. J. Micr. Sc. v. 12 p.200.

mst - lincil. Desm. olol. Irrakowa p. sep.p. 17).

1 81 - Wolle Desin. U. S. p. 120 t. 39 f. 1-2.

o St - Stokics Kiey Desm. p. 16-1.

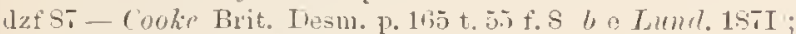
t. 5 f. 1 [e $\ln 7 f s]$.

mis - Iste. Jel. magyar. alg. p. 2031;.

1 89 - Tomi srll. alg. p. 1211.

u (x) PLEURENTERIUM Wille in Natürl.PHanzenfam. p. 11. m !l ștan r. Eichler. Spis Desm. Mipilz. 1. s!) t. 9 f. 39. d 92 - Wulle Desm. U. S. el. II p. 133 t. in) I. 1-2.

\section{tull!)}

a s.s STAURASTRU Hi Roldt sibir, Cliloroph. p. 114 t. 5 f.?2. d s.3-Tuni syll. alg. p. 114 ;

m!lt - f. Gutw. Flor, alg. Leopol. p. 613 t. 3 f. 12.

m 91 - Porge sitssw. Chtor. Arehang. 1.37. 'fri. Staul. granulosum Futw. 189:2.

\section{thimeriverwa}

d 1; STAURASTRUM Not. Desm. Ital. p. 51 t. \& f. 43. [ itaur. punctulatum b. turgescens Rub. 1ses].

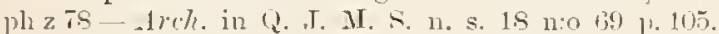

d $79-\beta$ arcticum Wille Ferskv. alg. Tov. Semlj. p.j1 t. $1: 3$ f. 5 .

d 87 - C'volie Brit. Desm p. 189 t. (66j f. 4 [e De Not. non exacte].

$m \leqslant 7$ - Murtel in Ann. Inst. bot. di Roma 3 p.11.

$1 \mathrm{S9}$ - Toni s.yll. al@. p. 1189.

d - vareticum ibil. p. 1140.

m 93 - Sckmirle Beitr. Alg. Śchwarzwald. p. 109 t. 5 f. 2 . d $9.5-v$. sudeticum Schröder Alg. H. Riesengel). p. 22.

o 95 - f. Schmidle Beitr. alp. Alg. p.62 (sep.p. 33 ) et, 1595, t. 16 f. 13.

\section{turyidulum}

d ti CLOSTERIUM Kint. Plyyeol. germ. 1. 132. [Clost, costatum b. Rub. 186ST.

d ts-Jiulfs Brit. Desm. p. 221.

1 19 - Kiitz. spec. Alg. p. 166.

1 i) - Iritch. Inf. p. 244 .

\section{tur)irlum- -}

d 3S CLOSTERIUM (Toxotium) Ehenb. Inf. 1\%.95 t. $13 \mathrm{f}$. VII Cl. ruficeps ex p.)

d 40 - Menegh. Syinop. Desm. 1.231 (Eep). 3. 31).

1 +1 - Hritch. Int. to? f. 60 [ex Lihtemb.]

n 43 - Ehrenb. Mikr. Leb. Siid. 11. X. Amer. t. IV I f. 27

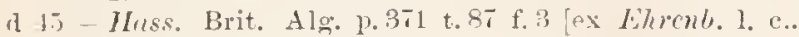
nt videtur delineatal. a $45-$ Kint: Phye. merno P. I31.

1) 48 - linlis Brit. 1esm. 1) 11,5 t. 27 f. 3.

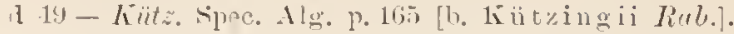

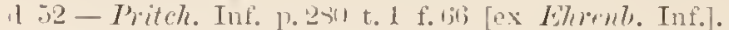

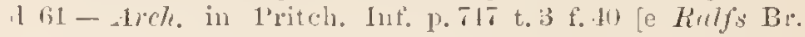
Desm.?.

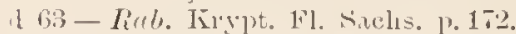

11 61)-Fyrich Algenfl. MTanuh. 1. 133.

o fit-Reinseh Alrent. Frank. p. 19t.

1) 6 S - Rab. Flor. Eur. Alg. 3 1. L2!!.

l. - b. Kützingii ibicl. (Cl. turgidum Kätz. Spee. Alg. 1. 11;.).

d 70-Nordst. Desm. Brasil. 1? 203; forma.

l $75-$ Microgr. Dict. p. 176.

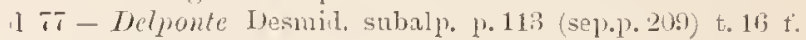
$21-30$.

d is - Kivelm. Alg. Schles. p. $18 \mathrm{~s}$.

a $79-$ a. typicum $K$ ilebs Desm. Ostpreuss. 17. 20 t. 2 f.s et 96 .

1 - b. didymotocnm ibil., a et $\beta$ t. 2 f. 9 \& (Cl. didy motocum (orl.).

d 80 - f. brasiliensis Nordst. in Wittr. et Nordst. Alg. exs. 11:0 381 ; et (18s!) in fasc. 21 p. 47 .

1 - * gigantenm Tordst. in Wittr. et Torlst. Alg. ex-

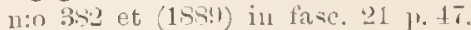

d 81 - Wolle Desm. L. A. p. 4 t. f; t. 15.

ms - Bullt sihir. Chloropli. p. 12.2.

o Sij- Stakes liey Desm. P. 11:.

mis - $\beta$ curtum lioy et Biss. Jap. Desm. p. 2ti) (sep.p. S .

d si-Cooke Brit. 1)esm. 1.21 t. If f.3 [e Rulfs et Klebs?].

si - f. Wolle Fr. Alg. U. \&. A. p. 2 t t. 55 f. $3-4$.

asi-Alexenko Chlorosp. Khark. p. 223.

a 88 - Honsq. Irodr. Algent. Bühn. p. 180.

a 88 - Tomi et Levi Fl. Alg. Venez. p.31.

a 59-Tuni Syll. Alg. p. $\$ 27$.

1 - v. brasiliense ibill. p. \$2s.

1 - v. giganteum ibil.

d - v. curtum ibid.

$m 90$ - f. brasiliensis Börg. Desm. Brasil. p. 29.

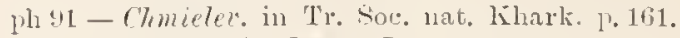

n al ARTHRODIA kuntze Rev. gen. pl. p. $89 t$.

m!1 Clost. Gutw. Fl. alg. Leopol. 1, 33.

1 92 - Wolle Lesm. U. S. al. 11 p. 43 t. 7 f. 15, t. 1 f. 3 et 4 .

m92 - West Alg. Engl, Lake Distr. 1. T.20.

a - v. decoratum ibid. et t.9 f.?.

o 93 - f. brasiliensis Nordst. in Wittr. et Nordst. Alg. exs. n:0 $1139-1141$.

94-subsp. giganteum Lïtliemïll. in Österr. bot. Zeitschr. 41 \%. 13.

m94 - Gutw. Fl. alg. Tarnapol. p. 79

Cfr. Cl. Iunula Buil. 18t1, Vibrio Ionula 1 Ü̈ll. $17 \mathrm{sin}$ ex p.

\section{turgidum - -lls}

(1 ts COSMARIUM Brit), in liulfs Brit. Desm. p. 110 t. 32 f. 8. [Cosm. Debaryi c. Kiteles 1,irio].

(1) 32 - Pritch. Inf. 1'. 256.

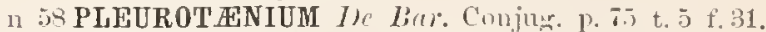

1158 DYSPHNCTIUM Grun. Desmil. 1).493. 501).

1) 5!l Plenr. Buluh. in Herlw. 1. 22 t. 2 f.?

d lil rosm. Arel. in Pritch. Inf, p. 735.

11 63 Pleur. Líab. Iírypt. Fl. Sachs. P.17\%.

m 67 Tis. Reinsch Algentl. Frank. 1. 174. a minus, b majos.

I fis Pleur. Liub. Flor. Eur. Alg. : p. 141, f. xyl. p. 104 le lle Bury].

noCIDIUM With. Skandin. Desm. p. 20).

n T1Cosm. (Plenlotæuiopsis) Lumrl. Desm. Suee, p. 51. 
त 77 Dis. Itrlyonte Desmid. subalp. 1. 133 (sep.p. 229 21 f. 1t;

1 Ti CALOCYLINDRUS Firchn. Alg. Sichles. p. 142.

d 85 - Kivchn. Mikr. Pflanz. d. Siissw. p. ․ㅡ t. 3 f. 67 .

d S5 Cosm. b. tinecence Riac. Nonn. Desin. Polon. p. 69 t. 10 f. 2 (sel).p. 13 t. 1; ; et a. genuinum.

d si Cal. Cooke Erit. Desm. 1, 12- t. $14 \mathrm{f}, 1$ [rerisiniliter e lialfs.

d si - d7exemlin Chlomsp. Kiharti. 1. 235.

o हi Cosm. p ovatum Nordst. Algolog. småsak. 4 r. 163.

n Ss CosMaRIDIUM IIrensy. Prodr. Algent. Buhm. p. 245 in nota.

o sucal. v. majus Riabin. Chloroph. env. Kharkow p. 319 (sep.p. 31).

d Ss Pleur. IIurpty. Zellm. u. Hüllgallerte Desm. p.S3 isep.1. 25 t. 2 f. 42 et 4.

o ss Cosm. Nordst. Fr, wat. alg. N. Zeal. p.63.

d - $\beta$ oratum ibid., t. 7 t. 30 .

d S9 PLEUROTENIOPSIS Toni syll. alg. p.607.

d - $-\mathrm{r}$. ovata ibil.

n 90 -- Wi7le Taturl. Pflanzenfan. 1'12 f. T B (e de Bary).

m go Cosm. Eichter sipis Desm. Mielz. p. sh.

1191 - Ist . Fragn. Alg. 1 p. 116.

m 91 - Gutu. Fl. alg. Leopol. 1.35.

m 91 Cal. Kirchn. Milir. Ptlanz. d. Nïssw. ed. 2 1. 23 t. 3 f. 76 .

m91 Dys. Hein.crl Desm. alp. 1. 594.

d 92 Plenroteniops is Müb. Austral. Süsswasseralg. p. 442.

d 92 - Timitey Contr. Queensl. Fl. p. 41 t. 15 f. 39 (e Coolie).

d 2 Cosm. r. subrotnndatum I'est Alg. Engl. Lake Distr. 1. 720. [Cfr Schmidle 1s45].

pha Pleurotimiopsis Lïtzemïll. Chlorophyllkörp. ein. Desul. p. 43 t. 3 f. 26.

m 93 - - Desm. Attersees p. 54.

ph 13 - . - in Terh. zool. bot. G. in Wien 1593 sitz. b. p. 3s. phat-Mob. Anstral. Süsswasselalg. II p.339 [Qnanue in Tiailey 1895 P. 39].

d 95-v. ornata Schmidle in Hedwig. 84 1. F.2 t. 1 f. 16.

\section{teryidum}

n 54 EUASTRUM Elertub. Microgeol. 1.324.

\section{ter)!gidum-a}

d no EUASTRUM Wrallich Desm. Low. Bengnl p. 253 t. 14 f. 17 \& 18

d $65-v$ ? Grun. Ins. Bank. 1. 1t t. 2 f. 22. [ $\beta$ Granovii Turner 1s:3].

d $89-T o n i$ syll. alg. p. $10 \%$.

n :1 HELIERELLA hunt:e Rev. gen. pl. p. sir.

in $93 \mathrm{E}$ u. a typicum Tumer Alg. In l. orient. p. It t. 10 f. 16.

d - $\beta$ Grunovii ibic. 1. 50 t. 10 f. 29 r. Gmun. 1n6ō.

d $\quad$ - f. bitumida ibid.

d $45-f, G$ Gunowii f. Schmid7e Alg. sumatr. 1. 305 t. 4 f. $12-14$.

Cir. En. verrucosum v. turgidnm Tiac. 1892.

\section{Tumeri}

$\mathrm{dz}$ (M) COSMARIUM lioy in Journ. of Bot. v. 2x p. 333 (Cosm. margaritiferum lialfs Brit. Desm. quoad t. i3i f. ii $b$, non $a$.

\section{Turmeri}

a y2 EUASTRUM West Fr. W. Alg. W. Irel. p.141 t.20 f.1. ("Eu, sp. ad E, denticulatmu acced." Tordst. 1sis. Fr. wat. alg. X. Zeal. p.35 t.3 f. 11 est forma hujus speciei). [Eu, binale Mnst. Mo1, Eu. denticulatum Mask. 1sis! uon Goul.

ns - Eichler in Paniet. Fizy. 13 p.61.

\section{Turneri}

n 91 EUASTRUM Wildem. Obs. crit. Desm. p.91 (E. Nordstedtiaum Tolle ex 1\%., inclus. Eu. clavatum Timn. Eu. radiatnm $T u m$.) - non Hest $15 \%$.

n - - . oruatum ibid.

\section{Turueri}

11 5TAURASTRUM West in Journ. of Bot. 33 p. 64. [Staur. Boergesenii Twrn. non like.].

\section{Turmeriamum}

(1) 89 CosMaridM Mask. Furth. Not. N. Z. Desm. p. 18 t. 3 f. 28 . [Cosm. cyclicnm f.?].

\section{Terpinie}

d of COSMARIUM Brél. List. 1. 127 t. 1 f. 11 [Heterocarpella Didelta Turpin sec. auctorem, sed verisimile non ita?.

d $61-$ drch. in P'riteh. Inf. p. 733.

d 68 - Rub. Flor. Eur. Alg. 3 p. 172.

d 71 -Lund. Desm. Suec. p. 24 t. 3 f.9; forma $[\beta$ L nndellii Gutw. 18st = f. typica Breb:i sec. Wordst. 1.sis; efr. lagert. 1s:01]; et f. gallica.

d 75 -Delponte Desmid. subalp. 1.23 (sep.p. 119) t. \& f. $40-43$.

a $84-$ b. Lundellii Gutwinski Fl. Wodor. Galic. p. 133 (sep.p. T) (Lund. 1851).

m $\mathrm{St}$ - a. Brebissonii liucib. Desm. okol. Kirakowa p. (sep.]. 11).

in - b. I mudellii ibid.

d St-Wulle Desm. U. ¿. p. 158 t. 17 f. $24-25$.

d 55 - r. cambricum Josh. in Journ. of Bot. v. 23 p. 35 t. 254 f. 8 [alia spec.]

in 8.j - Boldt sibir. Ghloroph. 1. 165.

s5-Tiacil. Nonn. Desm. Polon. p. 74 (sep.p. 18) cum his formis et val" :

a. Brebissonii.

b. L undelli

1. genuina.

a f. minor.

f. major.

2. elongata ibil. t. 11 (sep.t. 2 , f.9.

3. gostyniense ibil. f. 12 .

o s6-Stokes Key Desm. P. 130

d 5 - Cooke Brit. Desm. p. 106.

d - v.cambricum ibiu. p. 10 t t. 41 f. 4 [male e Josh. 1.85

m S. - f. gallica Jioldt Desm. Grönl. p. 24.

o ss - Nordst. Bornh. Desm. 1. 193.

m S5-Isti. Jel. magrar alg. p. 22t.

a 89 - Toni Syll. alg. p. 1013.

d - ? r. cambricum ibid.

- r. gostruiense ibil.

- f. elongatum ibid. p. 1020 .

d. 84 - т. subcrenatum Rocil. Tow. Desm. p. 94 (sep.p. 22) t. $;$ f. 26 .

o $40-\beta-$ Jugerh. Contrib. alg. Eeuad. p. 86 (sep.p.s) let de vare. p. kit)

o 90 -. 1. Lnudeliii Gutu. Mahr. d. Priorität p. 61.

d - c. Podolicun ibid.

d - d. gypsorun ibid.

d - e. elegans ibid.

un 90 - Eichle\% spis Desm. Miedz. p.si.

m 91 - r. Lu du lli West Freshw. Alg. W. Yorksh. p. 246. m 91 - Jorge Bidr. Sibil. Chloroph. p. 13.

n. URSINELLA Kuntze Rev. gen. pl. p. 926.

o 11 Cosm. b. Ln nyelli Gute. Flor. alg. Leopol. p. 62 t. 3 f. 1. 
d - v podolieum ihid.. t. 3 f. 2.

d - r. oypsorum ibjd., p.63 t.:3 f.:3.

d - r. elegans ibid. t. 3 f. 4 [alia species videtur].

m : 12 - v. Lundellii West Aid. Freslnw. Als. W. York. 1. 246.

- - Fr. w. Alg. Wr. lrel. 1. 155.

(1) (12 - Wolle Desm. U. S. ed. II p. st t. 20 f. $24-25$

m!2-v. gyporum Gutu. Flor. glon. Galie. 3 p. 131.

m9: - schmidle Beitr. Alg. Selnwarzwald. p. 111.

o $43-T$ - Tuner Alg. Ind. orient. p.47.

o 9:3-a. typicum Gutu. Glon. staw. Zluruczu 1. 29.

m 13 - $\beta$ suberenatum Lagerh. in Wittr. et Nordst. Alg. exs. 11:0 112?

m 94-f. Borge Süssw. Chlor. Arehang. 1. 20.

o 94 - Bärg. F. alg. Östgrönl. p. 13 t. 1 f. 7 (f. gallica).

o :4- - a. typicum Gute. Fl, alg. Tarnapol. 1. 57 t. 3 f. 32.

m - b. Lundellii ibil.

d - c. Turneri ibid. p. 98 t. 3 f. 33 [Quic] ?].

m 95 - v.podolicum Juhns. Rare Desm. II p. 294 t.240 f. 18.

mis-b. Lundellii Eichler in Pamiet. Fizy. p. 60.

Cfr. Cosm. Botrytis ex 1\%. Lidanum, ornatum $r$. polonicum Rac.?

\section{Tyleriallum}

d s! XANTHIDIUM Thest Massaclus. Desm. 1) 19 (sep.p". 1) t. 2 f. 1 -1. t. 3 f. 14. [Xanth. truncatum Jlest.

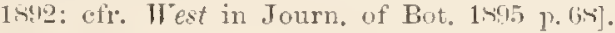

\section{Ervelinireum}

d. 91 COSMARIUM Alevenlio Alg. Poltava p. 7 t. 3 f. 1.

\section{CTII!}

d 47 CLOSTERIUM Focke Phy.s. Stul. J. 59 t. 3 f. 30 . [C1. striolatum $\gamma$ Ulna Jacols. 15i5.

o 9 - f. Turner Alg. Ind. orient. r. 20 (Cl. directum, intermedium et subjuncidum

\section{mbilicatum}

d 93 COSMARIUM Lïtlemïll. Desm. Attersees 1.5.50 t. 8 f. 2.

\section{mulumatum}

d 13 COSMARIUM Tumer Alg. Ind, orient. p. T() t. $10 \mathrm{f}$. 10 ("Forsan $\beta$ umbonatum C. Meneghinii ?")

\section{unciultulu- -}

d 45 CLOSTERIUM hïtz. Phre. germ. 1.131.

d $4.5-$ Ralfs Brit. Desm. p. 220 .

d 19 - hitz. Spee. Alg. p. 165.

d 52 - I'ritch. Inf. p. 284

d. 61 -Arch. in Pritch. Inf. p. 749.

d 6s-Jiab. Flor. Eur. Als. 3 p. 139.

(1 s.) -. Tomi syll. Alg. P. S54.

11 :1 ARTHRodIA Kuntze Rer. gen. pl. p.881.

\section{unrimrtum}

d hi) ONYCHONEMA Wallich Desm. Low. Bengal. p. 151 t. 8 f. $\bar{\imath}-11$.

d $59-$ Tomi syll. Alg. p. 795 .

n 90 - Wille in Xatür]. Pfanzenfam. 1.15 f.! B e Wolle

d $93-1$ Prionema) Tumer Alg. Ind. orient. p. 138 t.17 f. 11

$m$ - f. tenuis ilid.; t. 17 f. 16 .

\section{uncincutum}

d !3 STAURASTRUM Turner Alg. Ind. orient. p.127 t. 16 f. 3 .

\section{milulute}

it THYALOTHECA Norlst. in Wittr. D Nord-t. Alg.exs.

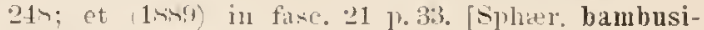
noides Heim. 1s:11]

d. 81 - Wo7le Desm. U. ‥ 1.28 t. 53 t.s.

o 86 - stolies liey Desm. 1) 111.

d sit - Toni syll. Alg. p. Tsis.

in 90 - West Fr. W. Alg. North Wales 1.243.

m 90-Eichler spis Desm. Mied\%. p. 44 t. 8 f. 1.

in 92 - West Fr. W. Alg. W. lrel. p.117.

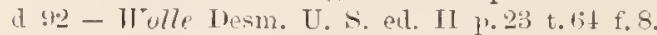

d 93 - v. producta Tumer Ale. Ind. orient. p. 152 t. 18 f. 15

In 93 - Jioy Scottish Desm. p. l'il t. 1 f. 1 (sep.p. 9).

o 44 - Johms. Rave Desm. U. ‥ p, 2 st.

\section{"mallutum}

(1) 81 APTOGONUM Mask. N. Z. Desm. p. 302 t. 11 f. $1-4$.

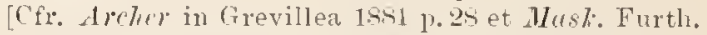
Not. Y. Z. Desm. 1.5. - Desn. Baileyi $\beta$ undula tim Nurdat. 1siriy].

\section{umallutum-}

phe COS HARIUM corle in Alm. d. Carlsb. 153! p. 243 t. 5 f. 2 ti [fig. non bona!?.

dzf 48 - Rulfs Brit. Desm. 1. "1 t. 15 f. 8. [Verisimiliter non omnes figurw ad nuam speciem pertineant].

dzf 52 - I'ritch Inf. 11. 253 t. 13 f. 38 et 34 [e Ralfs].

ph z 5 T- Ilofmeist. Fortpflanz. 1).21.

n 5S - Microcosmarium) Le Rorv. Conjug. 1. 72.

dzf 61 - Areh. in Pritch. Inf. 1. 732 t.2 f.33-34 [e lialfs].

d 63 - Rab. Kirytit. Fl. Sachs. p. 195.

d 66 -- Eyrich Algenf. Manul. p. 126.

67 DIDYMIDIUM Cosmarimu) Reinsel Algenfl. Frauk. p.117 inclus. Cosm. crenatum $R_{i .}$ et En. crena. tum Focke. ot ( . subcrenatum Juntzsch).

dz $65 \mathrm{Cosm}$. Jíul. Flor. Eur. Alg. 3 p. 165.

o 69- $\beta$ crenulatum Ifittr. Skandin. Desn. p.11. (Eu. crenulatum Nug. f. T e et d. non a et b).

d - $y$ minutum ibid. p. 11 t. 1 f. 3 C. crentum sec. Jacols; var. sec. liac. 1ssi

mo $-\beta$ creulatum Nordst. Desm. Brasil. p. 210.

- 71 - Lumd. Desm. Snec. 13.35.

- F2 - $\beta$ crenulatum Wittr. Gotl. Öl. sötr. Alg. p. is. o- - " minutum ibil.

mi2 - $\beta$ crenulatum Norlst. Desun. Spetst. p. 32.

o 73 - Nordst. Norg. Tesin. 1) 11:

d 73 - Wool Fr. Alg. p. 13:.

d $76-\mathrm{v}$. tumida Tacols. Desm. Danem. p. 197 t. 8 f. 18.

dz $78-$ Kirchn. Alg. Fichles. p. 11 !.

in 78 - Hempel Algenfl. Chemnitz p. 114.

m 80 - Wille Norg. Ferski, alg. I p. 27.

o 83 - ? p Mast: N. Zeal. Desm. Add. p. 212 t. 2.1 f.9 [C. impressulum Elfr.? sec. Mask. Furth. Not. 1ssy].

in $8 \pm$ EUASTRUM (Cosinarium) Gay Mon. loc. Conj. 1 . b0) f. minor.

d $-\beta$ monspeliense Gry ibid., t. 1 f. 18 [C. alpinum $\therefore$ mons]. Srlimidle 189t].

daf $54 \operatorname{Cosm}$. Wolle Desm. T. S. p. 15it. 16 f. 20 et 21 .

1 - v. crenulatum ibid.. t. 14 f. 10 et 19 [r. Wollei West $1 \times 92$

(1) 81 - r. ornatum Sichuarschm. A fohan. Alg. 1. 246 t. $5 \mathrm{f} .2 \mathrm{~s}$

o si-Stokes liey Iresm. 1. 127.

daf 57 - Coole Brit. Desm. p. yT t. 37 fo 16 [e Ralfs 1518]. m 85- Martel in Ann. Inst, bot. di Roma v. 3. 1 p. fi.

d si-Alexenko Chlorosp. Filark. p. 262.

dzss - Hansy. Prodr. Algenfl. Bülım. p. 196 
o 88 - Riabine Chloroph. env. Kharkow p. 324.

m Ss -- Poldt Desm. Grönl. p. 1\%.

o 88 - Nordst Bornli. Desm. p. 195 [inclus r. subundulatum Tille].

mss - Istr. Jel. magrar. alg. 1.2021.

us 85 - r. cremulatum West Massachus. Desm. p. 18.

dz 89 - Toni sill. alg. p.972.

d - v. minutun ibid. p. 973.

d - vomonspeliense ibil.

d - vornatum ibid.

n 90 - rmicter. in 'Tr. Soc. Nat. Khark. 23 1.99.

n 91 - v. crenulatum Heimerl Desm. alpin. 1. 599.

11 91 URSINELLA Kuntze Rev. gen. pl. 1\%.92.

un 11 Cosm. f. mioima Gutu. Flor, alg. Leopol. p. 40.

d ! t. 1 f.s.

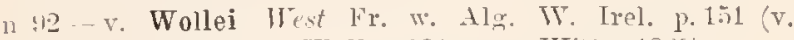
crenulatum Wolle 1sst. non Witts. 19isis.

1af 92 - Wolle Desm. U. - . ed. II 1. 72 t. 19 f. 24 et 21.

i) - v. crenulatum ibil. p. 73 t. 19 f. 10 et 19.

n 93 - Buhlin snöalg. Pit. Lapjm. p. 1t.

m 91 - 1lexuko Mater. a.g. Khark. 1.25.

d 94 - v. obtusatum Schmidle Alg. Geb. Oberrheins 1. 500 t. og f. 11.

dz 94 - Sumel. in Fl. Nebraska p.41 t. 7 f. $2-a, b, c$ Coolif'.

o 91 - v. subundalata Bürg. F. alg. Ostgrönl. p. 1 t t, 1 f. C Cosn. subund ulatum).

9 95 - $\mathrm{f}$. subundulata Selmille Alg. Sumatr. p. 303 t. 4 f.!

m 95 - v. stbundulata korge sverig. Chlom. II p. 17.

\section{mormlateme}

(t 10 DESMIDIUM Corlu in Aln. d. Carlsb. 1st1) P. 201 (sep.p. 19, t. 4 f. 27 [Quil ?].

d 19 - Ralfs Brit. Desm. p.207.

d 52 - Pritch. Inf. P. 241 .

d 61 - Areh. in Pritch. Inf. 13. T. 3.

4) $65-R a b$. Flor. Eur. Alg. 3 p. 155.

d ss-Hunsg. Protr. Algenfl. Bohm. p. 17 in nota.

d s! - Toni syll. Alg. 1. 795 .

\section{mormlatmur.}

d j1 D0CIDIUM Mail. Micr. abserv, 1, 31 t. 1 f. 2.

(1) 52 - Tritch. Inf. p. 2 -

d 61 - Arch. in Pritch. Inf. p. Tt.

d 69-Rab. Flor. Eur. Alg. 3 p. 145

PLeURotaniUM ibil. p. $111 \mathrm{f}$. xyl. [e Buil.].

- 71 Doe. Land. Desm. suec. p. 89.

(1) 33 Pleur. llood Fr. Alg. p. L20.

1) StDoc. Wolle Desm. U. S. 1. il t. 11 f. 5.

o Sf - Stokits Key Desin. 1) 11\%.

d 89 - Tuni syll. Alg. P. sit.

d 92 - Wolle Desm. U. S. el. II p. 55 t. 14 f. 万.

- 93 - Cedematilium) Thrner Alg. Ind. orient. p. 35 t. 1 t: 11 .

"fi. Pleur. nobile Riclit., Dor. dilatatum Lund. et Itrulle. non trere ser. I'um. Alg. Ind. or., 1593, p. $: 3$.

\section{$m m \pi n l u t m \| n$}

1) t.. f. 2.; Cosmarium sp. luabitu ad C. undulatum minutum [rittr: accelens].

\section{$m m \pi n 7 n+m m$}

d \% STAURASTRUM West $A$ lg. Marag. p. 78 t. 9 t.37

\section{mllnlosmm}

1 S9 EUASTRUM Hask. Furth. Not. N. Z. Desm. p. 13 t. 2 f. 1: [E. denticulatum $\beta$ elongatoin Nordst. f.?].

\section{Uı!)}

1) GTAURASTRUM Reinseh spec. Gen. alm. p. 132 t. 24 B I f.1-i (sep.p. 2t t.5) Forme $a$ trigonum et $p$ tetragomum.

(1) 57 DIDYMIDIUM (Stanr.) Reinseh Algenfl. Frank. P. 17 t. 11 f. 3. Forme nt supra.

d sikitaur. Toni Syll. alg. p. 115 .

\section{Ungeriammm -r}

1) 19 EUASTRUM (Cosmarium) Vey. einz. Alg. 1) 120 t. - A f: 10. Didymidiam Botrytis f. Reinsch - Cosin. Oligogongrus

n 5s CosmariuM (Eucosmarium) De Bur. Conjug. p. 72.

d $6 \mathrm{~L}-\mathrm{Areh}$. in Pritch. Inf. 1. T32.

d 6s-Rub. Flor. Eur. Alg. 3 p. 160 .

o 69 - With. skandin. Desm. W. 14.

m 89 - Nordst. Bornh. Desm. p. Lis.

d 59 - Tomi syll. alg. p.955.

n! URSINELLA hiuntze Rev, gen. pl. p. 5 21;

d 9.2 Cosm. Bum. Fr. Alg. S. TT. smrey p. 10 t. 2 f. 12 et 13 [malie].

\section{"uguiformm}

d 93 STAURASTRUM Twmer Alg. Int. orient. 1\%.130 t. 15 f. 18 [Cfr. Wildem. Obs. crit. Desm. 17.12!].

d - f. wajor ibid., t. 15 f. $1 !$.

\section{micomrn}

a 93 STAURASTRUM Tmmer Alg. Ind. orient. p.107 t. $15 \mathrm{f} .16$ [Cfr. Willem. in Notarisia 1893 p. 170 ; st. variabilo v. unicorne Witdem. 189t].

\section{midrututu-nme}

$1380 \mathrm{DONTELLA}$ ? IHrenb. Inf. p. $15 t$ [Sphrerozosma vertebr.

n 45 SCHIST0CHILIUM Ralfs in temn. Fl. Tumbr. Wells 1. $192(1.96)$ (in "erratis" ab ipso auctore ad "Sphrrozosina" emendatum).

d tiSPH正R0Z0SMA Rulfs in Ann. Nat. Hist. v. 16 p. 1.1 t. 3 f. 7 (et 1846 in Trams. Bot. Soc. Edinb. v. $21 \% 168$ t. 18).

1520dontella Pritch. Inf. p. 293.

\section{Upsatiensis}

o $\$ 1$ MICRASTERIAS Arch. in Grevillea v. 10 p. 29 (II. decemdentata $\beta$ Upsaliensis Cleve 1871).

\section{uniforme -is}

a sit EUASTRUM Wolle in Bull. Torm, bot. Club 1sst p. 15 ("mpentorme")

d st - Wolle bean. U. s. p. 100 t. .i2 f. $11-12$.

n s, HoL0CysTIS Bemn. Fr.-wat, Alw. Engl, Lake Distr. 1 p. S.

o $813 \mathrm{Eu}$. ritulies liey Desm. 1. 1 th.

d $89-T$ - Tul syll. alg. p. $106 \%$.

11 !1 HELIERELLA Kuntze Rev. gen. pl. p. s99 ("urıformis").

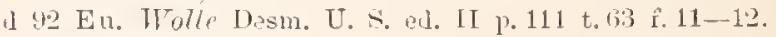

\section{"1иigel"uाl-a}

(1) 60 COSMARIUM Noidst. Desin. Brasil. p. $20 \mathrm{~s}$ (sep.p. 17u) t. 3 f?. 21.

11 s. - Tuni Srll. alg. 1.97T.

n! U1 URSINELLA himtie Rev. gen. pl. p. 9201\% 
UISSINELLA

a 28 Turpin Aperg. organ. p.316. Descriptione mala imprubabili nomen genericum est rejiciendum].

"91 Kuntze Rer". gen. pl. Il 11.920 Cosmarinu anet.) et $\left.11 \mathrm{I}^{2} 1 \mathrm{~s} 93\right) \mathrm{p}$. CCCXLAT [Cfr. Nordst. in Hedrigia 1893 p. 1527

\section{Crsinella}

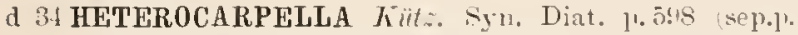
(1) [Ursinella margaritifera $l u r \%, 1-2, \cdot]$.

41 EUASTRUM Lujurl. Hist. Natur. d. Zooph. t. 2 f. 10.

\section{"ariabil"}

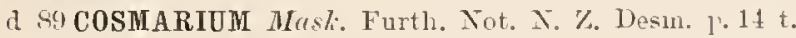
ㄴ. $f .15$.

\section{reniabile}

o 9t STAURASTRUM I"illd. Obs. r.rit. Desm. 1.12n.

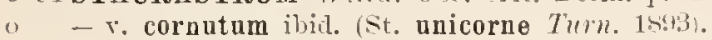

- - r. scolopacinam ibid. (\$. scolopaeinum Tum. $1 \mathrm{~s}(13)$.

o - r. ecorne ibid. s. eeorne Turn. 1, $13 \%$

\section{voriabilis}

d 10 ACTINOCYCLUS Corda in Alus, de Carlsb. 1810 p. 195 t. - f. 9-14 [Hyalotheea mucosa Ellr. see. Ehrenb. in Berl. Monatsber. 1440 p.212. sed dnbito]

\section{ravius}

d (iT DIDYMIDIUM Euastrum Rrumel Algenf. Frank. 1'. 131. 'Form. A., preeiqne $A \gamma=$ Eu. Didelta .

d - f. A. ibid. p. 132; $\alpha, \beta 1$ et 2. $\% 1$ et 2 .

d $->$ ibid. (Eu. humerosum).

d $-\varepsilon$ ibid. (Eu. sinuosum)

d - s ibid. p.139 (Eu. ampullaceum. - Inter et sest Eu. affine).

d -. f. B. ibil. (Eu. Jenneri

\section{iarians:}

d sistadrastrum lácil. Nonn. Desm. I'olon. j. St t. 12 f. 1 (sep.p. 30 t. 3 ) a. cosmarioides, b. trigonum. e. tetragonum et f. mixtr.

d $s$ s - Toni rirll. alg. p. 11 sis.

d - r. cosmarioides ibid. 10.11s!.

d :4 - r. badense Sclmidle Alg. Geb. Oberrheins p. 551 t. $2 \times$ f. 16 .

o $11 \mathrm{~F}$ - - f. Sehmidle Beitr. alp. Alg. p. 62 (sep.p. 38) ct, 1895. t. 16 f. 1 s.

o - f. (trigona) ibid.; t. 16 f. 1 (t) (incl. St. pygmæum v. tetragonum Foldt et v. subglabrum Fiollt).

\section{variolatum, -a}

d 7 cosmarium Lmd. Desm. Suec. \%.41 t. 2 f. 1!. [C. pseudopyramidatum $\beta$ Hans $\%$. 1888

d 84 - Wolle Wesm. U. S. p.63 t. 16 f. 3-4.

o 81;-Stolies key Desin. 1.127.

a Si-Cook - Brit. Desm. p. 84 t. 31 f. 10 [male e Thud.?]

$m$ si - $\beta$ extensum Nordst. Algolog. småak. p. 1hil.

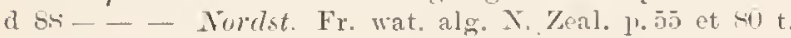
ii f. 3 a.

o - - - f. compressa ilid. f. 3 b.

d 89 - Toni sy-7l. alg. 1.954

d -ve extensum ibid. p. 155

d - r. compressum ibit.

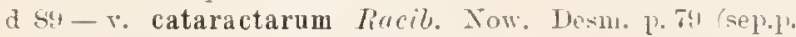
7. t. f. 3. [Cosm. cata 1.artum Fichl. 1s.45]

m n-Firhler spis Desm. Miedz. p. s..
11 91 URSINELLA К̈utie Rer. gen. ]1. 1. 11.

in al Cosm. Gutu, Flor. aly. Leopol. p. 4!!. pexteusum f. compressa ibil.

1112 - West Fr. W, Alg. W. [rel. p. 14 .

") - f. ibirl.

d 92 - Wolle Desm. U. S. ell. 11 1. 65 t. 19 f.3-4.

m $92-v$ - catharatarum Gutr. Fl. glon. Galic. 3 j. 126.

\section{Iroranrienso}

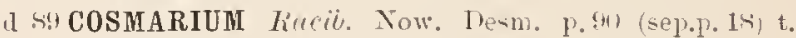
5 f. 2.2.

\section{vastum}

d inTAURASTRUM Schmille Beitr. alp. Alg. p.5st (sep. p. 31) St. areuatum $v$. vasta Seh.) [Staul. subavicula?.

d - f. tyrolensis ibid. p. (i0 et, 1865 . t. 16 f. 25.

\section{remtrir.osum-}

d 71 EUASTRUM Lund. Desin. Suec. p. 18 t. 2 f. 2 - non Kütz. 1245 .

a 81 - Wolle Thesin. T. S. p. 16rin.

msi - Lugerh. Amerik. Desm. P. 232.

o 87 - stulits liey Desin. 1. 145.

d sis-Coulir Brit. Mesm. p ii t. 33 f. 1 [e Lund. 18r1].

defs - Woll Fr. Alg. [T. S. A. p. 35 t. 58 f. 1-3.

d -4 - Tuni Syll. alg. 1) 10:41.

m! 10 - Wrest Fr. W: Alg. Xorth Wales p.25t.

n 11 HELIERELLA Limta Rer. gen. pl. p. s99.

m! E1r. West Fr. W. Alg. W. Irel. p. 137.

d 92 - Wolle Desm. U. S. ed. II p. 110 t 29 f. $1-3$.

o $93-v$. Floridannm Timm Alg. Ind. orient. p. Ts t. 11 f. 19 (Eu. Flor. Thrn. 1855).

\section{ientricostlm- -}

d t5 EUASTRUM Fïtz. Phycol. germ. p. 136 ?? Eu. cordatun Tab. 1sti. - Ser. Fulfs Brit. Desm. p. 212 $=$ starlinm ropulationis Cosmarii sp. verisimiliter.].

o 15 COSMARIUM Jialfs Brit. Desm. p.212.

a 49 - Kïtz. Sivee. Alg. 1) 175 .

d ris - Rerb. Flor. Eur. Alg. 3 p. 1 is.

1 89 - Tumi syll. alg. 1\% $16 \overline{3}$

1. 91 URSINELLA Kuntze Rer. gen. pl. p. 626.

\section{"entrirnsilll}

d TSTAURASTRUM Thlpante Desmil. subalp. p. Jy (sep. 1. 155 t. 1.2 1.3:1-11

d 89 - Tomi syll. alg. P. 1233.

\section{remtrirosum}

d 89 STAURASTRUM 1hast. Futh. Not. N. Z. Desm. p. 23 t. 4 f. 40. [10 D Delm.].

\section{Temlls}

(l 45 CLOSTERIUM Kïtz. Phy'e. germ. p. 130.

o 48 - Ralfs Brit. Desm. p. 220 t. 35 f. 12 a hïts. communieata

"I $49-$ Kiitz. siec. Alg. p. 164.

- 50 - Bréb. List. 1\% 150.

d. 68 - Rab. Frypt. Fl. saclls. p. 170

d fis - Rab. Flor. Enr. Alg. 3 p. 134.

in 71 - Lumet. Desn. Suee. 1. 81.

d 73 - Wood Fr. Alm. p. 11t t. 11 f. ז.

d 7 - Delponte Desmil. subalp. 1. 102 (sep.]. $19 \mathrm{~s}$ ) t. $18 \mathrm{f}$. (1) -41

m 79 - Wille Ferskr. alg. Nov. Semij. p.60

d S4 Wolle Desm. U. $\therefore$. H. 4 t. 7 f. 15

m $\mathrm{Al}$ - Arturi Liste alg. Moscon 1. 139. 
1 85 - Kirchn. PHanz. d. Sitissw. n. 21.

o 86 - Stokts Key Lesm. P. 113.

1) 88 - Hansg. Prodr. Algenfl, Böhm, [? 1s2

m.98 - Boldt Desm. Grönl. p. 42.

m SS - Iste. Jel. magrar. alg. p. 239.

a 89 - Mask. Furth. Tote N. \%. Derm. 1) 29 t. 6 f. 50 .

d 89 - Toni syll. Alg. p.810.

m 90 - Eichle syis Desm. Miedz, P. $\rightarrow 3$.

m 90 - Anderss. Sverig. Chlor. I p.1S.

191 - Kirchn. Mikr. Planz. 1. Sïssw. ed. 2 p. 23.

m 11 - Borge Bill. Sibir. Chloroph. 1) 14.

n 91 ARTHR0DIA huntze Rev. gen. 11. p. 48 .

I 92 Clost. Wrolle Desm. U. s. ed. II p.47 t. 5 f. 6 .

m 93 - Lüthemull. Desm. Attersees 1).543.

(z) 9 - Eichl, et Gutw, in Krakau Anzeig. 1.238.

in 94 - Guiw. Fl. alg. Tarnapol. 13. s).

zf 94 - Eichl, et Gutu. Spee, ald. nov, 1. 163 t. 1 f. 3.

('fr. Cl. Dianæ 1s.4. Cl. parvulum Heim. 1991.

\section{1.eml1stuml-11}

(1) 56 EUASTRUM Bril. Liste p. $12 \pm$ t. 1 f. 3.

d 61 COSMARIUM Arch. in I'riteli. Inf. 1. 732.

(i) 68 - Tub. Flor: Eur. Alg. 3 p. 164.

1] 69 Eu. fi majus Trittr. Skandin. Desm. p. 7 t. 1 f. 1.

n 70 - Nordst. Desm. Brasil. p. 21א.

- 71 --Lundell Desm. Snee. 1.23: f. (Didym. Braunii f. A. , Rivinseh.

o 73 -. Nordst. Norg. Desm. 1.10 (incl. Dill. Braunii A. , et $\boldsymbol{i}$.

d 75 Cosm. Nordst. Desm. arct. p.41 t. 8 f. 12 ; trigonum.

a is - Kirchm. Alg. Schles. p. 149.

m 79-? f. minor Ifille Ferskv, alg. Sov. Semlj. 1. 43.

mst-Racil. Desm. okol. Kirakowa p. sep.p.13.

1) 81 - Wulle Desm. U. S. p.lis t. 16 f. 37 [v. hypohexagonum f. sec. Hest 18:12].

in 85 -? f. minor Doldt sibir. Chloroph. p. 10t t. is f. 10.

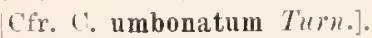

o stj-Stolies key Desm. 1.127.

1 Sc; Eu. Cuole Brit. Desm. 13. 76 t. 3is f. 11.

o 87 Cosm. $\beta$ induratum Norlst. Algolog. småsak. 4 1, 163.

o sis-Hansy. Trodr. Algenf. Bïhnn. r. 1w.

1 s $\$ 5$ - Boldt. Desm. Grönl. p. 14.

m 88 - Istv. Jel. magyar. alg. 1.2213.

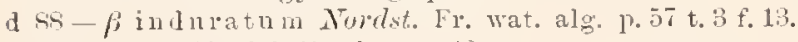

a s. - - Tomi Syll. alg. p. 4.t5.

d $--a$ ibid. 13.94i.

d 8: - f. Lrgerh. et Nordst. in Wittr. et Nordst. alg. exs. 11:0 98:4 et (16s:1 in fase. 21 p. 12.

ms 50 - Eichle suis Desn. Miedz. p.st.

m 11 - Hest Danish Alget p. 419.

d - $v$ punctulatum ibid.

11 9 URSINELLA Liunt: Rev. gen. pl. p.926.

m deosm. f. minor II est Fr. w. Alg. W. Irel, p. 147.

d - v. hypohexagonum ibil. et t. 21 f. 1 [alia spec? sec. Derege 1s:(1)].

d - - t. incrassata ibil. p. 145 t. 24 f. 23.

1) 92 - Wolle Desm. U. - .. ed. II p. 73 t. 19 f. 37 .

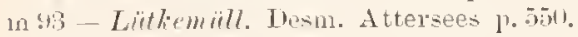

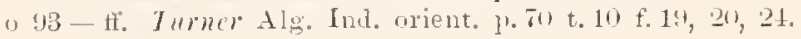
t. 11 f. 2.

o 91 - Waldem. Ohs. crit. Wesm. p. Tu.

o 94 - Burge silssw. (Mlor. Archang. 1\%26.

m 4 - Bürg. F. alg. Osterinl. 1. 17 t. 1 f. 11 .

95 - v. excavatum West in Jomm. of Bot. 33 1. 68 [Cosm, trilobulatum v. excav. Eichl. ct [rutw. 18:4]].

ms $95-$ Eichler in I'amiet. Fizy. p.til t. 1 f. 14.

m st. - t'. minor Schmidle Alg. Sumatr. 11.302.

mo- Lorge <iverig. Chlor. II p. 1:1.

\section{rrmustum-"}

o 63 EUASTRUM Hentasch in Rab. Alg. Eur. 11:0 1513. - nou Brib.

o 6 DIDYMIDIUM (Euastıum) Reinsch Algenfl. Franl. 1). 139.

a s9 Eu. Toni syll, alg. 1. 1114.

n 91 HELIERELLA Kimtie Rev. gen, pl. p. 899.

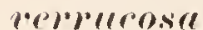

o s5 MICRASTERIAS ("liwy" in) Wolle in Bull. 'Torr. bot. Cl. 12 p. 127 t. 51 f. 10 . [Hisset non Roy est auctor speciei sec. Roy 1893].

o 85 - Stokes Key Desm. p. 148.

o 87 - Wolle Fr. Alg. U. S. A. p. 41 t. 59 f. 10 [= Wolle 1.555 ?

o 92 - Wulle Desm. U.S p. 120 t. 47 f. 10 .

1 19-Bisset in Tioy scottish Desm. F.174 t. 1 f. 2 (sep. P. 13 . Cir. Micr. rotata Ralfs Iftl ex p.

\section{ver)"110.sull!}

I 16 CLOSTERIUM Builey Catsk. Desm. p. 127 fig. xy$\log r .4$.

a 48 DOCIDIUM Rulfs Brit. Desn. p. 218.

d 52 - I'ritch. 111f. p. 275.

d 61 -Arch. in l'ritch. Inf. 1. 645.

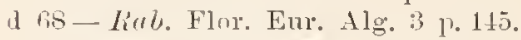

- 1 PLEUR0TANIUM Lind. Desm. Snee. p. 6.

d 73 - Wood Fr. Alg. p. 121 .

o 80 - Tordst. The Alg. et Charac. p. 2.

d 84 Duc. Holle Desm. U. S. p.52 t. 10 f. 4-5 [male sec. Johms.].

o 86- Stolies liey Desm. p. 113.

o s6 Plen1. Lugerh. Anerik. Desm. p. 252.

a 89 Tore. Toni syll. Alg. p. 876.

d 92 - Wolle Desm. U. S. ed. Il p. 50 t. 13 f. $4-5$.

n 93 - (Rutidium) Tumer Alg. Ind. orient. p. 39.

o 95 -Johns. Rare Desm. U. S. II p. 290 (incl, D. tessellatum).

Cfr. Arthrorhabdiom moluccense.

\section{$1 \cdot 6) .116021111$}

A 94 DISPHYNCTIUM Schmille AIg. Geb. Oberrheins p. 517 t. 2.5 f. 3.

\section{ver)"ur.osmul -}

d 34 EUASTRUM Ehrul. Organ. kl. Raum j) 247 (sep. 1) 103).

d 38 - Ehrenl. liff. r. 162 t. 12 f. V. (Cosm. Pelta Corde?).

n 3!? STREPHOCYSTIS Cordu in Alm. d. Carlsb. 1839) 1. 242.

1 to Cosmarium Tenegh. Synops, Desm. p. 222 (sep.1. 22).

d. $41 \mathrm{En}$. Iritch. Inf. P. f. 125 [fig. Whrent. repetita].

n 43 - Ehrent. Mikr. Leb. sïd. n. X. Amer. t. IV I f. 17. [?

d 44 - Rulfs in Amn. Nat. Hist. v. 14 p. 159 t. 1 f. 3 (et Trans. Bot. Soc. Ellin. v. 2 (1sti) p. 125 t. 10).

1 ta-Ilass. Brit. Alg. p. 37! t. 41 f. t [e Ralfs 1. c. dejictum].

d 45 - Kiitz. Plyycol. germ. p. 135.

d $4 \bar{t}$ - limb. Dent. Irypt. Fl. p. 5 .

o 47-Focke Phys. Stud. I p. 1t, bt, lits t. 1 f. 11, t. 2 f. 12. 13,23 .

d 18 - Lirlfs Brit. Desm. p. 79 t. 11 f. 2.

1 tis-Kitis. spec. Alg. p. 172.

$1149-$ Euensminm, Neg. einz. Alg. p, 120.

m to- l'trty in Ber"1. Mittheil. 1849 p. 143. 
d 52 - Iritch. Inf. p. ำs t. 2 t. 125 [ex Ehrent. Inf.].

n 513 - Brèt. List. p. 1233.

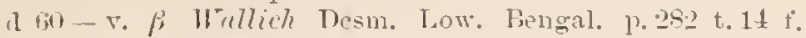
5-T [ Wallichianum Turm 1St:3].

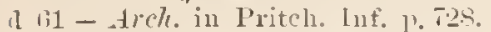

(1) 1 is - liub. Frypt. Fl. Sachs. p.145.

1] Git-Eyrich Almenfl. Mammh. p. 1으?

o tiT DIDYMIDIUM (Eucosm ium Reinsch Algenfl, Frank. 13. 1:24.

(i) Eur. Tot. Desm. Ital. t. 2 f. 10.

a 68 -Rab. Elor. Eur. Alg. 3 p. 179 Eu, papulosam Kiitz.).

d $71-$ Lumi. Desm. Suec. $]$. 10; forma $[\beta$ a latum $\mathrm{f}$. tragerh. 1siti].

1 $-\beta$ rhomboideam iuil.. t. 1 i. $s$

d 73 - Delyonte Desul. subalp. p.94 sep.p. 82) t. is f. 13 -15 .

d $-v$ coarctatmm ibisl. p.!5 t. 6 f. 16 .

I 73 - Woond Fr. Alg. p. 1313 .

a 75 - Microgr. Dict. p. 291 t. 10 f. $1 \pm$ [e Ralfs].

o 7 -Jacubs. Desm. Danem. p. 1 s9 incl. E. orbiculare Wull.).

d Ta-Kirchn. Alg. Richles. p. 160.

d so-p reductum Norlst. De Alg. et Charac. 1 p. 9 t. 1 f. 14.

m 81 - Hempel Algenfl. Chemnitz Forts. p. 20.

mst - Arturi Liste alg. Moscon P. 143.

a st-Wolle Desm. U. S. p. 190 t. 21i f. 1 et 5 .

c) - $\mathrm{r}$. Crux Africanum ibil. p. 101 t. $25^{\circ} \mathrm{f} .2$.

o - r. alatum ibia.. f.t prope C. alatum Cordu 15s!n, mon Kirchn. 1sisi.

n - - re relluctun ibid. f. b.

d s.i - $\beta$ simplex Josh. in Jonrn. of Bot. v. 23 p. 34 t. $254 \mathrm{f}$. 2. Alia spec.]

I s.i-Kivelın. Mikr. Pflanz. I. Sinssw. p. 21.

m s5-Bollt Sibir. Cluloroph. p. 98.

11 8.5-a. typicum Racib. Nonn. Desm. Polon. p.94 (sep. 1. 35 \%.

a - b. intermedium ibid. t. 13 (sep. 4) f. 19.

m - c. coarctatum ibid. f. 11.

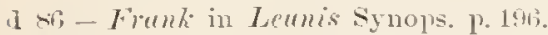

o shi-pi alatum f. Luger\%. in Wittr. et Nordst. Alg. exs. n:o sor í forma Lund. 1971) et 1989 in fasc. 21 p. 36.

o sti-Stukes Key Desm. 1) 145.

d si-Coule Brit. Desm. p. is t.31 t. 1 [partim e Delnonte 1onis].

th si - Klets Organisat. Gallerte b. Algen 1. 38. t. 4 f. 12.

1 $4 \mathrm{t}$ - v. apiculata Iste. Diagn. prev. in Yotar. p. 235 sep.p.1; .

ph 8 - Klebs in Ber. dentsch. bot. Gesell. 5 p.155.

I 8 - Alexcmko Chlorosp. Khark, p. 244.

d ss-Hunsg. Prodr. Algentl. Bölnm. p. 204.

d-piatanm ibid.

phs - Klelss Beitr. Physiol. 1. Pflanzenz. p. 587 et 51 t. 6 f. 13 .

I SS - Toni et Leri Fl. Alg. Venez. p. 5 .

mse - Rinlin. Chloroph. ent. Kharkow p.327.

m - - coarctatum ibir. p. 322 .

un - a. typicum Bollt Desm. Grïnl. p.1; sep.p.4); et f. Foclie 18it

o s - v. simplex Hure. Fr. Alg. Taine I p. 150.

un 88 - 7ste. Jel. magyar. alg. 1).2021.

1 - v. apienlata ibil. et t. 1 t. 4

un $88-c$ coar.tetum kucib. Mat, flor. glon. Polsk. 1) 112.

1 89 - Toni soll alg. p. 16 min.

d — - a a lattm ibi.t. p. 114;.

d - v. rlomboiclenm ibis. d $-r$. coaretatum ibil.

d - v. reductum ibid.

ll -vinterinedium ibid.

d $-r$ simplex ibir.

1 - v. apiculata ibil.

m $90-r$ simplex Weat Fr. w. Alo. Torth Wales p. 2s.

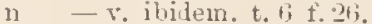

in 90 - Eichle\% Sipis Desn. Mierlz. p. 49.

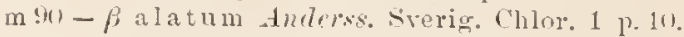

d "1 - Kirchn. Mikr. Pflanz. d. Sissw. ed. 2 p.25.

m 91 - Heimerl Desm. aljin. 11.601.

1291 HELIERELLA Kuntze Rev. gen. 11. 1. s.9!.

$m 91 \mathrm{Eu}$. fi a latum Gutw. Elor. alg. Lenpol. j. T2.

n $92-r$. simplex $M m \%$. Fr. Alg. Maine Ill t. 126 f. 24 - 25.

n $92-$ Borge Chloroph. Torsh Finmark. p.1i.

o - $\quad$ r reductum f. ibid.

m 92 - West Fr. W. Alg. W. Irel. 1. $131 \%$.

d - v.coarctatum f. iliul. et t. $20 \mathrm{f} .11$.

m 92 - Rac. Desmidya Ciastoni p. 34T.

- $\checkmark$ Crux australis ibid. p.37s [En. tur gidum sec. Hest in Jotn?. of Bot. 1895 p.666?.

d - f. genuina ibid.; t. 7 f. 26 a.

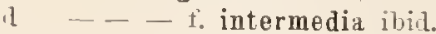

d - - f. evoluta iluil.. t. 7 f. 26 b.

11 - v. turgidam ilinl E. turgidum Wrallicle 1sioj.

$n-\mathrm{f}$. Grmnovii ibid. E. turgidnm v. Grunow 18tiō).

(1) $92-$ Trulle Desm. I. s. ed. II ].111 t. 3u t. 1 et 5 .

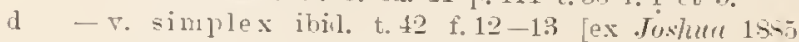
verisimiliter. sed non exacte].

- r. Cun Africannm ibid., t. 3) f. 2.

- . a latum ibid.. t. 30 f.. 1.

— ₹. reiluctum ibil. ]. 112 t. 30 f. 3.

2193 - a typicnm Tumer Alg. Ind. orient. p. Tt.

- $\beta$ Wallichianum ibid.; t. 11 f.s ( $\beta$ Wallich 1.960).

1 - $=$ simplex f. trmescens ibid. t. 11 f.

1) 4 - f. Mor. Austral. Sïsswasseralg. II p. $34+1$ t. 2 f. 21.

a ! 1 -Sumd. in El. Nebraska p. 12 t. 7 t. 15 a et b Fu ex Wolle Crux Africanum, $b$ e routiel.

m94-Alextnliv Mat, alg. Khark. p. 208.

d 15 - Bailey Contrib. Queensl. Fl. Xl p. 41 t. 10 f. 16 (e Mitius.

Cir. Cosm. cornutum et quadrangulare Curla.

\section{ievetebruturl -r}

d 35 DESMIDIUM Bréb. Alg. Falaise p. 269 (sep.p. 6is t. 2.

d 4) ISTHMIA Henegh. Synops. Thesm. p. 205 (sep.p.5).

d 45 ISTHMOSIRA Kït:. Plıycol. germ. p. $1+1$.

d 4 TFSSARARTHRA Kub. Deut. Kiypt. Fl. 1.56.

Izf tis SPH ÆR0ZOSMA lialf's Brit. Desm. p. 65 t. $i$ f. 1. t. 32 f. 2. [All fig. 2 revera luc pertineat]. Spliær. elegans Corda, Odontella? unidentata $E 7 \%$. Desm. compressum Ralfs 1512

1 I! Isthmosira Kütz. Spec. Alg. p. 1ss; a et $\rho$.

(1 $52 \mathrm{~s}$ ) hat: I'ritch. Int. ], 2-13

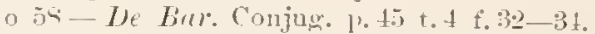

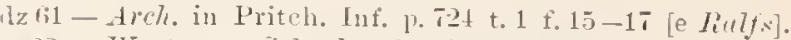

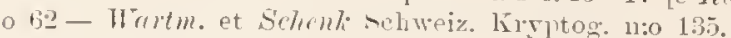

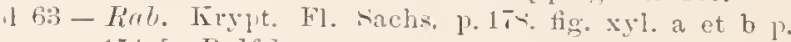
$15+$ [e Rullfs].

o li3-Cramer in Ral). Alg. Enr. n:0 14tr.

oztio - Biene ill Rah. Alg. Em1. n:o $175: 1$ [11 splu. Archeri Gutue."?].

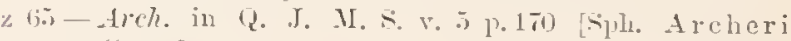
Gietw.].

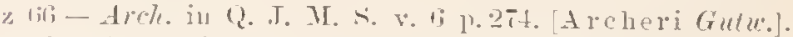

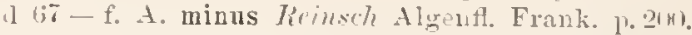

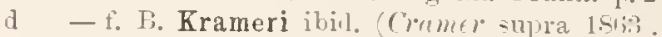


d 68 -Rab. Flor. Eur. Alg. 3 p. 118, f. xyl. 58 a p. 10. [e Rrilfs]: form. a et $b$.

d 75 - Microgr. Dict. p. 715 t. 10 f. 9-10 [e Rialfs].

d 78 - Kirchr. Alg. Schles. p. 133.

m 78 - Hempel Algenfl. Chemnitz p. 113.

n - b. secedens ibid. (Sphrrozosma sec. De Tar. 1855)

83 - Surotin in Arch. bot. d. Nord. 1. France 2 1) 30 f. 32 bis [Desm. Swartzii?].

d 81 - Wolle Desin. U. S. p. 30 t. 4 f. 13.

d 45 - Mirchn. Miks. Pflanz. d. Süssw. p. 21 t. 2 f. 60 (e Jir Iirvy 1858).

o sti - Stokes Ker Desm. 1) 110

dzf 86 - Cooke Brit. Desm. 1, 3 t. 2 f. 1.

d 8i-Alexenko Chlorosj. Trhark. p. 219.

dz 8 - IIunsy. Prodr. Algenfl. Bihm. p. 170 f. xyl. 102 [e le Rar. 185is].

d 88 - Tumi et Leri Fl. Alg. Tenez. p. 25.

o 88 - kiabin. Fhloropl. env. Tharkow 1. 320 (sep.p. 32).

d SA-IIuptfl. Zellm. u. Hüllgallerte Desm. p. İ et 10 ! (sep.1. 21 et 51 ) t. 2 f. $14 i-23,2$.

d si-Tomi syll. Alg. p. 78 s.

d 89 -f. Nurdst. in Witt, et Nordst. Alg. exs, n:0 907 et fasc. $21 \mathrm{p}, 34$ [sph. Archeri Gute. 1500].

m 90 - Eichler spis Desm. Miedz. p. 84 .

d !1 - Kireh. Mikr. Pflanz. d. Süssw. คd. 2 1. 22 t. 3 f. (3)! (e de linay).

ms - f. minor Tfest Adil. Freshw. Alg. W. York. 1, 244. m ! 1 - Raitey Fr. Alg. Maine III p. 121.

d 92 - $\|$ ulle Desin. T?. S. ed. 2 p. 30 t. 4 f. 13.

$1192-\mathrm{f}$. minor W'est Alg, Engl. Lake Distr. p. 71 t t. (1) f. 3.

d !3-- v. Indicum Turn. Alg. Ind. orient. 1. 1.10 t. 17 f. $1 \mathrm{~s}$ a: c et d. (f. lata; 1). (f, subacuta

\section{vertirillutum}

d 4ヶ D0CIDIUM lbuilcy in Rulfs Brit. Desn. 1.218 t.35

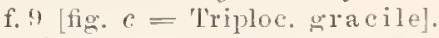

d 51 TRIPL0CERAS Iitil. Micr. observ. 1,.37 t. 1 f. $\%$

d 522 Ioc. I'ritch. Iuf. 1).275.

d til - treh, in pritch. Inf. p. 714 t. 3 f. 37 [e Rorlfs a a].

63 PLEUR0T EUNIUM Ilocidium) Richter in hiul. Alg. Eur. n:0 1570 f. 2 [Pl. nobile licht. sec. R. in Hedw, 1sisi,

d rif-Lúb. Flor. Eur. Alg. 3 p. 143, fig. xyl. 1. 107 [e lialfs?]

A 73 Triploceras Troud Fr. Alg. p. 121.

d sit Doc. Ilulle Desm. U. S. 1) 53 t. 10 f. 1.

m - v. turgidum ibin., f. 11.

an Sit Fleur. Latyerh. Amerik. Desm. p. 252.

m s6 Doc. (T'riploceras, Turner Not. Freshw. Alg. t. 1 f. 2. o st' Triploceras stolits Key Lesm. p. 11 .

o $87 \mathrm{Doc}$. II whe Fr. Alg. U. S. A. 1.27 t. $61 \mathrm{f}$. $1 \mathrm{~s}$.

d 88 Triploceras $=$ superbum Nordst. Fr, wat. alg. N. Zeal. 11.63 t. 7 f. 3-11. ('T'ipll, tridentatum $\beta$ sul'. M(r.slis).

d so - Toni syll. Alg. p. 809

d $-\mathrm{v}$. snperbum ilsid.

rl 92 - ITolle Desnt. U. S. ell. Il p. is t. 13 f. 1, t. 10 f. 18.

d - v. turgidum ibid, p, sis t. 13 f. 11.

n (n) M Irmerhilium) Twmer Alg. Ind. orient. p. 2T.

\section{"e)tirillutull}

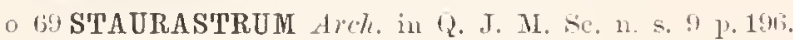

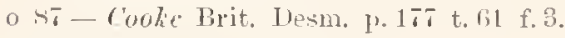

o s? - 7omi kiyll. alg. p. 1223.

\section{vesir"ulutull}

d s.s STAURASTRUM Wolle in Bull. Torr. bot. Club 15857.5 d 85 - Wolle Fr. Alg. U. S. A. p. 42 t. 54 f. $6-7$.

d 89 - Tomi Syll. alg. 1\% 1195.

d 92 - Wolle Desm. U. S. ed. 2 p. 132 t. 12 f. $6-7$.

\section{resirmlosir}

d 4 PALMOGLOEA Kïtz. Tab. phye. I p. 20 t. 25 f. 4 (P. macrococca $K$. ex p. olim.)

d $4: 1-$ Kutz. spec. Alg. p. 228.

o $6 \pm$ - Arch. Deseript. (sep.]), 10) in Dubl. Nat. Hist. Soc. Pr. 1. 21 (l. macrococea).

\section{restitum}

4 4 STAURASTRUM Iinlfs Brit. Desm. p.143 t. 23 f. 1.

d 52 - I'ritch. Inf. p. 268.

d 61 - Areh. in Pritch. Inf. p. Tt2 t. 3 f. $30-31$ [e linlfs].

d 63 - Rul. Kirypt. Fl. Sachs. p. 193.

d 67 DIDYMIDIUM (staur.) Reinsch Algent. Frank. p. 167. Forme A et B.

d. GrStaur. Rab. Flor. Eur. Alg. 3 p. 21 s.

d - 1. diplacanthum ibid. p. 219 (St. diplac. Not.).

d $70-f$ denudatum Nordst. Desin. Brasil. p. 230 t. 4 f. 40.

o 72 - Arch. in Q. J. Micr. Sc. v. 12 r. 44 f. 2 -rad.

d $7 T$ - Helponte Iremid. subalp. p. 62 (sep.p. 158) t. 12 f. 16-1:1\%.

d Ts-Kirchn. Alg. Sichles. p. 16t.

o $8: 3$ - r. distortum Thulle in Bull. Torr. bot. Club v. 10 1. 20 t. 27 f. 15 .

dzf st - Wolle Desm. U. S. 1.138 t. 45 f. $28-80$.

- 86 - Stukes Kiey Desm. 1’. 165.

d 87 - r. ornata lste. Diagn. 1rev. 1. 240 (sep.p. 11:

I ST-Cooke Brit Desm. p. 175 t. Go f. 3 [e Ralfs? ex 1.].

mst-Alexentio Chlorosp. Kihark. 1. 255.

o SS--v. a. Riatim. Chloroph, enr. Filarkow p. 332 t. \& f. 8 .

o - r. b. ibid. f. 9.

d fis - v. orilata Iste. Jel. magrar. alg. p. 285 t. 2 f. 34.

d so-Tomi sirll. alg. 1) 121s.

d - - or oratum ibid.

d - r. distortum ibid.

mo-Lichlo. Fis Tesm. Miedz. p. 10.

d 12 - Hansy. I'rorlr. Algenfl. Bühm. ed. bohem. p. 16ri, eil. germ. 1.25s.

d. 92-Tolle Desm. L. s. ed. II ]. 151 t. 56 f. $28-30$.

d $12-r$. semivestitum ITest Alg. Engl. Lake Listr. 1) 7.92 t. 9 f. 38 .

m 95 - fo? liorge sverig. Chlor. II p 25 t. 1 f. $1 \%$

\section{restitum!}

a 44 XANTHIDIUM White in Micr. Soc. transact. I 1\% 78 t. $\mathrm{S}$ f. 1. Fossile. [An Spongia?]. [Quorue in Micr. Journ. т. 2, 15.2. t. 4. - 11. เ.].

\section{rextum}

a 93 COSMARIUM Wist Alg. Engl. Lake Distr. p. 727 t. () f. 3 .

d $514-\mathrm{v}$. concavum schmulle Alg. Geb. Oberrheins 1. 550 t. 25 . 1.21 .

\section{r.illelllill)!}

d 13 SPHÆR0Z0SMA Twmer Alg. Ind, orient, p, 142 t. 22 f. 14

\section{rimgllmerlite}

d so ARTHRODESMUS Winte Norg. Ferskv. Alg. I p. 39 t. 21.25

d 89 - Toni s.1l. alg. p. 1062. Cfr. Staur. Dickiei f. Winlle $18 \%$. 


\section{violuseches}

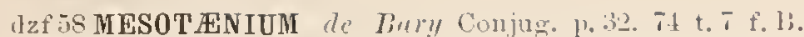
a 1;3 PALMOGLOEA Iiab. Kint. Fl. Sachs. ?o lit et fig.

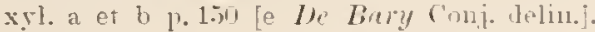

dzos- Riub. Fl. Eur. Alg. 3 p. 11\%, fig. i2 a et h p. 113 [ut supra].

daf So Mes. Cooke Brit. Desm. p. 4 t t. 1s t.j [e 1) Mrevy].

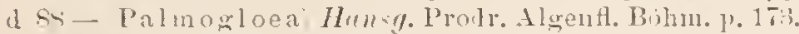
in sic Xes. Nordst. Fr. wat. alg. X. Zeal. p. i2.

dz. A. - Tuni sivll. Alg. p. R1?.

Cfr. Palmogloea lnrida et rupestris.

\section{rivirlis -e}

o ph 31 COLPOPELTA Corta in Aln. A. (arlsh. p. 17?. 2m; t. 2 f. 2.: [Euastrum læve? ser. Ehrub. in Wiegm. Areh. 1sist; p. 185. - Cosm. Colpopelta Mrob. 1:ib1; Cosm. Cordanum Riéb. 1s6s;.

1) 39 - Corda in Alm. d. Carlsb. 1839 p. 211.

o s.i COSMARIUM Jush. in Journ. Bot. 1.23 p. 3.1 t. 254 f. 3. a s. DISPHINCTIUM Tuni syll. alg. p. 865 .

in 2 Cosm. t. minor Hest Fr. W. Alg. W. Irel. p. 181. m!3 Dys. Turutv Alg. Int. orient. p. 10. m 95-Julns. Rare Desm. U. S. II p. 292.

m 95 - West Alg. Madag. p. 71 t. ? f.2 2 .

Cfr. Cosm. moniliforme f. subviride schm. 1894.

\section{virirlis}

d 24 GYGES Bury in Encyelop. mith. Hist. Xat. d. Zoo-

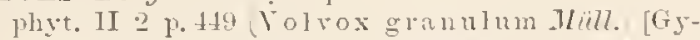
ges granulum sec. Ehrtul, in Isic 1s.3t [1. 11.46.]

\section{rittutem}

1 93 COSMARIUM Turne A]g. InA. orient. 1. 5. t. 8 f.!.

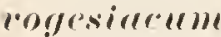

a s. COSMARIUM Lemaire Liste Desm. Vosges p. 20 t. 1 f. ‥ Cosm. Osteri

o 59 - Tomi syll, alg. T. 1051?.

11 URSINELLA huntze Rev, ren. pl. p. \$2r.

\section{rolulls}

d 9. STAURASTRUM West Alg. Malag. p. 79 t.9 f. 10-11.

\section{Iolliellsii}

(1) 1 PLEUROTENIOPSIS Hieron. in Pflanz.-1. O-tafrik. 1. 으.

\section{*ulunteis}

d $2+1$ LUNULINA Bory in Eneyc. méth. Hist. Nat. 1. Zoophrt. I ? 1. 5(11 Clost. Lunula sec. Ekrb. Inf.].

d 213 - Rory in Dict. class. hist. nat. v. 9 p. 512.

25 - Tup. Diet. d. se. nat. Planel. bot. Vég. acotyl. unilocu]. Tesicul. [t. I] f., 3. [Spec. nommule. Fig. 3 a lextra $=$ Cl. moniliferum sec. Fhrb.].

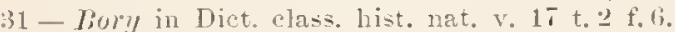

\section{Irallir)inlllll}

1 93 Docidium Tume Alg. Ind. orient. p. 30 t. 3 f. 2 .

\section{ITllir)ii}

(1) CLOSTERIUM Twne Alg. Inl. orient, \}, 21 t. 2 f. $1: 3$.

\section{Jrellirlli}

d 65 MICRASTERIAS Grun. Ins. Bank. p. 14 t. 1 f. 21.

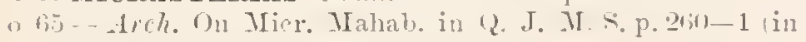
nota.

o is - Areh. in Q. J. MI. -c. p. I! u d iss - Rub. Fior. Eur. Alg. 3 \% 1 ! 13 .

o $71-L u n d$. Desim. sinec. P. 15.

1 T K- Kirchn. Alw. siohles. p. 1til. M. Herm. Reinsch.

d S! - Toni sill. alg. 1. 1123.

n 11 HELIERELLA Kiuntze Rer. gen. pl. p. 499.

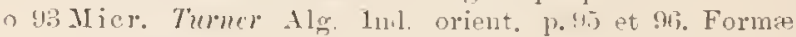
p. !16:

- f. typica.

- f. major (Lumlell 1s:1).

- v. Hermanniana (М. Herm. Reinsch). f. ampullacea M. ampull. Task. .

- - f. Fijionsis M. americana f. Fijiensis Mask. 1hitit.

In - $f$. Spenceri ihil. p. 4 M. ampnllacea var. $\beta$ spencer 1-452).

Cfr. Micr. americana et Mahabuleshwarensis.

\section{IThllireii}

1376 SPHÆROZOSMA Jucobs. Desm. Danem. p. 211 (sph. excavatum var. $\beta$ Wallich : $[-\beta$ Wallichii Norelst. 15s0?.

o - f. incisa ibiu. p. 212.

o 84 - ? Hulle Desm. U. S. p. 31) t. 4 f. 1.5.

o ti-stolies Kicy Desm. p.111.

d 89 - Toni syll. alo. 1\%. 7it.

o 92 - ? Wolle Desm. U..... ell. II 1).31 t. 4 f. 1.

o 93 -- Temuozosma) Turner Alg. Int. orient. p. 141 t. 1.s f. $1.12,13$.

m 94 - Julns. Rare Desm. U. S. p. 2si?.

\section{Wrellirlai}

d S STAURASTRUM Twmer Alg. Ind. orient. p.117t. 13 f.:34.

\section{Trel)de}

189 STAURASTRUM Racib. Desm. Lituan. p.65? (sep.

$$
\text { ?. G). }
$$

1) s! - Toni Syll. alg. p. 1145.

o .

o 95 - Racib. in Flora v. Si p. 34.

\section{Tremeingii}

d 10 COSMARIUM Lörg. Desm. Brasil. p. 41 t. 4 f. 34.

\section{ITr)millgii}

n 11 HELIERELLA Kuntze Rev. gen. pl. p.s9s (Eu. quadratum Norlst. 1soin.

\section{Warmilegii}

I tit PLEUR0TENIUM Wille sydamerik. Algh. p. 2.2 t. $1 \mathrm{f} .4$.

o $5 \overline{-}$ - $\beta$ birmense Lagerh. Irit. Bemerk. p. $5 \pm 0$ (Docidium coronulatnm Josh. 18.8\%, non Grun, 1865).

d 89 - Toni s.sll. alg. p. 90 ?

-v. birmense ibir.

\section{IIterulugii}

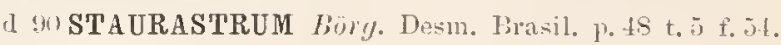

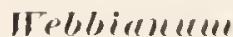

1) :13 EUASTRUM Turner $1 \mathrm{lg}$. Iud. orient. p. $83^{3}$ (t. major). m - $\mathrm{f}$ minor ibill: t.202 f. 4 .

in 13 - f. major Turner Desm. Yotes p. $81: 3$, f. 4 p. 344 .

\section{Weddellianuele -}

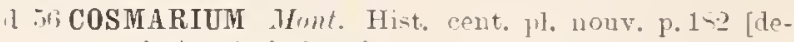
seriputio nimis brevis?. 
d S9 - ? Toni syll. als. N. 1056.

11 91 URSINELLA Kuntze Rev. gen. pl. p.ore.

\section{Testirllll!}

d 2 COSMARIUM $\operatorname{Iem} . \mathrm{Fr}$. Alg. SW. Surey p. 11 t. 2 f. 14. [An Cosm. caelatum ?].

\section{Westii}

d 93 STAURASTRUM Turncr Desm. Notes p.345, et f. 9 1. 341.

\section{Willermum}

d 92 COSMARIUM Tiuc. Desmidya Ciastoni. p. $37 t$ t. 7 f. 4. o $9 t$ - f. intermedia Eichl. et Gutu. Spec. alg. nov. p. 17 t. 5 f. 26 .

\section{Willei}

o s6 CoSMARIUM Lagerh. Amerik. Denm. p. 235 (C. Broomei fi obliquum Wille 1sis).

d $89-$ f. Luger\%. Bengal Desm. P. T.

\section{ITillei}

o 91 DISPHINCTIUM schmiale in Hedwig. 83 p.94 Cosm. excavatum v. ellipticum Wille 1Srg, non Tumer 1s03. [Cosm. isthmium v. Willei West 1892].

\section{Willei}

d 93 DYSPHINCTIUM Turner Alg. Ind orient. p. 42 t. S. . 40.

\section{Trillsirmum}

d 93 COSMARIUM 7mmer Alg. Ind, orient. p. 53 t. 5 f. 19.

\section{Willsii}

d 5S STAURASTRUM Turner Alg. Ind, orient. p.114 t. 13 f. 25.

\section{Wittrockirmum!}

d 93 CLOSTERIUM Tinner Alg. Ind. orient. p. 21 t. 1 f. 25.

\section{Wittrocliii}

II 71 COSMARIUM Lund. Desm. Snec. p.31 t. 3 f. 14

d T2 - $\beta$ angulare Wittr. Gotl. (il. sötv. Alg. p.58.

d $\mathrm{Ts}$ - Kirchn. Alg. Sichles. 1. 152.

n 79 - Wille Ferskv. alg. Now. Semlj. 1. 44.

d $-\beta$ intermedium ibid. $\rho^{3} 44$ t. 13 f. 35 .

m Sil - Wille Norg. Ferskr. alg. 1 p. 21.

ms $\$ 5$ - lioldt Sibir. Chloroph. p. 10s.

d 86 - I Bem. Fr.-wat. Alg. Engl. Lake Distr. 1 p. 10 t. 1 f. 15 [Cosul. minutum Del])? ?.

o S6-Stokes Kiey Desm. 1'. 126.

rl 8 i-Cooke Brit. Desm. p. 118 t. 42 f.s

d sa-Toni syll. alg. p.olit.

d $-r$. angulare ibid.

d - v. intermedium ibid.

m 90 - Eirhler spis Desm. Miedz. p. sit.

n :11 URSINELLA limtze Ret. gen. 1\% 1\%.921\%

m 93 Cosm. Selhmiale Beitr. Alg. Sehwarzwald. p. 99 t. 4 t. 23 [r. Siclninilei Borge].

o - v. elongata ibid.; t. 4 f. 21 .

m 44 - Gutu. Fl. alg. Tarnapol. 1. 5 t. 3 f. 17.

$0.5-v$ - Schmidlei Horge riverig. Chlor. II p. 16 (Schmidle $1 \times 18 \%$.

\section{Wittrocliii}

d 93 STAURASTRUM Twner Alg. Ind. orient. p. 126 t. $15 \mathrm{f} .2 \mathrm{ri}$.
Tollermumle -

d s6 CoSMARIUM Lagerh. Arerik. Desm. p. 237 (C. pseadogranatum Wolle 18st, non Nordst.).

1 - $\div$ grannliferum ibid., t. 27 f. 17 .

d 87 - v. granuliferum Wulle Fr. Alg. U. S. A. p. 29 t. Go f. 1 \& 2 [male e Lagerh.].

d $89-$ Toni s.rll. alg. p. 1045.

d - subsp. oranuliferum ilid.

n 91 ? URSINELLA Funtze Piev. gen. pl. p. 926.

d t2 Cosm. v. granuliferm Wolle Desm. U. S. ed. II p. lit t. 4 f. $1-2$.

\section{Wolleamum}

d 93 D0CIDIUM Twmer Alg. Ind. orient. p.33 (D. hirsutum Walle 18st. non Tail. 1851).

\section{Wollermum!}

d So STAURASTRUM Butler apud Wolle in Bull. Torr. bot. Club 1 ssa p. 6 t. 47 f. 1 \& 2.

d - - Kissimmense Trolle ibid. p. 128 t. 51 f. $1-3$.

o S6 - v. Ii issinmense Stokes liey Desm. p. 164.

d $8 \tau$ - Walle Fr. Alg. U.S. A. T. 44 t. 57 f. 1 \& 2 [ex Holle 1895 .

d - r. Kissimmense ibid., t. 54 f. $1-3$ [ex Holle 1855].

d $89-$ Toni ryll. alg. p. 1222.

d - $\because$. Kissimmense il,id.

d 92 - Wolle Desm. T. s. ed. It p. 163 t. 45 f. 1 is 2.

d - r. Kissimmense ibid. p. 164 t. 4 f. $1-3$.

$$
\text { Cir. Staur. Arctiscon } \mathrm{r}^{\circ} \text { crenulatum. }
$$

\section{Tollei}

- S6 EUASTRUM Layerh. Amerik. Desm. 1.233 (E. intermedium $a$ et $\beta$ euspidatum) Wolle 1884, non (lece).

d $-\beta$ quadrigibberum ibid., t. 27 f. 6 .

o 87 - Wolle Fr. Alg. U. S. A. p.37.

d - v. quadrigibberum ilid.. t. 60 f. 29 [e Layerh.?]. d 89 - Toni sorll. alg. p.110t.

I - v. quadrigibberum ibid.

d - $v$. cuspidatum ibicl.

u 91 HELIERELLA Kuntie Rev. gen. pl. p. Sig.

d $92 \mathrm{Eu}$. Wolle Desm. U. S. ed. II p. 108 t. 33 f. 1-5.

d - v, quadrigibberum ibid. t. ta f. 24.

d - v.cuspidatum ibid. p.109 t.33 f.3-5 [ex Wolle $1854]$.

\section{Woodii}

d T PLEUR0TÆNIUM Delponte Desmid, subalp. p. 125 (sep.p. 2.201) t. 18 f. $511-51$.

d sō DocIDIUM frulle in Bull. Torr. Bot. Club. 12 p. 2.

d si - Wolle Fr. Alg. U. \&. A. p. 26 t. 54 f. 4 .

d sopleur. Toni srll. alg. p. S98.

11 92 Doc. Wolle Desm. U. S. ed. II p. 50 t. 12 f. 4 .

\section{Hrightiamulu}

oz 83 COSMARIUM Areher in Ann. Mlag. Nat. Hist. Es ser n:o 63 1).20\%.

ozst-Coulie Brit. Desm. p. 187.

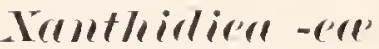

d 54 Fucke Ilyys. Stud. II 1. 23. Sectio Bacillariorum. Gen: Sintlidium. Staurastrum, Pentasterias, Tessararthra Hyalotheca. (iymnozyga) ete.

d 64 Grry Brit. Alg. p. 65. "Xanthidiex". Sect. Desmidiacearnm. Ge11.: Micrast.. Euastr.. Cosmar., Xanthid., Arthrodesm.. Staurastr.

o 94 Haclicl system. Plyylogen. d. Prot. u. Pflanz. p.10s. 
(Aanthiliea fossiles fortasse $=$ eellulio perdurantes" ("Danelsporen") algar. Xinuthellacenumu).

\section{XANTIIIISTRUM}

d T3 Delponte Dosinit. subalp. p.37 \& S1) (sलp.p. 25 et lis) [Onychonema see. Hansy. T’r. Mlg. Böhrm. 1Gise 1. 171].

\section{XANTHIDIUH}

d 34 l:wenl, Oroan. kl. Raum. p.317 (sep.p. 17:3) [Staurastrum et Xanthidinm nuct. recent.].

o 37 Jihrenl. in Wiegm. Arch. f. Natulg. p. 275. ph 85 Ehrend. in Abhand. Berlin. Akad. 1sise p. 111.

d 35 Ehromb. Inf, p. 116 .

d 41) Menegh, śnops. Desm. 1. 223 (sep.p. 23).

d 40 Burmeister in Ersch u. Gruber Allg. Encsklop. d. Wiss. II, 19 p. 205.

d 41 Pailey Amer. Bacill. p. 290 (sep.p. 9).

12 White in Micr. Tourn. v. 2 p. 35 [n, v.].

d 13 Kütz. Plyce gener. 1) 162.

0.14 White in Micr. Soc. Transact. p. 7 .

o 45 Mentell in Anm. Nat. Hist. v. 16 p. 73-8s ffossilia. Annon Fipongia?].

d 15 Ralfs in Anu. Nat. IIist. r. 11 p.465 (et 18lf in Trans. lot. Soc. Edin. v. 2 p. 152).

a t.i Hass. Brit, Alg. 3.s.

0 t6 Wilkinson in 'Transact. Mier. Soe. v. 2 p. 8!.

d 4 Tirab. Dent. Firpt. Fl. p.s.

d to Iidls Brit. Desm. p. 111.

d Lit Breb. in Dict. miv. hist. nat. 13 r. 30 .

d 49 hiliz. Splee. Alg. p. $17 \%$.

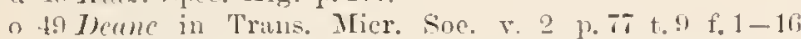
(fossilia) [Fipongixe?].

5) Agassiz in Ploc. Amer. Ass. Aldr. Ariene. 1819 p. Sa [n. r.].

d 52 Pritch. Inf. 1.2.\%.

n 5T Berlecl. Introd. Crypt. Bot. 1). 121.

d 5s De Rar. Conjug. p. 4. 50, 72.

o 5 G Grun. Desm. P. 493.

a $131 \mathrm{Arch}$. in Pritch. Inf. p. 720 et 73.

o 62 Thite in Amer. Journ. Sicienc. a. Arts $33 \mathrm{p}$. $38 \mathrm{f}$. xyl, 1--!. $14-2-2$ (fossilia).

d 6.3 Grogn. Plant. Crept. p. 203.

(1) 63 Rakl. Firyt. F1. Sachs. p. 195.

d 64 Grony Brit. Alg. p.68.

d fif Eyrich Algenfl. Mannh. p. 12:.

d fit Reinsch Algenfl. Frank. p. 125. Subgen. Dirlymirlii.

d hit Not. Desm. 1tal. p. 21.

d cos Riub. Flor. Fur. Alg. 3 p. 221.

d 7 lound. Desm. Suec. p. G. (Aubgen.: Schizasantlum P. 7 et Holacanthum 10.75 .

ph Te Arch. in Q. J. Micr. Se. v. 12 p. 200.

d 7 s Delponte Desm. subalp. p.38 (sep.p. 26).

o 73 Norelst. Norg. Desm. p. 37. (Subg. Tolacanthum).

d 73 Hood Fr. Alg. p. 155 .

d 75 Miclogr. Dict. p. 231 et 839 .

d Tr Front in Lemis Synops. p. 1633.

d 7 Delponte Dosm. subalp. p. 172 sep.p. IR.s).

d Tithirehm. Alg. Sichles. p. 151.

a siray Monogt. loc. Conjug. p.40. Suet. 1. Ifolaranthum Lund. (inel. Sitaulastri sect. Pleurente. rium). 2. Fielrizacantlum. Et in Not. Conj. d. 17. Franee 1, 333\%.

d st Wolle Desm. U. S. 1. 92.

o Si Stokes Iiey Desm. p.10?.

d 86 Fromk in Leunis Synops. \$ p. 197.

d si Cooke Brit. Desm. p. 12!?.

d si Alexenko Chlorosp. Filark. p. 250.

d sellansg. Prodr. Algentl. Böhm. p. 191 (Sect. L. Sichizacauthium Lund., 2. Holacanthium incl. Staur. Seet. Pleurenterium Lamhl.).

d SS Toni et Leri Fl. Alg. Ventez, p, 52.

1 s8 Roldt Desm. Grönl. p. 31 (sep.1. 29). Nubgen. A. Euxanthidium et I3. Centreuterium.

d 88 Hanytfl. Zellm. u. Hüll wallerte Desm. p. 89 (sep.1. B1). d 89 Tomi Syll. alg: p.antis et 91i.

ph sil Elfi. Anmälk. Desm. Nystem, p. S1.

o 90 White in Am. J. Sc. Arts 33 1.380 c, icon.

1) 91 Kirchn. Miks. Pflanz. d. Süssw. ed. 2 p. 21.

d st Wolle Desm. U. s. ed. 11 p. 99.

d 93 Tromer Alg. Int. orient. p. 10:3. Subgen. A. Sclizacautlun. B. Holacanthum.C. Micracanthum.

o 91 Wildem. Ols. erit. Desm. 1\%,113-126.

d 14 Sound. in Fl. Neluraska 1.3!.

phe thellheim in Pringsh. Jahro. 26 p. 730 (scn.p. 57 ).

d 95 Bailey Contrib. Queens. Fl. XI 1, 40.

\section{zelleri}

d 93 STAURASTRUM Twmer Alg. Ind. orient. r. $122 \mathrm{t}$. 16 f. 28 .

\section{xiphidiophormllm}

1 sis STAURASTRUM Wulle in Pull. Torr. hot. Club 1Rsis p. i) t. 47 f. $21 \& 22$.

d 8 - Wulle Fr. Alg. U. R. A. p. 44 t. 5 f. 21 \& 22 [ex Holle 1Raj]

d - v. simplex ibil. t.Go f. 19 .

o 87 - (v. simplex Twlle Desm. Pacif. Coast p. 136.

d 89 - Toni syll. alg" p. 1223 ("xyphiliophorom").

d 92 - Wolle Desm. U. s. ed. II p. 155 t. 19 f. 21 \& 22.

d $-r$ simple $x$ ibid., t. 4!) f. 1 ! .

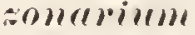

1 45 COSMARIUM West Alg. Markg. p. 71 t. 8 f. 13.

\section{$\approx 0 m a t m m$}

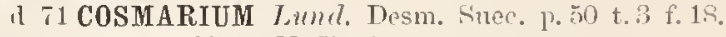

1 89 DISPHINCTIUM Tuni sivll. alg. p. 863 .

m 93 Cosm. Lütliemilll. Desm. Attersees p. 551 .

\section{*omatill}

d 91) STAURASTRUM Rörg. Desm. Brisil. p. 46 t.5 f. 48.

\section{ZYGOCISTELE}

p 85 Palsumo Alghe del eom. di Napoli p. 12..13. Seetio Zygosporear; = Desmidiacea.

\section{UIGXANTIIUM}

11 E.hent. in Berl. Monatsber. 1810 p.218. [Nulla descriptio generis. sed specini "Echini"].

rl 4.1 Kït... Spee. Alg. p. 17 . 


\section{Addenda ad I.}

nb1"1)tum p. 36 (supra in sectione I).

d 95 COSMARIUM v. granulatum Wrst Alg. Marlag. p.65 t. 7 f. 32 .

(er(u)hoj)

(1) 95 STAURASTRUM West Alg. Malag. 17. 72 t. 9 f. 10.

nr.proxull/ p. 35.

43 CLOSTERIUM E7renl, Mikr. Leb, Sild, u, T. Amer. t. 3 f. II. 7.

ph 40 - Echlard in Wiegm. Arch. f. Naturg. III. 1 l. 211 t. 7 f. 1.

o 95 - f. Tiurge Siverig. Chlor. If p. 12 t. 1 f. 3.

(16) ulutum p. 38.

o gis STARASTRUM Schmiale Beitr. alp. Alg. p. lit sep. p. 35 .

(16)

m 15 CLOSTERIUM f. minor simräter Alg. If. Rieseng. 1. 1 ?

"lli\|m) p. $t 1$

XANTHIDIUM = Sphærozosma excavatum $r$. NovarSomlix Wille sec. West in Joum. of Rot. 18 !n ]. 837 (= Tetraëdrou?!

ulfermulls p. 41.

$0 ! 5$ STAURASTRUM v. corouatn $\mathrm{f}$. Schminte in Hedw. 31 1.82 t. 1 f. 24 (vit punctulatum r. corolnatum ITest in J. of Bot. 18.4\% 17.337.

"mrrirrure ]. 42.

s8 MICRASTFRIAS $f$ excelsiol Thsl. Tot. Micr. Aner. p. $9=$ Micr. Mababuleshwarensis r.excelsior see. Tum. Als. Full. or. 1, 95.

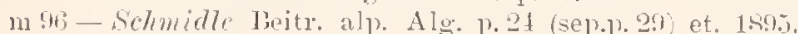
t. 10 f.s.

(III)

d "H STAURASTRUM v, alpinum rehmille Beitr. alp.

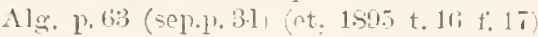

(I)\|l\|ル) ], 43.

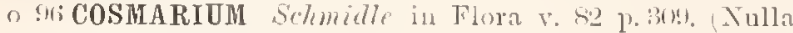
P'leurotieniopsis).

Anrex

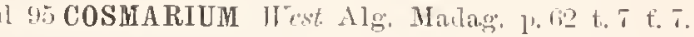

angliven) p. 11

m 5 EUASTRUM Rorge siverig. ('hInr. II 1.22.

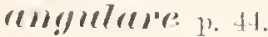

(1) STAURASTRUM f. polonica Firlle in Pamint. Fizy 11 l. 131 t. 1 f. 1 . 3 . "m!ntutum p. th.

m! COSHARIUM f. major Sctemidle in Flora v. 82 p. 307.

\section{"lumblum}

d 4s STAURASTRUM West Alg. Madag. p. is t. 9 f. 7.

"Usatull\%. 1. H\%.

m 95 EUASTRUM II est Alg, Madag, p. 51 t. \& f, 17

- -v. pyxidatum f. ibid.. t. !f f. 18.

1] 96 -f. Selmille beitr. alp. Alg. 13.21 (sep.p. 27) et, 1845. t. 17 f. 10.

o - f, scrobiculata ibid. p. 22 et. 1895, t. 17 f. 11

(1) $14 ;-f$. biscrobiculata schmidle in Flora v. 82 p. $309 \mathrm{t}$ 9 f. 15 .

a - v. attenuatum ihiu.. t. f. 16

notilupurm p. 17.

a) XANTHIDIUM $p$ dimazum Rorge Nrerig. Chlor. II 1. 11 t. 1 f., 6 .

uf 40 - West in T. R. M. S. 1 s:

"l)iculutu 1. 1\%.

o 7 MICRAS'TERIAS ducobs. Desm. Drnem. p. 189 t. 7 f. 2

Arrheriumll) 1.50.

m $\%$ CLOSTERIUM Diorge Srerig. Chlor. II p. 12 t. 1 f.

urrutum p. 3u.

9t STAURASTRUM v. vasta Selmille - St. vastum

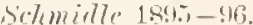

"rve"uturs p.5.

0 !1. ARTHRODESMUS Thest Alg. Malag. 1. 72 t. 8 f. 18 .

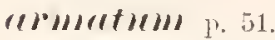

m. 9. XANTHIDIUM v. American $n \mathrm{~m}$, Eichler in l'amist. Fi\%x, 1, 129 t. 3 f. :3:3.

\section{")・(P):}

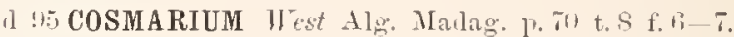

Grerillri'e 1. 5.5

$\circ$ ySTAURASTRUM $\beta$ obesum fo Firllor in Pamint. Fi\%y. 14 \}, $1: 39$ t. 4 fo

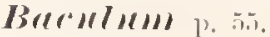

m 5 D0CIDIUM 11 est Alg. Madag. 1.41.

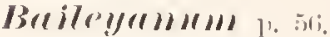

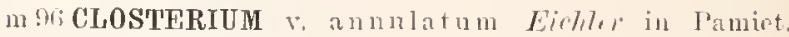
Fi\%, 14 1. 12\% 
Burleyi n. 5xi.

a 95 DESMIDIUM Ruilcy Contrib. Queensl. Lil. 11 1.37 t. 10 f. 4.

m55 - " genuina IVest Alg. Madag. P.11.

n 40 - Schmidle in Flora v. 82 p. 303.

bumbusinoides (s)hrerososmu) p. 5\%.

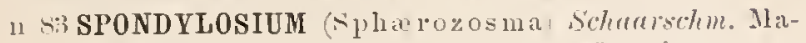
gyar. Desm. 1.279 ["pulchellum f;" omissum esse videtur, quia auctores "Willr.) Lumd." citati sunt].

bibrechiatum p. jo.

STAURASTRUM Wulle (non lieinsch) = St. tetracerum sec. 11 olle in litt.

birnorur p. is.

m 4.) STAURASTRUM ? f. Borge kverig. Chlor. Il p. 21 t. 1 f. 15. [St. Pseudosebaldi * Duacense sec. West LS!Ii!.

Birmermum 1.58.

ozf פi STAURASTRUM West in J. R. M. .

\section{bigibbre}

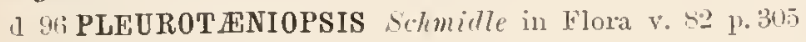
et 313 t. 9 f. 6 .

bioculatum p. 61 .

m 95 COSMARIUM Sehüder Alg. 1I. Ricsengeb. p. 18.

bipuluctutume p. 62.

d 96 COSMARIUM v. podlachicam Eichler in Paniet. lizy. 14 p. $12-9+3$ f. 2.

\section{Blyttii 1. 63.}

m 95 Cosmarium * Hoffii Borge sverig. Clilor. Il 1\% 16. 0 : 15 - f. australica Schmidle in Flora v. 52 p. 305 t. 9 f. 13. nu sil - West in Journ. of Bot. 34 p.šง.

Boecliii 1. 13 .

m! COSMARIUM f. minor Eichler in Pamiet. Fizy. 11 p. 126 .

\section{Boldtii P. 13.}

d ! EUASTRUM Schmidle Beitr. alp. Alg. 17.21 et (1.545) t. $16^{\circ}$ f. 5. [Eu. denticulatum sec. West in Journ. of Bot. 31 p. 330i].

Botintis p. fi.

nu cki COSMARIUM $\beta$ subtumidum Schmidle in Flora v. 82 1.318.

c su - Rorge Variabilität Desm. P. 293.

1 910 - v. snbpulchrum Eichles in Pamict. Fizy. 1.1 1) $12 \bar{i}$ t. 3 f. 22 [ $=\beta$ gemmiferum. ut mihi videtur]

1 - - ? f. ibil.. t. 3 f. 23 .

$p^{1 l_{2}} 96$ - Klels. Beding. Fortpflanz. Alg. 1.25\%.

b) lelutum p. 15.

oz!1; STAURASTRUM Tist in J. R. M. S. $1891 ; 1 \% 159 \mathrm{t}$. $1 \mathrm{f}, 53-6$.

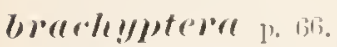

m 5.5 MICRASTERIAS liorge Sverig. Chlor. Il p. 23.

Hedisingii 1. 15.

m 90 COSMARIUM f. erosa Borge Srerig. Chlor. Il 1. 15. biebissomii 1\% 6i.

m 90 CYLINDROCYSTIS Amderss. Sverig. Clilor. I p. 19. m 96 - v. turgida fichmidle in Flora v. 82 1. 3113.

Brebissomii p. bs.

- 95 GONAT0ZYG0N v. Kjollmanni schrüder Alg. H. Ricsengeb. p. 11.

my - f. gracillima Jiorye sverig. Chlor. II p. 11.

Brevispilll 1\%

- 96 STAURASTRUM $\beta$ retusum Eichler in Pamict. Fizy. $11 \% 132$.

Bullleimii p. .0.

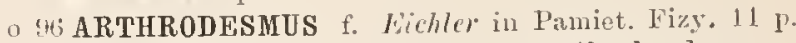
129 t. 3 f. 34. [Nova spec. ad $A$. nothochondrum accedens ?].

\section{CALODESWIUN}

(1) 36 Wimmer in Uelor, d. schles. Gesellsch. f. vater.l. Cult. im Jalne 1835 p. $8 \%$. Genus Diatomacearum .1\%. Micrasterias, Euastrum et Cosmarium? "Vermuthlicl Micrasterias ": Kirchn. in Alg. Schles. p. 1].

rolospormme 1. 11 .

ozf 96 CLOSTERIUM f. major West in J. R. M. $s .15,96$ p. 152 t. 3 f. 2.5 et 26.

m 96-Eichler in Pamiet. Fizy. 11 p. 12.5.

\section{canelirulutum}

d 96 CosmaRIUM West in J. I. M. S. 1896 p. 154 t. 4 t. $5 \overline{7}$.

cirenlare

d 16 STAURASTRUM Schmidle Beitr. alp. Alg. 1.92 (sep. p. 38) et. 1895 , t. 17 f. 8 -9. [Non Meyen].

clepsydue p. it.

- 4 STAURASTRUM $\beta$ a u uminatum fo biradiata Eichler in Pamiet. Fizy. 14 11. 131 t. 4 f. 43 . [?].

Clerei p. it.

m 96 PENIUM Eichler in Pamiet. Fizy. 14 p. 124.

CLOSTERIUII \%. 73 .

plız 94 Klebs VerhäItn. männ. u. weibl. Geschlechts in der Natur. p. 28.

Colleii 1. T.

a 96 COSMARIOM Eichler in Pamiet. Fizy. 14 p. 125 t. 2 f. 13.

compactuml p. it.

o $\$ 16$ EUASTRUM Selmidle in Flora v. 82 p. 310 t. 9 f. 1 i (efr Eu. incurvatum et annulatum).

iomelemsutre P. TR.

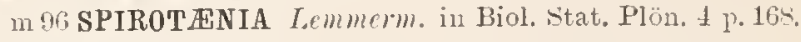

ronferta p. 78 .

m 95 MICRASTERIAS Jorge srerig. Chlor. Il p. 23.

ronfis:l) 1. 79.

zf 9 ) COSMARIUM v. regularius West in J. R. II. S. 1826 1. 156 t. 4 f. 41.

rosniculatume p.

ozf 96 STAURASTRUM West in J. R. M. S. 1846 p. $157 \mathrm{t}$. 1 f. 37 . 
Cur'mו 1. 8:2.

mo9t CLOSTERIUM v. Brasiliense Sclmidle in Flora v. 821.301.

roverutull p. s3.

lih SS PLEUROTENIUM Aderle in Jenaisch. Zeitschr. 22 1. 331 et 3336

roponteletum p. sis.

d !5 DOCIDIUM Mobius apud Bailey Contrib. Queensl. F1. II p. 38 t. 10 f. 1 et 2 (2) Mubius 1891).

COSMAIIUM P. S4.

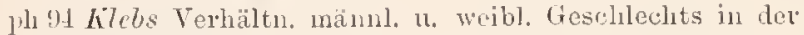
Natur p. 28.

COSMOCLA I I U. 1. 85.

o 93 Zopf in Beitr. z. Plyys. M1orph. nied. Organism. Kirylt. Lab. Halle TIT p. 23-2.3. Genus Sciadiac.

costutum 1).85.

12 ! CLOSTERIUM Eichler in Pamiet. Fizy. 1.125.

\section{(1)enctum}

d 3t CALODESMIUM Nimmer in Uebers. 1. Schles. Ges. f. vater. Cult. in Jalure 1535 j.87. Cosmarium?].

\section{crenctum. p. 8 .}

o 95 COSMARIUM f. Borge sverig. Chlor. Il p. 16 t. 1 f. $\mathbf{\imath}$.

\section{(")enulutum p. 88}

m 96 COSMARIUM sictemidle in Florn v. 82 1'.305.

cristrutull p. S!

m 96 XANTHIDIUM v. uneinatun $h \mathrm{cmmerm}$. in Biol. Stat. Plön. 4 p. 170.

Crux malitensis 1 . u.

91 MICRASTERIAS Istrinfi in Füluajzi Kinzlemrnyek 1864, fig. 8 ]. 166.

("uculluitu p. 12.

o 55 DISPHINCTIUM Mobius in Baitey Contrib. Queensl. F1. XI 1. 38 t. 10 t., 11.

o $96 \operatorname{Cosm}$ f. Wollei Eveleler in 1'aunet. Fizy. 11 p. 124; t. 2 f. 14 ( IV lle $188+$ t. 12 f. 11 .

(21)ertull p. 93.

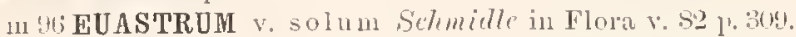

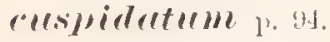

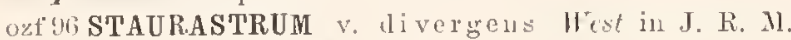
S. 1596 p. 157 t. 1 f. $5 \%$

cutirnlare

døf « PENTUM Itest i J. R. M. \$. 1. 153 t. 1 f. $13-11$.

eyrliculle 1. it.

a 10 COSMARIUM areticum f́, minutissima Eichler

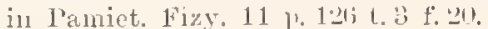

Cylimalls p. 91\%.

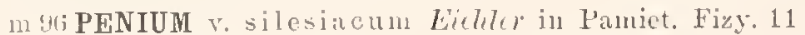
P. 125.

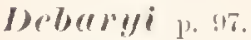

1195 COSMARIUM f, Borge sverig. Chlor. 11 p. 17 t. 1 f. 8 . decemalemtuta r.95.

- 95 MICRASTERIAS Mobius apul Buley Contrib. Queensl. Fl. p. 11 t. 10 f. 17.

m 96 - Schmidle in Flora v. 82 p. 310.

d - f. ibid. t. 9 f. 18.

drjectum T. IS.

d "5 STAURASTRUM $\beta$ Debaryanum f. Borge Sverien. Clilor. II p. 2.1 t. 1 f. 14 [Staur. glabrum sec. West in Journ. of Bot. 1896 p. 337].

Delpontei 1. 19.

m: ChOSTERIUM Eichler in Pamiet. Fizy, 11 p. 125.

antivellutr 1. 99.

m 16 MICRASTERIAS v. notata Lemmerm. in Biul. Stat. I'lïl 4 1\% 126 e. fig. 18.

oef - West in J. R. M. ค. 1890 p. 153 t. 3 f. 29.

DESHIJIACLA P. 101.

ph 88 Aderlotel in Jenaisch. Zeitschr. 22 p. 323 etc.

pls $\$ 6$ Hobirs in Biolog. Centralbl. AVT p. 133.

- 4 Forge Variabilität Desm. p. 289.

phat Klebs Beding. Fortpflanz. Alg. p. 256.

Jirlici p. 105.

- 55 STAURASTRUM $\beta$ parallelum f. Tiurge sverim. Chlor. II p. 23 t. 1 f. 13 [Staur. lanceolatum f. sec. Wrest in Journ. of Bot. 1840 1. 337].

didymotor:llm p. 10i.

o H CLOSTERIUM Eichlor in Paniet. Fizy. 11 1. 1:5 t. 2 f. 11.

\section{didymocrerpulm}

oz 96 PENIUM Wext in J. L. M. S. p. 153.

diffirile p. 1118.

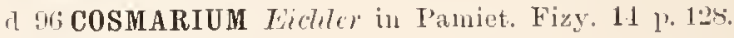

Digitus p. 108.

Ih 95 PENIUM Lagerth. Pliycoporplı. 1.3 (v. ventricosum Jagerll. ined.)

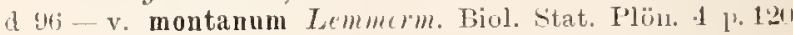
r. fig. 15-17 inclus. Heimerl 1891 et Liitkemill. 18931.

dilutritum l. 109.

o is STAURASTRUM Mobrits and liviley Contrib. Queensl. Fl. XI 1. 12 t. 10 f. 21.

(1) 96 - f. anstralica Selmidle in Flura s.2 p.311 t. f.

\section{MIPIAR'TIIRUM}

d 10) Cordu in Aln. d. Carlsb. 1sio p. 20s. Sect. Odontella $[=$ Onychonema $]$.

dissiliell: p. 110.

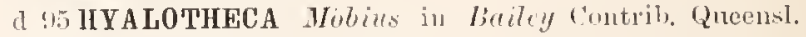
Fl. XI p. 37 t. 10 f. 3.

d $96-$ - v. punctata Lemmerm. in Biol. Stat. 1 I. 111.

diverirentull 1. 111.

m! EUASTRUM Eicher in Paniet. Fi\%y, 11 p. 130.

I) OCJIIU II 112.

d 95 Riviley Contrib. Queensl. Fl. Al p.38. 
Horeubergii p. 111.

3) CLOSTERIUM simith Conjug. of Clost. [Figg. i et 7 e Morren Mem. s. 1. Closter. (Cl. Lunula).

o* sij- Hest in J. R. M. s. 1896 p. 151.

d $: 16-v$ concavum Schmidle in Reinecke Fl. samo 1.

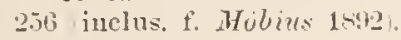

\section{ETHerubergii p. 111.}

m!6 PLEUROTENIUM Schmille in liencele Fl. sanoa 1. 2.55.

o :46- f. Fichler in Pamiet. Fizy. 11 r. 129 t. 3 f. 32.

Eirhleri p. 11\%.

a sisTAURASTRUM fo Eicher in laniet, Fizy. 11 l. $13: 3$ t. 4 f. 56 .

\section{regulls. p. 116.}

15 SPHÆR0Z0SMA Hus:, Brit. A!g., adde: t. 83 f. 11-12 ("Yery bad").

\section{cumrerginutoconstuirtum}

d !n COSMARIUM Lemmerm. in Biolog. Stat, Plön, 1 l. 1.1 Cosm. Botrytis v. emarg. Femm. 1ston.

Emallirheriallull p. 11s.

ะ 5 MESOT ENIUM Cohn in 83 Jahreshericht schles, fies. f. P. Cultur (1855) p. 1113.

\section{(2)0:11!m}

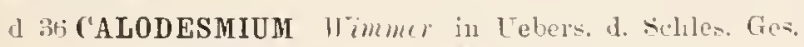
f. v. Cult. 1935 p. $\$ 6$. [Micrasterias sp.. ut milis videtur].

furcigermm $\mathrm{H} \cdot 12 \mathrm{2}$.

d (hiSTAURASTRUM f. pseudofurcigera Lickler in I'anicet. Fizy. 11 p. 13 to t. 1 f. 53.

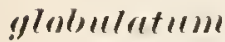

d ! M COSMARIUM lfest in Jouru. of Bot. 31 p. 380 t. 341 f. $i$ et 8 .

\section{Goebelii 1. 131.}

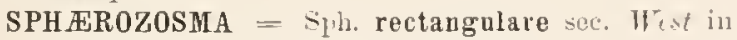
Jour:1, of Bot, 34 1.33is [terl dubitu].

\section{GONATOZIGON p. 131.}

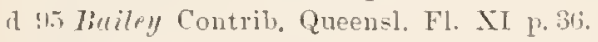

morile 1. 131.

15 CLOSTERIUM Mubins apud liailey Contrib. Qquecnsl. Fl. XI t. 10 f. 18.

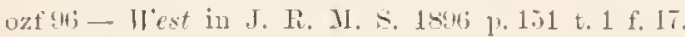

grovile p. 133.

m1 96 STAURASTRUM v. uniseriatum schmille in Flora v. $\$ 2$ p. 311 .

y)rerile p. 13:2.

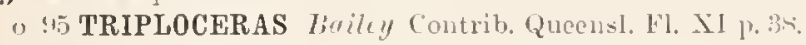

grullutorium! p. 1333 .

a USTAURASTRUM r. miedzyrzeczense Eichler in Pamict. Fizy. 11 p. 132 t. 1 f. .1 lichl. 1 s! 13 .

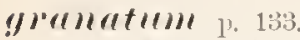

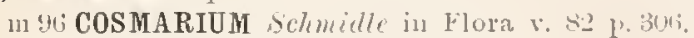

d - r. gibbosum ibid. et t. 9 f.s.

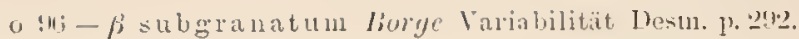
f. $1-1$ p. 293 .

"/ranulatus p. 135.

ph s' TETMEMORUS delerh, in Jenaisch. Zeitschr. 22 1. 386.

lelranyulare I. 135 .

o mi CoSMARIUM f. simplex bichle in Jamict. Fizy. 11 p. 127 t. 33 f. 21.

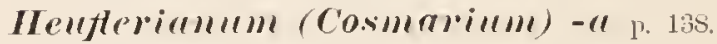

11 URSINELLA Kuntze Rev. gon. 1\% p. Y.1.

he.xogyolllll p. 1330

1. Sti EUASTRUM in Jouru, of Bot. 31 p. 378 t. $34 \mathrm{~L}$ f. 10.

hexcugomus p. 139.

m !n ARTHRODESMUS fichler in Paniet. Fizy. 11 p. 1:0.

liills p. 139.

n96 HYALOTHECA selmille in Flura v. 82 1. 203.

hume)osum p. 111.

o 9i; EUASTRUM Eichler in lamiet. Fizy. 11 p. 130 t. 3 f. 35 , monst 1 . ?

IIystivix p. 142.

d) 9 STAURASTRUM r. papillifora $1 . \mathrm{cmm}$ (m) in Biol. sitat. Plön. I 1.126 c. fig. $19 \div 1$.

imoisa P. 113 .

in 96 MICRASTERIAS $\beta$ Wallichiana schmidle in Flura v. 821 1.311.

\section{inrollsyirllum}

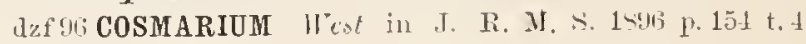
f. 15.

iाr"1)"11) 1. 111.

11 ؛ CLOSTERIUM $f ;$ majus Schmidle in Flora 5 . s. p. 304.

indir.1111 l. 14li.

o 96 PLEUROTANIUM Selmille in Reinecke Fl. Samba 1. $25 \%$

(l) - v. priklongum ibid.

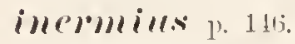

1196 EUASTRUM sichmille in Flura $v$. 8.309.

intrimedium r. 1 s.

o 5 EUASTRUM Eichler in Panifet. Fizy. 14 1. 130 t. 3 f. 37 moustr.।.

julvidum 1. 1.j.

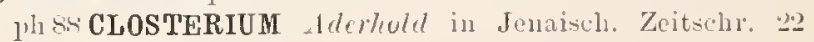
1. 331 .

Kjellmani 1. 15\%.

d !SSTAURASTRUM v. rotundatum Wiet i J. R. M. $\lesssim$. p. 15 s t. 1 fi. 11 ;

Kinlustai

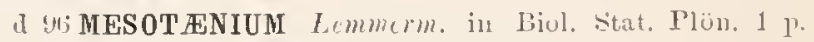

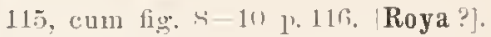

Kúllatugii 1. 15..

o 16 CLOSTERIUM Sichmille in Flora v. \&2 1.301. 
Ire'e 1. 153.

- 16 COSMARIUM f. Turge in But. Nut. 1 s:y p.111, f. 1 1. 112.

o - f. ibid. 11. 11: et f. 5 .

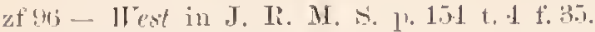

laureolntu11, 1. 15\%.

my 96 CLOSTERIUM West in J. R. M. s. 1 s. $\mathrm{p}, 150$.

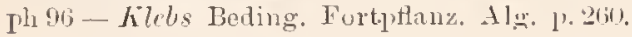

latipes (Eurest)ull') p. $15 \%$.

11 91 HELIERELLA Kuntze Rev. gen. 11. p. bis.

Lribleinii 1'. 15ir.

CLOSTERIUM f. borye siüsw. Clulor. Arely, f. y et $10=$ CI. littorale sec. 11 cest lsini.

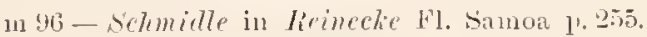

Teptodermenm p. 157.

:16 STAURASTRUM f. minor Eicleter in Pamiet. Fizy. 14 p. 132 t. 4 f. 52.

\section{Libellula 1. 15\%.}

m 96 CLOSTERIUM Lemmem. in Biol. Stat. Plön $\perp$ p.

Librltii p. 158.

mis STAURASTRUM Fichler in Pamict. Fizy, 11 p. 132

lineat 11m! 1. 15s.

plu $s$ CLOSTERIUM Aderhold in Jenaisch. Zeitsehr. 22.2 11. 331 et $381 \%$.

littorale p. 1.59 .

d 96 CLOSTERIUM $v$, crassum West in Joum. of Bot. 31 p. 378 t. 361 f. 18 . Cl. Leiblenii fo Morge süssw. Chlor. Arch. f.! et 11) ad Cl. littorale pertineat.

\section{LeIIII) p. 160 .}

jhz 96 - Klels. Beding. FortpHanz. Alg. 1, 260.

Jusitunicum p. 16?.

dzf 90 COSMARIUM West in J. R. II. $s .18916 \mathrm{p}, 155 \mathrm{t} .4$ f. 3 is.

margaritureuml 1., 161.

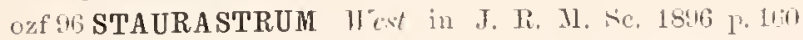
t. 4 f. 33 .

margaritiferull" $\mathrm{l}^{1}$. 16.

m 96 cosMaRIUM b. incisum ticher in Iamict. Fizy. 1.1 1. 1.2.

megriomotulll P. 16i.

STAURASTRUM f. hastata sehmidle = st. spongiosum sec. Ilrst in Juurn. of Bot. p. 33i.

Mrueglimii p. 1tit.

in 88 COSMARIUM Adcholl in Jenaiseh. Zeitsehr. 2? 1. 332.

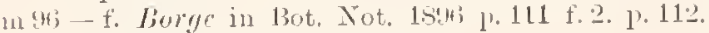

a - tr. ibill, 1'. 112 f. 7 et 8 .

$m$ - f. ibid. 1., 11 \%. f. 91 1. 112

l $-f$. ibill., t. 10.

6 96- - v. concinnum schmidle in Flora r. 82 1) 306.

Metula 1. 16?.

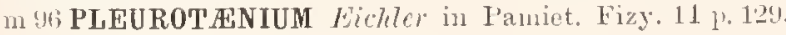

mir.m?m.

d 96 STAURASTRUM Test in J. F. M. \&. p. $159 \mathrm{t}$ t. $t \mathrm{f}$. $50-51$.

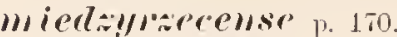

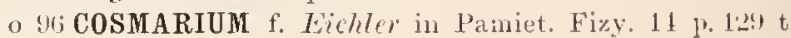
B f. 30 .

miแIt川II ]. 172.

o !li COSMARIUM schmidle in Flora v. 82 p. 30i.

monilifermm. p. 173.

o !H;CLOSTERIUM Rorye Tariabilität Desm. p. pul.

moniliforme p. 17.

o 96 COSMARIUM f. Schmidle in Flora v. 42 p. 30 i t.9 f. 9. [Amon potius Cosm, Jacobsenii ?].

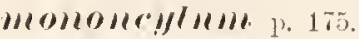

o me EUATRUM f. Ficher in Paniet, Fizy, $1.1 \mathrm{p}$. 130 t. 3 f. 36.

M1110.s\% 1. $16 \%$.

m $\oiiint$ HYALOTHECA Fichler in Pamiet. Fizy, 11 l. 12.

\section{MHeregredremense}

a se COSMARIUM Thest in Journ. of But. 31 p. $37: 1$ t. $31 ; 1$ f. 11 .

merpolitumuml p. 180.

d s) COSMARIUM $v$ australicum schmidle in Flora v. 83 1. 308 t. 9 f. 10.

\section{"lephroirlentm}

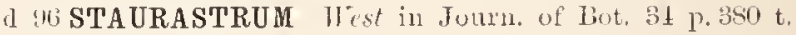
:3it f. 13.

morlulosum tr. 18?

fih 48 PLEUR0TANIUM Aderkold in Jenaisch. Zeitschr.

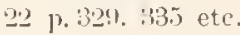

Nomalstedtiommm! 1. 1933.

o !h ONYCHONEMA Eichler in Pamiet. Fizy. 11 p. 121 t. .2 + : 4.

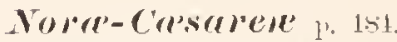

!ב STAURASTRUM Holle Desm. U. s. ed. If t, 19 f. 8 et ?.

obsolvetum l' 1s6

o so COSMARIUM v, punetatum schmidle in Flora v. $42 \mathrm{p}, 307$.

obtusa -llu! (Closterillim) P. 18\%.

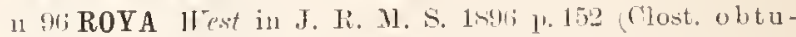
sum $\quad$ Brib.).

d - v. montana ibil. t. 3 f. 23 et 24 (Clobtusuin f. West in .J. R. M. S. 18t?. - l'ropria spee.?),

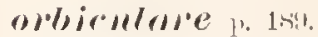

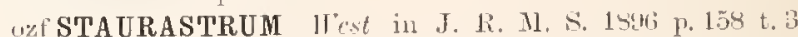
f. 29 .

m- f. re. Firhler in Pamiet. Fizy, 14 p. 132 to 1 f. 19.

m - fo p. iltit.. i. io.

omertume 1. 1!+1.

a 9i COSMARIUM v. depressum Eichler in l'amiet. Fizy. 14 j. 127 t. 3 f. 25. 


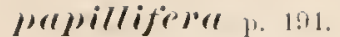

n! (i); MICRASTERIAS verucosa Schmidle trot in Jomr11, of Bot, 31 p. 330 (1111la var. sef. MT.).

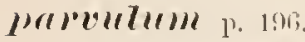

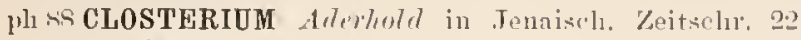
1. 3:39.

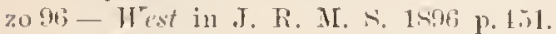

m Mi - schmidle in Reineclie Fl. Samoa p. 2.t;,

pertiultum ]. 197.

o a EUASTRUM f. Borge in Thot. Not. 1s:11 1. 111. f. 1 1. 112.

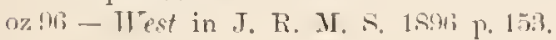

pertinoirles p. 15i.

o m COSMARIUM West in Journ. of Bot. 34 p.379 t. Bhil f.?.

Phuseo/us p. 199.

mini COSMARIUM llest in .Tomm. of Bot. 34 p. Bro.

\section{I'i('ll)!}

MSTAURASTRUM West in .T. R. M. S. 1 S. p. p. $159 \mathrm{t}$. 1 f. 4 ! .

pimmatifirle p. $2 u 1$.

0 !f MICRASTERIAS f, mixta kichle $\gamma$ in Pamint. Fizy. 14 1. I3 1 t. 1 f. 10 .

- f. granulata ibit.. t. 4 f. 11 .

miratum l. 20r?

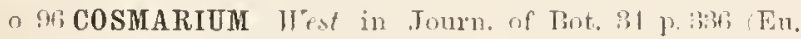
subcunoatum schmidle.

Porticumum p. 20.1.

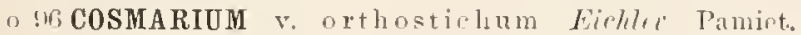
Fizy. 14 p. 127.

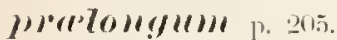

zo 96 CLOSTERIUM f. breyior Wrot in .T. R. M. S. ISen; 1) 151 .

m - f. hrevior I:ichler in Pamiet. Fizy. 14 j 125.

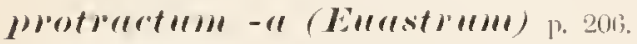

" 1 URSINELLA hum Rev. gen. 10, p. y.5.

motiontum p. 201.

STAURASTRUM Racil, 1895 (non .lolms.) = st. levispinam liss. sec. IT'st in Journ. of Tot, 18sh 1. 33.3.

motubroum (cosmanium) p. son.

n: !1 URSINELLA himt:e Rev. gen. 1]. 1, !2.

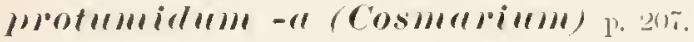

11 !1 URSINELLA Kuntze Rev. gen. 11. 1.!25.

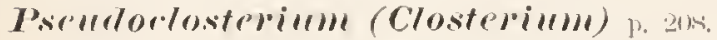

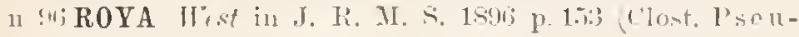
loclost. liou

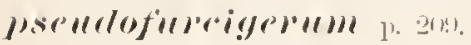

"w; STAURASTRUM t: minor Fichte in Panim, Fizy. 11 1. 1333 t. 1 f. . . 1.

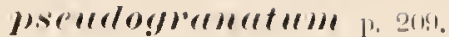

m !hi COSMARIUM Eichler iu t'aniet. Fizy, 14 p. 128 (sensu Gutw:i.

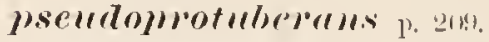

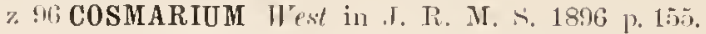

un Fizy. 11 1. 1:2-.

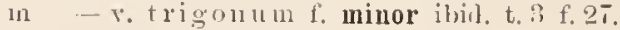

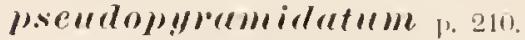

m !fi COSMARIUM * stenonotum Eichler in Paniet. Fizy. 11 1. 127.

m - f. angustior ilili., t. 3 f. 24.

Psemaloreynesi j. 210.

o 9icosmarium Tiest in Jomm, of Pot. $31 \mathrm{p} .333 \mathrm{fefr}$ Cosm. Regnesi v. montanmm).

\section{bsemilospirotrenium}

1) M CLOSTERIUM Lemmerm. Biol. Stat. Plön, 4 p. 11s,

d - a. typicum iluid. e. fig. 11.

1l - b. fasciculatum ilisl.

d - e. variabile ibil., fig. $12-11 \mathrm{p}, 11$.

funuctulatum 1\%. 21.2.

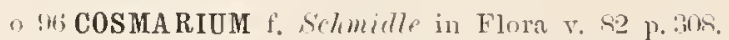

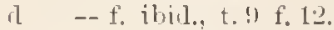

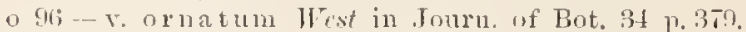

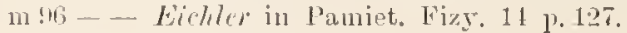

m-v. perforatum ibid. 1. 12!).

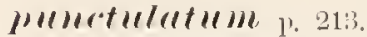

o :H STAURASTRUM v. coronatum ITest in Jomrn. of Pot. 31 p. 33 it. alternans v. coronat um f. Schmirll.)

11!!mmrellm P. 214.

- Mi STAURASTRUM v. subglobosum f. depauperata Eichler in 1'aniet. Fizy. 11 p. 131 t. 4 l.

yurdrangulare 1". 210.

m !h DESMIDIUM siclmidle in Flora v. 82 p.303.

yurdiangulare p. $21 \%$.

minisTAURASTRUM Eichter in l'amiet. lizy. 14 p. 131 t. 4 f. 4 ij.

il - $v$. sexcuspidatum ibid., t. 1 f. $4 \pi$.

yurelloum!/ulutum p. 2tri.

a Desmidou Fichlw in Pamiet. Fizy. 11 p. 121.

vuralutull 1. 217.

1) "i COSMARIUM f. cylindrica Firlite in Pamiet. Fizy. 14 p. 121 t t. 2 f. $1 \overline{5}$. Penium sp.. ar P. rufescent.].

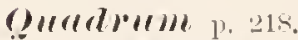

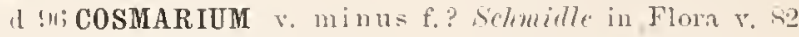
p. $3(19$ t. 9 f. 14.

(i) (1) - vamoense schmidle in Rincelic Fl. Samon p. 2.7 c. fig. 2 .

?"Imsillus 1, 2ts.

COSMARIUM v. a! pinmm est = Cosm. tetraophthalmum v. Lundellii sere. Hext in .Journ, of Pot. 1s'm; p. $333 \%$. 
lialfsii p. 220.

m ! CLOSTERIUM bo typicum selmidle in Flora v. 82 1. 301 .

vertumgulare T. 221.

d 9H COSMARIUM v. africanum Wrst in .Toum, of Bot. 34 p. 370 t. 361 f. 11.

$11-$ v. Cambrense ibil. (Cosm. gotlandicum v. Cam. brense $T$ (un.)

rectungulare p. 222.

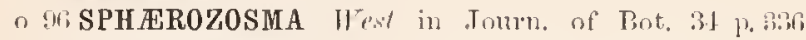
(sph. Goebelii.

liegrlelli n. 22?.?

mo cosmarium f. major Eichl. in lamiet. Fizy. 11 12. 127.

liegnesi p. 222.

z : If COSMARIUM West in T. R. MI. S. 1899 p. 15is.

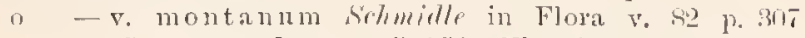
(Cosm. pseudoregnesi) [Cfr. West in .Tonn of Bot. $1.9113 \mathrm{p}, 33[i]$.

retusiforme p. 221.

d sf COSMARIUM f, ornata Eichler in I'amiet. Fizy. 14 1. 128 t. 3 f. 2 ?.

Rotsillsonianmm r. 22:).

a M XANTHIDIUM Iest in .T. R. M. S. $1990 \mathrm{p} .156 \mathrm{t} .8 \mathrm{f}$. $21-2.2$.

rostrotull! 1. 226.

m!

rotuta r. 220\%

a gr MICRASTERIAS v, pulchra $L \mathrm{emmem}$. in Rinl. Stat. Plöiı. 1 p. $17: 3$ e. fig. 7.

\section{IROY}

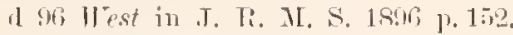

\section{"Scoiraliercersu"}

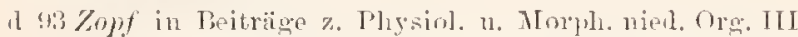
1. 2:?. Familia Chlorophycearum. Gen.: Dicetyospluzrium. Cosmocladium. Gocarlinm. Seialinm. Actidesuium.

scexcollgmlare p. $29: 3$

no mosmarium f. extensa Firhlor in Pamict. Fizy. 1.1 1. 1227 t. 3 fi. 2 ri

serimgulare p. 233.

is 1 STAURASTRUM $f$. anstralica, selmirlle in Flora $x$ 82 p. p.311 t. 4 f. 19.

Sibirirallll p. 28:3.

om 9 STAURASTRUM f. trigona trest in .T. R. M. S. p. 15.7 t. 4 f. 83

\section{simullutull}

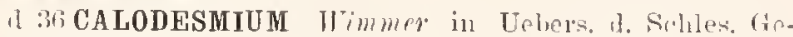

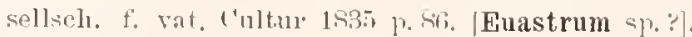

Sullthii p. 28.3.

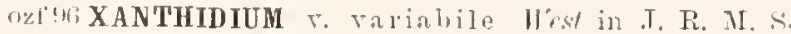
l. 1 isti t. 4 f. 4 (1) spimlllo.s"lll p. 23s.

m 96 EUASTRUM * a fricantum West in .Tonrn. of Bot. 34 p. 37.

spirostriolntum p. $23 \mathrm{~s}$

m 96 PENiUM f. scabra Fichlev in Pamiet. Fizy. 14 p. 12. t. 2 f. 10.

spongiosume p. 239.

m !n STAURASTRUM Eichler in Pamiet. Fizg. 14 p. 132.

subrostatum, p. 24.

o 96 COSMARIUM f. mingr West in Jomrn, of Bot. 31 p. 379 t. 361 f. 15.

subcrenritull p. 24.

$m$ an COSMARIUM Eichler in Pamiet. Fizy. 14 p. 128.

subrumertwm j. 24.

n !16 EUASTRUM W'est in Jonrn. of Bot. 81 p. 333 (verisimiliter $=$ Cosm. plicatum $\mathrm{f}$.

\section{subdilutrutum}

a 96 STAURASTRUM Irest in Joura. of Bot. $31 \mathrm{p}$. $390 \mathrm{t}$. :361 f. 16.

sublobutum p. 215.

n 96 COSMARIUM v, minntnm f. elliptica Eicher in Pamiet. lizy, 14 p. 126 t. 2 f. 18.

\section{subortiralare}

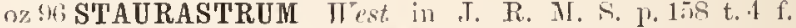
ts St. orbiculare loy seott. Desin. $18 ! 1$ t. 3 f. 7).

\section{sub)immutum}

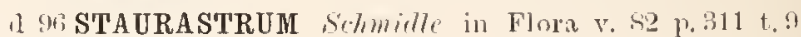
f. 20.

stbtumidmm p. 2th.

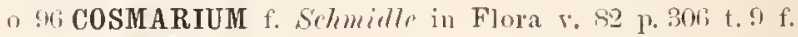
11. [Quill. ?].

subturgidum, -a (Dyspllimrtimu) r. 2.]8.

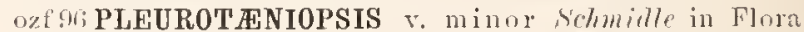

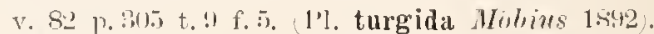

mi COSHARIUM schmille in Reinecke Fl. Samoa p. 25.

subermustum

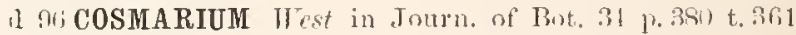
f. 17 .

Surrotiai p. et?.

n 96 DESMIDIUM f. puuctata Fichler in Pamint. Fizy. 14 1. 124 t. 2 f. 8

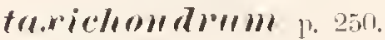

n ! th COSMARIUM $p$ lithuanjom Eichler in Pamiet. Fizy. 14 p. 128

telifirllm 1. 251.

o of STAURASTRUM West in Tomin, of Bot. $34 \mathrm{p}$. 3at it. polytrichum $r$. alpinum

trinte

1) M; PLEUROT ARNUM Schmirlle in Flnm r. 82 p. $304 \mathrm{t}$. !I f. 1. 
tetrachondrulue p. 253.

d to CosMaRIUM f. verrucosa Fichler in Pamiet. Fizy. 14 p. 1.26 t. 3 f. 14 .

tetrugoulum p. 253.

d ! (i COSMARIUM f. bipapillata kichler in Pamiet. Firg. 11 1. 12 is t. 2 f. 1 i.

trifidlllll P. 2.in.

o 16 STAURASTRUM Eichler in I'aniet. Fizg: $11 \mu, 132$ t. $4 \mathrm{t}, 4 \mathrm{~s}$.

\section{teoch iscosporthm}

daf w CLOSTERIUM West in J. R. M. \&. $1496 \mathrm{p}$. 151 t. 3 f. 1 ti- -9 \%.

\section{morhisrum}

d M COSMARIUM Thest in Journ. of Bot. 34 p. 37 t. $3 f i 1$ f. 12 .

\section{trulureete p. 2100.}

o 16 MICRASTERIAS $f$. Fichler in Pamiet. Fizy. 14 p. 130 t. 1 f. 38 .

o- f. elevata ibid.. t. 4 f. 39.

Hulleatulll p. 261.

mon PLEUR0TANIUM f. curta Fichler in Pamiet. Fizy. 14 p. 1.2. t. 3 f. 31 .

tumidum 1. 26:2.

m 9. CLOSTERIUM Schmidle in Teinecke Fl. Samon 1. 255. tul'gicluml p. 2ti3.

d EHCLOSTERIUM $f$, attenuata richler in l'amiet. Fizy. 14 1. 125 t. 2 f. 12.

\section{"1116bourtullm!}

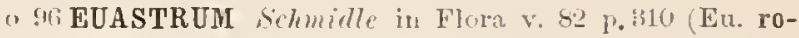
stratum subs]. umbou. West, iuclus. v. elegans liest und r. promorsum Nordst.).

rellustulle p. 2lin.

o :k COSMARIUM f. minor schmidle in Flora v. 82 1\% 307 . 1.erlelleosillll 1). 268.

m 1 HEUASTRUM West in Journ of Fot. 34 p. 378.

royesiclemll T. 2i1.

o $\$ 6$ COSMARIUH $r$. 0steri West in Journ. of Bot. $34 \mathrm{p}$. 33 (Cosm. Ostern.

Wallirhii p. 2it.

o !n MICRASTERIAS Schmidle in Reineck Fl. Samoa P. $25 \%$

solletulll p. 283 .

96 COSMARIUM Lichlor in Pamiet. Fizy. 14 p. 126 t. 2 f. 16 . 


\section{Sine nominibus enumeratæ chronologice species cum citationibus}

\section{descriptionum vel iconum.}

1 d 1774 Corti Oszervazione microse. s. "l'rem. p.112 t.2 f. 17 i, $q$ et l, s: "Corpicetti a bacello" [Clost, acerosum? sec, lihent. Inf. 17. 93$]$.

2 a - ibil, fig. 17 a. b et m. $n$ /Clost. Dianx sec. Flernb. Tuf. p. 92].

3 d 17s1 Fichlom Naturgesch, kleinst. Wasserthierch. p. the t. J t. (C: "Der" hal be Mond" Clost. Lunula sec. Jimul,; Clost. Dianæ sec. Jucols.].

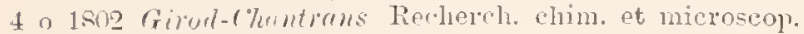
n. 20.21 t. 2:3 11:0 T: "Conferve inédite" [Clost.

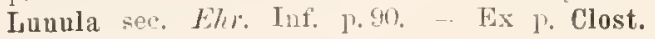
moniliferum?].

5. 1812 rmithuisen leitr. Physiognom. n. Eantoguns. 1). 322 t. 2 t. 11): "I uf fusor i um". [Clost. moniliferum sec. J'terenb. Inf. p. !1. - Cellnla prarum curvata pyrenoidihus semicellularmm $3-1]$.

6 - ibill. 1,.32:3 t. 2 f., 11 : ein grünes lnfusorium Cosm. fern inter pyramidatum et rectangulare?.].

7 त 1826 Puech Naturv, Obs. p. li1 t. 1 f. 2: Vibrio. Clost. parvolum ?].

8 d - ibil. f.: [ Clost. Diana 1. acuminatum ?].

(1) 1 - ihid. ], 62 f.t [Clost. acutum?].

10 a - abil. p.ti2 t: is Clost. striolatum? Cfr. Klels 1)-tpr. Ueam. t. 2 f. 1 a].

11 1 1s:30 l.cillsin Alg. Fennerk, in Flora 1930 1.31.5 t. 1 f. 2 sine nomine /Cymbella reniformis $-1 \%$.].

12 ph 1 s:3 H yen Beitr. z. Ptlanzenphys. in $11 \mathrm{regm}$. Areh. f. Yatm19. 3. I 17. 125 t. 10 f. 2: Clost. Clost. moniliferum ? 1. Ehrenbergii ?].

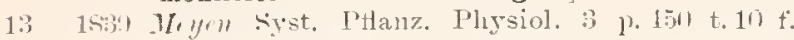
31: Euastr. Cosm. ar Phaseol. l. bioculatum -miss. latiol. .

141511 Jujwill llist, 12at. 1. zoophyt. t. 20 f. 1!): Staur. [Staur. paradoxım?].

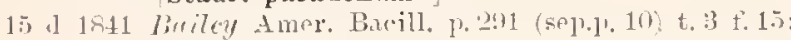
Xanthidinm n:0 2- Xanth. Arctiscou $k 7$ ven?. 1+13].

16 त - - ibil. p. 241 t. 3 f. 16 : Xanth. $11: 03$ [X. coronatum sec. Flurnh. 184:3, sen? non ita, potins Stanr. furcatum].

17 - ibill. 11. 2!:3 t. 3 t..21: Micr. n:n 3 [Pediastrum].

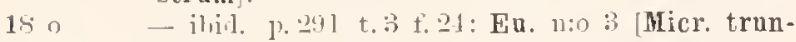
cata

1! - ibid. 1. 2445 t. 3 f. 25: En. 11:0 + [Euastr. ame ricanum litrenb. 181:?.

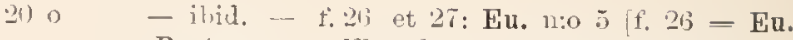
Pecten sec. Firent. 184:3 (Eu. oblongum); r. $27=$ Eu. ansatum sec. Hiteenb.; f. 27 a et $b$ Eu. Didelta esse mili villetur, $27 c=?, 27 d$ = En. gemmatum].

$210 \quad-$ ibid. - f. $28:$ En. n:0 b $\lceil$ Eu. cariuatum Eh. renb. 1813:; Cosm. ovale $\beta$ Rirlfs 1814 inter synonym.].

22 d - ibid. - t.2!): Eu. n:0 7 [Eu. pinnatifidum sec. hütz. 1815!]

23 d - ibid. p. 20\% t. :3 f. 9): En. n:o !) [Staur. rugulosum livel. in Ralfs 1.its: - Phyc. denticulatum kiltz. 184!). nee Neg. 1st9].

21 d $\quad-i b i c l$ t. 10: Eu. 12:0 10 [Xanth. antilopæum f.]. 2.) 1 - ihicl. f. 13: Eu. 11:0 11 [Xanth. bisenariam lehenb. 14t:3!].

20 o - ibil. f. 11 nt 12: Eu. 11:0 12 [f.11 Arthrodesm. convergens see. Hikn. 1843; f. 12 = Arthrod. subulatns Kiitz.].

27 - 2 ibid. f: 2-7: Eu. 11:0 1:3 [2--6 Desm. tridens sec. $F \%$. $14+3.7=$ Pentasterias radiata ibid. f. $1-5=$ Staur. gracile?; $\mathfrak{f}, \beta=$ Staur. cyrtocerum sec. liulfi; f. $7=$ St. Ophiura 1. coronulatum?!

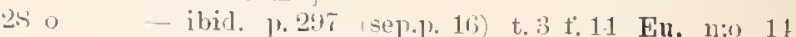
[Desmid. glabrum sec. Ehent. 184:3].

2.10 - ibid. 1.3183 (sep.1). 22) t. 3 f. 3 : : Clost. n:o !) Tetmemorus Brebissonii sec. Is lfls 1811].

31) 1\$12 117 ite in Micr. Journ. v. 2, t. 4 (Xanth.) [1. v.].

$31 \mathrm{zf} 1814$ - in Mier. Soc transaet. v, 1 to s f.1.t: Xanthidium.

32 1stis /hrss. Brit. Alg. t. 10 t. 11: En. [En. ampullaceum ser. Rulfs 1sisi]; f. 10 [idem?].

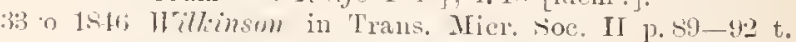
13 f. : "like Xanth. spiuosum"). 4 ("like X. crassipes"), ; "like $\mathbf{\perp}$. tnbifernm-recurvatum"). b ot 7 "like Whites sperimen from New York" - efr. supra 18.14).

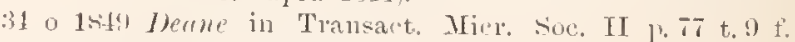
1-16 [Fossilns. Annon Spongiat?'].

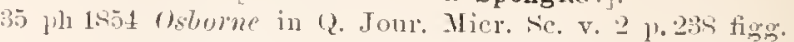
xylogr. $1-8[1=$ Clost. costatum ?; $2=\mathrm{Spi}$ rotinia condensata; $3=$ Penium 1 . Clost. ?; 1

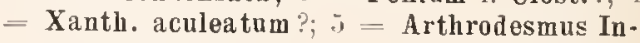
cus; $6=$ Staur. e. จ. ?; $7=$ Pen. Digitus; 8 $=$ Cl. Lunula sensin Osborm? ?]

36 ph 1riot Cohn llikr. Alg. 11. Pilge t. 16i f. 11), 13, 15, 19 
[Clost. Dianæ et Digitus sec. A. Braun Ueb. ['hytr. p. 3i'].

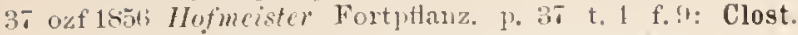
Ra phidium?) [Cfr. Clost. subtile.

34 phaf - ibil. 1.2: t. 1 f $11-17$ : Palmogloea sp.

39) 1.57 Macdumald in Amm. Mag. Nat. Hist. ser. 2 v. 2ul t. T cum fig.: Clost. [C'r'. Wullich in Ann. Mag. Nat. Ilist. ser. 3 r., 5. [siti, p.2]

40 o 1 isos Arch. Catalog. 1. Ti: Staur. iuter spinosum et Avicula.

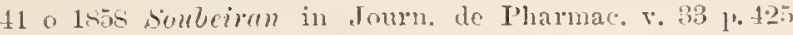
t. 2 f. 7 : Desmidium sir. [Ad aliul menms pertineat. nulla alga desmideacea esse videtur].

4.2 o - ibill. p. 131 t. 2 ti. 10: Desm. sp. [.1liul].

43 155! liublucim in Helw. '2 $10: 0$ \& t. '2 f. 4: Cosm. Cosm. oruatum]; f. 5: Cosm.; f. 10: Cosm. ad couspersum accellens; f. T: Staur. [-t. saxonicum liuluh; fig. mala].

1.1 1862 White in Amer. J. Se. Alts 33 p. 396 fig. xyl. $1-9$ et 14-22: Xanth. spl. (fossil.); 22 et 26 : Desmidiex.

4) ph Isis Hiclis in Popul. sc. Rev. If p.335-312 t.11 f. S-? et 11: Palmogloea [f. $8-4$ c Q. J. M. $\therefore$. c fi. P. macrococca].

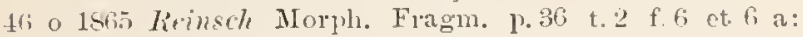
Staur. spee, nov. [St. flanconicum heinsch].

47 o 1866 Archer in Q. J. M. Se. צ. (i n. .. 1\%60: Cylindrocystis $11 . \mathrm{sp}$.

tit d 1867 leinsch Algenf. Frank. 1. 17心: Disphinctium n. $s \mathrm{~s}$.

49 o 1807 liciley in Americ. Taturalist I n:o 10 p. not f. 1-6 f. 1-5 e Bailer 1811 f. 3.1 i; a. 27 d, 23 ?. 30] Fig. (j p. 5 git fossile Xanth.. zy.gospor.

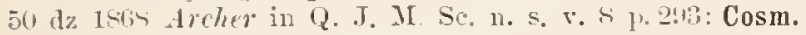
s1. Cosm. margaritifernm Tirlfs 18ts quoad fig. $2 d)$ Cosm. reniforme Arch.].

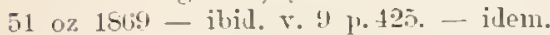

$52 \mathrm{dz}$ - ibid. $\because$. p. 423: Peuium [Pen. didymocarpum?.].

53 d 1870 - ibich. v. 10 p. 20.i: Cosm. sp. not. [Cosm. quadrifarium ?].

$5 \pm \mathrm{d} \quad-$ ibid. 11.3m: Cosm. sp. not. (ad C. commissurale pantlo accedens).

55 a - ibil. p. 8.: Staur. sp. [St. incouspicuum Nordst. sec. Arch. in Journ. Bot. 1574 p.!1].

5ti o $18 i 0$ Tordst. Desm. Brasil. p. 223: Micr. sp.

57 o 1871 croue in Q. .I. IT. Sie. n. s. vol. 11 p.915: Cosm. ad amoenum et cylindricum accedens.

50 d $18 i 1$ Archer in Q. J. M. Sic. n. s. rol. 11 1.93: Eu. 11. sp. [Eu. Armstrongianum Arch. $1863=$ En. pingue Elfr: 1882 sec. Roy 1893].

5 ? d 18.2 - ibid. v. 12 p. 211 : Stanr. sp.

60 - ibid. p. 2tr: Staur. [St. Cerastes sec. Areh. in Journ. Bot. 1.it 1. 44].

$61 \mathrm{z}$ - ibid. 1. 121: Cosm. (prope C. tenue et C. tiuctnm?.

(62) dz - ibid. 1. 422: Cylindrocystis Cfr. Areher 1856).

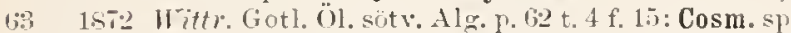
64 o 187:3 Nordst. sydl. Norg. Desm. p. 35: Staur. nov. s1.? [ad Staur. irregulare West accedens].

65 a 18.3 lveler in Q. J. M. Se. n. s. v. 13 p.101-2: Eu. sp. [Eu. binale $\beta$ angustatum Wittr. sec. Arch. 1. c. P. 31:5.

66 z 1874 Giblons in Trans. R. soc. Tictoria rol. 10 sub fig. photogr. 1. 2 et 5: Clost. 2 spec., Docid. zT" gospor.

67 daf 1875 Reinsel Contribut. p. $8+$ t. 12 f. 11: Palmogloea sp. Calocyliudrus curtus? sec. Kirchn. Beitr. Algent. Württ. p.17l].

ibid. 1., t. 12 f. 3: Cosm. sp. Cosm. oblongum liem.. non Tiril.|.

(6) a - ibil. p. 8.2 t. 12 f. 4 : Cosm. sp. [Staur. subsphatricum? sec. Nordst. in Helwier. p. (i5)].

(1) (1) - ibid. 1.. 3 t. 18 t. 4: Cosm. sp. [C. Reinschii Areh. 1mili].

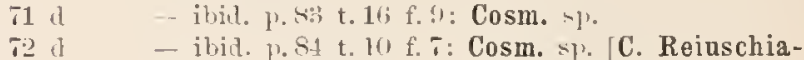
unm the Tomi.

73 द - ibil. 3\% $\$ 4$ t. 10 f. $5:$ Cosm. s1. Staur. orbicul. f. elliptica in explientione figur:).

71 d - ilid. 1. 45 t. 12 f.9: Staur. s]. [Xauthid. octocorne f. major trienala) relisimiliter sec. Nurdst. in Herluig. latio potifs.

Fo d - ibit. p.sit t.17 f. 4: Staur. sp.

.6 d - ibid. p. $\$ 6$ t. 17 f.s: Staur. s]. [St. Reinschii lioy 1.int].

it d - ibid. 1). hti t. 1it f. 10: Staur. sp. St. corniculatum?

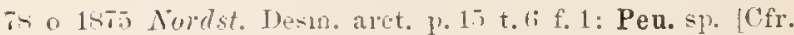
Dorges. 1.591].

7) - f.2: Peu. 41. [Cfr. Tiollt 1san et Schrouder $15: 40]$.

$80 \mathrm{~m}$ - ibial. 1. 15: Pen. sp.? lad Cosm. parrulum accedens).

s1 un - ibil. p. 33 t. 5 f. 37 : Staur. sp.? (Annon f. trigona perpusilla St. miuntissimi.

8. ph 1siti Arch, in Q. T. M. Sc. r., 15 1, 235: nov. gen.? (2 formie all Clost. obtnsum accedentes).

830 - ibid. $\because$. $16 \mathrm{P} 41 \%$ : Cosuaria ad C. annulatum accel.

84 a listi roup ibit. y.416 et 117: Cosm. sp. prope C. Biretmm)

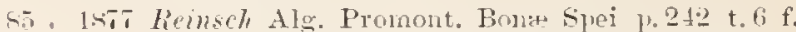
10-11: Cosm. sp. Cosm. Menegh. I subhexagonum IJansy. 188s. - Fig. $10=$ C. lave sec. liac. 1 1913$]$

56 oz 1575 Arch. in Q. J. M. Sc. ง. 17 p. $105=$ Cosm. 2 sp. Cosm. melanosporum? + ?].

si a - ibid. 1.101;: Gonatozygon 1. Clost. ?

Ss o - ibid. 1.464: Staur. nov. sp. (prope St. oligacauthum).

So ph 1sit Wallich in Popul. Se. Rer. p. 195 f. 2: Clost. [Cl. moniliferum] et p. 13! f. \pm B: Clost.

so wh - ibil. 1. 139 f. 4 A: Cosm.

(1) ph - ibil. n. 140 f. 5 D: Docidium.

92 phzf 187. Halsted in Americ. Naturnlist $1.514 \mathrm{f} .86^{\circ}$ a [Eu. ologans e Iloorl], h-f [Stanr.?]. g-1 Mesotiruium? copulans.

93 18\% Helponte Desm. subalp. t. 18 f. 52-5t [Closter. sp. ?].

24 1878 Thomas in Chicago $w$. Suppl. 1878 t. f.9: Clost. 95 — ibid. f. 10: En. [E. elegaus f.].

(46 - ibid. f. 11: Micr. [pinnatifida].

(1) - ibid. f. 15: Cosm. [Cfr. C. Brebissoui Hood].

18 - ibid. f. 16: En. [Cfr. Eu. oblongum f. TTulle D. U. ‥ t. 2 f. 6 ; ad Eu. crassnm paullo accedens?

99 - ibid. f. 17: Cosm. [ad Bortryt.

100 - ibicl. f. 1in et 19: Staur. [gladiosum Iu'n. $1485 ?]$.

101 - ibid. f. 21 : Cosm. 2:3 f. 1]. 
10:3 d 1ste Reinsch Freshu. Alg. Kerguel p. -3 (sep.p. 19): Palmogloea s 1 .

104 a 1879 ('olen Desm. Eong. r. 270 sep.p. 12): Eu. 110v. sp. 105 o leit Areleti in Q. J. II. Sc. v. 1!) p. 121: Xov. gen.? ad Clost. obtusum acced.).

101; ph 1 ise1 - in Amn. Mag. Nat. Hist. 5 ser.. vol. 7 n:o 41). 1. 340: Staur. brasiliense Lumrl., non Tordst.

10702 - ibid. p. 117: Stanr. 11. sp. prope St. turgescens'.

105 a 14s2 Spencer Froshw. Alg. New Zeal. p. 24r t. 7 f. $7: \operatorname{Cosm}$.

1119 त 1 - ibill. f. 8: Staur.

110 1.5s.3 Turn. Alg. Strensall f. 2: Staur. 1. Xanth. Lad St setigernm acced.?].

111 - ibic. f. 3: Stanr. [a.l S. spinosum aecedens].

112 - ibid. f. 11i-17. et 19: Xanthid.?. et Staur.:

113 1s83, rowkin in Arch. bot. Nort. France v. 2 1. 31 $\mathrm{f} .3: 3 \mathrm{a}: \operatorname{Cosm}$. sp. C. isthmium??].

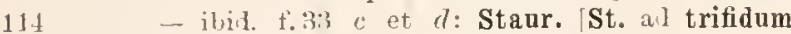
accet.].

115 - ibid. f. 34: Staur. [and bifidum accerl.?].

116 - ibil. 7. 32 f. 35 : Clost. ad Leibleinii ac(.eil. ?]

117 ibil. p.3s t. 47: Arthrod. [A. convergens].

118 - ibil. p. 11 f. 52 : Clost.

119 ph 1ss: Arethe in Anu. Wag. Nat. Hist. v. 12 p. 12.t: ar Clost. obtusum accerlens.

12001844 Ho7le Wesm. U. ‥ t. 24 f. 33: Clost.

121 o 1881 Aich. in Am. Mag. Nat. Hist. v. 14 p. 20s: Stanr. 11. sp. ad striolatam (Feinsch, non Nag.

122 1sh; Ruc. Nonm. Desm. Polon. p. Ts (sep.p. 19) t. 11 (sey.t. - t. 15: Cosm. sl. C. lati Broth. affine. Cosm. Raciborski hozl. 1. $6 \%$. non Layro\%.

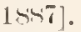

123 in 1 sse Boldt Sibir. Chloroph. p. 123 t. fit. fli: Clost. sp.? 124 d 1sar Arturi Nater. alo. Noscon p. 17u (sep.p. s): Staur. sp.

125 o 18ri Berthold stud. Protoplasmamech. r. 11:2 t. li to. !): Eu. |En. oblongum

120 - ibid. 1. 273 t. 15 f. 10 : Micr. [M. papillifera?].

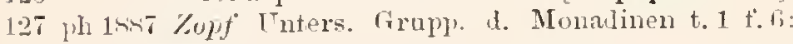
Cosm.

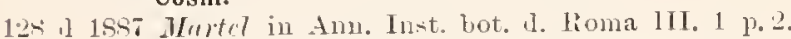
fir. 1 y. :3: Pen. sp. [ail P. Ralfsii Delponte].

$1290 \quad-$ iljid. p. 7 f. 2 : Cosm. sp.

1:30 o 1.84 - in Notarisia IIl n:0 8 p.339 bi<: Cosm. sp.

131 I 1887 .17exenko ('hlorosp. Khark. 1.215: Eu. ep.

$1: 32$ 1 $\quad$ - ibid. p. 2is: Staur. sl.

$1: 33$ a - ibil. 1\% 2013: Cosm. sr.

134 d - ibid. 10.210s 11:0 115: Cosm. sp.

135 a - ibid. n:o 116: Cosm. sl

133 a - ibil. n. 271 n:o 12:2: Cosm. $-p$.

137 d - ibid. 21:0 12:3: Cosm. 31 .

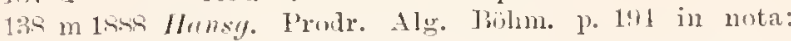
Cosm. arl nitidulum accer.

$139 \mathrm{~m}$ - ibiu. 1.214 in nota: Staur. all S. aspinosum aceod.

1.1) o - ibid. 1. 24! in nota: Cosm. all trigemmatum acreplens.

1110 - ihil. 1.2.2 in nota: Eu. al E. pseudelegans et $\mathbf{E}$. compactum accelens

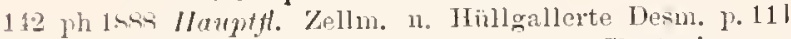

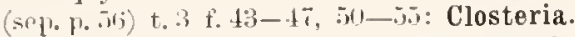

143 u 1895 Vordst. Fr. wat. Alg. N. Zeal. p. 35 t. 3 f. 11: Eu. $1 \%$ ad E. denticulatum et hinale $\mid$ Eu. Tur neri f. Wrst 1.9.2].
$141 \mathrm{~m}$ - ibil. p. 29: Cosmocladium? habitı Cosmarii subarctoi.

145 ph 1 iss Zopf in Nov. act. v. 52 p. 313 t. 20 f. S-10: Cylindr. [C. Brebissonii ?].

1413 fh - ivid. 1.314; t. 19 f. 15-10: En. [E. insigne].

147 ph - ibid. p. 343 t. 20) f. 13: Phycastrum [Staur. al pnnctnlatum].

148 th - ibid. p. 343 t. 201 f. 11-12: Pen. (P. margaritaceum].

14!) I 1.iss Riabin. Chloroph. env. Ihark. p. 3:32 sep.p. 44 t. $S$ f. 10-12: Staur. s].

1.5n A 1sse Boldt Desm. Grönl. p. 34 t.2 f. 51: Stanr. sp. St. sibiricum v. crassiangulata see. liöry. 18947 .

151 a 1589 hotowsk. Flor, vodorost. Sibir. II p. 19 t. 1 f. 11: Cosm. sp. (C. Ungeriannm ?'.

152 z 1849 Wrest Massachus. Desm. p.191 t. 3 f. 13: zygospora.

153 d 1 S.49 . Wusk. Wurth. Not. N. Z. Desm. p. 30 t. 6 f.61: Clost. 1. Raphidium.

1541890 ITest Fr.-w. Alg. North Wales t. if f. 29: Doc. sp.

15.) a 1890 rutw. Wahr. d. Priorität p.615: Cosm. sp.

liti o - ibid p. T2: Stanr. sp.

157 ph 16!n Compled in Bull. Torr. bot. Cl. v. 17 p. 11,5 t. 11.2 f. 9 [Arthr. convergens].

$15 \mathrm{~s}$ m 1890 Aulers. Sverig. Chlor. 1 p. 12 t. 1 f. 5: Staur. sp. (aul St. bicorne Heupty. accerdens).

154 ph 1890 Uungeard in Le Botaniste II p.9.3 t. 4 f. $19-$ 21: Clost.

160) ph 1891 - ibil. fase. it p. 231 et ser. t. 19 f.5-15: Clost. ¿ parasit.

161 phı $18: \% 1$ Wildem. Recherch. temperatur. caryocin. p. 35 et ser. t. 2 t. $1-18$ : Cosm. [C. Phaseolus $p$ elevatnm??

162 ht - ibid. I. 18 t. 2 t. $19,31,33-39$ : Clost [Cl. Ehrenbergii ete.].

163 d 1891 Gute. Flor. Alg. Leopol. p. 39 t. 1 f.9: Cosm. sp. [Disphinct. sp. Grutw. [895].

$164 \mathrm{~m} \quad$ - ibid. 1. 33 t. 2 t.6. Cosm. sl.

$165 \mathrm{~d}$ - ibil. 1\%.70 t. 3 f. 21 : Staur. s]) [St. nigræ silva sec. Selminlle fortasse].

161 o 1891 Lipsky in Bot. f. Naturw. II N:o - p. 66: Micr. (proje at M. oscitant.)

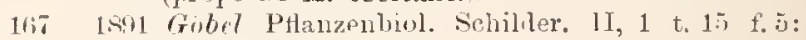
En. Micr. Jenneri? see. Prorye in N. Notar. 1890 1). 16i].

1hs o 1s:r Hensy. Beitl. Alg. Bact. Tirol. u. Bühm. p. 1:2: Cosm. (ail C. læve).

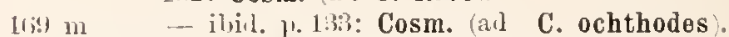

170 o $1.4+2$ Ruc. Desmidya Ciastoni p. 3132 et 370 t. 6 f. 31 et p. 391 t. 16 f. 333: Clost. sp. (cfr. calospornm.

1710 - ilid. 13.362 t.li f. 12: Pen. sp. (acl phymatospormm .

17.2 o - ibid. 11.352: Pen. cfr. polymorphum),

17:3 o 1sit2 Harso. Prodr. Algenfl. Bohm. II 1. 25:3: Cosm. sp. (ad C. orbiculatum sed glabrum).

171 dz 18tr Mobius Austral. Niisswasseralg. j. 111: Clost. (ad Dianæ) iterat. in Picil. Contr. Queensl. Fl. 11. 41].

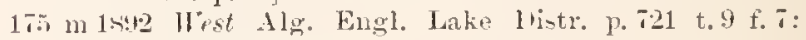
Pen. sp.

176 a $18+2$ - in Xotarisia 7 p. 1.1n): Pen. 1 . (prope P. phymatos porum.

17t d 1943 sichmille Beitr. Alg. Millwarzwald. p. 101 t. j f. 1 et is: Cosm. sl.

$178 \mathrm{~m} 1893$ Turne Alg. Ind. orient. p. 15 t. 1 f. 6 : Mesotrenium profic M. Endlicherianum . 
$17 \div d$

180 , 1 - ikil. 11.5: r. f. f. Cosm. sl\% (C. galeritum f. ?’.

- ibid. 1. 1i2 t.") f. [11: Cosm. sp. (prope C. perizosmum .

1810 - ibid. p.1:3 t.9 t. $113:$ Cosm. sp. (C. latvi propius).

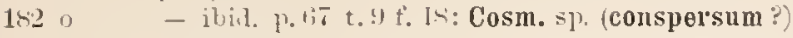
monstr.

183 o - ibil. p. 1is t.! i. 52: Cosm. sp. (C. punctul. acred.) moustr.

184 ozf - ibil. 1. il t. 20 f. 8: Cosu. sp.?

185 ozt $^{\circ}$ - ibil. 1. 11 1.11 f.6.2: Cosm. sp.?

1860

- ibia. 1. .2 t. 2:3 f. 10): Cosm. sp.

$\tan >\mathrm{m}$ หra? ? ?

187 in - ibil. 1. 72 n:0 129.) Cosm. sp. (C. quadrangulatum Huntisch?'.

lEs o - ibid. 1\%. 6 t. 11) f..2.: Eu.? sp. (C. Meneghinii ๖. Reinschii?

189 o - ibid. 11. 121i t. 15 f. 22: Staur. sp. (intel S. contortum i psendotetracernm et $\mathbf{S}$, inconspicuum Nordst.

$190 \mathrm{~m} \quad-$ ibil. 1.115 t. 15 f. 1!!: Spharoz. sp.

1910 - ibid. p. 150 t. 21 f. 4: Phymatodocis?

19.2 - ibid. p. 164 t. 23 f. 15: Spirotania? sp.

193 ple 1893 Wildem. Xnt. $13 y$ colog. IV t. 6 f. 17-23: Cosm.

C. tetrachondrum??].

194 - ilid. t. 1 f. 30-31, t.13 f. 6: Spirotænia.

$195 \mathrm{~m}$ 1.994 Borge siissw. Chlor. Arehang. p. 34 t.3 f. 3!): Eu. sl). (ad E. Turneri .

$196 \mathrm{~m}$ - ibid. p.34 t. 3 f. 4t: Staur. sp. (ad St. paradoxum fusiforme.
$1: 4$ a 1.491 Mol. Austral. Süssw. alin. II p. 337 t. 2 f. 16: Pen sp. Qquane in Britry Contrib. Queensi. Fl. XI 1. 38 t. 10 t.. 7 ].

1.4 1 - ibil. 11.311 t. 2 f. 24): Cosm. sl. [(2noune in Builuy C'ontrih. Quenensl. Wh. XI, $15 ! 35,1 \% 10$ t. 10 f. 20$]$.

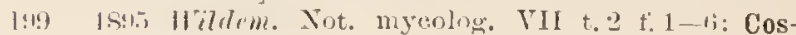
marium.

$2(k) \quad-$ ibil. t. 2 t. $7-9$ : Euastrmm [ansatum

$201-$ ibid. IV t. 4 f. 11-13: Closterium.

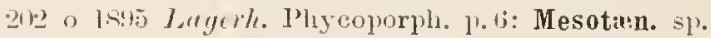

$3030 \quad-$ ibicl. 11. 6 : Penium 51 . (all P. oblongum accedens).

201 1595 Gutw. I'rotr. fior. alg. galireien. p. ar (in Rozpr. Akal. Tmiej. XXVIII 1.324! : Disph. sp. (Cosm. sp. Gutie. Fl. alg. Leopol., 1 S.)1. 11. 391).

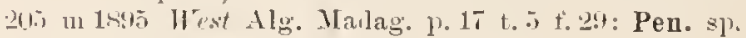

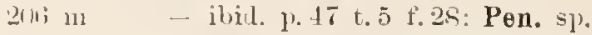

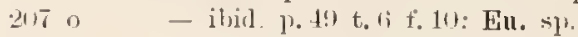

2018 i - ibid. 1). 71) t. 8 f. 15 : Cosm. sp.

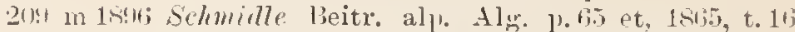
f. 12: Staur. (verisimiliter arl St. subtile).

210 1.9. Whilem. Not. myeolog. Fase. T n:o XXl t. 3 f. 22-24i et th) e. fig. $x y \log r .1$ : Clost. sp. (cum ('hytriil.).

211 - ibid. t. 3 f. 27-25: Cosm. sp. (cum Chytrid.). 212 - ibill. t. 3 f. 30 et 31: Cosm. sp. (cum Chytrid. ?

- ilis. t. 3 f. 2!) et 32: Stanr. sp). (cum Clyytriil.).

Anctores supra commemorati alphabetice ordinati:

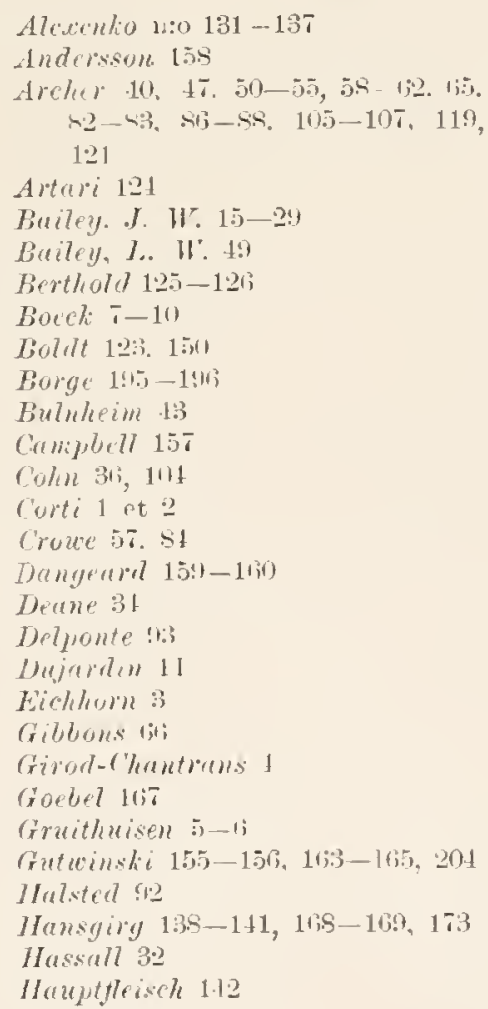

Hicks ty

Hofmeister 37-35

koslowshi 151

Lagerheim $202-20 \% 3$

Leiblein 11

Lipsliy 16ir:

Macrlonnlal 39

Hartn 128-13i)

Maskell 153

Wryen 12-1:3

Mopluius 17. 197-1:18

Nordstedt 513. 64. 7s-81, 143-144

(J)berne Bjo

Luciborski 12.2, 171)-172

lifinsch 46. 48, 67-75, 57, 103

Rivebinin 1.t!

schmille 175, 20!5

sorokin 113-11s

sipencer 10s-109

sombeirnn $11-42$

Thomas: : 1 - 1 1)

Turner 1111-112, 17x-1!1

Wallich 8!?-!1

Ifest 152, 154, 175-17i, $205-21 \mathrm{~m}$

White 30-31, 41

Hitdeman $161-162.193-191$. $196-201,210-213$

Wilkimson 33

Wittrock tis

Wolle 121

'opt 127. 1 15-1.1 


\title{
3. Addenda ad bibliographiam.
}

\author{
A. Libri.

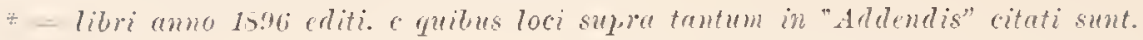

Aderhold, R. Beitrag zur lienutuiss richtender Tiräfte bei der Bewegung niederer Organismen. - [ph]. - Jenaisch. Zeitschr. f. Naturw issenseh. Bd. 2-2, N. F. 15. 18s9, 1. $310-312$.

Agassiz, A. 'The Vegetable Character of Xanthidium.Proc. Amer. Assoc. Adr. Sci. 15 Aug. 184, p. $89-1$. 1850. [n. r.].

(Bailey Contrib. (queensl. Fl. XI) Bailey, F. M. Contrihutions to the Queensland Flora. Botany Bulletin N:o XI. July 1895. $19 \mathrm{pl}+17$ t. [Figure a MLobins communicata]. - Departm. of Agriculture. Brisbane. Queensland. Bristune $18 \div 5$.

Belloc, F. Recherches sur les Algues des eaux douces. des eaux thermales et des eaux salées d'Alorie. de 'Tunesie et du Maroc. suivies d'une liste des Diatomées fossiles et d'm aperyu de la Florule diatomique marine littorale. - Rerue biologirue de Ford de la France. [1893-5? - 11. 1.$]$.

- La Flore algologirue d"eau donce de l’Island. 12 l'p. 1545. - $[\mathrm{g}]$ - Assoc. francais. 1'. larancem. d. sciences. 1 s.?.

(Barge Sverig. Chlor. II) - Borge, 0. Bidrag till kännedomen om sveriges Chlorophyllophyceer. II. Chlorophyllophyceen aus Falbyoden in Vestergütlaud. Stocklolm 1895. - Bih. K. Sv. Tet. Akad. Hand1. Bd. 21. Afd. III. N:o 6. $26 \mathrm{~m}^{3},+1 \mathrm{t}$

* - Uebersicht der nen erscheinenden Desmidiaceen-Litteratur, r. 2fi pl. - La Nuova Notarisia Ner. VI Apr. 18960 1) $44-640$.

* Nachtrag zur subfossilen Desmidiaceen-Flora Gotlands. Botaniska Notiser 1sin p. 111--113.

* (Burye Variabilität Desm.) - Ueber die Tariabilitat der Desmidiaceen. - Öfrers. K. Yet. Akadem. Förh. 1su; X̃:o 4 p. $289-294$.

Brand, F. Ueber die Vegretationsrerhältnisse des Würmsees und seine Grumdalgen. - $[\underline{g}]$ - Botan. Central. blatt Bd. 60 Ni:o 1 p. 1-13, 1896.

Brun. Tégétations pélagiques et microscopiques du lac de Genève au printemps de 1S81. - Soc. bot. de Genève. oct. 1 kist.

(Chmiel. in Tr. Soc. Nat. Kihark. 23) - Chmielevsky, V. IIatériaux pour servir i la flore des algues du gouvernement de Kharkow. - Travaux d. 1. Soc. d. naturalistes i 1'Tuir. Imp. de Kharkow. Tome 23. 1s.84. XIPlok, 18 (*).

Cohn, F. Ueber lebenlige Organismen in Trinkwasser. [g] ... Ein und dreissigster Jahres-Bericht d. Siclles. Gesellsch. f. vinterl. Cultur. Jahr. 1853, P. :1-94.

Ueber das Geachlecht der AIgen. - [ph.] - Drei und dreissigster Jalures-Bericht der B.hlesischen Gesellsch. f. raterl. Cult. (- im Jahre 1855). P. 95-104.

Compte rendu des traraux prisentés par à la soixantième session de la sociéte Helretiyue des sciences naturelle. réunie à Lausanne le 6 sept. 1893. [g - n. v.]
Eckhard, C. Die Organisationsterhältnisse der polygastrischen Infusorien mit besonderer Riucksicht auf die kiuzlich durch Herrn v. Siebold augesprochenen insichten iiher diesen Gegenstand. - [ph] - Archiv für Naturgoschichte, gegriind. v. Wiegman, rwölfter Jahrgangr (herausgegeb. von IV. P. Erichson), 1 Bd., 18t6, 1. $2(1: 4-235$ t. $T$ et $\rightarrow$.

Virleler in Pamiet. Fizy. 14). Eichler, E. Materyaly do flory wolorostín okolik Miedzsrzecza. - Pamietnik Fisyjoglaficzur, Tom. 14. 1894. Dzial III. 1. 119-136 t. 2-4. 1.in.

Hansen, C. Ostenfeld. Planteorganismerne i Ferskrandsplankton fra Jylland. 1S9\%. - $[g]$ - Videnskab. Meddel. fra den naturh. Foren. 15.5 p. $144-207$.

Heuscher, J. Hydrobiologische Excursionen in Kanton $\therefore t$. Gallen. - $\mathrm{g}^{\top}$ - Ber. ü. d. Thätigkeit d. st. Galliscl.. naturwiss. Ges. 1590-91. 11. 336i-352. St. Gallen $1 \leqslant 2$.

Hora, P. Versuch einer Flora von Pilsen. - [g] - Lottos, uene Folge Bd. 3 184? 1).81-10s.

Istvånffi, G. A Balaton nikroskopos novényzetéröl. Füllıajzi Közlemények. 1ه94. p. 160-16i.

Jenke, A., [Schorler, B., Wobst, K.]. Bereicherungen der Flora Saxnnica. 1sin - $[\mathrm{g}]$ - Sitzungsber. d. Natur. Ges. Isis in Dresden. 1895, Abl. 8, p. 89-94.

Klebs, G. Ueber das Terhältniss des inännliclıen und weiblichen Geschlechts in der Natur. Jena 18:4. $30 \mathrm{mp}$. $-[1, \mathrm{~h}]$

( Tlebs Beding. Fortpflanz. Alg.) - Ueber die Fortptlanzungs-Physiologie der niederen Organismen, der Protobionten. Specielles Theil. Die Bedingungeu der Fortpflanzung bei einigen Algen und Pilzen. Jena 1596. $\mathrm{XVIII}+51+\mathrm{pr}+3 \mathrm{t}$

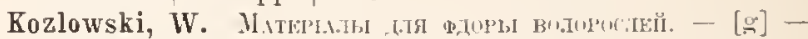

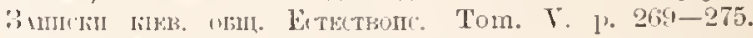
Kiew 1sis.

Lemmermann, E. Aus der Biologischen Station des Deutschen Fischerei-Tereins am Müggelsee. Die Planktonalgen des Müggelsees bei Berlin. $13 \mathrm{pp} .-[\mathrm{g}]$ - Zeitschr. f. Fischerei u. d. Hülfswissenschaften. Mitteilung. d. Dentsch. Fischerei-Yereins 15:46. Heft. 2-4.

(Lemmerm. in Biol. Stat. Plön. 4) - Zur Algenflora des Riesengebirges. - Forschungsher. d. Biolog. Station z. Plon. 'Th. 4, 1s

- Zweiter Beitrag zur Algenflora des Plöner Seengebietes. - Ibial. p. 131-1ss.

* Möbius, M. Ueber Entstehtung und Bedeutung der geschlechtlichen Fortpflanzung in PHanzenreiehe. - [ph] - Piolog. Centralblatt Bd. 16i N:0 4. 15 Febr. 1s:th p. 12!-153. [Nihil nov'nm de Desmid.].

Parfitt, E. Devon Fresli-water Alge. - [g] - Trans. Derou Assoc. Sicient. Vol. 18 (1886).

Plutenko, J. Materialien zur Algenflora des Poltawischen Gourernements. $13 \mathrm{pl}$. - [g] - Schriften d. Tiewschen Naturforscher Gesellschaft. 1871). 
Porter, H. Ch. Alhängigkeit der Breitling- unl TTuterwalnow-Flora rom Weehsel des salmpolaltes. Inangnral-linsertation 1. Universitit Rostock. Friistrow i M.

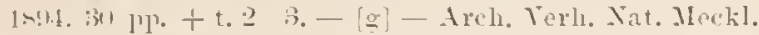

Rischawi, L. Materialien zur Algentora 1. Kiewsien Gouvernements. - [g] - Sohriten d. Kieusch. Naturfolsoh. Gesellseh. $15 i 1$ p. $71-\bar{i}-$.)

Roy, J. 'The Desmiliea of the stormont District. Pror. East seot. Un. Nat. Se. 1sil-15 p. 11-25. 11. v.].

(Achmille Beitr. alp. Alm.) - Schmidle, W. Poitragon zul"

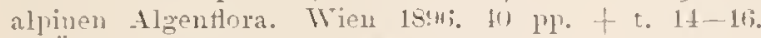

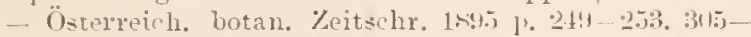
311. 34i-3.50. $357-3 \times 9.451-4$ et t. 11-11: 14!11: 13. 20-25, 59-15.3. 1194.

(Achmille Alg. tinnatı) - Einige Algon au- fimatra. - Healwigia 199.; p. 2013-307. t. 1.

* Gchmille in Flora y. 2.2, - Süsswasselalgen aus An-tralier. - Flora 1s\%, Bid. s2, Heft. 3 p. $257-313+t .9$.

* Sichminle in Reinecke Fl. Samoa) — Süsswasseralgen schizoluyceen. Conjugate unl Chlowoplyced, in: IV.

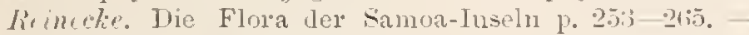
1. Funler. Botan. Jabrb. f. syst. PHanzengesch. u. l'flauzengeogr. Bl. 33. H. I-lI. 18!1\%, 1. 2:37-301.

Schmidt, R. und Müller, 0. Crutogamputlora von Gera. 1 Haelte. - $[\mathrm{g}]$ - Halle Zeitschr. f. sresammt. Xaturwiss. X1, 15.5.

(Airhicler Alg. H. Riesengeb.) Schröder, Br. Die Algpnflor ter Hochgelurgsregion des Riesengebirges. vehlesisch. lies. f. vaterl. C'nltur. zool.-lunt. Sect. Sit\%, 7 Yov้. 1s.5, 1\% 1--32. Breslau 18!5.

(Stull in Bot. \%eit. 38. Stahl. E. Teber den Eintluss fon Richtung nul stärke der Beleuchtung auf einige Bewegurgserscheinumgen im Pflanzenteiche. - [1, $]$ Botan. Zeitung 1850 1. 297-304. 321-34:3, 315-35\%. $311-308.37-352.393-100,409-413$. t. $1 \%$

Strodtmann, S. Planktoumtersuchungen in lrolsteinisclien und mecklenbugiselieu Seen. - $[\mathrm{g}]$ - Forschungsbe. rieht. ans der Biol. Stat. zu Plön. IT Ixin p. 27:3-2.s.

Tassi, Fl. Altre contribuzione alla Flora Nenes. - Alghe

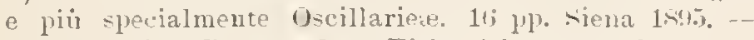
[g] - Atti d. R. Accad. A. Fisiocriti. Ser. 1 Tol. 7.

Théobald, G. Algues des environs de Creneve - $[\mathrm{g}]$ Comptes reudus les travaux le la sociéti Hallériemp de Genive, 14is it. 1. 199-7is.

" Tilden, E. List of Fresluwater algw. collectel in Minnesota luring 15\%\% - o] - Geol. Nat. Hist. Siurv. Minn.

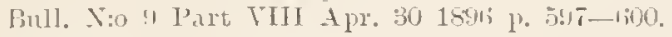

Torre, F. Del. Notizie intorno alle Alghe del distretto cividalese. - Rivista italiana li se. nat. Anuo SI, 15:1. 1) 129-132.

West, W. anl West, G. S. Totes on the Fresli-water Alga of the East Riding of Yorkshire. - [11. V.] Naturalist. July 18s: p. $211-221$.

(West Alg. Madag.) - - A Contribution to omr Finowled ge of Frewwater Alya of Madagascar. - Transact. Limean Sore of Louton 2nil Fer. Bot. Test. 5 Part. 2., 0.t. 15\%. p. $11-$ (1) t. . . - ! ! . $\div$ illest in .J. R. M. ‥ 1s:n; - - On some Tew and Iuteresting Freshwater Alga. - Journ. H. Vier. Soc. 1 s.1i; l. $14: 1-115$ t. 3 et 1 .

Hest in Journ. of Bot. $3+$ - - Sotis on recently published Ilesmilien. - Journ. of Botany Vol. 31. Ang.

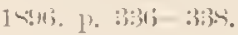
et $t .3101$.

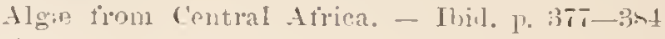

White, M. C. "Nute", in: Discovery of Microscopic Orgauism in the viliceons Todnles of the Fulazozoic Pous of Xew York. By the Elitors). American Journal of cicieuce and Arts, by illiuan anul Dana. Ser. 2,

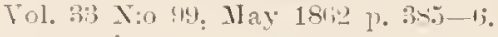

Wildeman, E. de. 'knelques Alpues récoltées aux environde Mahmédy. - $[g]$ - Bull, đ. l. tonc. belge de Micr.

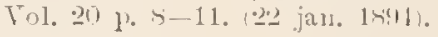

- Notes algologinues. - Jar Jotarisia v. 10. [yuoune:] p. 34 -3s t. 2.

- Les Algues de l'Herbier fichleicher. - [g] -. Bull. soe. belge de Microscopie. Tome 21, 1s94-45, p. 200-207. Bruxelles if fev. 1sir:

- Note mycologinne. XXI. liase. - - - Ann. d. 1. Soc. helge de llimoscopie. 'Tome 2n. 1n!ni, Jimoir., p. 19 - 6.t. t. $1-3$.

- Matéraux pour la Flore Algologinue du lépartement

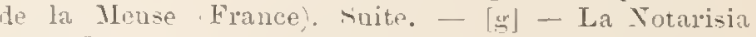

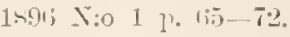

- Flore des Algues le Berluinte. Bruxelles 1s:mo. XXIX t5. 1 pl. [n. v.].

Wille, N. Resultate einiger vorliutigen Untersuchungen iiber Organisuen in Christiania-Trinliwasser. - [ $\mathrm{g}]-$ Biolog. Centralblatt. Bu. 16; 1S96. 1. 12j--6.

Wimmer. Ueber drei Algengelbilde. - Ueversicht der Albeiten unl Teränderungen aler sclilesischen fresellsel. f. vaterl. Cultur im Jahle 1sib. [Breslan 1s3t? P. $86 \rightarrow-57$.

Wolle, F. Cookes "Desmil wew to Britain". - Amer. Monthl. Micr. Journ. 2, 1sis. p. 11/i-11T. [n. v.].

Zacharias, 0. Zur Iiemuniss der nieleren 'lhierwelt des Riesengebirges nebst vergleichenden Ansulirken. - [q] - Forschungen z. leutsch. Landes- uni Tolkskumde.

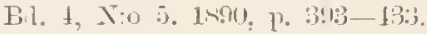

Zacharias, 0., Lemmermann, E. un] Peucker, E. Eryebnisie einel biologisı-lipn Exr.ursion an die Hocliseen und Inorgewässer des Riesengebirges nebst einer morplonetrischen Skizze ler beilen Foppenteiche. - [g] - Forschungsher. aus der Biol. Stat. zu Plön. IV. 18s; 1). $19,5-8 T$.

Zanfrognini, C. Contribuzione alla Hora algologica del Indenese. - Atti d. Sorotio dei natural. M[olena 1894. rier. III, Vol. 19 j. 10.1 120. [11. v.].

Zopf, W. Teber die eigenthümlichen strncturverhälmisse uni den Entwicklunss:ang de1. Dictyospheriun-Colonien. - Beitr. z. Plyys. u. Morpli. niederer Organismen, A. L. Kryptogam. Laborat. 1. Lniv. Halle a. S. heransq. v. IV. Zopt. Heft. :, 1s.t;. p. 1E-21 t t. 1 .

\section{B. Collectiones exsiccatæ editæ.}

Mnseum Palatinum Vindobonense. Kryptogamate exsiceatid. centuria 1. Wien 1-94.

- Tcheld al "liyptogamas exsiccatas". Centuria 1. Untor Mitwirling von - - - - horankgegeben volt der botaniachen tbtheilung les $k$. $k$. naturhistorischen
Hofnuseums in Wien. - Annal. l. k. k. naturluistolischen Hofmusenms. B.l. 9 Heft. 1 p. 11!-142. t. 2-:3. Wien 1 s:4.

Tilden, Josephine E. Ameriran Alge. rentury I. 1594. 


\section{Genera chronologice enumerata.}

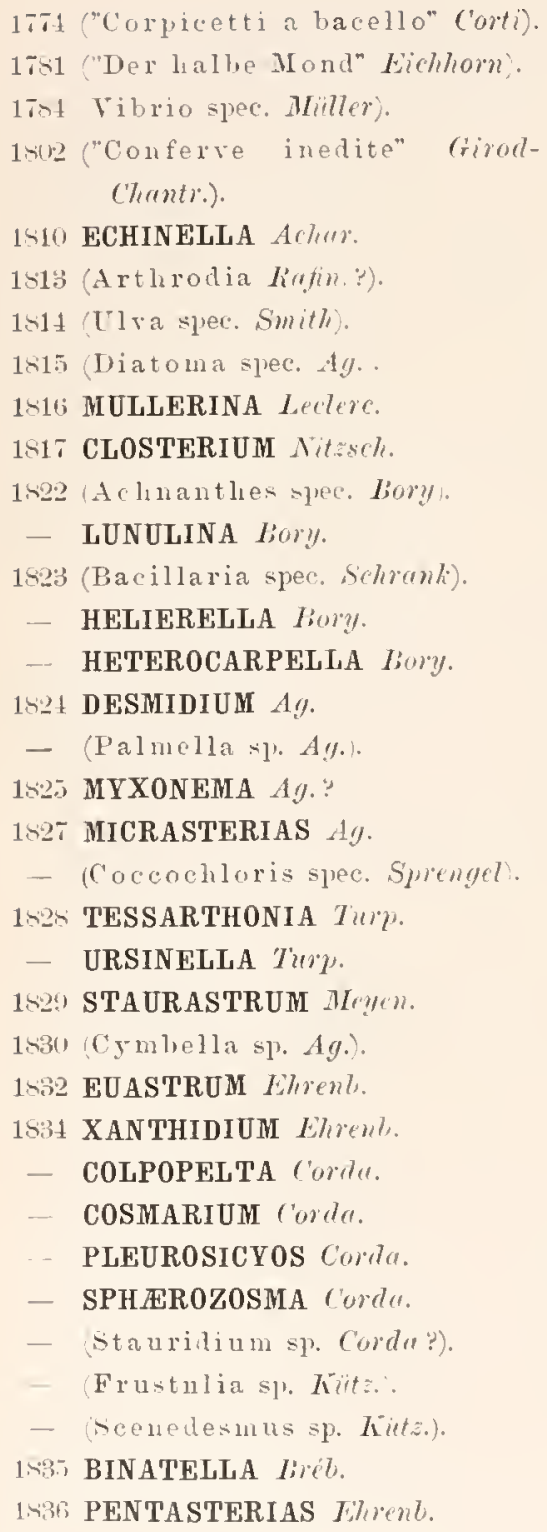

TESSARARTHRA Ehrenl.

- CALODESMIUM Wimmer.

1.3S APTOG0NUM Ehrent.

- ARTHRODESMUS Firent.

- 0DONTELLA kirent. CYLINDROCYSTIS Menegh.

1 S39 MESOTREMA Corda.

- STREPHOCYSTIS Corla.

$1 s t 0$ (Istliniasp. Menegh.).

1911 EUTOMIA $/ / 11)^{\circ}$

- GYMNOZYGA Ghrenb.

- HYALOTHECA Llenb. POLYSOLENIA Ehrenb.

- ZYGOXANTHIUM Ekenb.

1๖43 DIDYMOPRIUM Küt: PALMOGLOEA Kït?

$1 s 44$ DOCIDIUM lirel.

- PENIUM liréb.

- TETMEMORUS halfs.

1845 BAMBUSINA hït

- GLÆOPRIUM Tierlel. GONIOCYSTIS Hers.

- HOLOCYSTIS Hass.

- ISTHMOSIRA hïtz.

- PHYCASTRUM Kï:.

- PITISCUS Küt:

- SPIROT ÆNIA bré.

- STAUROCERAS hitz.

TRICHODICTYON hït.

1.47 ENTOSPIRA Küt:.

1SIS DIDYMOCLADON Riulfs.

-- GYMNODESMUS Treris.

1.49 ASTEROXANTHIUM Xer. DYSPHINCTIUM Noy.

- MESOTENIUM $N a^{\circ} g$.

- PLEUROTÆNIUM N N

\author{
SPONDYLOSIUM Trél. \\ - STEPHANOXANTHIUM Kütz. \\ 1550 ENDOSPIRA Trét. \\ 1851 TRIPLOCERAS Bailey. \\ -- SPHAROPRIUM Rab. \\ 1856 COSMOCLADIUM Brét. \\ - GONATOZYGON De Rary. \\ 1855 GENICULARIA $D C$ I \\ - LEPTOCYSTINEMA Areh. \\ 1859 TETRACHASTRUM Jixon. \\ 18ti LEURONEMA Trull. \\ - ONYCHONEMA W"all. \\ - STREPTONEMA Wull. \\ 18\%2? DIPLOSPHERIUM cramer. \\ 1867 DIDYMIDIUM leinsch. \\ 1869 ARTHRORABDIUM Ehrenb. \\ - PALMOGLOEITES Göprert. \\ 1 STI ANCYLONEMA Bergg ${ }^{\circ}$. \\ 18.3 MIXOTENIUM Delponte. \\ XANTHIDIASTRUM Delponte. \\ 15:- SCHIZ0SPORA keinsel. \\ 18.7 PHYMATODOCIS Tordst. \\ 1irit CALOCYLINDRUS (Arg.) Kirchn. \\ 18St COSMARIDIUM G \\ 1855 LEPT0Z0SMA Tum.

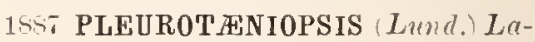 \\ gert. \\ 1885 ASTEROCOSMIUM Stockm. \\ 1685 DOCIDIOPSIS Racib. \\ NOTOCOSMARIUM Racib. \\ 1siu HOLACANTHUM Lund.) Wille. \\ PLEURENTERIUM Lund.) Wille. \\ - SCHIZACANTHUM (1 und.) Wille. \\ 1541 Gyges spee. O. Kuntze). \\ 1,aG ROYA West.
}




\section{Enumeratio generum cum speciebus alphabetica.}

\section{Arlumrentlies}

stomatimorpha 2-11. $1 ! 9$

stomatomorplia 211

\section{Actimoregrelus}

rariabilis : $17 \bar{T}, 17 \%$

\section{Amblynetinimb}

Lirsutum 1 111

\section{Anrylomente}

Tortenskiöllii 182, 5

Aletorgurmm Cfr Aptngonm

\section{1)10\%0)1111}

Baileyi sii

crelatum $71.56,10.2,253$

Desinilium 104. 1!!

Diagonum 144. 19, -1

tetragonum 2.53 .71

nululatum ? $21 \%$

\section{Artheodesmums}

acarthoplintus 34

acutus 10

apieulatus tis

areuatus 51,274

asper i2. 는

bicornutus is

lifidus of

Bulnleimii

controrersus $\$ 1$. 1:0

convergens $81,101.171,232.24 \mathrm{~s}, 282$ 11:0 261, 2.-1 11:0 15T

cosmarioiles $\$ 1$

crispus 8:1. 1:34

curvatus $44,82.130$

cylindricus !n

livergens 112

elegans 11.5

fragilis 12:;

(tangensis 128, 42. 1.51

gil.b. culus 130, si, 91, 12-9. 1-15

glatuceseens 131), ol

groeulandicus $1: 36$

hastiferus $1: 3$;

lexagonus 13:1. Ts: 27T

liatus 135\% 145

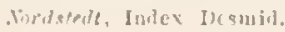

Numeri puginas sectionis: 2 indicant.

inearatus 143

incrassatus 1.4

ineurvus 111

T110us $145,70,94.118 .130 .189 .207$. 221, 25\%, 2-2 11:0 35

Indicus 116

lougieoruis 15 !

Micligauensis 10,

ninor 171 , 5 ?

minutus $1 \overline{2} \cdot 145$

Moerlianus 17:3

morsus 176

muerounlatus 1\%:

notoeliouting 181

obsoletus $18 i ;, 81,252$

netocornis $15 \overline{7}, 191$

orbicularis 1.:!

ovalis 192. 2.4.

pachycerus 193

pectinatus $19 \%$

phimus 2(x)

Pittacium 201

psilosports :211

puatlingulatis $216 ;$

quadricaudatus ․․

quadrideus 218

Ralfsii 220,145

Ranii 221

senilis 232 . 82

serratus $23:$

spicatus 237

striatulus 211

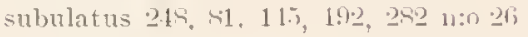

Tænia ?50

tenuissinus 251

triangularis $25 \% .115$

trinneatus $21 \% 2$

Fingulmarkias 270. 115

\section{Arthrodien}

acerosa 37

aeienlaris 39

acuminata $3 !$

acuta 10

Amblyonema 1.2

angusta 15

angustata 45

Areheriana ju

areolata i1 attematia is

Auerswallii ñt

australis it

Pacillum 5i

bienrvata jus

bienensis as

Brauniana 130

Brebissonii 67

calospora 71

candiana 71

eapillaris 72

Ceratium i2

compacta 7

complanata is

Cornu \$2

costata 8.5

crassa 97

crassestriata $\mathrm{Sl}$

Cucumis !1

Crnthia $51 \%$

decora !s

Delpontii 9!

Diana 105

didymotoea $10 \mathrm{~s}$

directi 110

eborace sis $11: 3$

Ehrenbergii 114

elegans 115

Ensis 118

fasciculata 1.2.

flaccida 121

fusiformis 127

Gigas 130

gracilis 132

Hantzschiana 137

Hirnlo $1 \mathrm{fl}$

inequalis 113

intermelia 145

1sidis 114

Japonica 15)

Jenueri 1in)

juncila 151

Tritzingii 1.52

lagoensis $15 \mathrm{l}$

lanceolata 155

lateralis 15.5

Leibleinii 1.);

Linea 1.ju

linearis $15 \mathrm{~s}$ 
lineata 158

lineolata 159

litoralis 150

Lundellii 160

Lunula 161

macilenta $16 ?$

Malinverniana 1(ii)

mediolrevis $16 ;$

monilifera 174

Monotenia 17.

nasuta 180

naviculoides 180

nemotorles 180

obtusa 196

obtusangula 186

oncospora 1 ss

paradoxa 195

parvula $1: 96$

peracerosa $19 \mathrm{~s}$

porrecta 201]

pragrandis $20 \%$

prelonga 205

Pritchardiana 246

pona 2013

pusilla 214

yuadrangularis 216;

Ralfsii 21!)

refracta 222

regularis 2.2:3

rostrata 225

splenea 231

setacea 232

spiralis 235

strigosa 24 ?

striolata 212

subcostata 214

subdirecta 215

subjuncida $211 ;$

subtilis 2-1S

subturgida 2.15

tetractinia $2 \%: 3$

tumidula $266^{3}$

turgida $2(i ; 3$

uncinata 265

Venus 268

\section{Arthurosablinm}

moluccense 173, 252, 2658

\section{Asteroxullilum}

Aretiscon 50

bisenariun 6.2. 127

coronatum S?

divergens 112

fuveatum 126;

furcigerum 127

ramosum 221

\section{Bureillarial}

acerosa $3 \overline{7}$

Lumula 160

multistriata 175. :3

\section{limmb)simll}

Pinrlexi 6:3, 18:3, 17:

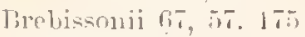

delicatissima :4!

aracilesens $1: 3$

\section{Iinatell"}

aculeata 39, rig

bacillaris 5.5

hrevispina

calcitrapa $i 1$

controversa $\$ 1$

eruciata $50,13 \div$

cuspidata !1

dejecta 98

duplicata 113, 25\%

furcellina 127

fureigera $12 \overline{7}$

lispida 1f1). 251

Incus 115

monticulosa 175

muricata $17 \mathrm{~s}$

mutica 175

polymorpha 2013

primorsa 205

rotundata 227

sexeostata 283

spongiosa 23!!

tetracantla 252

tetracera 252

tricornis 257

tricuspilata 258.94

tommida $26 \% 3$

\section{Cortmus}

dissiliens 111

\section{Carlocylimarus}

anunlatus 45

ansatus 418

attenuatus 54, 117

Brefellii fis

Clevei 71

Cohnii 7., 25.2

connatus Til

Cordanus 82

costatus 85

Cucumis 92

Cucurbita !12

curtus 53 , it. $28: 3$ n:o lit -

eylindricus $15,1: 3$

Cylindrus :16;

Debarri 97

diplosporus 111

giaudis 134

MTarkusovsliyi llifi

minutus $17 \cdot 0$

oblongus 185

Palangula 191

psemuretous 207

pseudoconnatus 218

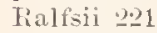

strangulatus 211

tessellatus $2: 2$

Thwaitesii 254

tuberculatus 292

turgidus 26t

\section{('elortrsmintm)}

crenatum $27 \%$

crosim $27 \%$

sinntum 2sil

\section{Closterium}

almuptum 86

arerosum $37,45.51,105.155,160,17 \%$. 17\%, 206, 251. 27 เ. 282 n:0 1

aciculare 38

acuminatum f'ordll 39. 161

acluminatum Kür. 39. जu, 105. 282 11:0 8

Arus 3!1, 225

asntum 39, 15., 2(16, 218, 251, 27.1. 282 11:0

affine to

aggrogatum 41

amlingum 42. 37

Amblyonema 42,158

angulatum 14,173

angustatum 45

nngustum $4 \overline{5}, 87.230$

antarcticum it

antiacerosum $4 \overline{7}$. sif

Areherianum 50, !6. 15\%, 274

areuatum 50. 39. 111\%

areolatum 51

attenuatum it. 89,71 , 20ri

Auerswaldii it

australe 54. 47

Bacillum 5.j

Baculum 5.5

(Baileyanum 5it, 27.

Paillyanum 5\%, 47. 107

lolmacarense in

bielavatum 58

bieurvatum 58. 182

bieneuse 58

Braunii 66. 51, 16을

(Braunianum (6i)

Brebissonit Delp.

Brebissonii Memegh, lis

*alospolum $71,156,275,284$ n:0 170

eandianum $\pi 1$, it

capense 72

capillare $7: 2$

maurlatum 72, H. "2.25

Ceratium 72. 201 i

clandestinum 7 \% , (1)?

compactum 7

complanatum $7 \overline{7}$

Cornu -2. 40 160, 206. 251. 262. 276

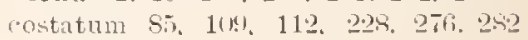
11:0 $3 \overline{5}$

crassestriatum sti

crassum Dely. 's . !n, 220

erassum Rull, it

erenulatum S8. 1 \%2

Cueumis :11, $11: 3$

curtum 93

cuspidatum 9.

Cylindrocystis $5 \%, 67$

Cylindus 96

Cynthia 96, 50, 150, 225

derorum 95

decnssatum !18, 114

Delpontii (19. 87. 105, 220, 27\%

Liants 104, 39, 50, 99, 141, 150, 15f,

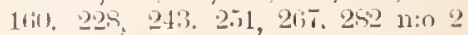
-3 ot 8,289 11:0 36, 284 11:0 17t 


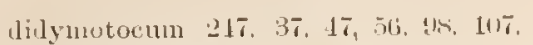
$118,125,140,2315,276$

Digitus 108, 151. 179, 283 n:o bit

dilatatum 10!?. Si)

Ilimoron 10!

directum 110, 112, 21:2, 215

doliolatum 112, 85

eburacense 113, !1

Elurenbergii 111, 1130, 163, 173. 22.5. 276,282 12:0 12, 281 11:0 11:3

elegans 11 ;

elongatum 117

Ensis Jelp. 118

Ensis Fucke 11s, 10T, 1.in

Entomon 118

falcatum 122

fasciculatum Joc. 12.2

fasciculatum liab. 1:2

filiforme 123

flaccidum 124, 161

fractum $125,11 \%$

fusiforme $12 \bar{\gamma}$

gigns 130

gracile 131, 5\%. 151, 22-

grauluatum 13.5

gresarium 135

Griffithii 136

Hantzschianum 137

Hirulo 140, 10s

inseriuale 143

incursum 114. 105, 156, 277

intermedium $148,110,2-12,21 \% 5$

interrutum 11 is

Isirlis $14: 4$

Japonicum 119

Jenneri 150, 105, 161, 173. 235

juncilum 151. 132, 115. 277

Kilrasianum 151

Kïtzingii 152, 118, 225, 232, 276

lieve 1 is

lagoense 151

lamellosum $15 \mathrm{~d}$

lanceolatum 15.5, 37, 141, 1912, 2015, 251. 278

laterale 15.5

latiuseulum 15ii

Leibleinii 15\%, 34. 160, 173. 175, $17 \%$. 27. 291 11:0 111i

Lens $15 \overline{7}, 75,154,150$

Libellula 157, 17. 75, 157, 278

Linea 15is, 10, zor;

lineare 1in

lineatum 1is. 12. 117. 132, 278

lineolatum $k \% \%, 15$ !

lineolatum hït: 15 :

littorale 154,2 is

Lunata 160. 161

Luudellii 1;0, 1332

Lunula 1611. 35, 3!1. 105. 111, 121. 1.51, 15, 15.5. 173. 171, 219, 25:3. 243. $271,275,282$ 110 3. 1 et 35

macilentum $16 \%$

maculatum 16:2

Malinvernianum 163, 111

margaritaceun 115.1

meliolieve $161 ;$

monile 173. 6s

monilifertun 173, 11. 111, 150, 156, 160, 1iil, 1(k), 19\%, 251, 271, 274, 2-242

(11:0 1. 5 et 12), 25:3 11:0 \$:1

monococecum 175

monotimitum 175

multistriatum $17 \%$

nasutum 17!

naviculoides 1 (4)

nematorles 1 ino

nodosum 182

obtusingulun 1si;

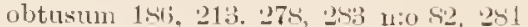
12:0 105 et 11!

oncospornu 188

ornatum 190,173

pachydermum 193

paradoxum 195

parasiticum 196

parvulum 196. 2135, 274, 285.2 4:0 7

P'nitum 19s, 75

peracerosum 194

polymorphum 203

polrectum 204

preprande 205,155

pralongum 205, 27:

Pritchardianum 215, 15,5, 206

prollum 2015 , 40. 15\%. 2:32

Pseudoclosterium 20s. 2Tis

Pseuludiante 208

pseulospirotenium 279

pusillum 213, 186

pygmatum 214

qualiangulare 240

Ralfsii 99, 87, 220. 284

refractum 222

regulare 223, 118,212

retusum 221,261

robustum 2.5

rostratum 225, 39. 34) 72, 152, 232. 216

rufice 15 22-2, 85, 96, 1111

Sreptrum 2:20.55

- reoticum 230

spleneum 231

sctaceum 232. 225, 24

sigmoideum 231

speciosum 230. 45

spirale 23\%, 150,243

spiraliferum 238, 23!

sryamatum 210

strigosum 241

striolatum 242, 101, 115, 238, 215. 240. 282 11:0 101

subaugustatum 213

sulbestatum 211

subcrassum 241

subdirectum 245

subjuncidum 215. 26อ̃

subpronitum 216

subrectum 217, 107

subtile 248. 293 11:0 37

subturgidum 24.5

subulatum $24 \div, 11,2 \% 2$

tenerimun 251, to

tenue 251, 38, 82, 1115, 15.5

tetractinium 253, 1131

Thureti 251. 173

toxoll 25.5

'l'rabecula 25.5, 55. 84, 111, 152, 2151

trabeculoides yintio 55 mipunctatum :259

trochiscosporum 281

truncatum Live. 2ij1, (Kuc/z) it

truncatum Trun. 211

tumidulum 262

tumidum 262, 82, 2\$1

turgidulum 24:83. 85

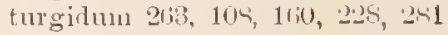

Ulna 26i., $110,115,212,215$

uucinatum 26.5

Veuts 217, 1915, 1115

verrueosum 268

Wallichii $2-1$

Wittrockianum 272

\section{Coccochloris}

Brebissonii 1i7, 56, 16\%

protuberans 207

\section{Colpopeltu}

deplanata 101, 61, S1

viridis $271,82,117,15 \%$

\section{Collecere}

Chauvinit 155

dissilicens 110

111ucosa 176,158

ovalis 192,111

\section{Cosmentidiulu}

Gucumis 12

Debaryi 47

clegantissinum 116

incisum 141

ovale 192

pregrande 205

psevdocolmatum 20s

pseudoexigum 208

Ralfsii :2:20

striolatum 213,7

turgilum 261

\section{Cosmererium}

aboreviatum 315

abuorme 36,85

abruptum 36. 271

aculeatum IPrib. 3!, 12.2

aculeatum Corde 3s

aculentum Wolle 35,220

iequale 10

affine 411

Aitchisonii 41, 175

alatum Corde 11, 269

alatum Firclen. 11

alpestre 11

alpinum 41, $88,125,365$

americanum 12

amoenum 13, 243 1เ:0 5\%

amplum 13.166, 271

Allax 27.1

anceps 7 th. 11

anceps Lumd. 11, 197

angulare 11

angulatum 11, 274

angulosum 4.5, 108, 167

angustatum 15, 60, 167, 202, 203

anisochonditum 45 
aluulatum (Nog.) De lior. t5. 116, $283 \quad 11: 0 \quad 83$

annulatum Delp. 46

anomalum 46, 62. So. 1is;

ansatum 46, 203

antilopeum 47

apertum 45

aphanichondrum 45

Areheri 19

arctoum 50

armatum Breb. 51

armatum Josle it

armillatum 51

Arnellii 5?

arrosum 52

Askenasyi 5:

asperuluin 53

asperum 58, 229

asplierosportum 53, 230

atlautoideum $58,5.5$

attenuatum 51, 95, 25.1

auriculatum $5 \hat{H}$

aversum 27

baceiferm 5.5

Baileyi 56, 101

Baronii 57

Barrackporeantum 57

beatum 57

bellum 57

Bengalense jo

biauritum of

Bicardia 58, 53, 71

bicrenatum Coole 58 , si

bicrenatum Tum. 59

bicuneatnun is

hicuspidatum 28,116

bidentatum 58,59

bidentulatum 5., 212

bifurium 59

bigemma 5\%, 54

bigorrense 59,253

bigranulatum $5.4,183$

binale 59

binerve 61,217

binolulum $61,14 !$

binum (i)

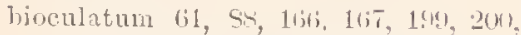
240, 251, 275. 2503 11:0 13

bipapillatun ti2

bipes 62,61

biptunctatuu1 69,23

bireme 62

biretum 62, 4i, 70, 216, 253 11:0 81

Pissetii 68

l)ivertex $6 ?$

Blonski 63. 2015)

Blyttii 63, 1.12, 233, 2-17, 275

Boeckii 63, 152, 241, 275

Boldtianum 6:3, sit, 88. 25\%

Boldtii 63

Botryt is 64, $12,99,1416,124,114,151$, 1is, 1(in, 1si, 207, 21!1, 211), 213, $254,29.5,275$

brasiliense 60,236

Jraunii $6 f$, 168

Brelissonii $67,61,79,275,24: 3511047$

1iruomei 70, 151, 166, 272

calatum 70, 236, 27: calcareun 71

calodermum $71,18: ;$

cambricum it

canaliculatum 275

caudianm 71

capax 72

capense 72

Capitulum 7.2. 202.2

cataractum 7:2, 20:7

centrosphinctun $\tau_{2}$

cinctutum 73

cineulare frütr. 63

circulare leinsch 73, 1.47, 21:

("lepsydra Thelp. i4, 147

Clepesyita Norlst. 71, 5s

coarctatum 73

(olunii $7 \bar{\tau}, 2 \pi$

coliferum $7 t$

coloratum it

Colpopelta $7 \pi, 2 \pi 1$

commissurale $77,230,28.3$ 11:0 51

commune $7 i, 208$

commutatum 7\%, 212

concentricum ts

concinmum $T \&, 211$

collfusum $79,67,24 x, 275$

conicnm 79

conuatim 7!. 117, 167, 208

connectum 79

conspersum $7(1,46,165,218,25:)$ 11:0 $43,25)^{\circ} \quad n: 0182$

constrictum Delp. so

constrictum (Arell.) lioy si

contractum $80,101,210$

controversum 81

convergens 81. 101

Corbula 82, 64, 240

Cordanum S2, 77, 271

cornutum Corda 83,243

cornutum Iimb. 83

corollatum $\$ 3$

Corriense 84

corruptum 44

costatum 85, 36, 63, 87, ㄴ11

crispedopleurum $86^{\circ}$

crassangulatum 86,251

crinsipelle 86

crassum 87

crenatum $57,11,63,45,116,235,258$, 265. 276

creniferum 8 s

crelulatum $\mathrm{x}, 2 \pi$, $2 \pi$

creperum s?

cristatum 8?

erueiatum 10

artuciferum (in)

(rux melitensis (yo)

ctenoidem 91

Cucmmis 91, 47, 97, 111, 147, 153, 217. 220,214

Cucurbita $92,71,91,191,217$

cumeatum 93

rultum 98, 5.1, 222

crelarlatum :11

cyelicum 91, 113i3, 183, 205, 211, 261, 27i

crlindricum $15,221,283$ n:0 5

'ymatonotophorum (ii);

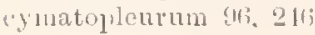

danicmus $97,142.247$

Davilsonii 97

Dobaryi 97, 251, 263, 276

decachoulrum 97,250

decedens $97,217,231$

decoratum gs

decornm stis

delicatulum 99

deltoides 99, 1 it

teltoideum 99

Le Notarisii $9 !$

dentatum

dentiferum 101

depanperatum 101

depressum Iivil. 101, ati

depressmon hiat: 101

depressum Land. 101

Ibiadema 101

diadematum 104

dichoudrum 105

I idelta 100, 203

didymochondrum 10 T

difficile 1115, 169, 27i

directum 110

dispersum 110

distichum 111

Domnellii 112

doviense 112, 87, 1941

duleiferun 113

eboracense 113

eductum 111

Eichleri 115

elaboratum 115

elegaus livel. 115

elegaus lioy et Riss. 115

elegantissimum 11ti, 46

Elfvingii 117, 139

rlipsoidem 117, 20:4

ellifticum $117, \pi 0$

Eloiseanum 11 .

dongatum 117, 51

cmarginatoconstrictum 27

cmargiuatum 117

cuाrginulum 117

crosuin Arch. 11s

crosum Delp. 119

Etchachanense 11:1

enastriforme 11 !

enastroides 11!

Euastrum 119

crerettense 120

exasperatum 121

excavatum 121, 119, 190, 227?

exigutu 121. 18;

eximinm 1:?

fenestratum 123, 17

Finmarkice 124

flavurin 121

Foersteri 121

foutigenum 125

formosulum $125,133,218$

forte 125

franconicum 125, 11\%, 25-

Fridie 126,222

furc itospermum 126;

fisum 128

gnielitum 125, $1111,233,24 \%, 155 \mathrm{n:1}$ $17: 1$ 
Gangense 128, 1.0

Garrolense 1.28, 11

Gianum 124, 11 T

Gavii 12s

geminatum 12.

genimatum Bréb. 1.sh

genmatum Tum. 1오, 14., ‥54

gemmifertm 12!!, 15, 1:28, 163

gentrostim 12 !

geometricum 129)

Georgicum 1:! !

Gerstenbergii 12:!, 153

flaziorii 130

ginlostum 130, !2, 171, 213

glyptodermum j:il

uronioilles 131

gotlandicum 131, 221, 280

Goulajerii 131

gralatum 13:12, 125

granatoides 133

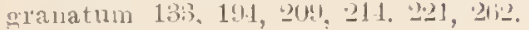
27

Grantii $13 \pm$

granulatum 134

graunissculum 13\%

Gregorii 13\%

guianense 133

Gutwinskii 131;

Hataboeliense $13 t, 7 i$

Hammeri 13\%, 111, 1-8. 215. 221, 213

Haynaldii 13S, ?.ฺ"

Heimer]ii 13ॅ

heleangulare $138,27 \%$

heliosporum $1 \mathrm{sin}$

lieterochondrum 135

Heuflerianum 138

hexagonum Fife. 1:3!!, 11 T

hexagormm fordst. 13!

liexalobum 13!

hexastichum 139, 21\%, 21!

hibernicum 13 !

lirsutum $\mathbf{1} 10$

Holmiense 141, 12x; 141, 242

Inolmii 141

Lomalodermum 1H1, 137. 215

Hookeri $1 \pm 1$

humile 142, 63. 211. 215, 217

Humyadranum 142

Hyacinthi 112

impressulum $113,71,164.235,205$

inequalipellicurn 1:1:3

inane 1.13

incaratum 113

incertum 1:1:3, 11j:

ineisum Jus?, 111

incisum lire. 114. $\$ 1$

inconspicutum $27 \%$

Incus 14 in

indieum 14 ;

inturatum 1110

inflatum 11 $119 ;$

inuotium 147

inornatum $11 \overline{7}, 2017$

insigne schmidle 117

insigne Tur. 117

integerrimum 147, 11;. $\overline{1} 1,125$

integrum 114

intermedium 1 lic irregulate 14 ! , 21s

istlminm 119, 121, 2015, 227:2, 281 11:0 113

istlmoehondrum 11!), (it, 216

. lacobsenii 11!4, 171, 르

jav:nutum 154

fonisojense 1\%, 1.2., "21.2, 2016

Ioshuce 151

. Iundzillii 151

lianitzit 151

lïrelneri 151, 25i;

Kitchelii 152

Kijellmani 152

lilebsii 152. 2om

Lititzingianum 152, 21?

laciuiatum 1 วั3

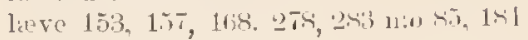
11:0 168, 193 11:0 lis

lagenarium $15 !, 1 i j$

Lagerlieinii 151

lagoense 1 ind

lasiosporum 155

laticeps 155

laticollum jis

latifuons 15

latum 155, 14. 165, 16iti, 1911, 21:1

leiolezmm 157,153

1epirlum 157

Lidanum 15, 6i5, 26is

limuophilum $15 \%, 2,23$

lobatosporum 1.5:1

lohatulum 15 !

lohatuin 159

lobulatum 1is

Logiense 15 ?

Lortetianum 160

lunatum (6)

Lundellii 160

Lusitanicum 16ㄹ. 20-4

macrosporum 162, 11 is

maeulatiforme $16 ; 3$

maculatum 162

magellanicum $16 ; 3$

maguificum 16:? 12 ?!

Valinvernianum 16:3, !1. 218

mammilliferum 16;1

marmaritatum $165,15 \%$

margariferum 145, (i.5, 50, 15, 205, 213. 215, 223, 2-15, 24il, 278, 283 n:0 วิ।

margaritum 1131;

medioglabrum 1titi

medioliuve 16 t

melanosportun 16, 2.4.3 11:0 8.3

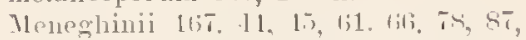

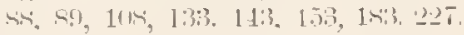
217. 21:. 274. 24\%. 11:0 85, 245 11:0 1nd

mentiens 19:1

messochondrion lite

micros]hinctum 17i, 1m1, 211

mietzrrzecense 171, $2 \pi$

minimum 171

Iinneapolitanum 17. 207

111 inn: 171

minutissinum $-1 / \mathrm{ch}, 1$ iा

minutissimum /leim. 171, 1:34

mintum 7icms. 17. 2013 minutum 7elf. 172, 17., 272, 274

Moerlianum 17:3

nonilifertm 17, 117

moniliforme 171. 113, 1301, 114, $11 ! 1$. $271,2 \pi$

monochomdrum 17 .

monomazum $175,171,-20.3$

IIoriax 175

lrolsum 176

munitum 175

Mwangadanense 2T.

Yegelianum 17!! s7. si

nasutum 180, 190, 22:30, 216

Nathorstii 1sin

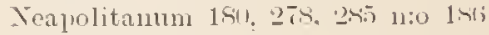

nepluroideum 1,-1

Netzerianum 181

nigroeilratum 1,i

Nilssonii $1: 1$

nitidulum 151, 22:2, 215, 2-4t n:0 13\%

nolusum 181

noiluliferum 182

Torlstedtianum 183, \%

Tordstedtii Dely. 18:3

Norlstedtii Fac. 18:3

Yordstedtii Wolle (183) 211

Norimbergense $1.43,121$

notabile 1s:

Notarisii 184, 99

notochondrum 181

Nove Senlize 18t, 210

inlieejıs 181

Nuttallii 184, 24s

Nrmannianum 1St, 137

obemeatum 1sit

oblifutum 1.54

oblongum Benn, 165, 263 11:0 68

oblongum Lrél. 1-5, 231

olsoletrm 156, 73. 194, 235, 27s

occidentale $15 \%, 12 !$

ocellatum $18 T$

oehthorles 18i, 1i1, 231;. 281 11:0 14:4

octogibbosum 1s's

octogonum 1si, 13i, 16!

oculiferum 18s

olontoplenrum list

Oligogongrus 168, $266^{\circ}$

Oliveri $14 \mathrm{~s}$

Onyelıonema 1sis

orbiculatum 1:0, 121, 11:1, 215, 251 11:0 173

orieutale 194)

oruatissimum 1!10, 180

olnatum 190, 7T, 15t, 2017, 20\%2, 2465, 275,283 11:0 13

orthogonum $191, \mathrm{si}, 17 !$

orthoplenrum $1: 1$

orthopunetulatur 1 ! 1

orthostichun 191

o1togonum 191

(rsteri 192, 271

oxale 1!r, 72, 20\%2 11:1) 21

pachyilermun $1: 3,215$

Preificum $1 ! 3$

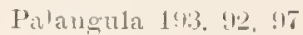

palustre 194, 189, 235

pinduratum 191

janduriforme 1 !1 


\section{COSMARIUM}

Papilio 191, 133

paradoxum 195,117

l'ardalis 194,156

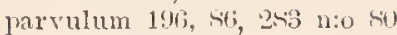

Paulense Borrg. 1st

Paulense folins. 1:\%, 203

pectinatum 197

pectinoides 197,27 !

Pelta 197, 268

pentachondrum 19s

peregrinum 198

perforatum 199, 2019

pericymatium 199

perizosmum 159, 285 11:0 1811

perpastum 196

perpusillum 10!

Pertyaum 199, si, 112

Phaseolus 199, 61, 101, 152, 279, 282 11:0 13, 2.51 n:o 161

pileigerum 200, 2210

1) lanum 201

llatyisthmum 202

plicatun 202, 97. 141, 231, 24., 27. 280

pluviale 202

Podlacline 20

polimorplunm 203

polonicum 2015, 1313, 77, 2[13

jolygonum $203,171,20$ !

polymazum 203, 175

polymorphun facols. 203

polymorphum Nordst. 203, 197

porrectum 201

Portianum 201, 193, 149, 181, 191, 2019, $27: 1$

preclsum 2015

pragrande 205, 2:34;

primorsum 205, 9.1

jominens $20 x^{\circ}$

prominulum 206

promontorium $24 ;$

proteiforme $200 ;$

protractum 207, 6i1

protuberans $207,171,201$

protumidum 207

pseudamoenum 207, 117

jesularetoum $20 \%$

jseudatlantoidenu 207

pseudisthmochondrum 207

pseudobioculatum ?18

jseudobireme 205

Psculobotrytis ?2x

P'seudobroonei 208

jiseudoconnatum 20\%. 7?

psendocoronatum 208

pseudocrenatum 208

jopudoexigum 208, 245

pseudo-fontigenum 208, 125

jiseudogranatum $209,272,27 !$

joseudomargaritiferm $2019,20.5$

pseudonitidulu 2 (15, 293

jiseudoornatum 20!, 190

pseudopachydermum 21:., 220

jsendopectinoides 209

jiscudoprotulerans 2019, 61, 203, 2017, 279

psendopyranilatum 210,' 11i, 147, 171, $1112,215,247,279$

I'sendoreguesii $210,154,275,280$ psendusperiostum 210, 185

psculostenonotum 211

jseulotaxichondrum 210, 200

pscudotetracerum 210

jitilotum 211

pulchellum 211

pulcherrimum 211, 81;, 218

julvinatum 212

punetulatum 212, 151, 55, 75, 235, 279, 285 n:0 18:

prisillum 214

puteale 211

pyenochondrum 214

lygmeum Arch. 214. 138, 230

lygmenm IIuntzsch 214: is

lyramilatum $215,15,72,141,192,2111$. $242 \quad 11: 06$

pyriforme 215

quadragies-euspidatum 211i, 260

Iuadrangulare 216, 26:

quadrangulatum 216, 62,285 n:0 18i

quadrans 216, 150

"1tadratulum 217

'11uadratum 217, 61, 92, 231, 27!

quadrifarium $218,165,211,219,243$ 11:0 53

'fuadrigramlatum 2ls

Quadrum 21s

Quasillus 218, 125, 119,279

quaternarimu 218, 161;

Quimbyii 218

quinarium 219

Raeiborski 219, 284 n:o 122

Raciborskiasnm 219, 73

Raciborskii 215, 1s:3

radiatum 219

radiosum 220

Ralfsii 2011. 11, 14it, :09

Raneegungense 221,133

rectangulare 221, $131,217,260,252$ $12: 0 \quad 6$

rectangulum Reinsel ?222

rectanguluu Schmidl. 222.2, 120 . 2301

rectosportum 222

Tieselianm 22:3

Regnellii $2 \cdot 2,280$

Regnesi 22:2, 88, 27!1, 264

regulare 223

Reinhardii '23?

Reinschiantum 2023, …3 n:o i2

Reinschii .lrch. 22:3, 158, 283 11:0 70

Reinschii Scha(t). 22:?

reniforme 22:3, 165, 1616, 24:3 n:0 511

repandum 221

retusiforme 22-1, 135,280

retustum $l i a b, 224$

letusum Tiossm. 2:-1

rhombusoides 221

Tiostafinskii 2.25

rostellum 2:\%

1.ostratum 2021;

Rota 226

rotuludum $22 \overline{7}, 11 ; \overline{7}$

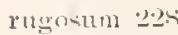

rmpestre $2: 26$

salinum 228

sansiluarense 226

scaluratulum :2?! scabrolatum 2.8!

scabrum 22:5

scalare 22 ?

Scenedesmus 22!

sclumidlei 230, 22:

Schliephackeanum 230, 5:3, 211. 231

Selneitleri 230

schüblelerii $2: 30$

scitum 2311

sicoticum 2:30

sculptum 230

sentellum 230

Seelyanum 231

sejurctiun 231

Fendtnerianum 232

septenarium 232

serratum 232

sexangulare 233,$128 ; 280$

sexnotatum $2: 33$

sigillatum $23: 3$

sikhimense 231

silesiacum 234, 230

Simii 234

simplex 231

Sinostegos 2:34

sintosum Corde 231, 147, 1.85

sinuosum Lund. 231, 47, 202, 210, 217

Slewdrumense 2:35

Smolandicum 235, 1 sit

sniatyniense 235

solidum 235, 85, 212

sparsum 236

speciosissimum "230;

speciosum 236, 165, 153, 217

speetabile $233 ;, 70$

spetsloergense 236

spharicum 230

sphitroideum 237

splualerostichum 237 , tili

spiculiferum 237

spinosportum 237,70

spiuostum 237

Fportella 210 . (55, 14\%

spyvition 210

stanrastroides "2 41

Stamochoudrum 241, 13

stellinum 241, 227

stiehochondrum 211, 1\$3

striatum 211. 1.2, 217

striolatum $21: 3$

stullmannii $24: 3$

sululatum "2l:3

subarctoum 21: 130, 281 11:0 111

sulaurienlatum 243

subbinale 243,137

subbotrytis 243 , 65

subbromei 2 t3

suber pitulum 214

subrirculare 211

suhcostatum 211,2 , sil

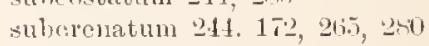

subcruciformp $24 t$

subeneumis 214

subcyclicuu 211

subeylindricum $211,9 !$

subdanicum $215,112,215$

subrlistichum 245

subeductum 215 
sıbexiguum 245. 208 subglobosum 245 suluhumile 245,247 subimpressulum 21.; sublaterimdatum 24. silblatum 2.15, 166; sublobatum 245, 250 sulumamillatum 2.46 subuasutun 216, 180 subnotabile $211 i^{\circ}$

subochtliodes ? 41 ; suborbiculare $24 ;$; 14 ! subortlogontum 2.10 silbortlosticlum 216 subprelyilermum 2ffi subpalangula 24i; subprotuberans 24; subprotumidum 240 subpunctulatum $216,203,212$ subpriforme $214 ;$ silbinaliatum 246 subquasillus 247 subrectangulare $2.1 \bar{\tau}, 221$ subreinscliii 21\%, 11s subreniforme 247

subretusiforme 245 subspeciosum 247, 129, 236

substriatum $21 \overline{7}, 63,142.241,215$ subtholiforme $217,103,79,25 ;$ subtumidum 215, 128, 181, 2501 subturgidum '24, 280 subundulatim 24. 184,263 sulvenentustum 280 suceismun $21 \mathrm{C}$ sulentrum 2.1 !

supergrautum 24! supraspeciosum 249,218 synthlibomenum :201 tatricum 250

taxichond iforme 2.5), 89

taxichondrum $250,97,139,2.90$

truerum 201

tenne Arch. 251, 61

tentre Mask, 25i

tessellatum 25:2

tetracantlinm 252, 14i;

tetrachoudrum 253. 281, 294. $11: 0$ 1:13

tetragonum $253,2.1$

tetrophthalmum 199, 64, 65. 49, 165, 253,279

tholiforme 251

Thwritesii $251,51,512,222$

tinctum $25 \%, 61,283 \quad n: 061$

tithophorum 2-5, 59, 71

Tittaghurense 255

trachyeyrtum 250

trachydermum 25i;

trachypleurum 2:if, 151, 171. 217

trafalgaricum 257

transiens $2.57,125$

triceps $25 \%$

tricrenatmm 258,13

trifasciatum 25

trigemmatum 258, 24t n:0 110

trilobulatum 25:9. Hi. 14i-. 212. 3is

trinoliferm 2.5!)

trinoulnlm 25 !)

trimstatum 2:-1! triordinatum 2:5!!

tripapillatım 25!

triplicatim 25.9, 12:!

trumeatellum 2)-1i1, 17

+rumcatiun 261,2206

troclisenum 2:1

tuberculatum 202

tumens 262,183

tumescens 262

tmmidum 20, 181,2019

tulgitum 208,07

Turneri $2(3.4,1(5)$.

Turnerinum 261, 95,

"Turpinii 264, (i1, (i), 106, 158

Uerainictum 20is

umbilicatum 2015

umbonatum 265, 16,208

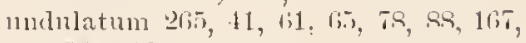
218,266

Tugeriauum 261;. 64, 284 n:0 151

unigerum $260 ;$

variabile 265

variolatum $267,72,211$

Vinsoriense $26 \%$

ventricosum 2013

renustum 265, 71, 25.9, 281

verrucosum 265

vexatium 270

viricle 271

vittatum $2-1$

vogesiacum $271.15 \cdot 2,2 \$ 1$

Warmingii 271

Weddelianm 271

Westianum 2:2

Willeaum 27:

Willei $2-72,7$

Willsinum 272

Wittrockii $2-2 \cdot 2.109,172$

Wolleanm 272. 209)

Wrightianum 27?

zonarism 273

zonatim 273, 281

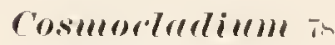

coustrictum sil

perissum $1: 49$

fulchellum 211, 229!

pusillum 214

Quimbyii 219

saxonicum 211, 22!

sllhramosum 217

tumidum "⿻f:3

\section{Cylindrorystis}

Brebissonii 67, 91, 1.⿲丿 139. 198, 27.. 2\$1 n:0 145

coerulescens $7 \bar{t}$

crassa sir, 67, 11i2, 22.

'yanosperma !1

Cylindrus $\$ 1 \%$

depressa 101

(liplospora 111, 1!:?

endospira $11 \mathrm{~s}$

margaritacea llil

minutisiuna 171

ovalis $1 !(0)$

jolonica $210: 3$

rosenla 22:5 tatrien 2.00

trumila $26: 2$

\section{C'ymbellu}

aeuta 3 !!

Hopkirkii 141, 15is, 1!12

letevirens 153,67

reniformis 223, 28.2 n:0 11

\section{Jesmidium}

neulsatum 38

amblyodon 42

apiculosum 45,178

aptogonum 4:, 101, 249

Raileyi 56, 71, 258, 265, 25

bambusinum $5 \overline{5}$, (іт

Bengalicum 57, ㅃt?

bifilum $5.9,108$

bispinosum 152, 251

Borreri 63, 67, 175

calatum 71

coarctatum 70

compressum 78, 116, 26:

curvatiom 94

cuspilatum 9.1

rylindricum 95, 78, 130

Diagonum 104

diilymum 10.9, 54, 250

divergens 112

clongatum $11 \%$

enstephanum 120, 59, 209

glabrum 130, 242 11:0 29

graciliceps 133, 163, 217

graunlosim 13\%, 7

Grevillii 136

liexacelos $139,1155,25 \%$

iudicum 141;

laticeps 15it

limbatum 158, 110

longatum 159, 117

majus 1133

monticulosum 175

mucosum 176, 1111, 1.5., 221

orbiculare 18!

quadrangulare 216, 27!)

qundrangulatum 216;

quarratum $21 \% ; 133$

1'nnosmm 221, 239

senarium 231

Swartzii $249,42,49.57,02,108,113$.

$$
111,211,270,280
$$

tenax 251

tetragoum 253, 54;

tricolne 257

tridens 25s, 138, 252 n:o 2t

undulatum 263

vertebratum 20 !

\section{Dirctomere}

dissiliens 110

swartzii 24 !

\section{Dirtyosplererium}

constrictum st)

\section{Didlymidium}

aculeatum 35

aculeatum :3: 
angulosiun 11 ansatum 4 is apiculatum 18 armatum il asperum 58 bacillare 5.5, 131 bicornutum 55 binale rit, 113 biorulatum $6 i 1$ bisenariun (i? Botrytis 61, 26ij Braninii iati, 205 Brebissonib 67 circulare 73 commissurale TT concinum 78 consiersum 7 ? convergens 81, 10 ; cristatum $\mathrm{s}$ ! Creumis I1 decemdentatim 5 dejectum 9s: denticulatum 100 elegans 115 evectum 11<, 115 Erlangense $11 \mathrm{~s}$ faseiculatim 122 fimbriatim 121 franeonicum 129i fulcatum 126 ; furcigerum 127 gemmatum 12!) gracile 132 granatum 133 Hammeri 137 Hermannianum 13\} his'sutum 14 ) Hystrix 142, 216, 251 insigne 147 Köitzingiann 152 margaritacerm 165 mrargaritifermm 166 Meriani 169 minutissinnm 171 unorsum $\quad 36$ muticun 178 Xegeliantm $17(4,54)$ Norimbergense 1.83 notabile 183

oblongum 185 obsoletum 181; netocorne 1st orbienlare $14 !$ papilliferum 1:!1 paradoxmen $15 \%$ pectinatum $15 \%$ pinnatifulum ?201 plicatum 202. 234 polygonum 203 polymorphinm 204, 15 Pringsleimii 20\%; protractim 207 jsendofurigertum 20 !) punctulatum $21: 3,41,22$. ly'ainislatim 215 qualyat $141121 \%, 72$ Ralfsii 220)

Regnesi 2.2?
Reluardii 20.23

rotatum 220

Selualdi 230

Sendtnerianm $2: 32$

sexcostatum 2833

spinosum 23\%

spinnlosum 235

spongiosum 239

tetroplithalnum $25-1$

Tigurinum 255, 101

trilobulatun 25 !

truncatium 260

mululatmu 265

Ungeri 266

varians 26it, 11, 41, 141, 1-12, 150, 235

venustum 208

verrucosim ㄹ!

restitum 270

\section{Didymortrram}

Cerberns 73

furcigertus 127

longispinus 15 !)

sexangularis 283

Stella 211, 2:33

\section{Dirlymopreiem}

Borreri 63

cylindriemm

graciliceps 183

Grevillei 136,95, It1

Gladratum $21 \%$

\section{Hiphesphereillm}

moniliforme 174 , 11i)

\section{Disphinterem}

(false pro Dyspluictinm).

\section{Doridiopseis}

norlosa 182

\section{I)oridiull,}

abbreviatum :3i

abruptum $31 ;$

aequale 10

alternans 11

anuulatum H;

Aluheri 49

asperum 53. 69. 220

laculiforme j.j

baculoirles 5.5

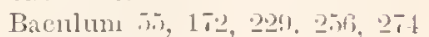

Bengalense $5 \pi$

breve (jis

Bumense $\sigma_{0}$

clavatum 71. 20\%

conjunctum 7 ?

constrictum \&()

coronatum 53,182

rolnsulatim $8.3,271.27$

costatnm \&ij

cremulatum si, $25 \%$

crispulum 8:1

eristatum 8!

eylindricum 5

(lenticulatum 100

dilatatum Mask. 109, 1!12 dilatatum Nordst. 109, 1:1, 2fir; egregium 111

Ehrenbergii 11. 25h

elatum 115

elongatum $11 \%$

eugeneum 120

excelsum 121

Farutuarsonii 12 ?

Flotowii 124,261

Georgicum 129

sloriostm 131

gracile 132 , 1si

granulatum 134

grautififerun 135;

lirsutum 140,272

Intehinsonii $1+2$

indicum $1 \mathrm{tf}$

inelme $141 ;$

inornatum 147

irregulare 119

Kayei 151

latiun $15 x$

longitsenlum 160)

maculatum 163

mamillatum 113

Mammbrinu 161

maximum 16,6

minutuin 172, 221

110bile 181

nodostum 182

nodulosum 182, 69, 25i;

oecilentale 1si

nelematrum 186

orientale 190

ovatiom 1:4, 10!)

parvum 1:T

perleve 196

poly"morphin 2013

Pristide 206; 1.32

prriforme ? 117

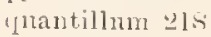

recturn 22:2

regale 222

repantum 224

thompheem 221

robustun 2025

rotumlatmm 22:-27

salebrosum 22s

scefitrum 22\%, 255

setigerum 232

sinuosim 231

Sonthaliannm 235

spinosum 2:38

spinnlusum 238

strulmannii 213

subeoronulatum 214

tessellatrm 252, 265

Trabecula $25 t ;$

trirlentulum 258,209

trunca.tulum 261

truncatmm 255, 7., 256, 261

turgilum 263

undulatu1n 266, 1119, 181

verrucosum 264,252

verticilatum 271,192

Wallichiamum $2-1$

Trolleanum 272, 141

Tondsii 272 


\section{I)!sphinrtim}

areeps 41. 214

numulatum 15

aspersum 52

attenuatum 5

basilecorum is

bifarium $5 \mathrm{~s}$

binerve bi

brefeldii $6 !$

clandestinum 7.1, !.

c'lepsyira 7.1

Clerei 7.1.

Colnii it

(onicum 7!)

comnatum 7!!

Colelanum 5?

costatum 8.

cluciferum (0)

Cucurbita $92.2 \pi$

('urtum !) 13

cylindricum 95

Crlindrus 96

leharyi 17.494

discretum 110

lubium 113

ellipticum $11 \bar{T}$

excaratum 121

exile 122?

glohosum 130

grande $1: 31$

heternloxitm 138

lonmieuse 1.11

inferum $14 t$ i

lagerlueimianum 151

Markusorsligi 10ip

Jeneghinianum 16:, 7!

microsphinetum 170

minutum 17?

monile 173

mouiliforme 174

notabile 1:3. 23\%

oblongum 15:

orbiculatum 16(k)

Palangula 19.1

parvulum 197, 41

paxillosum 195

perieynatium 199

pluviale 202

p.culamoonum 20 -

psemlaretoum 24

psendoeonnatum ? 118

jusillum -1.1, 21t

guadratum 217

yualum 218

Ralfsii 221

Regelianum 202.2, :1:3

rotusum 2.21

sinuosum -234

sparsipunctatum 23;

sleciosim 23r

strangulatum ?211

striolatum $21: 3$

subconuntum 211

subglobosum 245

subpalangula 24ij

subpriforme $214 i$

smbrotmulum 2!

diondreate, Index Desmid. subturgidum 2 l\%

siluraconnatum 21!1

tessellatum 252, TT

Thwaitesii 25!

trifaseiatum 25

tuberculatum $24 t^{2}$

tumens $24 t^{2}$

turgidum 20:3

verrucostum 24is

virile $2 \overline{5}$

Willei Schmirll. 272, 12I

Willei Turn. 27.?

\section{Erllillella}

Aelorii 38, 214

acuta 39

circularis 71

fusitormis 128

Luma 160, $15 t$

oblonga $18 \overline{5}, 19 \overline{7}, 2: 4$

radiosa 219, 35, 61, 113, 11i1, 11i2, 221, 231

Riccieformis 2.21, 0.1, 2019

rotata $226^{3}$

\section{Endospirn}

bryophila ti

truncorum 262, 75

Entospire

closterilia $7.5,11 k$

\section{Euerestrmem}

aboënse 36,146

abraptum 36

acanthopliorum 36

acauthopleurum si

aculeatum 38

acutilobum 30

affine $40,141,264$

amhigum 12

americanmm 42, 28? n:0 1!)

amcenum 13, 1(w)

ampullaceum $43,267.282$ n:0 32

anglicantum 14,274

angulatum 41,167

angulostm Corda 11

angulnsum E7werb. 45, 64, 253

angustatum 45

ammlatum 4f, 116, 275

anounalum $41 ;$

ansatum 11;. 7: , I0fi, 123, $117,154,162$, $210,22(1,250,274,24211: 020,245$ 11:0 2011

antarcticum 17

apiculatum 19,34

armatum is

Armstrongianum 51, 211, 243 n:o is

attenuatum it

anstrale 51

bellin $5 \overline{5}, 201$

Berlini it

bieornutum 58

bieuneatum is

lidelitatum 5S. 115. 111;

bifinum 59, 201

Bigorrianum is!

bilobum 5:3, $115,1.14$ binale 59, 45, 47, 86, $1041,100,109,115$ 159. 160. 220, 2:11, 235, 283 11:0 (6.). 24 -1 $11: 0 \quad 14: 3$

bioculatum 61

bisenarium 62

Boldtii $63,100,25$

lBorgei 63

Boryaniun 61

Botrytis 1;1, 15

breviceps 1;\%. 57, 2061

celatum 71

ealodermum 71

cambrense 7

eandianum 72

calductum 72,238

carinatum 72, 192, 282 n:0 21

eclatum 72

(instoni 73

(inetum $7 ?$

circulare 73. 46, 150, 235

elavatum 74,264

Clepsydra $7 t$

commissurale $7 \tau$

compactum $7 \bar{\tau}, 275,291$ 11:0 141

concinnum TS. 167

collvergens 81

coralloides $8: 2$

eordatum 82, 267

eormutun 83,57

corountum 8:3, 231

cosmarioides si

(rameri S6, 1st, 226

erassangulatum 86,60

crassicolle so

crossum 8т. S3, 163, 191, 198, 283 n:0 48

crassiun $\times$ lutumerosum 87, 141

crenatum Fuclif ST, 101, 199, 265

(renatum Kïrts. S.

crenulatum Benn. 88, 22.2

crenulatim Elrenb. 8.9, 91. 165

crueiforme no

Crux melitensis M. 113, 167

Cucumis 91

cunentum $93,4 \bar{i}, 276$

cuspidatım 14

Cymatimn 96, 228

decerlens $\$ 7$

deemilentatum 97

deelive 98

decoritn :18, 71

delicatulum y9

Delpontei o9, 115

deuticulatum $100,43,80,63,115,152$. 2tis, 265, 275, 291 n:o 143

dentiferum 101

depressum 101, S1, 200

Dulelta $106,17,59,123,141.267,292$ 11:0 20

Iidymaeanthum 106, 191. 201

aiodon 109, 61

divaricatum 111, 276

divergens 112

Donnellii 112

dubium 11:

Elurenbergii 11 :

elegank 115, 16. 58. 55, 111, 116, 144, $141,15 \%, 201,207,211,220,234$. 217,293 11:0 50 et 45 
EUASTRUM

elegantulum 116,115

ellipticum 117, 129

emarginatim 117

emarginulum $11 \%$

erosum 11!: 245

Everettense 121

exile Josh, 122

exile Tun. 122

expansum 122

faseiculatum 12?

farosum 12:3

flammerm 124

Florilanum 121

forcipatum 125

formosum Gay 12.), (51. 128

formosum Trolle 125

Gangense 12s

Gayantm 128, 125

gemmatum 129. 137, 175, 195. 19\%. 201. 237,252 n:0 20

miganterum 130

Glaziovii 130

granatiun 133

Hammeri 137

Hassallianum 137, 129

Trastingsii 138

lreptagonum 134

hexagonum 139. 130.27

lirsutum 140

Holmieuse $1+0$

Holoeystis 141, 191, 19!2

holocystoides 141

litumerosim 111, 11, 101, 295, 275

linmile 141,72

liypoeliondroides 142

liypochondrum 142

impressnlum 143

implessum 113

incavatum 143

incistum 143

inerassatum 114

inculiforme 11 t

inellyatum 144, 116, 2\%

Incus 145, 172

inerme 146, 36, 115, 219

inermius 146, 23r, 27

insigne $147,1.18$. 16.1. 1 !10, 284 12:0 1.46

insulare 147,6 )

integerimum 117.91

integrnm 148, 83, 231

intermedium $\mathrm{Cl} r, 145,147,272,217$

intermedinm Doly. 114. 9!

intermediun Gay 148, 125. 25

interstitiale 149, il

irregulare 149

Tenneli 150. 73, 235, $21 \%$

Tovis 151

Tíitzingianum 1,i2

læve $E \not h b, 158, ! 11,271$

lave Graly $1: 3$

Langei $10 i$ in

latipes 150

leiollnum $15 \%$

levatum 1 is

lobulatum 159, 65), 81,115

longieolle 15.9

Lomgifons 159, 239

Lumlollii 160,, $6(1$ lunulatum 161

magnificum 163. 8T

mammatum $16 i 4$

mammillostum 161

margaritacenm 164, 62, 4.9, $161 \%$

margaritiferum 165. 16it, 195, 25?, 25.

Meneglninii 16:

mieraithum 1 (lis)

minutum 172

mollodentatum 17.). 11

mononeylum 17, 12!, 278

multigibberum 176

multilobatum 177

muricatum 178

Negelianum 17!t

nitidulum 181

nolvile 1 si

Nordstedtianmm 1ৎ3, 10t, 23ৎ. 201

$n$ mmmularium 181

obestum 191

oblongiforme 1.4

oblongum 155. 231, 282 n:0 20, 28:3 11:0 (18. 25.1 13:0 1:5

obtusum 18i;

netreanthum 187, 188

octangulare 1sT. $\mathrm{si}$

octocorne 187

oetolobum 1 ss

neulatum $18 \mathrm{~s}$

nrbiculare 1s: 238 , 206

orientale 150, 147

ornatum Foclie 160, 30 ?

ninatum IIood 191. ST

ornithocephalum 191

oscitaus 191

ovale 19.2, 21:

Papilio Kïtz. 1!!

Papilio Ruc. 191

papulostm 195, 129, 26!

paradoxum 195

Paulense 1:97

Peeten 197, 155. 211, 231, 24.2 n:0 2i

peetinatum $197.129,279$

Pelta 198, si

pentangulare 198

perpusillum 1:4;

personatum 1,

Phaseolus 199

jictum 200

pingne 2(11,52, 283 n:ก 5\%

pinnatificum 201. 25? 11:0 22?

piunatum 201

Pittacium 2(1)

platyeerum 201, $5 \overline{7}, 67,12 !$

Pokolnyanum 2112, 45. 25!

polare $243,45,61$

polygonum 203

prepandum 205

projectum 206

prorum 2(11; 116

protraetum $20 \%$

psendelegans 24\%. 116. 284 11:0 141

psendobotrytis 20

jeudopyramilatum 210

pulchellum 211, 11:

purum $21: 3$

pnsillum 214

lygm:enm 24.1 pyramidatum 215

quadratulum 216;

qualration Nog. 217

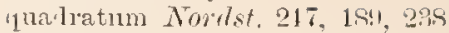

quadriceps 217

ftinemeiale 219, 238

quintanum 21!

Rabenhorstii 219. 14!

radiatum Nay. 219

radiatum Turn. 219. 261

lialfsii Kütz. 220, 46, ว9

Ralfsii Rub. 2201

reetangulare 221

retrorsm 224

retusum Kiitz. 224. 14.

retusum Perty 221

Richteri 221

rostratum $220,115,116,281), 2 \& 1$

Rota 2215. 227, 231, 241, 24i1)

rotundatum $22-5$

rotindum $22 \%$

rupestre 20.

Satkii 22 !

schizostaurum 230, it

Sehmidleanm 2:30

seitum 231)

sculptum 230, 235

Scutum 230. 150, 261

seuniladiatum 231, 26!1

Sendtnerianum 2:32

serratum 232

sexangulare 233

sibiricum 283

simplex Gay 234

simplex Wolle 231, (in), s.3, $11 \mathrm{~s}$

simplicius 231

singulare 234

simosum Kët: 23\%

sinuosul Lenorm, 2:3, 73, 267

snodowiense 23:-

Sol 235, 219, 220

specinsum 236

speetabile $231 ;$

spliyroides 237

spicatum $23 \overline{7}, 17 \overline{1}, 217$

spinosmm 237, 40. 61, 115

spinulosum 2:35, 72, $146,16 ! 1,217,230$, 280

stellatum 241

stigmosmu 241

snbamoenum ?1:;

sublinale 213

sulicuneatum 24. 240

subincisum 215

suljintegrum $24 \%$

sululobatum 245, 119

suluostratum $21 \%$

sulopinosum $24 \%, 11 \%$

sulostellatum 247, 237

subtetragonum 247

sympliagenm 250

tetragonim 2.5

tetralobum 253

tetraodon 239

tetrophthalmim 253

transiens $25 \pi, 1.14$

trapezicum $2 \pi \%$

tririenatim 258 
Prifolium 2.5

trieribberm 25s

trilobum 259

truncatellum 261

trumatum 26il. 151

turexidum ?264, 213is

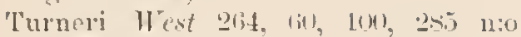
$19 \%$

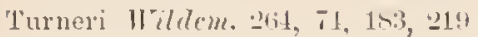

unbouatum 251, 2:206

undulatum 20 ij

unlulosum $266^{\circ}$

1'nerianum $260^{\circ}$

urniforme 260

Ursinella 2ti-

ventricosum hiut:。 267, 82

ventricosum Lumel. 267. 121

venustum biril. 268, titi

venustum Hantzsch 268

verrucosum 268, 11, 83. 195, 14s. 216, $264,2 \rightarrow 1$

Webuianum 27

Wollei $27 ?$

\section{Eutomia}

oblonga 18.j

rotata $:-2 \cdot 26$

\section{Finstulie}

ac'uta 3 !)

subtilis 214

subulata $21 \%, 40$

\section{Geniralaria}

americana 4 을

spirotienia 239

\section{Gleoprimm}

dissilieus 110

mucosum 170, 221

\section{Go\|(\|to:y!gu)}

aculcatum $3 \dot{4}$

asperum 53, 17:-

Brebissonii 65, 53, 152, 153, 156, 245. 275

Kiualıani 151

Kjellmani 152, 60

leve 153, 69

leioderutum 15 i

minutum 172, 53

monotenium $17.5,53,2020$

pilostun 200

Kalfsii 220,175

reticulatum 2.24

sex-spiniferum 2:3:3

spirotenium 239

\section{follioreystis}

aculeata 36

Arachne 19

bifida 59

dilatata 10:

gracilis 132

liexaceros $13: 1.41$

Jemmeri 150

marwaritacea 161 muclonata $17 \%$

muricata $17 \%$

orbicularis 159

paralloxa 195

tetracera 252

\section{Gyges}

bipartitus 6\%. 64, 135

$\mathrm{Cy}$ stula !)

diplosporus 110

encliclioides 117

Granulum 135, 102,271

lithuatus 159

lilpestris ges

saluguineus 228

tatricus 250

translucilus 257

tumidus $24: 2$

viridis 271,135

\section{CrymmodesmII)s}

bambusinus วิ

\section{G!J}

arnata 51

bambusina 5ี

Brebissonit 65

lelicatissima (y)

Grevillii 136

longata 150

longicollis $15 !$

moniliformis 170 , 67

\section{Itelievell",}

aboünsis 36

abrupta $31 ;$

alscendeus 411

affinis 11

alata 11

ambigua 12

americana 4 ?

ampullacea 44

angulosa 41

anomala 413

ansata $\mathrm{fl}$;

apiculata 18, 6ii

arcuata 5 !

attenuata 51

Dailcyi 5 i;

bella 57

Benuettii 57, 83

Jerlini $5 \pi$

binalis (in)

Boryana 61

brachyptera bi;

breviceps 69

Juluheimiana $7(1,21:$

caudiana 72

ceratophori $7: 3$

cireularis fiuntere 71

cireularis Heyen 1

Clepsyalra 74

compacta 77

conferta is

coralloirles sin

cornuta 43

coronata 83

crassa 47 c)assicullis 86

erenulata 84

rruciata (4)

Crux-africann 90

Crux-Melitensis :1

cuneata $9: 3$

cuspilata 91

decemdentata $5 \%$

Delpontei (4)

denticulata 100

depauperata 101

Detouiana 104, 183

dichotoma 105

Didelta 100

divaricata 111

divergens 112

Domellii 11:

elegans $111 i$

elegantula $111 ;$

erosa 119

euastroides 119

exilis 122

expansa 12 .

fenestrata 1.2:3

finbriata 121

flammea 12.4

Floridana 1:21

foliacea 125

formosa 125

furcata 126

Gayana 125

gemmata 129

gigantea 130

Halis 137

holocystoides 111

humerosa 112

hypochondra 14?

incavata 113

incisa 113

incrassata 114

inermis 146 ;

insignis $1+7$

integra 145

intermedia $11 \mathrm{~s}$

Janeira 149

Jemmeri 150

Joshuana 151, 261

Firchneri 152, 100

Fitchellii 1\%2

Iinctzingiana 152

laticeps $15 \%$

latipes 278

longicollis 1.59

Lundellii 160

Lux 162

Lyngui 162, 219

magnifica 163

Maluabuleshwarcusis 1603

mamillata $16 ; 3$

mamillosa lift

margaritifera 160

muerouata $17 \%$

multifida $17 \bar{T}$

multigibuera 175

multilobata 175

muricata 178

Napoleonis 179

Nordstedtiana 182 


\section{HETEROCARPELLA}

1) ummularia 181

obesa 18.1

obtusa 186

orbicularis 189

ornata 191

ornithocephala 1!!

oscitans 192

Papilio 191

papillifera 195

I'ceten 197

pectinata $1: 17$

pinguis 201

jimuata 201

platycerea 201

platyptera 202

pseuluelegans 247

pseudofurcata $205^{\circ}$

Pseulotorreyi 210

pulchella 211

jura 213

pusilla 213

quadrata 216

"Iladriceps: 217

Rabenhorstii 21!!

Renicarpa 2.3

retrorsa 221

ringens 225

rostrata 220

rotata 227

Scluweinfurthii 230

Sendtneriana 232

serrata 232

sibirica 233

sinuosa 235

Sol 235

speciosa $230^{\circ}$

spliyrodes $2: 37$

spinulosa 238

stellata 211

subincisa 215

subintegra 2.5

suboblonga $211 ;$

substellata 247

subtetragona 217

tetraloba 253

'homasiana 251

Torreyi 255

triangularis

Trifolium 258

tropica 260

truncata 2100

tureida 261

turniformis 26;

ventricosa $26 \%$

venusta 268

verrucosa $26 !$

Wallichii 271

Warmingii 271

Wollei 272

\section{IIeterorariluella}

aculcata 39

antilopea 17

areuata $5(1)$

Baillyana 50;

binalis 5 ?

bioculata li1

Botrytis 61

$$
-3111-
$$

commissuralo 77

craša 87

Didelta 1196, 16, 20it

elegans 115

grminata 128, 5.2

Ineus 14.

monadina 172

palinata 191

pectinata 198

Phaseolus 19!

jolymorpha $203,16,106$

pulelsra 211

reniformis 221

sinutata 234,165, , 21!!

tetracarpa 252

tetropinthalma 25:3, 2.2:3

Ursinella 265. Ilis

\section{Hotaranthumer}

aculeatum 39

calcarato-aculeatum 71

eristatum 90

enastroides 119

fasciculatum 12:

sansibarense 228

Stuhlmanni 213

\section{Holocystis}

disputata 110

incisa 143,97

intermedia $1 \pm s$

Kitchelii 1 \%

laticeps 1 ว̃

oxcitans 191, 201

pinmatifida 201

urniformis $203 i$

\section{Iryalothecet}

bambusina is

confervoides $7 !$

cyliutrica 95

dissiliens 1117, 1.5, 176, 2710

Inbia 11.

elegans $110^{\circ}$

limus $139,27 \%$

indica 146

minima 171

mucosa $176,51,159,-267,278$

neglecta 180

Ralfsii $221,17 i$

zundulata $26.5,5$

\section{Isthemire}

filiformis 123

stomatomorpha :-11

vertebrata 260

\section{Isthulosilu}

elegans 116

excavata 121

filiformis 123

vertebrata 2001

\section{Leptorystimemalle}

asperum 53

Tinalhani 151

Portii 68,205

\section{Leptososmll}

catenula 72

Lenronema

nitens 181

\section{Lumulina}

monilifera $173,37,175$

Nongeotii 176,161

vulgaris 271, 161

\section{Iesoteruillm}

Bergarenii 57, 182, 180

Braunii $60,13 t^{\circ}$

caldariorum 71,11

chlamydosportum 73, 11i2, 207

Clepsydra $7 t$

le Grevii 136

Endlicherianum 118, 71, 2013, 277, 255 n:o 178

fusisporum 125

giganteum 13 !

Greyii 136

Kranstai $27 \%$

micrococeum 170, iti

mirificum 173

neglectum 180

obseninm 181;, 57

violascens 271,162

\section{Hesotrema}

undulatum $261 ;$

\section{Micrusterills}

aculeata 35, 121

adscendens 10, 192

alata 11

americana 42, 138, 163. 175, 271, 27t

ampullacen $13,12,163.2-1$

angulosa Ehrent. 11

angulosa Huntisch 11, 100, 150, 214, 2027

anomala $11 ; .15$

apiculata $48,46,66,124,137,271$

ineuata 50, 12?

articulata 52

Thileyi 56

Foryana 6.1

Boryi 61

bracliyptera 66, 15, 275

ceratophora $7: 3$

conferta $75,194,275$

Corde S2, 11

cornuta 8i?, $5 \overline{7}, 100$

coronula 83

crenata si. $224 ;, 200$

cruciata fill: (0)

ruciata 11'ull. 90

erueigenia

Crux africana :M

Crux malthensis 40.91

Crux melitensis $91,90,126,119,21 ! 1$, 276

decendentat $9 \overline{7}, 119,219,261,261 i$ $0-10$

denticulata $99,10.45,83,124,126$, $195,221,2.27,251,257,260.276$ 
(ใepuperata 101,152

lichotoma 105

didyumeantha 106

disjutata $110.13,15 \%, 14.2$

duplex 113

ellipti:a 11 ,

emarginata 117

euastroides 11!, 2011

expansa 122, 50, 260

falcata 1‥2

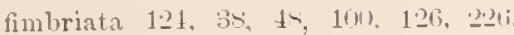
234.21:

foliacea 121

furcata 121\%, (11, 100, 124, 167. 20!): 21! 2020, 20.25

Glibellina 130, 13:4

granulata 1:31, To

Halis $13 \bar{\tau}, 18$

liamata 137. ix

Heliactis 138

hepactis 138, 2.21

Ifermanuiana 138. 4.2. 163. 271

lexactis $13 ! 1$

hexagona 139

incisa $113,155.191 .27$

integra 147

Itrigrsolnii 149, 97. 150, 201,260

Janeirie 14!, !1

Tenneri 150, 45, 22:-20, 2\$4 11:0 1197

lihasia 151

liteliclii 152: 2013.261

lacerata 153

laticeps 155. 13, 110,143.192

lux 162

Mahabuleshwarensis $163,42.43 .134$. 176. 271.271

mamillata 169

margaritifera 16 j

melitensis 167,$121 ;, 219$

morsa 175,163

mucromata 177,192

multifida 17

muricata 1 is

Tamoleonis 179

Veolamensis $180,11: 1$

Sorlateltiana Hicron. 182

Norlsteltiana Wolle 1-2, 25.5

oblonga 1si

octocornis 1 in

oscitans 191. S2, 11)6. 155. 17\%, 2011. 2ut n:0 11iri

papillifera 151, 74, 100, 259, 251 11:0 121 paradoxa $155.15 \%$

pinnatifida 2!1, 54. 1415. 143, 144. 191. 279,253 10:0 913

platyptera $20 ?$

polonica $203,1.52$

ysendofurcata 2ir. 126j

I'seulotorreyi 21 '

pusilla 213

quarlragies-cuspilata 216, 231

"1uadrata 241,151

Rabenhorstii 21!1, 71. 91. 211

radlians ? $2 \mathrm{~L}$ ?

ruliata 219, 12:, 167

ra.liosa 21:1,45, 1j4. 235, 21!

renic:arpa 2.2.3

ricele formi- ?2-21 rillgens :20.7

Rosula 2.20;

Rota 2021; 1018, 121

rotatia $226,-15,83,85,101,126,280$, 211. 2.4. 260, 264. 200

Rotula 2-2.

Shweinfurthii $2314,2 \cdot 27$

- elenicar -3:31

seniriraliata $2: 31$. 216. 24011

sellaria -2:31

simplex Bory. 20:31

simples hïts. $23 \pm$

simplex Wulle 234

siunata 234.185

Sol 2:35)

speciosa 23ti. 191

Thloprastrun 236

Staurastrum 210, 195

st.uromorplia $2 \pm 1,219$

stululmamii 2 -1:

sulfiubriata 215

suboblowge :-41;

swainei 249

tetracera $25 \%$. 145

'Tetras 25:

Thomasiana 25.110

Torreyi $255,1-2$

triangularis $25 \overline{5}, 10: 1$

tricera $257.195,2013$

tricyclia 258

trofica $2(j), 11 ! 1,12-2$

truncata $260,57,97,11 \div, 152$. 216, 221, 280, 281, 251, 25:2 n:0 15

Upsaliensis $204,97,143$

veriucosa $20 \mathrm{~s}$

Wallichii $271,42,13,138,163,281$

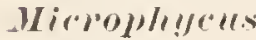

octoceras 1 si

\section{Mirentherer}

octoceras $18 \mathrm{~s}$

Mixotemillm

armillare 51, 176

Hialleria (Inlleriur)

Lunula 1100

\section{Myenomemer}

dissiliens 110

\section{Vothoressmm!nit!m}

obliquam 18:

Odontella

Desmidium 101, !!!

filiformis 1?:3

tetraolon 25

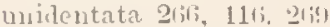

\section{()11,yrloneme}

filiforue 1:23. 16:3

lave 153. 196, $2: 32$

Forlsteltianum 1×3, 1.2:3, 27:

laraloxum 196;

seriatum :3:

nucinatum $26 i^{2}$

\section{Opllarillm}

jiterophorum :211

J'rgetopliza

spăngoromiana 2:35

\section{I'almerlla}

botrvoides $151 ;$

cylindrospora 4 , ii

protulerans 201

rubescens 227

rupestris 12-4, 173

\section{I'llmonglocites}

adamantinus (1)

I'almoglocre (Pahmogloia)

Brebissonii $6 \bar{T}$

calcarea $i 1$

chlamydospora 73

clessyelra $7 t$

(-losterilia 7 i)

concatenata Tis

crissa sit

dimorplin 109, 16:2

Endliclieriana 118

eudospina 11s, 7U. 17s, 20?

fusispora 126

gigantea 130

lurida 162. 2-20, 27

macrococea 10\%2. $151 ;, 67,109,207,228$ $270,2 \times 3 \quad 11: 0 \quad 40$

ILneghinii 14:4. 68

micrococen 170

mirifica 173

monococea 175

protuberans $20 \overline{4}, 162$

Röueriana 2.25

rupestris 2.28. 1102, 2 27

vesiculosa 270,162

violascens $2-1,162$. 20.9

\section{I'enillm!}

acanthosporum 35

(acutuin 39)

adelochomirum 4 (t)

affine 41

anuulare tij

annulatun 45

armatum 5

anstrale it

Baculum กิ

Berginii 3\%, 1-0

bisporum $6: 3$

blandum 63, ti

Brebissonii hïts. (is

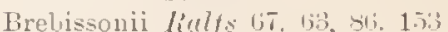

hreve bid

hrevicylindricum 6 (6)

clandestinum $i$

clavatum it

Cleve $71,254.275$

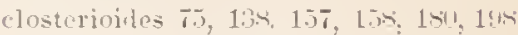

comspersum sil, 61j, 16.1

crasillu $=1 ;$

crassiusculum 8\%, (iT, 197, 24:3

crenulatum ss 
PENTASTERIAS

arnciferum 90

cueurbitinum 92, 251

curtum 98

enticulare $27 i$

Cylindrus $97,80,27 \%$

delicatulum 49

didymocarpum 107, 171, 2633 n:0 5르.

Digituts 108, 148: 150. 150. 185, 276. $222 \quad 11: 0 \quad 35$

diplosportum 110

Ehrenbergii 114

exiguum 121. 157

fusiforme 127

gelidum $12 \mathrm{~S}$

granulatum 13 ว

Hasnaldii 138, 23!)

Heimerlianum 138, 75

inconspicum $\mathbf{1 1 4}$

incrassatnm $14 t$

interruptum 118, 168

Jenueri 150. 65

lave 154

lagenarioides 1 is

lamellosum 151. 10\&, 179

lanceolatum 15.3

latiusculum 156

leptodermum $15 \%$

Lewesii $15 \%, 122$

Libellula $157,11 s, 161$

lizeare 15.5

margaritaceum 161, S0, 171, 191, 2\$1 a:o 148

minutissimum 171

minutum 172, 55, 158, 2013,221

monile 17

Mlooreanum 176

Nitgelii 175, 109, 1.it

Navieula 180, 57. 75, 10\%, 157

navigium 1 so, 105

notabile 183

oblongum 185. 115. 255 11:0 203

orbiculatum 190

Palaugula 198. tis

pandurans 191. 161

phymatosportum 200, 2.s1 11:0 171 et $17 \%$ polonicum 203

polymorphum 208, s6, 11.4, 2sit u:0 172

pursillum :211

Ralfsii the Ber. 221, 172

Ralfsii Kuitz. 221, 95, 281 11:0 123

rectum 222

liegeliaum 222

retusum 221

rotuntatum 227

Royanum 227

I"ufescens $22 \pi, 64,2 \cdot 24,2 \pi$

rufo-pellitum 2:-2. 22\%

rupestre 228

Scandinavicum 229.235

šcelitrunt 29?

Sibiricum 233

simplex 2:1

spinospermum 283

spirostriolatum 23s, 13s, 22:1. 240

striato-punctatum 211 , is

sublanellosum 2-15

sliboctangulare 2413
'Thwatesii 251, 74

tridentulum 2os

truncatum 261

tumidum 262

\section{Peretcesterius}

margaritacea 164,207

minor 171, 165

obtusa 1.40

radiata 21!, 28:2 n:0 나

\section{I'Hycustrum}

aculeatum 38

apiculosum 15,110

Arachne 1!

anserum 53, 191, 199

bacillare 5̄

lifidum $5 y$

brachiatom 65

ciliatospinosum

commutatum 77,135

couvergens 82

crenulatum 8!): 130, 165. 201

cristatum 89. 179

cuspidatum (1., 79, 98, $17 \%$

cyrtocerum 96

denticulatum Kiitz. 1(x), 20.24, 25? n:0 23

denticulatum Ney. 101, 255

depressum 101, 178

dilatatum 109

disjar 110

Ehrenbergianum $11 \pm$

furcigerum 127

glabrum 130

gracile $1: 32$

grande 1:31, 189

g'anulosun $135, \pi$

Griffithiantum 130, 2:34

hexaceros $139,89,6$

hispidum 110 , is

Tenneri 150

longispinum 15!)

margaritaceuth 165

minus $1 \% 1$

monticulosum 17j

mucronatum $17 \%$

muricatun 178

inuticum rït:. 178

muticum l'evty 17 !

obtusum 18:;

orbiculare 18 !

pradoxum 1:5

l'ecten 197, 113

pilosum 200

polytrichum 20il

radiatum 21!

lialfsii Külz. 221, 155, 257

Ralfsii $\boldsymbol{N}_{\mathrm{reg}} \cdot 2 \cdot 21$

reparulum 224

rotumlatum 227, 10!3 161

spinulosiun 23s.94

striolatum 213

tricorne 257

trilens 2.58 .81

trilobatum 25!1. 41. 25

truncatum 262

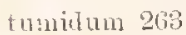

Plymetodocis

alteruans 11

Nondstedtiana 182

Pithiscus

angulosus $45.91,-215$

Plenrenteriulu

grande 131

tumidum 263

\section{Plemosicyos}

myriopodus 17!, 10s

reuroteniopsis

ampla 1 is

bigibla $2 \overline{7}$

capax 72

Ciastonii is

Cueumis 91

Debaryi 97

Diadema 101

elegantissima 11 i;

elongata 117

lieterodoxa 138

incisa 144

javanica 150

magnifica 103

ovalis 192

pregrandis 205

pseuloconuata 215

psendoexigua gus

pseudopachyderma :20!

unaternaria 218

Rialfsii 220

spluerica 237

-tuhlmannii "243

subturgida 280

striolata 243

tessellata 252

turuida 264,261

Vulkensii 271

\section{Plenroterllill}

alteruans $\$ 1$

Archerii 49

baculiforme 5 5

Baculum 55

basinndatum 57

bidentatum 58, 133

brefeldii lig, ati

breve Rac. (3)

breve Hood 6!

caldense it

elavatum $7 t$

constrictum ơ

coronatum 63,276

coronulatum si?

cosmarioides 81,97

crenulatum ss

dilatatum 109

Elnentergii 114, 15"3, "2-7

elephantiunm $11 \%$

firmum 1?-1

Flotowii 12.1

Georgien 129 
gracile 132

lisisutum 1 (1)

indicum $116,27 \%$

liarei 151

ligatum 1.5

naximum 11 2. 2.4i

Metula 169. 279

minutum 172

moniliferun 171

nobile $151,109.266,271$

nodosum 1S?

nolulosum $1.2,83,85.27$

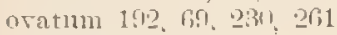

parallelum 1\%;

phanoilermum 199

quantillum 21s

rectum 222

retusum 2.21

sceptrum 22!)

schmeinfurtlii 23n, 192

subcoronulaturn 241

tcuue 280

tessellatum 252, 173

Trabecula 256. 11.4, 2.2.

tridentulum 25

truncatum 261, $6 ! !, 71,124,192.224$, 281

turgidum 2463

undulatum 200

verrucosum 24is, 173

verticilatum 270,181

Warmingii 2:1, .4:3

Woolsii 2.7?

\section{Polysolenio}

Closterium 7 , Bis

\section{Royn}

obtusa 2-T

Prendoclosterium 27?

śremolesmus sonerlesmus

achutus 40

convergens is

moniliformis 17 !

Pyrus 10

stomatomomplus 211

\section{Srhistormilium}

excaratum 121

unilentatum glit;

\section{Sroisoromethum}

armatum 51

\section{Sirlisosporre}

dirlymocarpa

diplospora 110

minor 171. 16n

pachydermum 19:3, 110, ?201

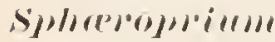

Inebneri 111, 1:3;

\section{Sple(e)onosmll}

Areleri 1:4. 121, 21:4

Aubertianum

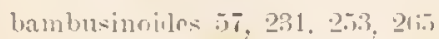

Pengalcuse

ciliatum $7: 3$

co:mplessum $\mathrm{TA}$

constrictum sil

cosmarioilds: 81

lepressum 101

elegans 11i, 219, 27

excavatum 121, 1:3, 140, 231, 23९. 2-1

cxignum 1.22

filiforme $12: 3,511$

formostum 12:

Gocbelii 131, 27, 291

granulatum 134

indicum 146, 121

lamelliferum 151

moniliforme 175

neglectmm 1 Ro

nitens $1 \mathrm{hl}$

Torlstcdtianum 152

pulchelinm 211, 231. 253

pulchrum 212

punctulatum 213

Hgineum Cooke 214

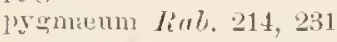

rectmigularc 222, 277, 240

secedens $2: 31,121,211,211,269$

serratum 282, 1 is

spinulosmu 23s, 121

stomatomorjhum 211

strongrlotoeclitum 21:3

tetraodon 203

tinetutn 2.si

midentatun 266 ;

vertcbratum 269, $70.74,116,250.266$

vineulatum 270

Ta!lichii :2T1. 11

\section{silivotrenier}

acuta 39

alpina 11

Bahusiensis at

bispiralis 62. 186,

bryopluila 7), 11: 17s

closteridia 75, 1!";

condensata $7-2,25,282$ n:0 35

endospira $11 \mathrm{~s}$

erythrocephata 11?. 171

gracillima 13:3, 251

grandis 131. 1 itit

minuta 171. 1!

muscicola 17. $70,11 \%$

Nordsteltiann 183

obscura 1\$6, (53, 131, 220?

parrula Iskj

Rectispira 2-2.2, 18\%

tcherriuta 251, 183

trabeculata 2.51 ;

trumeata $2 ; 1$

\section{syomdylosimm}

armillatnon is

lambusinoiles 27.5

repressum 10 !

fragile 1:2:

geminatun 124

curvatmu 14

lamelliterum 151

unnile 173 moniliforme 175

Mumgulporcanum 17

neglertum 1. Sil

nitens 181

ovale 1!! ․ㅡ

l?apillosum 19\%

pulchellum 211, 57

pulchrum 21?

1ำ

rectrim 202.)

reniforme 2.23

sceelens 231

scriatum 232

-tomatomorlyum 241

tetragonum $253,5 \overline{5}, 211$

\section{Stumlu(s)}

reanthoides $31 ;$

acauthophorum 2ז1

acalides 37

aciculiferum 38 , it

aculeatum 35, 81, 229, 2-1

acutum 10, s. $11 \%$. 135

nerumm til

alpinum 11

alternans $11,109,213,221.25,254$ 271, 27!

ambiguum 4 ?

anocnum 43, 72, 201

anpluiloxon $43,27 t$

anatinum 1.1

(aucyroitles 45 )

angulare 14,$2 ; 1$

angulatum 44,135

anky roiles 4 ;

numulatum 27t

apiculatum 4R, 9,

apieuliferum tit

Ararluse 49, 25:3

nrachnoides 14

Arclieri io

Aretiscon 50, 17, 272

arcuatum 50, 20?, 243, 25\%. 2-1

aristiferum is

ก'migerum 52, 126, 127. 238

Aruchlii 52

anticulatum is

nsperum Brob. 53, 199, 20ki

asperum (Perty) Rab. $5: 3$

axpinosum 5:3, 202, 294 n:0 1:39

assurgens 53

aversum 51

Aricula 51, 38, $59.101 .213,211.283$ 11:0 10

bacillare $55,2 \div 1$

baculiferum is

Baronii $\div$

basidentatum $\overline{5}$

bellnm

Bengalense i-

Bonkoci อт

bibrachiatum leiusch 5T

bibrachiatum Wolle 5T. $21:$, 25

bicorne 5s. 27.; 281 n:ก 154

hirormatum is

bidentatum $5 ., 159$

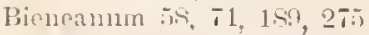

bifilum 5!!, 65. 122. 221, 294 n:ก 115 
bifurcum,$: ! 1,70$

binaculeatum $5 ! 1$

Bissettii $6: 3$

bisuleatum bi:;

blandum

Boergesenii Rae. 1:?, 211

Bonrgesenii Tum. ris, 264

Boldtii 63. 9?

hotropliiln (i.t

brachiatum 65, 351, 14.1, 221, 275

luachioprominens 6 ;

brachyacathum 6i:

brachyecrmen $630,-204$

Brasiliense 6i;, 17\%, 2\%1 11:0 106;

Brelissonii $68,110,200$

Brevispina $00,134,134,155,275$

lullosum 70

Tuluheinianum 70

Thumense 7 (1) 5 !)

calyxoides 71,79

eandianum 72.127

Capitulun 72. 4is, 198

Cerastes 72, $28: 3$ 11:0 130

ceratodes $7: 3$

ceratopliormm 73

Cerberus 73

ciliatospiuosum is

rireulare theyen 7.1

rirenlare sichmidle 27.

Clepsyctra I zund. 71, ?-10

Clepsydu Nordst. T1, is, 27.

('lepsydra Syene. 71, 7)

C'levei $75,15 \%$

roaretatum is

rommutatun is

complanatum is

comptum is

eonicum is

monuatum 7!, 71. 82, 98

rontectum so

contortum 80, 210, 255 n:0 Is:?

controversum 81. 38, 254

convergens Meneyh. S1

convergens Rab. S2

(:orditum \$:2, 18 ;

corriculatum s2, 79. 2-7., as: $13: 0$ 76

colnijermus S3;

comuliense 83,127

rorintutum Arele. 43

comntum $W^{\circ}$ oll, $83.2+1$

coronatum lialfs .83

coronatum Irolle s.i, st

coroniforum 83

corounlatum $81,83,242$ 11:0 2.7

cosmarioides Nordst. 81

cosmarioides lirinsch 84, our

cracoviense 80

"renatum sis

("renulitum S., 11 .

rescentum 89. 125

"ristatum 59, 40, 151

"ruriatum Hexm. 90, 1:34

(Prociatum Holle (m)

Crinx (m)

('umbicum 93

"uneatum lioldt 913, 193

cuneatum II olle 93

curvatum 'Tum. 11, 119 curvatum West !1

eurvirostrum 9-1

cmspilatum 91. !s, 235. 27i;

cyatholes 91

crrtocerum !n;, 2n1, 28:2 11:0 27

decipiens 97

dejectmm 98. 15, 7!) 91, 1111, 118, 130, $15 \overline{1}, 17,270$

denticulatum 101. 5t

derressum 101

Detouii 104, 12 i

diacanthum $11 \%$

Dickici 105. 199, (1), 115, 155, 270, $27 \%$

dilatatum 10!1, $41,110,115,2.27,231$. 2713

diplieanthum 109,270

diptilum 110

dislar $1111,11,10 !)$

distentum 111

divaricatum 11:2, 121;

divergens 112

Donnellii 112

dorsuosum 112

inbium Eichl. et Gutu, 11?

dubium West 113

duplex 113

Dziewulkii 113

eboracense 113

cehinatun $113,99.130,197,229$

ecorne $113,26 i$

Ehrenbergiautum 114, 127

Elinenbergii 115, 126, 238

Eichleri 115, 275

elegantissimum 11t;

ellipticum 117

Eloiseanm 117, 22:3

elongatum 117

enorme $11 \mathrm{~s}$

ensiferum 118

Eutvösii 118

erastim 118

crectum 11 s

Erlangense 11s, w

custeplianum 120. 127

excavatum 121

exigumn Reimsch 122

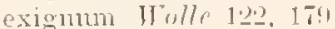

exile 1?23

eximiun $1: 22$

exsectum 122

falcatum 122

Far'pularsonii 12.?

[ascictuloides 1:23

festivum $12: 3$

fissuin $121,15 \%$

foliatom 125

foreipatum 1:2;

forfieulatum 125, si

Franconicum 125, 112, 28,? 11:0 11;

Friburgense 126, 213

furcato-stellatum 126, 22:3:3

furcatum 126;, 101, 115, 120, 20(5, 234, 252 11:0 16

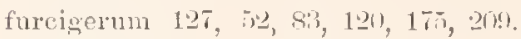
2.73. 278

fusiforme $12 ;$

galeatim 12.4

gemelliparmu 124 gemiluatun 129

gemmulatum 12 ?

glabrum 13\%, $2 \pi \%$

gladiosum 130, 22. 24.3 n:o 1(n)

glaphyrum 130

globosum 131

globulitum 131 ,

gracile 132, 114, 2210, 27. 242 11:0 27

graeillimum $13: 3$

grallatorium 133, 207, 22-24, 277

grarde 131

granulatum 135, 41

grannlosm $135,10,263$

Griffithiannm 136

tinreliense 136

gyrans 136

Haboelience $13 f$;

Hantzschii 137, 149, 160

Haynaldii 13s, $14 \pm$

Heimerlianmm 139, m

lelencantum 138

lexaenthum 138

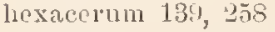

hexagonuin 13!! !5, 16!

hibernicnm 110, 190

hirsutum 1.41). $4.9,178$

liorametrum $1+1$

horrescens $1 \notin 1$

horridum 141

lypocephalophorum 1.12

Hystrix 142, $27 \%$

ignotum $11: 3$

inequale 143

incisum 14. s9

inconspicumm the Not, 141, 132

incouspicum forlst. 141. 171, 222,

$147,25: 3,243$ n10 5., 295 n:0 18 !)

incurvatum 141

1ncus 145

lullicum 14li

inclitum 1ff; 1 1!)

inerme $140 ;$

infestum $14 \bar{\gamma}, 15 ;$

inflexum 11\%. 16is

insigne $14 \pi$

intricatum 119, 137. 2203

involutum 149,91

iotantum 1-19

imegulare 144, 2893 11:0 1 il

jaculiferum 14 !

Japonicum 150, 137

Tenneri 1.50

lianitzii 151

Kerguelense 151

Kitchelii 1:2?

Kjellmami 152, 16!, 27\%

Kozlowskii 152

livetzingii $1 \% 3,195$

fiurzianum 1:2

laceratum 153

liere $153, \pi, 14$

lanceolatum $155,189,27 \%$

laniatum $155,70,100$

lejpacnuthum 1 \%

leptocladum $15 \%$

leptodermum 157, 20\%

levispinum 1 :

Lewisiantum 1 का 
Lowisii 15 to

Lubltii lis. 27s

longispintum 1.3, is

lulkitum 1lit, R!!, 141, 21.1

Lumlellii lito

lnteolum 16:2. se

Manmense 1liz, 2015

marrocerum 1 tio?

magnum $14: 3$

majus(1) แ1แ $11 ; \%$

mamillatum $16 ; 3$

Manfoldtii loit

maloaritacomu fi; 1, 1.16, 151, 27

Masknllii lbit

meliolure 11it

megacanthum 167

megalonotum 11; si, 27s

Meriani $4(4 !, 9 \%, 139,152$

mesoleium 11,!

microu 2 -

microseopiem 170

Minneapoliense 171

Minnesotmuse 171

iniulus 17

minusculuม 17

minutissimum 171. 14. . 2x:3 n:0 81

uinutulum $5: 1$

montanum 17i. 12 T

noutieulosum 175. 109. 232

meronatum 17. 79. (1). ؛

multicorne $17 \%$

munitum 17 . . :0

murieatiforme 178

muricatum 1R. 14, 99. 1.10, 245, 234 $25 \%$

mutabile 178

mutioun Brit. 17. 5. 101, 117, 189, [?II)

muticum Ral. 179, 259

mutilatum 179

Xiegeliamm 17?

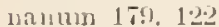

natator 1 in

Nathorstii 180

nephroideum 2 is

Yigre-silve 1s1. 2:34, 2S1 n:o 10\%

nitidum 151, S3, 16(1)

nouliferum 181

nonanนาม 1:2, 2.5.5

Norilsterltii 183

Fotarisii [., 2, 20?

Nore-Casater 181, 2-8

Noves Semlia 181

ollongum 1sis

nchthodes 187

octocorn is $1 \mathrm{int}$

olontatum 1 ss

oligncanthum 1.6, 2(r), 2.8.3 n:0 8s

(). Iearii $1 \mathrm{SQ}, 115$

Nplisura 189. 134. 242 n: 27

opimmm 1.59

orbienlare 82. 5., 1.10. 15. 1.99, 25.1, $27-250$, 2.43 $11: 07: 3$

ordinatum 190

orientale 190

oruatum 191, 53, 16is

ornitloecplaslum 191

ostennium 192

dimertscedt, Inder Dismid.
Oxyacantla $192,2,2(i, 2: 30)$

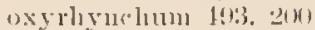

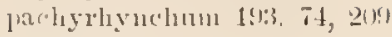

paniculasum 191

paแsแn 191

japillosum 15:

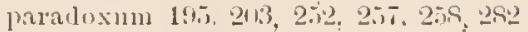

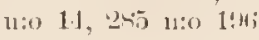

parc:ulu $194 ;$

patens 194

pancidentatum I!17

Paulense 1:47

Pecten 19;

pentacladum: 195

Pertyi 1:14, 503, (6.)

Piemm 27:

pileatum 20

pileolatum 2(n). 43

pilosim 200

pinnatum 201

pisciforme :211

platrectum 202, 53

podlachicum 202

polonieum 208

polymorplum 204, 66, 16;.

polytriclum $204.2(15,232,240,251,24 t$

Pottsii 211.5

l'ringlei 2015

Pringsheimii 20i5, 2011

proboscilleum 206,

protractum Jolens. 207, 1333

jrotractum liac, 2017, 279

joeudassurgens 20t

Psemlincus $20 \overline{7}, 14 \bar{i}, 116$

Pseudo-Cosmarimn 20, st

p)endocrenatun 2015,162

psendoenspidatum 208

1seudofureigerum 니, $120,12 \%, 127$. 279

psendoligarantlum 209

psendopachy rly uchnu 20r, 193

pseudopisciforme 20!, all

psendosebalili 210, 132. 27i

psendotetraeertu 2 (1)

psilosporum 210

jiterosporum 211

fulchrim 212

junctulatum $213, \quad 101,152,263,27 \div$, $284 \quad 12: 0117$

purgens $21: 3$

jusillum $21 \cdot 4$

yу.

jomidatun $215,1 \overline{1}, 237,25$

'pulraugnare 216, $112,27 !$

chalratum 21 i

quadricoruntum 218

chadri-spinatum $21 \mathrm{~A}$

quaterninm 218

Ratrenellii :201, 233

reeurvatum 2.2

refractim 2.2., 114, 24:3 n:o if

Reinschii '20:3

Renardii 22:3, 14 $\overline{7}, 119,261$

repandum 221

resupinm 2:1

retusxum $2: 21$

rliabioplionm 221

robustim 20:-
Rostafustii 20:-

rostellum 2.2.)

rostratum 2021; 196

Rotula 2:7

rotumdatium $22 \pi$

Royautum 2:7, 232

Revii 227

rugulosum 228, $1(1), 242$ n:o 23

rusticum 20요

sagitarium 229

sagittifermm 22.28, 130

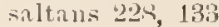

saxonicum Buluh. 229, 98, 113, 181, 2030 n:0 $4: 3$

saxonicum lieinsch 22!1. 2.5i

seabrum 2:29!

scolopaciunm 230, 2067

sentioidenm 230. 193

Solalili 2:30

senatium 231. 127

senticosmm 232, 2011

selviforme 232

setigerum 232, 22., 254 n:0 110

sexangulare $2: 33,126,127.211,2,90$

sexcostatim 233,150

sibiricum 233, 2-41, 281 n:0 1:0

silatatum 231

Silesiaenm 231. 53, 178

Simonyi 231, 1s1

smaracilimun $2 \% 5$

sociatuin 235

Sontlualianum 2:35

sparsiaculeatum 235, 221

Speneerianm 년, 71

spicatum $23 \bar{\imath}, 113$

spinifermm 235

spinosissimm 2:37

spinosum 23s, 52. 115. 126, 28.3 n:0 40. $28 f$ 11:0 111

spinuliferum 238

splendiclum 239

spongiosum 23!1, 136, 221, 27s

Sitella 211

stellatum lourg. 241

stellatum lieinsch 241

stellinum 241

Strensaliense $2 \pm 1$

striolatum 243. 284 n:0 121

subamoenum 243

subarcuatum 243, is, 214

subarmigerum 243

subavienla $243,50,267$

subbibrachiatum $213, \pi$

snbhrebissonii 243

snbcolnutun 214, 89

subcosmarioides 24 !

subcruciatum 2.14 , it, 213

sublentieulatum 245. in

stubdiatatum $2 \times 0$

subgemmilatum 245

submonticulosum 246

suborbieulare 250

subpinnatum 280

subpunctulatun 210

sublygmethm 21t, $71,114,201,21$;

snbrefractun $21 \%, 1.1$

Sinbrotula $24 \overline{7}$

subsiabrum 217 


\section{STAURIDIUM}

subsplaterieum 247, $283 \mathrm{n:0}$ b!

sntitelifermm 24

subtile 248, 285 u:0 209

sunderlumilense 2.t!

teliferum 250, 142, 2014, 251, 290

tenuissimum 251

terelirans 251.117

tetrectum 2.12, 89, 19\%, 21:3, 25

'Tohopekaligense 255,182

torsum 25

trachylermum 256

traclyganmm 25,

trachynotum 25i, 22:4

trapezicnm 2is, 1 is

Trellechense 25T

triaculeatum 257

triangulare $25 \%$

tricorne 25\%, 11. 10n, 113, 13n, 221, 250

tricornutum 2 is

tridens 228

triclentifermm 258

trifilum 25i, 281, 284 n:o 111

Trifolitum 258

trifurcatim 2 is

trihedrale 258

trilobum 25!), 178

tripes 250

tristichum 25 !

trisulcatum 25 !

tropieum 260, 41

truncatulum 261, 223

truncatum Menegh. 202

truncatum Tum. 262

tubereulatum 262.2

tumidulum 262

tumilum 2t:3

tunguscanum 263, 135

turgescens 263, 213, 281 n:0 107

Tumeri 264,68

uncinatum 265

mudulatum 26 it

Ungeri 266

nuguiferum 26;

unicorne 266,267

variabile $267,114,230,264$

varians $26 \overline{7}, 214,215$

vastum 267,243

ventricosmu Delp. 26T

ventricosum Mask. 237

verticillatum 270

vericulatum 270

vestitum 270.10 ,

rolaus 271

Wallicliii 271

Wande 271

Warmingite 271

Westii 27.

Willsii 272

Wittrockii 227

Wolleanum 272. हो

xipliblioplorm 27 ?

Zelleri :-t:

zonatum 273

\section{Struridium}

lic.nspidatum $1: 34$

('tux Molinensis !) $1,82,130$

$-3(1)-$

\section{Strutrocerers}

Aens 39

nentum 40

Cornus \&2

intermelium 1.i? 119,292

subulatum 218, 40

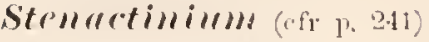

crentulatum $\nleftarrow$ ?) 253

\section{Strpleaseonerethium}

custephanmm 120

monticulosum 175

senarinm 231

sexeostatim 233

\section{strephorystis}

lipes 6,2

deltoides no

didymella Jur, on

intererrintum [-a ] 1.4

vervucosum[-a] 26s

\section{Streptonema}

trilobatmm $25 ?$

\section{Tressurarthere}

ampullacen 13

crispa 89

elegans 116

fasciculata $12 \cdot 2$

filiformis 123

moniliformis 174.129 .172

orbieulata 190

vertebrata 269

\section{Texserthomire}

moniliformu is 174

\section{Tetmemortes}

Brebissonii 6, 151, 173, 241, 282 11:0 29 girantus $1: 0$

granmlatns 135. 151, 27\%

linvis $15 \%$, 6 is, 13.

minutus 172

pentioines 198

\section{Tetracleastrume}

americanum $13,110,113,15.5$

didymacanthun 106;

incistum 14 ti

meronatun $17 \pi, 191$

oscitans 191

pimnatifilum 201

quadratum :216

\section{Troicerss}

paradoxus liti;

\section{Trirluorystis}

givantea 130

\section{Trirllodictyon}

rupestre 228, lis. 80

\section{Tililorerrs}

abbreviatnu si; grapile 132, $\mathrm{x}, 206,270,27$

trirlentatum $2.2 \%, 270$

rerticillatum 270 , 2is

\section{Trorllisclicr}

moniliformis 17\}, 290

\section{Cliol}

protulyerans 207

\section{Ursimeller}

alureviata 30

abrilpta 30

aculeata 39

Aitselnisonii 11

alata 11

alpina 41

muericana 43

amoena 43

augulata $4 t$

angustata th

anisochomira 15

annulata $11 ;$

ansata 16

aplianiclondra is

aretoa 50

armatia 51

Arnellii 52

ณ'rosa 52

aspluerospora is

atlantoden 53

anriculata 5.1

Baileyi 50

lianrita 5-

Bicarelia 59

bicunpata 59

bidentula is

bina 61

binsinla of

bioculata lil

liremis 62

hireta $6 \%$

Plyttii is?

Boecliii 63

Botrytis 65

braxiliensis fof

Brel,issonii fir

Bromei 70

cetlata 70

calcarea $T 1$

caloilerma 71

cambrica 51

camcliana 72

capensis 72

capitulum 72

cinctuta 73

rirenlaris 73

Clepsydra $7 t$

colifera $i t$

commissuralis $7 \bar{t}$

confusa 7 !

conspersa sin

coustricta Si

contracta 81

Corbula $\$ 2$

coronata 83

custata 81 
classipallis si

erenata sis

cristata 89

eruciata

euneata 93

arelien

"ymatopleura mi

deoucliondra

decora us

dolicatula 99

Acltoilloa !?

dentata

(1) pauperata 101

depuresea $10 \mathrm{~L}$

diulemata 101

Didelta 100

lislymochomira 107

disticha 111

Domnellii 142

torrensis 112

elucta 11.1

Flfvingii 117

ellipsoidea 11 T

elliptica 117

eloiseana 11 i

emarginula 11.

erosa 115

cuastroides 119

Euastron 11!)

ewcrettensis 120

"xasperata 121

exigua 121

foutigena 12i)

formosula 125

fusa 125

galerita $12 \mathrm{~s}$

Gryana 128

geminata 12s

gemmata 129

gemmifera 129

genuosa 12 !!

Glazioni 130)

granata 134

haaboeliensis 130

Trmmeri 137

Iaynallii $13 \mathrm{~s}$

lelcangularis $1: 38$

heterocinoudra 138

Ilcutleriana 27

liexagona 139

hexaloba 139

hexasticla 139

holmiensis $1+1$

TIolmij 1.11

lomaloderma $1+1$

Hookeri 141

humilis 11 ?

Hunyadyana 142

impressula 1-13

incisa 111

inflata 115

inoruata 1 t

intermedia $1.1 \mathrm{~s}$

isthmochourlea 119

jenisejensis 1.j()

Juntzillii 1 iil

Kanitzii 151

Fitcliclii 152
Fjotlınanii 152

linvis 153

lagonsis 1it

lasiosprom 1 in

lata lini

laticollis diti

latiffolss 15ir

leioderma

lilajer 1 ing

lobatula 15is

Tortetiana 1 lio

lumata 14il

Tumlellii ltiol

margaritifera 16is

margarita 16 is;

melamospora 16i

Meneglninii 16 s

mentiens 1 (i)

mierosplineta 170

mimeapolitana 171

minuta 172

monilitera 174

moniliformis 17

monocliomlia 175

monomaza $17 \%$

Nirgeliana 17!)

nasuta 1 so

Nathorstii 180)

neapolitana 180

Nilssonii 181

niti.lula 1,81

Nordstedtiana 183

Nortstedtii 183

norimbergensis 183

Notarisii 184

Nove-Semlie 181

Nymanniana 181

oblífua 184

obsoleta 18i;

oelitliodes $18 \pi$

oculifera 16s'

oligrogongra $18 s$

Oliveri 1 is

orbicularis 190

ornata 191

ortlogoria 191

orthopleura 1!1

orthosticha 1:1

pachiyderma 1!:3

finudiuata 1!)

Papilio 1s!

Jardalis $196^{\circ}$

parvula 197

pectiundes 197

Pelta 1!s

perforata 194

periesmatia 109

Phascolus 200

pilleigera 20x

piriformis 216

platyistlima 202

prolonica :2l:3

jolymona 203

polymorphat 2013

porrecta 2114

Portiana 205

fretmorsa 215

prominula $20 ;$ protracta 27!

protuberans 27 !

jutominila $20 \pi$

jechloamocha $20 \%$

psetuloliremis ens

Psemolobotrytis 218

pendoisthmorlumura 205

pseudogranata 2us!

pseudomargaritifera 2 us

jseulonitilula 2019

jiseudopectinoirles 2os

jucudoju'otuberass 20 !

pesaldnytramilata 210

pseudotaxichondra 210

pulcherinar $2 ! 1$

punctulata 212

pusilla 211

lyehnochondra 211

lygmara 214

lyranirlata 21.

pyriformis 211 ?

cuadrangulata 216

chuadratula 217

qualrifaria 218

Quadrum 21s

Quasilus 218

quinaria 219

Raciborskiana 21!

Raciborskii 219

radiosa 220

rectangula 222

rectangularis 221

Regnellii 22?

Regnesii 22?

Reinschiana 223

Reinscluii 223

reniformis 223

repanda 22.1

retusa 221

rlomb(us)oirles 221

rostrata $221 ;$

rotundata 2.27

salina 228

Scenelesmus 22!

Sehlicphaekenna 230

Selumebeleri 2nit

Seelyana 231

sejuncta 231

sexangularis 233

simplex 231

sinostegos 234

smolandica 235

solida 235

spetsbergensis 298

sphalerosticha 237

spinosa 237

spinospora 237

sportella 240

staurochonlra 211

stichochomela 2.11

striata 241

subcostata 211

suberenat. 211

subertuformis 211

sublata 21

stublobata 2.ji)

sulmasuta 216

subuotabilis 210 


\section{VIBRIO}

suborluicularis 246 subprotumida 24 i subpunctulata 216 ; sulyuadrata 216; subryasillus 2.47 subreniformis ?17 subsieciosa $24 \%$

subtholiformis 248

subtumida 218

subumlulata 2 ls

sulcata $21 !$

smpinspeciosa 21!

tatrien 25it

taxichondra gin

tetracentha $25 \%$

tetrachondra 253

tetragona 25.3

tetraoplithalma 25.

tholiformis 251

tincta 255

titlonpliora 25i

tracliyeyrta $2.0 \%$

trachypleme 25

trafalgarica 257

trausiens $25 \%$

trigemmata 2is

trilobulata 20.5

trinorlula 20!

triplicata 25!

truncata 201

truncatella 261

tumila 282

Turpinii 2i:

umlulata $263 i$

Ungeriana gin;

monigera 260

variolata 207

ventriensa $20 \%$

renusta $2 f, 5$

rogesiaca 271

Weldelliana 272

Wittrockii 272

Vollena 272

\section{Jibrio}

amposts 37

Lmmula 16il, 82, 150, 173, 17f

tripumetatus 2.56

\section{Irmthidiontrum}

paraloxum 19;, 1.3

\section{Iremthidiulu}

acantlophorum 37

aculeatum 301, 49, 6!), 189, 242 n:0 85

alpinum 11, 27t

antilupenu 17, :3, 919, 123, 137, 203, $238,2 \pi 1.282$ n:० 21

apienlatum 1s

apicnliferum is

Aretiseon 51, 282 $11: 015$

arnatum 51, 5!, $11: 1,126,254$

articulatum 52,125

asteptum i3

Bengalicum 5\%, 137

bicorrutum 58,184

Digrrianum 5!), 51

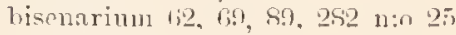

Brolissonii 6.9, 39, fi?

brexicorne bis

bulbosum 70

Chaluhinskii 73

claviferum it

Columbiamm 7 it

concinnum is, 13!

convergens $\$ 1$

coronatum 83, 127, 282 n:0 16

momariforme 84

crassipes si, 282 11:0 :33

mistatum $8: 1,47,62,129,157,276$

deliticnse !!), 2니

deltoideum $4: 4,175,225$

difforme 1 ths

dilatatum $1\{1\}$

Echinm $11: 3$

Ehrmbergii 115, 127

cximiun 122

fasciculatum 122, $39,47,-18,183,203$, 2.5.5

finbriatum 121

fureatum 126, 51, 127

glabrum 130, 55, 15

globosum $1: 31$

groculandicum 136;

lastifornm 187, 57, 123

lieteracantlum 1:3, 135

loxacanthlitm 1:3!) lipxagomm 139

lirsutun Ekremb. 140, 201, 2.1

lirsutnon firchn. 140

hirtum 1 (t)

incliontum 143

imlieum 1 to

ineptun 111 i

intermedium 14s

leiodermun 157, ! I

malleoforme 10;3

Nomistedtianum 153, 123

actocorne 157. 39, 253 n:0 74

octonarimm 1.58

jenicillatum 1 (m)

pilosmu 201, 1 10

jolygonum ?:13

pulclurm 212

I'yritie 210

pyxiliculun 216

'patricorne 3!)

'1ualricornutum $21 \mathrm{~s}$

ramosum 221, 99

Raneegummorise 221

rectocornutum 22:?

regulare 223

Robinsonianum 225, 200

renrsolense 230

simplicius 2:34

Smithii 235, 280

spinosun 23\%, 282 n:ก $\mathrm{n}$

spinulosum 23s, 48

subhastifertm 2 t:

superum 219

tenuissinum 2:1

tetracantlum 252

tetracentrotum 2.22

torquatum 255

'Jorreyi 25

trilobum 259

truncatum 2602, 20i:

tulifertum 2(i2, 71, 282 n: $3:$;

Tylerianum 26i5, 47, 262

restitum 270

\section{Yy!go.xumthillu}

aculeatum 30

Bignriantum in

Eolnints 113 , ถt 


\section{Errata.}

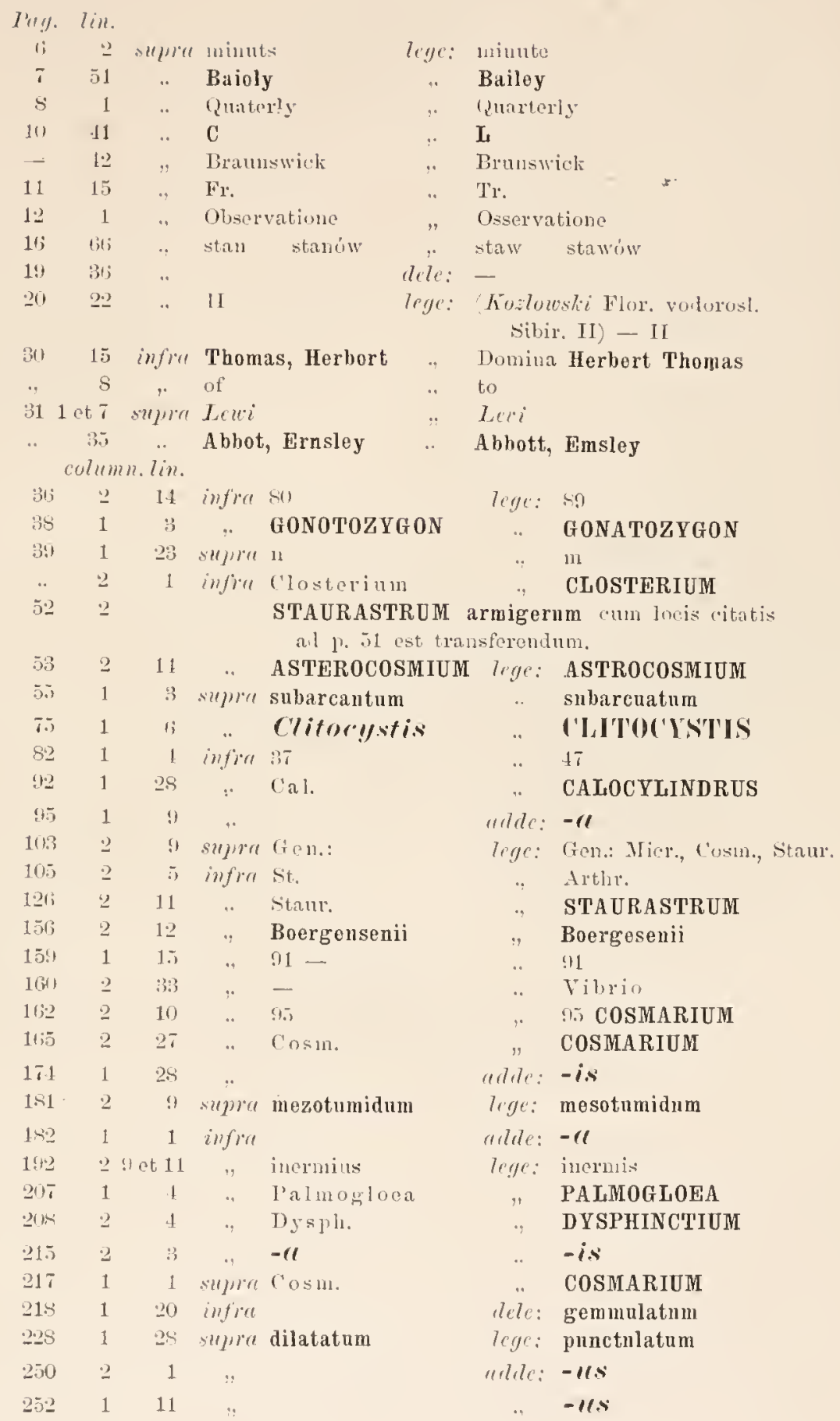




\section{Summarium.}

Pag.

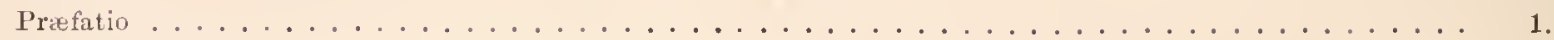

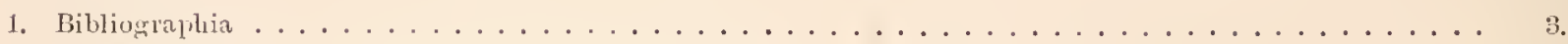

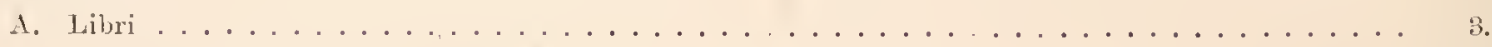

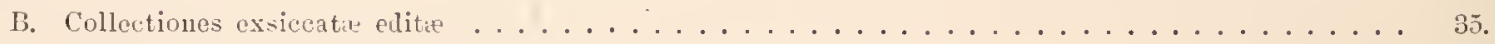

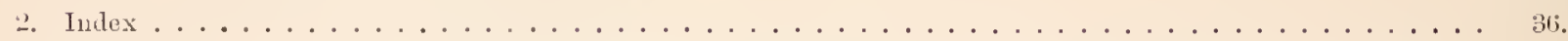

I. Tominm familiam. tribus. divisiones. genera. sulggenera vel sectiones, species (cum subspeciebus, varietatibus ac formis) designautiun enumeratio alphabetica cun citationibus suo loco chrono-

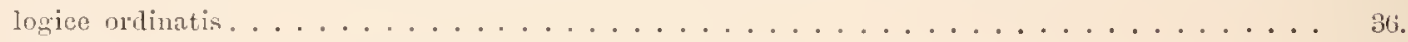

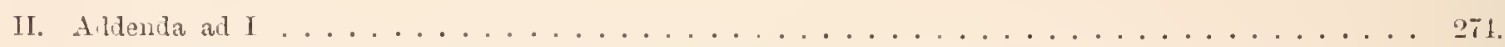

IIT. Sine nominibus enumerate chrowologice species cum citationibus descriptionum vel iconnn . . 252.

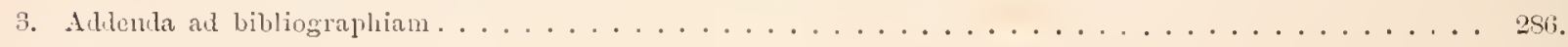

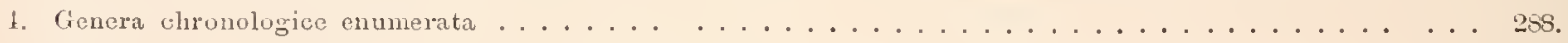

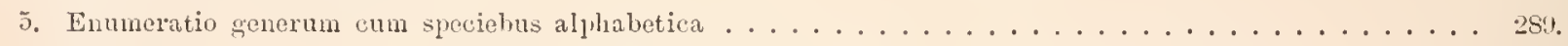

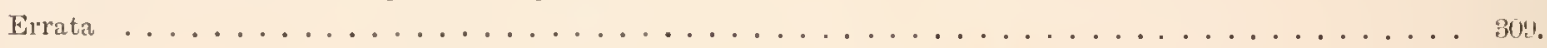




